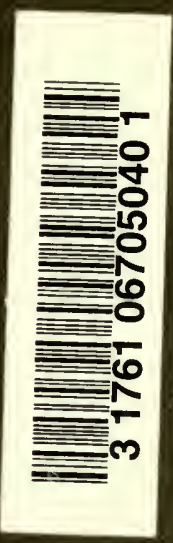




Digitized by the Internet Archive in 2007 with funding from Microsoft Corporation 





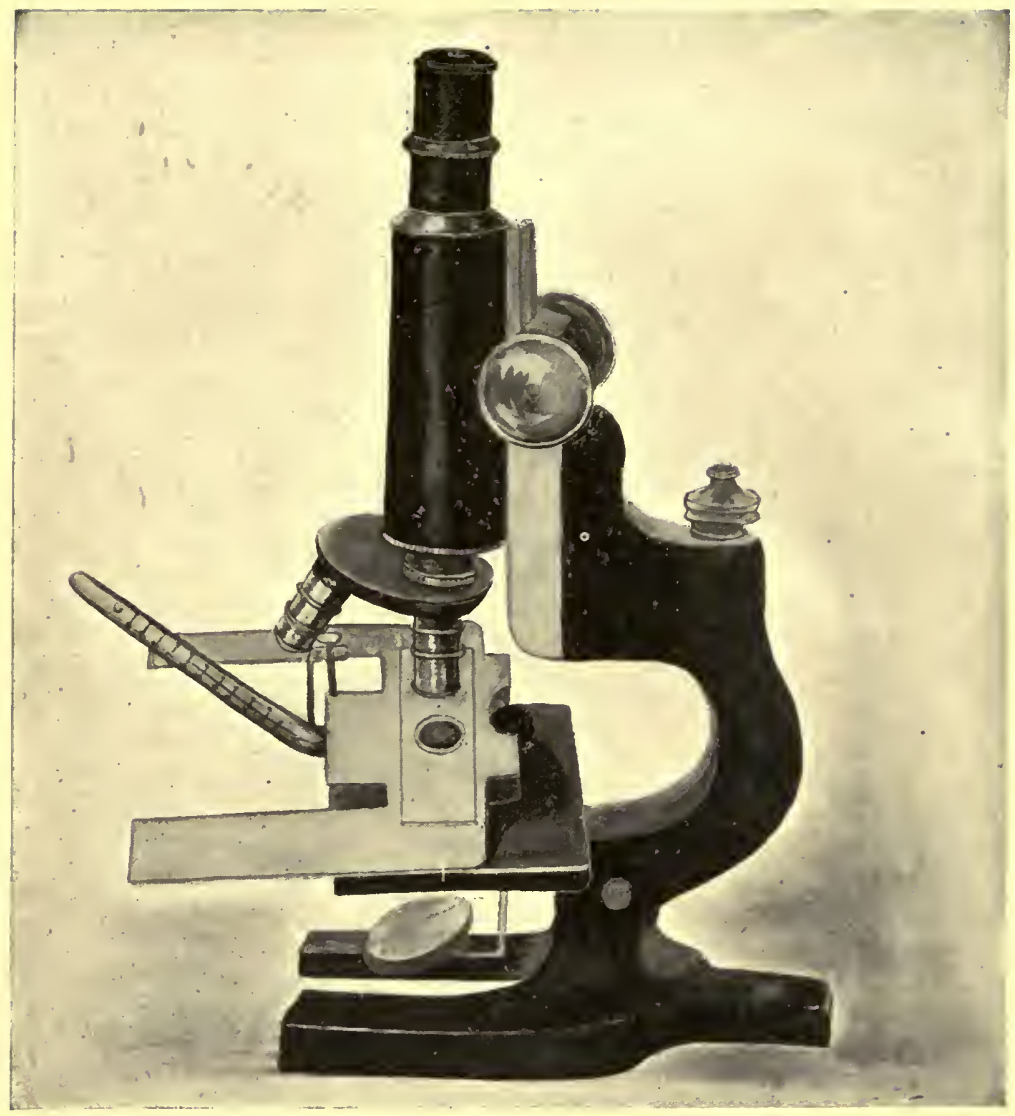

Frontispiece.

FIG. 1.-Compouna microscope with thermo-stage. The heating plate is clamped on the stage of the microscope and is warmed by means of an alcohol lamp or small gas burner. The temperature is indicated on the thermometer. The thermo-stage is almost indispensable in the examination of proximate principles, especially organic substances where differences in melting-points may be used in their identification.

Thermo-stages are also constructed which are electrically heated. These are provided with an adjustable electro-thermostat that automatically maintain a constant temperature. These are usually made for the study of living organisms, but can be obtained to register as high as $100^{\circ} \mathrm{C}$. 


\section{SCIENTIFIG AND APPLIED}

\section{PHARMAGOGNOSY}

INTENDED FOR THE USE OF STUDENTS IN PHARMACY, AS A HAND BOOK FOR PHARMACISTS, AND AS A REFERENCE BOOK FOR FOOD AND DRUG ANALYSTS AND PHARMACOLOGISTS

\section{BY \\ HENRY KRAEMER}

Ph.B. (in Chemistry), Ph.M. (in Pharmacy: Ph.D. (in Botany).

DEAN OF THE COLLEGE OF PHARMACY AND PROFESSOR OF PHARMACOGNOSY IN THE UNIVERSITY OF MICHIGAN COLLEGE OF PHARMACY; MEMBER OF THE EXECUTIVE COMMITTEE OF REVISION OF THE PHARMACOPGIA OF THE UNITED STATES OF AMERICA; CORRESPONDING MEMBER OF THE SOCIÉté DE PHARMACIE DE PARIS, ETC.

\section{ILLUSTRATED}

With over 300 plates comprising about Iooo figures. SECOND EDITION, THOROUGHLY REVISED

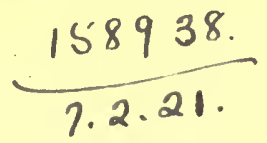

NEW YORK

JOHN WILEY \& SONS, INC.

LoNDON: CHAPMAN \& HALL, Limited 
Copyright, 1915, 1920, BY HENRY KRAEMER

ALL RIGHTS RESERVED 


\section{PREFACE TO SECOND EDITION}

THE results of the work in Pharmacognosy are being increasingly appreciated not only in pharmacy and medicine, but in those arts and professions in which technical skill is required. The demand in every form of industry to-day is for those who can perform the exceptional task, for those who can detect the defects in common practice and devise ways of improvement. The training in Pharmacognosy, as was pointed out in the first edition, is very thorough, and the scope of the work is exceedingly broad. While the science of Pharmacognosy was developed to promote the study of drugs, yet in its application it requires a very practical knowledge of nearly every substance found in nature. The author therefore has modified the definition and enlarged the scope of the subject. Either this was necessary or it would have been incumbent to originate a new word. But as usage eventually determines a definition, it is believed that nearly all pharmacognosists will agree with the author in the position he has taken.

Since the publication of the first edition of this book there have been a great many contributions to the literature of Pharmacognosy. These papers, prepared largely by American authors, deal with adulterations and the variations in constituents, due to the cultivation of medicinal plants. Cognizance of all of this work has been taken and incorporated in this new edition, thus practically bringing it up to date. There has also been incorporated the Government standards for spices and flavoring substances. This has been done to enable the pharmacognosist to keep in mind the exact requirements which must be met in the examination of commercial products. There are a great many subdivisions of Pharmacognosy and the two which are commanding greatest attention to-day are, the cultivation of medicinal plants and pharmaco-chemistry, the latter dealing with the study of the constituents of plants. In the present volume, under the several drugs which have been cultivated, will be found references to the literature of important papers published since the 
first edition was published. The study of plant constituents is receiving greater attention and the papers dealing with the microscopical studies are increasing in number. The examination of sublimates obtained upon pyro-analysis of drugs is deserving of greater attention. During the past few years the author has had a great many students follow this kind of work with a great deal of success. The number of active principles which can be sublimed is increasing and one is almost constrained to say that there are very few drugs which do not yield a characteristic sublimate on igniting the drug. Furthermore, these sublimates can be further tested for identity so that in applying this form of analysis it has a specific value in identifying the drug and may be used as a criterion of its quality. For these reasons this subject has been enlarged upon and a few illustrations have been introduced.

The general make-up of the book has been improved in several particulars. The size of the printed page has been increased, thus decreasing the number of pages and making it a more convenient hand-book for the student. A most notable change has been in the use of bold-face type to distinguish the titles of drugs discussed and to indicate some of the more important features. These changes will facilitate the use of the work by students and analysts.

H. K.

January, 1920. 


\section{PREFACE TO FIRST EDITION}

Owing to the rôle played by vegetable substances in the treatment of disease, pharmacognosy takes rank as one of the most important divisions of applied botany, as by far the great majority of substances used in medicine are derived from the plant kingdom. The training for this study is fundamentally botanical, and the technique employed is essentially that of the plant morphologist, physiologist and taxonomist. Moreover, the value of drugs depends upon their constituents, and so the pharmacognocist must possess a working knowledge of chemistry. He must not only be familiar with plant principles in their isolated and purest forms, but must apprehend their nature, combination and location in the plant. Pharmacognosy, therefore, is on the one hand an applied branch of botany, and on the other of chemistry. But even in this statement we have only a partial view of the nature of the problems that confront the pharmacognocist, as he must be prepared to directly apply the results of science to practice and assist in the solution of a great variety of practical problems. The present work abounds in illustrations which show that practical pharmacognosy is dependent upon the progress of scientific pharmacognosy. Among the problems which require the attention of the pharmacognist is the relation of soil and climatic conditions to the variation in the constituents of drugs, and the nature of the chemical changes that ensue in their drying or curing. The problems of the pharmacognocist begin with the living plant and are not entirely completed when the drug reaches the retail pharmacist, as there are pharmacological questions which frequently await his solution.

At present it is becoming recognized that the pharmacognocist should work in the field with the drug collector, stand at the port of entry of commerce to determine what drugs are fit for use, and act as the analyst for the state and Pharmaceutical Examining Boards in determining to what an extent there is uniformity in the drugs and preparations that have been dispensed. 
The domain of pharmacognosy because of the diversity of interests is one of the most fascinating studies that can engage the attention of pharmacists. The first question that should be asked in any undertaking, viz., "is the work worth while?" must be answered in the affirmative owing to the fundamental importance of the subject. The work in pharmacognosy ought to be stimulating to the student, for in the meaning of the word is implied the thought that he desires to know drugs and to understand them from every angle.

The modern study of pharmacognosy would be rather difficult if the student did not have some special work on botany as his guide in the study of fundamental facts and principles. The author has published a work on "Applied and Economic Botany" which supplies this deficiency. It should be used preparatory to taking up the pharmacognosy as considered in the present work. There are many phases of botanical investigation which are not considered in the usual courses in botany, especially those relating to cell contents, cell walls and the variations in tissues. These must be dealt with at great length in the botanical courses of colleges of pharmacy and will be found to be adequately considered in the text book referred to. Furthermore, in this work will be found a large amount of practical information concerning medicinal and economic plants, with which the pharmacognocist should be acquainted, and which to a large extent supplements the text of the present volume. In addition the illustrations of living plants and technical products will stimulate the student, and had they been included in the present volume would have made it unwieldy as a text book or as a hand book for the pharmacist.

In the present volume drugs are arranged according to families for the reason stated on page xxviii. It will be noted that in connection with each of the families there is given a synopsis of the morphological characters and more especially the histological characteristics of each group. A few of the important animal drugs are also considered and a key for the identification of powdered drugs is appended. In connection with each drug an adequate literature citation is given. This has not been extended, as Zörnig in his work on "Arzneidrogen" has given a very complete bibliographical summary, and it should be consulted by investigators.

The present work is illustrated throughout, and the student is advised to consult the illustrations freely, not only on account of their value in elucidating the descriptions, but also because the legends contain information which, in some instances, supplements that given in the text. It should be stated that a large proportion of the 
illustrations are reproductions of photographs and drawings made by the author, and that in all cases where illustrations are borrowed, or drawings have been especially made for this book, credit is given each author in connection with the reproduction.

One of the most difficult questions which arises in writing a work of this kind is that relating to nomenclature. Owing to the desirability of maintaining a stable nomenclature, particularly for medicinal plants, the author has adopted a rather conservative course and has been largely guided by Engler and Prantl and Index Kewensis, or, in the case of plants growing in the United States preference is given to the names adopted in Gray's New Manual of Botany, revised by Robinson and Fernald.

In the preparation of a book like the present it is self-evident that it is based upon the work of the great masters who have developed pharmacognosy from its inception. In the Introductory chapter and throughout the work the names of these men are referred to and in some instances illustrations are given which stand as monuments to their labors. .

Among the works consulted by the author, and of which special mention should be made, are the following: Systematic Anatomy of the Dicotyledons, by Hans Solereder, translation by Boodle, Fritsch and Scott; Arzneidrogen, by Heinrich Zörnig; Pharmakognosie, by Vog]; Traité de Toxicologie Végétale, by M. Eug. Collin; Pflanzenmikrochemie, by O. Tunmann; Die Heilpflanzen, by Georg Dragendorff; The Volatile Oils, by Gildemeister \& Hoffmann, translation by Edward Kremers; Die Pflanzen-Alkaloide, by Jul. Wilh. Brühl, E. Hjelt and O. Aschan.

Grateful acknowledgment is also made to the following publishers for permission to reproduce illustrations from the works mentioned: Wilhelm Engelmann, of Leipzig: Die natürlichen Pflanzen-familien by Engler and Prantl. Gebrüder Borntraeger, of Berlin: Handbuch der systematische Botanik by E. Warming. Weidmannsche Buchhandlung, of Berlin: Wissenschaftliche Drogenkunde by Arthur Meyer. Gustav Fischer, of Jena: Lehrbuch der Botanik by Strasburger, Noll, Schenck and Schimper. The publishers of Merck's Report and the Editor of the American Journal of Pharmasy.

Acknowledgment also is made to Dr. Charles Travis for his cooperation and careful studies of the alkaloidal crystals described in this book, and to Dr. Walter E. King for revising the manuscript, of the pages on Applied Bacteriology.

H. K. 



\section{CONTENTS}

INTRODUCTORY .......... PAGE

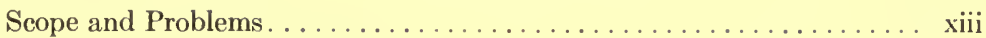

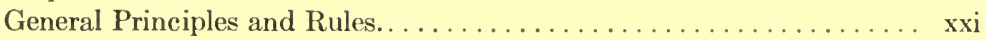

Thallophytes.......................................... 1

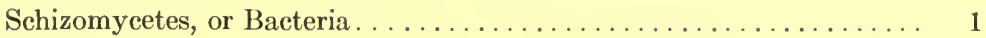

Algæ........................ 5

Phæophyceæ, or Brown Algæ.................. 6

Rhodophyceæ, or Red Algæ.................. 7

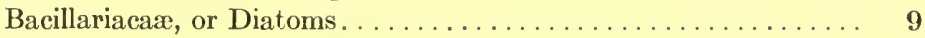

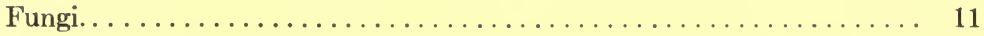

Poisonous Fungi....................... 18

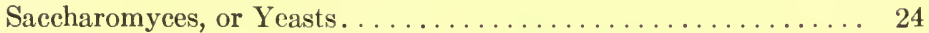

Lichens.............................. 26

Archegoniates................................... 29

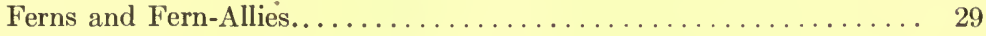

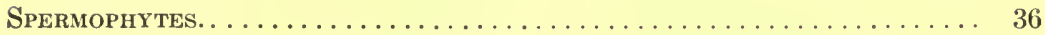

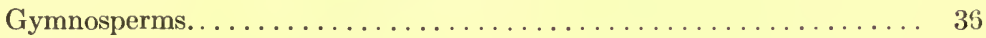

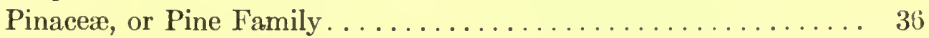

Angiosperms................................ 50

Monocotyledons.............................. 51

Gramineæ, or Grass Family.................... 51

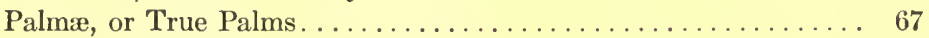

Araceæ, or Arum Family...................... 73

Commelinacxa, or Spiderwort Family.............. 76

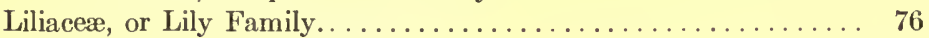

Dioscoreaceæ, or Yam Family. . . . . . . . . . . . . . . . 108

Amaryllida ex, or Amaryllus Family................ 109

Iridaceæ, or Iris Family..................... 110

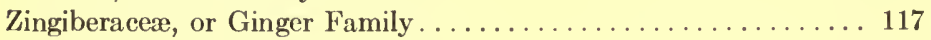

Marantaceæ, or Arrowroot Family.................. 128

Orchidaceæ, or Orchid Family...................... 130

Dicotyledons................................... 140

Piperaceæ, or Pepper Family.................... 142

Salicaceæ, or Willow Family.................... 155

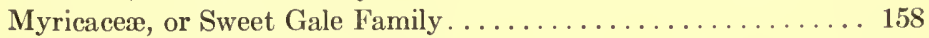

Juglandaceæ, or Walnut Family. . . . . . . . . . . . . . . 159

Betulaceæ, or Birch Family .................... 162

Fagaceæ, or Beech Family....................... 165 
PAGE

Urticaceæ, or Nettle Family. . . . . . . . . . . . . . . . 170

Ulmaceæ, or Elm Family.. . . . . . . . . . . . . . . . . . . . . 172

Moraceæ, or Mulberry Family ................... 173

Santalaceæ, or Sandalwood Family . . . . . . . . . . . 181

Aristolochiacex, or Birthwort Family . . . . . . . . . . . 184

Polygonaceæ, or Buckwheat Family . . . . . . . . . . . . . 187

Chenopodiaceæ, or Goosefoot Family . . . . . . . . . . . . . 195

Phytolaccaceæ, or Pokeweed Family . . . . . . . . . . . 198

Caryophyllaceæ, or Pink Family . . . . . . . . . . . . . . 200

Anonaceæ, or Custard Apple Family................. 202

Myristicaceæ, or Nutmeg Family................. 203

Ranunculaceæ, or Crowfoot Family................. 208

Berberidaceæ, or Barberry Family. . . . . . . . . . . . . 230

Menispermaceæ, or Moonseed Family................. 238

Magnoliaceæ, or Magnolia Family.................. 245

Monimiaceæ, or Monimia Family... . . . . . . . . . . . . 248

Lauraceæ, or Laurel Family. . . . . . . . . . . . . . . . 250

Papaveraceæ, or Poppy Family . . . . . . . . . . . . . . 263

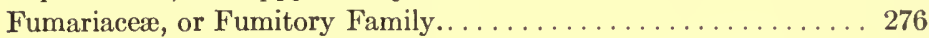

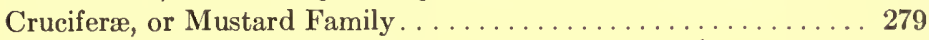

Droseraceæ, or Sundew Family................... 285

Saxifragaceæ, or Saxifrage Family . . . . . . . . . . . . 286

Hamamelidacex, or Witchhazel Family. . . . . . . . . . 287

Rosacex, or Rose Family... . . . . . . . . . . . . . . . 294

Leguminosæ, or Pulse Family .................. 310

Geraniaceæ, or Geranium Family.................. 348

Linaceæ, or Flax Family . . . . . . . . . . . . . . . . 350

Erythroxylaceæ, or Coca Family . . . . . . . . . . . . 352

Zygophyllaceæ, or Caltrop Family ................. 359

Rutaceæ, or Rue Family . . . . . . . . . . . . . . . . . . . 362

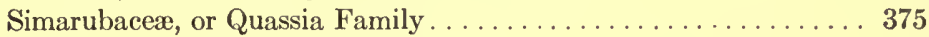

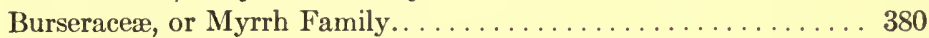

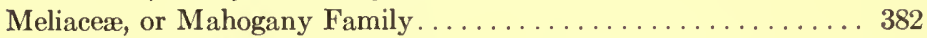

Polygalaceæ, or Milkwort Family.................... 387

Euphorbiaceæ, or Spurge Family . . . . . . . . . . . . . . 390

Anarcardiacex, or Sumac Family. . . . . . . . . . . . . 401

Celastraceæ, or Staff-free Family. . . . . . . . . . . . . . 409

Aceraceæ, or Maple Family.................... 411

Sapindaceæ, or Soapberry Family. . . . . . . . . . . . 414

Rhamnaceæ, or Buckthorn Family................ 423

Malvaceæ, or Mallow Family.................. 427

Sterculiaces, or Cola Family... . . . . . . . . . . . . . . 435

Guttiferæ, or Gamboge Family.. . . . . . . . . . . . . . . 443

Cistaceæ, or Rockrose Family.................... 444

Bixaceæ, or Annatto Family . . . . . . . . . . . . . . . . 446

Winteranaceæ, or (Canellaceæ), or Canella Family.......... 447

Turneraceæ, or Damiana Family . . . . . . . . . . . . . 449

Passifloraceæ, or Passion Flower Family............... 451

Caricaceæ, or Papaw Family..................... 453

Cactacex, or Cactus Family . . . . . . . . . . . . . . 455 
Thymelæaceæ, or Mezereon Family.............. 457

Punicacea, or Pomegranate Family................. 460

Myrtaceæ, or Myrtle Family.................... 463

Combretaceæ, or Myrobalans Family . . . . . . . . . . . . 470

Araliaceæ, or Ginseng Family. ..................... 473

Umbelliferæ, or Carrot Family .................... 478

Cornaceæ, or Dogwood Family...................... 502

Ericaceæ, or Heath Family ....................... 503

Sapotaceæ, or Gutta-percha Family................. 510

Styracaceæ, or Styrax Family.................. 511

Oleaceæ, or Olive Family .... . . . . . . . . . . . . . 513

Loganiacex, or Nux-vomica Family. . . . . . . . . . . . . . 517

Gentianacex, or Gentian Family . . . . . . . . . . . . 532

Apocynaceæ, or Dogbane Family .................. 540

Asclepiadaceæ, or Milkweed Family . . . . . . . . . . . . . 549

Convolvulaceæ, or Morning Glory Family . . . . . . . . . . 552

Hydrophyllaceæ, or Waterleaf Family................ 560

Boraginaceæ, or Borage Family ................. 562

Verbenacex, or Vervain Family . . . . . . . . . . . . . 563

Labiatæ, or Mint Family ....................... 564

Solanaceæ, or Nightshade Family................... 580

Scrophulariaceæ, or Figwort Family................ 616

Rubiaceæ, or Madder Family ..................... 632

Caprifoliacex, or Honey Suckle Family... . . . . . . . . . . . . 648

Valerianacex, or Valerian Family................... 652

Cucurbitaceæ, or $\cdot$ Pumpkin Family.................... 654

Campanulaceæ, or Bluebell Family.................. 661

Compositæ, or Composite Family.................... 664

Animal Drugs. . . . . . . . . . . . . . . . . . . . . . . . . . . . . . . 699

Powdered Drugs................................ 713

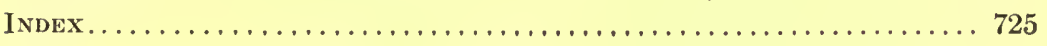





\section{INTRODUCTORY}

\section{SCOPE AND PROBLEMS}

Pharmacognosy is essentially the study of raw materials and the products manufactured from them. While the origin of this science dates back more than a century in the Old World, it is only within the last twenty years that the subject has received any serious attention in this country. During this time much has been done to make pharmacognosy and chemistry the fundamental sciences in pharmacy.

In a narrow sense pharmacognosy embraces the study of medicinal plants and their crude products commonly designated as drugs. It has, however, many ramifications and its branches extend into nearly all of the industries, requiring the consideration of a very great number of economic plants and their products. The divisions extend into the drug business, the spice trade, cereals and food products, the gums yielding varnishes, the origin of vegetable dyes, the properties of woods, the nature of fibers, papers and fabrics, etc., so that, in short, pharmacognosy deals with the properties, identification, sources, and nature of raw materials and their products.

Use of Microscope.--Inasmuch as pharmacognosy requires that one shall be expert in the use of the microscope it might be said to be equivalent to technical microscopy or microscopical technology, meaning thereby the use of the microscope for the identification of, or confirmation of analytical data obtained in the examination of any natural or commercial product. An excellent illustration of the value of the microscope in the examination of a commercial product is in the case of a seizure of apple jelly many years ago. The price was such that at once the health authorities suspected that it was an artificial product. As the nature of it could not chemically be detected, it occurred to someone to examine it under the microscope and it was found to contain the skeletons of certain specific diatoms. In tracing the habitat of these organisms it was ascertained 
that they grew upon certain seaweeds in the Pacific ocean, especially in the vicinity of the Japan Sea. This led to the discovery that agar-agar, now a common commercial article, had been employed in the making of the jelly.

Aim of Pharmacognosy.-The ultimate aim of the science of pharmacognosy is to obtain a knowledge of the chemical nature and the properties of all commercial products, from their origin in nature to the final changes produced in their manufacture. To attain this object requires that the student in pharmacognosy should be welltrained in chemistry.

The term pharmacognosy was introduced by Seydler in 1815 , and is formed from two Greek words, Фáp

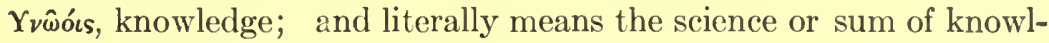
edge of drugs. ${ }^{1}$ The most comprehensive idea of the scope of pharmacognosy has been given to us by Flückiger, who states that it " is the simultaneous application of various scientific disciplines with the object of acquiring the knowledge of drugs from every point of view." The subject was unusually well expounded by Martius, who, in 1825, published a work entitled "Grundriss der Pharmakognosie des Pflanzenreiches," and may be regarded as a great pioneer in pharmacognosy.

Historical.-Tschirch has well said that pharmacognosy dates back further than any of the departments of pharmacy. He rightly states that the old herbalists (rhizotomists) were really the first pharmacognocists, and he considers that Dioscorides, by reason of his writings on medicinal plants, was the first teacher in pharmacognosy. One is sometimes tempted to draw a narrow line and say that the history of the subject begins with the work of Martius.

While it is true that Martius appreciated the significance of the word "pharmacognosy," we must not forget that prior to the last century and even much later it was usual for people to get their drugs directly from the living plants. Up until comparatively recently the identification of drugs was based on a study of living plants, and it was necessary, therefore, not so much to distinguish between the substances which were brought to market as it was for those who gathered medicinal plants to identify them in the field.

The work of the herbalists and systematists of earlier times gradually merges with that of the morphologists of more recent years. There has been a growing tendency to study not only the

${ }^{1}$ Henry Kraemer, "The Rise and Development of Pharmacognosy," Pharm. Era, Oct., Nov. and Dec., 1912. In this article there occurs citation of the important literature of the subject. 
portions of living plants furnishing the drugs of commerce, but the entire plant. This is necessary, if we would understand the real significance of the characteristics of drugs. Fortunately, also, plants are being studied at close range and under conditions of cultivation, so that there will be less misapprehension in regard to the authenticity of the materials entering commerce. In former years a number of mistakes have been made in describing drugs which might have been avoided had the identity of the material been first determined and the foundation studies made upon the living plant.

Histological Pharmacognosy.-The development of modern pharmacognosy may be said to date from the initial studies on the inner morphology or the anatomy of plants. All of these studies show that in the cellular structure of plants we find the plant unit. The importance of this discovery will be at once apparent when we recall that very many plants, as well as drugs, may resemble each other very closely when viewed macroscopically, but when we come to examine their cellular structure we find that the nature of the cells and their contents or their arrangement is constant for the most part for the same drug, and vary in different plants or drugs.

This advance in the study of plants is largely due to Schleiden, who, in 1838, announced that the cell is the fundamental unit in plants and showed that all the different tissues are combinations of cells. Schleiden not only contributed very largely to the knowledge of the structure of plants, but was among the first to recognize that drugs of different origin might be determined by their cellular differences. Without having any knowledge, for instance, that the several commercial sarsaparillas were obtained from different species of Smilax, he showed by reason of certain differences in the cells of the hypodermis and endodermis that they must be obtained from different species, which has since been proven to be the case.

Schleiden early saw that pharmacognosy was to be a distinct science. He designated pharmacognosy as a botanical discipline, indeed he said: "Pharmacognosy is the mother of all scientific discipline." When Schleiden said this he no doubt had in mind the difficulties attending pharmacognostical work and recognized the value of the training required in this study. For the pharmacognocist working upon dried materials must have in mind the relationship between the fragments of the drug he is examining and the growing plant.

Adulteration in Drugs.-By adulteration we mean the deterioration or deficiency in quality of a commercial product, $\$ no matter what this may be due to. It may be due to a variety of causes such 
as aging, lack of care in preparation, substitution, extraction of important constituents, or the addition of other substances which may be either harmless or harmful. Adulteration may occur in a great variety of forms. The following may be mentioned as giving some idea of not unusual occurrence:

Large pieces of iron may be used to increase weight, as in Burgundy Pitch; pieces of lead pipe may be inserted in the fresh root as in Ginseng; bullets are occasionally found in the masses of opium; pebbles and rocks admixed with asafœetida; large quantities of dirt may be left in the middle of the bundles of sarsaparilla; the substitution for a proximate principle, as papain by bread; admixture or even substitution by other species as apocynum, hyoscyamus and scammony, in which occur closely related forms; the substitution by widely separated genera as Mountain maple bark for Viburnum Opulus; in still other cases toxic drugs may be substituted for the genuine, as spurious cubebs for true cubebs, belladonna for inula.

Micro-chemistry.-During the past fifteen or twenty years there has been a growing interest in the study of plant constituents by the application of chemical reagents to microscopic sections.

Up until recently we have been largely ccncerned in the identification of raw materials and have been quite content to be able to distinguish the genuine article from spurious substances. This work has been based largely upon the forms of cells and composition and structure of the cell wall. In some instances the study of some of the cell contents, as of starch grains and crystals of calcium oxalate, has afforded an important clue to the identity of the product under examination. As our interest in the study of the quality of the drugs increases, and this is based upon the constituents or those principles called active principles, it is very important that these constituents be studied in the cells of the plants and drugs.

A careful perusal of the literature will show that very many observations have been made showing the separation out in microscopic sections of definite crystalline substances. In some cases these occur even upon the outside of the drug, as the coumarin crystals on tonka beans and vanillin crystals on vanilla pods. Again, these crystals may be formed upon heating the material, as in benzoin and many other drugs. ${ }^{1}$ Again, crystalline substances separate upon the addition of mineral acids, as when nitric or sulphuric acid is added to sections of hydrastis. Cognizance of these crystals is being taken to some extent in all of the progressive pharmacopœias, and while the subject is in a more or less chaotic condi-

1 Otto Tunmann, "Pflanzenmikrochemie," 1913; Kraemer's "Applied and Economic Botany," 1916. 
tion at present, yet the interest in this method of analysis is growing to such an extent that we may expect before long that the erystallographic methods of analysis will play quite as important a part in the work of the pharmacognocist as the anatomical or histological methods have up until this time.

Problems of Pharmacognosy.-Pharmacognosy has for its object the study of drugs and the plants yielding them. The main object is not only to determine the identity of the drug and its origin, but the study of its constituents and the factors influencing their variation in the living plant as well as after collection. In the pursuit of pharmacognosy we examine drugs which for the most part consist of broken fragments, and from these pieces, frequently microscopic in size, the plants from which they are derived must be determined. Again, particles which resemble each other or are obtained from very closely related species must be separated. Parts of other plants growing with them in the soil must be distinguished and standards established showing how much of this extraneous material is permissible, and these standards must be so framed that drugs collected at widely separated points will be of uniform quality and efficiency.

The problems of pharmacognosy take us at once into the field where the origin of the drugs can be studied at first hand. A second phase of the subject are the studies of pure morphology dealing with the development of certain structures as the stipes in cubeb, or the origin of tissues in seeds, and scars or markings in roots and rhizomes. The difference in constituents of different parts of the same plant, as the oils in the leaves and bark of cinnamon or difference in the proportion of alkaloids in the different kinds of cinchona, offers a most fertile opportunity for the application of physiological studies. Furthermore, when we approach the subject of the cultivation of medicinal plants we are confronted with the problems of hybridization and mutation. We may further expect those who have had special training in the literature and language are likely to become interested in the historical study of drugs and in the nomenclature employed in designating them in commerce. In the historical study of drugs such phases are considered as the origin of their introduction into medicine, the dissemination of information concerning their uses among other nations, the official recognition by some of the more important pharmacopœias, and finally the facts regarding their real usefulness as supplied by modern pharmacological investigations and clinical experience.

The study of synonyms is one of the most important departments of pharmacognosy. While there have been some attempts to treat 
of the synonyms of drug names and their derivation, nothing has been written which is adequate to the needs of this subject. It is one of the most difficult phases of pharmacognosy, and requires that the student shall be acquainted not only with the principles of scientific nomenclature, but that he shall be familiar with the several languages and the historical development of pharmacognosy. Tschirch has designated this department of pharmacognosy, pharmacoetymology.

Finally, there is a phase of pharmacognostical work that is receiving greater attention each year, and this is the division which relates to the study of drugs from the time they are shipped by the collector until they reach the retail pharmacist or even the consumer. This subject cannot be ignored, for it involves the study of the packing of drugs, the conditions of storage, and the changes in the quality of drugs in passing from hand to hand. While some few drugs remain more or less unaltered, or even may be improved on storing for a limited time, a large number of the more valuable of them require that they be kept under special conditions and for a very limited period of time. As indicating the importance of the subject the various pharmacopœias are giving very explicit directions regarding the manner in which certain drugs shall be kept and how long they will retain their active constituents. This study requires an intimate acquaintance on the part of the pharmacognocist with the collector, the appraiser's stores, the wholesale warehouse, and the retail drug store.

It should also be stated that in practice we have a scientific pharmacognosy and a practical one. The problems of these two departments of pharmacognosy may be the same, as may also be the results, but the objects in view are very different. In the one, investigations are carried on that our knowledge of drugs may be made more complete and the investigator considers neither the cost nor the time. In the other the expert proceeds so far in the search for this knowledge as the problem in hand permits. The results of the scientific investigator will be published, whereas the results of the practical expert are usually withheld.

To a scientific mind the practices of commercial life are enigmatical, especially as they relate to the sale of foods and drugs. The scientist is familiar with the great variation of commercial products and has been publishing for many years the results of his studies with the view of benefiting mankind. So engrossed is he in his search for the truth that he can hardly conceive that others are not working toward this same end. One can imagine his disappoint- 
ment in finding that the motive of the manufacturer, in practice at least, works out quite to the contrary.

There are several reasons that may be given for the conditions that have prevailed in commercial life up until very recently. In the first place the public could not distinguish whether the commodities they were buying were pure or adulterated. Then price competition and the demand of the public for "cheap foods and cheap drugs" must have caused manufacturers at first to shorten the process of purification, and this was but a step leading to the addition of more or less harmless substances until finally harmful foods and inert drugs were generally exploited. A third factor was the lack of knowledge on the part of the manufacturers and dealers to distinguish genuine foods and drugs from those which were adulterated, spurious or worthless. This condition was remedied so soon as analytical data concerning the composition of foods and drugs were published in the scientific journals and some of the State Boards of Health employed analysts who published reports from time to time on market conditions.

These published results were rather startling, as up to within fifteen years ago it was stated that "of the whole food supply of the country one-seventh is adulterated." One can readily obtain figures in any of the pharmaceutical journals during the past ten years showing that something like 50 per cent of the powdered drugs upon the market were adulterated. The trade in spices was even worse, for we read that " the adulteration of spices is a practice so common that we would really be surprised to find goods pass through the grocery trade that are absolutely pure." This condition, of course, could not continue indefinitely, and fortunately a few manufacturers, who valued the reputation of their products even more than the money they could make out of them, lent support to National and State legislation which should fix standards of purity for foods and drugs. This finally ended in the passage of the Food and Drugs Act in 1906, which was followed by co-operative legislation in the various states.

The Microscope has been employed in the examination of drugs since 1847, when Schleiden used it in the examination of the sarsaparillas. In 1853 Schacht showed its value in the examination of textile fibers. The earliest reference in English to the use of the microscope as a means of detecting the admixture $\mathrm{Ol}^{*}$ adulteration of drugs is the statement of Professor Pereira in his introductory lecture before the Pharmaceutical Society of Great Britain in 1851, when he said: "You are doubtless conversant with the recent very extensive employment of the microscope for disclosing the adultera 
tion of food. No less useful-no less powerful is it in disclosing the contamination of drugs; and I cannot too strenuously recommend you to employ it."

The investigations of Pereira, Hassal and others showed even at that time not only that the microscope had unlimited valuable practical applications, but that it was the only means which had been discovered to detect the admixture or adulteration of noncrystalline organic substances. An article published in the American Journal of Pharmacy in 1853 (pp. 45-48) on the use of the microscope in the examination of drugs shows that in spite of the fact that it has only recently come into general use its value was very early appreciated.

Some years ago a pharmacist, who had made a specialty of spices and endeavored to purchase only the purest available, became suspicious upon opening one keg of ground black pepper and finding a large fragment of a pod of cayenne pepper. A subsequent examination of the powder showed that it was an artificial product which was very common some years ago, the strength being reinforced by the use of cayenne pepper.

Very many instances could be given showing the value of the microscope in the examination of commercial products and the detection of adulteration as the presence of poke-root in belladonna root, or the substitution of ruellia for spigelia, foreign starches in cacao, presence of capsicum in ground ginger, the endocarp of olive (commonly called olive pits) in ground pepper and other spices as well as in powdered drugs, the presence of wheat middlings in ground mustard as well as in ground spices and drugs, and even to the detection of organic or inorganic crystalline substances in complex preparations. The use of the microscope is not only valuable in analytical work, but it is also valuable in synthetic work, as in determining the composition of cattle powders, medicinal teas, flavoring mixtures and practically all artificial combinations.

Those who are especially interested in this subject and are considering the advisability of preparing themselves for this work may ask for a definite statement as to the subjects that one should be proficient in in order to be a successful pharmacognocist. Taking it for granted that this inquiry is being made by the student who has his whole future ahead of him and who, it is presumed, can take the necessary time to qualify, we may say that the pharmacognocist of the future should have as a foundation rather thorough laboratory instruction in botany, chemistry, physics and crystallography. Not one of these branches can he afford to neglect, and the amount of 
instruction should be at least the equivalent of that given in these various subjects in the undergraduate courses of any of the best American universities.

On the other hand, no amount of reading or scientific training will quite take the place of a real interest in the subject. This interest can be acquired not only in the drug store or large warehouse, but in college laboratories with their extensive collections.

\section{GENERAL PRINCIPLES AND RULES}

Before taking up the individual drugs some general definitions should be discussed and some generalizations concerning the collection and preservation of drugs should be given consideration.

The natural origin is the scientific name (generic and specific names) of the plant or animal yielding the drug. In the case of vegetable drugs the natural origin is spoken of as the botanical origin. A vegetable drug usually represents some special part of the plant, but in some instances the entire plant is employed as chirata.

The habitat of plants is the region where they grow. Sometimes this term is applied erroneously to the drugs themselves. Neither the scientific name of the plant nor the commercial name of the drug may be relied upon as indicating the true habitat of medicinal plants. For example, the specific name of Spigelia marilandica indicates that the plant is found in greatest abundance in Maryland, whereas it is only occasionally met with in that state. In other cases plants are common to a much larger territory than the specific name would indicate, as Prunus virginiana. The geographical names associated with drugs frequently apply to the places from which they are exported rather than to the habitat of the plant yielding the drug, as, for example, Para sarsaparilla, which is obtained from a plant growing in the upper Amazon region, is shipped to Para, from whence it was formerly exported.

Plants which yield drugs may grow wild, as is most usually the case, or they may be cultivated, as those yielding digitalis, cannabis indica and the solanaceous leaves. Plants growing in their native countries are said to be indigenous to those regions, as Stillingia sylvatica, of the Southern United States; Aconitum Napellus, of the mountainous regions of Europe, etc. Plants are said to be naturalized when they grow in a foreign land or in another locality than their native home. Some of these may have been distributed by natural agencies, or they may have escaped from 
cultivation, or they may have been introduced with the seeds of cultivated plants or with the ballast of ships.

The term commercial origin applies solely to the drugs themselves, and indicates their commercial source, which may be either the country where the plant yielding the drug is grown, or the port from which the drug is sent into the marts of the world. English hyoscyamus leaves are gathered from plants grown in England; Canton rhubarb is the product of plants grown in various parts of China, but shipped by way of Canton.

The official or pharmacopœial titles of vegetable drugs are derived from either the generic name of the plant, as gelsemium, or the specific name, as ipecacuanha, or they may include both the generic and specific names, as viburnum prunifolium, or they may be derived from other sources, as opium and sarsaparilla.

In addition to the botanical names of plants and the pharmacopœial titles of drugs, a number of vernacular names and synonyms are also applied to vegetable drugs, as licorice root for glycrrhiza, prickly ash for xanthoxylum.

The official or pharmacopœial definition of drugs is given in the leading paragraph under each drug in the different pharmacopœias, and includes the botanical origin as well as the name of the part of the plant yielding the drug; and in some cases other special features or requirements are given, as the habitat of the plant yielding the drug, the time of collection, mode of preservation, etc.

The time of the collection of vegetable drugs is of prime importance, and, while we may not be able to make extended generalizations, still, the following general rules for the collection of various drugs may be given:

(1) Roots, rhizomes and barks should be collected immediately before the vegetative processes begin in the spring, or immediately after these processes cease, which is usually in the fall.

(2) Leaves should be collected when photosynthesis is most active, which is usually about the time of the development of the flowers and before the maturing of fruit and seed.

(3) Flowers should be collected prior to or just about the time of pollination.

(4) Fruits should be collected near the ripening period, i.e., when full grown but unripe.

(5) Seeds should be collected when fully matured.

The preservation of vegetable drugs is likewise deserving of careful consideration, and attention should be given to the influence of temperature, moisture, air and light, and the attacks of insects. 
The temperature of the room or part of the store devoted to the storage of dry drugs should not be more than about $25^{\circ} \mathrm{C}$., and maintained nearly uniform throughout the year.

Drugś containing volatile principles require to be kept in airtight containers, as the herbs of the Labiatæ and Compositæ, and wild-cherry bark. Air-tight tin cans are probably the most economical and satisfactory containers for the purpose, and the suggestion has been made to coat the edges of the cans with melted paraffin. Drugs are sometimes stored in wooden boxes or in drawers. This method is objectionable, not only because they are more liable to deteriorate, but because the odors are communicable from one to the other. The storage of drugs in parcels is the most objectionable, particularly, as is usually the case, when the different parcels are stored together.

Those drugs that are difficult to dry, as the inulin-containing drugs, and some fleshy roots and rhizomes, as Veratrum, are liable to become moldy and should be thoroughly dried before placing them permanently in containers.

The preservation of drugs against the attacks of insects is, unfortunately, generally overlooked. Most drugs are subject to their depredations, and are usually attacked by the insects in the larval stage. The insects -which infest vegetable drugs belong chiefly to the Lepidoptera, Coleoptera and Diptera. The Lepidoptera are the most destructive, and include the cornmeal moth (Tinea zea), which, during its larval (the caterpillar or grub) stage, is known to attack aconite, capsicum, ergot, lappa, linseed, rhubarb, taraxacum and many other drugs. Among the Coleoptera are various members of the Ptinedæ, as Ptinus brunneus, Anobium paniceum and Lasioderma serricorne, which attack the spices chiefly, as capsicum, cinnamon and pimenta. Chief among the Diptera is Trypeta arnicivora, which is sometimes found in the receptacles of arnica flowers.

For the destruction of these insects and prevention of their attacks a number of substances and methods have been employed, the simplest method of all being to expose the drug to a temperature of about $65^{\circ} \mathrm{C}$. This method is probably the most efficient in not only preventing inse ct attacks, but all other forms of deterioration. Camphor and tar-camphor have been employed, but it is doubtful if they should be used, unless in the case of animal drugs. $\angle$ In some instances, as with nutmeg and ginger, the drug is sprinkled in the drying-room, or when packed for market, with quicklime. Benzin and carbon disulphide have been proposed, but these are of a disagreeable odor as well as inflammable. Ether has been suggested, but it is very vola- 
tile and inflammable. Formaldehyde has been proposed for the preservation of orris root. Chloroform and carbon tetrachloride are probably the best preservatives that have been proposed. A few drops of chloroform or carbon tetrachloride added to a drug on placing it in the container will usually prevent it from becoming "wormy." The amoun of chloroform or carbon tetrachloride to be used should be about 25 c.c. to 100 cubic feet of drug. To be effective the drug should be treated on two separate occasions.

Commerical Forms of Drugs.-Vegetable drugs are brought into market in various forms; they may be crude; that is, more or less entire, or in a powdered condition. Crude drugs may be nearly entire, as seeds, flowers, fruits, leaves, and some roots and rhizomes; or they may be cut or sliced, as in woods, barks, many roots and a few rhizomes. They may be more or less matted together, as in chondrus and the solanaceous leaves; or they may be pressed together by means of hydraulic pressure, giving the so-called pressed drugs; or they are first powdered and then molded into forms, as "rhubarb fingers." In some cases the periderm is removed, as in roots (althea), rhizomes (zingiber) and barks (ulmus).

The quality of vegetable drugs is injured by a number of factors, of which the following may be mentioned: (1) Lack of knowledge or want of care in collecting them; (2) carelessness in drying and keeping them; (3) insufficient care in garbling and preparing them for the market; (4) inattention in preserving them and storing them; (5) accidental admixture in the store, and (6) adulteration and substitution.

The influence which the time of collection has on the quality of vegetable drugs may be best shown by a few illustrations. It is well known that when the fruits of conium are green they will yield over 3 per cent of coniine, but when they become yellow the alkaloid diminishes rapidly in quantity, and, therefore, much of the commercial drug will not yield 1 per cent of coniine. The same thing may be said of santonica; when the flower heads are unexpanded they will yield over 3 per cent of santonin, but just so soon as the flowers mature there is a rapid disappearance of the anthelmintic principle. Dealers in insect powder (Pyrethri Flores) know that the flowers gathered when they are closed produce the finest and most powerful insect powder, worth nearly twice as much as that made from the half-closed or open flowers. It may be that the variation in quality of some of the commercial aconite is due to improper drying, or to the extraction of the active principles; still, there is no doubt but that much of the trouble with this drug is due to the variation in 
the time of collection in different countries, as well as to its being collected from different species.

Another factor affecting the quality of vegetable drugs is carelessness in drying them and caring for them after they are gathered. At one time the Pharmacopœia specified that some drugs should be kept a certain length of time before being used, as in frangula and cascara sagrada. In these instances the results of the changes on keeping have been ascertained, and since a similar effect may be obtained by heating the bark at $100^{\circ} \mathrm{C}$. for forty-eight hours, this specification is deemed no longer necessary.

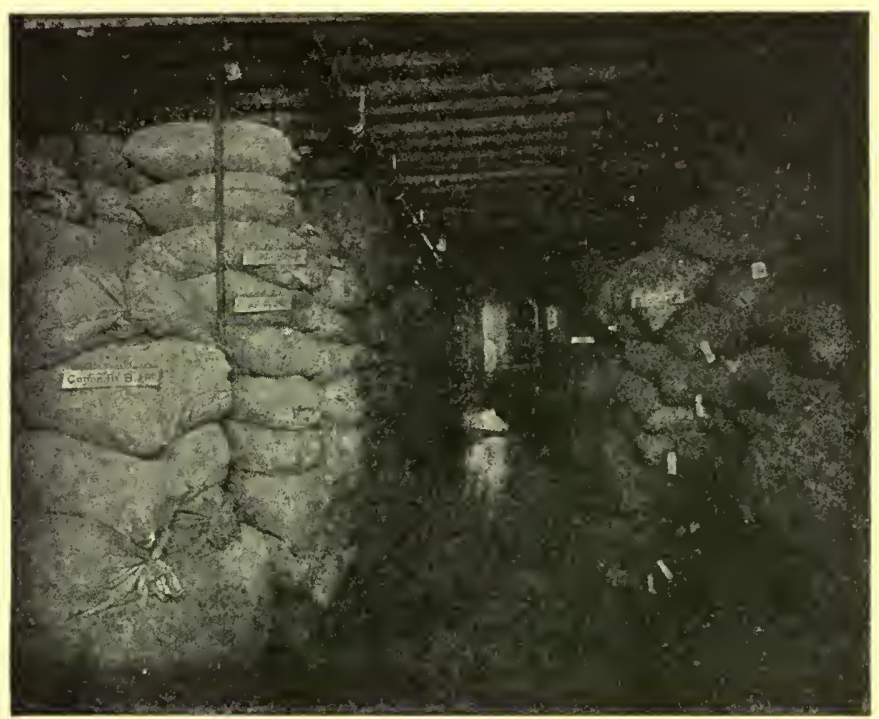

Fig. 2,-A section of crude drug warehouse of Sharp \& Dohme, Baltimore, Md.

In some drugs a sort of ripening process takes place in the drying, as in gentian, guarana, vanilla and the solanaceous leaf drugs. In still others a marked deterioration takes place if they are placed in heaps and allowed to ferment, as in the case of lavender and most other drugs yielding essential oils. In the preparation of oil of peppermint, the yield of oil is greater and the quality better if the plants are allowed to dry and are distilled immediately or soon after. On the other hand, the yield of methyl salicylate is greater in the leaves of Gaultheria procumbens or the bark of Betula lenta if they are first macerated in water for about twelve hours.

Quite a number of drugs are not infrequently observed in commerce in a moldy condition, as taraxacum, veratrum, aconitum, zing- 
iber and others. The question as to what influence this mold has on the quality of the drug has not been decided. ${ }^{1}$

A third cause of inferiority of vegetable drugs is lack of sufficient care in garbling. This applies to a number of drugs, as leaves, with which may be admixed a large number of stems and roots; rhizomes and tubers, in which the proportion of stem-remnants may be excessive, or, as in other cases, the proportion of roots to rhizomes may be large. The roots contain much less of the active principles, and have been found in cypripedium and hydrastis to the extent of 50 per cent of the amount present in the rhizomes.

A fourth factor influencing the quality of drugs is the manner of preservation. While it is generally conceded that most drugs deteriorate on keeping, still this depends largely upon the manner in which they are kept. Thus, the Pharmacopœia limits the time of keeping of ergot and states how it shall be preserved; yet a number of writers call attention to the fact that, if properly prepared and preserved, the time of keeping may be very much extended. In order to preserve ergot, Grover proposed the removal of the oil, and Moss found the drug thus treated to retain its therapeutic value for six and a half years. Zanon suggests placing the drug in alternate layers with sand and keeping it in a closely sealed jar. Others grind the fresh ergot and preserve with chloroform in paraffin paper, while some first extract the oil from the powder with alcohol or ether.

Accidental admixture in the store or warehouse depends upon the care of the individual, and need not receive attention here.

The Valuation of Drugs.-In the identification of vegetable drugs certain characters are taken into account, such as color, odor, general appearance, structure, texture, etc., these at the same time indicating in a greater or less degree the qualitative value of the drug. While these characters may enable the expert to detect very slight variations in quality, and to estimate approximately the value of a given drug, still the true value is based upon the amount of the medicinal principles or so-called active constituents. The methods employed in the valuation of drugs may be grouped as follows: (1) Chemical, (2) Physical, (3) Microscopical, and (4) Biological.

(1) Chemical methods are more generally employed and usually involve the isolation and estimation of the active principles.

(2) Physical methods involve such processes as the determination of specific gravity of the drug as of jalap, or the determination of the elasticity or measurement of the fibers, as of cotton, and still other

${ }^{1}$ Viehoever, Detection of Mold in Drugs, Foods and Spices, Jour. A. Ph, A., 1917,6 , p. 518 . 
special methods which apply to individual drugs, showing indirectly their quality.

(3) Microscopical methods of valuation may oftentimes be employed when other methods fail, as, for example, when foreign starches are added to starchy products, as the cereals and spices. Microchemical reactions may also be depended upon in some instances to indicate the value of a drug, as in strophanthus, where the quality of the drug appears to bear a direct relation to the number of seeds giving a green coloration with sulphuric acid. The separation of the salts of the alkaloids in hydrastis on the addition of sulphuric acid is also of value in determining the quality of this drug.

(4) Biological methods involve the consideration of the effects of drugs upon animals or plants. They may be conveniently grouped as follows: 1. Effects or influence upon animals, including $(a)$ those dependent upon the perceptions or senses of the experimenter or tester, as color, taste and odor; $(b)$ those which are physiological or pathological. These are usually determined by experiments upon insects, frogs, rabbits, guinea pigs, fowls, cats, dogs, fish and even upon man. 2. The effect or influence produced upon plants by drugs, or solutions of their active principles. For experiments of this kind seedlings are usually employed and the effects are based upon the amount of growth of the root of the plant in a given time when placed in the solution. ${ }^{1}$ Some of the lower plants are also used in testing the properties of chemicals, which may have a toxic action on the protoplast or a plasmolytic action on the protoplasm.

Drug Collections.-It is important that the student, pharmacist and analyst possess a collection of typical drug specimens. It is necessary in the study of drugs and also for purposes of identification and comparison. Specimens may be kept in various kinds of boxes and bottles, but one of the most satisfactory ways is to keep them in type cases, such as are used by printers, the top being covered with glass which can be removed. The glass can be kept in place by means of long, broad-headed tacks or can be fastened permanently by means of hinges. The frames may be hung on the wall or held by means of molding.

The Study of Drugs may be pursued from a number of viewpoints. In an artificial system they may be grouped according to the parts of plants from which they are derived, as roots, rhizomes, leaves, etc. This method has much to commend it in practice, but unfortunately the form of the commercial article is not such that it is always pos-

${ }^{1}$ Kraemer, "Assay of Drugs by means of Living Plants," Amer. Jour. Pharm., 1900, p. 472; Saylor, Ibid., 1916, p. 8. 
sible to determine whether it should be placed among roots or rhizomes, leaves or herbs, etc. A second system of arranging drugs is according to their important constituents. This may seem to many very desirable and enable us to develop a scientific pharmacognosy to be used as a basis for a rational pharmacology. Unfortunately our knowledge of the chemical constituents of drugs is very meager, and in those drugs which have been investigated there may be present a number of principles, each one of which serves a useful purpose. A third method is to consider the plants yielding drugs according to their natural relationship. With our knowledge of the morphology, including both organography and the inner structure of such a large number of plants, it would seem that this would furnish the best system for practical pharmacognosy and be the most stimulating to the investigator. In a large number of families we find there are certain morphological characters that are more or less distinctive for each. The Compositæ, for instance, are distinguished by their containing inulin. The Labiatæ have not only square stems and bilabiate calyces and corollas, but typical 8-celled glandular hairs. Furthermore, two or more drugs are not infrequently derived from a single plant, and the reason for this can be better considered in connection with the products derived from a single plant than if they are placed in widely divergent groups. After many years of experience as a teacher and trying out the several methods in class work I have come to the conclusion that the natural classification of plants is not only the most systematic, but the most effective in practice.

Literature.-Tschirch, Handbuch der Pharmakognosie, 1912.

Power, The Aims and Developments of Phytochemical Research. Am. Jour. Pharm., 1917, 89, p. 97.

Lloyd, Plant Textures, Amer. Jour. Pharm., 1917, 89, p. 387.

Ewing and Stanford, Botanicals of the Blue Ridge. Jour. A. Ph. A., 1919, 1 p. 169.

Taylor, The Pharmaceutical Chemist and the Scope of his Work. Jour. Indus. Eng Chem., 1919, 11, p. 239.

Alsberg, Viehoever and Ewing. Some of the Effects of the War upon Crude Drug Importations. Jour. A. Ph. A., 1919, 8, p. 459.

Beal, George D., Chemistry's Opportunity in Pharmaceutical Research. Jour. A. Ph. A., 1919, 8, p. 260.

Kebler, Fraudulent Advertising. Jour. A. Ph. A., 1919, 8, p. 201.

Power. The Distribution and Characters of some of the odorous Principles of Plants. Jour. Indus. Eng. Chem., 1919, 11, p. 344. 


\section{SCIENTIFIC AND APPLIED PHARMACOGNOSY}

\section{THALLOPHYTES}

The Thallophytes, while of very great botanical interest, comprise about 100,000 species, yet relatively few are of any economic importance. The Algæ are chiefly used because of the mucilage that they contain and as a source of iodin. A number of lichens contain important coloring matters. A few of the fungi are used in medicine, although a great number of them contain exceedingly toxic principles.

\section{SCHIZOMYCETES OR BACTERIA}

Bacteria and their products are extensively used in medicine, as well as in the industries. The preparations, known as serums and vaccines are employed as specific cures for certain diseases, and are especially valuable in prophylaxis and diagnosis. Their manufacture requires great skill and special facilities are necessary to produce them. Furthermore, they can be manufactured only under government license and inspection. While there are many biological products used in diagnosis, prevention and treatment, which cannot properly be placed under any definite classification, yet for the greater part these products may be grouped under two chief classes, vaccines and antiserums.

Vaccines are essentially weakened or modified viruses. The general action of vaccines is therefore preventive or prophylactic and not curative. There are several methods which may be employed in modifying or attentuating viruses. The processes involve the treatment of viruses in such ways that they may be injected into the animal body without danger of producing serious pathologic conditions, while at the same time sufficient specific infectious qualities must be present to produce mild reactions. The 
successful vaccine must be attenuated to the point which represents a happy medium, and which clearly indicates both safety and activity. Some of the more common methods used in attenuating viruses are attenuation by passage of the virus through some species other than the animal for which the virus is specific (smallpox vaccine); attenuation by drying at constant temperature (rabies vaccine, Pasteur); attenuation by growth at a temperature above the optimum (anthrax vaccine); and attenuation by chemicals.

Some of the more important vaccines are smallpox vaccine, blackleg vaccine, rabies vaccine and anthrax vaccine.

Bacterial vaccines or bacterins consist of suspensions of young, living cultures of specific bacteria which have been killed chemically or by the application of moist heat at a temperature slightly above their thermal death point. Wright and Douglas first advanced the theory of opsonic action and suggested that the subcutaneous injection of a given species of bacteria which had been killed, conferred to the blood of the treated individual greater opsonic activity towards the species of organisms in question. The opsonic activity is expressed by the degree of readiness with which the phagocytes destroy invading micro-organisms. Bacterial vaccines may be used in the form of autogenous or stock vaccines. An autogenous or "personal" vaccine is one prepared from a culture of the specific organism isolated from the patient in question. Stock bacterial vaccines are prepared from stock cultures of the various organisms. The latter may be manufactured and stored until required for treatment. Some of the more common bacterial vaccines are typhoid (especially as a prophylactic), streptococcus, staphylococcus, streptococcus and staphylococcus combined, gonococcus, pertussis, acne, colon, canine distemper and equine influenza.

Tuberculins are preparations made from the human and bovine strains of Bacterium tuberculosis and are used both in diagnosis and treatment. Koch's Tuberculin (Old) is the concentrated, glycerinated beef bouillon, in which the tuberculosis organism has been grown. The active substance of the Tuberculin, which is apparently an albuminous derivative insoluble in alcohol, is elaborated by the organisms during their multiplication. In human, as well as in veterinary practice, Tuberculin may be applied as a diagnostic agent in various ways. In addition to the hypodermatic injection of Tuberculin Old, the methods of Calmette, von Pirquet and Moro may be used. Calmette's 'test consists in the instillation in the eye of Koch's Tuberculin Old which has been prepared by precipitating and washing the resulting precipitate. Von Pirquet's reaction de- 
pends upon the cutaneous application of Tuberculin Old, while Moro's modification of von Pirquet's method consists in the use of Tuberculin Ointment, which is vigorously rubbed on a small area of the skin. A positive reaction is evidenced by the appearance of an eruption at the point of application after about twenty-four hours. Tuberculin T. R. (tuberculin residuum) is prepared by repeatedly centrifugalizing a suspension in water of the dried and ground tubercle organisms. Tuberculin B. E. (bacillary emulsion) is composed of a suspension of crushed or thoroughly ground tubercle organisms in 50 per cent glycerin solution. Tuberculin T. R. and Tuberculin T. E. are used as therapeutic agents, and are administered subcutaneously.

Antitoxic and antimicrobial serums are prepared from the blood of animals which have been immunized by repeated injections of specific organisms, in live or dead condition, or by repeated treatments with specific bacterial toxins. Antiserums may be employed in the form of liquid or dried serums or as precipitated globulins. The immunity induced by the use of antiserums is passive in nature. In other words, the protective material or antibodies are furnished to the treated individual ready-made, therefore the immunity which follows is relatively temporary. Antitoxic serums consist of those serums which are prepared from animals, treated with repeated doses of the specific toxins. The antibacterial serums, which are not as specific as the antitoxic, are the result of the treatment of the animals with increasing doses of the dead, attenuated or live bacteria. The important antitoxic serums are the antidiphtheritic and antitetanic, while the antibacterial serums are the antigonococcic, antimeningococcic, antistreptococcic and antituberculic.

In an interesting work entitled "Prolongation of Life," Metchnikoff advanced the theory that duration of life may be prolonged if measures were taken to control intestinal putrefaction. $\mathrm{He}$ found that there was a widespread popular belief in the advantage of a diet consisting largely of sour milk, and that there was a fair parallel between unusual longevity and such a diet. He also observed that the cause of much sickness and debility was due by reason of gastrointestinal autointoxication. It can be demonstrated by laboratory and clinical experiments that the lactic acid, due to the action of Bacillus lactis acidi, in the beverages known as koumys, kefir yoghurt, rapi and buttermilk, tend to inhibit intestinal putrefaction. It has been found that the organism causing Bulgarian sour milk is especially active in lactic acid production. This organism, known as Bacillus bulgaricus, is now prepared commercially on a rather 
large scale and sold in the form of tablets. The tablets, consisting of slowly dried cultures mixed with milk sugar, are taken as such or after having been added to sterile milk, thus effecting the souring of the same. In addition to tablets of Bacillus lactis acidi and Bacillus bulgaricus, a mixture of bacteria and yeast capable of producing lactic acid fermentation of milk is sold under the name of "Kefir fungi." Carter has made an examination of commercial cultures of Bulgarian Bacillus. (Jour. A. Ph. A., 1919, 8 p. 179.)

Very great interest has been aroused in the manufacture of nitrogen-fixing bacteria in cultures for the use of farmers. Probably no question is of greater fundamental importance to the agriculturist than the supply of nitrogen to the soil. It has been known for very many years that nearly all other plants except the Leguminosaæ (clover, alfalfa, soy beans, etc.) rob the soil of its nitrogen while plants of this family serve to enrich it in nitrogen, hence they have been called "collectors or accumulators of nitrogen." For more than a century it was known that the Leguminosæ produced nodules or tubercles on their roots which were supposed to be evidences of disease in the plants. In 1836 Treviranus found that these nodules were normal growths, and in 1865 Woronin discovered in them cells that were filled with bacteria. Hellriegel in conjunction with Wilfarth carried on a number of investigations and arrived at the incontrovertible conclusion that the production of nitrogen by leguminous crops was through the absorption of atmospheric nitrogen and connected with the development of the nodules on the roots of these plants. Beyerinck in 1888 isolated the bacteria and studied them and their products in artificial media. The organism found in the nodules on the roots of the Leguminosæ is a single species of bacillus known as Pseudomonas radicola. Prazinowski in 1889 inoculated pure cultures into leguminous roots with successful results, and since that time very much work has been done by manufacturers to supply farmers growing leguminous crops with cultures of nitrogenfixing bacteria which would give them the maximum yield of crops. This is particularly important where the leguminous crops are used in rotation in a soil where the nitrogen-fixing bacteria are desirable.

In the brief space allotted in a few pages it is impossible to adequately cover even the more important phases of applied bacteriology. Mention cannot be made of many products which are based upon the presence of bacteria or which are due to bacterial action, neither can a detailed discussion be given relative to many industrial operations which depend upon bacterial activity, such as the curing of vanilla, the fermentation of tobacco, the manufacture 
of vinegar, the tanning of hides, the ripening of cheese and the retting of flax.

To-day the study of Bacteriology as an applied science is becoming so broad that it consists of several special branches, the most important of which are Bacteriology in relation to Disease of Animals and Plants, Dairy Bacteriology, Soil Bacteriology, Bacteriology in relation to Water Supply and Sewage Disposal, and Household Bacteriology.

\section{ALGA}

Nearly all of the Algæ which are of any economic importance are included in the marine forms collectively known as seaweeds. Of the four principal groups only two, namely, the brown algæ (Phæophyceæ) and red algæ (Rhodophyceæ), yield commercial products. On account of their large yield of mucilage quite a number are used locally for food purposes. The ash of a number of the kelps, as Fucus, Laminaria, etc., still continue to be the source of iodin. A few of the kelps have been used in phthisis, their value no doubt being due to the iodin content.

LAMINARIA.-Devil's Apron. The cylindrical stipes and basal portions of the midribs of the fronds of Laminaria digitata and $\mathrm{L}$. Clustoni (Fam. Laminariaceæ). The former is a very characteristic kelp which is common north of Cape Cod. The fronds are attached to the rocks by fibers which are frequently arranged in whorls and from which arise a stout and solid stipe, from 3 to $15 \mathrm{dm}$. in length and which is more or less cylindrical below, compressed above and free from distinct mucilaginous cavities (muciparous glands). When well developed the stipe projects rigidly above the surface of the water at low tide and from which extends the oval or lanceolate lamina, which at the summit is split into digitate segments varying from 6 to $18 \mathrm{dm}$. in length and 3 to $9 \mathrm{dm}$. in width. L. Clustoni is a common European form and resembles L. digitata. In the preparation of the commercial article the stipes and lower portion of the midribs are cut into pieces of convenient length and quickly dried. They were formerly used in the manufacture of tents and bougies, to which they were well adapted, owing to the fact that the cell walls are mucilaginous, so that the stipes increase six-fold upon the absorption of water from the parts to which they may be applied. As they cannot be sterilized without losing this property, they have been replaced by other materials. In a similar way a number of other vegetable substances have been used. 
Description.-In more or less cylindrical or slightly flattened or bent pieces of variable length and 10 to $20 \mathrm{~mm}$. in thickness; externally, grayish-brown or dark brown, longitudinally furrowed and wrinkled; fracture tough, horny; internally, dark brown having a slight saline odor and a mucilaginous, slightly saline and bitter taste.

Inner Structure.-The stipes show two well-differentiated layers, an outer one of narrow cells with brownish walls, and a middle portion consisting of very long hyphæ-like cells, with thick, porous, mucilaginous walls. The cells contain numerous brown chromatophores, the brown pigment of which is soluble in water, leaving the green chloroplasts unaffected.

Constituents.-About 47 per cent of mucilage; tangic acid 19 per cent; cellulose 11 per cent; ash 13 per cent, of which two-thirds is soluble in water; iodin from 0.06 to 0.11 per cent. The iodin is apparently combined in an organic form and is soluble in water, alcohol, acetone, alkalies and acids. Tunmann was able by means of very clever technique to detect microchemically the presence of iodin in 0.001 to $0.002 \mathrm{gm}$. of Laminaria. Sections of the fronds were placed in conjunction with starch upon slides and strong nitric acid added, the liberated iodin unites with some of the starch grains, staining them a blue color.

Literature.-Tschirch, Handbuch der Pharmakognosie.

\section{PHEOPHYCEE, OR BROWN ALGE}

Fucus.-Bladder Wrack. The entire, dried plant of Fucus vesiculosus (Fam. Fucaceæ). A common seaweed growing on rocks near the coast of the northern countries bordering the Atlantic Ocean. The fruiting plants are most active and are collected in autumn, although fructification continues during the winter, or may be seen to some extent at any time during the year. According to Farlow in his monograph on "The Marine Algæ of New England," there are several varieties of Fucus vesiculosus, dependicg upon the character of the fronds and receptacles.

Description.-Fronds diœcious, $20 \mathrm{~cm}$. to 1 meter in length; dichotomously branching with a distinct midrib throughout; margin entire and often wavy, sometimes repeatedly forked or in some varieties short or spirally twisted; on either side of the midrib occur vesicles containing oxygen and which vary from spherical to ellipsoidal in shape. The receptacles, containing either oogonia or antheridia, are terminal, swollen, ellipsoidal or oval, often forked; the color when fresh, olive-brown becoming blackish-brown on drying; somewhat 
cartilaginous, having a saline odor and a mucilaginous, somewhat saline and nauseous taste.

Inner Structure.-The tissues consist for the most part of a pseudo-parenchyma, the cells upon the outer surface of the thallus being somewhat smaller and arranged in close tangential rows, while those distributed throughout the central portion are hyphælike and with thick mucilaginous walls. The cells contain a brownish protoplast, the coloring principle of which is soluble in a hydroalcoholic solution. If the material is first treated with a saturated solution of sodium chloride and alcohol then added, the chlorophyll may be extracted.

Constituents.-From 22 to 62 per cent of organic substances, consisting mostly of mucilage (algin) and a peculiar cellulose; 0.5 per cent of mannite; 0.1 per cent of a volatile oil, to which its odor is partly due; from 3 to 16 per cent of ash, containing both iodin and bromin. The ash contains from 0.7 to 1 per cent of iodin.

Allied Plants.-Fucus serratus, a very common species of Europe but very rare on our coast. It grows in deeper water than F. vesiculosus and is easily recognized by the serrated margin of the thallus and the absence of bladders. The receptacles are also serrate, considerably flattened, and acute at the summit. Its composition is similar to that of F. vesiculosus.

A number of other species of Fucus, besides those mentioned as well as other Algæ, are gathered under the name of kelp off the coast of Cherbourg, France, and Glasgow, Scotland, and are used as a source for the production of iodin and bromin.

\section{RHODOPHYCEA, OR RED ALGE}

Chondrus.-Irish Moss or Carrageen. The entire plant of Chondrus crispus (Fam. Gigartinaceæ), a common red alga found along the northwestern coast of Ireland and the coast of Massachusetts. The plants are collected chiefly during June and July, spread out on the beach and bleached by the action of the sun and dew, then treated with salt water, finally dried and stored. The chief points of collection in this country are 15 to 25 miles south of Boston.

Description.-Consisting of a number of dichotomously branching, somewhat enlarged segments, becoming emarginate or twolobed, which arise from a slender, somewhat flattened base about one-half the length of the entire thallus; yellowish-white, translucent; sometimes with fruit-bodies or sporangia embedded near 
the summit of the segments; somewhat cartilaginous; having a slight saline odor and a mucilaginous, saline taste.

One part of Chondrus when boiled for ten minutes with 30 parts of water yields a solution which gelatinizes on cooling, and is not colored blue by iodin test-solution (absence of starch); nor precipitated by alcohol (distinction from true plant gums); nor precipitated by tannin (distinction from gelatin); nor precipitated by lead acetate (distinguishing it from pectin).

Constituents.-From 55 to 90 per cent of carrageenin, a mucilaginous principle which is but slightly adhesive; about 10 per cent of proteins, and 10 to 15 per cent of ash, consisting of calcium oxalate and compounds of sodium, potassium, magnesium and calcium with chlorin, iodin, bromin and sulphur.

Allied Plants.-Gigartina mamillosa somewhat resembles Chondrus, but it is most abundant north of the region where Chondrus is gathered and thus rarely enters commerce in the drug collected in the United States. It is not unusual, however, in the imported article, and is distinguished by having the sporangia borne on short, tuberculated projections or stalks scattered over the upper portion of the segments.

An artificial gum is prepared by adding starch to the mucilage of Chondrus, and is said to be a good substitute for acacia, and may be employed as a base for fixing colors in fabrics.

Literature:-Anatomy and Constituents by Tunmann, Apoth. Zeit., 1909, p. 151. Morphology and Collection by Kraemer, Amer. Jour. Pharm., 1899, p. 479. For illustrations see Kraemer's Applied and Economic Botany.

AgAR-AGAR.-Japan or Chinese Gelatin. The dried mucilaginous substance obtained from several species of Gelidium, and Pterocladia capillaceum, red algæ (Rhodophyceæ) growing along the Eastern coast of Asia. The algæ are collected and prepared in much the same manner as Chondrus. The bleached material is then boiled with water, strained through a cloth, and the mixture allowed to cool. It is finally dried in the sun during rather cold weather. It is used to some extent in medicine, but its chief use is in the preparation of a solid culture medium which is extensively used in bacteriology.

Description.-Mostly in bundles, consisting of thin, transparent, membranous, agglutinated pieces, 4 to $6 \mathrm{dm}$. in length and 4 to 8 $\mathrm{mm}$. in width; externally oyster-white or brownish-white, shiny; tough and brittle when dry; odor slight; taste mucilaginous.

Inner Structure.-A granular or mucilaginous mass in which are imbedded the frustules of one or more diatoms, those of Arachnoidis- 
cus Ehrenbergii, being especially characteristic and are disk-shaped, from 0.100 to $0.200 \mathrm{~mm}$. in diameter. Through this mucilaginous matrix there are small swollen aggregates of starch grains of some of the Florideæ. In poorer specimens of Agar-agar the fragments of diatoms and spicules of sponges are rather numerous.

Powder.-Pale buff in color and consisting of angular fragments which when mounted in water are transparent, more or less granular and striated. It also shows masses of swollen starch grains, frustules of diatoms, and spiculæ of sponges mentioned above.

Constituents.-About 65 per cent of a mucilaginous substance (Gelose) yielding galactose on hydrolysis and mucic acid on oxidation; about 6 per cent of nitrogen-containing substances; 3.5 per cent of cellulose; not more than 5 per cent of ash; and about 22 per cent of water.

Agar-agar is insoluble in cold water, but if 1 part of Agar-agar be boiled for about ten minutes with 100 parts of water it yields a stiff jelly upon cooling. A solution made by boiling $0.100 \mathrm{gm}$. of Agaragar in 100 c.c. of water, upon cooling should not yield a precipitate with a solution of tannic acid (absence of gelatin), and not give more than a slightly reddish or reddish-violet color upon the addition of an iodin solution.

Literature.-Tschirch, Handbuch der Pharmakognosie; Takao, Jour. Pharm. Chim. 1917, 15, p. 175.

\section{BACILLARIACEA, OR DIATOMS}

TERrA SilicEA.-Siliceous Earth, Kieselguhr, Infusorial Earth. This occurs in natural deposits which are mined and usually calcined to destroy the organic matter, after which it is washed and dried. The article used in pharmacy is further purified by boiling with diluted hydrochloric acid, washing and calcining, and is known as Terra Silicea Purificata.

Description.-Purified siliceous earth is a very light and fine powder, odorless, and of an oyster-white color. It is insoluble in water, and upon boiling with distilled water and filtering, the filtrate should be colorless and neutral to litmus paper. It should be practically free from any carbonates or sulphates and contain not more than a trace of iron.

Inner Structure.-While siliceous earth consists almost entirely of the frustules of diatoms yet they may be variously preserved in different samples. In some specimens a large number of nearly perfect forms may be discerned, whereas in others they are for the most part broken up. It will be interesting to determine the relative 
decolorizing and clarification value of different specimens depending on the various forms of diatoms present and their condition.

The forms of diatoms present may be readily studied in mounts made with water or solutions of hydrated chloral. In special cases the material may be cleared for microscopical examination by first thoroughly mixing it with nitric acid and then adding a crystal of

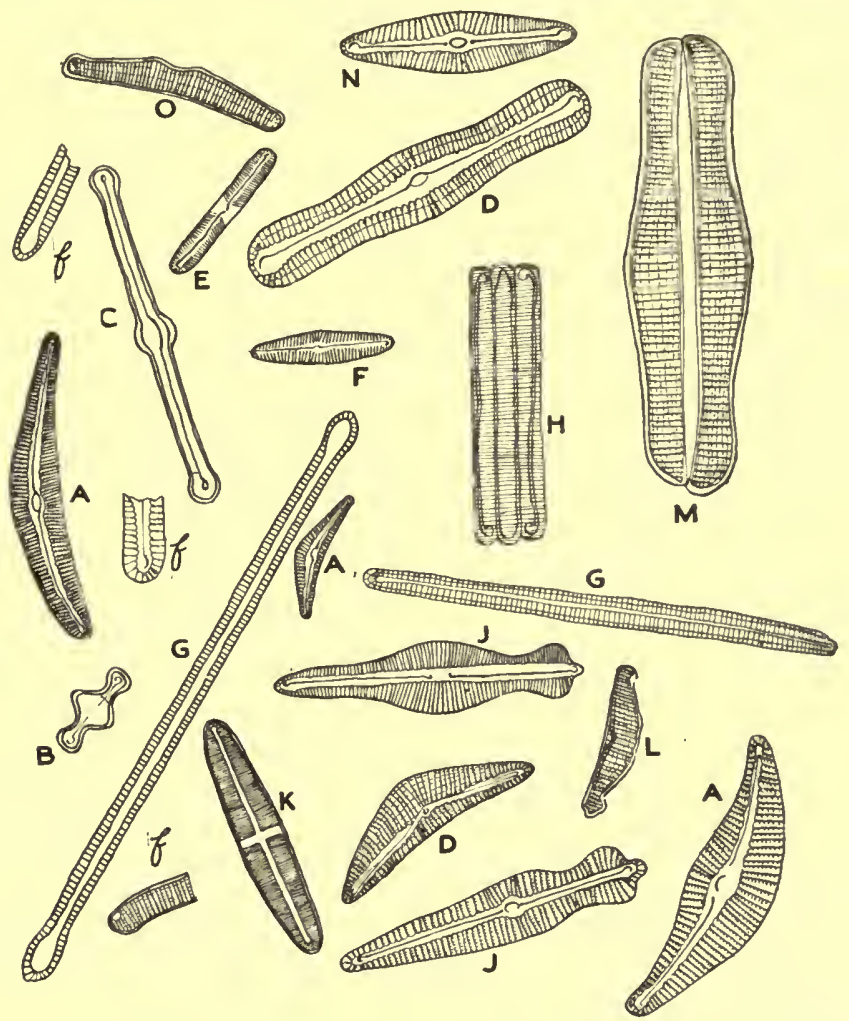

Fig. 3.-Some common forms of diatoms found in Diatomaceous earth. $A$, a species of Cymbella; $B$, Tabellaria floccolsa; $C$, another species of Tabellaria; $D$, two views of Navicula viridis; $E$, Navicula Phoenecenteron; $F$, Navicula lacustris; $G$, Synedra Ulna; $H$, several frustules of a Navicula; $J$, Gomphonema geminatum; $K$, a species of Stauroneis; $L$, Epithemia Hyndmannii; $M$, some frustules of Epithemia; $N$, Pinnularia Brebessonii; $O$, Eunotia diodon; $f$, fragments of broken diatoms.-Identified by Chas. Boyer, drawn by W. F. Haase.

potassium bichromate. The mixture is then gently heated and the reaction allowed to continue for ten or fifteen minutes. The acid solution is then carefully decanted and the residue washed repeatedly with distilled water until practically free from acid. In some cases the diatomaceous material is boiled with solutions of potassium 
hydroxide or sodium hydroxide, but great care must be exercised, as otherwise the markings are destroyed.

In making microscopic examinations it is important that the diatoms be uniformly distributed. This can be accomplished by placing a small quantity of the material in a 1- or 2-drachm homeopathic vial and nearly filling with water. The mixture is vigorously shaken, a small quantity is removed, transferred to another vial containing distilled water, and after vigorously shaking the mixture remove about 10 minims and place upon a slide. The excess of water is allowed to evaporate, the slide passed through a flame two or three times and the material mounted in Canada balsam. Of course examinations can be made direct in water. In the identification of the various genera and species it is necessary to bear in mind that there are two and sometimes even three views which may be obtained of the same diatom. Some of the common forms of diatoms occurring in commercial Siliceous Earth are shown in Fig. 3.

\section{FUNGI}

The fungi comprise a multitude of lower plants of quite diverse structure. They are distinguished by the fact that they do not produce chloroplastids and hence are either parasitic or saprophytic. It has been estimated that the several groups comprise about 65,000 species. The economic relations of the Fungi are of great importance, causing as they do considerable depredation to both animal and plant life. Some few are edible and are even cultivated for this purpose. Others are exceedingly toxic and not infrequently gathered with some of the edible forms. Relatively few are used in medicine, and of these Ergot is official in nearly all of the Pharmacopœias.

Ergota.-Ergot of Rye. The sclerotium of Claviceps purpurea (Fam. Hypocreaceæ), a fungus having two distinct periods in its life history - an active and a resting stage. During the latter it forms a compact mycelium, or sclerotium, which replaces the flowers and grains of rye. Ergot is picked by hand from the ears of rye, or it is separated after the threshing of the rye; it is carefully dried, and preserved against the attacks of insects by the use of small quantities of carbon-tetrachloride or chloroform. It deteriorates with age, particularly when powdered, and is not considered so valuable after one year. Various methods have been proposed for preparing the drug so as to preserve its medicinal properties for a longer period of time. Grover proposed the removal of the oil and Moss found the drug thus treated to retain its therapeutic value for six and a half 
years. Zanon suggests placing the drug in alternate layers with sand and keeping it in a closely sealed jar. Others grind the fresh Ergot and preserve with chloroform in paraffin paper, while some first extract the oil from the powder with alcohol or ether. Russia, Spain and Germany furnish the chief part of the commercial supply, the Russian drug being considered the most active.

Spanish Ergot usually consists of large grains, having a fine appearance, but is not so active as that from the other countries mentioned, and contains considerable starch.

Description.-Sub-cylindrical, tapering toward but obtuse at both ends, somewhat curved, 2 to $4 \mathrm{~cm}$. long and about $3 \mathrm{~mm}$. thick; externally purplish-black, longitudinally furrowed, occasionally transversely fissured, one end with the whitish remains of mycelial threads, fracture short; internally whitish or pinkish-white, sections somewhat triangular or two-lobed; odor peculiar, heavy, increased by trituration with potassium or sodium hydrate solution; taste oily and disagreeable.

Inner Structure.-An outer portion consisting of small violetcolored cells, the color of which is changed to blood-red upon the addition of sulphuric acid and is soluble in solutions of the alkalies producing a violet color. The rest of the sclerotium consists of nearly colorless thin-walled hyphæ which contain numerous globules of fixed oil.

Powder.-Grayish-brown; consisting for most part of thin-walled hyphæ, containing numerous globules of fixed oil which are liberated in mounts of solutions of hydrated chloral or sulphuric acid, which reagents also produce a reddish or rose-purple color in the powder.

Constituents.-The constituents of Ergot have been the subject of considerable investigation, and owing to the fact that the older investigators worked with mixtures rather than pure principles there has been some confusion in connection with the same. It contains at least two alkaloids and a series of active amines.

Ergotoxine or hydroergotinine is an amorphous alkaloid, insoluble in water and petroleum benzin, sparingly soluble in ether and readily soluble in most other organic solvents. It exists naturally in Ergot, is readily soluble in cold alcohol and consequently occurs in alcoholic extracts of Ergot. It is soluble in dilute solutions of sodium hydroxide. The salts form colloidal solutions with water, but they are precipitated by electrolytes (salts of mineral acids). It has a characteristic action on the cock's comb and is concerned in the uterine and vascular effects. It is rather unstable and by loss of water changes into its lactone, the second alkaloid of Ergot. 
Ergotinine or Ergotine is a crystalline alkaloid and while soluble in nearly all of the solvents for Ergotoxine it differs from this alkaloid in being only sparingly soluble in cold alcohol, and the solutions of its alkalies are partly converted. Its physiological action is rather weak. The name Ergotine is applied to a variety of pharmaceutical extracts which are generally prepared in such a way that they contain mainly the amines and relatively little of the alkaloid.

Para-hydroxyphenylethamine is closely related to epinephrine in structure and action. It is mainly responsible for the pressor effect, and is not concerned in the uterine action.

Beta-iminazolyle thylamine (4-meta-aminoethylglyoxaline), lowers the blood-pressure, and stimulates the excised uterus powerfully.

A number of other aromatic amines occur casually, such as agmatine (guanidobutylamine), which has a weak stimulant action on the excised uterus, isoamylamin, etc.

These aromatic amines are also produced in the putrefaction of meat and in the intestinal tract, and have been prepared synthetically. They are derived from the amido-acids by the elimination of carbon dioxide; para-hydroxyphenyl-ethyl-amine from tyrosine; beta-iminazolyl-ethyl-amine from histidine; agmatine from arginine; isoamylamine from leucine.

It will be seen that several of the constituents exert uterine actions, and it is not yet known which of these is the most important in the effects of the crude drug. The galenic preparations vary in composition according to the solvent used. The alcoholic fluid extract probably owes its activity mainly to ergotoxine; the aqueous preparations, including the solid extracts and "ergotines," owe theirs probably to the amines, particularly to histamine. The isolated principles have not been used sufficiently for it to be said whether or not they can take the place of the natural mixture.

All ergot preparations, especially those containing water, deteriorate with age. It would, therefore, be of advantage to standardize the ergot preparations. Because of the complex composition, no satisfactory chemical assay has been devised. Different methods of bio-assay have been proposed; but because of the multiplicity of the actions, it is not certain how perfectly these tests reflect the therapeutic efficiency of the drug. The cock's comb method is the most widely employed. It has at least a negative value, for samples which do not respond to this test may be considered worthless.

Allied Plants.-Ergot is also found on other cereals, as wheat, barley and rice and wild grasses, as quack grass (Triticum). 
To Remove Ergot in Rye.-Johnson and Vaughan give a method of separation based on the fact that the grains of ergot are lighter than the sound rye. Their method is as follows: Make a salt brine of about 20 per cent strength. This can be done by dissolving 40 pounds of common salt in 25 gallons of water, or in that proportion. Have this solution in a tub, barrel, or other suitable container. When the salt is well dissolved pour in the rye slowly and stir vigorously at the same time. It is a job for two men. The ergot and light seeds will rise to the top and the sound kernels will sink to the bottom. Skim off the ergot or add rye until the solution rises and runs over the side of the tub, carrying with it the ergot, when assisted by hand or skimmer. If the ergot does not float, strengthen the solution by adding more salt and stirring until it dissolves. Grain in different stages of dryness will require a slightly different strength of solution.

A good arrangement is to have two tubs or half-barrels, one set above the other, so that the overflow containing the ergot will fall into the lower tub. Cover this lower tub with cheese cloth to catch the ergot and let the brine run through so that it may be used over again. With the addition of more salt to replace that which sticks to the kernels, the solution is good as long as it lasts. When vigorous stirring brings up no more ergot, pour off or drain off the solution. Then rinse at once with fresh water to remove the salt. This wash. ing is necessary to prevent injury to germination and to allow the wet grain to dry more readily.

Air drying is quickly and easily accomplished if the wet grain is spread thinly on a clean floor or canvas and shoveled over a few times. The clean rye may be used for any purpose desired without any fear that it will carry the disease.

Ustilago.-Corn Smut.-The fungus, Ustilago Maydis (Fam. Ustilaginaceæ), occurs upon the stem and flowers of the Indian corn (Zea Mays) and was formerly official.

Description.-It occurs in irregular, somewhat cylindrical or globose masses from 10 to $15 \mathrm{~cm}$. in diameter, consisting of a whitish membrane, becoming dark with age, and a brownish-black mass of spores, which are nearly spheroidal and about $0.007 \mathrm{~mm}$. in diameter. The drug has a heavy odor and a disagreeable taste. Ustilago should be carefully dried and not kept longer than one year.

Powder.-Grayish-brown; nearly spheroidal spores about 0.007 $\mathrm{mm}$. in diameter; little or no foreign substances. Spores of Coprinus comatus, blackish and ellipsoidal, about $0.005 \mathrm{~mm}$. to $0.010 \mathrm{~mm}$. in diameter. Spores of Agaricus campestris more brownish than those 


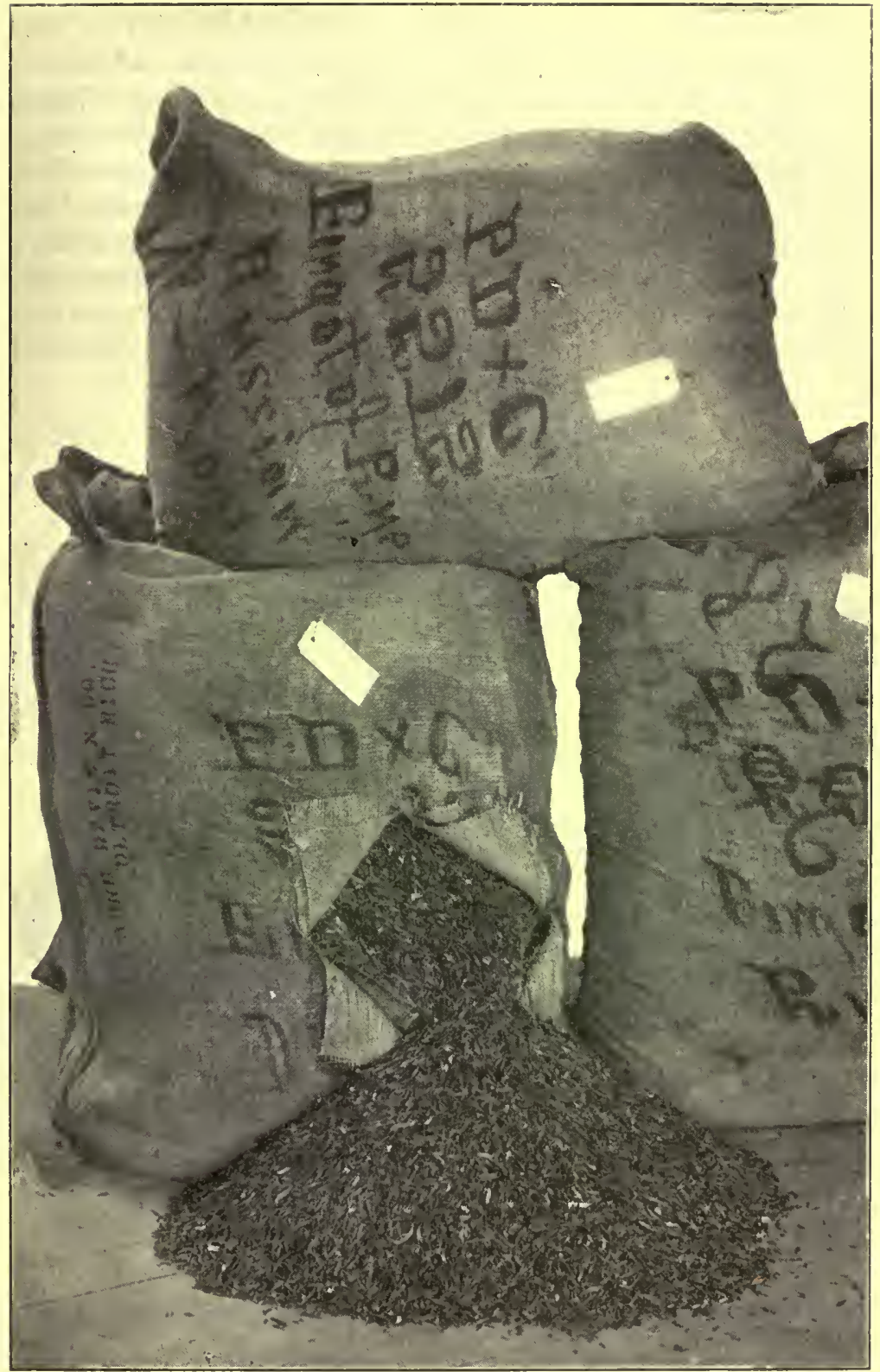

FIG. 4. Original packages of Ergot imported from Russia. After a photograph by Parke, Davis \& Co. 
of corn smut. ovoid and about $0.005 \mathrm{~mm}$. to $0.007 \mathrm{~mm}$. in diameter.

Constituents.-Corn Smut contains a crystallizable alkaloid, ustilagine, which is soluble in water and alcohol and forms crystalline salts; from 0.5 to 5.5 per cent of a crystallizable acid substance, maizenic acid, which resembles sclerotic acid; about 1.5 per cent of a volatile base resembling trimethylamine; 2.5 to 6.5 per cent of a dark brown fixed oil, insoluble in alcohol and having the odor of the drug; about 8 per cent of two resins, one being soluble in alcohol and

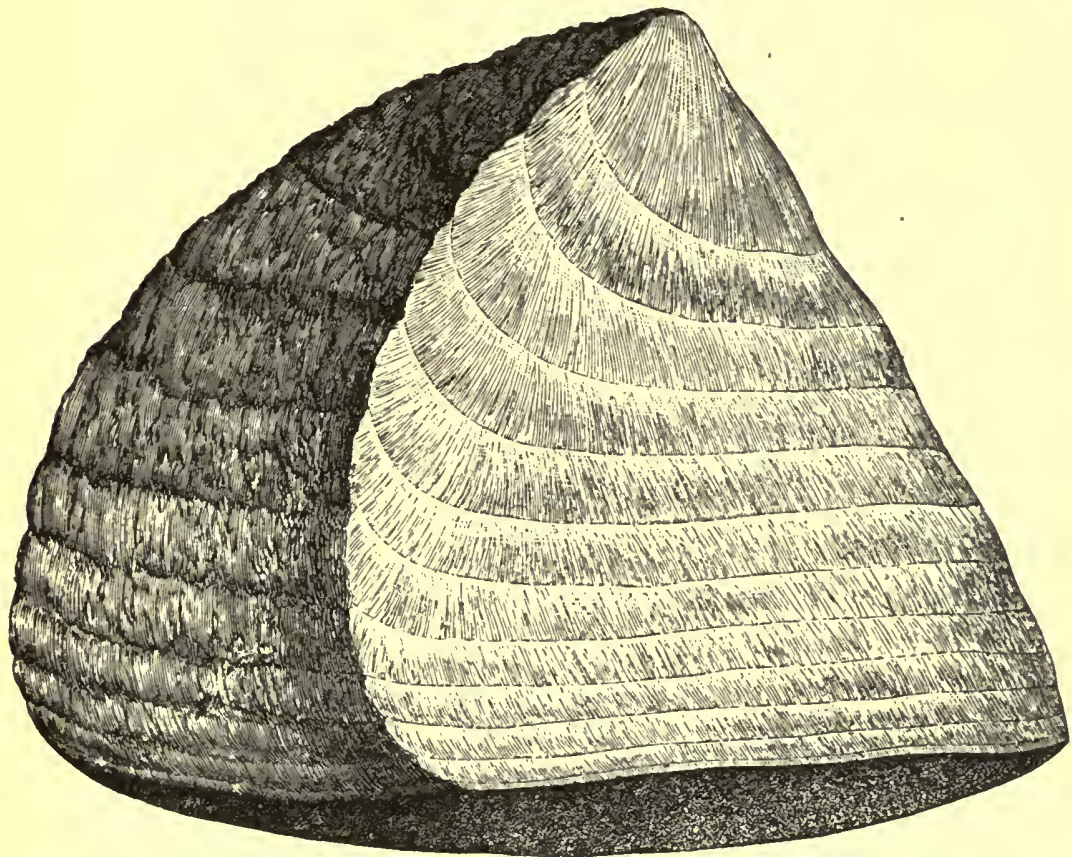

Fia. 5.--Polyporus officinalis Fr., showing the annular increments and at the basal portion the numerous characteristic small pores. It grows on the larch trees of Europe and Asia, which countries furnish the commercial article. It is also found on the larch, pine and spruce trees of Michigan Montana, California, and British Columbia. Some specimens are quite large and weigh as much as $\mathbf{1 5}$ pounds in the dry state. After Hennings in Engler and Prantl's "Die natürlichen Pflanzenfamilien."

the other in ether; 3.75 per cent of a non-reducing sugar which crystallizes in needles, and yields 4.5 per cent of ash.

Agaricus.-White Agaric, Larch Agaric.-The dried fungus Polyporus officinalis (Vill.) Fries (Fam. Polyporaceæ). (Fig. 5.) The commercial supplies are obtained from the mountainous regions 
of Southern Europe and Siberia, the product being collected from larch trees, and deprived of the firm outer rind.

Description.-In light spongy, irregular pieces; 8 to $14 \mathrm{~cm}$. in diameter; externally yellowish-white to yellowish-brown and showing at places the characteristic porous surface so common in the genus; easily cut, having a corky texture; internally whitish or light brown with yellowish striations and sometimes a smooth shiny surface, occasionally with pieces of larch wood imbedded; odor aromatic; taste slightly aromatic, acrid and intensely bitter.

Inner Structure.-Consisting mostly of numerous ramifying thin-walled hyphæ, containing occasionally one or more peculiarly

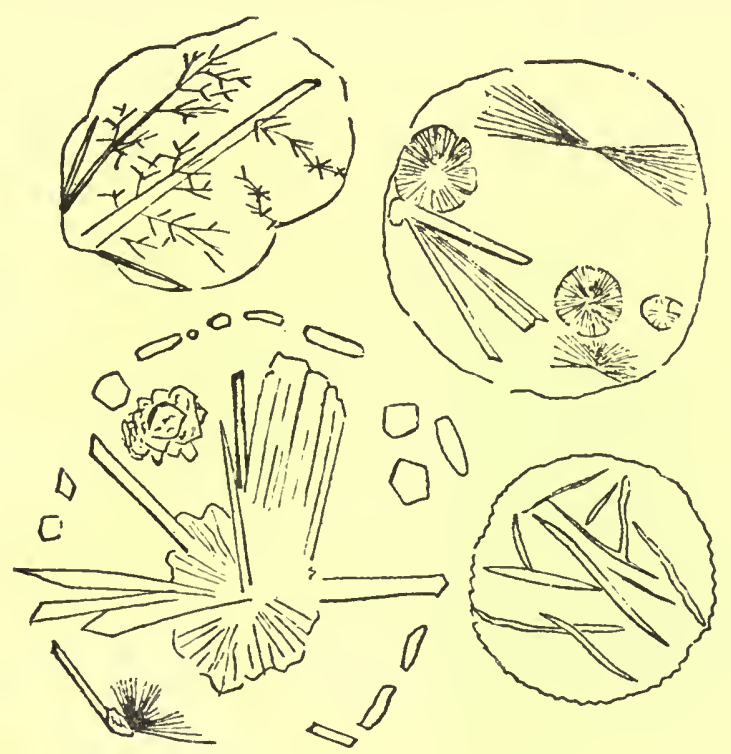

FIG. 6.-Sublimate crystals obtained upon heating small quantities of powdered Polyporus officinalis. The crystals resemble those of Agaricinic acid. The sublimate consists first of slightly colored globules, in which on drying there separates needles or needle aggregates and in some cases large plates, which are strongly polarizing and show extinction parallel with the long axis.-After Tunmann in Apoth. Zeit., 1914, p. 120.

shaped structures resembling branching bast fibers which grow out from the mycelium and numerous resinous masses in the knotted hyphæ in which the activity of the drug resides. Upon heating a small quantity of drug or powder under conditions so as to catch the sublimate upon a slide it will be found that characteristic crystals of agaricinic acid have been deposited. (Fig. 6.) 
Constituents.-About 50 per cent or more of resin consisting of 3 or 4 resinous substances; $\alpha$-resin consisting of a reddish, bitter and pungent principle. $\beta$-resin or agaricinic acid, which is the most important principle. It occurs in yellowish crystals which are slightly soluble in water and ether and very soluble in boiling water or hot alcohol. $\gamma$-resin is amorphous and is present from 3 to 4 per cent; $\delta$-resin being a soft resin and in small quantities; it also contains a fatty substance, mannit, a nitrogenous substance, tannic acid, phosphoric acid, malic acid, tartaric acid and oxalic acid. The cellulose varies from 10 to 30 per cent and the ash from 1 to 2 per cent, being particularly high in phosphorus.

Uses.-Polyporus and agaricinic acid are official in several of the foreign Pharmacopœias and used because of their anti-diaphoretic properties, being fully equal to atropine in the effect of suppressing dermic action.

Literature.-Schmieder, Arch. der Phar., 1886, p. 641; Tunmann, Apoth. Zeit., 1914, p. 120.

\section{POISONOUS FUNGI}

On account of the high protein content in some of the edible Fungi, varying from 20 to 60 per cent in the dried material of Agaricus campestris, considerable interest has been shown, especially in foreign countries, in teaching their citizens the food value of mushrooms. In this country there are quite a number of persons who make it a practice to gather edible mushrooms and each year there are numerous cases of poisoning reported through the newspapers. This practice will continue and the pharmacist will be frequently called upon to identify the species which has been the cause of poisoning. A very excellent Bulletin has been prepared by Flora W. Patterson and Vera K. Charles of the Bureau of Plant Industry, U. S. Department of Agriculture, entitled "Mushrooms and other Common Fungi." Some of the most common poisonous fungi which are described in this publication are the following:

Amanita Muscaria.-The Fly Amanita.-(Very poisonous.) Cap globose, convex, and at length flattened at maturity margin sometimes slightly striate; flesh white, sometimes yellow under the pellicle; remnants of the volva persisting as scattered, floccose, or rather compact scales, color subject to great variation, ranging from yellow to orange, or blood-red, gills white or yellowish, free but reaching the stem; stem cylindrical, at first stuffed, later 
hollow, upper part torn into loose scales; bulb prominent, generally marked by concentric scales forming irregular ridges; ring typically apical, lacerated, lax, large.

Cap 8 to $14 \mathrm{~cm}$. broad, stem 10 to $15 \mathrm{~cm}$. long. (Fig. 7.)

A. muscaria may be found during the summer and fall, occurring singly, or in small associations, or in patches of considerable size. It grows in cultivated soil, partially cleared land, and in woods or roadsides. It does not demand a rich soil, but rather exhibits a preference for poor ground. The color is of an exceedingly variable character, the plants being brighter colored when young and fading as they

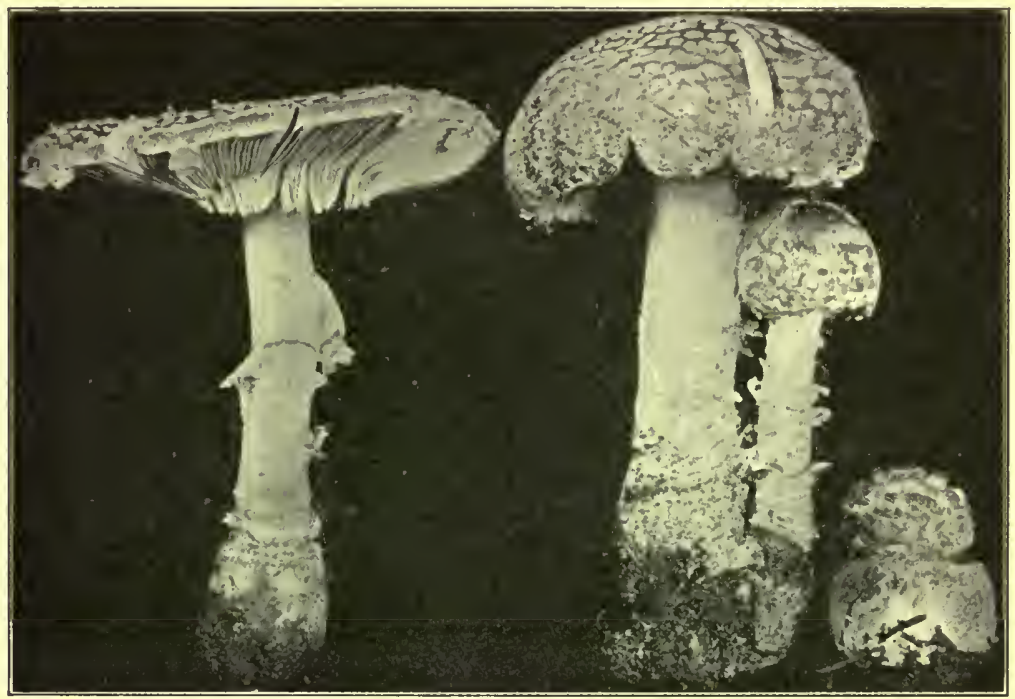

FIg.-7. The Fly Amanita (Amanita muscaria), a very poisonous fungus, which has been responsible for many deaths and numerous cases of severe illness. It is found during the summer and fall growing in partially cleared land and in woods and roadsides. The flesh is white, the upper portion or cap is convex, becoming at maturity flattened, and marked by scattered, floccose or rather compact scales, varying from yellow to orange or red in color. The stem is cylindrical, marked by a ring at or near the middle portion and a prominent bulb at the base.-After V. K. Chestnut, Bureau of Plant Industry, U. S. Department of Agriculture.

mature. The European plant possesses more gorgeous colors than the American form.

This is a very poisonous species, and it has been the subject of many pharmacological and chemical investigations. Its chief poisonous principle is muscarine, although a second poisonous 
element is believed to be present, as atropine does not entirely neutralize the effect of injections of A. muscaria in animals.

This species has been responsible for many deaths, and numerous cases of severe illness have been caused by persons mistaking A. muscaria, the poisonous species, for A. cæsarea, the edible species. While typical specimens of these two species possess distinguishing characters, it is recommended to shun all Amanitæ.

In Siberia, Russia, the natives make several uses of A. muscaria. Preserved in salt it is eaten, though probably more as a condiment than as a main article of diet; a decoction is popular as an intoxicant and deaths are reported upon good authority as resulting from a " muscaria orgy."

Amanita Phalloides.-Death Cup.-(Deadly poisonous.) Cap white, lemon, or olive to umber, fleshy, viscid when moist, smooth or with patches or scales, broadly oval, bell shaped, convex, and finally expanded, old specimens sometimes depressed by the elevation of the margin; gills free, white; stem generally smooth and white, in dark varieties colored like the cap but lighter, solid downward, bulbous, hollow, and attenuated upward; ring superior, reflexed, generally entire, white.

The large, free volva, its lower portion closely adherent to the bulb, and the large ring are of assistance in distinguishing this species.

Cap 7.5 to $10 \mathrm{~cm}$. broad; stem 7.5 to $12.5 \mathrm{~cm}$. long. (Fig. 8.)

This species and its forms are subject to great variation in color, ranging from white, pale yellow, and olive to brown. A. phalloides is a very cosmopolitan plant and one of very common occurrence. It is the most dangerous of all mushrooms, for no antidote to overcome its deadly effect is known. It exhibits no special preference as regards habitat and is found growing in woods or cultivated land from summer to late autumn. When fresh it is without scent, but a peculiarly sickening odor is present in drying the plants.

Amanita Verna.-Destroying Angel.-Cap white, smooth, viscid when moist, convex when expanded, margin even; gills free and white; stem stuffed, or hollow in age, bulbous, sheathed at the base by the membranous volva; ring reflexed, forming a wide collar.

By most authorities Amanita verna is considered a mere form of A. phalloides, as it has no constant morphological characters and is only separated by the pure white color and its generally more slender form. Because of its exceedingly poisonous nature it is popularly known as the "destroying angel." 


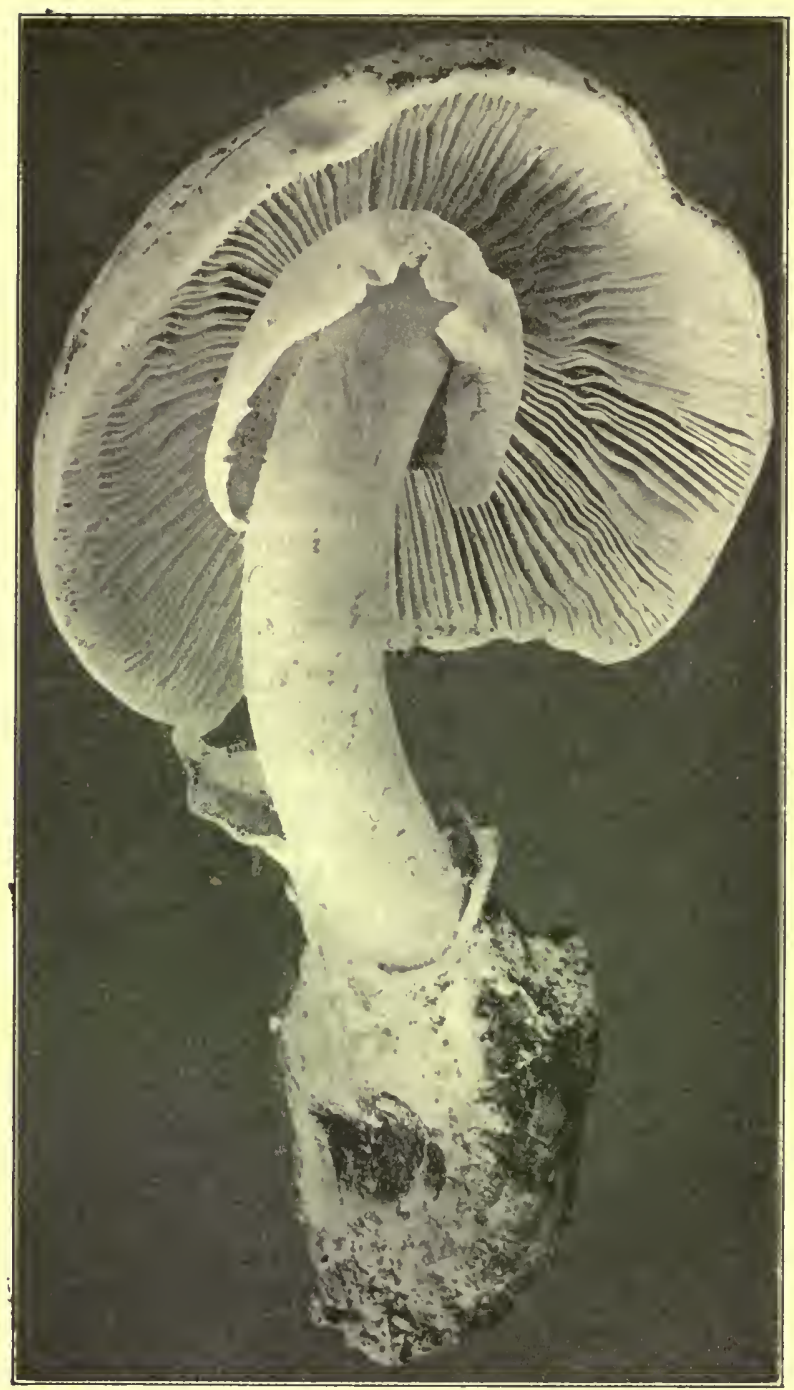

FIG. 8.-Death Cup (Amanita phalloides). This is probably the most toxic of all mushrooms and is of very common occurrence. It is usually found during the summer and autumn and may be found in woods or in cultivated lands. The upper portion or cap varies in color from white, pale yellow, olive to brown. The gills are white, as is also the stem, the latter having a reflexed ring at the upper portion and a bulb at the lower part. When fresh it is nearly odorless, but on drying has a sickening odor.-After Patterson and Charles, Bureau of Plant Industry, U. S. Department of Agriculture. 
Lepiota Morgani.-Green Gill.-Cap fleshy, globose when young, on expansion plane or slightly depressed, not umbonate, white with a yellowish or brownish cuticle, which breaks up into scales except in the center; flesh white, changing to reddish or yellowish on being cut or bruised; gills close, lanceolate, remote, white becoming green; stem firm, smooth, hollow, subbulbous, tapering upward, white with brewnish tinge; ring large, movable.

Cap 12.5 to 22.5 or even $30 \mathrm{~cm}$. broad; stem 15 to $22.5 \mathrm{~cm}$. long, 8 to $16 \mathrm{~mm}$. thick.

Great care should be taken to avoid this species. Many instances of poisoning are well substantiated, and extreme inconvenience and serious illness have resulted from eating very small pieces of the uncooked mushroom. The gills are slow in assuming the green tinge characteristic of this species, but after being allowed to remain in ordinary room temperature the color is quite noticeable. This fungus occurs mostly on grassy places, such as lawns and parks, during the summer months, frequently forming large "fairy rings."

Clitocybe Illudens.-Cap fleshy, convex or expanded, then depressed, sometimes with a small umbo, saffron yellow, in age becoming sordid or brownish; gills broad, distant, unequally decurrent; stem solid, firm, smooth and tapering toward the base. ascending, curved, rarely erect, color same as cap.

Cap 10 to $15 \mathrm{~cm}$. broad; stem 12.5 to $20 \mathrm{~cm}$. long.

This is a very striking fungus both on account of its color and the large clumps it forms about stumps or decaying trees. It is often irregular in form, from the crowded habit of growth. On account of the phosphorescence which renders it conspicuous at night, it is commonly known as the jack-o'-lantern. While not considered poisonous, it produces illness and is to be carefully avoided. It may be found from August to October.

Lactarius Fumosus.-Cap convex, plane or slightly depressed, snuff brown or coffee-colored, dry glabrous or pruinose, very smooth, margin entire or sometimes wavy; flesh white, changing to reddish when wounded; gills subdistant, adnate, or slightly decurrent, white then yellow, becoming pinkish or salmon where bruised; stem nearly. equal or slightly tapering downward, stuffed, then hollow, colored like the cap.

Cap 5 to $7.5 \mathrm{~cm}$. broad; stem 4 to $6 \mathrm{~cm}$. long, about $12 \mathrm{~mm}$. thick. This species varies considerably in size, color, and closeness of the gills. The distinguishing features for field identification are the coffee-colored cap and the changeable color of the flesh and gills. Its use should be strictly avoided, as it closely resembles Lactarius 
fuliginosus, a poisonous species. These two species, L. fumosus and L. fuliginosus, are sometimes considered identical.

Lactarius Torminosus.-Cap convex, then depressed, surface viscid when young or moist, yellowish red or ochraceous with pink shades, margin involute when young, persistently tomentose hairy; gills crowded, narrow, of ten tinged with yellow or a flesh color; stem cylindrical or slightly tapering at the base, hollow, whitish.

Cap 5 to $9 \mathrm{~cm}$. broad; stem 3.75 to $7.5 \mathrm{~cm}$. long, 8 to $16 \mathrm{~mm}$. thick.

According to some authors this species is injurious only when raw. It is cooked and eaten in Sweden. In Russia it is enjoyed dressed with oil and vinegar or it is preserved by drying.

Russula Emetica.-Cap oval to bell-shaped, becoming flattened or depressed, smooth, shining, rosy to dark red when old, fading to tawny, sometimes becoming yellow, margin finally furrowed and tuberculate; flesh white, but reddish under the separable pellicle; gills nearly free, somewhat distant, shining white; taste very acrid; stem stout, spongy-stuffed, fragile when old, white or reddish.

Cap 7.5 to $10 \mathrm{~cm}$. broad; stem 6 to $10 \mathrm{~cm}$. long.

Russula emetica is a handsome plant of wide distribution found during summer and autumn on the ground in woods or open places. Although some enthusiastic mycophagists testify to its edibility, it is best to consider the species poisonous.

Panus Stiptrcus.-Bitter Panus.-Cap pale cinnamon to grayish, kidney shaped, scurfy, tough; gills not decurrent, thin, narrow, crowded, connected by veins; stem short, lateral, solid, ascending pruinose.

Cap 12 to $25 \mathrm{~mm}$. broad.

This little species is common on stumps, shriveling in dry and expanding in wet weather. It is characterized by a pronounced astringent taste, which is very unpleasant in its effect on the mouth and throat, and is considered poisonous.

Constituents.-The toxic principles of a number of the poisonous fungi have been studied. They belong to several distinct classes. (a) In some cases the toxic principle is an alkaloid as muscarine, being the active principle of Amanita muscaria. It is an alcohol-soluble crystalline substance and usually classed with the ammonia bases. It has been prepared synthetically by the oxidation of choline, but the artificial body does not produce quite the same symptoms and it is easily decomposed. Muscarine is physiologically neutralized by atropine and this alkaloid is therefore used as an antidote in cases of poisoning by Amanita muscaria. 
(b) The toxicity in other cases is due to a very sensitive glucoside which has the property of dissolving the red blood corpuscles. It is found in Amanita phalloides ard is so powerful that even in a dilution of 1 in 125,000 it is still operative upon the red blood cells of ox blood. Abel and Ford have given it the name of Amanitahemolysin and have found that it is destroyed by heating to $70^{\circ} \mathrm{C}$. and by the action of digestive ferments. Ford has been able to prepare an anti-poison or an anti-hemolysin, the action of which is to completely neutralize the blood-laking properties of this glucoside.

(c) A third class of principles have been isolated and these belong to the group of bacterial toxins. Their real nature is unknown, but they have been thus classified by Ford by virtue of their causing characteristic lesions in animals after a definite latent period. The best known of these is Amanita-toxin, which is probably the most toxic principle known and occurs in Amanita phalloides. It is the cause of death when this fungus is eaten.

(d) In other fungi the active principle is in the nature of an acid. The one most carefully studied is the agaricinic acid occurring in Polyporus officinalis. In Helvella amara, fungus used in medicine in Cochin China, the active principle is helvellic acid. Kobert states that he has found mushrooms that emitted an odor of hydrocyanic acid and that poisonous symptoms resembling those produced by this acid sometimes occur in mushroom poisoning.

In testing fungi Ford employs the dried fungus and makes an aqueous extract, using 6 gms. to 50 c.c. of water. These solutions are then diluted to a strength from 1 in 20 to 1 in 200 and subcutaneously injected into guinea pigs, when, if they are made from poisonous fungi they show within twenty-four hours the characteristic symptoms and reactions of either acute or chronic intoxication.

Literature.-Ford, Science, July 23, 1909, p. 98; Kobert, Lehrbuch der Intoxikationen; Blakeslee and Gortner, Biochemical Bulletin, 1913, 2, p. 542.

\section{SACCHAROMYCES, OR YEASTS}

Yeasts are unicellular organisms and are usually regarded as being greatly reduced sac-fungi. They belong to the family Saccharomycetes and of which there are several classes, the principal one of which is Saccharomyces, being the organism used in the manufacture of beer and compressed yeast. The real Saccharomycetes are capable of forming endospores and are further subdivided according to whether they ferment maltose, as brewer's yeast, or not.

The yeast cell is more or less globular or ovoid in form and varies 
from 0.006 to $0.010 \mathrm{~mm}$. in length (Fig. 9). The wall is very thin and encloses a ramifying protoplasm with a single nucleus and numerous vacuoles. The vacuoles vary in number and the nucleus, in some cases, is of considerable size; being one-third of the diameter of the cell. As the yeast cell grows one end may enlarge, gradually becoming the size of the original cell. Yeast in this condition is said to be budding. A short chain of cells may be formed in this way, the individuals separating and forming new organisms. Yeast not only multiplies in this manner but also by the production of endospores which are usually formed when the necessary nutriment is lacking. Certain

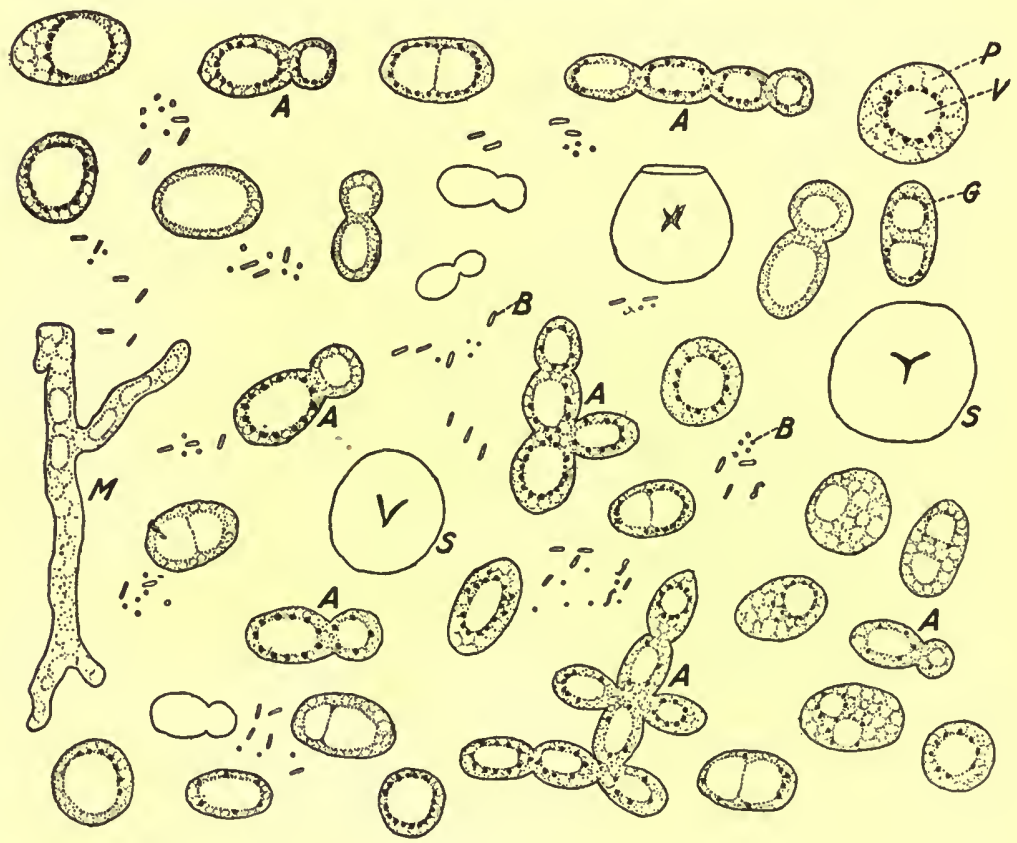

Fig. 9.-Yeast cells in compressed yeast and brewer's yeast. $A$, budding cells; $P$, protoplasm; $G$, granules showing molecular motion; $M$, foreign mold; $B$, bacteria; $S$, Cassava starch grains in yeast cake.-Drawing by Hogstad.

substances have been found to be essential for the growth of yeast; these include sugar, albuminous material or ammoniacal salts, sulphate of magnesia and potassium phosphate. For the study of yeasts in the laboratory they may be grown in Pasteur's Solution, consisting of potassium phosphate, $2 \mathrm{gm}$.; calcium phosphate $0.2 \mathrm{gm}$.; magnesium sulphate $0.2 \mathrm{gm}$.; ammonium tartrate $10 \mathrm{gm}$. ; cane sugar $150 \mathrm{gm}$; ; water sufficient to incke 1000 c.c 
The action of yeasts upon sugars is to form alcohol and carbon dioxide, the former being the important product in the brewing industries and the latter for the raising of the dough in bread making. This reaction is due to the production of the enzyme zymase. Yeast also contains the enzyme known as invertase. In commercial mixtures other enzymes are doubtless present. The use of yeast in medicine is due to the collective action of the several enzymes and for this purpose both brewer's yeast and compressed yeast are. employed. The latter is used under the name of Faex Compressa and contains besides yeast, starch grains and a few bacteria. Compressed yeast has a characteristic odor and should be free from molds and unpleasant odors.

\section{LICHENS}

Lichens are a peculiar group of plants being composed of some of the higher fungi which are parasitic upon some of the green and blue Algæ. They are of rather common occurrence upon the barks of trees, rocks and some grow upon soil. They consist of a thallus in which the algal cells have a more or less definite position. The upper portion consists of compact hyphæ comprising what is known as the cortical layer. Beneath this is the algal layer from which the fungal hyphæ draw their nourishment. The lower surface is differentiated into a cortical layer from which the hyphæ are extended in the form of rhizoids attached to their substratum. The fruit or sporocarp varies, depending upon the fungus entering into the lichen, but the apothecium is the most common. Owing to the fact that many of them contain lichenin, a carbohydrate resembling starch, a few of the lichens have been used as food. While some are of medicinal interest, as Cetraria, their chief interest is in the coloring principles which they contain and which have been the subject of painstaking investigations of $\mathrm{O}$. Hesse during a great many years.

Cetraria.--Iceland Moss.-The entire dried plant of Cetraria islandica, one of the Ascolichens which is widely distributed over the northern part of both continents. The chief commercial supplies are obtained from Scandinavia, Germany, Switzerland and parts of Austria.

Description.-Consisting of a number of somewhat dichotomously branching, more or less curled, papery, fringed segments, 5 to $10 \mathrm{~cm}$. long and about $5 \mathrm{~mm}$. wide; upper surface greenishbrown, with occasional dark reddish-brown cupular apothecia; under surface grayish, with numerous small, whitish, depressed 
spots; tough when damp, but brittle when dry; odor slight; taste mucilaginous and bitter. For illustrations consult Kraemer's "Applied and Economic Botany."

Inner Structure.-Sections through an apothecium show the hymenium with their asci each containing 8 ascospores and 2 paraphyses beneath which is distributed the hypothecium composed of fungal hyphæ; an algal layer in the middle subtended by a medullary layer of loose fungal hyphæ and a lower or ventral surface composed of several rows of small compactly arranged cells. Tunmann has been able to obtain from small pieces of thallus microsublimates containing crystals of lichenostearic acid. (Fig. 10.)
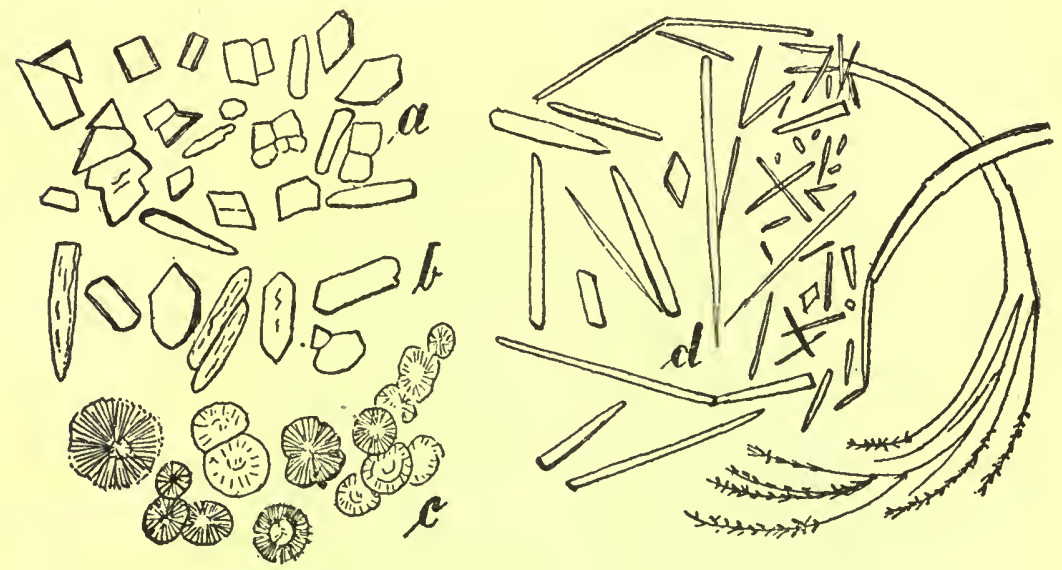

FIG. 10.-Crystals of lichenostearic acid obtained by micro-sublimation of pieces of the thallus of Cetraria, not larger than $0.5 \mathrm{~cm}$. square. $a$, crystals obtained by sublimation; $b$, a granular sublimate which was recrystallized from alcoholic solution; $c$, sublimate treated with sodium carbonate and showing crystal aggregates of the sodium salt of lichenostearic acid; sublimate treated with ammonia giving crystals of the ammonium salt of lichenostearic acid.-After Tunmann, Apoth. Zeit., 1913, p. 892.

Constituents.-The principal constituents are lichenin and isolichenin (about 70 per cent), the former of which appears to be intermediate between starch and cellulose, and is soluble in hot water, the solution becoming gelatinous on cooling, but not colored blue with iodin; isolichenin (dextrolichenin) somewhat resembles soluble starch, being soluble in cold water and giving a blue reaction with iodin. The drug also contains 2 to 3 per cent of a bitter crystalline principle, cetrarin, which is colored blue with concentrated hydrochloric acid and yields on hydrolysis cetraric acid, which is also intensely bitter; 1 per cent of a tasteless, crystalline principle, licheno- 
stearic acid; several organic acids, as oxalic, tartaric and fumaric (lichenic); about 15 per cent of cellulose; about 3.6 per cent of an uncrystallizable sugar; 3.7 per cent of gum; a principle resembling chlorophyll, thallochlor, which is unaffected by hydrochloric acid; and yields less than 2 per cent of ash.

The bitter principle in Cetraria may be removed by treating the drug with a 1 per cent solution of potassium carbonate at about $60^{\circ}$ C. for several hours.

Iceland moss jelly (Gelatina lichenis islandica) is official in the German Pharmacopœia, and is prepared by making a decoction of 3 parts of washed cetraria and 100 parts of water, adding 3 parts of sugar and evaporating the whole to 10 parts. Dried, saccharated Iceland moss, which is official in the French Codex, is prepared somewhat similarly to the Iceland moss jelly, but the product is evaporated to dryness and then powdered.

Allied Plants.-Usnea barbata and Cornicularia aculeata contain a principle resembling lichenin, which on hydrolysis yields glucose. Evernia prunastri contains a carbohydrate evernin, which resembles lichenin but is dextrogyrate. The following lichens do not contain lichenin, but yield carbohydrates which on hydrolysis give little or no glucose: Cladonia rangiferina contains 30 per cent of mannose; Stereocaulon pascale and Peltigeria aphthosa yield on hydrolysis dextromannose and dextrogalactose.

Literature.-For illustrations consult Kraemer's Applied and Economic Botany; the Microchemistry, Tunmann, Apoth. Zeit., 1913, p. 892.

Orchil.-Archil.-A coloring substance obtained by the fermentation of Roccella tinctoria, R. fuciformis and other lichens. R. tinctoria is abundant in the Levant, the Canary Islands and the Cape Verde Islands while R. fuciformis is quite common on the islands of the Indian Ocean adjoining the African coast. The lichens grow on the rocks near the sea and after being cleaned they are ground into a pulp with water. They are then treated with some ammoniacal liquid, at the present time dilute solutions of ammonia being used, and allowed to ferment for nearly a week. As a result of fermentation the mother principle, which is colorless, changes to orcinol, which is also colorless, and is finally converted into orcein, which produces scarlet solutions with either water or alcohol. Orcein is readily soluble in alcohol, somewhat soluble in water, and insoluble in ether. It forms beautiful lavender-colored solutions with the alkalies.

Cudbear.-Persio or Red Indigo.-A dried paste obtained in much the same manner as orchil and is made from Lecanora tartarea 
(Swedish Moss or Dyer's Moss), a lichen of northern Europe. It may also be prepared from the same lichens yielding orchil. The coloring principle is apparently orcein. It is largely used as a coloring agent for pharmaceutical preparations as well as in dyeing. The commercial article varies considerably in tinctorial properties, this being due to the crude methods of manufacture.

Literature.-Beringer, Proc. N. J. Pharm. Assoc., 1912; Arny, Jour. A. Ph. A., 1913, p. 47; Gardner, Ibid., p. 51.

LACMUS. - Litmus.-A dried extract obtained by the fermentation of lichens yielding orcinol. The process of fermentation is similar to that in the preparation of orchil and cudbear, but potassium carbonate is added and the time of fermentation is longer. When the color of the solution is of the desired tint it is mixed with calcium carbonate or gypsum, molded into small cubes and finally dried. Most of the litmus is manufactured in Holland.

The blue color of litmus is due to an amorphous brownish-red substance known as azolitmin. It is a weak base which is soluble in water and insoluble in alcohol. Commercial litmus contains several other coloring principles. Litmus is chiefly used as an indicator of neutrality in pharmaceutical and chemical work.

\section{ARCHEGONIATES}

\section{FERNS AND FERN-ALLIES}

The Archegoniates, representing the highest group of Cryptogams, include the Bryophytes and the Pteridophytes. The latter includes the ferns and their allies, viz.: the horsetails and club mosses. From a botanical viewpoint, as well as for economic reasons, it is one of the most interesting groups of plants. The Pteridophytes are a very old group, being first found in the Devonian and attaining their maximum development in the Carboniferous age, during which time they formed the bulk of the vegetation comprised in the coal-measures. The forms existing upon the earth are still very numerous, comprising about 5000 distinct species. The chief interest lies in their use as ornamental plants.

Aspidium.-Male Fern.-The rhizome and stipes of Dryopteris Filix mas and Dryopteris marginalis (Fam. Polypodiacceæ), perennials (Fig. 11), of which Dryopteris Filix mas is more widely distributed, being indigenous to Europe, Asia, North America, west of the Rocky Mountains, and in the Andes of South America; while D. marginalis is found in the Eastern and Central United States and 


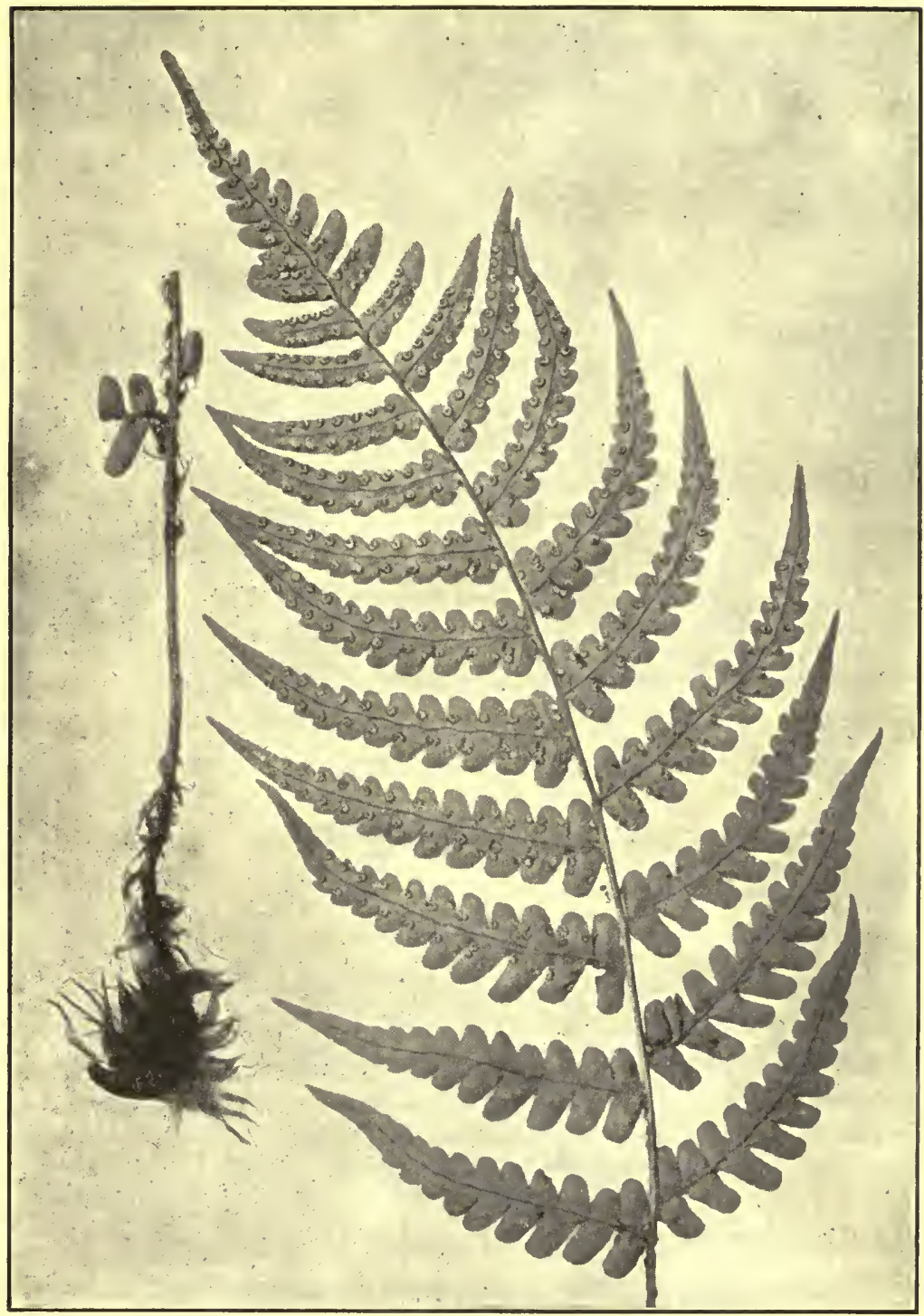

Fig. 11.-Leaf and a portion of rhizome of Dryopteris marginalis, the upper pinnæ (divisions), showing the sori near the margins, 
extends north to Prince Edward's Island. The rhizome is collected in early autumn, the leaves cut off, leaving the lower portions or stipes attached to the rhizomes; the dead portions of the rhizomes and the chaff are removed. Usually the drug consists of the stipes only, which are separated from the rhizome, the periderm being removed (Fig. 12). The drug is carefully dried and preserved and should not be used after it loses its green color.

Description.-Of horizontal or oblique growth, 5 to $15 \mathrm{~cm}$. long and 1 to $25 \mathrm{~cm}$. thick, mostly covered with nearly cylindrical slightly curved stipe-remnants (Fig. 12), which are about $25 \mathrm{~mm}$. long and

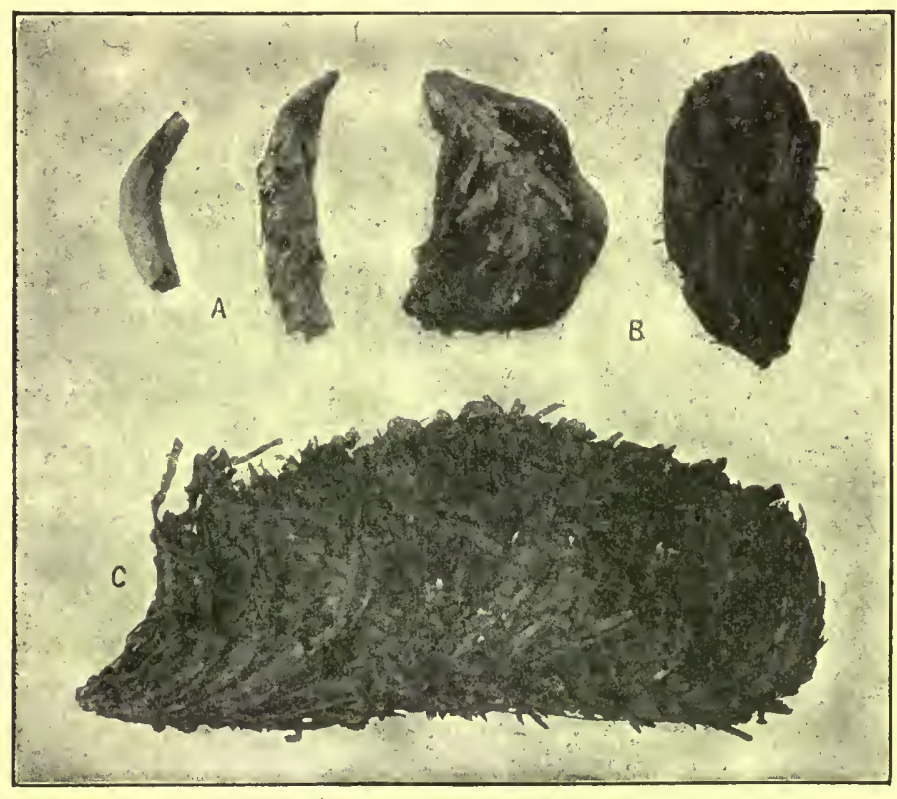

Frg. 12. $-A, B$, Dryopteris Filix mas, showing a decorticated stipe and piece of rhizome $(A)$, and rhizomes and stipes $(B) ; C$, probably the rhizome of Osmunda Claytoniana, which is sometimes substituted for Aspidium.

5 to $10 \mathrm{~mm}$. thick, between which is a dense mass of dark-brown, glossy, transparent and soft chaffy scales; internally spongy, pale green, becoming brownish with age; in transverse section showing an interrupted circle of about six (D. marginalis) or seven to nine (D. Filix mas) groups of fibro-vascular tissue, each of which is surrourded by an endodermal-like layer; odor slight, taste acrid, somewhat bitter and nauseous.

Inner Structure.-See Fig. 13. 
Powder.-Light brown or light greenish-brown (Fig. 14); starch grains numerous, ellipsoidal, ovoid, oblong and irregularly shaped, varying in length from 0.002 to $0.018 \mathrm{~mm}$.; numerous oil globules seen in chloral mounts; tracheæ long and with scalariform and reticulate thickenings, the cells being 0.025 to $0.075 \mathrm{~mm}$. in width. The tracheæ are colored reddish-violet on the addition of concentrated sulphuric acid, the reaction resembling that of lignified cells with phloroglucin; few reddish-brown epidermal cells are present, and the strongly lignified cells of the hypodermis resemble the libriform

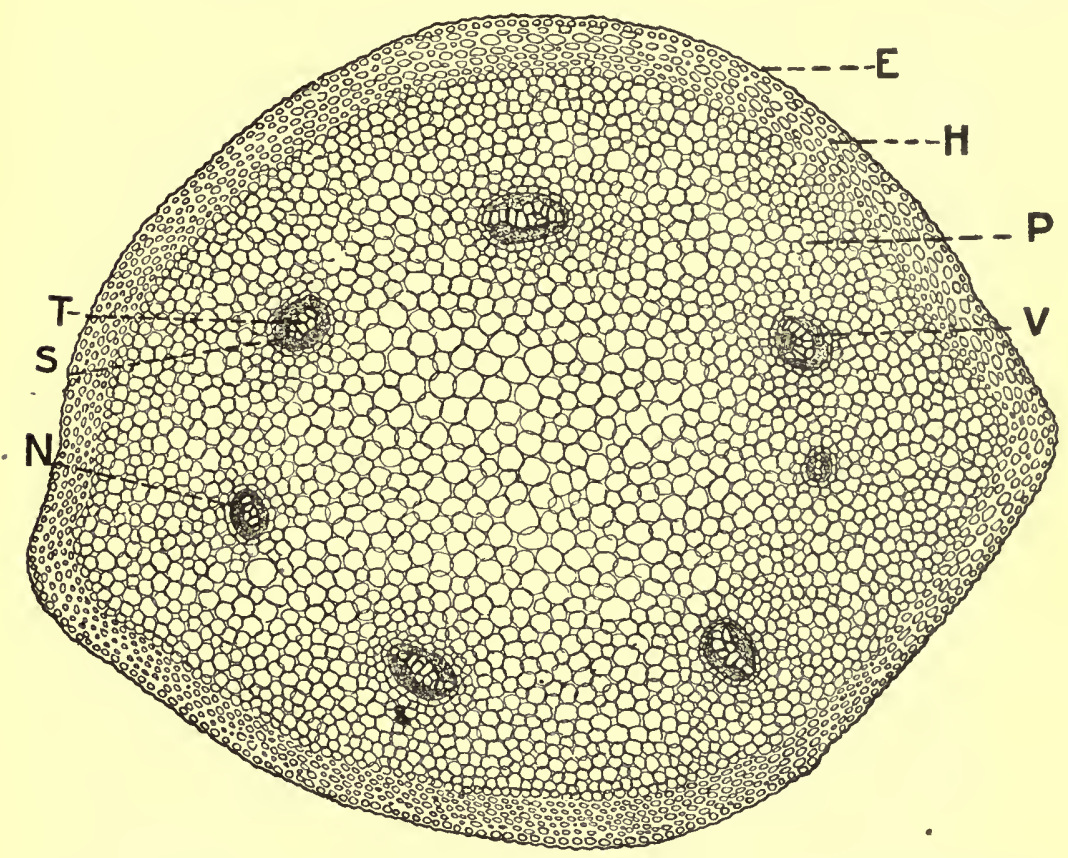

FIG. 13.-Transverse section of stipe of Dryopteris marginalis, showing epidermis $(E)$, hypodermis $(H)$, endodermis $(N)$, completely surrounding the vascular bundle $(V)$, and which consists of sieve $(S)$, tracheæ $(T)$.

cells in higher plants. Many of the cells of the parenchyma contain nuclei which may be differentiated by the use of iodin-green or methyl green.

Constituents.-An active, amorphous substance, filicic acid, 2 to 8 per cent, being contained apparently in greatest abundance in rhizomes collected in autumn, and readily decomposing with the formation of an inactive but crystalline anyhdride; and filicic anhydride (filicin, or so-called crystalline filicic acid). The latter occurs 
from 19 to 31 per cent in the drug, and may be converted into filicic acid by dissolving in alkalies and precipitating with acids. The drug also contains from 0.025 to 0.045 per cent of a light yellow volatile oil with an intense odor of the drug and an aromatic, burning taste. It consists of free butyric and allied acids and hexyl and octyl esters of the fatty acid series, ranging from butyric acid to pelargonic. From 6 to 7 per cent of a green fixed oil is present, which consists of the glycerides of oleic, palmitic, cerotinic and filosymlic acids, the latter being volatile. Also filmaron (active); a small amount of a bitter principle; about 10 per cent of filixtannic acid; a soft black resin and a hard red resin; about 11 per cent of an uncrystallizable sugar; starch, and 2 to 3 per cent of ash.

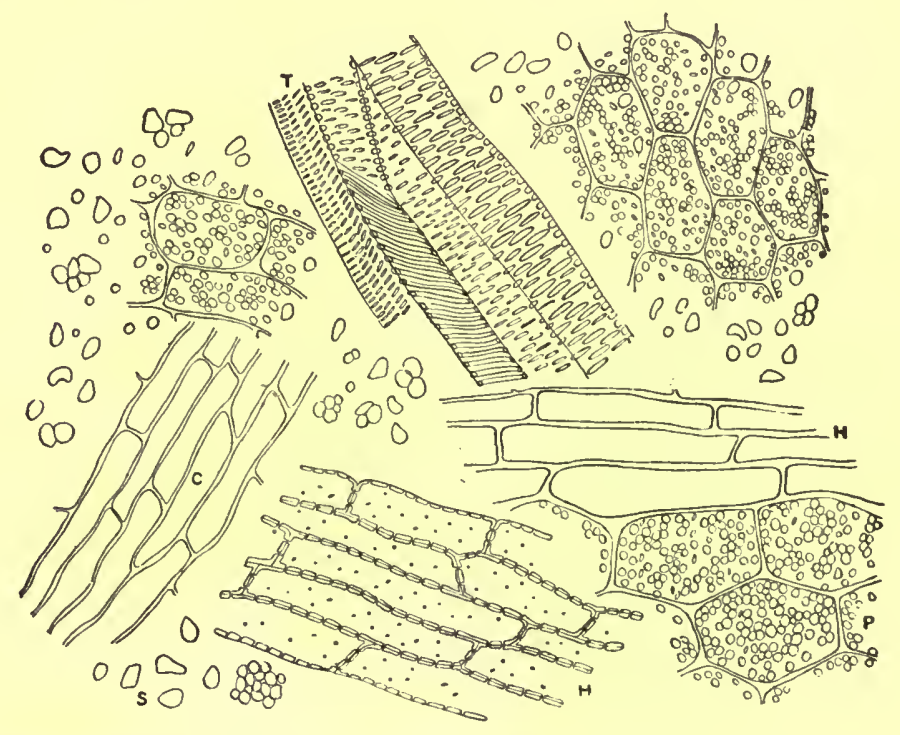

FIG. 14.-Aspidium: $P$, parenchyma containing starch grains; $S$, starch grains; $T$, trachex; $H$, hypodermal cells with thickened walls and simple pores; $C$, yellow, thick-walled cells of chaff.

Allied Plants.- The rhizome of Aspidium spinulosum appears to possess properties similar to the official drug; it somewhat resembles that of A. Filix mas, but the chaffy scales possess marginal glandular hairs and the number of fibrovascular bundles in the rhizome is usually but 6 or 7 .

The, rootstock of Pteris aquilina (Pteridium aquiiinum) contains a cyanogenetic anygdalin-like glucoside. (Bot. Abstracts, 1919, 1, p. 220.) 
Adulterants.-The rhizomes of other ferns are sometimes substituted for those of the true drug. The botanical origin of these substitutes is not clear. A very common substitute is shown in Fig. $12, C$, which is derived from Osmunda Claytoniana or a related species. It occurs in large pieces with coarse, wiry roots, flattened stipes and is free from chaffy scales.

Adiantum.-Maidenhair or Venus Hair.-The fronds of Adiantum pedatum or A. Capillus-Veneris (Fam. Polypodiaceæ). These well-known ferns are rather common in Eastern and Central United States and are occasionally used in medicine. They are among the most graceful and delicate of the North American ferns. The rhizomes are horizontal, slender and with blackish roots. The leaves are few but well developed in the early part of the summer. They consist of long, blackish and shining petioles, pedately branching at the summit, first into two recurving, primary forks, and then into several spreading divisions, each of which bears numerous regularly alternating leaflets. The latter are obliquely triangularoblong, the upper margin being incisely lobed and serrate; the surface is glaucous. and very smooth. The odor is slight; the taste being slightly bitter and somewhat astringent.

Inner structure.-Consult Holm, Merck's Report, 1909, p. 62.

Lycopodium.-The spores of Lycopodium clavatum, and of other species of Lycopodium (Fam. Lycopodiacex), perennial herbs indigenous to Europe, Asia, North America and Central America. The spores are obtained from the ripened cones by shaking the fruiting tops (sporogonia) and the extraneous matter is removed by sieving. The principal sources of supply of Lycopodium are Germany, Russia and Switzerland.

Description.-A light-yellow, very mobile powder, nearly inodorous and tasteless, floating upon water and not wetted by it, but sinking on being boiled with it, and burning quickly when thrown into a flame.

Spores tetrahedral (Fig. 15), from 0.025 to $0.040 \mathrm{~mm}$. in diameter with one convex side, and delicately reticulate on the surface.

Constituents.-About 50 per cent of a deep green odorless, nondrying oil with an acid reaction, which consists chiefly of oleic acid, with some lycopodic (di-oxy-stearic), palmitic, and myristic acids (Rathje, Archiv. Pharm., 246, 1908, p. 699); a small amount of phytosterin, and 3 to 8.2 per cent of glycerin. The spores also contain 5.3 per cent of a nitrogenous substance; about 3 per cent of a sugar, and yield about 1 per cent of ash. On heating with a solution of potassium hydrate, monomethylamine is liberated, and on macer- 
ating the spores in alcohol a part of the alcohol is converted into an aldehyde.

Allied Plants.-The spores of other species of Lycopodium are sometimes collected with those of $\mathrm{L}$. clavatum, as fir club moss (L. Selago); stiff club moss (L. annotinum); bog club moss (L. inundatum), and the ground pine (L. complanatum). From the latter an alkaloid, lycopodine, has been isolated. A toxic alkaloid, piliganine, has been obtained from piligan (L. Saururus), growing in Brazil. L. polytrichoides, of the Hawaiian Islands; L. rubrum, of Venezuela; L. cernuum, of the Tropics, and L. Selago of Europe, are also employed in medicine.

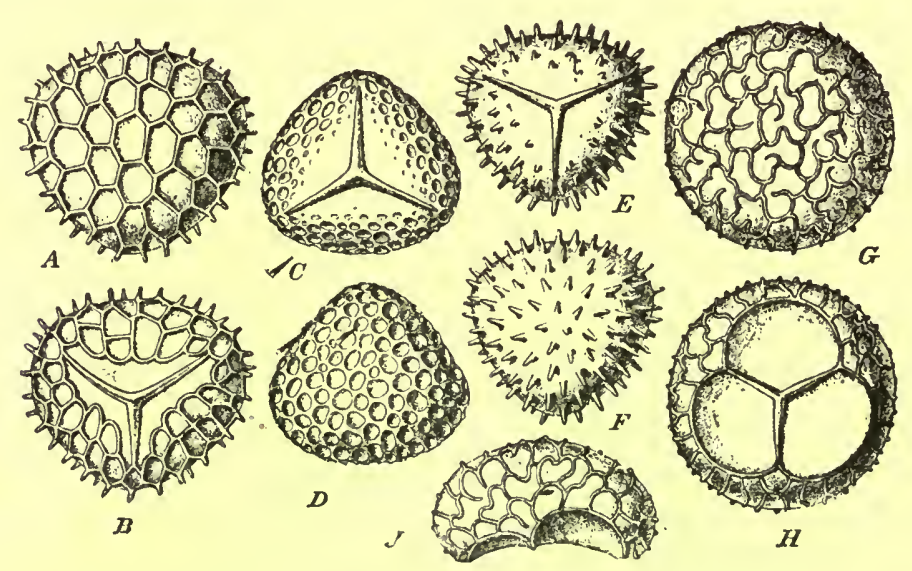

FIG. 15.-Spores of various species of Lycopodium. $A, B$, reticulated spores of Lycopodium clavatum; $C, D$, spores of $\mathrm{L}$. phyllanthum marked by pores; $E, F$, spinous spores of L. densum; $G, H, J$, spores of $\mathrm{L}$. inundatum with wavy reticulations.-After Pritzel.

Adulterants.-Lycopodium is sometimes admixed with pine pollen, starchy materials, and various inorganic substances, as sulphur, talc and gypsum. A recent adulterant of Lycopodium has been found to consist of corn starch which had been treated in a special manner and then colored with methyl orange. An artificial lycopodium is prepared by treating Bordeaux turpentine (galipot resin) at near the melting point with dry ammonia, the resulting product being then dried and powdered. The fragments are irregular, transparent and are detected by means of the microscope. 


\section{GYMNOSPERMS}

This is an ancient group of plants and was especially predominant during the Triassic age. The surviving forms are represented by about 450 species and divided into three classes, viz.: Cycads, Coniferæ and Gnetaceæ. The most important of these are the Coniferæ, which include the two families Taxaceæ and Pinaceæ. The latter include about 300 species and are especially abundant in the Northern Temperate regions of the world. They are mostly resinous trees or shrubs and of very great economic importance for timber, ornamental purposes, and they also furnish valuable products which are used in the arts and in medicine. The Pinacer include pine, spruce, hemlock, fir, larch, the bald-cypress, the redwoods, arbor vitæ, and juniper. The Araucarias belonging to the Coniferæ resemble in general habit the pine and are the lofty evergreen trees of tropical America and Australia. The Sequoias include the redwood (S. sempervirens) and the big tree (S. gigantea), both natives of California and are among the most massive of any trees in the world, attaining a diameter of 8 meters. They are practically exempt from disease and some are estimated to be nearly 2000 years old. Amber, a valuable fossil resin, is an exudation from trees of the Pinaceæ, that formerly grew along the shores of the Baltic Sea, especially in East Prussia.

\section{PINACEE, OR PINE FAMILY}

Pinus Alba.-White Pine Bark.-The dried inner bark of Pinus Strobus (Fam. Pinaceæ). P. Stobus, commonly known as white pine or Weymouth pine, is the principal timber pine of the northern United States and Canada. The bark contains from 8 to 9 per cent of tannin, but is not usually employed for tanning except when other sources of supply are limited. It is collected to a limited extent and is popular in the making of expectorant syrups. After the outer corky layer is removed it is then dried.

Description.--In flat pieces usually not more than $3 \mathrm{dm}$. in length, nor more than $12 \mathrm{~cm}$. in width and from 1 to $3.5 \mathrm{~mm}$. in thickness; outer surface varying from yellowish-brown to cinnamon-brown and not infrequently with silver-white patches of the inner layer of the periderm and occasional patches of blackish-brown cork, otherwise longitudinally striate with numerous small blisters of oleo-resin cavities and large more or less depressed irregular scars; inner surface yellowish-brown or dark brown and finely striate; fracture tough, 
fibrous; transverse surface porous, resinous and with yellowish groups of bast fibers; odor terebinthinate; taste slightly mucilaginous, terebinthinate, bitter and astringent.

Inner Structure.-Bast fibers with non-lignified walls, the cells being tabular and tangentially compressed and distributed in radial more or less wavy rows throughout the inner bark; secretion cells consisting for the most part of mucilage and to some extent of oleoresin or tannin arranged in tangential rows between the bast fibers; parenchyma cells containing starch grains, the latter being single or in groups, the individual granules from 0.005 to $0.020 \mathrm{~mm}$. in diameter and varying from spheroidal, ellipsoidal to club-shaped or even irregular forms.

Powder.-Tissues and cell contents described above; lignified woody elements few or wanting.

Constituents.-Alcoholic extract 30 per cent, consisting of 9 per cent of tannic acid and the remainder made up mainly of an oleoresin. The bark also contains considerable mucilage and a small quantity of coniferin; the latter is usually present in the cambiallayer of all of the species of Pinus as well as in other genera of the Pinaceæ.

Literature.-Bastin and Trimble, Amer. Jour. Pharm., 1896, p. 28.

Terebinthina.-Turpentine.-An oleo-resin obtained from Pinus palustris and other species of Pinus (Fam. Pinaceæ), evergreen trees indigenous to the southern United States. The oleo-resin is secreted in the sapwood and is obtained by making triangular incisions in the bark and wood in the spring; it flows into cavities (or boxes) made lower down on the trunk, from which it is dipped into barrels or other receptacles. The product of the first year's cutting is of superior quality and is known as "virgin" turpentine. It yields about 15 per cent of oil of turpentine, while the product of the second or third year yields 10 per cent.

Description.-In yellowish, opaque masses, brittle in the cold; lighter internally, sticky and more or less shiny; odor and taste terebinthinate. One part dissolved in 5 parts of alcohol gives a clear solution having an acid reaction.

Constituents.-Turpentine consists of 70 to 80 per cent of resin and 15 to 30 per cent of volatile oil; it also contains a bitter principle and various organic acids, as pinic, sylvic, etc.

Oil of turpentine is obtained chiefly from the following pines growing in the Southern States: Pinus palustris, P. glabra, P. cubensis, P. echinata and P. Tæda. The important constituent is the 
hydrocarbon pinene $\left(\mathrm{C}_{10} \mathrm{H}_{16}\right)$, which, in the oil from some plants, is dextro-rotatory, while in that from other plants it is lævo-rotatory. On allowing a moisture-containing oil to stand exposed to the light, crystals of pinol hydrate separate out in the course of time.

Turpentine Substitutes.-A number of inferior substances are sold for oil of turpentine. They are decidedly inferior as they have no binding capacities nor do they combine with colors. The composition of some of these is as follows: (1) Oil of turpentine 2 parts, rosin spirit 1 part, benzin 1 part. (2) Oil of turpentine 1 part, naphtha 1 part, petroleum spirit 2 parts. (3) Oil of turpentine 1 part, naphtha 1 part. (4) Petroleum spirit 2 parts, rosin spirit 1 part, naphtha 1 part. (5) Oil of turpentine 10 liters, rosin spirit 10 liters, benzin 5 liters, rosin 500 gms., sandarac 500 gms. (6) Rosin spirit 10 liters, naphtha 10 liters, benzin 10 liters, sandarac 250 gms., rosin 600 gms.

Allied Plants.-Various other species of Pinus yield an oleo-resin resembling turpentine, as Pinus Tæda, a tall tree growing in the regions where Pinus palustris is found; the yield of oleo-resin from this and other trees is considerably less. Pinus sylvestris, or Scotch fir, which is indigenous to the mountains of Europe and Asia and extensively cultivated in this country, is the source of much of the turpentine used in Europe.

Bordeaux turpentine is a product resembling American turpentine, and is obtained from Pinus maritima and other species of Pinus growing in Southern France, the resin consisting chiefly, however, of the anhydride of pimaric acid.

Austrian turpentine oil is obtained from Pinus Laricio, and apparently consists of dextro-rotatory pinene.

The oil known as French turpentine oil is derived from Pinus pinaster, and, while it resembles the American variety, consists entirely of lævo-rotatory pinene.

Pine needle oil is obtained by steam distillation from the leaves of Pinus pumilio, a tree of the Tyrolese Alps. It is a colorless oil with an aromatic odor and taste, and contains from 5 to 7 per cent of bornyl acetate, cadinene, phellandrene, pinene and sylvestrine.

Pine needle oil is also obtained to a limited extent from the Scotch fir (Pinus sylvestris). The German product closely resembles the oil obtained from Pinus pumilio, as probably also does the Swedish oil, but the English oil is lævo-rotatory.

Birch tar is the product of the destructive distillation of the wood and bark of the white birch (Betula alba). It is chiefly made in Russia, has a strong, penetrating odor and does not solidify. It is 
distinguished from beech wood tar and pine tar in not being completely soluble in 95 per cent acetic acid, and is distinguished from juniper tar by not being entirely dissolved in anilin and in being colored greenish with ferric chloride.

An oily product is obtained in the destructive distillation of the wood of the Prickly cedar (Juniperus Oxycedrus), a tree indigenous to the countries bordering the Mediterranean, and is official as oil of cade. It is a brown, viscid liquid with a tarry odor and a pungent, bitter taste. The oil varies in composition and the only constituent that has been isolated is the sesquiterpene, cadinene. Of the phenols which it contains nothing is known.

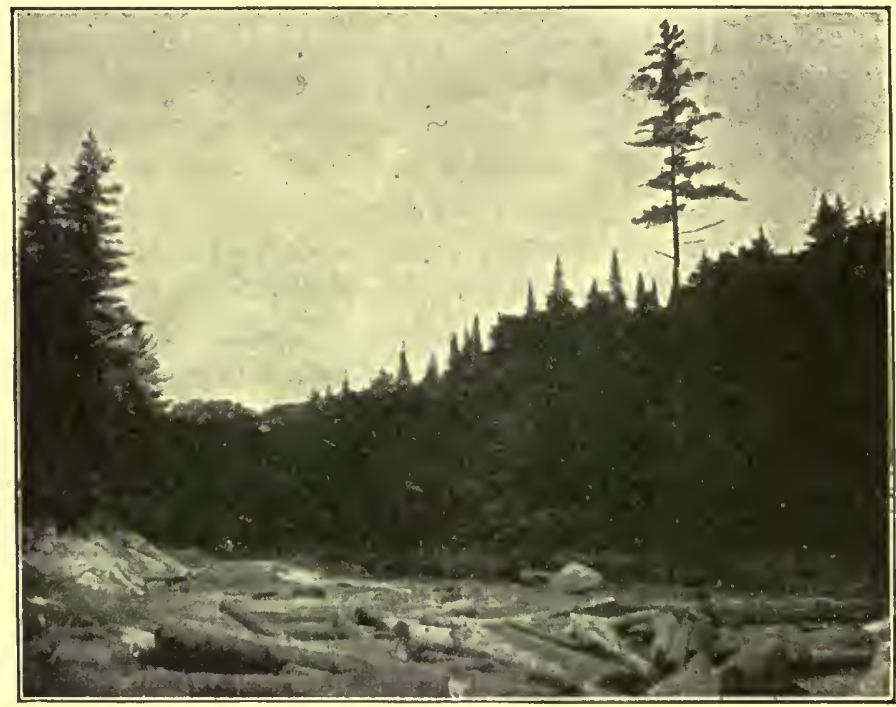

FIG. 16.-Typical view in the Adirondacks, showing the spire-like balsams (Abies balsamea) and a single white pine (Pinus Strobus).

An oil known as kien oil is obtained by the destructive distillation of the wood of the root of Pinus sylvestris. The oil is prepared in Germany, Russia, Finland and Sweden, and consists of d-pinene, $\mathrm{d}$-sylvestrine and in addition, in all except the Swedish oil, dipentene has been determined.

Colophony.-Rosin or Resin.-The residue after the distillation of the crude oleo-resin (or turpentine) of Pinus palustris and other species of Pinus (Fam. Pinaceæ), evergreen trees indigenous to the southern United States. There are two commercial varieties of Colophony: (1) one which is amber colored and derived from the 
oleo-resin of trees tapped for the first time; and (2) a yellowish-red or reddish-brown variety derived from the oleo-resin of trees that have been tapped for a number of years. The former article is preferred.

Description.-Usually in sharp, angular fragments; translucent, amber-colored, usually covered with a yellowish dust, hard, brittle pulverizable, fracture shiny and shallow-conchoidal; odor and taste faintly terebinthinate.

Rosin has a specific gravity of 1.070 to 1.080 , and it is soluble in alcohol, ether, benzol, carbon disulphide, acetic acid, fixed and volatile oils and in solutions of potassium or sodium hydrate.

On heating a small quantity of colophony and neutral methyl sulphate or neutral ethyl sulphate in a test-tube the mixture assumes a rose, then violet and finally a deep violet color.

Powder.--Pale to dark yellow; irregular fragments, soluble in alcohol, forming a straw-colored liquid, which becomes milky-white on addition of water; on heating fragments of rosin in water they melt, flow together and form a sticky mass.

Constituents.-From 80 to 90 per cent of an anhydride of abietic acid, which, on treatment with alcohol, is changed into abietic acid, which latter is crystalline; sylvic acid, which is probably a decomposition product of abietic acid; ash, about 1 per cent.

White rosin, prepared by agitating melted rosin in water, occurs in whitish, opaque masses, due to inclusion of air.

Rosin is not infrequently used as an adulterant of other resinous products, as of Burgundy pitch and Venice turpentine. A mixture of rosin and oil of turpentine is sometimes substituted for the latter.

Resins are a class of substances which may be looked upon as final products in destructive metabolism. They result from the oxidation of oils and allied products and usually accompany them, as oleo-resins, gum-resins, etc. They are insoluble in water, soluble in alcohol, acetone, ether and similar solvents, and burn with a yellow flame, forming considerable soot. Several kinds of resins are recognized, depending upon the nature and constitution of their important constituents:

(1) Resinolic Acid Resins include those that contain a large proportion of oxy-acids, and have been obtained in a crystalline condition, as abietic acid in colophony; copaivic and oxy-copaivic acids, in copaiba; guaiaconic acid, in guaiac; pimaric acid in Burgundy pitch and frankincense; and sandaracolic acid, in Sandarac.

(2) Resinol Resins are alcoholic or phenolic resins, a number of which have been crystallized, as benzoresinol, from benzoin; stores- 
inol, from styrax; gurjuresinol, from gurjun balsam; and guaiacresinol, from guaiac resin.

(3) Resinotannol Resins are aromatic derivatives that behave towards iron salts and some other reagents like tannin and yield picric acid on oxidation with nitric acid. The following have been isolated: Aloeresinotannol, from aloes; ammoresinotannol and galbaresinotannol, from ammoniac; peruresinotannol, from balsam of Peru; siaresinotannol and sinnaresinotannol, from benzoin; and toluresinotannol, from balsam of Tolu.

(4) Resene Resins form a group of resins which appear to be associated with bitter principles. They are insoluble in alkalies and with difficulty acted upon by reagents. They include alban and fluavil, from gutta percha; copalresene, from copal; dammaresene, from dammar; dracoresene, from dragon's blood; olibanoresene, from olibanum.

(5) Glucoresins or glucosidal resins, as the resins of jalap and scammony.

Resins occur in 33 families of the Spermophytes.

Pix Liquida.-Tar.-A product obtained by the destructive distillation of the wood of Pinus palustris and other species of Pinus (Fam. Pinacex), evergreen trees indigenous to the southern United States, particularly near the Atlantic Coast and the Gulf of Mexico. Tar is obtained by distillation of the wood without access of air, the tarry liquid being separated from the aqueous mixture consisting of wood naphtha and pyroligneous (crude acetic) acid. The amount of tar obtained in the operation varies, depending on how rapidly the wood has been heated. If the wood is heated slowly the yield is about 5 per cent, if rapidly heated it is increased to nearly 10 per cent.

Description.-Semi-fluid, viscid, blackish-brown, non-crystalline, transparent in thin layers, becoming granular or crystalline (due to the separation of pyrocatechin) and opaque with age; odor peculiar, aromatic, taste pungent. Tar is soluble in alcohol, fixed or volatile oils, and solutions of potassium or sodium hydrate; it is heavier than water and slightly soluble in it; the solution is of a pale yellowishbrown color, has an acid reaction, yields with a dilute solution of ferric chloride, a reddish color, and with a stronger solution, an olivegreen color, due to the presence of pyrocatechin (distinguishing it from Juniper Tar), and is colored brownish-red by an equal volume of calcium hydrate test-solution. The petroleum ether extract is colored greenish by a 0.1 per cent solution of copper acetate.

Constituents. - Tar consists of a resinous substance, with which are admixed a small quantity of turpentine, acetic acid, methyl 
alcohol and various volatile empyreumatic substances. On distillation four distinct classes of products are obtained: (1) An aqueous distillate, from 10 to 20 per cent, consisting chiefly of acetic acid, methyl alcohol and acetone. (2) A light oily distillate, from 10 to 15 per cent, coming over under $150^{\circ} \mathrm{C}$, and consisting of mesit, toluene, xylene, cumene, methene and eupion, which products are used as solvents for varnishes and similar substances. (3) A heavy oily distillate, about 15 per cent, distilling over between $150^{\circ}$ and $250^{\circ}$ C., and consisting of the creosote oils, viz.: phenol, cresol, creosote, paraffin, naphthalene, pyrene, chrysene, retene and some other substances. (4) A black resinous mass, called pitch (50 to 65 per cent) which has the odor of tar and is still official in some pharmacopœias.

In the distillation of pine wood tar the distillate, which is lighter than water, contains a volatile oil known as oil of tar (Oleum Picis Liquidæ). When recently prepared it is colorless, but it gradually darkens, becoming finally dark reddish-brown, there separating at the same time a blackish, resinous substance. Oil of tar consists chiefly of oil of turpentine, with some of the lighter hydrocarbons and phenol compounds, acetic and other acids, and a number of empyreumatic products.

Allied Products.-Beech-wood tar is the product of the destructive distillation of the wood of Fagus sylvatica and F. ferruginea (Fan. Fagaceæ). It is distinguished from pine tar by the petroleum ether extract not giving a green color with copper acetate solution, and in the creosote oils containing a considerable amount of guaiacol. The official creosote is a mixture of guaiacol and creosol with some other phenol derivatives, as xylenol, methyl creosol and methyl guaiacol, obtained from the heavy oily distillate of beech-wood tar. Guaiacol is of interest because on treatment with chemicals it may be converted into vanillin.

Terebinthina Laricina (Terebinthina Veneta.)-Larch Turpentine or Venice Turpentine.-An oleo-resin obtained from the European larch, Larix decidua (Fam. Pinaceæ). The tree is indigenous to the Alps and Carpathian Mountains and is extensively cultivated. The oleo-resin is obtained by making incisions into the heart wood in the spring of the year and these are then plugged until the fall, when the plug is removed and the viscid liquid is collected by means of a spoon. From each incision about 250 c.c. of oleo-resin is obtained annually. The yield from each tree is limited, as the oleo-resin is only secreted for a few years. The commercial supplies are obtained mostly from the Southern Tyrol. 
Description.-A thick, mostly clear and transparent liquid of a yellowish, yellowish-green, or brown color, a slightly green fluorescence, a characteristic aromatic odor and a slightly bitter but not acrid taste. On carefully drying a thin layer it leaves a transparent film. The Sp. Gr. is 1.1850 and the alcoholic solution shows a slight acidity to litmus paper. It is completely soluble in alcohol, ether, chloroform, acetone and almost entirely soluble in petroleum benzin. The acid number varies from 65 to 85 . The saponification number ranges from 35 to 110 .

Constituents. - A volatile oil, with a terebinthinate odor, from 20 to 22 per cent; laricinolic acid (crystalline), 4 to 5 per cent; $\alpha$ and $\beta$-larinolic acid (amorphous), 55 to 60 per cent; resin, 14 to 15 per cent; traces of benzoic acid, a bitter principle and a small quantity of unsaponifiable material.

Adulterants.-Mixtures containing colophony and turpentine are said to be either mixed with the genuine article or substituted for it.

Strasburg Turpentine is the product of the European silver fir (Abies alba). It closely resembles the Canada turpentine, but has a lemon-like odor. It contains 24 to 30 per cent of a greenish, fluorescent volatile oil, consisting chiefly of l-pinene; 46 to 50 per cent of $\alpha$ and $\beta$-abietinolic acid; about 2 per cent of a crystalline resin, abietolic acid; 10 per cent of an amorphous resin, abiennic acid; and small quantities of a bitter principle, succinic acid and a coloring principle.

LARICIS CoRTEX. - Larch Bark.-The inner bark of the branches and trunk of Larix decidua (Fam. Pinaceæ). It occurs in quills and flattened more or less transversely curved pieces, outer surface being light to dark red; inner surface yellowish-white to pinkish-red; fracture short-fibrous, outer portion deep red; odor aromatic, taste astringent and somewhat bitter. The drug is characterized by scattered groups of stone cells with thick lamellated walls, the cells varying in shape from branching to long spindle-shaped forms resembling bast fibers (Moeller, Anatomie der Baumrinden). Larch Bark contains 10 to 15 per cent of tannin, a small quantity of volatile oil, resin and larixinic acid. The latter sublimes at $93^{\circ} \mathrm{C}$, , forming crystals resembling those of benzoic acid. It is allied to pyrogallol and pyrocatechin and occurs mostly in the bark of young trees:

Pix Burgundica.-Burgundy Pitch.-The resinous exudation of the stems of the Norway Spruce Fir (Picea excelsa, Fam. Pinaceæ), an evergreen tree indigenous to Europe and Northern Asia. The resin is obtained by making incisions through the bark into the wood, the resin exuding and solidifying; it is then collected and purified 
by melting it in hot water and straining the mixture. The chief supplies of the drug come from Finland, the Black Forest (Germany) and the Jura Mountains. It is doubtful if the commercial supplies have ever been derived from the French province, Burgundy, from which it takes its name.

Description.-Irregular, hard, opaque or translucent pieces, more or less plastic and strongly adhesive, yellowish-brown or reddish-brown, brittle, the fracture shiny, conchoidal; odor agreeable, terebinthinate; taste aromatic and sweetish.

Burgundy Pitch is partly soluble in cold alcohol (1 to 20), and almost entirely soluble in boiling alcohol or in glacial acetic acid.

Constituents.-Chiefly resin, consisting of two crystallizable resin acids: dextropimaric and lævopimaric acids; a volatile oil (isomeric with oil of turpentine), about 5 per cent, to which its peculiar fragrance is due; and about 10 per cent or less of water, which is included during the preparation.

Substitute.-An article is sometimes sold under the name of Burgundy Pitch which is prepared by melting colophony with fat or pitch and mixing with water.

Adulterants.-Burgundy pitch is sometimes adulterated with various mixtures, as of other coniferous products and palm oil; these are distinguished by being more or less opaque and somewhat porous and not having the characteristic odor of the genuine article, and also by the formation of a turbid mixture on the addition of two parts by weight of glacial acetic acid.

Pix Canadensis.-Canada (or Hemlock) Pitch is the oleo-resin of the common Hemlock [Tsuga (Abies) canadensis] which is obtained by making incisions in the trunk and collecting the exudate, or by boiling pieces of the wood and bark and skimming off the melted oleo-resin. It occurs in dark, reddish-brown, opaque or translucent pieces resembling Burgundy Pitch, and probably contains similar constituents.

Hemlock Bark is very extensively used in the United States for tanning. The inner bark is used to some extent in medicine. The drug comes in flattened pieces, varying in size; the outer surface is cinnamon-brown or blackish-brown and longitudinally wrinkled, or evenly furrowed; inner surface yellowish-brcwn to cinnamon-brown, finely striate and with numerous small crystals; fracture short in the outer portion and strongly fibrous in the inner bark; the odor is faint and the taste strongly astringent. The inner structure is shown in Fig. 17. It contains from 10 to 15 per cent of tannin and a small quantity of volatile oil and resin. 
Terebinthina Canadensis.-Canada Turpentine, Canada Balsam or Balsam of Fir.-A liquid oleo-resin obtained from Abies balsamea (Fam. Pinaceæ), a tall evergreen tree (Fig. 16) indigenous to the Northern United States and Canada. The oleoresin occurs normally in reservoirs in the bark and forms in vesicles or blisters on the surface, from which it is obtained by puncturing them with the spout of the can used by the balsam collectors. Canada Turpentine is collected chiefly in Quebec.

Description.-Viscid, pale yellow or greenish-yellow, occasionally with a greenish fluorescence; transparent; odor agreeable, terebinthinate; taste bitter, slightly acrid.

When exposed to the air Canada turpentine gradually dries, forming a transparent varnish; it solidifies on mixing 5 or 6 parts with 1 part of magnesia previously moistened with water (distinguishing it from other coniferous resins); it is completely soluble in ether, chloroform, benzol or oil of turpentine and about $\varepsilon 0$ per cent is soluble in alcohol (distinguishing it from other coniferous resins).

Constituents.-About 75 per cent of a resinous substance, consisting chiefly of 4 acid resins: canadinic, canadolic, and $\alpha$ - and $\beta$ canadinolic resins, and 11 to 12 per cent of an indifferent resin canadoresene; 16 to 25 per cent of a volatile oil, consisting chiefly of l-pinene; and pimaric aicid.

Oregon Balsam.-This is a recent article of commerce and is obtained from the red fir or Douglas spruce (Pseudotsuga taxifolia), a tree common in the western United States and British Columbia. According to Fry the oleo-resin is collected by incising the tree, and draining by means of a spout, collecting the exudation in a suitable container. It is afterwards strained and shipped in barrels. The genuine article has all of the properties of true Canada balsam. (Mahood, Amer. Jour. Pharm., 1919, 91, p. 345.)

Adulterants.-Mixtures consisting of oil of turpentine, colophony, oil of eucalyptus, and oil of nutmeg have been sold under the name of "Oregon balsam," and for this reason, the true balsam has come to be looked upon with suspicion.

Spruce Gum is a natural exudation on the branches of the black or bog spruce (Picea mariana), red spruce (P. rubra) and white spruce ( $\mathrm{P}$. canadensis). It is gathered in considerable quantities, principally in northern New England and Canada and is used chiefly in the manufacture of chewing gum. The gum occurs in longitudinal rifts on the branches and trunk; the finest flavored and cleanest gum is found on the south side of the tree. In the early spring the gum exudes slowly and continues to flow during the summer, hanging in 


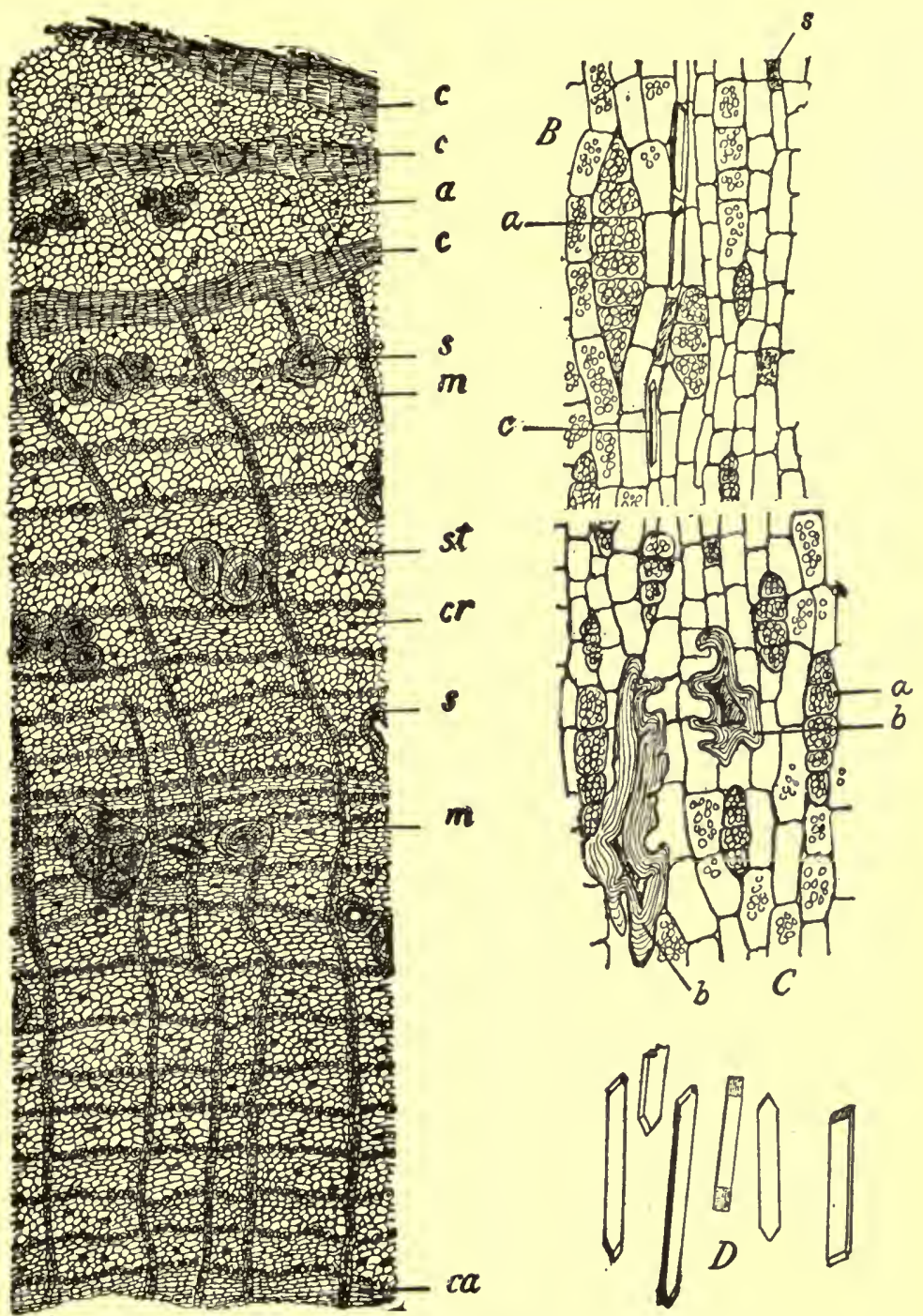

FIG. 17.-Cross-section of bark of T'suga canadensis. c, c, c, secondary cork formation; $a$, dead phloem tissues rich in coloring, resinous and tannin-like substances; $s, s$, stone cells; $m, m$, medullary rays; $c r$, cells containing long prisms of calcium oxalate; $c a$, cambium; st, bands of starch-bearing parenchyma cells. $B$, tangential-longitudinal section of inner bark showing medullary ray cells $(a)$ and crystal cells $(c)$; an oleoresin-secretion cell $(s)$. $C$, stone cells from the inner bark $(b) . \quad D$, various forms of prismatic crystals of calcium oxalate.-After Bastin. 
pendulous bags from the tree. The mass grows daily until the middle of July, when the sap ceases to run. The quality of the gum varies considerably, not only during the flowing period but for some time afterwards. During May and June the exudation has a decidedly pungent taste resembling turpentine. As the mass hardens it becomes intensely bitter. During the cold weather of winter the turpentine-like odor and bitter taste are entirely dissipated and the gum is ready to be harvested. It is assorted into several grades according to its color and aroma. Thousands of tons are used for commercial purposes annually. While the gum is used extensively, very little has been written concerning its constituents. It consists largely of a gummy substance, a small quantity of volatile oil (apparently a simple terpene), and several resins.

Sandarac. - The dry resinous exudation of Callitris quadrivalvis (Fam. Pinaceæ), a large shrub of northwestern Africa. The resin exudes spontaneously and in order to facilitate the flow and increase the yield incisions are made.

Description.-In pale yellow, cylindrical tears, attaining a length of $3.5 \mathrm{~cm}$. and varying in thickness from 5 to $30 \mathrm{~mm}$; the outer surface smooth and covered with a whitish dust; fracture, short, glasslike; inner surface lustrous and transparent; odor balsamic and taste slightly aromatic and bitter. It is distinguished from mastic in that it is not plastic on chewing.

Sandarac melts at $135^{\circ} \mathrm{C}$. and is completely soluble in alcohol (96 per cent), ether, amyl alcohol, acetone and hot linseed oil. It is only partly soluble in chloroform, carbon disulphide, petroleum ether, and volatile oils such as oil of turpentine. Benzol dissolves only about 40 per cent of the best grades.

Powder.-Almost insoluble in alcohol (95 per cent), the solution remaining almost colorless; the fragments do not melt when heated with water.

Constituents.-About 95 per cent of a resin consisting of 85 per cent of sandaracolic acid and 10 per cent of callitrolic acid; from 0.25 to 0.5 per cent of volatile oil composed principally of pinene; a small quantity of a bitter principle which forms a crystalline sodium salt; and yields about 0.10 per cent of ash.

Allied Plants.-A resin closely resembling sandarac is obtained from Actinostrobus pyramidalis, a shrub growing in southwestern Australia and from one or more species of Callitris growing in Australia and Tasmania.

Adulterants.-A fictitious Spanish article has been found in commerce apparently manufactured from ordinary colophony. It was 
formed in tears, became plastic on chewing, and had a melting point and gave an acid number corresponding to colophony.

ThujA.-Arbor Vitæ or White Cedar.-The young twigs of arbor vitæ (Thuja occidentalis, Fam. Pinaceæ), a conical tree indigenous from Canada to Virginia and extensively cultivated, and also used in medicine. The leaves are 4-ranked, of two kinds, those of the lateral pairs being more or less elongated, clasping, and triangular in section, those of the other pair being flattened, appressed and with a prominent oleo-resinous gland near the middle of the dorsal or outer surface, the arrangement of the leaves being such as to give the branches a flattish appearance. The fruits are small cones with six to ten carpels, each bearing a narrow-winged seed.

Thuja contains 1 per cent of a volatile oil with an odor resembling tansy and containing $d$-pinene, l-fenchone, $d$-thujone, and an inactive oxime; two resins; a glucoside thujin, which resembles quercitrin; a bitter glucoside pinicrin, and pinitannic acid. The two latter principles are also found in Pinus sylvestris.

Juniperus.- Juniper Berries.-The carefully dried ripe fruit of the common juniper (Juniperus communis) and its varieties (Fam. Pinaceæ). The plants are small evergreen trees with subulate, prickly-pointed, verticillate leaves and indigenous to North America, Europe and Asia.

Description.-The berry-like fruits are nearly globular, from 5 to $10 \mathrm{~mm}$. in diameter, somewhat wrinkled, purplish-black or dark brown, frequently with a whitish bloom, with three to six minute bracts at the base, and a triangular scar at the summit marking the line of separation of the carpels. The pulp is brownish and usually contains three ovoid seeds, attached to which are 3 to 4 ellipsoidal oleo-resinous masses. The odor is slight and the taste is sweet and resinous.

Inner Structure.-Epidermal cells with thick walls and brownish amorphous contents; a hypodermis of 2 to 3 rows of collenchymatous cells with brownish-red amorphous contents; pulp or sarcocarp consisting of thin-walled parenchyma cells with large intercellular spaces; fibrovascular bundles associated with yellowish stone cells and ovoid schizogenous oil-secretion canals; inner layer of pericarp of small thick-walled cells separated from the sarcocarp; the seed coat to which are attached the secretion reservoirs is characterized by a closed ring of stone cells, most of which contain a prism of calcium oxalate, cells of endosperm and embryo filled with aleurone grains and an oily cytoplasm. 
Powder.-Calcium oxalate in monoclinic prisms about 0.030 $\mathrm{mm}$. in length, occurring in stone cells, which are about $0.060 \mathrm{~mm}$. in diameter and with walls that are about $0.015 \mathrm{~mm}$. in thickness; a small number of nearly spheroidal starch grains from 0.005 to 0.007 $\mathrm{mm}$. in diameter; fragments with oil glands and brown pigment cells.

Constituents.-Juniper berries contain 0.5 to 1.5 per cent of a volatile oil containing pinene, cadinene, and a juniper camphor; 10 per cent of resin; 15 to 30 per cent of dextrose; a yellow coloring principle; and yield 2 to 4 per cent of ash. The oil and the fruits are chiefly used in the manufacture of gin.

LIGNUM JUNIPERI.-Juniper wood.-The wood of the roots, stems and branches of Juniperus communis is official in the Austrian Pharmacopœia. It occurs in commerce in pieces varying from 2 to $10 \mathrm{~cm}$. in thickness with the thin bark usually adhering. The wood of the root is preferred to that of the stems and branches, in that it is more aromatic. It contains a small quantity of volatile oil and resin.

The juniper wood oil of commerce consists apparently of oil of turpentine to which some juniper oil has been added, or it is turpentine oil which has been added to juniper wood or branches and redistilled. The oil is used to some extent in veterinary medicine

Sabina.-Savin.-The young and tender, green branches of Juniperus Sabina (Fam. Pinaceæ), an evergreen shrub indigenous to the mountainous regions of southern and central Europe and extendas far as Siberia. The young twigs are collected in the spring, stripped from the older woody branches and dried. In the preparation of the volatile oil, which is official, they are used in the green state.

Description.-Branchlets 1 to $5 \mathrm{~cm}$. long, 1 to $2 \mathrm{~mm}$. in diameter; covered with closely appressed (except those at the base of the branches or branch-scars), grayish- or brownish-green, rhomboidal, scale-like leaves which are about $1 \mathrm{~mm}$. long, 4-ranked, closely imbricated, thus completely covering the branchlets, and show in crosssection a single large oil-gland directly beneath the epidermis of the dorsal surface. Some of the berry-like fruits are usually present. They are globular or ellipsoidal, brownish-yellow or purplish-black, 5 to $7 \mathrm{~mm}$. in. diameter, with a whitish bloom, wrinkled and more or less tuberculate, due to the tips of the fleshy scales; the puilp is brownish and contains from 2 to 6 ovoid, yellowish-brown seeds, 3 to 4 $\mathrm{mm}$. long, longitudinally grooved, particularly on the dorsal side and enclosed by a resinous membrane. The odor is slightly terebinthinate, and the taste, bitterish and resinous.

Inner Structure.-See Fig. 18. 
Powder.-Starch, $0.004 \mathrm{~mm}$; characteristic hypodermis, consisting of long fibers $0.015 \mathrm{~mm}$. wide, associated with epidermis; narrow tracheids; numerous oleo-resin masses.

Constituents.-From 4 to 6 per cent of a volatile oil, consisting of about 10 per cent of an alcohol sabinol; 40 to 44 per cent of an ester of sabinol and acetic acid; a sesquiterpene; and a principle with an odor of cumin aldehyde. Also resin, and a small amount of tannin.

Allied Plants.-Red Cedar (Juniperus virginiana) is a tree or shrub of wide distribution in North America. The fruits are purple,

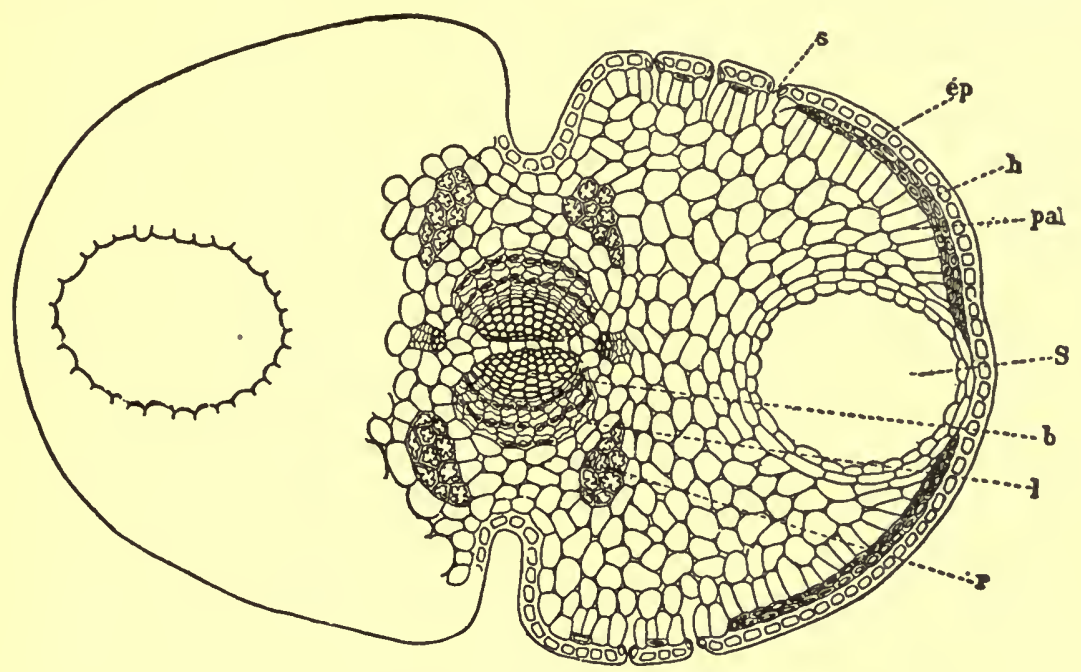

FIG. 18.-Transverse section of the stalk of Juniperus Sabina at the point of attachment of two leaves. $e p$, epidermis; $s$, stomata; $h$, hypodermis; pal, palisade cells; $l$, bast fibers; $b$, xylem; $r$, mechanical tissue; $S$, oilsecreting gland or reservoir.-After Mongin.

smaller, and contain fewer seeds than those of J. Sabina. The constituents are also similar. The volatile oil of the wood is known as red cedar wood oil and occurs to the extent of 2.5 to 4.5 per cent. The oil consists of so-called cedar camphor, or cedrol, and cedrene.

\section{ANGIOSPERMS}

The Angiosperms or flowering plants include the highest group or phylum. They are represented by at least 130,000 living species and about 10 per cent of which have been used by man either as food, in medicine, or for some distinct economic purpose. 


\section{MONOCOTYLEDONS}

This subdivision includes those plants in which the seeds contain but a single cotyledon, the leaves are usually parallel-veined, the flowers are mostly 3-merous and in the stems the fibrovascular bundles are of the concentric type.

\section{GRAMINEA, OR GRASS FAMILY}

These are mostly herbs with cylindrical, usually hollow stems (culms) closed at the swollen nodes. The leaves are alternate, the basal portion or sheath enveloping the culm and bearing at the orifice an appendage called the ligule. Under the epidermis of both stems and leaves there is a more or less strongly developed ring of sclerenchymatous fibers; similar fibers surround the concentric fibrovascular bundles which occur in 1 or 2 circles beneath the endodermis.

Triticum - Couch Grass, Dog Grass, or Quick Grass.The rhizome and roots of Agropyron (Triticum) ripens, a common perennial grass indigenous to Europe and Asia, and naturalized in North America except in the Arctic regions. It forms slender jointed rhizomes, by means of which the plant is extensively propagated; the culms vary from 0.3 to $1 \mathrm{M}$. in height, the spikelets have 3 to 7 flowers; and the empty glumes are 5- to 7-nerved, acute or with an awn-like summit. The rhizome is gathered in spring, usually deprived of the rootlets, cut into pieces and carefully dried. The commercial supplies come chiefly from central Europe.

Description.-Horizontal, somewhat cylindrical or 4- to 6-angled, usually cut into pieces 5 to $8 \mathrm{~mm}$. long, 1 to $2 \mathrm{~mm}$. in diameter; externally light yellow, longitudinally furrowed, smooth, shiny, nodes with circular leaf-scars and few root-scars; fracture tough, fibrous; internally, bark light brown, about $0.5 \mathrm{~mm}$. thick, wood light yellow and porous, center hollow; odor slight, taste sweetish, slightly acrid.

Roots filiform, irregularly branching, attaining a length of $5 \mathrm{~cm}$. and not more than $0.5 \mathrm{~mm}$. in thickness, light brown or yellowishbrown, frequently covered with long root-hairs.

Inner Structure.-(Fig. 19.) Epidermis of a single row of strongly lignified cells; hypodermis of 3 to 6 rows of strongly lignified cells; cortex of thin-walled parenchyma and a few small fibrovascular bundles; endodermis, the lateral and inner walls being thick, porous, and strongly lignified; fibrovascular bundles collateral, with several large tracheæ and imbedded in a layer of sclerenchymatous fibers; 
pith with several rows of parenchyma cells and scattered fibrovascular bundles; central area hollow.

Powder.-Light yellowish; tracheæ lignified, with spiral or annular thickenings or simple pores; sclerenchymatous fibers long, thickwalled, strongly lignified; endodermal cells with inner walls thickened and slightly lignified; parenchyma with irregular masses of a soluble carbohydrate.

Constituents.-Triticin, a lævo-rotatory carbohydrate resembling inulin, 8 per cent; dextrose and levulose 2.5 to 3.3 per cent; a nitrogenous, gummy substance, 11 per cent; acid malates; and about 4.5 per cent of ash containing much silica. The rhizome is free from starch and calcium oxalate, and the lactic acid found in the extract is apparently a fermentation product.

Adulterant.-Bermuda grass, the rhizome of Capriola dactylon, has been used as a substitute. The rhizomes are from 2 to $3 \mathrm{~mm}$. in diameter, hard and brittle. There is no endodermis and the parenchyma is filled with starch. (Zufall, Jour. A. Ph. A., 1919, 8, p. 472; Gathercoal, ibid, p. 26.)

ZEA.-Corn Silk.-The fresh styles and stigmas of Zea Mays (Fam. Gramineæ), an annual plant indigenous to tropical America and known only in cultivation, being cultivated widely in nearly all tropical, sub-tropical and temperate regions.

Description.--In matted masses consisting of several hundred or more slender, very delicate, thread-like, purplish-red to greenishwhite, more or less translucent styles; 10 to $20 \mathrm{~cm}$. long; stigmas bifid, slender, 2 to $3 \mathrm{~mm}$. long; odor slight; taste insipid.

When viewed under the microscope the upper part of the styles and the stigmas are seen to have numerous multicellular, non-glandular hairs from 0.2 to $0.5 \mathrm{~mm}$. long, among which are numerous spinose pollen grains 0.010 to $0.015 \mathrm{~mm}$. in diameter.

Constituents.-Not much is known concerning the constituents of this drug, and the analyses have been chiefly of the dried commercial article. The fresh drug contains about 83 per cent of water. The dried drug contains a volatile alkaloid; two resins about 5.5 per cent; a crystalline principle, maizenic acid, about 1.25 per cent; fixed oil, 5.25 per cent; sugar; ash, about 12 per cent. The coloring principle of the fresh drug is soluble in water and alcohol and is changed to yellowish-red with acids, green with alkalies, purple with potassium alum, and olive-green changing to greenish-brown with ferric chloride.

The Starches.-Large amounts of capital are invested throughout the world in the manufacture of starch. In the United States alone not less than $300,000,000$ pounds of this material are marketed 

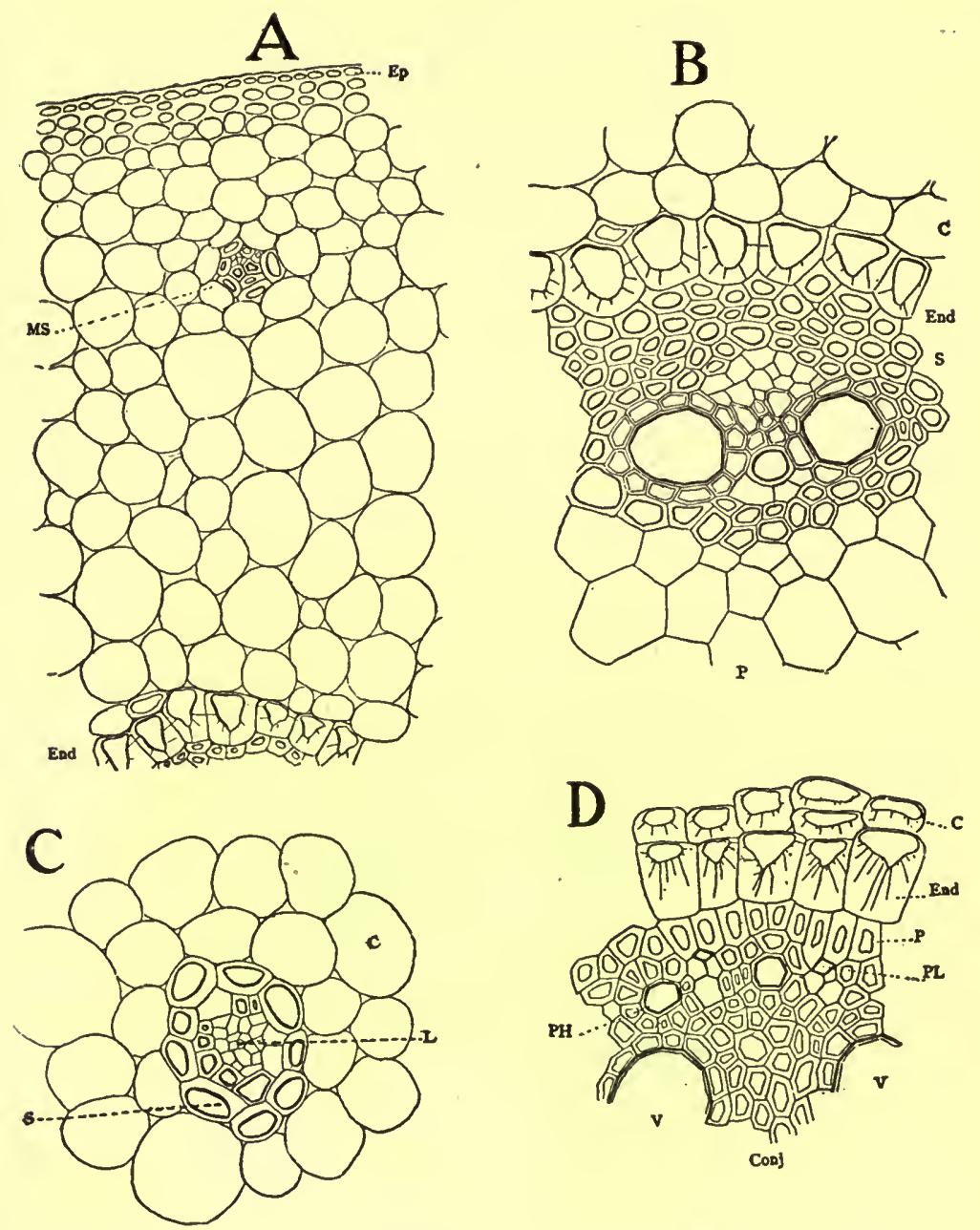

Frg. 19.-Triticum. A, transverse section of a rhizome or stolon; Ep, epidermis; $M S$, a vascular bundle situated in the cortical parenchyma; End, endodermis. B, continuation of section figures in $A$ showing cortical parenchyma $(C)$; endodermis $(E n d)$; sclerenchymatous fibers or stereome $(S)$ surrounding a mestome strand with two large tracheæ having porous walls and small tracheæ with annular thickenings between them; parenchyma cells of pith $(P)$. C, a vascular bundle or mestome strand from the cortex $(C)$ showing that it is surrounded by a closed sheath of sterome $(S)$ and contains almost exclusively leptome. D, transverse section of a portion of a secondary root; $C$, thick-walled cells of inner layer of cortex; End, endodermis; $P$, pericambium; $P L$, the proto-leptome; $P H$, the proto-hadrome in which the earliest vessels are developed; $V$, portions of two trachex; Conj. thick walled conjunctive tissue.-After Holm. 
annually; of this amount almost five-sixths is made from Indian corn. While starch is widely distributed in the plant kingdom, there are relatively few plants from which it is extracted on a large scale. In addition to corn other cereals, as rice and wheat, contribute to the world's supply. Starch is also obtained from potato tubers, maranta rhizomes, and cassava roots. In order to facilitate their comparative study they are considered at this point, and it is desirable to know something of the general properties of the starch grain, no matter what its origin may be.

General Properties of Starch.-Starch is insoluble in cold water or alcohol, but forms a white jelly when boiled with water, which, when cool, gives a deep-blue color with iodin and should give a neutral rection to litmus paper (commercial corn starch is usually alkaline); ash not more than 1 per cent.

If starch is triturated with water and the mixture filtered, the filtrate does not give a reaction with iodin solution; if, on the other hand, the starch is previously triturated with sand and then with water, the filtrate becomes blue on the addition of iodin solution. It appears that in the latter operation the wall of the grain is broken and the soluble starch present in the grain is liberated.

If dry starch and iodin are triturated together no color or, at the most, a faint blue color is produced; whereas, if a little water is added and the trituration repeated, a deep blue color is immediately produced.

The blue color of starch solution and iodin disappears on the application of heat, but slowly returns on cooling the solution, but not with the same degree of intensity, part of the iodin being volatilized.

When starch is heated with glycerin it dissolves, and if alcohol is added to the solution, a granular precipitate is formed which is soluble in water, the solution giving a blue reaction with iodin.

When starch is heated with an excess of water at $100^{\circ} \mathrm{C}$. for even several weeks, dextrinization of the starch does not take place, i.e., the solution still gives a blue color with iodin. If, however, a mineral acid be added, it is quickly dextrinized, turning violet-red, reddish and yellowish with iodin; finally, maltose and dextrose are produced, these giving no reaction with iodin, but reducing Fehling's solution. The ferments and other chemicals have a similar effect on starch.

When dry starch is heated at about $50^{\circ} \mathrm{C}$. from fifteen to thirty minutes the lamellæ and crystalloidal structure become better defined and the polarizing effects produced by the grains also become more pronounced. When starch is mounted in a fixed oil, as almond, the 
polarizing effects are more pronounced than when it is mounted in water, but the inner structure is not usually apparent, unless the starch has been previously heated.

Literature.-Kraemer, Bot. Gazette, Nov., 1902; Ibid., Oct., 1905; and Eighth International Congress of Applied Chemistry, Vol. 17, p. 31. Also Kraemer's "Applied and Economic Botany."

AмYLUм.-Starch.-The starch grains obtained from the grains of wheat (Triticum sativum and its varieties), corn (Zea Mays) and rice (Oryza sativa) (Fam. Gramineæ). The grains are separated from the cells, purified in various ways, and subsequently washed with large quantities of water. In the U. S. Pharmacopœia corn starch alone is recognized.

In the preparation of corn starch the corn grains are softened by being placed in running water and kept at a temperature of about $60^{\circ} \mathrm{C}$. for several days, care being taken to prevent any fermentation. The grains are then crushed between burr-stones and the paste carried by means of water to large sieves, the strained magma then being reground and carried to sieves made of bolting cloth. The milky-fluid containing the starch is then run into settling vats, the starch separating out. The starch is then freed from oil, albuminoids and other substances by treating it with a 15 per cent solution of caustic soda. The supernatant liquid is removed and the starch washed with water to remove all traces of alkali. The starchy mixture is allowed to stand, when the starch separates out and is dried. Commercial starch is likely to contain some free alkali, which is readily detected by the addition of an aqueous solution of fuchsin, which becomes decolorized immediately in the presence of a starch containing free alkali.

Varieties of Corn.-There are a large number of varieties and subvarieties of Zea Mays, some of the former being ranked as species. The following well-defined varieties may be mentioned:

(1) Zea Mays everta, to which belong the pop-corns. The size of the ears and grains is about one-half or less that of the other corns; the grains have a more or less translucent and horny. endosperm, the cells of the latter containing numerous compactly arranged polygonal starch grains, which are from 0.007 to $0.010 \mathrm{~mm}$. in diameter and have a central rarefied area from 0.002 to $0.007 \mathrm{~mm}$. in dianeter. It is owing to the structure of the starch grains that the peculiar popping of the corn grains results when they are heated. Heating the corn grains at $145^{\circ}$ to $160^{\circ} \mathrm{C}$. for from four to ten minutes causes the bursting of the starch grains, and at the same time a rupture of the cells and splitting of the pericarp into 4 parts. The white appearance 
of the popped grains is due to the inclusion of air in the bursted cells. During the heating the starch is converted into a soluble form, and this gives popped corn its nutritive value. Some of the flint and dent corns show a similar tendency to pop when heated, but it is only in those parts of the endosperm that are horny and the cells of which contain compactly arranged polygonal starch grains in which the rarefied area is at least from one-tenth to one-fifth the diameter of the entire grain. Pieces of the pop-corn, as well as the horny portions of some of the flint and dent corns, will pop as readily as the whole grains.

(2) Zea Mays indentata yields the dent or flint corns, the grains of which have a corneous (horny) endosperm on the sides and are indented at the summit, owing to the shrinking of the cells, which contain more cell-sap and less compactly arranged starch grains.

The starch grains in the cells of the horny endosperm resemble those of pop-corn, but the starch grains in the other cells are more or less rounded or slightly polygonal, and vary from 0.005 to $0.025 \mathrm{~mm}$. in diameter; the central rarefied area is either wanting or usually not more than $0.002 \mathrm{~mm}$. in diameter.

(3) Zea Mays saccharata yields the sugar corns. While the grains are more or less translucent and horny, they have a wrinkled or shriveled surface. The cells of the endosperm contain gum-like substances and a relatively small number of nearly spheroidal starch grains from 0.004 to $0.010 \mathrm{~mm}$. in diameter.

Corn Starch.- This occurs as a fine, somewhat cream-colored, mobile powder, which is practically free from cohering particles. The starch grains (Fig. 20) are more or less polygonal or somewhat rounded, usually with a distinct circular, or 2- to 5-rayed cleft in the center, and vary from 0.010 to $0.035 \mathrm{~mm}$. in diameter. When examined by means of the micropolariscope the grains show a distinct cross, but the display of colors when the selenite plate is used is less pronounced than in potato starch. This starch frequently contains traces of alkalies, which may be detected by adding $0.5 \mathrm{gm}$. of the starch to 2 c.c. of an aqueous solution of fuchsin, when the latter is decolorized.

Corn Meal is whitish or yellowish, and in addition to the parenchyma which contains oil and characteristic starch grains there are also present fragments of the pericarp. The latter are free from hairs; the cells of the epicarp have thick walls with simple pores; beneath the latter occurs a layer of parenchyma cells which are thinwalled, more or less branching, between which are large intercellular spaces; running at right angles across the branching parenchyma 


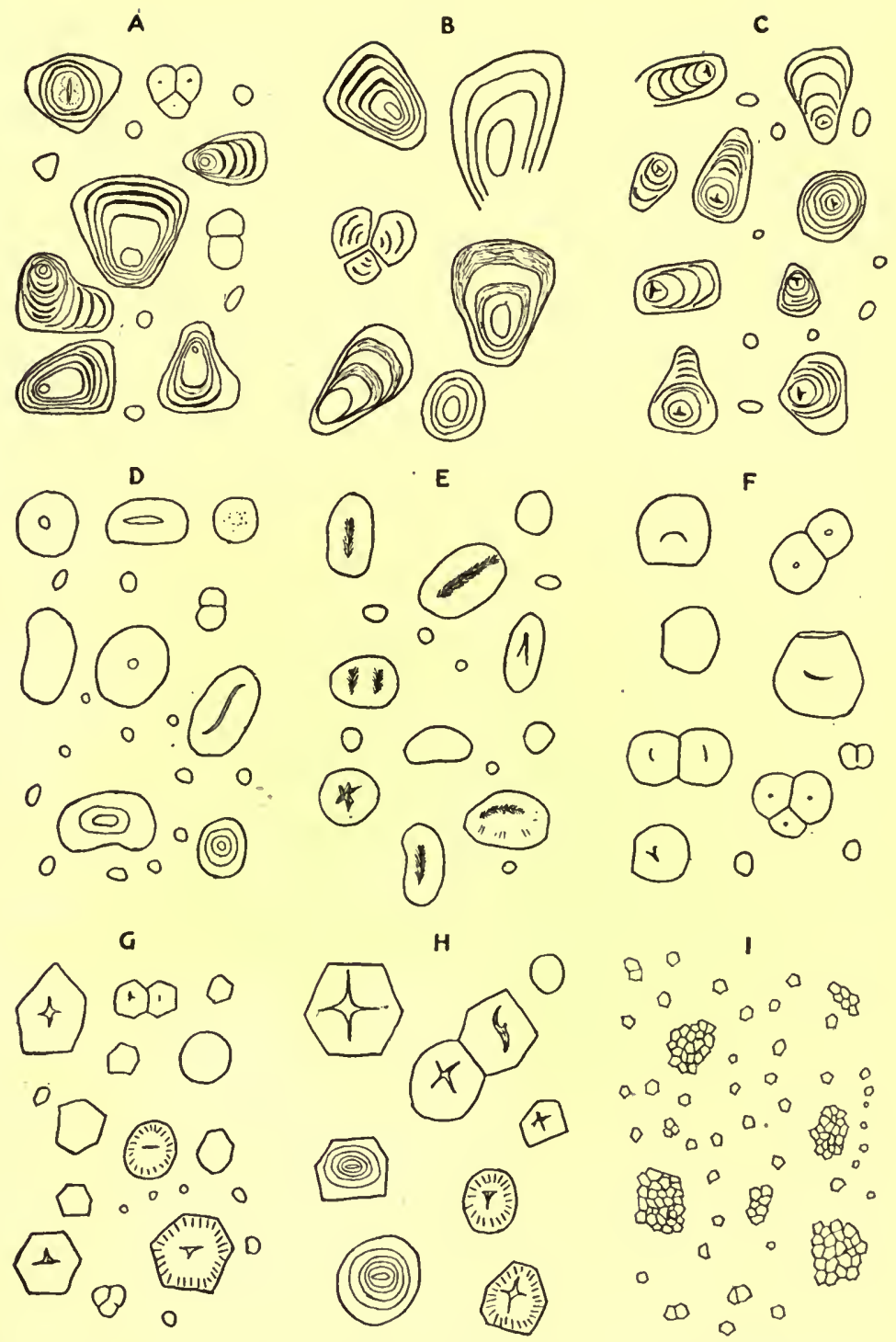

Pra. 20.-Commercial Starches and Dextrins. $A$, potato starch; $B$, altered starch grains in potato dextrin; $C$, maranta starch; $D$, wheat starch; $E$, altered starch grains in brewer's malt; $F$, cassava starch; $G$, corn starch; $H$, altered starch grains in corn dextrin; $I$, rice starch.-Drawing by Hogstad. 
cells are narrow thin-walled tube-cells, which are also found in the other cereals. Corn meal contains more starch and oil and little hull, as compared to corn bran. In Broom Corn and Sugar Sorghum the tangential walls of the cells of the epicarp are undulate and distinctly porous; and the more or less polygonal cells of the perisperm are quite prominent. These two kinds of cells serve to distinguish these fruits from either corn or any of the other cereals.

Corn Bran.--Less starch and oil and more hull, as compared to corn meal.

Rice Starch.-This is prepared by the use of chemicals much the same as in the preparation of corn starch and is either in the form of a white or cream-colored powder of small, irregular masses. The individual grains like those of oat (Fig. 20), are polygonal, from 0.002 to $0.010 \mathrm{~mm}$. in diameter, with a central cleft, and usually united into small aggregates of two or more. The product sold for rice starch is frequently rice flour, and is characterized by the large, oval aggregates of numerous grains, as well as cellular tissue.

Rice Flour consists chiefly of the small, angular starch grains and aggregates like those of oat. There are also present some of the polygonal cells containing aleurone grains and a few fragments of the pericarp. The latter is especially characterized by the radially elongated cells of the epicarp, which are 0.100 to $0.500 \mathrm{~mm}$. long and 0.025 to $0.100 \mathrm{~mm}$. wide, and the end walls of which are deeply undulate, resembling the epidermal cells of some leaves.

The Rice Powder of commerce may consist of mixtures of rice starch with any of the following substances: corn starch, talc, zinc, oxide, chalk or bismuth subnitrate.-(LaWall, Amer. Jour. Pharm., 1915, p. 299.)

Rice Bran.-It has been known for some years that while polished rice produces in chickens the symptoms of beri-beri, the same chickens fed with rice bran recovered. What constituent of rice bran produces this result has been the subject of considerable investigation in Japan, and Suzuki isolated a principle which he called aberinic acid, and later obtaining it much purer he called the latter product, oryganin. Kondo and Gorin have recently studied the use of these rice bran preparations in beri-beri. They find that the bran and its extract made with 90 per cent alcohol were efficacious in the disease produced in doves; that an extract made with 20 per cent alcohol is of service, but not so efficacious as the extract made with stronger alcohol; and that Suzuki's oryganin does not seem effective.

This latter substance was found to be a mixture, containing choline, nicotinic acid and adenin. In addition, rice bran contains 
fat, phosphateides, starch, acids, betamin and sugar. So far, Kondo and Gorin have been unable to isolate from rice bran any individual chemical to which the therapeutic effect of the bran could be ascribed.

Wheat Starch usually occurs in very hard, somewhat elongated and columnar or irregular masses, varying from 1 to $3 \mathrm{~cm}$. in length. The starch grains are more or less rounded or flattened-circular, and depending upon the surface presented to view under the microscope, appear circular or elliptical in outline (Fig. 20); they vary from 0.015 to $0.035 \mathrm{~mm}$. in diameter and are without distinct markings except when heated or treated with dilute acid or alkaline solutions. When viewed under the micropolariscope the grains do not show a distinct cross, except when viewed on edge, and the play of colors when the selenite plate is used is scarcely discernible. Wheat starch does not agglutinate on mixing with water as wheat flour does.

Wheat Flour.-Agglutinates with water (distinction from wheat starch); few tissues of wheat grain.

Wheat Middlings are grayish-white and in addition to the characteristic starch grains there are numerous fragments of tissues, as the thick-walled polygonal cells of the endosperm, which contain small aleurone grains and have a more or less distinct nucleus; the cells of the embryo containing aleurone grains and fixed oil; and the tissues of the pericarp. The latter include unicellular hairs, which are 0.5 to $1 \mathrm{~mm}$. in length and 0.015 to $0.025 \mathrm{~mm}$. in diameter, have a sharply pointed summit and rounded base, and a narrow lumen, which is but 0.001 to $0.002 \mathrm{~mm}$. wide; a layer of tangentially-elongated cells from 0.100 to $0.200 \mathrm{~mm}$. long and 0.015 to $0.025 \mathrm{~mm}$. in diameter, which are slightly thickened and with simple pores; and running across the latter are a number of more or less isolated vermiform cells with rounded ends (Fig. 21).

Wheat middlings which have been kept for some time acquire an odor suggestive of elm bark or fenugreek. It is extensively used in veterinary medicine as a basis for the inclusion of bitter tonic substances. It has also been extensively used in adulteration of spices, foods and powdered drugs.

Wheat Bran is said to be sometimes adulterated with "inner coffee hulls," which consist of the inner tissues of the pericarp of the coffee fruit, and are readily detected by the fragments of palisade cells and the somewhat elongated, narrow, sclerenchymatous fibers which cross one another.

Wheat Germ.-The material known as wheat germ was formerly a waste product of the flour mills, or used only as a fodder, but recently it has been utilized in the forms of certain kinds of bread and 
in various other foods. Chemical analysis has shown this material to contain choline, betaine, allantoin, cane sugar, dextrose and raffinose. In addition thereto, a fatty oil, consisting of palmitic, stearic and linolic acids, the latter predominating. A very small amount of sinapic acid was also obtained, which probably exists in the wheat germ in the form of sinapine, the latter being a choline ester of sinapic acid. The material yields, furthermore, a small amount of an amorphous, glucosidic product, and the proportion of resinous substances is exceedingly small. (Power, Pharm. Journ., 1913, pp. 117-120.)

Rye Flour is faintly grayish-white, the starch grains closely resembling those of wheat, but sometimes larger $(0.020$ to $0.060 \mathrm{~mm}$.); the lamellæ are distinct and the point of origin of growth is sometimes marked by a star-shaped cleft or fissure. Rye flour when mixed with water does not agglutinate like wheat flour. A few fragments of the pericarp are also present (Fig. 21).

Rye Middlings.- In addition to the starch grains in rye flour a considerable amount of the tissues of the pericarp are present. The latter closely resemble those of wheat, but hairs from the summit of the fruit have thinner walls, the lumina being two or three times the thickness of the walls; and the tangentially-elongated cells have simple pores only on the tangential walls, and do not lie close together, so that there are intercellular spaces between them (Fig. 21).

Barley Flour.-The starch grains closely resemble those of wheat, but are smaller, usually not more than $0.025 \mathrm{~mm}$. in diameter, and in the case of malt the grains show distinct radial and circular clefts, due to the action of the diastase; the hairs from the summit of the grain resemble those of both wheat and rye but are shorter than either, being from 0.040 to $0.150 \mathrm{~mm}$. long; the tangentiallyelongated cells are non-porous, the walls being 0.001 to $0.002 \mathrm{~mm}$. thick (Fig. 21).

Buckwheat Flour.--Light grayish-brown; pericarp of elongated epidermal cells with latticed walls, due to the pores of the outer and inner walls running obliquely and at right angles to each other; short sclerenchymatous fibers with somewhat curved or oblique end walls, large simple pores and brown contents; parenchyma with brown contents. Seed-coat showing in surface section epidermal cells with undulate walls; branching parenchyma with greenish or brownish-yellow contents; and an inner epidermis of elongated cells. Endosperm having a layer of cells containing aleurone grains, resembling those found in the true cereals, and parenchyma with numerous angular or somewhat rounded or ellipsoidal starch grains (resembling 


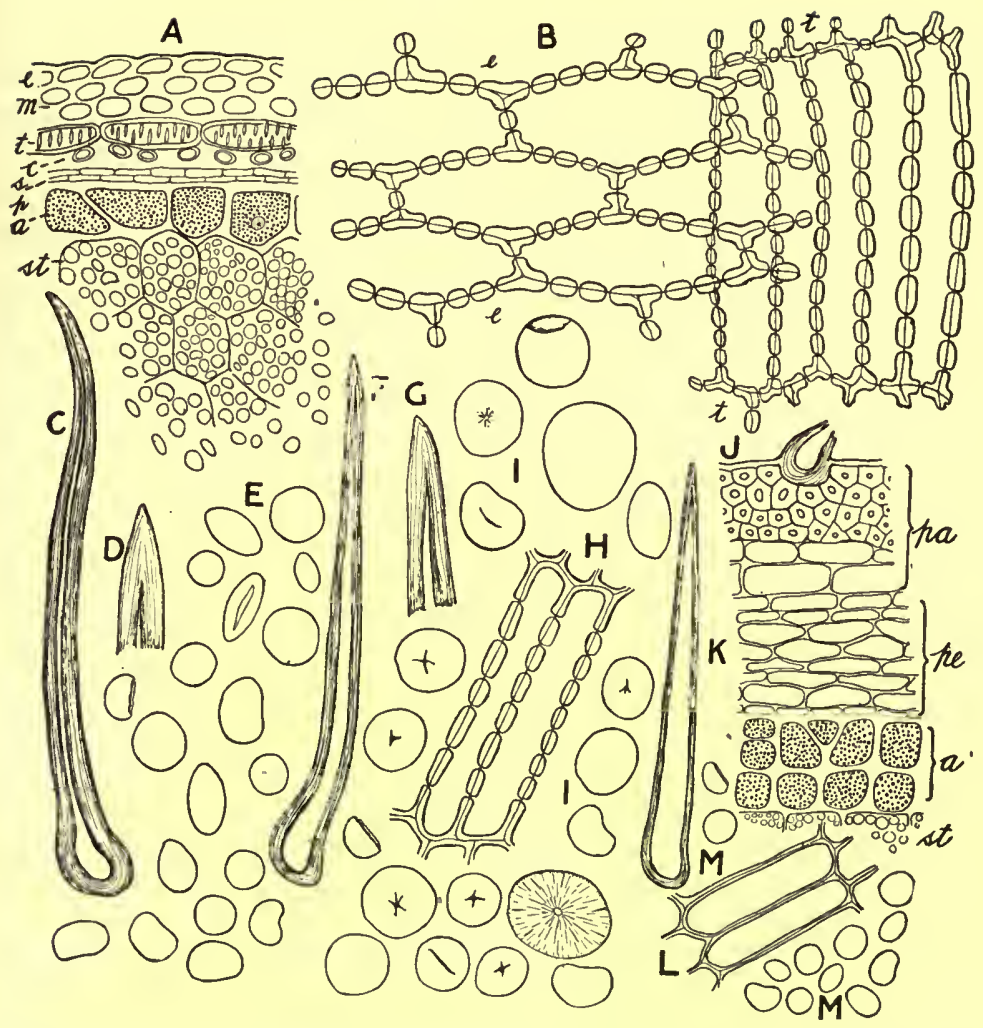

Fig. 21.-Wheat grain (Triticum sativum): $A$, transverse section showing epicarp $(e)$, cells of mesocarp $(m)$, tangentially-elongated cells (querzellen) $(t)$, tube cells $(c)$, spermoderm $(s)$, perisperm $(p)$, aleurone cells $(a)$, parenchyma containing starch $(s t) ; B$, surface section of pericarp showing relation of epidermal cells $(e)$ to tangentially-elongated cells $(t)$; $C$, hair from the summit of the grain with thick wall and very narrow lumen; $D$, apical portion of a hair; $E$, starch grains.

Rye grain (Secale cereale): $F$, hair with wall comparatively thinner than in the hair of the wheat grain; $G$, apical portion of a hair; $H$, tangentially-elongated cells in which the pores occur only on the tangential walls; $I$, starch grains which vary from 0.020 to $0.070 \mathrm{~mm}$. in diameter, and occasionally have delicate clefts.

Barley grain (Hordeum sativum): $J$, transverse section of palet ( $\bar{p} a$ ) and pericarp (pe), aleurone layer (a) composed of two or three rows of cells, parenchyma of endosperm containing starch $(s t) ; K$, hair from epicarp with very thin wall and large lumen; $L$, tangentially-elongated cells which differ from those of wheat and rye in being without pores; $M$, starch grains which resemble those of wheat but are uniformly smaller. 
those of rice or oat), with distinct central cleft and varying from 0.005 to $0.012 \mathrm{~mm}$. in diameter.

Potato Starch occurs as a more or less finely granular powder, and appears to have less tendency to form coherent masses than arrowroot starch. The grains (Fig. 20) are somewhat shell-shaped, having distinct lamellæ and a circular point of origin of growth, which is at the smaller end of the grain. They vary in size from 0.005 to $0.125 \mathrm{~mm}$., there being a large number of smaller, somewhat ellipsoidal or spheroidal grains, and a few 2- or 3-compound grains. Under the micropolariscope the grains show a distinct cross, and a striking play of colors when a selenite plate is used. On heating the starch to a temperature of $65^{\circ} \mathrm{C}$. or treating it with very dilute alkali or acid solutions, the grains swell to four times their original size and finally burst.

Maranta or Arrowroot Starch.-There are a number of commercial kinds of this starch, depending upon the countries in which it is produced. Bermuda arrowroot is in the form of somewhat hard, irregular granules or masses, varying from 1 to $6 \mathrm{~mm}$. in diameter. When rubbed between the fingers it is reduced to a smooth powder, which is velvety to the touch. The starch grains (Fig. 20) vary in shape from ellipsoidal to ovoid or oblong, and from 0.010 to 0.065 , $\mathrm{mm}$. in diameter. The lamellæ are mostly indistinct and there is usually a transverse or crescent-shaped cleft at the middle or near the broad end of the grain. Montserrat arrowroot closely resembles the Bermuda starch, but the grains are a little larger and more of them show the cleft. St. Vincent arrowroot is slightly darker in color and is in the form of masses or granules, which are sometimes $20 \mathrm{~mm}$. in diameter. The starch grains resemble those of the Bermuda arrowroot, but the grains having clefts are more numerous.

The arrowroot starches all show a distinct cross with the micropolariscope and a marked play of colors when a selenite plate is used. These starches usually contain about 15 per cent of water, the remainder being mostly starch.

Other Starches.-Among the other commercial starches the following may be mentioned:

$a$. Consisting of Single Grains; Yam starch (from several species of Dioscorea) occurs in narrow, ellipsoidal grains, 0.030 to $0.050 \mathrm{~mm}$. long, with distinct lamellæ and point of origin of growth at narrow end. Canna starch (tous les mois arrowroot), derived from several species of Canna, occurs in broadly ellipsoidal or ovoid grains varying from 0.050 to $0.125 \mathrm{~mm}$. in diameter and with distinct lamellæ and circular point of origin of growth. Bean starch consists of ellipsoidal 
or reniform grains, which vary from 0.025 to $0.050 \mathrm{~mm}$. in length and have a distinct, branching, elongated cleft in the middle. Pea starch grains resemble those of bean starch, but the grains are smaller and more or less irregular on the surface. Queensland arrowroot is obtained from Canna edulis.

b. Consisting of 2- to 3-compound grains: Cassava or tapioca starch is obtained from the Sweet and Bitter Cassava, and occurs in somewhat plano-convex or bell-shaped, 2- to 3-, or èven 4- to 8-compound grains, which vary from 0.006 to $0.030 \mathrm{~mm}$. in diameter an have a distinct central, circular, or radiating cleft. Sweet potato starch resembles Cassava starch, but some of the grains are larger.

Dextrin.-Sticky mass with water, consisting chiefly of altered starch grains, but usually sufficient unaltered grains are present to determine the source of the dextrin (Fig. 20, B, H).

It is chiefly made from either potato or corn starch and depending upon the nature of the process two kinds are manufactured. When heat alone is used yellow dextrin is formed, and when the hydrolysis is assisted by the use of acids, white dextrin or so-called soluble starch results. Dextrin is almost completely soluble in hot water and should not contain more than 5 per cent of dextrose, 10 per cent of moisture and 0.5 per cent of ash.

Sago starch is obtained from Cycas revoluta and other cycads as well as a number of palms. It occurs in commerce in small, horny granules, which are slowly affected by cold water, when there separates the characteristic ellipsoidal or truncate-ellipsoidal starch grains. The latter vary from 0.015 to $0.050 \mathrm{~mm}$. long and have a large central area surrounded by rather narrow distinct, altered lamellæ.

Sago (imitation).--Usually made, from corn starch and breaks down quickly in water, showing characteristic corn-starch grains.

MALTUM.-Malt.-The partially germinated and dried grains of Hordeum sativum, particularly of the variety vulgare (Fam. Gramineæ). In the preparation of malt the barley grains are soaked in water for twelve to twenty-four hours, placed in heaps, allowed to germinate, being occasionally stirred so that the heat generated on germination does not become excessive. After the protrusion of the caulicle and radicle the material is quickly dried and deprived of these parts.

Barley.-Narrow-ellipsoidal, somewhat 4-angled, 8 to $10 \mathrm{~mm}$. long, 2 to $3 \mathrm{~mm}$. in diameter, having an outer, readily separable coat consisting of the inner and outer pales, which are membranous, chafflike, pale straw-color and somewhat translucent; within the pales 
and adhering to the base of the grain, two very small lodicules consisting chiefly of unicellular hairs from 0.5 to $1 \mathrm{~mm}$. long. Grain nearly smooth, grooved on one side and with a slight projection at the summit consisting of numerous 1-celled hairs, usually with pollen grains, adhering, embryo on side opposite the groove and forming a slight projection at the base of the grain; endosperm large and consisting chiefly of cells filled with spheroidal starch grains resembling those of wheat, the two to four outer layers of cubical cells containing aleurone grains. The embryo is connected with the endosperm by means of a sheathing membrane (by some regarded as a modified cotyledon), through which it obtains nutriment during germination. On germination the embryo produces about 5 multiple primary rootlets and a stem portion with sheathing green leaves.

Malt.-Grains resembling those of barley, of a yellowish-brown to dark brown color, and with a short fracture; starch grains altered, exhibiting numerous radial and concentric fissures; odor agreeable and taste sweetish. (Fig. 20.)

Constituents.-Barley grains contain from 60 to 68 per cent of starch; 12 to 18 per cent of proteins; about 1.5 per cent of sugar, and 1 to 3 per cent of fixed oil. Two ferments are developed during the process of germination, namely, diastase, which acts on the starch, changing it to dextrin and maltose; and another ferment which acts on the proteins, converting them into peptones. The germinating seeds of barley contain a white crystallizable alkaloid, hordenine, which is slightly toxic.

Commercial malt contains nearly the same constituents as are found in barley, the starch grains being somewhat altered and converted partly into soluble starch through the action of the ferment diastase, a small amount of which is still present in malt after drying. In the preparation of the extract of malt the starch is mostly converted into dextrin and maltose, the proportion of the latter being larger.

Literature.-Mann, "Morphology of the Barley Grain with Reference to its Enzym-Secreting Areas," Bulletin of the U. S. Department of Agriculture No. 183.

Vetiver.-Radix Iwarancusæ, or Cuskus Root.-The rhizome and roots of Andropogon squarrosus (Fam. Gramineæ), a perennial grass indigenous to the East Indies and cultivated in various parts of tropical America, also growing in the vicinity of New Orleans. It easily adapts itself to cultivation in the greenhouse.

Description.-The rhizome is upright, cylindrical, from 10 to 30 $\mathrm{mm}$. in length and 5 to $15 \mathrm{~mm}$. in thickness; it is yellowish-while 
and marked with numerous circular scars from the sides of which emanate the long, cylindrical, tortuous roots which are beset with numerous fine branches inter-twining with each other and forming a mat. The roots may attain a length of over $30 \mathrm{~cm}$. and a diameter of $2 \mathrm{~mm}$. and are very tough, fibrous. When fresh they are of a slight yellowish-brown color, becoming when dried reddish-brown. The drug has an aromatic odor and a somewhat bitter taste. The volatile oil resides in the bark, which should be present in the commercial article.

\section{Inner Structure.-See Fig. 22.}

Constituents.-From 0.4 to 0.9 per cent of volatile oil; a large amount of starch; a small amount of resin and a bitter principle. The volatile oil of Vetiver varies in color from dark yellow to dark brown and is the most viscid of all the volatile oils. It is heavier than water, intensive and very persistent in odor, being used primarily in finer perfumery for fixing the more volatile odors.

Adulterants.- The commercial article is frequently contaminated with red sand. The root, from which a part of the volatile oil has been extracted, is frequently found in commerce and can be recognized by its lighter color.

Allied Plants.-The rhizomes and roots of a number of other species of Andropogori growing in Brazil and Persia have apparently the same properties as the genuine Vetiver.

StIPA VASEYI.-Sleepy Grass.-This grass grows throughout the southwestern part of the United States and Mexico and from its property of putting to sleep any animal that has eaten it it has come to be known, especially in Mexico and New. Mexico, as "Sleepy Grass."

Description.- The plant is a stout, leafy, densely tufted, perennial grass from 1 to $2 \mathrm{M}$. high, with broad loose and overlapping lower sheaths, longer than the internodes and bearing broad flat leaves often $6 \mathrm{dm}$. in length; the upper sheaths are smaller and shorter than their respective internodes, bearing smaller, often involute leaves; the culm is terminated by an erect, dense panicle from 1.5 $\mathrm{dm}$. to $4.5 \mathrm{dm}$. in length; spikelets about $9 \mathrm{~mm}$. in length, the glumes minutely scabrous on the back and acuminate; flowering glume pubescent; awn $15 \mathrm{~mm}$. to $35 \mathrm{~mm}$. in length, twice bent and twisted up to the second bend; callus densely hairy acute.

Inner Structure.-Consult Farwell, Merck's Report, 1911, p. 271.

Constituents.-Practically nothing is known concerning the active principles upon which its physiological action depends. The drug is best extracted with weak solutions of either acetic or hydrochloric 


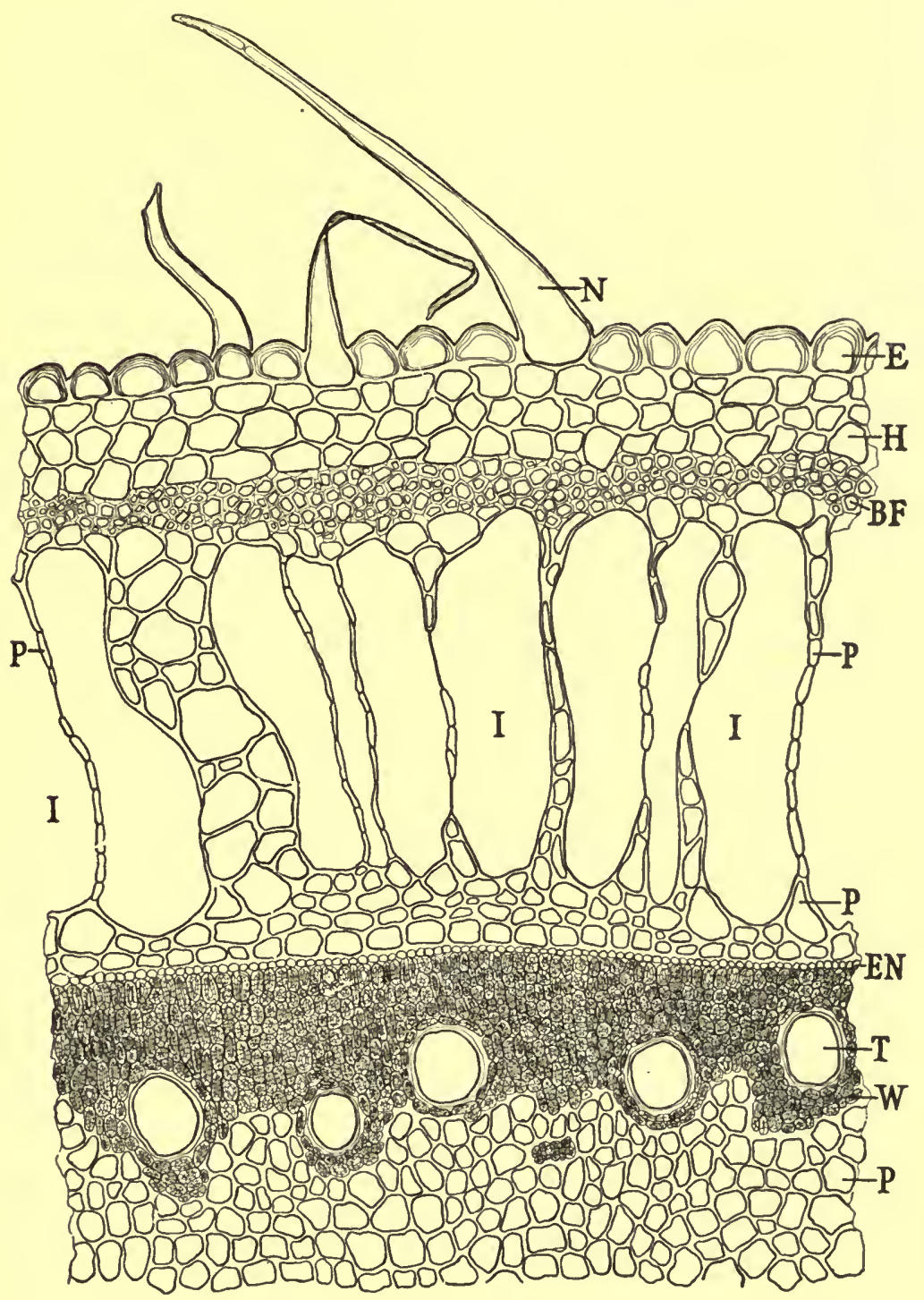

FIG. 22.-Transverse section of rhizome of Vetiver (Andropogon squarrosus) growing in the vicinity of New Orleans. $E$, epidermis; $N$, unicellular nonglandular hairs; $H$, hypodermis; $B F$, closed ring of bast fibers; $P$, parenchyma cells separated by large intercellular spaces $(I) ; E N$, endodermis; $W$, wood fibers; $T$, trachex; $P$, parenchyma cells of pith.-Drawn by Haase. 
acids, or dilute alcohol. According to Lescohier (Ibid,, p. 273) Sleepy Grass has some hypnotic properties but no anesthetic effects. The drug will probably never assume any therapeutic importance, as its marked depression on the vital functions of the body obviates the possibility of utilizing its hypnotic properties.

Allied Plants.-Other species of Stipa are known to be poisonous to cattle; among these the following may be mentioned: Stipa inebrians, of Mongolia, is said to be poisonous to the stock of that region and to produce effects exactly like those produced by the sleepy grass of New Mexico. Stipa sibirica, of central and northern Asia, is poisonous to stock, which die within a few hours after feeding upon it unless remedial treatment is quickly given. Stipa leptostachya and S. hystricina, of Bolivia and Argentina, are fatal to stock of those countries. Heim and Herbert found that these plants contain a glucoside that splits up and yields 0.02 per cent of hydrocyanic acid, which probably is the real cause of the death of the stock that have eaten the grass. Stipa capillata, of Europe and Asia; S. spartea, the porcupine grass, and S. setigera, of North America, may be fatal to stock in a purely mechanical manner. The hard pointed, hairy callus of the seed may puncture the skin and work its way inward until it strikes a vital organ. killing the animal.

\section{PALMAE, OR TRUE PALMS}

They are mostly shrubs and trees restricted to tropical and subtropical countries. They were at one time quite extensively distributed and very numerous and at the present time they are represented by about 1000 species. They are mostly unbranched shrubs and trees and the trunks may reach the height of $35 \mathrm{M}$., and usually bear at the summit a cluster of large leaves which are either pinnate (feather palms) or palmate (fan palms). Some of the palms are low growing, as the saw palmetto of the southern United States, which has a creeping and branching root stock or rhizome. They are of very great importance to man, being employed for a large number of purposes. The anatomy of the stem is quite characteristic, consisting of an epidermal layer with siliceous walls; the fibrovascular bundles, consisting of 1 to 3 tracheæ and numerous tracheids, are of the concentric type and lie quite close to each other forming a rather characteristic woody portion. The leaves usually possess on the dorsal surface a hypodermal layer beneath which occur radially elongated groups of sclerenchymatous fibers and between which is distributed the chlorophyll-containing parenchyma, which resembles 
those of the mesophyll. The seeds have a large thick-walled endosperm as seen in the date and vegetable ivory.

Sabal.-Saw Palmetto.-The ripe drupe of Sabal (Serenoa) serrulata (Fam. Palmæ), a small palm found growing in sandy soil from South Carolina to Florida. The fruit is partially dried by artificial means (Fig. 23).

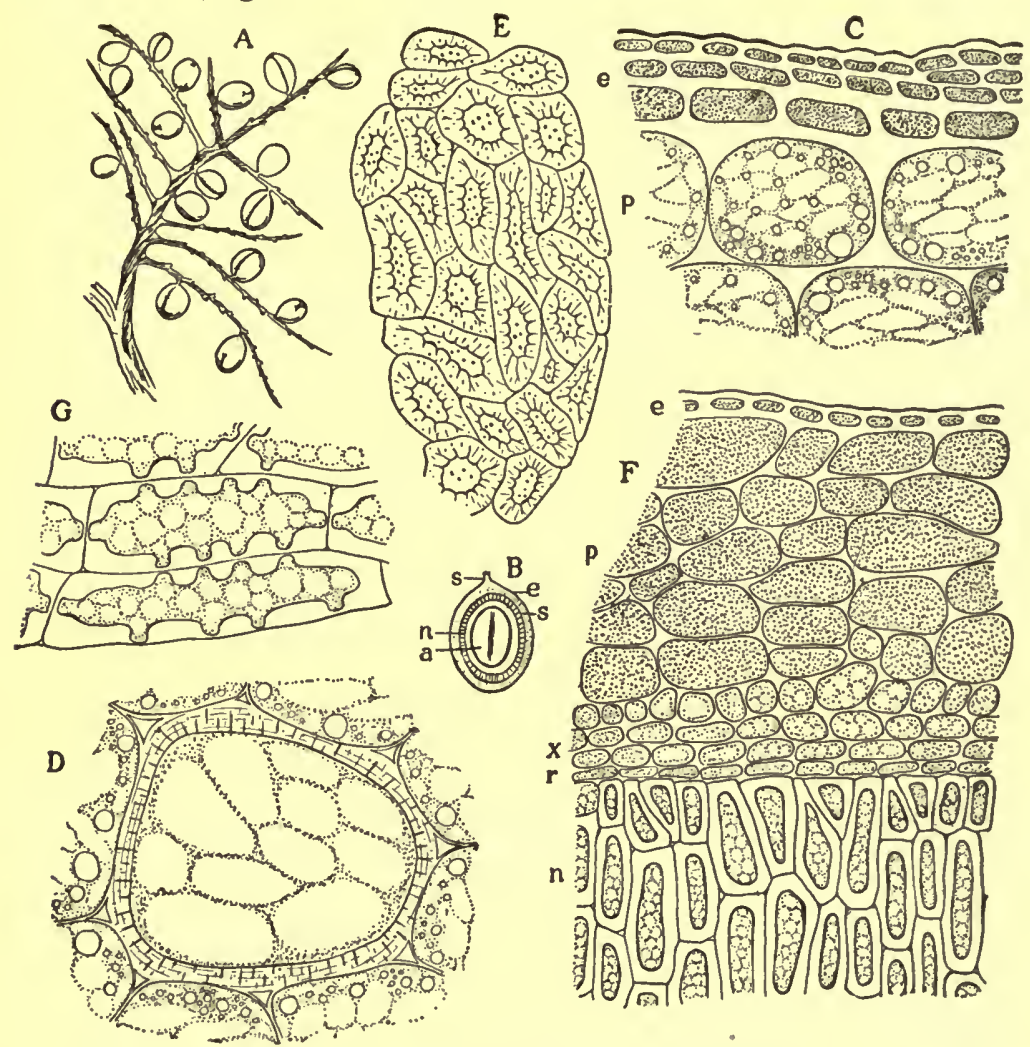

FIg. 23.-Saw palmetto (Sereona serrulata): $A$, fruiting branch; $B$, longitudinal section of fruit showing short stalk $(s)$, epicarp $(e)$, sarcocarp $(s)$, endocarp; $(n)$, and anatropous seed with raphe $(a)$; $C$, cross-section of outer portion of fruit showing epidermis $(c)$ composed of several layers of cells having a dark reddish-brown content, cells of sarcocarp $(p)$ with reddish-brown content and oil; $D$, a sclerotic cell from the sarcocarp showing the fine radiating pores and concentric lamellæ of the wall; $E$, sclerotic cells from endocarp; $F$, cross-section of portion of seed showing epidermal cells $(e)$, large parenchyma cells $(p)$, inner epidermis $(x)$, perisperm $(r)$, endosperm $(n) ; G$, some thick-walled endosperm cells from the inner portion of seed.

The saw palmetto is characterized by having a creeping rootstock or rhizome one end of which rises a short distance above 
ground, this portion being surmounted by a dense crown of leaves. The petioles are slender and spinose on the edges; the blade is fanshaped and consists of a number of palmate divisions which are slightly cleft at the summit. The inflorescence is densely tomentose and shorter than the leaves. The fruit is a 1-seeded drupe (Fig. 23).

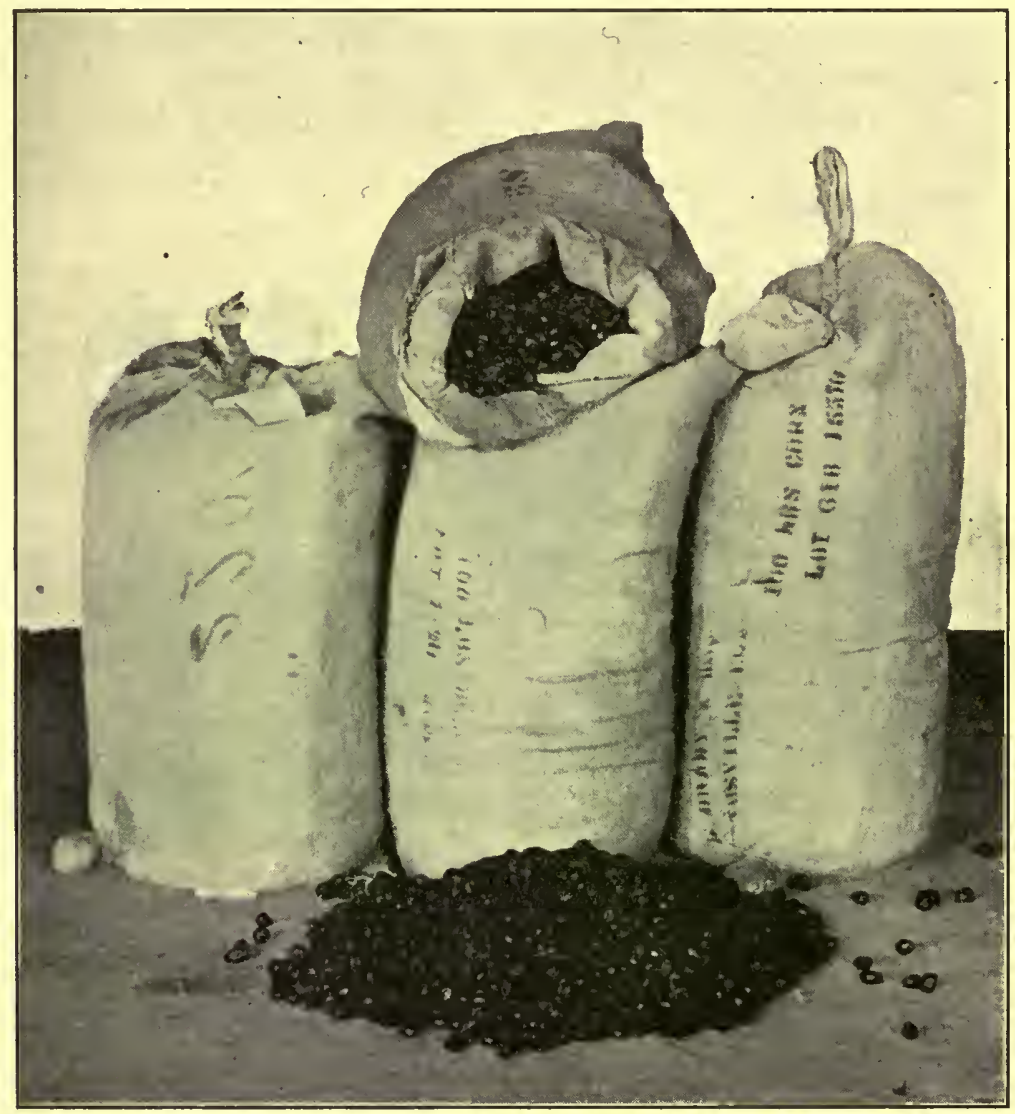

Fra. 24.-Original packages of Saw Palmetto Berries (Sabal). After a photograph by Parke, Davis \& Co.

Description - Drupe superior, ellipsoidal, ovoid or somewhat globular, 1.5 to $3 \mathrm{cr}$. long. 1 to $1.5 \mathrm{~cm}$ in diameter; externally brownish-black, smootk somewhat oily, with a few large, somewhat angular depressions due tc the contraction of the inner layer on drying; summit marked by remains of style; base marked by stem-scar or with remains of stem; epicarp and sarcocarp together forming a thin cori- 
aceous shell enclosing a hard but thin endocarp which is externally reddish-brown and somewhat fibrous, as is also the inner layer of the sarcocarp; inner layer of endocarp smooth, enclosing an ellipsoidal or ovoid, hard, somewhat flattoned, anatropous, reddish-brown seed which is marked on the raphe side by an arillus-like appendage and on the opposite side near the end by the micropyle, which forms a slight projection; internally, with a large endosperm of thick-walled parenchyma and a very small embryo at the micropyle; odor pronounced, aromatic and fruity; taste sweetish, aromatic and slightly acrid.

Inner Structure.-See Fig. 23.
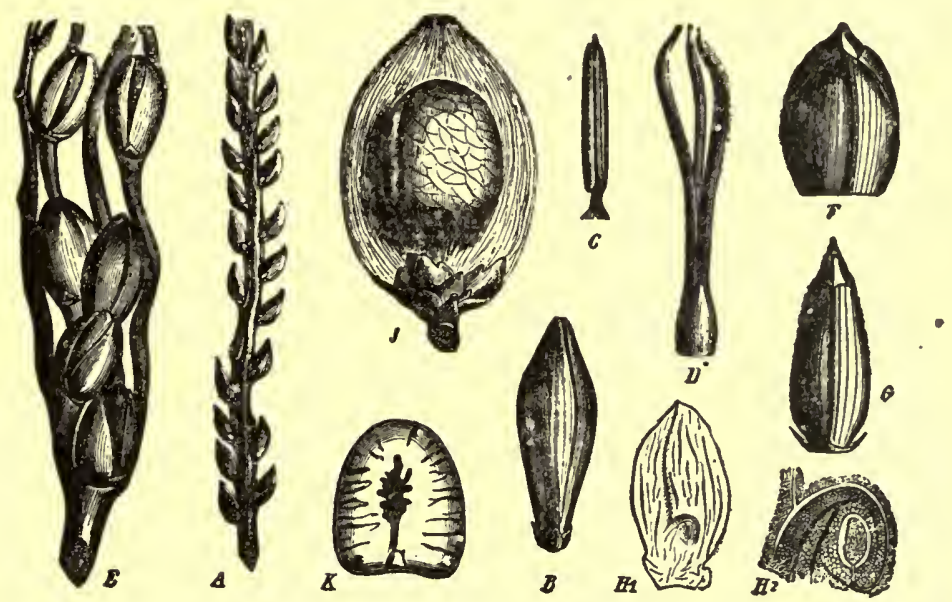

Fig. 25.-Areca Catechu (Betel-nut palm). $A$, upper portion of an inflorescence bearing staminate flowers; $B$, enlarged view of staminate flower; $C$, 3 stamens; $D$, upper part of ovary with 3 styles; $E$, a branch bearing 4 pistillate flowers in the lower portion and 2 staminate flowers above; $F$, a pistillate flower with bracts removed showing the calyx; $G$, an ovary with rudimentary stamen; $H 1$, longitudinal section through ovary; $H 2$ the same giving a magnified view of the ovule; $J$, section through a berry showing the fibrous sarcocarp and the seed covered by reticulated branches of the raphe; $K$, section of seed showing the ruminating endosperm with small embryo near the base.-After Drude.

Constituents.-A "so-called" volatile oil consisting of a mixture of ethyl esters of fatty acids. It is formed by the condensation of the free fatty acids, which are naturally contained in the berries, with ethyl alcohol, the preservative. The fresh berries contain traces of a volatile oil, which is semi-solid, resembling that of the 
cocoanut. The berries also contain an enzyme lipase. (Mann, Bull. Univ. Wis., No. 767, 1915).

Literature.-Kraemer, Practical Drug., 1910, 28, p. 97.

Semen Arecre.-Areca Nut or Betel Nut.-The seed of Areca Catechu (Fam. Falmæ). A beautiful tall palm very extensively cultivated in southeastern Asia and the East Indies. The Areca nut (Fig. 25) is very highly esteemed by the people of the East as a masticatory. The powdered nut is used to some extent as a vermifuge both upon lower animals and man. The seeds are 20 to $25 \mathrm{~mm}$. long, conical, grayish-brown, with numerous spiral, reddish veins, heavy, hard, somewhat aromatic, astringent and slightly acrid. They contain about 0.1 per cent of an oily liquid alkaloid, arecoline, which chemically and in its physiological action resembles pelletierine; 14 per cent of tannin, resembling catechutannic acid; gallic acid; a red coloring principle; and 14 per cent of a fixed oil. They also contain three other alkaloids: arecaine, arecaidine and guvacine, but these do not seem to give the drug its properties.

Literature.-Zörnig, Arzneidrogen, p. 576.

Coconnut.-Cocanut.-The Cocoanut palm (Cocus nucifera) growing in the coast regions of all tropical countries, yields the cocoanut of the market and is probably one of the most useful palms to the natives, furnishing as it does, food, clothing, utensils of all kinds, building materials, etc.

The following classification of the products obtained from the Cocoanut palm has been prepared by Toothaker of the Philadelphia Museum and shows the manifold uses of this palm.

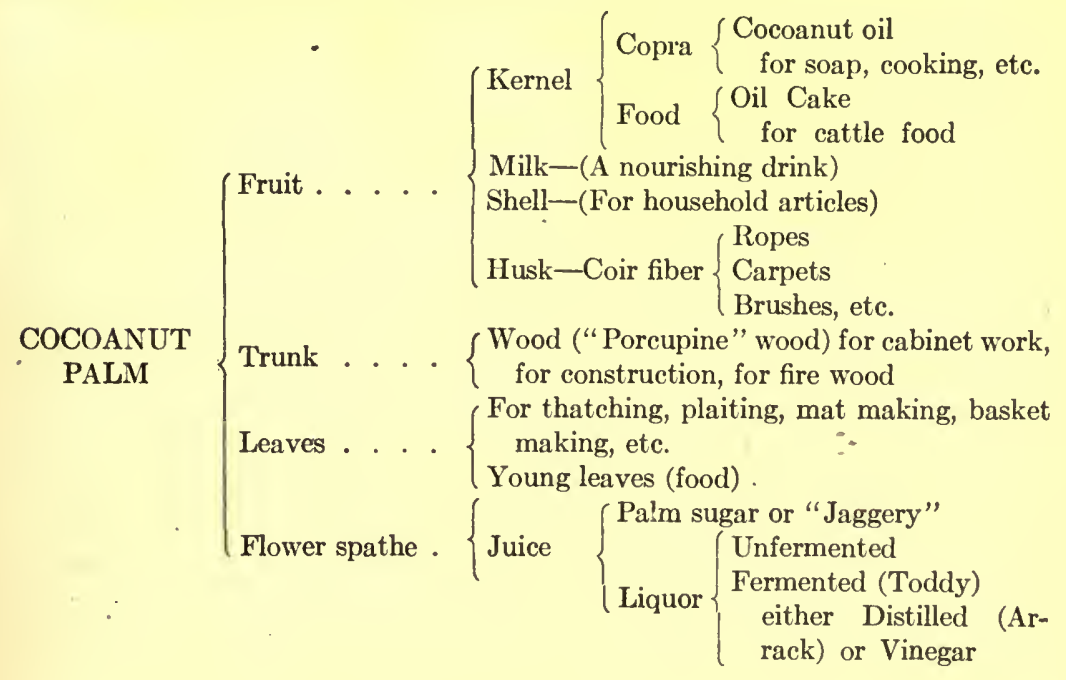


Cocoanut Oil.- The ripe kernels of the Cocoanut are removed from the seeds, dried in the sun, the resulting product being known as " copra." This is then shipped to Europe and other countries and a fixed oil is obtained either by extraction or pressure, using a hydraulic press. Cocoanut oil at ordinary temperatures is of the consistence of lard, is colored white or pearl-white and has a peculiar odor and taste. The unrefined oil readily becomes rancid and acquires a very disagreeable flavor and taste. It closely resembles palm-nut oil in its chemical composition, with the exception of the relative proportion of palmitic acid. Cocoanut oil may be regarded as the one edible oil which approximates in constitution ordinary butter.

Cocoanut Shells.-The endocarp of the fruit, while used as a household article by the natives, is to some extent ground up and used extensively as an adulterant of powdered foods and drugs. The presence of cocoanut shells may be detected by their yellow stone cells, which have thick yellow walls with branching pores and darkbrown contents. The stone cells vary from polygonal and isodiametric shape, to cylindrical and wedge-shaped forms that are quite characteristic. In addition there occur fragments of long thickwalled, porous fibers with accompanying stegmatic cells, each containing a spheroidal, tuberculated silicious granule. The darkbrown fragments in the powder are not affected by bleaching agents, such as Schulze's macerating solution.

Double Cocoanut.-The fruit of Lodoicea sechellarum, a palm growing in some of the Seychelles Islands. It is the largest sized fruit growing on shrubs or trees, being about $3 \mathrm{dm}$. in length, nearly $3 \mathrm{dm}$. in width and about $1.5 \mathrm{dm}$. in thickness. It is shaped like a beef-kidney, consisting of two symmetrical halves joined at the upper portions. The outer surface is smooth, of a grayish-brown color and marked by long longitudinal wrinkles. It consists of a very hard shell from 4 to $6 \mathrm{~mm}$. in thickness and encloses an edible endosperm similar to that of the true cocoanut. Many fabulous stories have had their inception in the double cocoanut and it is considered a sovereign antidote in poisoning.

Palm Oil.-A fixed oil obtained from the fleshy part of the fruit of Elæis guineensis, a palm of western Africa and cultivated in other tropical countries. The oil has the consistency of butter, a reddishyellow color, an agreeable odor and a pleasant taste. It is chiefly used for making soap and in the manufacture of galvanized iron, the oil being spread over the hot iron surface to preserve it from oxidation until it is dipped into the bath of melted tin. 


\section{ARACEEE, OR ARUM FAMIY}

A family of mostly tropical plants characterized by an inflorescence consisting of a spadix placed within a spathe. There are about 900 species mostly of tropical and sub-tropical countries, only about 1 per cent growing in temperature regions. The latter are mostly perennial herbs possessing rhizomes or acrid corms. The inner morphology is not constant, some genera containing characteristic spicular cells; a few contain tannic acid; others contain oil cells as in calamus, and quite a number contain laticiferous cells. Some of the plants are highly ornamental and are extensively cultivated as the Caladiums. One of the species, Caladium sequinum, of the West Indies and South America, possess a very acrid principle and when chewed causes the tongue to swell and produces temporary dumbness, whence the name "Dumb Cane" is derived.

Rhizoma Aronis.-Aronwurzel, Calf's Foot Root, Cuckow Pint Root.-The carefully dried rhizome (corm) of the European Arum, Arum maculatum and its varieties (Fam. Aracex), perennial herbs growing in middle and southern Europe. The tubers are gathered in the fall or spring, preferably the latter, the outer layers removed, cut transversely into slices and carefully dried.

Description.-In discs from 2 to $5 \mathrm{~cm}$. in diameter and 4 to 8 $\mathrm{mm}$. in thickness, whitish; fracture mealy, somewhat horny; scattered, somewhat irregular fibrovascular bundles; taste pungent.

Inner Structure.-A brown corky layer; numerous thin-walled starch-bearing parenchyma and a few cells containing long raphides of calcium oxalate; fibrovascular bundles scattered and distributed irregularly; starch grains mostly single and from 2- to 4-compound, the individual grains spheroidal from 0.005 to $0.010 \mathrm{~mm}$. in diameter and with a small central circular marking.

Constituents. - From 0.004 to 0.005 per cent of a liquid alkaloid resembling coniine; 0.1 per cent of a glucoside, arin, which appears to be in the nature of a saponin; 70 per cent of starch; and calcium oxalate, sugar, mucilage and a fixed oil.

Allied Plants.-The drug is sometimes prepared from the corms of Arum Dracunculus and A. italicum, which are larger in size than the genuine article.

Arum.-Indian Turnip, Jack-in-the-Pulpit.-The corm of Arisæma triphyllum, a common plant of the Araceæ growing in rich woods in eastern North America. The corms are gathered, cut transversely into pieces and dried. 
Description.-The entire corm is ovoid, from 1 to $3 \mathrm{~cm}$. in length and 1 to $5 \mathrm{~cm}$. in diameter; outer surface dark brown, deeply wrinkled, the sunimit depressed and near which arise numerous rather coarse roots; taste acrid especially when recently gathered.

Inner Structure.-Resembling the European Arum (Rhizoma Aronis). Consult Holm, Merck's Report, 1911, p. 66.

Constituents.-Probably the same as in the European Arum.

Calamus.-Sweet Flag.-The dried, unpeeled rhizome of Acorus Calamus (Fam. Araceæ), a perennial herb widely distributed in all north-temperate regions. The commercial supplies are obtained from the United States, Germany, England, Russia and India. The rhizomes are collected in autumn, the drug from India being the more aromatic, whereas the German product, on account of the removal of the outer portion of the rhizome, is probably the least aromatic. A confection was at one time made by "candying" the fresh rhizome.

Description.-Horizontal, cylindrical, slightly compressed, usually split longitudinally into pieces 5 to $15 \mathrm{~cm}$. long, 5 to $12 \mathrm{~mm}$. in diameter; externally light brown or yellowish green, annulate from remnants of circular bud-scales, upper surface with triangular leaf-scars or hair-like fibers of fibrovascular tissue, the sides with large circular branch-scars, and the under and side portions with root-scars or short fragments of roots; fracture short; internally light brown, distinctly porous, with numerous intercellular spaces, endodermis distinct; odor aromatic; taste strongly aromatic.

Inner Structure.-See Fig. 26.

Powder.-Light brown; tracheæ spiral, scalariform or reticulate; sclerenchymatous fibers slightly lignified, with oblique simple pores; starch grains nearly spheroidal, 0.004 to $0.008 \mathrm{~mm}$. in diameter; crystal fibers containing monoclinic crystals of calcium oxalate; oil-secretion cells with suberized walls; contents of parenchymatous cells colored ruby-red by a strong alcoholic solution of vanillin and hydrochloric acid. The powder of the peeled rhizome is less aromatic, and cells of the epidermis and cork, and crystal fibers are wanting. The yield of aqueous extract should be between 18 and 20 per cent. Powdered calamus has been reported as being admixed with as much as 30 per cent of diatomaceous earth.

An Indian variety contains from 1 to 2.5 per cent of oil and is mostly preferred.

Constituents.- -Volatile oil 1.5 to 3.5 per cent, having the odor and taste of the drug; acorin, a bitter, viscid, aromatic glucosidal principle, which when hydrolized in a current of hydrogen yields oil 

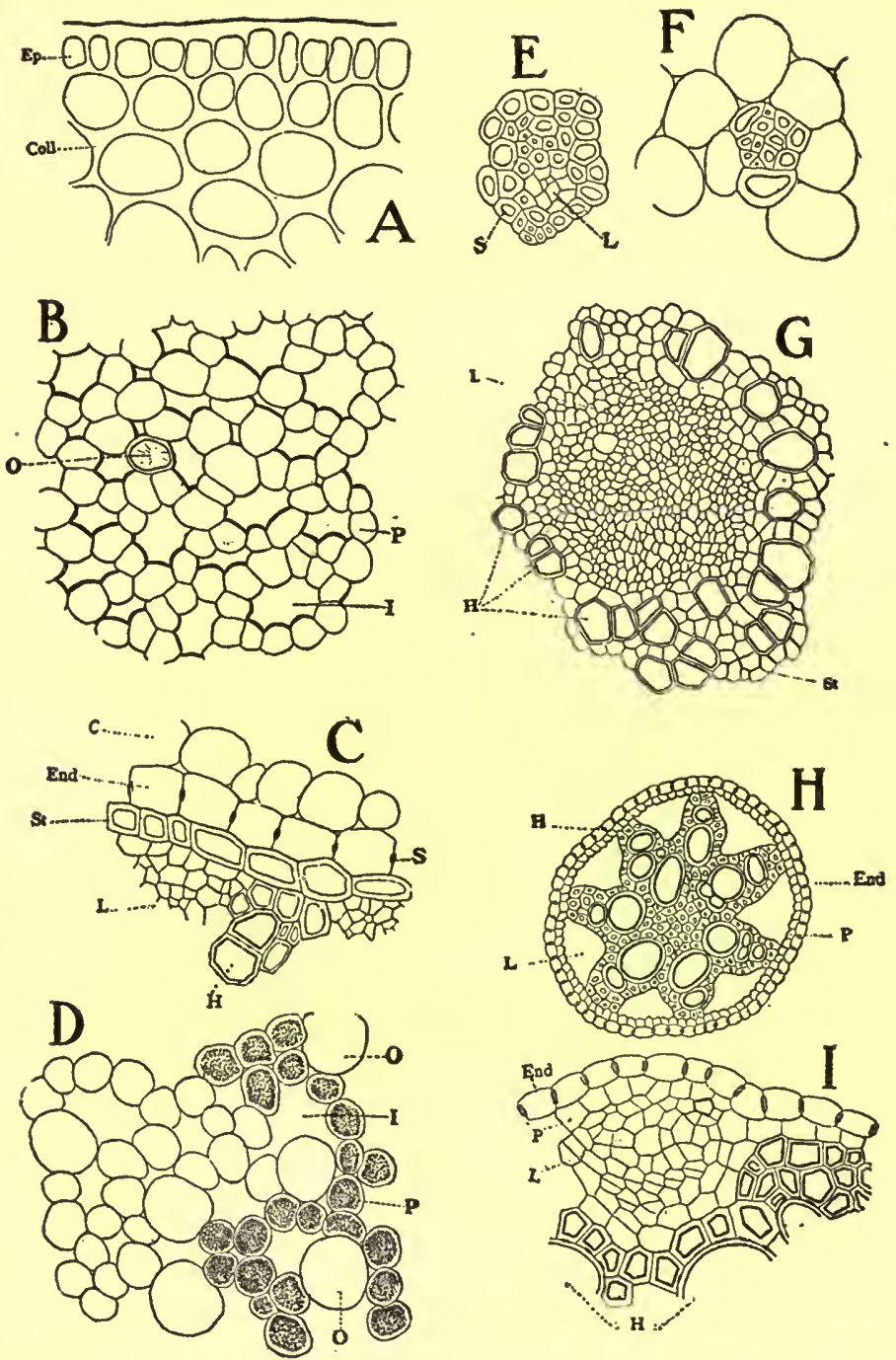

Fig. 26.-Calamus. $A$, transverse section of rhizome showing epidermis $(E p)$ and collenchyma (Coll.). $B$, cells of cortex showing isodiameteric, thinwalled parenchyma $(P)$ separated by large intercellular spaces $(I)$ and an oil cell $(O) ; C$, section of part of stele of rhizome showing cortical parenchyma $(C)$; cells of endodermis (End) with thin walls and Casparyan spots $(S)$; stereomatic pericycle $(S t)$; leptome $(L)$ and vessels or tracheæ $(H) ; D$, portion of pith showing starch-bearing parenchyma $(P)$; intercellular spaces $(I)$ and large oil cells $(O) . E$, a leptome strand from the pith of the rhizome showing leptome $(L)$ surrounded by sclerenchymatous fibers or stereome. $F$, a stereome strand from the pith of the rhizome consisting entirely of 
of calamus; choline (trimethyl-oxyethyl ammonium hydrate), a strong, non-poisonous base, and formerly known as calamine; a soft resin about 2.3 per cent; tannin; mucilage; starch and calcium oxalate.

\section{COMMELINACEE, OR SPIDERWORT FAMIIY}

Annual or perennial herbs, mostly indigenous to the tropics and represented by nearly 400 species. It is represented in the United States by Tradescantia and Commelina, some of the species of the latter being used in medicine.

Commelina.-Day Flower.-The entire plant of Commelina communis, a perennial herb growing in the United States south of New York and west to Kansas and Texas. The stem is procumbent or creeping and the plant produces roots at the nodes rather freely. The leaves are broadly lanceolate, being acute at the summit and contracted at the base into sheathing petioles. The floral leaves are large, heart-shaped, clasping bracts enclosing 2 to 4 flowers arranged in cymes. The fruit is a 3 -locular capsule containing 1 or 2 seeds in each locule. The seeds are oblong, about $2 \mathrm{~mm}$. in length and reticulated. For illustrations of morphology see Fig. 27.

Commelina probably contains a small amount of an alkaloid and a glucoside; mucilage 13 per cent and starch 0.5 per cent. The drug has hemostatic properties. Several species of Commelina growing in Mexico are also used for the same purpose.

Literature.-Herrera, Amer. Jour. Pharm., 1897, p. 290; Preston, Ibid., 1898, p. 321.

\section{LILIACEEE, OR LIIY FAMIIY}

They are mostly perennial herbs having bulbs or tubers and rarely fibrous roots. There are about 2500 species and are found in nearly all portions of the globe. A few are used in medicine, some furnish food products, but their chief interest is in their ornamental uses. The leaves are for the most part parallel-veined and the flowers are regular and with 6 stamens. There are no striking anatomical

sclerenchymatous fibers. $G$, a leptocentric mestome strand from the pith of the rhizome showing leptome $(L)$ tracheæ or vessels $(H)$ and sclerenchymatous fibers $(S t) . \quad I$, transverse section of root stele showing endodermis $(E n d)$; pericambium $(P)$; a 7 -rayed hadrome $(H)$ consisting of large tracheæ surrounded by sclerenchymatous fibers; leptome $(L)$ only indicated by $V$ shaped open spaces. $I$, transverse section of part of root stele showing tangential cell division on the inner flank of the leptome; letters as in H.After Holm. 
characteristics; the fibrovascular bundles are concentric and arranged in several rows outside of which and within the endodermis is a ring of sclerenchymatous fibers. The underground organs usually contain starch and not infrequently mucilage cells enclosing raphides.

Helonias.-False Unicorn Root.-The dried rhizome and roots of Chamælirium luteum (Fam. Liliacæ). The plant commonly
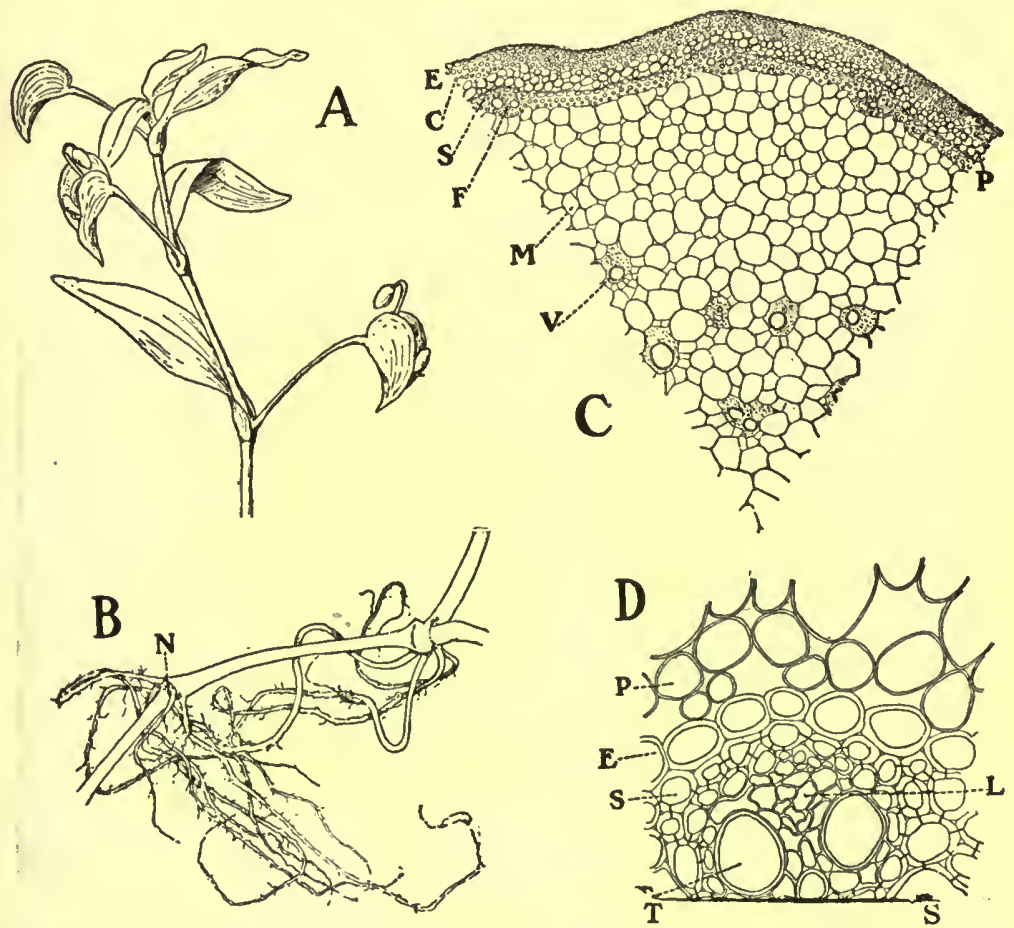

FIG. 27.-Commelina communis. $A$, part of flowering branch. $B$, portion of the prostrate stem. $C$, transverse section of stem showing epidermal layer $(E)$; a collenchymatous layer composed of from 3 to 6 rows of cells $(C)$; cortical parenchyma $(P)$; a well-defined cylinder sheath $(S)$ composed of rather large and strongly lignified cells and in which in the entire section are included about 14 fibrovascular bundles $(F)$, parenchyma of the pith $(M)$ in which are scattered fibrovascular bundles $(V)$. $D$, a collateral fibrovascular bundle.-After Preston.

known as Blazing Star was formerly called by botanists Helonias dioica, the name first given to it by Pursh. It was for some time also referred to as Chamælirium carolinanum. The name now generally applied is the Linnæan name, Chamælirium luteum, which was restored by Gray in the 5th edition of his Manual. While to those who are acquainted with taxonomy this use of synonomy is intelligible 
yet it is apt to produce a certain amount of confusion by drug collectors, as the generic name Helonias is applied to the Swamp Pink, a beautiful bog plant occasionally rather abundant in certain localities from New York to Virginia.

Chamclirium Luteum is a perennial, diœcious herb having a rather fleshy bitter rhizome, a number of basal leaves which vary from lanceolate to elliptical-spatulate and an herbaceous slender stem from 3 to $5 \mathrm{dm}$. in length terminated by a spike-like raceme of small white flowers. It grows in moist meadows and thickets throughout the eastern United States. The plant is quite readily

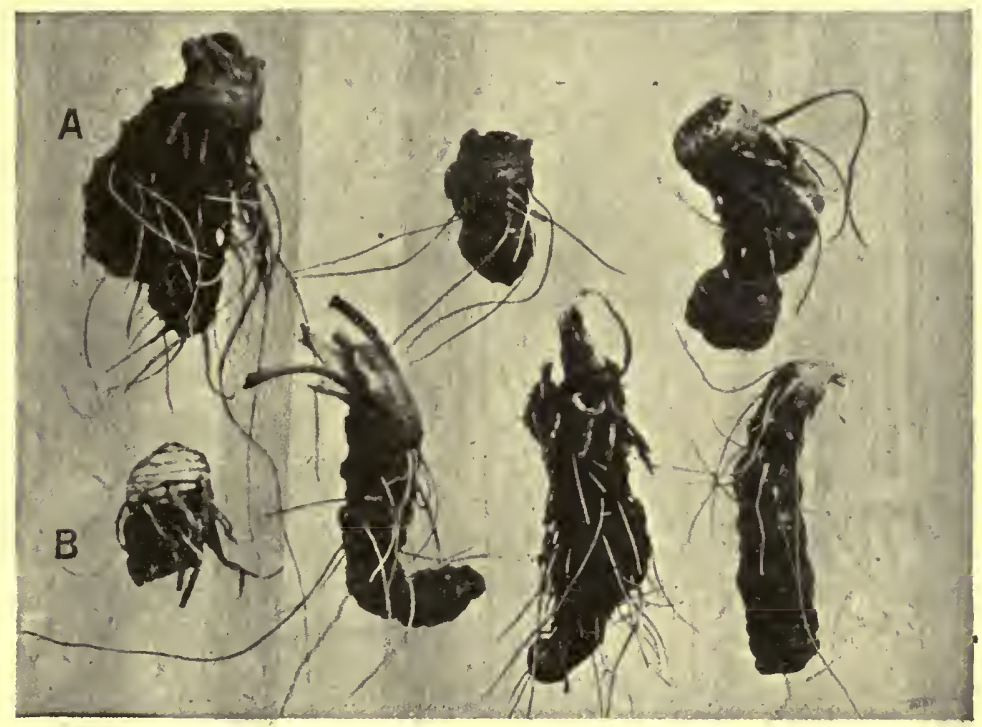

Fig. 28.-Several types of Helonias rhizome: $A$, oblique rhizome with stem base and two stem sears; $B$, upright rhizome showing new growth at top. (Moser, Amer. Jour. Pharm., 1917, 89, p. 191).

distinguished from Helonias bullata, which produces a short upright rhizome, very long elliptical-spatulate or oblanceolate leaves which are crowded at the base and from the middle of which arises the bracteate scape usually not longer than the leaves and terminated by a dense raceme of rather large, perfect purple flowers. The latter grows in bogs and appears to be localized in its habitat.

Description.-Rhizome upright, or oblique, nearly cylindrical and slightly tapering from 0.5 to $3 \mathrm{~cm}$. long, about $1 \mathrm{~cm}$. in diameter; externally grayish-brown, annulate from scars of bud-scales, upper portion with leaf bases enclosing a small bud, lower portion with 
numerous whitish or pale yellowish nearly straight or slightly curved wiry roots, free from the cortical layer, from 5 to $8 \mathrm{~cm}$. long, and numerous pits from which former roots once protruded; fracture hard and horny; internally grayish-yellow, cortex 3 to $4 \mathrm{~mm}$. thick, central cylinder with three or four circles of small nearly circular fibrovascular bundles; odor distinct; taste bitter, slightly astringent.

Inner Structure.-See Fig. 28.

Constituents.-A bitter glucoside, chamælirin, about 10 per cent. This is a light yellowish-red amorphous substance, soluble in water, causing the solutions to froth like saponin. It is also soluble in alcohol, sparingly soluble in ether and insoluble in chloroform, petroleum benzin and benzol. With dilute acids it forms a resinous body, chamæliretin, which is also soluble in water. The so-called neutral substance known as helonin is merely a hydroalcoholic extract prepared from the drug and is a mixture of principles.

Adulterants. - The rhizome of several species of Liatris, especially L. spicata (Fam. Compositæ) is said to have been substituted for Helonias. These rhizomes have an aromatic, somewhat terebinthinate odor and a bitter more or less acrid taste. They contain 0.1 per cent of a volatile oil; 5 per cent of resin and 2 per cent of a caoutchouc-like substanice.

Literature.-Greene, Amer. Jour. Pharm., 1878, p. 250; Henry, Ibid., 1892, p. 603.

Veratrum.-The rhizome and roots of Veratrum viride (Fam. Liliaceæ), a perennial herb (Fig. 29) found growing in wet meadows usually associated with skunk cabbage (Spathyema fotida), and indigenous to the eastern and central United States and naturalized in Canada, British Columbia and Alaska; and Veratrum album, a similar plant, indigenous to Central and Southern Europe, the former being known as American or green hellebore and the latter as European or white hellebore. The plant dies down early in the summer and the rhizome may be collected soon thereafter. It is cut longitudinally and dried. Much of the drug used in this country is derived from Veratrum album and imported from Germany.

American or Green Hellebore--Rhizome upright, obconical, usually cut longitudinally into halves or quarters, 2.5 to $5 \mathrm{~cm}$. long, 1.5 to $3 \mathrm{~cm}$. in diameter; externally dark brown or brownish-black, rough and wrinkled, somewhat annulate from scars of bud-scales, top truncate, lower part more or less decayed, with numerous roots and few root-scars; fracture hard and horny; internally light yellow, cortex 2 to $3 \mathrm{~mm}$. thick, endodermis distinct, central cylinder with 
scattered yellow fibrovascular bundles; odor slight; taste bitter and acrid.

Roots yellowish-brown, nearly cylindrical, 3 to $8 \mathrm{~cm}$. long, 2 to $3 \mathrm{~mm}$. in diameter; externally yellowish-brown, longitudinally or transversely wrinkled; internally, bark white, 1 to $2 \mathrm{~mm}$. thick; wood porous, cylindrical; fracture short.

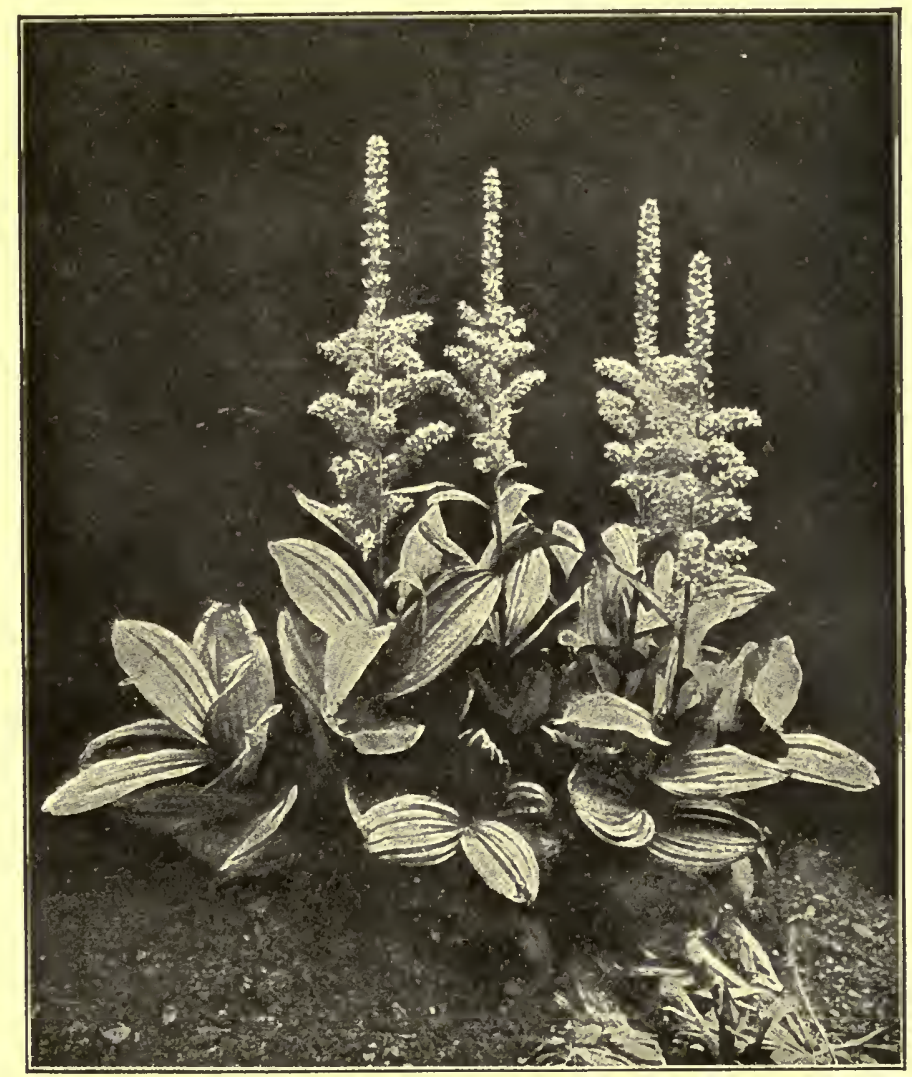

FIG. 29.-Plants of Veratrum viride growing in the Royal Botanic Society's Gardens (London) and showing the parallel veined (or nerved) leaves with entire margin, and the large terminal panicles of flowers.-After Pérrédès.

European or White Hellebore closely resembles the American Hellebore, but the color varies from light- to yellowish-brown and usually the rootlets are removed.

The drug should be kept in tightly closed vessels, and the leaf and stem bases, if present, should be removed. 
Inner Structure.-See Figs. 30, 31. Also Meyer, Arch. der Pharm., 1882, p. 80.

Powder.-Grayish-brown to dark brown; strongly sternutatory; starch grains numerous, from 0.003 to $0.020 \mathrm{~mm}$. in diameter, spheroidal or ellipsoidal, single or 2- to 3-compound, the individual grains having a circular central cleft and often being swollen or otherwise more or less altered; calcium oxalate in raphides, from 0.015 to 0.150 $\mathrm{mm}$. in length; fragments with tracheæ, the walls being more or less strongly lignified and marked with scalariform or reticulate thicken-

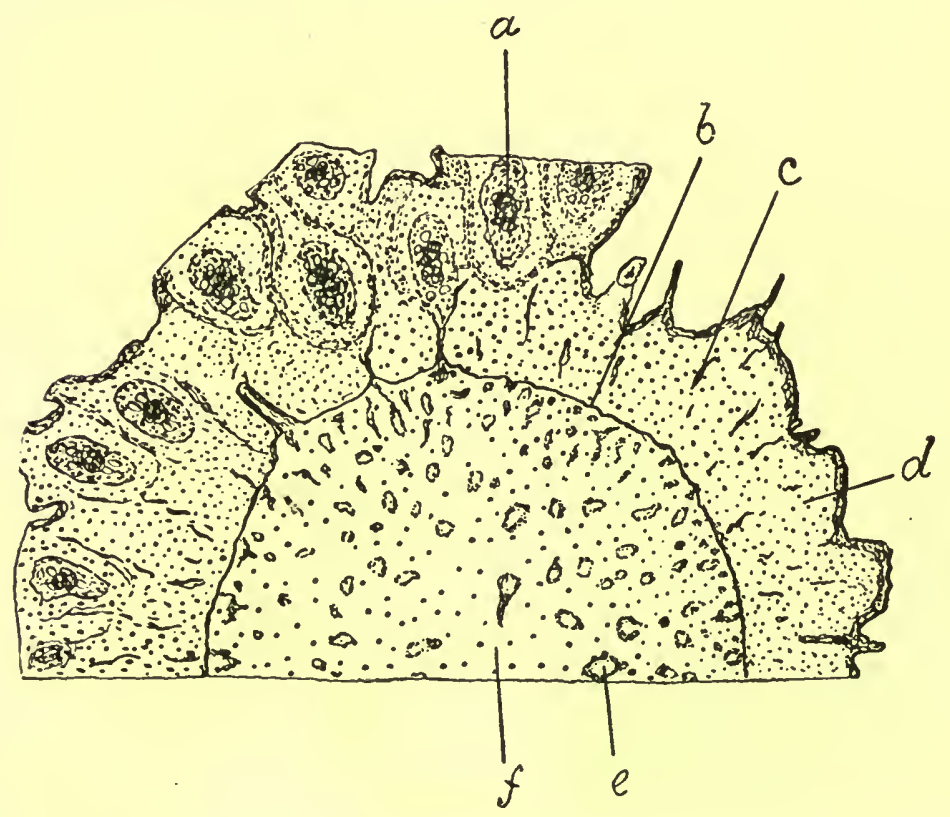

FIG. 30.-Cross-section of rhizome of Veratrum viride; $a$, section of a root near its origin; $b$, endodermis; $c$, one of the wavy fibrovascular bundles in the cortex; $d$, parenchyma; $e$, fibrovascular bundle of the central cylinder; $f$, parenchyma.-After Bastin.

ings, frequently containing a lemon-yellow substance and associated with narrow, slightly lignified, porous, sclerenchymatous fibers; endodermal cells thickened on the inner tangential wall, "occasional reddish-brown or brownish-black cork fragments. The powders of Veratrum album and Veratrum viride cannot be distinguished one from the other by their microscopic characters, but appear to differ chemically; a mount of $\mathrm{V}$. viride in concentrated sulphuric acid gives a yellowish-red color and that of V. album a dull red color. 
The so-called powdered hellebore, used as an insecticide by gardeners, consists of either V. album or V. viride, the former being mostly employed.

Constituents of Veratrum Album.-The drug contains a number of alkaloids, of which the most important is protoveratrine, which occurs to the extent of 0.03 per cent and forms monoclinic prisms which are insoluble in water, soluble in strong alcohol, and with concentrated sulphuric acid give a greenish-colored solution which gradually changes to blue and finally to violet. It also contains the following alkaloids which are physiologically inactive or but

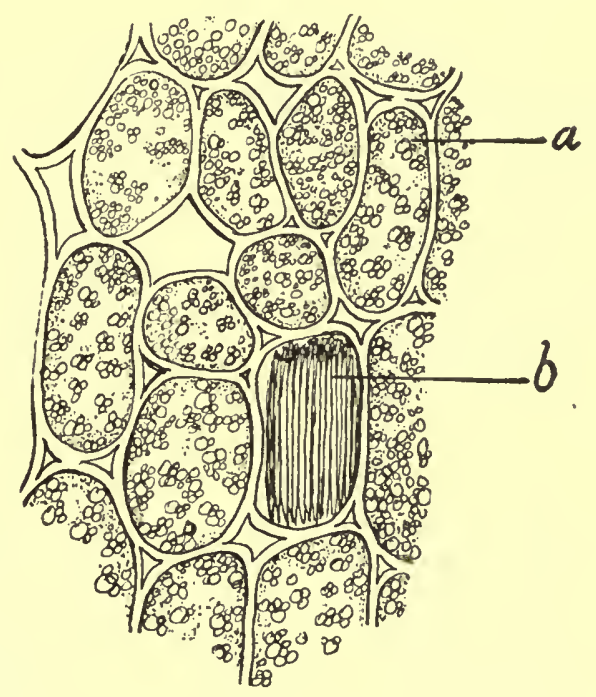

FIG. 31.-Several parenchyma cells from rhizome of Veratrum viride: $a$, cell containing starch grains; $b$, cell containing raphides of calcium oxalate.After Bastin.

feebly toxic: jervine ( 0.10 to 0.13 per cent) forms satiny, lustrous prisms which are colored yellow with hydrochloric acid, the solution afterwards changing to green; rubijervine (about 0.005 per cent) forms long prisms which are colored yellow with concentrated sulphuric acid, the solution becoming orange and finally red; pseudojervine forms hexagonal prisms which are colored yellow with concentrated sulphuric acid; protoveratridine is a decomposition product of protoveratrine and forms cubical prisms which are colored violet with concentrated sulphuric acid, the solution afterward becoming 
cherry-red. Veratrum also contains a bitter glucoside veratramarin; jervic acid, which is identical with chelidonic acid, and crystallizes in silky needles; considerable starch; ash 3 to 4 per cent; and calcium oxalate in the form of raphides.

Constituents of Veratrum Viride.-Green hellebore contains about 0.08 per cent of total alkaloids. Of these about one-half consists of cevadine, an exceedingly toxic ether-soluble alkaloid, also found in Sabadilla seeds, which crystallizes in needles and gives a violet color on warming with nitric acid, the solution changing to scarlet-red on boiling. The remainder consists chiefly of the etherinsoluble alkaloids jervine and pseudojervine, both of which are found in Veratrum album; a small quantity of Veratrine, that occurs as an amorphous, resinous mass which is colored yellow with concentrated sulphuric acid, the solution becoming deep red (thus resembling protoveratrine); and veratalbine, an amorphous alkaloid. Veratroidine is now considered to be a mixture of amorphous bases.

Allied Plants.-The rhizome of Veratrum viridifolium, a plant with greenish flowers growing in the mountainous districts of Europe and Northern Asia, contains jervine and veratroidine. The rhizome of Veratrum nigrum, a plant with purplish-red flowers, indigenous to Middle and Eastern Europe, Siberia, Manchuria and Japan, contains jervine.

Sabadilla seeds are the source of the official veratrine. They. are obtained from Schœnocaulon officinale (Fam. Liliaceæ), a bulbous plant indigenous to Mexico and the West Indies. The seeds are brownish-black, 5 to $8 \mathrm{~mm}$. long, narrow, angular, flat, beaked and have a very bitter and acrid taste. They are frequently exported from Mexico in the small trilocular dehiscent capsules, there being 3 to 6 seeds in each loculus. They contain about 1 per cent of a mixture of alkaloids known as veratrine. This consists of cevadine and veratrine (veratridine), both of which are found in the rhizome of Veratrum viride, and three other alkaloids: cevadilline, sabadine and sabadinine, the latter two being crystalline.

Death Camas.-One or more species of Zygadenus, growing in Montana, Wyoming, Colorado and other Northwestern States, cause considerable loss to the stock men of this region. The entire plant including bulbs, leaves and flowers are eaten, particularìy by sheep, and are highly toxic, causing heavy stock losses, particularly among sheep. Slade investigated the bulbs of Zygadenus venonosus and obtained an alkaloid resembling veratralbine. Heyl and others obtained from the leaves of $\mathrm{Z}$. intermedius a crystalline alkaloid, zygadenine, which resembles in its physiological action veratrine. 
Literature.-Slade, Amer. Jour. Pharm., 1905, p. 262; Heyl and others, Jour. Amer. Chem. Soc., 1911, p. 206; Ibid., 1913, p. 258; Ibid., 1913, p. 803.

Black Hellebore consists of the rhizome and roots of Helleborus niger (Fam. Ranunculaceæ), a perennial herb indigenous to the Eastern and Southern Alps and also cultivated. The rhizome is 2.5 to $7.5 \mathrm{~cm}$. long, 6 to $12 \mathrm{~mm}$. in diameter; with numerous short, knotty branches and short, brittle roots; externally, of a grayishblack color; internally, with a characteristic dicotyledonous structure; odor slight; taste sweet, somewhat bitter and acrid. The drug contains two crystalline glucosides; helleborin, a narcotic poison with a burning taste, and helleborein, a cardiac stimulant and having a sweetish taste. The former gives a violet-red color with concentrated sulphuric acid and the latter a deep violet color with the same reagent. The drug also contains a volatile oil, two acrid resins, an acrid fixed oil, aconitic acid and gallates of calcium and potassium.

The rhizome of Helleborus viridis (so-called "Green Hellebore ") a plant found in Middle and Southern Europe, has been used similarly to that of $\mathrm{H}$. niger. It contains the same principles as $\mathrm{H}$. niger, the helleborein apparently predominating.

False Hellebore is the entire herb of Adonis vernalis (Fam. Ranunculaceæ) and other species of Adonis indigenous to Europe and Asia. The drug contains adonidin, a mixture of several principles, the most important being the amorphous glucoside picradonidin, a principle resembling digitalin in its physiologic action.

Colchici Conmus. - Colchicum Corm. - The corm of Colchicum autumnale (Fam. Liliaceæ), a perennial bulbous plant native of and growing in moist meadows and pastures of England, Southern and Middle Europe and Northern Africa. The corm is collected in early summer before the flowering period, deprived of the membranous, scaly coat, cut into transverse pieces, and dried at a temperature of $65^{\circ} \mathrm{C}$. Tubers that are collected in the fall, either during the flowering season or later, are considered to be more active. The commercial supply is obtained from England and Germany.

Description.--Obconical, with a groove on one side, sometimes with fragments of the flower-stalk, usually in transverse, reniform sections from 15 to $20 \mathrm{~mm}$. long, about $12 \mathrm{~mm}$. wide and 3 to $5 \mathrm{~mm}$. thick; externally dark brown, longitudinally wrinkled; fracture short, mealy; internally light brown, with numerous scattered fibrovascular bundles; odor slight; taste bitter and acrid.

Inner Structure.-Consisting mostly of starch-bearing parenchyma and a few scattered concentric fibrovascular bundles having 
spiral tracheæ and thin-walled sclerenchymatous fibers. The epidermis consists of tangentially-elongated thick-walled cells having yellowish-brown walls. The addition of sulphuric acid to the section causes some of the tissues to become yellow, changing to red.

Powder.-(Fig. 32). Light brown or grayish-brown; starch grains numerous, single or 2- to 6-compound, the individual grains varying from spheroidal or ovoid to polygonal, and marked with a

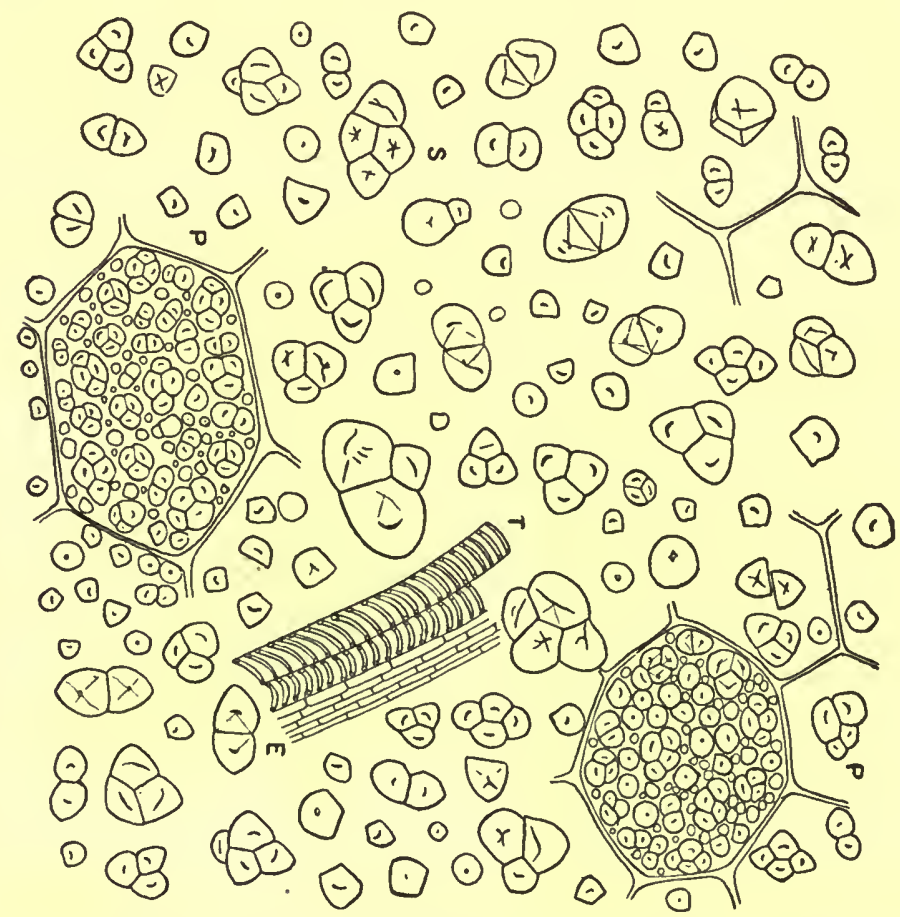

FIG. 32.-Colchicum corm: $S$, 2- to 4-compound starch grains which make up the greater proportion of the powder; $P$, parenchyma with numerous starch grains; $T$, tracheæ; $E$, sieve.

triangular or star-shaped, central cleft, from 0.003 to $0.030 \mathrm{~mm}$. in diameter; tracheæ few and with spiral or scalariform.thickenings; occasional fragments of epidermal cells with thick, reddish-brown walls.

Constituents.-A yellowish, amorphous alkaloid, colchicine, about 0.4 per cent, which has a peculiar odor, particularly on heating slightly, is soluble in hot water and gives with concentrated sulphuric acid a yellowish solution which is colored deep red on heating. If 
the sulphuric acid contains a mere trace of nitric acid the solution of the alkaloid becomes yellowish-green, green, bluish-green, blue, violet, wine-red and finally yellow. The salts of colchicine are quite unstable. The drug also contains the alkaloid colchiceine, which crystallizes in needles and is apparently formed during the extraction of the drug by reason of the decomposition of colchicine. The latter may be formed on the esterification of colchiceine with methyl alcohol. The corm also contains two resins; a large amount of starch; ash about 2.5 per cent.

Colchici Semen.-Colchicum Seed.-The dried, ripe seeds of Colchicum autumnale (Fam. Liliaceæ), a perennial bulbous plant, native of and growing in moist meadows in Southern and Middle Europe and Northern Africa. The commercial supplies come chiefly from England and Germany.

Description.-Hemi-anatropous, ovoid or irregularly globular, more or less beaked, with an easily detachable strophiole, 2 to 3 $\mathrm{mm}$. in diameter; externally dark brown, becoming darker with age, minutely pitted, the epidermis detached in irregular patches in older seeds; frequently agglutinated when fresh, due to the presence of a saccharine exudation; very hard when dry, tough when damp, internally whitish, endosperm hard, embryo $0.5 \mathrm{~mm}$. long and situated at end opposite the strophiole; nearly inodorous; taste feeble, bitter and somewhat acrid.

Constituents.-Proteins; fixed oil about 6 per cent; a tannin-like substance in the seed coat; starch grains in the caruncle; an alkaloid colchicine 0.4 to 0.6 per cent ( 0.55 per cent required by the U.S.P.); a resinous principle colchicoresin; ash about 2.5 per cent.

Inner Structure.-Seed-coat consisting of 6 or 8 rows of more or less collapsed cells; endosperm made up of numerous thick-walled porous cells containing oil globules and aleurone grains, the latter being from 0.003 to $0.015 \mathrm{~mm}$..in diameter; embryo small, the beaked portion, or caruncle, containing numerous, somewhat ovoid, ellipsoidal or polygonal starch grains, from 0.005 to $0.016 \mathrm{~mm}$. in diameter.

Powder.-Light or dark brown; sclerenchymatous cells with pigment soluble in potassium hydrate solution, and reacting with iron salts somewhat like tannin; cells of endosperm thick-walled, with simple pores and few oil globules; parenchymatous cells of strophiole thin-walled, and with numerous nearly spheroidal starch grains 0.007 to $0.015 \mathrm{~mm}$. in diameter.

AloE.-Aloes.-The inspissated juice of the leaves of various species of Aloe (Fam. Liliaceæ), perennial succulents (Fig. 33) 
indigenous to Africa and India and naturalized in the West Indies. There are three principal commercial varieties of aloes: (1) Socotrine (and Zanzibar) Aloes, derived from Aloe Perryi, and probably other species of Aloe, growing on the island of Socotra and in Eastern Africa, and exported by way of Bombay; (2) Curaçao (and Barbadoes) Aloes, obtained from Aloe chinensis and Aloe vera, growing in Curaçao and other islands of the Dutch West Indies; and (3) Cape and Uganda Aloes, obtained probably from Aloe ferox, growing in Southern Africa, and exported from Cape Town and Mossel Bay. The leaves of the Aloe plant are cut transversely and the juice which

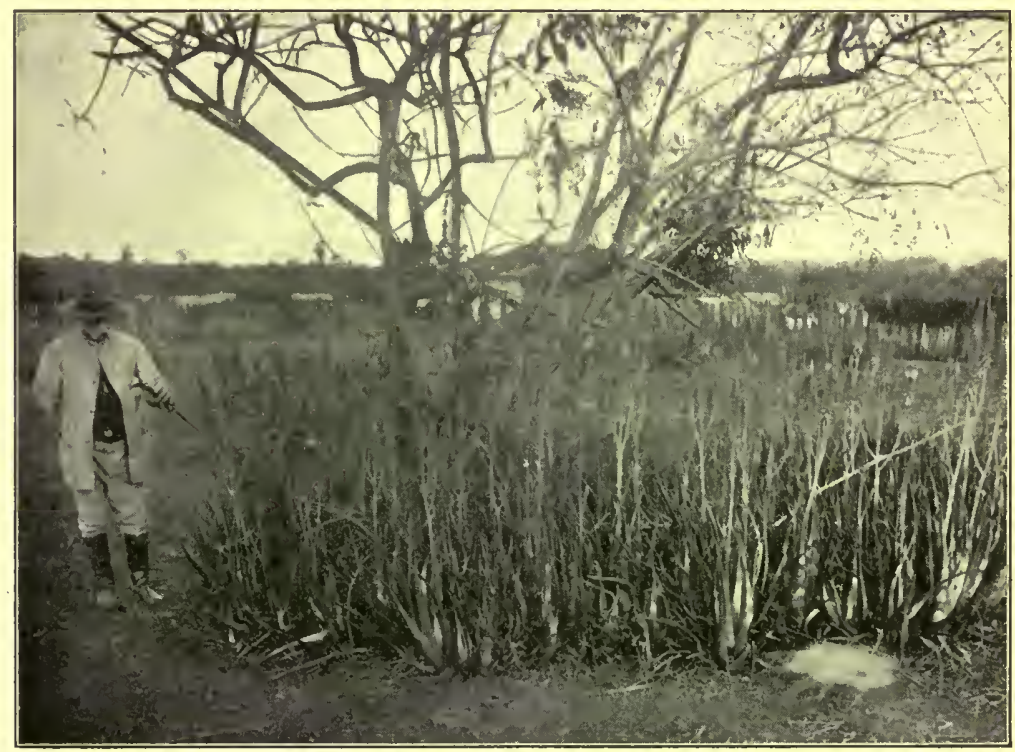

FIG. 33.-A small clump of plants of Aloe Perryi growing in Minas Geraes, Brazil. The spinose, fleshy leaves are clustered at the base and from the middle of the cluster arises a scape terminated by a raceme of orange-red or scarlet flowers. The plant is native to the island of Socotra and the southern shores of the Red Sea, and is the source of Socotrine aloes. The latter is chiefly produced on the island of Socotra and consists of the inspissated juice of the leaves.-Reproduced by permission of the Philadelphia Commercial Museum.

exudes is allowed to evaporate spontaneously, it being usually, however, concentrated by boiling and then poured into boxes (Fig. 34) or gourds, and occasionally it is found in commerce enclosed in monkey-skins (Fig. 35). Socotrine aloes commands the highest 
price. The latter variety when fresh has an unpleasant odor, but on keeping develops an odor resembling myrrh and saffron.

1. Socotrine Aloes.-In yellowish-brown to dark-brown opaque masses, or smooth and glassy, fracture somewhat conchoidal; sometimes soft or semi-liquid; odor saffron-like; taste, nauseous and

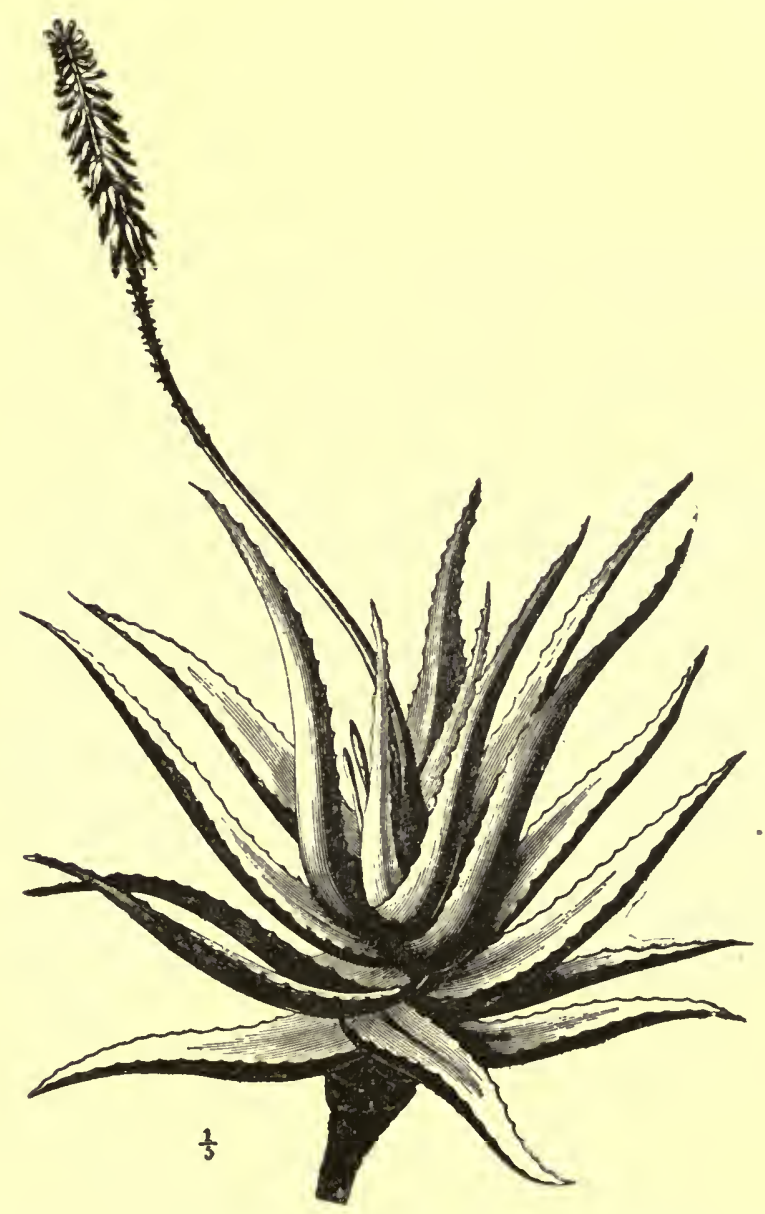

Aloe vera, the plant yielding Barbadoes aloes. Showing crown of thick, succulent leaves and the long spike (inflorescence) with the flowers on the upper portion of the axis.-After Engler.

bitter. Powder yellowish-brown or brownish-yellow, giving a yellowish or reddish-brown color with nitric acid. About 50 per cent of socotrine aloes is soluble in cold water. It is almost completely 
soluble in 60 per cent alcohol or in water at $100^{\circ} \mathrm{C}$. On cooling the latter solution there separates from 40 to 60 per cent of the so-called "resin of aloes," which is soluble in alkalies with a red color and is reprecipitated on the addition of acids. About 36.6 per cent of aloes is soluble in chloroform, and from 4 to 5.5 per cent in ether, the solution being of a yellow color. It should contain not more than 8 per cent of moisture and yield not more than 4 per cent of ash.

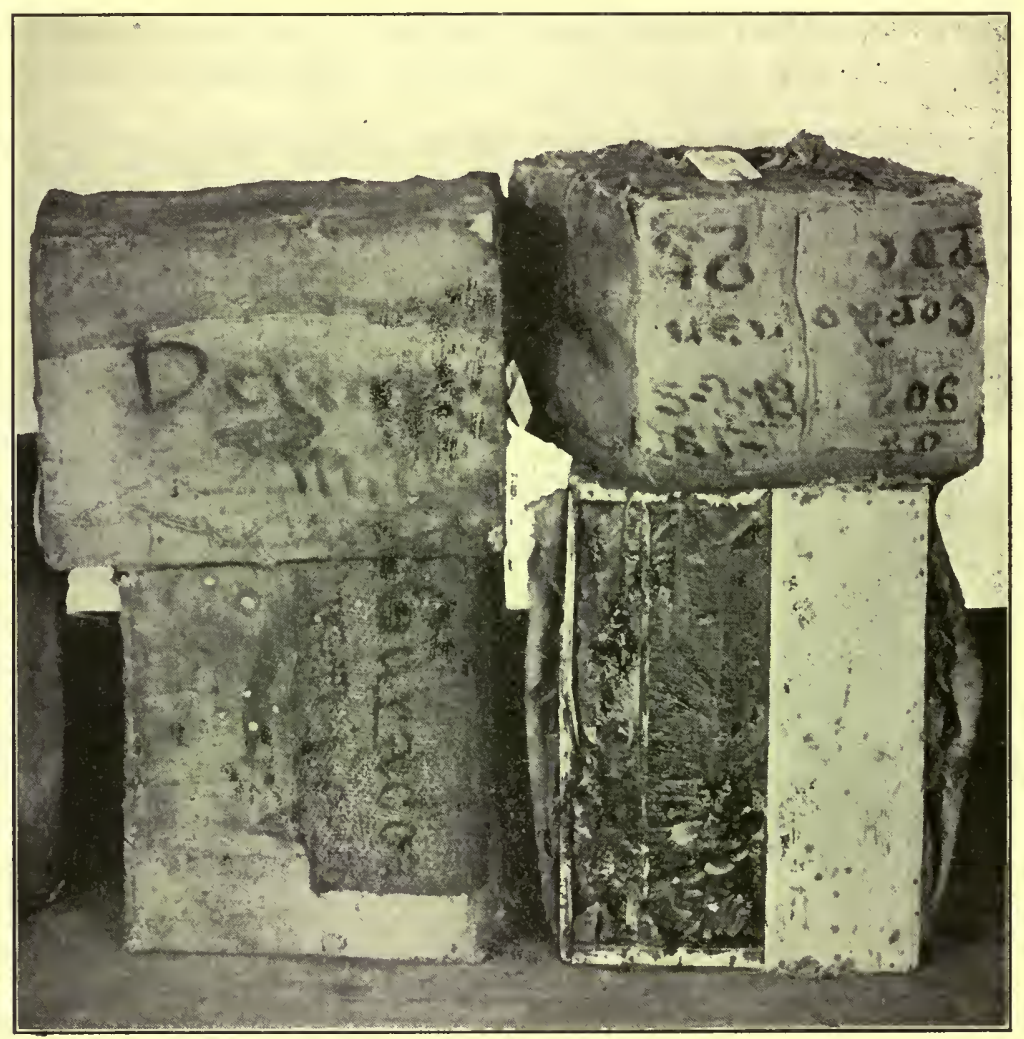

FIG. 34.-Original packages of Curaçao Aloes. After a photograph by Parke, Davis \& Co.

Zanzibar Aloes is a hepatic (or liver-colored) variety ' of 'Socotrine Aloes, produced by slowly evaporating the juice of the plant. It comes into market frequently in monkey-skins, has a dark-brown color, a dull, waxy fracture, and a nearly smooth, even surface. It is crystalline under the microscope and forms a reddish-yellow powder that is colored dark yellow with nitric acid. 
2. Curaçao Aloes.-Orange to blackish-brown opaque masses, translucent in thin pieces; fracture uneven, waxy, somewhat resinous, occasionally exhibiting microscopical crystals of aloin; odor distinct, unpleasant; taste nauseous, bitter. The powder is dark reddish-brown and gives an immediate deep reddish color with cold nitric acid or with solutions of the alkalies.

About 60 per cent of Curaçao Aloes is soluble in cold water. It is almost completely soluble in 60 per cent alcohol or boiling water; on cooling the solution made with boiling water there separates from 40 to 60 per cent of "resin of aloes," which is similar to

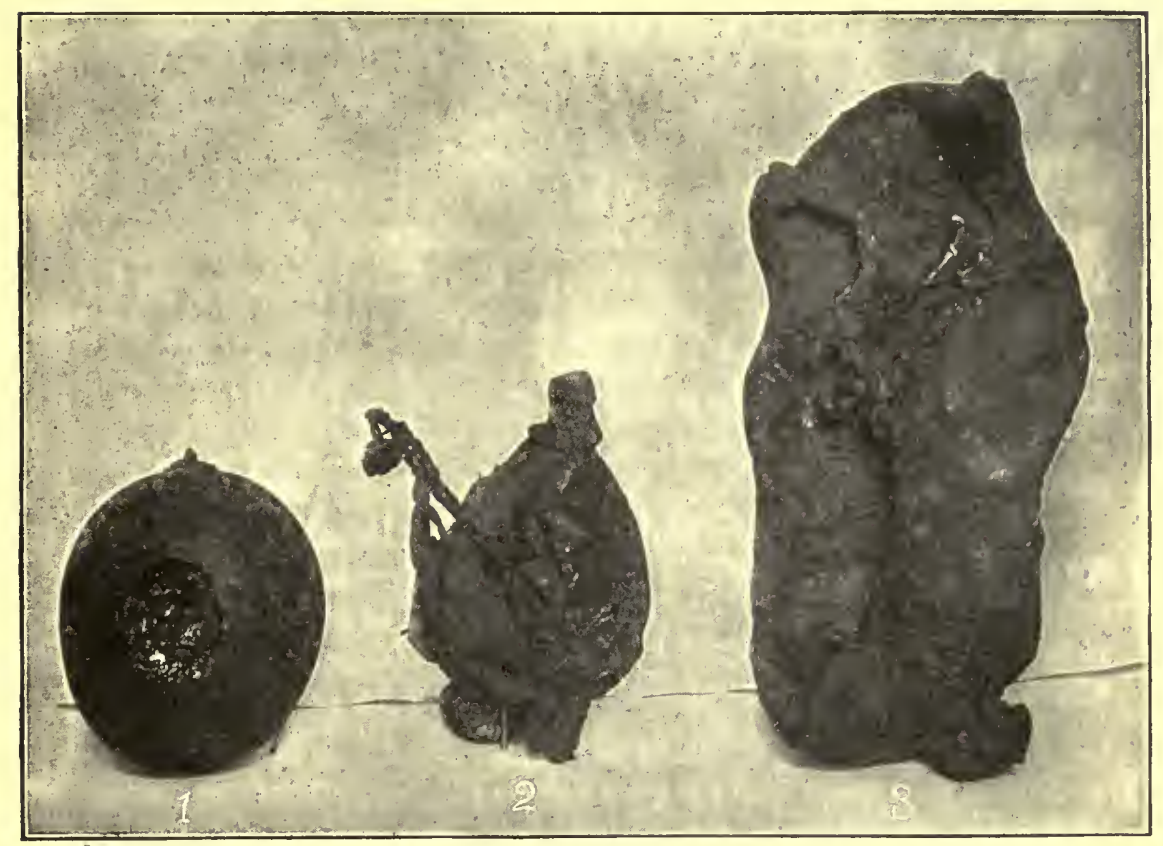

Fig. 35.-Special containers used in the shipment of aloes, the one on the left being a gourd and is still commonly used; the other two being sewed up monkey-skins which are now only occasionally seen in the market.

that of Socotrine aloes. About 66.6 per cent is soluble in chloroform and not less than 10 per cent in ether. It contains less than 8 per cent of moisture and yields from 1.5 to 4 per cent of ash.

Barbadoes Aloes is a hepatic variety of Curaçao Aloes, which is not obtained at the present time from Barbadoes, but from the Dutch ${ }^{\circ}$ West Indies. It occurs in dark brown, dull, opaque masses, giving a yellow powder that is colored red with nitric acid. About 
72.4 per cent of fresh and 62.8 per cent of old Barbadoes aloes is soluble in chloroform. It contains about 9 per cent of moisture.

3. Cape Aloes.-Of a reddish-brown or of an olive-black color, usually covered with a yellowish powder, transparent in thin pieces; fracture smooth and glassy; odor characteristic; powder greenishyellow, becoming light brown and giving a greenish color with nitric acid.

About 60 per cent of Cape Aloes is soluble in cold water. It is almost completely soluble in alcohol or boiling water; and the latter solution gives a precipitate of 60 per cent of "resin of aloes." From 81 to 86.8 per cent is soluble in chloroform, and from 1.5 to 6.5 per cent in ether. It contains about 9 per cent of moisture, and yields but a small percentage of ash.

Uganda (or crown) Aloes is a hepatic variety of Cape Aloes prepared by allowing the juice to stand and undergo a partial fermentation, after which the clear liquid is decanted and evaporated by exposure to the sun. It occurs in reddish-brown masses, producing a powder, which is colored yellow to brown with nitric acid.

Microscopic Examination.-Powdered aloes may be examined under the microscope and is best mounted in one of the fixed oils. Socotrine aloes consists of yellowish- or reddish-brown, irregular and more or less angular fragments. In Curaçao aloes the fragments are irregularly angular, blackish-brown or reddish-brown and more or less opaque. The fragments in Cape aloes are bright yellow and distinctly angular.

Constituents.-A crystalline, bitter principle, aloin, the percentage ( 4.5 to 30 per cent) and composition of which varies in the different varieties, and which is supposed to occur in largest amount in old aloes; emodin (see Rhubarb); a pale yellow, volatile oil, which is apparently not identical in the different varieties, giving them their characteristic odors; 13 to 63 per cent of resinous material, which consists chiefly of a resinotannol ester of cinnamic acid (Curaçao and Barbadoes aloes) or of a resinotannol ester of paracumaric acid (Cape aloes); and 1 to 4 per cent of ash.

Aloin is a neutral, bitter principle, which on distillation with zinc dust yields anthracene. It forms minute, lemon-yellow to yellowishbrown acicular crystals, which are sparingly soluble in water but more so in alcohol, the solutions becoming brown on standing (Fig. $36, \mathrm{C})$. Alkaline solutions of aloin have a deep red color and exhibit a greenish-red fluorescence. Upon the addition of aloin to sulphuric acid a yellowish-red solution is formed, which, upon the addition of a small quantity of potassium dichromate is changed to olive-green 
and finally to a blue color. Ferric chloride gives a brownish-green color to an alcoholic solution of aloin. The amount of aloin varies from 4 to 10 per cent in Socotrine (Zanzibar) aloes, is about 6 per cent in Cape (Uganda) aloes and is stated to range from 10 to 30 per cent in Curaçao (Barbadoes) aloes. The aloin obtained from Curaçao or Barbadoes aloes gives with nitric acid a cherry-red color
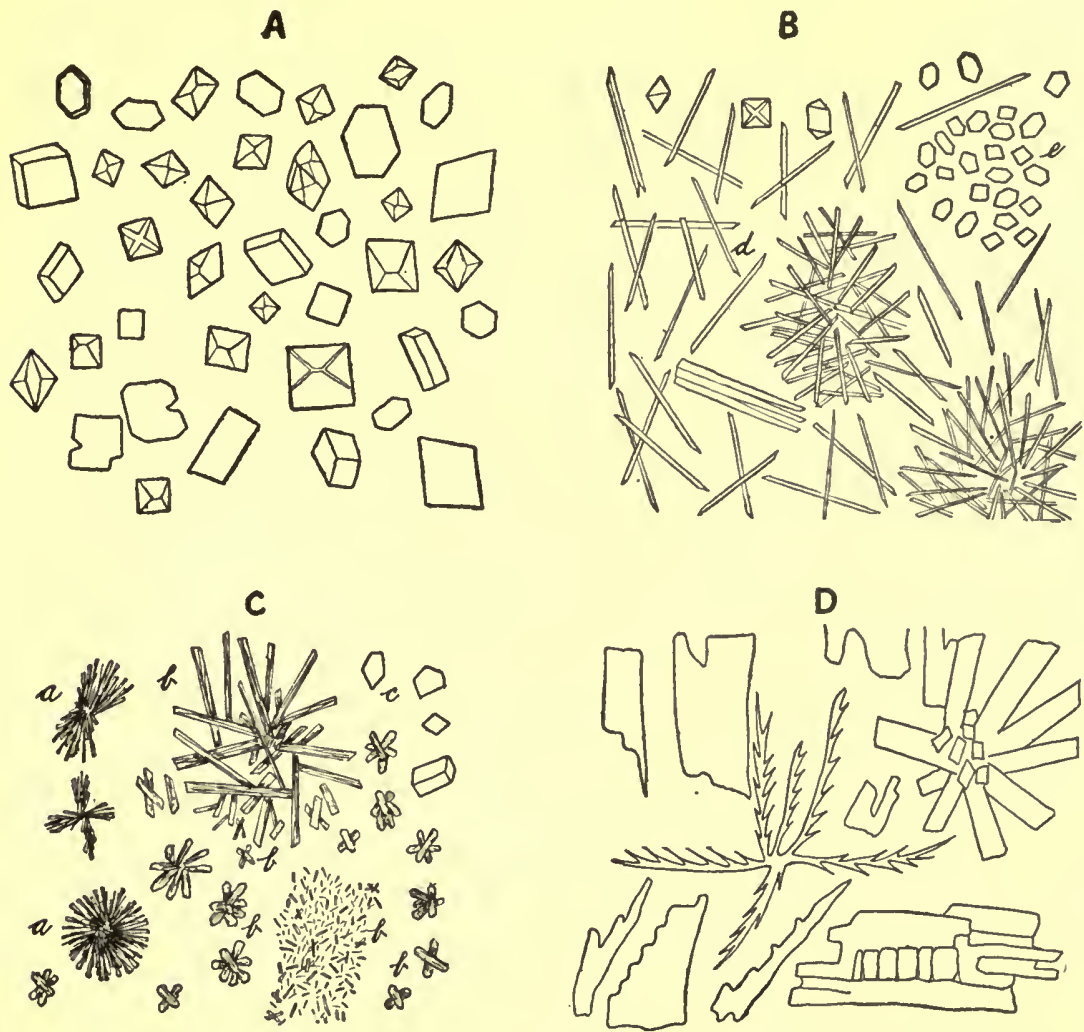

FIG. 36.-Crystals from exudations and extracts; $A$, crystals found in the residue after treatment of catechu with water; $B$, long prisms of catechin $(d)$ found on treatment of gambir with a solution of hydrated chloral, the crystals soon dissolving, and prismatic plates (e) usually seen in glycerin mounts of gambir; $C$, crystals from aloes, including aloin $(a)$, broad prisms $(b)$ from Barbadoes aloes, and plates $(c)$ from Cape aloes; $D$, crystals of benzoic acid obtained by subliming benzoin on a slide or in a watch crystal.

or with Klunge's reagent a deep-red color. These color reactions are due to the presence of about 0.5 per cent of an isomeric body (isobarbaloin), which is not found in the aloins of Socotrine and Cape aloes. Alcoholic solutions of barbaloin and isobarbaloin lose their 
bitterness on standing, the aloin being replaced in part at least by a sugar aloinose, which forms yellow crystals that are colored red and then green with concentrated hydrochloric acid and orcin. Aloin is considered by some to be an emodin-glucoside which on oxidation splits off emodin, the latter on further oxidation forming rhein.

Stacy uses a freshly made solution of potassium ferri-cyanide which is added to the cold aqueous solution of aloes. This reagent gives a pink color for Barbadoes aloes in dilutions of 1 part in 10,000. Cape and Socotrine aloes give an emerald-green color as also does aloin. Extracts of cascara and rhubarb give no reaction. (The Analyst, 1916, p. 75.)

Adulterants.-Aloes formerly contained various mechanical impurities, and this was the reason for the introduction of a purified aloes into the U. S. Pharmacopœia. As heat impairs the quality of the aloes and as the requirements forbid adulteration the untreated aloes should be employed. The aloin is sometimes removed, as in the Curaçao aloes, when it has the appearance of Cape aloes and is sometimes sold for it. Recently aloes has been coming into market packed in thin layers separated by paper.

Allied Plants.- Natal Aloes is a hepatic variety of aloes which was at one time exported from Natal, the botanical origin being unknown. It occurs in grayish-brown or greenish-black, dull, opaque masses, often covered with a brownish powder. The odor somewhat resembles that of Cape aloes. The powder is grayish-green or pale yellowish-brown and microcrystalline, giving a permanent crimson color with nitric acid and a deep blue with sulphuric acid and vapor of nitric acid. The latter test serves to distinguish this aloes from all the other varieties. The drug contains aloin (nataloin), but not emodin. Both Natal aloes and nataloin are physiologically inactive.

Jaffarabad Aloes is a vitreous variety obtained from the East Indies and is exported from Bombay. It occurs in circular, flattened cakes, of a deep black color externally, and with a black, glossy, slightly porous or somewhat laminated fracture. It yields 13 to 20 per cent of aloin, which is apparently chiefly barbaloin, and gives a deep crimson color with nitric acid.

Detection of Aloes in Mixtures.-According to Mossler (Pharm. Post, 1913, 46, 313, 325), the following method may be used for the detection of aloes in mixtures containing cascara, rhubarb, senna, etc. The extract, etc., is evaporated to drive off alcohol and the residue dissolved in water. The filtered solution is heated with $10 \mathrm{cc}$. of normal sulphuric acid for thirty minutes on the water-bath. The sulphuric acid is then exactly precipitated with barium hydroxide 
solution and the barium sulphate removed by filtration. The filtrate is concentrated to 100 c.c., treated with slight excess of basic leadacetate solution in order to remove coloring-matter, and the filtrate treated with sodium sulphate solution to remove excess of lead. This liquid is then divided into several portions. One is extracted with benzol, and the benzol layer shaken with dilute ammonia water. Oxymethylanthraquinones derived from other drugs, which would interfere with the aloin test, should be completely precipitated by the lead acetate. If this is the case the ammoniacal layer will be only of the faintest rose color, whereas if precipitation be not complete the ammonia will be of a fine red color, and the bulk of the solution must be again treated with basic lead acetate solution and the test repeated. Wiren oxymethylanthraquinones are shown to be completely precipitated another small portion of the filtrate is treated with excess of bromine solution, which, in the presence of aloin, yields a flocculent precipitate. If this reaction be given, confirmation should be obtained from the main bulk of the solution by shaking a 10-c.c. portion with 2 to 3 grams of sodium borate and allowing the solution to stand for a quarter of an hour. In the presence of aloes a green fluorescence appears. Another portion of 10 c.c. is heated with a drop of hydrogen peroxide and a drop of copper sulphate solution. A red coloration, becoming intensified on standing, indicates the presence of aloes. Samples free from aloes give an orange color, which does not alter on standing. It is claimed that 0.2 gram of extract of aloes in the presence of 5 grams of a mixture of extracts of rhubarb and cascara, etc., can be detected.

Allium.-Garlic.-The undried bulb of Allium sativum and the var. vulgare (Fam. Liliaceæ). A hardy perennial plant closely allied to the onion. It is a native of Southern Europe and extensively cultivated. The bulb is the part used and is composed of several parts or bulbels, called "cloves." The latter are planted similarly to the sets. The bulbs are gathered and braided together by their tops and in this form are usually seen in the market. Garlic should be used in the fresh condition only.

Description.-Bulb subglobular, 4 to $6 \mathrm{~cm}$. broad, compound, consisting of 8 to 15 bulbels and surrounded by 1 or 2 dry, whitish, membranaceous scales and attached to a flattened circular base, from the lower portion of which arise numerous yellowish-white roots; bulbels more or less ovoid, in transverse section 3- to 4-sided, the outer surface being convex, summit acute and narrowed into a thread-like fibrous portion, base truncate; each bulbel covered by one or two layers of whitish, membranaceous, scale-like leaves, 
beneath which is the light brown and pinkish, thin and coriaceous layer of epidermis, cohering but easily separable from the solid portion of the bulbel; odor of broken or bruised bulbel aromatic, disagreeable; taste intensely pungent and persistent.

Inner Structure.-Transverse sections show: $(a)$ an outer fleshy scale, $(b)$ a middle scale, and $(c)$. in the center a bright green leaf folded lengthwise along the midrib so that the ventral surfaces lie close together. The outer and middle scales consist chiefly of parenchyma enclosing scattered vascular bundles. The parenchyma cells of the middle scale contain numerous yellowish-brown plastids.

Constituents.-From 0.005 to 0.009 per cent of a yellowish, volatile oil having a strong unpleasant odor. It contains sulphur and was formerly supposed to consist principally of allyl sulphide, but this was shown by Semmler not to be the case. Garlic also contains considerable mucilage and sugar, and a small quantity of a fixed oil.

Scilla.-Squill.-The fleshy scales of the bulb of Urginea maritima (Fam. Liliacex), a perennial herb indigenous to the Mediterranean region. The bulbs are collected late in August, and after the removal of the membranous outer scales and the central portion, the fleshy scales are cut into transverse pieces and dried in sunlight or by artificial heat. The article used in France is collected from bulbs having reddish scales and is obtained from Algeria and Malta.

Description.-In irregular, curved, flat, narrow, somewhat translucent pieces 3 to $5 \mathrm{~cm}$. long, 5 to $8 \mathrm{~mm}$. wide, 2 to $7 \mathrm{~mm}$. thick, whitish, lemon-yellow or light brown, epidermis forming a thin layer, mesophyll more or less shrunken, slightly crystalline and with numerous circular projections of fibrovascular bundles; fracture brittle when dry, tough when damp; odor slight; taste bitter and acrid.

Inner Structure.-Epidermal layer of thin-walled cells and stomata; mesophyll of numerous slightly elongated, thin-walled parenchymatous cells, usually containing a crystalline sugar which readily separates in material placed in alcohol or glycerin. Interspersed among the parenchyma are a few concentric fibrovascular bundles (having spiral or reticulate tracheæ) and numerous cells containing mucilage and raphides of calcium oxalate. The latter vary in length from 0.075 to $1.0 \mathrm{~mm}$., or even longer. These crystals are probably the longest in any drug and alone serve to identify it.

Powder.-Light yellow, and unless kept in a dry atmosphere shows a tendency to cake, and in this form it is very likely to be mis- 
taken for some gum. It is distinguished by the characteristic crystals of calcium oxalate and the few spiral or reticulate tracheæ.

Constituents.-Squill contains a number of active principles, of which the most important are the amorphous glucoside scillitoxin, which resembles digitoxin physiologically, and scillipicrin, an amorphous, bitter principle, which is employed as a diuretic. It also contains a yellow crystalline glucoside scillin; an amorphous bitter glucoside, scillain; a little volatile oil; sugar, about 22 per cent; considerable calcium oxalate in the form of raphides, which is associated in the parenchyma cells with a peculiar mucilage sinistrin, which yields levulose on hydrolysis.

Allied Plants.-The bulbs of several species. of Crinum (Fam. Amaryllidaceæ) found growing in Brazil, China, Southern Asia and the East Indies are used as substitutes for squill.

Literature.-Hartwich, Arch. der Pharm., 1889, p. 583.

Convallaria.-Lily of the Valley.-The dried rhizome and roots of Convallaria majalis (Fam. Liliacex), a low-growing perennial herb indigenous to Europe, Asia and the higher mountains of Virginia, North Carolina and South Carolina and extensively cultivated for its flowers. The rhizome and roots should be collected late in summer and carefully dried. The leaves and flowers have also been used in medicine.

Description.-Rhizome horizontal, cylindrical, and sometimes branched, jointed, in pieces from 3 to $17 \mathrm{~cm}$. long, internodes 10 to $50 \mathrm{~mm}$. long, 1 to $3 \mathrm{~mm}$. in diameter, nodes with a circular scar, not much thickened; externally light or dark brown, 'longitudinally wrinkled, somewhat annulate from scars of bud-scales, mostly smooth between the nodes, upper surface of nodes marked by stem-scars, side and under surface with root-scars, or usually with three to five roots; fracture short or fibrous; internally light or dark brown, cortex $0.5 \mathrm{~mm}$. thick, separable from the central cylinder; odor faint; taste bitter, slightly acrid.

Roots somewhat tortuous, 5 to $6 \mathrm{~cm}$. long, about 0.3 to $0.5 \mathrm{~mm}$. in diameter, rootlets few.

Inner Structure.-See Fig. 37.

Powder.-Dark brown; calcium oxalate in raphides from 0.020 to $0.045 \mathrm{~mm}$. long; starch grains somewhat spheroidal, 0.003 to 0.012 $\mathrm{mm}$. in diameter, single or 2- to 4-compound; tracheæ with spiral or scalariform thickenings or porous walls; sclerenchymatous fibers long, thin-walled, with simple pores; endodermis with inner walls much thickened. 


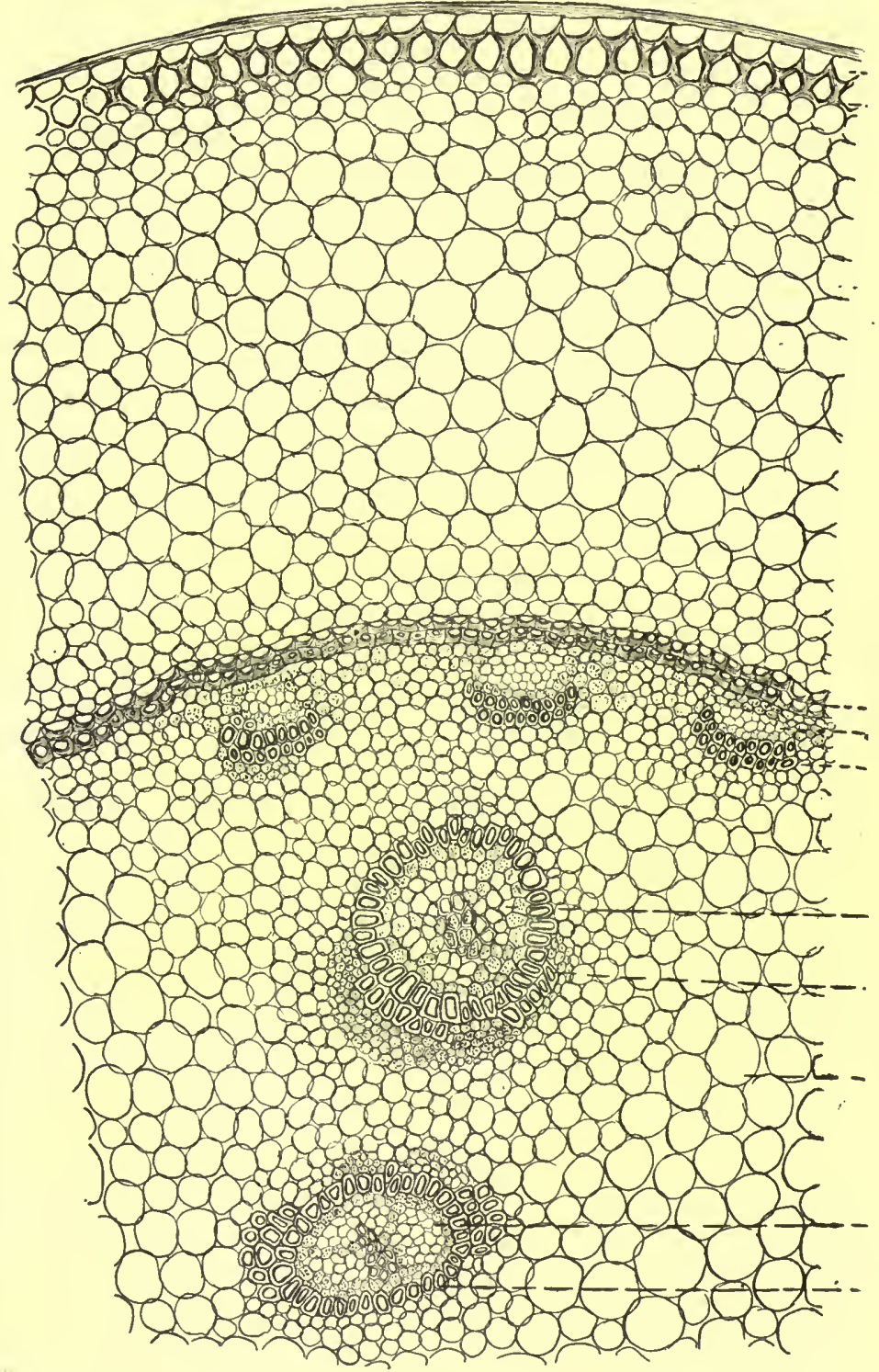

FIG. 37.-Portion of a transverse section of convallaria rhizome; $\dot{E}$, epidermis; $H$, hypodermis composed of collenchyma; $C$, cortex; $E N$, endodermis; $S$, perihadromatic sieve; $T$, tracheæ or vessels; $P$, parenchyma. The bundles are of the collateral and concentric types. 
Constituents.-A bitter, somewhat crystalline glucoside, convallamarin, about 0.6 per cent, which is soluble in water, alcohol and ether and has a physiological action similar to digitalin. An acrid glucoside, convallarin, forming rectangular prisms which are insoluble in ether and sparingly soluble in water, the solution foaming on shaking like a saponin solution.

Convallarie Flores.-Lily of the Valley Flowers. The racemes of Convallaria majalis (Fam. Liliaceæ). The white or pinkish flowers are arranged in racemes upon scapes and are among the most fragrant and beautiful of all flowers. For use in medicine they are gathered in the spring and early summer from wild plants and carefully dried. On drying they turn brown in color but are easily distinguished by their bell-shaped, 6-parted perianths, the segments of which are recurved. Inside of this occur 6 stamens, the anthers of which are introrse and longer than the filaments. The ovary is 3-locular and tapers into a 3-grooved, stout style, having at the"summit a triangular stigma. The odor is fragrant and the taste sweetish and acrid.

The flowering scape is distinctly 2-winged, smooth and glabrous. In transverse section it shows 2 circles of collateral mestome strands, those situated at the periphery having a rudimentary cambial strata between the leptome and the tracheæ, a structure very seldom occuring in monocotyledonous plants.

The powdered drug is yellowish-brown and shows numerous smooth, ellipsoidal pollen grains and fragments with raphides of calcium oxalate varying from 0.010 to $0.040 \mathrm{~mm}$. in length. Fragments of perianth with elliptical stomata, also broken lobes of the anthers are quite common. The tracheæ of the scapes possess either simple pores or reticulate thickenings, and are associated with a few sclerenchymatous fibers having thin, lignified and porous walls.

The flowers contain a volatile crystalline principle which is fragrant even in dilute solutions. The other constituents on which the activity of the drug depends probably resemble those found in the rhizome.

Literature-Holm, Merck's Report, 1910, p. 160.

Aletris.-Unicorn Root, True Unicorn Root, Colic Root or Ague Root.-The rhizome and roots of Aletris farinosa (Fam. Liliaceæ), a perennial herb with spreading lanceolate leaves crowded at the base and a long slender scape terminated by a raceme of small, white, tubular flowers (for illustration of flowering plant consult Kraemer's "Applied and Economic Botany," p. 490. It is common 
in the pine barrens and grows in sandy and grassy woods throughout the eastern United States.

Description.-Rhizome horizontal or slightly oblique, somewhat contorted, laterally compressed above, from 2 to $4 \mathrm{~cm}$. in length, 5 to $12 \mathrm{~mm}$. in diameter; externally grayish-brown, upper portion with a circular stem scar at one end, from 3 to $7 \mathrm{~mm}$. in diameter and with numerous leaf bases, the sides and lower portion with numerous pale yellow roots which are more or less flexuose and provided with short branches; the roots are often stripped of the cortical layer, exposing the reddish-brown or purplish endodermal layer of the stele and giving them a wiry appearance; the surface of the rhizome covered with glandular hairs consisting of a unicellular or bi-cellular head and a short stalk; fracture short; internally light brown, cortex 1 to $2 \mathrm{~mm}$. thick, central cylinder with numerous circular, twisted and branching fibrovascular bundles. Odor slight; taste sweetish, somewhat bitter.

Inner Structure.-See Fig. 38.

Constituents.-A bitter principle soluble in water or alcohol.

Adulterant.-The drug is not infrequently mixed with helonias or entirely substituted by it. (U. S. Dept. Agric.)

Literature.-Holm, Merck's Report, 1910, p. 33.

Sarsaparilla.-The dried root of various species of Smlax (Fam. Liliaceæ), perennial climbers indigenous from Mexico to Brazil. There are three principal commercial varieties: (1) Honduras sarsaparilla yielded by Smilax officinalis, growing in Guatemala, Honduras and Nicaragua, and exported from Honduras and Belize; (2) Mexican sarsaparilla, yielded by Smilax medica, growing in Mexico, and exported from Vera Cruz and Tampico, and (3) Jamaica or Central American sarsaparilla, derived from Smilax ornata, growing in Colombia (South America), Costa Rica and Nicaragua, and shipped to Jamaica, whence it is exportedchiefly to London. There is also a native Jamaica sarsaparilla which is obtained from plants cultivated in Jamaica. The Honduras and Mexican varieties are chiefly used in this country.

Description.-Honduras Sarsaparilla.-In bundles (Fig. 39) about $1 \mathrm{M}$. in length and from 8 to $15 \mathrm{~cm}$. in diameter, consisting of the long, folded roots, and rhizomes, bound together by roots of the same plant or stems of some other plant, the ends of the bundles rarely being trimmed at the present time; roots about $2 \mathrm{M}$. long and uniformly about 2 to $6 \mathrm{~mm}$. in diameter; externally dark or reddishbrown, longitudinally furrowed, minutely hairy and having slender 

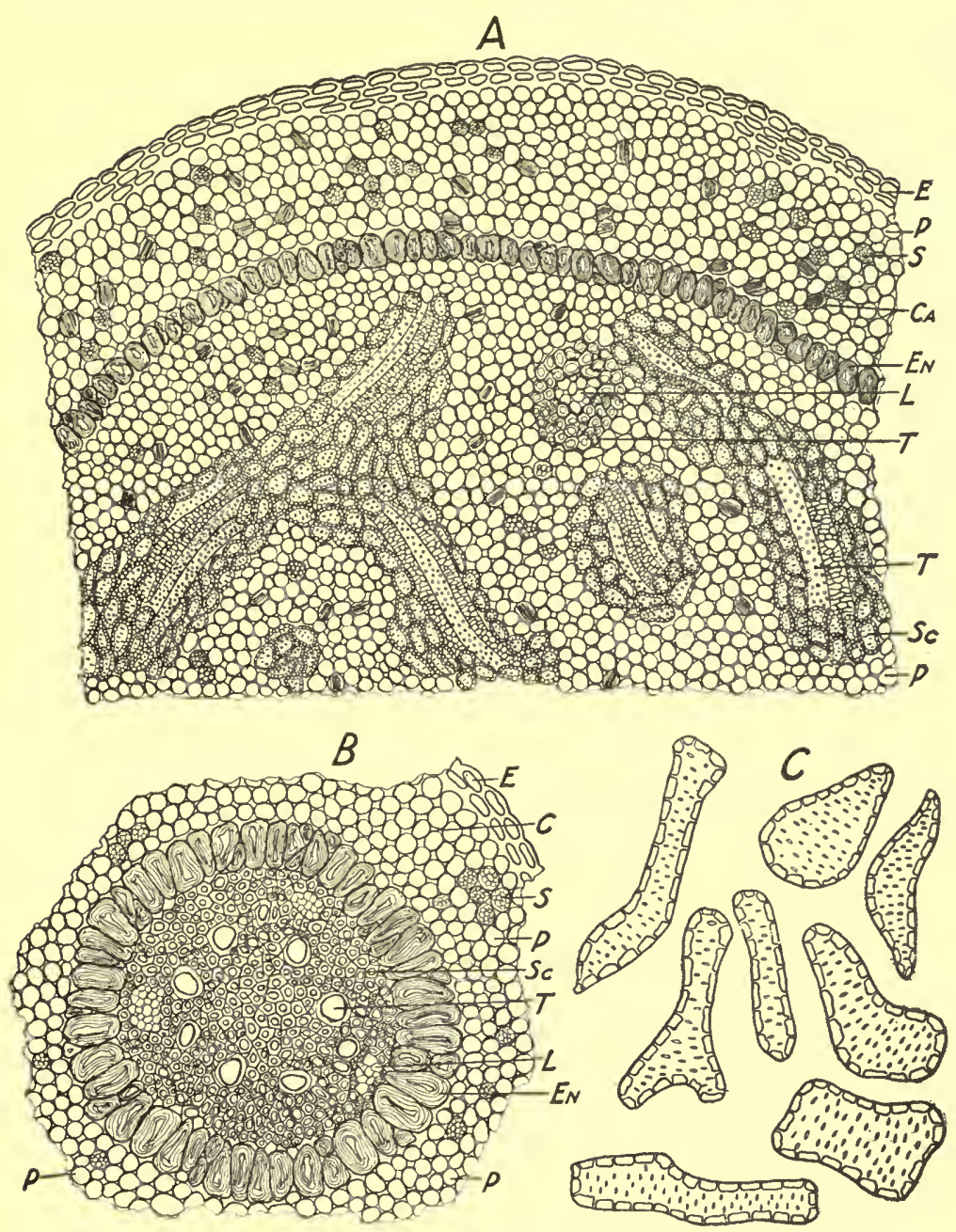

FIG. 38.-Aletris. $A$, transverse section of rhizome showing epidermis $(E)$; cortical parenchyma containing either starch grains $(S)$ from 0.002 to 0.010 $\mathrm{mm}$. in diameter or raphides of calcium oxalate $(C a)$ from 0.015 to $0.035 \mathrm{~mm}$. in length; endodermis $(E n)$ more or less distinct in the living plant but usually not well-marked in the drug; fibrovascular bundles composed of tracheæ $(T)$ and sieve $(L)$; sclerenchymatous fibers $(S c)$. $B$, transverse action of root showing epidermis $(E)$; cortical parenchyma containing starch $(S)$; endodermis $(E n)$ consisting of thick-walled reddish fibers; tracheæ $(T)$; sclerenchymatous fibers $(S c)$; sieve $(L)$. $C$, isolated short, porous sclerenchymatous fibers from the rhizome.-Drawn by Haase. 


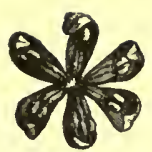

1

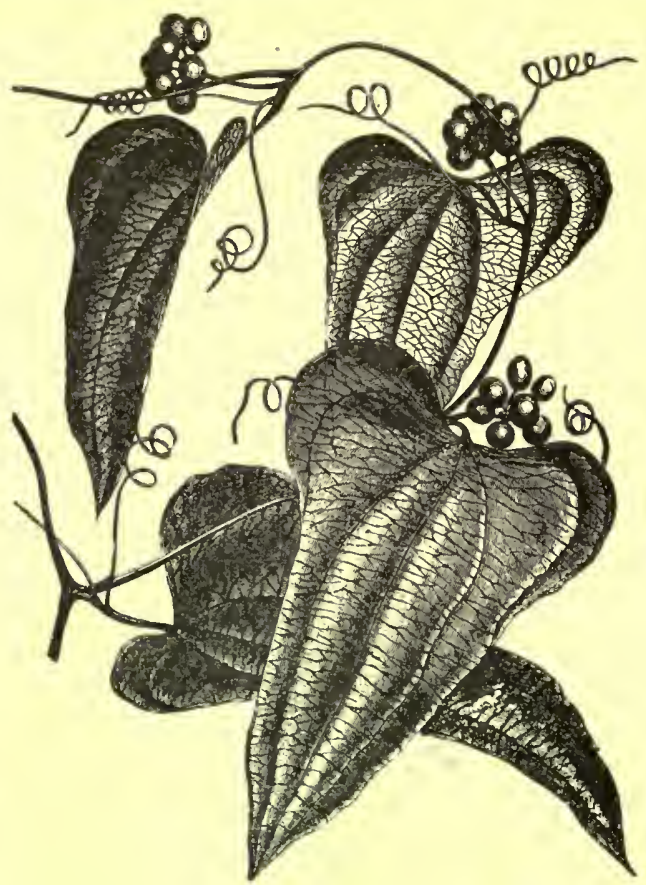

Smilax medica, the roots yielding Mexican sarsaparilla. To the right a portion of branch showing the characteristic veined leaves, the tendril-like appendages on the petioles, and the axillary, umbel-like clusters of fruits; $A$, staminate flower; $B$, pistillate flower in longitudinal section; $C$, transverse section of the tri-locular ovary; $D$, longitudinal section of ovary $E$, seed.After Bentley and Trimen.

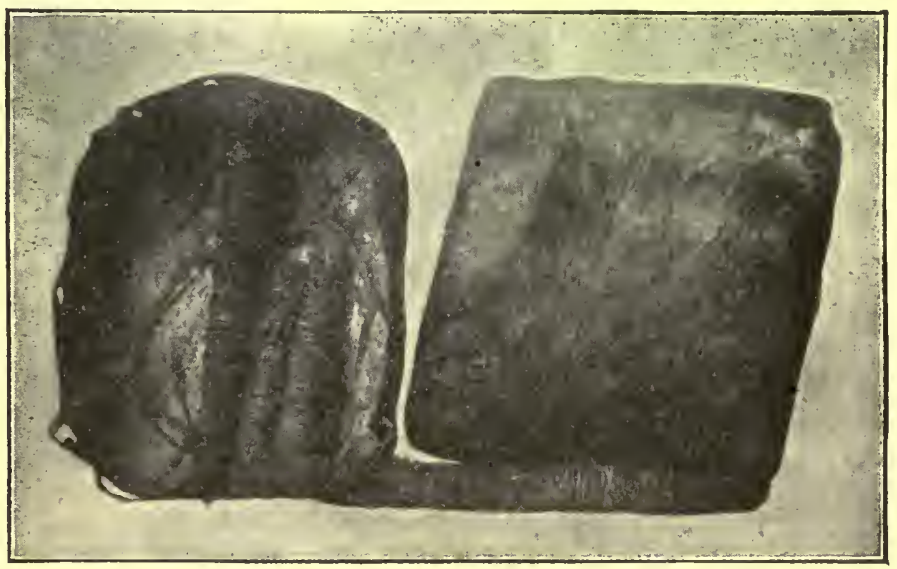

"Ceroons" made of hide, in which Honduras sarsaparilla is imported. 
rootlets, the furrows usually free from soil; fracture fibrous; internally consisting of a white pith, a light-yellow, porous, central cylinder and a grayish-white or dark-brown cortex, the latter being

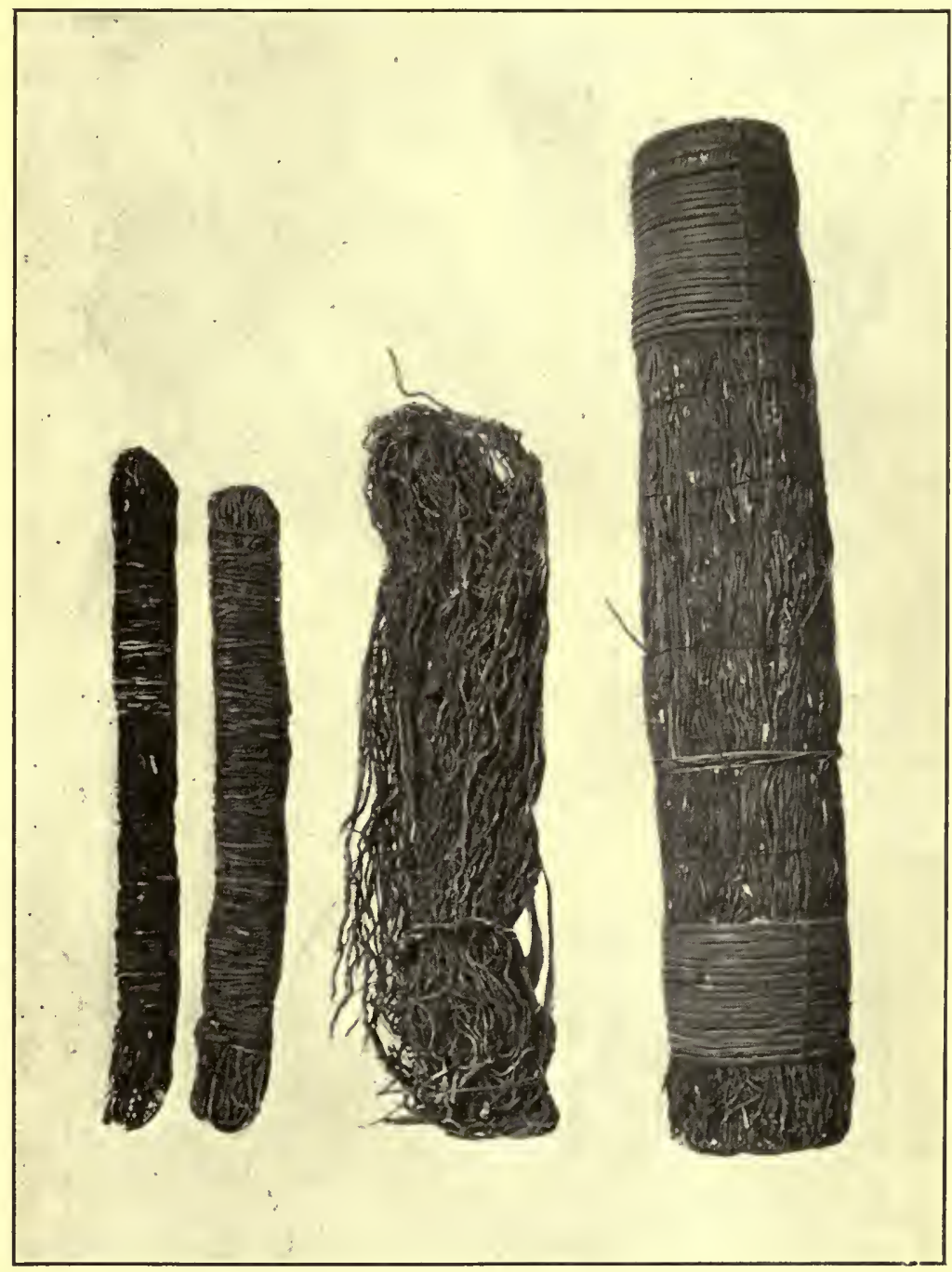

Fig. 39.-Bundles of Sarsaparilla, the two on the left being Honduras; the next one, Mexican, and the large one, Para, which is, however, not an article of commerce at the present time.

lighter and more starchy near the growing end, and darker (more resinous) at the portion near the rhizome; odor slight; taste slightly acrid. 

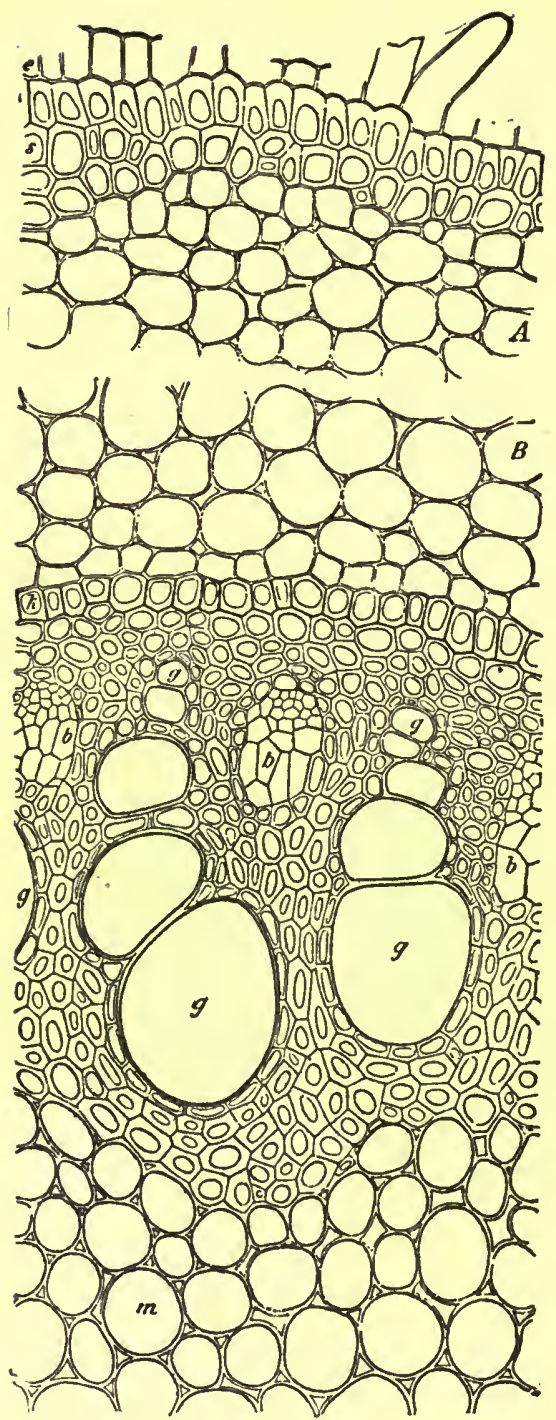

FIG. 40.-Transverse section of Honduras sarsaparilla in which the middle portion of the cortex is omitted; $e$, epidermis with root hairs; $s$, hypodermis; $A$, outer portion of cortex; $B$, inner portion of cortex; $k$, endodermis; $g$, tracheæ; $b$, sieve cells; $m$, parenchyma of the pith, the cells resembling those of the cortex. The thick-walled cells around the tracheæ $(g)$ and leptom (b) are sclerenchymatous fibers.-After Luerssen. 
The cells of the endodermis and hypodermis are oblong in transverse section and nearly uniformly thickened (Fig. 41).

Mexican Sarsaparilla.-In bundles (Fig. 39), with the roots usually more or less free; the latter gravish-brewn, somewhat shrunken, the furrows containing larger or smaller amounts of soil. The outer walls of the cells of the hypodermis and the inner walls of the cells of the endodermis are considerably thickened (Fig. 41).
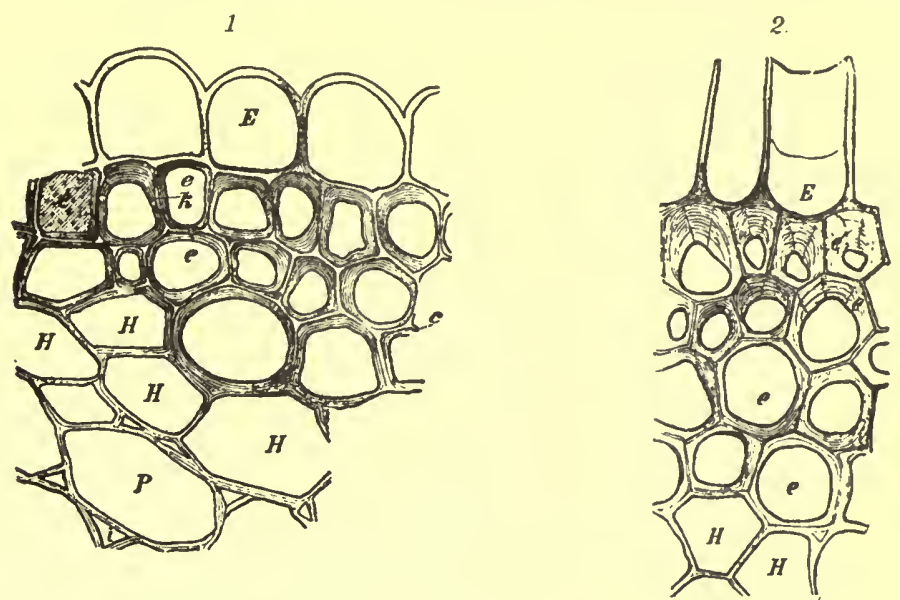

4.
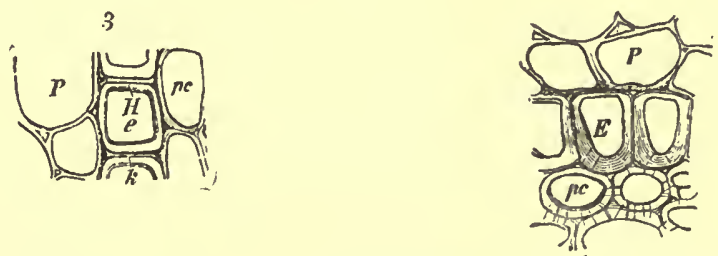

FIG. 41.--1, transverse section of Honduras sarsaparilla showing the uniformly thickened hypodermal cells $(e)$ with cork lamellæ $(k) ; E$, epidermal cells; $H$, hypodermal cells. 2 , similar section of Mexican sarsaparilla; 3 , transverse section of Honduras sarsaparilla showing endodermal cells (e) with cork lamellæ $(k)$ and lignified walls $(H)$; 4, similar section of Mexican sarsaparilla showing endodermal cells $(E)$.--After Meyer.

Jamaica Sarsaparilla occurs in rather loose bundles. The roots are especially marked by the numerous coarse rootlets. The cells of the hypodermis and endodermis somewhat resemble those of Mexican sarsaparilla.

Inner Structure.-See Figs. 40-42.

By reason of the differences in the shape and thickenings of the walls of the cells of the endodermis Hartwich (Ber. d. pharm 
Ges., 1907, p. 250) distinguishes the following different commercial varieties of sarsaparilla. 1. Honduras, in which the cells of the endodermis are mostly quadratic in shape, seldom tangentially elongated and only slightly thickened. 2. Vera Cruz (a Mexican variety), the cells being radially elongated and considerably thickened upon the inner side. 3. Tampico (a variety of Mexican), in which the endodermal cells show considerably variation and are frequently not to be distinguished from the first two varieties. 3. Guatemala or Manzamillo, in which the cells of the endodermis are tangentially elongated and are strongly thickened upon the inside. Nicaragua sarsaparilla resembles the drug known as Honduras, but is distinguished from this by the greater thickness of the endodermal cells.

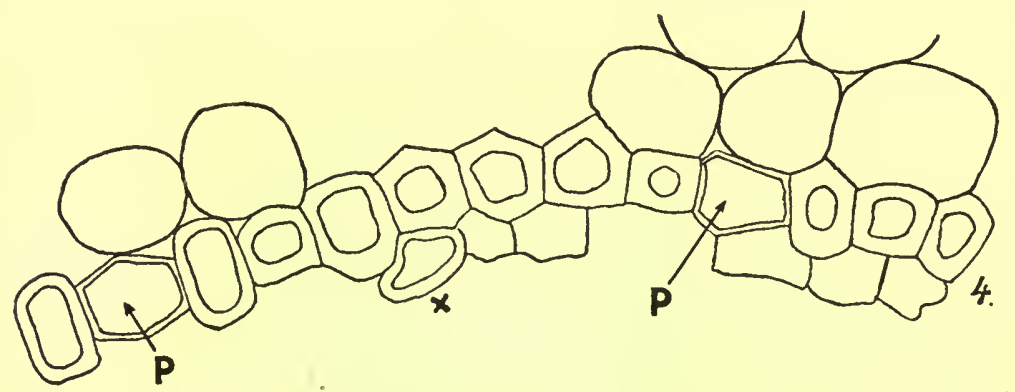

FIg. 42.-Transverse section of Sarsaparilla in the region of the endodermal cells. As pointed out by Hartwich, the inner walls are usually furnished with pores The radial walls are always suberized and this fact may be determined by the use of chromic acid. Sometimes some of the adjoining parenchyma cells in the pith are thickened and resemble the endodermis $(x)$. The endodermal cells are not always thickened but may have comparatively thin walls $(P)$; forming " passage cells" for the exchange of material between cortex and pith. The thickening of the cell walls of the endodermis consists of a modified cellulose. It is not colored either blue or violet upon the addition of chlorzinc-iodide, unless the sections have been first treated with chromic acid. Lignification of the walls is most pronounced in young roots and is not pronounced ir old roots such as we find in the article of commerce. The cell walls of the endodermis consist of lamellæ of celiulose, lignin, subcrin, and other substances.-After Hartwich.

Starch occurs in the parenchyma of the cortex and central pith. When heat is used in drying, the starch is altered, giving the root on breaking the appearance of being resinous, and hence sarsaparillas are sometimes distinguished as "mealy," containing unaltered starch (Vera Cruz), and "resinous" when the starch is swollen and agglutinated (Honduras). Calcium oxalate occurs in special mucilage cells in the form of raphides and is found in the cells of the cortex 
as well as pith. The amount varies in different lots of the same commercial varieties, sometimes being present only in the cortex and occasionally is wanting entirely. Even the quantity of starch may vary, sometimes being present in the central parenchyma only and sometimes being wanting entirely throughout the root.

Powder.-(Fig. 43.) Light to dark grayish-brown; consisting mostly of starch-bearing parenchyma and separate starch grains,

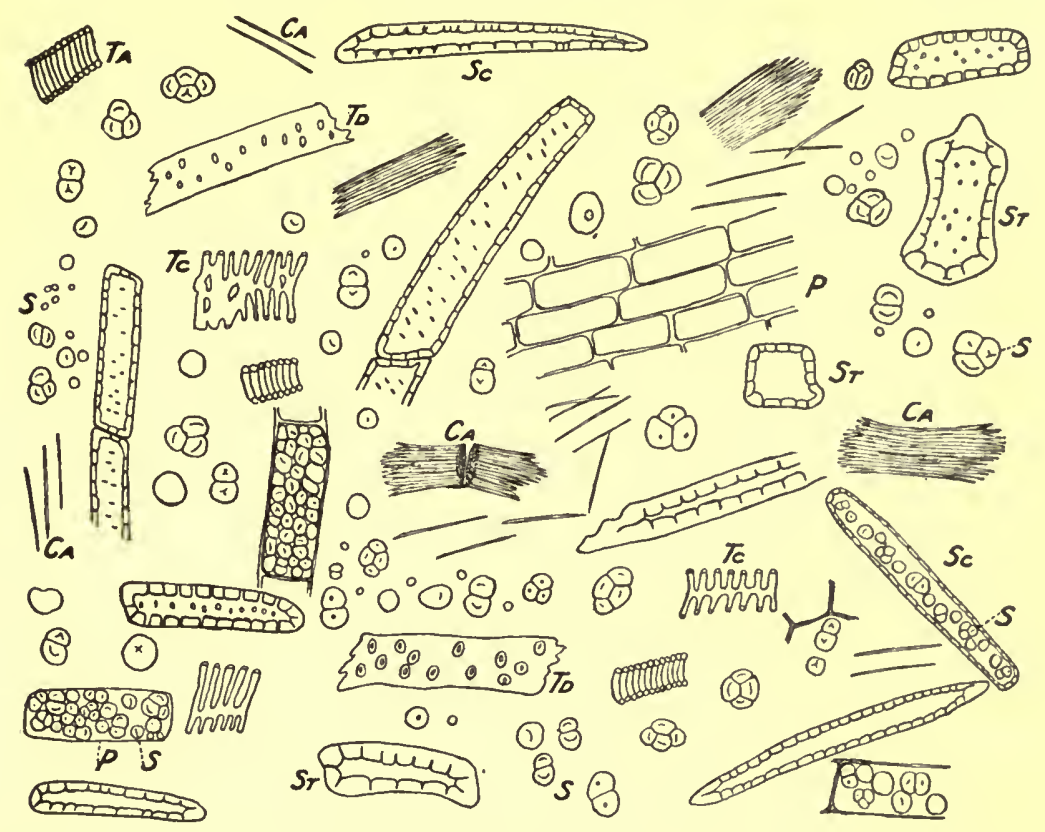

FIg. 43.-Powdered Sarsaparilla. Sc, sclerenchymatous fibers; $S t$, stone cells which are present in portions of the stems or "butts;" $S$, starch grains from 0.003 to $0.023 \mathrm{~mm}$. in diameter; $\mathrm{Ca}$, raphides of calcium oxalate from 0.006 to $0.100 \mathrm{~mm}$. in length; $P$, parenchyma cells containing starch; $T a$, close annular tracheæ; $T c$, reticulate tracheæ; $T d$, tracheæ with simple and bordered pores.-Drawing by Hogstad.

the latter from 0.003 to $0.023 \mathrm{~mm}$. in diameter, spheroidal, or biconvex or spheroidal-tetrahedral, single, or 2- to 4-compound, and frequently with a central elliptical cleft; calcium oxalate in raphides, $0.006 \mathrm{~mm}$. in length, also attaining a length of $0.150 \mathrm{~mm}$. occurring singly or in groups; cells of the hypodermis and endodermis with lemon-yellow or reddish-yellow porous walls and in the case of Mexican Sarsaparilla showing an uneven or irregular thickening, the individual cells, 0.080 to $0.500 \mathrm{~mm}$. in length; fragments of tracheæ with simple and 
bordered pores or scalariform or reticulate thickenings associated with sclerenchymatous fibers having rather thin, very slightly lignified and porous walls.

Constituents. - Sarsaparilla contains three glucosidal principles, which are present to the extent of about 3 per cent-parillin, saponin and sarsosaponin, of which the latter is the most active; it also contains about 15 per cent of starch; raphides of calcium oxalate; volatile oil, and resin.

Allied Products.-American Sarsaparilla is the rhizome of wild or Virginia sarsaparilla (Aralia nudicaulis, Fam. Araliaceæ), a perennial acaulescent herb, indigenous to Canada and the Northern United States as far west as Nebraska. The rhizome is of variable length, from 5 to $15 \mathrm{~mm}$. thick; externally brownish-gray and somewhat annulate; internally light brown, more or less spongy, and with an aromatic odor and taste.

The rhizome and roots of American spikenard (Aralia racemosa), growing in the Eastern and Central United States, have constituents similar to those of $\mathrm{A}$. nudicaulis, but are more aromatic. The bark of Hercules' Club (Aralia spinosa), of the Eastern and Central United States, contains the glucoside araliin and possibly also saponin.

The roots of Cocculus villosus (Fam. Menispermaceæ) are used in the East Indies like sarsaparilla.

Literature.-Schleiden, Archiv. d. Pharm., 1847, p. 25; Meyer, Ibid., 1881, p. 272; Holfert, Ibid., 1889, p. 507; Hartwich, Ibid., 1902, p. 325; Hartwich, Ber. Deutsch. Pharm. Ges., 1907, p. 250.

Erythronium.-Of the 12 species of this genus all but one are indigenous to North America. The species represented in the United States are commonly known as dog's tooth violet, or adder's tongue. The plants have a solid, scaly corm set deeply in the ground, which is used to a very limited extent in medicine. The corms contain large quantities of starch and it is surprising that they are not utilized commercially in this country to some extent. In Japan, starch is manufactured from E. Denscanis and is official in the Japanese Pharmacopœia. The starch grains are mostly single, from 0.020 to $0.025 \mathrm{~mm}$. in diameter and which vary from broadly ovoid or pear-shaped, to irregularly club-shaped grains, having an excentral point of origin of growth and indistinct lamellæ.

Literature.-Holm, Merck's Report, 1907, p. 223.

TriLlium.-Bethroot or Birthroot.-The rhizome and roots of Trillium erectum (Fam. Liliaceæ), a low perennial herb growing in rich woods from North Carolina to Quebec and Ontario. It produces a rather stout stem, having three leaves, arranged in a 
whorl at the summit, and subtending the large sessile dark purple flowers which have an unpleasant odor and for this reason the plant is called "ill-scented Wake-robin."

Description.--Rhizome upright or horizontal, obconical or somewhat cylindrical and compressed from above; from 2 to $6 \mathrm{~cm}$. in length and 0.75 to nearly $3 \mathrm{~cm}$. in diameter; externally yellowishto reddish-brown, distinctly annulate from scars of bud scales, the summit being terminated by a small bud, and the upper surface of the oblique rhizomes marked by a few scars of ascending branches, in addition the outer surface is marked by numerous circular root scars or has attached the long fibrous roots; fracture short, somewhat uneven and mealy; the fractured surface being yellowish-white or light brown, mealy, and with a waxy luster; odor distinct; taste starchy, bitter and acrid.

Inner Structure.-Epidermal layer of somewhat tabular cells with very thick reddish-brown porous walls; the hypodermal layer consisting of tangentially elongated cells, the outer layers of which have reddish-brown thick walls; the remainder of the rhizome consists of large thin-walled starch-bearing parenchyma, interspersed among which are the lepto-centric vascular bundles and cells containing raphides of calcium oxalate; starch grains mostly single, nearly spheroidal, having a distinct central cleft and varying in size from 0.003 to $0.020 \mathrm{~mm}$. in diameter, occasionally more or less altered and swollen starch grains from 0.020 to $0.030 \mathrm{~mm}$. in diameter; acicular crystals of calcium oxalate from 0.015 to $0.060 \mathrm{~mm}$. in length; tracheæ about $0.025 \mathrm{~mm}$. in width and with spiral or reticulate thickenings.

Constituents.-Saponin (trilline), 4.86 per cent; a resinous substance; considerable starch; a small quantity of volatile oil; ash, 4 to 5 per cent.

Ornithogalum Thyrsoides.-A bulbous plant (Fam. Liliaceæ), which is common in Cape Colony. Chemical examination of the entire flowering plant, including the underground, bulbous portion, shows the toxic principle to be chiefly contained in the resin. Attempts to obtain a definite active principle have been unsuccessful.-Power, Pharm. Journ., 1910, p. 32.

\section{DIOSCOREACEE, OR YAM FAMIY}

These are mostly twining plants with large tuberous roots or knotted root stocks. There are about 175 species most of which are indigenous to the West Indies and South America. The anatomy of 
the stems is interesting in that the fibrovascular bundles are collateral and arranged in a manner similar to those found in dicotyledons. In the rhizomes the fibrovascular bundles are of a collateral type but are separated from each other as is usual in the monocotyledons.

Dioscorea.-Wild Yam Root, Colic Root or Rheumatism Root. The rhizome of Dioscorea villosa (Fam. Dioscoreaceæ), a perennial herbaceous, twining plant, with beautiful cordate, 9- to 11-ribbed leaves, small greenish-yellow flowers and triangular winged capsules. The plant is common in the Eastern and Central United States and is easily cultivated. The branching rhizomes with adhering roots are gathered in the spring and fall, and dried.

Description.-Rhizome horizontal, woody, somewhat knotted and compressed; the pieces usually not more than $5 \mathrm{~cm}$. in length and $12 \mathrm{~mm}$. in thickness; externally light or yellowish-brown with small circular stem-scars on the upper surface and with conical shaped buds and slender wiry roots on the lateral portions; fracture short; inodorous; taste somewhat acrid.

Inner Structure.-Epidermis thin-walled and provided with large water pores. The starch-bearing cortical parenchyma is of two kinds, that in the periphery being thin walled and is frequently abraded in the drug, while the inner layers are thick-walled and impart to the drug its hardness. There is no endodermis or pericycle and the collateral vascular bundles are scattered throughout the central parenchyma. Raphides of calcium oxalate are also present.

Constituents.-An acrid resin and a principle allied to saponin. Continued boiling is said to impair the acrid properties of the drug.

Literature.-Holm, Merck's Report, 1913, p. 311.

Yam Root.-Yam is a popular name for several of the edible species of Dioscorea and is sometimes incorrectly applied to certain varieties of the sweet potato. The tubers of D. alata weigh as much as $25 \mathrm{~K}$. In the South Sea Islands they are eaten after boiling, which destroys the acrid principle. The starch is also separated and is sometimes marketed under the name of "South Sea Island Arrowroot." The starch grains are mostly single, ellipsoidal or ovoid, frequently bent and characterized by an excentral point of origin of growth and numerous lamellæ.

\section{AMARYLLIDACEA, OR AMARYLLIS FAMIIY}

A group of herbaceous plants mostly indigenous to tropical and subtropical regions. It includes a number of genera, which are used for ornamental purposes, as Amaryllis, Crinum, Galanthus (or snow 
drop, which flowers very early in the spring), Narcissus and Agave. The latter resembles the Aloe plant in its growth and general appearance, and the best known species, Agave americana, is properly known as the American aloe. The plant is frequently seen in cultivation and it is commonly supposed that it does not bloom until it is 100 years old, and hence is referred to as the Century plant. The notion as to its flowering is erroneous, as in hot climates it will flower in a few years. The Agave is among the most useful plants of Mexico, and is extensively cultivated in tropical countries for its fiber. The latter is obtained from the leaves, and is known in commerce as Sisal or Manilla hemp. The sap of the leaves contains large quantities of sugar, and is used in the manufacture of an intoxicating beverage, called pulque. The inner structure of the Amaryllidaceæ resembles that of the other monocotyledons. Calcium oxalate occurs in the form of raphides in special mucilage cells and the stomate are sunk below the other epidermal cells.

Buphane Disticha.-A bulbous plant (Fam. Amaryllidaceæ), native of South Africa, where it is known as the "poison bulb." The plant is stated to have been used as an "arrow-poison," and in the treatment of the disease known as "red water." Chemical examinations of the bulbs show them to contain a mixture of alkaloids, the principal constituent of which is an amorphous, strongly basic product, designated buphanine, which possesses a distinct physiological action. It also contains a weakly basic and a water-soluble alkaloid, together with a small amount of narcissine; a volatile oil; acety-vanillone; pentatriacontane; a phytosterol; a phytosterol glucoside; a mixture of fatty acids; chelidonic acid, and considerable amounts of lævulose and copper.-Power, Journ. Chem. Soc., 1911, p. 1240 .

\section{IRIDACEE, OR IRIS FAMIIY}

Plants are mostly perennial herbs with erect, bilateral leaves, and interesting, frequently handsome flowers. There are about 800 species occurring in both temperate and tropical climates. The rhizomes are creeping as in Calamus and the fibrovascular bundles are of the concentric type, being only at the beginning of their entrance into the rhizome of the collateral type. Of special interest is the fact that the calcium oxalate occurs in the form of long styloids, which are surrounded with mucilage, and the walls of the cells in which they are enclosed are suberized.

Crocus.-True Saffron or Spanish Saffron.-The stigmas of Crocus sativus (Fam. Iridaceæ) to which may be attached portions 
of the styles. The plant flowers in the autumn and consists of a more or less globular corm, a few linear leaves, and a scape with lilac-purple flowers. The plant is cultivated extensively in Spain, and to some extent in France, Austria, Germany, Switzerland and Italy. It has also been successfully grown in Lebanon County, $\mathrm{Pa}$. The flowers are collected in autumn, the stigmas and upper portions of the styles separated and dried. As the plant only produces one or two flowers, the styles and stigmas only being used, a good quality of drug is expensive. The labor involved is necessarily tedious and the loss on drying is about 80 per cent. The figures vary considerably but it is estimated that 100,000 flowers are gathered in order to obtain but $500 \mathrm{gm}$. of drug. There are two principal commercial varieties, viz.: Valencia, consisting almost entirely of stigmas, and the Alicante being usually contaminated with larger percentage of fragments of styles, stamens and corolla. Saffron should not be exposed to the light, and should be kept in tin containers or amber-colored bottles.

Description.- Stigmas separate or three attached to the top of the style; stigmas about $25 \mathrm{~mm}$. long, cornucopia-shaped with a dentate or fimbriate margin, and of a dark rich red.color; styles about $10 \mathrm{~mm}$. long, more or less cylindrical, solid, yellowish; odor strong, peculiar, aromatic; taste bitterish, aromatic.

On placing the stigmas in sulphuric acid they are immediately colored blue, gradually changing to violet, and finally become a deep wine-red color.

If $0.010 \mathrm{gm}$. of finely comminuted saffron is added to 100 c.c. of cold water and allowed to macerate for several hours and filtered, then 10 c.c. of this filtrate when added to 100 c.c. of water should give a distinct yellow colored solution.

On macerating $0.010 \mathrm{gm}$. of saffron in 5 c.c. of methyl alcohol a strong orange color is imparted to the liquid. On the addition of $0.010 \mathrm{gm}$. of saffron to 5 c.c. of acetone, alcohol, or absolute alcohol a distinct lemon yellow color is produced. With ether a very light lemon yellow color is produced. With chloroform a very slight yellow tinge is imparted and with xylol, benzol, carbon disulphide, carbon tetrachloride, and petroleum benzin the solvents remain colorless.

Inner Structure.-A microscopic view of the upper end of the stigma shows the presence of numerous papillæ which are cylindrical and about $0.150 \mathrm{~mm}$. long, in among which occur a few pollen grains which are spheroidal, nearly smooth, and about 0.040 to $0.075 \mathrm{~mm}$. in diameter; occasionally some of the pollen grains have germinated and show pollen tubes of various lengths. 
Powder.-(Fig. 44.)-Orange red; glycerin mounts of deep orange color; few, nearly smooth, nearly spheroidal pollen grains, 0.085 to $0.100 \mathrm{~mm}$. in diameter; papillæ of stigma; coloring principle soluble in water but not in fixed oils, being the reverse in capsicum; with sulphuric acid fragments become blue immediately.

A.

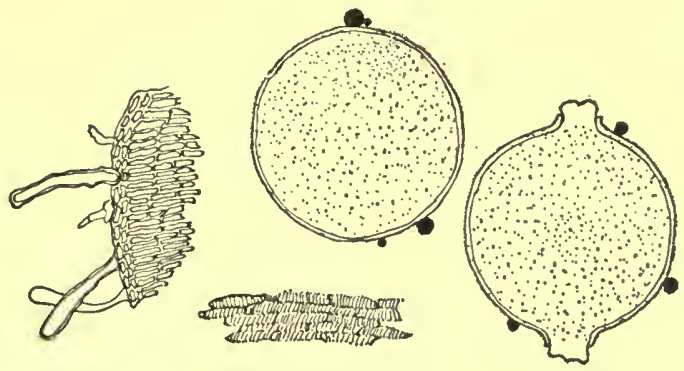

B.
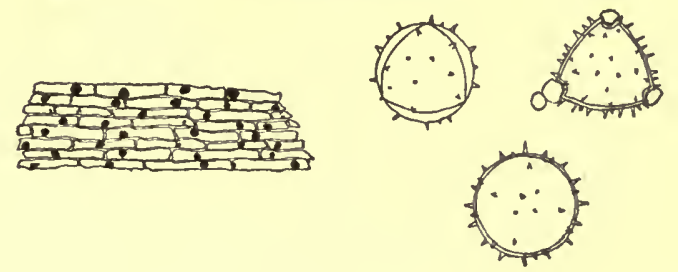

C.
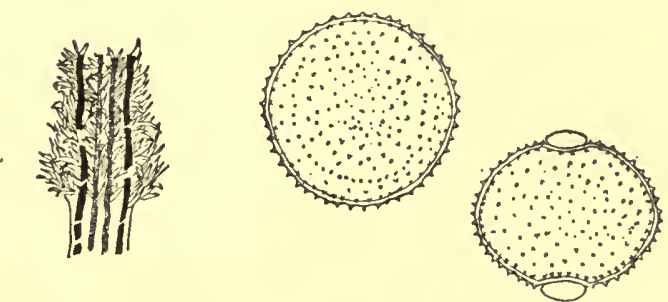

FIG. 44.- $A$, Crocus (Spanish saffron), showing two spheroidal pollen grains, a fragment of stigma with papillæ, and fragment of an anther; $B$, Calendula, showing three spinose pollen grains and fragments of corolla, the cells of which contain oil-like globules; $C$, Carthamus (so-called American saffron), showing two slightly spinose pollen grains and a fragment of the corolla with brown laticiferous vessels and numerous unicellular hairs.-After Weakley.

Constituents.-A yellow glucoside, crocin, which is very powerful, 1 part imparting a distinct yellow color to 100,000 parts of water. It is a yellow amorphous substance which is readily soluble in water and dilute alcohol, but only slightly soluble in absolute alcohol or ether. It is colored blue with either sulphuric or nitric acid. It 
also contains another glucoside, picrorocin, which is soluble in ether, forms prismatic crystals and yields on hydrolysis a volatile oil. The latter may be obtained on distillation to the extent of 1 per cent and possesses when freshly distilled a yellowish color and the odor of saffron. It also contains a hydrocarbon of the methane series, a wax, a fixed oil and dextrose. The ash, which is rich in phosphoric acid, varies from 4.5 to 7.5 per cent. The commercial article should not contain more than 14 per cent of moisture.

Standard of Purity.-Saffron is the dried stigma of Crocus sativus L. It contains not more than 10 per cent of yellow styles and other foreign matter, not more than 14 per cent of volatile matter when dried at $100^{\circ} \mathrm{C}$., not more than 6 per cent of total ash, nor more than 1 per cent of ash insoluble in hydrochloric acid. (U. S. Dept. Agric.)

Adulterants.-A large number of vegetable, mineral and animal substances and also dye stuffs have been employed to adulterate saffron. It is frequently confused with and substituted by safflower (Carthamus tinctorius) a plant of the Compositæ, the tubular flowers of which are sold under the name of "American saffron." The latter are readily distinguished by their corollas possessing very long slender yellow tubes and five bright red lobes. The pollen grains are very numerous, somewhat triangular in shape, the surface being very prickly (Fig. 44).

The ligulate flowers of Calendula are sometimes colored with one of the red dyes as hæmatoxylin, safranin or fuchsin and employed to adulterate saffron. These are distinguished by their rather broad ligulate corollas having 4 prominent veins and 4 teeth at the summit. The epidermal cells contain characteristic yellowish oily drops (Fig. 44).

Literature.-Kraemer, Amer. Jour. Pharm., 1898, p. 386; Zörnig, Arzneidrogen; Valdiguié, Bot. Abstracts, 1918, 1, p. 179.

IRIs.-Larger Blue Flag, Water or Poison Flag.-The dried rhizome and roots of Iris versicolor (Fam. Iridaceæ), one of the most common Monocotyledons in the United States. The plant is a perennial herb, with long sword-shaped or grassy leaves and possesses large violet-blue flowers. It grows in wet places and produces a thick fleshy rhizome. The latter is collected, freed from the scaly decayed leaves and dried.

Description.-Rhizome cylindrical, more or less flattened, occasionally branched; outer surface annulate with numerous stem scars on the upper surface and numerous root scars on the lateral and under portions. Usually cut lengthwise into pieces 2.5 to $10 \mathrm{~cm}$. in length and 5 to $20 \mathrm{~mm}$. in diameter; externally grayish-brown to 
blackish-brown and occasionally with the fibrous bases of decayed leaves and short fragments of the stout roots; fracture, short, resinous; internally reddish-brown, with a distinet yellowish endodermis within which are the whitish, scattered vascular bundles; odor slightly aromatic; taste sweetish, bitter and slightly acrid.

Inner Structure.-See Fig. 45.
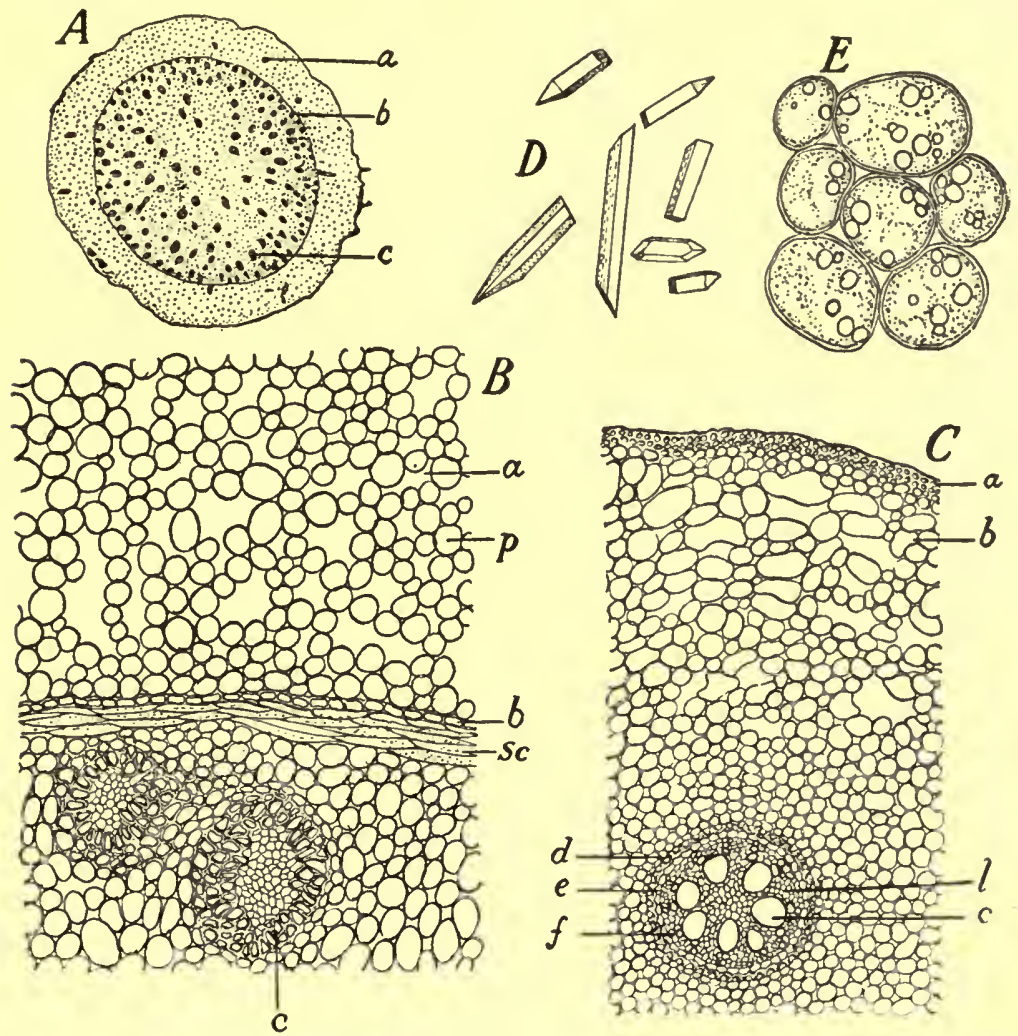

FIG. 45.-Rhizomes of Iris versicolor. $A$, diagram of transverse section showing vascular bundles ( $a$ and $c$ ); endodermis $(b) . \quad B$, portion of rhizome showing parenchyma $(p)$ and intercellular spaces $(a)$, endodermis $(b)$; closed ring of sclerenchymatous fibers shown in longitudinal view $(s c)$; concentric vascular bundle of the leptocentric type. $C$, transverse section of root showing epidermis (a); cortical parenchyma $(b)$; central stele with endodermis $(d)$; pericambial layer $(e)$; leptome $(l)$ and trachex $(c$ and $f)$, those at the periphery being smaller. $D$, crystals of calcium oxalate. $E$, cells of parenchyma with amylo-dextrin starch grains, i.e., becoming reddish with solution of iodin.-After Bastin.

Powder.-Reddish-brown; numerous fragments of parenchyma associated with resin cells, the latter being colored from a yellowish- 
to an orange-brown; calcium oxalate in long solitary prisms with pyramidal ends, as in quillaja, and varying from 0.100 to $0.350 \mathrm{~mm}$. in length; parenchyma cells containing small amylo-dextrin grains, colored reddish with iodin and occasionally with typical starch grains giving a blue reaction with iodin. Tracheæ with spiral or reticulate thickenings.

Constituents.-About 25 per cent of acrid resins and a small quantity of volatile oil. An alkaloid has also been reported to occur in Iris. The so-called "irisin" or "iridin" is a mixture of the resins and the powdered drug.

Adulterants.-The drug on the market varies considerably owing to some extent to the lack of uniformity in its collection. The con-

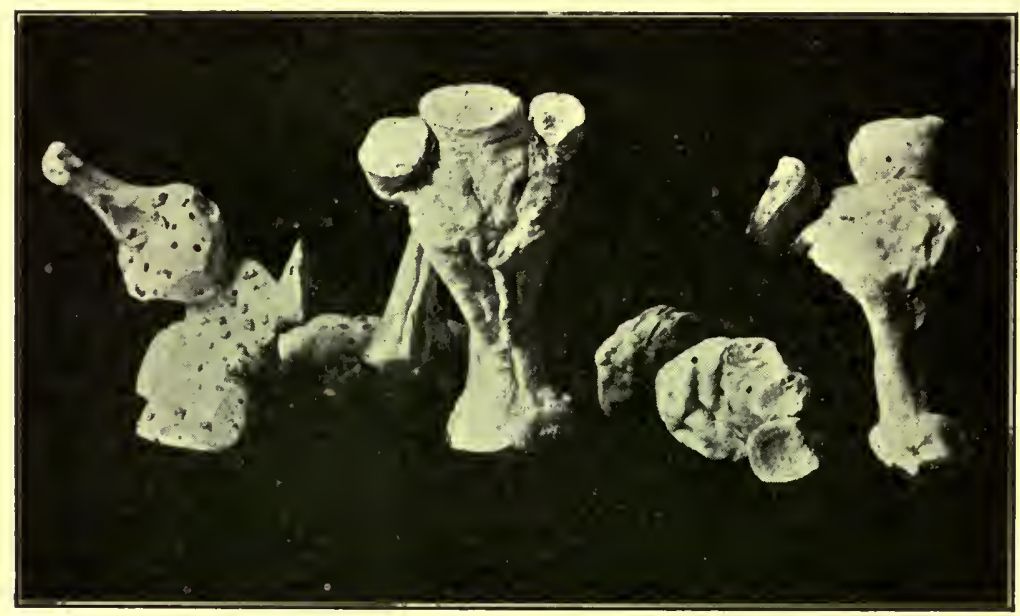

Fig. 46.-Specimens of "orris root" of commerce consisting of the dichotomous rhizomes of Iris florentina.

stituents are apparently very labile, the resins becoming changed to insoluble and inert substances.

Literature.-Bastin, Amer. Jour. Pharm., 1895, p. 78.

Iris Florentina.-Iridis Rhizoma, Florentine Orris, oR ORRIS RooT.-The prepared rhizome of Iris florentina and other species of Iris (Fam. Iridaceæ), cultivated in Italy. The rhizomes are gathered in the fall, freed from the roots and outer cortical layer and slowly dried. The fragrant odor is developed during the drying process. There are two principal varieties, Florentine and Verona, the former is more fragrant, lighter in color and is preferred.

Description.-In irregularly cylindrical, somewhat flattened, more or less branched pieces (Fig. 46), from 5 to $10 \mathrm{~cm}$. in length and 
about 2.5 to $4 \mathrm{~cm}$. in thickness; externally oyster-white or yellowishwhite, and marked by numerous circular root-scars; hard and heavy; fracture irregular, the broken surface exhibiting a distinct endodermis and numerous circular vascular bundles. It has a violet-scented odor and a slightly aromatic, somewhat bitter and acrid taste.

Inner Structure.-Consisting mostly of starch-bearing parenchyma, in the intercellular spaces between which occur large prisms of calcium oxalate, varying from 0.100 to $0.500 \mathrm{~mm}$. in length and from 0.015 to $0.025 \mathrm{~mm}$. in diameter. The walls of the endodermal cells are of a collenchymatous nature and contain starch. The fibrovascular bundles are of the. leptocentric type and the tracheæ show mostly annular or spiral thickenings, although scalariform or reticulate forms may occur.

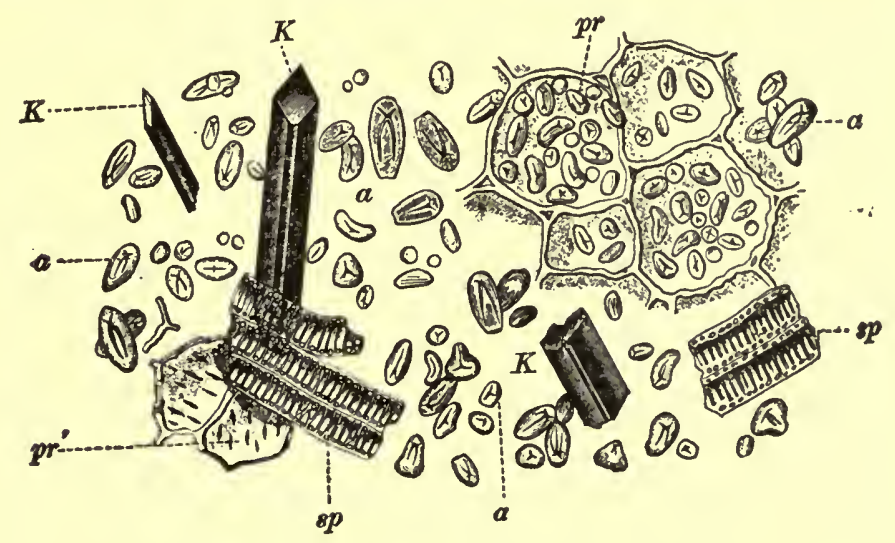

FIG. 47.-Orris root: $p r$, parenchyma containing starch grains; $a$, starch grains with characteristic cleft; $p r^{\prime}$, parenchyma with narrow oblique pores; $s p$, fragments of tracheæ; $K$, prisms of calcium oxalate-After Vogl.

Powder.-(Fig. 47.) Starch grains, 0.005 to $0.030 \mathrm{~mm}$. in diameter with a characteristic cleft like a pair of open shears. Calcium oxalate in solitary prismatic crystals with pyramidal ends and attaining a length of $0.500 \mathrm{~mm}$. Tracheæ with markings as indicated above. There are neither cork cells nor sclerenchymatous fibers present.

Constituents.-From 0.1 to 0.2 per cent of a yellowish-white volatile oil which is almost solid at ordinary temperatures, whereby it is known commercially as orris butter. It consists chiefly of myristic acid and owes its odor to the ketone, irone. It also contains a small amount of a crystalline glucoside, iridin, which is soluble in hot alcohol, sparingly soluble in water and insoluble in ether, chloro- 
form and benzol. There is also present in addition an acrid resin and a tannin, the latter being colored greenish with ferric salts.

\section{ZINGIBERACEA, OR GINGER FAMILY}

Perennial herbs characterized by long or tuberous rhizomes and strongly thickened roots. They are indigenous to the tropics of the eastern hemisphere, especially the countries bordering the Indian Ocean and Malay Islands, only two of the genera being found in tropical America. The leaves are lanceolate and ligulate at the basal portion of the petiole. The fibrovascular bundles are concentric and arranged in one or more rows within the central cylinder. The walls of the cells of the endodermis are thin and mostly suberized. The plants usually contain a volatile oil which is colored by a yellow coloring principle curcumin, this being found in special secretion cells which somewhat resemble the surrounding parenchyma. The starch grains are quite characteristic, having a distinct acute termination or beak near the point of origin of growth.

Zingiber.-Ginger.-The rhizome of Zingiber officinale (Fam. Zingiberaceæ), a perennial herb (Fig. 48) indigenous to Asia, and cultivated in tropical countries, notably in the West Indies, India and Africa. The rhizomes are collected between December and March; they are cleaned by washing, peeled, again washed in water, sometimes containing juice of the lime fruit, and dried in the sun. There are several kinds of the drug, depending upon the manner of treatment. That from Africa has the periderm removed from the vertical sides only, and is known as " coated" ginger; in the Jamaica variety the periderm is completely removed and the product is known as "peeled" or "uncoated" or "scraped" ginger. The latter is sometimes steeped in milk of lime to protect it against the attacks by insects. The Jamaica variety has a very delicate aroma.

Jamaica Ginger.-Horizontal, laterally compressed, irregularly branched pieces (Fig. 49), 4 to $10 \mathrm{~cm}$. long, 4 to $20 \mathrm{~mm}$. broads 5 to $10 \mathrm{~mm}$. thick; externally light brown, longitudinally wrinkled, having somewhat elliptical, depressed stem-scars, with few fibers of fibrovascular tissue or adhering fragments of periderm; fracture mealy and with short projecting fibrovascular bundles:- internally, cortex light brown, 0.1 to $0.4 \mathrm{~mm}$. thick; central cylinder with numerous circular groups of fibrovascular tissue and yellowish secretion cells; odor strongly aromatic; taste pungent.

Inner Structure.-See Fig. 50. In fresh ginger and in the confection "crystallized ginger" the contents of the secretion cells are 
oily and of a yellow color, but in old dried rhizomes the contents are darker and insoluble in alcohol, ether, glacial acetic acid, with solutions of potassium hydrate or hydrated chloral.

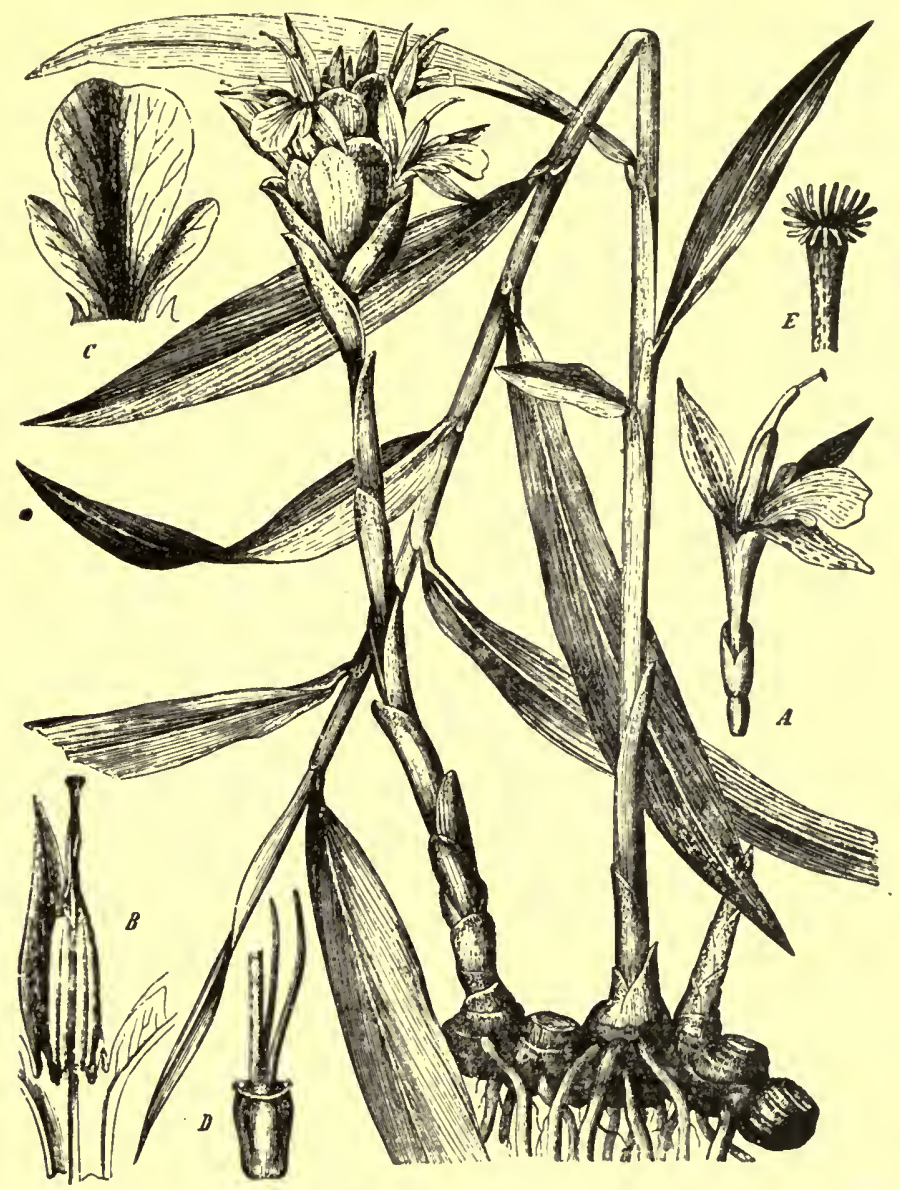

FIG. 48.-Zingiber officinale, the rhizome of which constitutes the ginger of the market. Entire plant showing rhizome and roots, a leaf-branch and a flowerbranch as also scars of previous year's growth after decay of leaf- and flowerbranches. $A$, entire flower, $B$, section of flower showing beak-like appendages at the summit of the fertile stamen, which encloses the style; $C$, threeparted labellum or irregular segment of corolla showing two tooth-like staminodes (rudiments of stamens) at the base; $D$, tho ovary with lower portion of style and two epigynous filiform processes which secrete nectar; $E$, summit of funnel-shaped, fringed stigma.-After Berg and Schmidt.

Powder.-(Fig. 51.) Light yellow; numerous starch grains ellipsoidal or somewhat ovoid, slightly beaked, 0.015 to $0.060 \mathrm{~mm}$. in 
diameter; secretion cells with suberized walls and yellowish oily contents; tracheæ large, thin-walled, annular or reticulate; scleren-

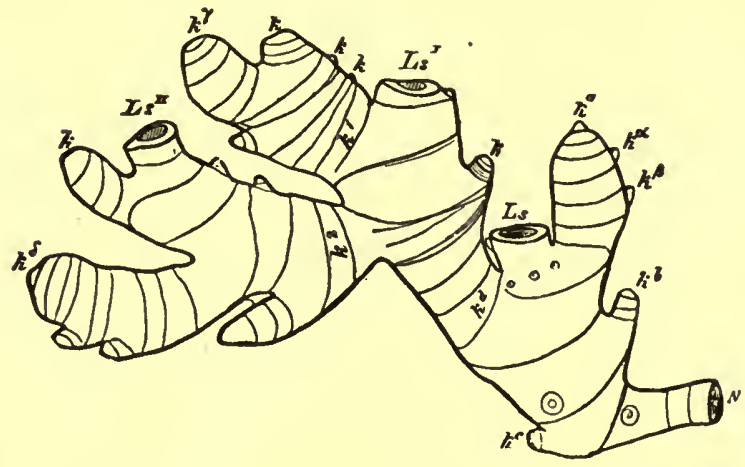

Fig. 49.-Rhizome of African ginger showing scars of overground branch (Ls) and buds $(k)$. The more or less parallel lines represent leaf-scars and scars of bud-scales, and the small circles, root-scars.-After Meyer.

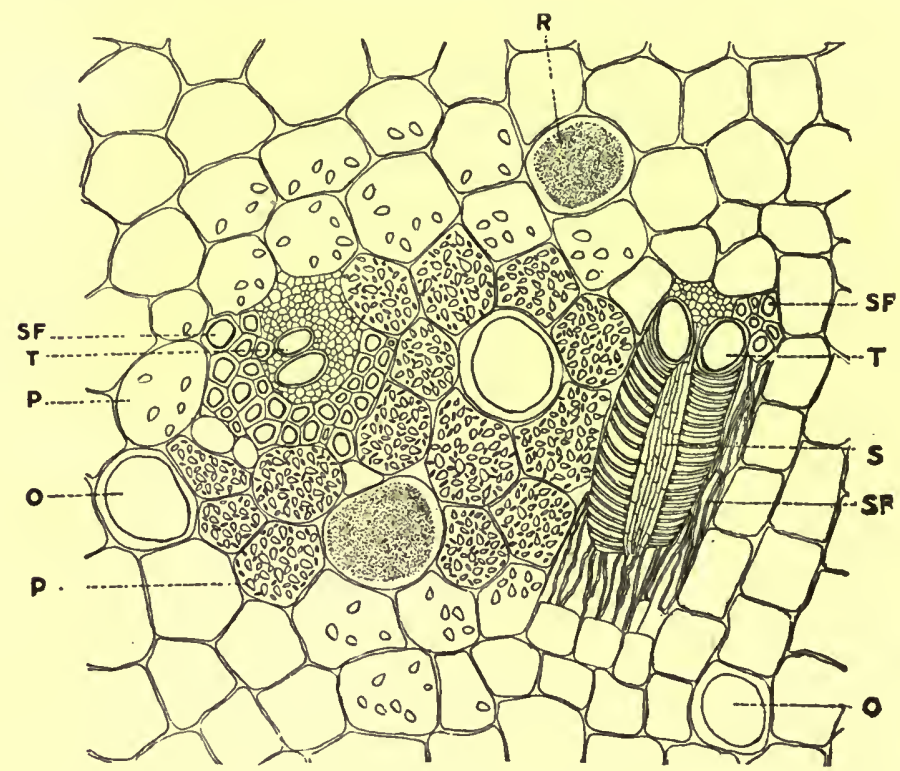

FIG. 50.-Transverse section of portion of rhizome of ginger; $P$, parenchyma containing ovoid starch grains; $O$, oil cells; $R$, cells containing resin; $S F$, sclerenchymatous fibers; $T$, tracheæ; $S$, sieve.

chymatous fibers long, thin-walled, non-lignified and with oblique pores. 


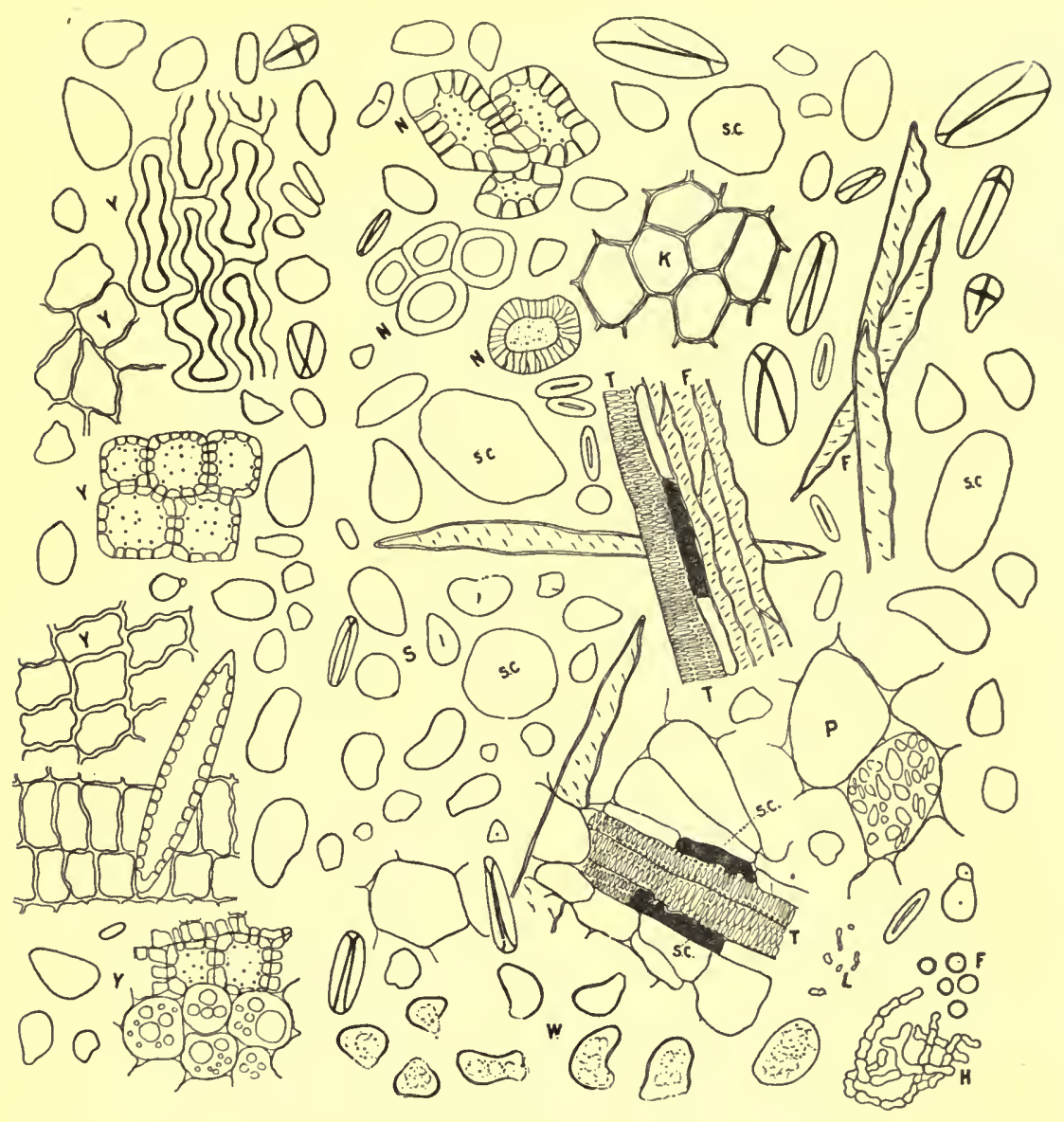

FIG. 51.-Powdered ginger containing foreign tissues. The following are the typical elements of ginger: $F$, sclerenchymatous fibers which vary from 0.3 to $1.3 \mathrm{~mm}$. long and from 0.020 to $0.030 \mathrm{~mm}$. in diameter, the walls being somewhat undulate, about $0.003 \mathrm{~mm}$. thick, slightly yellowish, non-lignified and having slender, oblique, simple pores; $T$, reticulate tracheæ varying from 0.030 to $0.060 \mathrm{~mm}$. in diameter, the walls consisting mostly of cellulose, and with phloroglucin giving but a faint reaction for lignin; $S C$, secretion cells, the walls of which are suberized and the contents of which in the fresh rhizome are oily and of a light yellow color, changing to golden yellow with sulphuric acid, whereas in the older commercial specimens the contents are yellowish, or reddish-brown, balsam-like or resinous, becoming of a deep brownishblack on treatment with sulphuric acid; $K$, cork cells which on an average are about 0.060 in length and $0.025 \mathrm{~mm}$. in width; $S$, starch grains which vary from 0.020 to $0.060 \mathrm{~mm}$. in length, the largest being found in Jamaica ginger, have indistinct lamellæ, and so do not polarize well unless mounted in a fixed oil, as almond or olive; $W$, swollen starch grains; $L$, small, swollen, altered 
Constituents.-Volatile oil, possessing the aromatic odor of the drug, 1 to 3 per cent, and consisting chiefly of a sesquiterpene, some dextro-camphene and phellandrene; a colorless, viscid principle gingerol, which has the pungent taste of the drug, 0.5 to 1.5 per cent; two resins, one of which is acid in character; starch, 20 per cent.

Commercial Varieties.-The following are derived from Zingiber officinale: (1) Natural Jamaica ginger occurs in long, slender, flattish, branching, light yellowish-brown pieces, the periderm being completely removed. (2) Bleached Jamaica ginger is the natural Jamaica rhizome frequently coated with lime. (3) African ginger consists of grayish-brown pieces which are partly peeled on the flattened sides, in section exhibit garnet resin dots, and the taste is intensely acrid. (4) Calcutta ginger resembles African ginger, but has a greater proportion of cork, and yields a higher percentage of ash than the other commercial gingers. (5) Calicut ginger also resembles African ginger. (6) Cochin ginger is a scraped ginger, internally is of a light cream color and exhibits numerous black resin dots. (7) Japan ginger is probably derived from Z. Zerumbet. It belongs to the class of scraped and limed gingers, and has a short and mealy fracture. The resin dots are reddish, and it differs from all the other gingers in having numerous compound starch grains varying from 0.004 to $0.025 \mathrm{~mm}$. in diameter.

The powder of African ginger is dark yellow or dark brown, more aromatic and pungent, and has numerous fragments of cork.

In Japan ginger there are numerous compound grains varying from 0.004 to $0.025 \mathrm{~mm}$. in diameter, while in Calcutta ginger there are numerous spheroidal grains 0.015 to $0.025 \mathrm{~mm}$. resembling those of wheat.

Standard of Purity.-Ginger is the washed and dried, or decorticated and dried, rhizome of Zingiber officinale Roscoe. It contains not less than 42 per cent of starch, not more than 8 per cent of crude fiber, not more than 1 per cent of lime $(\mathrm{CaO})$, not less than 12 per cent of cold water extract, nor more than 7 per cent of total ash, not more than 2 per cent of ash insoluble in hydrochloric acid, nor less than 2 per cent of ash soluble in cold water.

starch grains; $P$, parenchyma cells; $H, F$, hyphæ and spores of a fungus which are usually present in African ginger and easily detected in mounts prepared with sulphuric acid.

In Calcutta ginger occur a large number of spheroidal starch grains resembling those of wheat, and in Japan ginger there are numerous compound grains.

Adulterated ginger may contain fragments of tissues of Capsicum $(Y)$, stone cells of endocarp of olive $(N)$, or tissues of soap bark. 
Jamaica ginger is ginger grown in Jamaica. It contains not less than 15 per cent of cold water extract, and conforms in other respects to the standards for ginger.

Limed ginger, bleached ginger, is whole ginger coated with carbonate of calcium. It contains not more than 4 per cent of carbonate of calcium, nor more than 10 per cent of total ash, and conforms in other respects to the standards for ginger. (U. S. Dept. Agric.)

Adulterants.-Exhausted ginger is sometimes used to adulterate powdered ginger. If the exhaustion has been by means of water the starch grains are somewhat altered. If the extraction has been made with alcohol the light yellowish oleo-resin cells are not so abundant. Ginger, particularly the decorticated varieties, loses, on keeping, part of the pale yellowish oil, being replaced by a reddish, almost insoluble resin. Ginger is also sometimes adulterated with wheat middlings and flaxseed meal. Curcuma is sometimes added to an exhausted or adulterated ginger to bring up the color to that of the normal drug.

Ginger which is bleached by means of sulphur fumes or bleaching powder (chlorinated lime) or that is coated with lime should not be used.

Literature.-Kraemer, Amer. Jour. Pharm., 1908, p. 303; Kilmer, Ibid., 1898, p. 75; Snyder, Amer. Jour. Pharm., 1918, 90, p. 253.

Curcuma.-Rhizoma Curcumæ, Turmeric or Yellow Root.The prepared rhizome of Curcuma longa (Fam. Zingiberaceæ). The plant is cultivated in all tropical countries by methods similar to those used in the cultivation of ginger. The rhizomes are collected at the end of the growing season, cleaned, boiled for some hours and then carefully, but rapidly, dried in the open air. Two commercial forms are recognized and both may be obtained from the same plant: the one known as " round curcuma," being obtained from the swollen internodes which arise from the hypogeous leaf-buds; the other, furnishing the "long curcuma," being obtained from the less fleshy underground branches.

Description.-Cylindrical or fusiform (Curcuma longa or long curcuma) or ovoid and somewhat flattened (curcuma rotundi or round curcuma); from 2 to $5 \mathrm{~cm}$. in length and from 1 to $2 \mathrm{~cm}$. in thickness; outer surface light or dark yellowish-brown, smooth and irregular, marked by root-scars and occasionally by somewhat spira. leaf-scars; heavy and of an almost horny fracture; inner surface orange-yellow with a waxy luster, distinct endodermis and numerous vascular bundles seen either in transverse or longitudinal view; odor aromatic; taste pungent and somewhat bitter. 
Inner Structure.-Epidermal layer of thin-walled cells; occasionally a hypodermal layer of suberized parenchymatous cells; parenchyma of cortex and pith filled with starch paste in which are sometimes seen the long lens-shaped unaltered starch grains; distributed among the parenchyma are the oil cells having suberized walls and in the lumina either orange-yellow globules of a volatile oil or amorphous resinous masses; the endodermis consists of thinwalled partly suberized cells; the vascular bundles are of the collateral type and sclerenchymatous fibers are only occasionally present.

Powder.-Bright yellow. See Fig. 52.

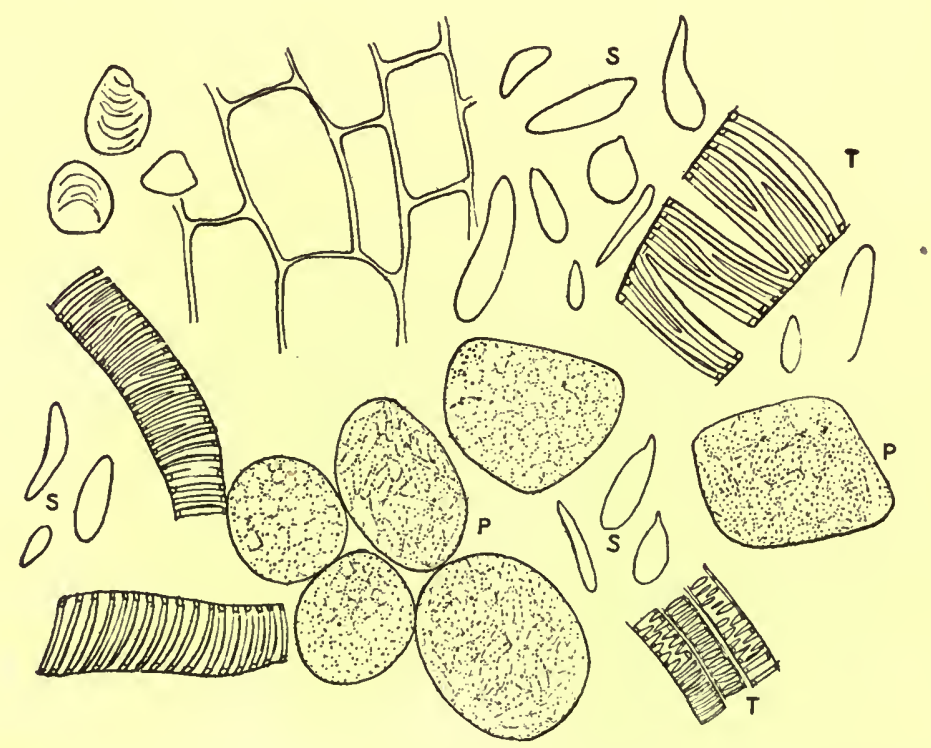

FIG. 52,-Curcuma (Turmeric): $P$, fragments of parenchyma containing swollen and altered starch grains which form an indistinguishable mass within the cells and constitute the greater proportion of the powder; $T$, tracheæ; $S$, unaltered starch grains.

Constituents. - From 1 to 5 per cent of an orange-yellow, somewhat fluorescent volatile oil; about 0.3 per cent of curcumin, which crystallizes in orange-red, short rods or prisms having a beautiful blue refraction, and is freely soluble in alcohol, ether, fixed and volatile oils; from 30 to 40 per cent of starch; 4 to 7 per cent of ash; and a small quantity of a fixed oil.

East Indian Arrowroot.-Also known as Bombay, Malabar, or Tellicherry-Arrowroot is the starch obtained from Curcuma angustifolia and other species of Curcuma. The starch is manufactured in 
the countries of southwestern India. The grains vary in shape from narrow ellipsoidal to broadly ovoid, are somewhat flattened, more or less acute or beaked at one end and possess numerous distinct lamellæ. They vary in size from 0.010 to $0.075 \mathrm{~mm}$. in length. According to Flückiger the grains begin to swell at $72^{\circ} \mathrm{C}$. when heated with water.

ZEDOARIA.-Rhizoma Zedoariæ, Radix Zedoariæ or Zedoary.-The rhizome or tuber of Curcuma Zedoariæ (Fam. Zingiberaceæ), a plant cultivated in southeastern Asia, Madagascar and other tropical countries. The rhizome is collected in Ceylon and Madras, cut transversely into pieces, dried and shipped to Bombay, most of the exported article being sent into market via Trieste.

Description.-In nearly circular disks, from 1 to $4 \mathrm{~cm}$. in diameter and 4 to $10 \mathrm{~mm}$. in thickness; outer corky ay erlight yellowish-brown, roughly wrinkled and marked by circular root-scars or short root bases; cut surface, white, or grayish-white, nearly smooth, with a distinct dark endodermis, numerous orange-colored resin cells and light-colored circular vascular bundles; fracture short, mealy; odor aromatic, camphoraceous; taste pungent and somewhat bitter. The drug and powder are distinguished by the presence of non-glandular hairs, resembling those of matico, attaining a length of $1 \mathrm{~mm}$., consisting of 1 to 6 cells and possessing very thick walls. The starch grains vary from 0.010 to $0.075 \mathrm{~mm}$. in length and very closely resemble those of Zingiber. The oil-secretion cells are suberized and have a colorless and not a yellow content, distinguishing them from those in Zingiber.

Constituents.-From 1 to 1.8 per cent of a cineol-containing volatile oil; a soft resin; 50 per cent of starch; ash, 4.5 to 7 per cent; and small quantities of sugar, fixed oil and mucilage.

In a proprietary preparation said to contain "Latalia radix" it was found that powdered Zeodary had been employed.-Kraemer, Jour. Amer. Med. Assoc., 1908 (Vol. L.) p. 977.

Galanga.-Galangal, Rhizoma Galange, Galgant, Galanga Minor or Lesser Galangal.-The rhizome of Alpinia officinarum (Fam. Zingiberacex), a plant indigenous to and cultivated since ancient times in the countries of Eastern and Southeastern Asia. The sympodially branching rhizome may attain a length of $1 \mathrm{M}$. and is collected from plants that are from 4 to 10 years old. It is cut into small pieces and dried. The commercial supplies are obtained from Hainan and shipped from Shanghai and Hang-Chow, China. 
Description.-Rhizome nearly cylindrical, distinctly branched, from 2 to $10 \mathrm{~cm}$. in length and from 7 to $20 \mathrm{~mm}$. in diameter; externally reddish-brown, annulate from circular scars of bud scales, otherwise nearly smooth and but slightly wrinkled; fracture very tough; cut surface grayish-brown, porous with a very thick cortex, and with numerous brownish-red secretion cells and yellowish vascular bundles; odor aromatic; taste aromatic and pungent.

Inner Structure.-(Fig. 53.) An epidermal layer of several rows of small brownish cells; cortex with starch-bearing parenchyma, numerous brownish secretion cells and collateral vascular bundles, each surrounded by a ring of thick-walled sclerenchymatous fibers; endodermis with thin-walled cells and free from starch; the pith is composed of cells similar to those in the cortex; the tracheæ have either porous walls or scalariform or reticulate thickenings; distributed throughout the parenchyma also occur non-suberized secretion cells which contain a dark brown amorphous substance which is said to resemble tannin or an altered product.

Powder.-Reddish-brown; starch grains numerous, ellipsoidal, ovoid, more or less spatulate (Fig. 53), from 0.010 to $0.045 \mathrm{~mm}$. in length, having a circular point of origin at the broad end and indistinct lamellæ; numerous yellowish-red secretion cells being frequently separated from the starch-bearing parenchyma; parenchyma with porous walls and occasionally without starch; the walls of the tracheæ with adjoining sclerenchymatous fibers are non-lignified; cork cells wanting.

Constituents.-From 0.5 to 1.0 per cent of a cineol-containing volatile oil; a soft acrid resin containing a pungent principle, galangol; three yellowish crystalline principles, alpinin, galangin, and cæmpferid, each occurring to the extent of about 0.1 per cent; starch from 20 to 25 per cent; and ash, containing manganese, 4 per cent.

Cardamomum.-Cardamom.-The fruit of Elettaria Cardamomum (Syn. E. repens) (Fam. Zingiberaceæ), a perennial herb indigenous to Indo-China and cultivated near the Malabar Coast and in Ceylon. The commercial article is obtained from wild plants growing in the southern part of the western coast of Indo-China. The fruit is gathered in autumn-either the entire spike, when some of the fruits have matured, or the full-grown fruits are cuit from the rachis in succession as they ripen; they are bleached by exposure to the sun, sometimes sulphurous acid or steam being also used, after which they are dried and freed from extraneous matter. Seeds which have been discharged from the capsules are inferior to those 
which have been retained. A greater portion goes to Bombay, from where it is estimated that 100,000 kilograms are exported yearly to
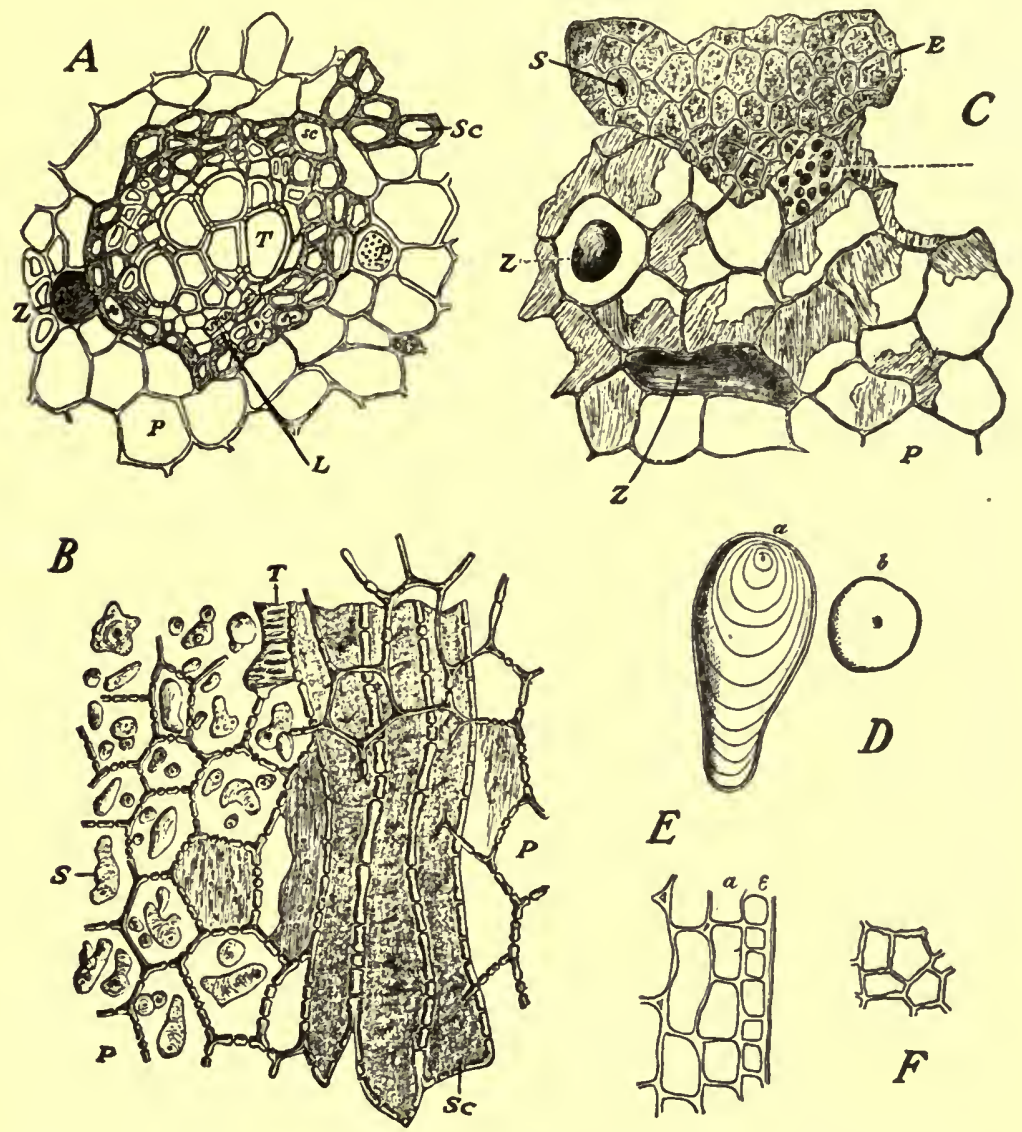

Fig. 53.-Galangal. A, section of a collateral fibrovascular bundle showing leptome $(L)$; tracheæ $(T)$; sclerenchymatous fibers $(S c)$; oil-secretion cells $(Z)$; parenchyma $(P)$. B, longitudinal section of portion of fibrovascular bundle showing portions of reticulate tracheæ $(T)$; sclerenchymatous fibers $(S c)$; porous parenchyma $(P)$; starch grains $(S) . C$, cortical tissue of rhizome seen in surface view showing epidermal layer $(E)$ with a stoma $(S)$; cortical parenchyma $(P)$; secretion cells $(Z)$. $D$, starch grain seen in two views; $a$, when viewed from above, and $b$, as seen in section through the broad end. $E$, transverse section of outer layers showing epidermis (e) and underlying parenchyma $(a) . F$, surface view of epidermal cells. $-C$, after Moeller, the remainder after Meyer.

London. The commercial varieties are known as Malabar and Mysore Cardamom. 
Malabar Cardamom.-Capsule loculicidally dehiscent, broadly ellipsoidal, occasionally ovoid, more or less triangular in transverse section, 10 to $17 \mathrm{~mm}$. long, 6 to $8 \mathrm{~mm}$. in diameter, pericarp about $0.5 \mathrm{~mm}$. thick; externally light brown or faintly pink, summit slightly beaked, and with remnants of style, base rounded, with scar of stalk, longitudinally striate, 3-grooved, 3-valved, 3-locular, dissepiments thin; seeds 15 to 18 in number, anatropous, irregularly angular, enclosed in a thin membranous aril, about $3 \mathrm{~mm}$. long, externally dark reddish-brown, deeply wrinkled, embryo small, straight, endosperm and perisperm distinct; odor aromatic; taste aromatic, pungent.
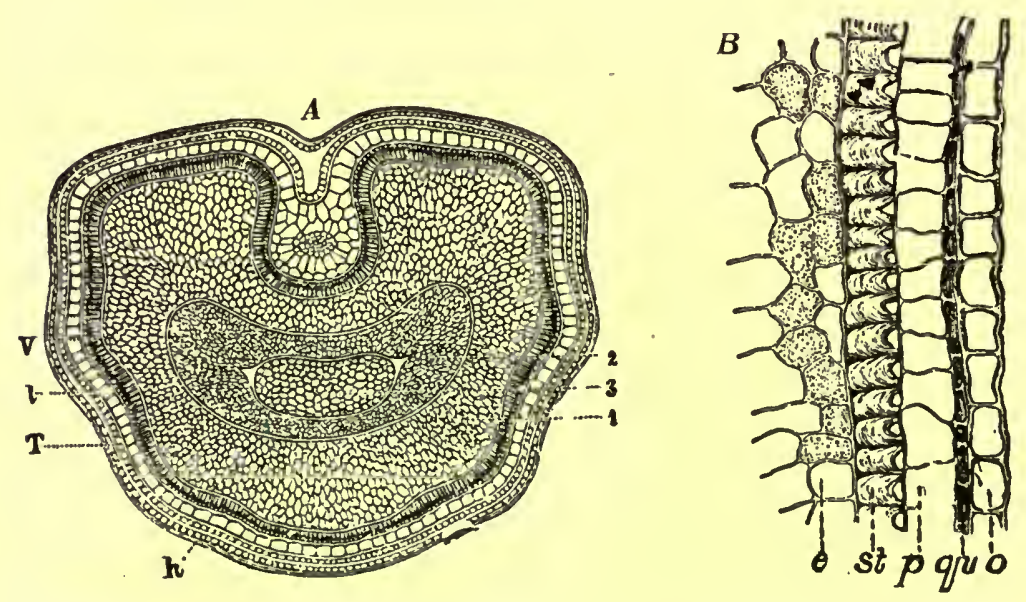

FIG. 54.-Cardamom: $A$, transverse section showing the arillus $(h)$, the several layers of the seedcoat $(T, l, V)$, perisperm (1), endosperm (2) and embryo (3) at the center. $B$, transverse section of the seedcoat and perisperm of Malabar cardamom showing epidermal cells $(o)$, cells having a brown content $(q u)$, cells containing ethereal oil $(p)$, brown stone cells $(S t)$ with very thick inner walls, and perisperm (e), the cells of which contain numerous small starch grains and usually a pair of small crystals which may be seen on treating sections with solutions of hydrated chloral. $-A$, after Meyer; $B$, after Moeller.

Mysore Cardamom.-Ovoid, somewhat oblong, white or very light brown, 12 to $20 \mathrm{~mm}$. long, 7 to $9 \mathrm{~mm}$. in diamèter, nearly smooth or faintly longitudinally striate; seeds 9 to 12 , and less pungent than those of Malabar Cardamom.

Inner Structure.-See Fig. 54.

Powder.-Greenish-trown; stone cells dark brown, slightly elongated, 0.015 to $0.025 \mathrm{~mm}$. in diameter, the inner wall thickened; 
outer epidermal cells 0.020 to $0.030 \mathrm{~mm}$. in diameter, elongated on surface view, inner and outer walls thickened; oil-secretion cells with suberized walls; starch grains spheroidal or angular, single or compound, 0.001 to $0.004 \mathrm{~mm}$. in diameter; monoclinic prisms of calcium oxalate few, 0.010 to $0.025 \mathrm{~mm}$. in diameter. The powder of the pericarp and seeds is pinkish and contains, in addition, sclerenchymatous fibers which are non-lignified, relatively thin-walled and with simple, slightly oblique pores; parenchyma frequently with calcium oxalate crystals. The powder of Ceylon cardamom contains the unicellular hairs of the capsule; and the cells, as also the starch grains and calcium oxalate crystals, are larger.

Constituents.- Volatile oil 4 to 5 per cent, with a penetrating but agreeable odor and a camphoraceous, burning taste; fixed oil 10 per cent; starch about 3 per cent; calcium oxalate; ash 4 to 10 per cent. The pericarp contains about 0.2 per cent of a volatile oil.

Standard of Purity.-Cardamom is the dried, nearly ripe fruit of Etettaria Cardamomum White \& Maton.

Cardamom seed is the dried seed of cardamom. It contains not more than 8 per cent of total ash, nor more than 3 per cent of ash insoluble in hydrochloric acid. (U. S. Dept. Agric.)

Allied Plants.-Ceylon Cardamom is obtained from wild plants of Elettaria major. The capsules are 2 to $4 \mathrm{~cm}$. long and about 10 $\mathrm{mm}$. in diameter, distinctly triangular in transverse section, deeply longitudinally striate and slightly pubescent. In each loculus there are about 20 seeds, which are about $4 \mathrm{~mm}$. long, bitter and less aromatic than the official cardamom.

The so-called bastard cardámoms are yielded by one or more species of Amonum, but these rarely find their way to market.

\section{MARANTACE $Æ$ OR ARROWROOT FAMILY}

Plants of this family are mostly perennial herbs having thick fleshy rhizomes or tubers. They are found mostly in the tropics and are represented by about 150 species. The leaves are long petioled and characterized by a swollen, long, sac-like sheath at the base. Sections of the leaf show a hypodermis with unusually large cells. The petiole of the stem contains large lysigenous lacunæ and in the diaphrams is developed a star-shaped parenchyma. Calcium oxalate occurs in the form of rod-like crystals.

Amylum Marante.-Arrowroot Starch.-The starch grains obtained from the rhizomes of Maranta arundinacea (Fam. Marantaceæ). The plant is indigenous to the West Indies and northern 
part of South America and is now extensively cultivated in nearly all tropical countries. One-year old rhizomes are collected, carefully washed, then beaten into a pulp, mixed with water and the starch removed by filtering through copper sieves; this is then carefully dried and shipped to market in kegs. The commercial supplies come chiefly from St. Vincent and Bermuda. The rhizome yields about 20 per cent of dried starch.

Bermuda Arrowroot occurs in the form of somewhat hard, irregular granules or masses, varying from 1 to $6 \mathrm{~mm}$. in diameter. When rubbed between the fingers it is reduced to a smooth powder, which is velvety to the touch. The starch grains (Fig. 20) vary in shape from ellipsoidal to ovoid or oblong and from 0.010 to $0.065 \mathrm{~mm}$. in diameter. The lamellæ are mostly indistinct and there is usually a transverse or crescent-shaped cleft at the middle or near the broad end of the grain.

St. Vincent arrowroot is slightly darker in color and is in the form of masses or granules, which are sometimes $20 \mathrm{~mm}$. in diameter. The starch grains resemble those of the Bermuda arrowroot, but the grains having clefts are more numerous.

The arrowroot starches all show a distinct cross with the micropolariscope and a marked play of colors when a selenite plate is used.

Maranta starch contains about 10 per cent of water, and less than 1 per cent of ash, the remaining portion consisting chiefly of starch grains except for certain impurities. Owing to the fact that it enters largely into infant and convalescent foods it should be as free as possible from these impurities. Upon boiling 1 part of starch with 10 parts of diluted hydrochloric acid, for ten minutes with occasional shaking of the mixture and filtering, the starch grains should not become agglutinated nor the filtrate mucilaginous or emit an unpleasant odor. When examined on the thermo-stage of the microscope the granules begin to swell at $70^{\circ} \mathrm{C}$. One part of starch heated to $100^{\circ} \mathrm{C}$. with 20 parts of distilled water gives a transparent, mucilaginous mixture which is practically free from odor.

Maranta starch sometimes becomes moldy and should not be used, although Procter stated that he was able to restore musty arrowroot to its original condition by washing it thoroughly in water and then drying.

So-called American Arrowroot consists of one of the other commercial starches, as potato or corn and may be readily detected by means of the microscope (Fig. 20).

The name Arrowroot is applied to the starches obtained from a number of different plants. Tahiti Arrowroot is obtained from Tacca 
pinnatifida; East Indian Arrowroot is prepared from several species of Curcuma; South Sea Island Arrowroot is obtained from several species of Arum and Dioscorea; Brazilian Arrowroot is identical with Cassava or Tapioca starch.

\section{ORCHIDACEE, OR ORCHID FAMILY}

A family of more than 12,000 species and on account of their flowers it is probably the most interesting group in the entire plant kingdom. They are widely distributed, although most abundant in the tropics. They are sometimes classified according to habit of growth as saprophytic, epiphytic and terrestrial. Most of the orchids common to the United States are either saprophytic or terrestrial plants. The epiphytic orchids are characteristic of the tropics and are by far the most valuable of the orchids. They are sometimes spoken of as parasitic, but this is erroneous, as none of the members of this family are parasitic. The stems show a characteristic monocotyledonous structure. Mucilage, in the form of a cell-content, occurs in those genera producing tubers. Similar mucilage cells are also found in the leaves and also in the roots of the epiphytic forms.

Vanilla.-The fruit of Vanilla planifolia (Fam. Orchidaceæ), a perennial climbing plant indigenous to Eastern Mexico, and now cultivated in various tropical islands, including the Seychelles, Mauritius, Java, as well as in the provinces of Vera Cruz and Oaxaca, in Mexico, from whence the best fruit is derived. Most of the vanilla used in the United States comes from Mexico. Some of the Reunion (or Bourbon) fruit is now also entering the market.

The pollination of the flowers of the vanilla plant may be effected by insects but is usually brought about by artificial means (handpollination). The fruits require several months to become fully grown and an equal period of time is necessary for their maturity, which is indicated by their yellow color. They are then gathered and cured by alternately steaming and drying them, when they acquire the dark-brown color and the odor of the commercial article. Vanilla is cultivated in all tropical countries where the temperature does not fall below $18^{\circ} \mathrm{C}$., and the humidity is very great. Usually vanilla culture is combined with that of Cacao. The plants begin to yield fruits the third year and continue bearing for thirty or forty years.

Mexican Vanilla.-Pods narrow, linear, about $20 \mathrm{~cm}$. long, $7 \mathrm{~mm}$. in diameter, $4 \mathrm{~mm}$. thick; summit oblique, with a circular scar; 
base curved or bent, with a slightly enlarged circular scar; externally blackish-brown, longitudinally wrinkled, moist, glossy, sometimes with acicular crystals or monoclinic prisms; pericarp about $1 \mathrm{~mm}$. thick; internally dark brown, 1-locular, with numerous seeds embedded in a dark-colored pulp; seeds anatropous, ovoid, flattened, 0.2 to $0.3 \mathrm{~mm}$. in diameter, black, finely reticulate, reserve layers wanting, embryo shrunken; odor and taste distinct.

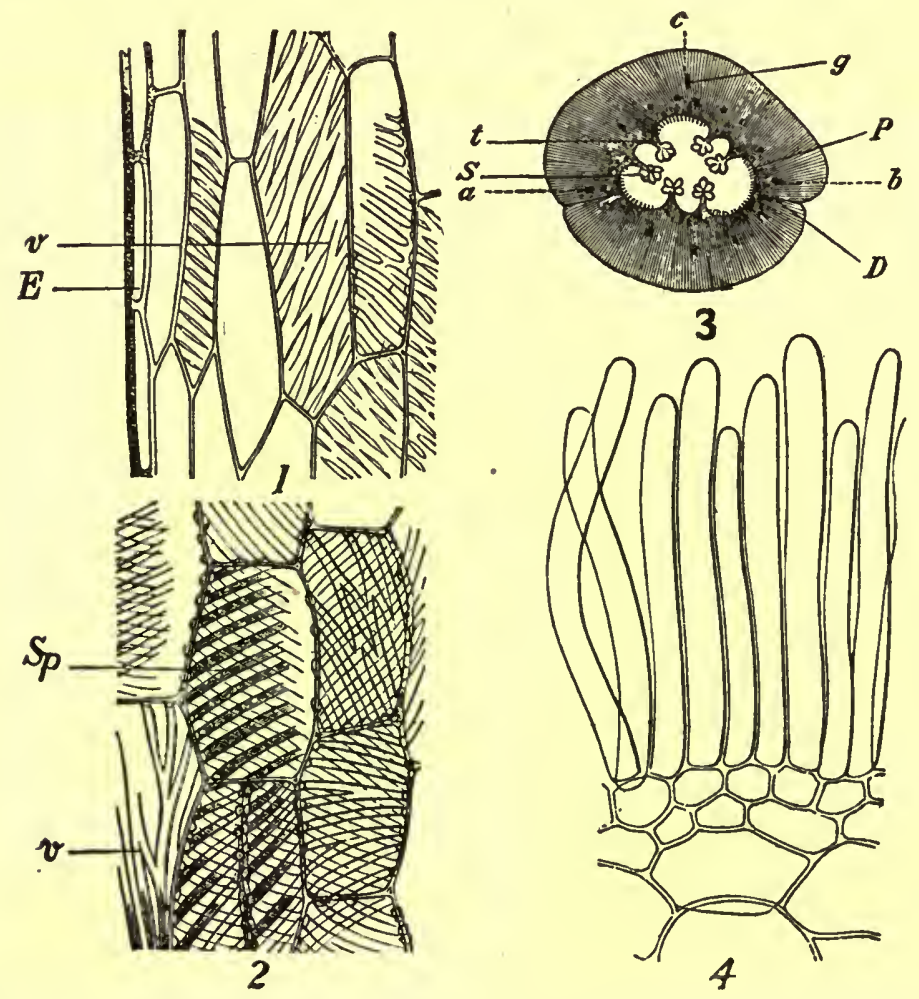

FIG. 55.-Vanilla; 3, transverse section of an unripe fruit showing lines of union of the three carpels $(a, b, c)$, line of dehiscence $(D)$, placenta $(t)$, seeds $(S)$, fibrovascular bundle $(g)$, papillæ $(P)$. 1, radial-longitudinal section of the outer part of the pericarp showing epidermis $(E)$, and parenchyma cells with oblique pores $(v) .2$, tangential-longitudinal section of the outer part of the pericarp showing cells with oblique pores $(v)$ and spirally thickened bands $(S p)$. 4, inner layer of the pericarp showing the very long simple hairs or papillæ.-After Meyer.

Bourbon Vanilla resembles the Mexican Vanilla, but is about twothirds as long and the outer surface is usually covered with crystals. Inner Structure.-See Fig. 55. 
Powder.-(Fig. 56.) Blackish-brown; calcium oxalate in monoclinic prisms 0.007 to $0.035 \mathrm{~mm}$. in length, or in raphides about 0.4 $\mathrm{mm}$. long; occasional unicellular glandular papillæ with rounded summit and containing oil-like globules of a balsam; sclerenchymatous fibers more or less thick-walled, strongly lignified and with numerous oval pores; tracheæ with spiral or reticulate thickenings; minute, black, ovoid seeds about 0.5 in diameter, the structure being apparent only after boiling with chloral solution or solutions of the alkalies. The powder on treatment with a phloroglucin solution

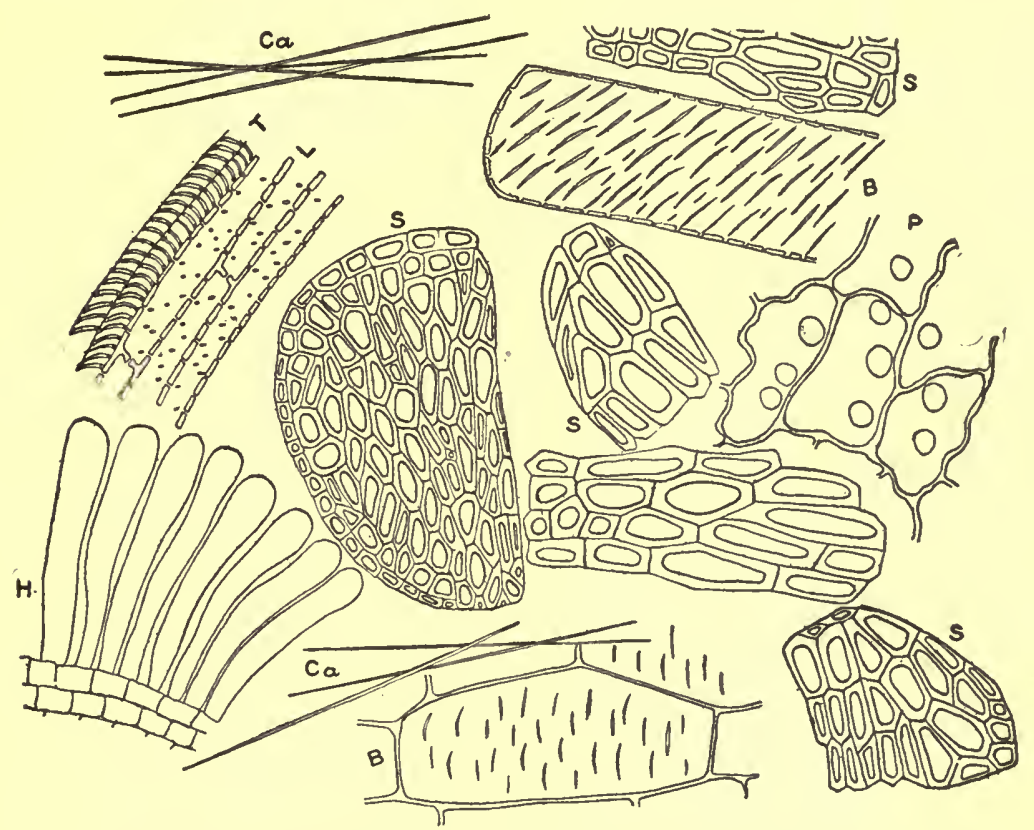

Fıg. 56.-Vanilla: $S$, fragments of seeds showing characteristic stone cells; $B$, parenchyma cells with narrow-elongated simple pores; $P$, parenchyma containing oil globules; $T$, trachex; $L$, lignified cells with simple pores; $C a$, raphides of calcium oxalate; $H$, papillæ-like hairs from the inner surface of the pericarp which are occasionally seen massed together.

and sulphuric acid assumes a deep red color, due to the presence of vanillin.

The powder is frequently admixed with tonka, which is easily determined by the presence of starch grains. Some of the so-called vanilla powders are mixtures containing vanillin or coumarin but none of the tissues of either vanilla or tonka. 
Constituents.-An odorous crystalline principle, vanillin, from - 1.5 to 3 per cent; an odorous, balsamic or resinous principle, which is developed during the process of curing and to which the peculiar odor of vanilla is due; sugar about 10 per cent; fixed oil about 10 per cent; calcium oxalate in raphides; ash about 5 per cent.

Vanillin or methyl-protocatechuic aldehyde is manufactured on a large scale from eugenol or coniferin. It occurs in white, acicular crystals (Figs. 57 and 58), which are sparingly soluble in water, soluble in alcohol and glycerin, the solutions being colored blue with ferric chloride. Vanillin may be formed as a result of certain oxida-

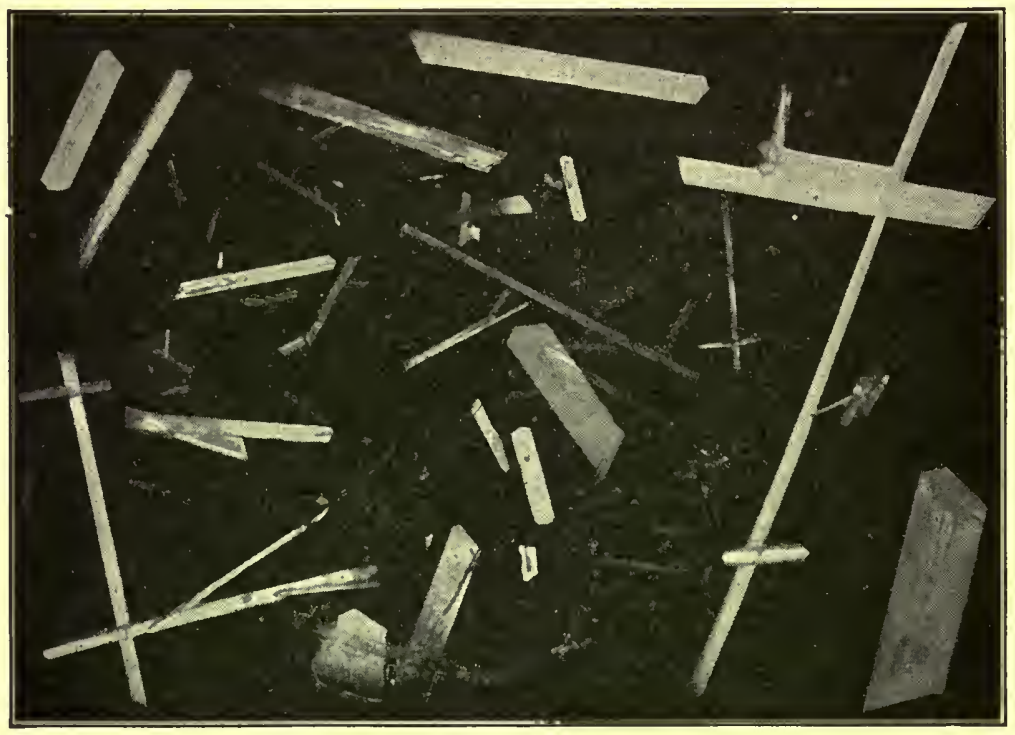

FIg. 57.-Vanillin, orthorhombic crystals obtained from saturated aqueous solutions.

tion changes rather than through the action of a ferment-like emulsior. which, as has been recently shown, does not exist in the fresh pods.

The fruits of a number of species of Vanilla yield vanillin, which is also found in the Orchid, Selenipedium Chica, of Panama; the fruit of Rosa canina, of Northern and Middle Europe; the flowers of Spireæ Ulmaria; the balsams and resins of the genus Toluifera; in the seeds of Lupinus albus, of Europe, which is cultivated; and in the bulbs of Dahlia.

Commercial Varieties.-In addition to the Mexican and Bourbon beans, other varieties are found in the market. Mauritius Vanilla 
occurs in cylindrical pods that are as nearly as long as the Mexican variety, but paler in color and less odorous. Tahiti Vanilla, which is produced on the Island of Tahiti and the Hawaiian Islands, occurs in somewhat broader, flattened pods. The pods are nearly as long as the Mexican variety and sharply attenuated and twisted at the lower portion. The color is reddish-brown and the odor is disagreeable, unfitting it for use for flavoring. Vanillons are the fruits of wild plants and are used in the manufacture of tobacco and sachet powders. They are 10 to $12 \mathrm{~cm}$. long, 1.5 to $2.5 \mathrm{~cm}$. in diameter, gradually tapering towards each end, somewhat triangular in outline, externally, dark-brown to reddish-brown, frequently with transverse markings, due to their being wrapped with twine during the process of curing, when they are spoken of as " braided," and generally longitudinally split; the odor is peculiar, somewhat resembling "heliotrope," and is due to the presence of phenol aldehyde, heliotropin (piperonal) which is closely related to vanillin.

Pompona Vanilla is the fruit of wild and cultivated plants of Vanilla pompona, which is considered to be the original plant from which V. planifolia has been derived by cultivation. The fruits resemble the vanillons in appearance, but the odor is disagreeable, like that of Tahiti Vanilla.

Vanilla splits and cuts represent the more mature fruits in which dehiscence has taken place and which are cut up into short lengths.

Tonka seeds contain the odorous principle coumarin, which somewhat resembles vanillin. The ripe seeds of Coumarouna odorata (Fam. Leguminosæ), growing in the northern part of the Amazon region, furnish Dutch tonka, and C. oppositifolia, of Northern Brazil and Guiana, yields the English tonka. The Seeds are oblong, ovoid, somewhat flattened, 3 to $4 \mathrm{~cm}$. long and about $1 \mathrm{~cm}$. wide, externally nearly black, covered with crystals of Coumarin, the coriaceous testa being deeply wrinkled; internally yellowish-brown, consisting of two plano-convex cotyledons, enclosing a plumule with two pinnately compound leaves and a fleshy radicle which is directed towards the micropyle situated at the rounded end of the seed; the odor is fragrant, and the taste aromatic and somewhat pungent.

Tonka seeds contain 1.5 to 3 per cent of coumarin or orthooxycinnamic anhydride, which forms colorless prisms having a fragrant odor and a bitter, aromatic taste. Coumarin is sparingly soluble in water, but quite so in alcohol. Tonka also contains a large quantity of a fixed oil, irregularly elongated aleurone grains 
Coumarin Vanillin Benzoic Acid.

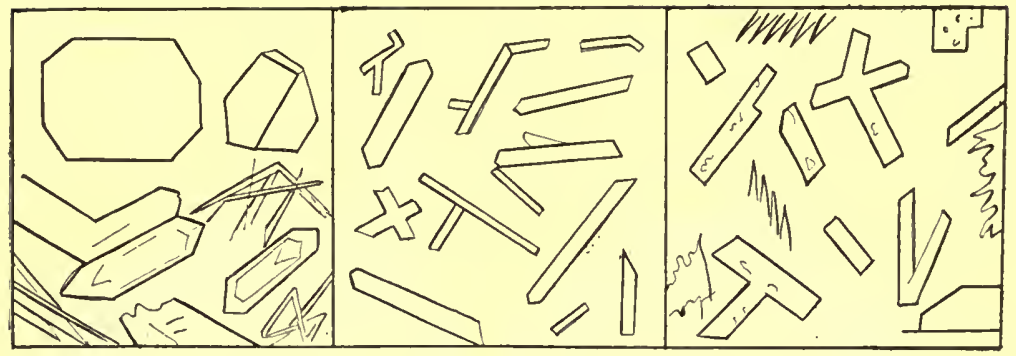

Crystals at Ordinary Temperature.

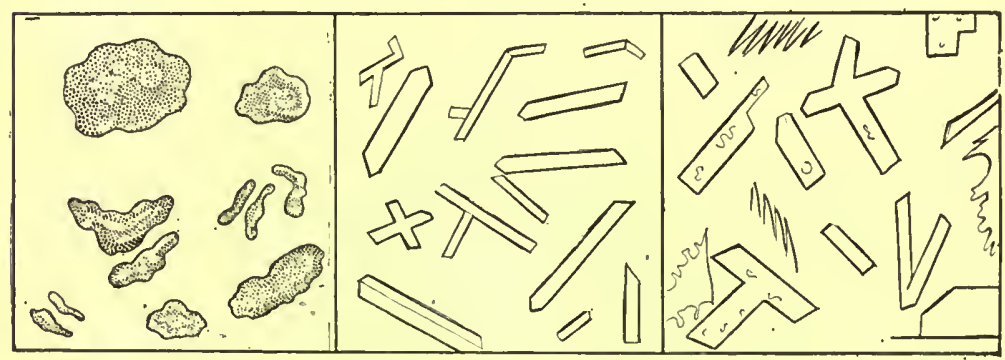

Crystals at 54 to $56^{\circ} \mathrm{C}$.

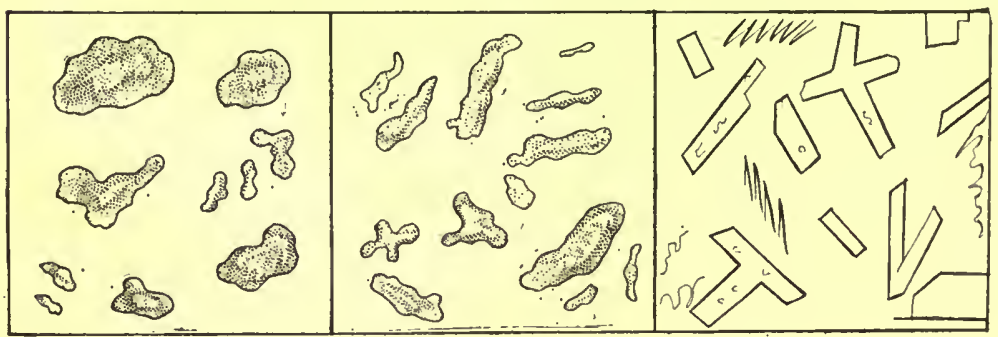

Crystals at $80^{\circ}$ to $82^{\circ} \mathrm{C}$.

FIG. 58.-Examination of crystals by means of a thermo-stage. (1) Crystals at ordinary temperature. (2) Slide heated to $54-56^{\circ} \mathrm{C}$. when Cóumarin melts, the crystals of vanillin and benzoic acid remain normal. (3) Crystals heated from $80-82^{\circ} \mathrm{C}$., at which temperature vanillin melts. 
0.010 to $0.035 \mathrm{~mm}$. long, and spheroidal starch grains from 0.004 to $0.008 \mathrm{~mm}$. in diameter.

Coumarin (Figs. 58 and 59), is rather widely distributed in nature. Of the plants in which it has been found the following may be mentioned: Vanilla grass or sweet vernal grass (Anthoxanthum odoratum); Carolina vanilla or dog's tongue (Trilisa odoratissima), one of the Compositæ; the yellow melilot (Melilotus officinalis), a leguminous herb found in waste places in the Eastern United States
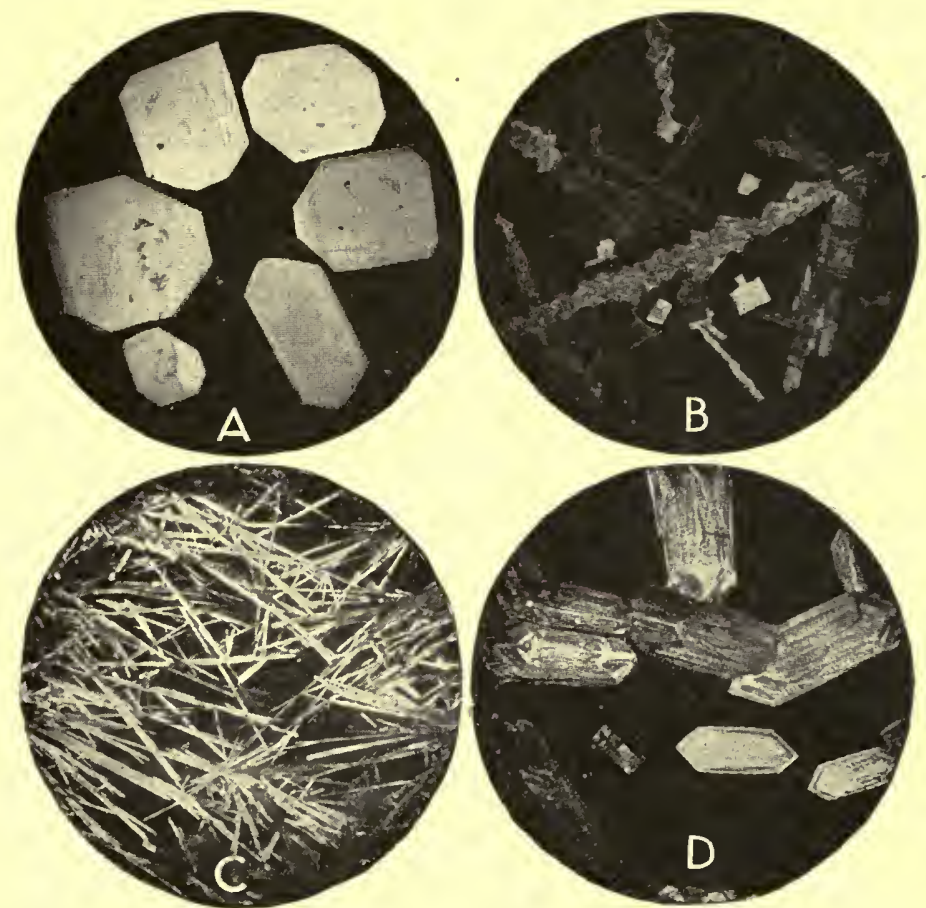

Fig. 59.-Coumarin. Type $A$, tabular crystals obtained by cooling melted coumarin to $54^{\circ}-56^{\circ} \mathrm{C}$; t type $B$, aggregates of tubular crystals: type $C$, needles; type $D$, short prisms obtained from hot aqueous solutions.

and in which it occurs free as well as combined with melilotic acid; other species of Melilotus, as well as in other genera of the Leguminosæ; sweet-scented bed straw (Galium triflorum), an herb of the Rubiacex growing in the United States; the rhizome of Vitis sessilifolia (Vitacex) of Brazil, and in Prunus Mahaleb (Fam. Rosaceæ), of Europe.

A number of the orchids contain coumarin, and these belong chiefly to the genus Orchis, as Orchis odoratissima, of Europe; O. 
coriophora, of Europe and the Orient; O. Simia, of Europe and the Orient; O. militaris, of Europe and Asia; Habernaria conopsea, of Europe and Asia; Aceras anthropophora, of Europe and Arabia.

Cypripedium. - Lady's Slipper. - The dried rhizome and roots of Cypripedium parviflorum (Smaller Yellow Lady's Slipper)
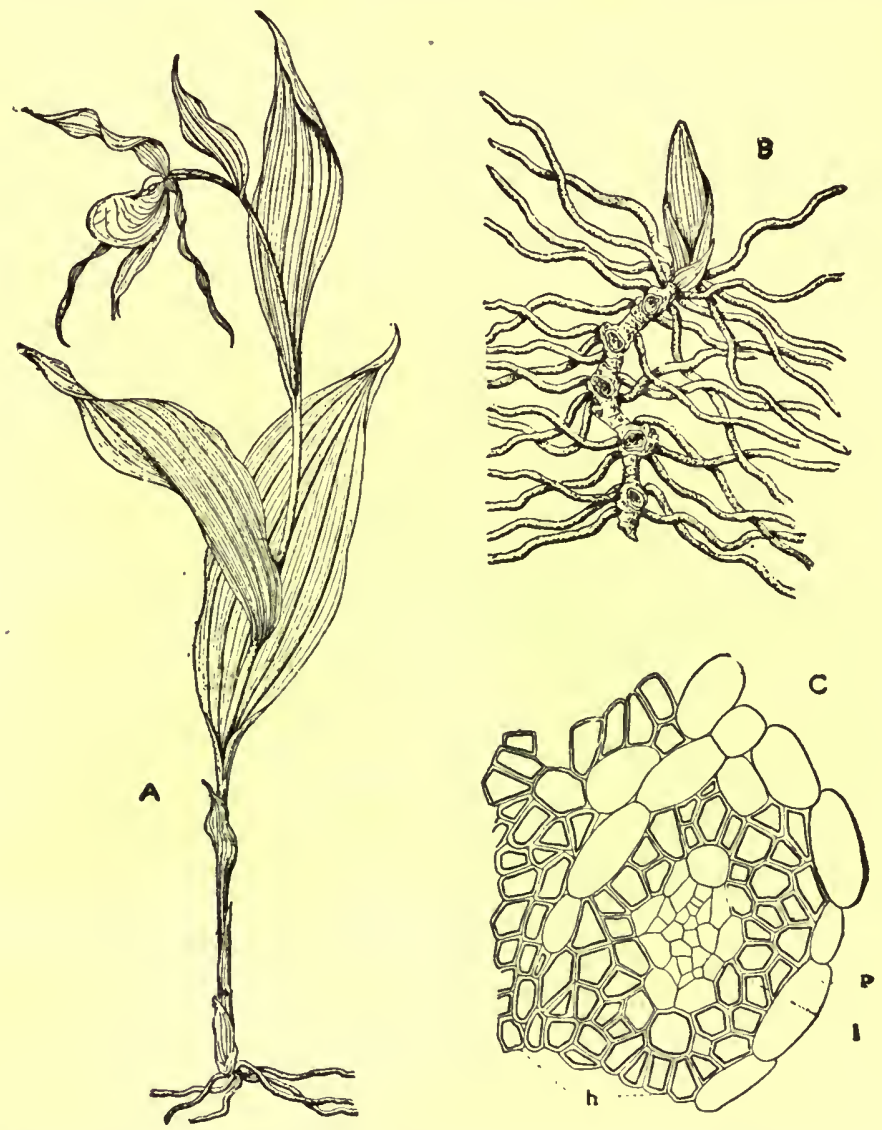

Fia. 60.-Cypripedium parviflorum pubescens. $A$, flowering plant; $B$, rhizome seen from above; $C$, cross-section of a ieptocentric mestome strand from the rhizome showing parenchyma $(p)$, hadrome $(h)$, and leptome $(l)$.-After Holm.

and Cypripedium parviflorum pubescens (Larger Yellow Lady's Slipper) (Fam. Orchidaceæ), perennial herbs (Fig. 60) native in woods and thickets of the Eastern and Central United States and Canada.

Description.-Rhizome horizontal, somewhat tortuous and bent, 3 to $7 \mathrm{~cm}$. long, 2 to $4 \mathrm{~mm}$. in diameter; externally dark brown, annu- 
late from scars of bud-scales, upper surface with numerous large, sometimes repressed scars, under and side portions with numerous roots and few root-scars; fracture short; internally light brown, cortex about $0.5 \mathrm{~mm}$. thick, central cylinder somewhat porous, and with numerous scattered fibrovascular bundles; odor heavy, distinct;
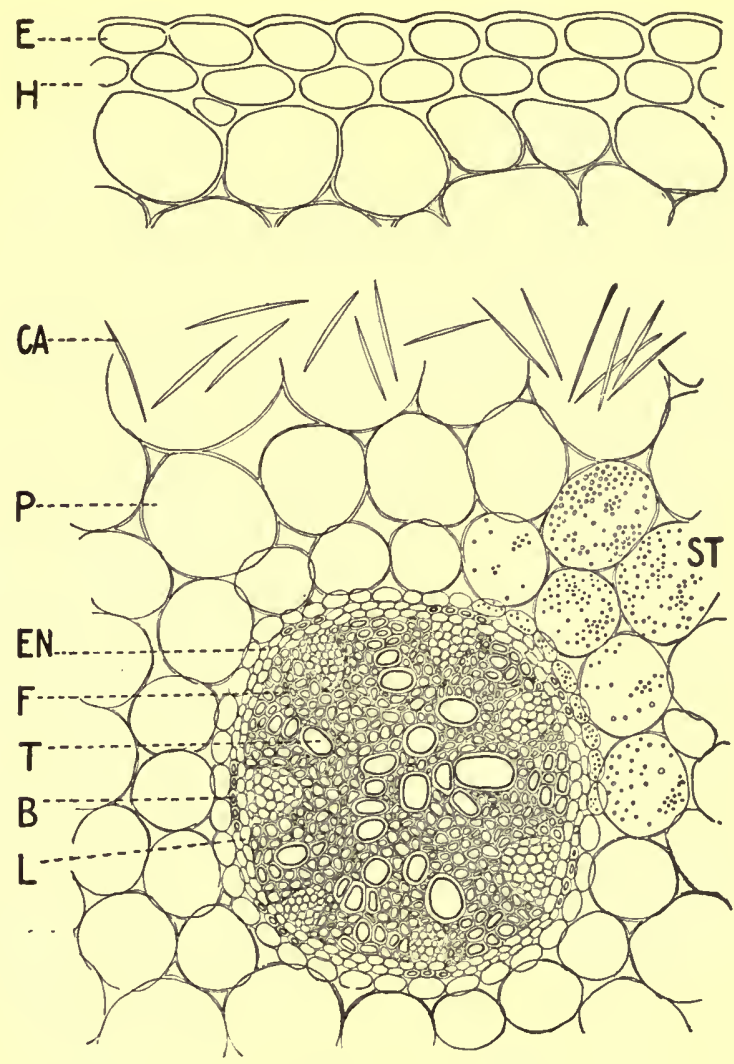

FIG: 61.- Transverse section of central cylinder and portion of cortex of root of. Cypripedium parviflorum pubescens: $E$, epidermis; $H$, hypodermis; $C a$, Raphides of calcium oxalate; $P$, parenchyma containing starch $(S t) ; E n$, endodermis; $F$, lignified sclerenchymatous fibers; $T$, tracheæ; $B$, non-lignified, thick-walled fibers exterior to sieve groups; $L$, peripheral layer of central cylinder. The latter usually consists of 6 to 8 radial fibrovascular bundles.

taste bitter, somewhat pungent. The walls of the endodermal cells are slightly cutinized (Fig. 61). 
Roots 3 to $11 \mathrm{~cm}$. long, 0.5 to $1.5 \mathrm{~mm}$. in diameter; externally light or dark brown, longitudinally wrinkled; fracture somewhat fibrous; internally, cortex white, central cylinder yellowish.

Inner Structure.-See Figs. 60 and 61.

Powder.-Yellowish or brownish-black; calcium oxalate in raphides about $0.040 \mathrm{~mm}$. in length; starch grains somewhat spheroidal, 0.002 to $004 \mathrm{~mm}$. in diameter, single or compound; tracheæ spiral, scalariform or with simple pores; sclerenchymatous fibers long, thin-walled; parenchyma thick-walled, with numerous simple pores.

Constituents.-Volatile oil, several resins, a bitter glucosidal principle, tannin, gallic acid, starch, calcium oxalate in the form of raphides, and ash about 6 per cent.

The principle known as cypripedin is a resinous extract prepared by pouring a concentrated alcoholic tincture into water, collecting the precipitate and mixing it with some absorbent powder. In some cases it is merely an evaporated aqueous extract, but in either case it is practically worthless.

Allied Plants.-The rhizomes and roots of other species of Cypripedium possess properties analogous to the drug just described and of these the following may be mentioned: Cypripedium aretinum, C. candidum, C. hirsutum and C. acaule.

Salep.-Radix Sảep or Tubera Salep.-The fleshy tuberous roots of various species of Orchis and other allied genera (Fam. Orchidaceæ). The tubers are collected from wild plants growing in Asia Minor, southern and southwestern Asia and Germany. At the flowering period the plant has 2 tubers (Fig. 62), the one shriveled and from which the flowering plant is developed and another joined to it from which a new plant will be developed in the following season. Sometimes the commercial article shows both of these tubers; the shriveled one, however, should be rejected and only the young firm and fleshy tubers selected for the market. These are stripped of their brown outer covering, carefully washed, being boiled in order to destroy their vitality and to facilitate drying, which is done in the open air. The commercial supplies are chiefly obtained from Asia Minor, especially the ports of Smyrna and Constantinople.

Description.-Nearly globular, ovoid or somewhat ellipsoidal, more or less compressed; from 1 to $4 \mathrm{~cm}$. in length and from 0.5 to 2 $\mathrm{cm}$. in diameter; externally light yellowish or grayish-brown, somewhat translucent, irregularly furrowed but otherwise nearly smooth, and occasionally with a small conical bud at the summit; hard and of a horny texture; inner surface with numerous scattered vascular 
bundles each surrounded by an endodermis so that no ring of endodermal tissue is present as is characteristic for the monocotyledons; inodorous and very mucilaginous.

Inner Structure.-(Fig. 62). An epidermal layer, when present, of tabular cells, with suberized walls and sometimes developed into long root hairs. The drug consists for the most part of parenchyma either filled with a pasty mass of altered starch grains, or with mucilage cells each containing a bundle of raphides of calcium oxalate. The fibrovascular bundles are of the radial type each being surrounded by a thin-walled endodermis.

Powder.-Yellowish-brown, consisting of the tissues above mentioned.

Constituents.-Mucilage, 48 per cent; starch, 25 per cent; nitrogenous substances, 5 per cent; sugar 1 per cent; ash, from 1.5 to 4 per cent; and a trace of volatile oil.

Adulterants.-The flattened, 2- to 5-branched tubers, known as Radix Palmæ Christi, do not contain as much mucilage and are sometimes seen in the drug of commerce. The Royal Salep of Afghanistan is edible and is derived from Allium Macleanii.

\section{DICOTYLEDONS}

The plants of this group are the highest in the plant kingdom and comprise from two-thirds to three-fourths of the living Angiosperms. They are characterized by having two seed-leaves. These leaves also known as primordial leaves are distinguished from those formed later on the stem known as foliage leaves. The latter are usually reticulately veined, i.e., the veinings forming a network. The flowerparts are arranged in spirals of 2 to 5, and are usually readily distinguished from those of the monocotyledons. The roots and stems are characterized by a distinct wood and bark being formed by a cambium and hence the class is sometimes known as Exogens. The studies on this group of plants have been very extensive and their comparative anatomy is included in an excellent work on "Systematic Anatomy of the Dicotyledons" by Hans Solereder, an English translation of which is available. The general outer morphology of the orders comprising this group are enumerated in Kraemer's Applied and Economic Botany and hence special attention will be given here to generalizations concerning their inner morphology. While, of course, there are some difficulties in framing hard and fast rules, yet the considerations here given will be found very helpful in practice when identifying unknown drugs. 

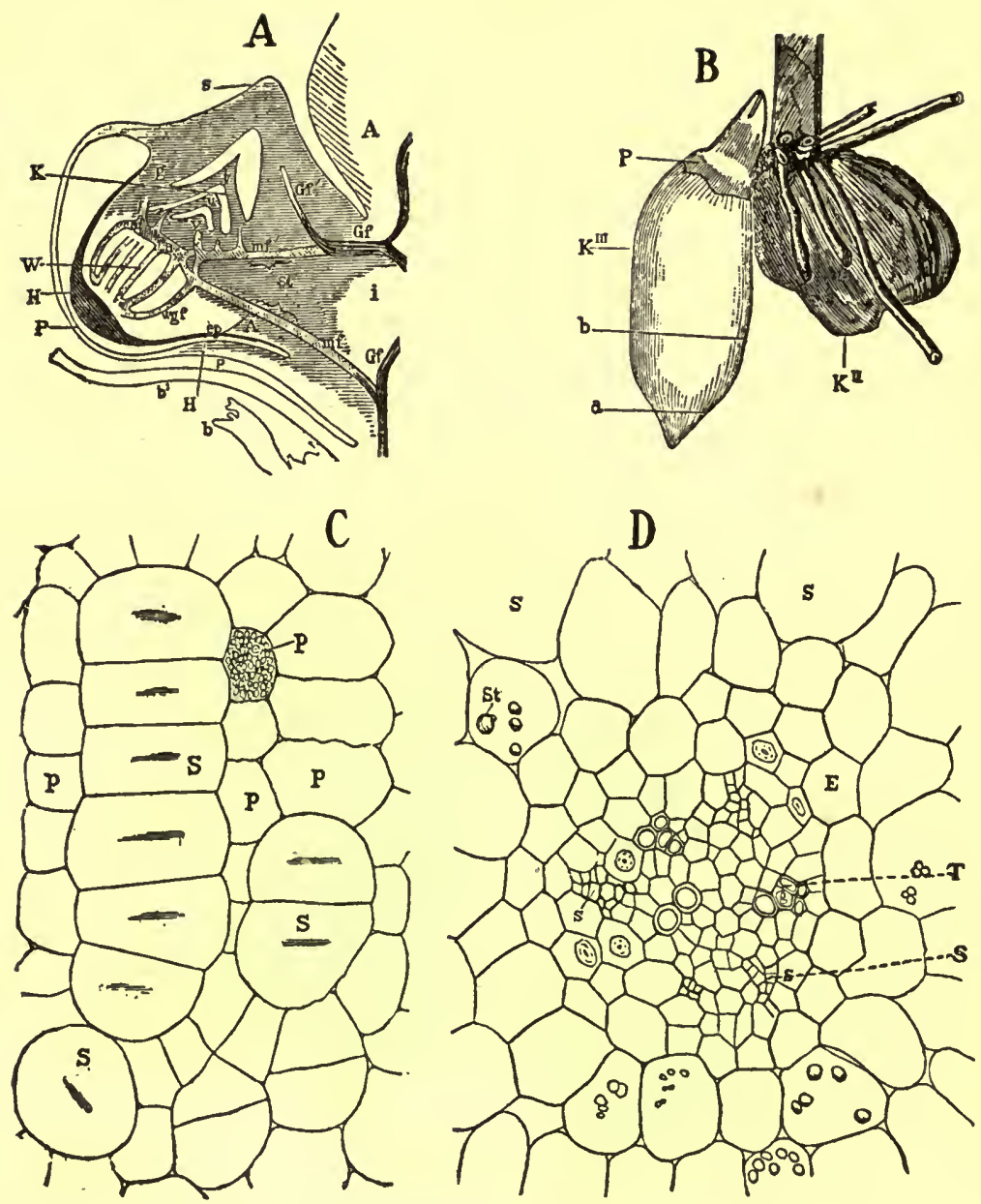

Fia. 62.-Salep. $A$, longitudinal section through the middle of a young tuberous root or tuber, showing portion of the old tuber $(A)$ and the vascular bundles (Gf) connecting the two tubers, and the following parts of the young tuber; $s, b, u$, bud scales; $w$, root; $h$, root-cap, the whole being developed within the tissues of the axis of the mother tuber in a kind of sac $(P) . \quad B$, a pair of tubers, the one on the right being the parent tuber, and that on the left the young tuber from which the new plant will be developed in the coming season. The latter shows the remains of the sac-like scale $(P)$ and through which the tuber has developed. $C$, longitudinal section through some of the parenchyma cells $(P)$ showing the mucilage cells $(S)$ with their small bundles of raphides. $D$, a radial vascular bundle showing the alternating plates of leptome $(S)$ and tracheæ $(T)$.-After Meyer. 


\section{PIPERACEE, OR PEPPER FAMILY}

Mostly herbs and shrubs which are characterized by having secretory cells in the stems and leaves. In the latter they are conspicuous as small transparent dots. The secretory cells are spheroidal in shape, with suberized walls that contain a whitish or brownish-red secretion. The leaves are all bifacial in structure, the stomata occurring only on the lower surface being usually surrounded by a cluster of epidermal cells in the form of a rosette. Both non-glandular and glandular hairs may be present. Calcium oxalate occurs in the form of raphides, rosette aggregates or micro-crystals. The tracheæ possess either simple pores or scalariform thickenings. There are four types of vacular bundles in the stems of the plants of this family.

Piper.-Black Pepper.-The fruit of Piper nigrum (Fam. Piperaceæ), a woody, perennial climber, indigenous to Cochin China and various parts of India and cultivated in the East Indies, West Indies and other tropical countries. The fruit is gathered when full grown, removed from the rachis and dried in the sun. The commercial supplies are obtained from plants cultivated in Java, Sumatra and other islands of the Malay Archipelago, the principal points of export being Batavia and Singapore. The latter furnishes the best grade of black pepper and as it is dried by artificial heat it has a somewhat smoky odor and taste. The most of the other black peppers or peppercorns are dried in the sun.

Description.--Drupe dry, superior, nearly globular, 4 to $6 \mathrm{~mm}$. in diameter, epicarp very thin, easily separable from the sarcocarp; externally blackish-brown, coarsely reticulate, summit with remains of sessile stigma, base with scar of pedicel, sarcocarp and endocarp dark brown and with numerous longitudinal veins; seed atropous, broadly ovoid, 4 to $5 \mathrm{~mm}$. in diameter, externally reddish-brown, micropylar end pointed, chalazal end marked by a small scar; internally yellowish-green; perisperm large and usually with a cavity near the middle $1 \mathrm{~mm}$. or more wide, the endosperm small, situated at one end of the fruit and embryo small, frequently more or less shriveled; odor aromatic, slightly empyreumatic; taste aromatic and pungent.

Inner Structure.-(Fig. 63). The epicarp consists of a layer of polygonal cells with dark brown content; beneath this, one or more interrupted rows of strongly lignified, more or less radially elongated stone cells occur; the sarcocarp contains a more or less interrupted layer of oil cells with suberized walls; the endocarp consists of characteristic stone cells, which are horse-shoe shaped, the inner and radial 
walls being thickened and commonly referred to as "beaker cells." The perisperm consists chiefly of radially elongated cells containing numerous starch grains which are 0.002 to $0.006 \mathrm{~mm}$. in diameter; some resin cells; cells containing needle-shaped crystals of piperine, and in the outer layers small aleurone grains.

Powder.-(Figs. 63 and 64.) Grayish-brown; stone cells nearly isodiametric, uniformly thickened or with only three walls thick. ened, the contents consisting of yellowish-brown tannin masses,

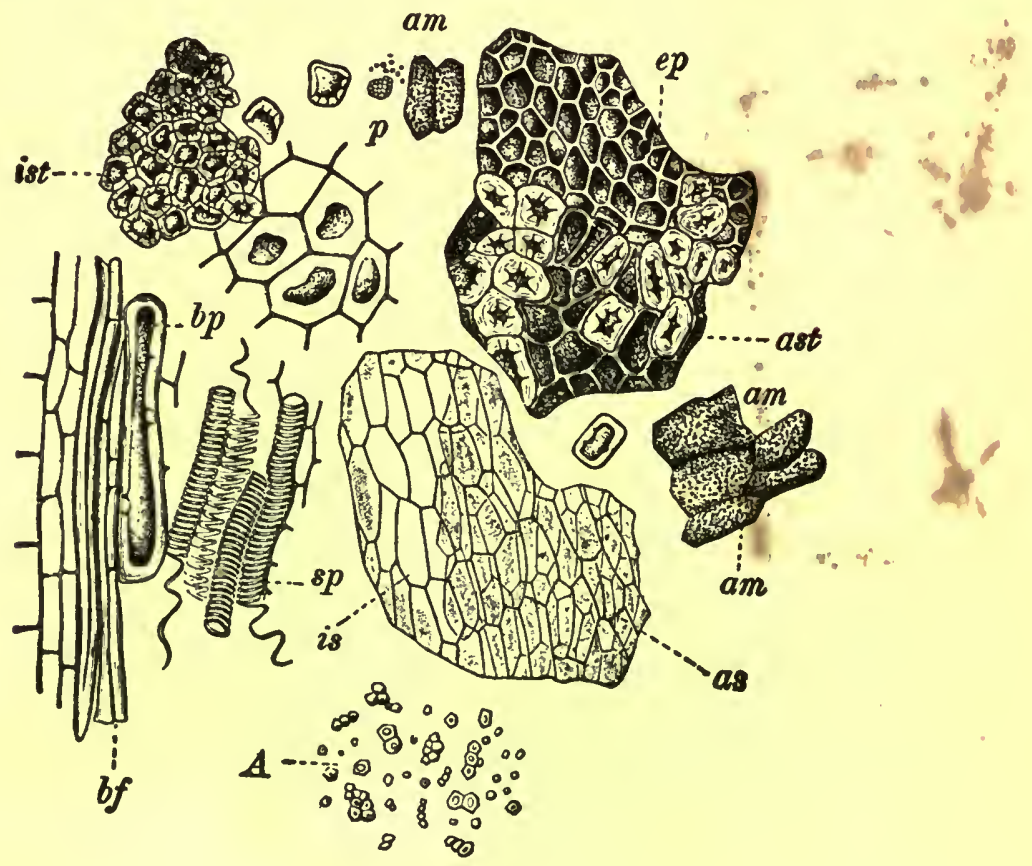

FIG. 63.-Black pepper: $e p$, polygonal cells of the epicarp, beneath which are the hypodermal stone cells ( $a s t)$; $b f$, elongated bast fibers; $b p$, short bast fibers; $s p$., tracheæ with spiral markings; $i s t$, stone cells of the endocarp; $i s$, "as, fragments of tissues beneath the endocarp; am, parenchyma cells of the perisperm containing stareh grains; $A$, starch grains; $p$, oil cells. $\rightarrow$ After Moeller.

which give a blue reaction with ferric ammonium sulphate solution; starch grains spheroidal or angular, from 0.001 to $0.003 \mathrm{~mm}$. in diameter; parenchyma with remains of chromoplastids and reddishbrown amorphous masses; oil-secretion cells with suberized walls; oil globules numerous.

Constituents.-Volatile oil 1 to 2 per cent, containing dipentene, phellandrene and a peculiar terpene; the alkaloid piperine, 4.5 to 


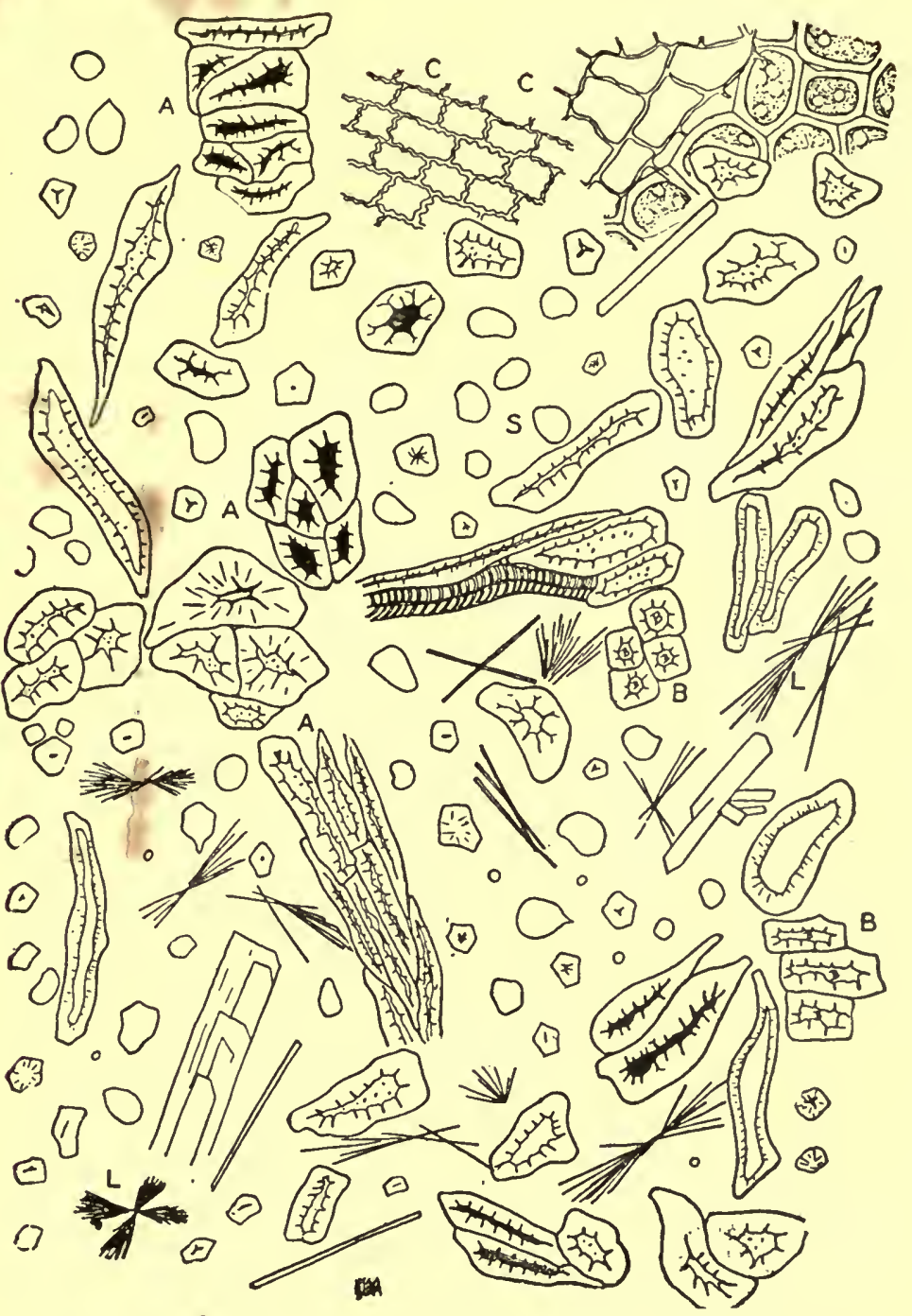

Fig. 64.-A mixture sold as ground black pepper: $A$, stone cells of olive endocarp; $S$, corn and wheat starch grains; $B$, stone cells of pepper hulls; $C$, fragments of seed coat and pericarp of cayenne pepper; $L$, crystals of calcium sulphate which separate on mounting the specimen in 25 per cent sulphuric acid. 
8 per cent, which crystallizes in colorless, tasteless, 4 -sided prisms which are colored bright green by means of concentrated sulphuric acid and formaldehyde, and with potassium hydrate or sulphuric acid give a red color; piperidine, a colorless liquid alkaloid, which is a derivative of piperine, about 0.5 per cent; a pungent resin, chavicin; starch, 25 to 40 per cent; tannin; proteins, about 10 per cent; ash, about 5 per cent.

Black pepper should yield not less than 6 per cent of a non-volatile ether extract nor less than 25 per cent of starch. The ash should be not more than 7 per cent, of which only 2 per cent is insoluble in hydrochloric acid. The crude fiber should be not more than 15 per. cent.

Piperine is rather easily prepared from white pepper as follows: The ground pepper is mixed with an equal weight of lime and a small quantity of water is added. The mixture is heated to boiling for about fifteen minutes, and is then evaporated and carefully dried upon a water-bath. The residue is powdered and extracted with ether. The ethereal solution contains the piperine, which separates in the form of crystals. It is purified by recrystallization from hot alcoholic solutions.

Piperine is a weak base, dissolving in dilute acids without forming salts and on this account may be separated from acid solutions with petroleum ether. It forms crystalline double salts with platinic chloride, mercuric chloride and iodin-potassium-iodide. At $25^{\circ} \mathrm{C}$. one part of piperine is soluble in 15 parts of alcohol; 36 parts of ether and 1.7 parts of chloroform. It is nearly insoluble in water. The individual crystals formed on a microscopic slide from hot alcoholic solutions of piperine vary in length from $0.1 \mathrm{~mm}$. to $1.5 \mathrm{~mm} .{ }^{1}$ Isolated aggregates are also formed. As in cubebin we find numerous oily-looking drops of the amorphous substance, but with piperine they often have the outline of crystals, as if the latter were first formed, and later transformed by fusion or otherwise into the amorphous material. On the other hand the crystals grow, on long standing, at the expense of the drops. In sections of the crude drug it is not at all uncommon to find in the oil secretion cells the characteristic crystals of piperine.

Standard of Purity.-Black pepper is the dried immature berry of Piper nigrum L. It contains not less than $6 \frac{75}{100}$ per cent of nonvolatile ether extract, not less than 30 per cent of starch, nor more than

${ }^{1}$ For micro-photographic illustration of crystals of piperine, consult Kraemer's Applied and Economic Botany, pp. 161, 771. 
7 per cent of total ash, nor more than 1.5 per cent of ash insoluble in hydrochloric acid.

Ground black pepper is the product made by grinding the entire berry of Piper nigrum L. It contains the several parts of the berry in their normal proportions.

Long pepper is the dried fruit of Piper longum $\mathrm{L}$.

White pepper is the dried mature berry of Piper nigrum L., from which the outer coating, or the outer and inner coatings have been removed. It contains not less than 7 per cent of non-volatile ether extract, not less than 52 per cent of starch, not more than 5 per cent of crude fiber, not more than 3.5 per cent of total ash, nor more than 0.3 per cent of ash insoluble in hydrochloric acid. (U. S. Dept Agric.)

Allied Products.-The fruits of Piper nigrum are sometimes allowed to ripen and the epicarp is separated by hand or machinery after the fruits have been soaked in salt water or lime water. The fruits are then known as white peppercorns or white pepper, are nearly smooth, of a light gray or yellow color, and, while less aromatic and pungent than the black pepper or black peppercorns, possess a fine flavor. White pepper yields 3.9 to 6.47 per cent of piperine.

Piper longum, a shrub indigenous to the Malay Archipelago, yields the so-called "long pepper," which consists of the entire spikes of the immature fruit; the spikes are cylindrical, from 2.5 to $4 \mathrm{~cm}$. long, about $5 \mathrm{~mm}$. thick, of a grayish-black color, and the drupes are less aromatic and pungent than the official pepper. In structure long pepper is distinguished by the absence of oil cells in the sarcocarp, and "beaker cells" of the endocarp, and the larger starch grains $(0.002$ to $0.010 \mathrm{~mm}$. in diameter) in the perisperm. Long pepper yields about 1 per cent of a volatile oil with the pungent taste of the oil of pepper but an odor resembling that of ginger; and about 4.24 per cent of piperine.

Long pepper is also obtained from Piper officinarum, of Java, India and the Philippine Islands; Piper sylvaticum, of Eastern India; Chavica officinarum, of the West Indies; and Pepperonia acuminata, of Peru.

Adulterants.-The poorer black peppers, known as Acheen pepper, are light in weight, consist more or less of shells and are usually considerably broken. They are frequently contaminated with stems, earth and small stones. Penang white pepper has a grayish color and is coated with a substance containing considerable calcium carbonate. Pepper hulls or pepper shells, representing the broken pericarp of the fruit obtained in the preparation of white 
pepper, consist of small grayish-black fragments, containing numerous stone cells, and they yield a high percentage of fiber and ash.

Ground black pepper is sometimes adulterated with pepper hulls or pepper shells, which are the outer layers of the ripe fruit and are obtained in the preparation of white pepper. Pepper hulls consist chiefly of the stone cells described above. They increase the percentage of crude fiber and ash in the powder, the latter being due to adhering dirt. Ground black pepper sometimes consists of a mixture of pepper hulls, capsicum and the endocarp of the olive (Fig. 64). In the latter the lumen of the stone cells is filled with air. Black pepper has also been adulterated with flaxseed meal and buckwheat hulls. The latter are distinguished by the epidermal cells with peculiar diagonal thickening of the walls and the hypodermal fibers which have thick, porous walls and brown contents.

Substitutes.-The fruit of Embelia ribes (Fam. Myrsinaceæ), a small tree of India, has been used as an adulterant of both pepper and cubeb. The blackish drupes resemble black pepper. They are very aromatic and yield a principle, embelic acid, which crystallizes in golden-yellow prisms, the alcoholic solution of which is colored red with ammonia.

The fruit of Polyadenia pipericarpa (Fam. Lauraceæ), of Sumatra, is also used in place of pepper. The fruits of a number of species of Xylopia (Fam. Anonaceæ) contain aromatic and bitter principles, some of these being used as a condiment like pepper, as $\mathrm{X}$. æthiopica, which are also used as a medium of exchange by the natives of Uadai (Africa), and X. grandiflora, X. sericea and X. frutescens of Brazil. $\mathrm{X}$. aromatica yields the Guinea pepper.

Literature.-Kraemer and Sindall, Amer. Jour. Pharm., 1908, p. 1; Molisch, Grundriss einer Histochemie der Pflanzlichen Genussmittel, (1891), pp. 27-29.

Matico.-The dried leaves of Piper angustifolium (Fam. Piperaceæ), a shrub indigenous to Peru and Boliva.

Description.-Usually in large, compressed, matted masses; lamina narrow, oblong-lanceolate, 10 to $20 \mathrm{~cm}$. long, 2 to $5 \mathrm{~cm}$. broad; summit acute and long-tapering; base unequal, slightly cordate; margin finely crenulate, with broad, truncate teeth; upper surface dark green, tessellated, harsh to the touch from the presence of numerous very small papillæ and minute, bristly hairs; lower surface grayish-green, reticulate, matted-hairy, velvety to the touch, the veins being very prominent and yellowish-brown, those of the first order diverging at an angle of $65^{\circ}$ to $80^{\circ}$, then curving and converging at the summit; petiole 2 to $3 \mathrm{~mm}$. long, texture fragile when 


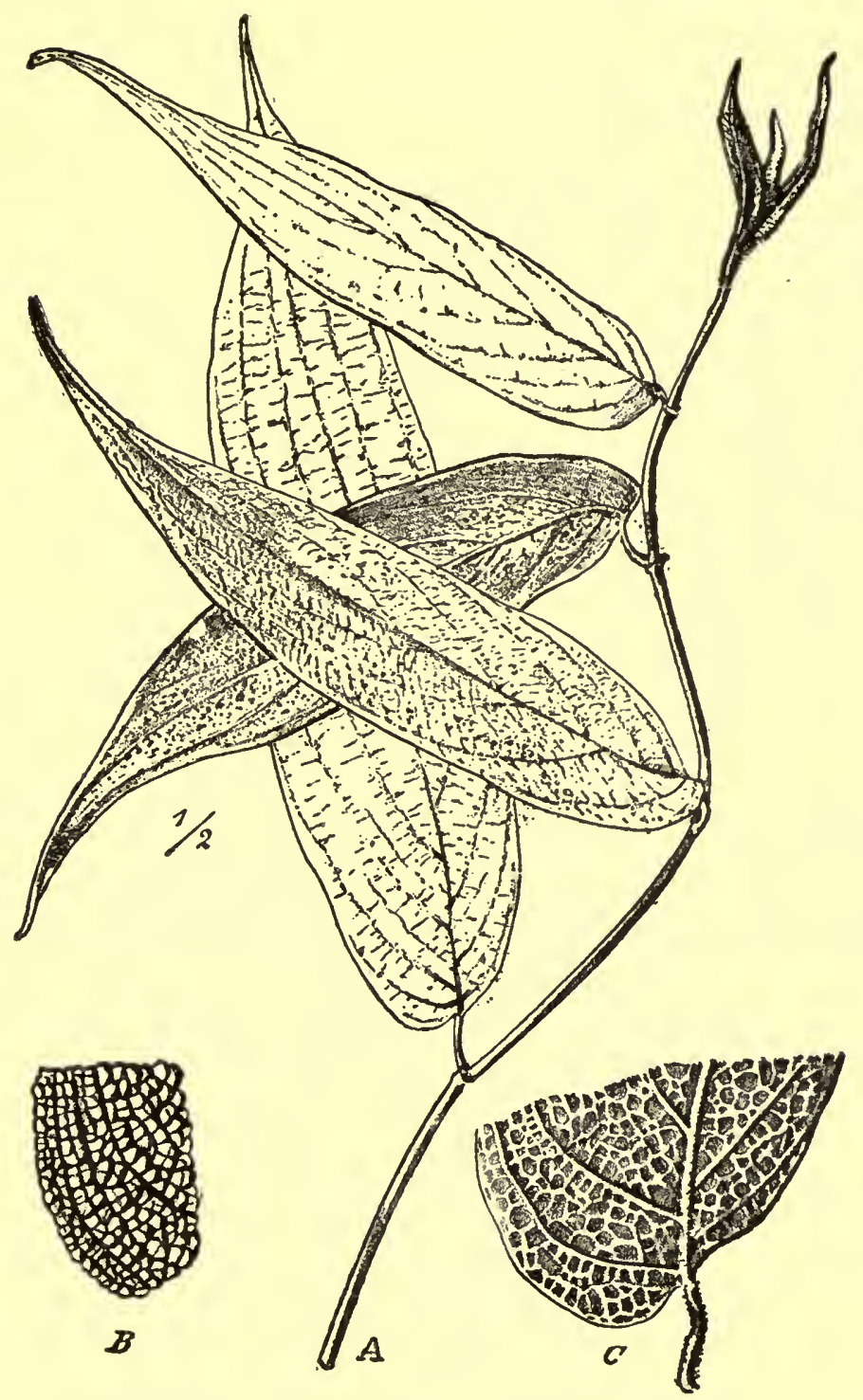

FIG. 65.-Matico. A, branch of Piper angustifolium. $B$, fragment showing upper surface. $C$, fragment showing petiole and lower deeply reticulate surface.-After Thoms. 
dry; odor pronounced, aromatic; taste aromatic, pungent, pepperlike.

The drug is generally admixed with the flower spikes, which are 2.5 to $15 \mathrm{~cm}$. long and about $2 \mathrm{~mm}$. in diameter, yellowish-brown, and consisting of very small perfect flowers, which are subtended by bracts fringed on the margin with long, multicellular, non-glandular hairs; or the spikes may bear the mature fruits, consisting of somewhat cubical or tetragonal, reddish-brown drupes, which are 0.5 to 1 $\mathrm{mm}$. in diameter and finely reticulate, somewhat like the seeds of lobelia.

A few of the jointed stems with swollen nodes are also present. Inner Structure.-See Fig. 66.

Powder.-(Fig. 66). Grayish-green or greenish-yellow; nonglandular hairs numerous, 1 - to 6-celled, varying from 0.2 to $1 \mathrm{~mm}$. in length, with walls 0.002 to $0.004 \mathrm{~mm}$. thick and striate, the apical cell being sharply pointed; numerous globular, yellowish or reddish resin masses in oil glands of leaf; fragments of perianth with fanshaped upper portion, composed of numerous long, non-glandular hairs, which are much collapsed and deeply striate; seeds reddishbrown and distinctly reticulate.

Constituents.-From 2 to 3 per cent of a volatile oil, containing a stearoptene matico camphor, which appears to be the most important constituent. It also contains an acrid resin, a bitter principle and a crystalline principle artanthic acid.

Adulterants.-The drug is frequently admixed with, or entirely substituted by, other species of Piper. Of these may be mentioned P. camphoriferum (the oil of which contains borneol and camphor), P. lineatum, P. angustifolium Ossanum, P. acutifolium subverbascifolium, P. molliconum and P. asperifolium.

Matico has also been substituted by the leaves of Eupatorium glutinosum, Fam. Compositæ. The latter are opposite, having a serrate margin and cordate base. (U. S. Dept. Agric.)

Literature.-Thoms, Arbeiten d. Pharm. Institut d. Universität Berlin, 1910, p. 70.

Cubeba.-Cubeb Berries.-The fruit of Piper Cubeba (Fam. Piperaceæ), a woody climber, indigenous to Borneo, Java and Sumatra, where it is apparently also cultivated. The fruit is gathered when full grown but still green, and carefully dried in the sun, the commercial supplies being shipped from Batavia and Singapore.

Description.-Drupe dry, superior, globular, 4 to $6 \mathrm{~mm}$. in diameter, with a straight, slender peduncle 5 to $7 \mathrm{~mm}$. long; externally dark brown, coarsely reticulate summit with remains of 3 to 


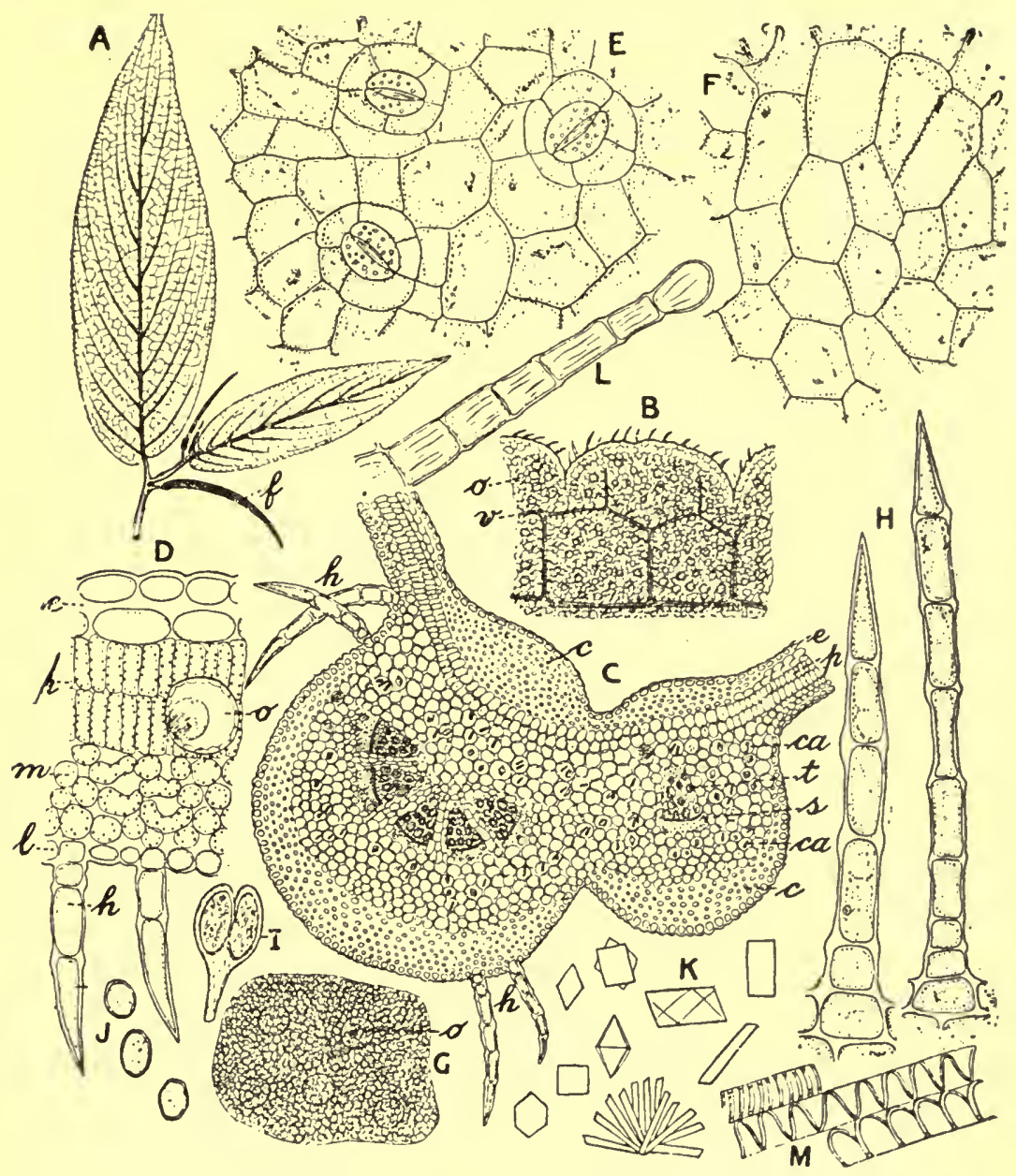

FIg. 66.-Matico. $A$, branch with lcaves and flower spikes $(f) ; B$, section of leaf showing one of the truncate tecth, fibrovascular bundle $(v)$, oil-secretion reservoirs $(o) ; C$, transverse section of leaf near two veins, showing upper epidcrmis of several layers $(e)$, palisade cells $(p)$, tracheæ $(t)$, sieve $(s)$, collenchyma $(c)$, loose parenchyma containing crystals of calcium oxalate $(c a)$, hairs $(h) ; D$, transverse section of leaf showing in addition an oil-secretion reservoir $(o) ; E$, portion of lower epidermis showing three stomata; $F$, portion of upper epidermis; $G$, portion of leaf showing the glandular-punctate character due to the oil-secretion reservoirs $(o) ; H$, non-glandular hairs; $I$, stamen; $J$, pollen grains, which are about $0.010 \mathrm{~mm}$. in diameter; $K$, prisms of calcium oxalatc; $L$, a hair from the perianth; $M$, trachex from the stem with spiral and annular markings. 
4 stigmas; pericarp about $0.3 \mathrm{~mm}$. thick; internally light brown, smooth, oily, 1-locular, 1-seeded; seed atropous, broadly ovoid, 4 to $5 \mathrm{~mm}$. in diameter, reddish-brown, straight, mostly smooth on one side where it lies against the pericarp, chalazal end with a broad scar, micropyle with a slight depression, a small embryo at the upper end of the reserve layer; odor distinct; taste aromatic and pungent.

Inner Structure.-See Fig. 67.

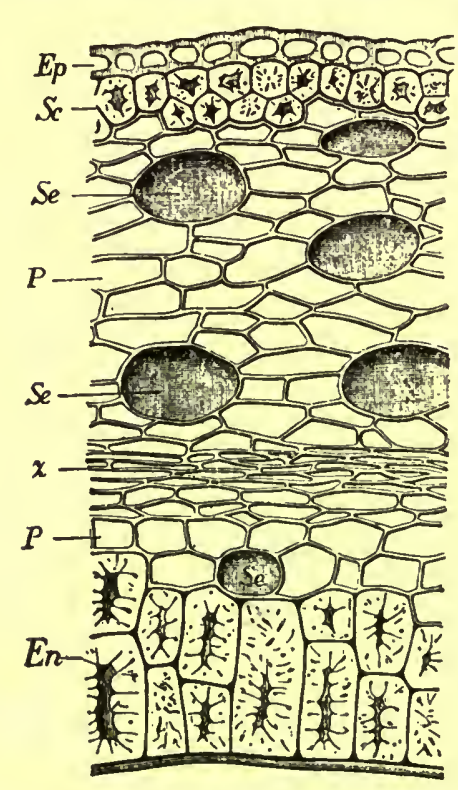

A

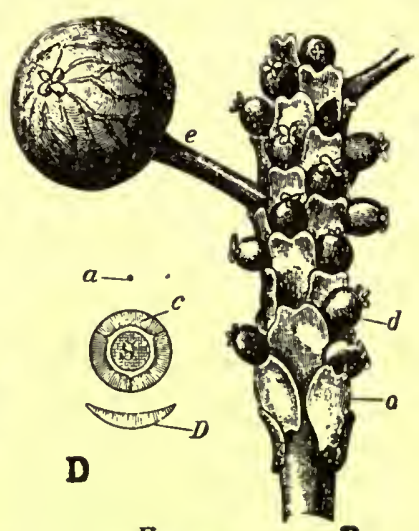

B

FIG. 67.-Cubeb: $A$, transverse section of the pericarp showing epidermis $(E p)$, stone cells $(S c)$, oil cells $(S e)$, parenchyma $(P)$, collapsed parenchyma tissue $(z)$, endocarp $(E n)$ composed of stone cells. $B$, spike showing bracts $(o)$, young sessile fruits $(d)$, and a mature fruit with long pedicel $(e) . C$, longitudinal section of mature fruit showing pericarp $(i)$, union $(l)$ of seed and pericarp, large perisperm $(k)$, small endosperm $(m)$, which surrounds the embryo $(E)$. $D$, flower diagram showing the position of the flower in reference to the rachis $(a)$, bract $(D)$ and pericarp $(c)$ which surrounds the ovule $(S)$.-After Meyer.

Powder.-(Fig.68). Light brown to blackish-browir; stone cells single or in isolated groups, nearly isodiametric, thick-walled, with numerous simple pores, and colorless or light-yellow contents; sclerenchymatous fibers few, short, thick-walled, strongly lignified; parenchymatous cells with reddish-brown tannin masses; oil-secre- 
tion cells with suberized walls; oil globules numerous; fragments of powder becoming wine-colored with sulphuric acid.

Constituents.-Volatile oil 10 to 18 per cent, consisting chiefly of terpenes and sesquiterpenes and a sesquiterpene hydrate known as cubeb camphor; several resins, 2.5 to 3.5 per cent, one of which is acrid, the other a so-called indifferent resin; cubebic acid, 1 to 3.5 per cent, this being colored reddish with sulphuric acid; a bitter crystalline principle, cubebin, 0.4 to 3 per cent; fixed oil, 1 per cent; gum, 8 per cent; starch, and about 6 per cent of ash.

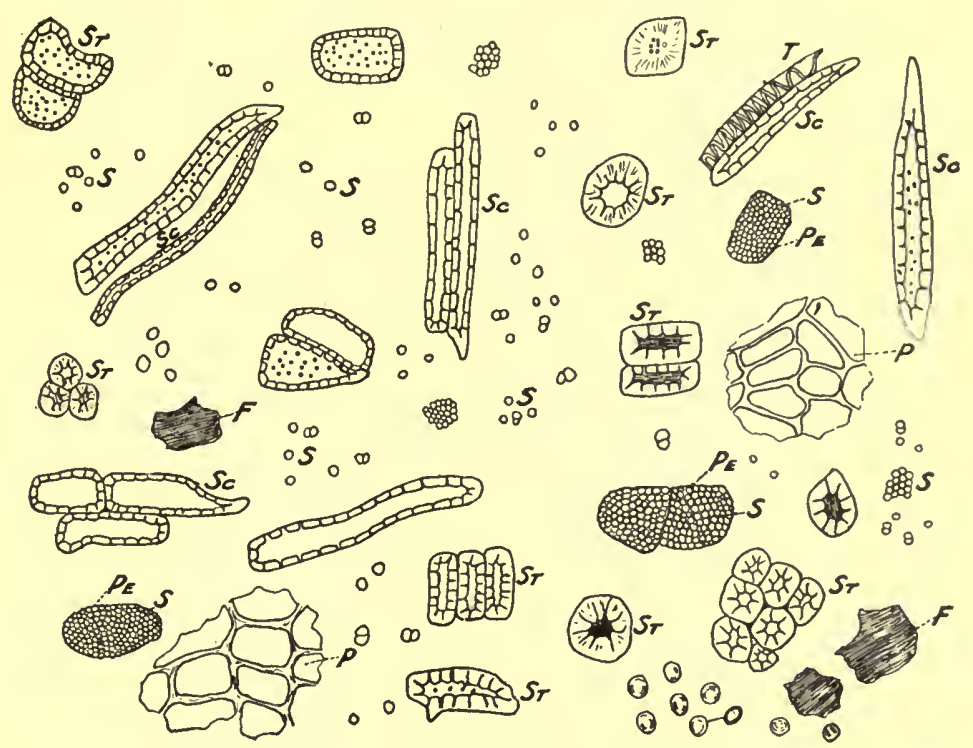

Fig. 68.-Powdered Cubeb. Sc, sclerenchymatous fibers; St, stone cells; $P$, parenchyma cells; $P e$, parenchyma of perisperm filled with starch; $S$, starch grains 0.002 to $0.012 \mathrm{~mm}$. in diameter; $T$, tracheæ; $O$, oil globules; $F$, reddish-brown amorphous fragments. Drawing by Hogstad.

Allied Plants.-A number of other species of Piper yield fruits resembling cubeb, as Piper Clusii, of West Africa; P. borbonense, of Bourbon; P. sumatranum and P. pedicellosum, of Indo-China.

The fruit of Toddalia lanceolata (Fam. Rutaceæ) is used in Africa in place of cubeb (berries). The fruits of Litsea citrata have been sold as false cubeb, and those of Litsea Cubeba (Fam. Lauraceæ) are substituted for cubeb in Cochin China.

Adulterants. - The fruits of other species of Piper sometimes find their way into market; these are grayish in color, somewhat bitter, 
and do not give a wine-colored reaction with sulphuric acid. Not infrequently a considerable amount of the rachis is present and this contains a relatively small amount of the active principles.

Literature.-Zörnig, Arzneidrogen.

Kava.-Kava-Kava, Methysticum, Kave Rhizoma or Rhizoma Kawa-Kawa.-The rhizomes of Piper methysticum (Fam. Piperaceæ), a plant indigenous to and cultivated in the South Sea Islands from Hawaii to the East Indies. The rhizome is largely used in these countries in the preparation of an intoxicating drink, which is prepared by macerating the drug in water. It has only recently come into prominence again and is used to a limited extent in medicine. Formerly the entire rhizome was found in commerce but at the present time the drug is carefully prepared by first removing the outer corky layer with roots, cutting it into short pieces, and dried.

Description.-In irregular transverse and longitudinal pieces, varying from 3 to $8 \mathrm{~cm}$. in length and 1 to $5 \mathrm{~cm}$. in diameter; externally light yellowish or grayish-brown, longitudinally wrinkled and with large circular root scars; fracture of small pieces short and mealy and of thicker pieces tough; inner surface light yellowishbrown, with a large pith, a distinctly radiate xylem and occasionally a thin bark; a drop of sulphuric acid applied to the surface produces a deep cherry red color; odor slight; taste sweetish, pungent, followed by a slight numbness. Pieces of the stem are more woody and have a hollow pith.

Inner Structure.-Hypodermis of several rows of cells containing a greenish-yellow or yellowish-brown resin; in the layers of collenchymatous cells occur stone cells and cells containing an amorphous resinous substance; leptome composed of thin-walled more or less collapsed cells; xylem composed of wood wedges with broad medullary rays, the walls of the latter being more or less lignified and the lumina containing a brownish amorphous resinous substance; pith consisting of starch-bearing parenchyma in which are distributed concentric fibrovascular bundles largely composed of tracheid-like cells. The roots show a distinctly radiate structure, the medullary rays being of a sclerenchymatous nature.

Powder.-(Fig. 69.) Light yellowish-brown; starch grains numerous, single or 2- to 3-compound, the individual grains being spheroidal or planoconvex, from 0.006 to $0.045 \mathrm{~mm}$. in diameter and marked by nearly central radial clefts or triangular fissures; lignified elements consisting of scalariform or reticulate tracheæ and sclerenchymatous fibers; secretion cells containing either greenish-yellow, 
yellowish-red or yellowish-brown amorphous masses. Micro-sublimate crystals of methysticin are readily obtainable (Fig. 69).

Constituents.-About 5.3 per cent of resin consisting of two distinct resinous principles, a free resin acid and resene; the active constituent, methysticin, 0.30 per cent, $\omega$-methysticin 0.27 per cent; yangonin, 0.2 per cent; an alkaloid 0.02 per cent; two glucosides amounting to 0.7 per cent; an amorphous acid insoluble in water,

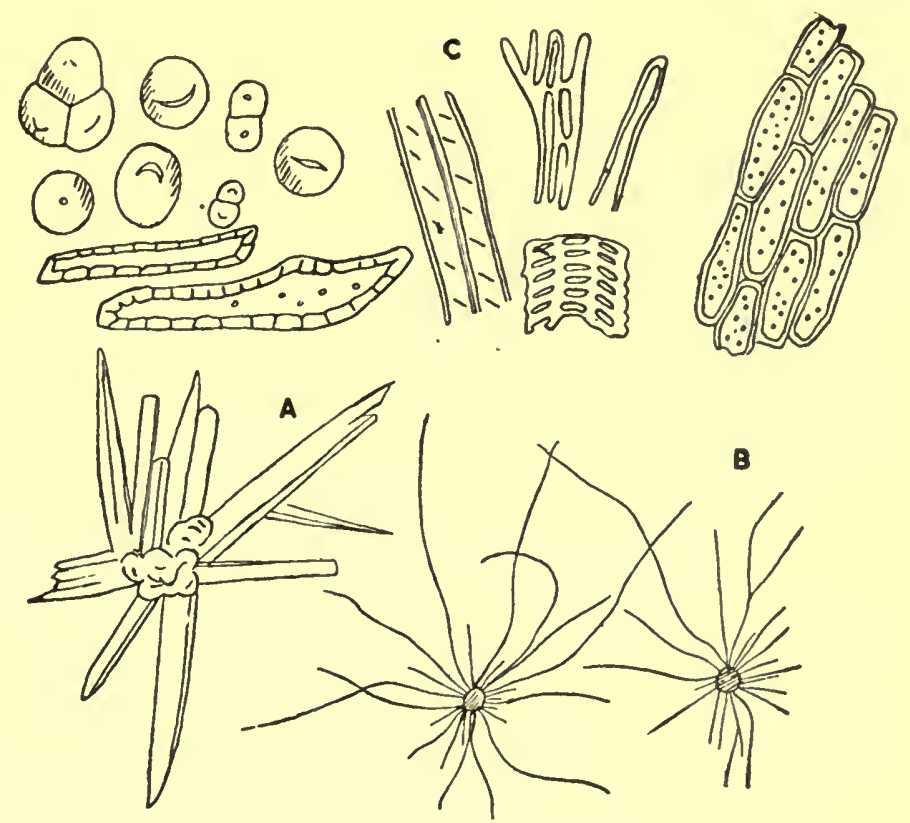

Fig. 69.-Microcrystals formed in Kava-kava, the root of Piper methysticum: $A$, crystals of methysticin obtained on treatment on sections of the root or the powder with alcohol, the crystals being of a light yellow color, attaining a length of $0.160 \mathrm{~mm}$. and becoming of a violet red on the addition of sulphuric acid. $B$, crystals of methysticinic acid obtained upon heating a small quantity of the powder with one or two drops of a solution of potassium hydroxide and adding dilute alcohol and allowing the slide to stand for twenty-four hours. Crystals of methysticin can also be obtained upon sublimation, providing the powder has been acted on previously with dilute sulphuric acid, emulsin or saliva.-After Tunmann in Gehe \& Co.'s Handelsbericht, 1912.

0.75 per cent; ash not more than 8 per cent; starch 50 per cent: also mucilage and sugar.

Literature.-Zörnig, Arzneidrogen. 


\section{SALICACEE, OR WILLOW FAMIIY}

This family consists of two genera, viz.: Salix and Populus, and of which there are 200 or more species. They are mostly native of the north temperate zone, some growing in the Arctic regions and necessarily being of diminutive stature. The willows usually grow in wet ground and are sometimes used, like the Australian eucalyptus, in drying out damp ground especially where the conditions are unsanitary. The willows are extensively cultivated not only for ornamental purposes but for economic purposes. The twigs are used in the making of baskets, and the wood furnishes a charcoal which is employed in medicine and in making crayons and gunpowder. The "pussy willow" (Salix discolor) is a small tree rather common in low meadows and river banks and is marked by thick cylindrical aments, the scales being copiously clothed with long glossy hairs. The Poplars are sometimes planted because of their rapid growth as shade trees. They are also grown to serve as windbreaks in the Western States. The wood is largely used in making paper, card-board, etc. The balsam-poplar or tacamahac (Populus balsamifera) and balm of Gilead (P. candicans) are well-known trees of the United States and distinguished by their large buds, which are copiously covered with a fragrant resin.

Some of the important anatomical characteristics of this family are the following: In the stem there is a superficial development of the periderm and isolated bundles of bast fibers: the medullary rays are from 1 to 2 cells in width; the tracheæ usually possess simple pores and the wood parenchyma, which is scantily developed, contains thick, porous walls. In the leaves the inner walls of the epidermal cells may be modified to mucilage; the stomata are accompanied by subsidiary cells arranged parallel to the pores, the hairs are of the simple unicellular type, and the leaf-teeth may become glandular, excreting an excess of balsam in certain species of Salix and Populus. Calcium oxalate occurs in the form of rosette aggregates and solitary crystals. In some cases the pith may contain a deposition of carbonate of calcium.

SALIX.-Cortex Salicis, Willow Bark.-The bark of Salix alba (Fam. Salicacex), a noble tree indigenous to Europe, and naturalized in the northern United States and Canada. In the spring of the year the bark is stripped from the two or three year old branches and quickly dried. The commercial article frequently consists in a large part of the bark of more mature branches or the trunk of young trees and is frequently deprived of the periderm. 
Description.--In quills or in long flat pieces, sometimes as long as $1 \mathrm{M}$. and from 0.5 to $1 \mathrm{~mm}$. in thickness; outer surface yellowishbrown or blackish-brown, irregularly wrinkled and rough-scaly in the older bark; inner surface cinnamon brown, finely longitudinally wrinkled; fracture short fibrous, the inner portion separable into thin layers; the cut surface colored red with sulphuric acid (presence of salicin), and colored dark green upon the addition of a solution of a ferric salt (presence of tannin); odor slight, aromatic; taste bitter and astringent.

Inner Structure.-The epidermal cells when present possess thick, nearly uniform outer walls. The cork cells are developed within the hypodermis and are much thickened on the outer walls. The primary bark consists of a layer of small collenchymatous cells and parenchyma containing starch, rosettes of calcium oxalate, tannic acid and sometimes chloroplastids. The inner bark consists of small groups of bast fibers and leptome separated by 1-celled medullary rays; the groups of bast fibers are surrounded by crystal fibers, each containing a rhombohedral crystal of calcium oxalate.

Constituents.-A bitter glucoside, Salicin, the amount of which varies in different portions of the bark and according to the time when it is gathered, as follows: outer bark, 2.5 per cent; middle bark, 5.8 per cent; innermost layers, 11.3 per cent; bark collected in spring, 7.38 per cent; and that gathered in the fall, 6.66 per cent. Salicin through the actions of ferments forms saligenin, which latter when taken into the human system is decomposed into salicylic acid. The drug also contains 13 per cent of tannic acid; calcium oxalate, gum and wax.

Salicin crystallizes in orthorhombic prisms and when examined by means of polarized light, using crossed Nicols, they display beautiful colors. For color plate showing these crystals in polarized light, consult Kraemer's Applied and Economic Botany.

Allied Plants.-The bark of the black willow (Salix nigra) is used to some extent in this country. The tree is rather common in the United States, growing almost everywhere excepting California. The bark of Salix discolor contains, in addition to salicin, the glucoside of metahydroxybenzaldehyde, salinigrin.-Power, Pharm. Jour., 1902 (69), p. 157.

Literature.-Zörnig, Arzneidrogen.

Carbo Ligni.-Carbo Ligni Pulveratus, Carbo Ligni Depuratus, or Wood Charcoal.- The carbonaceous residue that remains after heating, without access of air, the wood of one of more species of the following genera: Salix, Populus, Quercus or Corylus. 
A number of methods are employed in the production of Charcoal as the use of heaps, iron cylinders or overheated steam. The yield of Charcoal varies from 15 to 25 per cent and that made from the willow is preferred. Maple charcoal is also largely employed.

Charcoal retains the shape of the pieces of wood from which it is formed. It is black, inodorous, tasteless, very porous, brittle and insoluble in any of the ordinary solvents. In medicine it is usually used in the powdered form and when examined by means of the microscope it is seen to consist for the most part of purplishblack irregular structureless fragments. It consists largely of pure carbon, retaining the ash of the wood from which it was derived. Upon heating a small quantity of charcoal with alcohol and filtering, the filtrate should leave no residue upon evaporation. If $1 \mathrm{gm}$. of charcoal is boiled with 5 c.c. of a solution of one of the alkalies and filtered, the filtrate should be colorless (evidence of complete carbonization). The soluble ash in charcoal may be extracted by means of dilute hydrochloric acid.

A fine charcoal is made from the wood of the Linden and Poplar in Europe; and under the name of Carbo Panis a charcoal is made from bread.

Gemme Populi.-Turiones Populi, Balsam Poplar Buds or Balm of Gilead Buds. - The buds of the balsam poplar or Tacamahac (Populus balsamifera) (Fam. Salicaceæ). This tree is found in the northern United States and British America, and its trunk sometimes measures nearly $2 \mathrm{M}$. in diameter. In the early spring the buds are gathered before they open. They are lanceolatecylindrical, with a broad base and sharp-pointed summit; from 20 to $25 \mathrm{~mm}$. in length and about $5 \mathrm{~mm}$. in diameter at the base, the terminal buds being longer than the axillary ones. They are saturated with a yellow balsamic exudation, which in the fresh buds is very sticky, and are covered with fine oblong, pointed, concave, closely imbricated, thick scales having a light-brown color and being very lustrous on the outer surface. These latter form a thin shell inside of which at the base are the young leaves, with their protecting scales and hairs, arranged on a cylindrical axis. They have a balsamic odor somewhat suggestive of chamomile and an aromatic and bitter taste.

The poplar buds contain 0.5 per cent of a light yellow volatile oil, which is soluble in alcohol, and consists principally of humulene. They also contain a soft balsamic resin, gallic acid; malic acid, salicin, populin, mannit, chrysin, fixed oil and tectochrysin.

The buds of other species of Populus are also said to furnish some of the commercial article. The buds of the fir (Albies balsamea) 
furnish an article known as False Balm of Gilead Buds which are very aromatic and resinous and contain besides tannin a bitter glucoside, picein.

Populus.-Poplar.-The bark of the White or Silver poplar, also known as the Great Aspen or Abele (Populus alba). The drug consists of quills or flat pieces, varying in length and from 0.5 to 3 $\mathrm{mm}$. in thickness; outer surface greenish-white, smooth and with numerous lenticels; inner surface light brown and longitudinally striated; fracture short-fibrous; odor slight; taste bitter and astringent. The bark contains in addition to salicin, the glucoside, populin or benzoyl-salicin, which forms needle-shaped crystals, having a somewhat sweetish and acid taste and yield upon hydrolysis saligenin or salicylic alcohol and benzoic acid.

\section{MYRICACEAE, OR SWEET GALE FAMIYY}

A family consisting of a single genus and of which the wax myrtle or bayberry (Myrica cerifera) is best known. The latter is a small shrub growing in sandy soil in North America, especially near the sea coast, and produces diminutive clusters of small berries which are covered with a wax, which is used when mixed with tallow to form candles, hence it is sometimes known as Candleberry. As a matter of fact, all of the species yield useful products, some furnishing astringent barks while from the leaves of the sweet gale (M. Gale) is derived a volatile oil.

It is sometimes stated that none of the species contains either bast fibers or stone cells, but in Myrica Gale there are isolated bundles of primary bast fibers with intermediate groups of stone cells, which, in other species, form a continuous ring. The tracheæ have scalariform thickenings. Stomata are found only on the lower surface. The hairs are unicellular and in the form of peltate glands. In Myrica Gale the non-glandular hairs are lignified.

MYricA.-Myrica Bark or Bayberry Bark.-The bark of the root of Myrica cerifera (Fam. Myricaceæ), a common shrub growing on the borders of the sea coast from Maine to Florida. The roots are gathered late in the fall, freed from dirt, the bark separated and carefully dried. Sometimes the bark is prepared by contusing the roots, separating the bark, drying and powdering. Both the bark and the powder should be kept in tightly closed containers and not exposed to light.

Description.-In transversely curved strips, or quilled pieces; from 2 to $15 \mathrm{~cm}$. in length, 0.5 to $2 \mathrm{~cm}$. in breadth and from 1 to $2 \mathrm{~mm}$. 
in thickness; outer surface reddish-brown, nearly smooth, sometimes wrinkled, with occasional silver gray patches of the epidermal layer; inner surface very dark brown and finely striate; fracture short, mealy, emitting a dust which is sternutatory; fractured surface light brown in the outer portion and yellowish-brown in the inner layer; odor distinct, aromatic; taste slightly bitter and astringent, becoming pungent and acrid.

Powder.-Light reddish-brown; sternutatory; starch grains numerous, single or 2- to 4-compound, the individual grains from 0.003 to $0.012 \mathrm{~mm}$. in length; calcium oxalate in monoclinic prisms or rosette aggregates, from 0.015 to $0.045 \mathrm{~mm}$. in diameter; bast fibers with strongly lignified, porous walls and often accompanied with crystal fibers; stone cells with thick lignified, finely lamellated, porous walls; cork cells with thick lignified or brownish walls and filled with a reddish amorphous substance; occasional woody fragments showing tracheæ having bordered pores.

Constituents.-A small quantity of a volatile oil; two resins, the one soluble in alcohol and ether, the other insoluble in ether and astringent; myricinic acid; from 2.5 to 3.5 per cent of tannic acid; a trace of gallic acid; 4 per cent of sugar and 0.6 per cent of mucilage.

Allied Plants.-The leaves of Myrica cerifera yield about 3 per cent of a greenish, aromatic volatile oil. The fruits of this same plant contain 32 per cent of a solid fat consisting of palmitin, palmitic acid and lauric acid; and 5 per cent of resin and 45 per cent of starch.

The rhizome and leaves of the Sweet Fern (Myrica asplenifolia), a common low shrub, growing with Ericaceous plants in northeastern United States and Canada, have been used in medicine. The leaves contain 0.08 per cent of a volatile oil; 7 to 10 per cent of tannic acid; resin and a saponin-like substance. The rhizomes yield 6 per cent of tannic acid and 8 per cent of starch.

The leaves of the Sweet Gale (Myrica Gale) contain 0.03 per cent of a volatile oil. The leaves and branches are strongly aromatic and have an astringent and bitter taste.

Literature-Hambright, Amer. Jour. Pharm., 1863, p. 193; Peacock, Ibid., 1892, p. 303. Beringer, Ibid., 1894, p. 220; Manger, Ibid., 1894, p. 211; Krembs and Denniston, Proc. A. Ph. A., 1901, p. 414; Youngken, Bot. Lab. U. of Penn. IV, No. 2.

\section{JUGLANDACEE, OR WALNUT FAMILY}

A small family of six genera, the most important of which are Juglans and Carya. They yield useful woods, the barks are used in tanning and dyeing and the fruits are edible. The inner morphology 
is rather distinctive, all of the species contain peltate-glandular hairs and some of the genera including Juglans show a septation of the pith resembling that which is found in Phytolacea. In the bark of Carya there are isolated groups of primary bast fibers and in Juglans there is a composite sclerenchymatous ring. The tracheæ usually have simple pores and the wood parenchyma are rather abundant. The stomata are usually restricted to the lower surface of the leaves and in the loose mesophyll are cells containing rosette aggregates. Solitary crystals of calcium oxalate are also occasionally present in some of the genera. The non-glandular hairs are either unicellular or of the tufted type.

Carya illinoensis (Wang.), K. Koch, which bears the pecan nut found in the Middle and Southwestern States; C. ovata (Mill.) K. Koch, a large and handsome tree, known as shell-bark or shag-bark hickory and is the chief source of the hickory nuts of the market. There are six other common species of Carya which are indigenous to the United States and Canada and all yield edible fruits.

Juglans.-Butternut Bark.-The bark of the root of Juglans cinerea (Fam. Juglandaceæ), a tree growing in rich moist soil in the Eastern and Central United States. The roots are collected in the autumn, the bark separated and dried.

Description.-In quills or flattened somewhat channeled pieces, of variable length and from 2 to $10 \mathrm{~mm}$. in thickness; both the outer and inner surfaces are dark brown, the outer being somewhat scaly; fracture short, fibrous, the surface being somewhat checkered; odor distinct; taste bitter, pungent and acrid.

Inner Structure.-See Fig. 70.

Powder.-Dark brown; calcium oxalate usually in rosette aggregates from 0.015 to $0.050 \mathrm{~mm}$. in diameter or in monoclinic prisms from 0.010 to $0.025 \mathrm{~mm}$. in length occurring in parenchyma or in crystal fibers; bast fibers, $0.030 \mathrm{~mm}$. wide and very long; stone cells, from 0.035 to $0.100 \mathrm{~mm}$. in diameter; oily drops and purplish-brown tannin masses in parenchyma. Starch grains mostly single, or 2to 4-compound, the individual grains from 0.003 to $0.015 \mathrm{~mm}$. in diameter, occasionally with a central cleft. J. cinerea is distinguished from J. alba and J. nigra in that both of the latter possess numerous crystal fibers containing prismatic or rhombohedral crystals. J. nigra has also in the medullary rays rosette aggregates of calcium oxalate. J. regia appears more nearly to resemble J. cinerea.

Constituents.- It contains about 7 per cent of a yellow, crystalline acrid principle which is colored purple with alkalies; 2 to 
2.5 per cent of a crystalline resin; volatile oil, tannin, sugar, and a fixed oil.

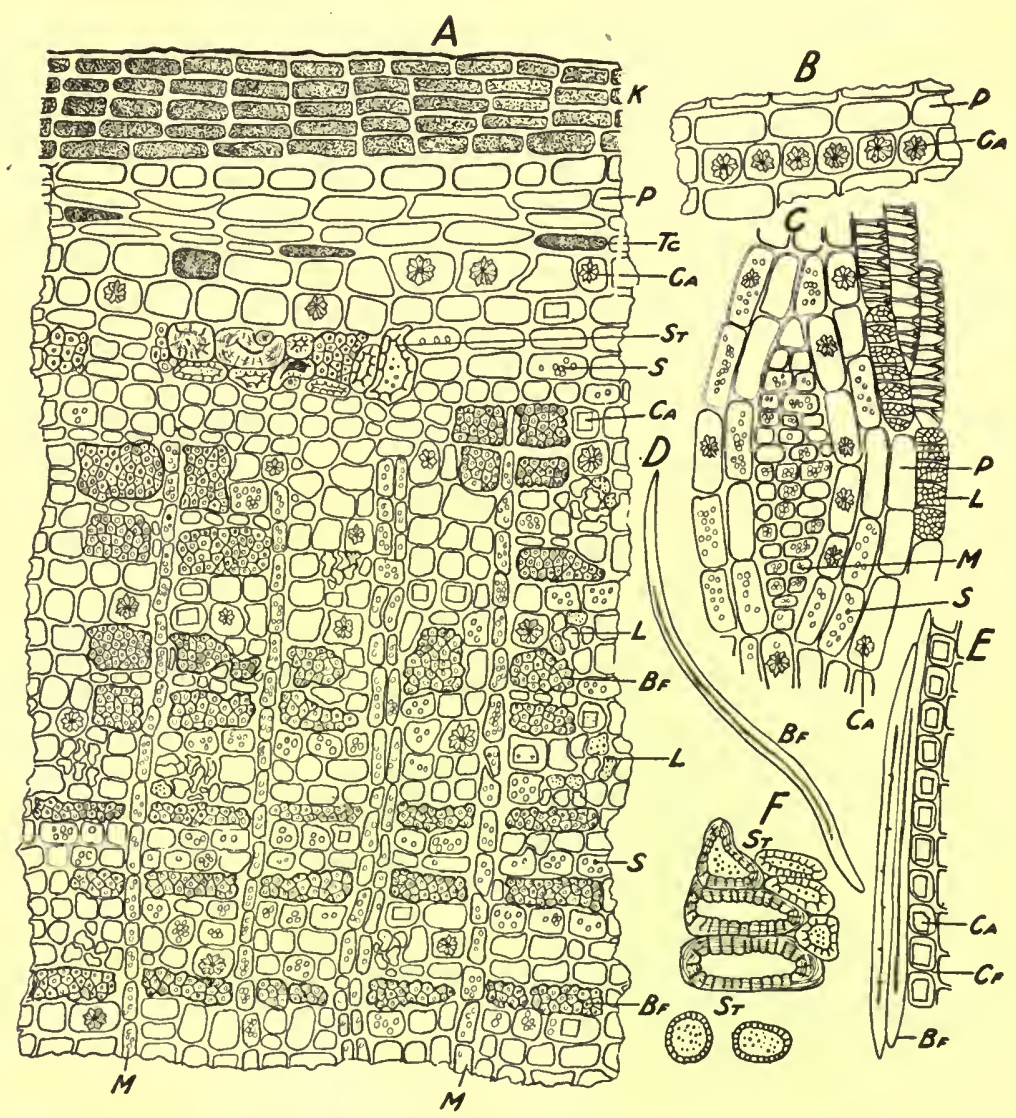

Fig. 70.-Juglans. $A$, transverse section showing cork $(K)$; parenchyma cells $(P)$; parenchyma cells filled with tannin $(T c)$; rosette aggregates and monclinic prisms of calcium oxalate $(C a)$; stone cells $(S t)$; sieve $(L)$; bast fibers $(B f)$; starch grains $(S)$; medullary rays $(M)$. $B$, fragment showing parenchyma cells $(P)$, and rosette aggregates of calcium oxalate $(\mathrm{Ca}) . \mathrm{C}$, tangential section showing medullary rays $(M)$, sieve $(L) . \quad D$, bast fiber in longitudinal view. $E$, fragment in longitudinal view showing 4-sided calcium oxalate crystals $(C a)$ in cells forming a crystal fiber $(C f)$ and adjoining 2 bast fibers. $F$, characteristic stone cells $(S t)$. - Drawing by Hogstad.

Adulterants.-The stem bark of Juglans cinerea is sometimes mixed with the drug and is distinguished by the outer surface possessing occasional grayish patches of certain lichens. 
Allied Plants.-The bark of the black walnut (Juglans nigra), somewhat resembles butternut bark, but is more coarsely striate and the fractured surface is more uniformly brown.

Literature.-Holm, Merck's Rept., 1918, 27, pp. 115 and 168.

Cortex Fructus Juglandis.-Cortex Nucum Juglandis Viridis, English Walnut Shells.-The hulls (outer portion of the pericarp) of the fruit of the Persian or English walnut (Juglans regia) have been used in medicine in the fresh and green condition. The dried hulls have been recently imported under the name of "vegetable shells" apparently for the purposes of using them in the ground condition as an adulterant.

The dried hulls, or "shells," consist of pieces or fragments composed for the most part of the outer layers of the pericarp, i.e., the epicarp and sarcocarp. The pieces are more or less irregular, involuted and shriveled, from 5 to $35 \mathrm{~mm}$. in diameter, and break with a short fracture. Some of the pieces are marked by the stem-scar or still have attached to them portions of the stem. Externally, the epicarp, or outer layer, is rather smooth, though coarsely wrinkled, marked by numerous small dots, and varies in color from light to dark brown. The sarcocarp, or inner layer, is somewhat spongy, dark brown or blackish-brown in color, and more or less fibrous, due to the shrinking of the parenchyma from the fibrovascular bundles. The taste of the hull is markedly acid and somewhat bitterish, but the odor is not very pronounced or characteristic.

The microscopical characteristics of the powder are illustrated in Fig. 71.

Literature.-Kraemer, Amer. Jour. Pharm., 1911, p. 377.

\section{BETULACEE, OR BIRCH FAMULY}

A group of 6 genera of monœcious trees or shrubs. They are common to both hemispheres. The two genera of greatest importance are Betula or birch, and Corylus or hazelnut. The birches are extremely hardy and some grow within the Arctic circle. They find a great many uses. A volatile oil, closely resembling true oil of wintergreen, is obtained from the twigs and bark of the trunk of the sweet or black birch (Betual lenta), a tree growing in the eastern portion of the United States. The bark of the white birch serves a number of useful purposes, slabs of it being used for the thatching of roofs, the outside covering of boxes for window gardens, as well as a variety of other purposes. It contains a yellow coloring principle, making it serviceable in dyeing, and sufficient tannin to make it 


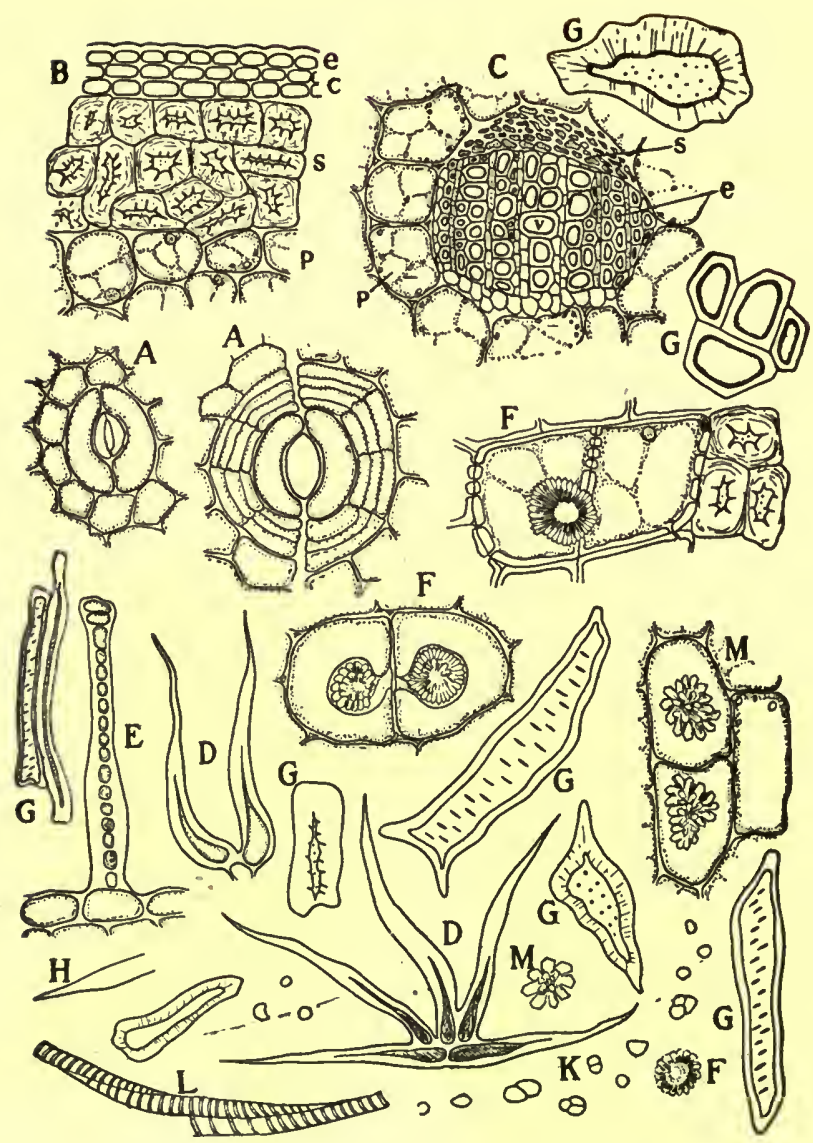

FIG. 71.-Pericarp of fruit of Juglans regia: $A$, stomata of epicarp; $B$, crosssection of pericarp showing epidermis $(e)$, cells with reddish-brown contents $(c)$, sclerotic cells $(s)$, parenchyma $(p)$ containing protoplasm and starch grains; $C$, mestome strand of the sarcocarp showing vessels $(v)$, libriform $(l)$, leptome $(s)$, parenchyma containing protoplasm and starch $(p) ; D$, nonglandular hairs from the apical and basal portions of fruit; $E$, glandular hairs from base of fruit similar to those found in large numbers on the surface of the butternut (Juglans cinerea); $F$, rosette aggregates resembling the membrane crystals of Rosanoff; $G$, sclerotic cells found in the powder; $H$, fragment of non-glandular hair; $K$, starch grains from 6.002 to 0.010 $\mathrm{mm}$. in diameter: $L$, tracheæ with annular markings $M$, calcium oxalate crystals. 
valuable for tanning. The wood varies in color, is firm and tough in texture and is used for highly ornamental furniture. The hazlenut or filbert is chiefly known for its edible nuts, yet the tree serves many other useful purposes.

The wood of the plants of this family is extremely tough and flexible and the branches are used in the making of fishing rods, hurdles, crates and, when split, into hoops for casks. The wood like that of the birch is used in the manufacture of charcoal. The forked twigs of the European hazel were formerly used like those of witchhazel as a divining rod.

The cork arises in the outermost layers of the bark, forming large plates, so that it can be removed in large pieces. The exfoliating cork of the birch is also distinguished by the long, linear, transverse lenticels. The bark is free from secondary bast fibers and usually contains numerous groups of stone cells. In Betula and Alnus the tracheæ possess bordered pores and scalariform thickenings. A mucilaginous epidermis is not of infrequent occurrence in the leaves and the stomata usually occur only on the lower surface. The hairs are both non-glandular and glandular, and glandular scales occur on species of Betula and Alnus. Calcium oxalate occurs in the form of rosette aggregates and solitary crystals.

Betula Lenta.-Cherry, or Sweet Birch.-The bark of the trunk and larger branches of Betula lenta, a handsome tree and the most conspicuous of American birches, yields a volatile oil known as oil of birch. It is obtained from the bark by first macerating the pieces with water and then distilling the oil by means of copper stills. The oil does not pre-exist in the bark, but is formed from a glucoside, gaultherin. The latter forms colorless needles and is soluble in alcohol and water. It is very easily decomposed, even being hydrolysed in alcohol of 94 per cent. The bark also contains about 3 per cent of tannin.

Cortex Betula.-Birch Bark.-The bark of the European white birch (Betula verrucosa) is used to some extent in medicine. The bark of the older branches and trunk is collected, and after removing the periderm, is carefully dried.

It consists of more or less flattened pieces from 0.5 to $2 \mathrm{~cm}$. in thickness. The outer surface is orange-yellow, with whitish patches and occasional scales of cork; inner surface yellowish-brown, smooth and finely wrinkled; fracture granular and even; odor slight and taste bitter.

The bark is distinguished by not having any bast fibers, these being replaced by stone cells which occur in groups forming an inter- 
rupted circle. The parenchyma associated with the sieve is in part lignified; calcium oxalate occurs in monoclinic prisms, rosette aggregates and as micro-crystals; medullary rays are from 3 to 5 cells wide, the walls being very thin and occasionally those near the stone cells are lignified.

It contains betulin, a camphoraceous, resin-like substance; 3 per cent of tannic acid which is colored greenish by solutions of ferric salts; also gallic acid and a bitter principle.

Literature.-Zörnig, Arzneidrogen.

\section{FAGACE\&, OR BEECH FAMILY}

A family of monœcious trees or shrubs which are of a very wide geographic distribution. The three general representatives are beech or Fagus, the chestnut or Castanea, and the oak or Quercus. The oaks are among the most historic of our trees, and are noted for their strength, durability and longevity. While they do not attain the height of the Eucalypts or Sequoias, their trunks may be of considerable circumference (Fig. 72). Most species do not attain maturity before fifty or one hundred years, and some have attained an age between five hundred and one thousand years. They furnish the most important woods of the world, and the bark is used in tanning and dyeing and some are used in medicine. The acorns are largely used as a food for swine. The chestnuts are chiefly valued on account of their edible nuts, although the bark is aiso used in tanning and the leaves have been used in medicine.

The beeches are among the most beautiful forest trees. Owing to the fact that the wood is not affected when immersed in water, it is largely used in the construction of dams, water mills, etc. In connection with the distillation of the wood of the red beech of Europe (Fagus silvatica) and the Southern beech (F. ferruginea) a beech-wood creosote is obtained which is largely employed in medicine for a number of purposes.

The barks of Quercus and Castanea are distinguished by the production of interrupted circles of groups of bast fibers, each being surrounded with crystal fibers. In addition there are-numerous groups of stone cells. The parenchyma and medullary ray cells are filled with tannin. The hairs are unicellular in Fagus and tufted as well as peltate in both Castanea and Quercus. The stomata do not possess any neighboring cells. Calcium oxalate occurs in the form of rosette aggregates and solitary crystals. 
Quercus.-White Oak Bark.-The bark of Quercus alba (Fam. Cupuliferæ), a tree indigenous to the eastern and central United States and Canada. The bark is collected in spring from the branches and trunks of trees from ten to twenty-five years of age, and deprived of the periderm and dried.
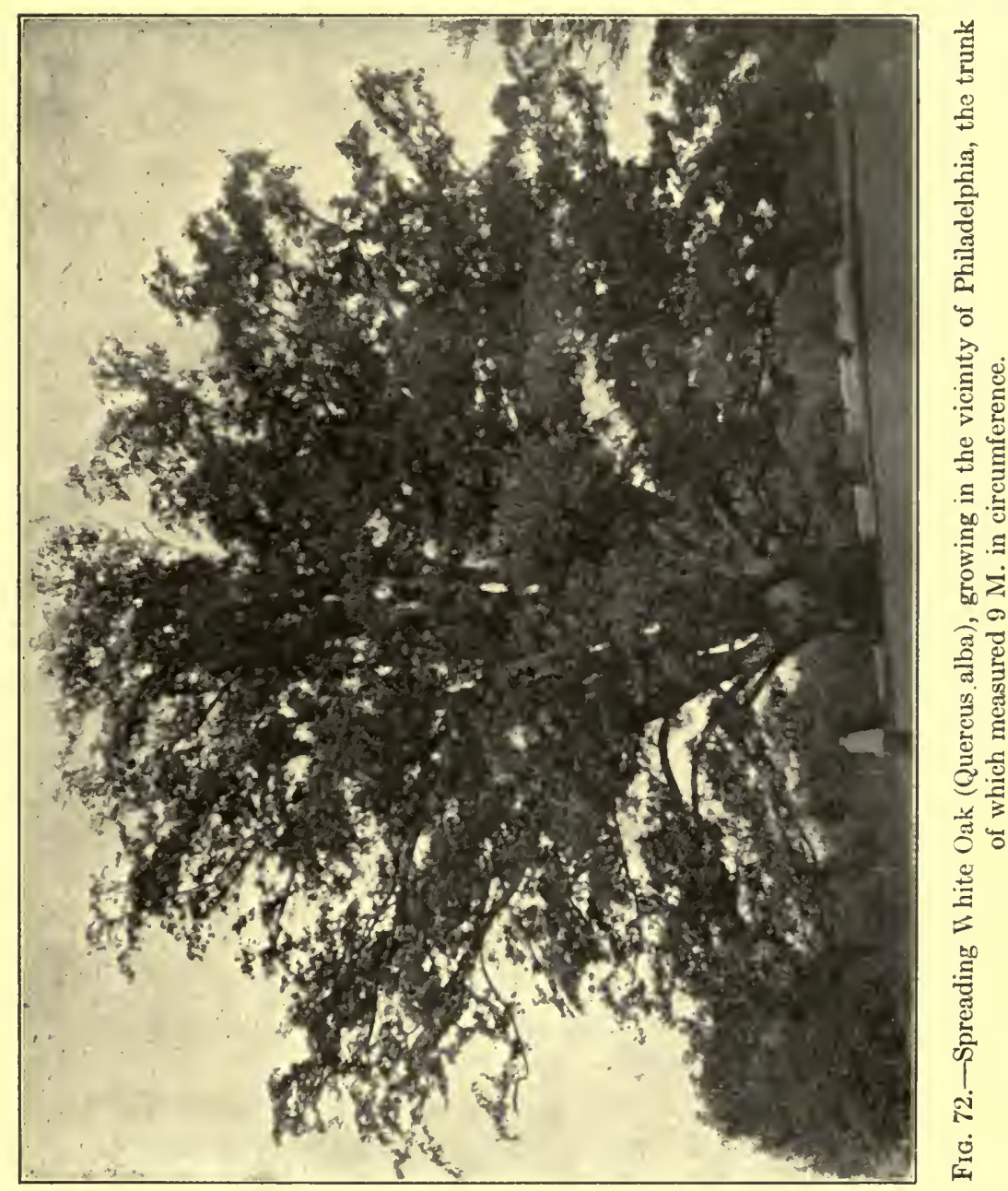

Description.-In flat, irregular, more or less oblong pieces 5 to 30 $\mathrm{cm}$. long, 10 to $20 \mathrm{~mm}$. in diameter, 2 to $4 \mathrm{~mm}$. thick; outer surface light brown, longitudinally striate, with occasional patches of darkbrown periderm; inner surface yellowish-brown, coarsely striate and fissured longitudinally, and with detachable bast fibers; fracture 
uneven, coarsely fibrous, surface porous and dotted with groups of white sclerenchymatous cells and fibers; odor slight; taste astringent.

Inner Structure.-For illustration of microscopic sections, consult Kraemer's Applied and Economic Botany, p. 511.

Powder.-Light brown; bast fibers long, thick-walled, lignified; crystal fibers containing rosette aggregates or monoclinic prisms of calcium oxalate from 0.010 to $0.025 \mathrm{~mm}$. in diameter: stone cells thick-walled, with numerous lamellæ and simple pores: parenchyma with irregular yellowish-brown tannin masses.

Constituents.-Tannin about 10 per cent; starch and calcium oxalate. The tannin yields upon sublimation a crystalline principle resembling pyrocatechin; upon fusion with potassium hydrate, a phenol similar to protocatechuic acid is formed; dilute solutions are colored olive-brown with ferric chloride and possess a slight fluorescence; alkalies give a deep red color to the solutions.

Allied Plants.-Quercus robur, indigenous to Europe, is the source of the bark used in England and Continental Europe; the bark closely resembles that of Quercus alba, but the periderm is not removed; it contains from 10 to 16 per cent of tannin, besides gallic and ellagic acids. Quercus velutina, or black oak, yields the quercitron bark, which resembles that of Quercus alba, but is reddish-brown, and tinges the saliva yellowish; it contains besides tannin a yellow glucosidal principle quercitrin, which yields quercetin, a yellow coloring principle.

Literature.-Kraemer, Amer. Jour. Pharm., 1890, p. 236.

Galla.-Nutgall.-An abnormal development on the young twigs of Quercus infectoria (Fam. Cupuliferæ) due to the puncture and presence of the deposited ova of a Hymenopterous insect, Cynips tinctoria. The galls are collected before the maturing of the insect, and are obtained principally from Aleppo, in Asiatic Turkey.

There are three stages in the development of galls corresponding to the development of the insect and during which the composition varies: (1) When the galls are first formed and the larva is beginning to develop, the cells of the outer zone, as well as those of the central zone, contain numerous small starch grains. (2) When the insect reaches the chrysalis stage, the starch in the cells near the middle of the galls is replaced in part by gallic acid, while the cells at the center and near the periphery contain masses of tannic acid. When the winged insect is developed nearly all of the cells contain amorphous masses of tannic acid with some adhering crystals of gallic acid. After the insect has emerged from the gall the constituents again undergo a change, depending largely on the presence of moisture, 
when the tannic acid is changed into an insoluble oxidation product and the gall becomes more porous, constituting the so-called white gall of commerce (Kraemer, Bot. Gaz., 1900, p. 275).

Aleppo Galls.-Somewhat spheroidal, 1 to $2 \mathrm{~cm}$. in diameter; externally grayish-brown or dark grayish-green, more or less tuberculate above, the basal portion nearly smooth, and contracted into a short stalk, sometimes with a perforation on one side; heavy; fracture horny; internally yellowish or dark brown, consisting of a central portion which contains starch, and occasionally the partly developed insect, and an outer zone which is porous, lustrous and occasionally traversed by a radial canal, these two zones being separated by a layer of nearly isodiametric stone cells or parenchyma cells with thick cellulose walls; odor slight; taste strongly astringent.

Powder.-Yellowish-brown; starch grains numerous, more or less free in the powder and varying in shape from spheroidal or ellipsoidal to polygonal, and from 0.005 to $0.030 \mathrm{~mm}$. in diameter; numerous fragments of thick-walled, starch-bearing parenchyma; stone cells few, resembling those found in fruits and seeds, varying considerably in shape and size, from 0.025 to $0.300 \mathrm{~mm}$. in length; occasional fragments with spiral or reticulate tracheæ; fragments mounted in very dilute ferric chloride solution should become of a deep blue or greenish-blue color.

A rough method of obtaining an idea of the value of powdered nutgalls is as follows: Macerate $0.5 \mathrm{gm}$. of powdered nutgall with 2 c.c. of alcohol for a few minutes, add 500 c.c. of water, stir the mixture well for five minutes and filter. On adding a drop of ferric chloride solution to 1 c.c. of this filtrate, diluted with 10 c.c. of distilled water, a distinct blue or violet-blue color should develop.

Constituents.-The principal constituent is tannic acid, which is found to the extent of 50 to 70 per cent; the drug also contains gallic acid 2 to 4 per cent, starch and resin.

Tannic Acid (gallotannic acid or digallic acid) is a yellowish-white amorphous substance, with a characteristic odor and astringent taste. It is soluble in cold water and alcohol; forms amorphous salts; gives a blue color and precipitate with ferric chloride; forms a soluble compound with iodin and prevents the latter from giving the characteristic reaction with starch.

Two classes of tannic acid are recognized, depending on their behavior with iron salts and other reagents: (1) Tannic acid, giving a bluish color with ferric chloride, as that of Aleppo galls, and also found in chestnut (Castanea), pomegranate (Punica) and sumac (Rhus); (2) tannic acid, giving a greenish color with ferric chloride, 
as that contained in oak barks (Quercus), catechu (Acacia), kino (Pterocarpus), rhatany (Krameria), canaigre (Rumex), tormentilla (Potentilla) and mangrove (Rhizophora).

For a full discussion of the nature of tannin, its chemical properties and distribution in plants, consult Kraemer's Applied and Economic Botany, pp. 202-210.

Gallic Acid crystallizes in silky needles or prisms which are inodorous and possess a faintly astringent taste. It is sparingly soluble in cold water, but soluble in alcohol; forms crystalline compounds with the alkalies, alkaline earths, lead and copper salts; and gives a bluish-black precipitate with ferric chloride, which is soluble in acetic acid and loses its color on boiling.

Allied Plants.-On a number of species of Rhus, galls due to the stings of certain plant lice (Aphis) are formed, as Chinese galls, formed on Rhus semialata; Japanese galls, formed on R. japonica, and American Rhus galls, formed on Rhus glabra and R. hirta. Chinese and Japanese galls are very rich in tannin, and as they contain less coloring matter than the oak galls are used in the manufacture of gallic acid. They are more or less irregular in shape, but somewhat ovoid, more or less tuberculate, grayish-brown, very hairy, light in weight, brittle. The wall is about $1 \mathrm{~mm}$. thick, and the cavity contains the remains of numerous insects in the form of a grayish powder.

The powder of Japanese or Chinese galls is grayish-green and contains numerous non-glandular hairs; starch grains from 0.015 to $0.040 \mathrm{~mm}$. in diameter; rosette aggregates of calcium oxalate, from 0.015 to $0.25 \mathrm{~mm}$. in diameter; occasional fragments of tracheæ and laticiferous cells. Mounts in glycerin may show separation of acicular crystals.

American nutgalls are formed on Quercus coccinea and Q. imbricaria by Cynips aciculata. When fresh they are globular, 1.5 to 3 $\mathrm{cm}$. in diameter, and of a yellowish, somewhat mottled color. On drying they become yellowish or dark brown and much shriveled externally. Texas nutgalls are formed on the live oak (Quercus virens) and yield 40 per cent of tannic acid. California oak balls are excrescences on Quercus lobata and are about $5 \mathrm{~cm}$. in diameter, and said to contain considerable tannic acid.

Other tannin-yielding plants are found in the following families: Combretaceæ, Leguminosæ, Myrtaceæ.

Castanea.-Chestnut Leaves. - The leaves of Castanea dentata (Fam. Fagaceæ), one of the most useful and beautiful trees of the forests of eastern North America. The leaves are usually gathered in the early fall and carefully dried. It is very probable, how- 
ever, that the leaves at the time of the flowering of the tree or shortly afterward will be found more active.

Description.-Oblong-lanceolate, from 10 to $20 \mathrm{~cm}$. in length and 4 to $6 \mathrm{~cm}$. in breadth; summit acute and long-pointed; base acute or wedge-shaped; margin coarsely serrate with ascending mucronate teeth; upper or ventral surface dark yellowish-green, puberulous, midrib and veins of the first order prominent, the latter diverging at an angle of $50^{\circ}$ to $60^{\circ}$, and extending into the teeth; lower or dorsal surface pale yellowish-green, with a fine cobweb-like tomentum; petiole 15 to $20 \mathrm{~mm}$. in length, slightly angled and with a swollen base, yellowish or sometimes tinged with red; texture coriaceous, fibrous; odor slight astringent.

Inner Structure.-See Fig. 73.

Powder.-Olive-green or grayish-brown; non-glandular hairs either single or peltate from 0.060 to $0.200 \mathrm{~mm}$. in length, nearly smooth and very thick-walled; calcium oxalate occurs in the petioles in the form of rosette aggregates from 0.010 to $0.040 \mathrm{~mm}$. in diameter; tannin-containing parenchyma cells colored bluish-green with solutions of the ferric salts; tracheæ, mostly close annular. Stem fragments show long bast fibers with adjoining crystal fibers, the cells of the latter each containing a monoclinic prism of calcium oxalate from 0.010 to $0.025 \mathrm{~mm}$. in length; and also groups of small stone cells.

Constituents.-Tannic acid, 9 per cent, colored green with ferric salts and not precipitated with a solution of tartar-emetic. The drug also contains a mucilage which is insoluble in alcohol; and ash 45 per cent.

Allied Plants.-An extract used in the tanning of sole leather is made from chestnut wood. The seeds of the chestnut tree are edible and fresh chestnuts contain on an average 42 per cent of starch and other carbohydrates; 6 per cent of protein; 5.5 per cent of fixed oil; 1.3 per cent of ash; the remainder being water. The testa is said to contain a bitter principle.

The seeds of the Chinquapin (Castanea pumila), a low-growing shrub of the southern United States, resemble those of C. vesca, but are smaller. They contain 45 per cent of starch; 8 per cent of ash, and 2.5 per cent of protein. (Kraemer, Amer. Jour. Pharm., 1895 , p. 453.)

\section{URTICACEE, OR NETTLE FAMILY}

The plants are largely tropical, and include herbs, shrubs and trees. There are about 1500 species, and as there are some funda- 
mental differences in their morphology they have been divided into three families, viz.: 1, The Ulmaceæ, or Elm Family; 2, the

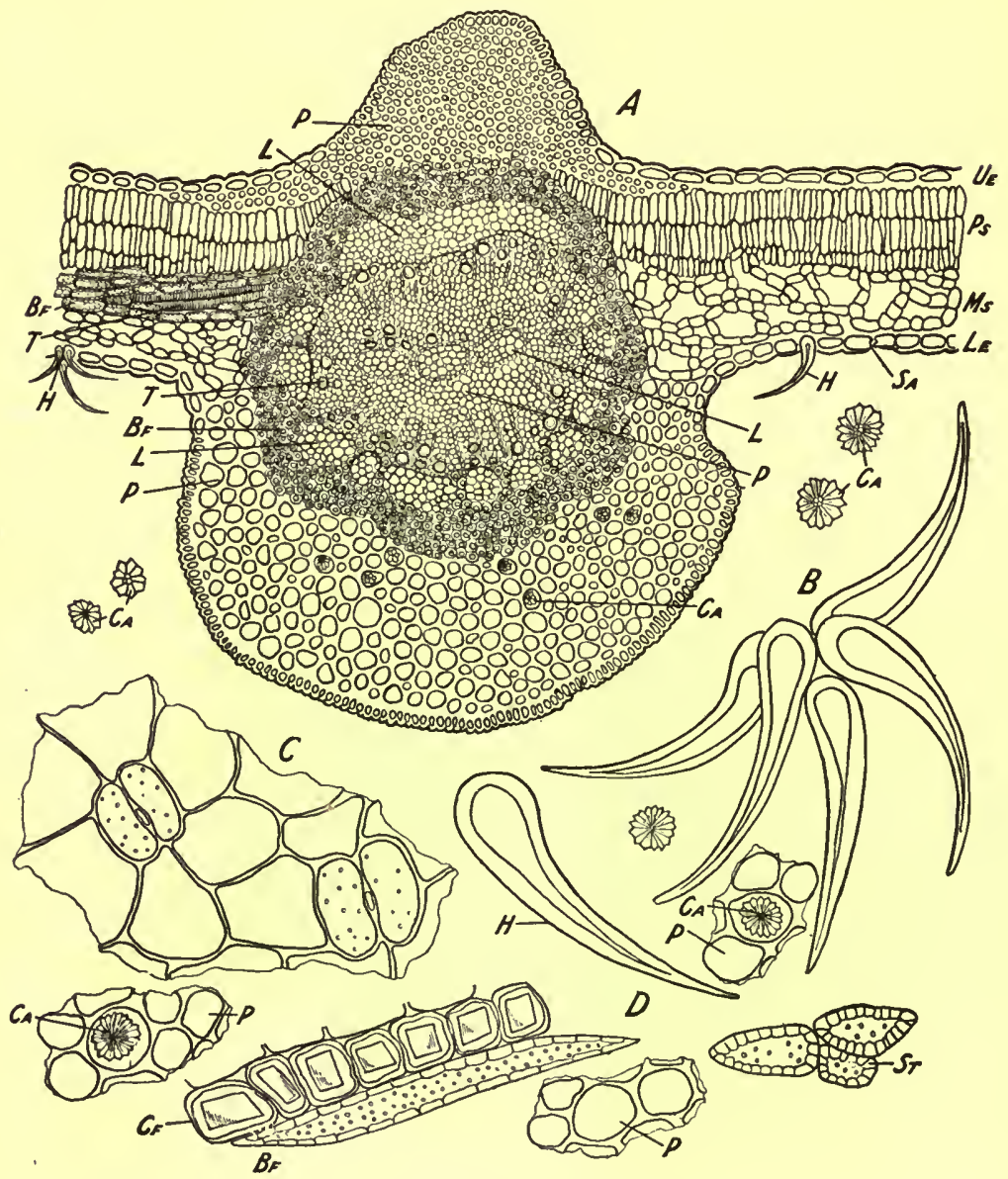

FIG. 73.-Castanea. $A$, transverse section of leaf through the midrib showing upper epidermis $(U e)$; palisade layers $(P s)$; loose mesophyll $(M s)$; bast fibers $(B f)$; sieve $(L)$; trachex $(T)$; parenchyma $(P)$; non-glandular hairs $(\mathrm{H})$; rosette aggregates of calcium oxalate $(\mathrm{Ca})$; stoma $(\mathrm{Sa})$; lower epidermis $(L e)$. $B$, stellate hair. $C$, fragment of leaf showing 2 stomata. $D$, fragments of powdered drug showing crystal fiber $(C f)$; bast fiber $(B f)$; stone cells $(S t)$; parenchyma $(P)$ containing calcium oxalate $(C a)$; non-glandular hair $(H)$.-Drawing by Haase.

Moraceæ, or Mulberry Family, and 3, the Urticaceæ, or Nettle Family proper. By some authors the plants of the genera Cannabis and Humulus are separated and brought under a fourth group, 
Cannabineæ. The Urticaceæ have a number of distinctive anatomical features. Cystoliths or cystolith-like structures are very general; the cell walls are not infrequently silicified or calcified; the bast fibers are of considerable length; calcium oxalate occurs in the form of rosette aggregates or solitary crystals; and both glandular and non-glandular hairs may be present.

\section{ULMACEE, OR ELM FAMILY}

They consist mostly of shrubs and trees growing in the tropics and in temperate regions. In addition to the general anatomical features already mentioned, under the Urticaceæ, many of the plants of this family have distinct mucilage cells, as in Ulmus, in which they are very prominent. In the latter they are in the form of short cylindrical cells and very regularly arranged in the bark, giving the transverse section a checkered appearance.

Ulmus.-Slippery-Elm Bark.-The bark of Ulmus fulva (Fam. Ulmaceæ), a tree indigenous to the eastern and central United States and Canada. The bark is collected in spring, deprived of the periderm and dried, the commercial article coming chiefly from Michigan.

Description.-In flat oblong pieces about $30 \mathrm{~cm}$. long, 10 to $15 \mathrm{~cm}$. in diameter, 3 to $4 \mathrm{~mm}$. thick; outer surface light brown, longitudinally wrinkled and furrowed and with occasional dark-brown patches of periderm; inner surface yellowish or light brown, more or less uniformly wrinkled longitudinally; fracture fibrous, surface light brown, porous from large mucilage cells; odor slight, distinct; taste mucilaginous.

Inner Structure.-Bast fibers in small groups forming an interrupted circle separated by the 4- to 6-celled medullary rays; leptome in alternating interrupted circles, each band or plate having a large mucilage cell. Parenchyma (occasionally reticulately thickened), and cells of the medullary rays frequently contain very small starch grains. The bast fibers are usually surrounded by a nearly closed ring of crystal fibers, each of the cells containing a monoclinic prism of calcium oxalate.

Powder.-Very light brown; bast fibers numerous, very long, about $0.020 \mathrm{~mm}$. in diameter, with rather thin, slightly lignified walls; calcium oxalate in monclinic prisms, mostly in crystal-fibers, the individual crystals from 0.010 to $0.025 \mathrm{~mm}$. in diameter; fragments of large mucilage cells with adhering starch grains; the latter 
mostly spheroidal or more or less polygonal, usually about $0.003 \mathrm{~mm}$. in diameter, but also attaining a diameter of $0.025 \mathrm{~mm}$.

Ground elm bark has been reported to be adulterated with wheat starch or wheat middlings, but this does not seem to be the case. The small quantity of wheat starch which is sometimes detected is considered to be in the nature of an accidental contamination. The usual adulterant is a bark from which the mucilage has been extracted or at least barks poor in mucilage are sometimes found on the market. Good elm bark gives a rather thick mucilage on digesting one part of the ground bark in 40 to 45 parts of cold water.

An odor, resembling that of Ulmus, occurs in fenugreek, and in wheat middlings which have been kept in more or less closed containers for some time.

Constituents.-The principal constituent is mucilage; it also contains starch and calcium oxalate.

Allied Plants.-Ulmus campestris, or European elm, yields a bark which is dark brown, and contains, besides mucilage, a bitter principle and tannin.

\section{MORACEAE, OR MULBERRY FAMILY}

They are herbs, shrubs or trees, and distinguished for the most part in having laticiferous cells, which occur in both the axis and leaves of the mature plant. The laticiferous tubes in the pith often extend through the medullary rays, uniting with those in the cortex. In the leaves of some species of Ficus the laticiferous tubes are found associated with vascular bundles only, while in other species, as the common rubber plant in cultivation (Ficus elastica) the tubes send out branches which traverse the mesophyll tissue. The latex of certain plants of this family contain very large granules, the nature of which has not been determined, as in the black mulberry (Morus nigra), the fig (Ficus Carica), the common rubber plant (Ficus elastica) and the osage orange (Maclura pomifera). Upon making a microscopic mount of the latex of the leaves of the common cultivated rubber plant, it is seen to consist of numerous globules and very soon shows a separation of sphærite aggregates of crystals. See Kraemer's "Applied and Economic Botany," p. 240.

Cannabis Indica.-East Indian Hemp.-The flowering tops of the pistillate plants of Cannabis sativa, or the variety indica (Fam. Moraceæ), an annual herb indigenous to Central and Western Asia, and cultivated in India and other tropical countries and also in temperate regions for the fiber and seed. The drug, however, is 
obtained from plants cultivated in tropical India. The flowering tops are made into more or less compressed masses, forming what is known as "ganja " or "guaza." The best grade of ganja is obtained from unfertilized plants grown in India and shipped via Calcutta and Bengal. The leaves may be collected and dried separately and constitute what is known as "bhang." The resin which separates from ganja and bhang, or that which is collected from the growing plant, constitutes the product known as "charas." The article ordinarily imported into this country is grown on the farms near Calcutta, the pistillate plants only being allowed to develop, and these are pruned in such a way as to encourage the production of flowering branches and an increase of resin. Fruiting spikes with mature seeds should be removed.

Description.--Usually in compressed masses 5 to $14 \mathrm{~cm}$. long. Stem cylindrical, about $3 \mathrm{~mm}$. in diameter, longitudinally furrowed and wrinkled, light green, pubescent, internodes 2 to $20 \mathrm{~mm}$. long. Leaf digitately compound, with three to seven linear-lanceolate, nearly sessile leaflets, summit of leaflets acuminate, base acute or cuneate, margin deeply serrate; upper and under surfaces dark green, pubescent, glandular, veins of the first order diverging at an angle of $65^{\circ}$ and terminating in the teeth; petiole 1 to $5 \mathrm{~cm}$. long. Inflorescence in sessile spikes, each flower subtended by an ovate, pubescent bract; calyx entire, ovate or oblong-acuminate, about $4 \mathrm{~mm}$. long, dark green, pubsecent, split longitudinally on one side, somewhat enlarged at the base and folded around the ovary; styles two, about $8 \mathrm{~mm}$. long, filiform, pubescent, ovary oblong, about $1 \mathrm{~mm}$. long, with a single campylotropous ovule. Odor distinct. Taste slightly acrid.

Inner Structure.-Both the upper and the lower surfaces of the leaves possess numerous, more or less bent, 1-celled non-glandular hairs which contain a spheroidal cystolith. Glandular hairs are also present on the leaves, and these possess usually a 1-celled stalk and a 2- to 16-celled glandular summit or head. Calcium oxalate occurs in the form of small rosette aggregates.

Powder.-(Fig. 74.) Dark green; non-glandular hairs, 1-celled, more or less curved, with numerous slight projections, and sometimes with cystoliths of calcium carbonate; glandular hairs two kinds-either with short unicellular or multicellular stalks-and 8- to 16-celled glandular heads; calcium oxalate, in rosette aggregates from 0.005 to $0.025 \mathrm{~mm}$. in diameter; numerous oil globules and resin fragments; few nearly spheroidal pollen grains 0.025 to $0.035 \mathrm{~mm}$. in diameter, with numerous centrifugal projections, 
among club-shaped unicellular hairs of style; tracheæ spiral or with simple or bordered pores; sclerenchymatous fibers long, thin-walled, non-lignified, and with few simple pores; laticiferous vessels with reddish-brown contents. When mature seeds are present, palisadelike stone cells occur, which are very thick-walled, and have a small lumen.

The drug is said to lose its activity when in the powdered condition. The same statement is true in regard to the powdered extract.

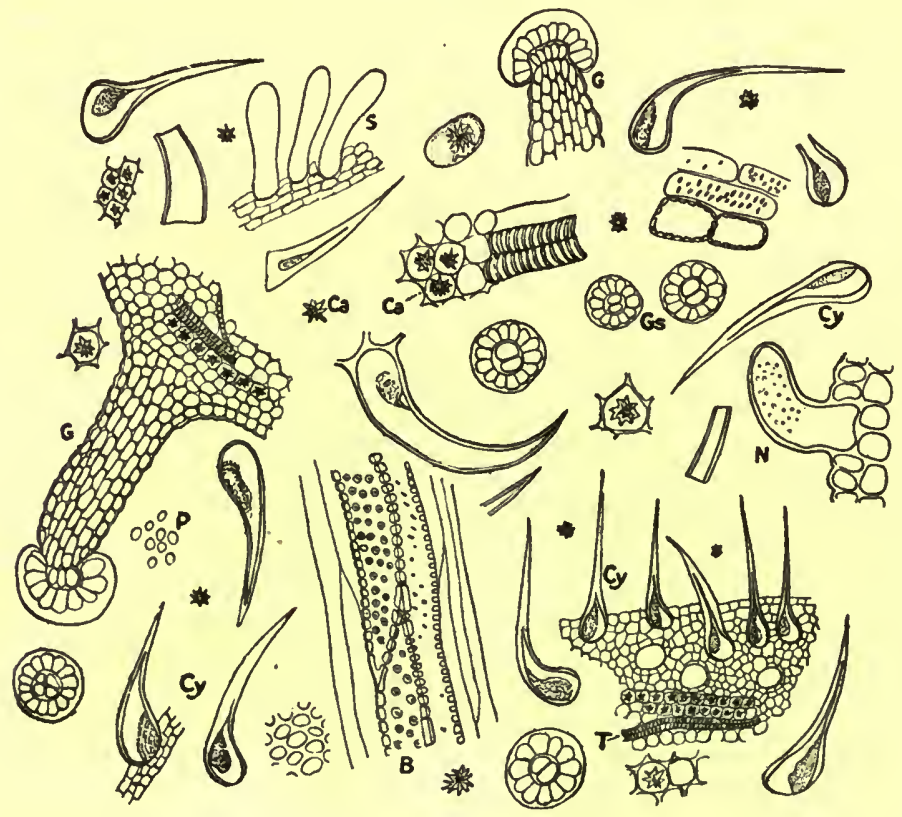

FIG. 74.-Cannabis indica: $C y$, non-glandular hairs containing calcium carbonate in the form of cystolith; $G$, multicellular glandular hairs of the bracts; $G s$, hairs of the bracts; $G s$, multicellular heads of glandular hairs; $S$, papillæ of stigma; $B$, tracheæ with bored pores, present in stem fragments; $T$, tracheæ with annular markings; $P$, pollen grains; $C a$, rosette aggregates of calcium oxalate; $N$, thick-walled non-glandular hair with numerous papillæ on the surface.

Constituents.-From 15 to 20 per cent of a resin (called cannabin), consisting of a number of substances, one of which, cannabinol (cannabindon), occurs as a red, oily substance and is said to possess the intoxicating properties of the drug. The drug also contains 0.3 per cent of a yellowish volatile oil, which consists chiefly of a sesquiterpene, cannibene and a stearoptene. A similar sesquiterpene 
is present in the staminate plant of Cannabis gigantea. The nonflowering herb yields about 1 per cent of a narcotic volatile oil which has an odor that is not unpleasant. The volatile alkaloid cannabinene is supposed to be trimethylamine.

Cannabis Americana.-American Cannabis. The flowering and fruiting tops of the pistillate plants of Cannabis sativa (Fam. Moraceæ) grown in the United States. This drug was at one time official, but owing to the fact that the Indian Government has placed an export duty upon the East Indian hemp, American manufacturers have renewed their interest in the possibilities of obtaining American supplies. Experiments have been made in growing the American Cannabis in various parts of the United States, and while the reports at first showed that the drug only contained from 50 to 85 per cent of the activity of the Indian drug, yet later reports have been more encouraging.

Description.-Varying from light green to greenish-brown and consisting of the stems, foliage leaves, flowers and more or less mature fruits; stems cylindrical, of variable length, and not more than $2.5 \mathrm{~mm}$. in thickness; longitudinally furrowed, light green to light brown, strigose-pubescent; leaves digitately-compound; leaflets linear-lanceolate, nearly sessile, margin deeply serrate, otherwise as in Indian Cannabis.

Powder.-Dark green to greenish-brown, resembling Indian Cannabis, but with a larger proportion of tissues of the stem and leaves.

Allied Plants.-Owing to the high price of East Indian Cannabis, for reasons already stated, the drug has been imported to some extent from other countries. An African Cannabis has been imported which, while not of as good appearance as the East Indian drug, yielded 14.06 per cent of a resin having full therapeutic activity. A Turkish Cannabis has been imported which yielded 9 per cent of resin, having the average therapeutic activity of the standard drug When it is recalled that there is shipped from India very large quantities of an inferior grade of Cannabis tops at a very much lower price, and upon which there is placed a very low rate of export duty or it comes in duty free, then it would seem that manufacturers were justified in encouraging the importation of the Cannabis grown in other countries than India. No harm can arise from the use of these different varieties, as reliable manufacturers market preparations on the basis of their physiological activity and are not likely to use inferior drugs, because it is far more expensive and unsatisfactory. The only logical limitation of source in the Pharma- 
copœia would be one which includes situations in which a potent drug could be grown and excludes those in which Cannabis is known to be deficient in activity. Physiologically active Cannabis also comes from Turkestan, Asia Minor, France, Italy, Spain, Mexico and from the warmer and more arid regions in the United States.

The alkaloids harmine and harmaline are found in the seeds of Peganum Harmala (Fam. Zygophyllaceæ) of India, and have narcotic properties similar to Cannabis indica.

Literature.-Hamilton, Jour. A. Ph. A., 1915, 4, p. 448; Ballard, Ibid., 1299; Sayre, Ibid., 1303.

Humulus.-Hops.-The fruit of Humulus Lupulus (Fam. Moraceæ), a perennial herbaceous climber, indigenous to Europe, Asia and North America, and extensively cultivated in England, Germany and various parts of the United States, South America and Australia, where it is also naturalized. Hops are collected in September, when they are ripe, carefully dried by means of artificial heat, and packed into bales or sent loose into commerce. They are sometimes treated with sulphur dioxide to improve the color and to prevent change of the active principles. The development of the odor of valerianic acid is said to be prevented by sprinkling the hops with a small quantity of alcohol before packing them. Hops lose their active properties on keeping.

Description.-Cone-like, flattened, oblong or ovoid, 2 to $3 \mathrm{~cm}$. long, 1.5 to $2 \mathrm{~cm}$. wide, about $7 \mathrm{~mm}$. thick, consisting of a sharpundulate rachis and about 50 membranous bracts, the latter distinctly veined, light green or brownish-green, glandular-hairy, entire, 10 to $14 \mathrm{~mm}$. long, 7 to $11 \mathrm{~mm}$. broad, with acute summit and rounded base, frequently infolded on one side and enclosing a sub-globular, light-brown, very glandular achene; the seed with two flat, spirally coiled cotyledons and without a reserve layer; odor aromatic; taste bitter.

Powder.-Light green; calcium oxalate in rosette aggregates, 0.010 to $0.015 \mathrm{~mm}$. in diameter; non-glandular hairs unicellular, more or less bent, thin-walled, 0.2 to $0.3 \mathrm{~mm}$. long; glandular hairs of two kinds (Fig. 75), either with a 3-celled stalk and a nearly colorless, multicellular, glandular head $0.050 \mathrm{~mm}$. in diameter, or with a short 4-celled stalk and a multicellular, bright yellow; glandular head 0.1 to $0.3 \mathrm{~mm}$. in diameter.

Constituents.-Volatile oil about 0.7 per cent, of which 60 to 70 per cent is humulene; a crystalline, bitter principle, lupamaric acid; tannin 4 to 5 per cent; resin 10 to 18 per cent; asparagin, about 1 per cent; trimethylamine; choline or lupuline; malic and 
citric acids, chiefly in the form of salts; calcium oxalate, and ash about 10 per cent.

The aroma of hops, which is an important factor in judging them, is due to a volatile oil. Several factors influence the composition of the oil and also the aroma, viz., climate, soil, etc.

The volatile oil of hops has been shown to consist chiefly of the terpene myrcene, the heptoic, octoic, and nonoic acid esters of the alcohol myrcenol, and the sesquiterpene humulene, with traces of free acids, formaldehyde, and probably some free alcohols. The constituents of chief importance as regards odor are the above-named esters, which constitute a large portion of the oil.

The several oils examined by Rabak (Journal of Agricultural Research, Vol. II, No. 2) have been found to contain varying pro-
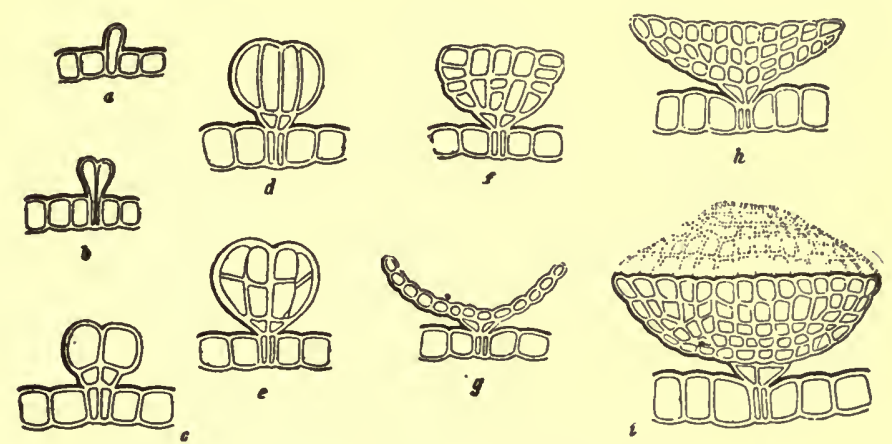

FIG. 75.-Lupulin: $a-h$, successive stages in the development of the glandular hairs on the bracts and floral envelopes of Humulus; $g$, longitudinal section through a mature hair as seen at $h ; i$, glandular hair with the cuticle raised due to the accumulation and pressure of the oily secretion beneath it.After Holzner.

portions of the esters, as well as the terpene myrcene and the sesquiterpene humulene, the variable content of esters being most significant. The curves of the ester content of the various oils and fractions of the oils show at a glance the remarkable differences in the oils from the several geographical sources. The courses followed by the imported oils are most conspicuous because of their constantly lower ester content. More remarkable is the fact that the ester content of the imported oils remains lower from year to year, practically every sample under observation possessing an exceedingly low ester value. The oils from the California hops are both physically and chemically very similar from season to season. 
Those from the various sections of California show no important differences in their properties during any particular season, the curves showing considerable parallelism. The Oregon and Washington oils are very similar in their properties, but differ somewhat from the California oils. The New York oils seem to be the most closely related to the foreign oils in all properties, with the exception of the ester content, which is considerably higher. From the standpoint of the increasing ester content the various oils arrange themselves in the following order: Imported, California, Washington, New York and Oregon, the three latter being very closely related.

LuPULINUM.-Lupulin.-A powder separated from hops (see Humulus), and consisting chiefly of the glandular hairs. Lupulin may be systematically separated from the hops, or it may be obtained as a by-product during the handling of the hops. Commercial lupulin consists for the most part of sweepings collected where hops are prepared for the market, the extraneous matter being removed by sifting and washing. The powder is then carefully dried and preserved.

Description.-Granular, yellowish- or reddish-brown, consisting of glandular hairs with a somewhat globular or ellipsoidal, brightyellow, multicellular head 0.1 to $0.3 \mathrm{~mm}$. in diameter (Fig. 75); odor aromatic; taste aromatic and bitter.

Not less than 60 per cent of lupulin should be soluble in ether, and the ash should not be more than 10 per cent.

In fresh lupulin there are more light yellow glandular hairs than in old. In the latter there are yellowish- or grayish-brown resinous masses replacing the light yellow oil. The amount of Humulus fragments should not be too large in lupulin of good quality.

Constituents.-A volatile oil, identical with that of hops, about 3 per cent; a crystalline bitter principle, lupamaric acid (hop bitter), which becomes yellow on exposure to air and on hydrolysis yields lupuliretin and a crystalline substance lupulic acid; a tasteless resin; myricin; valerianic acid, which together with the oil is obtained on the distillation of lupulin with water; and ash from 3 to 5 per cent.

The volatile oil of hops or lupulin is sparingly soluble in alcohol and is not converted into valerianic acid by means of oxidizing agents. This acid is, however, produced upon treating-the extract of hops with potassium permanganate.

Ficus.-Fig.-The fruit of Ficus Carica (Fam. Moraceæ), a tree indigenous to Persia and cultivated in most sub-tropical and tropical countries. The fruit is collected when ripe, partially dried in the sun, and tightly packed in boxes. 
Description.-Syconium pyriform or obovoid, usually compressed, about $6 \mathrm{~cm}$. long and $1.5 \mathrm{~cm}$. in diameter; externally light brown, longitudinally veined, wrinkled, frequently with an efflorescence of grape sugar, summit with a small scaly orifice, base with a scar or stalk about $7 \mathrm{~mm}$. long and $4 \mathrm{~mm}$. thick, and also with a leaf-remnant; torus hollow, the walls 2 to $3 \mathrm{~mm}$. thick, coriaceous, tough, the inner portion with numerous lanceolate divisions, upon which are borne numerous ovoid, brownish-yellow, glossy achenes about 1 $\mathrm{mm}$. in diameter, the latter with a reserve layer and a curved embryo; odor distinct, fruit-like; taste sweet.

Constituents.-Grape sugar 50 to 60 per cent; about 1.5 per cent of fat in the form of oily globules found in the milk-vessels; starch in the form of spheroidal grains; water about 30 per cent in the partially dried fruit.

Allied Plants.-Other species of Ficus also yield edible figs, as the mulberry fig tree (F. Sycomorus), of Africa; F. religiosa, of India; F. glomerata, of Burmah; the false banyan tree, G. bengalensis, of tropical Africa and India, and F. Rumphii, of Asia.

A peptonizing ferment is obtained from the milk-juice of Ficus Carica, F. Sycomorus, of Africa, and F. exima, of Brazil.

When figs are dried, roasted and ground, they form a coffee substitute known as Fig Coffee, which is also used sometimes as an adulterant of coffee. It is detected by the large, thin-walled and broad non-glandular hairs of the outer epidermis; the broad latex-tubes, 0.030 to $0.050 \mathrm{~mm}$. in width, and the small achenes. The latter somewhat resemble the achenes of strawberry fruits, but are distinguished by the reticulated thickening of the outer cellwall.

UrTica.-Stinging Nettle.-The flowering plant of Urtica urens and Urtica dioica (Fam. Urticaceæ). The plants are rather common in waste places of Europe and the United States, the former being known as the "small nettle" and the latter as the "stinging or great nettle." Urtica urens is an annual herb, while Urtica dioica is a perennial herb. The leaves and flowering tops are gathered in the late summer and carefully dried.

Description.-Urtica urens has a rather stout, stinging bristly stem; the leaves are thin, elliptical or ovate and with slender petioles; the summit and base are obtuse, and the margin is very coarsely and deeply serrate, the teeth being ascending or spreading; both surfaces are light green and more or less glabrous; the flowers are small, green and in axillary clusters.

Urtica dioica has much thicker stems, which are densely covered 
with stinging hairs; the leaves are ovate with long petioles, the summit being acute or acuminate; the base cordate; the margin very deeply serrate with triangular or lanceolate teeth; the lower surface is pubescent, as is also the upper part of the stem. The flowers are diœcious or androgynous and occur in much branched spikes.

The presence of stinging hairs was long known, being referred to by Pliny. Their structure was examined in detail by Haberlandt. They are unicellular, rather long and conical, the summit bearing a small spheroidal or ovoid head, which is obliquely inserted, and readily breaks off, thus leading to the emission of the contents of the stinging hair. The hair is frequently seated on a multicellular pedestal, which surrounds its base like a cup, and is partly formed by the periblem. The nature of the wall of the stinging hairs is peculiar. The head and the neighboring portions of the wall of the hair are silicified; in the latter the amount of silicification gradually decreases toward the base of the hair, and finally is entirely replaced by the calcification. It is the unequal thickening of the walls of the head that causes the characteristic line of fracture and the emission of the cell sap on slight pressure.

Constituents. - It was formally stated that the stinging action is due to the presence of formic acid. In the light of later research this seems doubtful and the activity is now ascribed to a ferment. The plant contains a glucoside, tannic acid, mucilage, a coloring principle and possibly also an alkaloid.

\section{SANTALACEA, OR SANDALWOOD FAMILY}

Mostly shrubs or trees that are indigenous to the tropics. A few are found growing in the United States, as the Oil-nut or Buffalo-nut (Pyrularia pubera), the fleshy fruit of which is edible and the seeds contain an acrid fixed oil. Others are parasitic on the roots of other plants. The following anatomical features of this family may be mentioned: The wood is of uniform structure and consists of tracheæ having simple and bordered pores, and tracheidlike wood fibers, i.e., with bordered pores. In the pericycle of the bark occur isolated bundles of primary bast fibers, a ring of sclerenchyma being rarely developed in the secondary phloem. In the leaves are found groups of silicifiea cells and calcium oxalate occurs in the form of rosette aggregates or solitary crystals. The hairs when present are non-glandular and unicellular. 


\section{Lignum Santali.-Santalum Album or Sandal Wood.-} The wood of Santalum album (Fam. Santalaceæ), a parasitic tree indigenous to India. It attains a height of $10 \mathrm{M}$. and produces a dense evergreen foliage. It is extensively cultivated in southeastern Asia and the Sandal Wood Islands of the Indian Archipelago. The trees, when twenty to forty years of age, are cut down, the bark removed and the wood cut into billets. It is then sorted and sent through Bombay to China, Europe and the United States. There are some eighteen different commercial varieties which are recognized. The most select wood being used in India for the distillation of the oil, the wood of the stems and twigs only being exported.

Description.-In billets or logs from 10 to $35 \mathrm{~cm}$. in length and 5 to $12 \mathrm{~cm}$. in diameter (Fig. 76); outer surface light yellowishbrown, smooth, and marked by more or less flattened areas due to the barking process; inner surface distinctly radiate and with numerous concentric rings; hard and heavy; odor agreeably aromatic and markedly persistent; taste strongly aromatic.

The tracheæ are large, having bordered pores and contain in the lumina yellowish-brown or reddish-brown globular or more or less irregular amorphous masses. The wood fibers are strongly lignified and possess thick porous walls and contain in the lumina spheroidal starch grains from 0.006 to $0.015 \mathrm{~mm}$. in diameter. The medullary rays are in short longitudinal rows and from 1 to 2 cells wide, the walls being very thick and porous.

Constituents. - A volatile oil, the amount depending upon the altitude at which the trees grow, those growing at a higher altitude yielding ten times as much oil as those growing in the lower situations. The oil obtained from the heartwood is superior to that obtained from the sap wood and that obtained from trees which have been slow in developing is best of all. The methods of distillation in India are rather crude and they do not secure the yield that is obtained by distillers in Europe and United States. The yield of oil from the imported Indian wood is from 3 to 5 per cent.

Oil of Sandalwood is a rather viscid, nearly colorless or lightyellowish liquid of a peculiar, but persistent odor. It contains from 80 to 98 per cent of santalol; 6 per cent of a sesquiterpene (santalen); 3 per cent of an aldehyde (santalal); a ketone (santalon); santalic acid, teresantalic acid, formic acid and acetic acid in the form of esters amounting to 3 per cent; and about 0.3 per cent of a strongly odorous constituent.

Allied Plants.-West Indian Sandalwood oil is obtained from Amyris balsamifera (Fam. Rutaceæ). West Australian Sandalwood 
oil is obtained from one or more species of Santalum and is exported from Fremantle, West Australia, being used in India and China as

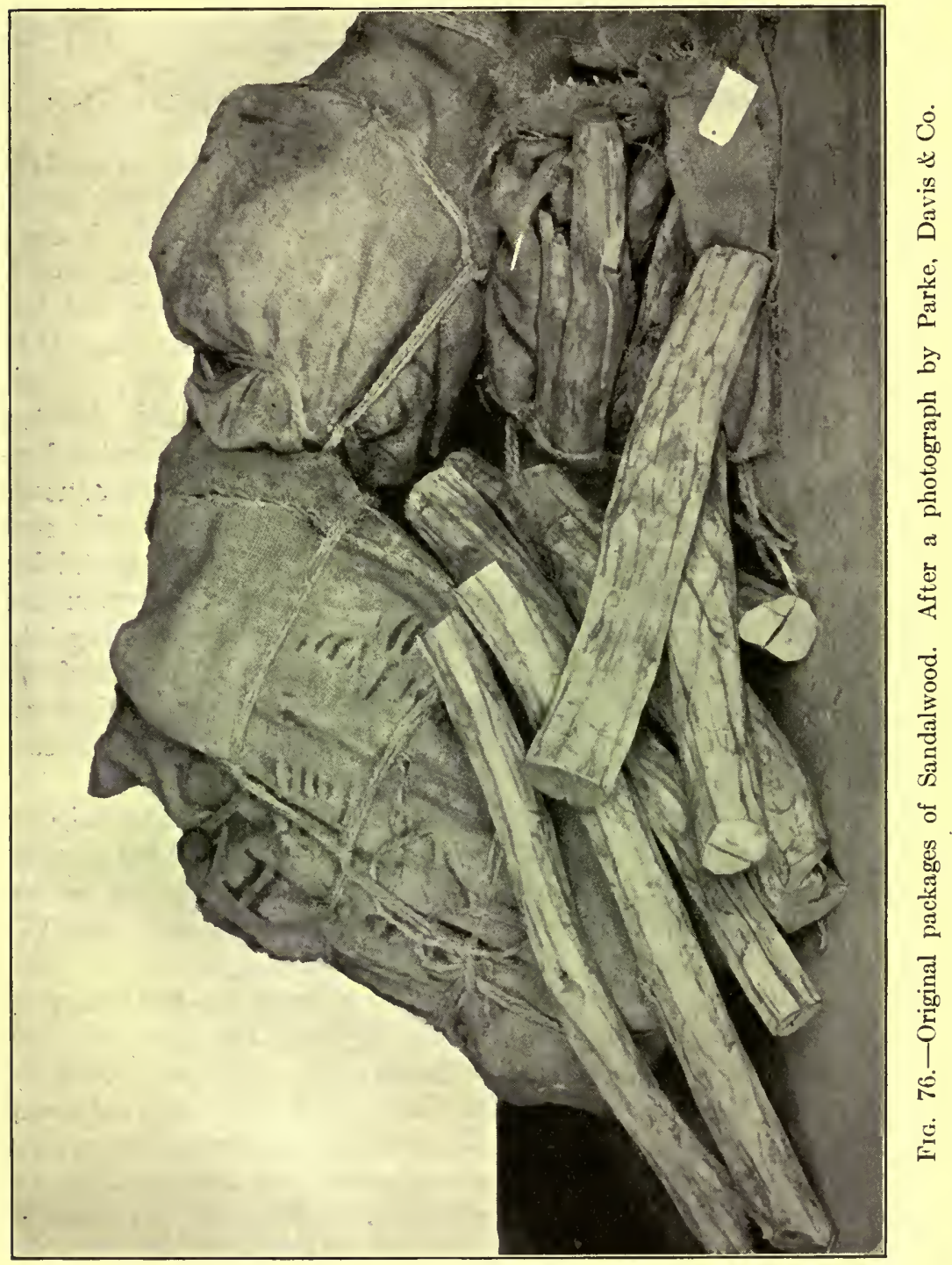

a substitute for the genuine oil, although it has very different properties. South Australian Sandalwood oil is derived from Santalum Preissianum and has a cherry-red color, with an odor similar to that 
of roses. East African Sandalwood oil is obtained from Osyris tenuifolia and yields an oil having an odor resembling that of West Indian Sandalwood oil.

Literature.-Zörnig, Arzneidrogen.

\section{ARISTOLOCHIACEÆ, OR BIRTHWORT FAMILY}

Herbs or mostly twining woody plants with reniform or cordate, palmi-nerved leaves. There are about 200 species, mostly represented in tropical and sub-tropical countries. The family is especially characterized by the presence of secretory cells having a volatile oil. These occur not only in the epidermal cells of the leaf, but in all other parts of the plants. The secretory cells are from 0.012 to $0.075 \mathrm{~mm}$. in diameter, the walls are usually suberized, and the oil occurs in the lumina, usually in colorless or yellowish globules. The oil is not of uniform composition, the cells of Aristolochia Lindeniana Plagiophylla being colored an indigo blue with aqueous solutions containing chlorin, which is apparently due to the conversion of a mother substance into indigo. Tannin-containing cells are also present in certain of the Aristolochias. Calcium oxalate generally occurs in the form of small prismatic or clustered crystals. Cells with silicified walls are found in the upper epidermis of the leaf and the palisade tissue. A non-glandular hair, the terminal cell of which is curved like a hook, is rather characteristic in Aristolochia (Fig. 79) and other genera.

Asarum.-Canada Snake Root or Wild Ginger.-The rhizome of Asarum canadense (Fam. Aristolochiaceæ), a common acaulescent, perennial herb growing in rich woods of northern and central United States. The rhizome is gathered in the spring, deprived of the roots and carefully cleaned and then dried.

Description.-Horizontal, more or less branched, quadrangular, curved or twisted; from 3 to $10 \mathrm{~cm}$. in length and 2 to $4 \mathrm{~mm}$. in thickness; externally light and dark brown with prominent nodes, on the upper side of which occur the irregular scars of the ascending branches, otherwise longitudinally wrinkled and marked by circular scars on the scaly leaves; fracture short, the fractured surface resinous and marked by a small circle of yellowish fibrovascular bundles; odor aromatic; taste pungent and bitter.

Inner Structure.-See Fig. 77.

Powder.-Light yellowish-brown; starch grains numerous, single or 2- to 5-compound, the individual grains irregularly spheroidal, from 0.003 to $0.020 \mathrm{~mm}$. in diameter, frequently marked by a central 
cleft; fragments with tracheæ showing close annular or reticulate thickenings of the wall.

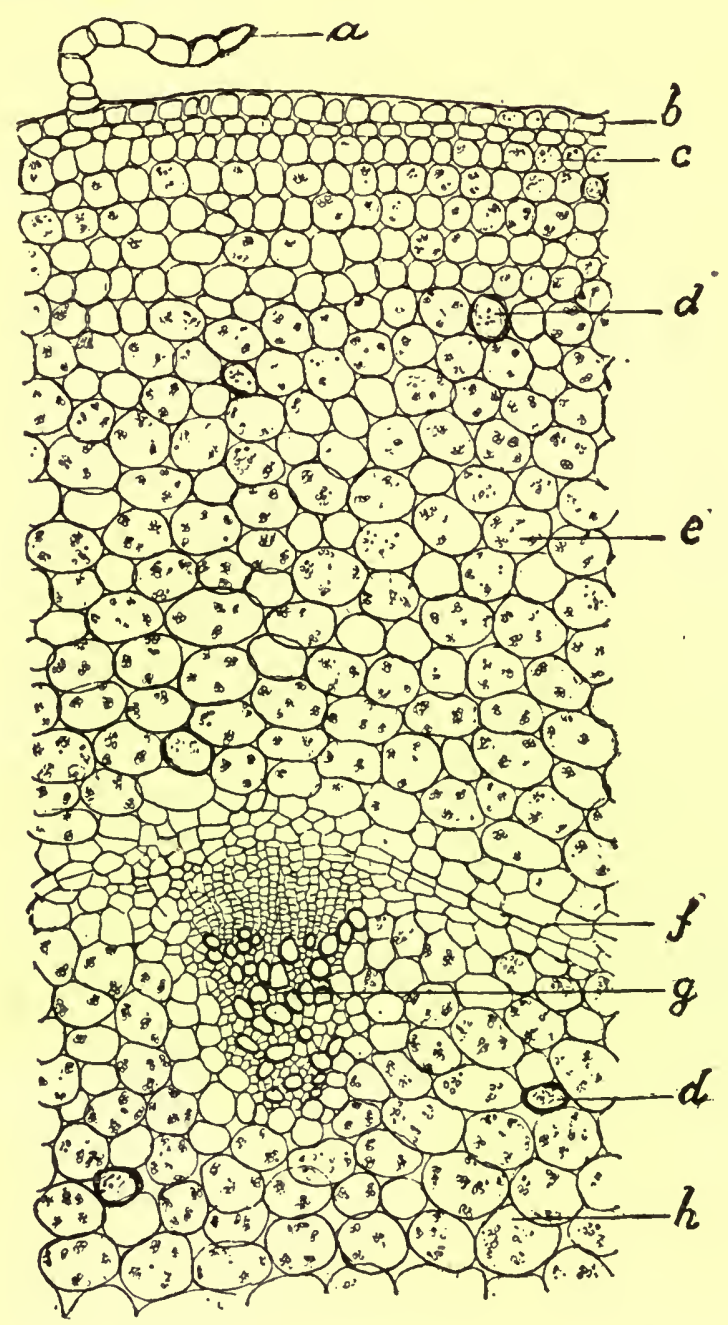

FIG. 77.-Asarum. Transverse section of the rhizome showing a uniseriate nonglandular hair $(a)$; epidermal layer $(b)$; several layers of collenchymatous cells $(c)$; starch-bearing parenchyma of cortex $(e)$; oil cells with suberized walls $(d)$; endodermis $(f)$; tracheæ $(g)$ with spiral or scalariform thickenings of the wall and associated with small tracheids; starch-bearing parenchyma of pith $(h)$.-After Bastin, Amer. Jour. Pharm., 1894, p. 574.

Allied Plants.-The rhizome of a related species, Asarum europæum, a common plant of the mountainous regions of Europe, is 
used in those countries. It very closely resembles Asarum, is of a grayish- or reddish-brown color, with an aromatic and pungent taste and the powder is sternutatory. It contains 1 per cent of a volatile oil which consists in part of a camphor known as asarin or asaron; 1 per cent of tannic acid colored green with ferric salts; 2 per cent of starch and 0.15 per cent of resin.

Serpentaria.-The rhizome and roots of several species of Aristolochia (Fam. Aristolochiacex), perennial herbs indigenous to the southern Inited States. There are two commercial varieties:

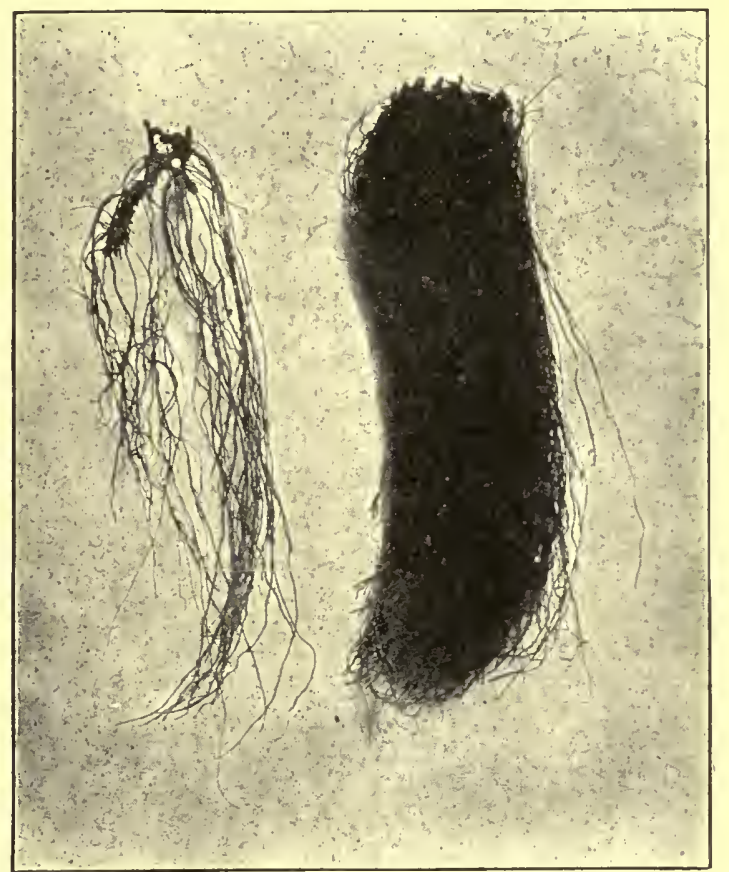

FIG. 78.-Serpentaria (Virginia snakeroot) showing oblique rhizomes with numerous long, slender roots.

(1) Virginia Snakeroot, yielded by Aristolochia Serpentaria, found growing east of the Mississippi, and (2) Texas or Red River Snakeroot, yielded by Aristolochia reticulata, growing west of the Mississippi. The rhizome and roots are collected in autumn and dried (Fig. 78).

Virginia Snakeroot.-Rhizome oblique, sub-cylindrical, with numerous slender roots and frequently with leaves or fruiting stems, 10 to $25 \mathrm{~mm}$. in length, asd 1 to $2 \mathrm{~mm}$. in diameter; externally dark brown, slightly annulate from sears of bud-scales, upper portion 
with stem-scars or stem-remnants, under and side portions with numerous roots and root-scars; fracture short; internally, bark dark brown, 0.3 to $0.5 \mathrm{~mm}$. in thickness, wood yellow, radiate, porous, 1 to $1.5 \mathrm{~mm}$. in thickness, pith $1 \mathrm{~mm}$. in diameter; odor terebinthinate; taste bitter, aromatic.

Roots nearly straight, 4 to $7 \mathrm{~cm}$. in length, about $0.3 \mathrm{~mm}$. in diameter, longitudinally wrinkled, bark light brown, wood yellowish, 5-rayed.

Texas Snakeroot.-Rhizome 10 to $40 \mathrm{~mm}$. in length, 1 to $3 \mathrm{~mm}$. in diameter; roots about $0.5 \mathrm{~mm}$. in diameter, with numerous more or less interlacing rootlets.

Inner Structure.-(Fig. 79.) Rhizome with an outer corky layer; bast fibers either single or in groups and forming a more or less closed ring; xylem composed of tracheæ and wood fibers forming broad wedges; medullary rays about 8 cells wide the walls being porous and strongly lignified. Numerous starch grains occur in the parenchyma cells of the cortex and pith and in the medullary rays. The root in section shows a compact 4- to 6-rayed stele and a wide starchbearing cortex. The stem is distinguished by a continuous ring of schlerenchymatous fibers, and a few typical non-glandular hairs, the terminal cells being somewhat recurved in the form of a hook.

Powder.-Grayish-brown or dark yellow; starch grains numerous, single and 2- to 4-compound, the individual grains, from 0.003 to $0.014 \mathrm{~mm}$. in diameter, being more or less spheroidal or plano-convex, and frequently with a central cleft; lignified elements numerous, consisting of tracheæ, wood-fibers, medullary ray cells and pith cells; a few typical non-glandular hairs of the stem are occasionally present.

Constituents.- Volatile oil 0.5 to 1 per cent, the important constituent of which is borneol; a bitter poisonous principle, aristol lochin (serpentarin), an alkaloidal principle, aristolochine; several organic acids; starch; ash about 10 per cent.

Substitutes.-The rhizome of yellow root (Jeffersonia diphylla) is sometimes substituted for serpentaria, from which it is distinguished by its lack of odor and by having a bitter, acrid taste.

\section{POLYGONACEA, OR BUCKWHEAT FAMILY -}

Mostly herbaceous plants, with nearly entire leaves, and distinguished by having jointed stems, usually sheathing united stipules and a 3 - to 4 -angled achene. The plants also usually contain tannin cells and resinous secretory cells, the latter sometimes being branched 

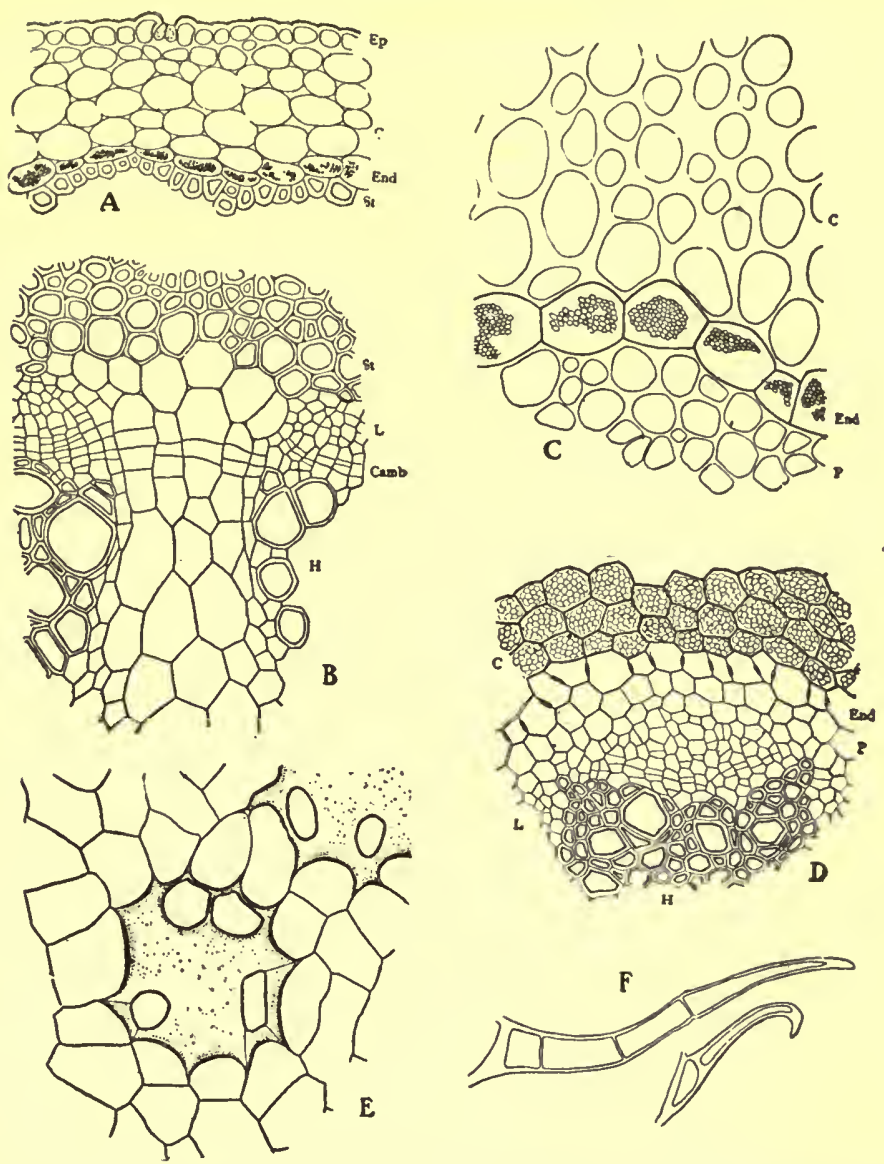

Fig. 79.-Serpentaria. A, transverse section of stem-internode showing epidermal layer $(E p)$ with a single stoma; cells of cortex of which the outer strata are collenchymatous, the remainder being parenchymatous and containing chloroplastids and oil; endodermis consisting of a layer of thin-walled starch-bearing cells $(E n d)$; pericycle of several layers of thick-walled sclerenchymatous fibers $(S t) . \quad B$, section of stele of stem-internode showing sclerenchymatous fibers $(S t)$; leptome $(L)$; cambium extending to the parenchymatous rays between the vascular bundles $(\mathrm{Camb})$; and hadrome $(H)$ or tracheæ portion of the vascular bundle. $C$, transverse section of a swollen node showing collenchyma $(C)$ of which the entire cortex is made up; starch-bearing endodermis $(E n d)$ and steromatic pericycle $(P)$ which is very much reduced. $D$, transverse section of a secondary root showing starch-bearing parenchyma cells of cortex $(C)$; endodermis $(E n d)$ of thin-walled cells with distinct (Casparyan spots and free from starch; pericambium $(P)$; leptome $(L)$; hadrome $(H)$. $E$, epidermis with silicified cells from the upper or ventral surface of the lamina of the leaf and are the cause of the small perforations seen in the leaf blade when held toward the light. $F$, non-glandular hairs from the leaf, one of which is very prominently curved forming a small hook. After Holm, Merck's Report, 1907, p. 276. 
The hairs include both non-glandular and glandular, the head in the latter being usually small, but sometimes large and peltate. Calcium oxalate usually occurs in the form of rosette aggregates.

RHEUm.-Rhubarb.-The rhizome of Rheum officinale, Rheum palmatum, Rheum palmatum tanguticum, and probably other species of Rheum (Fam. Polygonaceæ), perennial herbs (Fig. 80) indigenous to northwestern China and eastern Thibet, and sparingly cultivated in other parts of the world. The rhizomes are collected in autumn from plants that are eight to ten years old, most of the bark is removed, and they are then perforated, strung on ropes and dried either in the sun or by artificial heat. The drug is exported chiefly from Shanghai. The principal commercial varieties are known as Chinese rhubarb, Canton rhubarb and Shensi rhubarb, the latter being preferred.

Description.-Cut into irregular plano-convex and oblong pieces, frequently with a large perforation, hard and moderately heavy, 5 to $15 \mathrm{~cm}$. in length, 5 to $8 \mathrm{~cm}$. in breadth and 3 to $6 \mathrm{~cm}$. in thickness, externally mottled from alternating striæ of light brown parenchyma cells and dark-brown medullary rays, occasionally with reddish-brown cork patches and small radiate scars of fibrovascular tissue, smooth and sometimes covered with a light-brown powder; fracture somewhat granular; internally light brown; odor distinct; taste bitter, astringent and gritty.

Light and spongy rhizomes should be rejected.

Inner Structure.-See Fig. 81.

Powder.-(Fig. 82.) Yellowish-brown; crystals of calcium oxalate in rosette aggregates, 0.050 to $0.150 \mathrm{~mm}$. in diameter; starch grains numerous, spheroidal, from 0.002 to $0.020 \mathrm{~mm}$. in diameter, either single or 2- to 4-compound; tracheæ few, reticulate, occasionally spiral. The powder is colored reddish with alkalies. A common adulterant is wheat middlings. The exhausted drug is frequently added to the powder and may be detected by the somewhat altered starch grains and the decrease in the amount of the aqueous or dilute alcoholic extract, which in genuine rhubarb is about 35 per cent.

Constituents.-The principal constituent appears to be a glucoside (possibly the chrysophan of some authors) or an undetermined substance which yields successive oxidation products, viz.: chrysophanic acid (di-oxy-methyl-anthraquinone), emodin (tri-oxymethyl-anthraquinone), and rhein (tetra-oxy-methyl-anthraquinone). Chrysophanic acid crystallizes in golden-yellow, clinorhombic prisms and dissolves in alkalies and in concentrated sulphuric acid, 
the solutions having a deep-red color. It is reformed in rhubarb after extracting it by exposing the moistened root to air. Emodin

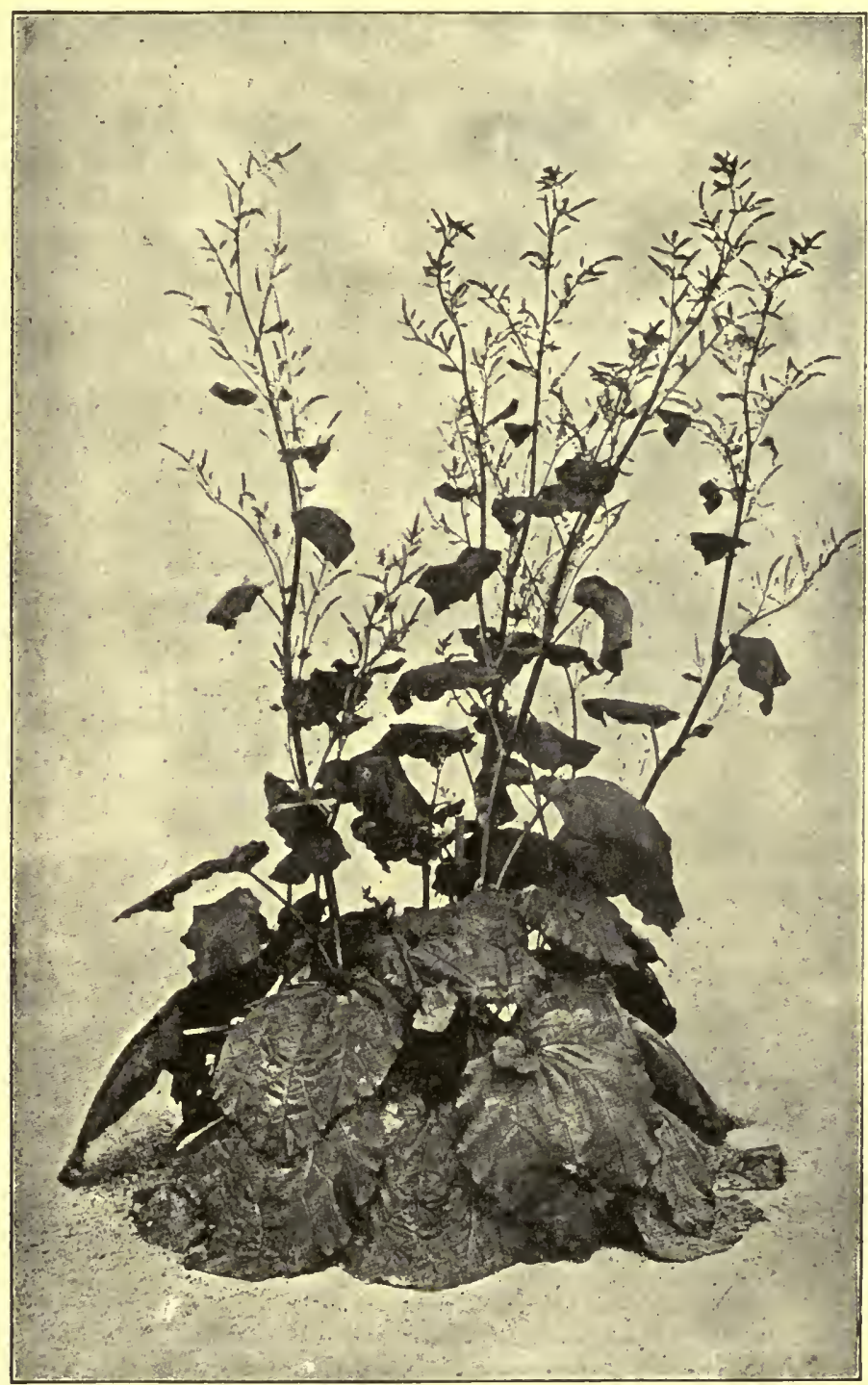

Frg. 80.-Rheum officinale, growing in the Chelsea Physic Garden (London). $\neg$ After Pérrédès.

occurs to the extent of 1.5 per cent and forms orange-red needles which are soluble in hot toluene and give with alkalies and alkali 
carbonates purplish colored solutions. Rhein forms yellowish-brown scales which are insoluble in hot toluene, soluble in hot acetic acid and produce purplish-red solutions with the alkalies or alkali car-

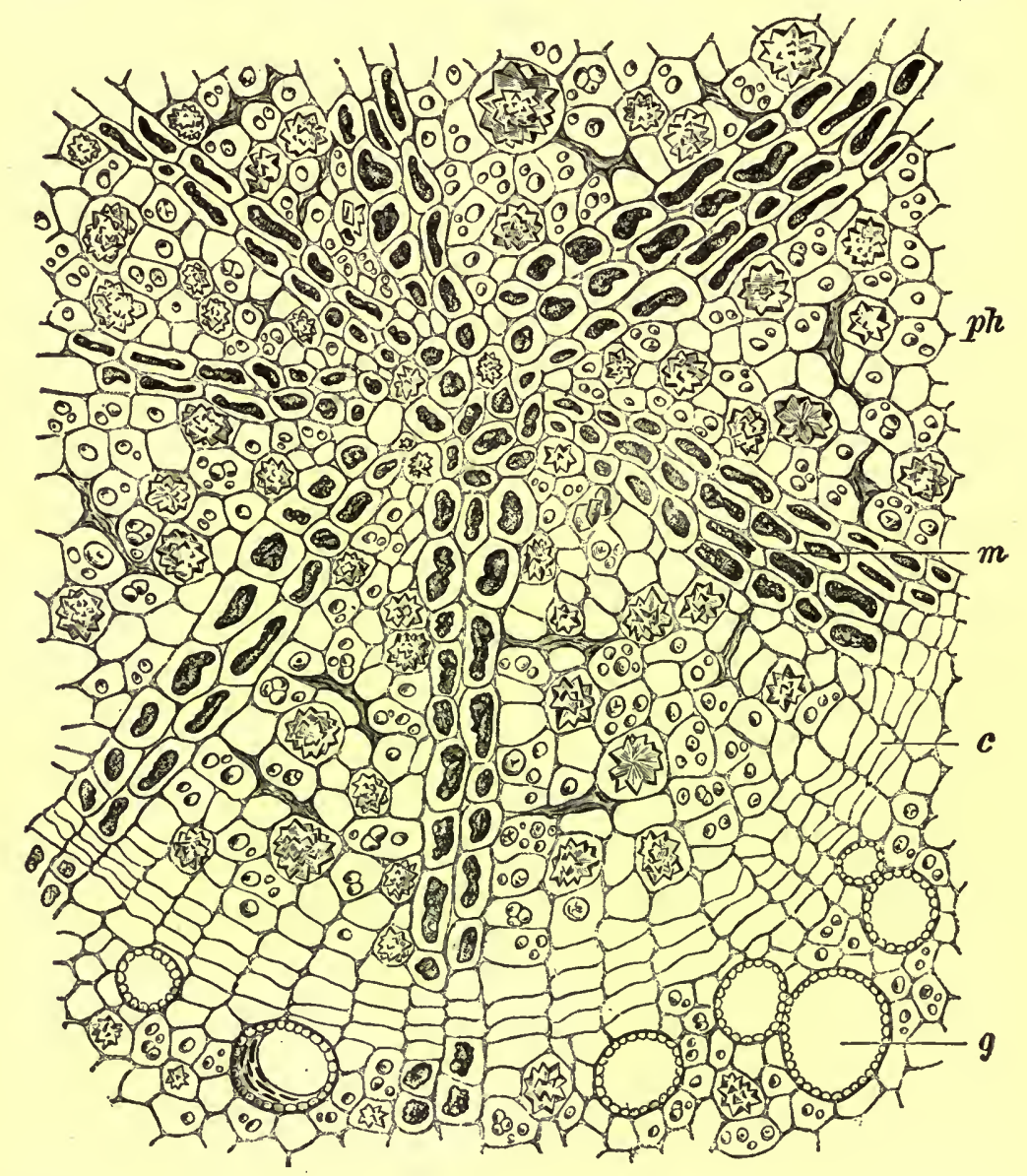

Fig. 81.-Rhubarb.-Characteristic group of compound fibrovascular bundles seen in transverse section. $(P H)$, a wedge-shaped group of leptome with starch-bearing and crystal cells, cambial layer $(c)$ separating phloem from the xylem with their large tracheæ $(g)$; medullary rays cells $(m)$ filled with a brownish amorphous substance.-After Moeller.

bonates. Recently another oxymethylanthraquinone-yielding substance, rheopurgarin, has been isolated from Shensi rhubarb. It forms yellow needles, and appears to be composed of four glucosides: $(a)$ one related to emodin, (b) one related to rhein, $(c)$ chrysophaneir 
which yields chrysophanic acid, and $(d)$ rheochrysin, which yields a yellow crystalline body, rheochrysidine, considered to be identical with Hesse's rhabarberon or iso-emodin. The following glucosidal tannoid constituents are also present: glucogallin, yielding gallic acid, and tetrarin, yielding in addition to gallic acid, cinnamic acid and rheosmin, an aldehyde having the odor of rhubarb. A catechin resembling the catechin of gambir has also been found. Rhubarb also contains considerable starch; calcium oxalate; and yields about 15 per cent of ash.

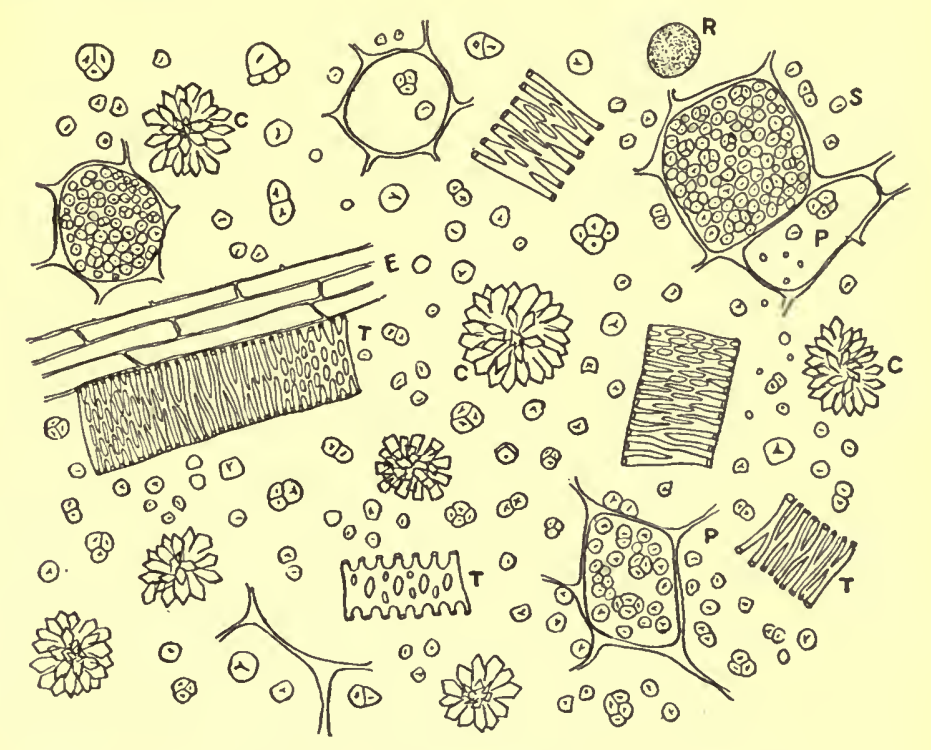

FIG. 82.-Rhubarb: $C$, rosette aggregates of calcium oxalate; $P$, parenchyma containing starch grains $(S) ; T$, tracheæ; $E$, sieve; $R$, reddish-brown amorphous masses separated from the resin or tannin cells.

Rhubarb leaves contain oxalic acid and cases of poisoning are recorded from their consumption. (Jour. A. M. A., 1917, p. 1954).

Allied Plants. - The rhizomes of other species of Rheum are also used to a limited extent, as English or Austrian rhubarb from Rheum rhaponticum; they are more or less cylindrical, distinctly radiate, and contain, besides chrysophanic acid, rhapontin. Rheum palmatum, which is cultivated in France, Germany and Russia, produces rhizomes that are lighter in color and less valuable than the Chinese rhubarb, the constituents being similar to those of Austrian rhubarb.

Rhapontic rhubarb contains a crystalline glucoside rhaponticin, which is colored purplish-red with sulphuric acid, changing to orange. 
It is insoluble in ether and readily separates from a dilute alcoholic fluid extract on the addition of ether.

Compound Powder of Rhubarb.-Consisting of powdered rhubarb, magnesium oxide and powdered ginger. A pinkish-white mobile powder, becoming darker on exposure to air; when examined the compound powder of rhubarb shows a finely granular ground mass of magnesium oxide, numerous starch grains and characteristic fragments of vegetable tissues; starch grains of ginger more or less elliptical or ovoid, frequently with a prominent beak, from 0.005 to $0.060 \mathrm{~mm}$. in diameter, starch grains of rhubarb, single or compound, either spheroidal or polygonal, often with a central cleft and the individual grains from 0.002 to $0.020 \mathrm{~mm}$. in diameter;
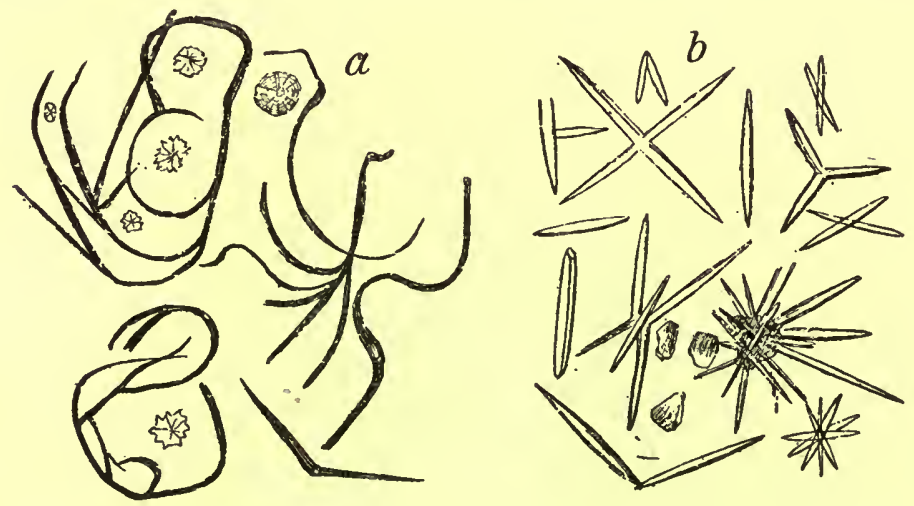

FIG. 83.-Crystals of oxymethylanthraquinones sublimed from rhubarb. $a$, crystals obtained at higher temperatures; $b$, crystals obtained by sublimation at a lower temperature or may be obtained by re-crystallizing the form shown in (a).-After Tunmann, Pflanzenmikrochemie.

mounts made with solution of hydrated chloral show a strong effervescence and show more clearly the fragments of reticulate tracheæ, the reddish-brown parenchyma of rhubarb in some of the cells of which occur numerous small starch grains, and the characteristic rosette aggregate crystals of calcium oxalate varying from 0.050 to $0.100 \mathrm{~mm}$. in diameter; with solutions of the alkalies many of the fragments become of a deep red color.

Ruxix.-Yellow Dock.-The rhizome and roots of the common yellow dock or curled dock (Rumex crispus). The drug is collected in the autumn, freed from adhering rootlets, cut into longitudinal pieces or into transverse segments and dried.

Description.-Usually in small pieces from 1 to $4 \mathrm{~cm}$. in diameter and 3 to $25 \mathrm{~mm}$. in thickness; or split into pieces attaining a length 
of $15 \mathrm{~cm}$., occasionally entire, attaining a length of $3 \mathrm{dm}$.; externally reddish- to grayish-brown, upper or rhizome portions distinctly annulate, showing stem scars or stem bases and numerous small circular root scars; lower or root portion longitudinally wrinkled; fracture either short and mealy, or tough and fibrous; cortex narrow, reddish-brown, wood portion yellowish-brown to reddish-brown, somewhat radiate, pith usually depressed; odor slight; taste astringent, somewhat bitter and nauseous.

Inner Structure.-Outer layer of a single row of dark-brown cells; a stratum of collenchyma of several rows of very narrow tangentially elongated cells; parenchyma of cortex of thin-walled cells and containing either starch or rosette aggregates of calcium oxalate and distributed among which occur occasioned vascular bundles; the stele is composed of numerous small vascular bundles with a small number of tracheæ separated by a cambium from the leptome which is distinct and composed of rather thick-walled more or less collapsed cells; pith composed of starch-bearing parenchyma and calcium oxalate. Sections mounted in solutions of ferric salts are colored bluish-green. The tannin cells may be determined by placing the fresh drug in solutions containing about 7 per cent of copper acetate. If sections are mounted in solutions of the alkalies they are colored deep red, due to the presence of chyrsophanic acid.

Powder.-Dark brown; calcium oxalate in rosette aggregates from 0.020 to $0.080 \mathrm{~mm}$. in diameter; starch grains numerous, ellipsoidal or narrowly elongated, from 0.003 to $0.025 \mathrm{~mm}$. in length; stone cells occurring beneath the cork cells, 0.040 to $0.125 \mathrm{~mm}$. in diameter, with walls that are somewhat lamellated, 0.015 to $0.020 \mathrm{~mm}$. in thickness and with few simple pores; cork cells light brown; sclerenchymatous fibers wanting; tracheæ about $0.100 \mathrm{~mm}$. in width with scalariform and reticulate thickenings of the wall. On mixing the powder with water and adding a solution of one of the alkalies a red color is produced. In Rumex hymenosepalus the parenchyma cells are about $0.200 \mathrm{~mm}$. in diameter, with reddish colored walls and contain numerous spheroidal or ellipsoidal starch grains from 0.008 to $0.015 \mathrm{~mm}$. in diameter; calcium oxalate crystals are few or wanting.

Constituents.-Several crystalline principles, viz.: Rumicin, a principle isometric with chrysophanic; nepodin, which occurs in in greenish prisms; and lapodin, which forms small needle-shaped crystals. The drug also contains a small amount of tannin, which is colored green with ferric salts.

Radix LaPathi.-Bitter Dock Root.-The rhizome and roots of Rumex obtusifolius (Fam. Polygonaceæ), a perennial herb which is 
indigenous to Europe and naturalized in the United States, growing in waste places throughout the Eastern and Central States. The rhizome and roots are gathered late in the summer, cut longitudinally and transversely into pieces in order to facilitate their drying.

The drug resembles that obtained from Rumex crispus, but is dark brown and considerably branched at the crown. In structure it resembles $\mathrm{R}$. crispus, but there are small groups of yellowish bast fibers in the cortical layer; the wood parenchyma is furthermore thick-walled and lignified. The following constituents have been isolated from it: Rumicin or chrysophanic acid, emodin, tannic acid, resin, lapathinic acid, sugar and ash. The latter is found to the extent of 9 per cent and contains iron.

Bistorta.-Rhizoma Bistorte, Bistort, Snakeroot or English Serpentary. - The rhizome of Polygonum Bistorta (Fam. Polygonaceæ), a tall perennial herb growing in moist woods of Europe and Asia. The rhizome is collected in the fall, deprived of its roots, cut into smaller pieces and dried.

The rhizome occurs in laterally flattened, occasionally branching pieces, from 2 to $6 \mathrm{~cm}$. in length and 10 to $15 \mathrm{~mm}$. in diameter; externally dark brown, more or less annulate, with a few slender roots and number of root scars; hard, tough and breaking with an almost smooth fracture; internally reddish-brown, distinctly radiate and showing a circle of darker vascular bundles, separating the large pith from a moderately wide cortex.

In microscopic sections the rhizome shows either an epidermal layer of thick reddish-brown cells, or the development of one or more rows of brownish-black cork cells; the parenchyma of both the cortex and pith contain either starch, rosette aggregates of calcium oxalate, or tannin; the collateral vascular bundles are separated by medullary rays from 2 to 8 cells in width.

Bistort contains from 15 to 20 per cent of gallic acid; 0.5 per cent of ellagic acid; 30 per cent of starch; 0.5 per cent of sugar; and 10 per cent of a nitrogenous substance.

Literature.-Zörnig, Arzneidrogen.

\section{CHENOPODIACEA, OR GOOSEFOOT FAMILY}

The plants are annual or perennial herbs and are widely distributed. The leaves are mostly alternate and without stipules, the flowers are usually small and of a green color, and the fruit is a 1seeded utricle. The most prominent characteristic in the structure 
of the plants of this family is the anomalous development of the stem in which secondary cambiums arise producing additional vascular bundles at the periphery of those originally formed. In the pericycle of the stem occur isolated groups of sclerenchymatous fibers. A great variety of forms of non-glandular hairs occur. Glandular hairs are rare except in a few genera, including Chenopodium, in which they consist of a series of superimposed cells the terminal cell of which is always glandular. Another rather interesting feature of this family is the presence in Atriplex and Chenopodium of bladderlike hairs for the storing of water.

Chenopodium.-American Wormseed.-The dried ripe fruit of Chenopodium ambrosioides anthelminticum (L.) Gray, an annual or perennial herb growing in waste places throughout the United States. The plant flowers from July until September and its fruits ripen in the autumn, at which time they are gathered. Most of our supplies come from Florida.

The fruit was at one time official but it has been replaced by its volatile oil. Considerable interest has been revived in this drug owing to the European war, which curtailed the supply of thymol and which has been used almost as a specific in the treatment of the hookworm disease. The oil of Chenopodium has fortunately been found to possess properties that make it a valuable substitute for thymol as a vermifuge. The plant is cultivated in Maryland for the distillation of the oil, and the oil distilled here is known commercially as Baltimore Oil of Chenopodium.

Description.--Somewhat globular, frequently more or less compressed, occasionally with portions of a short stem; from 0.75 to $1.5 \mathrm{~mm}$. in diameter; pericarp inflated, greenish-brown, thin and friable; seeds reddish-brown or brownish-black, ellipsoidal, somewhat reniform, nearly smooth and shining; odor aromatic, distinct; taste pungent and bitter.

Powder.-Yellowish-brown; fragments of membranous pericarp composed of elongated, colorless and thin-walled cells; seeds blackish shiny, reniform, about $0.150 \mathrm{~mm}$. in diameter; seed-coat with polygonal, thin-walled reddish-brown pigment cells; numerous starch grains and small aleurone grains.

Constituents.-From 0.6 to 1 per cent of a nearly colorless or yellowish volatile oil, having the odor and taste of the drug. It, consists of 45 to 70 per cent of an oxygenated compound, Ascaridol; 22 per cent of p-Cymol; also a terpene and d-camphor. The leaves yield 0.35 per cent of volatile oil, and the fresh plant contains a white, crystalline inodorous alkaloid, Chenopodine. 
Allied Plants.-Under the name of Herba Chenopodii, the Austrian Pharmacopœia recognizes Chenopodium ambrosioides. This plant, also known as Mexican Tea resembles very closely Cheno-

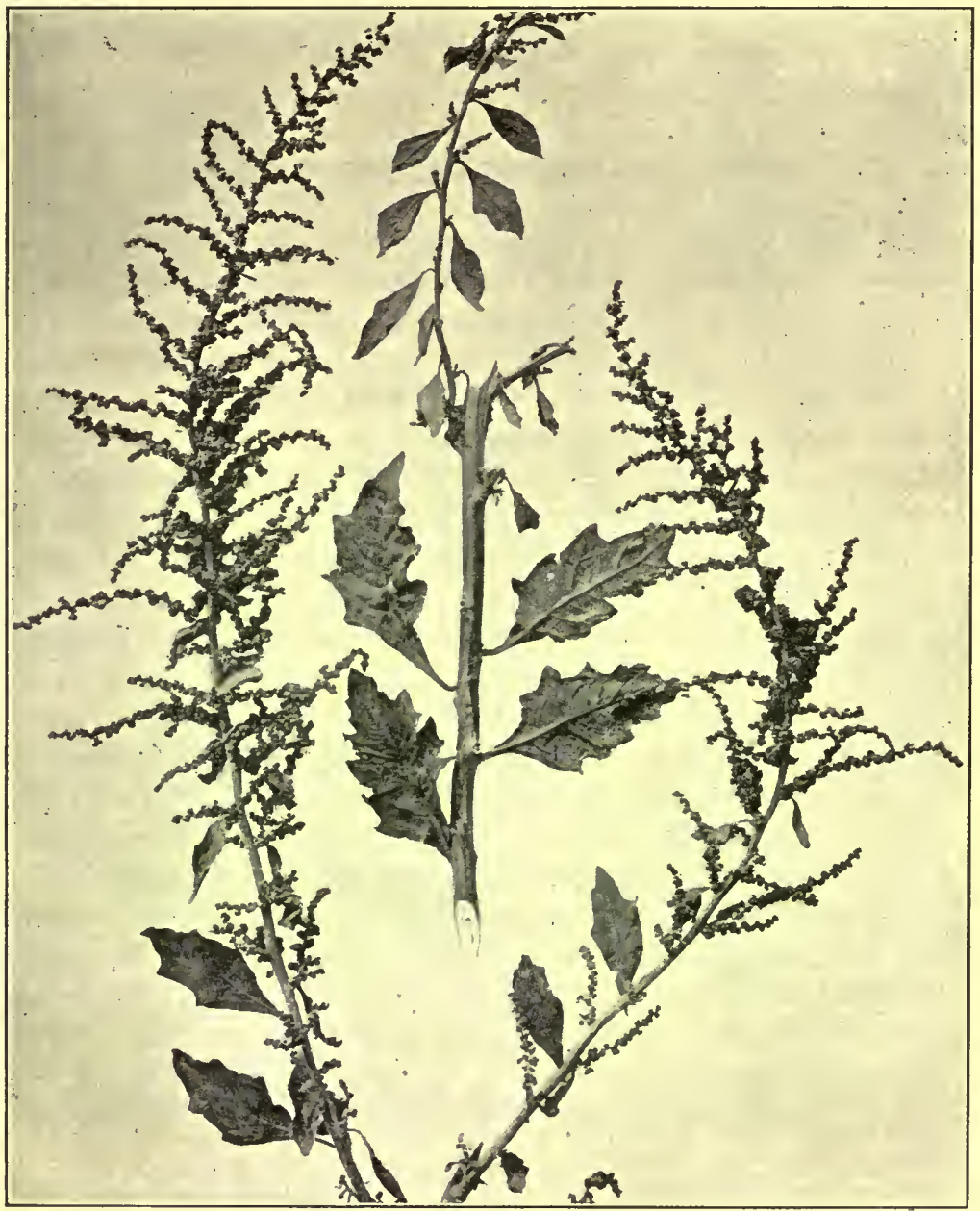

FIG. 84.-American wormseed. Fruiting branches of Chenopodium ambrosioides anthelminticum.-From Bulletin No. 26, U. S. Department of Agriculture.

podium ambrosioides anthelminticum, and is widely distributed in the United States. It is an annual with oblong-lanceolate, nearly entire or repand-toothed leaves and has densely flowered, leafy spikes. Microscopically it is characterized by possessing glandular 
hairs and numerous cells that are filled with microcrystals of calcium oxalate. The plant yields 0.33 per cent of a volatile oil having a strong aromatic odor and a bitter, pungent taste. The oil is used in Brazil as a popular anthelmintic. The leaves of this plant yield a volatile oil having a repulsive, narcotic odor resembling trimethylamine.

\section{PHYTOLACCACEE, OR POKEWEED FAMIIY}

The family includes herbs, shrubs and trees and of which there are less than 100 species. They are for the most part indigenous to tropical and sub-tropical America and Africa, being represented in the United States by one genus, Phytolacca. The inner morphology is quite distinctive. Calcium oxalate usually occurs in the form of raphides and styloids, also occasionally in microcrystals. In the stem, the pericycle is a continuous sclerenchymatous sheath and the vascular bundles are of the medullary type, i.e., separated by broad medullary rays. The structure of the root is anomalous, consisting of the formation of successive secondary rings of vascular bundles. The hairs are of the simple, uniseriate type. Neither glandular hairs nor special secretory cells occur in plants of this family.

Phytolacca.-Poke Root.-The root of Fhytolacca decandra (Fam. Phytolaccaceæ), a perennial herb (Fig. 85) indigenous to eastern North America, and naturalized in the West Indies and southern Europe. The root is collected in autumn and, after removal of the rootlets, cut into transverse and longitudinal pieces and dried.

Description.-Fusiform or nearly cylindrical, tapering, usually in longitudinal ribbon-like slices, 8 to $16 \mathrm{~cm}$. in length, 5 to $15 \mathrm{~mm}$. in diameter, 2 to $10 \mathrm{~mm}$. in thickness; externally, bark dark brown, more or less wrinkled; fracture fibrous, tough; internally light brown, characterized by alternating zones of collateral fibrovascular bundles and parenchyma formed by secondary cambiums; odor slight; taste acrid.

Inner Structure.-See Kraemer's "Applied and Economic Botany," p. 318.

Powder.-Dark yellow; sternutatory; fragments with long sclerenchymatous fibers and large scalariform tracheæ; starch grains 0.007 to $0.020 \mathrm{~mm}$. in diameter; calcium oxalate in raphides $0.030 \mathrm{~mm}$. in length or in sphenoid microcrystals.

Constituents.-A bitter, acrid glucoside resembling saponin; a crystalline alkaloid phytolaccine, which is soluble in alcohol and sparingly soluble in water; sugars 10 per cent; starch 10 per cent; 
phytolaccic acid; formic acid; potassium formate 2 per cent; calcium oxalate 6 per cent; and ash 13 per cent of which about onehalf is potassium oxide.

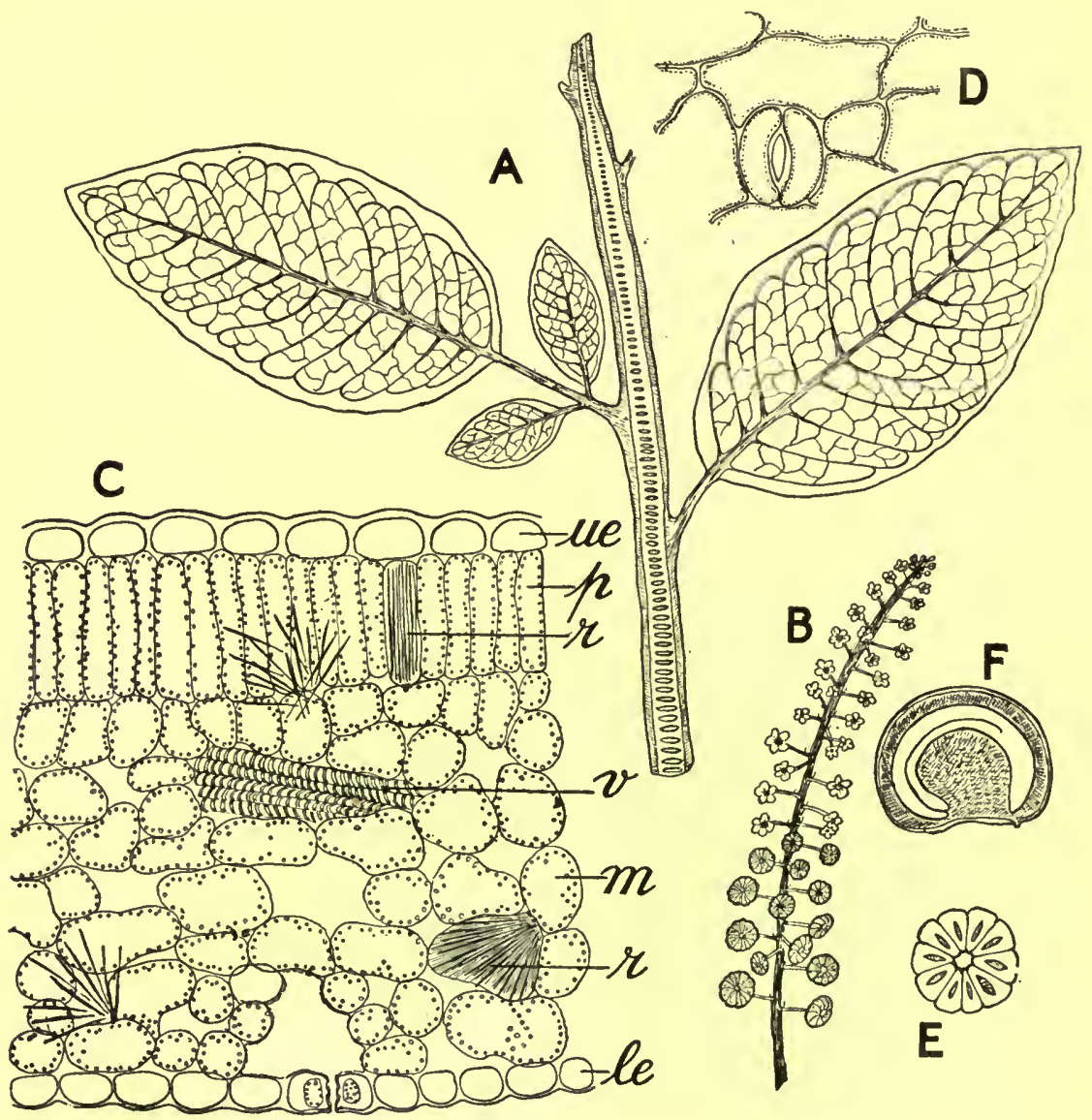

FIG. 85.-Poke weed (Phytolacca decandra): $A$, portion of shoot showing leaves and stem which has a large pith with bi-convex cavities resembling the pith of certain xerophytic Compositæ, as Senecio præcox of Mexico; $B$, raceme showing fruits at the lower portion and flowers at the summit; $C$, transverse section of leaf showing upper epidermis (ue), palisade cells $(p)$, raphides $(r)$, spiral tracheæ $(v)$, parenchyma $(m)$ with large intercellular spaces, lower epidermis $(l e) ; D$, stoma of lower surface of leaf; $E$, transverse section of fruit; $F$, longitudinal section of seed, the embryo being curved and the endosperm containing starch.

Phytolaccæ Fructus or Phytolacca Fruit occurs in agglutinated masses of a purplish-black color, and consists of the compound 
berries, which are about $8 \mathrm{~mm}$. in diameter and composed of 10 loculi, each of which contains a single, lenticular, black seed. The sarcocarp is fleshy, sweet and slightly acrid and contains a purplish-red coloring principle which is soluble in water but not in alcohol, and which is decomposed on heating the aqueous solution. The fruit also contains phytolaccic acid, several fruit-acids and phytolaccin, a substance resembling tannin.

Literature.-Holm, Merck's Report, 1907, p. 312.

\section{CARYOPHYLLACEÆ, OR PINK FAMILY}

Mostly annual or perennial herbs represented by about 1500 species and are found mostly in the Northern Hemisphere, a large number growing in the United States. The stems are mostly swollen at the nodes; the leaves are entire and opposite and the flowers are symmetrical and 4- to 5-merous. Calcium oxalate occurs in the form of rosette aggregates ormicro crystals. The hairs, both glandular and non-glandular, are simple and uniseriate. Especially characteristic are the stomata, the walls of their two neighboring cells being transverse to the pores. Sclerenchymatous tissue is wanting in the leaf, but present in the form of a closed ring in the cortex of the stem. In the latter, the medullary rays are replaced by parenchyma.

Radix Saponariæ Rubra.-Red Soaproot, Soapwort or Saponary.-The rhizome and roots of the perennial herb cornmonly known as Bouncing Bet or Soapwort, Saponaria officinalis (Fam. Caryophyllaceæ). The plant has been naturalized from Europe and is very common in certain localities, growing along roadsides, river banks and in waste places. The flowers are showy and vary from white to rose pink in color. The thick rhizomes, with their more or less fleshy roots, are gathered from one- or two-year old plants. deprived of the smaller roots and cut transversely into pieces of suitable length.

Description.-Cylindrical, more or less branched, from 5 to 12 $\mathrm{cm}$. in length and 5 to $10 \mathrm{~mm}$. in thickness; outer surface reddishbrown, longitudinally wrinkled and furrowed and occasionally spirally twisted; fracture short and even; inner surface with a brownishred corky layer, cambial zone distinct separating the non-radiate yellowish wood from the whitish, yellowish or grayish-brown cortex; odor slight; taste sweetish and bitter. Rhizomes usually more or less knotted and 4-angled and possess 2 to 4 characteristic wood wedges.

Inner Structure.-See Fig. 86. 

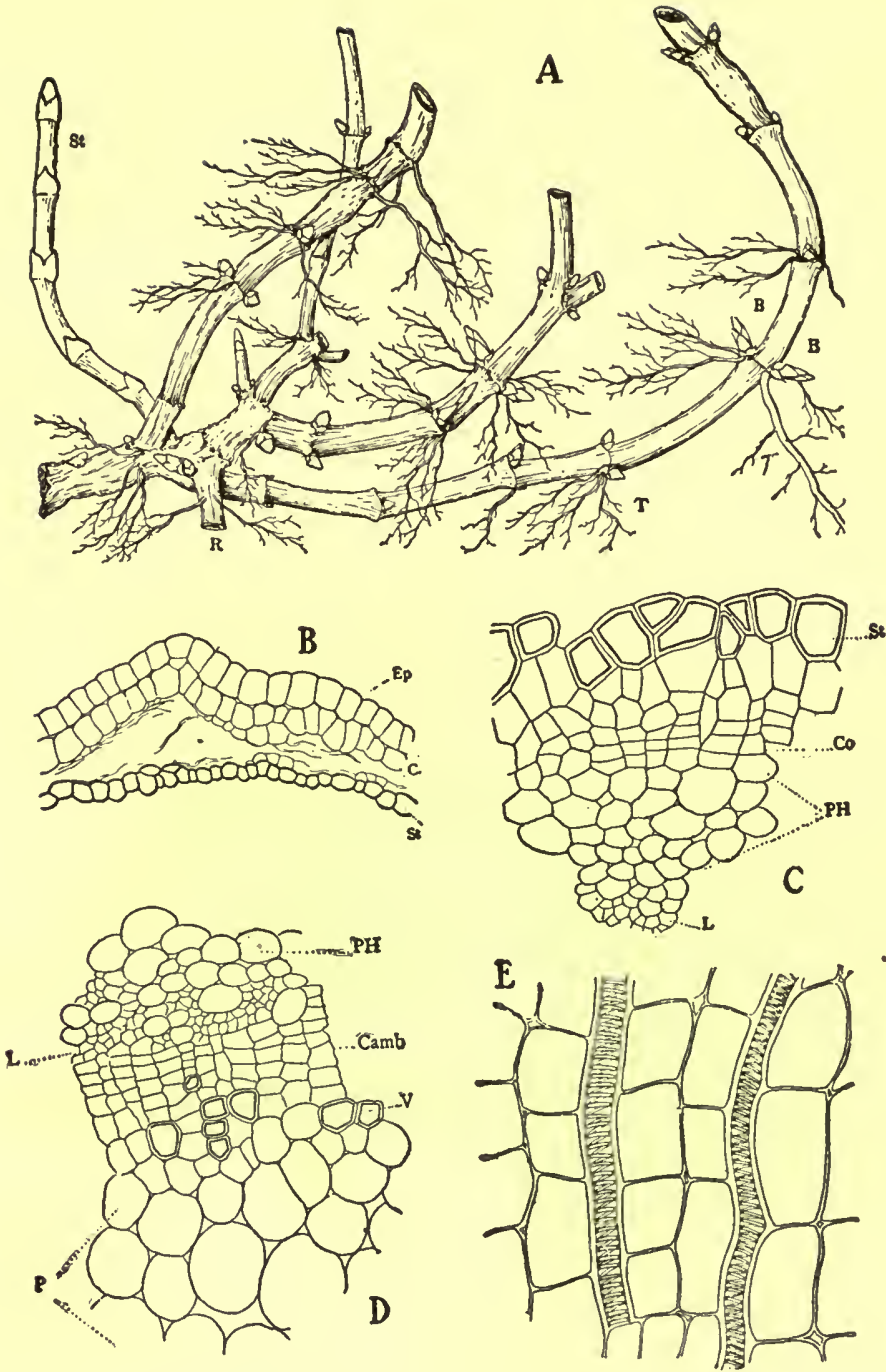

Fig. 86.-Saponaria officinalis. $A$, showing the thick, branching, horizontally creeping rhizome (stolon), producing numerous buds $(B)$ and ramifying roots $(T)$ at the nodes; $R$, base of a long thick secondary root; $S t$, an ascending stolon which has not yet reached the surface of the ground. $B$, transverse section of an apical internode of a stolon, showing epidermal cells $(E p)$, the inner collapsed portion of cortex $(C)$, and the outermost layer of pericycle consisting of sclerenchymatous fibers $(S t) . \quad C$, transverse section of apical internode of a stolon, showing the innermost layer of sclerenchymatous fibers of the pericycle $(S t)$, underneath which is the underlying cork $(C o)$; phelloderm $(P h)$ and leptome $(L) . \quad D$, transverse section of part of a 
Constituents.-Saporubrin, a saponin-like glucoside, to the extent of 4 per cent. The drug also contains Saporubic acid, which resembles the Quillajic acid found in Quillaja. The leaves of this plant are said to contain another glucoside, termed by Barger, Saponarin.

Allied Drugs.-The over-ground stems are sometimes collected and cut into small pieces about $5 \mathrm{~mm}$. in length. These resemble Dulcamara and have been sold for it. It is distinguished by the stems of Saponaria being nearly cylindrical, marked by distinctly swollen nodes and usually having a solid pith.

\section{ANONACEE, OR CUSTARD APPLE FAMIIY}

A family of trees or shrubs common in the tropics and represented in the eastern United States by the North American Papaw (Asimina triloba). The fruits of the latter are ellipsoidal berries, from 5 to $15 \mathrm{~cm}$. in length, having a yellowish-brown pulp and contain a number of dark-brown seeds. The fruit ripens after frost, possesses a sweetish taste resembling the banana, and is highly esteemed by the negroes.

The leaves of this family are mostly aromatic, due to the presence of resin-secretion cells, which are similar to those found in the Magnoliaceæ. Mucilage cells are also present in some of the genera. It is not infrequent to find in the pith large lacunæ separated by groups of stone cells. Calcium oxalate usually occurs in the form of rosette aggregates, although isolated crystals are also present. The non-glandular hairs are of different types. Glandular hairs are absent.

Anona Muricata.-Soursop.-The leaves of Anona muricata (Fam. Anonaceæ), a shrub growing in the Savannas of the Antilles and Brazil and cultivated to some extent, are reputed to possess medicinal properties. A chemical examination of the leaves which were obtained from Dominica, W. I., showed them to contain a small amount of a volatile oil; an alkaloidal substance which could not be crystallized; myricyl alcohol; sitosterol; a substance designated anonol, which is probably a phytosterol-glucoside; a mixture of fatty acids; and considerable potassium chloride, together with

stele of an apical internode of a stolon showing the phelloderm $(P h)$ and the inter-fasicular tissue which has developed into leptome $(L)$; cambium (Camb) and hadrome $(V)$; pith $(P) . E$, longitudinal section of the pith portion of a thick root showing 2 of the spiral vessels.-After Holm. 
dextrose, tannin, and amorphous products. (Power, Pharm. Journ., 1911, p. 743.)

\section{MYRISTICACEE, OR NUTMEG FAMILY}

A small family consisting of about 80 species of tropical trees and shrubs. The leaves are entire and evergreen, the flowers are small, and the plants are diœcious. The fruit is a fl shy capsule and the seeds are covered by a fleshy arillus. The family is furthermore characterized by the presence of spheroidal secretion calls, containing a semi-fluid or crystalline oily substance, which is variously colored from yellow or red to brownish-black. The cells possess suberized walls and are distributed in all parts of the plant. Calcium oxalate occurs in the form of small needle-shaped crystals, which frequently are arranged in aggregates. The hairs are of the stellate type and are very characteristic for several of the species.

MYristica.-Nutmeg.-The kernel of the seed of Myristica fragrans (Fam. Myristicaceæ), a tree indigenous to the Molucca and neighboring islands, and now extensively cultivated in other tropical regions, including the West Indies. The commercial supply is largely derived from the Malay Archipelago, whence it is shipped to Amsterdam and London. The testa and arillode are removed, the latter constituting mace. With the exception of those from Penang, nutmegs are not infrequently partially coated with lime to protect them from the attacks by insects. The Banda Islands produce a large part of the world's supply of nutmegs, as well as the other spices, and the term "Banda" when applied to either nutmeg or mace indicates a superior quality.

Description.-Ellipsoidal, 20 to $30 \mathrm{~mm}$. in length, 15 to $20 \mathrm{~mm}$. in diameter; exte.nally lignt brown, usually whitish from a dressing of lime, reticulately furrowed, at one end a white, smooth projection 3 to $5 \mathrm{~mm}$. in diameter, in the center of which is the micropyle, the chalaza indicated near the other end by a slight, dark depression from which there extends a more or less distinct furrow indicating the position of the raphe; easily cut, the surface having a waxy luster, and mottled by reason of the light-brown perisperm penetrating into the yellowish-brown endosperm, the shrunken embryo lying in an irregular cavity about 4 or $5 \mathrm{~mm}$. in length, near the micropyle; odor and taste aromatic and pleasant.

Inner Structure.-See Fig. 87.

Powder.-Dark reddish-brown; numerous irregular yellowishbrown or brownish-black fragments of secondary perisperm, showing 

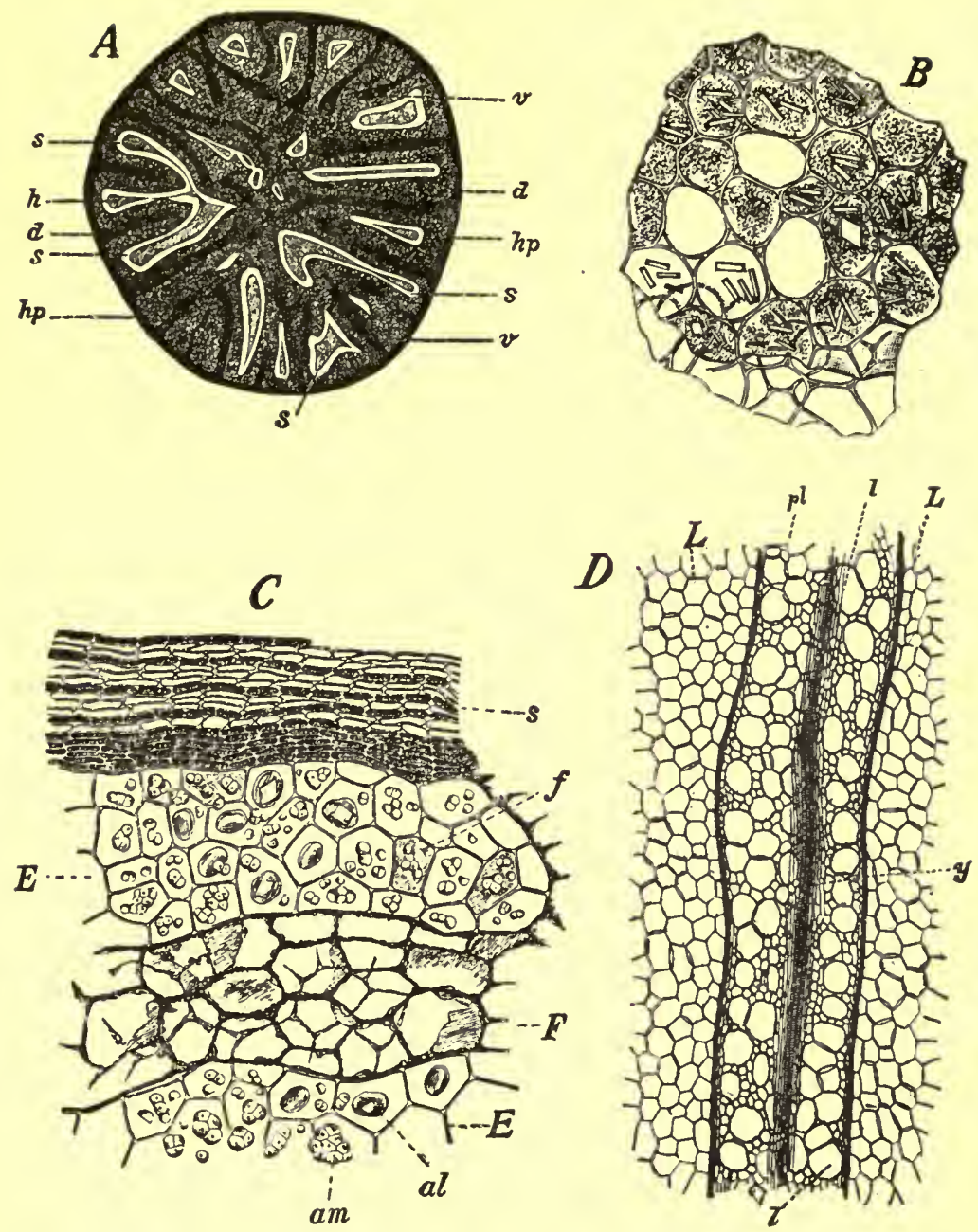

FIG. 87.-Myristica. A, transverse section through the kernel showing the outer layer of perisperm $(h p)$ with its inward ramifying projections $(v)$, which extend into the endosperm $(d)$; in the latter are irregular cavities $(s)$ in which occurs a lighter and more recently developed tissue corresponding to the endosperm. $B$, a surface view of the perisperm with brownish thinwalled cells and containing an amorphous reddish-brown substance in which rod-shaped crystals of either calcium carbonate or a salt of tartaric acid may separate. $C$, transverse section showing perisperm composed of thinwalled lignified cells having a reddish-brown content; cells of endosperm $(E)$ containing either starch grains $(\mathrm{am})$, aleuronc grains $(\mathrm{al})$, tannic acid, or a reddish-brown amorphous substance $(f)$; secondary perisperm $(F)$ composed of secretion cells having an amorphous brownish content and small parenchyma. $D$, transverse section through one of the infolded strands of peri- 
the large nearly transparent spheroidal or ellipsoidal oil-secretion cells, associated with small polygonal parenchyma and spiral tracheæ; parenchyma cells of the endosperm more or less polygonal, and filled with starch grains and aleurone grains; starch grains single or 2to 20-compound, the individual grains being spheroidal, planoconvex or polygonal, from 0.003 to $0.020 \mathrm{~mm}$. in diameter and colored blue with iodin solution (distinction from starch grains in mace, which are colored yellowish-red); fragments of parenchyma containing aleurone grains show frequently large rhombohedral prisms. Mounts made with hydrated chloral solutions show numerous globules of a fixed oil which later may separate in the form of rod-like crystals; mounts in any of the fixed oils show the separation of spheroidal aggregates of crystals of the fixed oil which polarize light strongly. The powder made from "limed" Nutmeg shows, under the microscope, upon the addition of water containing 25 per cent of sulphuric acid, the immediate separation of crystals of calcium sulphate in the form of small needles or short rods which do not polarize light.

Constituents.-Fixed oil, sometimes occurring in prismatic crystals, 25 to 40 per cent; volatile oil 8 to 15 per cent. The oil is official as Oleum Myristicæ and contains myristicin and a number of terpenes. Nutmegs also contain considerable proteins and starch, the latter being colored blue by iodin solutions.

Standard of Purity.-Nutmeg is the dried seed of Myristica fragrans Houtt., deprived of its testa, with or without a thin coating of lime $(\mathrm{CaO})$. It contains not less than 25 per sent of non-volatile ether extract, not more than 10 per cent of crude fiber, not more than 5 per cent of total ash, nor more than 0.5 per cent of ash insoluble in hydrochloric acid.

Macassar nutmeg, Papua nutmeg, male nutmeg, long nutmeg, is the dried seed of Myristica argentea Warb., deprived of its testa. (U. S. Dept. of Agric.)

Allied Plants.-Other species of myristica yield nutmegs which are used by the natives, as M. succedanea of Timor, M. fatua of the Indian Archipelago, and M. Kombo of Guinea. The kernels of the seeds of M. fatua constitute the long, wild, or male nutmeg. They are narrow-ellipsoidal, feebly aromatic and have a more or less dis-

sperm showing a central vascular bundle $(y)$, having on either side a layer with large oil-secretion cells and small polygonal parenchymatous cells; cells of the endosperm $(L)$ surrounding the strand of secondary perisperm,$A$ and $D$, after Meyer; $B$ and $C$, after Moeller. 
agreeable taste. The seeds of M. officinalis and M. Bicuhyba of Brazil have medicinal properties, a balsam being obtained from the latter, which is used as a substitute for copaiba. The so-called African nutmegs derived from M. surinamensis of the West Indies soon lose their odorous properties. M. sebifera of Guiana yields a fixed oil which has but little odor of nutmeg. Fatty and ethereal oils resembling those of nutmeg are found in the "American nutmegs" obtained from Cryptocarya moschata (Fam. Lauraceæ) of Brazil.

Adulterants.-Kernels which are wormy or more or less broken should be rejected. Imitation nutmegs have been made by molding the exhausted powder or other substances into forms resembling nutmeg. These can be distinguished on cutting into the kernel, or if it is made from a powder, on placing it into water it will immediately disintegrate. During Colonial times, when spices were expensive luxuries, imitation nutmegs were made in Connecticut from the basswood, or linden (Tilia americana).

MAcis.-Mace.-The arillode of the seed of Myristica fragrans (Fam. Myristicaceæ). According to Warburg the arillode arises in the region of the hilum before the flower opens and fertilization is effected. The mace, as it occurs on the seeds (see Nutmeg) recently collected, is of a brilliant red color. It is removed by hand, dried in the sun and acquires a yellowish or orange-brown color. It is usually shipped to Java or Singapore for exportation. The genuine article is usually referred to as Banda Mace.

Description.-In coarsely reticulate bands about $1 \mathrm{~mm}$. in thickness, the whole having the outline of the nutmeg, the basal portion united, but with a small, irregular opening; usually in compressed, nearly entire pieces, reddish or orange-brown, somewhat translucent, brittle when dry; odor and taste aromatic.

Inner Structure.-See Fig. 88.

Powder.-Yellowish- or orange-brown; very oily and with an aroma resembling nutmeg, but more delicate; numerous fragments with elongated epidermal cells and starch-bearing parenchyma, intermixed with which are the large, transparent, more or less spheroidal oil-secretion cells. The latter are about $0.065 \mathrm{~mm}$. in diameter and contain a yellowish or yellowish-brown oily substance. The starch grains are of an amylo-dextrin nature, being colored red with iodin, and the individual grains are mostly irregular, rod-like and from 0.003 to $0.010 \mathrm{~mm}$. in length. The addition of solutions of potassium hydrate to the sections liberates the oil, producing a yellow color. The use of concentrated sulphuric acid, in a similar 
manner, dissolves the oil, imparting to the globules a light orangered color, which is more or less permanent and does not become reddish-brown.

Constituents.-An aromatic balsam 24.5 per cent; volatile oil 4 to 7 per cent and resembling that obtained from nutmegs but containing a larger percentage of terpenes; fixed oil, and considerable starch, which is colored red by iodin solution, distinguishing it from nutmeg starch. Mace also contains from 2 to 4 per cent of a

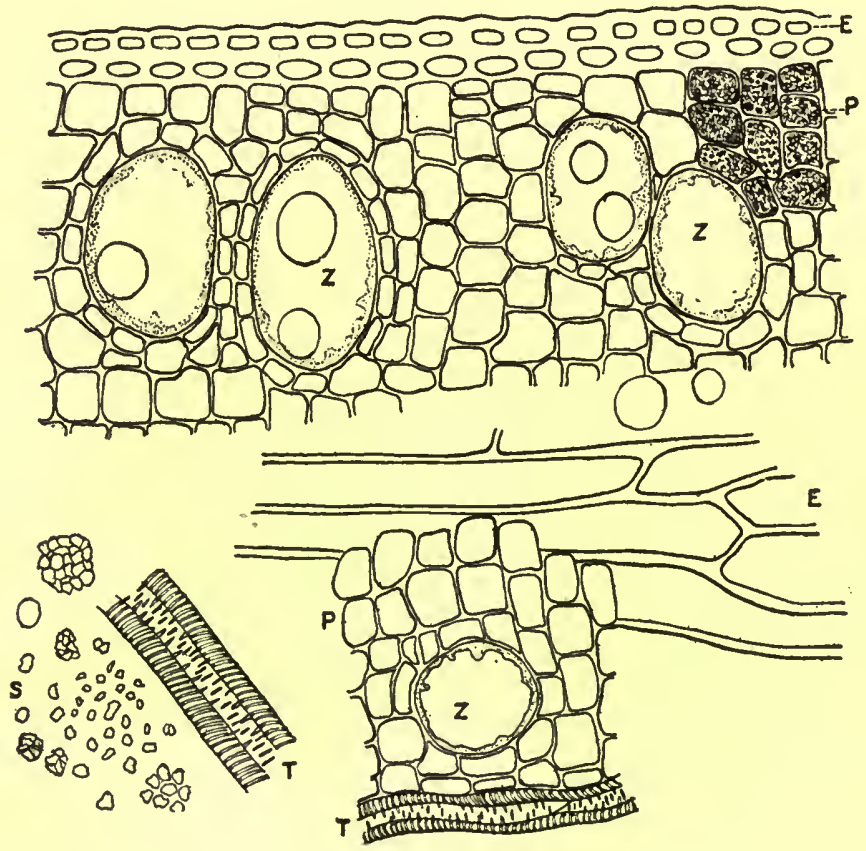

FIG. 88.-Mace: $E$, epidermal cells, which in transverse section are nearly isodiametric, but in longitudinal section are elongated, sometimes being $1 \mathrm{~mm}$. in length; $P$, parenchyma cells with small starch grains which are colored reddish with iodin; $Z$, large oil cells showing oil globules and protoplasmic contents lining the walls; $T$, tracheæ; $S$, small, irregular starch grains.

dextrogyrate sugar. (Power and Solway, Amer. Jour. Pharm., 1908, p. 563.)

Standard of Purity.-Mace is the dried arillus of Myristica fragrans Houtt. It contains not less than 20 per cent nor more than 30 per cent of non-volatile ether extract, not more than 10 per cent of 
crude fiber, not more than 3 per cent of total ash, nor more than 0.5 per cent of ash insoluble in hydrochloric acid.

Macassar mace, Papua mace, is the dried arillus of Myristica argentea Warb. (U. S. Dept. Agric.)

Allied Plants.-Macassar or Papua mace, derived from Myristica argentea, is somewhat darker, with broader segments than true mace and possesses an odor suggestive of methyl salicylate. It gives a cherry-red color with solutions of the alkalies or concentrated sulphuric acid, is very pungent and yields over 50 per cent of nonvolatile ether extract, and less than 10 per cent of starch.

Bombay mace, or Wild mace, is the product of Myristica malabarica; it is distinguished from true mace in that the entire mace is narrow-ellipsoidal, the reticulations are not so coarse, the summit is divided into numerous narrow lobes, and it is darker in color. With alkalies or sulphuric acid wild mace assumes a darker red color than the true mace. It is slightly aromatic, but has little value as a spice, and yields nearly 60 per cent of non-volatile ether extract.

Bombay mace is very largely used to adulterate genuine mace and is usually suspected when a powdered article has a pronounced reddish color. It can readily be distinguished by its more numerous oil-cells and the fragments being colored bright red upon mounting the powder in concentrated sulphuric acid or a solution of potassium hydroxide.

\section{RANUNCULACEE, OR CROWFOOT FAMIIY ?}

A large family, consisting of about 1000 species, widely distributed except in the tropics. They are mostly annual or perennial herbs, a few being somewhat woody and climbing, as Clematis. The parts of the flower are numerous, the sepals and petals being from 3 to 15 , the stamens indefinite, and the carpels usually 5 to 20 . The fruits are either achenes, follicles or berries. Among the anatomical characteristics of this family the following may be mentioned. In transverse sections the xylem of the collateral vascular bundle is heart-shaped, having the phloem distributed in the sinus. The pericycle, especially in the woody species, is in the form of a closed ring of sclerenchyma. The hairs are both glandular and nonglandular, the former being always 1-celled and usually mucilaginous. In the leaves of Aconitum and Anemone occur so-called "arm cells" in the palisade layer.

Hydrastis.-Golden Seal.-The dried rhizome and roots of Hydrastis canadensis (Fam. Ranunculaceæ), a perennial herb 
(Fig. 89) indigenous to the eastern United States and Canada. The rhizome and roots are collected in autumn.

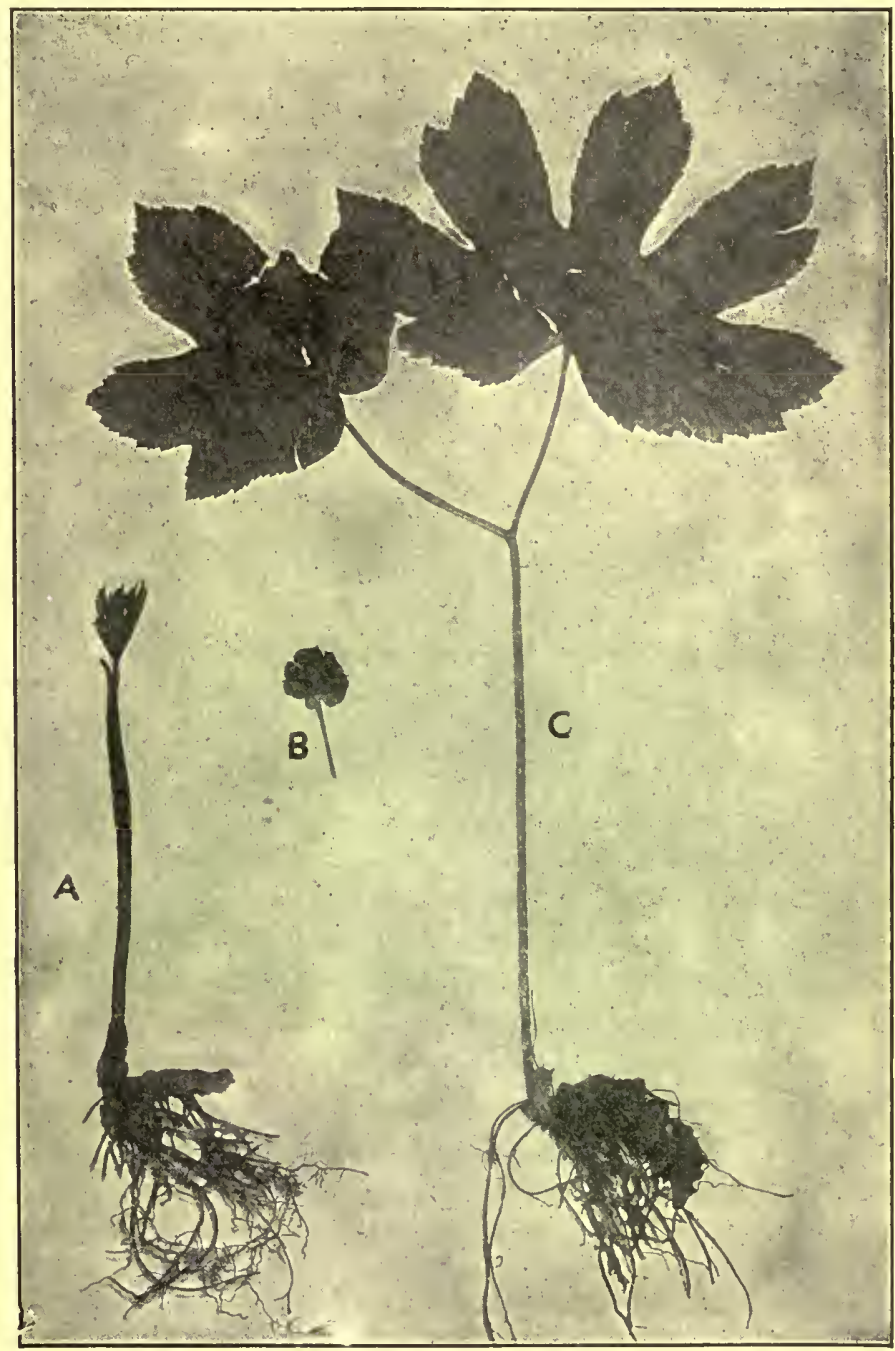

Fra. 89.-Golden seal (Hydrastis canadensis): A, young plant with horizontal rhizome and numerous roots. $B$, fruit-head of small berries. $C$. older plant showing the palmately lobed leaves.

Description.-Rhizome horizontal or oblique, sub-cylindrical, 2 to $5 \mathrm{~cm}$. in length, 3 to $6 \mathrm{~mm}$. in diameter; externally yellowish or dark brown, slightly annulate from circular scars of bud-scales, 
upper surface with numerous short stem-remnants or stem-scars, under and side portions with numerous roots or root-scars; fracture short, waxy; internally deep yellow, bark about $0.5 \mathrm{~mm}$. in thickness, wood radiate, about $1 \mathrm{~mm}$. in thickness, pith light yeliow; odor distinct; taste bitter.

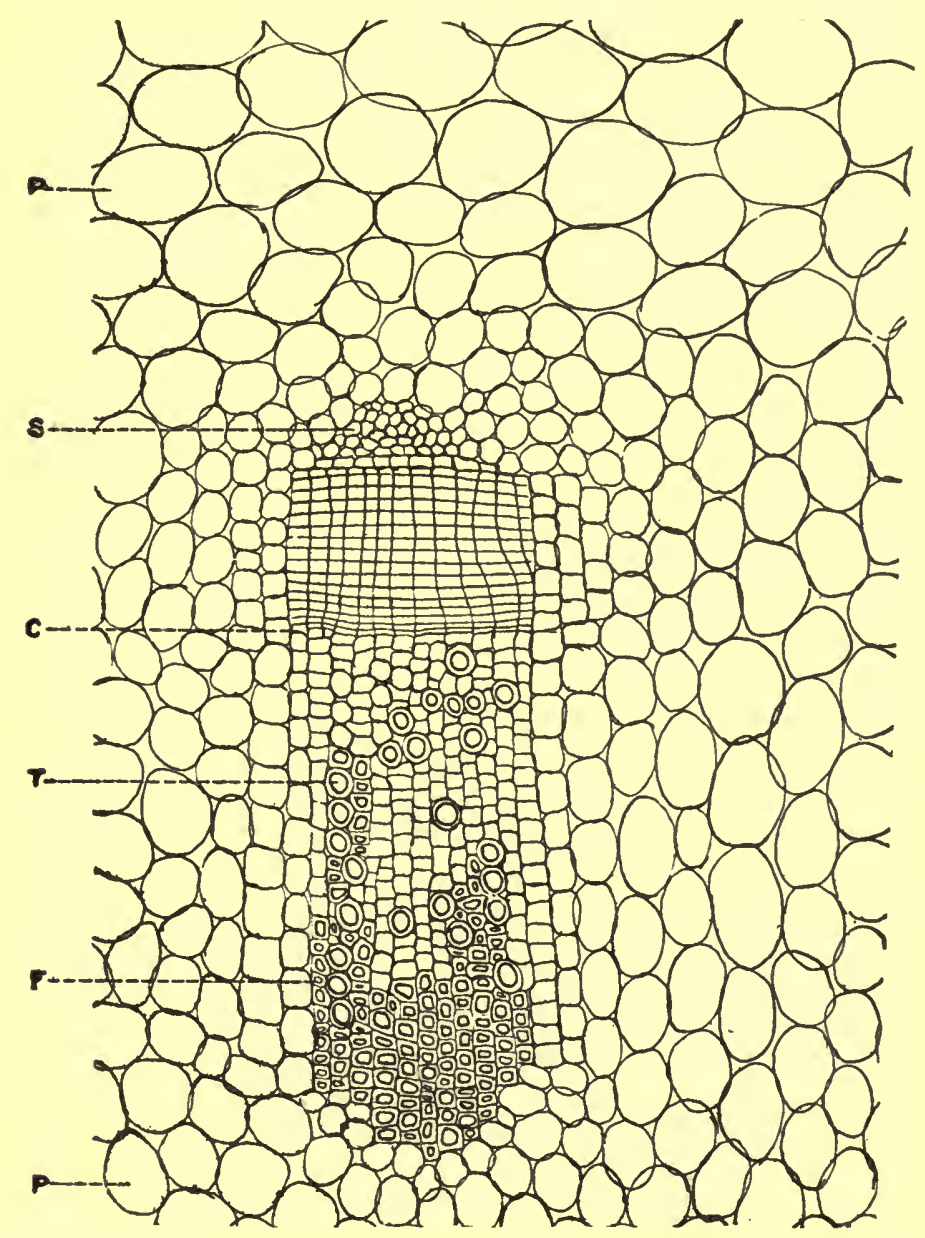

FIG. 90.-Transverse section of a part of the rhizome of hydrastis near the cambium: $P$, parenchyma; $S$, sieve; $C$, cambium; $T$, trachex; $F$, wood fibers.

Roots 4 to $7 \mathrm{~cm}$. in length, 0.2 to $0.4 \mathrm{~mm}$. in diameter; internally bright yellow, wood somewhat quadrangular.

Inner Structure.-See Fig. 90. 
Powder.-(Fig. 91.) Bright yellow to brownish-yellow; starch grains numerous, from 0.002 to $0.015 \mathrm{~mm}$. in diameter, being mostly single, nearly spheroidal, and either free or in the parenchyma cells; fragments with the tissues of the fibrovascular bundles mostly associated with starch-bearing parenchyma; tracheæ, with simple and bordered pores and occasionally spiral thickenings, and associated with short sclerenchymatous fibers possessing thin walls with simple pores; occasional fragments of tabular cork cells with reddish-brown walls.

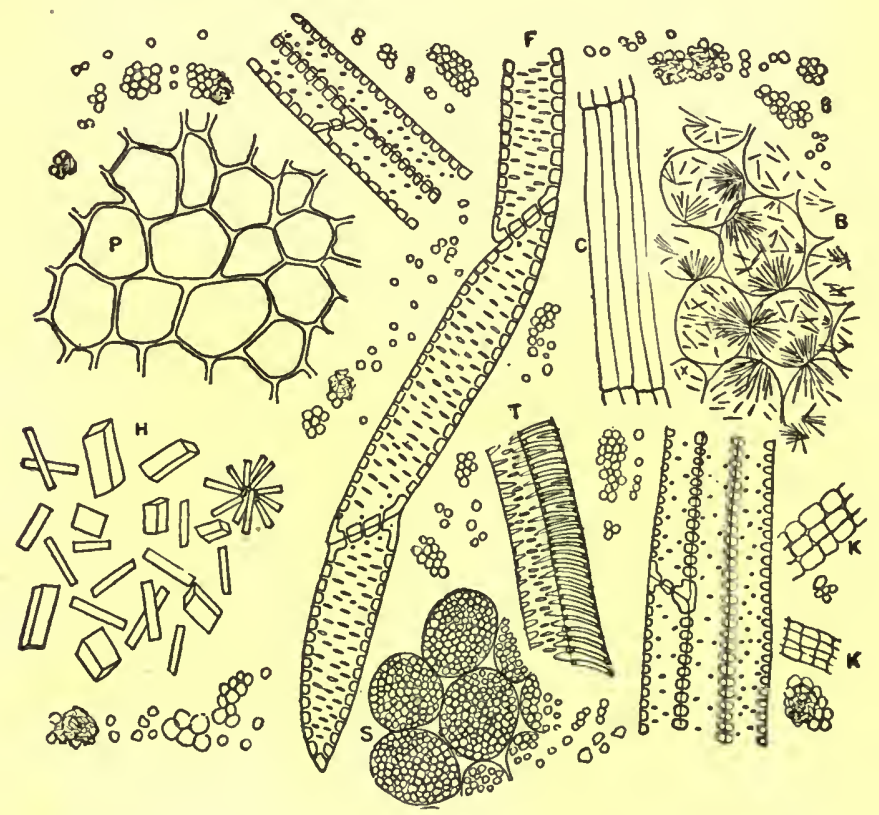

FIG. 91.-Hydrastis: $P$, parenchyma; $S$, parenchyma containing starch; $T$, trachex with annular and reticulate thickenings of the walls; $F$, tracheids with simple pores; $C$, cambium; $K$, cork; $B$, parenchyma cells showing the separation of acicular crystals of one of the alkaloids on the addition of concentrated sulphuric acid; $H$, prisms of one of the alkaloids which separate on the addition of concentrated sulphuric acid to a powder previously moistened with water.

Constituents.-Two alkaloids-one, hydrastine, occurring to the extent of 2 to 3 per cent, and forming colorless, tasteless 4 -sided prisms, although the salts are pale yellow and bitter; the other, berberine, occurring to the extent of 3 to 4 per cent in the form of yellow rods (Fig. 92), which are bitter and readily form compounds 


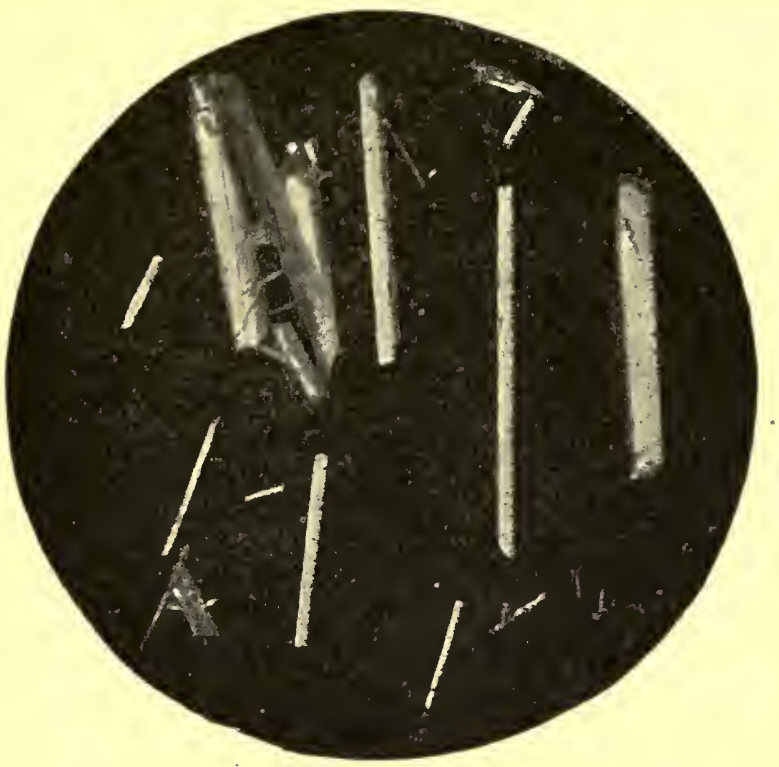

FIG. 92.-Berberine sulphate: orthorhombic crystals from aqueous solution.

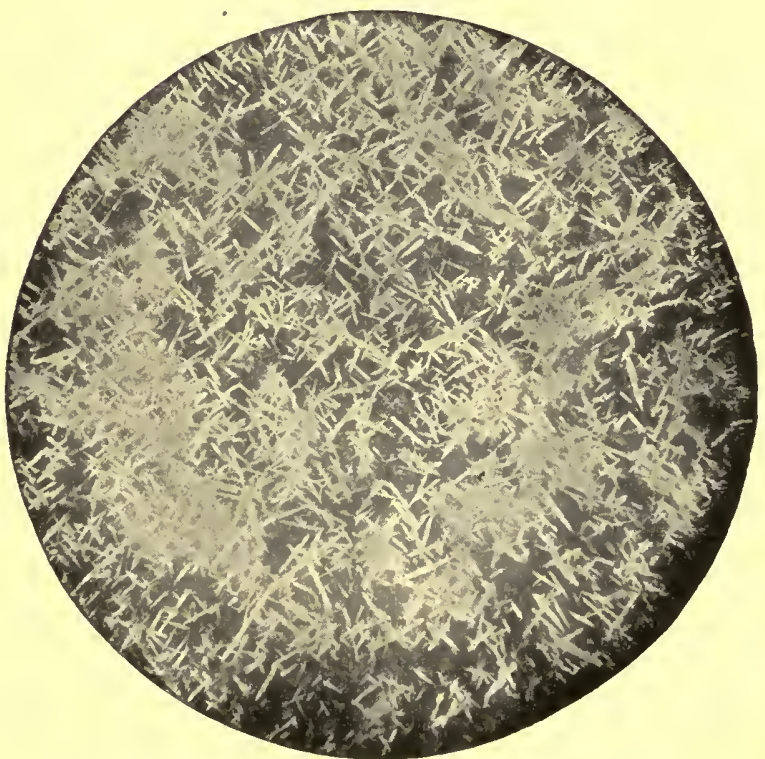

Berberine hydrochloride: small orthorhombic needles, from aqueous solution, 
with acetone, alcohol and chloroform. In addition, the drug contains a small amount of an alkaloid, canadine (tetrahydro-berberine), and considerable starch. Calcium oxalate is wanting.

From the point of view of the study of crystals obtained by microsublimation, Hydrastis is one of the most interesting. It is possible to obtain appreciable quantities of a crystalline sublimate by heating from 0.010 to $0.050 \mathrm{gm}$. of powdered Hydrastis to a temperature of $80^{\circ}$ to $95^{\circ} \mathrm{C}$. Furthermore there are certain confirmatory tests that may be directly applied to the microcrystals, using special reagents, so that in some respects Hydrastis becomes one of the most fascinating drugs for this kind of study. These crystal sublimates are illustrated in Kraemer's Applied and Economic Botany, pp. 174 and 175 . In this work is also shown a photomicrograph of crystals of hydrastine obtained from alcoholic solutions (Fig. 423, p. 770).

Elsa Schmidt gives a method for separation of hydrastine and berberine on a large scale. (Amer. Jour. Pharm., 1919, 91, p. 270).

Allied Plants.-The alkaloid berberine, or a principle closely resembling it, is found in the following plants of the Ranunculaceæ: False rhubarb (Thalictrum flavum) of Europe; and the following plants growing in the United States: Gold-thread (Coptis trifolia), yellow root (Xanthorrhiza apiifolia), and marsh marigold (Caltha palustris). A principle resembling berberine is found in the following plants belonging to the Rutaceæ: Several species of Zieria found in Southern Australia and Tasmania, and Toddalia aculeata found in the mountains of eastern Africa, tropical Asia and the Philippine Islands. (See also Berberis.)

Aconitum.-Aconite.-The tuberous root of Aconitum Napellus (Fam. Ranunculaceæ), a perennial herb growing in the mountainous districts of Europe, Asia and western North America. It is also cultivated in temperate regions. The commercial supplies are obtained from England and Germany, and in England the root is collected in autumn from cultivated plants after the overground parts have died down, whereas in Germany the roots are collected from wild plants during the flowering period, this being done to distinguish the particular species yielding the drug. The root should be carefully dried.

Description.-More or less conical or fusiform, 4 to $10 \mathrm{~cm}$. in length, 5 to 20 in diameter; externally, dark brown, smooth or somewhat wrinkled, the upper portion with a bud, remains of bud-scales or stem-scars, with numerous root-scars or short roots; fracture horny, somewhat.mealy; internally, bark light or dark brown, 1 
to $2 \mathrm{~mm}$. in thickness, cambium irregular, 5- to 7 -angled, wood yellowish, in small bundles at the angles, pith light brown, about 2 to $6 \mathrm{~mm}$. in diameter; odor very slight; taste sweetish, acrid, pungent, accompanied by a sensation of numbness and tingling.

The shrunken, hollow, older tubers, together with the overground stem-remnants, should be rejected.

Inner Structure.-See Fig. 93.

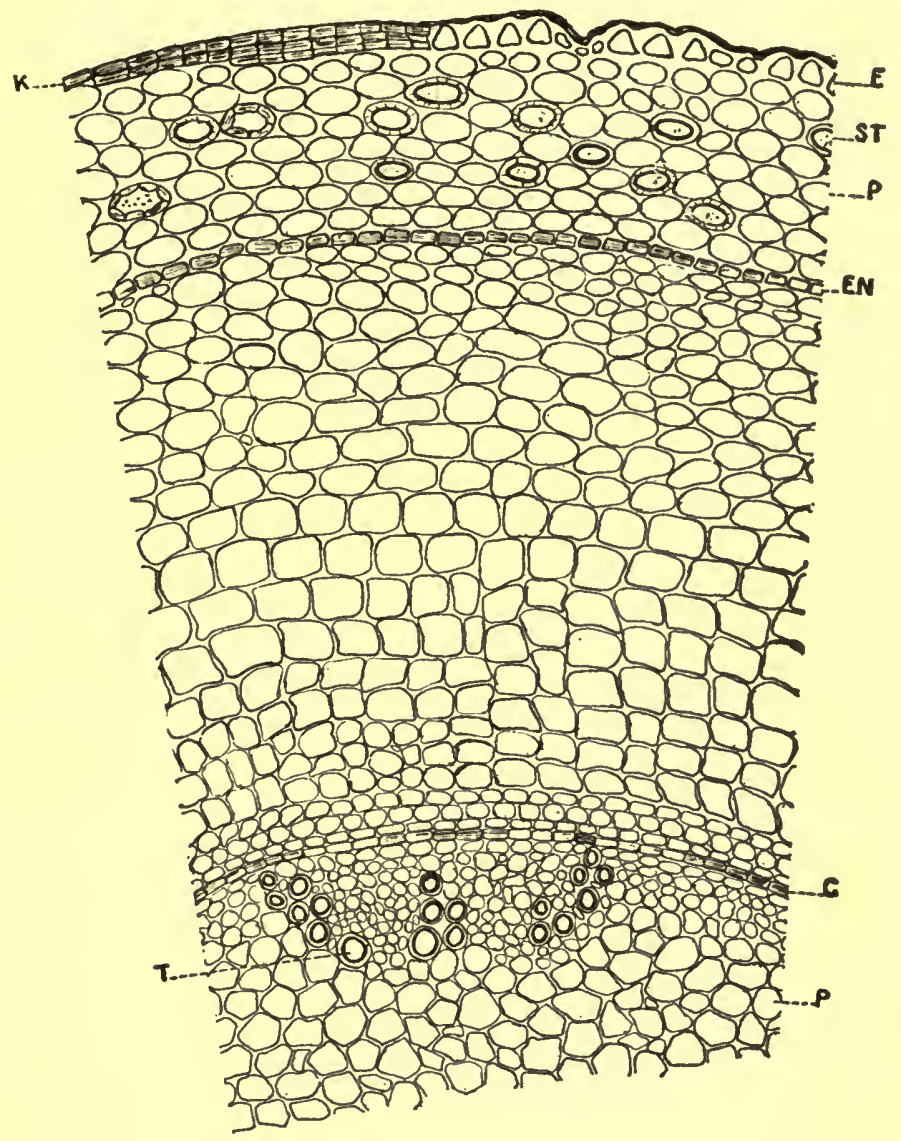

Fig. 93.-Transverse section of aconite: $K$, cork; $E$, epidermis; $S T$, stone cells; $E N$, endodermis; $C$, cambium; $T$, tracheæ; $P$, parenchyma.

Powder.-(Fig. 94.) Grayish-brown to dark brown; starch grains numerous, spheroidal, somewhat plano-convex, single or 2 - to 5-compound, the individual grains from 0.003 to $0.015 \mathrm{~mm}$. in diameter and frequently with a central cleft; tracheæ mostly 
with slit-like, simple pores, sometimes with spiral or reticulate thickenings or with bordered pores; stone cells (Fig. 95) single, tabular, irregular in shape or elongated to fibers from 0.100 to 0.400 $\mathrm{mm}$. in length, walls from 0.008 to $0.025 \mathrm{~mm}$. in thickness, strongly lignified and having large simple pores; fragments of cork few, yellowish-brown; fragments of parenchyma numerous, the cells being filled with starch grains; bast-fibers from stems few, very

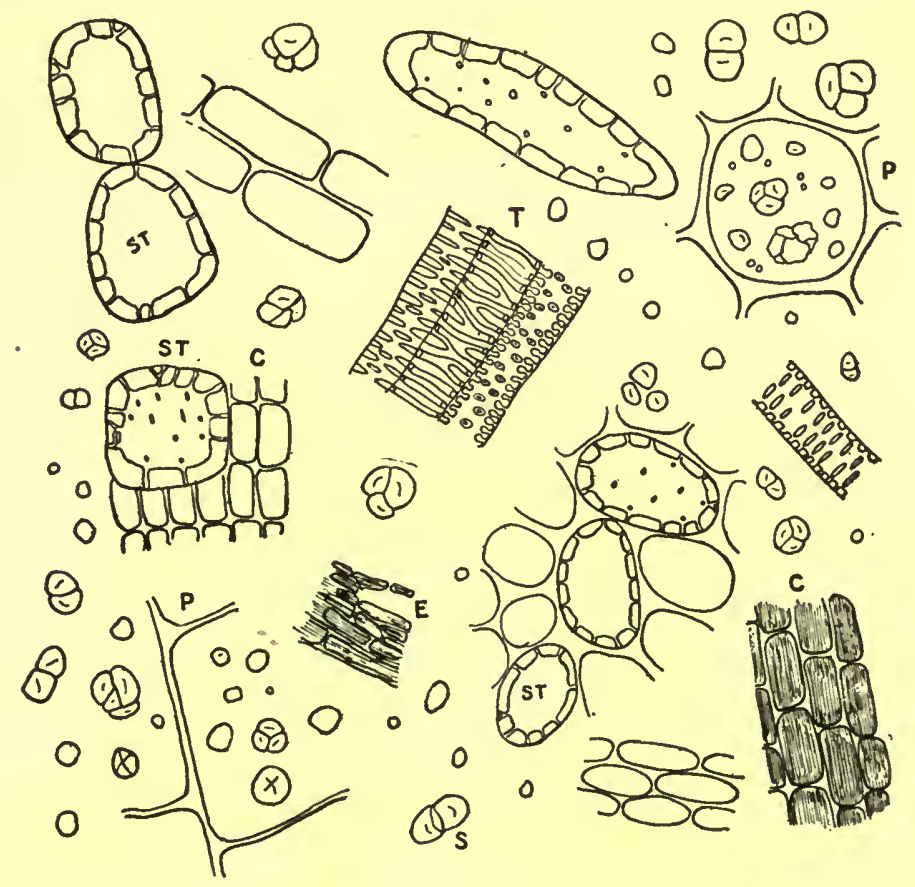

FIG. 94.-Aconite: $T$, tracheæ with scalariform thickenings and bordered pores; $S T$, stone cells; $P$, parenchyma with starch grains; $S$, starch grains; $C, E$, cork.

long, with lignified walls about $0.005 \mathrm{~mm}$. in thickness, and marked by transverse or oblique, slit-like pores.

A qualitative test having some quantitative value in determining the potency of powdered Aconite is as follows: $0.500 \mathrm{gm}$. of the finely powdered aconite (containing 0.50 per cent of -aconitine) is mixed with 500 c.c. of water and shaken occasionally during the course of five minutes. A few cubic centimeters of the filtered solution, if swallowed, produces a distinct and characteristic sensation in the throat. 
Constituents. - A number of alkaloids have been isolated, of which aconitine is the most important; it occurs to the extent of
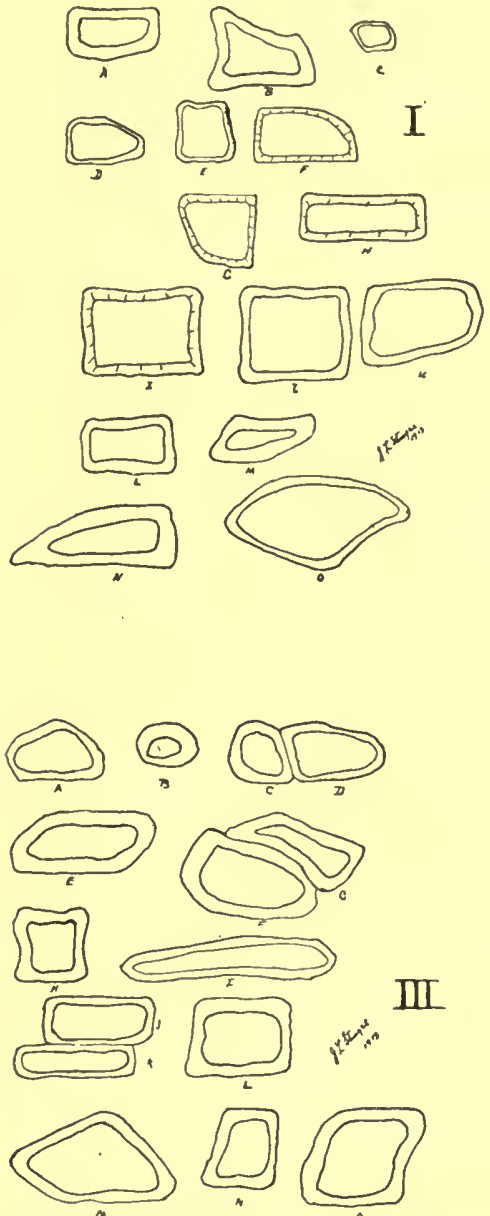
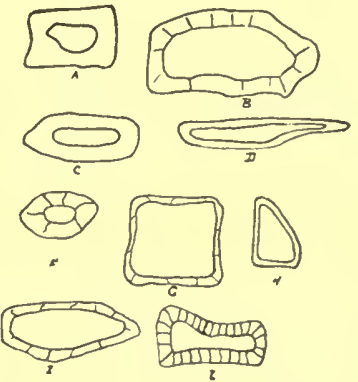

II
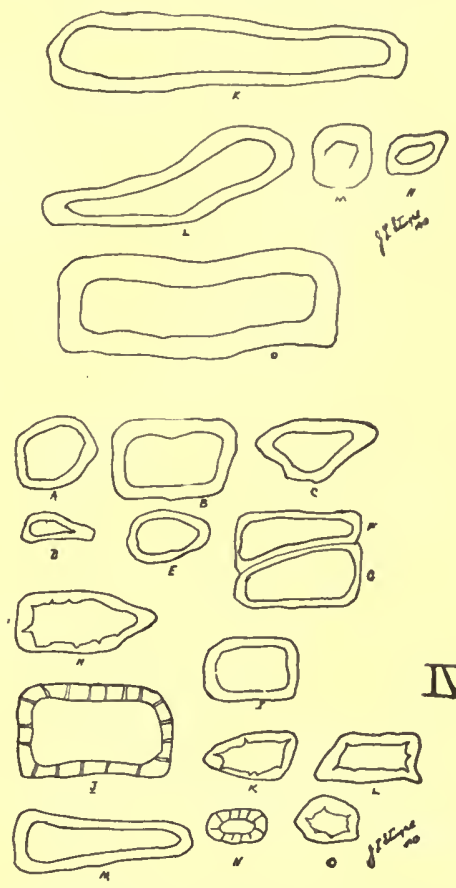

IV

Frg. 95.-Various forms of stone cells in Aconite root. The cells vary in form, size and thickness of the walls. They are from 0.051 to $0.391 \mathrm{~mm}$. in length, fom 0.034 to $0.102 \mathrm{~mm}$. in width, the thickness of the wall being 0.008 to $0.025 \mathrm{~mm}$. The average length is about $0.120 \mathrm{~mm}$., width $0.070 \mathrm{~mm}$. and thickness of wall $0.010 \mathrm{~mm}$. The outline of the lumina of the cells varies from nearly smooth to slightly irregularly undulate or more or less ragged and angular.-After Stingel, Amer. Jour. Pharm., 1913, p. 391.

about 0.75 per cent, and forms prisms (Fig. 96), which are not colored by concentrated sulphuric or nitric acid. An aqueous solution 
of the alkaloid, after acidulating with acetic acid, gives on the addition of a solution of potassium permanganate a red crystalline precipitate. Aconitine decomposes quite readily and several of its derivatives have been isolated: benzaconine, an inert alkaloid and aconine which produces apparently contrary physiological effects to aconitine. The alkaloid napelline may be isomeric with aconine. Aconite also contains considerable aconitic acid, which is chiefly combined with calcium and occurs in other genera of the Fam. Ranunculaceæ, viz.: Delphinium and Adonis; besides considerable starch; a little mannitol and a resin. The other alkaloids are

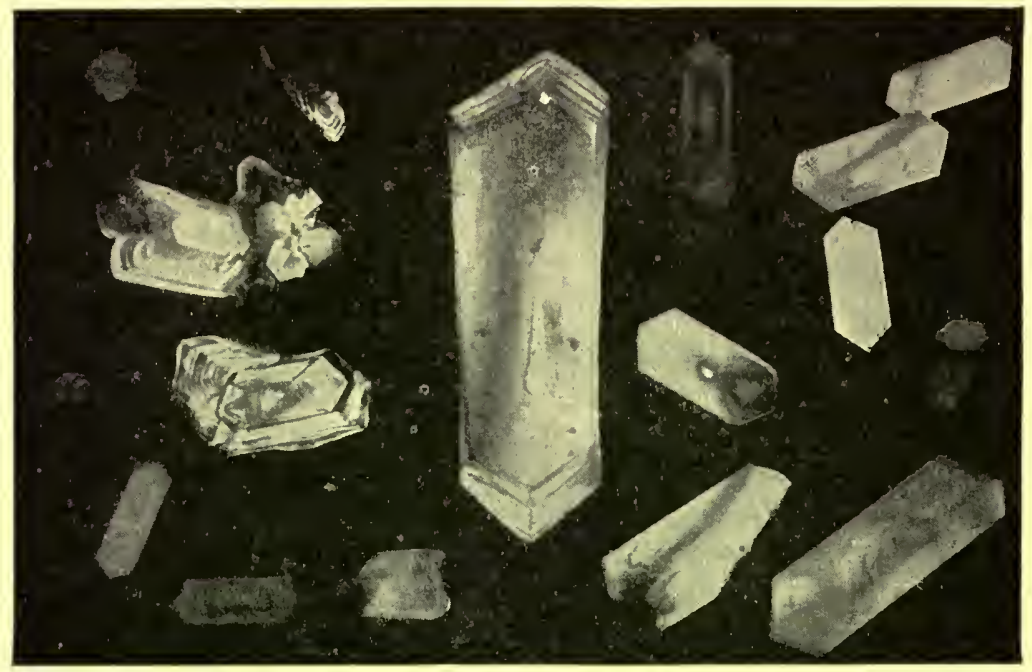

FIG. 96.-Aconitine: orthorhombic crystals, crystallized from alcoholic solutions.

amorphous and non-toxic, and of these isaconitine (napelline) has been employed medicinally.

Aconitine (acetyl-benzoyl-aconine) occurs in colorless, nearly transparent, glistening crystals. From alcoholic solution orthorhombic prisms (Fig. 96) usually predominate while from solutions in which chloroform is the solvent, the tendency is for small isolated rosette aggregates to separate. The crystals vary in length from $0.1 \mathrm{~mm}$. to $1 \mathrm{~mm}$., although crystals as large as $1 \mathrm{~cm}$. in. length and $0.5 \mathrm{~cm}$. in thickness have been obtained. Upon rapidly heating, the M. P. is $197^{\circ}-198^{\circ} \mathrm{C}$. At $25^{\circ} \mathrm{C}$. one part of aconitine is soluble in 3226 parts of water; 22 parts of alcohol; 44 parts of ether; and 5.6 parts of benzene. The gold salt of aconitine is amorphous when 
first precipitated, but may be obtained in three crystalline modifications by the use of various solvents. ${ }^{1}$

Allied Plants.-Japanese aconite is obtained from Aconitum Fischeri; the root is smaller, conical, nearly smooth and the starch grains are much larger than those of the official drug. Indian aconite, the product of Aconitum ferox, is a much larger root and somewhat horny, owing to the gelatinization of the starch in its preparation for market.

A very large number of species of Aconitum are used medicinally. These may be brought into five groups: (1) Those containing the alkaloid aconitine, as Aconitum Napellus; (2) those containing pseudaconitine, which, while it resembles in some of its properties aconitine, is not chemically identical with it, and is found in the Indian aconite obtained from A. ferox, A. luridum and A. palmatum; (3) those containing the alkaloid, japaconitine, which closely resembles pseudaconitine and is found in Japanese aconite, obtained from A. Fischeri; (4) those which contain the narcotic bases, lycaconitine and myoctonine, found in A. lycoctonum of Asia and Europe; (5) those yielding lappaconitine, a powerful alkaloid occurring in A. septentrionale, a nearly related species to A. lycoctonum.

Adulterant.-The roots of Aconitum chasmanthum are about $2 \mathrm{~cm}$. in length and $0.75 \mathrm{~cm}$. in thickness, nearly smooth and the rootlet stubs are usually clustered at the basal end; the inner surface is lighter in color and less resinous. (U. S. Dept. Agric.)

Aconiti Folia.-Aconite Leaves, Herba Aconita.-The leaves and flowering tops of Monkshood or Wolfsbane, Aconitum Napellus (Fam. Ranunculaceæ). The drug is gathered from wild plants at about the time of flowering during June or July and carefully dried. It should be stored in tightly closed containers and not exposed to light.

Description.-More or less crumpled or broken; entire leaves long petiolate, and palmately divided into 3,5 or 7 segments; the latter are wedge-shaped, having 2 or 3 deeply incised lobes, which are linear or linear-lanceolate and acute or pointed. The flowers are dark blue, usually arranged on a spike-like raceme, the upper sepal being hooded or helmet-shaped and covering the 2 long-clawed smaller petals; fruit consisting of 2 or 3 separate, somewhat flattened lanceolate follicles and enclosing several seeds. The latter are somewhat triangular, grayish-brown, $4 \mathrm{~mm}$. in length and more or less wrinkled and scaly. Fragments of stems attaining a length of

${ }^{1}$ A. E. Tutton, Zeitschr. f. Krystallog., 1891 (19), p. 178. 
$2 \mathrm{dm}$. and a diameter of $4 \mathrm{~mm}$.; light yellowish-brown to grayishbrown, longitudinally wrinkled and marked by numerous branch, leaf or flower bases.

Inner Structure.-See Kraemer's Applied and Economic Botany, p. 534 .

Powder.-Dark yellowish-green; numerous fragments showing wavy epidermal cells and elliptical stomata; tracheæ either close annular, spiral or with simple pores; bast fibers with strongly thickened, lignified and porous walls; non-glandular hairs few, unicellular, more or less curved and papillose. Fragments of the blue sepals are colored purplish-red upon the addition of dilute hydrochloric acid, and bright green upon the addition of solutions of the alkalies.

Constituents.-Aconitine from 0.15 to 0.3 per cent; also aconitic acid, tannic acid, inosit and sugar. The yield of ash is from 15 to 20 per cent.

CimicifugA.-Black Snakeroot. Black Cohosh.-The dried rhizome and roots of Cimicifuga racemosa (Fam. Ranunculaceæ), a perennial herb, indigenous to Asia, eastern Europe and North America. The drug is collected in autumn, the United States furnishing the principal supply.

Description.-Rhizome horizontal, with numerous upright or curved branches and few roots, 2 to $15 \mathrm{~cm}$. in length, 1 to $2.5 \mathrm{~cm}$. in diameter; externally dark brown, slightly annulate from circular scars of bud-scales, the upper surface with buds, stem-scars and stem-remnants, under and side portions with numerous root-scars and few roots; fracture horny; internally, bark dark green, about $1 \mathrm{~mm}$. in thickness, wood dark brown, 4 to $5 \mathrm{~mm}$. in thickness, distinctly radiate; pith 3 to $5 \mathrm{~mm}$. in diameter; odor slight; taste bitter and acrid.

Roots brittle, nearly cylindrical or obtusely quadrangular; externally dark brown, longitudinally wrinkled, 3 to $12 \mathrm{~cm}$. in length, 1 to $2 \mathrm{~mm}$. in diameter; fracture short; internally, bark dark brown, 0.2 to $0.4 \mathrm{~mm}$. in thickness, wood light brown, usually four-rayed.

Inner Structure.-An epidermal layer composed of yellowishbrown cells with suberized walls; a cortex of starch-bearing parenchyma cells; fibrovascular bundles, collateral, the xylem consisting of tracheæ, with bordered pores, and resembling tracheids in that the ends are rather acute; wood-fibers numerous, thin-walled, strongly lignified and with simple, oblique pores; the bundles separated by starch-bearing parenchyma strands from 5 to 30 cells 
wide; pith cells numerous, resembling those of the cortex. For structure of root, consult Fig. 97.

Powder.-Light to dark brown; starch grains numerous, single or compound, the individual grains from 0.003 to $0.015 \mathrm{~mm}$. in diameter; spheroidal or more of less polygonal, each with a somewhat central cleft; fragments of tracheæ with scalariform thicken-

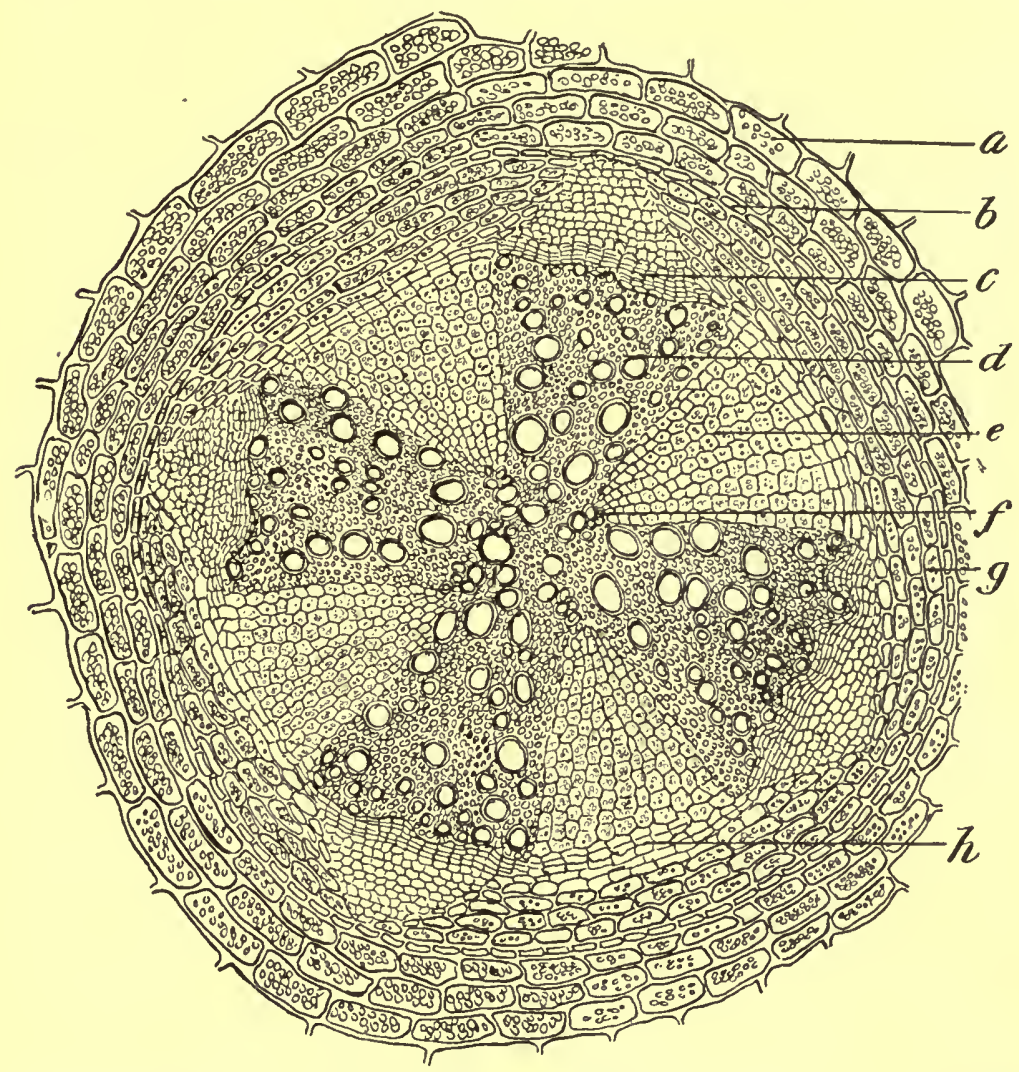

FIG. 97.-Cimicifuga. Transverse section of the central part of a mature root in which the secondary changes are completed: $a$, parenchyma; $b$, endodermis; $c$, cambium zone; $d$, tracheæ in secondary xylem; $e$, broad, wedgeshaped medullary rays; $f$, outer portion of one of the primary xylem bundles; $g$, parenchyma beneath the endodermis; $h$, inter-fascicular cambium.After Bastin.

ings or bordered pores and lignified wood-fibers; irregular, yellowishbrown fragments of suberized epidermis made up of more or less tabular cells, sometimes elongated and considerably thickened. 
Constituents.-Two crystalline principles soluble in chloroform; a colorless crystalline substance soluble in ether; a crystalline principle soluble in water; a trace of an alkaloid and several organic acids; considerable starch and a tannin-like principle giving a green color with ferric salts, thus distinguishing the drug from the rhizome of Helleborus niger; ash not exceeding 10 per cent.

Literature.-Holm, Merck's Report, 1908, p. 263; Bastin, Amer. Jour. Pharm., 1895, p. 121.

Staphisagria.-Stavesacre.-The ripe seed of Delphinium Staphisagria (Fam. Ranunculaceæ), an annual or biennial native of southern Europe and Asia Minor, and cultivated in Austria (Trieste), Italy and southern France, from which latter countries the commercial supplies are obtained.

Description.-Anatropous, irregularly triangular or somewhat tetrahedral, one side convex, the others plane, the micropylar end acute or obtuse, 5 to $6 \mathrm{~mm}$. in length, 3 to $6 \mathrm{~mm}$. in breadth; externally dark brown, becoming lighter and duller with age, more or less uniformly reticulate, the pits being about $0.5 \mathrm{~mm}$. in diameter, raphe forming a more or less distinct ridge on the largest of the plane surfaces or on the edge of two united sides, epidermis modified to distinct papillæ, inner seed-coat yellowish-brown, adhering to the endosperm when moistened, the latter white or yellowish, and enclosing at the pointed end a small, straight embryo $1 \mathrm{~mm}$. in length and with a relatively large hypocotyl; slightly odorous; taste of endosperm intensely bitter and acrid.

Inner Structure.-An epidermal layer of yellowish, nearly tabular, thick-walled, non-lignified cells, some being extended centrifugally, and forming the reticulations of the seed-coat; 2 or 3 rows of parenchyma cells with more or less irregular thin walls; a thin layer of very small, thick-walled cells with numerous, lattice-like or reticulate pores; endosperm large, composed of polygonal cells enclosing small aleurone grains and fixed oil, the latter forming in large globules on the addition of solutions of hydrated chloral, the alkalies or sulphuric acid.

Powder--Grayish-brown or light brown; stone cells of outer epidermis radially elongated, with thick walls and simple pores as described above; a layer of pigment cells; fixed oil, and aleurone grains.

Constituents.-Two alkaloids, about 1 per cent. These are delphinine, which crystallizes in rhombic prisms and resemble aconitine in its physiological action; and staphisagroine, which is amorphous and insoluble in chloroform. The alkaloids delphisine 
and delphinoidine are probably decomposition products of delphinine. The seeds also contain 25 to 30 per cent of a fixed oil; an equal amount of proteins; 8 or 9 per cent of ash; and several resins.

Allied Plants. - A number of other species of Delphinium have been investigated and found to have poisonous properties.

Delphinium.-Larkspur Seed.-The seeds of the field larkspur, Delphinium Consolida (Fam. Ranunculaceæ), a common annual herb, widely distributed throughout Europe and somewhat naturalized in the eastern United States. The dried seeds are replacing Staphisagria to some extent. They resemble the latter in form, but are of a black or blackish-brown color and about $2 \mathrm{~mm}$. in diameter. The constituents appear to be identical with those of Staphisagria.

The tall larkspur (Delphinium urceolatum) is common to the stock ranges of the Western States, and cattle grazing in these territories become poisoned by eating it. The plant is said to lose its toxic properties after it has flowered. The low larkspur has the same poisonous properties as the former. In case of poisoning, it is customary to keep the animal's head erect and to give hypodermic injections of physostigmine and whiskey.

Pulsatilla.--The entire herb of Anemone Pulsatilla, A. pratensis, and A. patens. (Fam. Ranunculaceæ), perennial herbs indigenous to central and southern Europe. The entire herbs are gathered in the early spring, when the flowers are in bloom, and carefully dried. It should be kept in air-tight containers. Pulsatilla deteriorates with age.

Description.-Leaves radical, long petioled, 2 or 3 parted or pinnately-cleft, the lobes linear and acute; flowers solitary on long scapes and subtended by a pinnately parted involucre of 3 sessile leaves; the flowers consist of large showy sepals, which in A. pulsatilla and A. patens are of a light violet or blue color, and in A. pratensis a dark blue; stamens numerous, being as long as the petals in A. pratensis and much shorter in A. pulsatilla; pistils numerous, becoming in fruit long, plumose, flattened achenes; odor slight, but when fresh penetrating; taste very acrid. For illustrations of leaves, flowers and fruits, see Kraemer's Applied and Economic Botany, Fig. 359.

Powder.-Grayish-green; fragments of epidermis with undulate-polygonal cells and elliptical stomata; non-glandular hairs numerous, unicellular, from 0.230 to $2.5 \mathrm{~mm}$. in length and from C.010 to $0.020 \mathrm{~mm}$. in diameter, with very thick walls and narrow lumina; parenchyma cells with microcrystals. 
Constituents.-An acrid volatile oil, the principal constituent of which is a camphor (anemonol). The latter is easily decomposed into anemonin, which on fusion becomes exceedingly acrid. Similar principles are found in other species of Anemone as well as in certain species of Ranunculus (buttercup) and in Clematis vitalba of Europe.

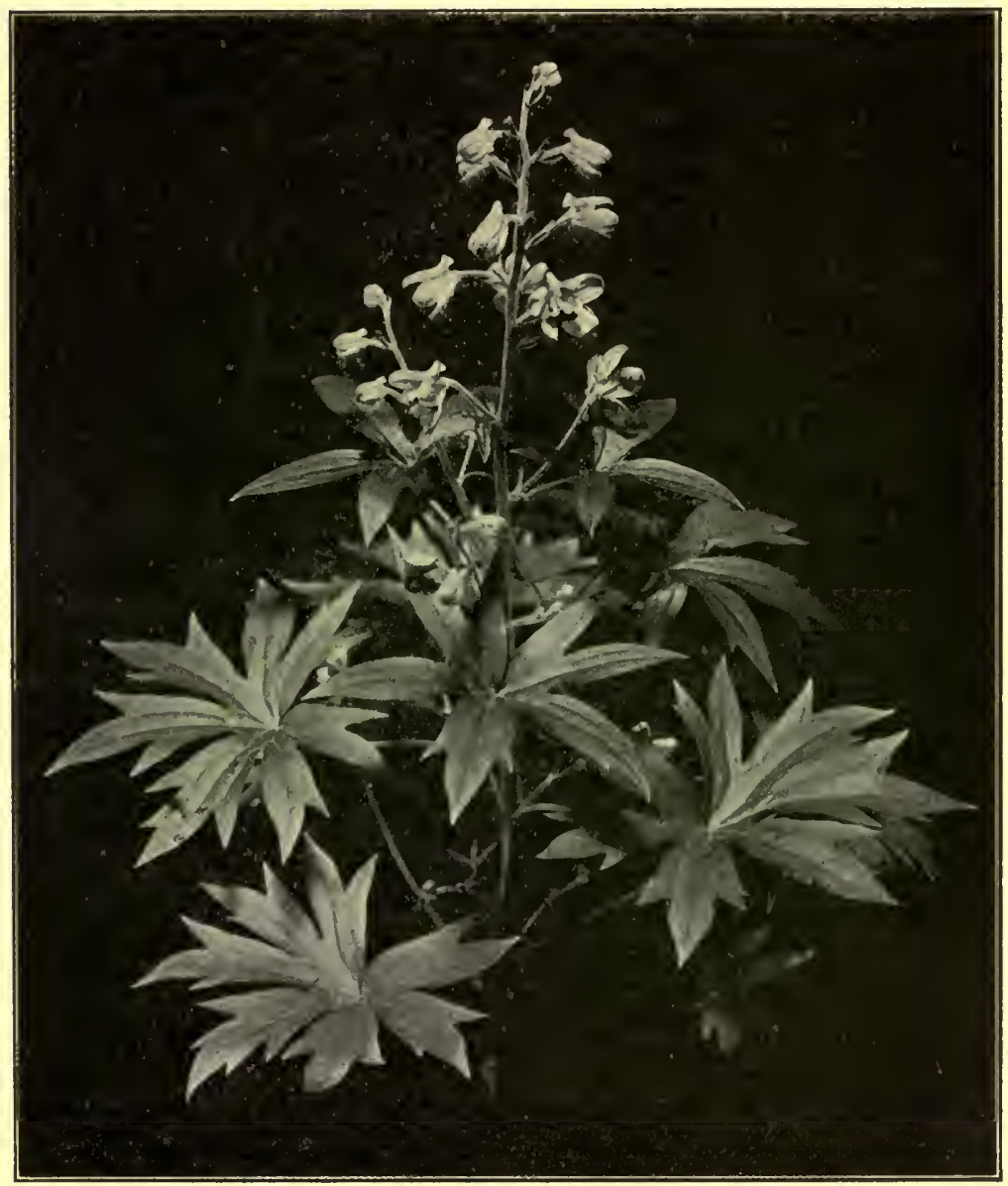

Frg. 98.-Delphinium Staphisagria. Plants grown from the commercial drug and showing the palmately lobed leaves, and the terminal raceme of blue flowers.-After Newcomb.

Coptis.-Goldthread.-The entire plant of Coptis trifolia (Fam. Ranunculaceæ), a low perennial growing in moist woods and 
swamps of northeastern United States and Canada, extending to Alaska.

Description.-In loose matted masses consisting of a nearly equal mixture of the filiform, orange-colored rhizomes and pressed leaves, having a slight odor and bitter taste. Rhizomes wiry, cylindrical, irregularly curved, from 5 to $20 \mathrm{~cm}$. in length and about $0.3 \mathrm{~mm}$. in thickness, internodes about $15 \mathrm{~mm}$. in length, nodes with a distinct elliptical scar on the upper surface and numerous dark brown hairlike roots on the lower surface. Leaves radial, ternately divided and frequently attached to the upper portion of the rhizome; petioles from 2 to $6 \mathrm{~cm}$. in length; leaflets coriaceous, broadly obovate, nearly sessile, about $15 \mathrm{~mm}$. in length; base cuneate; margin obscurely 3-lobed and sharply toothed; upper surface dark green and shining, veins prominent; lower surface light green and veins depressed. Flowers if present, small, whitish or light brown. Follicles divergent, membranaceous and enclosing a few small seeds.

Powder.-Yellowish-green; starch grains numerous, mostly single, spheroidal, from 0.003 to $0.010 \mathrm{~mm}$. in diameter; epidermal cells with wavy vertical walls and broadly elliptical stomata; fragments of the nerved scales, from the nodes of the rhizome, composed of cells with yellowish walls; leaf parenchyma cells containing green plastids; few, simple thick-walled hairs, from the midrib of the leaf, $0.035 \mathrm{~mm}$. to $0.075 \mathrm{~mm}$. in length; elongated epidermal cells from the roots having yellowish walls and filled with reddish contents; fragments of epidermal and sub-epidermal cells from the rhizome, similar to those from the root, but without reddish contents, often filled with yellowish contents; groups of elongated parenchyma, about $0.060 \mathrm{~mm}$. in length and about $0.010 \mathrm{~mm}$. in width, many of the cells being filled with starch grains; tracheæ with bordered pores or spiral markings about $0.020 \mathrm{~mm}$. in width; occasional narrow, thin-walled, porous sclerenchymatous fibers. An infusion prepared by placing $5 \mathrm{gm}$. of the powdered drug in 50 c.c. of cold water and allowing to stand for a few minutes with occasional stirring and then filtering gives a golden yellow colored solution.-Newcomb.

Constituents.-Two alkaloids, berberine and coptine, the latter being crystalline and becoming purple on the addition of sulphuric acid and warming. Ash, 6 to 8 per cent.

Radix Coptidis.-Coptis Root.-The dried rhizome of Coptis anemonæfolia and of several other species of Coptis (Fam. Ranunculaceæ). The drug is official in the Pharmacopoeia of Japan. The rhizome is tuberculate, more or less curved, about $4 \mathrm{~cm}$. in length 
and from 1 to $5 \mathrm{~mm}$. in thickness; externally grayish-yellow, bearins; at the crown the remains of the leaf bases and beset with numerous thin roots; fracture short, fibrous; inner surface with a dark orange colored cortex, a pale yellow wood, and a large hollow pith; inodorous; taste bitter.

Helleborus Niger.-Black Hellebore.-The rhizome and roots of the Christmas or New Year's Rose, Helleborus niger (Fam. Ranunculaceæ) a perennial herb indigenous to the forests of the eastern and southern Alps and also cultivated. It produces pinkish flowers during the winter, or very early in the spring, long before any other plant flowers.

Description.-Rhizome horizontal, with numerous short, knotty branches and moderately long roots; from 2 to $8 \mathrm{~cm}$. in length and 0.5 to $4 \mathrm{~cm}$. in diameter; externally grayish- or brownish-black, upper surface with numerous stem bases and depressed circular scars, under and side portions with numerous root bases; fracture short and mealy; internally light yellow, showing a number of broad wood wedges; odor distinct; taste bitter.

Roots from 0.5 to $6 \mathrm{~cm}$. in length and from 2 to $3 \mathrm{~mm}$. in thickness; yellowish or dark brown, with a thick light brown cortex and a narrow central, porous, yellowish wood.

Inner Structure.-An epidermal layer consisting of reddishbrown thick-walled cells; cortex made up of about 30 rows of starchbearing parenchyma, having very thick walls; leptome in the form of broad plates near the cambium; xylem in long wedges consisting mostly of porous tracheæ surrounded by wood parenchyma; medullary rays from 10 to 20 cells in width and resembling the parenchyma cells of cortex and pith. In the parenchyma cells there also occurs a fixed oil, and a few secretion cells having a colorless or slightly yellowish balsamic substance. Tracheæ often filled with a reddish-brown amorphous substance. In the epidermal layer of the root the outer walls are yellowish-brown, considerably thickened and lamellated; cortex of starch-bearing parenchyma and light yellowish oil secretion cells; the stele is 5-rayed, consisting mostly of small tracheæ.

Constituents.- Two crystalline glucosides: helleborin, a narcotic poison with a burning taste, and helleborein, a cardiac stimulant and having a sweetish taste. The former gives a violet red" color with concentrated sulphuric acid and the latter a deep violet color with the same reagent. The drug also contains a volatile oil, two acrid resins, an acrid fixed oil, aconitic acid and gallates of calcium and potassium. 

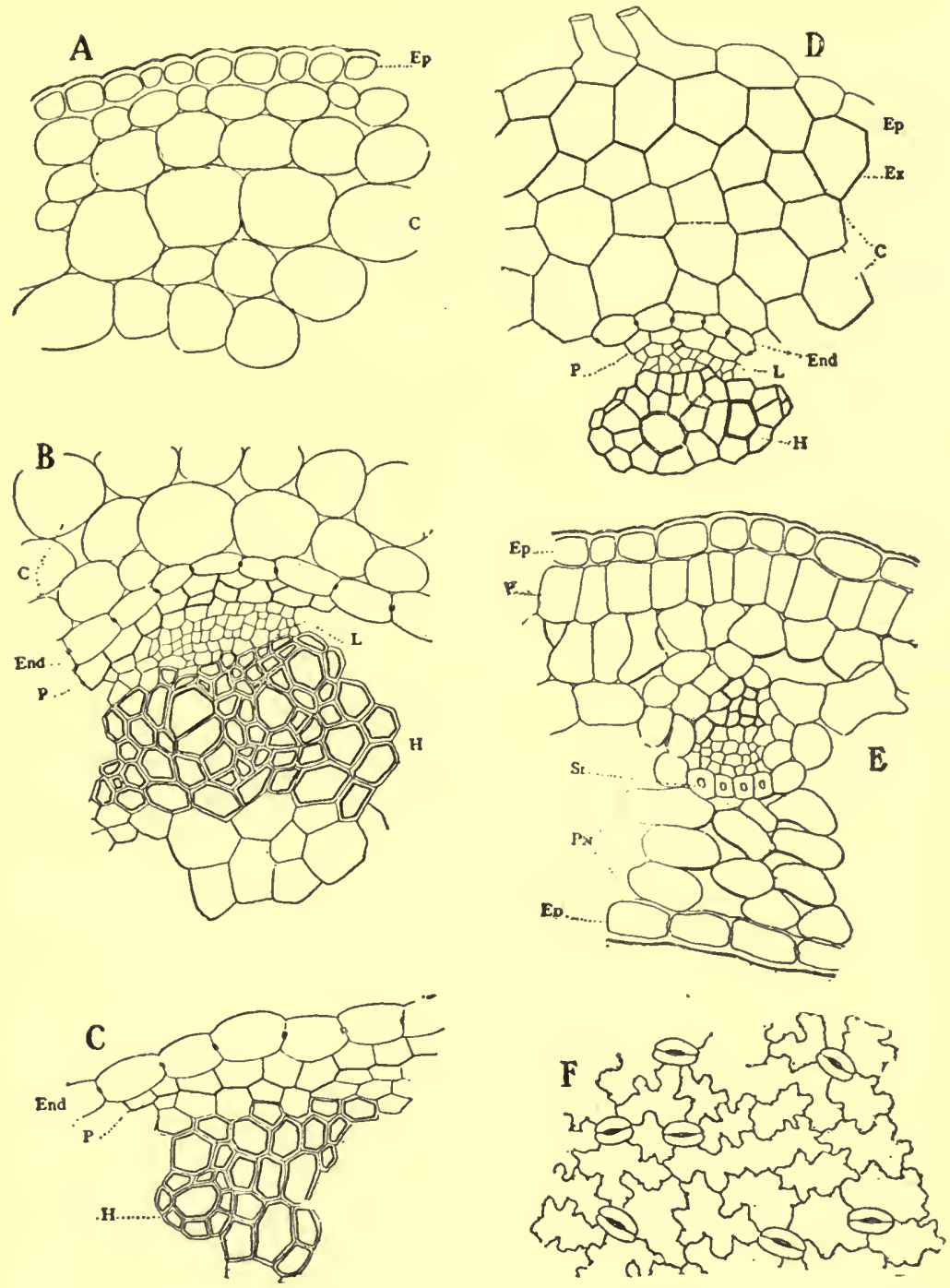

FIg. 99.-Coptis. A, transverse section of peripheral portion of a stretched internode in the rhizome; $E p$, epidermis; $C$, cortex. $B$, transverse section of rhizome: $C$, cortex; End, endodermis; $P$, pericycle; $L$, leptome; $H$, the xylem or vessels. $C$, section of same internode as in $A$ and $B$ showing the libriform or wood fibers $(H)$ between the two arches of collateral mestomebundles. $D$, transverse section of a root; $E p$, epidermis; $E x$, exodermis; $C$, cortex; End, endodermis; $P$, pericycle; $L$, leptome; $H$, hadrome. $E$, transverse section of a leaflet: $E p$, the epidermal cells of the ventral surface; $E d$, epidermal cells of the lower or dorsal surface; $P$, palisade cells; $P n$, loose mesophyll or dorsal pneumatic tissue; $S t$, stereome on the leptome- 
Helleborus Viridis.-Radix Hellebori Viridis, Rhizoma Hellebori Viridis, or Green Hellebore.-The rhizome and roots of Green Hellebore or Christmas Flower, Helleborous viridis (Fam. Ranunculaceæ), a perennial herb indigenous to central and southern Europe and naturalized to some extent in the Middle Atlantic States.

Description.-Rhizome, horizontal or oblique, with numerous short branches and brittle roots; from 3 to $6 \mathrm{~cm}$. in length and about $1 \mathrm{~cm}$. in thickness; outer surface blackish-brown, annulate from leafscars, upper surface with stem bases about $1 \mathrm{dm}$. in length; fracture horny; bark thick, grayish-white and xylem with from 6 to 16 yellowish wood wedges; odor slight, when fresh, penetrating; taste bitter, becoming acrid. Roots about $2 \mathrm{~mm}$. in diameter, with a thick cortex and a 4-rayed central xylem.

Inner Structure.-Epidermis of brownish cells with strongly thickened outer walls; a layer of collenchyma; primary cortex of tangentially elongated starch-bearing parenchymatous cells; inner bark with the strands of leptome separated by broad medullary rays; wood consisting of radial rows of short reticulate tracheæ, surrounded by thin-walled wood-parenchyma and separated by broad medullary rays; pith cells resembling those of cortex. Roots having a starch-bearing cortical parenchyma, an endodermis, a thin-walled pericycle and collåieral vascular bundles. Starch grains small, spheroidal; oil secretion cells colored yellow with solutions of potassium hydrate; resinous secretion cells colored orange-red with iodin. Cell walls of parenchyma more or less modified to pectin.

Constituents.-It contains the same principles as $\mathrm{H}$. niger, the helleborein apparently predominating.

Literature.-Vogl, Pharmakognosie.

Adonis.-Herba Adonidis, False Hellebore.-The over-ground plant of the spring-flowering Adonis, Adonis vernalis (Fam. Ranunculacex), a low perennial herb indigenous to eastern and southern Europe and more or less cultivated. The herb is gathered during April or May, at the time of flowering, dried and made into bundles.

Description.-Stem, cylindrical, more or less branching, sharply wrinkled and somewhat hairy, with a few blackish-lanceolate leaf scales at the base. Foliage leaves, numerous, sessile, clasping the

side of a lateral vein. $F$, surface view of the dorsal or lower epidermis of a leaflet showing the stomata and foldings of lateral cell walls.-After Holm, Merck's Report, 1911, p. 4. 
stem, smooth or slightly hairy, the lower palmately divided, the upper pinnately-compound, the ultimate divisions being narrowly linear and acute. Flowers mostly single, at the summit of the scape, about $3.5 \mathrm{~cm}$. in breadth, pendulous, with a calyx consisting of 5 ovate hairy sepals, a corolla of 10 to 20 lanceolate, nearly spatulate, yellowish petals, stamens indefinite, pistils numerous, forming in fruit a dense head of ovoid achenes; odor slight; taste bitter and slightly acrid.

Inner Structure.-Leaves unifacial, the epidermal cells being longitudinally elongated and having wavy walls; the stomata, which are without neighboring cells, are deeply imbedded upon the lower surface. Fibrovascular bundles having tracheæ with spiral thickenings or marked with bordered pores and associated with narrow, lignified sclerenchymatous fibers. Non-glandular hairs, 1-celled, more or less curved and occasionally in the form of double hairs.

Powder.-Grayish-green; numerous fragments of pith parenchyma with a few simple pores, the cells attaining a length of 0.250 $\mathrm{mm}$.; groups of narrow sclerenchymatous fibers, mostly with lignified walls from 0.005 to $0.007 \mathrm{~mm}$. in thickness and having few round or oblique simple pores; tracheæ $0.017 \mathrm{~mm}$. in width, with spiral thickenings or bordered pores, epidermal cells from the stem and petiole, elongated in surface view and associated with elliptical stomata, the latter $0.064 \mathrm{~mm}$. in length; fragments of the epidermal tissue from the lamina of the leaf, composed of finely striated cells with wavy vertical walls, associated with broadly elliptical stomata, the latter attaining a length of $0.047 \mathrm{~mm}$; ; brownish-colored fragments from the scales at the base of the stem, composed of elongated cells with somewhat rounded ends and yellowish-brown walls; starch grains and calcium oxalate crystals are very few or wanting.-Newcomb.

Constituents.-Adonidin, a mixture of principles having the physiological action of Digitalis, and of which Picroadonidin, an amorphous glucoside, is the cardiac acting principle. Also Adonidinic acid and a substance resembling Quercitrin.

Adonis.-Herba Adonidis Astivalis.-The overground plant of Adonis æstivalis (Fam. Ranunculaceæ), an annual herb common in southern and central Europe. The plants are gathered in May or June at the time of flowering, and dried after removing the roots.

The stem is nearly smooth, furrowed and in the upper portion, more or less branched; the leaves are pinnately divided, the ultimate segments being linear and acute; the flowers are terminal, consisting of a 5-parted calyx, the sepals being narrow-lanceolate; corolla of 
5 to 7 petals, twice as long as the sepals, lanceolate-ovate, reddish or yellow and usually having at the base a black spot; stamens indefinite, with brownish-red anthers; pistils numerous, forming in fruit a dense head of achenes and subtended by the remains of the calyx; achenes ovoid, compressed and pointed at the summit.

The drug contains 0.215 per cent of a glucoside, which resembles adonidin, but is weaker in its physiological action.

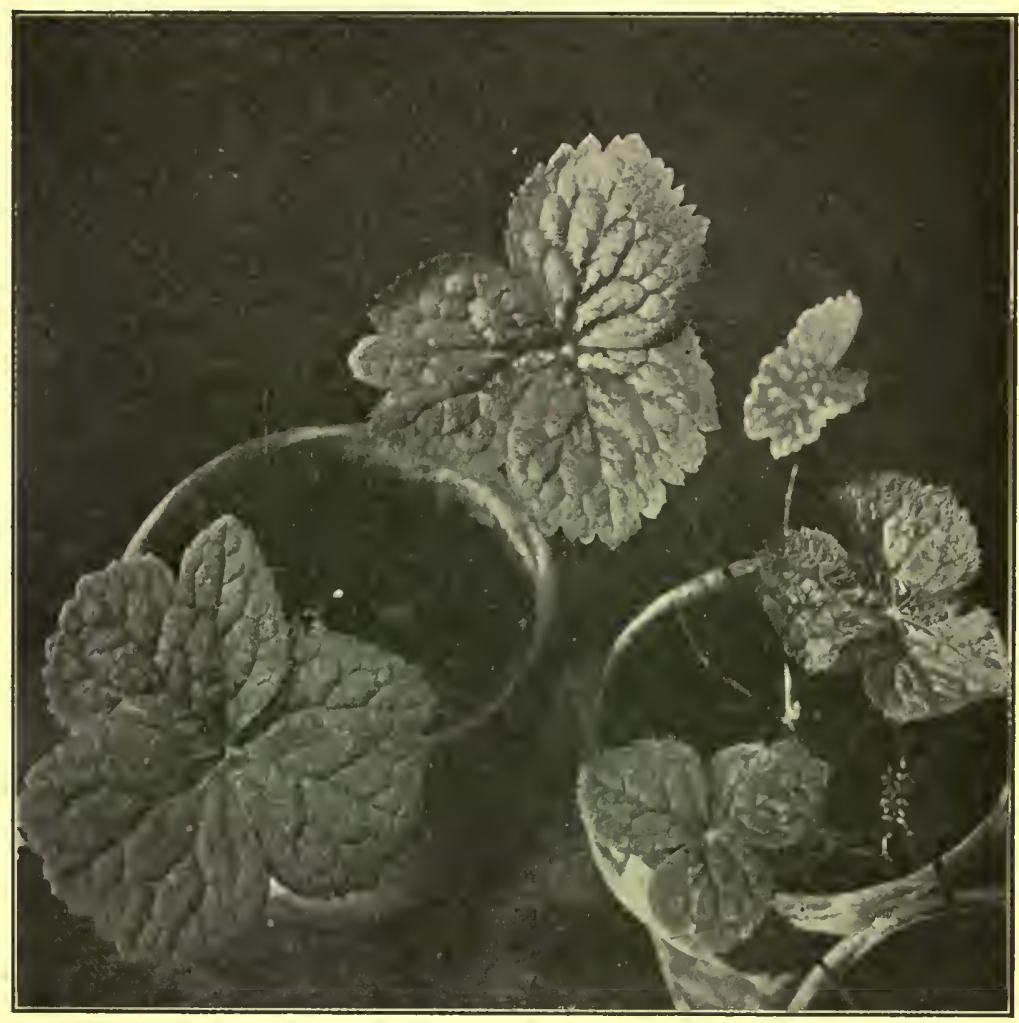

Fig. 100.-Podophyllum Emodi, a Himalayan plant now more or less cultivated and showing the long petiolate, deeply 3-lobed leaves and their strongly toothed margins.-Photographs of plants growing in Botanical Gardens, University of Minnesota.

Allied Plants.- In Adonis microcarpa, growing in Sicily, occurs a principle resembling Adonidin. Also an ash, of which 10 per cent is completely soluble in hydrochloric acid, and an aqueous extract amounting to 32 per cent.

Literature.-Zörnig, Arzneidrogen. 


\section{BERBERIDACEE, OR BARBERRY FAMILY}

A small family of about 100 species of herbs and shrubs, growing mostly in temperate regions. The leaves are simple or compound, the flowers are either single or in racemes and the fruit is a berry or capsule. Among the anatomical characteristics the following are most prominent: The tracheæ are usually marked with simple pores and the primary wood wedges are separated by broad medullary rays (Fig. 104). Calcium oxalate occurs in the form of aggregates or solitary crystals. There are no special secretion cells or glandular

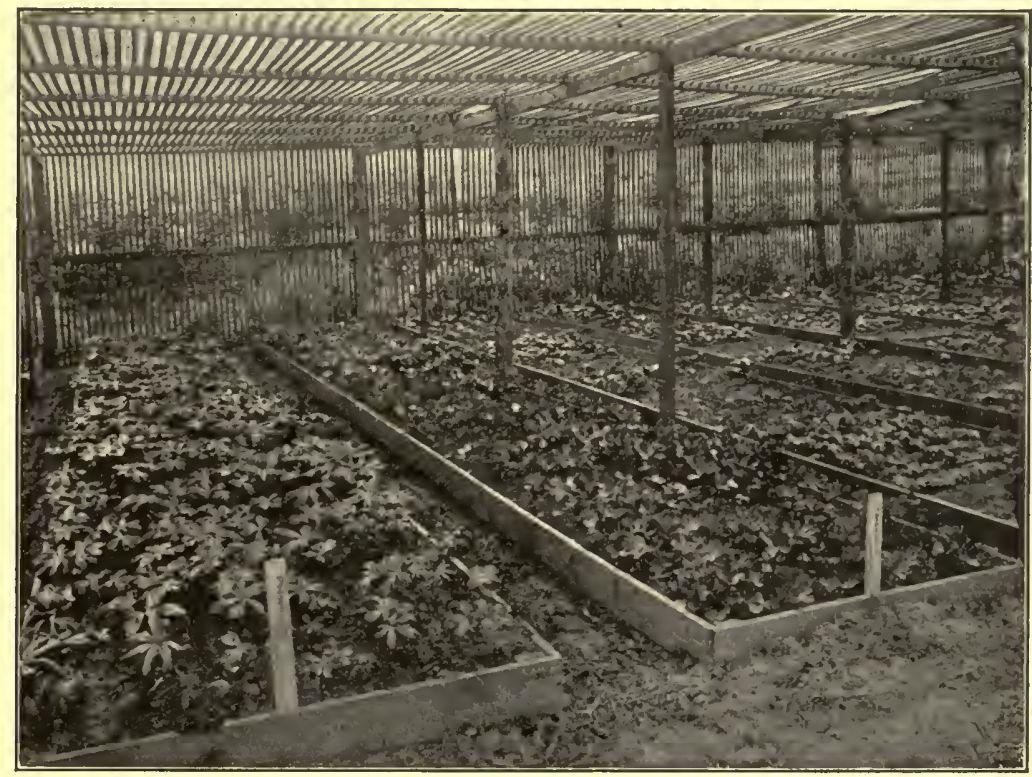

FIg. 101.-Lath-shade, affording partial shade, especially adapted for growing woodland plants, such as Podophyllum peltatum, Sanguinaria canadensis, Panax quinquefolium (Ginseng), etc. From Farmers' Bulletin 551, U. S. Department of Agriculture.

hairs. A number of crystalline substances are present and some of these, as berberin, are very characteristic of the plants of this family. In the epidermal cells of certain species of Mahonia occur greenish or prismatic crystals of an organic substance. Globular bodies, resembling silica, have been found in the medullary ray cells of the petioles of Lardizabala. In the chloroplasts of the palisade tissues of Berberis vulgaris occur acicular or sphenoidal crystalloids. The non-glandular hairs are usually unicellular, in some instances they 
consist of a chain of cells, the terminal one of which is filled with a yellowish or brownish amorphous substance.

Podophyllum.-May Apple.-The rhizome of Podophyllum peltatum (Fam. Berberidaceæ), a perennial herb (Fig. 102) indigenous to eastern North America. The rhizome is coll scted late in summer and dried, after the removal of the rootlets. Russell obtained the greatest percentage of resin in the early spring-collected drug. Scott and Petry found the resin to vary in plants grown in different soils and different seasons of the year. Most of the commercial supplies come from the Central States. Both the leaves and the fruit appar-

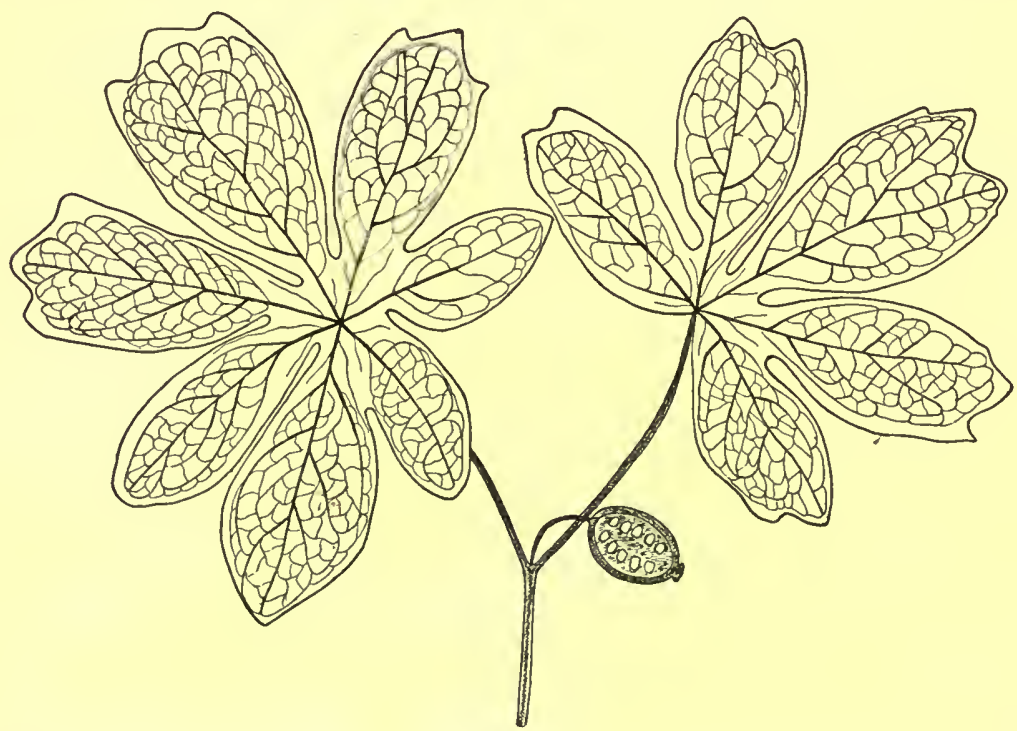

Fig. 102.-Top of fertile shoot of May apple (Podophyllum peltatum) having two large peltate, palmately-lobed leaves, in the axil of which arises the fleshy fruit, shown in longitudinal section and containing numerous truncate, ovoid seeds.

ently contain a purgative resin similar to that found in the rhizome. The berry, which is known as May, Indian, hog or devil's apple, wild or ground lemon, and raccoon-berry, is generally considered to be edible, but several cases of poisoning from eating it have been recorded.

Description.-Horizontal, nearly cylindrical, flattened, sometimes branched, jointed, in pieces 3 to $8 \mathrm{~cm}$. in length, internodes 4 to $10 \mathrm{~cm}$. in length, 5 to $9 \mathrm{~mm}$. in diameter, nodes 7 to $18 \mathrm{~mm}$. in diameter and 5 to $12 \mathrm{~mm}$. in thickness; externally dark brown, 
longitudinally wrinkled or nearly smooth, with irregular scars of bud-scales, nodes annulate from remains of bud-scales, upper part marked with large circular, depressed stem-scars and sometimes with buds; numerous root-scars at and near the lower portion of the nodes; fracture short; internally lemon-yellow, bark $1 \mathrm{~mm}$. in
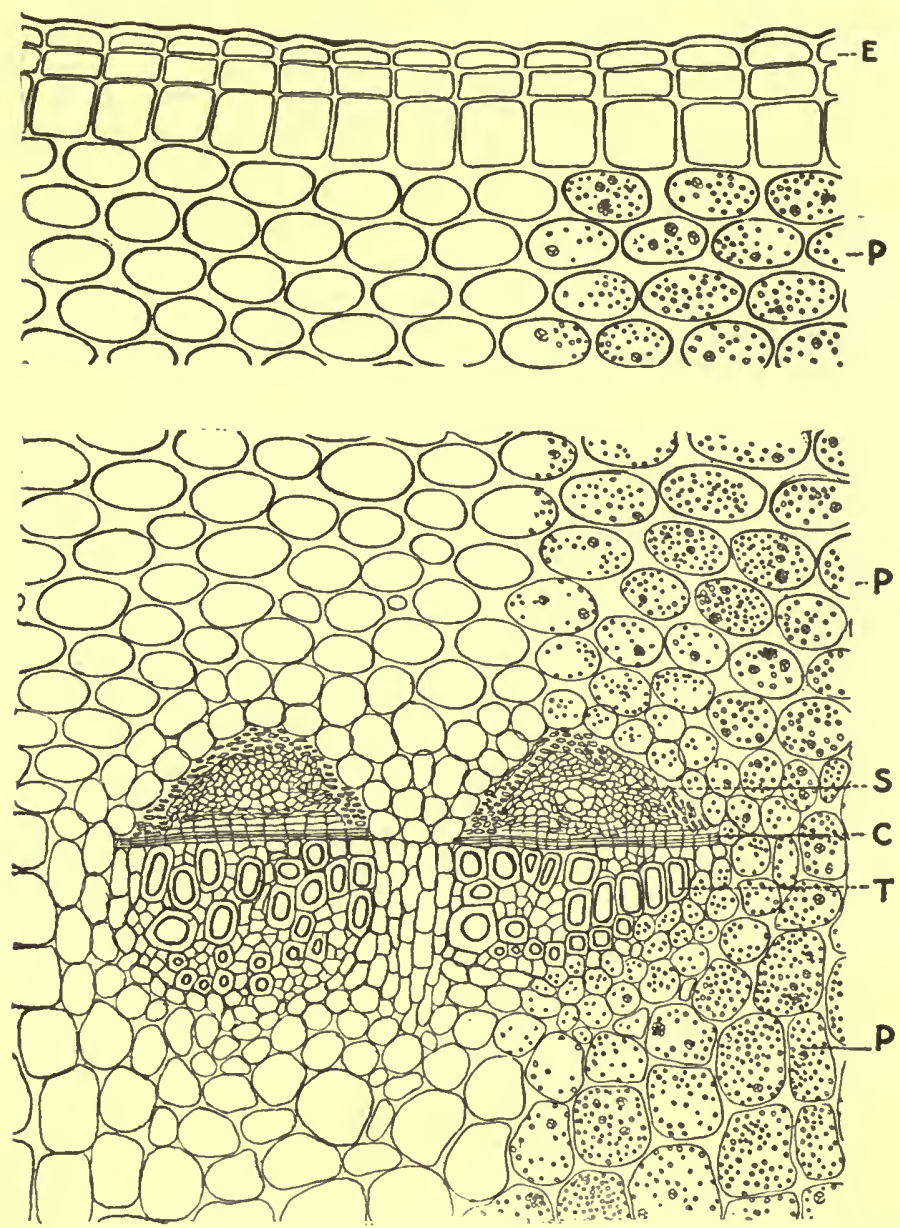

Fig. 103.-Transverse section of podophyllum rhizome: $E$, epidermis; $P$, parenchyma containing starch; $S$, sieve; $C$, cambium; $T$, tracheæ.

thickness, wood yellowish, $0.5 \mathrm{~mm}$. in thickness, pith large, white; odor slight; taste somewhat bitter and acrid.

Inner Structure.-See Fig. 103.

Powder.-Light brown and with a pronounced and characteristic odor; starch grains numerous, spheroidal, polygonal or 2- to 
6-compound, the individual grains from 0.003 to $0.015 \mathrm{~mm}$. in diameter, calcium oxalate crystals few, in rosette aggregates from 0.050 to $0.080 \mathrm{~mm}$. in diameter, and occasionally in raphides 0.030 to 0.090 $\mathrm{mm}$. in length; tracheæ with simple pores or close annular and reticulate thickenings; fragments of starch-bearing parenchyma and reddish-brown cork cells.

Constituents.-Resin (official as Resin of Podophyllum) 3.5 to 5 per cent, consisting of two poisonous principles: (a) podophyllotoxin, 20 per cent, occurring in white crystals that are sparingly soluble in water and yield on treatment with water podophyllic acid and picropodophyllin; and $(\vec{b})$ picropodophyllin (an isomer of podophyllotoxin), which crystallizes in needles and is insoluble in water but soluble in 90 to 95 per cent alcohol. The resin also contains a yellow crystalline coloring principle resembling quercetin, a green fixed oil and podophyllic acid. The rhizome also contains a purgative resin, podophylloresin; considerable starch, and some gallic acid.

Allied Plants. - The rhizome of Podophyllum Emodi (Fig 100), a plant growing on the lower slopes of the Himalayas, is large and yields 11.4 to 12 per cent of resin, which consists of but half as much podophyllotoxin as the resin obtained from P. peltatum.

Literature.-Russell, Amer. Jour. Pharm., 1918, 90, p. 8; Scott and Petry, Mich. Acảd. Sci., 1919, xxi.

Berberis.- Oregon Grape-root.-The rhizome and roots of Berberis Aquifolium (Fam. Berberidaceæ), a low trailing shrub, which is irdigenous to the Rocky Mountain region of the United States, extending into British Columbia and as far east as Nebraska. Berberis should be kept in closed tin or glass containers, to which a few drops of chloroform should be added from time to time to prevent the development of larvæ.

Description.-In cylindrical pieces which vary from 8 to $12 \mathrm{~cm}$. in length and 1.5 to $4.5 \mathrm{~cm}$. in diameter; externally pale yellowishbrown to dark yellowish-brown, longitudinally wrinkled, with few root branches and occasionally rootlets; hard and tough. Internally, bark dark brown, less than $1 \mathrm{~mm}$. in thickness and rather soft; wood lemon-yellow, distinctly radiate, with narrow medullary rays; pith bright yellow, 2 or $3 \mathrm{~mm}$. in diameter; slightly odorous; taste bitter.

Inner Structure.-See Fig. 104.

Powder.-(Fig. 105). Yellowish-brown, composed chiefly of fragments of wood-fibers associated with a few tracheæ and medullary rays; wood fibers yellowish, scarcely giving any reaction 
with phloroglucin and hydrochloric acid and with simple transverse pores; tracheæ chiefly with bordered pores, occasionally reticulate; medullary rays, 2 to 3 cells wide, and in very long rows; starch grains not numerous, occurring in pith and medullary ray cells, single or 2- to 3-compound, the individual grains being irregu-

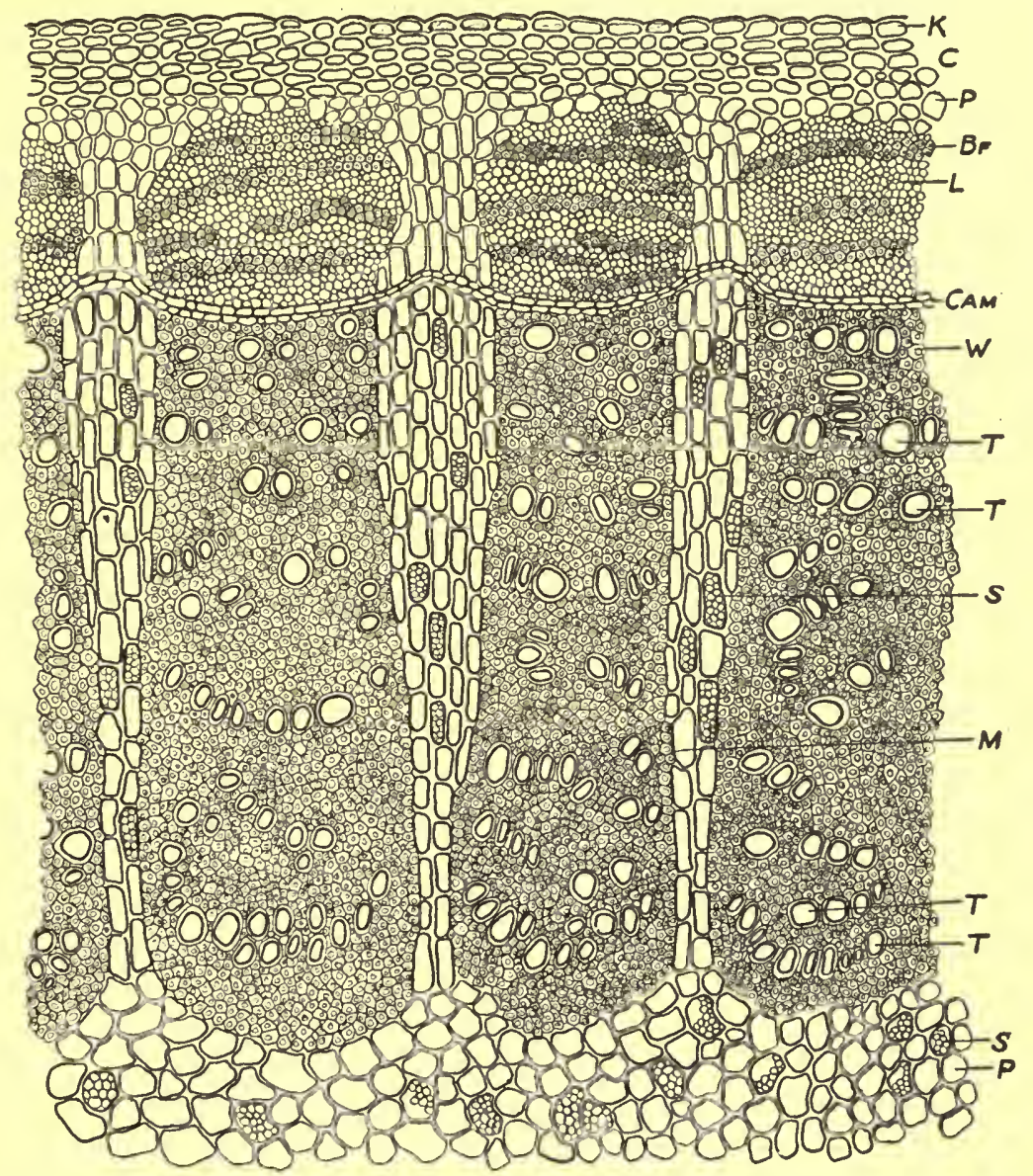

FIG. 104.-Transverse section of Berberis. $K$, cork; $C$, cortex; $P$, parenchyma; $B f$, bast fibers; $L$, leptome; Cam, cambium layer; $W$, wood fibers; $T$, trachex; $M$, medullary ray cells; $S$, starch grains.-Drawing by Haase.

larly spheroidal and from 0.003 to $0.010 \mathrm{~mm}$. in diameter, occasionally larger.

A powder made from the worm-eaten drug shows upon the addition of iodin solution fe:w or no starch grains, a large number of 
fine particles exhibiting a Brownian movement and very short fragments of the several tissues.

Constituents.-Four alkaloids, namely, berberine; oxyacanthine, which acquires a yellow color in sunlight; berbamine, which is distinguished from the above-mentioned alkaloids by being soluble in water; and another alkaloid whose properties have not been investigated. The drug also contains resin and considerable starch.

Allied Plants.-Berberis vulgaris (European barberry), naturalized in the United States, furnishes a drug which has similar properties. Not only the rhizomes and roots, but also the stem and root

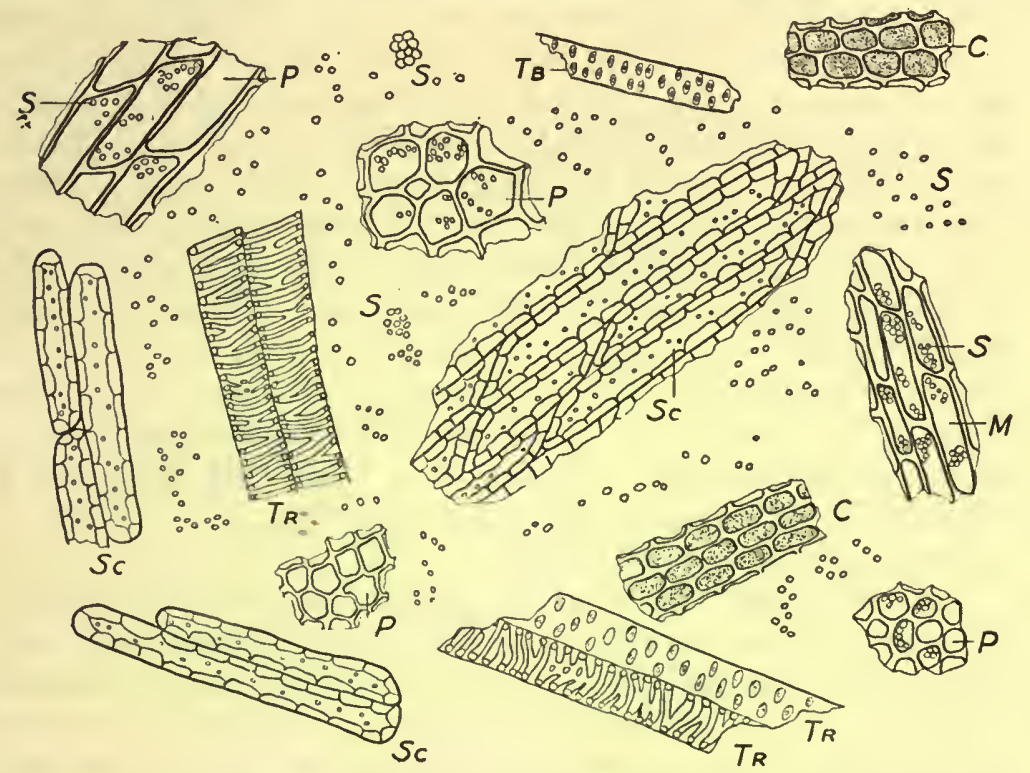

FIG. 105.-Powder of Berberis. Tr, reticulate tracheæ; $T b$, trachex with bordered pores; $P$, fragments of parenchyma cells; $S$, starch grains; $S c$, sclerenchymatous fibers; $C$, fragments of cortical parenchyma with a yellowish amorphous content; $M$, starch-bcaring medullary ray cells having yellowish walls.-Drawing by Haase.

barks are employed, the root bark containing a arger amount of alkaloids than that of the stem.

The bark and root of Berberis asiatica of the Himalaya region and B. aristata of India are similarly employed, the latter containing about 2 per cent of berberine.

The flowers of berries and Berberis Aquifolium and B. vulgaris contain berberine, oxyacanthine, volatile oil, about 6 per cent of malic acid and 3.5 to 4.7 per cent of sugar. 
The alkaloid berberine is also found in Argemone mexicana (Fam. Papaveraceæ) and in the following members of the Ranunculaceæ: Hydrastis canadensis, Coptis trifolia and Xanthorrhiza apiifolia.

Caulophyllum.-Blue Cohosh.-The dried rhizome and roots of Caulophyllum thalictroides (Fam. Berberidaceæ), a perennial herb indigenous to the eastern United States and producing a thick rhizome and large ternately compound leaves.

Description.-Consisting of rhizomes and numerous long, wiry, matted roots. Rhizome horizontal, with a few upright branches from 5 to $25 \mathrm{~cm}$. in length and from 4 to $16 \mathrm{~mm}$. in thickness; externally grayish-brown to dark reddish-brown, slightly annulate from the leaf scars, the upper surface with numerous depressed scars or short stem bases; under and lateral portions with numerous grayishbrown or yellowish-brown branching roots; fracture short, fibrous; inner surface light grayish-brown, having a waxy luster and showing a thin bark with numerous small wood wedges and a large pith; odor slight, sterrutatory; taste bitter and acrid. Roots wiry, much branched, nearly cylindrical, externally yellowish-brown to dark brown, longitudinally wrinkled, attaining a length of $3.5 \mathrm{dm}$., and having a diameter of 1 to $3 \mathrm{~mm}$.; fracture of bark short, wood tough; internally grayish-white consisting of a thick bark composed of starch-bearing parenchyma, and a 4-rayed xylem.

Inner Structure.-See Fig. 106.

Powder.-Light brown; starch grains numerous from 0.003 to $0.016 \mathrm{~mm}$. in diameter, mostly single, somewhat spheroidal in shape; fragments of cork composed of cells about $0.050 \mathrm{~mm}$. in diameter and having yellowish-brown walls; tracheæ from 0.025 to $0.050 \mathrm{~mm}$. in width, with bordered pores; sclerenchymatous fibers with strongly lignified walls; tracheids with bordered pores, and fragments of starch-bearing parenchymatous tissue.-Newcomb.

Constituents.-A crystalline alkaloid, Methylcytisine (caulophylline); a crystalline glucoside, Caulosaponin (ieontin); a second saponin-like glucoside, Caulophyllosaponin; a phytosterol glucoside, to which the name Citrullol has been applied; a phytosterol; a volatile oil; an enzyme; a reducing sugar; a resinous substance, and a mixture of fatty acids.

Literature.-Holm, Merck's Report, 1907, p. 94; Power and Salway, Jour. Chem. Soc., 1913, p. 191. 

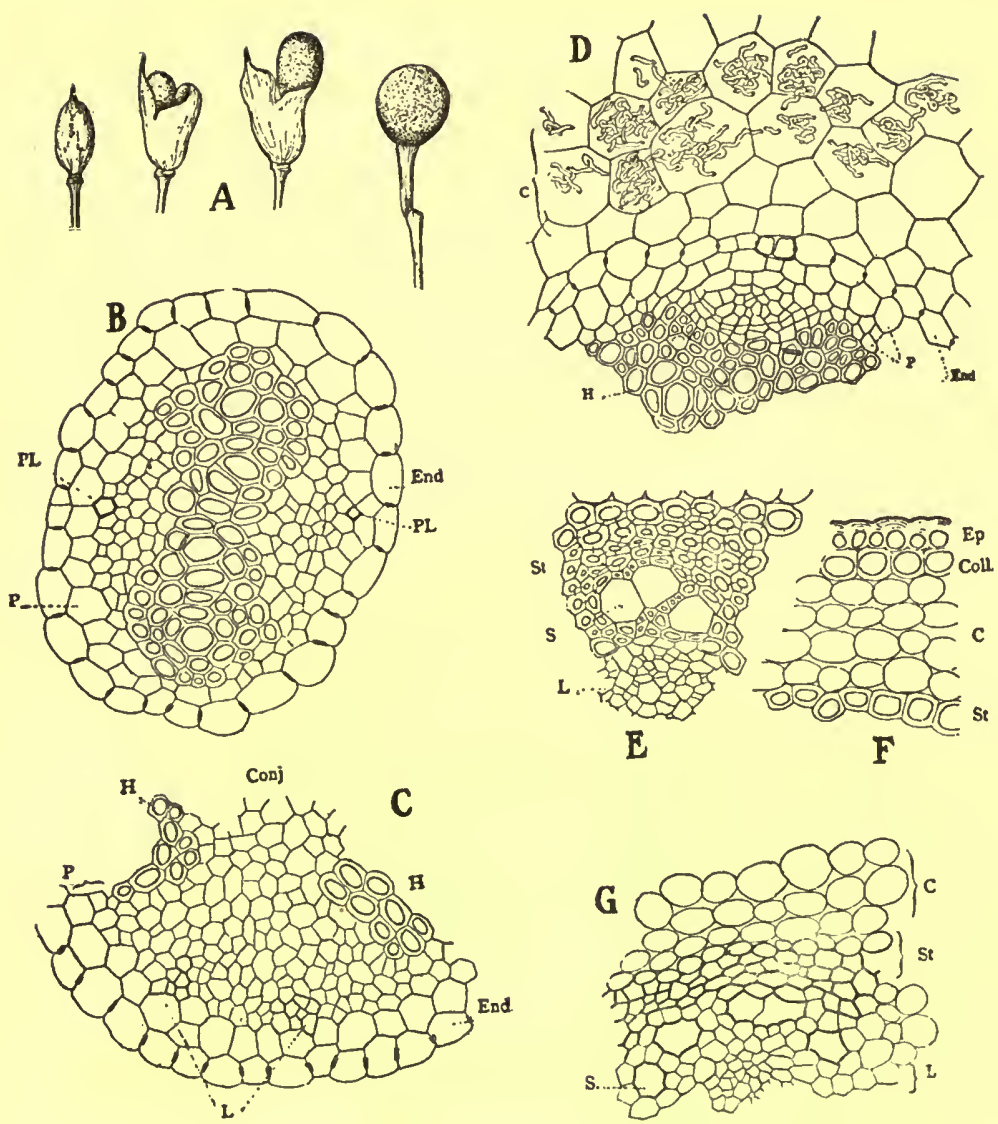

FIG. 106.-Caulophyllum. A, development of fruit and seeds. The seed forces its way through the young pericarp, the latter withers and the seeds mature, becoming globose and deep blue when ripe. $B$, transverse section of a secondary root, showing endodermis $(E n d)$ with prominent Casparyan Spots; the pericambium made up of a single layer of thin-walled cells $(P)$; a central hadrome on the other side of which is the leptome, each strand of which contains a proto-leptome cell $(P L)$. $C$, transverse section of a secondary root, showing endodermis $(E n d)$; pericambium $(P)$; leptome $(L)$; tracheæ $(H)$; and pith (Conj). $\quad D$, transverse section of a secondary root showing the hyphre of one of the fungi. $E$ and $F$, transverse sections of a mature stem showing epidermis $(E p)$; collenchyma $(C o l l)$; cells of cortex $(C)$; stereome $(S t)$ in which occur large secretory ducts $(S)$. $G$, transverse section of a young stem showing the origin of the secretory ducts; the nature of these has not been determined, although they seem to be characteristic of Caulophyllum.After Holm. 


\section{MENISPERMACEA, OR MOONSEED FAMILY}

A family of mostly tropical plants, being in the nature of climbing or twining, frequently woody vines. The leaves are entire or lobed, the flowers are small, white or green, and diœcious. The stems are characterized in having broad primary medullary rays and in the pericycle there is usually a continuous sclerenchymatous ring. The tracheæ are porous and very wide and associated with tracheid-like wood fibers, i.e., possessing bordered pores. In certain of the genera in which the stem is thick and woody an anomalous structure is found consisting of several concentric rings of vascular bundles, which either completely encircle one another or are developed excentrally; that is, more strongly on one side, as in Pareira. Calcium oxalate usually occurs in the form of small rod-shaped or acicular crystals, sometimes in aggregates or large solitary crystals. Both glandular and non-glandular hairs may be present and peculiar hydathodes, i.e., water-absorbing and water-excreting organs are observed situated among the trichomes in Anamirta cocculus. Elongated secretory sacs occur in the stems and petioles of Cissampellos, Jateorhiza and Anamirta. A "sub-epidermal mucilaginous layer occurs in a number of species.

Menispermum.--Yellow Parilla or Canada Moonseed.-The dried rhizome of Menispermum canadense (Fam. Menispermacex), a high-climbing vine indigenous to northern United States and Canada and having broadly ovate, cordate and 3- to 7-lobed leaves. The flowers are in panicles and the fruit is a bluish-black berry. The rhizome is gathered, cut into convenient pieces and dried.

Description.-Rhizome horizontal, cylindrical, much branched, attaining a length of 1 or $2 \mathrm{M}$. and having a diameter from 2 to $20 \mathrm{~mm}$.; externally yellowish to dark brown, longitudinally wrinkled and somewhat scaly, having upon the upper surface at the nodes a central bud in a nearly circular overground stem-scar, and scattered roots arising from all portions of the rhizome; fracture of bark short, wood tough and very fibrous; inner surface yellowish-white with a thin bark, a broad porous radiating-wood, and a white pith which is frequently hollow in the larger pieces; inodorous; taste bitter and somewhat sweetish. Roots cylindrical, more or less branching, from 1 to $10 \mathrm{~cm}$. in length and from 0.5 to $2 \mathrm{~mm}$. in diameter, dark brown, tough, wiry.

Inner Structure.-See Fig. 107. 
Powder.-Very light brown; tracheæ from 0.030 to $0.150 \mathrm{~mm}$. in width, marked with slit-like simple pores or with elliptical bordered pores, frequently with the transverse walls remaining; wood fibers narrow, strongly lignified and with numerous large simple pores and frequently tracheid-like, i.e., possessing bordered pores; bast fibers long, narrow, with relatively thin, strongly lignified walls marked by simple oblique pores; stone cells mostly cubical and with rather thin, porous walls; starch-bearing medullary ray cells resembling the parenchyma of cortex and pith, the latter being composed, however, of a number of larger cells, the walls of which are more or

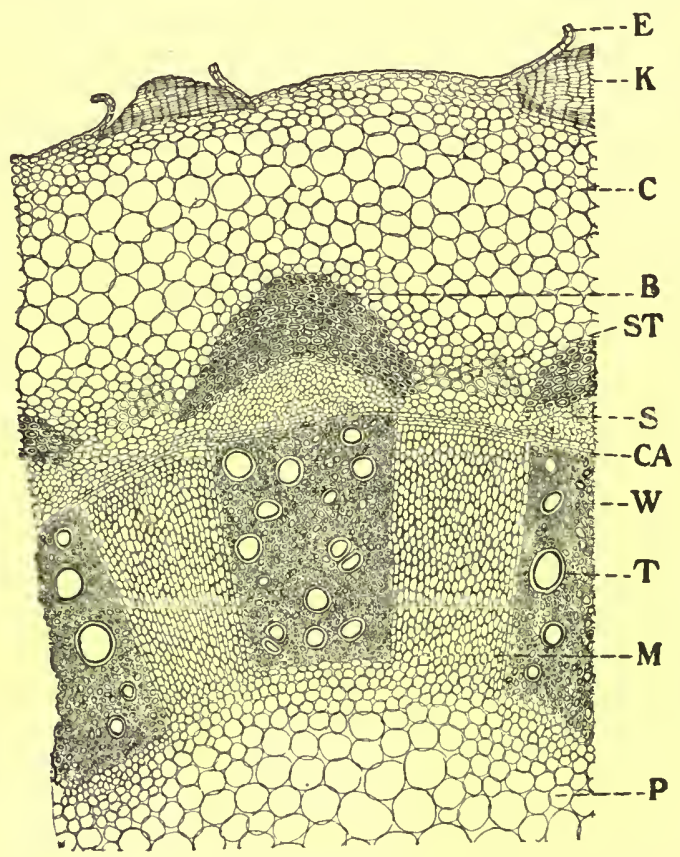

Fig. 107.-Menispermum. Transverse section through rhizome; $E$, epidermis; $K$, sub-epidermal cork; $C$, cortex; $B$, bast fibers; $S$, sieve; $S T$, stone cells; $C A$, cambium; $T$, large tracheæ or vessels; $W$, wood fibers; $M$, medullary ray cells; $P$, pith.

less broken; starch grains mostly single, spheroidal and from 0.002 to $0.012 \mathrm{~mm}$. in diameter; epidermal cells elongated and with nearly straight, yellowish slightly porous walls; few yellowish-brown cork cells, usually with adhering yellowish epidermis.

Constituents. - Ii contains a bitter alkaloid, menispine, berberine and starch. In addition it contains the alkaloid oxyacanthine, which is also found in Berberis vulgaris of Europe and the West Indies. 
Calumba.-Columbo.-The root of Jateorhiza palmata (Fam. Menispermacex), a perennial herbaceous climber, native of the forests of eastern Africa. The large, fleshy roots are collected in the dry season, cut into transverse pieces, dried and exported by way of Zanzibar and Bombay.

Description.-In nearly circular or elliptical disks, sometimes irregularly bent, 2 to $5 \mathrm{~cm}$. in diameter, 2 to $10 \mathrm{~mm}$. in thickness; bark externally yellowish-green or dark brown, wrinkled; fracture short, mealy; internally, radiate, yellowish-green, collateral wood bundles forming a concentric zone, bark 4 to $6 \mathrm{~mm}$. in thickness, cambium zone distinct, center either depressed or more or less prominent; odor slight; taste bitter and aromatic.

Inner Structure.-See Fig. 108.

Powder.-Greenish-brown, grayish-yellow or bright yellow starch grains numerous, mostly single, occasionally 2- to 3-compound, the individual grains from 0.003 to $0.085 \mathrm{~mm}$. in the long diameter, ovoid, ellipsoidal, frequently very irregular, slightly lamellated, with excentral linear, $\mathrm{x}$-shaped or branching clefts; stone cells few, but very characteristic, having irregularly thickened, strongly lignified, coarsely porous walls and containing one or more prisms of calcium oxalate from 0.010 to $0.030 \mathrm{~mm}$. in length or numerous small, sphenoidal microcrystals; fragments with tracheæ few, the latter with reticulate thickenings, or bordered pores, and associated 'with woodfibers having long, oblique, slit-like pores.

Constituents. - Two yellowish alkaloids, closely resembling berberine and varying from 0.98 to 1.38 per cent in the bark and 1.02 to 2.05 per cent in the wood. To one of these bases the name columbamine has been given. Calumba also contains a volatile oil 0.056 per cent, starch about 35 per cent, pectin 17 per cent, resin 5 per cent, calumbic acid, calcium oxalate, mucilage, and yields 6 per cent of ash.

Substitutes.-Various substitutes for calumba have been offered, but these are free from starch, or they may contain tannin, as American columbo, the root of Frasera carolinensis (Fam. Gentianaceæ), an herb indigenous to the eastern United States. This root formerly occurred in the market in transverse disks somewhat resembling calumba, but without the radiate structure. It contains a larger amount of a yellow coloring principle and less gentiopicrin than gentian.

Adulterants.-Calumba has been adulterated with the roots of Tinospora Bakis of tropical Africa and Coscinum fenestratum (both of the Fam. Menispermaceæ), the latter growing in India. 
The disks are woody, the center being prominent and not depressed, and the ash varies from 11.9 to 16.6 per cent.

Cocculus.-Cocculus Indicus, Fructus Cocculi or Fish Berries. - The dried fruit of Anamirta Cocculus (Fam. Menispermaceæ), a woody climber growing in the mountainous woods of southeastern Asia. The berries are commonly used by the natives to
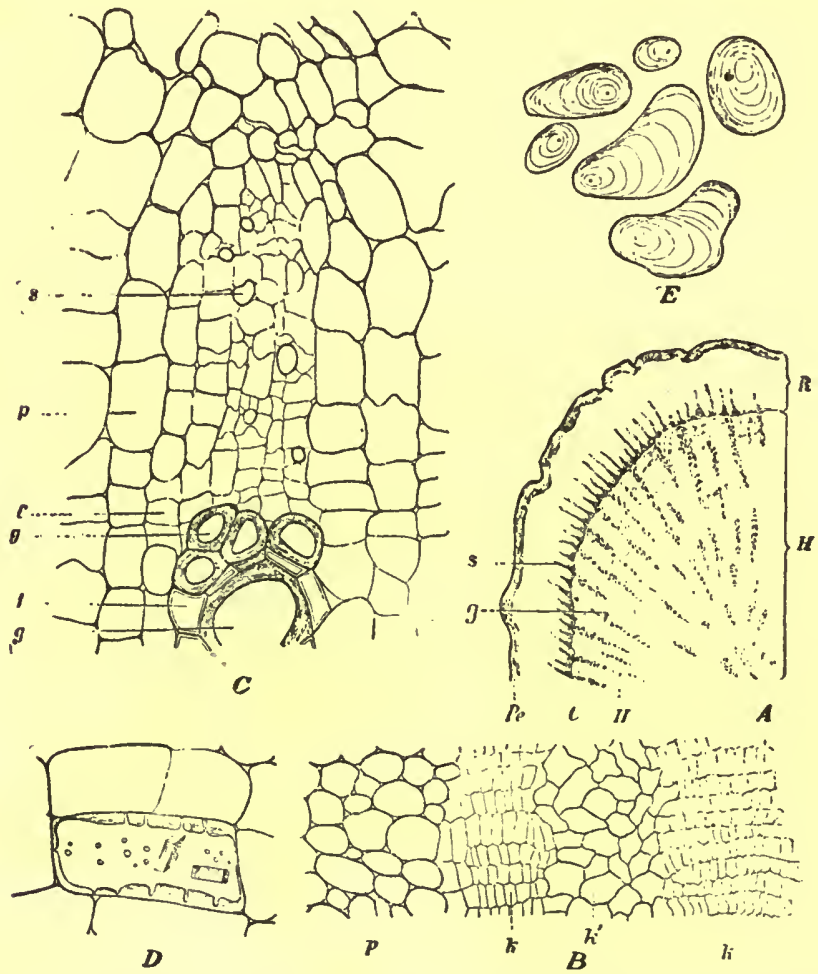

Frg. 108.-Calumba: $A$, transverse section showing bark $(R)$, cambium $(C)$, and wood $(H)$, wood fibers $(H)$, trachex $(g)$, periderm $(P e)$ and sieve $(s)$; $B$, longitudinal section of periderm showing parenchyma $(p)$, small-celled cork $(k)$ and large-celled cork $\left(k^{\prime}\right) ; C$, transverse section near cambium showing tracheæ $(g, g)$, intermediate fiber $(i)$, cambium $(c)$, parenchyma $(p)$ and sieve cell $(s) ; D$, stone cell from the periderm containing calcium oxalate; $E$, lamellated starch grains.-After Meyer.

stupefy fish, thus making it possible to catch them by hand. The fruits when ripe are of a reddish color and are removed from their stalks and dried. The drug seems to deteriorate with age, and those fruits which are of a dark color, having the seeds well preserved are 
preferred. It is shipped to Calcutta and Bombay, thence to London, from which it is distributed.

Description.-Nearly spheroidal or ovoid, subreniform, from 0.5 to $10 \mathrm{~mm}$. in length; externally grayish- to blackish-brown, wrinkled, the summit and base separated by a narrow and shallow sinus, the former being somewhat acute and the latter marked by a depressed, circular stalk-scar, sometimes marked by a slight ridge

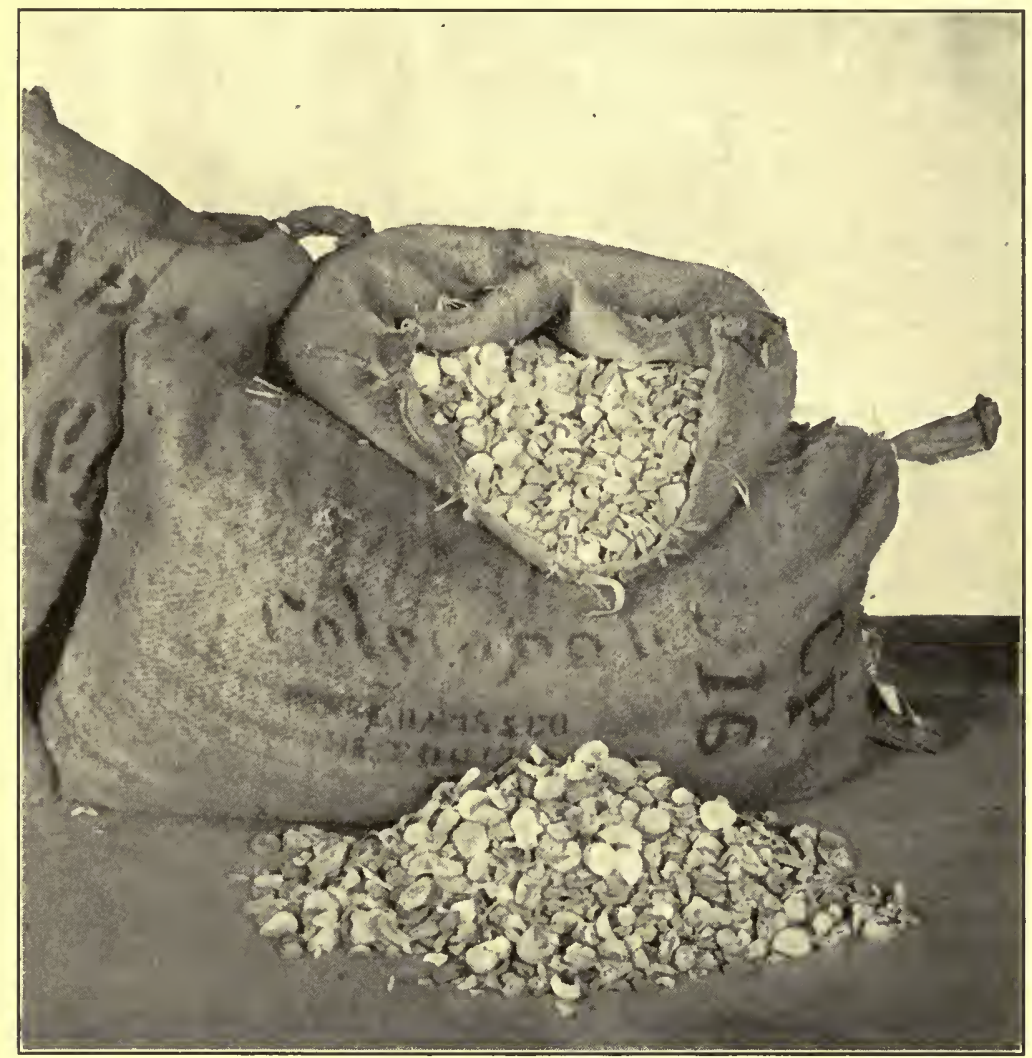

Fig. 109.-Original packages of Columbo (Calumba). After a photograph by Parke, Davis \& Co.

or a narrow, yellowish, thread-like, fibrous separable band extending over nearly the entire circumference of the fruit; pericarp about $1 \mathrm{~mm}$. in thickness, consisting of an outer grayish-brown fibrous layer, and an inner light yellow layer made up of sclerenchymatous fibers which completely surround a single reniform seed; pericarp inodorous and tasteless; seed oily and intensely bitter. 
Inner Structure.-Epicarp of a single row of nearly cubical cells; a broad layer of thin-walled tangentially elongated cells, having thin, brownish walls and a brownish granular content, the latter becoming reddish-brown with solutions of the alkalies; a layer of reddish-brown elongated cells in among which are distributed the i small fibrovascular bundles; a few rows of light yellow, porous cells; endocarp composed of thick-walled, strongly lignified sclerenchymatous fibers which ramify among each other; endosperm of large polygonal cells, having thin walls and containing an oily cytoplasm and large protein grains. In the cells of the endosperm and in large diaphragms formed by the separation of the cells, occur small acicular or prismatic crystals, frequently united to form aggregates. These crystals are of the fixed oil and are insoluble in water and dilute acids, but soluble in ether and solutions of the alkalies.

Constituents. - The seeds contain 1.5 per cent of Picrotoxin (cocculin), a neutral principle which forms colorless, inodorous prisms, having a bitter taste and very toxic properties. From 11 to 25 per cent of a fixed oil consisting chiefly of stearic and oleic acids. They also contain small quantities of resin, wax, gum and starch. The pericarp contains 2 tasteless, non-toxic, crystallizable alkaloids, viz., menispermine and taramenispermine.

Pareira.-Pareira Brava.-The root of Chondrodendron tomentosum (Fam. Menispermaceæ), a perennial climber indigenous to Brazil and Peru. The commercial article is exported from Rio Janeiro.

Description.-(Fig. 110.) Nearly cylindrical, more or less tortuous, cut into pieces up to $20 \mathrm{~cm}$. in length, and varying from 1 to 6 $\mathrm{cm}$. in diameter; externally brownish-black to blackish-brown with tranverse ridges and knot-like projections and occasionally fissures, and longitudinally wrinkled or even furrowed; hard, heavy and tough; when freshly cut having a waxy luster; the transverse surfaces exhibiting several successive excentral and distinctly radiate concentric zones of projecting secondary fibrovascular bundles, each 2 to $4 \mathrm{~mm}$. wide and separated by distinct concentric zones of parenchyma and stone cells; odor slight; taste very bitter.

The pieces of stem which are sometimes admixed with the drug and which should be rejected are deeply furrowed, usually covered with grayish foliaceous patches of lichens bearing their blackish apothecia, and are more of a grayish-yellow color internally, distinctly woody and without a waxy luster.

Inner Structure.- Transverse sections show an anomalous structure, consisting of eight or more concentric or excentric rings, each 
made up of distinctive tissues as follows: (1) Alternate rings or zones composed of wood-wedges having large tracheæ, surrounded by wood fibers and separated by broad starch-bearing medullary rays; each wood-wedge also has at the periphery a semicircular strand of leptome. (2) Alternate rings or zones of starch-bearing parenchyma marked upon the inner face by a nearly closed ring of stone cells. Periderm consisting of a number of layers of narrow blackish-brown cork cells and having beneath usually a distinct phellogen layer.

A distinct pit is absent in the root and only occurs in the stem which otherwise has a structure resembling the root.

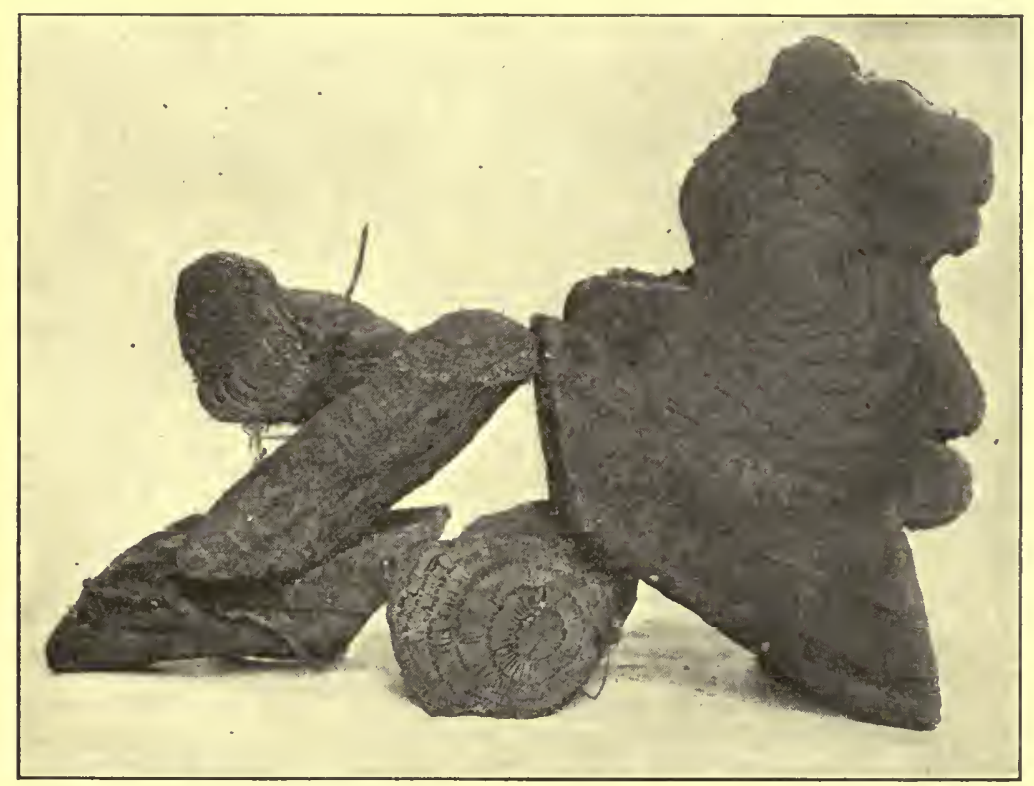

Frg. 110.-Photographs of typical specimens or true Pareira, the pieces in transverse section showing concentric rings of fibrovascular tissue.

Powder.-Dark brown or yellowish-brown starch grains numerous, mostly single, occasionally unequally 2- to 4-compound, the individual grains ellipsoidal, spheroidal, or oblong, varying from 0.005 to $0.020 \mathrm{~mm}$. in diameter and occasionally with clefts or irregular markings; fragments of long wide tracheæ, marked mostly with numerous slit-like pores and associated with long thick-walled porous and strongly lignified wood fibers; stone cells in small groups with thick walls and numerous radiating pores; fragments of parenchyma filled with starch grains, those of the root being thick-walled, 
strongly lignified and provided with large longitudinal elliptical pores; occasional fragments of blackish-brown cork.

Constituents. - An alkaloid pelosine (cissampeline) about 1 per cent, somewhat resembling berberine in bebeeru bark (Nectandra Rodiæi, one of the Lauraceæ, and buxine in box wood (Buxus sempervirens, one of the Sapindaceæ); starch, tannin, wax, ash 4 to 5 per cent.

Substitutes.-Other roots are frequently substituted for genuine pareira brava, which are no doubt derived from other menispermaceous plants; these roots are of a brownish color, possess numerous concentric zones of fibrovascular bundles, and do not have a waxy luster when cut.

False Pareira is obtained from a related species (Cissampelos Pareira), growing in South America, West Indies and East Indies. The root is somewhat flattened, externally dark brown, internally yellowish-brown, free from the concentric zones of wood bundles, and contains about 0.5 per cent of pelosine.

The stems of Chondrodendron tomentosum are also sometimes found in the drug; these are more woody, possess a distinct pith and are marked externally by the apothecia of lichens.

The roots of several other plants of this family are used as substitutes for pareira, among which may be mentioned Chondrodendron platyphyllum of Brazil and Paraguay, and Stephania discolor of India. White Pareira is obtained from Abuta rufescens, the roots of which are whitish or pale yellow and very starchy. Yellow Pareira is obtained from A. amara. The root is bright yellow internally, very bitter and apparently contains alkaloids resembling beberine and berberine.

Literature.-Holm, Merck's Rept., 1918, 27, pages 7 and 60.

\section{MAGNOLIACE巴, OR MAGNOLIA FAMILY.}

The plants are mostly trees or shrubs and are represented in the United States by the magnolias and tulip tree also called yellow poplar or white wood. The plants are characterized by having in the pericycle small isolated groups of bast fibers. The tracheæ are marked either by simple pores, scalariform thickenings of bordered pores. The pith is frequently hollow, surrounded by more or less empty cells, those at the periphery being thick-walled and living. The stone cells are of various shapes, being not infrequently much branched as in magnolia. Calcium oxalate occurs in the form of 
small octahedral or prismatic crystals or in rosette aggregates, seldom in the form of large prisms. An important character is the presence of more or less spheroidal secretory cells which are distributed in among the parenchyma of the stem and leaves and contain either a volatile oil or resin. In the leaves they give rise to pellucid dots, which are apparent on holding the leaves to the light.

\section{Illicium.-Fructus Anisi Stellati, Chinese Anise or Star} Anise.-The dried ripe fruit of Illicium verum Hook. f. (not Illicium anisatum L.), a tree of the Magnoliaceæ, which is indigenous to southeastern Asia and now extensively cultivated in southern China, French Indo-China, Japan, the Philippines and Jamaica. Most of the commercial supplies are shipped from Tonkin (Tongking) and are used in the manufacture of a volatile oil, which closely resembles the oil obtained from the fruits of Pimpinella Anisum and is recognized by most of the Pharmacopoias as a source of true oil of anise. The carpels of the flower are erect, assuming a horizontal position after fertilization, and the fruit is collected usually when the follicles are more or less unequally developed.

Description.-Fruit consisting of 6 to 11 (usually 8) outspreading boat-shaped follicles, arranged around the central axis or columella, and subtended by a short nearly cylindrical stalk. Carpels unequal, from 5 to $20 \mathrm{~mm}$. in length and 5 to $12 \mathrm{~mm}$. in height, broadly ovate, laterally compressed; basal portion attached to the columella, flat; cummit acute and tapering to a nearly straight beak; outer surface reddish-brown, nearly smooth or rough wrinkled; inner surface light yellowish-brown, smooth and shiny and showing in the dehiscent capsules a single seed, which is compressed-ovoid, from 0.005 to $0.008 \mathrm{~mm}$. in length, very smooth and shiny, marked at the pointed end by a distinct hilum-scar, and on the edge with a narrow raphe; odor and taste aromatic, resembling anise.

Inner Structure.-Outer epidermal layer of the pericarp made up of cells with very thick, porous outer walls; the middle layer composed of brown parenchyma and enclosing numerous oil-cells, a few idioblasts and vascular bundles; an endocarp of a single layer of palisade-like stone cells. The seed is made up of an outer layer of very strongly thickened palisade-like stone cells, a broad layer of loose parenchyma having more or less thickened walls and surrounding one or more rows of obliterated cells; the endosperm consists of polygonal cells, containing an oily cytoplasm and numerous aleurone grains; the latter vary from 0.010 to $0.026 \mathrm{~mm}$. in diameter, and are made up of one or more globoids and a large cystolith-like globoid. In the columella occur a number of more or less branching 
and thick-walled stone cells (astroclerotic cells), which are about $0.220 \mathrm{~mm}$. in length and $0.145 \mathrm{~mm}$. in thickness.

Powder.-Dark reddish-brown; palisade-like stone cells from 0.3 to $0.6 \mathrm{~mm}$. in length and from 0.020 to $0.050 \mathrm{~mm}$. in width; isodiametric stone cells and irregularly branching forms (astrostone cells) having thick lignified walls and branching pores; fragments of sclerenchymatous fibers with more or less irregularly thickened walls and simple pores; outer epidermal cells with striated cuticle; aleurone grains from 0.010 to $0.020 \mathrm{~mm}$. in diameter, usually containing a number of globoids and a large cystolith-like crystalloid. The poisonous shikimmi fruit is distinguished by somewhat shorter palisade cells; somewhat rounded stone cells; the aleurone grains contain 2 or 3 globoids and a few large prismatic crystalloids; alcoholic solutions yield an oil with a disagreeable odor, and furthermore deposits upon evaporation numerous crystals of shikimminic acid. For illustration of stone cells consult Kraemer's Applied and Economic Botany, page 268.

Constituents.-True Illicium yields a volatile oil consisting chiefly of anethol and small quantities of phellandrene, pinene, methyl chavicol, hydroquinone-ethyl-ether, and probably safrol. The pericarp yields from 5.3 to 5.65 per cent of volatile oil, while the seed yields only 1.7 to 2.7 per cent; the seed also contains 22.3 per cent of a fixed oil and 2.6 per cent of a reddish-brown resin. The latter exists to the extent of 10 per cent in the pericarp. The drug also contains anisic acid, protocatechuic acid and shikimminic acid.

Adulterants.-The fruits of Illicium religiosum (also known as I. japonicum and I. anisatum L.) are very poisonous and are obtained from trees which are extensively cultivated in Japan, especially in groves of Buddhist temples. The fruits are known in commerce as Japanese Star Anise, Shikimmi fruits or Skimmi fruits. They are readily distinguished by their odor, which is very different from anise and more nearly resembles that of such oils as cajuput, cardamom, sassafras or laurel. The taste is intensely pungent, becoming aromatic, somewhat bitter and camphor-like. The carpels, of which there are usually 6 to 8 , are mostly of uniform size, being somewhat smaller than true Illicium, the summit being acuminate and terminated by a short curved beak. The seeds are less-compressed and are of a light yellowish-brown color. Among the anatomical characters which serve to distinguish Japanese star anise the following may be mentioned: (1) The absence of irregularly branching stone cells, the latter being usually circular in section and only 
slightly irregular in Japanese star anise. (2) The aleurone grains consist of one or two globoids and two or three distinct crystals, occasionally single aggregates from 0.020 to $0.025 \mathrm{~mm}$. in diameter.

The Japanese star anise yields 1 per cent of a volatile oil containing eugenol, safrol and shikimmen, the latter being a terpene compound. It also contains shikimmin, which forms large crystals that are soluble in alcohol, but insoluble in water, and to which the poisonous properties are due. There has also been isolated a toxic alkaloid, skimmianin. An alcoholic solution of the carpels, upon evaporation, yields numerous crystals of shikimminic acid.

\section{MONIMIACEE}

The plants are mostly tropical trees or shrubs having opposite leaves and cymose flowers. They are especially distinguished by the presence of oil secretion cells, which give an aromatic odor and a transparent dotting to the leaves (Fig. 111). These cells are found not only in the leaves, but are distributed among the parenchymatous cells of the axis. In some cases they are colored reddish-brown, due either to tannin or a resinous substance. A number of forms of non-glandular hairs occur, and these are of generic value. Calcium oxalate, when present, is in the form of small acicular or rhombohedral crystals, one or more occurring in the same cell; hippocrepian stone cells, i.e., in the shape of a horseshoe are found in the cortex of very many of the genera, and there is usually a continuous sclerenchymatous ring in the pericycle. Neither glandular hairs nor mucilage cells are present in this family.

Boldus.-Boldo.-The dried leaves of Peumus Boldus (Fam. Monımiaceæ) an evergreen tree indigenous to Chili.

Description.-Broadly elliptical or ovate, 3 to $6 \mathrm{~cm}$. in length, 1 to $5 \mathrm{~cm}$. in breadth; summit acute, rounded, emarginate; base acute or more or less rounded; margin entire, distinctly revolute; upper surface light green, with numerous small spherical projections, veins depressed; under surface brownish-green, veins very prominent, pubescent, those of the first order diverging at an angle between 35 and 45 degrees and uniting with each other 3 to $4 \mathrm{~mm}$. of the margin, surface between the veins minutely and coarsely papillose; petiole 3 to $5 \mathrm{~mm}$. long; texture coriaceous, brittle; odor aromatic; taste aromatic and pungent.

Inner Structure.-See Fig. 111.

Constituents.-A volatile oil, 2 per cent; an alkaloid, Boldine, 0.1 per cent, which is bitter, very slightly soluble in water and sol- 


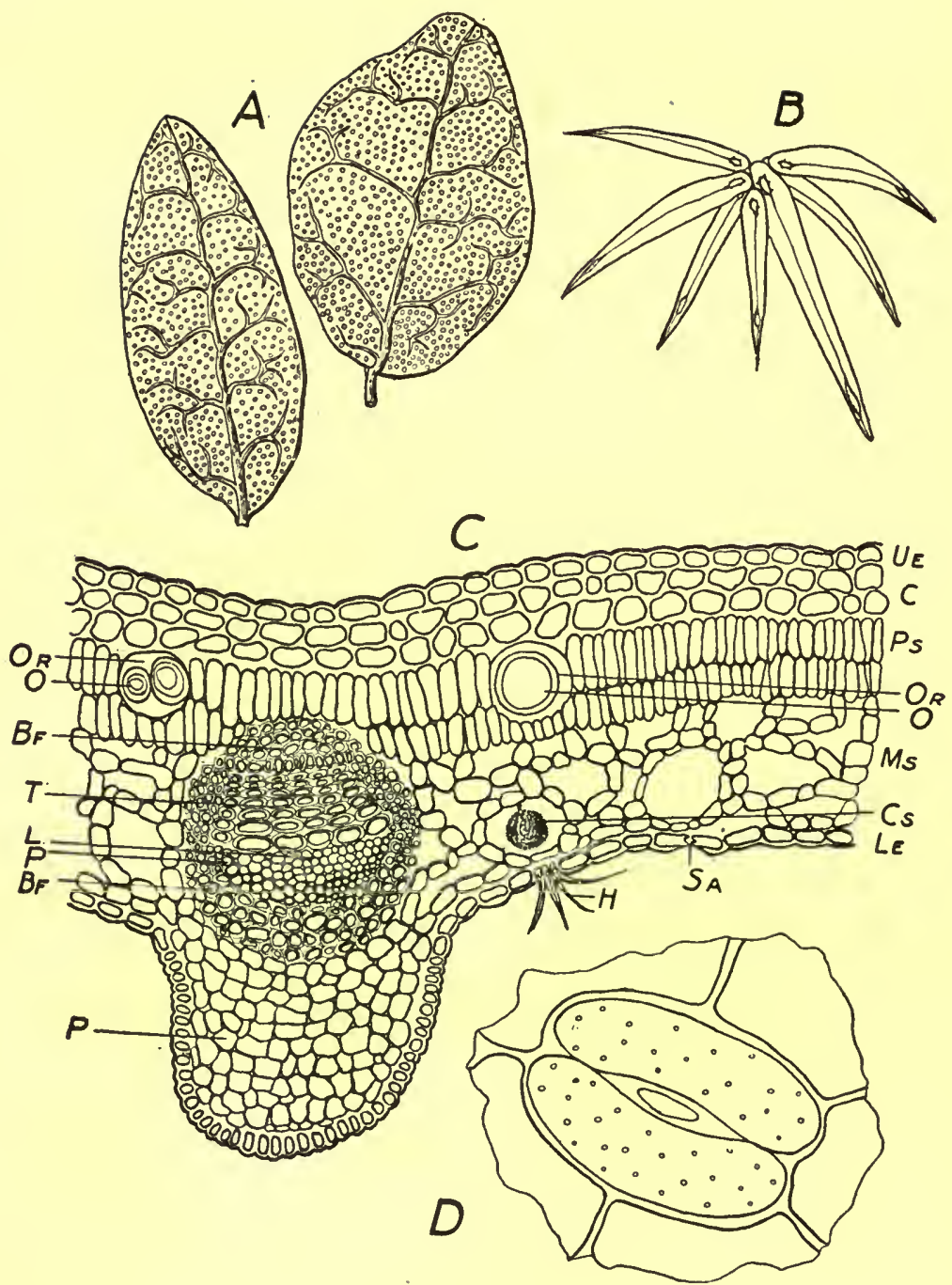

FIg. 111.-Boldo. $A$, leaves showing branching veins and small circular glandular punctations; $B$, a stellate hair with thick transparent walls; $C$, transverse section through the midrib showing upper epidermis $(U e)$; hypodermis $\left(C^{\prime}\right)$; palisade layers $(P s)$; mesophyll $(M s)$; oil réservoirs $(O r)$; containing oil globules $(O)$; cystolith $(C s)$; a stellate hair $(H)$; stoma $(S a)$; bast fibers $(B f)$; tracheæ $(T)$; sieve $(L)$; parenchyma $(P)$; lower epidermis $(L e) ; D$, a stoma on the lower epidermis.-Drawing by Haase. 
uble in alcohol, ether and chloroform; a resinous substance ${ }^{\cdot}$ and tannic acid.

\section{LAURACEE, OR LAUREL FAMILY}

A family of aromatic shrubs and trees, comprising about 1000 species. They are mostly found in the tropics, although a few of the genera are rather common in the temperate regions. They have alternate leaves, small green or yellow flowers and their fruits are either drupes or berries. Oil secretion cells are found in all parts of the plant, giving them a distinct fragrance. These cells are usually spheroidal in shape, with suberized walls and usually contain a yellowish oil. Many of the plants also contain mucilage cells, and these may occur in the same parts of the plant where secretion cells occur, and it has been suggested that there is a relationship between the two. It is well known that in those varieties of cinnamon which are deficient in oil, that there is an increase in the number of mucilage cells and vice versa. The mucilage cells are usually somewhat elongated and are distributed in the palisade tissue of leaves and the cells of the inner bark and pith. Calcium oxalate occurs in the form of small acicular or spindle-shaped crystals. The hairs are non-glandular, unicellular and occasionally sclerenchymatous. The stone cells of the inner bark are usually unequally thickened and frequently are U-shaped.

Cinnamomum.-Cinnamon Bark.-The dried bark of the stem and branches of various species of Cinnamomum (Fam. Lauraceæ), trees indigenous to tropical Asia, where they are now extensively cultivated (Fig. 112) and from which three commercial kinds of bark are obtained: (1) Saigon Cinnamon, obtained from Cinnamomum Loureirii (?) and other species cultivated in Cochin China and other parts of China, and exported from Saigon; (2) Cassia Cinnamon, yielded by Cinnamomum Cassia, cultivated in the southeastern provinces of the Chinese Empire, and exported by way of Calcutta, and (3) Ceylon Cinnamon, collected from Cinnamomum zeylanicum, indigenous to and cultivated in Ceylon (Fig. 113).

Saigon Cinnamon.-In bundles about 30 to $40 \mathrm{~cm}$. in length, and $20 \mathrm{~cm}$. in width, $10 \mathrm{~cm}$. in thickness, weighing 1.5 to $2 \mathrm{~K}$., and consisting of pieces varying in size and color from small brownishblack single quills to large, thick grayish-brown, transversely curved pieces. Pieces 6 to $30 \mathrm{~cm}$. in length, 1.5 to $3 \mathrm{~cm}$. in diameter; bark 0.2 to $2 \mathrm{~mm}$. in thickness; outer surface dark brown, longitudinally wrinkled, with grayish patches of foliaceous lichens, and numerous 
lenticels; inner surface light brown, smooth; fracture short; thick inner bark separated from the very thin periderm by a layer of small stone cells; odor aromatic; taste mucilaginous, aromatic and pungent.

Cassia Cinnamon.-In quilled pieces, usually shorter than those of Saigon Cinnamon, the periderm more or less removed, and the bark aromatic and somewhat astringent.

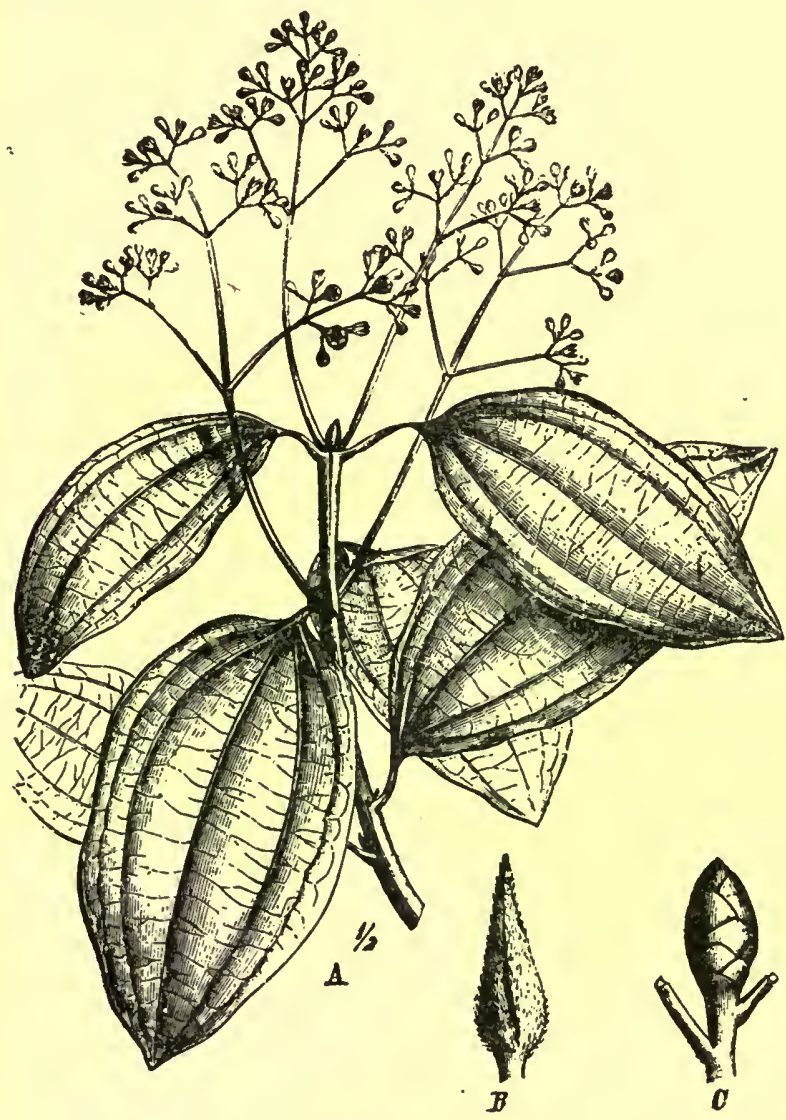

Fig. 112.- $A$, flowering branch of Cinnamomum zeylanicum; $B$, leaf-bud of the same; $C$, leaf-bud of Cinnamomum Camphora. $-A$, after Berg and Schmidt; $B, C$, after Pax.

Ceylon Cinnamon occurs in closely rolled double quills composed of numerous thin layers of the inner bark of the shoots; the odor is delicately aromatic, and very distinct from either Cassia or Saigon bark. 


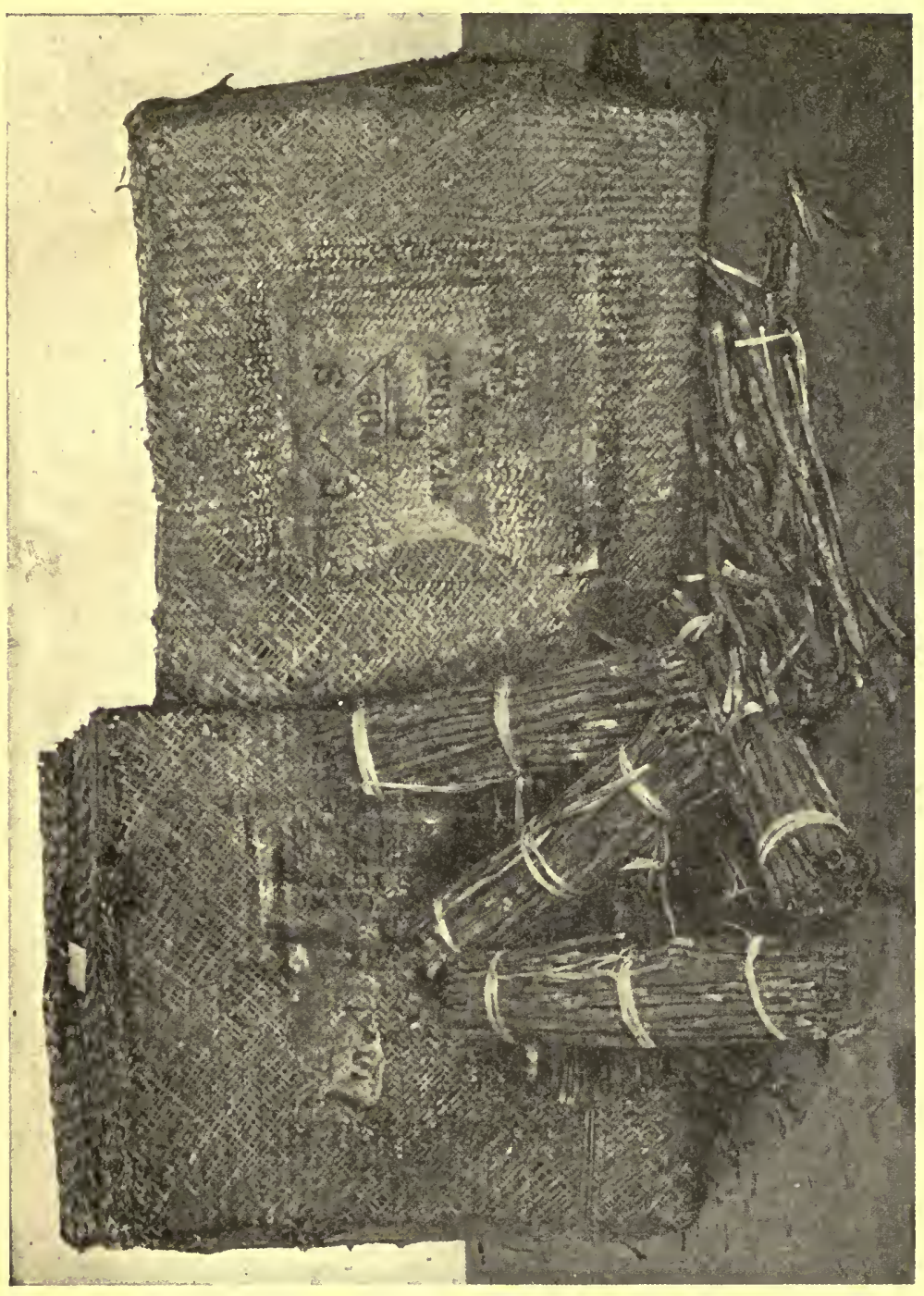

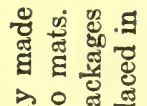

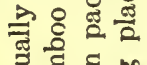
कृ हี . 동

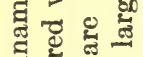
: ชิ

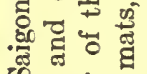
के क्षे : . क्ष है

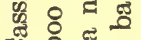

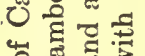
调范 若证宽 용후 형유 สํ. उृ. 嘆 它记 幽它 E

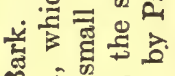
$\infty$ i

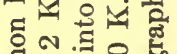
E \pm 羊串

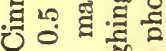
4 ह of

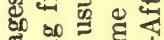

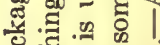
ह. 霖 .

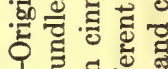
1.

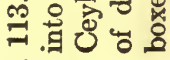
悹 
Inner Structure.-See Figs. 114, 115.

Powder of Saigon Cinnamon.-Yellowish- or reddish-brown; starch grains numerous, single or compound, the individual grains

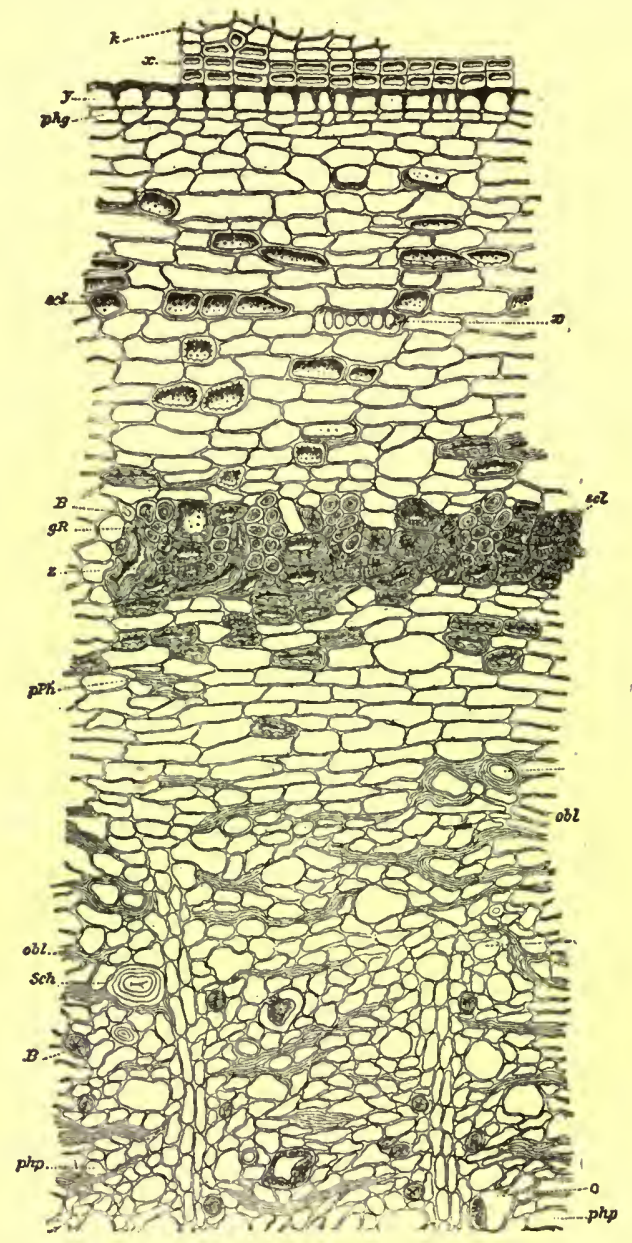

FIG. 114.-Transverse section of Cassia cinnamon bark: $k$, cork; $x$, thick-walled cork cells; $y$, cork cells, the outer walls of which are thickened; phg, cork cambium; scl, stone cells; $x$, parenchyma cell with large pores; $B$, bast fibers; $g R$, short sclerenchyma; $z$, parenchyma separating the groups of sclerenchymatous tissue; $p P h$, protophloem; obl, collapsed sieve; $S c h$, mucilage canals; $p h p$, bast parenchyma; $o$, oil cells.-After Tschirch and Oesterle.

being somewhat ellipsoidal or polygonal and from 0.003 to 0.020 $\mathrm{mm}$. in diameter; stone cells rather prominent, the walls being 
colorless, very irregular in shape, and contain either air or a reddishbrown amorphous substance; bast fibers from 0.300 to $1.50 \mathrm{~mm}$. in length and usually in groups of from 2 to 20 with very thick and slightly lignified walls; numerous cellular, reddish-brown fragments in which the oil cells are not readily distinguishable.

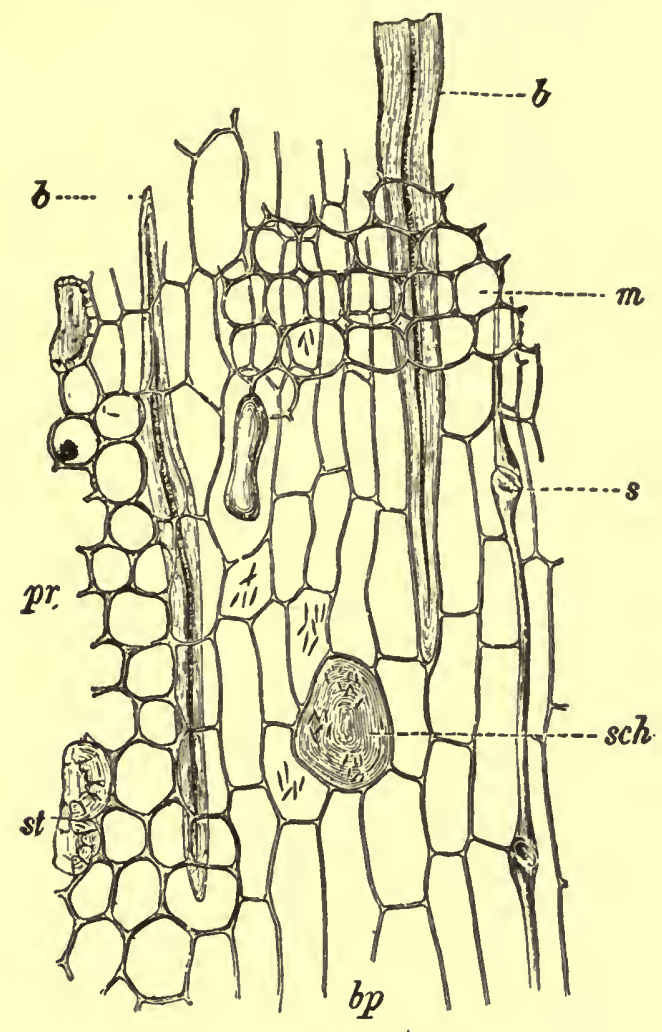

FIg. 115.-Radial-longitudinal section of China Cassia (Cinnamomum Cassia) bark; $p r$, parenchyma of outer bark; $b p$, parenchyma of the inner bark, some of the cells of which contain raphides; $b$, bast fibers; st, stone cells; $s c h$, mucilage cells; $s$, sieve; $m$, medullary rays.-After Moeller.

Powder of Cassia Cinnamon.--(Fig. 116). Dark brown; resembling that of Saigon Cinnamon, but usually with fewer cork cells and a larger number of sclerenchymatous cells and fibers.

Powder of Ceylon Cinnamon.-Light- or yellowish-brown; starch grains numerous, either single or compound, the individual grains being spheroidal or polygonal, from 0.003 to $0.020 \mathrm{~mm}$. in diameter; bast fibers from 0.300 to $0.800 \mathrm{~mm}$. in length, usually 
single, spindle-shaped with attenuated ends, the walls being very thick and but slightly lignified; colorless stone cells resembling those of Saigon Cinnamon; numerous cellular fragments with yellowishbrown walls or contents; calcium oxalate in raphides from 0.005 to $0.008 \mathrm{~mm}$. in length.

The Powder of Cassia Buds (flowers of Cinnamomum Cassia) is characterized by numerous thick-walled, irregularly curved simple hairs; fragments of reticulate and scalariform tracheæ; and broad, blunt bast fibers.

Constituents.-The most important constituent is the volatile oil, which in Ceylon Cinnamon is delicately aromatic and is present

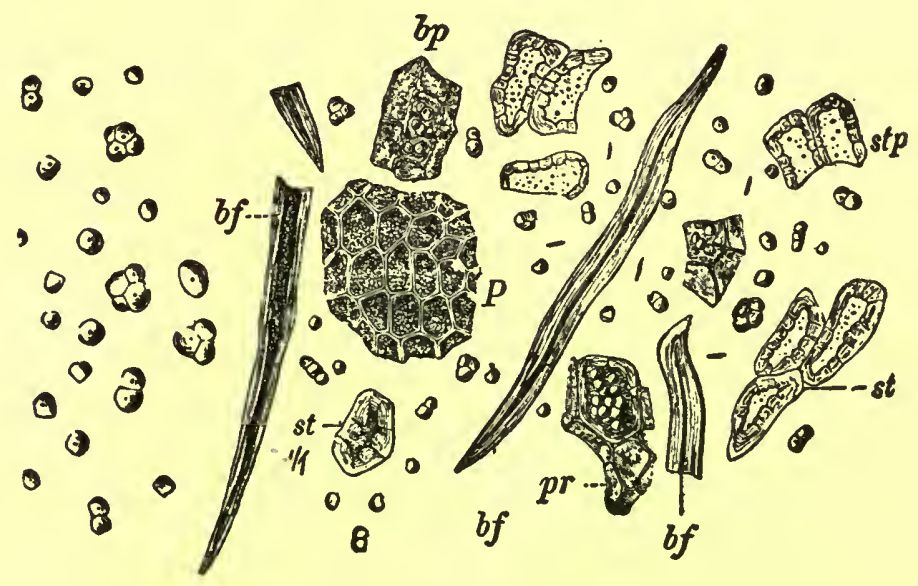

FIG. 116.-Cassia cinnamon: st, st $p$, stone cells; $p r, b p$, parenchyma containing starch grains; $b f$, bast fibers; $P$, cork cells with lignified walls. Numerous simple and compound starch grains are shown at the left and among the fragments of tissues.-After Moeller.

from 0.5 to 1 per cent, in Cassia from 0.93 to 1.64 per cent, and in the Saigon from 3 to 6 per cent, the latter bark being most pungent and aromatic. The oil of cinnamon consists in large part of cinnamic aldehyde (not present in the oil of the root bark) and other compounds, such as camphor, which is present in the oil from the root bark; safrol, which is found in the leaves; and eugenol, which is found in both leaves and stem bark and which gives the characteristic odor to Ceylon Cinnamon.

Cinnamon also contains the hexatomic alcohol mannitol (cinnamanin) giving the sweetish taste to the several barks; a tannin (3 to 5 per cent) somewhat resembling that in Quercus alba and 
found in greatest amount in Cassia bark and least in the Saigon variety; a bitter principle especially characteristic of Cassia bark; and a mucilage which may be the source, at least in part, of the volatile oil.

Standard of Purity.-Cinnamon is the dried bark of cultivated varieties of Cinnamomum zeylanicum Breyne or of Cinnamomum Cassia (Nees) Blume, from which the outer layers may or may not been removed.

Ceylon Cinnamon is the dried inner bark of cultivated varieties of Cinnamomum zeylanicum Breyne.

Saigon cinnamon, Cassia, is the dried bark of cultivated varieties of Cinnamomum cassia (Nees) Blume.

Ground cinnamon, ground cassia, is the powder made from cinnamon. It contains not more than 5 per cent of total ash, nor more than 2 per cent of ash insoluble in hydrochloric acid.-U. S. Dept. Agric.

Allied Plants.-Batavia Cassia or Fagot Cassia is the bark of Cinnamomum Burmanni. In double quills, the larger sometimes enclosing smaller quills, 5 to $8 \mathrm{~cm}$. in length, 5 to $15 \mathrm{~mm}$. in diameter, bark 0.5 to $3 \mathrm{~mm}$. in thickness; outer surface light- or reddish-brown, nearly smooth; inner surface dark-brown with occasional longitudinal ridges and depressed areas; fracture short; odor pronounced, aromatic; taste aromatic and distinctly mucilaginous. It forms a shiny glutinous mass with water and yields with alcohol 11 to 17 per cent of an extract. A number of barks come into the market under the name of "Cassia bark." In fact, Cassia Cinnamon is frequently known as China Cassia, or Canton Cassia or Cassia lignea, all being synonyms for the same variety of bark. Saigon Cinnamon is also known commercially as Saigon Cassia. The barks of other species of Cinnamomum also find their way into market and are used as substitutes or adulterants of Cassia Cinnamon. These are bitter or nearly tasteless and are free from any aromatic properties.

Clove bark is obtained from Dicypellium caryophyllatum (Fam. Lauraceæ), a tree indigenous to Brazil. The bark comes in long quills, consisting of 6 to 10 pieces of bark. Externally dark brown or purplish-brown; fracture short, with a circle of whitish stone cells near the periderm; odor clove-like; taste mucilaginous and aromatic, resembling cinnamon.

A number of other products are also derived from species of Cinnamomum, as the immature fruits of C. Loureirii, which constitute the Cassia buds of the market. The latter are club-or top-shaped, 5 to $10 \mathrm{~mm}$. in diameter, with a short stem or pedicel, externally 
dark brown, the 6-lobed perianth folded over the depressed and smooth ovary. The odor is aromatic; taste pungent, aromatic and astringent. Cassia buds yield a volatile oil containing cinnamic aldehyde, which resembles that of Cassia Cinnamon.

Wild Cinnamon, the bark of Cinnamomum pedatinervum, a tree indigenous to the Fiji Islands, yields a volatile oil containing from 40 to 50 per cent of linalool and safrol, 15 to 20 per cent of a terpene; 1 per cent of eugenol, and about 3 per cent of eugenolmethyl-ether.

Aromatic Powder.-Consisting of powdered saigon cinnamon, powdered ginger, crushed cardamom deprived of pericarps and powdered myristica. Light reddish-brown; with a strong distinct aromatic odor; consisting chiefly of the characteristic starch grains of Ginger, being ellipsoidal or ovoid, slightly beaked and from 0.005 to $0.060 \mathrm{~mm}$. in diameter; numerous yellowish-brown, brownishred and occasional blackish fragments, the cellular structure of which is not distinct; occasional stone cells, the lumina being filled usually with a reddish-brown amorphous substance or containing air; occasional fragments with sclerenchymatous fibers, the walls being scarcely if at all lignified; calcium oxalate crystals very few and only in the form of short raphides.

Camphora.-Camphor.-A crystalline product deposited in the wood and present-in the volatile oil occurring in Cinnamomum (Laurus) Camphora (Fam. Lauraceæ), a small tree indigenous to eastern Asia and cultivated in Formosa, Japan and other subtropical countries. It has been grown successfully in Florida and California. Camphor occurs as a crystalline deposit in lacunæ or clefts in the stem, but occurs in larger quantities dissolved in the volatile oil. The latter exists to the greatest extent in the roots and the least in the leaves and twigs. Camphor arises as a product of the oxidation of the volatile oil.

In the preparation of commercial camphor, the tree is cut down and the roots and lower portion of the trunk subjected to distillation. This is usually accomplished in the winter time when the camphor is deposited in greatest amounts. The product which is distilled consists of a granular and light reddish mass containing about 80 per cent of camphor and 20 per cent of a volatile oil. It is collected in bamboo canes or tubs and sent from Formosa to Europe and America, where it is refined by sublimation. Japan and Formosa produce annually about $4,000,000 \mathrm{~K}$. of camphor, a smaller quan tity, about $120,000 \mathrm{~K}$. being produced in the Chinese province, Fokein. About one-third of all the camphor produced is shipped 
to the United States. The oil of camphor is refined and those fractions having a specific gravity similar to that of true sassafras oil are sold under the name of artificial sassafras oil.

Description.-Refined camphor occurs in commerce in large slabs, weighing from 1 to $5 \mathrm{~K}$. It is composed of nearly colorless, crystalline, shining granules, which are somewhat oily in appearance, brittle and form a whitish powder, having a distinct penetrating odor, and a pungent, bitter and cooling taste. It is sublimable, forming hexagonal plates or prisms, which are very soluble in alcohol, ether, chloroform, petroleum ether, and carbon disulphide. One part of camphor is soluble in 1.5 parts of oil of turpentine; 4 parts of olive oil; and 1000 parts of water. It forms a liquid when rubbed with equal parts of any of the following substances: hydrated chloral, phenol, salicylic acid, salol, menthol, naphthol, pyrogallol, resorcin and thymol.

Powder.-Whitish; glycerin mounts show irregular masses which gradually dissolve; nearly insoluble in water, but soluble in solutions of hydrated chloral, alcohol and fixed or volatile oils. On heating some of the powder on a microscopic slide and covering with a watch crystal, a sublimate is obtained, composed of radiating aggregates of feather-shaped crystals, which are isotropic. A drop of a solution of vanillin ( 1 in 100) and a drop of sulphuric acid added to powdered camphor produces immediately a yellow color, changing to red, then violet and finally blue.

Constituents.-Camphor consists almost entirely of a dextrogyrate modification of the saturated ketone, $\mathrm{C}_{9} \mathrm{H}_{16} \mathrm{CO}$. Japan camphor contains less impurities than the Formosa variety.

Adulterants. - To both crude camphor and the powder are sometimes added 50 per cent of stearic acid. The adulterated article is incompletely soluble in 90 per cent alcohol.

Allied Plants.-Borneo camphor or borneol is a product found in clefts of the wood of Dryobalanops Camphora (Fam. Dipterocarpaceæ), a large tree indigenous to Borneo and Sumatra. The camphor is obtained by scraping the wood and not by distillation. It somewhat resembles true camphor, but is distinguished by being heavier than water, and not volatilizing at ordinary temperatures, and having a somewhat pungent taste. It is converted by nitric acid into true camphor. It should also be stated that true camphor when treated with reducing agents is converted into Borneo camphor. The latter is seldom seen in commerce on account of its high price.

Sassafras.-Sassafras Bark.-The bark of the root of Sassafras variifolium (Fam. Lauraceæ), a tree indigenous to eastern 
North America. The bark is collected in the early spring, or autumn, deprived of the periderm, and used either in the fresh or dried condition.

Description.-In transversely curved or recurved, irregular, oblong pieces, 3 to $8 \mathrm{~cm}$. in length, 10 to $30 \mathrm{~mm}$. in diameter, 0.5 to $3 \mathrm{~mm}$. in thickness; outer surface light reddish-brown, nearly

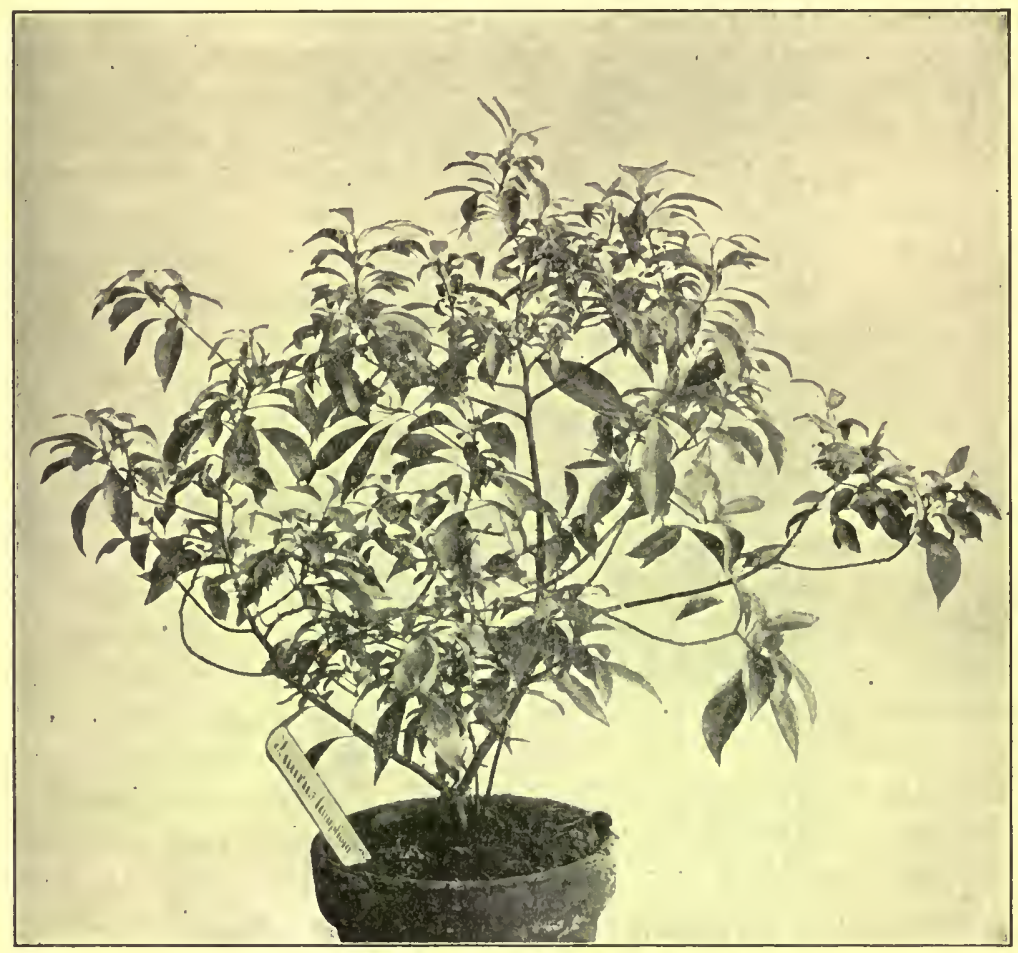

Fig. 117.-Cinnamomum Camphora. Young plant grown in greenhouse of Philadelphia College of Pharmacy from cuttings introduced into Florida by U. S. Department Agriculture, Washington, D. C., many years ago. The plant is an evergreen, very hardy, producing numerous aromatic roots, which soon work their way through the pots, which necessitates frequent transplanting.

smooth, somewhat porous; inner surface distinctly striate, somewhat scaly; fracture short, soft, surface slightly porous; odor aromatic; taste somewhat mucilaginous, astringent and aromatic.

Inner Structure.-See Fig. 118.

Powder--Light, reddish-brown; starch grains numerous, either single or 2- to 4-compound, the individual grains being more or less 


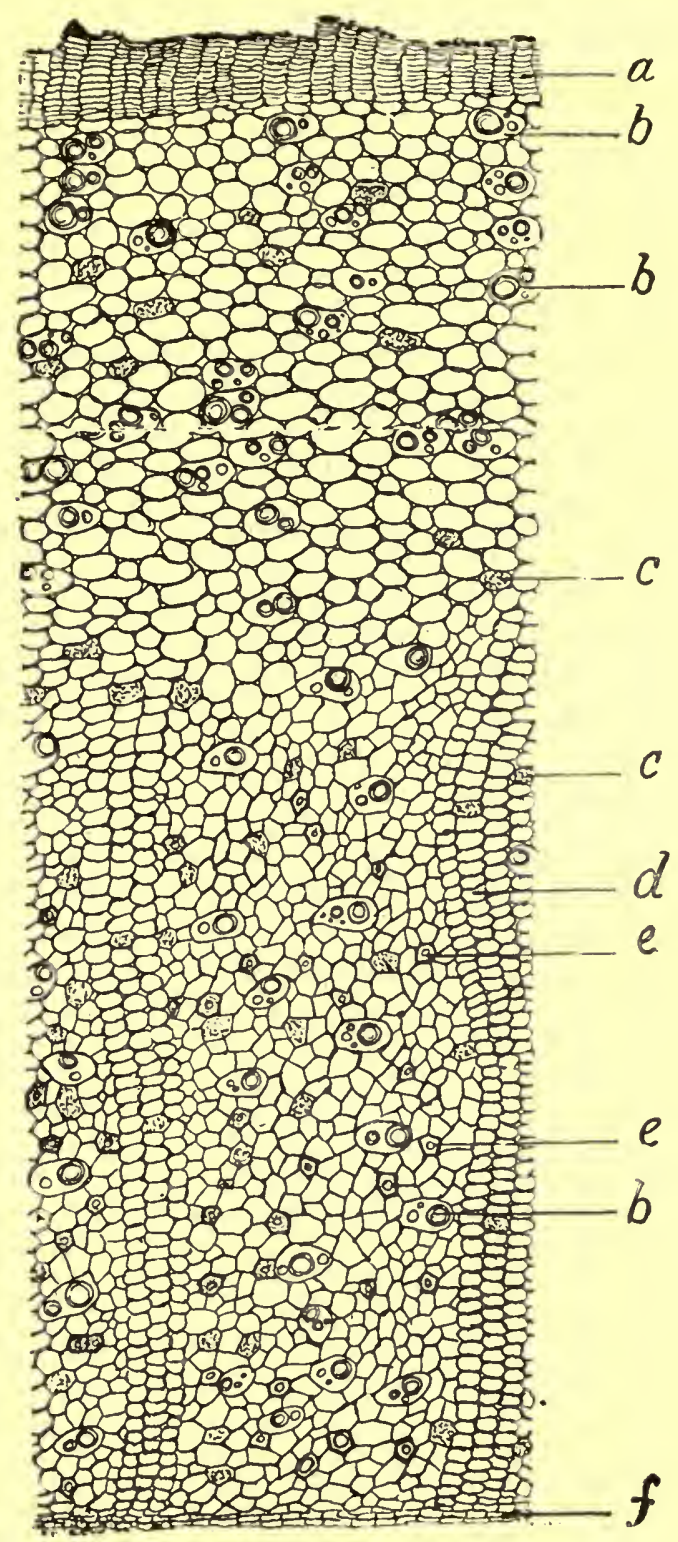

FIg. 118.-Transverse section of root bark of sassafras: $a$, cork; $b$, oilcells; $c$, tannin cells; $d$, medullary rays; $e$, bast fibers; $f$, cambium.-After Bastin. 
spheroidal or polygonal and frequently with a distinct cleft and from 0.003 to $0.020 \mathrm{~mm}$. in diameter, some of the smaller or altered grains attaining a diameter of $0.030 \mathrm{~mm}$.; bast fibers spindle-shaped, occasionally very irregular in outline, with sharply pointed ends, from 0.150 to $0.400 \mathrm{~mm}$. in length, $0.025 \mathrm{~mm}$. in diameter, and with very thick, strongly lignified walls; parenchyma cells containing either starch grains or irregular yellowish-red masses of tannin and becoming bluish-black upon the addition of solutions of ferric chloride, fragments of wood few, with large, thin-walled tracheæ marked by simple pores and associated with rather thin-walled wood-fibers. The stem bark contains groups of bast fibers and stone cells, and the , parenchymatous cells contain chloroplastids.

Constituents. - Volatile oil 5 to 9 per cent; tannin about 6 per cent; a reddish-brown altered tannin compound (sassafrid) about 9 per cent; resin and starch.

The principal constituent of the volatile oil is safrol. The oil from the leaves differs essentially in composition from that of the root bark, containing linalool and geraniol.

Allied Plants.-Other plants of this family also yield a volatile oil containing safrol, as Beilschmiedia oppositifolia of Queensland and New South Wales; Mespilodaphne Sassafras and Nectandra Puchury-minor, both of Brazil.

Sassafras Medulla.-Sassafras Pith.-The pith of young stems and branches of Sassafras variifolium (Fam. Lauraceæ) a tree indigenous to eastern North America. The pith is collected late in autumn, after frost, and dried.

Description.-In sub-cylindrical, often curved or coiled pieces from 2 to $10 \mathrm{~cm}$. in length and from 2 to $5 \mathrm{~mm}$. in diameter; very light in weight, externally whitish, occasionally with small fragments of wood adhering; fracture short; with a slight odor of sassafras; taste mucilaginous.

Inner Structure.-For illustration of structure of walls, consult Kraemer's Applied and Economic Botany, p. 263.

Transverse sections show that it consists of nearly isodiametric cells with large intercellular spaces, the walls being more or less lignified and provided with numerous simple pores; mounts made in water show the separation of a thin layer of mucilage from the inner walls of the cells, this being characterized by the gradual disappearance of the pores. The cells occasionally contain sphenoidal microcrystals of calcium oxalate.

Constituents.-The principal constituent is the mucilage, which is not precipitated by alcohol; it also contains a trace of volatile oil. 
On macerating $0.5 \mathrm{gm}$. of Sassafras Pith in $25 \mathrm{cc}$. of cold distilled water for several hours and filtering through cotton, a mucilaginous solution is obtained which is not precipitated upon the addition of 1 c.c. of alcohol.

Сото.-Cortex Coto Verus, Coto Bark.-The bark of an unknown tree growing in Bolivia and apparently belonging to the Lauraceæ.

Description.-In flattened or transversely curved pieces, from 2 to $20 \mathrm{~cm}$. in length and from 1 to $7 \mathrm{~cm}$. in width, the bark from 7 to $20 \mathrm{~mm}$. in thickness; outer surface reddish-brown, occasionally with grayish patches of foliaceous lichens, nearly smooth or longitudinally fissured and occasionally with transverse clefts, the smooth bark being marked with large lenticular lenticels or large branch scars; inner surface very coarsely longitudinally striate; hard, and fracture very tough; fractured surface light reddish-brown, porous and showing numerous yellowish groups of sclerenchymatous cells and fibers; odor distinct, aromatic, somewhat camphoraceous; taste aromatic and pungent.

Inner Structure.-Numerous irregular layers of cork cells having a brownish amorphous content; a layer of tangentially elongated cells, those nearest the cortical phelloderm possessing strongly thickened side walls; a phelloderm layer of thick-walled more or less collapsed cells; secondary cortex composed of strands of phloem separated by medullary rays which are from 2 to 3 cells wide. The phloem consists of (1) small groups of sclerenchymatous fibers which occur in tangentially elongated strands; (2) groups of stone cells similarly disposed and consisting either of isodiametric cells, very irregular branching forms, or elongated fibers; (3) a distinct leptome of collapsed cells and among which are distributed (4) numerous oil cells having a diameter of $0.040 \mathrm{~mm}$. The cells of the medullary rays are in part metamorphosed to stone cells. Starch occurs in form of either single or compound grains, the individual grains being either spheroidal or ellipsoidal, and from 0.003 to $0.020 \mathrm{~mm}$. in length. Small acicular crystals are also said to occur in the medullary ray cells.

Constituents.-A pale yellow volatile oil, having an aromatic odor and pungent taste; a light yellow crystalline substance, cotoin, 1.5 per cent, which is acrid and sternutatory, soluble in boiling water and alcohol, and which possesses the activity of the drug; also a soft resin; dicotoin; pseudodicotoin; paracotoin; tannic acid, and the following organic acids: formic, acetic and butyric. 
PARA-Coto.-Cortex Coto Para, Para-coto Bark.-A bark of unknown origin and apparently derived from Palicurea densiflora (Fam. Rubiacex), a tree indigenous to Bolivia. It resembles Coto bark and has a grayish or whitish periderm. The fracture is not so splintery, the odor is less aromatic, and the taste not so pungent. It contains paracotoin, which resembles cotoin in its physiological action; also hydrocotoin; protocotoin; methyl-hydrocotoin; methylprotocotoin, diperonylic acid and tannic acid.

False coto bark is obtained from Cryptocarya pretiosa (Fam. Sapotaceæ), a tree growing in the Amazon district. It occurs in pieces about $15 \mathrm{~cm}$. in length, $5 \mathrm{~cm}$. in width and $7 \mathrm{~mm}$. in thickness; externally light brown and without cork; fracture short, fibrous; internally brown with yellowish groups of stone cells, which are arranged in radial rows, thus distinguishing this bark from true coto bark. The odor is slight, resembling cinnamon. It contains a brownish-yellow volatile oil, with an odor suggestive of cinnamon,. but it does not contain any cinnamic aldehyde. It also contains 0.145 per cent of an alkaloid.

\section{PAPAVERACEE, OR POPPY FAMILY}

A small family of about 200 species occurring most abundantly in north temperate regions. They are especially characterized by their milky and frequently yellowish colored latex, which arises either in laticiferous vessels or in special laticiferous sacs. The former are found in Papaver, and consist of tubes formed as a result of the fusion of cells in close proximity to each other, the dividing walls having become absorbed. The laticiferous sacs, which are present in Chelidonium, are either spheroidal or more or less cylindrical and elongated cells, having very thin walls and occur either isolated or arranged in longitudinal chains. The tracheæ in this family are marked by simple pores. Calcium oxalate does not occur, except in Bocconia. Non-glandular hairs, when present, consist of a chain of cells. Glandular hairs have not been observed in this family.

PaPaver.-Papaveris Fructus, Papaveris Immaturi, Poppy Capsules.-The full-grown unripe fruits of Papaver somniferum and the varieties album and nigrum (Fam. Papaveracex). These are annual, herbaceous plants, indigenous to the countries bordering the eastern Mediterranean and extensively cultivated in warm and temperate zones. They occur in a great many forms and varieties, and the capsules of the white variety are usually gathered. It is cultivated for the drug Opium as well as the seeds, which contain a 
fixed oil. The commercial supplies are obtained from Asia Minor, Persia, Egypt, China, the East Indies and Europe. The capsules are collected in July when full grown, but still green, and contain their milky juice. They are carefully and rapidly dried over a low burning fire.

Description.-Ellipsoidal, ovoid or depressed globular, from 6 to $7 \mathrm{~cm}$. in length and from 4 to $7 \mathrm{~cm}$. in diameter; very light, weighing from 3 to $4 \mathrm{gm}$.; summit acute or somewhat rounded, occasionally depressed and crowned by the 12- to 18-rayed stigma, base usually tapering into the stalk; externally yellowish-brown or light brown, often marked with nearly circular bluish-black patches, smooth, except in the upper and lower portions, which are glaucous, also marked by slight ridges, indicating the dissepiments; unilocular, and containing numerous seeds; inner surface with numerous, thin, cartilaginous dissepiments, about $10 \mathrm{~mm}$. in width, of a light yellowish-brown color and marked by numerous small, circular, brownish spots, representing groups of stone cells; fruit stalk from 10 to $15 \mathrm{~mm}$. in length, cylindrical, contracted in the middle and spreading into the basal portion of the capsule; internally with a large whitish pith; inodorous; taste bitter and slightly astringent. Seeds (commonly known as Maw seeds), reniform, from 0.5 to $1 \mathrm{~mm}$. in diameter, externally yellowish-white, reticulate and with a small yellowish hilum scar; endosperm white and oily and enclosing a curved embryo; taste slight and oily.

Inner Structure.-Epidermis of pericarp consisting of a layer of cells having strongly thickened outer walls and numerous stomata; hypodermis of one or more layers of tangentially elongated, thickwalled cells; a middle layer of thick-walled parenchyma and vascular bundles, the latter having spiral tracheæ, latex tubes associated with the leptome and a ring of sclerenchymatous fibers; inner epidermis composed of tangentially elongated, thick-walled cells and depressed stomata; the placenta, triangular in section and containing numerous simple, more or less branching cells with large intercellular spaces. The seed coat consists of an epidermal layer composed of polygonal cells; a layer of thin-walled parenchyma cells containing numerous small microcrystals of calcium oxalate; a layer of strongly thickened somewhat spindle-shaped sclerenchymatous fibers; several layers of either strongly thickened porous cells, or thin-walled cells, or small obliterated cells, some of which in the black poppy seeds contain a brownish pigment. The endosperm consists of thin-walled cells containing an oily cytoplasm and numerous small aleurone grains. 
Powder.-Grayish-yellow; fragments of the epicarp composed of thick-walled polygonal cells, the cells of the outer layer, non-porous, about $0.050 \mathrm{~mm}$. in diameter and with occasional stomata, the latter attaining a length of $0.035 \mathrm{~mm}$.; the cells of the inner layer of the epicarp often with numerous simple pores; portions of the soft spongy sarcocarp consisting of isodiametric or irregular parenchyma cells and branching latex tubes, the latter about $0.060 \mathrm{~mm}$. in width of variable length and with thin non-porous walls; fragments of the
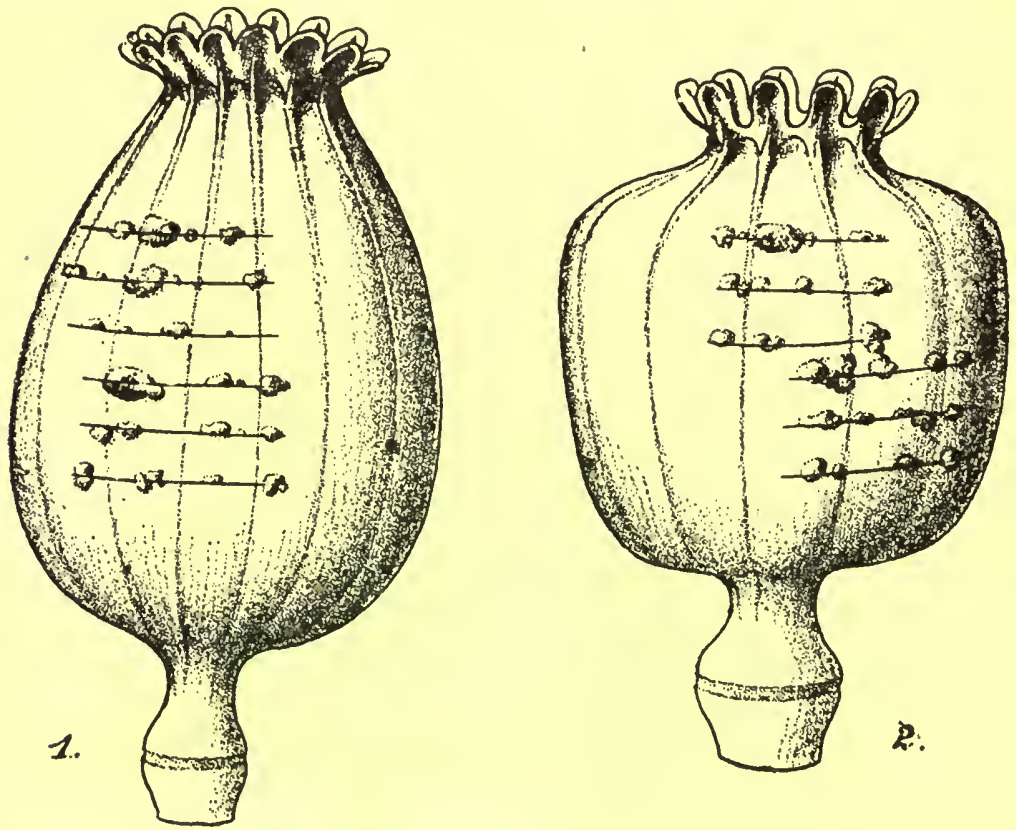

Fra. 119.-Poppy Capsules grown in the gardens of the Pharmaceutical Institute of the University of Berlin in Dahlem, Germany. Two of the capsules grown from white seeds and showing the transverse incisions from which the milk juice exudes, forming irregular globular masses on the surface of the capsules.-Thoms, Ber. d. d. pharm. Ges., 1907, p. 31.

inner wall of the pericarp and the outer wall of the placental tissue composed of polygonal or somewhat elongated cells, with porous walls $0.060 \mathrm{~mm}$. in width, and attaining a length of $0.300 \mathrm{~mm}$., the walls of the latter cells are often slightly lignified; spiral and annular tracheæ $0.35 \mathrm{~mm}$. in width, and reticulate tracheæ $0.060 \mathrm{~mm}$. in width; sclerenchymatous fibers and cells with simple or oblique pores few; starch grains very few, small and somewhat rounded; fragments of the reticulately pitted seed coat very few or wanting.-Newcomb. 
Constituents.-From 0.13 to 0.36 per cent of a mixture of alkaloids consisting of morphine, codeine and narcotine. The upper portions of the fruits contain the largest percentage of alkaloids, and during ripening the amount of morphine decreases while the percentage of codeine and narcotine increases. The fruits also contain narceine, papaverine, papaverosin and some of the other alkaloids of opium. There is also present meconic acid, citric acid, tartaric acid and wax; and ash from 10 to 15 per cent.

Opium.-The dried milk-juice of the capsules of Papaver somniferm (Fam. Papaveraceæ), an annual herb, probably indigenous to Asia, and now cultivated in Asia Minor, China, India, Persia and European Turkey. Experiments have been made both in this country and Europe to cultivate the opium poppy, but so far these experiments have been unprofitable. Opium is obtained by making transverse, oblique or longitudinal incisions in the unripe capsule (Fig. 119); the latex which exudes is collected when partly dry and made into a mass. The latter is enclosed in a covering of rumex or poppy leaves and further dried, subsequently being packed in bags with rumex berries to prevent the masses from sticking together. While there are a number of varieties of opium, that used in this country is principally from Turkey and is exported chiefly from Smyrna and Constantinople. There are two principal kinds of Smyrna opium, namely, Karahissar, which occurs in spherical, somewhat flattened masses, and Balukissar, which is in the form of flattened, planoconvex masses, both kinds being wrapped in poppy leaves, packed with Rumex seeds, and yielding about 13 per cent of morphine (Fig. 120).

Turkey Opium.-In irregular, flattened, more or less rounded masses of variable size and weighing from 250 to 1000 grammes; externally grayish-brown, covered with remnants of poppy leaves and with occasional fruits of a species of Rumex; internally dark brown, granular, somewhat lustrous, more or less plastic when fresh, but becoming hard and darker on keeping; odor distinct, heavy; taste peculiar, bitter.

Powder.-(Fig. 121.) Light brown; in glycerin mounts showing grayish-brown, irregular granular fragments, 0.035 to $0.40 \mathrm{~mm}$. in diameter; little or no starch; thick-walled polygonal cells of epidermis of capsule; epidermal cells of Rumex leaves (used in wrapping opium) somewhat polygonal on surface view, with elliptical stomata about $0.070 \mathrm{~mm}$. in length, having a narrow opening; fragments of wings of Rumex fruits (used to prevent cohesion of opium masses), with prominent, brown fibrovascular tissue composed of spiral 
tracheæ and narrow sclerenchymatous fibers; parenchyma of seeds colorless, containing air; epidermal cells with large, elliptical, oblique pores; taste bitter; sparingly soluble in water or potassium hydrate solution. The Smyrna opium has the largest number of epidermal

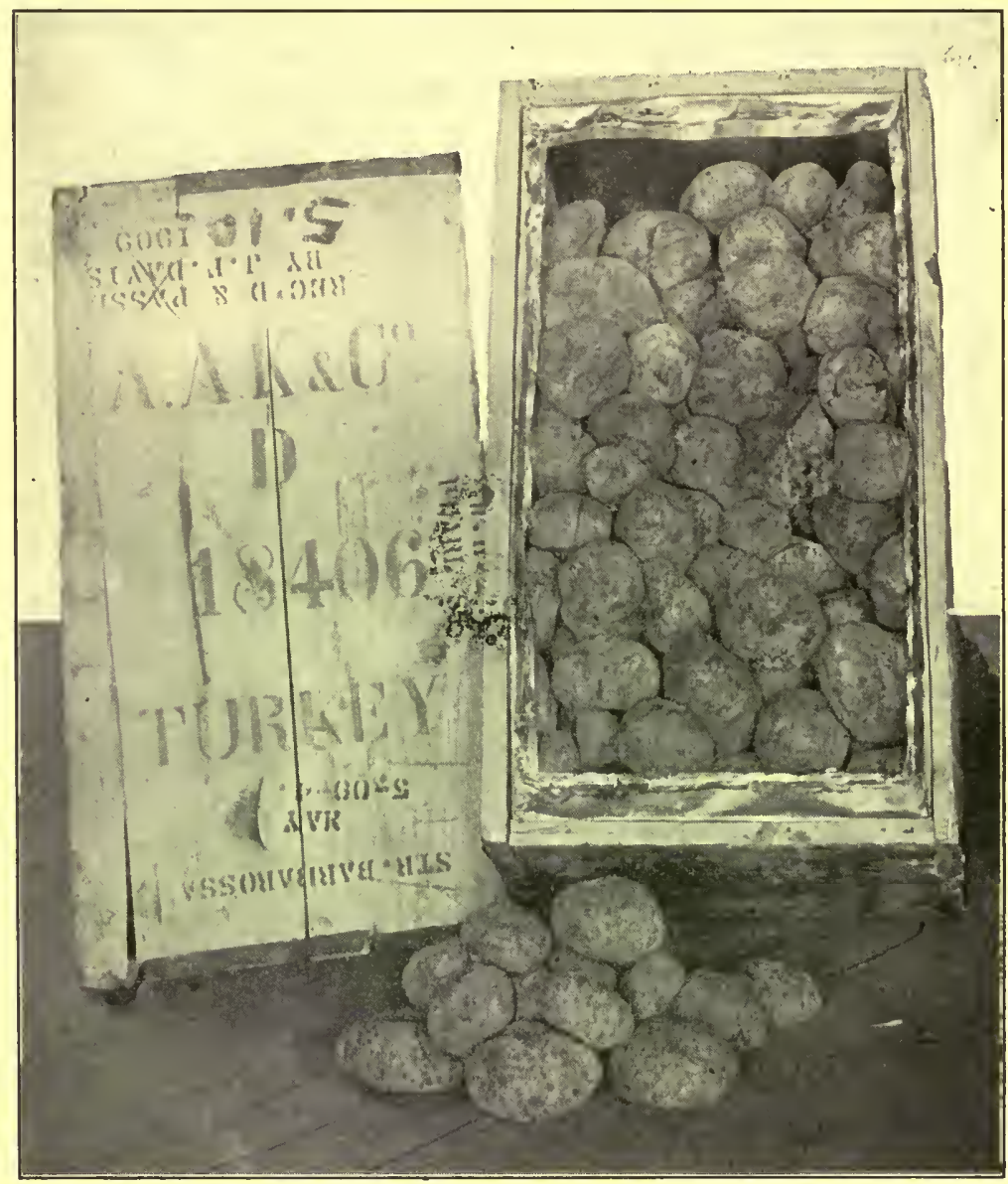

FIg. 120.-Original packages of Opium imported from Turkey. After a photograph by Parke, Davis \& Co.

cells of capsule, the Indian few or none and the Persian very few. The Persian always has an appreciable amount of starch.

Powdered opium not infrequently shows fragments of Cacao shells and crystals of sugar of milk, these being used as diluents in bringing high grades of opium down to the official standards. 
Constituents.-A large number of alkaloids have been obtained from opium and its extracts, some of which are, no doubt, alteration products of the alkaloids naturally occurring in the drug; the most inportant of these is morphine, which exists to the extent of 5 to 22 per cent, the largest amount being obtained from Turkey opium, the Persian ranking next, and the smallest amount being obtained from Indian opium.

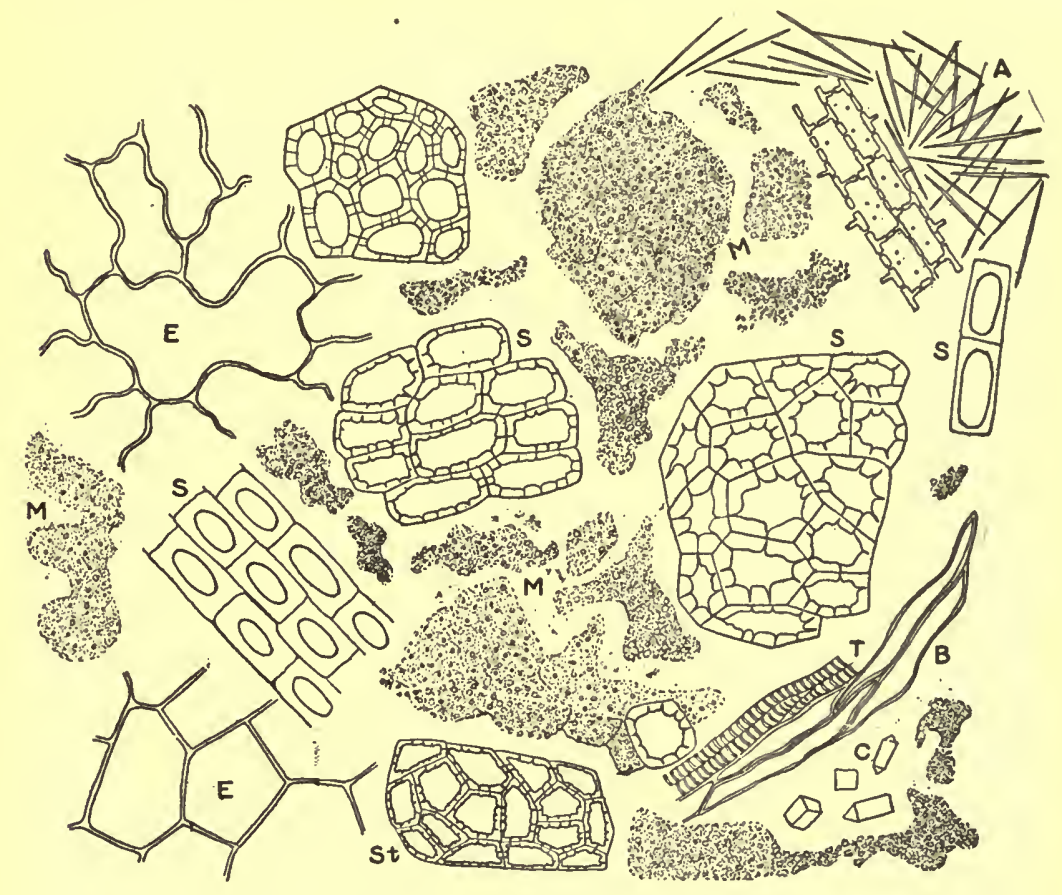

FIG. 121.-Powdered opium: $M$, protoplasm-like latex, which constitutes the greater proportion of the powder; $S, S t$, thick-walled cells of capsule; $A$, needle-shaped crystals which sometimes separate in chloral-iodin mounts. The fo!lowing Rumex tissues are also generally present: $E$, epidermal cells of leaf; $B$, bast fibers, and $T$, tracheæ from Rumex fruit; $C$, crystals (probably of calcium oxalate).

Morphine is a derivative of 3-6 dioxy-phenanthryleneoxide, which crystallizes from alcoholic solutions in orthorhombic prisms or needle-like crystals, containing one molecule of water of crystallization, which it gradually loses at $75^{\circ} \mathrm{C}$. It forms a number of crystalline salts of which the sulphate is here only described. There are at least two different morphine sulphates, the neutral salt containing 5 molecules of water of crystallization being the article usually 
found in commerce. It readily loses some of its water of crystallization even at a temperature of $30^{\circ}-40^{\circ} \mathrm{C}$. At $25^{\circ} \mathrm{C}$. one part of morphine sulphate is soluble in 15.3 parts of water; 465 parts of alcohol; it is nearly insoluble in ether or chloroform. The crystals formed on a slide from alcoholic solutions vary in length from 0.1 $\mathrm{mm}$. to $0.8 \mathrm{~mm}$. When prepared from aqueous solutions they may attain a length of $20 \mathrm{~mm}$. (Fig. 122).

The following color tests are of some practical value in the identification of morphine and its salts. On the addition of morphine to

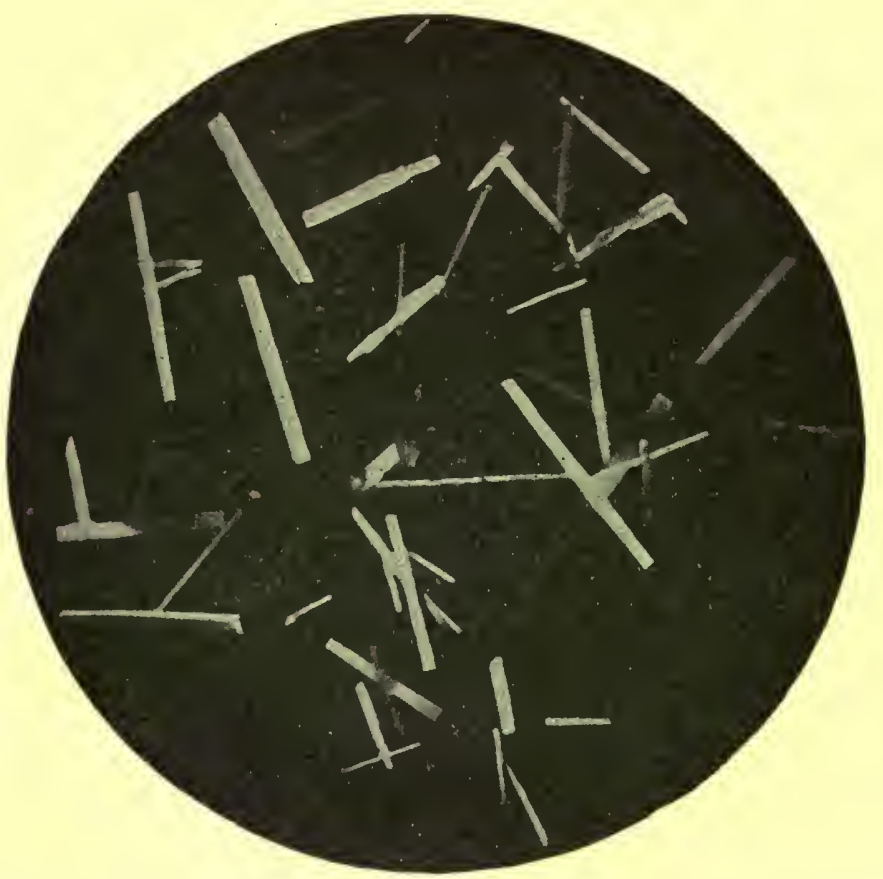

FIG. 122.-Morphine sulphate: orthorhombic crystals from aqueous solution.

concentrated sulphuric acid containing a little potassium dichromate, little or no change is produced at first, but the solution later becomes of a green color. On the addition first of some cane sugar to morphine and then of concentrated sulphuric acid and a little bromin water, the solution becomes purplish-red, changing to violet-blue, blue-green and finally a dingy yellow. Morphine gives a blue color with dilute solutions of ferric chloride, which is destroyed on heating, and it gives an orange or reddish color with nitric acid. On heating mor- 
phine in a sealed tube with hydrochloric acid a new salt is formed, known as apomorphine hydrochloride. The latter occurs in minute, nearly colorless, monoclinic prisms, which become greenish on exposure to air and moisture; and the solutions are colored reddish on the addition of dilute solutions of ferric chloride. Pseudomorphine is a crystalline compound that is formed on heating alkaline solutions of morphine with oxidizing agents. It is insoluble in water, alcohol or even dilute sulphuric acid, but is readily soluble in a solution of potassium hydrate.

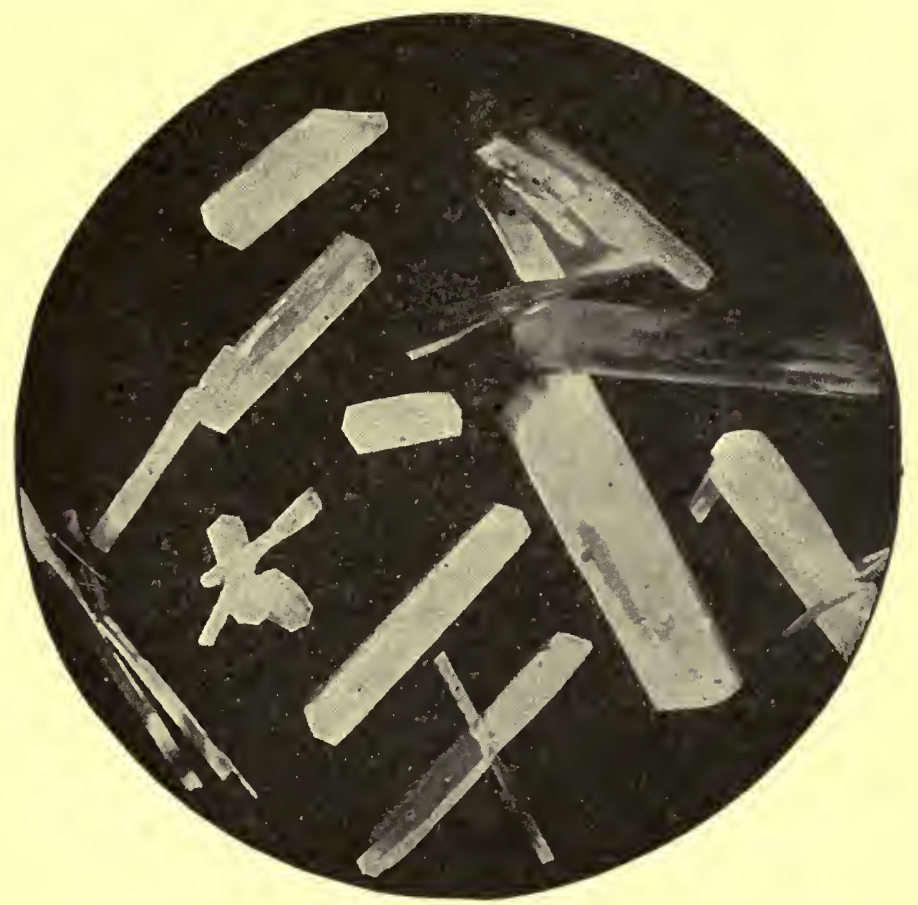

FIG. 123.-Codeine sulphate: orthorhombic erystals from hot alcoholic solution.

Codeine (the methyl ether of morphine) forms anhydrous crystals from solutions in ether or benzol, but the crystals from aqueous solutions contain one molecule of water of crystallization. Microscopic $\mathrm{x}$-shaped skeleton crystals separate from alcoholic solutions, which vary in length from about 0.050 to $0.100 \mathrm{~mm}$. and a photomicrograph of which is shown on p. 767 of Kraemer's Applied and Economic Botany. It forms crystallizable salts, of which the sulphate only will be described. At $25^{\circ} \mathrm{C}$. one part of codeine sulphate is soluble in 30 parts of water, and 1035 parts of alcohol. It is insoluble in 
chloroform or ether. The microscopic crystals from hot alcoholic solutions vary in length from $0.3 \mathrm{~mm}$. to $2.5 \mathrm{~mm}$. (Fig. 123).

The following color tests are distinctive for codeine: On heating codeine with concentrated sulphuric acid the solution is colored blue. On the addition of concentrated sulphuric acid containing traces of iron or nitric acid to codeine, the solution becomes green, changing to blue, a blue precipitate finally separating. Dilute solutions of ferric chloride give a blue color with codeine, which is permanent if the solution be gently warmed. Codeine crystals are colored red with nitric acid, the solution remaining colorless or only becoming yellow on heating. On heating a solution of codeine hydrochloride in an autoclave with zinc chloride, an amorphous, yellowish-gray powder is formed, known as apocodeine hydrochloride, and having the same physiological action as apomorphine hydrochloride.

Some opium obtained from plants cultivated in France yielded 2.81 per cent of codeine, while the morphine was but 2.41 per cent and the narcotine 0.10 per cent.

Narcotine exists in opium to a very large extent as a free base. It is found in greater amount in Persian and Indian opium than in Turkey opium. It forms colorless, shining, rhombic prisms or needles, that are tasteless, insoluble in water, but soluble in alcohol. With concentrated sulphuric acid narcotine is colored greenish-yellow, the solution on heating changing to red and finally violet. It may be converted into a number of compounds, of which hydrocotarnine and vanillin are probably the most interesting.

At about $15^{\circ} \mathrm{C}$. one part of narcotine is soluble in 100 parts of alcohol (85 per cent); 166 parts of ether; 2.7 parts of chloroform, and 22 parts of benzene. One part of narcotine is soluble in about 7000 parts of boiling water. Narcotine is a feeble base and forms salts, which for the most part crystallize with difficulty or not at all. A crystalline double salt, however, is readily formed with methyliodide. The crystals of narcotine prepared on microscopic slides from alcoholic solution vary in length from $0.4 \mathrm{~mm}$. to $2 \mathrm{~mm}$. (Fig. 124).

Papaverine occurs to the extent of about 1 per cent and forms colorless needles or prisms, which are partly soluble in water and alcohol, and colored deep purple or violet-blue on warming with sulphuric acid.

Thebaine (gramorphine) occurs to the extent of 0.15 per cent in opium. It crystallizes in prisms which are insoluble in water or alkaline solutions, soluble in alcohol, and gives with sulphuric acid a deep red color. 
Narceine (0.1 to 0.2 per cent) occurs in silky needles or quadrangular prisms, which are nearly insoluble in cold water and alcohol, and are colored blue with iodin solutions and blood-red with chlorin water and ammonia.

Protopine occurs in monoclinic prisms, which are insoluble in water and sparingly soluble in alcohol, the solution having a bitter taste. Sulphuric acid dissolves protopine with a beautiful blueviolet color, which later becomes dull violet and finally greenish. Protopine is also found in a number of other plants of the Papaver-

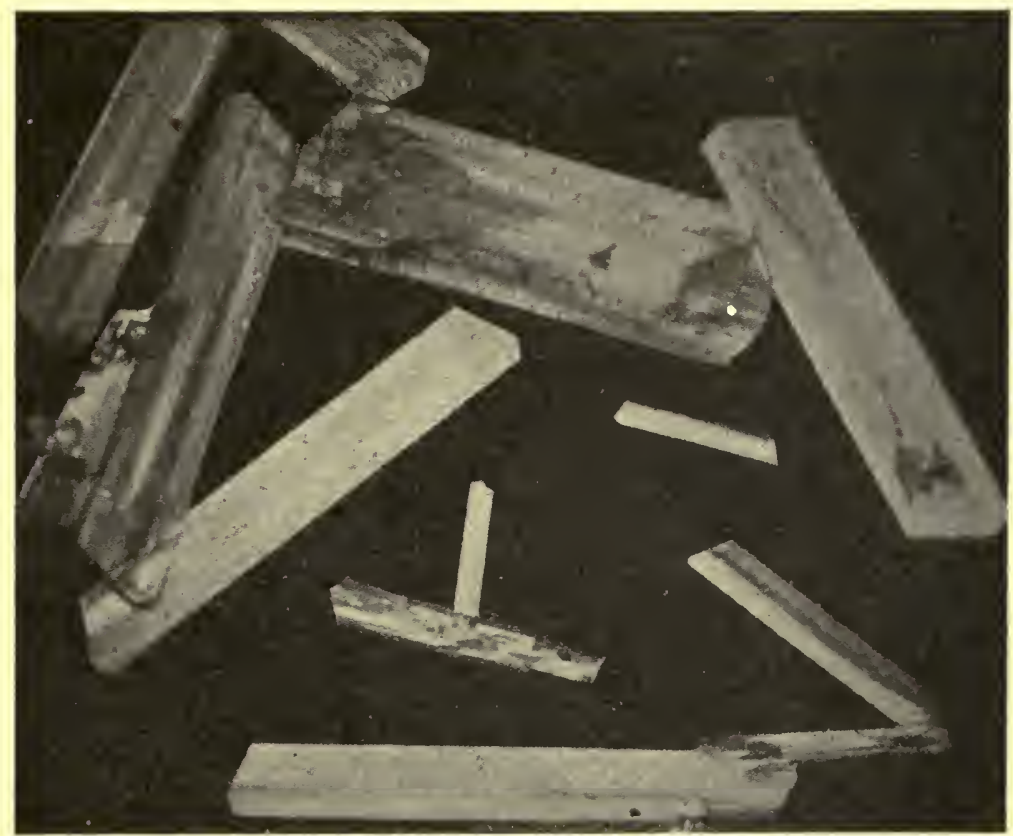

FIG. 124.-Narcotine: orthorhombic crystals from alcoholic solution.

aceæ, as the roots of Macleya cordata and Chelidonium majus; the rhizome of Sanguinaria, and other plants as well.

Of the other alkaloids in opium the following may be mentioned: Codamine, cryptopine, gnoscopine, lanthopine, laudanine, laudanosine, meconine, meconidine and xanthaline.

Opium also contains from 3 to 5 per cent of meconic acid, which exists in combination with morphine, codeine and other alkaloids. It forms rhombic prisms that are soluble in water and alcohol and give a deep-red color in solutions of ferric chloride, which is not altered on the addition of dilute hydrochloric acid. 
The yield of ash in Opium is from 4 to 8 per cent.

Persian Opium.-Usually in masses weighing about 350 grammes and internally more or less homogeneous. There are three commercial kinds of Persian opium: (1) Persian green, which is in planoconvex masses that are of a greenish color and with a closely adhering covering of leaf-tissue; (2) Persian white, which is in oblong, cubical masses, that are coated with a layer of closely adhering white paper; (3) Persian red, which is in either oblong, cubical, or truncate, cone-like masses, that are covered with a grayish-white layer and usually wrapped in red paper.

Turkey Opium is produced in various parts of European and Asiatic Turkey, and there are three principal kinds on the market, namely: (1) Malati opium, which is in the form of ellipsoidal or oblong, flattened cakes, with a closely adhering coating of leaftissue, and yields about 10 per cent of morphine; (2) Salonica opium, which is in the form of long, broad, flattened cakes, coated with leaftissue, and yields about 15 per cent of morphine; (3) Gheve opium, which is obtained from plants with red flowers, occurs in flat, oval masses, wrapped in poppy leaves, and yields 12.5 per cent of morphine.

Egyptian Opium is in somewhat rectangular masses, that are covered with poppy leaves, and yields from 3.5 to 7 per cent of morphine.

Indian Opium is in flat cakes weighing about 200 grammes, or rounded masses weighing about 2 kilogrammes, wrapped in oiled paper. This variety is sent chiefly to China.

Adulterants.-Opium sometimes contains fragments of the capsules, the pulp of figs and other fruits, tragacanth, starch, and various inorganic substances, as clay, sand, stone, lead piping, lead bullets, etc. While starch is not usually admixed with Turkey opium, it is nearly always present in the Persian variety.

Opium Substitutes.-Owing to the habit-producing effects of the alkaloids of opium other drugs are sought. Among those which have been proposed as substitutes for opium, the following may be mentioned: Cannabis (Jour. A. Ph. A., 1918, p. 431); Chelidonium and Gelsemium.

Literature.-Warren, Amer. Jour. Pharm., 1915, 87, p. 439; Wilbert, Jour. A. Ph. A., 1916, 5, p. 688.

Powder of Ipecac and Opium.-Consisting of powdered ipecac, powdered opium and sugar of milk. Grayish-white or very light brown; consisting mostly of coarse angular, frequently more or less cone-shaped, colorless fragments, from 0.030 to $0.400 \mathrm{~mm}$. in length, 
insoluble in water and solutions of hydrated chloral and very strongly polarizing with a rich display of colors (fragments of crystals of sugar of milk); numerous starch grains of ipecac, their presence confirmed by the addition of solutions of iodin, and varying from 0.003 to 0.017 $\mathrm{mm}$. in diameter; occasional fragments of tracheids of ipecac, and occasional fragments with the more or less tabular characteristic stone cells of the capsules of the opium poppy, with their light brown, porous and strongly lignified walls.

Compound Powder of Morphine.-Consisting of morphine sulphate, camphor, powdered glycyrrhiza and precipitated calcium carbonate. Very light brown; with a strong camphoraceous odor and a characteristic sweetish and camphoraceous taste; mounts of compound powder of morphine made in solutions of hydrated chloral show a strong effervescence; if a slight excess of a solution of hydrated chloral containing an equal volume of glycerin is added to a few milligrammes of the powder upon a slide, slightly heated until effervescence ceases and examined it shows numerous rosette aggregate crystals of calcium carbonate, varying from 0.010 to $0.025 \mathrm{~mm}$. in diameter, and fragments of licorice distinguished by their sclerenchymatous fibers associated with crystal fibers, tracheæ with bordered pores and small starch grains in parenchyma cells or isolated, the presence of the latter being confirmed upon the addition of a drop of a solution of iodin; mounts made in any of the fixed oils show numerous rodshaped crystals of morphine sulphate, which are strongly polarizing and often show a strong play of colors; upon adding a small quantity of the powder to a watch crystal, covering the same with a similar crystal or glass plate and heating cautiously until sublimation is effected, the sublimate shows numerous radiating aggregates of feather-shaped crystals of camphor, which are non-polarizing and readily soluble in alcohol.

Chelidonium.-Celandine.-The dried flowering plant of Chelidonium majus (Fam. Papaveraceæ), a perennial herb having an orange milky juice, and common in waste places in the northeastern United States and Canada. The plant should be collected at the time of flowering and used in a nearly fresh condition, as the active principles are partially destoryed and diminished on drying.

Description.-Root fusiform, gradually tapering, from 4 to 10 $\mathrm{mm}$. in thickness, becoming very fleshy, attaining a length of $8 \mathrm{~cm}$. and a thickness of $3 \mathrm{~cm}$., externally dark brown, wrinkled and with a few short roots; internally light brown, having a thin bark. Stem cylindrical, somewhat flattened, longitudinally furrowed and wrinkled, more or less branching and distinctly jointed, sparingly pubescent, 
except in the basal portions, which are frequently strongly pubescent. Leaves thin, more or less crumpled, and when entire pinnately divided, the segments being elliptical or ovate and either deeply crenate or lobed; upper surface dark olive-green, lower surface greenish-gray, glaucous and sparingly pubescent; petioles from 2 to $10 \mathrm{~cm}$. in length, more or less pubescent. Flowers yellowish brown (when fresh orange-yellow), occurring in axillary umbels, consisting of 4 to 9 pedunculate flowers; sepals 2 , occurring only in the buds petals 4, the lobes being rounded; stamens numerous; ovary with 2 placentæ and a 2-lobed sigma; fruit a dry unilocular pod, cylindrical, tapering at the summit and tipped with the persistent stigma, from 12 to $35 \mathrm{~mm}$. in length and 1 to $2 \mathrm{~mm}$. in thickness, and containing numerous seeds which are usually arranged in 2 rows. Seeds spheroidal, ovoid, or ellipsoidal, about $1 \mathrm{~mm}$. in diameter, dark brown and nearly smooth.

Powder.-Light green; aqueous solutions of a golden yellow color; seeds composed of nearly cubical thin-walled cells; nonglandular hairs, uniseriate, composed of 6 to 8 long cylindrical cells, some of which are collapsed and somewhat enlarged or swollen at their dividing walls; fragments of leaves with spiral tracheæ, and latex tubes with light yellowish contents; elliptical or spherical stomata on lower surface only, walls rather indistinct; pollen grains spheroidal, about $0.025 \mathrm{~mm}$. in diameter, nearly smooth, and having 3 pores; fragments of petals with distinctly yellowish fibrovascular bundles. Starch grains and calcium oxalate crystals are wanting.

Constituents.-From 5 to 7 alkaloids: Chelidonine (stylophorine) 0.03 per cent, in colorless monoclinic prisms; chelerythrine, which is fluorescent; $\alpha$-, $\beta$-, and $\gamma$-rhomochelidonine and protopine. These several alkaloids are combined with the following acids: chelidonic, malic, citric and tartaric. It also contains chelidoxanthin, a bitter neutral principle, possessing a yellow color and resembling berberine; and a small quantity of a volatile oil. Another alkaloid, chelilysime, is said to disappear in the drying of the drug.

Literature.-Schmidt, Arch. d. Pharm., 1886, p. 531; Ibid., 1893, p. 136; Wintgen, Ibid., 1901, p. 438.

SANGuinaria.-Bloodroot.-The rhizome of Sanguinaria canadensis (Fam. Papaveraceæ), a perennial herb indigenous to the eastern and central United States and Canada. The rhizome should be collected in July or August and dried.

Description.-Horizontal, irregularly cylindrical, flattened, sometimes branched, 2.5 to $6 \mathrm{~cm}$. in length, 5 to $10 \mathrm{~mm}$. in diameter; externally dark brown, slightly annulate, with few buds or stem- 
scars on upper surface and numerous root-scars on lower surface; fracture short and somewhat waxy; internally, bark dark brown, about $0.5 \mathrm{~mm}$. in thickness, wood and pith with numerous reddish resin-cells; odor slight; taste bitter and acrid.

Shriveled rhizomes which are gray internally and free from starch should be rejected.

Inner Structure.-(Fig. 125.) A layer of small, thin-walled epidermal cells; cortex of 10 to 15 rows of thin-walled parenchyma cells containing numerous starch grains, or a small amount of fixed oil; a strand of cambium, most of which is interfascicular: a narrow circular zone of small collateral fibrovascular bundles, separated from each other by parenchyma; pith large, consisting of starchbearing parenchyma cells; laticiferous sacs containing a red or orangecolored latex, either isolated or in longitudinal rows and distributed among the parenchymatous cells of the middle bark and pith; sections treated with glycerin show in the secretion cells, after twentyfour hours, spheroidal aggregates of crystals which strongly polarize light.

Powder.-Brownish-red; sternutatory; starch grains numerous, 0.003 to $0.020 \mathrm{~mm}$. in diameter, being mostly single, seldom 2 - to 3 -compound, the individual grains nearly spheroidal or ovoid, sometimes more or less plano-convex, somewhat resembling those of wheat starch in outline, but which polarize light more strongly; numerous fragments of short reddish-brown resinous laticiferous sacs; tracheal fragments few, having numerous transverse slit-like pores.

Constituents.-The drug contains a number of alkaloids, of which the most important is sanguinarine; it occurs to the extent of about 1 per cent, crystallizes in colorless needles and yields reddish salts with nitric or sulphuric acid. The other alkaloids include chelerythrine, which forms yellowish salts; protopine, also found in other plants, and $\beta$ - and $\gamma$-homochelidonine, which, like the last two alkaloids, are found in Chelidonium and some other plants. In addition, the drug contains a reddish resin, several organic acids, as citric and malic, and considerable starch.

\section{FUMARIACEE, OR FUMITORY FAMILY}

Mostly delicate herbs and a few green shrubs. The leaves are usually compound and the flowers irregular, one or both of the petals having a spurred or a saccate base. The fruit is a unilocular capsule containing one or more seeds. They are especially characterized by 

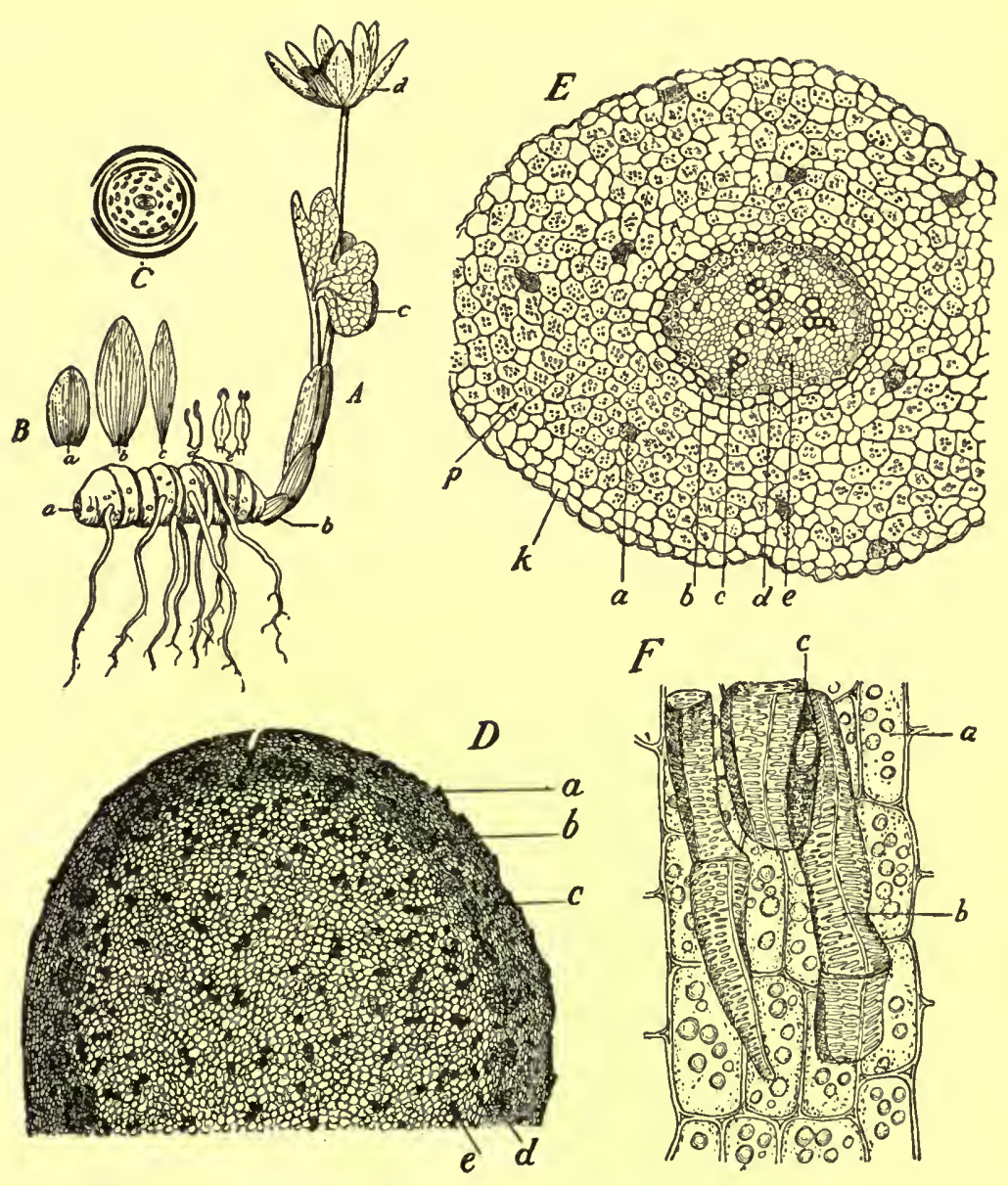

FIg. 125.-Sanguinaria. $A$, entire flowering plant: $a$, rhizome with long rootlets; $b$, one of the outer bud-scales; $c$, young leaf; $d$, the nearly complete flower, in which the caducous sepals have fallen away. $B$, the separated floral organs: $a$, sepal; $b$ and $c$, different petals; $d$, stamens; $e$, pistil in different views. $C$, diagram showing position of parts of the flower. $D$, transverse section of rhizome: $a$, cork; $b$, vascular bundle; $c$, cluster of reddish secretion cells or laticiferous sacs in the middle cortical layer; $d$, cambium of one of the collateral bundles; $e$, one of the numerous red latex cells of pith. $E$, transverse section of a young root before any important secondary changes have occurred: $k$, layer of epidermal cells; $p$, starchbearing parenchyma of cortex; $a$, laticiferous sacs; $b$, endodermis; $c$, tracheæ; $d$, pericambium layer, the cells of which are filled with very small starch grains; $e$, leptome. $F$, longitudinal section through tracheal portion of one of the vascular bundles of the rhizome: $a$, starch-bearing parenchyma; b, scalariform trachex.-After Bastin, Amer. Jour. Pharm., 1895, p. 4. 
having special secretion cells termed idioblasts. These are more or less elongated cells, varying from 2 to $10 \mathrm{~mm}$. in length, and occur in the leaves as well as in the axis of the plant. Their contents are either colorless, yellow or red. They have been variously termed tannin and anthocyanin-receptacles or alkaloidal-receptacles. They probably contain a mixture of substances, including a fixed oil, a pigment resembling anthocyanin, tannic acid and one or more alkaloids. The idioblasts are either isolated or arranged in long longitudinal rows. For further discussion and illustration of these cells, consult Kraemer's Applied and Economic Botany, pp. 208-210.

Conydalis.-Turkey or Squirrel Corn.-The dried tubers of Dicentra (Corydalis) canadensis and the granulate bulbs of Dicentra Cucullaria (Fam. Fumariaceæ). These are low, stemless, perennial herbs, common in rich woods in the eastern and central United States and Canada. The plants have ternately compound and dissected leaves and form racemes of characteristic flowers, having heart-shaped, and spurred corollas, those of D. canadensis being tinged with purple, while those of $\mathrm{D}$. Cucullaria are yellow at the summit.

D. Canadensis.-The tubers are rounded and frequently vertically depressed, the flattened surface more or less concave, from 5 to $15 \mathrm{~mm}$. in diameter; usually single, rarely two or more in a cluster; externally, minutely pitted or nearly smooth, grayishbrown, grayish-black or amber colored and more or less translucent; one of the flattened surfaces having a triangular scar from detached rhizome, the other usually with the short rhizome base and numerous fine roots; fracture either hard and horny (the inner surface being yellowish and waxy), or somewhat tough (the fractured surface being yellowish-white and granular); odor slight; taste bitter.

D. Cucullaria.-The bulbils of the granulate bulb are plump, ovoid or triangular-ovoid, from 5 to $12 \mathrm{~mm}$. in length; the larger bulbils distinctly concave on one surface, with a scar at the summit from the detached petiole, and usually attached to the short rootstock in clusters of three; the smaller bulbils usually separated from the root-stock and having an acute summit and a scar at the base; externally, yellowish or grayish-brown, usually translucent; fracture either hard and horny, the inner surface being grayish and waxy, or tough and whitish granular; odor slight; taste slightly bitter.

Powder.-Light yellow or yellowish-gray; starch grains numerous, mostly single or 2-compound, the individual grains from 0.003 to $0.060 \mathrm{~mm}$. in length, ovoid or oblong, the broad end of the grain sometimes truncate, and usually having at the point of origin of 
growth a distinct cleft or horseshoe-shaped fissure, occasional altered and swollen grains from 0.060 to $0.090 \mathrm{~mm}$. in diameter; tracheæ few, with simple pores, or reticulate, annular or spiral markings; fragments of epidermal cells with thin brownish walls; sclerenchymatous fibers very few or wanting; sclerotic cells in D. Cucullaria very characteristic, being irregular in outline, mostly elongated, attaining a length of $0.750 \mathrm{~mm}$. and a width of $0.100 \mathrm{~mm}$., walls heavily lignified and about $0.020 \mathrm{~mm}$. in thickness, and porous, occurring either isolated or in groups of from two to four: sclerotic. cells from the rhizome of $\mathrm{D}$. canadensis, few, mostly isodiametric, uniformly smaller than those of $\mathrm{D}$. Cucullaria, the walls being about $0.012 \mathrm{~mm}$. in thickness and not distinctly irregular in outline; rosette aggregates of calcium oxalate, from the portions of rhizome of $\mathrm{D}$. canadensis, few and $0.020 \mathrm{~mm}$. in diameter.-Newcomb.

\section{CRUCIFERE, OR MUSTARD FAMILY}

The plants are mostly herbs, occasionally woody, and include about 1500 species, which are widely distributed. The flowers consist of 4 sepals, 4 petals, 6 tetradynamous stamens, and a single compound pistil, becoming in fruit usually a 2-locular silique or silicle. They are especially characterized by their colorless secretion cells. These very closely resemble their neighboring cells, but in the cortex and mesophyll are usually somewhat elongated. Their exact location may be determined by the use of certain reagents. They are stained by the anilin dyes; with solutions of orcin or orcein and hydrochloric acid they are colored violet; with Millon's reagent, consisting of a solution of mercuric nitrate, the contents are precipitated and colored red. In alcoholic material the contents of the secretion cells are precipitated and their position more readily determined. Myrosin-secreting cells occur in nearly all of the Cruciferæ, with the exception of Capsella, Lepidium, Cakile and a few others. In the leaves of the Cruciferæ occur large water-storing cells. These occur among the epidermal cells and are readily distinguished by their greater size. The non-glandular hairs are unicellular and of various characteristic shapes for the different genera. Glandular hairs are seldom found, and calcium oxalate is wanting.

SinAPIS Alba.-Brassica Alba, White Mustard.-The dried, ripe seeds of Brassica (Sinapis) alba (Fam. Cruciferæ), an annual herb native of Europe and southwestern Asia, also naturalized and extensively cultivated in many countries. The commercial supply 
of the drug is obtained from plants grown in England, Germany, Holland and Italy.

Description.-Campylotropous, irregularly spheroidal, somewhat compressed, 1 to $2 \mathrm{~mm}$. in diameter, externally yellowish-brown, seed-coat membranaceous, and minutely pitted, marked on one side by a distinct ridge and two parallel furrows formed by the hypocotyl and cotyledons; internally light ycllow, without a reserve layer, hypocotyl curved, cotyledons conduplicate; inodorous; taste pungent and acrid.

Inner Structure.-See Figs. 126 and 127.
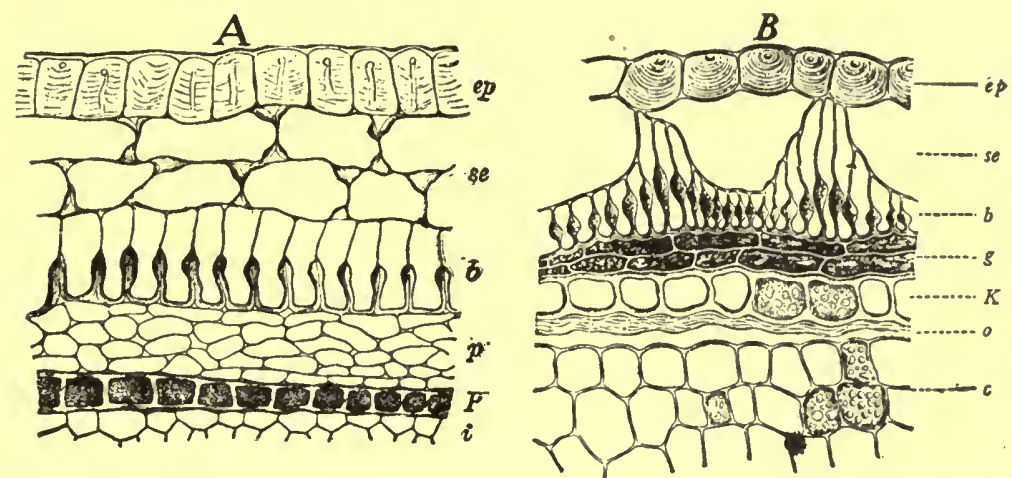

FIG. 126.-A, transverse section of Brassica alba (white mustard). $e p$, epidermis; $s e$, collenchyma; $b$, palisade layer of stone cells which have the inside and lower portions of the side walls considerably thickened (so-called beaker cells); $p$, several layers of parenchyma; $P$, aleurone layer consisting of thick walls and having an oily cytoplasm and numerous very small, somewhat spheroidal aleurone grains; $i$, layer of usually more or less compressed cells, but here shown as being polygonal in outline. $B$, transverse section of Brassica nigra (black mustard). ep, epiderms; se, collenchyma which are modified to large giant cells and which give rise in part to the reticulations of the seeds; $b$, palisade layer of peculiarly thickened stone cells (so-called beaker cells) which are of unequal height; $g$, brown pigment layer consisting of 1 or 2 rows of cells which are tangentially elongated and colored blue with solutions of ferric salts; $K$, aleurone layer consisting of thick walls and having an oily cytoplasm and numerous very small, somewhat spheroidal aleurone grains; $o$, several layers of more or less collapsed cells; $c$, cells of embryo containing an oily cytoplasm and small aleurone grains, the latter being either nearly spheroidal or somewhat ellipsoidal, and composed mainly of globoids.-After Moeller.

Powder.-(Fig. 127.) Light yellow; fragments of seed-coat with mucilaginous epidermal cells; a sub-epidermal collenchymatous layer of 1 or 2 rows of cells; a layer of radially elongated palisade or stone cells (forming the so-called "beaker cells"), the walls of the 
lower part being slightly thickened and polygonal in surface view; two or more inner layers of thin-walled colorless cells; a single layer of cells containing aleurone grains and fixed oil, and some obliterated cells, which, together constitute the endosperm. The embryo makes up the greater portion of the seed, and the cells contain aleurone grains and an oily cytoplasm.

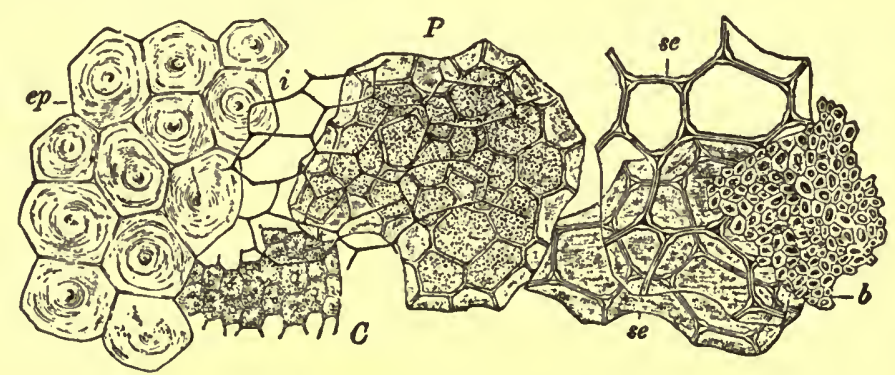

FIG. 127.-White mustard. Surface view of the different tissues as seen in the powder: $e p$, polygonal cells of the outer epidermis showing mucilage lamellæ and the reduced lumina due to swelling of the lamellæ; se, collenchymatous cells beneath the epidermis; $b$, elongated stone cells (so-called beaker cells); $i$, parenchyma cells beneath the stone cells, which are distinguished from the corresponding layer in a number of other seeds by not containing any pigment; $P$, cells of endosperm containing aleurone; $C$, tissue of cotyledon containing aleurone grains and oil.-After Moeller.

Constituents.-Fixed oil 20 to 25 per cent; mucilage in the outer wall of the epidermal cells; proteids about 30 per cent; a glucoside sinalbin and a ferment myrosin, which yield on interaction a yellowish non-volatile oil (acrinyl sulphocyanide) which is pungent to the taste, but owing to its non-volatile character, does not affect the eyes or nose. In the reaction there is also formed glucose and acid sinapine sulphate. Sinapine is an alkaloid which is decomposed, on heating its solutions with alkalies, into choline and sinapic acid.

White mustard should contain not more than 24 per cent of oil; not less than 35 per cent of protein substances, and not more than 12 per cent of crude fiber.

Standard of Purity.-Mustard seed is the seed of Sinapis alba L. (white mustard), Brassica nigra (L.) Koch (black mustard), Brassica juncea Hook $\mathrm{f}$. et Th., or varieties or closely related species of the types of Brassica nigra and Brassica juncea.

Sinapis alba (white mustard) contains no appreciable amount of volatile oil. It contains not more than 5 per cent of total ash, nor more than 1.5 per cent of ash insoluble in hydrochloric acid. 
Brassica nigra (black mustard) and Brassica juncea yield 0.6 per cent of volatile mustard oil (calculated as allylisothiocyanate and determined by the method given in Service and Regulatory Announcements, Chemistry 20). The varieties and species closely related to the types of Brassica nigra and Brassica juncea yield not less than 0.6 per cent of volatile mustard oil, similar in character and composition to the volatile oils yielded by Brassica nigra and Brassica juncea. These mustard seeds contain not more than 5 per cent of total ash, nor more than 1.5 per cent of ash insoluble in hydrochloric acid.

Ground mustard is the powder made from mustard seed, and conforms to the standards for mustard seed.

Mustard flour is the powder made from mustard seed with the hulls largely removed and with or without the removal of a portion of the fixed oil. It contains not more than 1.5 per cent of starch, nor more than 6 per cent of total ash.

Prepared mustard, German mustard, French mustard, mustard paste, is a paste composed of a mixture of ground mustard or mustard flour, with salt, a vinegar, and with or without spices or other condiments which do not simulate the color of yellow ground mustard. Calculated free from water, fat, and salt, it contains not more than 24 per cent of carbohydrates (calculated as starch), not more than 12 per cent of crude fiber, nor less than 5.6 per cent of nitrogen derived solely from the materials herein named. (U. S. Dept. Agric.).

Adulterants. - While the whole mustard is seldom, if ever, adulterated, ground mustard may contain wheat middlings or shorts, and occasionally rice or pea flour; when these flours are employed, turmeric is also added to bring up the color, which is readily detected by means of the microscope (Fig. 88) and by its becoming deep red with sulphuric acid and blue with iodin. Prepared mustard is sometimes adulterated with white mustard hulls separated from the seed before expression of the fixed oil.

Allied Plants.-In Indian Colza (Brassica campestris Sarson) the epidermis forms a homogenous layer, a sub-epidermal layer not being present. The seeds of Turnip (Brassica campestris) are supposed to be the white mustard of Sanscrit writers.

Ground White Mustard or white mustard flour is prepared from the seed of Brassica alba with or without the removal of a part of the seed-coat (hulls) and the fixed oil. In fact, not infrequently mustard seed-cake is employed. 
Prepared Mustard (German Mustard, French Mustard of Mustard Paste) is a paste composed of a mixture of ground mustard (either Brassica alba or Brassica nigra, or both) salt, spices and vinegar.

Sinapis Nigra.-Brassica Nigra, Black Mustard.-The dried, ripe seeds of Brassica nigra (Fam. Cruciferæ), an annual occurring much the same as Sinapis alba.

Description.-Campylotropous, ellipsoidal or irregularly spheroidal, 1 to $1.5 \mathrm{~mm}$. in diameter; externally brownish-red, seed-coat membranaceous, finely pitted, hilum whitish, forming a conical projection, micropyle occurring as a slight depression; . without a reserve layer, hypocotyl curved, cotyledons conduplicate; inodorous: taste pungent and acrid.

Inner Structure.-See Figs. 126 and 128.

Powder.-(Fig. 128.) Yellowish-brown; fragments of seedcoat with mucilaginous epidermal cells; a single layer of thin-walled,
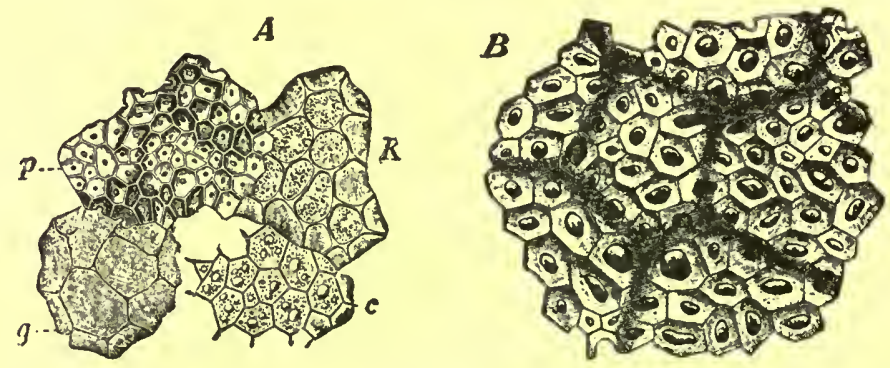

FIG. 128.-Black mustard. A, surface view of some of the characteristic cells seen in the powder: $p$, elongated stone cells (beaker cells), beneath which is the pigment layer $(g) ; K$, endosperm cells containing aleurone; $c$, cells of cotyledon containing aleurone and oil. $B$, enlarged surface view of the stone cells, showing a shadow-like reticulum composed of broad lines which appearance is due to the fact that some of the cells are tangentially elongated (compare with Fig. 126, B).-After Moeller.

unequal sub-epidermal cells; a layer of palisade or stone cells (socalled " beaker cells"), thickened much the same as in Brassica alba, but of unequal height, giving the section a somewhat reticulate appearance; a pigment layer of one or two cells which may be tabular or considerably tangentially elongated and with a brown content which is colored blue with ferric chloride, as in flaxseed. The endosperm and embryo contain fixed oil and aleurone grains, these layers practically making up most of the drug. Starch grains are not present in mustard and the powder should not contain more than ten granules to a milligram. 
Ground Black Mustard or Black Mustard Flour is usually prepared from the cake which has been deprived of the hulls and part of the oil. It is customary to mix some of the white mustard with the black mustard, it being supposed that the excess of the ferment in B. alba will change the unconverted glucoside into volatile oil of mustard. It is likely, however, that the enhanced quality of the product is due to the pungent and non-volatile character of the oil in white mustard.

Mustard Paste is sometimes adulterated with starches. At one time, the addition of other substances was considered to be necessary on account of the pungency of the drug.

Constituents.-Black mustard contains the same constituents as white mustard, save that it contains more fixed oil (30 to 35 per cent); less of the ferment, myrosin; and the sinalbin is replaced by the glucoside, sinigrin (potassium myronate), which is present to the extent of about 1 per cent and yields on interaction with the myrosin a light yellowish volatile oil (allyl isosulphocyanide or volatile oil of mustard), which has an acrid, burning taste, pungent odor, and also affects the eyes. In the reaction there is also formed glucose and potassium acid sulphate.

The U. S. Department of Agriculture has ruled that black mustard-seed should yield a volatile oil containing not less than 0.6 per cent of allyl iso-thiocyanate.

Allied Products.-Of the seeds of the other Cruciferæ, which somewhat resemble black mustard, the following may be mentioned: The seeds of Field mustard or Brassica arvensis, which are almost black and perfectly smooth; the seeds of Sarepta mustard (Brassica Besseriana), which are larger and distinctly reticulate; Rape or colza seeds (Brassica Napus), which are larger, not reticulate and of a bluish-black color; Turnip seeds yielded by Brassica campestris, which are somewhat larger but less acrid, and are used in India in place of black mustard; and Brassica juncea, which is cultivated in tropical Asia for the same purpose.

Adulterants.-A large percentage of the black mustard of commerce is admixed with the seeds of wild mustard or Charlock (Brassica arvensis). The plant is very common in the wheat fields of the northwestern States and the seeds are almost always present in the mustard from this territory. A product known as Dakota Mustard consists largely of the seeds of this plant. They are very easily detected by the use of a small magnifying glass, as they are brownish-black, from 1 to $1.5 \mathrm{~mm}$. in diameter, nearly smooth and not reticulated as true black mustard. Charlock, when admixed 
with powdered black mustard, can be detected microscopically by the palisade-stone cells, which become blood-red on heating with a solution of hydrated chloral.

\section{DROSERACEE, OR SUNDEW FAMILY}

A small family of biennial or perennial herbs which are very widely distributed. In some respects these plants are among the most interesting in the plant kingdom, being of very great biological interest. It includes Dionæa muscipula or Venus' fly-trap, which is found in the sandy bogs of a limited area in the vicinity of Wilmington, N. C. It exhibits in a remarkable degree the irritability common to some plants; a slight touch to the sensitive hairs on the leaf causes a rapid movement of the modified leaf-blade. For illustration of the plant consult Kraemer's Applied and Economic Botany, p. 362. The typical genus of the family, Drosera, has about 110 species, which are most abundant in Australia, several species, however, being rather common in the United States. They all possess peculiarly stalked glands, forming in Drosera the so-called glandular tentacles, and of which there are 2 types $(a)$.those situated upon the surface of the leaf possessing an ellipsoidal glandular head, and $(b)$ those occurring on the margins of the leaf in which the head has the form of a spoon.

Drosera.-Sundew.-The entire plant of Drosera rotundifolia or other closely allied species of Drosera (Fam. Droseracex). The plant is collected at the time of flowering, the roots washed, the lower withered and darkened leaves removed, and carefully dried.

Description.-More or less crumpled and matted; leaves petiolate, mostly basal, except in submerged plants which have more or less lengthened internodes; laminæ sub-orbicular or broadly elliptical, 7 to $15 \mathrm{~mm}$. in diameter, abruptly narrowed into the petioles and covered with numerous pinkish-red glandular tentacles, about $4 \mathrm{~mm}$. in length; petioles very slender, from 2 to $4 \mathrm{~cm}$. in length and 0.5 to $2 \mathrm{~mm}$. in diameter, somewhat flattened and pubescent; scapes filiform, from 5 to $10 \mathrm{~cm}$. in length, having the flowers in a 1-sided raceme-like inflorescence; flower buds about $5 \mathrm{~mm}$. in length, having an imbricated calyx and convoluted corolla; lower portion of the stem somewhat flattened, tapering, from 5 to $30 \mathrm{~mm}$. in lèngth and bearing a few very slender roots.

Inner Structure.-Glandular tentacles, from 0.250 to $0.400 \mathrm{~mm}$. in length, and consisting of a long multiseriate stalk traversed by a strand of tracheids, which become broader on extending into the 
glandular hair; pigment cells colored deep red and changing to a bright green upon the addition of solutions of the alkalies; epidermal cells elongated with straight walls, having numerous elliptical stomata about $0.025 \mathrm{~mm}$. in length, and many 2-celled glandular hairs about $0.040 \mathrm{~mm}$. in diameter, the dividing wall usually more or less curved and the cells being filled with a granular substance, occasionally the short glandular hairs are 4-celled, the individual cells being of irregular shape.

Constituents.-A greenish-brown resin, having a slight odor and a very acrid taste; an enzyme capable of converting albumin into peptone; also citric acid and probably malic acid.

Allied Plants.-Drosera longifolia, an allied species, frequently growing with Drosera rotundifolia, is sometimes admixed with or entirely substituted for it.

\section{SAXIFRAGACEE, OE SAXIFRAGE FAMILY}

Mostly perennial herbs, seldom annual plants or shrubs, and represented by about 200 species, which are mostly indigenous to the North Temperate zones. There is considerable variation in the position of the leaves, the number of parts to the flower, the character of the inflorescence, and the nature of the fruit. They are especially characterized by having a small embryo embedded in a large endosperm. The tracheæ always possess scalariform perforations and the walls adjoining the parenchyma are usually marked by simple pores. The wood fibers have either simple or bordered pores. The non-glandular hairs are of several types and in some genera are calcified, as in Hydrangea, Philadelphus and Deutzia. The glandular hairs usually possess a uniseriate stalk. Calcium oxalate occurs in the form of styloids, raphides, rosette aggregates, or sphenoidal microcrystals.

Hydrangea.-Wild Hydrangea Root or Seven Barks.The rhizome and roots of Hydrangea arborescens (Fam. Saxifragaceæ), a beautiful shrub, growing wild on rocks and near streams throughout the central and southern United States. The rhizome and roots are very fleshy and are cut into pieces to facilitate drying.

Description.-Rhizome, cylindrical, usually in pieces 3 to 10 $\mathrm{cm}$. in length, 3 to $20 \mathrm{~mm}$. in diameter, light brown to yellowishbrown with a pinkish tinge, longitudinally wrinkled, marked by few elliptical lenticels and occasional prominent buds, short branches or stem scars, and from the lower surface arise a few coarse fibrous roots; fracture tough, splintery; internally yellowish-white or 
light brown, bark thin, easily separable from the distinctly radiate wood which surrounds a prominent whitish pith; inodorous; taste of the bark sweetish, becoming slightly acrid. Roots attaining a length of $25 \mathrm{~cm}$. and a thickness of $2 \mathrm{~mm}$., irregularly bent and branching, otherwise resembling the rhizome with the exception of the pith being wanting.

Inner Structure.-A corky layer consisting of several rows of grayish-white tabular cells; cortex consisting chiefly of starchbearing parenchyma, large cells containing raphides, small isolated groups of stone cells, and sclerenchymatous fibers; a woody cylinder composed of slender wedges made up of prominent tracheæ with reticulate thickenings and tracheids, separated by the starch-bearing medullary rays which are from 1 to 3 cells wide; pith of large polygonal cells with prominent simple pores.

Powder.-Light yellowish-brown; irregular fragments consisting of strongly lignified tracheæ, tracheids and medullary ray cells; stone cells and sclerenchymatous fibers, 0.050 to $0.200 \mathrm{~mm}$. in length, strongly lignified, the walls being marked by simple and branching pores; raphides numerous, from 0.070 to $0.130 \mathrm{~mm}$. in length; starch grains mostly single, more or less ellipsoidal, occasionally with a prominent central cleft, and varying from 0.002 to $0.010 \mathrm{~mm}$. in diameter.

Constituents.-A glucoside, hydrangin, about 1 per cent, crystallizing in aggregates, soluble in alcohol and ether, and giving with solutions of the alkalies a bluish fluorescence, which immediately disappears on the addition of acids. Also a volatile oil, resin and starch. It probably also contains a saponin. A glucoside, parahydrangin, is also present in the root of the arborescent Hydrangea (H. Paniculata grandiflora), a variety extensively cultivated.

\section{HAMAMELIDACEE, OR WITCHHAZEL FAMILY}

Mostly sub-tropical trees or shrubs and represented by about 35 species. The leaves are alternate, the flowers perfect or polygamous, usually having an imperfect perianth, and the fruit is a woody capsule, dehiscing at the summit. In the axis the tracheæ are usually narrow and possess scalariform perforations or have simple pores when in contact with the medullary ray cells. The wood fibers bear simple pores and the medullary rays are but a few cells wide and a great many rows in height. The non-glandular hairs are either stellate or tufted. Calcium oxalate is excreted either in the form of 
solitary crystals or rosette aggregates. Tannin secretion cells are very characteristic in Hamamelis. Schizogenous resin canals occur in Liquidambar. They occur commonly at the margin of the pith and can be traced into the finest branches of the veins of the leaves. In roots they are associated with the development of primary and secondary phloem.

Hamamelidis Folia.-Witchhazel Leaves.-The leaves of Hamamelis virginiana (Fam. Hamamelidaceæ), a shrub indigenous to the eastern and middle United States and Canada. The leaves are collected in autumn, and are used in the fresh condition, or dried; when dried they should be carefully preserved and not kept longer than one year.

Description.-Broadly elliptical, or rhomboid-obovate, more or less unequal; 3.5 to $12 \mathrm{~cm}$. in length, 2.5 to $7 \mathrm{~cm}$. in breadth; summit rounded, acute or acuminate; base obliquely cordate; margin sinuate or sinuate-dentate; upper surface dark green, veins of the first order diverging at an angle of about $60^{\circ}$ and running nearly parallel to the margin, with grayish patches of a mold and slightly pubescent; under surface light green, pubescent, midrib and veins prominent; petiole 5 to $12 \mathrm{~mm}$. in length; texture coarse, brittle; odor slight; taste astringent.

Inner Structure.-(Fig. 129.) Epidermal layer of the ventral surface, glabrous except above the midrib and the large secondary veins; stomata are only found upon the lower surface, these being narrow elliptical, about $0.015 \mathrm{~mm}$. in length with 2 to 4 neighboring cells; from both surfaces, but especially from the under surface, arise stellate hairs composed of from 4 to 12 cells united at the base, the individual cells being from 0.030 to $0.075 \mathrm{~mm}$. in length, either straight or more or less bent and with very thick walls and narrow lumina, sometimes only apparent in the lower portion of the cells; a palisade layer consisting of a single row of cells and a dorsal pneumatic tissue made up of from 3 to 6 rows of strongly branching cells; the fibrovascular bundles occurring in the midrib and petiole are large and of the collateral type, with a central area composed of parenchyma, surrounded by a strongly developed xylem, the tracheæ being narrow, mostly spiral and associated with numerous narrow, strongly lignified wood fibers, the pores being prominent: the phloem consists of leptome surrounded by a nearly continuous circle of bast fibers, the walls of which are strongly lignified; calcium oxalate occurs in monoclinic prisins from 0.010 to $0.035 \mathrm{~mm}$. in diameter, occurring either in the cells of the mesophyll or in crystal fibers, the latter associated with the bast fibers. 

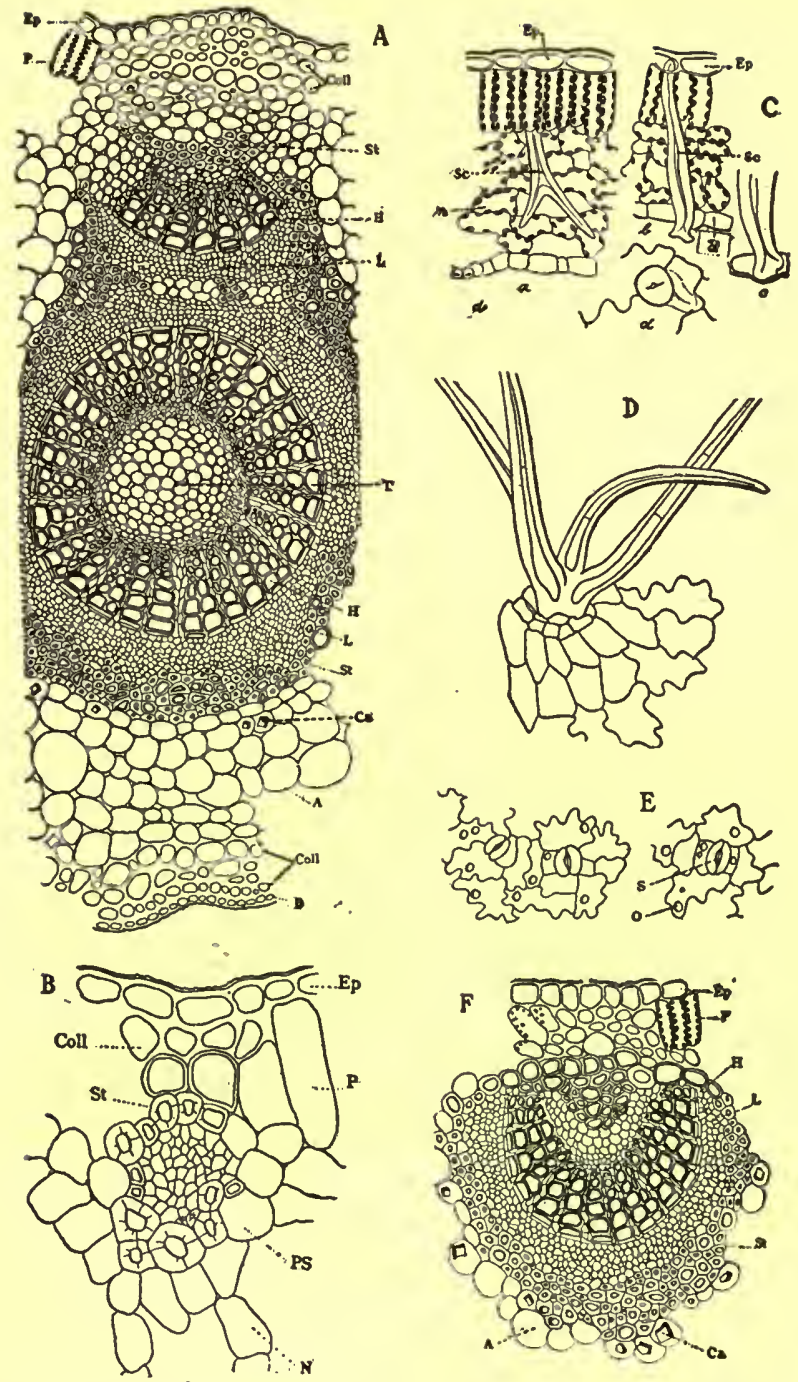

FIG. 129.-Hamamelis. $A$, transverse section of a midrib from about the middle of the leaf-blade, showing an arch-shaped collateral vascular bundle situated near the upper or ventral epidermis and a stele with a central pith ( $T$ ) near the center of the section. Ep, ventral epidermis; coll, collenchyma; $P$, palisade cells; $S t$, stereome or sclerenchymatous fibers; $H$, trachex or vessels; $L$, leptome; $T$, pith; $C a$, calcium oxalate; $A$, colorless tissue; $D$, dorsal epidermis. $B$, transverse section of a thin mestome strand of leaf blade; $E p$, ventral epidermis; Coll, collenchyma; $P$, palisade tissue; $S t$, stereome; $P S$, parenchyma sheath; $N$, loose mesophyll or pneumatic tissue. $C$, transverse sections of leaf-blade; $E p$, ventral epidermis; $D$, dorsal epi- 
Powder.-Dark green; calcium oxalate in monoclinic prisms 0.007 to $0.035 \mathrm{~mm}$. in diameter, frequently in crystal fibers; nonglandular hairs 1-celled, about $0.5 \mathrm{~mm}$. in length, more or less curved, thick-walled, with yellowish-brown contents, arranged in groups of 2 to 15 , and spreading from the base; numerous cells of loose mesophyll with irregular tannin masses; sclerenchymatous fibers thick-walled, lignified and with simple pores.

Constituents.-Volatile oil; a bitter principle; tannin, about 3 per cent; gallic acid, and calcium oxalate.

The distillate, obtained on distilling either the fresh or dried leaves of Hamamelis with water, contains an aromatic substance that apparently does not exist as such in the leaves. The substance sold as hamamelin is a mixture consisting of an evaporated alcoholic extract of either the leaves or bark, that of the former being greenish-black and more permanent and the latter brownishblack and more or less hygroscopic.

Hamamelidis Cortex.-Witchhazel Bark.-The bark and twigs of Hamamelis virginiana (Fam. Hamamelidaceæ), a shrub indigenous to Canada and the United States and extending west to Minnesota and south to Texas.

Description.-Bark is transversely curved pieces 5 to $20 \mathrm{~cm}$. in length, 5 to $15 \mathrm{~mm}$. in diameter, bark 0.5 to $1 \mathrm{~mm}$. in thickness; usually with the grayish-brown or reddish-brown periderm removed, outer surface light brownish-red, smooth; inner surface light reddishbrown, longitudinally striate; fracture short-fibrous; odor slight; taste astringent.

Twigs 2 to $5 \mathrm{~mm}$. in diameter; the outer surface varying in color from yellowish-brown to blackish-brown, smooth or somewhat scurfy, longitudinally wrinkled, and with numerous small lenticels; small, twigs somewhat zigzag from numerous leaf-scars; bark thin, easily separable from the whitish, hard, radiate wood; pith small.

Inner Structure.-(Fig. 130.) A layer of phelloderm consisting of from 10 to 15 rows of cells with yellowish-brown contents; outer

dermis; $S c$, sclereids or colorless stone cells (also called idioblasts); $N$, loose mesophyll; in figures $a$ and $b$ the palisade and pneumatic tissue are shown with thick-walled stone cells, branched in $a$, penetrating epidermis in $b$; in $c$ one end of a sclereid is entering an epidermal cell, and in $d$, is shown a surface view of the epidermis with the end of a stone cell. $D$, basal portion of a 4-branched hair from the dorsal epidermis of leaf, showing very thin cross-walls in the branches. $E$, surface view of dorsal epidermis of leafblade, showing the stomata $(S)$ and oil globules $(O) . F$, transverse section of a midrib from near the summit of the leaf-blade, letters as in A.-After Holm, Merck's Report, 1912, p. 5. 
bark with a continuous layer of stone cells, the walls being very thick, lamellated and with large simple and branching pores; parenchyma of primary cortex containing either reddish-brown amorphous tannin masses, or very small starch grains; inner bark with medullary rays usually 1 cell wide, occasionally 2 to 5 cells wide, separating the bast fibers which occur in tangentially elongated groups, plates of parenchyma and sieve tissue; bast fibers with thick, more or less lignified

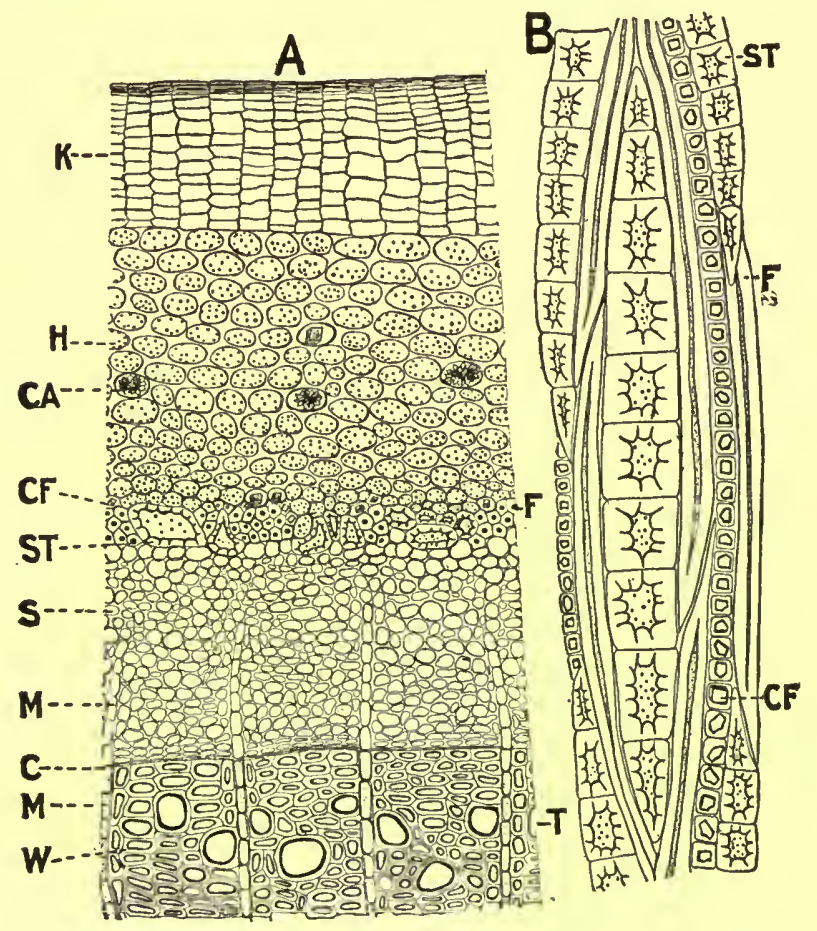

Fig. 130.-Hamamelis virginiana: $A$, transverse section of twig: $K$, cork; $H$, cells of hypodermis with simple pores, the cells containing chloroplasts and small starch grains; $C a$, calcium oxalate crystals; $C f$, crystal fibers; $F$, bast fibers with thick, strongly lignified walls; $S$, sieve cells; $M$, medullary rays; $C$, cambium; $W$, wood fibers; $T$, tracehr. $B$, tangential section of a twig showing stone cells $(S t)$, crystal fibers $C f)$, and thick-walled bast fibers (F).

walls and associated with crystal fibers usually consisting of monoclinic prisms, 0.015 to $0.040 \mathrm{~mm}$. in length; adhering wood of tracheæ having bordered pores, numerous strongly lignified wood fibers with prominent oblique slit-like, simple pores or bordered pores and medullary rays 1 cell wide, the walls being more or less lignified, with numerous simple pores and the lumina occasionally filled with starch. 
Constituents.-Gallotannic acid, a glucosoidal tannin, and gallic acid. The bark apparently also contains a volatile oil consisting chiefly of a terpene, which is obtained by distillation in the preparation of hamamelis water or extract of witchhazel.

Caules Hamamelidis. - Hamamelis Twigs. - Witchinazel Twigs.-The fresh twigs of Hamamelis virginina (Fam. Hamamelidaceæ), collected in the fall.

Twigs with nodes 2-ranked giving the younger portions frequently a zigzag outline; externally yellowish-brown.

Inner Structure.-(Fig. 130.) The epidermal layer of young twigs show numerous stellate branching hairs similar to those described under Hamamelis Leaves (Fig. 129) - a hypodermis of 6 or 8 rows of cells; a cortical layer, the cells for the most part being filled with chloroplasts, otherwise containing small starch grains and occasionally crystals of calcium oxalate either in the form of monoclinic prisms or rosette aggregates; a continuous circle of mechanical tissue consisting of groups of bast fibers separated by stone cells, the walls of both being strongly lignified; a narrow leptome or sieve area; a xylem composed of large tracheæ, with scalariform or reticulate thickenings and associated with numerous tracheids having numerous bordered pores, the medullary rays being one cell wide and filled with very small starch grains; pith nearly circular, the cells having thick porous walls and the lumina more or less filled with small, somewhat angular starch grains. In the thicker stems the epidermis is replaced with cork, the walls of the cells being usually yellowish-brown and the lumina often filled with a yellowish-brown amorphous substance, otherwise the structure is the same as that of the young twigs.

Styrax.-Storax.-A balsam obtained from the trunk of Liquidambar orientalis (Fam. Hamamelidaceæ), a tree indigenous to Asia Minor and the Levant. The balsam is a pathological product, and is produced by bruising the bark of the tree, removing it and then boiling the inner bark in sea-water, the balsam which rises to the surface being skimmed off.

Description.-A viscid, grayish, more or less opaque semi-liquid mass, depositing on standing a heavier, dark brown, oleo-resinous stratum; translucent in thin layers; odor agreeable; taste balsamic.

Storax is insoluble in water; between 60 and 70 per cent is soluble in warm alcohol, and the residue on evaporation of the alcoholic solution is almost completely soluble in ether, carbon disulphide, or benzol, but insoluble in benzin; the portion undissolved after thorough extraction with boiling alcohol should not be more than 
4 per cent. When boiled with a solution of potassium dichromate and sulphuric acid it evolves an odor resembling that of bitter almonds (due to the presence of cinnamic acid); it forms little or no foam when mixed with an equal volume of alcohol and shaken with ammonia water, indicating the absence of turpentine and fixed oils.

Constituents.-Storax consists of about 50 per cent of two resin alcohols, $\alpha$-storesin and $\beta$-storesin, which are partly free, partly in combination with cinnamic acid and partly with sodium. $\alpha$-storesin $(\alpha$-storesinol) is an amorphous substance that is very sparingly soluble in water and forms a crystalline compound of potassium. $\beta$-storesin ( $\beta$-storesinol) occurs in white flakes which are somewhat soluble in water but do not form a crystalline compound of potassium. Storax also contains from 10 to 20 per cent of an ester consisting of cinnamic acid and storesin; from 5 to 10 per cent of cinnamyl or styryl cinnamate (styracin) which occurs in colorless, odorless and tasteless needles and which on hydrolysis yields cinnamic alcohol (styrone) and a salt of cinnamic acid; about 10 per cent of an odorless, viscid substance, phenyl-propyl cinnamate; from 2 to 3 per cent of phenyl ethylene (styrol or styrene), which occurs as a colorless liquid possessing the odor and pungent taste of storax; from 0.5 to 1 per cent of a volatile oil which is lævo-rotatory and consists of a hydrocarbon, styrene, about 0.4 per cent of an oxygenated compound (styrocamphene), and cinnamates of ethyl, benzyl, phenylpropyl and cinnamic alcohols; from 2 to 5 per cent of free cinnamic acid; a small quantity of iso-cinnamic acid which occurs in colorless crystals; a crystallizable substance, styrogenin; about 0.15 per cent of vanillin; a trace of benzoic acid; ethyl vanillin; resin, and caoutchouc. Storax sometimes yields more than 20 per cent of free cinnamic acid and is the best available source of this substance.

Allied Plants.-Liquidambar Styraciflua, a tree indigenous to the eastern and southern United States and Mexico, yields the American storax, which occurs as a yellowish-brown, semi-liquid mass somewhat resembling Levant storax. It probably contains related storesins (storesinols), which appear to form similar combinations with cinnamic acid. On distillation of the fresh balsam about 7 per cent of a volatile oil is obtained, which is dextrorotatory and contains styrol and a body with the odor of oil of turpentine, the cinnamyl-ethyl-ester and cinnamyl-benzyl-ester being wanting. It also contains phenyl-propyl-cinnamate, styracin, styrol, free cinnamic acid and vanillin. On account of the scarcity of Levant styrax, the American product has attracted considerable attention. It contains 28 per cent of cinnamic acid, 22.86 per cent of cinna- 
mene, 34.76 per cent of resin esters and 2 per cent of resin acids. (Jordan, Amer. Jour. Pharm., 1917, 89, p. 581.)

Styrax is also obtained from Altingia excelsa, of the Indian Archipelago. It yields a soft, white, crystalline balsam developing the fragrant odor of styrol and contains about 50 per cent of an ester of cinnamic acid. A brown solid balsam is also obtained from this tree. It has an odor of cinnamon and contains a trace of free cinnamic acid and 9.7 per cent of cinnamic acid in the form of an ester. The oil from this plant is known as "Rasamala wood oil," and contains a ketone.

Literature.-Van Itallié and Lemkes, Bot. Abstracts, 1918, I, p. 179.

\section{ROSACEA, OR ROSE FAMILY}

A family of about 1200 species of great diversity of form. With the exception of the flowers, there are no constant morphological characters. The flowers are regular and with numerous stamens. The tracheæ usually have bordered pores and occasionally scalariform perforations. The wood fibers possess bordered pores and are of the tracheid type. In the woody species the pericycle is composed of either isolated groups of bast fibers, or a composite and continuous sclerenchymatous ring, being composed in part in some instances of U-shaped stone cells. Calcium oxalate occurs in the form of solitary crystals or rosette aggregates, and with the exception of Quillaja styloids are not present. The secretion cells contain either tannin or mucilage. Lysigenous mucilage canals have only been found in Neurada. Gummosis of the parenchyma cells of the cortex and wood is characteristic of many of the species of Prunus. The gum exudes spontaneously through rifts or channels in the bark as the result of the pressure of the gum and collects upon the outer surface in the form of irregular tears. Both glandular and nonglandular hairs are very common to the epidermal tissues of the plants of this family.

Amygdala Amara.-Bitter Almond.-The ripe sead of Prunus Amygdalus amara (Fam. Rosacex), a tree native of Asia Minor, Persia and Syria, cultivated and naturalized in all tropical and warm-temperate regions. The commercial product is obtained mostly from Sicily, southern France, southern Italy and northern Africa. In commercial almonds the yellowish, more or less porous, fibrous and brittle endocarp is frequently present, and this should be removed (Fig. 131). 
Description.-Anatropous, ovate or oblong-lanceolate, flattened, more rounded on one margin, summit acute or beaked, chalazal end rounded or obliquely truncate, 20 to $30 \mathrm{~mm}$. in length, 11 to 17 $\mathrm{mm}$. in breadth, 7 to $9 \mathrm{~mm}$. in thickness; externally light brown, with numerous parallel veins extending from the chalaza to the micropyle, outer walls of epidermal cells modified to distinct papillæ, seed-coat thin, membranaceous, easily removed on soaking the seed in water, the raphe extending on the more rounded edge as a more or less distinct ridge from the hilum to or near the chalaza; fracture short; without reserve layers, embryo straight, whitish, hypocotyl conical, 2 to $3 \mathrm{~mm}$. in length, cotyledons plano-convex, sometimes
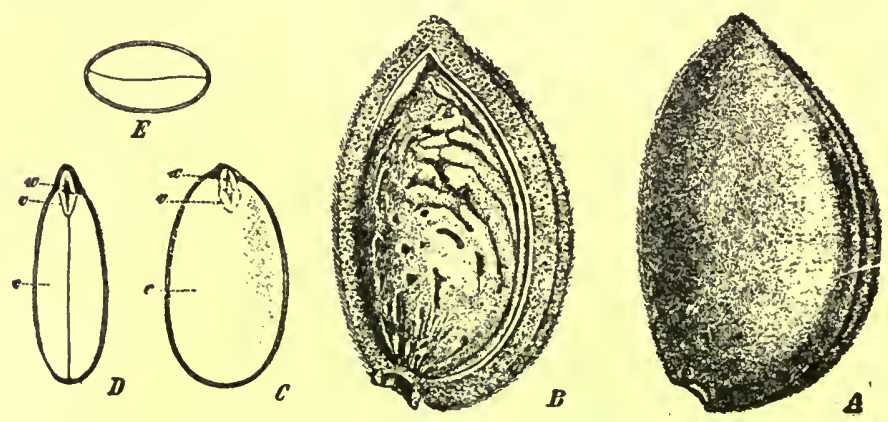

FIG. 131.-Drupe-like fruit of almond (Prunus Amygdalus): $A$, whole fruit with distinct suture; $B$, longitudinal section showing fibrous sarcocarp, and thinshelled endocarp; $C, D, E$, sections of the seed; $c$, cotyledons; $w$, hypocotyl; $v$, epicotyl or plumule.-After Focke.

slightly unequal, plumule $1 \mathrm{~mm}$. in length; odorless, except on treatment with water, when an odor of hydrocyanic acid is emitted, or of benzaldehyde when the seeds have been kept for some time; taste bitter.

Inner Structure.-See Figs. 132 and 133.

Constituents.-Fixed oil 45 per cent; proteins 25 to 30 per cent; a glucoside, amygdalin, 1 to 3 per cent; and a ferment, emulsin, which acts upon amygdalin, decomposing it into a volatile oil (benzaldehyde or oil of bitter almond) and hydrocyanic acid. In addition to the protein emulsin, there is another casein-like protein present, amandin, both of which act as emulsifying agents in the preparation of emulsion of almonds.

Amygdalin, or a similar principle, is found in the young shoots and flower-buds, as well as seeds, of apricot, peach, plum, cherry and cherry laurel. (See Wild Black-cherry Bark.) 


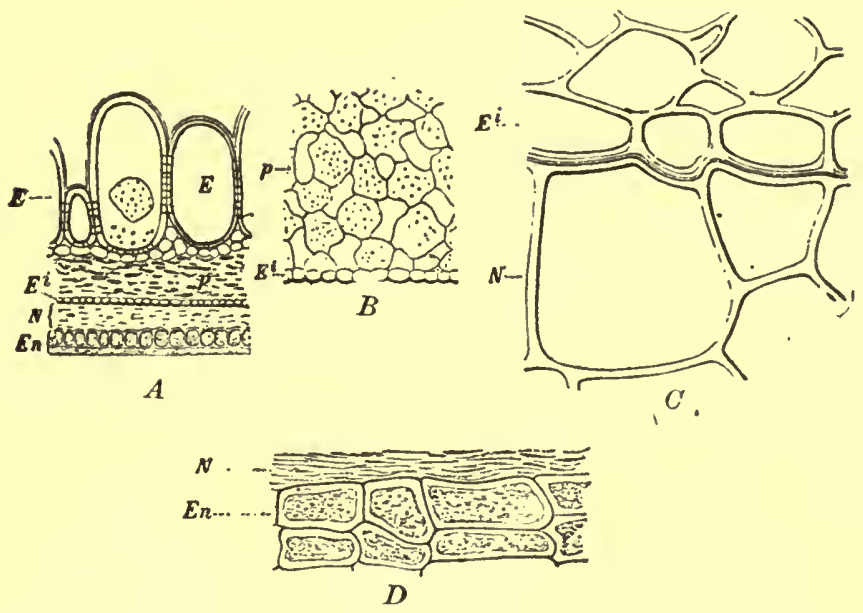

FIG. 132.-Sections of almond seed: $A$, cross-section of seed-coat treated with cold potassium hydrate solution and showing outer epidermis $(\boldsymbol{E})$, inner epidermis $(E i)$, between which is rather loose parenchyma $(p)$, tissues of nucellus $(N)$ and endosperm $(E n)$. $B$, parenchyma $(p)$ with large intercellular spaces and the inner epidermis of the seed-coat $(E i) . \quad C$, transverse section of inner epidermis $(E i)$ and the outer cells of the nucellus $(N) . D$, more or less obliterated cells of nucellus $(N)$ and two layers of the endosperm $(E n)$, which remain intact in the ripe seed.-After Meyer

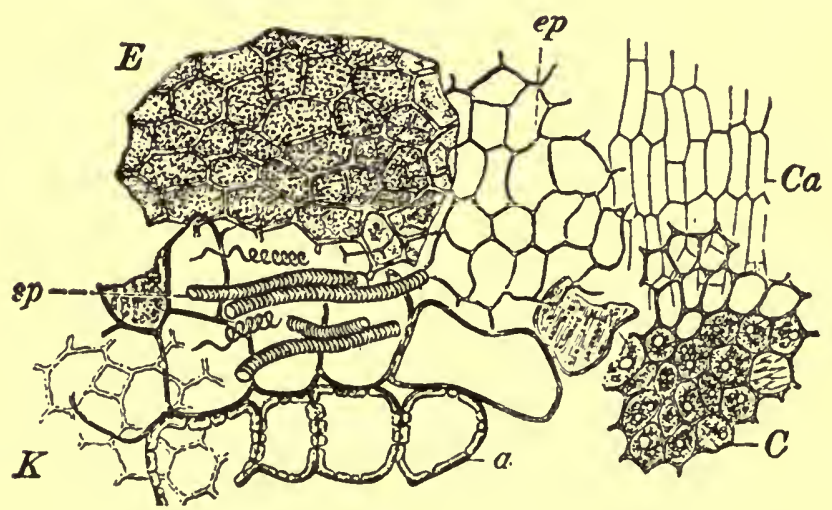

Fig. 133.-Almond meal: $a$, stone cells of the outer epidermis; $K$, brown hypodermal cells; $s p$, spiral tracheæ of the seed-coat; $e p$, cells of inner epidermis which contain a brownish content that is not shown here; $E$, cells of the endosperm containing numerous small aleurone grains; $C a$, epidermal cells of cotyledons; $C$, parenchyma of the cotyledons containing aleurone grains and oil.-After Moeller. 
Amygdala Dulcis.- Sweet Almond.-The ripe seeds of Prunus Amygdalus dulcis (Fam. Rosaceæ), a tree like the bitter almond but more extensively cultivated. The commercial supply is obtained from northern Africa, southern France, Italy and Spain, the choicest seeds being imported from Malaga and known as "Jordan almonds."

Description.-Closely resembling the Bitter Almond, but giving no odor of hydrocyanic acid when treated with water, or of benzaldehyde when old; taste bland and sweet.

Inner Structure.-(Fig. 132.) In both bitter almonds and sweet almonds the outer epidermal layer of the seed-coat is composed of characteristic, rectangular, somewhat rounded stone cells. The latter are from 0.070 to $0.175 \mathrm{~mm}$. in length and from 0.065 to 0.100 $\mathrm{mm}$. in width; the walls are from 0.010 to $0.015 \mathrm{~mm}$. in thickness and have numerous simple pores. The seed-coat also contains tracheæ with spiral thickenings, associated with which are cells containing rosette aggregates or prismatic crystals of calcium oxalate that are about $0.007 \mathrm{~mm}$. in diameter. The endosperm consists of a single layer of nearly cubical cells about $0.015 \mathrm{~mm}$. in diameter. The cells of the embryo contain numerous aleurone grains, which are from 0.005 to $0.015 \mathrm{~mm}$. in diameter and consist of crystalloids, globoids and calcium oxalate.

Powder.-Usually'sold under the name of Almond Meal and consists chiefly of the tissues of the embryo. It is yellowish-white in color and contains numerous fragments of parenchyma, containing oil globules and aleurone grains; also occasional fragments of seed-coat with characteristic, more or less scattered, large elliptical, thin-walled, strongly lignified epidermal cells and narrow, closely spiral tracheæ; numerous separated oil globules of different sizes and crystalloids, the latter occasionally with adhering globoids; few or no starch grains should be present. The so-called almond meal, which is used as a cleansing agent, consists of almond cake, a by-product in the manufacture of almond oil, to which are added other substances to give it a pleasant odor, as orris root (Fig. 47). A spurious almond meal consists of wheat middlings (Fig. 21) to which powdered soap and sufficient volatile oil or triple extract are added to perfume it.

Constituents.- Resembling bitter almond, but containing slightly more fixed oil (about 50 per cent), and being free from amygdalin.

Substitutes.-The seeds of other plants of the Rosaceæ are sometimes substituted for almond seeds. These usually have a bitter and more or less disagreeable taste; the outer epidermal cells in apricot and plum being tangentially elongated, while those of peach 
are somewhat narrower and more or less conical. For the distinguishing characteristics of these and other seed-coats, consult Fig. 134.

Literature.-Tschirch, Handbuch der Pharmakognosie, p. 605.

Prunus Virginiana.-Wild Black Cherry Bark.-The bark of the stem and branches of Prunus serotina Ehrhart (Syn. Prunus virginiana Miller) (Fam. Rosaceæ), a tree indigenous to the eastern and central United States and Canada. The bark is collected in
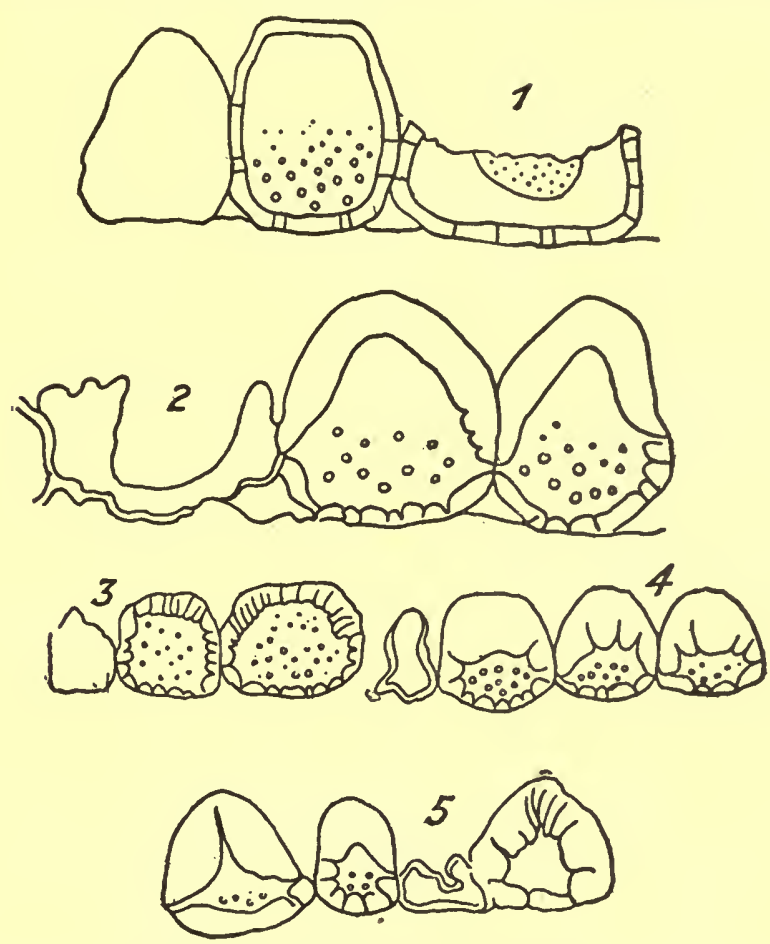

FIG. 134.-Epidermal cells of the seed-coat of: 1, almond; 2, peach; 3, apricot; 4, plum; 5, prune.-After Hanning.

autumn, and should be carefully dried and preserved in air-tight containers.

Description.-Usually in transversely curved pieces 2.5 to $8 \mathrm{~cm}$. in length, 1 to $5 \mathrm{~cm}$. in diameter, 0.5 to $4 \mathrm{~mm}$. in thickness; outer surface light brown or greenish-brown, somewhat glabrous, with numerous lenticels 3 to $4 \mathrm{~mm}$. in length; inner surface light brown, longitudinally striate and occasionally fissured; fracture short, granular; cork dark brown, thin, easily separable from the green phelloderm, inner bark porous and granular; odor of the drug dis- 
tinct, and on the addition of water developing an odor of benzaldehyde and hydrocyanic acid; taste astringent, aromatic.

The bark of the trunk is dark brown and rough externally.'

Inner Structure.-See Fig. 135.
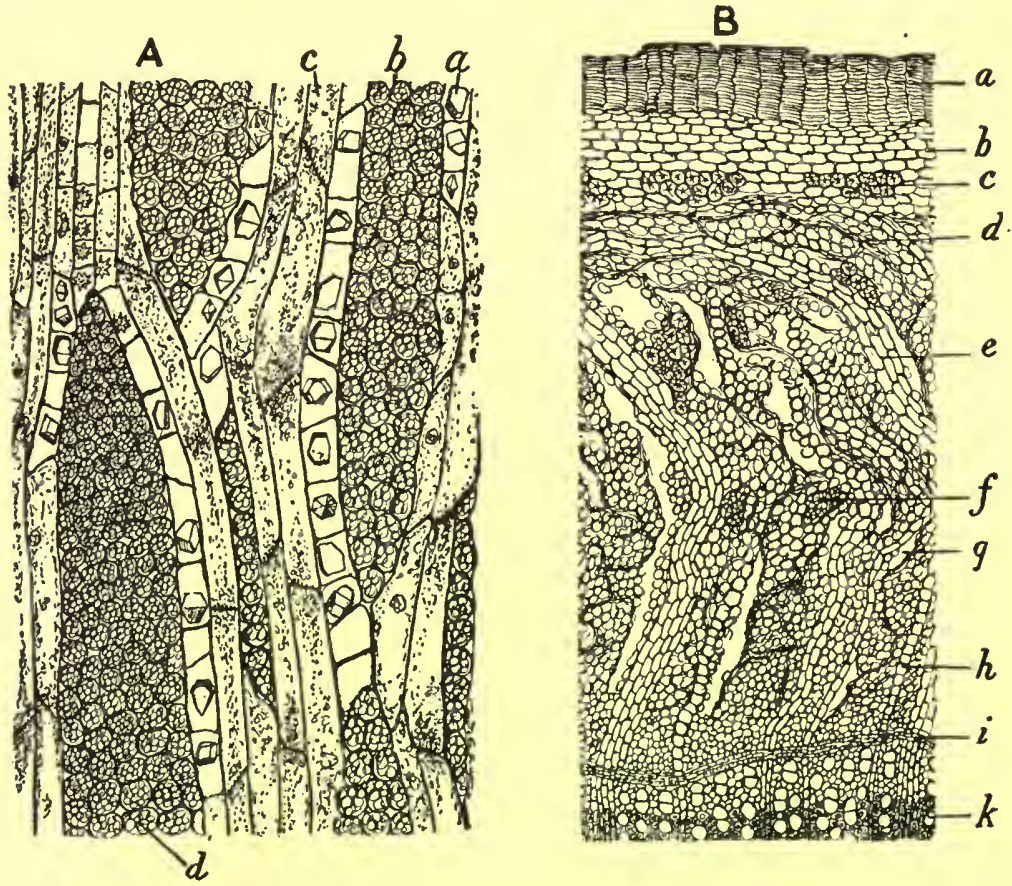

Fig. 135.-Prunus serotina Ehrhart: $A$, longitudinal section of inner bark, showing crystals of calcium oxalate $(a)$, medullary ray cells containing starch $(b$ and $d$ ), and leptome or sieve $(c)$. $B$, transverse section of stem bark showing cork, probably secondary periderm $(a)$ cells of cortex $(b)$ containing chloroplasts, groups of sclerotic cells $(c)$, compressed leptome in the outer portion of the bast layer $(d)$, medullary ray cells $(e)$, group of sclerotic cells $(f)$, fissures $(g)$ between medullary ray cells and adjacent phloem tissues, cambium zone $(i)$, vessel or trachea in mature wood $(k)$.-After Bastin.

Powder.-Light brown; bast fibers and stone cells with much thickened and strongly lignified walls; crystal fibers containing monoclinic prisms and rosette aggregates of calcium oxalate from 0.020 to $0.040 \mathrm{~mm}$. in diameter; starch grains nearly spheroidal about $0.003 \mathrm{~mm}$. in diameter.

Constituents.-A cyanogenetic glucoside, identified by Power and Moore as l-mandelonitrile glucoside, a compound which has been 
prepared by Fischer by the partial hydrolysis of amygdalin and is isomeric with sambunigrin (d-mandelonitrile glucoside) from the leaves of Sambucus nigra and prulaurasin (di-mandelonitrile glucoside) from the leaves of Prunus laurocerasus. It also contains a ferment resembling emulsin; $\beta$-methylæsculetin (methyl ether of di-hydroxy-coumarin) which probably occurs in combination as a crystalline glucoside, the solutions giving a blue fluorescence; 9. phytosterol; l-mandelic acid, oleic acid; p-coumaric acid; trimethyl-gallic acid; ipuranol; dextrose; sugar; tannin 2.5 to 4.5 per cent; starch and calcium oxalate. The yield of hydrocyanic acid varies from 0.23 to 0.32 per cent (inner bark) to 0.03 per cent (trunk bark) and varies even in the bark of the same thickness from the same tree. When the exposure is such that the chloroplastids are abundant in the cells of the bark, then the percentage of the l-mandelonitrile glucoside is higher, whereas when the exposure is such that the cells do not take an active part in photosynthesis the percentage, of the glucoside is lower. In the latter case the bark is yellowish-brown. Nichols found from 3.19 to 3.70 per cent amygdalin in bark on north side of trees and 2.60 to 2.97 per cent in bark on south side of trees. On keeping the bark for a year it deteriorates from 10 to 50 per cent.

The bark of Prunus pseudo-cerasus var. Sieboldi of Japan contains a glucoside (sakuranin) which crystallizes in needles and is soluble in dilute alcohol, the solution being colored yellow with ferric chloride.

Adulterants.- It is likely that the barks of other species of Prunus are now entering the market. They are more astringent and less aromatic.

Allied Plants.-The leaves of the Cherry laurel (Prunus LauroCerasus) are used in the fresh condition. They are oblong or oblonglanceolate, about $15 \mathrm{~cm}$. in length, sharply serrate, coriaceous, with an almond-like odor on being bruised and an aromatic, bitter taste. They contain about 1.3 per cent of a glucoside laurocerasin, which is associated with amygdalic acid; a ferment emulsin, which acts on the laurocerasin, causing it to be more slowly decomposed than amygdalin and yielding but half as much hydrocyanic acid (about 0.12 per cent) and benzaldehyde (about 0.5 per cent). The leaves also contain a crystalline principle, phyllic acid, which is insoluble in water, soluble in alcohol and occurs in the leaves of almond, peach and apple. A glucoside resembling laurocerasin is found in the leaves of Sambucus nigra.

The leaves of the Peach (Persica vulgaris), which is extensively 
cultivated for its fruit, contain about 3 per cent of amygdalin (see Almond).

The fruit of Prunus serotina consist of small, black drupes, which when ripe are sweet, slightly acid and astringent. They are used in making a wine and might be employed in other preparations of wild cherry.

Literature.-Bastin, Amer. Jour. Pharm., 1895, pp. 435 and 595; Stevens, Proc. A. Ph. A., 1896, p. 215; Ibid., 1899, p. 184; Ibid., 1900, p. 207; Power and Moore, Trans. Jour. Chem. Soc., 1909, p. 243; Nichols, Jour. A. Ph. A., 1917, 6, p. 540.

RuBus.-Blackberry Bark.-The bark of the rhizome of the perennial shrubs Rubus villosus, $R$. nigrobaccus and $R$. cuneifolius (Fam. Rosacæ). R. villosus occurs in dry fields from Canada to Virginia and as far west as Kansas. R. allegheniensis (R. nigrobaccus) or common blackberry occurs in woods in the eastern and central United States and extensively cultivated. R. cuneifolius is the sand blackberry and is found in sandy woods from New York to Florida and west to Missouri and Louisiana. The bark should be collected in spring or autumn and dried.

Description.-In flexible, transversely curved or slightly quilled pieces 4 to $20 \mathrm{~cm}$. in length, 3 to $5 \mathrm{~mm}$. in diameter, bark 0.2 to $2 \mathrm{~mm}$. in thickness; outer surface light brown, longitudinally wrinkled, with few root-scars, periderm frequently exfoliated; inner surface light brown, coarsely longitudinally striate; fracture short, fibrous, surface light brown, with oblique radiate wedges of bast; odor slight; taste astringent.

Inner Structure.-The capillary lateral roots possess a thin epidermis with numerous hairs; a homogeneous cortex and an endodermis of thin-walled cells; a pericambium; a stele that is triarch and minus a pith. In primary roots the pericambium gives rise to several layers of cork, which replace the peripheral tissues from endodermis to epidermis; a secondary cortex consisting of starch-bearing parenchyma; the stele consists of a compact mass of porous tracheids, thick-walled parenchyma and a few wood fibers, separated by a cambial layer from the leptome, which consists of several strands of sieve and thin-walled parenchyma. In thick roots a stereome, in the form of isolated strands, occurs between the parenchyma of the secondary cortex and cork. Rosette aggregates of calcium oxalate occur in the secondary cortical parenchyma.-Holm, Merck's Report, 1910, p. 218.

Powder.-Light brown; bast fibers numerous, long, thick-walled, lignified; calcium oxalate in rosette aggregates from 0.025 to 0.035 
$\mathrm{mm}$. in diameter; starch grains nearly spheroidal from 0.003 to 0.010 $\mathrm{mm}$. in diameter, occurring either singly or compound.

Constituents.-Tannin 10 to 20 per cent; gallic acid about 0.4 per cent; a bitter, crystalline glucoside villosin, somewhat resembling saponin, about 0.8 per cent; starch; calcium oxalate; ash about 3 per cent.

Allied Plants.-Blackberries (the fruits of R. nigrobaccus, $R$. nigrobaccus sativus and $R$. villosus), Red Raspberries (the fruit of R. Idæus, a plant native to the Old World), Black Raspberries (the fruit of R. occidentalis, native of the northern United States) and Strawberries (the fruits of cultivated varieties of Fragaria chilœensis, $F$. vesca and $F$. virginiana) all contain about 2 per cent of malic and citric acids, 4 per cent of levulose, about 4 per cent of pectin substances and a small amount of volatile oil to which their distinctive flavors are due. Blackberries contain in addition considerable tannin and the wine made therefrom is valued in addition for its astringency.

QuillajA.- Soap Bark.-The bark of Quillaja Saponaria (Fam. Rosaceæ), a large tree indigenous to Chile and Peru. The bark is removed in large pieces, deprived of the periderm and dried.

Description.-In flat pieces 25 to $90 \mathrm{~cm}$. in length, 10 to $15 \mathrm{~cm}$. in width, 4 to $6 \mathrm{~mm}$. in thickness; outer surface light brown, longitudinally striate, with numerous crystals of calcium oxalate and occasional patches of the dark-brown periderm; inner surface yellowishbrown, finely wrinkled, with numerous crystals of calcium oxalate, and occasional circular depressions, conical projections or transverse channels; fracture uneven, coarsely fibrous, surface porous and with groups of light yellow sclerenchymatous fibers; odor slight; taste acrid.

Inner Structure.-Consisting only of the tissues of the secondary cortex, i.e., inner bark; radial rows of groups of bast fibers, the latter having strongly thickened walls, of irregular contour and with branching ends. Crystal fibers, containing monoclinic prisms of calcium oxalate surround the groups of bast fibers; the sieve tubes have simple horizontal walls with distinct sieve plates; starch-bearing parenchyma and crystal cells each containing long prisms, from 0.060 to $0.200 \mathrm{~mm}$. in length.

Powder.-(Fig. 136.) Pinkish-white; very sternutatory; calcium oxalate in elongated prisms from 0.035 to $0.200 \mathrm{~mm}$. in length; bast fibers numerous, thick-walled, strongly lignified; crystal fibers containing elongated prisms of calcium oxalate; stone cells more or 
less thick-walled and with simple, oblique pores; starch grains nearly spheroidal, from 0.003 to $0.010 \mathrm{~mm}$. in diameter.

Constituents.-The drug contains two amorphous glucosides amounting to about 9 per cent, which are closely related to saponinone soluble in alcohol and known as quillajic acid, and the other nearly insoluble in alcohol and known as quillajasapotoxin; it also contains starch and about 10 per cent of calcium oxalate.

Substitutes.-A spurious Quillaja is being offered at the present time. The bark yields less saponin, is more brittle than the genuine bark and is covered with a thin, brownish layer.

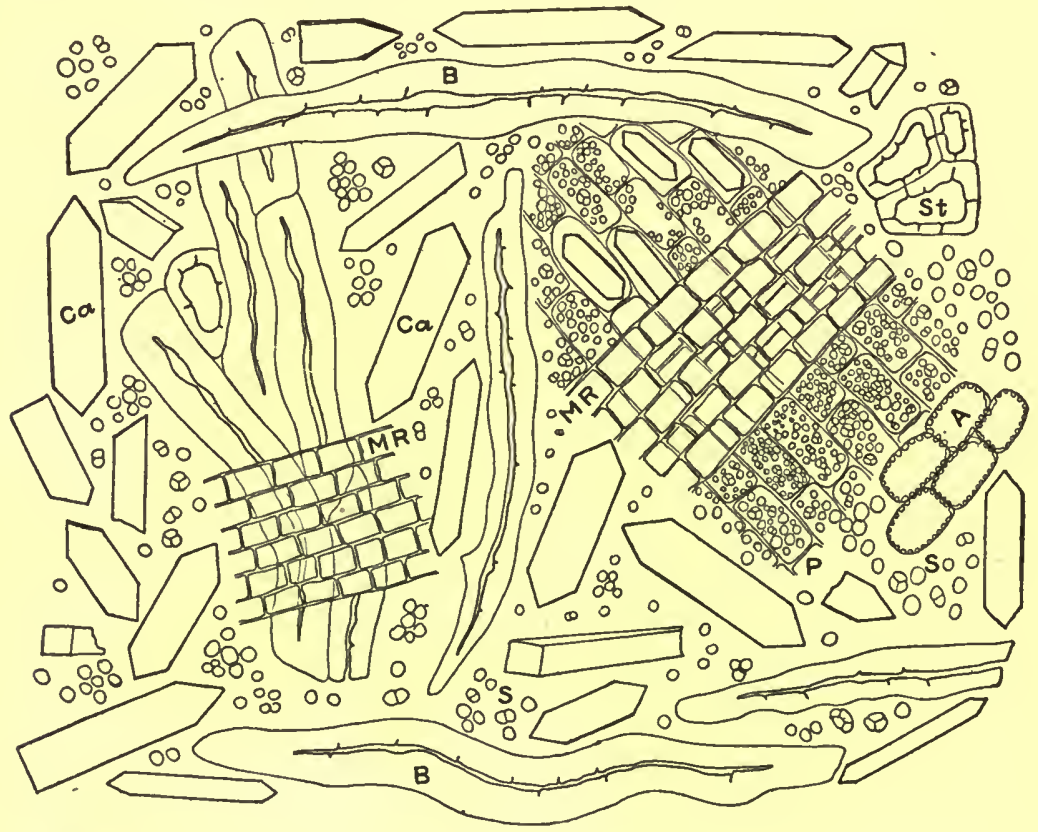

Fig. 136.-Soap bark: $C a$, pyramids of calcium oxalate; $B$, bast fibers; $S t$, stone cells; $S$, starch grains; $P$, parenchyma containing starch and calcium oxalate; $M R$, medullary rays; $A$, parenchyma with simple pores.

Cusso.-Kousso, Brayera.-The pistillate flowers of Hagenia abyssinica (Fam. Rosaceæ), a tree indigenous to northeastern Africa, and cultivated in Abyssinia. The entire panicles are collected soon after pollination and dried in the sun; the flowers are sometimes stripped from the panicles, or the panicles are made into rolls.

Description.-(Fig. 137.) In more or less cylindrical rolls about $30 \mathrm{~cm}$. in length and about $5 \mathrm{~cm}$. in diameter; branches cylindrical, 
flattened, about $3 \mathrm{~mm}$. in diameter, longitudinally furrowed or wrinkled, internodes about $15 \mathrm{~mm}$. in length, externally light brown, tomentose, glandular, internally, cork yellowish-brown, fibrovascular bundles in distinct wedges, bast and wood fibers yellow, distinct, pith large, yellowish-brown; flowers subtended by two ovate, reddish, pubescent and glandular bracts, pedicel short, calyx tur-

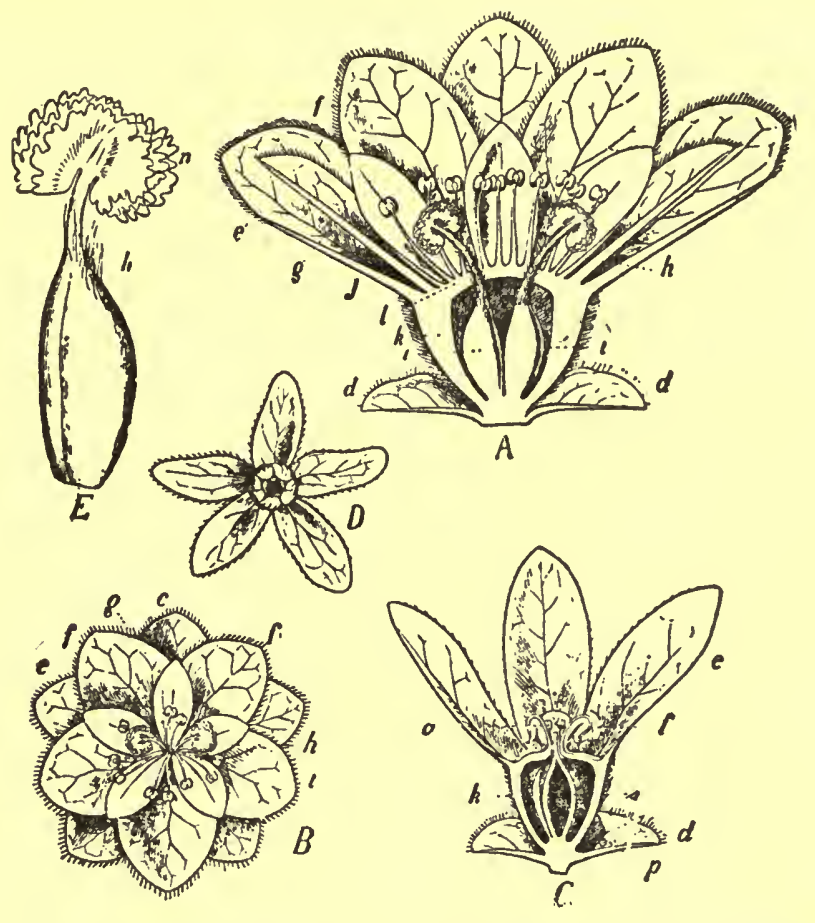

FIG. 137.-Cusso: $A$, longitudinal section through an expanded pistillate flower showing bracts $(d)$, outer series of sepals $(e)$, inner series of sepals $(f)$, petals $(g)$, perianth tube $(k)$, sterile stamens $(h)$, pistil $(i)$. $B$, mature flower viewed from above and showing the relation of sepals and petals. $C$, flower; just before the maturing of the fruit showing pericarp $(p)$, seed $(s) . D$, mature pistillate flower as seen from above. $E$, pistil showing cylindrical ovary, slender style with hairs $(h)$ and large, slightly lobed stigma.-After Meyer.

binate, pubescent below, consisting of two alternate whrols of four of five obovate or oblanceolate sepals, the outer ones 10 to $12 \mathrm{~mm}$. in length, obtuse, entire, purplish veined, persistent and becoming much elongated in the fruit, the inner about 3 to $4 \mathrm{~mm}$. in length, becoming shriveled and bent over the young fruit; carpels two, ovary about 1 
$\mathrm{mm}$. in length, the upper portion very pubescent, styles exserted, about as long as the ovary, stigma large, compressed, with prominent papillæ; fruit an ovoid achene, about $2 \mathrm{~mm}$. in diameter, inclosed by the remains of the calyx; odor slight; taste bitter and acrid.

Powder.-Light brown; calcium oxalate in rosette aggregates, about $0.020 \mathrm{~mm}$. in diameter; non-glandular hairs 1-celled, curved, thick-walled, 0.2 to $0.5 \mathrm{~mm}$. in length; glandular hairs with 2- or 3-celled stalk, glandular head unicellular or consisting of one or two pairs of cells; tracheæ spiral, scalariform, or with bordered pores; sclerenchymatous fibers long, thick-walled, strongly lignified, with numerous simple oblique pores; parenchyma of pith more or less lignified and with simple pores; pollen grains few, somewhat ellipsoidal, 0.025 to $0.040 \mathrm{~mm}$. in diameter, with three pores.

Constituents.-The active principle appears to be an amorphous substance cosotoxin; several other principles have been isolated, but their real nature and properties have not been fully deternined; the drug also contains about 3 per cent of an inactive crystalline principle, cosin (koussein or brayerin), which is bitter and acrid, and sparingly soluble in water but soluble in alcohol; a crystalline principle which on hydrolysis yields isobutyric acid; about 6 per cent of a resinous principle; volatile oil; tannin about 24 per cent, and about 5 per cent of ash.

Adulterants.-Sometimes the flowers are stripped from the panicles and sold as such, when the drug is known as "loose cusso." In this condition they are likely to be admixed with the staminate flowers, which, with their numerous stamens, are readily distinguishable and are inferior in quality.

Rosa Galdica.-Red Rose.-The petals of Rosa gallica (Fam. Rosaceæ), a shrub indigenous to southern Europe and probably western Asia, and extensively cultivated in all parts of the world. The petals are obtained from cultivated plants before the expansion of the flower, the lower clawed portion usually being removed; they are used fresh or are carefully dried and preserved. The chief supply of the drug is from the southern portion of France.

Description.-Imbricated, numerous, usually in small cones; petals broadly ovate, the upper part rose-colored and retuse, the lower part brownish-red, more or less rounded, acute or truncate, with numerous papillæ and fine longitudinal veins; texture velvety; odor agreeable; taste astringent and slightly bitter.

Inner Structure.-(Fig. 138.) The upper epidermal cells modified to conical papillæ and containing a purplish-red cell sap, a loose mesophyll composed of 2 to 10 rows of cells, in among which are the 

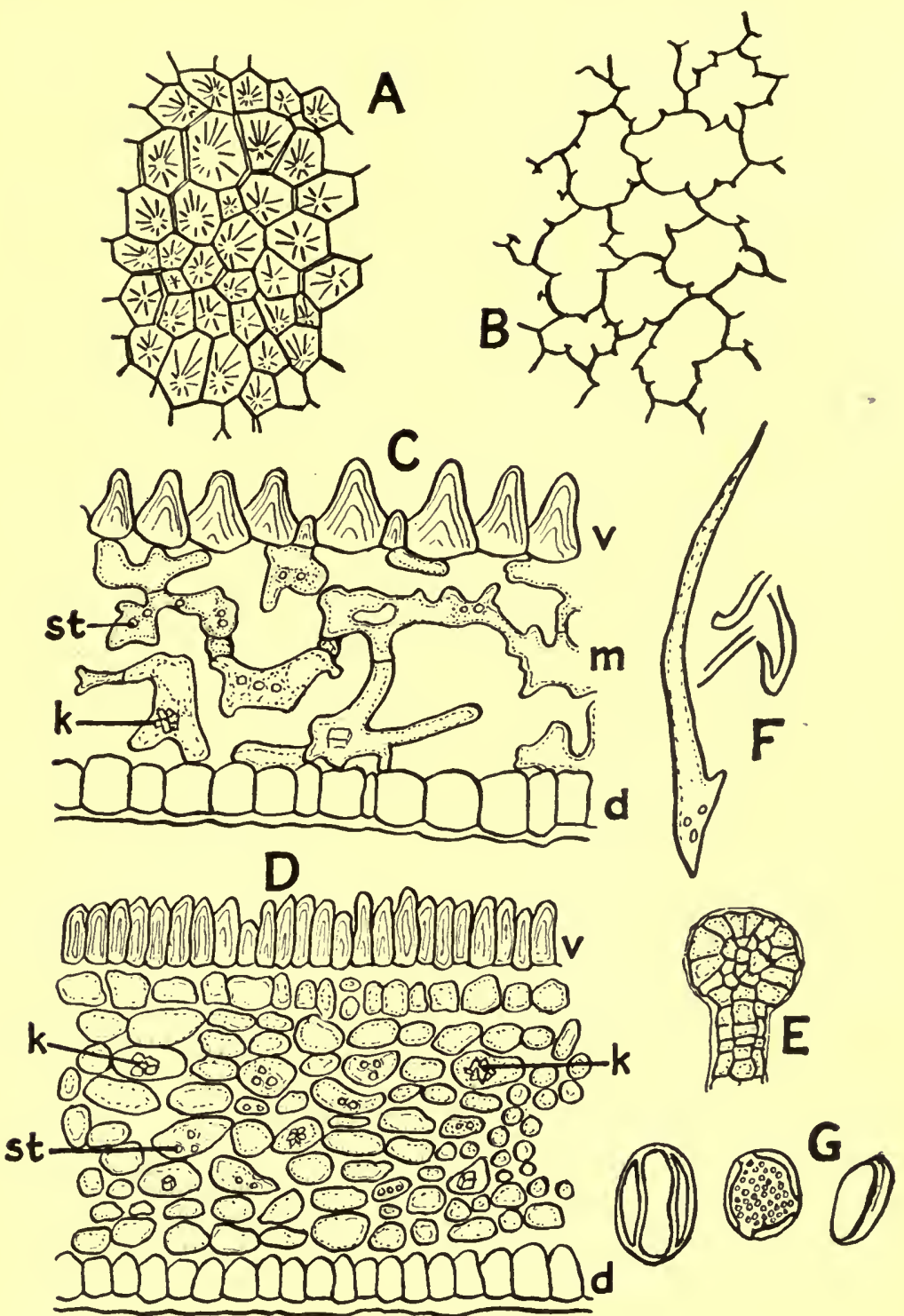

Fig. 138.-Rosa Gallica: $A$, surface view of the ventral or upper surface of petal, showing polygonal cells, the radiating line indicating the folds formed by the papillæ. $B$, surface view of cells on the dorsal or lower surface of the petal with inner projections being sometimes of a T-shape. $C$, cross-section from the middle of the petal, showing the upper epidermal cells with papillæ $(v)$, loose mesophyll cells $(m)$, some of which contain small crystals of calcium oxalate $(k)$ and starch grains $(s t)$; and cells of lower epidermis in which the 
fibrovascular bundles with spiral tracheæ, and a lower epidermis of rectangular cells filled with a purplish-red cell sap.

Constituents.-Volatile oil in a small amount; a yellow, crystalline glucoside quercitrin, which yields, on decomposition, quercetin; tannin and gallic acids. The coloring principle is soluble in water and alcohol and gives a deep yellowish-red color with acids; a green color changing to brown with alkalies; purple or violet with potassium alum or iodin solutions; and a deep blue with ferrous or ferric salts.

Allied Plants.-The petals of Rosa centifolia are collected after the expansion of the flowers and dried; they are brownish and not so fragrant as those of Rosa gallica. The flowers of cultivated plants of Rosa damascena yield the commercial volatile oil of rose.

Roses Canine Fructus.-Rose Hips.-The fresh fruits of Rosa canina and other allied species of Rosa (Fam. Rosacex), a shrub common throughout Europe and the British Isles.

Description.-Ovoid, from 15 to $20 \mathrm{~mm}$. in length, externally, of a red or scarlet color, smooth and shiny, and having at the summit the 5 calyx-teeth, beyond which project the hairy appendages of the achenes; pericarp of a fleshy texture, becoming on maturity, especially after frost, soft and pulpy, the pulp of the sarcocarp being of an orange color and an agreeable, acidulous taste; the hollow receptacle bears on its inner surface numerous small, hard achenes, which, as well as the walls of the former, are covered with unicellular, thickwalled hairs.

Powder.-Dark brownish-red; non-glandular hairs of torus unicellular, from 0.5 to $2 \mathrm{~mm}$. in length, about $0.035 \mathrm{~mm}$. in width, gradually tapering toward the base as well as the summit, having very thick walls and narrow lumina; parenchyma cells with brownish-red masses of plastids; calcium oxalate crystals in rosette aggregates from 0.035 to $0.050 \mathrm{~mm}$. in diameter; sclerenchymatous cells and fibers of seed-coat with colorless, rather thick walls and numerous simple and branching pores; an inner epidermis of elongated cells containing a brown pigment; the cells of the embryo with small, nearly spheroidal aleurone grains and considerable oil.

papillæ are wanting. $D$, transverse section through the base of a petal, the letters as in $C$. Fragments found in the powder show in addition to the cellular elements of the petals, a glandular hair $(E)$ and non-glandular hairs $(F)$ which occur on the stems and sepals; and pollen grains $(G)$.Re-drawn by Haase from plates of Hans Kramer, in Ber. d. d. pharm. Ges., 1907, p. 354 . 
Constituents.-Citric acid, 3 per cent; malic acid, 8 per cent; mucilage, 25 per cent; an uncrystallizable sugar, 30 per cent; also citrates, malates and mineral salts.

Cydonium.-Semen Cydoniæ, Quince Seed.-The ripe seeds of Cydonia vulgaris (Fam. Rosaceæ), a shrub indigenous to southwestern Asia and extensively cultivated. The fruits are gathered in the fall when they are ripe, the seeds removed and dried. The commercial supplies come chiefly from southern Russia and Portugal.

Description.--Single or in agglutinated masses; the individual seeds being somewhat ovoid and compressed, with 2 or more sharp ridges, convex on one side and flattened or somewhat shallow on the other, from 5 to $10 \mathrm{~mm}$. in length and from 2 to $6 \mathrm{~mm}$. in breadth; outer surface reddish-brown or brownish-violet, more or less covered with adhering grayish gum; fracture short; inner surface showing a large yellowish-white embryo and a thin, reddishbrown seed-coat, which is easily separated by placing the seeds in water; inodorous; taste mucilaginous, slightly aromatic, similar to that of benzaldehyde.

Inner Structure.-A mucilaginous epidermal layer, the cells being tangentially elongated and upon the addition of water swelling to such an extent as to separate the thin cuticle from the rest of the wall; several rows of thick-walled sclerenchymatous fibers, having a brownish-red, amorphous content; a layer of colorless, thin-walled cells; inner epidermis of somewhat tubular cells having a brown amorphous content; an endosperm composed of 5 to 7 layers of polyhedral cells; cotyledons of thin-walled cells, containing an oily cytoplasm and numerous aleurone grains, the latter from 0.006 to $0.028 \mathrm{~mm}$. in diameter. Starch occurs only in the unripe seeds.

Powder.-Yellowish-red or reddish-brown; fragments of seedcoat with polygonal, mucilaginous epidermal cells, the walls of which are readily stained with methylene blue; a number of rows of sclerenchymatous fibers with strongly thickened walls and brown contents; several layers of elongated, thin-walled cells resembling the "tube cells" in cereals; a colorless layer with minute starch grains; and an inner epidermis, the cells of which contain a brown pigment. The perisperm consists of several layers of more or less obliterated cells. The outer layers of the endosperm, as well as the cells of the embryo, contain aleurone grains and a fixed oil.

Constituents.-Mucilage, 22 per cent, yielding on hydrolysis oxalic acid, and forming arabinose, on treatment with dilute sulphuric acid. It is distinguished from cherry gum and the mucilages of other Mimoseæ in being precipitated upon the addition of creosote 
water. Upon macerating $1 \mathrm{gm}$. of cydonium with 50 parts of water, it should yield a thick, transparent jelly.

The seeds also contain 15 per cent of a fixed oil, amygdalin, emulsin, tannic acid, a coloring principle, and 13 per cent of ash, nearly half of the latter being combined with phosphoric acid.

Adulterants.-Apple and pear seeds are sometimes substituted. They are readily identified by being ovoid, flattened, acute and pointed at the base, of a uniformly dark brown color and not whitish; and having a smooth, shiny outer surface which is not mucilaginous.

Prunum.-Prune.-The fruit of Prunus domestica, and of the var. Juliana (Fam. Rosaceæ), a small tree indigenous to southern Europe, and largely cultivated in southern France, Germany, Asia Minor and California, but not found growing wild. The fruit is collected when ripe and partially dried by artificial means, or completely dried in the sun. The fruit exported from Bordeaux is of superior quality.

Description.-Drupe superior, fleshy, ellipsoidal, more or less compressed, 3.5 to $4 \mathrm{~cm}$. in length, about $3 \mathrm{~cm}$. in breadth; externally brownish-black, glabrous, wrinkled, with two faint lines indicating the dorsal and ventral sutures, summit with a slight scar from the remains of the style, base with a depressed stalk-scar 3 to $5 \mathrm{~mm}$. in diameter, sarcocarp yellowish-brown, fleshy, somewhat stringy, $1.5 \mathrm{~cm}$. in thickness; taste sweet and acidulous; endocarp ellipsoidal. flattened, about $2 \mathrm{~mm}$. in thickness, externally dark brown, reticulate, with a groove on one side, frequently extending nearly around the edge, internally light brown, smooth, 1-locular, 1-seeded, occasionally 2-seeded; seed about $2 \mathrm{~cm}$. in length, $8 \mathrm{~mm}$. in width, $5 \mathrm{~mm}$. in thickness, closely resembling Bitter Almond (see Amygdala Amara).

Constituents.-Sugar 25 to 44 per cent; organic acids, as malic and tartaric, partly free and partly combined, chiefly with potassium, about 2 per cent, and water about 30 per cent.

ToRmentilla.-Rhizoma Tormentillæ, Tormentill.-The rhizome of Potentilla silvestris (Tormentilla erecta), a common plant, belonging to the Rosacer and indigenous to central and northern Europe and northern Asia. In the spring the rhizome is collected from wild plants and dried.

Description.-Cylindrical, somewhat fusiform, branching and more or less curved; from 2.5 to $8 \mathrm{~cm}$. in length and from 0.5 to 1.5 $\mathrm{cm}$. in thickness; outer surface dark reddish- or blackish-brown, longitudinally wrinkled, with numerous stem-scars and root-scars and bearing at the summit of the upper portion, young buds and their bud scales; fracture mealy and somewhat horny, in older pieces more 
or less resinous; inner surface dark red or reddish-brown, with one or two circles of collateral fibrovascular bundles separated by broad medullary rays, pith large; odor slight; taste strongly astringent.

Inner Structure.-A thick stratum of reddish-brown cork cells; the cortical parenchyma, containing either starch, resin or tannin, the walls being colored reddish-brown; fibrovascular bundles in two circles $(a)$, those near the cambium ring having on the exterior small groups of collapsed sieve cells surrounded by parenchyma having lattice-like thickenings of the wall; and $(b)$, an inner circle of bundles composed of whitish wood wedges separated by broad parenchymalike medullary rays; wood wedges composed of porous tracheæ and wood fibers, among which are distributed the wood parenchyma containing a reddish-brown amorphous tannin content: pith composed of starch-bearing, nearly isodiametric parenchyma cells containing rosette aggregates of calcium oxalate. In young rhizomes starch grains preponderate, being replaced in older and more fleshy rhizomes by resin.

Constituents.-Tannic acid from 18 to 30 per cent; tormentilla red, a product of decomposition of the tannin; ellagic acid, a trace of volatile oil and a resin.

\section{LEGUMINOSA, OR PULSE FAMIIY}

The second largest family of plants, comprising almost 8000 species. They are widely distributed and are most numerous in the tropical and sub-tropical regions. They exhibit a great range of habit from creeping annual herbs to climbing shrubs, and vary from delicate herbs to very tall trees. They are characterized by alternate, stipulate, usually compound leaves; papilionaceous or sometimes regular flowers, having usually monadelphous or diadelphous stamens, and a single free pistil, becoming in fruit a legume. It is by reason of the latter feature that the family receives its name.

As to be expected in a large family like this, there are certain distinct morphological characters which admit of dividing it into smaller groups. This is done by some botanists and the groups given the rank of families. These are the following: 1, Papilionaceæ, those plants which produce irregular, papilionaceous flowers. They are also characterized in having calcium oxalate in the form of styloids or small rod-like crystals, being not infrequently inserted in the thickenings of the cell walls. Tannin-sacs, secretion cells, resin canals, lysigenous gum canals and other secretory cavities occur 
in the species of this group. About two-thirds of the Leguminosæ belong to this sub-division. 2, Cæsalpinaceæ, those plants in which the corollas are imperfectly or not at all papilionaceous and sometimes nearly regular. These plants contain in addition to solitary crystals, usually rosette aggregates of calcium oxalate. Tannin sacs are, as a rule, absent or only rudimentary in their development and do not appear as idioblasts. The hairs are of the unicellular type, and are entirely wanting in the Papilionaceæ. 3, Mimosaceæ, plants in which the flowers are small and regular; calcium oxalate occurs either in the form of rhombohedral crystals or styloids, only occasionally being embedded in the thickenings of the cell wall. Rosette aggregates have been observed in Mimosa and Piptadenia. Sacs corresponding to the tannin-sacs of the Papilionaceæ are common in the strands of leptome and the contents are very various. The cells are exceptionally large and the contents quite various, being either colorless or yellowish, and readily soluble in water or consisting of a mucilaginous substance containing resin and glucosidal substances. In some of the members of this family the walls of the cells of the pericycle, the leptome and wood undergo a metamorphosis into mucilage, which then exudes and collects in the form of tears upon the outside of the bark of the branches.

GLYCYRRHIZA.-Licorice Root.-The dried rhizome and root of Glycyrrhiza glabra, and the varieties typica and glandulifera, (Fam. Leguminosæ, sub-fam. Papilionaceæ), perennial herbs, found growing in the countries of the eastern Mediterranean region and southwestern Asia and cultivated in Spain, Russia, other parts of Europe, England and at one time, to a limited extent, in the United States. There are two principal commercial varieties: (1) Spanish Licorice, yielded by cultivated plants of G. glabra typica, and chiefly exported from Spain and southern France, and (2) Russian Licorice, obtained from wild plants of G. glabra glandulifera or G. echinata, growing in southern Russia. The latter consists chiefly of large roots deprived of the periderm, whereas the Spanish variety consists mostly of unpeeled rhizomes (Fig. 139).

Spanish (Italian) Licorice.-Nearly cylindrical, more or less tortuous, cut or broken into pieces 14 to $20 \mathrm{~cm}$. in length, 5 to $25 \mathrm{~mm}$. in diameter; crown knotty, externally dark brown, longitudinally wrinkled-or furrowed, with few rootlet-scars, rhizome with corky patches and numerous small conical buds; fracture coarsely fibrous; internally lemon-yellow, radiate, bark 1 to $3 \mathrm{~mm}$. in thickness, wood porous, rhizome with small pith; odor distinct; taste sweetish, slightly acrid. 
Inner Structure.-(Fig. 140.) A periderm of numerous layers of yellowish-brown cork cells; a phellogen and one or more rows of cells of the phelloderm, the cells showing a tendency to collenchymatous thickenings; primary cortex of starch-bearing parenchyma, with whitish groups of bast fibers surrounded by crystal fibers; secondary cortex or inner bark with a very characteristic, radial arrangement of phloem and medullary rays, the phloem consisting of wedges of small groups of bast fibers and parenchyma, separated

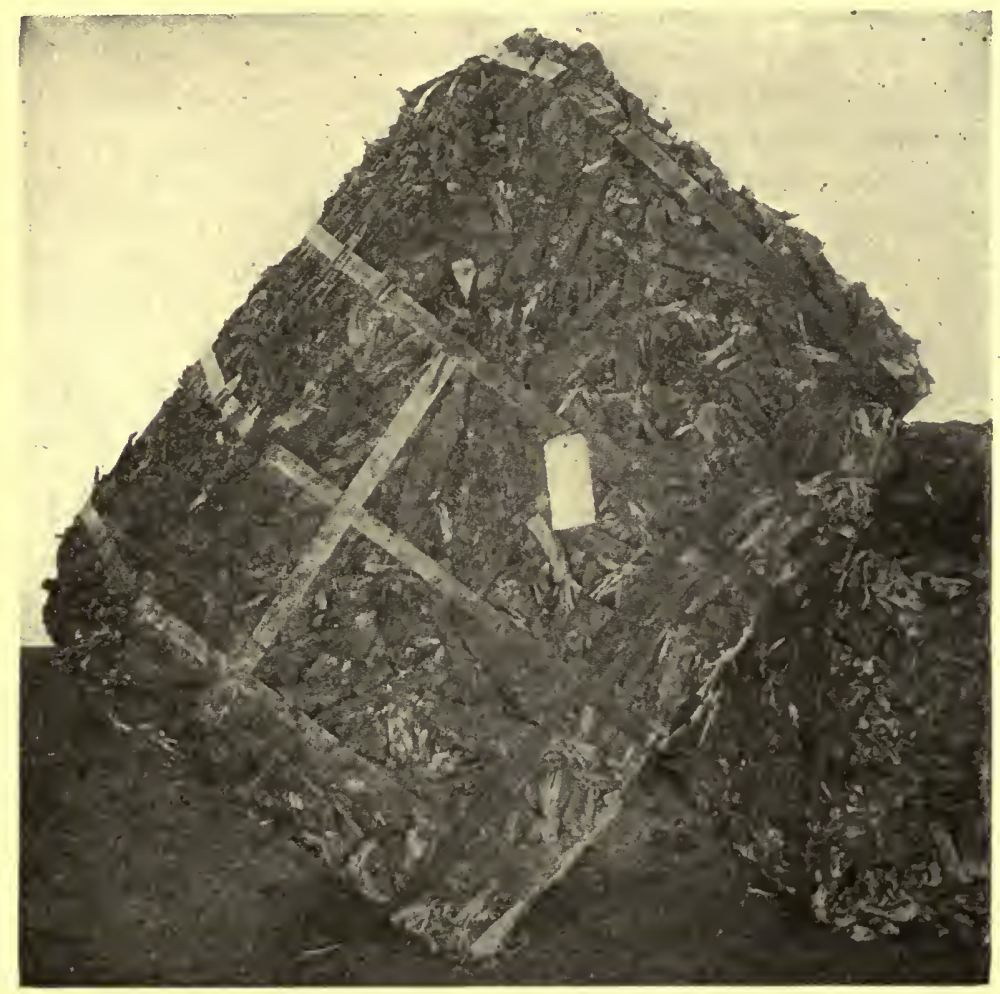

Frg. 139.-Original packages of Licorice Root (Glycyrrhiza) imported from Persia.-After a photograph by Parke, Davis \& Co.

by an almost continuous strand of leptome, the cells being very irregular in outline and with thick, highly refracting walls, medullary rays 1 to 8 cells wide; wood wedges, broad, consisting of large tracheæ with yellowish walls, small compact groups of wood fibers and starchbearing parenchyma, alternating with the broad medullary rays; 
pith composed of somewhat polyhedral parenchyma, containing numerous starch grains, or prisms of calcium oxalate. In roots the pith is wanting.

Powder.-Light brownish-yellow; starch grains numerous, mostly single and ellipsoidal or ovoid, and from 0.002 to $0.020 \mathrm{~mm}$. in diam-

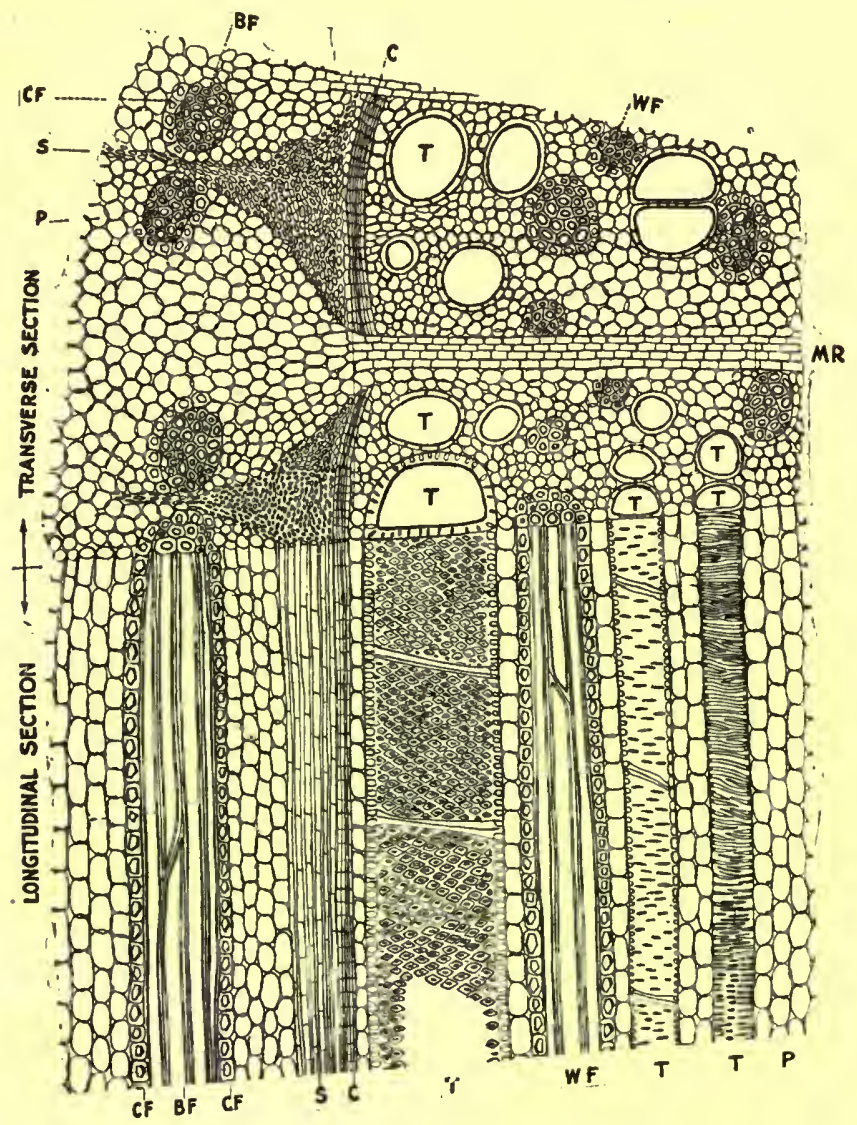

Fig. 140.-Longitudinal-transverse section of licorice rhizome including the cambium: $P$, parenchyma; $T$, trachex or vessels; $W F$, wood fibers; $C$, cambium; $S$, sieve; $C F$, crystal fibers; $B F$, bast fibers; $M R$, medullary ray.

eter; tracheæ mostly with bordered pores; wood and bast fibers numerous, strongly lignified, very long, much attenuated at the ends, and about $0.010 \mathrm{~mm}$. in width; crystal fibers with monoclinic prisms of calcium oxalate, the latter from 0.010 to $0.020 \mathrm{~mm}$. in diameter; occasional fragments of reddish-brown cork cells. 
Russian Licorice.-Nearly cylindrical, tapering, sometimes split longitudinally, 15 to $30 \mathrm{~cm}$. in length, 10 to $30 \mathrm{~mm}$. in diameter; externally lemon-yellow, nearly smooth, porous, with detachable bast fibers and circular rootlet-scars, cork if present, more or less easily abraded; internally lemon-yellow, bark, coarsely fibrous, wood radially cleft, not so fibrous as in the Spanish variety.

Inner Structure.-Resembling Spanish licorice, but the periderm layers are wanting.

Constituents.-About 3 per cent of glycyrrhizin, a crystalline, intensely sweet substance consisting of the calcium and potassium salts of glycyrrhizinic acid, which latter is an ester of glycyrrhetinic acid: asparagin 2 to 4 per cent (see Althæa); a bitter principle glycyramarin, which occurs principally in the bark and hence is less abundant in the Russian licorice; a volatile oil 0.03 per cent; mannit; considerable starch and calcium oxalate chiefly in crystal fibers.

Houseman claims that a 99 per cent alcohol gives an extract which corresponds more nearly to the amount of total resins in the drug. The alcohol extract in different varieties of licorice varied as follows: Italian 4.8; Spanish (Toledo), 4.9; Turkish-Arabic 5.4; Anatolian, 5.5; Russian, 5.6; and Syrian, 7 per cent. He also found nitrogen in glycyrrhizic acid. Aqueous licorice extract contains a coloring principle which dyes silk a fast yellow. (Amer. Jour. Pharm., 1912, 84 , p. 531; Ibid., 1916, 88, p. 97).

Licorice is a valuable corrective for disagreeable-tasting medicinal substances. Glycyrrhizin in dilutions of 1 in 20,000 still possesses a distinct sweet taste. (Kobert, Amer. Jour. Pharm., 1915, p. 555).

Allied Plants.-The root of wild or American licorice. Glycyrrhiza lepidota, a perennial herb indigenous to western North America, is somewhat similar to Spanish licorice. It contains 6 per cent of glycyrrhizin and considerable glycyramarin.

A number of plants of this family contain principles similar to glycyrrhizin, as the root and leaves of Indian or Jamaica licorice (Abrus precatorius) of India and the West Indies; the root of Ononis spinosa, a perennial herb of Europe, and other species of Ononis as well; the locust (Robinia Pseudacacia) of the United States and Canada; Caragana pygmœa of Siberia and northern China; Hedysarum americanum of the northern United States and Canada; Periandra mediterranea, and P. dulcis of Brazil and Paraguay, also the root of the English walnut (Juglans regia); the rhizome of Polypodium vulgare (Filices); and wild licorice, Galium circæzans (Fam. Leguminosæ). 
The root of G. uralensis of Siberia is said to be only slightly inferior to the best kind of Russian licorice.

Compound Powder of Glycyrrhiza.-(Fig. 141.) Consisting of powdered senna, powdered glycyrrhiza, washed sulphur, oil of

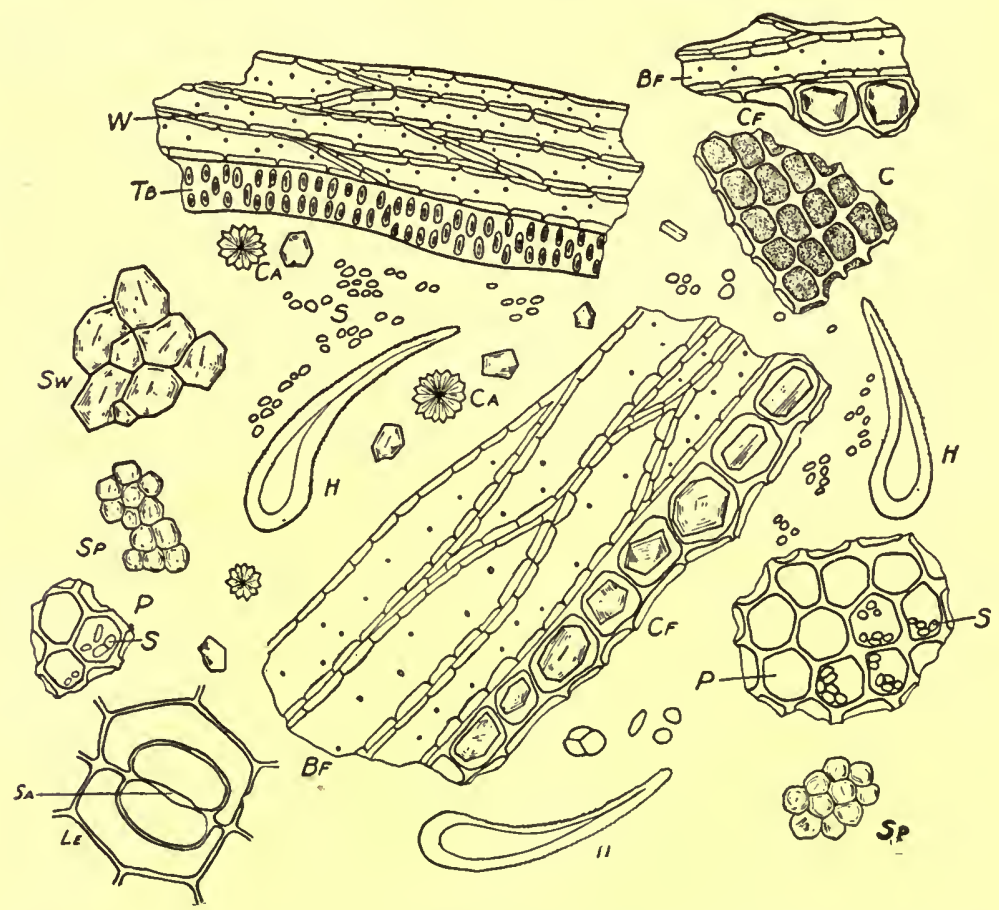

Fig. 141.-Compound Licorice Powder. Fragments of Glycyrrhiza: Bf, bast fibers; $C f$, crystal fibers; $W$, wood fibers; $T b$, trachex having bordered pores; $C$, cork cells, filled with a reddish-brown amorphous content; $C a$, monoclinic prisms of calcium oxalate from 0.010 to $0.020 \mathrm{~mm}$. in length; $P$, parenchyma cells containing starch grains $(S)$, from 0.002 to $0.020 \mathrm{~mm}$. in diameter.

Fragments of Senna: $H$, non-glandular hairs with papillose walls; $L e$, fragment of lower epidermis showing a stoma $(\mathrm{Sa})$; $\mathrm{Ca}$, rosette aggregates of calcium oxalate about $0.010 \mathrm{~mm}$. diameter.

Fragments of Sulphur: $S w$, aggregates of angular fragments of washed sulphur; $S p$, aggregates of spheroidal fragments of precipitated sulphur.Drawing by Haase.

fennel and powdered sugar. Greenish-yellow to greenish-brown; when mounted in water or in solutions of hydrated chloral the powder shows fragments of licorice with their characteristic yellowish fibers associated with crystal fibers, large tracheæ with elliptical bordered 
pores and cells containing numerous spheroidal starch grains varying from 0.002 to $0.020 \mathrm{~mm}$. in diameter; fragments of Senna determined by their characteristic, more or less curved, unicellular, non-glandular hairs from 0.100 to $0.350 \mathrm{~mm}$. in length, fragments of epidermis with elliptical stomata and their two neighboring cells and fragments with crystal fibers; when mounted in a fixed oil and examined under the petrographical microscope it shows a large number of irregular, angular fragments of sugar, which polarize light strongly and are furthermore readily soluble in mounts made with water; upon the addition of solutions of potassium hydroxide to aqueous mounts of the powder, the fragments of Senna are immediately colored a yellowish-red changing to a reddish-brown. On adding 0.100 gm. of compound powder of licorice to a test-tube, moistening with 2 c.c. of alcohol and then adding 10 c.c. of water and boiling, allowing to cool and then filtering, the filtrate should be of a pale yellowishbrown color, which, upon the addition of a drop of solution of potassium hydroxide, changes to a yellowish-red (Senna).

SenNa.-Senna Leaves.-The leaflets of various species of Cassia (Fam. Leguminosæ, sub-fam. Cæsalpinaceæ), small shrubs indigenous to upper Egypt and southern Arabia. There are two important commercial varieties: (1) Alexandrian Senna, derived from wild plants of Cassia acutifolia, a small shrub (Fig. 142) growing in the region of the Nile River from Assouan to Kordofan, and exported by way of Alexandria and Red Sea ports; (2) Indian or Tinnivelly Senna derived from cultivated plants of Cassia angustifolia, growing on the east African coast, in Arabia and northwestern India, and cultivated in southern India. The leaves are carefully collected and dried, the Tinnivelly variety being more largely used, although the Alexandrian is more highly esteemed.

Alexandrian Senna.-Lanceolate or ovate-lanceolate; 1.5 to $3 \mathrm{~cm}$. in length, 5 to $8 \mathrm{~mm}$. in breadth; summit acute mucronate; base unequal, acute; margin entire; upper surface pale green, nearly glabrous, midrib sometimes depressed, veins of first order more or less prominent, under surface light grayish-green, midrib prominent, minutely pubescent, especially near the veins; petiolule about $1 \mathrm{~mm}$. in length; texture coriaceous, fibrous; odor slight; taste somewhat bitter.

Inner Structure.-Similar to that of Indian senna (Fig. 143).

Powder.-Light green; fragments colored reddish with solutions of the alkalies; non-glandular hairs, 1-celled, pointed, often curved, from 0.100 to $0.350 \mathrm{~mm}$. in length, walls thick and papillose; calcium oxalate in rosette aggregates, from 0.009 to $0.010 \mathrm{~mm}$. in diam- 
eter, and in 4- to 6-sided prisms, about $0.015 \mathrm{~mm}$. in length, usually in crystal fibers; stomata broadly elliptical, about $0.020 \mathrm{~mm}$. in length and having two neighboring cells.

Tinnivelly Senna.-From 2.5 to $5 \mathrm{~cm}$. in length, upper surface light green, lower surface slightly pubescent.

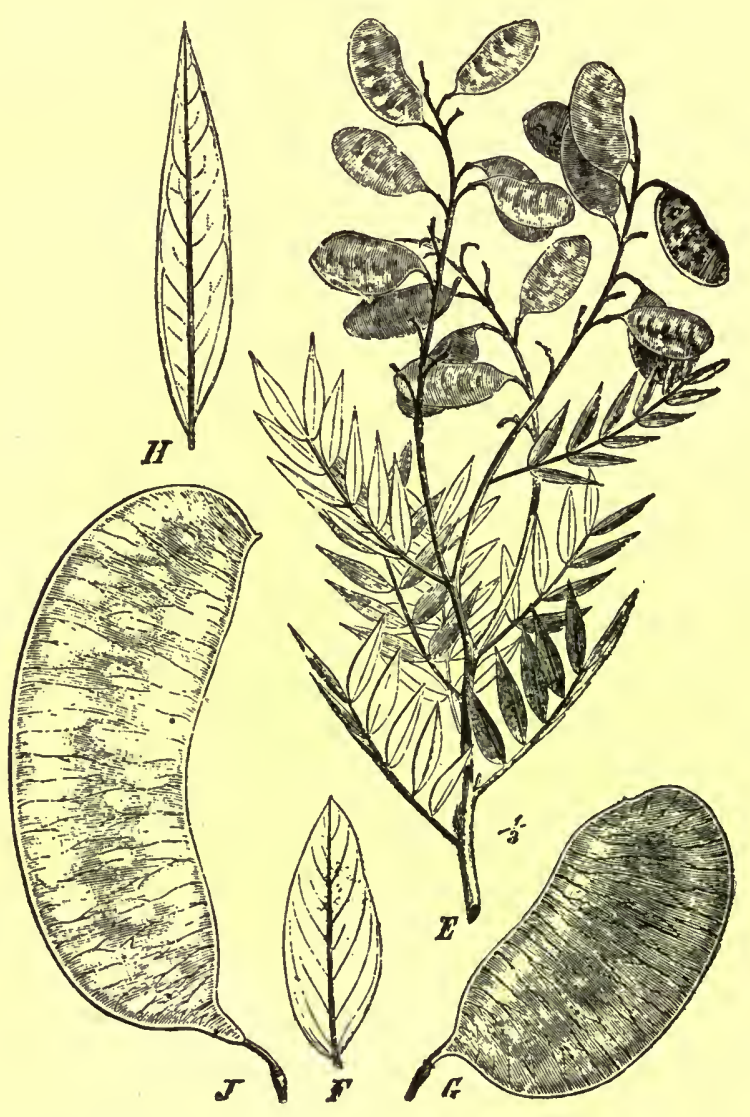

Frg. 142.-Cassia acutifolia: $E$, fruiting branch; $F$, a single leaflet; $G$, a pod. Cassia angustifolia: $H$, a single leaf; $J$, a pod.-After Taubert.

\section{Inner Structure.--See Fig. 143.}

Powder.-Dark green, resembling Alexandrian sennā, but has relatively few non-glandular hairs.

Constituents.-Senna leaves contain several glucosides which yield oxymethylanthraquinone compounds resembling those found in aloes and rhubarb; a glucosidal substance, anthraglucosennin, 
which occurs as a brown-black powder and yields on hydrolysis senna-emodin (tri-oxymethylanthraquinone) and senna-chrysophanic acid (di-oxymethylanthraquinone). (See Rhubarb.) Anthraglucosennin when acted upon by alkalies produces an amorphous, black
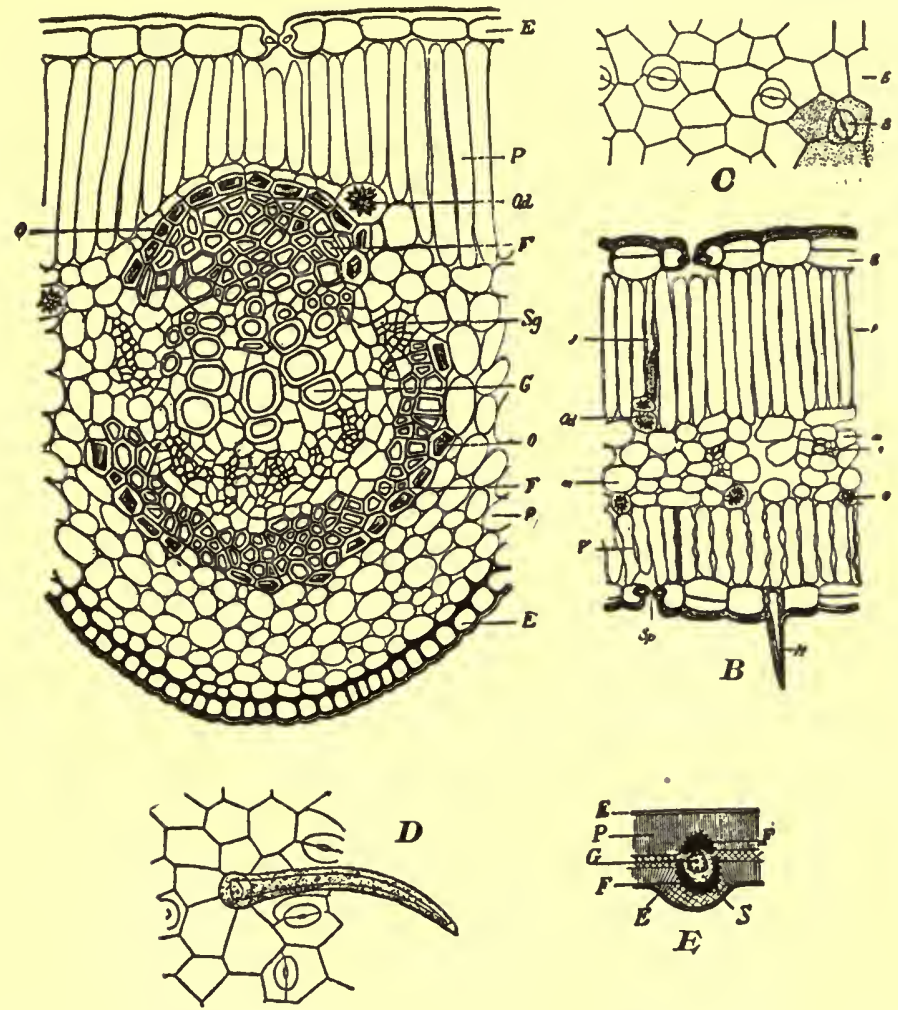

Frg. 143.-Cassia angustifolia (India senna): $A$, transverse section through the middle vein showing upper epidermis $(E)$, palisade cells $(P)$, rosette aggregate of calcium oxalate $(O d)$, monoclinic prisms of calcium oxalate, $(o)$, tracheæ $(G)$, sieve $(S g)$, sclerenchymatous fibers $(F)$, lower epidermis with rather thick-walled cells $(E)$. $B$, transverse section through portion of leaf between the veins showing the absence of monoclinic prisms of calcium oxalate, the presence of palisade cells and stomata on both the lower and upper epidermis, and a hair $(H)$ on the lower surface. $C$, lower epidermis on surface view. $D$, upper epidermis showing stomata and a single hair. $E$, diagram of section through the middle vein, the letters corresponding to those in A.-After Meyer.

powder, senna-nigrin, which also yields on hydrolysis emodin and chrysophanic acid. Senna also contains a yellowish, amorphous glucoside, glucosennin; a reddish-brown, amorphous substance, 
senna-rhamnetin, which differs from rhamnetin found in the fruit of Rhamnus cathartica in that the latter is crystalline and forms a fluorescent solution with sulphuric acid; senna-isoemodin (isomeric with senna-emodin), which is soluble in petroleum ether; cathartic acid; calcium oxalate; and ash 10 to 12 per cent. The active principles of senna are emodin, chrysophanic acid and cathartic acid. The percentage of emodin is from 0.6 per cent in Tinnivelly leaves to 1 per cent in the Alexandria variety.

Power (Jour. Chem. Soc., 1913, p. 2006) recently isolated from Alexandria Senna in addition to the substances already referred to: isorhamnetin, rhein (tetra-oxymethylanthraquinone), myricyl alcohol, a phytosterol glucoside, and kaempferol. From Tinnevelly leaves, with the exception of isorhamnetin, he obtained in addition the following substances: volatile oil, salicylic acid, kaempferin, the magnesium salt of an unidentified organic acid, palmitic and stearic acids, also a quantity of sugar, together with some amorphous glucosidal material. Peruvian senna leaves closely resemble Tinnevelly leaves in their chemical composition, with the exception of the magnesium salt and the addition of isorhamnetin.

Allied Plants.-Senna pods (Fig. 142), derived from both C. acutifolia and C. angustifolia, are also found in the market, either admixed with the leaves or sold separately; they are from 3.5 to 7 $\mathrm{cm}$. in length and about $2 \mathrm{~cm}$. in breadth, greenish-brown to dark brown, and contain from five to seven obovate, dark brown, nearly smooth seeds. They contain apparently the same active principles as the leaves.

Similar principles are found in other species of Cassia, especially in the American senna (C. marilandica), which is an herbaceous perennial, indigenous to the eastern and central United States and Canada, with 12- to 20-foliate leaves, yellow flowers and linear, slightly curved legumes. The leaves of senna are sometimes admixed with those of Cassia obovata, which are broad and obovate, while the pods of the latter species are distinctly curved. Mecea or Arabian senna is obtained from a variety of C. angustifolia, growing in Arabia. The leaves of C. holosericea, of Abyssinia, are quite hairy. and found occasionally in the market under the name of Aden senna. The leaves of other members of the Leguminosæ are used like senna as Cytisus purgans of southern France, Tephrosia Apollinea of Egypt, and Colutea cruenta of the Caucasus region.

The root of Viviania esculenta (Fam. Geraniaceæ), of the East Indies, contains a principle resembling cathartic acid.-Hooper, Pharm. Jour. and Trans., 1889 (3), p. 77. 
Adulterants.- In the powder of Argel Leaves (Solenostemma Argel, Fam. Asclepiadaceæ) the non-glandular hairs are 3- to 4celled; in the leaves of Castanea dentata (Fig. 73), the non-glandular hairs are relatively few, 0.2 to $0.5 \mathrm{~mm}$. in length, nearly smooth, thick-walled, occasionally in groups of three to eight and spreading from the base. The calcium oxalate crystals are numerous, in rosette aggregates or in monoclinic prisms, 0.010 to $0.035 \mathrm{~mm}$. in diameter, occasionally in crystal fibers; the parenchymatous cells contain irregular yellowish-brown tannin masses which are colored blue with ammonio-ferric alum solution.

Scoparius.-Broom.-The tops of Cytisus Scoparius (Fam. Leguminosæ, sub-fam. Papilionaceæ), a shrub indigenous to the temperate parts of Europe, and naturalized in waste places from Virginia to Nova Scotia. The tops are gathered before flowering and are used in the fresh condition, or they are dried.

Description.-Usually cut into pieces; branches alternate, pentangular, 2 to $3 \mathrm{~mm}$. in thickness; externally dark green, with 5 yellowish-green wings and numerous reddish-brown cork patches, the younger branches somewhat pubescent; fracture short, fibrous, or of the larger pieces, tough, splintery; internally yellowish, bark thin, wood slightly porous, pith large, about $1 \mathrm{~mm}$. in diameter. Leaves elliptical, obovate, simple about 5 to $10 \mathrm{~mm}$. in length, 3 to $4 \mathrm{~mm}$. in breadth, digitately trifoliate below; summit of both leaves and leaflets acute; base acute; margin entire; upper surface dark green, nearly glabrous; under surface slightly pubescent; petiole wanting in the simple leaves and about $5 \mathrm{~mm}$. in length in the compound leaves, pubescent; odor peculiar; taste bitter.

Powder.-Dark green; non-glandular hairs 1-celled, 0.5 to 0.7 $\mathrm{mm}$. in length, thick-walled; tracheæ with spiral or double spiral thickenings, slightly lignified; sclerenchymatous fibers narrow, thin-walled and with simple pores.

Constituents. - A volatile, liquid alkaloid sparteine (0.03 per cent), forming crystalline salt, the sulphate of which has physiological properties similar to digitalin; a yellow erystalline principle scoparin, which yields picric acid on treatment with nitric acid; volatile oil; tannin; ash about 5 per cent.

Allied Plants.--Several plants of the Leguminosæ are used like Scoparius. Spanish broom is obtained from Spartium junceum, a shrub indigenous to the Mediterranean region. Coronilla scor. pioides yields a yellow glucoside coronillin.

Cassia Frstula.-Purging Cassia.-The ripe fruit of Cassia (Carthartocarpus) Fistula (Fam. Leguminosæ, sub-fam. Cæsal- 
pinaceæ), a tree indigenous to India, and naturalized in tropical Africa, South America and the West Indies. The principal supply of the drug used in this country comes from tropical America.

Description.-(Fig. 144.) Legume nearly straight, indehiscent, cylindrical, 25 to $50 \mathrm{~cm}$. in length, 15 to $20 \mathrm{~mm}$. in diameter; externally reddish-brown, summit acute or acuminate, base rounded, sometimes with a woody pedicel about $15 \mathrm{~mm}$. in length and $4 \mathrm{~mm}$. in diameter, smooth, shiny, transversely striate, on one side with a longitudinal groove (the ventral suture), and on the other a smooth line or slight ridge (the dorsal suture); pericarp hard and woody; internally divided by transverse partitions into numerous compartments about $5 \mathrm{~mm}$. in length, each containing a brownish-black pulp and a single seed; seed anatropous, ovoid, compressed, about $8 \mathrm{~mm}$. in length, $6 \mathrm{~mm}$. in width, $4 \mathrm{~mm}$. in thickness, light brown, the raphe as a distinct lime on one of the compressed sides, internally light yellow, embryo curved and embedded in the endosperm; odor of pulp distinct, prune-like; taste sweet.

Constituents.-The fruit yields about 30 per cent of pulp, which contains 40 to 60 per cent of sugar. The drug apparently does not owe its laxative properties to any of the anthraquinone derivatives found in senna and related plants.

Allied Plants.-The legumes of related species of Cassia found in tropical America are similar to those of Cassia Fistula, and are also used in medicine.

The pods of Cassia grandis (C. brasiliana), a tree growing in northern Brazil, Central America and the West Indies, are known as horse cassia. They are nearly cylindrical, attaining a length of $65 \mathrm{~cm}$. and a diameter of $4 \mathrm{~cm}$; ; externally reddish-brown, having a deep longitudinal groove on the ventral surface and a prominent ridge on the dorsal surface; prominently reticulately wrinkled; very woody, divided into transverse segments as in Cassia Fistula and containing in each compartment a large amount of a reddishbrown pulp and a single, broadly elliptical, light pinkish-brown seed. Pulp of a somewhat butyraceous odor and a sweet, acid taste. It contains a large amount of sugar, and small quantities of butyric acid and tannin.

Tamarindus.-Tamarind.-The preserved pulp of the ripe fruit of Tamarindus indica (Fam. Leguminosæ, sub.-fam. Cæsalpinaceæ), a tree (Fig. 145) indigenous to tropical Africa and cultivated in the West and East Indies, from whence the two chief commercial varieties are obtained. 
West Indian Tamarind.-Usually a blackish-brown mass, with a distinct odor and strongly acidulous, sweet taste, and in which are

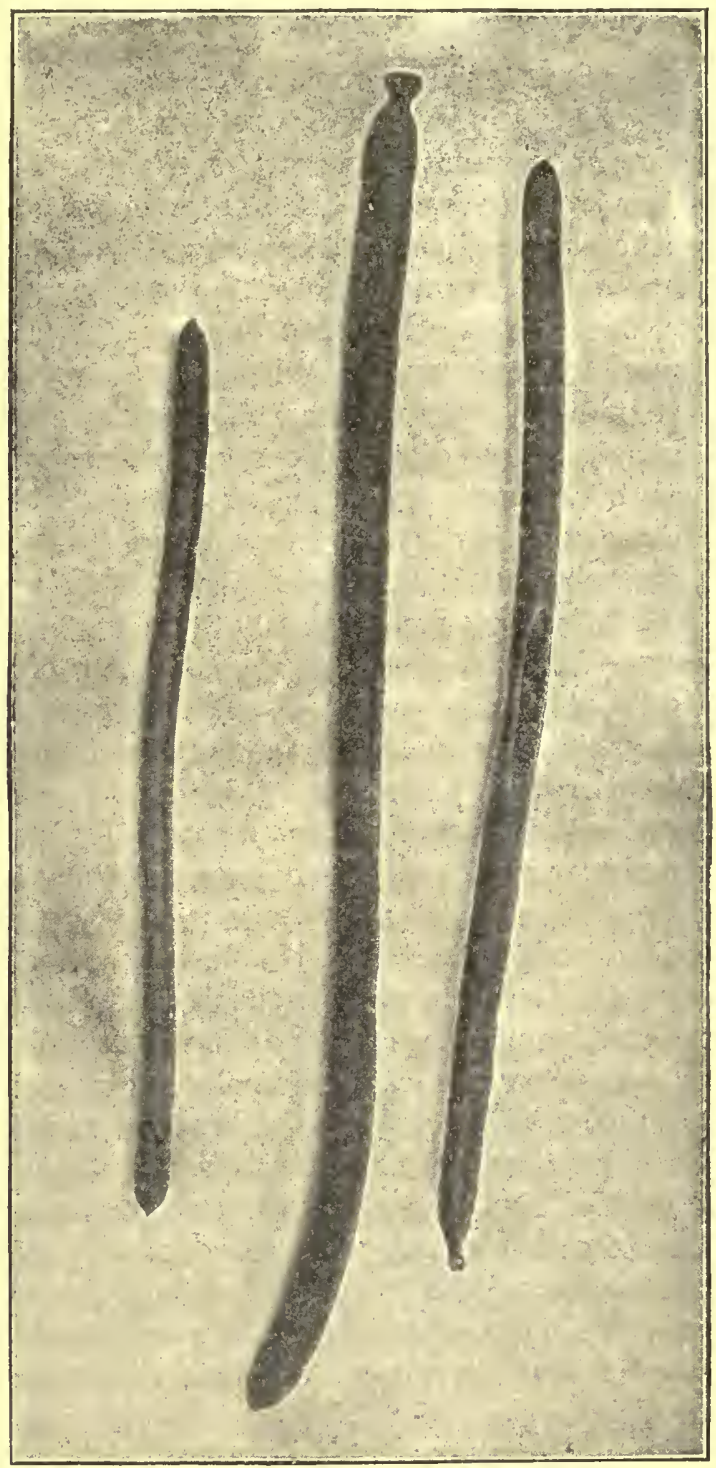

Fig. 144.-Legumes of Cassia Fistula, the one to the right cut to show the transverse partitions.

embedded numerous seeds enclosed in a loose, tough membrane; seeds anatropous, oblong or flattened-quadrangular, 12 to $14 \mathrm{~mm}$. in. 
length, 8 to $11 \mathrm{~mm}$. in breadth, 5 to $7 \mathrm{~mm}$. in thickness, dark reddishbrown, smooth, one edge furrowed, transversely striate, very hard; cotyledons plano-convex.

East Indian Tamarind.--In blackish cakes, containing less sugar and more acid.

Constituents.-Tartaric acid 5 to 9 per cent; citric acid 3 to 6 per cent; potassium bitartrate 6 to 7.3 per cent, and other salts of organic acids; invert sugar 32 to 42 per cent; tannin (in the seedcoat).

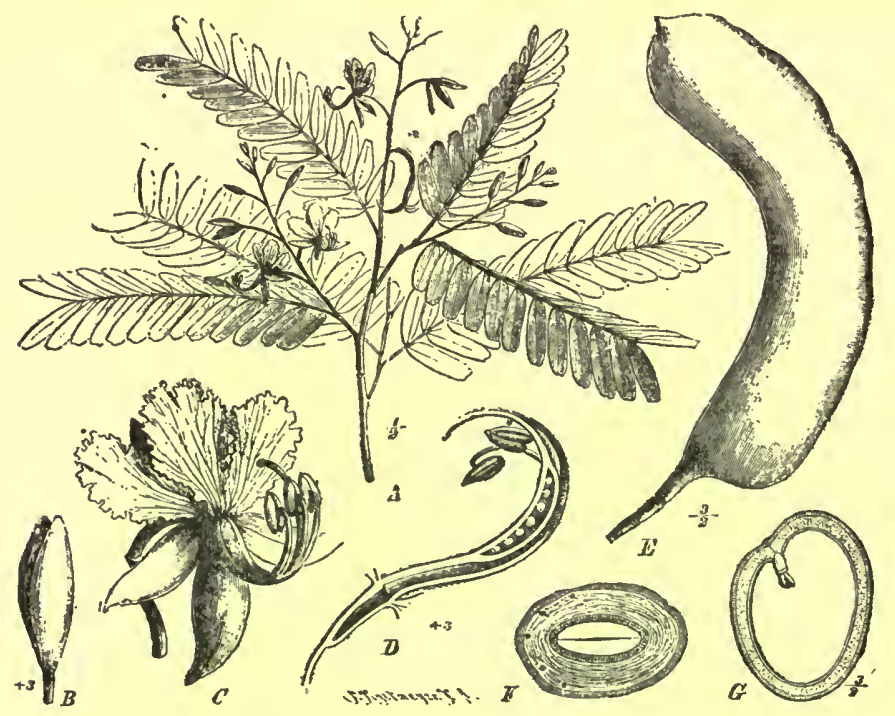

FIG. 145.-Tamarindus indica: $A$, flowering branch with paripinnate leaves. $B$, flower bud. $C$, dorsiventral (irregular) flower. $D$, longitudinal section of flower showing unilocular ovary. $E$, somewhat curved, indehiscent legume. $F, G$, transverse and longitudinal sections of the seed.--After Taubert.

Allied Plants.-The pulp of the fruits of several species of Nephelium (Fam. Sapindaceæ), of southern China, resembles tamarind.

Physostigma. - Calabar Bean.-The ripe seeds of Physostigma venenosum (Fam. Leguminosæ, sub-fam. Papilionaceæ), a woody climber growing in the region of the Gulf of Guinea on the western coast of Africa (Fig. 146). The seeds are also known as " the"ordeal bean of Calabar."

Description.-Anatropous, somewhat reniform or irregularly oblong or ellipsoidal; 25 to $30 \mathrm{~mm}$. in length, 15 to $18 \mathrm{~mm}$. in diam. 
eter, 10 to $15 \mathrm{~mm}$. in thickness; with a brownish-black groove from 1 to $2 \mathrm{~mm}$. in diameter extending about half way around the edge, containing the raphe as a narrow line, and in which is frequently found the remains of the white membranaceous funiculus, the micropyle occuring near one end of the groove as a slight depression; seedcoat brownish-red, hard, thick, smooth, but somewhat rough near the groove; reserve layers wanting; embryo large, white, with a short hypocotyl and two concavo-convex cotyledons; inodorous; taste starchy.

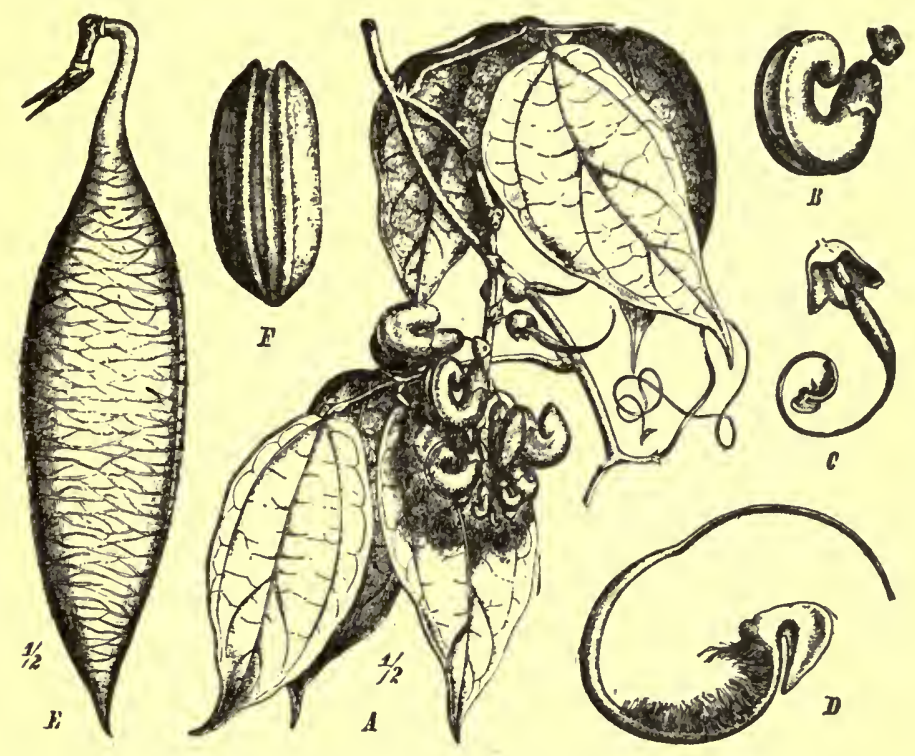

FIG. 146.-Physostigma venenosum: $A$, flowering branch. $B$, a single flower. $C$, flower showing ovary and part of the calyx. $D$, enlarged view of style and stigma. $E$, legume. $F$, seed.-After Bentley and Trimen.

Powder.-Grayish-white; starch grains numerous, from 0.005 to $0.150 \mathrm{~mm}$. in diameter, ellipsoidal or somewhat reniform, and usually with a distinct cleft and frequently with radiating or irregular fissures; fragments of seed-coat with very thick, reddish-brown cells, being either palisade-like in shape, or very irregular and resembling stone cells, but the walls are not lignified; an occasional fragment with tracheæ showing reticulate thickenings.

Constituents.-Starch about 45 per cent; proteins about 20 per cent; fixed oil about 2 per cent; ash about 3 per cent. Several alkaloids have been isolated, the most important of which is physos- 
tigmine (eserine), which occurs in the embryo to the extent of 0.1 to .25 per cent. It crystallizes in rhombohedra (Fig. 147), which are colored red with solutions of the alkalies and yellow with sulphuric or nitric acid. With the latter reagent the solution changes to olive-green. The aqueous solutions of physostigmine are alkaline and easily decomposed, with the separation of a reddish-colored substance, rubreserine. The salicylate and sulphate of physostigmine are official, the solutions of the former being more stable. Physostigma also contains eseridine (isophysostigmine), an alkaloid resembling physostigmine in its physiological action; a liquid alkaloid,

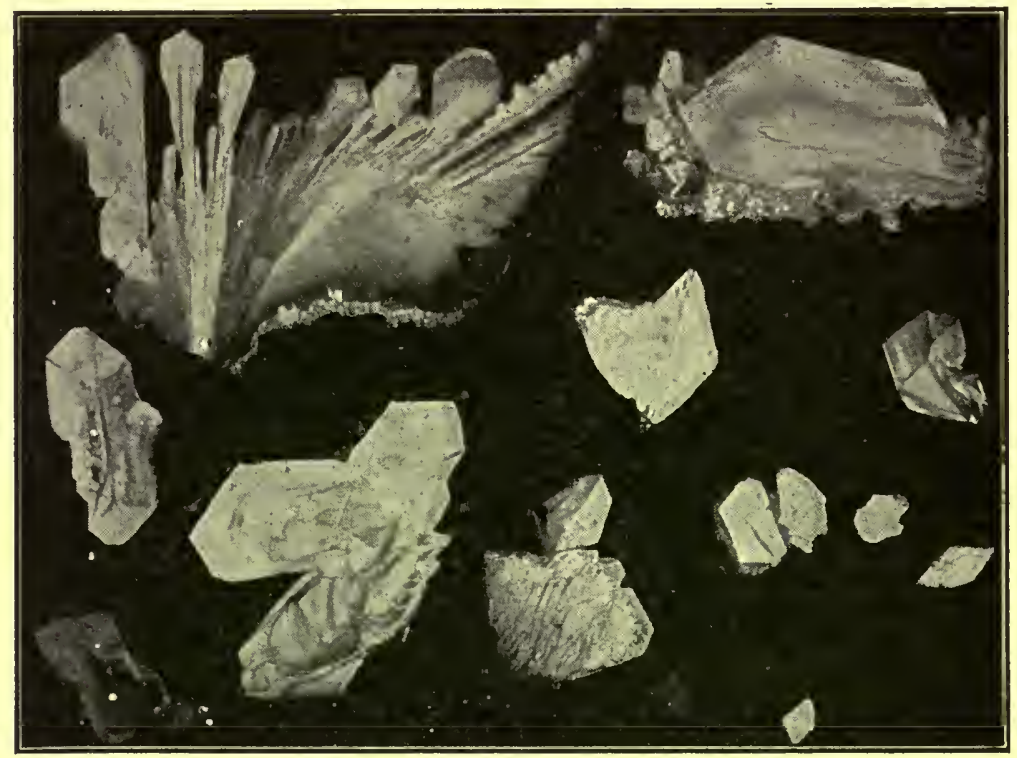

FiG. 147.-Physostigmine salicylate: orthorhombic crystals from a solution in chloroform.

calabarine, which is physiologically antagonistic to physostigmine, and a crystalline alkaloid, eseramine, which is inactive.

In addition a new alkaloid, physovenine, has been isolated by Power (Jour. Chem. Soc., 1912, p. 978; 1913, p. 351 and p. 1988). Also the following constituents: stigmasterol; sitosterol; several phytosterol glucosides; a mixture of fatty acids; sugar; and resinous material.

Allied Plants.-The seeds of P. cylindrospermum have been substituted for Calabar bean; they are nearly cylindrical and are said also to contain physostigmine. 
The lenticular, brown, glossy seeds of Entada scandens contain saponin and have been offered as a substitute for physostigma. Canavalia obtusifolia, of the East Indies, is also said to have been used as an adulterant of physostigma.

The Jack-bean (Canavalia ensiformis) contains about 23 per cent of protein. The latter consists of two globulins. (Jour. Franklin Ins., 1917, p. 119.),

Fœnum Græcum.-Semen Fenu Graci, Semen Feni Graci, Fenugreek.-The dried ripe seeds of Trigonella Fœnum græcum (Fam. Leguminosæ, sub-fam. Papilionaceæ), an annual herb indigenous to the Mediterranean region and extensively cultivated in southern Europe, northern Africa and India.

Description.--Oblong flattened or rhomboidal; from 3 to $5 \mathrm{~cm}$. in length and 2 to $3 \mathrm{~mm}$. in breadth; externally light to dark yellowish-brown, nearly smooth, and having on one side a diagonal depression dividing the seed into two unequal portions, the smaller containing the embryo and the larger the cotyledons; hard, heavy, pebble-like; inner surface of embryo light yellowish-brown, waxy, of endosperm white and mealy; odor distinct, resembling that of elm bark; taste mucilaginous and slightly bitter. Cn placing the seeds in water they become swollen, permitting of the easy removal of the seed-coat. If allowed to remain for a few days in a moistened condition they germinate rapidly.

Inner Structure.--See Fig. 148.

Powder.-Yellowish-brown; an outer epidermal layer of mucilage cells beneath which occur 1 to 3 layers of radially elongated stone cells having triangular lumina and thick, porous walls. As seen in transverse section, the stone cells are polygonal in outline and have simple, narrow, and distinct pores; beneath the latter is a layer of broad, thick-walled cells with large, radiate, simple pores; the endosperm consists chiefly of mucilage cells with wavy mucilaginous inner walls and a single layer of small aleurone cells; the embryo consists of yellowish cells containing an oily cytoplasm, small aleruone grains and occasionally small starch grains. Aleurone grains from 0.005 to $0.015 \mathrm{~mm}$. in diameter; starch grains about $0.003 \mathrm{~mm}$. in diameter.

Constituents.-Fenugreek contains 22 per cent of proteins; 28 per cent of mucilage (in the cells of the endosperm); 0.13 per cent of trigonelline (isomeric with pyridine-betaine); 0.05 per cent of choline; and an odorous hydrocarbon.

Adulterants.-The powder is sometimes adulterated with pea flour, which is readily detected by the presence of numerous characteristic starch grains. Wheat middlings, which have been 
kept for some time, acquire an odor suggestive of fenugreek or elm bark.

Tonka.-Semen Tonco, Tonka or Tonquin Beans, Tonka SEEDS.-The ripe seeds of Coumarouna odorata and C. oppositifolia

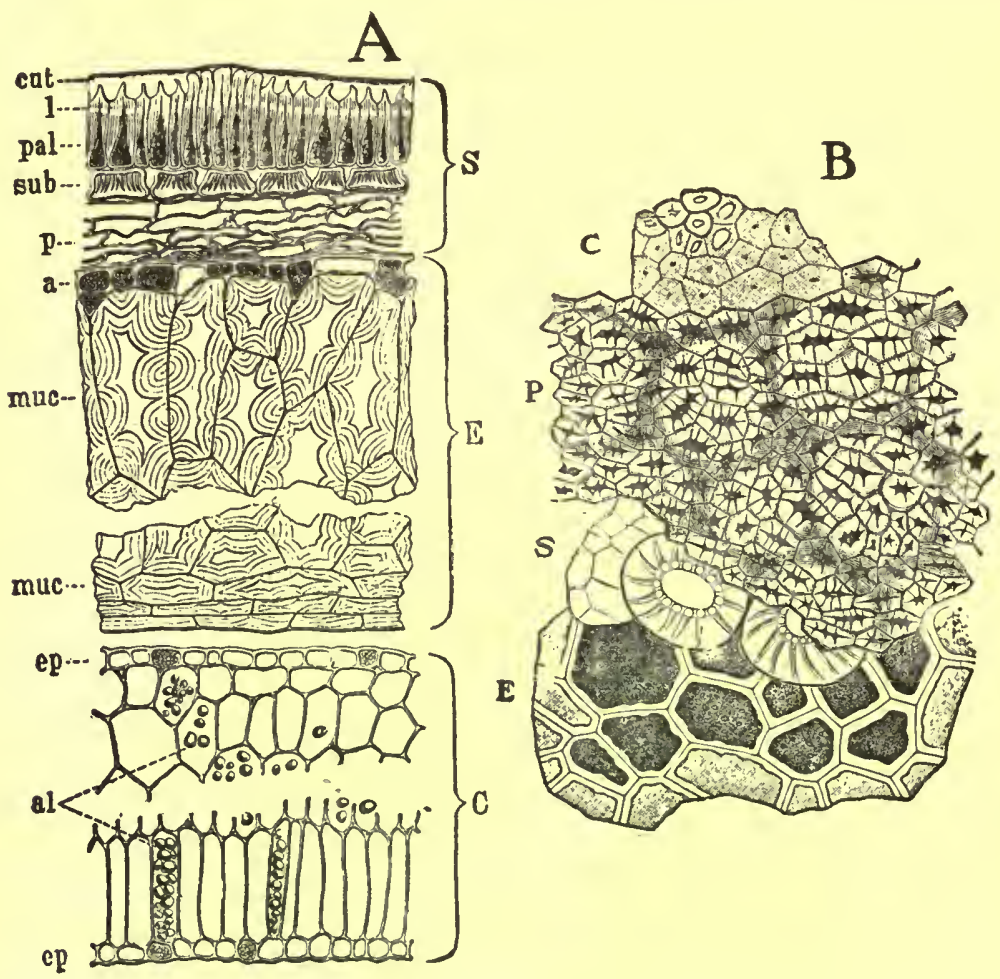

FIG. 148.-Fœcum græcum: $A$, transverse section of seed; $S$, tests or serd-coat consisting of palisade cells ( $p a l)$, with thick cuticle (cut) and thick lamellated walls $(l)$; hour-glass-shaped column cells $(s u b)$; and parenchyma $(p) ; E$, endosperm layer consisting of cells containing small aleurone grains $(a)$; and thick-walled mucilage cells $(m u c) ;$.$C , tissues of cotyledon consisting$ of the two epidermal layers $(e p)$ and cells containing small aleurone grains $(a l)$. $B$, surface section of tissue of the seed-coat and endosperm; $C$, cuticle and palisade cells with small lumina; $P$, palisade cells with thick radiating porous walls and large lumina; $S$, sub-cpidermal or column cells and parenchyma; $E$, cells of endosperm containing aleurone grains. $-A$, after Winton; $B$, after Tschirch.

(Fam. Leguminosæ, sub-fam. Papilionaceæ), trees growing in tropical South America. The natives collect the fruits, crush them between stones, separate the seeds and allow them to dry in the sun. They are 
then shipped to Ciudad, Venezuela, or Trinidad, where they are steeped in rum or other alcoholic liquors and by a process of fermentation the fragrant principle, coumarin, is developed. The seeds are removed and dried, when there forms upon the seed-coats the crystallized coumarin. There are two principal varieties: (1) Dutch Tonka obtained from Coumarouna odorata, growing in the northern part of the Amazon region, and (2) English Tonka from C. oppositifolia of northern Brazil and Guiana.

Description.-Oblong-ovoid, somewhat flattened, 3 to $4 \mathrm{~cm}$. in length and about $1 \mathrm{~cm}$. in width, externally nearly black, usually covered with crystals of coumarin, the coriaceous testa being deeply wrinkled; internally yellowish-brown, consisting of two planoconvex cotyledons, enclosing a plumule with two pinnately compound leaves and a fleshy radicle which is directed towards the micropyle situated at the rounded end of the seed; odor fragrant; taste aromatic and somewhat pungent.

Inner Structure.-The easily separable seed-coat contains an outer epidermal layer of stone cells, which possess rather porous, somewhat thickened walls and a brownish-red or brownish-black content; a layer of spindle-shaped cells which are more or less undulated in outline and unequal in thickness; a layer of parenchyma of tangentially elongated compressed cells, interspersed with vascular bundles; an inner epidermis of thin-walled rectangular cells with a brownish content; perisperm made up of cells containing aleurone grains; an endosperm of thin-walled cells; the cotyledons of polyhedral, thin-walled parenchyma containing an oily cytoplasm, numerous starch grains and aleurone grains.

Powder.-Brownish-black; the parenchyma cells of the cotyledons with numerous spheroidal starch grains from 0.004 to $0.010 \mathrm{~mm}$. in diameter; large, irregular aleurone grains from 0.020 to $0.035 \mathrm{~mm}$. in length, and considerable fixed oil. The easily separable seed-coat contains rather characteristic stone cells, which on surface view are polygonal and possess rather porous, somewhat thickened walls and brownish-red or brownish-black contents. Beneath the stone cells is a layer of broad, spindle-shaped cells with rather thick walls and numerous intercellular spaces.

Constituents.-From 1 to 10 per cent of coumarin, which crystallizes in various forms (Fig. 59), having a characteristic aromatic odor and a bitter taste. It is apparently developed from a mother substance contained in the fixed oil. The latter occurs to the extent of about 25 per cent. The seeds also contain starch, sitosterin, stigmasterin, sugar and gum. Ash from 3 to 4 per cent. 
HжMatoxxLon.-Logwood.-The heartwood of Hæmatoxylon campecheanum (Fam. Leguminosæ, sub-fam. Cæsalpinaceæ), a tree indigenous to Central America, and naturalized in the West Indies. Much of the commercial logwood being used for dyeing is allowed to ferment, and as a result the chips become dark red and have a greenish, metallic luster, but it is the unfermented wood that should be used for medicinal purposes.

Description.-Usually in small chips, externally reddish-brown, the freshly cut surface dark yellowish-red, in transverse section slightly radiate and with numerous, alternate, yellowish and reddish

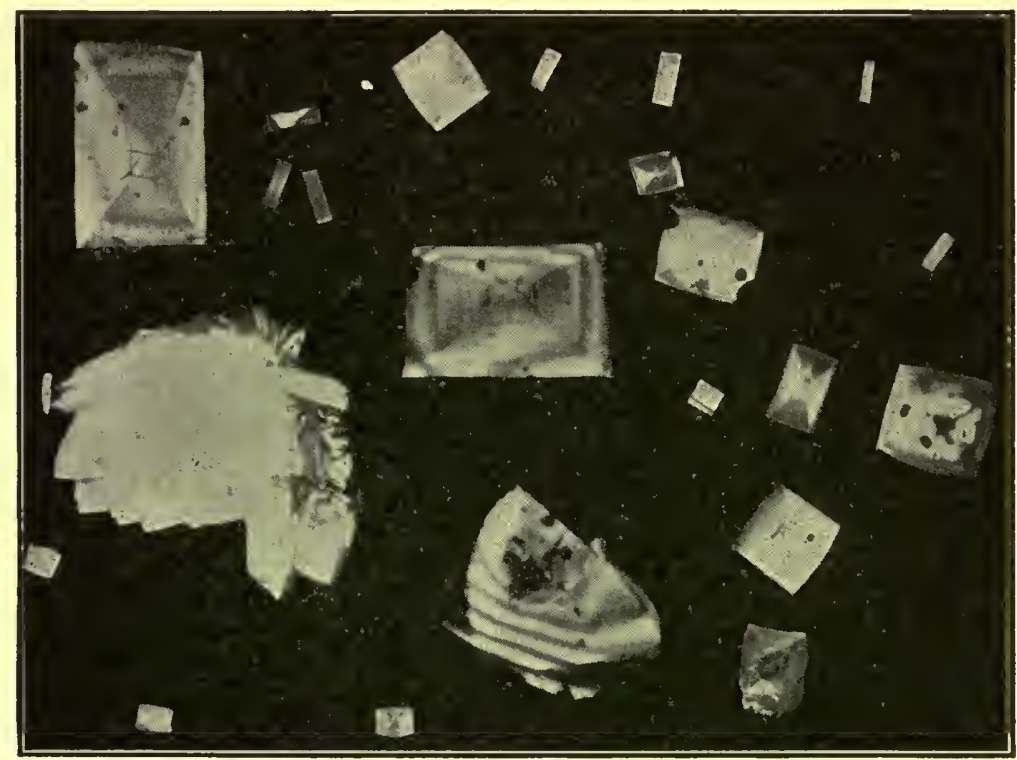

FIG. 149.-Hæmatoxylin: Monoclinic tabular crystals from aqueous solution.

concentric rings, medullary rays four cells wide; fracture hard, fibrous; odor slight; taste sweet, astringent; the wood imparting to water a violet or wine color.

Powder.-Dark brown; tracheæ with simple pores; sclerenchymatous fibers long, thin-walled; crystal fibers with monoclinic crystals of calcium oxalate.

Constituents.-Hæmatoxylin, 10 to 12 per cent, occurs in colorless or pale yellow prisms (Fig. 149), having a taste like glycyrrhizin, becomes red on exposure to light and is soluble in water and alcohol. The solutions are colored with solutions of the alkalies, purplish-red, 
then purple and finally deep red. The compound formed with ammonia yields hæmatein, a dark violet, crystalline principle having a green, metallic luster and which is supposed to form in the fermented wood used by dyers. Logwood also contains volatile oil, resin, tannin and calcium oxalate.

Allied Plants.-The woods of certain species of Cæsalpinia also contain red coloring principles and furnish the red woods of tropical America. Brazil wood is obtained from C. echinata and contains the principle known as brasilin, which is colorless when first extracted, but assumes a red color on exposure. Sappam or false sandal wood is obtained from C. Sappam of Indo-China. Red coloring principles are also found in other species of Cæsalpinia and in a number of other genera of the Leguminosæ as well.

Santalum Rubrum.-Red Saunders.-The heartwood of Pterocarpus santalinus (Fam. Leguminosæ, sub-fam. Papilionaceæ), a tree indigenous to the southern part of Indo-China, and cultivated in the southern Philippines, Ceylon and southern India, the chief supplies coming from Madras.

Description.-Usually in small chips or coarse powder, red or brownish-red, in transverse section slightly radiate, with numerous alternate lighter and darker concentric rings, medullary rays onecell wide; fracture hard, fibrous; inodorous; taste slight.

Powder-Reddish; tracheæ with bordered pores; sclerenchymatous fibers long, thin-walled; crystal fibers with monoclinic crystals of calcium oxalate. The coloring principle is insoluble in water but soluble in alcohol and in solutions of the alkalies.

Constituents.-A coloring principle santalin (santalic acid), which occurs in red needles that are insoluble in water, soluble in alcohol, forming a deep red solution which is colored violet with solutions of the alkalies. It also contains tannin and several colorless crystalline principles.

Allied Plants.-The African sandal wood or barwood is obtained from P. santalinoides of tropical West Africa. Cam-wood or African red-wood (obtained from Baphia nitida, in Sierra Leone) is also valued on account of its red coloring principle.

ACACIA.-Gum Arabic.-A dried, gummy exudation from the stem and branches of Acacia Senegal and probably other species of Acacia (Fam. Leguminosæ, sub-fam. Mimosaceæ), trees growing in sandy soil and forming forests in tropical Africa. The gum exudes spontaneously from the bark of the tree and is apparently formed by the action of a ferment on the cell-contents, as it does not contain any remains of cell walls. The trees are also incised, which increases 
the production of gum. The more or less hardened pieces are collected and then sorted into different grades, the market supplies being obtained from Egypt by way of Alexandria (Kordofan gum), from the Soudan by way of Suakin ("Turkey sorts" and "Trieste picked "), and from Senegambia by way of the port of St. Louis. The Kordofan gum is considered to be the best. The best grade of gum Arabic (gum Senegal) is obtained from Acacia Senegal and A. glaucophylla, both of tropical Africa.

Description.-In roundish tears of variable size, or broken into angular fragments; externally whitish or yellowish-white, with numerous minute fissures; translucent; very brittle, with a glasslike, sometimes iridescent fracture; nearly inodorous; taste mucilaginous.

Acacia is not soluble in alcohol, but is completely soluble in cold water; the solution is adhesive, gives an acid reaction with litmus paper. 10 c.c. of a 10 per cent solution does not yield a gelatinous precipitate with 0.2 c.c. of normal lead acetate test solution, but is precipitated with 0.1 c.c. of a test solution of ferric chloride (Mesquite gum is not precipitated); a cold solution does not give a bluish or reddish color with iodin (absence of artificial gums containing starch or dextrin), or a brownish-black precipitate with solutions of ferric chloride (absence of gum of Australian species). A 10 pel cent aqueous solution of acacia when examined by the polariscope should show but a slight lævorotation. The U. S. Bureau of Standards proposed a method for the quantitative estimation of Gum Arabic using an alcoholic-copper acetate-ammonia solution.

Powder.-Oyster-white; soluble in cold water, forming a sticky paste and containing few or no altered or unaltered starch grains or vegetable tissues.

Constituents.-A crystalline glucoside, which is apparently arabic acid (arabin or gummic acid) in combination with calcium, magnesium and potassium, and which constitutes the greater part of the gum; water, 12 to 17 per cent; ash 2.7 to 4 per cent.

Allied Plants. - Gums with a brown or red color are obtained from A. arabica, A. Seyal, A. stenocarpa and A. Ehrenbergiana. There are a number of gums which have many of the properties of gum Arabic, as Cape gum, from A. horrida and A. Giraffæ; Australian or wattle gum, from the golden wattle (A. pycnantha), tan wattle A. decurrens) and A. homalophylla. Gums are also obtained from other genera of the Leguminosæ, as Mesquite gum, from Prosopis juliflora, of the southern United States and Mexico. The tears of Mesquite gum are nearly smooth, light yellowish-brown to dark 
brown, more or less opaque, but translucent and glassy when fractured. The powder is of a whitish or grayish-white color. The gum is further distinguished by not giving precipitates with solutions of lead sub-acetate, ferric chloride and sodium borate. Mesquite forms a somewhat adhesive mucilage and can be used as an emulsifying agent.

Ghatti gum or Indian gum is an exudation from the wood of Anogeissus latifolia (Fam. Combretaceæ), a tree indigenous to India and Ceylon. It occurs in yellowish-white tears with a dull rough surface and a vitreous fracture. It is entirely soluble in cold water, forming a very viscous mucilage.

Adulterants.-An artificial gum has been prepared by heating starch with sulphuric acid in an autoclave, the resulting product being neutralized, washed and then dried. It is said to resemble acacia in appearance and adhesiveness.

The powder, while sometimes adulterated with dextrin and rice starch, is more frequently mixed with inferior gums, especially the Mesquite gum.

Tragacantha.-Tragacanth.-A gummy exudation from the stem of Astragalus gummifer and other species of Astragalus (Fam. Leguminosæ, sub-fam. Papilionaceæ), small shrubs indigenous to southeastern Europe and western Asia. Some of the walls of the pith and medullary rays are transformed into mucilage, which exudes spontaneously, but is obtained in commercial quantities by making incisions in the bark, the gum being collected after it dries. The principal points of export are Smyrna and various ports along the the Persian Gulf; that obtained from the latter is known as Persian or Syrian Tragacanth and is preferred.

Persian or Syrian Tragacanth.-In flattened, lamellated, ribbonlike pieces, 0.5 to $2.5 \mathrm{~cm}$. in length, about $1 \mathrm{~cm}$. in width and from 1 to $3 \mathrm{~mm}$. in thickness, irregularly oblong, more or less curved; externally nearly colorless or pale yellowish, with numerous concentric ridges or lamellæ; translucent; fracture short, tough, horny, rendered more easily pulverizable by a heat of $50^{\circ} \mathrm{C}$.; inodorous; taste insipid.

Inner Structure.-Pieces of the gum softened in water and mounted in glycerin show numerous lamellæ and a few starch grains, the latter being mostly spheroidal and single, occasionally 2- to 4compound, the individual grains from 0.003 to $0.015 \mathrm{~mm}$. in diameter and colored blue with iodin.

Powder.-Whitish; slowly affected by water; starch grains mostly single, occasionally 2 - to 4 -compound, the individual grains 
spheroidal or ellipsoidal, from 0.003 to $0.015 \mathrm{~mm}$. in diameter, a few of the grains being swollen and more or less altered.

Constituents.-Bassorin (traganthin), 60 to 70 per cent, which gives the mucilage made from this gum its peculiar density, and which serves to distinguish it from acacia, which contains little or no gassorin; a carbohydrate apparently in the nature of an insoluble compound of arabic (gummic) acid, which swells in water but is insoluble in it; arabin, about 10 per cent, soluble in water and probably formed from traganthin; starch; ash about 3 per cent, of which one-half is calcium carbonate.

A solution of $2 \mathrm{gm}$. of gum tragacanth and 100 c.c. of water is neutral in reaction to litmus; gives a blue color with iodin; froths on shaking with an equal volume of a 5 per cent solution of potassium hydroxide, becoming yellow on heating; darkens slowly when 2 per cent of powdered borax is dissolved in it in the cold, but does not change in consistency even on standing two or three days (while Indian gum becomes slimy and stringy).

Indian gum, or Karaya gum, is obtained from Cochlospermum gossypium (Fam. Bixaceæ) and is used in India as a substitute for tragacanth. This name is also applied to a gum obtained from Sterculia urens, a tree growing in Africa and Australia. The gum occurs in vermiform or rounded tears, with a dull, rough surface and uniform vitreous fracture. Pieces of the gum, softened in water and mounted in glycerin, show numerous threads of a granular substance, sometimes the hyphæ of a fungus and chains of bacteria, and occasional fragments of a yellowish-brown or reddish-brown color, containing lignified wood fibers, a few rosette aggregates of calcium oxalate from 0.020 to $0.030 \mathrm{~mm}$. in diameter, and a few spheroidal starch grains from 0.003 to $0.007 \mathrm{~mm}$. in diameter. Although inferior to Tragacanth, Karaya gum has valuable properties and its commerical use should be extended. (See Ewing, Jour. A. Ph. A., 1918, 7, p. 787.)

Ghatti gum is also called Indian gum (see Acacia).

Sarcocolla is a gummy exudation of Penæa Sarcocolla and P. mucronata (Fam. Penæaceæ, one of the Myrtifloræ), small shrubs indigenous to southern and central Africa. The gum occurs in small, globular, yellowish-red or brownish-red friable grains, which are often agglutinated into masses and admixed with a few hairs. Sarcocolla has a licorice-like taste. It is soluble in water and alcohol, and contains an uncrystallizable principle, sarcocollin, having a taste of glycyrrhizin; a resin; and a gum.

Catechu.-An extract prepared from the heartwood of Acacia Catechu (Fam. Leguminosæ, sub-fam. Mimosaceæ), a tree indigenous 
to India and Burmah, and from the leaves and twigs of Uncaria (Ourouparia) Gambir (Fam. Rubicaceæ), a climbing shrub or liane indigenous to Malacca, Java and Sumatra and mostly cultivated near Singapore, the former being known as "black catcheu" or "cutch," and the latter as "pale catechu," "gambir," or "terra japonica." These extracts are prepared by boiling the parts of the trees and shrubs yielding catechu with water, evaporating the strained liquid to a syrupy consistence and allowing it to harden.

Black Catechu.-In irregular masses, with fragments of leaves or mats upon the outside reddish-black, somewhat shiny; brittle, more or less porous internally; odor slight; taste astringent and sweetish.

Inner Structure.-Pegu Catechu, when examined in water, shows in the residue a number of anisotropic octahedral crystals (Fig. 36), from 0.010 to $0.035 \mathrm{~mm}$. in diameter; a few tracheæ associated with wood fibers and leaf fragments; numerous reddish brown granular or amorphous fragments containing more or less rod-shaped bacteria.

Catechu is somewhat soluble in cold water, and almost entirely soluble in boiling water, the solution giving an acid reaction, a dense precipitate with solutions of copper sulphate and a greenishblack precipitate with dilute ferric chloride solution; not less than 70 per cent should be soluble in 90 per cent alcohol. Few or no starch grains or vegetable tissues should be present, and the ash should not be more than 5 per cent.

Gambir or Pale Catechu.-Usually in more or less porous irregular cubes, about $25 \mathrm{~mm}$. in diameter; externally dull reddishbrown; friable; internally paler, consisting chiefly of microscopic crystals when examined in hydrated chloral; odor slight; taste bitter and very astringent. About 85 per cent of gambir is soluble in water and about 70 per cent is soluble in 90 per cent alcohol. The aqueous solution gives an intense green color with dilute ferric chloride solution and does not yield a precipitate with copper sulphate solution.

Inner Structure.-Upon scraping a piece of gambir and mounting the separated fragments in solutions of hydrated chloral it shows numerous acicular crystals from 0.010 to $0.030 \mathrm{~mm}$. which separate (Fig. 36) close to the edges of the fragments, and gradually dissolve, leaving a few of the non-glandular hairs, which, when entire, may be as long as $0.350 \mathrm{~mm}$., the walls being very thick and with an even outline; a few fragments of leaves showing small narrow tracheæ with spiral or annular markings; a few starch grains single or compound, from 0.005 to $0.015 \mathrm{~mm}$. in diameter, a number of bacteria are usually present. 
Constituents.-Catechutannic acid, 25 (black catechu) or 22 to 50 per cent (pale catechu), giving a green color and precipitate with solutions of ferric chloride and in other respects resembling the tannin in oak bark, kino and krameria; a substance somewhat resembling gallic acid, catechin, which crystallizes in silky needles; catechu-red; quercetin and ash about 3 per cent. Pale catechu contains in addition a fluorescent principle.

Mangrove Extract.-The bark of the red variety of Rhizophora Mangle or R. mucronata (Fam. Rhizophoraceæ), contains from 17 to 39 per cent of tannic acid. An extract is prepared and sometimes sold for catechu. It gives a green precipitate with solutions of ferric salts; a reddish-black color with a solution of copper sulphate and ammonia; a reddish-brown color with sulphuric acid; a reddish precipitate with lime water, darkened by excess; and a slight reddening with a solution of stannous chloride and hydrochloric acid. It apparently belongs to the same class of tannins as hemlock, oak, rhatany and canaigre.

Allied Plants.-Black catechu is also extracted from the wood of Acacia Suma, of India. The barks of a number of species of Acacia growing in Australia, and known as wattle barks, are used in the preparation of an extract resembling black catechu. The tannin of Acacia arabica and of several species of Cæsalpinia yield on hydrolysis gallic and ellagic acids.

A tannin resembling catechu is obtained from the bark of Eugenia Smithii (Fam. Myrtaceæ) of Australia. A catechu-like extract is obtained from the bark of the Mahogany Tree (Swietenia Mahogoni), one of the Meliceæ, of the West Indies and Central America.

An extract (known as Than), prepared from Terminalia Oliveri (Fam. Combretaceæ), a large tree growing in the dry regions of the Irrawaddy Valley, is used to adulterate Catechu. It contains a darkred coloring principle, but apparently no tannin, although the latter has been reported as occurring to the extent of between 14 and 68 per cent.

Literature.-Ridenour, Jour. Franklin Inst., 1903, p. 417.

KINo.-Malabar or East Indian Kino.-The inspissated juice of Pterocarpus Marsupium, and probably other species of Pterocarpus (Fam. Leguminosæ, sub-fam. Papilionaceæ), trees indigenous to southern India and Ceylon. The juice exudes through incisions made in the bark, and is allowed to dry in the sun. The drug is exported from Madras and is known as Malabar or East Indian Kino.

Description.-Small, angular, opaque, black or reddish-black, translucent, glistening, brittle pieces, nearly free from dust; the 
thin laminæ appearing transparent and ruby-red on the edges; inodorous; sweetish, very astringent and adhering to the teeth when chewed, the saliva being colored red.

Kino is only partly soluble in cold water, and not less than 40 per cent should be soluble in boiling water, the solution having an acid reaction and giving a dark green precipitate with a solution of ferric chloride and a reddish-violet color with solutions of the alkalies. The alcoholic extractive is about 45 per cent. The yield of ash should not exceed 3 per cent.

Powder.-Brownish-red; consisting of sharp angular fragments, which upon the addition of water, partially dissolve, the solution becoming deep red in color and leaving numerous small granules, small rod-shaped bacteria, and a few indistinguishable plant tissues.

Constituents.-Tannin, 40 to 80 per cent, which resembles catechutannin and gives a blackish-green color and precipitate with solutions of ferric chloride, a violet color with solutions of ferrous salts, and the aqueous solutions of which deposit on exposure to air an insoluble, amorphous, reddish substance, kino red; 1.5 per cent of kinoin, a colorless, crystalline substance, which is sparingly soluble in water and yields on hydrolysis, kino red. Kino also contains a small quantity of catechol (pyrocatechin), kino red, gallic acid, resin, gum, pectin, 13 to 15 per cent of moisture; and yields 2 to 6 per cent of ash.

Allied Products.-The term kino is applied to various astringent plant juices which, while they contain large amounts of tannin, do not appear to be as valuable as either the Malabar or Australian kino.

Allied Plants.-Australian kino (Red gum or Eucalyptus gum) is obtained from Eucalyptus rostrata and other species of Eucalpytus. It occurs in masses or small fragments, which are of a ruby or garnetred color (not reddish-black), somewhat dusty, but not so brittle as Malabar kino. It contains 45 to 50 per cent of tannic acid; kino red, and catechin. About 80 to 90 per cent is soluble in cold water, the solution having a neutral reaction. Australian kino seems to be more unstable than Malabar kino and is converted into insoluble kino red, particularly if not thoroughly dried.

Eucalyptus kino is also obtained from the following species: Iron-bark tree (E. Leucoxylon), E. Gunnii, E. obliqua, E. piperata, E. ficifolia, E. stellulata, E. Macrorhyncha, E. amygdalina radiata. Several species of Angophora yield a kino which is wholly soluble in alcohol and is entirely free from gum. So-called Botany Bay 
(Australian) kino was at one time supposed to be obtained from Eucalyptus resinifera.

Jamaica kino is obtained from Coccoloba uvifera (Fam. Polygonaceæ). A number of other India species of Pterocarpus also furnish kino. An African or Gambia kino is obtained from P. erinaceus, of Senegambia.

Butea or Bengal kino is obtained from Butea monosperma, a tree growing in western India and Indo-China.

American dragon's blood, resembling black kino, is obtained from P. Draco, of the West Indies and Guiana. A false dragon's blood is obtained from Copaiba Mopane, of southwestern Africa.

A tannin resembling kino is obtained from the Jambul tree (Syzygium Jambolana), of India. Tannin is also found in the root bark of Jambosa vulgaris, of the East Indies; the bark of Myrtus brabantica, of Mexico and Peru. A tannin and a coloring principle are found in the bark of Myrtus Arayan, of Mexico and Peru. A tannin and resin are found in the bark of Psidium Guajava, of South America and the West Indies; Spermolepis gummifera, of New Caledonia, and the Myrtle tree (Myrtus communis), of southern Asia and the Mediterranean region, the tannin in the latter plant occurring in larger proportion in.the galls which are produced upon it.

Krameria.-Rhatany.-The dried root of various species of Krameria (Fam. Leguminosæ, sub-fam. Cæsalpinaceæ), small shrubs indigenous to South America, Mexico and the West Indies. There are three principal commercial varieties: (1) Peruvian Rhatany, which is derived from plants of Krameria triandra, growing in Peru and Bolivia; (2) Savanilla Rhatany, which is derived from more or less disputed species of Krameria (K. Ixina), growing in the United States of Colombia, British Guiana and Brazil, and (3) Para or Brazilian Rhatany, which is supposed to be derived from Krameria argentea, growing in Brazil.

Peruvian Rhatany.-Consisting of a more or less cylindrical crown $50 \mathrm{~mm}$. in length and 15 to $20 \mathrm{~mm}$. in diameter, and numerous cylindrical, somewhat tapering, branching roots 10 to $40 \mathrm{~cm}$. in length and 1 to $7 \mathrm{~mm}$. in thickness; externally brownish-red, crown with rugged and scaly bark, roots smooth or slightly wrinkled longitudinally; fracture of bark slightly fibrous, of wood, tough and splintery; internally reddish, bark 1 to $2 \mathrm{~mm}$. in thickness, somewhat easily separable from the lighter colored, slightly radiate wood; odor slight; wood nearly tasteless, bark astringent.

Inner Structure.-See Fig. 150. 


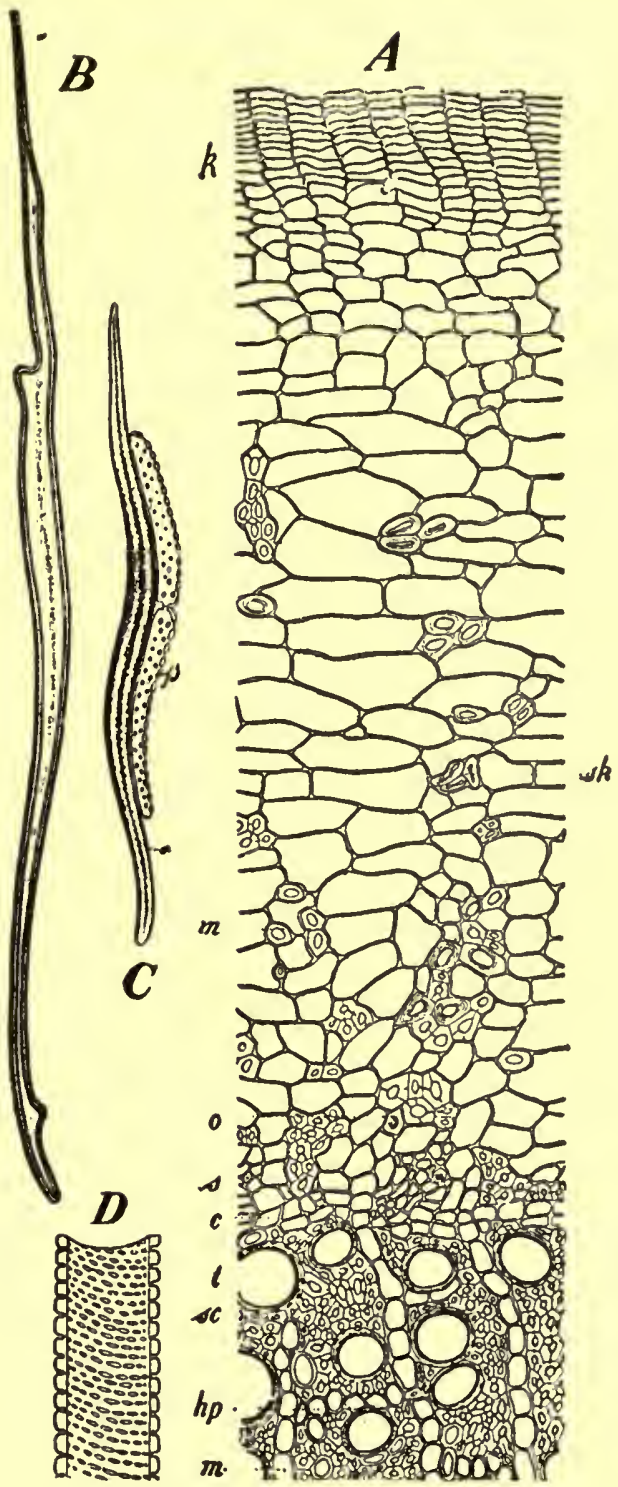

FIg. 150.-Peruvian rhatany: $A$, transverse section showing cork $(k)$, a group of bast fibers $(s k)$, parenchyma of cortex $(p)$, medullary-ray cells of inner bark $(m)$, cambium $(c)$, tracheæ $(t)$, wood fibers $(s c)$, wood parenchyma $(h p)$, medullary rays one cell in width $(m) . \quad B$, an isolated bast fiber. $C$, a wood fiber with neighboring parenchyma cells which are somewhat elongated and have somewhat thickened, porous walls. $D$, portion of a trachea.After Meyer. 
Powder.-Reddish-brown; bast fibers with slightly undulating, non-lignified walls and sharp-pointed ends, frequently associated with crystal fibers; starch grains numerous, single or 2- to 5-compound, the individual grains spheroidal, ellipsoidal, or plano-convex, from 0.003 to $0.035 \mathrm{~mm}$. in diameter and sometimes with a central, radial or star-like cleft; tracheæ with simple or bordered pores, associated with narrow, spindle-shaped, wood fibers having thick, porous, slightly lignified walls; numerous cellular fragments with yellowishor reddish-brown walls; calcium oxalate in monoclinic prisms, 0.010 to $0.100 \mathrm{~mm}$. in length, or in microcrystals.

Savanilla Rhatany.-Crown more or less cylindrical or truncate, rough, knotty; root externally dark reddish-brown, somewhat purplish, with numerous transverse fissures at more or less regular intervals; periderm not scaly; bark about twice as thick as that of Peruvian rhatany.

Para Rhatany closely resembles the Savanilla variety.

Constituents.-Tannin from 8 to 20 per cent, krameric acid, starch, an uncrystallizable sugar, and calcium oxalate. The tannin is colored dark green with solutions of ferric salts and is in the nature of a glucoside resembling the one found in Potentilla Tormentilla (Fam. Rosaceæ) and Esculus Hippocastanum (Fam. Hippocastanaceæ). The tannin also yields phloroglucin and protocatechuic acid.

The tincture of Savanilla rhatany forms a clear solution with water, which gives with an alcoholic solution of lead acetate a purplish precipitate and a colorless filtrate; the tincture of Peruvian rhatany forms a cloudy mixture with water, and gives with an alcoholic solution of lead acetate, a reddish-brown precipitate and a light-brown filtrate, which is not further or altered upon the further addition of a drop or two of the reagent, and should give an olivebrown solution, having a purplish fluorescence, upon the addition of a drop or two of a solution of ferric chloride. Aqueous extractive about 9 per cent. Ash about 5 per cent.

Allied Plants.-Krameria lanceolata of the southern United States furnishes the Texas krameria, and K. cistoides of Chile is the source of the Payta krameria. The root of Leea speciosa (Fam. Vitaceæ), of India has been used as a substitute for Krameria.

Chrysarobinum.-Chrysarobin. Araroba Depurata.-A neutral principle extracted from Goa powder, a substance formed as a result of pathological changes in the woody tissues of Vouacapoua (Andira) Araroba (Fam. Leguminosæ, sub-fam. Papilionaceæ), a large tree growing in the southern portion of the province of Bahia, 
Brazil. Goa powder arises in the living cells of the wood of the stems. The cell walls becomes metamorphosed, finally disintegrated, forming large lacunæ, in which are deposited the altered products in the form of a yellowish-brown powder, which is more or less admixed with the tissues of the bark and wood. The trees are hewn and cut into convenient pieces, the Goa powder being scraped out. The crude article is shipped from Brazil to Europe, where it is purified.

Goa powder when fresh is of a light-yellow color, but on exposure to air it becomes dark brown or brownish-purple. It is composed of small, wine-colored, somewhat translucent, irregular, angular fragments, with a few fragments of tracheæ and libriform cells having bordered pores. It is nearly insoluble in water, soluble in alcohol, chloroform and solutions of the alkalies, the latter being colored deep red and showing a green fluorescence. It should contain between 50 and 75 per cent of a neutral principle, chrysarobin, which is official in several of the Pharmacopoias. It also contains about 2 per cent of resin; 7 per cent of bitter extractive; a small amount of chrysophanic acid, and yields about 3 per cent of ash. Under the microscope the powder sometimes shows colorless prismatic crystals.

Hesse considers that the therapeutic activity of the drug is due to two anthranols. (Pharm. Jour., 1917, p. 353.)

Chrysarobin or purified Goa powder is a golden yellow crystalline powder, becoming dark brown on exposure to the air and is inodorous and tasteless. It consists of needle-shaped crystals or large prisms, frequently united in spheroidal or irregular aggregates. Upon mixing $0.001 \mathrm{gm}$. of chrysarobin with 2000 c.c. of hot water, a light yellowish or brownish solution is obtained, which does not change litmus paper, nor give a precipitate with solutions of ferric salts. Upon treating chrysarobin with ammonia or lime water and exposing it to air for a day or so it assumes a carmine-like color changing to violet, due to its oxidation to chrysophanic acid. With either sulphuric acid, or strong solution of the alkalies, chrysarobin is colored red. It is almost insoluble in dilute solutions of the alkalies.

Copaiba.-Balsamum Copaive; Balsam Copaiva or Balsam of Copaiba.- An oleo-resin obtained from several species of Copaiba (Fam. Leguminosæ, sub-fam. Cæsalpinaceæ), trees growing in tropical South America. The oleo-resin is formed in schizo-lysigenous cavities, being a metamorphosed product of the cell walls of the wood parenchyma. The cavities increase in size, unite with each other to form large reservoirs, holding sometimes from 40 to $50 \mathrm{~L}$. of oleo-resin. It exudes spontaneously, but is usually obtained by making incisions into the heartwood, about $60 \mathrm{~cm}$. from the ground. 
There are two principal commercial varieties: (1) Para or Maranham Copaiba obtained from Copaiba Langsdorffii and C. coriacea, which is optically lævogyrate. (2) Maracaibo or Venezuela Copaiba from Copaiba officinalis and Guyanensis, which is more viscid, darker in color and dextrogyrate.

Description.-A pale yellowish to yellowish-brown, viscid liquid, more or less transparent and highly refracting, sometimes slightly fluorescent, having a distinct aromatic odor and a bitter, acrid, persistent taste. It is soluble in absolute alcohol, chloroform, ether, and carbon disulphide. When gently heated it should not emit an odor of oil of turpentine or colophony. Upon mixing $3 \mathrm{gm}$. of the oleoresin with 2 c.c. of petroleum ether it should yield a clear solution (distinction from Gurjun Balsam). Upon mixing $1 \mathrm{gm}$. of Copaiba with 3 c.c. of alcohol, heating to boiling for one minute and allowing it to cool, the liquid should remain clear without the separation of oily globules (absence of liquid paraffin or castor oil).

Constituents.-Volatile oil from 40 to 65 per cent, containing caryophyllene, which also occurs in Oil of Cloves; resin acids from 35 to 40 per cent; a small quantity of a bitter principle and an indifferent resin acid, resene.

Allied Plants.-Trinidad Copaiba is obtained from Copaiba Jacquini and possesses a terebinthinate odor. African Copaiba, obtained from an unknown tree of western Africa, contains 10 per cent of water and yieids from 40 to 45 per cent of a volatile oil, which is free from caryophyllene.

Adulterants.-Oil of turpentine, Gurjun balsam, eastor oil, olive oil, liquid paraffin, colophony and styrax.

Balsamum Peruvianum.-Balsam of Peru or Peru Balsam.A balsam obtained from Toluifera Pereiræ (Fam. Leguminosæ, subfam. Papilionaceæ), an evergreen tree with a short, thick trunk, growing in the mountainous forests on the coast of Salvador, Central America. Tschirch considers the tree yielding Peru balsam merely as a physiological variety of the same tree yielding Tolu balsam, Toluifera Balsamum Pereiræ. The balsam is formed by reason of mechanical injuries to the trees. Schizogenous secretion canals occur only in the young twigs, petioles and leaves, but are not formed in the older bark. The process of producing the balsam is an ancient custom, and is in essential points the following: During the rainy season in November and December the bark of the balsam trees is beaten with a hammer on all sides, leaving uninjured areas between, this being done so as not to kill the trees. The injured bark soon cracks and can be stripped off in rather long pieces. The cell-walls of the 
inner bark and their contents change to a balsam, due to the decomposition of the cell sap or metamorphosis of the cell-walls. In the course of a week or so, the maximum yield of balsam is obtained, and it soaks into the rags which have been applied to the bark. The rags are then collected, thrown into vessels containing water and boiled, until the balsam is liberated, and settles to the bottom. The water is decanted and the balsam poured into gourds or tin containers, the latter when filled, weighing from 10 to $40 \mathrm{~K}$. and are usually shipped direct to Hamburg.

Description.-A dark brown, viscid liquid, ruby-red and transparent; in thin layers, free from stringiness or stickiness; of an empyreumatic, aromatic vanilla-like odor, and a bitter acrid persistent taste. Soluble in alcohol, chloroform, and only partially soluble in ether and petroleum benzin. Upon digesting $1 \mathrm{gm}$. of Peru balsam with 10 c.c. of petroleum ether in a reflux condenser for ten minutes, and filtering, the ethereal solution should yield on evaporation a residue that is not colored bluish-green with nitric acid; nor should 3 c.c. of the petroleum ether solution give a green or bluishgreen color upon shaking it with 3 c.c. of a solution (1 in 1000) of copper acetate (detection of Colophony).

Constituents.-A volatile oil known as Cinnamein or Peru Balsam Oil, from 62 to 64 per cent and consisting chiefly of benzyl benzoate and a small quantity of benzyl cinnamate and other aromatic compounds. Peru Balsam also contains $\mathbf{0 . 0 5}$ per cent of vanillin; from 30 to 38 per cent of resin esters, consisting chiefly of a cinnamic ester of peru-resinotannol and a small quantity of a benzoic ester of peruresinotannol; free cinnamic acid peruviol, and dihydro-cinnamic acid. The Peru balsam is valued according to the content of volatile oil or cinnamein which it contains.

Literature.-Zörnig, Arzneidrogen.

Balsamum Tolutanum.-Balsam of Tolu or Tulo Balsam.A balsamic resin obtained from Toluifera Pereiræ (Fam. Leguminosæ, sub-fam. Papilionaceæ), a tree growing in the lower Magdalene River, Colombia. The balsam is largely produced in the province of Tolu and from which it derives its name. According to Tschirch the plants yielding Tolu and Peru balsams are physiological varieties of the same species. Balsam of Tolu is usually considered to be a pathological product similar to balsam of Peru; this, however, seems to be doubtful in view of the manner in which the balsam is obtained. It is collected after the same manner as that of the coniferous oleoresins, V-shaped incisions are made through the bark, extending into the wood, sufficiently to place a calabash cup so as to receive the 
flow of balsam. Similar cuts are made higher up in the trees, sometimes as many as twenty incisions being made on one tree. The balsam gatherer from time to time empties the exudation which fill the calabashes into bags of hide. These are then shipped to Savanilla and transferred to cylindrical tin vessels, in which form they are sent to Europe.

Description.-A semi-liquid mass of a yellowish-red color, which gradually hardens becoming yellowish- or reddish-brown; transparent in thin layers; pulverizable, and showing numerous crystals of cinnamic acid; odor agreeably aromatic, suggesting vanilla and benzoic acid; taste aromatic, slightly pungent and acid. Soluble in alcohol, acetone, chloroform and solutions of potassium hydrate. An alcoholic solution ( 5 or 10 per cent) of tolu balsam gives an acid reaction with litmus paper, a greenish color with a solution of ferric chloride, and upon evaporation yields crystals of cinnamic acid.

Constituents.-About 7 per cent of an aromatic volatile oil, consisting chiefly of benzyl benzoate and a small quantity of benzyl cinnamate; from 0.2 to 1 per cent of a light volatile oil having a pleasant, aromatic odor, suggestive of hyacinth. From 75 to 80 per cent of a resin consisting chiefly of a cinnamic ester of toluresinotannol, and a small quantity of a benzoic ester of tolu-resinotannol. Tolu balsam also contains 0.25 per cent of vanillin; 12 to 15 per cent of free cinnamic acid and from 1 to 2 per cent of free benzoic acid.

Literature.-Cocking and Kettle, Pharm. Jour., 1918, 101, p. 40.

BAptisIA.-Radix Baptisiæ Tinctoriæ, Wild Indigo Root.The dried rhizome and roots of Baptisia tinctoria, a perennial herb growing in the eastern United States and Canada. The drug is gathered in the fall, cut into small pieces and dried.

Description.-Rhizome cylindrical, branching, short, from 1 to 2 $\mathrm{cm}$. in thickness; the terete roots usually in pieces, from 8 to $30 \mathrm{~cm}$. in length and 2 to $5 \mathrm{~mm}$. in thickness, externally light reddish-brown, longitudinally wrinkled, occasionally spirally twisted, cork somewhat scaly and roots with long wiry, somewhat branching rootlets; fracture short, fibrous; inner surface light yellow, bark thick, and easily separable from the porous radiate wood; odor distinct, fragrant; taste bitter and slightly acrid.

Inner Structure.-See Fig. 151.

Powder.-Light brown; starch grains numerous, either single or compound, the individual grains spheroidal, plano-convex or polygonal, from 0.003 to $0.015 \mathrm{~mm}$. in diameter; tracheæ with simple, long slit-like pores or bordered pores; wood and bast fibers very long, 

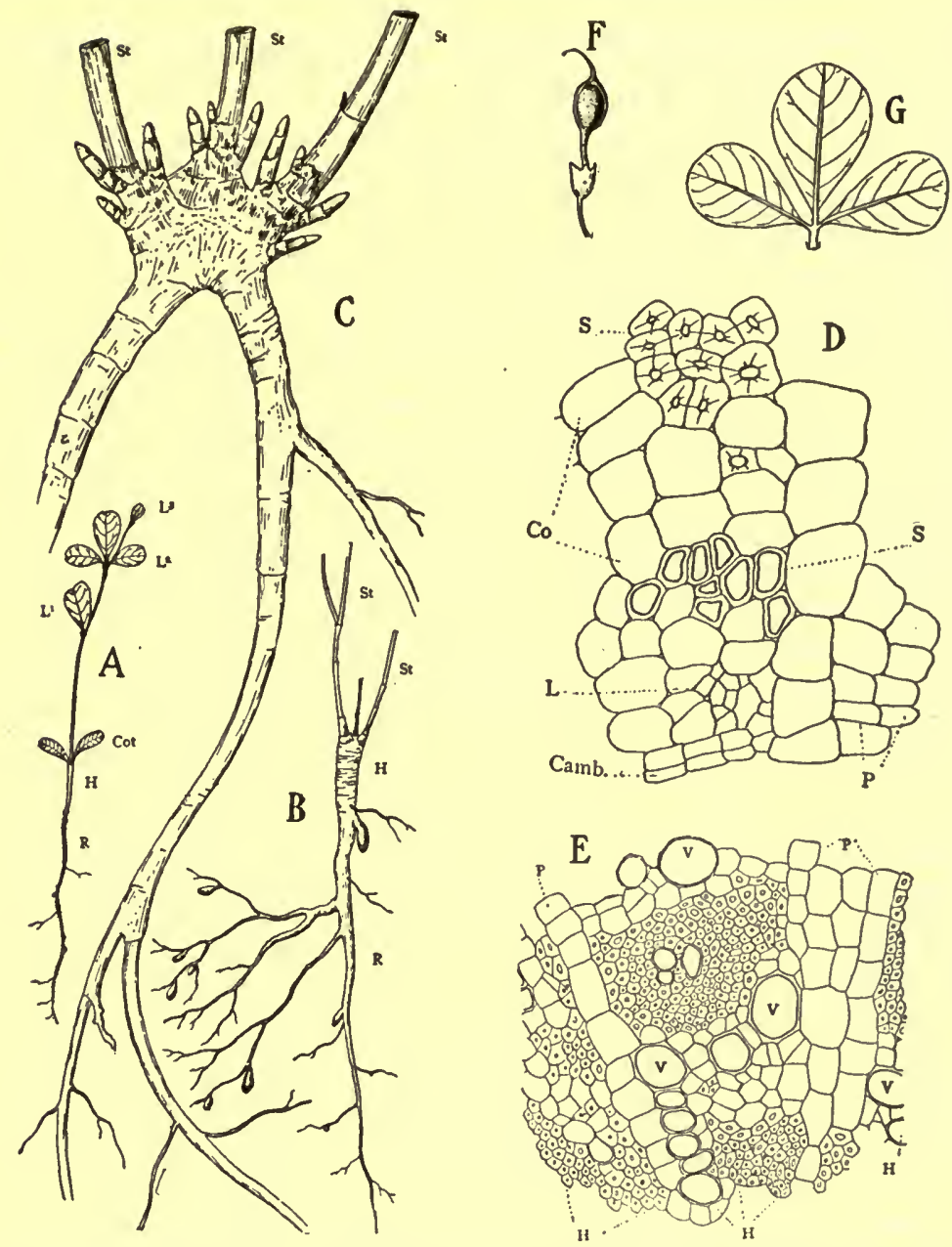

FIg. 151.-Baptisia: $A$, seedling plant in its first year, showing the primary root $(R)$, the hypocotyl $(H)$, the cotyledons $(C o t)$, and a stem above ground with three green leaves $(L)$. $B$, a seedling in its second year, showing the base of two aerial stems $(S t)$, developed from the axils of the cotyledons; between these stems is the withered base of the first shoot of the seedling. The young rootlets show the production of tubercles which contain the nitrifying bacteria. $C$, rhizome bearing at the crown a number of over-wintering buds. the base of three aerial shoots and two long roots. $D$, transverse section of part of a root, showing strands of stereome or sclerenchymatous fibers $(S)$, which occur in the secondary cortex $(C o)$; a strand of leptome $(L)$, cambium $(C a m b$.$) and medullary rays (P) . \quad E$, transverse section of part of root-stele; the hadrome or xylem $(H)$ occurs in three rays separated by narrow medullary rays $(P)$ consisting of parenchyma; trachex or vessels $(V) . F$, an ovoid legume, tipped with the long, curved, subulate style. $G$, one of the 3 -foliate leaves, the individual leaflets being obovate.-After Holm, Merck's Report. 1908, p. 295. 
with sharp attenuated ends and very thick, non-lignified walls; medullary rays 1 to 2 cells wide, having thick porous walls and containing numerous starch grains; starch-bearing parenchyma; fragments of yellowish-brown cork, the walls becoming faintly cherry-red upon the addition of a solution of phloroglucin and hydrochloric acid.

Constituents.-A crystalline alkaloid, cytisine (baptitoxine), which is very soluble in water and alcohol and is almost insoluble in ether and chloroform. It also occurs in Laburnum (Cytisus Laburnum). It also contains baptin, which forms acicular crystals and is purgative; and about 6 per cent of baptisin which occurs in crystals and appears to be a glucoside.

GaLEGA.-Herba Galegæ, European Goat's Rue.-The dried flowering tops of Galega officinalis (Fam. Leguminosæ, sub-fam. Papilionaceæ), a perennial herb common in southern Europe and to some extent cultivated. The tops are gathered in July and August, at the time of the flowering of the plant, and carefully dried.

Description.-Stem cylindrical, hollow, from 2 to $5 \mathrm{~mm}$. in diameter, pale green or greenish-brown, distinctly longitudinally ribbed or furrowed; leaves odd-pinnate, leaflets nearly sessile, elliptical, entire and mucronate tipped, from 10 to $40 \mathrm{~mm}$. in length and from 5 to 12 $\mathrm{mm}$. in width, of a light green or greenish-brown color, nearly glabrous; flowers about $15 \mathrm{~mm}$. in length, white or violet-blue and borne in racemes; calyx tube about $4 \mathrm{~mm}$. in length and with long, bristly pointed teeth; corolla papilionaceous; fruit a flat, linear legume from 2 to $4 \mathrm{~cm}$. in length and from 2 to $4 \mathrm{~mm}$. in width with a very sharp, bristly pointed or thread-like summit; seeds from 4 to 6 in each legume, broadly elliptical, compressed from 2 to $4 \mathrm{~mm}$. in length, brownish-black in color; odor slight; taste slightly bitter.

Constituents.-A bitter principle and tannic acid.

Melilotus.-Herba Meliloti, Yellow Melilot, Yellow Sweet Clover.-The dried leaves and flowering tops of Melilotus officinalis (Fam. Leguminosæ, sub-fam. Papilionaceæ), a biennial herb indigenous to Europe and common in waste places throughout the United States.

Description.-Stem from 2 to $5 \mathrm{~mm}$. in thickness, longitudinally furrowed, light olive-green and nearly glabrous, or the young twigs finally pubescent; leaves trifoliate, having petioles from 5 to $10 \mathrm{~mm}$. in length, the leaflets obovate-oblong, summit rounded or obtuse margin closely serrate; flowers in small spike-like racemes; corolla papilionaceous, when fresh yellow, on drying, yellowish-brown, and about $3 \mathrm{~mm}$. in length; pods ovoid, about $4 \mathrm{~mm}$. in length, scarcely dehiscent and containing 1 or 2 seeds; odor fragrant, resembling coumarin; taste slightly bitter and pungent. 
Powder.-Light green; non-glandular hairs, uniseriate, 3-celled; fragments of calyx having glandular hairs, consisting of a 2- to 3celled stalk and a multicellular head; tracheæ and sclerenchymatous fibers associated with crystal fibers, each of the cells of the latter having a single rhombohedral crystal; pollen grains ellipsoidal, having three thin places for germination of pollen tubes.

Constituents.-Coumarin; melilotic acid, in part free and combined with coumarin; a volatile oil (melilotal) which is probably anhydride or lactone of melilotic acid.

Soy Bean.-The seeds of Glycine hispida (Fam. Leguminosæ, sub-fam. Papilionaceæ), an important food plant and forage crop. The plant is an annual with trifoliate hairy leaves, rather inconspicuous pale or violet-colored flowers, and with broad pods containing 2 to 5 seeds. The seeds are more or less compressed, spheroidal or elliptical and vary in color from whitish or yellowish-green to brownish-black. The yield of seed per acre may run as high as 40 bushels. As a forage crop it yields when cured as high as 2 to 3 tons of hay per acre. The seeds contain about 5 per cent of starch and nearly 50 per cent protein substances. The seeds are, therefore, very nutritive and are extensively used in feeding of live stock. In Japan the seeds are known as " Soy," being derived from the Japanese word "Shoyu," in allusion to a preparation made from the seeds. In Europe it is also used to a limited extent as a food. In this country it is used to some extent as a food for persons suffering from diabetes.

Literature.-Manufacture of oil. Amer. Jour. Pharm., 1918, 90, p. 139.

Trifolium.-Red Clover Blossoms.-The flowering heads of Trifolium pratense (Fam. Leguminosæ, sub-fam. Papilionaceæ), a perennial herb commonly cultivated for fodder and naturalized throughout the United States.

Description.-Heads globose or ovoid, from 1.5 to $3 \mathrm{~cm}$. in length, consisting of numerous purplish-red or pinkish-brown papilionaceous flowers, about $10 \mathrm{~mm}$. in length; calyx pubescent, and with subulate teeth shorter than the corolla; odor fragrant; taste somewhat sweetish and bitter.

Constituents. - A volatile oil, coumaric acid, salicylic acid, myricyl alcohol, heptacosane, hentriacontane, sitosterol, isorhamnetin, together with several new phenolic substances and glucosides, a mixture of fatty acids and a considerable quantity of sugar.-Power, Journ. Chem. Soc., 1910, p. 231.

Allied Plants.-The flowers of Trifolium incarnatum (Fam. Leguminosæ), contain a volatile oil, a quantity of sugar, benzoic 
and salicylic acids, with apparently a trace of P-coumaric acid, partol, quercetin, and a new glucoside, designated incarnatrin, an alcohol, hentriacontane, a phytosterol, a phytosterol glucoside and a mixture of fatty acids.-Power, Journ. Chem. Soc., 1910, p. 1004.

Abrus.-Abri Semina, Semen Jequirity, Jequirity, Wild Liquorice SEeD.-The seeds of Abrus precatorious (Fam. Leguminosæ, sub-fam. Papilionaceæ), a climbing shrub common to tropical and sub-tropical countries of both hemispheres. The roots are known as Wild or Indian liquorice and contain 1.5 per cent of a substance resembling glycyrrhizin. They also contain 8 per cent of an acrid resin and a small quantity of an alkaloid, abrine, which precludes the root being substituted for glycyrrhiza. The leaves yield about 10 per cent of glycyrrhizin. The seeds have been employed in the making of rosaries and are known as prayer beads. Owing to their toxic properties, care should be exercised when they are used by children.

Description.-Ovoid, globular, from 5 to $9 \mathrm{~mm}$. in length, hard, smooth and shining, of two distinct colors, the lower or hilum portion scarlet red and with a large lenticular scar; the upper portion purplish-black; testa, shell-like and enclosing a light yellowishbrown embryo having two large cotyledons and an incurved radicle.

Inner Structure.-Epidermis of palisade-like stone cells having characteristic thickened walls and containing either a reddish pigment, colored orange-red upon the addition of solutions of the alkalies, or a violet pigment in the blackish layers; a layer of peculiarly thickened cells having large intercellular spaces; a broad strand of parenchyma; perisperm of thin-walled mucilage cells; cotyledons of polyhedral parenchyma cells with thick porous walls, and containing a granular content which is apparently neither starch nor aleurone.

Constituents.-Abrin (jequiritin), an agglutinating phytalbumose, resembling in its physiological action ricin. It is very toxic, is soluble in a solution of sodium chloride and decomposed upon heating to $85^{\circ} \mathrm{C}$. Recent researches show it to be composed of abrusalbumin ( $\alpha$-phytalbumose) and abrusglobin. It also contains an enzyme, abric acid and a coloring principle.

Phaseolus Multiflorus.- Scarlet Runner Bean.-A wellknown, largely used vegetable (Fam. Leguminosæ, sub-fam. Papilionaceæ). It has been stated that the roots of this plant are narcotic and poisonous. A chemical examination was made of a quantity of roots which were obtained from plants cultivated at Dartford, Kent, and the following products were isolated: an enzyme which hydrolyzed amygdalin; a small amount of an essential oil; furan- 
$\beta$-carboxylic acid; allantoin; a phytosterol; small amounts of a phytosterol glucoside and pentatriacontane; a new crystalline glucoside, phaseosaponin, and a mixture of fatty acids. The roots also contain some resin and amorphous glucosidic material and a quantity of reducing sugar. No alkaloid was present, nor could any trace of a compound capable of yielding hydrogen cyanide be detected. Physiological tests, in conjunction with the results of the chemical examination, afforded no evidence that the roots of the scarlet runner bean, as obtained from cultivated plants, possess the toxic properties ascribed to them.-Power, Pharm. Jour., 1913, p. 550.

Erythrophloeum Guineense.-The bark of Erythrophloeum Guineense (Fam. Leguminosæ, sub-fam. Cæsalpinaceæ), a tree indigenous to central and western Africa. The bark of the tree is also known as sassy bark, casca bark, doom bark, and in the vernacular of the Congo as Nkasa. It has been employed by the natives of western Africa as an ordeal in their trials for witcheraft and sorcery, as well as for other criminal purposes, and apparently also enters into the composition of the arrow-poison of the Pigmies. A chemical examination of the bark resulted in the isolation of several wellknown compounds and the presence of a highly toxic alkaloid, designated by previous investigators as erythrophleine. Neither this alkaloid nor its salts could, however, be obtained in a crystalline state.-Power, Amer. Jour. Pharm., 1912, p. 337.

Robinia Pseudo-acacia or common locust (Fam. Leguminosæ, sub-fam. Papilionaceæ).-The bark of this well-known tree possesses highly poisonous properties. These are due to the presence of a protein, Robin, which is soluble in water.-Power, Amer. Jour. Pharm., 1913, p. 339.

Derris Ulignosa (Fam. Leguminosæ, sub-fam. Papilionaceæ).The stem of this species of Derris is used in the Far East as a fish poison. The material employed for its investigation was obtained from the Fiji Islands. It was ascertained that the poisonous property resides in a resin, which, together with other constituents of the drug, was chemically examined.-Power, Proc. A. Ph. A., 1902, p. 296.

\section{GERANIACEE, OR GERANIUM FAMILY}

A small family of about 500 species, native to temperate climates and most abundant in South Africa. The flowers are perfect, regular, 5-merous and hypogynous. The fruit is an elastically dehiscent capsule separating with their long styles from the axis. 
Among the anatomical characters peculiar to the plants of this family, the following may be mentioned. Schizogenous secretory cavities containing either an amorphous or crystalline brownish-red substance are found in a number of species of Oxalis. Tanninsecreting cells are common in the roots of Geranium. Calcium oxalate is secreted usually in the form of solitary crystals or rosette aggregates, raphides occurring only in the mucilage cells of Impatiens. In the pericycle there occur either isolated groups of bast fibers or a composite and continuous ring of sclerenchymatous tissues. The tracheæ have either simple porous walls or annular and spiral thickenings. Myrosin cells, which are characteristic of the Cruciferæ and have already been described, occur in Tropæolum.

Geranium.-Wild or Spotted Cranesbill.-The dried rhizome of Geranium maculatum (Fam. Geraniaceæ), a perennial herb, indigenous to Canada and the eastern and central United States. The rhizome is collected in the late summer or early autumn.

Description.-Horizontal, cylindrical, tuberculate, or irregularly curved, 2.5 to $5 \mathrm{~cm}$. in length, 3 to $10 \mathrm{~mm}$. in diameter; externally dark brown, wrinkled, upper and side portions with numerous buds or circular stem-scars, under surface with numerous root-scars; fracture short; internally light brown, bark thin, wood indistinct, pith large; odor slight; taste astringent.

Inner Structure.-Cork consisting of several rows of tangentially elongated cells; cortex of starch-bearing parenchyma and cells containing rosette aggregates of calcium oxalate. The stele is somewhat excentric, having a closed ring of cambium, of which the interfascicular is especially developed. Fibrovascular bundles are of the col. lateral type and between them occur isolated strands of leptome (several in each ray) which are developed from the interfascicular cambium; pith composed of numerous starch-bearing parenchyma cells and apparently free from calcium oxalate. With the exception of the tracheæ there are no lignified tissues.

Powder.-Dark brown; starch grains somewhat ellipsoidal or ovoid, from 0.010 to $0.015 \mathrm{~mm}$. in diameter; rosette aggregates of calcium oxalate, 0.045 to $0.070 \mathrm{~mm}$. in diameter; tracheæ annular or scalariform; parenchyma with irregular tannin masses.

Constituents.-Tannin 15 to 25 per cent, which on hydrolysis yields gallic acid; starch, and calcium oxalate.

Allied Plants.-Other species of Geranium contain similar principles. 


\section{LINACEE, OR FLAX FAMILY}

A small family of herbs and shrubs having perfect, regular, 4to 6-merous, hypogynous and nearly symmetrical flowers. The fruit is usually a capsule, containing 1 or 2 seeds in each locule, there usually being twice as many locules as there are styles. Of special anatomical interest is the mucilaginous epidermal layer in the seeds and leaves of Linum. Calcium oxalate is secreted only in the form of solitary crystals. The non-glandular hairs are of the unicellular type. Glandular hairs when present always have a multicellular stalk. The tracheæ usually have simple pores and the sclerenchymatous fibers are generally marked by bordered pores.

Linum.-Linseed or Flaxseed.-The seed of Linum usitatissimum (Fam. Linaceæ), an annual, which is cultivated in nearly all temperate and tropical regions, either for the fiber (flax) or seed.

Description.-Anatropous, ovid or oblong-lanceolate, flattened, somewhat less rounded on one side and on one margin, summit acute or beaked, chalazal end rounded, plano-convex in cross-section; from 4 to $5 \mathrm{~mm}$. in length, 2 to $2.5 \mathrm{~mm}$. in breadth, 0.5 to $0.75 \mathrm{~mm}$. in thickness; externally light brown, very smooth and glossy, the raphe extending as a distinct, light yellow ridge along one edge, outer wall of epidermal cells transparent, mucilaginous and swelling in water; easily cut; endosperm white, adhering to the seed-coat, embryo light green, straight, 3 to $4 \mathrm{~mm}$. in length, 1 to $2 \mathrm{~mm}$. in breadth, cotyledons plano-convex; odor slight; taste mucilaginous and slightly unpleasant.

Inner Structure.-(Fig. 152). A thin mucilaginous epidermis; two layers of parenchyma which overlie a continuous ring of stone-

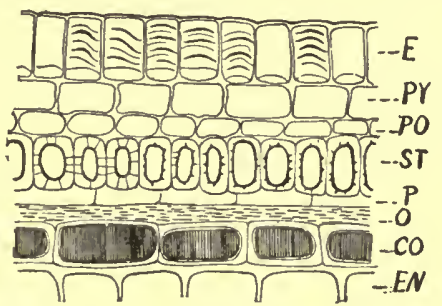

Fig. 152.-Transverse section of flaxseed: $E$, epidermal cells with small lumina and very thick outer wall showing mucilage lamellæ; $P Y, P O$, parenchyma cells; $S T$, stone cells; $P$, parenchyma beneath stone cells; $O$, obliterated cells; $\mathrm{CO}$, cells with reddish-brown contents; $E N$, endosperm.

cells having yellowish, porous walls and rather large lumina; a pigment layer, the cells having a reddish-brown content; endosperm 
consisting of from 6 to 10 rows of cells, surrounding the two large plano-convex cotyledons; the cells of both the endosperm and the cotyledons contain a fixed oil and aleurone grains, the latter being from 0.003 to $0.020 \mathrm{~mm}$. in diameter.

Linseed or Flaxseed Meal.-(Fig. 153.) Lemon-yellow; fragments of seed-coat with mucilaginous epidermal cells; sub-epidermal tissue composed of two rows of yellowish cells with rather large intercellular spaces; a layer of sclerenchymatous fibers, which are 0.100 to $0.250 \mathrm{~mm}$. in length and about $0.010 \mathrm{~mm}$. in diameter and with numerous simple pores; several layers of obliterated cells; and a layer of pigment cells which are more or less tabular or polygonal, tangentially elongated and with a reddish- or yellowish-brown pigment, which is colored dark blue with solutions of ferric chloride.

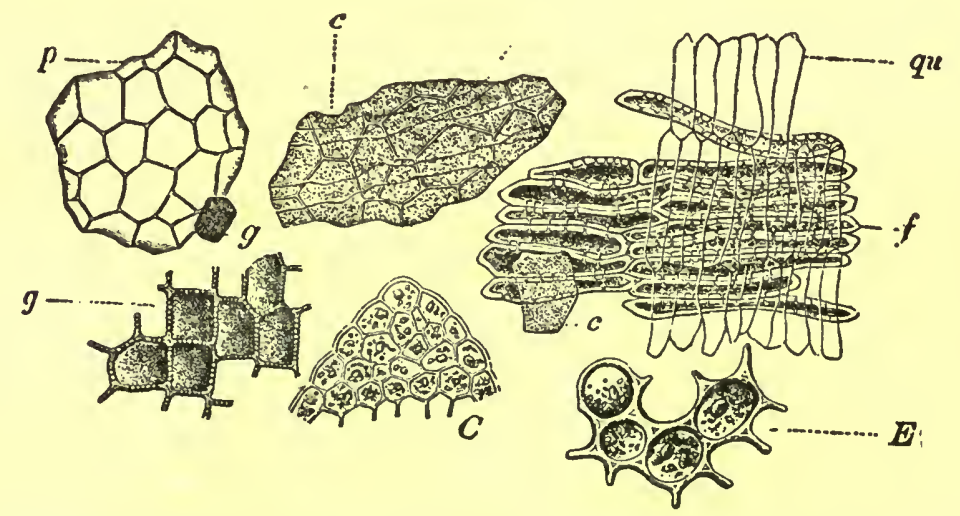

FIG. 153.-Ground flaxseed: $p$, epidermis; $c$, epidermal cells with broken cutinized layer; $E$, parenchyma cells beneath the epidermis; $f$, short sclerenchymatous fibers; $q u$, colorless cells beneath the sclerenchymatous fibers; $g$, pigment cells with thick, porous walls and yellowish-brown contents; $C$, cells of cotyledons containing aleurone grains.-After Moeller.

The endosperm is made up of 2 to 6 layers of cells containing oil and difficultly distinguishable protein grains. The embryo contains considerable oil and large aleurone grains 0.010 to $0.020 \mathrm{~mm}$. in diameter, the crystalloids of which can be more readily discerned on treating the material first with chloroform and then mounting in an iodin solution. Flaxseed does not contain starch and the commercial product should not show more than 10 starch grains to a milligram of powder; it should yield not less than 30 per cent of a saponifiable oil, and not more than 6 per cent of ash.

Ground flaxseed is sometimes infested by maggots. In order to 
obviate this, it should be recently prepared and carefully preserved in tin cans with the addition of a few drops of chloroform.

Ground flaxseed (flaxseed meal or crushed linseed) is not infrequently deficient in oil on account of its being admixed with " oilcake" or "cake-meal." The latter is the residue after expressing about 20 to 30 per cent of the oil naturally occurring in the crushed linseed, and the deficiency is sometimes made up by the addition of mineral oils. Ground flaxseed sometimes contains fragments of the cereals rye and wheat, which is partly due to the fact that these cereals grow in with the flax, and partly because it is sometimes shipped in meal or flour sacks.

Constituents.-Fixed oil 30 to 40 per cent; proteins about 25 per cent; mucilage in outer walls of the epidermal cells; ash 1 to 4 per cent.

Allied Plant.-In False Flax (Camelina sativa) of Europe the sclerenchymatous fibers are replaced by broad, short stone cells, and the epidermal cells on the addition of water eject a central column of mucilage.

\section{ERYTHROXYLACEE, OR COCA FAMIY}

A very small family represented by 2 genera, the more important of which is Erythroxylon. They are mostly tropical shrubs with entire leaves, 5-merous flowers and the fruit is a 1-seeded, reddish drupe resembling that of dogwood. The anatomy of the plants of this family closer resembles that of the Linaceæ. Of special interest is the development of papillæ on the dorsal surface of the leaves and is characteristic of Erythroxylon Coca (Fig. 155).

Coca.-Coca Leaves.-The leaves of Erythroxylon Coca, and its varieties (Fam. Erythroxylaceæ), shrubs (Fig. 154) probably indigenous to Bolivia and Peru, where they are extensively cultivated, as well as in Java and Ceylon. The leaves when fully grown are picked and quickly dried in the sun. Two or three harvests are obtained a year. There are two principal commercial varietiesBolivian (Huanco) and Peruvian (Truxillo), the former being preferred. On keeping the leaves the alkaloid cocaine is dissipated and they lose their stimulating properties, particularly if they are not thoroughly dried.

Bolivian Coca.-Oval, obovate or elliptical, 3 to $7 \mathrm{~cm}$. in length, 2 to $3 \mathrm{~cm}$. in breadth (Fig. 154); summit acute, slightly mucronate; base acute; margin entire, somewhat revolute; upper surface dark green, glabrous, midrib with a distinct ridge; under surface yellowish- 
green, distinctly undulate, with numerous minute papillæ, frequently with a parallel line about $4 \mathrm{~mm}$. from the midrib on either side and extending from the base to the summit; petiole dark brown, 1 to 6 $\mathrm{mm}$. in length; texture somewhat coriaceous; odor distinct; with a bitter taste, and producing a sensation of numbness.

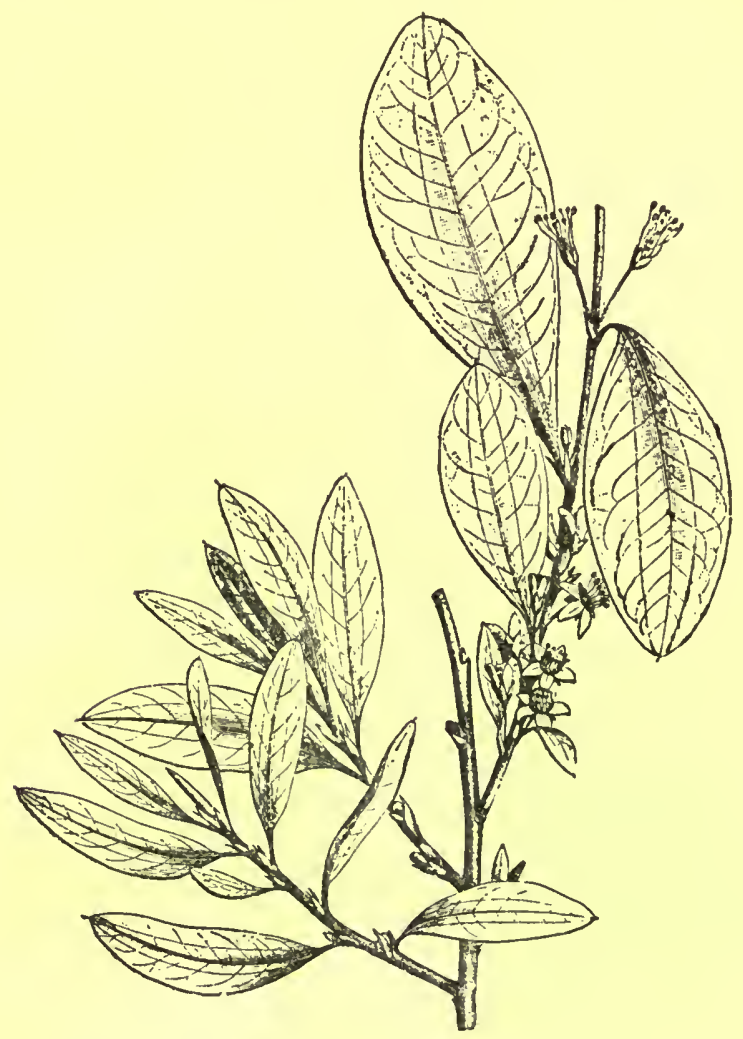

FIG. 154.-Flowering branch of Erythroxylon Coca, showing the parallel lines on either side of the midrib, which are not true veins, but due to an extra development of hypodermal cells in this region.-After Reiche.

Inner Structure.-See Fig. 155.

Peruvian Coca.-Leaves usually more broken, 3 to $5.5 \mathrm{~cm}$. in length, 1.5 to $2 \mathrm{~cm}$. in breadth; upper surface light green, ridge in the midrib faint or wanting; under surface light yellowish-green, the curved line on either side of the midrib usually wanting; more or less fragile; sensation of numbness on tasting the drug not so pronounced. 
The flowers of a species of Inga (Fam. Leguminosæ) are frequently present. The pedicel is about $2 \mathrm{~mm}$. in length; the calyx yellowishbrown, about $1 \mathrm{~cm}$. in length, 5-toothed, pubescent; corolla cylindrical, or somewhat funnel-shaped, 5 -toothed, about $1 \mathrm{~cm}$. in length,

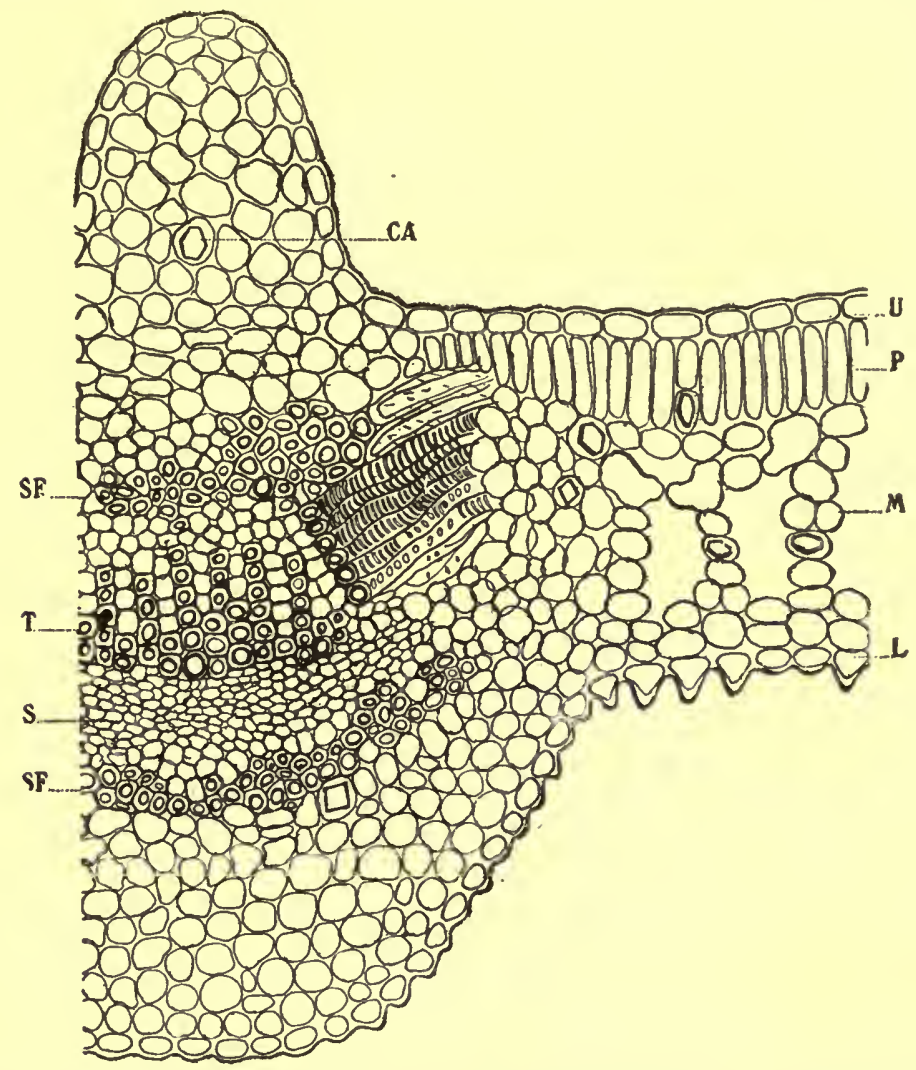

FIg. 155.-Transverse section of coca leaf near the midrib: $U$, upper epidermis; $P$, palisade cells, some of which contain monoclinic prisms of calcium oxalate; $M$, loose parenchyma, some of the cells of which also contain monoclinic prisms of calcium oxalate; $L$, lower epidermis with distinct papillæ; $C A$, monoclinic prism of calcium oxalate; $S F$, sclerenchymatous fibers; $T$, tracheæ; $S$, sieve.

yellowish-brown, very pubescent; stamens numerous, more or less united into a tube exserted; filaments reddish-brown.

Inner Structure.-See Fig. 155.

Powder.-(Fig. 156.) Dark green, fragments of epidermal tissue of more or less polygonal cells and elliptical stomata, the latter usually with two neighboring cells; papillæ of under surface appear as cir- 
cular markings, one occurring in the center of each of the polygonal cells; calcium oxalate in monoclinic prisms from 0.003 to $0.015 \mathrm{~mm}$. in diameter, occurring either singly or in crystal fibers; fragments of tracheæ and thin-walled sclerenchymatous fibers. In the powder of Huanuca Coca the very long, separate hairs of the corolla of Inga flowers with their thick yellowish walls are occasionally present; as also the curved, unicellular, non-glandular hairs from the stems of this plant.

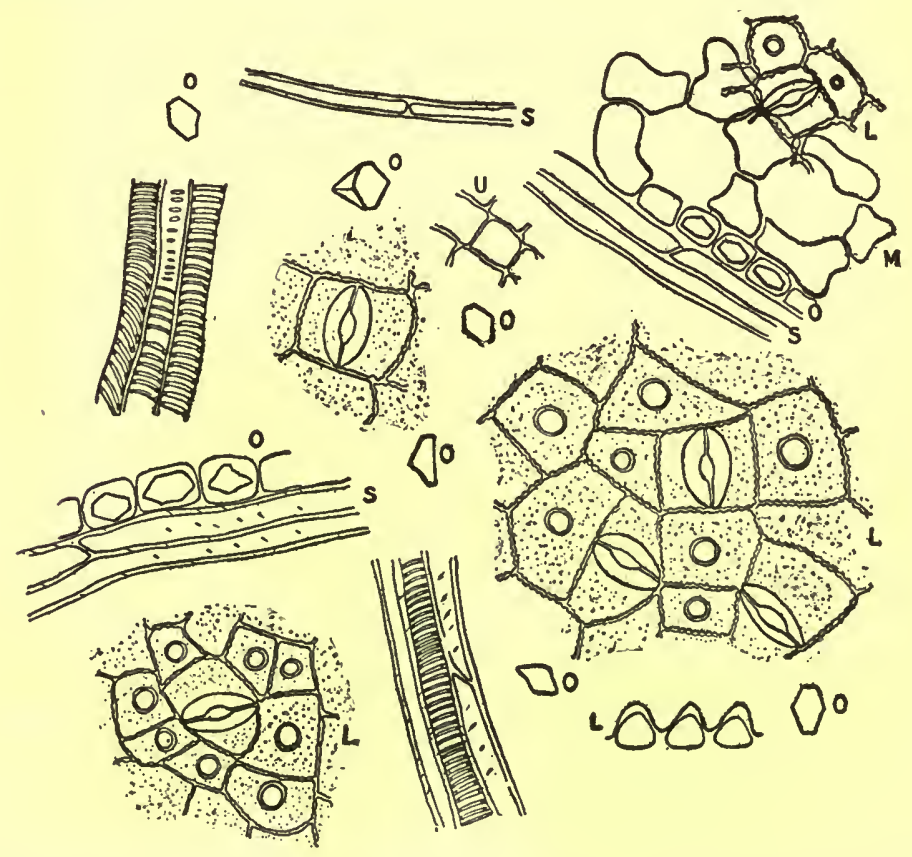

Fig. 156.-Coca leaf: $O$, hexagonal prisms of calcium oxalate; $U$, surface section of a cell of the upper epidermis; $L$, fragments of dorsal or lower epidermis in surface section showing the papillæ, in the form of circles when seen in surface view, also transverse sections showing the papillose epidermal cells; $S$, sclerenchymatous fibers; $M$, loose parenchyma. Two fragments with annular tracheæ are also shown.

Constituents.--Several alkaloids, including cocaine, cinnamylcocaine, truxilline and ecgonine. Of these, cocaine is the most important, the Bolivian leaves containing the greatest-amount, or 0.5 to 1 per cent; the other alkaloids preponderate in the Peruvian leaves, which usually do not contain more than one-half or twothirds as much cocaine as the Bolivian leaves; the Java leaves also contain benzoyl-pseudotropine; in addition, coca leaves contain a 
volatile aromatic principle; a tannin giving a green color with solutions of ferric salts; and calcium oxalate.

It has been shown that young coca leaves contain 2.02 per cent of total alkaloids, or more than twice as much as the older leaves, while

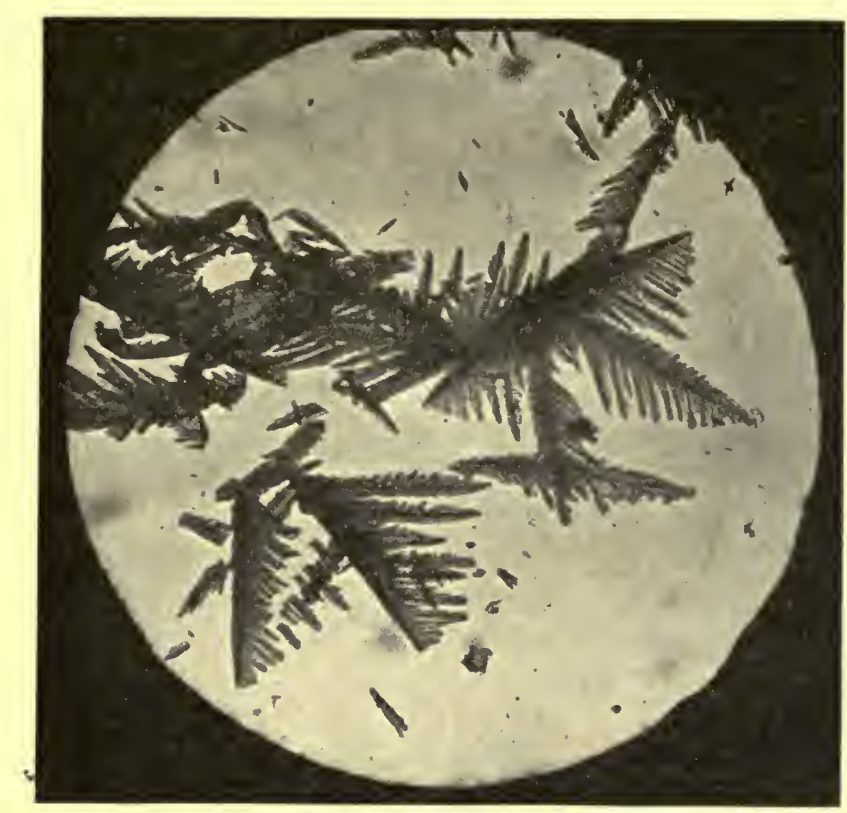

FIG. 157.-Crystals of cocaine chloro-platinate. To $\frac{1}{2}$ c.c. of a 1 per cent solution of cocaine are added 2 drops of platinum chloride test solution. The test-tube should not be shaken, as larger and better formed crystals will result when the solution is undisturbed. A buff-colored precipitate is formed which, under the microscope, appears as large feathers or plumes, sometimes arranged in stellate pattern. In higher dilutions (1:600) crystals slowly form which "resemble carpet tacks."

Alpha-eucaine, with the above test, forms bundles of fine needles; betaeucaine, after thirty minutes, gives a few large, leaf-like forms, rosettes and cubes; holocaine gives small stars; acoine gives an amorphous precipitate, while stovaine and euphthalmine give no precipitates. None of the precipitates yielded by the cocaine substitutes resemble the cocaine chloroplatinate in any way.-After Seiter and Enger, Amer. Jour. Pharm., 1911, p. 195.

the amount of ash yielded by them is slightly less, being 6.4 per cent. The constituents of Ceylon Coca resemble those of the Java variety.

Cocaine (the methyl ester of benzoyl-ecgonin). At $25^{\circ} \mathrm{C}$. one part of cocaine is soluble in 600 parts of water; 5 parts of alcohol; 3.8 parts of ether; and one part of chloroform or benzol. It is 
insoluble in glycerin. The individual crystals as usually obtained on a microscopic slide vary in length from $0.4 \mathrm{~mm}$. to $2 \mathrm{~mm} .^{1}$

Cocaine hydrochloride occurs in two forms, the hydrous salt crystallizing from aqueous solutions; and the anhydrous, from non-

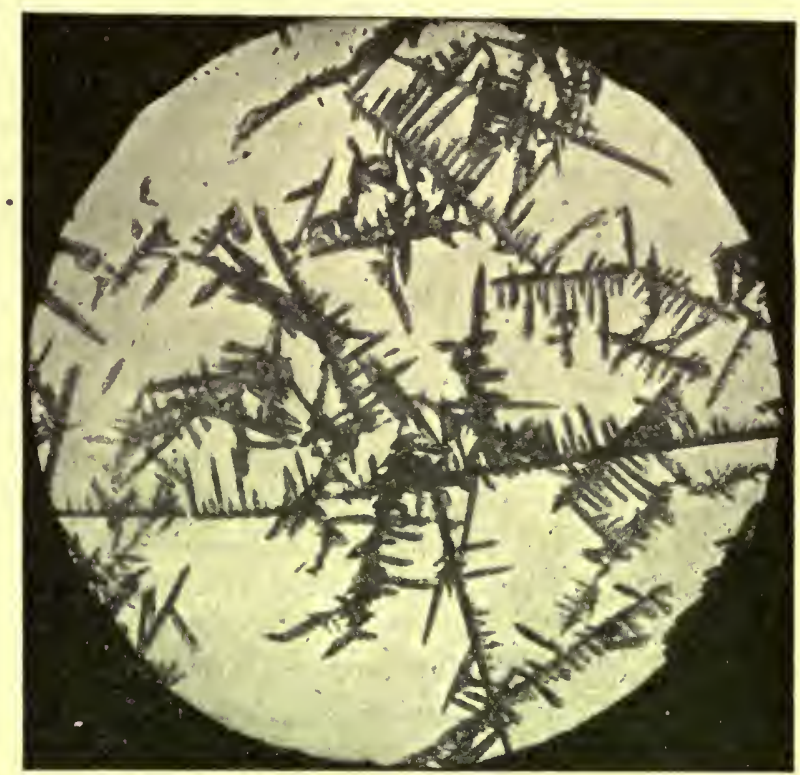

F10. 158.-Crystals of cocaine-chloro-aurate. To 1 c.c. of a dilute solution (1:300) of cocaine are added 3 drops of gold chloride test solution, avoiding shaking as in the case of the platinum chloride test. A precipitate immediately forms and slowly changes from the amorphous into the crystalline state. Under the microscope, the crystals rescmble fcrn-fronds, generally with a stellate arrangement. In dilutions of $1: 12,000$, similar crystals form after long standing.

With the gold test, alpha-eucaine gives branching, twig-like crystals; stovaine gives large crystals resembling those of cocaine chloroplatinate in general structure, but differ in that the branches possess smaller branches, which is not the case with the cocaine chloroplatinate. Amorphous precipitates are given with beta-eucaine, acoine and holocaine. Euphthalmine gives no precipitate.-After Seiter and Enger, Amer. Jour. Pharm., 1911, p. 195.

aqueous solvents, such as alcohol. The latter is supposedly the official salt and is erroneously stated to crystallize in monoclinic prisms. At $25^{\circ} \mathrm{C}$. one part of cocaine hydrochloride is soluble in

1 Tschermak in Lossen's paper, Ann. Chem. Pharm., 1865, 133, p. 355 . See also A. Fock, Zeitschr. f. Krystallog, 1890, 17, p. 370. 
0.4 part of water; 2.6 parts of alcohol; 18.5 parts of chloroform; and 4 parts of glycerin. The microscopic crystals of the anhydrous salt may attain a length of $3 \mathrm{~mm}$. The hydrous salt affords long needles or elongated plates, which, when crystallized on a micıscopic slide, may attain a length of $20 \mathrm{~mm} .{ }^{1}$

Cocaine Hydrochloride and Palladous Chloride.-Cocaine and cocaine hydrochloride give with a number of reagents, including solutions of Palladous Chloride, characteristic crystalline double salts. ${ }^{2}$ The crystals of cocaine hydrochloride and palladous chloride are prepared in the same manner as the caffeine gold chloride, with the exception that to the solution containing the cocaine hydrochloride a small quantity of hydrochloric acid is added. To a few drops of this solution upon a slide are added a few drops of the solution of palladous chloride, the two are mixed by means of a glass rod and the slide is set aside to allow the crystals to form. This frequently occurs almost immediately. The individual crystals vary in length from $0.3 \mathrm{~mm}$. to $1.6 \mathrm{~mm}$. Skeleton crystals are also formed from 0.5 $\mathrm{mm}$. to $6 \mathrm{~mm}$. in length. For illustrations of these several forms of crystals, consult Kraemer's Applied and Economic Botany, p. 164.

The crystals have a strong tendency to form radiating aggregates and skeleton crystals, due, no doubt, to the fact that the substance is only slightly soluble and the crystals therefore form rapidly.

Ecgonine crystallizes in monoclinic prisms, which are slightly bitter, readily soluble in water and sparingly soluble in alcohol. Cinnamyl cocaine is found in commercial cocaine and occurs in rosettes of needle-shaped crystals which are nearly insoluble in water, soluble in alcohol and on hydrolysis yield cinnamic acid, methyl alcohol and ecgonine. $\alpha$-Truxilline (cocamine) is a bitter alkaloid, which occurs either in an amorphous form or in large crystals and yields on hydrolysis truxillic acid, methyl alcohol and ecgonine. Truxilline occurs sometimes to the extent of 0.5 per cent in Peruvian (Truxillo) leaves. Cocaine is found in the seeds and roots as well as in the leaves. The leaves contain a small amount of methyl salicylate.

Synthetic Local Anesthetics.-A number of substances have been manufactured, with a view of increasing their stability, reducing their toxicity and their injurious effects. Their anesthetic power is also as a rule somewhat less than that of cocaine and most of them

1 Valentin, Zeitschr. f. Krystallog., 1889, 15, p. 36.

2 W. Lossen, Ann. Chem. Pharm., 1865, 133, p. 355; and Howard and Stephenson Proc. A. O. A. C., Nov., 1908, printed in Bulletin No. 122, pp. 97-100, of Bureau of Chemistry, U. S. Department of Agriculture. 
present the usually undesirable effect of dilating the blood-vessels or at least of not constricting them as does cocaine; hence some of them are almost always employed in conjunction with epinephrin. They owe their origin to the discovery that local anesthetic action of cocaine is due to the radical of benzoic acid in combination with a nitrogen-containing basic group. The simplest of these compounds, anesthesin, propaesin and cycloform, are, respectively, ethyl, propyl and insobutyl esters of para-amino benzoic acid, $\mathrm{C}_{6} \mathrm{H}_{4}\left(\mathrm{NH}_{2}\right) \mathrm{COOH}$; orthoform and orthoform-new are the methyl esters of oxy-amino benzoic acids, $\mathrm{C}_{6} \mathrm{H}_{3}(\mathrm{OH})\left(\mathrm{NH}_{2}\right)(\mathrm{COOH})$. All of these are too weak or too insoluble in water to be useful for hypodermic injections; they are used as local applications. Procaine is a compound of paraamino-benzoic acid with diethyl-amino-ethyl alcohol; its salts are readily soluble in water. Stovaine and alypin are esters produced by combination of benzoic acid with derivatives of an amino-amyl alcohol; their salts are easily soluble in water, but they are much more toxic than the preceding compounds. Beta-eucaine is a compound of benzoic acid and derivative of oxypiperidin. Tropacocaine is much more closely related to cocaine than are the preceding.

Cocaine Substitutes.-The relative toxicity of the synthetic substitutes for cocaine, included in New and Nonofficial Remedies, 1919, p. 27, are exhibited in the following table:

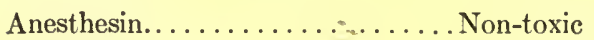

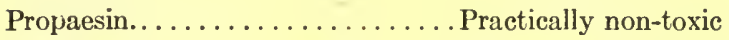

Stovaine................ From one-third to one-half as toxic as cocaine

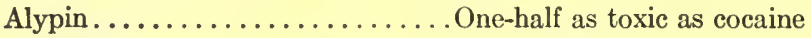

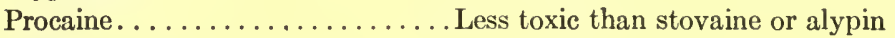

Beta-eucaine hydrochloride.......Much less poisonous than cocaine

Tropacocaine hydrochloride....... One-half as toxic as cocaine

\section{ZYGOPHYLLACEE, OR CALTROP FAMILY}

The plants are mostly herbs and shrubs which are widely distributed in warm-tropical regions. The leaves are mostly opposite, pinnate and stipulate. The flowers are perfect, regular and mostly 5 -merous. The fruit is usually capsular. The hairs are usually simple and unicellular, occasionally there is a metamorphosis of the wall to form a resinous excretion. A similar modification of the walls of the epidermal cells of the stipules occur in Larrea tridentata, a plant common in Mexico and southwestern United States and known as Crecsote bush. True glandular hairs do not occur in the plants of this family. Mucilage cells and tannin-secreting cells are also occasionally present. The tracheæ usually have simple pores and in 
Guaiacum are filled with resin. Calcium oxalate is secreted in leaves in the form of rosette aggregates and in the axis in solitary crystals.

Guiaci Lingnum.-Lignum Guaiaci, Lignum Vitæe, Lignum Sanctum, Lignum Benedictum or Guiac Wood.-The wood of Guaiacum officinale and G. sanctum (Fam. Zygophyllaceæ), small evergreen trees of tropical America. Either the heartwood is used, or the wood from the younger twigs and stems freed from the bark is employed.

Description.-Heartwood in billets from 10 to $30 \mathrm{~cm}$. in length, dark brown, becoming on exposure greenish-brown; wood of twigs and stems in pieces from 2 to $3 \mathrm{~cm}$. in thickness, light yellow, becoming on exposure greenish-brown; very heavy, hard; fracture tough, splintery; inner transverse surface showing irregular concentric layers of alternating dark and yellow zones, tracheæ large, dark brown, medullary rays narrow and yellow.

Inner Structure.-Tracheæ comparatively few with large lumina, rather short, having thick walls and containing a light yellowish or dark brownish-red resin; wood parenchyma having monoclinic prisms of calcium oxalate; wood fibers numerous with very thick walls, of an irregular contour, and containing a yellowish-red or brownish-red resin; medullary rays mostly 1 cell wide, occasionally 3 to 6 cells wide, and arranged in 4 longitudinal rows.

Constituents.-About 15 per cent of resin, the constituents of which are given under Guaiac resin. Also, 1 per cent of volatile oil, vanillin, saponinic acid and saponin. The latter principle occurs in large amounts in the bark and in least quantity in the heartwood. The activity of the drug is supposed to be due to its saponin and not its resin and we would naturally expect the bark to be used in medicine rather than the wood or its resin. The latter, however, is official in a number of Pharmacopoias.

Guaincum.-Guaiac Resin.-A resin obtained from the stem and branches of Guaiacum officinale, a small tree growing in Florida, the Antilles and northern South America, and Guiacum sanctum (Fam. Zygophyllaceæ) indigenous to the West Indies and the northern part of South America. The resin exudes spontaneously or is obtained from incisions in the bark or by heating the fallen trunks. The commercial article comes chiefly from Cuba and Hayti. The resin obtained from trees growing in the Bahama Islands is most highly esteemed.

Description.-Usually in irregular masses; externally greenishbrown, frequently covered with a greenish powder; brittle, the fracture having a glassy luster and being yellowish-green or reddish- 
brown and more or less transparent in thin pieces; fusible; odor balsamic; taste somewhat acrid.

The powder of guaiac is of a grayish color, but becomes green on exposure to the air, and on heating gives off an odor of benzoin. It is readily soluble in ether, alcohol, chloroform, solutions of the alkalies or hydrated chloral. It is sparingly soluble in benzol, fixed or volatile oils. The alcoholic solution has a brown color, which is changed to blue by the addition of solutions of ferric chloride, or oxidizing agents (as chromic acid or ozone) or through the action of chlorin, bromin or iodin. An alcoholic solution of guaiac is colored blue by enzymes. The blue color is destroyed on the addition of reaucing substances.

The powder when examined under the microscope shows numerous lemon-yellow or dark-brown resin masses, which when mounted in solutions of hydrated chloral are wine-colored at the margin; few fragments of tissues with characteristic sclerenchymatous cells and fibers; few crystals of calcium oxalate in monoclinic prisms.

Constituents.-Several acids are present, including guaiaconic, guaiaretic, guaiacresinic, guaiacinic, and guaiacic. Guaiaconic acid (alpha resin) occurs to the extent of 50 to 70 per cent, and forms a brown powder, which is insoluble in water, soluble in alcohol and gives a blue color with nitric acid and other oxidizing agents; and on dry distillation yields guaiac oil and pyroguaiacin. Recent investigations show that guaiaconic acid consists of two crystalline substances: $\alpha$-guaiaconic acid and $\beta$-guaiaconic acid. The latter crystallizes in rhombohedra and does not give a blue color with oxidizing agents. When a solution of $\alpha$-guaiaconic acid in chloroform is treated with lead peroxide guaiac blue is formed, which may be obtained, as a blue mass having a metallic luster, on evaporating the chloroformic solution. On reduction with sulphurous acid it is changed to $\alpha$-guaiaconic acid. Guaiaretic acid (about 10 per cent) occurs in colorless needles and forms crystalline salts with the alkalies. Guaiacresinic acid occurs in white, shining plates that are soluble in alcohol and give on dry distillation the same products as guiaconic acid. Guaiacinic acid (beta resin) occurs as a yellowishbrown powder and yields on dry distillation tiglic aldehyde (dimethyl acrolein). Guaiacic acid forms colorless needles which are soluble in water, but probably does not occur in the natural product, being in the nature of a decomposition product. Guaiac resin also contains a yellow coloring principle, guaiac yellow (about 0.7 per cent), which occurs in light yellow, hard octahedra that are sparingly soluble in hot water and give a blue color with concentrated. sulphuric 
acid; and a light yellow, rather thick ethereal oil (guaiac oil), which cannot be obtained by distillation and possesses a characteristic aromatic odor. Among the other constituents are vanillin and a yellow gum. The yield of ash should not be more than 4 per cent. Guaiac wood yields from 20 to 25 per cent of resin.

Of particular interest are the decomposition products obtained on heating guaiac resin. On dry distillation the following substances are obtained: Tiglic aldehyde, a colorless, aromatic liquid with the odor of benzaldehyde; guaiac oil; and a crystalline substance, pyroguaiacin, which on distillation with zinc yields guaiacene (an aldehyde of tiglic acid).

\section{RUTACEE, OR RUE FAMILY}

Mostly trees and shrubs, with compound leaves, regular, 3- to 5 -merous flowers and capsular fruits. With very few exceptions they always possess schizogenous or schizo-lysigenous cavities in the branches and leaves, giving rise to transparent dots in the latter. They usually have isolated groups of bast fibers in the pericycle, in Pilocarpus, however, there is a composite and continuous sclerenchymatous ring. The tracheæ and wood fibers usually possess simple pores, except when the tracheæ are in contact with parenchyma cells, when they are replaced by bordered pores. Calcium oxalate is usually secreted in the form of rosette aggregates, but styloids, raphides and membrane crystals are also present, the latter being especially prominent in the genus Citrus. Both glandular and nonglandular hairs are present, stellate hairs being quite common in the family.

Zanthoxylum.-Xanthoxylum, Prickly Ash Bark.-The dried bark of Zanthoxylum americanum and Zanthoxylum (Fagara) ClavaHerculis (Fam. Rutaceæ). Z. americanum is a shrub or small tree indigenous from Quebec to Virginia and west to South Dakota, Nebraska and Kansas, and yields Northern Prickly Ash. Z. ClavaHerculis is a shrub found south from Virginia to Texas, and furnishes the Southern Prickly Ash. The latter, however, appears to be less valuable medicinally.

Northern Prickly Ash.-In transversely curved pieces, occasionally in single quills, 2 to $17 \mathrm{~cm}$. in length, 1 to $2 \mathrm{~cm}$. in diameter, 0.5 to $3 \mathrm{~cm}$. in thickness; outer surface light brown to brownishblack, with grayish patches of foliaceous lichens, numerous small black apothecia and whitish lenticels; fracture short, uneven; inner surface light brown, finely longitudinally striate, with numerous 
rod-shaped crystals, phelloderm layer dark green, inner bark with groups of converging modullary rays; odor slight; taste bitter, acrid and pungent.

Inner Structure.-(Compose with Fig. 159.) Periderm of strongly thickened and lignified cork cells; collenchyma of several
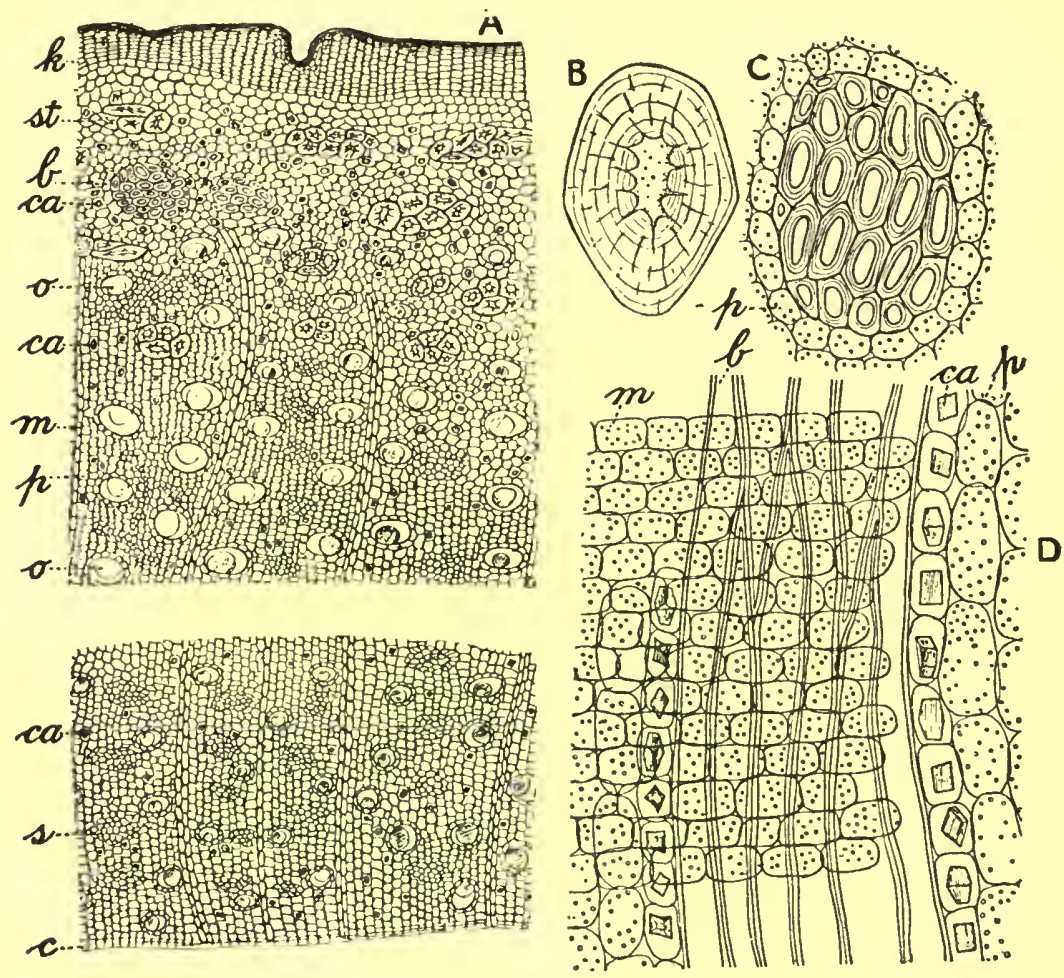

FIG. 159.-Southern prickly ash, Zanthoxylum (Fagara) Clava-Herculis: $A$, transverse section showing cork $(k)$, stone cells $(s t)$, groups of primary bast fibers $(b)$, calcium oxalate $(c a)$, medullary rays $(m)$, parenchyma $(p)$ containing starch, oil-secretion cavitics $(o)$, sicve $(s)$, cambium $(c) . \quad B$, isolated stone cells showing pores and lamella. $C$, group of bast fibers found in young, thin bark and surrounded by parenchyma $(p) . \quad D$, longitudinal section near a group of bast fibers showing non-lignified bast fibers $(b)$, calcium oxalate $(c a)$ in crystal fibcrs, medullary rays $(m)$, parenchyma $(p)$ containing starch.

rows of thick-walled, tangentially elongated cells; a more or less indistinct row of endodermal cells beneath which is an interrupted circle of small groups of primary bast fibers; inner bark of numerous starch-bearing parenchyma cells among which are included the 
secretory cavities having light yellow oily globules; medullary rays mostly one cell in width; the parenchyma cells as well as the oil secretion cavities contain numerous colorless oily globules. Scrapings from the inner surface show numerous rod-shaped crystals and flat prisms from 0.015 to $0.250 \mathrm{~mm}$. in length, which polarize light with a display of bright colors.

Southern Prickly Ash.-Transversely curved or irregularly oblong flattened pieces, occasionally in single quills 5 to $30 \mathrm{~cm}$. in length, 1 to $7 \mathrm{~cm}$. in diameter, 1 to $4 \mathrm{~mm}$. in thickness; outer surface with numerous conical cork-wings or their scars; inner surface free from crystals.

Inner Structure.-(Fig. 159.) Periderm of strongly lignified cork in the form of rings, the successive layers being separated by several rows of narrow tabular cells, strongly thickened on the tangential walls; a thin layer of collenchyma; tissues of the primary cortex contain small groups of rather large stone cells and occasional scattered groups of bast fibers and parenchyma; the inner bark consists of parenchyma, a more or less indistinct leptome or sieve tissue and among which are numerous large, light-yellowish oil-secretion cavities, and occasional groups of stone cells and bast fibers; medullary rays from 1 to 2 cells in width; starch grains numerous, nearly spheroidal, from 0.002 to $0.010 \mathrm{~mm}$. in diameter, and occurring in the parenchyma cells and medullary rays; calcium oxalate chiefly in monoclinic prisms from 0.010 to $0.025 \mathrm{~mm}$. in diameter, occurring in crystal fibers and in parenchyma cells of the primary cortex.

Powder.-Light grayish-brown or dark brown; calcium oxalate in monoclinic prisms, frequently in crystal fibers; starch grains small and nearly spheroidal; oil secretion cavities having a nearly colorless or light yellowish oil; cork cells strongly thickened and lignified; bast fibers, thick walled, slightly lignified, swelling perceptibly in hydrated chloral.

In Southern Prickly Ash occur groups of large, more or less lignified sclerenchymatous cells, and the lignified cork cells are more numerous.

Constituents.- Two resins, one acrid, the other crystalline and bitter; an acrid volatile oil; a bitter, alkaloidal principle, somewhat resembling berberine; a crystalline phenol compound zanthoxylin; ash about 12 per cent.

Allied Plants.-The fruits both of Zanthoxylum americanum and Z. Clava-Herculis are found in commerce and known as Prickly Ash berries. They consist of 2 to 3 follicles, each of which is 5 to $6 \mathrm{~mm}$. 
in length, brownish-green, dehiscent along the ventral suture and contains one or two sub-globular, somewhat flattened, black, glossy seeds; odor aromatic; taste pungent and bitter. Zanthoxylum fruits contain a volatile oil and resin.

Pilocarpus.-Jaborandi.-The leaflets of various species of Pilocarpus (Fam. Rutaceæ), shrubs indigenous to Brazil. There are three principal commercial varieties: (1) Pernambuco Jaborandi, obtained from P. Jaborandi; (2) Paraguay Jaborandi, yielded by P. pinnatifolius, and (3) Maranham Jaborandi, obtained from P. microphyllus. The name, jaborandi, is applied to a number of other p!ants growing in Brazil besides those of the genus Pilocarpus.

Pernambuco Jaborandi.-Elliptical, lanceolate or oblong-lanceolate, 6 to $12 \mathrm{~cm}$. in length, 1.5 to $4 \mathrm{~cm}$. in breadth; summit obtuse, more or less emarginate; base rounded or acute, unequal; margin entire, slightly revolute; upper surface dark green or brownishgreen, glabrous, midrib more or less depressed near the summit, veins of the first order prominent, diverging at an angle of $35^{\circ}$ to $50^{\circ}$ and uniting with each other near the margin; under surface yellowishor greenish-brown, pubescent, with numerous light-brown projections, midrib prominent, yellowish-brown; petiolule 3 to $5 \mathrm{~mm}$. in length; glandular-punctate; texture coriaceous, brittle; odor slight; taste bitter, somewhat aromatic, becoming pungent.

Paraguay Jaborandi.--Oblong-lanceolate, ovate or obovate, 8 to $12 \mathrm{~cm}$. in length, 2.5 to $5 \mathrm{~cm}$. in breadth; summit slightly emarginate; base equal; margin very slightly revolute; upper surface dark green, midrib and veins of the first order not very prominent, the latter diverging at an angle of $25^{\circ}$ to $45^{\circ}$; under surface grayish-green or light green, glabrous, with numerous papillæ; midrib yellowish, with few short hairs; frequently with black disk-like fruits of a species of Puccinia on both surfaces; texture as in Pernambuco jaburandi, but only about one-half as thick.

Maranham Jaborandi.-Oblong-ovate, or oblanceolate, 1.5 to 4 $\mathrm{cm}$. in length, 1.5 to $2.5 \mathrm{~cm}$. in breadth; summit deeply emarginate; base tapering into the petiolule; margin distinetly revolute; upper surface bright green, glabrous, sometimes shiny, midrib prominent, veins of the first order not very prominent, diverging at an angle of $35^{\circ}$ to $45^{\circ}$; under surface grayish-green; frequently with black disklike fruits of a species of Puccinia on both surfaces; petiolúle about 8 $\mathrm{mm}$. in length; texture as in Paraguay jaborandi, but thinner.

Inner Structure.-(Fig. 160.) Epidermal cells with a yellowish layer of cutin, from 0.005 to $0.010 \mathrm{~mm}$. in thickness, palisade cells, 1 to 3 rows deep, among which occur large, nearly circular, oil secretion 
reservoirs from 0.080 to $0.150 \mathrm{~mm}$. in diameter; the cells of the loose mesophyll occasionally with rosette aggregates of calcium oxalate from 0.010 to $0.025 \mathrm{~mm}$. in diameter; collateral fibrovascular bundles
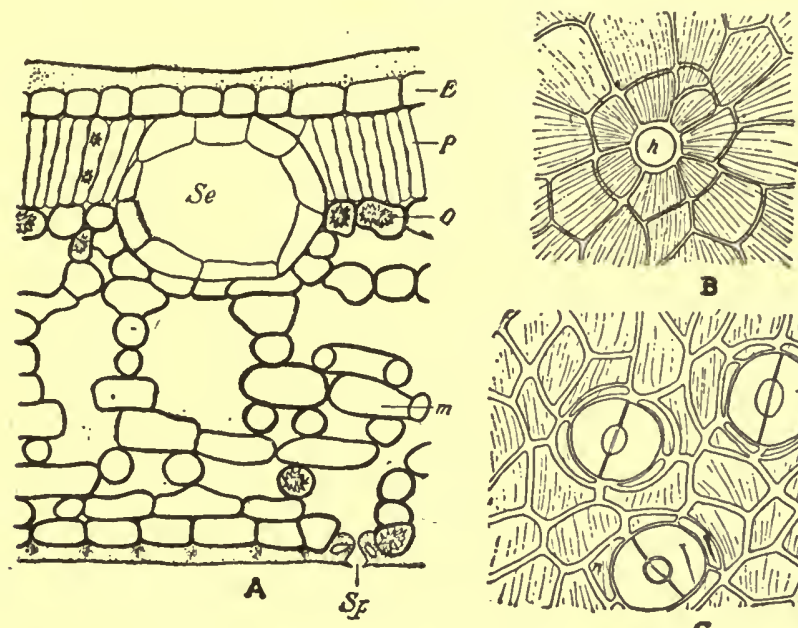

B

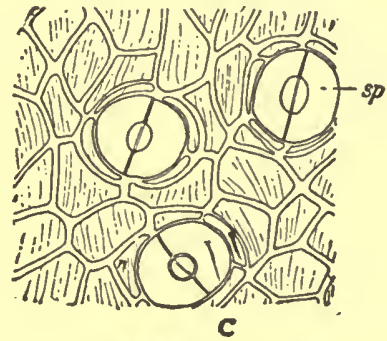

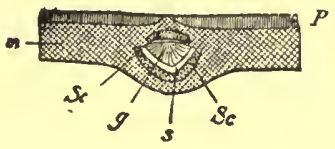

D

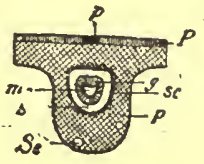

E

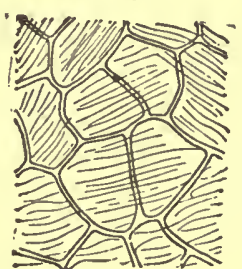

$\boldsymbol{F}$

FIg. 160.-Pilocarpus pinnatifolius: $A$, transverse section of lamina showing upper epidermis $(E)$, oil cavities $(S e)$, palisade cells $(P)$, some of which contain rosette aggregates of calcium oxalate, loose parenchyma $(m)$, some of the cells of which contain calcium oxalate $(o)$, and lower epidermis with a stoma $(S p)$. $B$, surface view of epidermis showing basal portion of a nonglandular hair $(h)$. The basal remains of the hairs are often present, the upper portions being detached. $C$, view of the under surface of the lamina showing stomata $(s p) . \quad D$, diagram showing the arrangements of the tissues in one of the secondary veins: $P$, palisade cells; $m$, loose parenchyma; $S c$, sclerenchyma; $s$, sieve; $g$, trachex. $E$, transverse section of the primary or middle vein showing palisade cells $(P)$, elongated parenchyma $(p)$, oil glands sieve $(s)$, trachex $(g)$, which surrounds parenchyma $(m)$, thus distinguishing it from the secondary vein. $F$, surface view of upper epidermis of lamina.After Meyer.

each surrounded by a more or less interrupted circle of several rows of thick-walled, slightly lignified sclerenchymatous fibers; tracheæ associated with strongly lignified wood fibers; among the cells of the 
lower epidermis occur numerous stomata. On surface view the stomata are broadly elliptical, 0.025 to $0.040 \mathrm{~mm}$. in length, being uniformly smaller in Maranham Jaborandi. Upon both surfaces of Pernambuco Jaborandi occur a number of non-glandular, 1-celled hairs, which are more or less curved, from 0.080 to $0.500 \mathrm{~mm}$. in length, thick-walled and with numerous, slight, centrifugal projections.

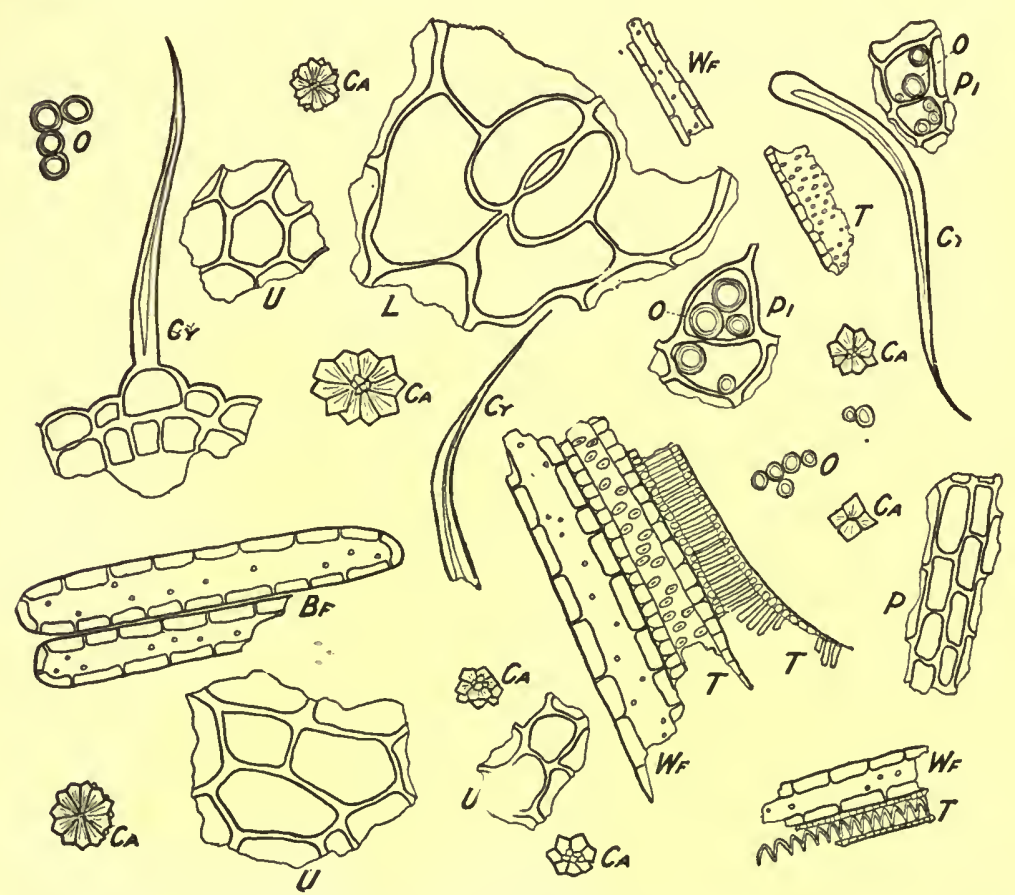

FIG. 161.-Powder of Pilocarpus. $U$, fragments of upper epidermis; $L$, fragment of lower epidermis with a stoma; $C y$, non-glandular hairs; $C a$, rosette aggregates .010 to $.027 \mathrm{~mm}$. in diameter; $B f$, bast fibers; $W f$, wood fibers; $T$, tracheæ with close annular thickenings and simple and bordered pores; $P i$, parenchyma cells containing oil globules; $O$, oil globules; $P$, parenchyma cells.-Drawing by Haase.

Powder.-(Fig. 161.) Dark-green or greenish-brown, epidermal cells on surface view 5- to 6-sided, stomata broadly elliptical, from 0.020 to $0.040 \mathrm{~mm}$. in length, usually with four neighboring cells; fragments of fibrovascular bundles showing tracheæ with simple or bordered pores or spiral thickenings, associated with thick-walled and strongly lignified wood fibers; sclerenchymatous fibers few, walls thick and only slightly lignified; calcium oxalate in rosette aggre- 
gates, 0.010 to $0.025 \mathrm{~mm}$. in diameter; fragments of laminæ showing large oil secretion cavities and usually containing one or more globules of an oily substance; mesophyll cells frequently with reddishbrown tannin masses, turning green with ammonio-ferric sulphate solution; non-glandular hairs 1-celled, thick-walled, with numerous slight centrifugal projections, 0.4 to $0.6 \mathrm{~mm}$. in length in P. Jaborandi and 0.040 to $0.060 \mathrm{~mm}$. in length in P. pinnatifolius and $P$. microphyllus. In P. microphyllus the stomata are smaller than in the other two species.

Constituents.-About 0.5 to 1 per cent of the alkaloid pilocarpine, which occurs as a colorless, syrupy liquid, but forms well-defined crystalline salts, the hydrochloride and nitrate being official. It is very soluble in water, the solutions being dextrorotatory. Pilocarpine is decomposed by heat or alkalies and yields an isomeric substance, isopilocarpine, which is an oily compound and is usually present in the commercial nitrate of pilocarpine. The alkaloid pilocarpidine has been obtained from the mother liquors, after the crystallization of pilocarpine, as a syrupy substance forming a crystalline nitrate and resembling somewhat pilocarpine in its physiological action. An alkaloid related to pilocarpine has been isolated from the leaves of $\mathrm{P}$. pinnatifolius in the form of an amorphous substance called jaborine, and resembling atropine in its physiological properties. Recent investigations do not seem to show that these alkaloids occur in either the leaves of Paraguay or Maranham Jaborandi. Fresh pilocarpus leaves also yield 0.2 to 1.1 per cent of a volatile oil which contains a hydrocarbon pilocarpene and a stearoptene belonging to the olefine series.

Allied Drugs. Nearly all of the species of Pilocarpus contain some pilocarpine, as well as other principles which are found in the true leaves. Many of these find their way into commerce and in some instances their assays compare favorably with the official leaves. Aracati Jaborandi is obtained from P. spicatus, the leaflets being broad and coriaceous and said to contain 0.16 per cent of alkaloids. The leaflets of $P$. racemosus of the West Indies are large and nembranous and contain about .66 per cent of pilocarpine.

Buchu.-The leaves of several specier of Barosma (Fam. Rutaceæ), a shrub indigenous to Cape Colony. There are two chief commercial varieties: (1) Short Buchu, obtained from B. betulina and (2) Long Buchu, obtained from B. serratifolia (Fig. 162). The two drugs differ considerably in their constituents.

Short Buchu.-Obovate, rhomboid-obovate, ovate or elliptical or somewhat cuneate; 9 to $18 \mathrm{~mm}$. in length, 6 to $12 \mathrm{~mm}$. in breadth; 
summit obtuse, somewhat recurved; base acute or cuneate; margin sharply dentate or denticulate and with an oil-secretion cavities at the base of each tooth; upper surface yellowish-green, glabrous; under surface yellowish-green, longitudinally striate; both surfaces papillose; petiole about $1 \mathrm{~mm}$. in length; texture coriaceous; odor and taste distinct, aromatic.

Long Buchu.-Linear-lanceolate, 25 to $40 \mathrm{~mm}$. in length, 4 to 6 $\mathrm{mm}$. in breadth; margin sharply serrate and glandular; summit somewhat rounded or truncate. Stems in both Short and Long Buchu about $1 \mathrm{~mm}$. in diameter, yellowish-green or brownish-red,

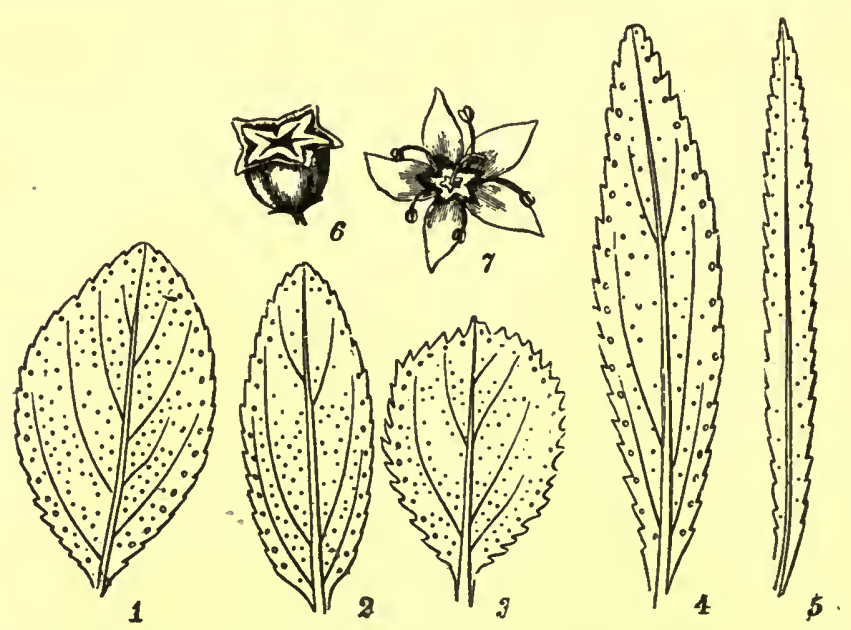

FIg. 162.-Buchu leaves showing oil cavities which give the leaves a glandularpunctate appearance: 1, Barosma crenata ovalis; 2, B. crenulata latifolia; 3, B. betulina; 4, B. serratifolia; 5, Empleurum ensatum; 6, dehiscent fruit of B. crenulata; 7, flower of the same.-After Tschirch.

cylindrical, longitudinally furrowed, with prominent leaf-scars nearly opposite to each other and giving the stems a jointed character.

Inner Structure.-See Fig. 163.

Powder.-Light green; calcium oxalate in rosette aggregates, 0.015 to $0.025 \mathrm{~mm}$. in diameter; epidermal cells with irregular masses or sphere-crystals of hesperidin, 0.030 to $0.500 \mathrm{~mm}$. in diameter, and with walls modified to mucilage; oil globules numerous.

Constituents.-Short buchu contains about 1.2 to 1.45 per cent of a volatile oil, of which about 30 per cent is the crystalline body diosphenol; long buchu contains only about one-third as much volatile oil and it contains little or no diosphenol; buchu also contains 
two crystalline glucosides, diosmin and hesperidin (see Aurantii Amari Cortex); mucilage and calcium oxalate.

Allied Plants. - The leaves of Barosma crenulata are occasionally found in the market; they are ovate, obovate or oblong-lanceolate, about twice as broad as long buchu, with a slightly toothed and glandular margin, more or less rounded summit, and yield 1.6 per cent of volatile oil resembling that of short buchu. Short Buchu has been substituted by the leaves of Barosma pulchellum.

Adulterants.-The leaves of Empleurum ensatum (Fam. Rutacex) have been offered for long buchu (see Fig. 162). They have a bitter taste and yield about 1 per cent of a volatile oil which does

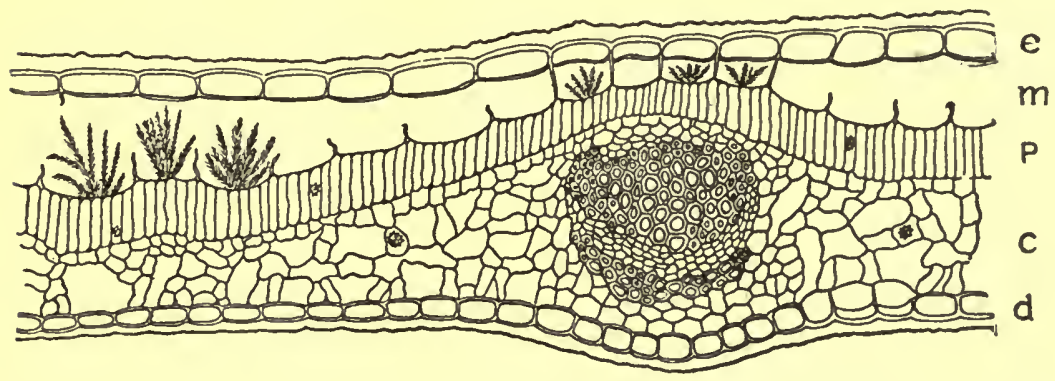

FIG. 163.-Transverse section through the leaf of Barosma serratifolia Willd; $e$, epidermal cells of upper surface, the inner walls of which are mucilaginous. The mucilage $(m)$ frequently includes dendritic excretions of hesperidin in the form of feather-like aggregates, which dissolve in solutions of potassium hydroxide, giving a yellow color: $p$, palisade cells, some of which contain rosette aggregates of calcium oxalate; $c$, chloronchyma, some of cells containing rosette aggregates of calcium oxalate, also a large vascular bundle (mestome strand) with a stereomatic pericycle forming an arch on the dorsal face; $d$, epidermis of lower (or dorsal) face of the leaf.-After Solereder.

not contain a crysialline principle. Long Buchu has also been substituted by the leaves of Empleurum serratulatum.

The trifoliate leaves of Psoralea obliqua are obtained from a South African shrub. The leaflets are oblique or unequal-sided, dentate, bitter, glandular and have numerous simple hairs.

- Karoo Buchu is delived from Diosma succulenta, of South Africa. The leaves are ovate, 3 to $6 \mathrm{~mm}$. in length, coriaceous, obtuse and . slightly recurved at the summit. They yield an oil with a peppermint-like odor containing diosphenol, and 26 per cent of extractive. The leaves of aniseed buchu (B. pulchella) are smaller than those of B. betulina and have an odor of citronella. 
Literature.-Cultivation of Buchu Amer. Jour. Pharm., 1918, 90, p. 600; Chem. and Drug, 1918, 90, p. 31.

Aurantil Dulcis Cortex.- Sweet Orange Peel.-The outer layer of the rind of the fresh fruit of Citrus Aurantium sinensis (Fam. Rutaceæ), a tree quite extensively cultivated in sub-tropical countries and warm-temperate regions (Fig. 164). The outer yellowish layer is the part employed, and is usually removed from the fruit by grating. The dried rind is an article of commerce.

Description.-The outer, orange-yellow layer recently separated by grating or paring and consisting of epidermal cells, thick-walled

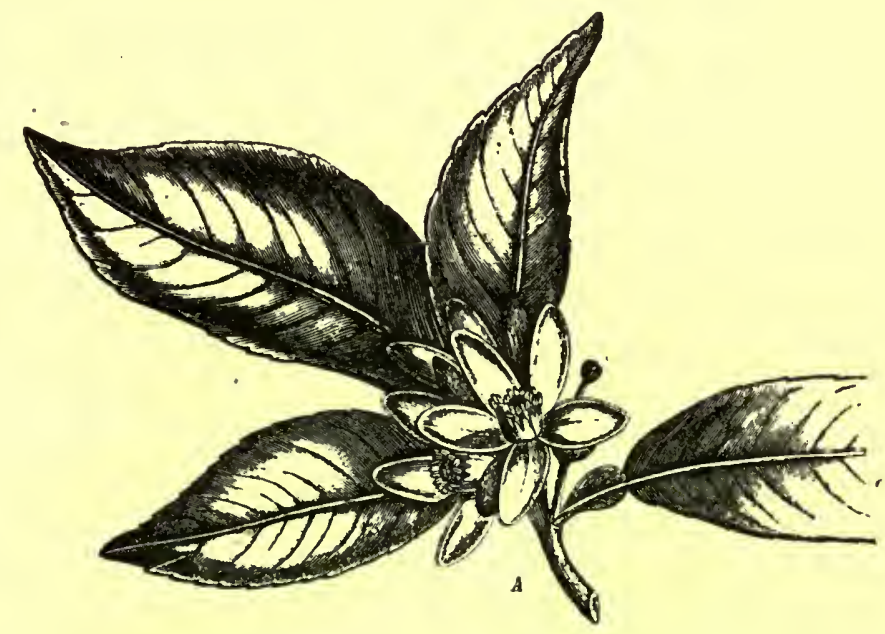

Fıg. 164.-Citrus Aurantium, showing axillary cluster of flowers.-After Berg and Schmidt.

parenchyma cells of the sarcocarp, with chromo-plastids, schizolysigenous oil cavities and globules of volatile oil; odor highly fragrant; taste pungently aromatic.

Powder.-Light brown; calcium oxalate in monoclinic prisms 0.020 to $0.335 \mathrm{~mm}$. in diameter; walls of parenchymatous cells about $0.004 \mathrm{~mm}$. in thickness; numerous globules of volatile oil and fragments showing schizo-lysigenous oil cavities.

Constituents.--Resembling those of bitter orange peel, except that there is but a very small quantity of the bitter principle. The volatile oil which exists in large cavities beneath the epidermis is obtained by expression from the fresh peel and is official. It consists of about 90 per cent of d-limonene and 5 per cent of citral, citronellal and the methyl ester of anthranylic acid. 
Auranti Amari Cortex.-Bitter Orange Peel.-The rind of the unripe fruit of Citrus Aurantium amara (Fam. Rutaceæ), a tree (Fig. 164) indigenous to northern India and cultivated in the Mediterranean region, the West Indies and the States bordering on the Gulf of Mexico. The fruit is collected before it is ripe, the rind removed and used either in the fresh or dried condition. The commercial article is obtained from Malta, Sicily and Spain.

Description.-Usually cut longitudinally into quarters; elliptical, acute at both ends, 4 to $6 \mathrm{~cm}$. in length, 2 to $3 \mathrm{~cm}$. in width, 2 to $6 \mathrm{~mm}$. in thickness; externally yellowish or brownish-green, with numerous circular depressions, a scar at one end and occasionally the remains of the calyx; internally light yellowish-brown, wrinkled, with numerous conical projections and numerous large schizo-lysigenous oil cavities; fracture short, tough, surface porous; odor aromatic; taste aromatic and bitter.

Occasionally in ribbon-like bands 2 to $12 \mathrm{~cm}$. in length, 5 to 10 $\mathrm{mm}$. in width, about $2 \mathrm{~mm}$. in thickness; externally yellowish-brown.

Powder.-Dark yellow or light brown; parenchymatous cells either somewhat collenchymatous or with simple pores, walls 0.010 to $0.015 \mathrm{~mm}$. in thickness; calcium oxalate in monoclinic prisms, 0.015 to $0.035 \mathrm{~mm}$. in diameter; tracheæ few, spiral, annular or with simple pores, fragments showing large schizo-lysigenous oil cavities.

Constituents.-Volatile oil, resembling that of sweet orange peel but with a superior flavor and a bitter taste; several bitter principles: (a) aurantiamarin (1.5 to 2.5 per cent), an amorphous, bitter glucoside, to which the bitter taste is chiefly due; (b) aurantiamaric acid ( 0.1 per cent), a very bitter, green, amorphous, resinous principle; (c) naringin (aurantin), a yellowish, crystalline, bitter glucoside; (d) isohesperidin ( 0.4 to 3 per cent), a slightly bitter glucoside. The drug also contains 5 to 8 per cent of a white, crystalline, tasteless glucoside, hesperidin, which separates in sphere-crystals on placing the fresh fruit in alcohol. Hesperidin is colored reddishbrown with solutions of ferric chloride and on hydrolysis yields a sweet principle hesperetin, which crystallizes in prisms. A fixed oil, resin, and a principle resembling tannin; calcium oxalate, in the form of rhombohedral crystals; and ash about 5 per cent are also present.

Allied Drugs.-The immature fruits of Citrus Aurantium are sometimes collected and are known as orange berries. They are nearly globular; 5 to $20 \mathrm{~mm}$. in diameter, greenish or brownishblack, granular rugose; the internal structure resembles that of 
orange fruits, but the seeds are rudimentary; and the taste is aromatic and bitter.

Limonis Contex.-Lemon Peel.-The rind of the fresh fruit of Citrus medica Limonum (Fam. Rutaceæ), a tree indigenous to northern India and cultivated in the European countries bordering the Mediterranean, the West Indies and other tropical and subtropical countries. The outer yellowish layer is the part used and it is removed by grating.

Description.-The outer, lemon-yellow or dark yellow layer recently separated by grating or paring and consisting of an epidermal layer, numerous parenchyma cells containing yellow chromoplastids and large schizo-lysigenous oil cavities with globules of the volatile oil; odor highly fragrant, distinct; taste pungently aromatic.

Inner Structure.-An epidermal layer composed of small tabular cells, a hypodermal layer containing numerous plastids, a mesocarp with colorless, thin-walled parenchyma and large, ellipsoidal schizolysigenous oil cavities; parenchyma cells containing a layer of granular protoplasm adhering to the walls and occasionally membrane crystals of calcium oxalate, which are irregularly polygonal in shape, polarize light strongly and from 0.015 to $0.025 \mathrm{~mm}$. in diameter.

Constituents. - Volatile oil; a very small quantity of hesperidin and other bitter principles (see bitter orange peel); a principle resembling tannin; calcium oxalate; ash about 4 per cent. The volatile oil obtained by expression from fresh lemon peel consists of 90 per cent d-limonene; 7 to 10 per cent of citral, which is the most imporant constituent; and a small quantity of citronellal, geranyl acetate, terpineol, methyl heptenone, a sesquiterpene and octyl and nonyl aldehydes.

Limonis Succus, or lemon juice, consists of 5.39 to 8.30 per cent of citric acid, in part free and also combined as an ester; saccharose, 0.52 per cent; invert sugar, 1.42 per cent; extract, 10.44 per cent; nitrogenous substances, 0.32 per cent; and ash, 0.2 per cent, the latter consisting chiefly of potassium and calcium phosphates.

Casimiroa Edulis.-The seeds of Casimiroa edulis (Fam. Rutaceæ), a tree widely distributed throughout Mexico and Central America. The fruit and seed of this tree are recognized by the Pharmacopœia of Mexico under the title of Zapote blanco. The fruit is edible, although stated to induce sleep, whereas the kernels of the seed have been regarded as deleterious or even fatal in their effects. A chemical examination of the seeds showed them to contain a number of interesting compounds; two new, crystalline alkaloids, one of the latter having been designated as casimiroine, and the other casi- 
miroedine; an essential oil; an enzyme which hydrolyzed amygdalin, and a quantity of sugar; benzoic acid; sitosterol; a phytosterol glucoside; a mixture of fatty acids; a yellow, phenolic substance; and a new lactone, casimirolid, which yields a new hydroxyl-acid, designated as casimiroic acid. The reputed hypnotic or toxic properties of the seed could not be confirmed.-Power, Jour. Chem. Soc., 1911, p. 1993.

Angustura.-Cortex Angosture Versus, Cusparie Cortex. Angostura Bark or Cusparia Bark. - The bark of Galipea officinalis (Fam. Rutaceæ), a small tree growing abundantly in the mountainous districts of Venezuela. It was formerly used in the preparation of Angostura Bitters, which also contained gentian and a number of aromatic substances, as ginger, cinnamon, cardamom, orange or lemon peel, and caraway or cloves.

Description.-Mostly in quills or in transversely curved pieces, from 5 to $12 \mathrm{~cm}$. in length, 2 to $3 \mathrm{~cm}$. in width, and from 2 to $3 \mathrm{~mm}$. in thickness; externally light yellowish- or grayish-brown, with occasional patches of a velvety porous cork; inner surface light brown and finely striate; fracture short, smooth and resinous; transverse surface of middle bark brownish-red, inner bark brownish-yellow with numerous shining resin canals and groups of bast fibers; odor distinct; taste bitter.

Inner Structure.-Cork cells more or less tabular, compressed and somewhat thickened on the tangential walls; phelloderm cells, thin-walled and of several layers; middle bark of thin-walled, starch-bearing parenchyma, yellowish secretion cavities, from 0.060 to $0.130 \mathrm{~mm}$. in diameter and cells containing small, fine acicular crystals of calcium oxalate; stone cells occur in the inner layers of the middle bark; inner bark having numerous characteristic plates of bast fibers, the latter being spindle-shaped, somewhat knotty and with tapering and branching ends; leptome of collapsed sieve tubes showing the porous plates on the longitudinal walls; medullary rays from 1 to 3 cells in width and from 10 to 20 longitudinal rows in height; secretion cavities possess cellulose walls and contain a yellowish oily secretion and are distributed throughout the inner and middle bark; calcium oxalate in crystal fibers accompanying the bast fibers, the crystals being in the form of rhombohedra; starch grains very small, irregularly spheroidal and occurring in the parenchyma and medullary ray cells.

Constituents.-About 2.4 per cent of alkaloids; (1) cusparine (angustarine) which crystallizes in bitter needles and small tetrahedrons and forms white salts which are sparingly soluble in water; 
(2) galipine, which crystallizes in white needles and forms yellow crystalline salts; (3) cusparidine, and (4) galipidine yield bitter salts, the former being white and the latter pale yellow; and (5) cuspareine, which crystallizes in white needles. It also contains from 1.5 to 1.9 per cent of a volatile oil; a bitter principle angosturin which forms a white microcrystalline powder; and a glucoside.

Allied Plants.-The drug has been adulterated with and substituted by the barks of a number of other plants, among which the following may be mentioned: Cusparia febrifuga, a tree growing in Venezuela, Brazil and Colombia. The bark resembles the true Angostura bark, but possesses a yellowish-white cork, the walls of which are not thickened; secretion cavities and raphides of calcium oxalate are both wanting; the bast fibers occur in regular tangentially arranged groups and the walls are nearly straight; stone cells are very few and quite small; the bark yields only a small quantity of alkaloids.

Brazilian Angostura is the bark of Esenbeckia febrifuga, a tree growing in the forests of Brazil. It is externally of a silver-gray or grayish-brown color, and marked by numerous lenticular lenticels and dark patches of lichens; internally the color is brownish and marked by distinct transverse light and dark areas. It contains numerous groups of stone cells and tannin secretion cells; calcium oxalate in the form of prisms are abundant; the oil-canals are very large and distributed throughout the parenchyma of primary and secondary cortex. Esenbeckia contains 0.1 per cent of volatile oil and a number of alkaloids.

The bark of Strychnos Nux vomica has been substituted and has produced serious consequences, causing the use of Angostura to be prohibited at one time in some countries. It is distinguished by a distinct line of stone cells separating the inner bark from the middle cortical layer.

\section{SIMARUBACEE, OR QUASSIA FAMILY}

Chiefly tropical or sub-tropical trees and shrubs, with alternate and pinnately compound leaves, regular flowers and drupaceous or samara-like fruits. In the pericycle occur isolated groups of bast fibers and in some cases it is made up of a composite and continuous ring of sclerenchyma. The tracheæ usually have simple perforations and the wood fibers either possess slit-like, simple pores or are free from any perforations. The tracheæ when adjoining parenchyma cells have bordered pores on the dividing wall. Resin canals occur 
only in the peripheral region of the pith and are seldom found in the cortex. The hairs are usually both unicellular, non-glandular and multicellular, glandular. Calcium oxalate is usually secreted in the form of rosette aggregates or solitary crystals; in some instances styloids occur.

Quassia.-Quassia Wood.-The wood of Picrasma excelsa (Fam. Simarubacex), a tree indigenous to Jamaica and other islands of the West Indies. The trees are felled and cut into billets. The latter are exported and afterward manufactured into " quassia cups," the shavings constituting the drug known as Jamaica Quassia. The market supply of this drug was at one time almost exclusively obtained from Quassia amara (Fam. Simarubaceæ), a small tree or shrub indigenous to Brazil and cultivated in Colombia, Panama, West Indies and other tropical countries. The wood of the latter is exported from Surinam and is known as Surinam Quassia; this variety is used in continental Europe and now quite largely in the United States.

Jamaica Quassia.-Usually in raspings, light or bright yellow, medullary rays two to five cells wide in transverse section, the cells containing tetragonal prisms or sphenoidal microcrystals of calcium oxalate; fracture fibrous; odor slight; taste bitter.

Inner Structure.-(Fig. 165.) Tracheæ wide, single or in groups of 2 to 5 , having bordered pores and a yellowish content; medullary rays mostly 1 to 5 cells wide and from 10 to 20 rows deep; crystal fibers containing calcium oxalate in 4 - to 6 -sided prisms, from 0.006 to $0.030 \mathrm{~mm}$. in length; wood fibers with thin walls and oblique pores; starch grains few, spheroidal or ellipsoidal, 0.010 to $0.015 \mathrm{~mm}$. in diameter.

Surinam Quassia usually occurs in small billets; the medullary rays are 1 to 2 cells wide in transverse section, and calcium oxalate crystals are wanting.

Inner Strusture.-(Fig. 165.) Tracheæ usually single or in pairs, sometimes in groups of 3 or 4 ; medullary rays from 1 to 4 cells wide and from 10 to 30 rows deep; calcium oxalate crystals few or entirely wanting and distinguishing this variety from Jamaica Quassia.

Powder.-Light yellow; tracheæ wide with bordered pores; sclerenchymatous fibers long, thin-walled and with oblique simple pores; medullary rays with calcium oxalate in monoclinic prisms or in sphenoidal microcrystals, or with few spheroidal starch grains. When bark of the wood is present a few stone cells and cork cells are also present. In the bark of Surinam quassia stone cells are numerous.

Constituents.-Jamaica quassia contains from 0.05 to 0.75 per 
cent of a bitter crystalline substance, quassiin. This really consists of two crystalline bitter principles- $\alpha$-picrasmin and $\beta$-picrasmin. Jamaica Quassia also contains a crystalline alkaloidal principle which gives a blue fluorescence in acidified alcoholic solution.

Surinam quassia contains one or more bitter principles, which are related to the picrasmins of Jamaica quassia, and which are known as quassiins.

Allied Drugs.-The barks of Picrasma excelsa and Quassia amara are used in medicine and probably contain similar principles to the
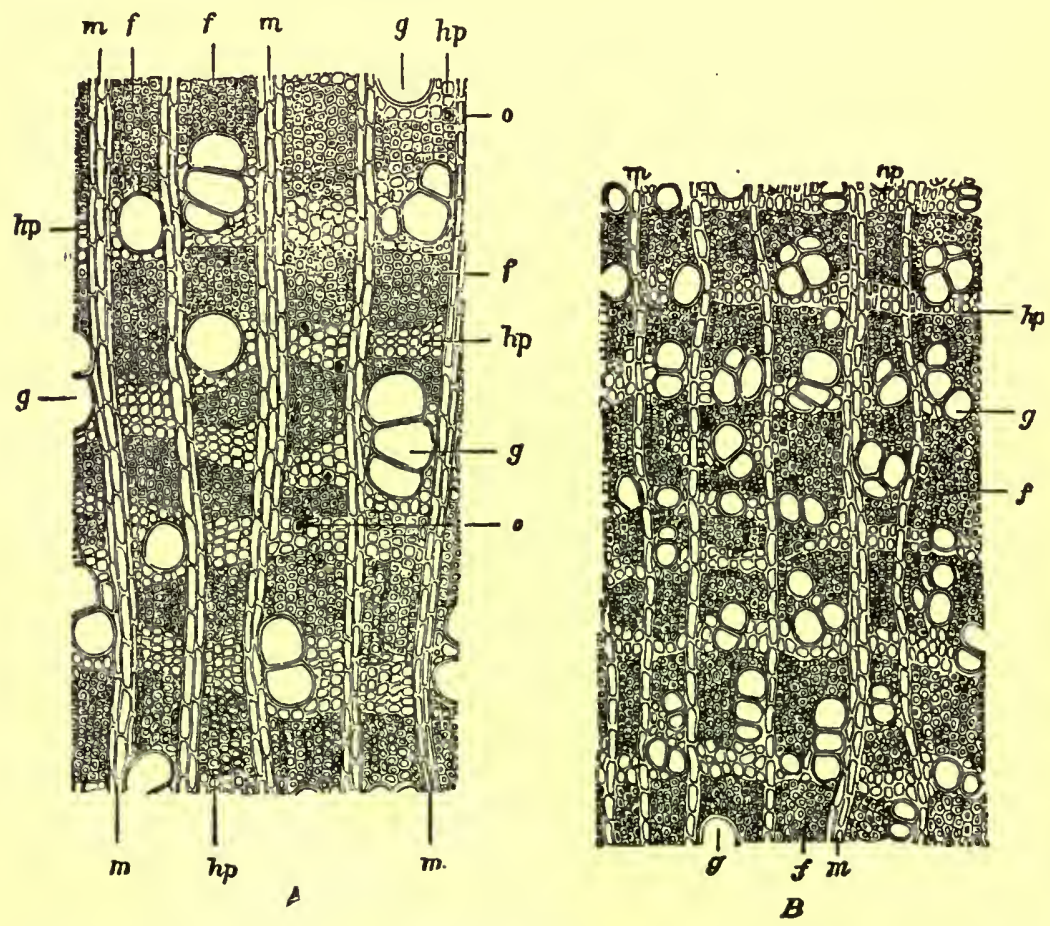

FIG. 165.-A, transverse section of Jamaica quassia. $B$, transverse section of Surinam quassia; $g$, tracheæ; $f$, wood fibers; $h p$, wood parenchyma; $o$, cells containing calcium oxalate; $n$, medullary rays.-After Meyer.

wood. The Surinam bark occurs in thinner, light-colored pieces and is sometimes admixed with the powdered drug. It is determined by the large stone cells. The wood of Picræna quassisioides quite closely resembles Jamaica Quassia in general appearance, microscopical structure and chemical constituents. Bitter principles are also found in other species of Picrasma and Quassia. An allied bitter 
principle and an alkaloid are found in Cascara Amarga or Honduras Bark, which is derived from Picræna Vellozii, of southern Brazil.

Simaruba.-Cortex Simarubæ, Simaruba Bark.-The bark of the root of Simaruba officinalis and S. amara (Fam. Simarubaceæ), stately trees, the former indigenous to northern Brazil, French Guiana and Guatemala, and furnishing the bark known commercially as Orinoco Simaruba; the latter growing in Panama, Guatemala, the Bahama Islands and in Florida, and yielding the bark known as Jamaica Simaruba. The root bark is collected and deprived of the periderm. Most of the commercial supplies come from Ciudad Bolivar (Angostura) on the Orinoco River, Venezuela.

Orinoco Simaruba. (Fig. 166.) - In flattened or somewhat transversely curved pieces, from 0.3 to $1 \mathrm{M}$. in length, 4 to $12 \mathrm{~cm}$. in width, and from 2 to $5 \mathrm{~mm}$. in thickness; externally grayish- or yellowish-brown, somewhat velvety to the touch, irregularly wrinkled, marked with a few, irregular, brownish scars and with occasional patches of the shining silvery periderm; inner surface yellowishbrown, longitudinally striate; fracture short fibrous, porous and with yellowish stone cells; inodorous; taste very bitter and slightly aromatic.

Inner Structure.-Middle bark consisting of tangentially elongated parenchyma, having thin walls and containing small, nearly colorless or yellowish-brown granules, and interspersed among which are the light yellowish resin secretion cavities, and numerous more or less irregular, very thick-walled, light-yellowish stone cells either single or in small groups, usually surrounded by crystal fibers, the crystals being nearly cubical and from 0.010 to $0.025 \mathrm{~mm}$. in diameter; inner bark with irregular groups of bast fibers consisting of thin, bright yellow, somewhat lignified walls, separated by narrow strands of more or less obliterated leptome and parenchyma; medullary rays in somewhat wavy rows from 1 to 20 cells in width and having usually slightly thickened porous walls. In the broad wavy wedges of phloem are distributed large stone cells, the walls resembling those found in the middle bark but being comparatively thinner, and are arranged in spindle-shaped longitudinal rows, and like the bast fibers are usually surrounded with crystal fibers. The drug is apparently free from starch.

Jamaica Simaruba.-In flattened pieces about $50 \mathrm{~cm}$. or more in length and about $10 \mathrm{~cm}$. in width; flexible, very fibrous and bitter. The inner structure closely resembles the Orinoco bark.

Constituents.-A volatile oil having an odor resembling benzoin; a non-volatile oil; a crystalline bitter principle, giving a violet 
color with sulphuric acid; a crystalline non-bitter substance; a fluorescent principle; a resin; gallic acid, and calcium oxalate and malate.

Allied Plants.-In 1904 the bark of the stems and branches of a tree growing in Ciudad Bolivar was found in commerce under the name of Maracaibo Simaruba. The pieces consisted chiefly of the inner bark, varying from 0.7 to $0.9 \mathrm{~cm}$. in thickness; externally they were mottled, showing groups of yellowish stone cells in among the parenchyma; the inner surface was brownish-yellow, smooth, and with shallow furrows; the fracture being short, granular. The bark appears to be derived from Simaruba officinalis (Fig. 166).
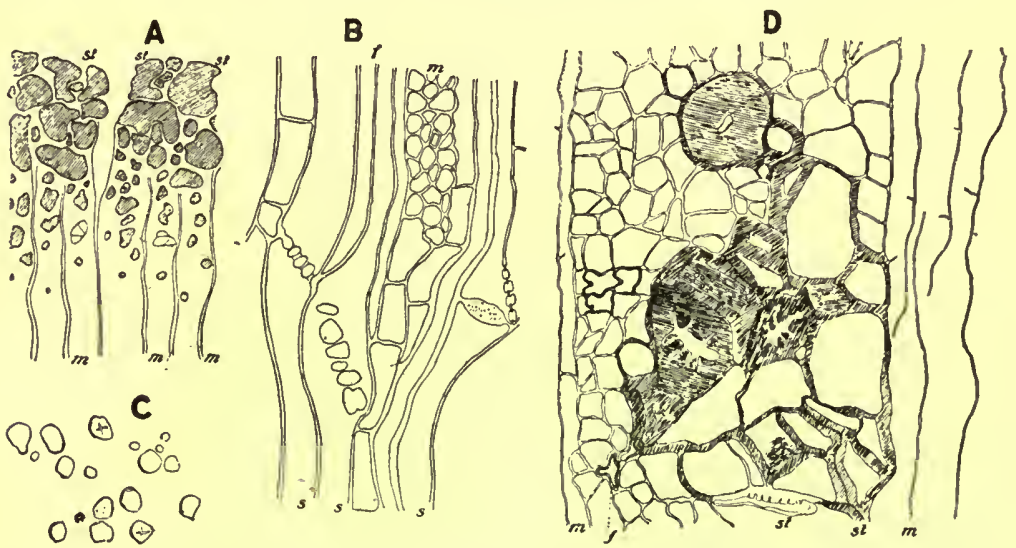

FIG. 166.-Maracaibo Simaruba Bark probably derived from the stems of Simaruba officinalis: $A$, transverse section showing medullary rays $(m)$; and stone cells (st) in the outer bark. $B$, tangential-longitudinal section showing medullary ray cells $(m)$; sieve tubes $(s)$; and bast fibers $(f) . \quad C$, starch grains mostly single, spheroidal, somewhat pyriform and about $0.020 \mathrm{~mm}$. in diameter. $D$, transverse section of the outer bark showing the large group of stone cells $(s t)$; irregular bast fibers $(f)$; and medullary ray cells $(m)$.- After Rosenthaler and Stadler, Ber. d. d. Pharm. Ges., 1907, p. 137.

\section{Literature.-Zornig, Bot. Abstracts, 1918, 1, p. 30.}

Brucea Sumatrana and B. Antidysenterica (Fam. Simarubaceæ).-The fruits of Brucea Sumatrana, popularly known as Kô-sam Seeds, were obtained from the East Indies; where they are reputed to be a valuable remedy in the treatment of tropical dysentery. The fruits and other parts of the plant of Brucea antidysenterica are similarly employed in Abyssinia. Both the fruit and the bark of these two species of Brucea contain, amongst other constituents, several amorphous bitter principles. Certain statements by previous investigators, regarding the character of the active prin- 
ciples, are probably erroneous.-Power, Pharm. Jour., 1903, p. 183; 1907 , p. 126.

\section{BURSERACEA, OR MYRRH FAMUY}

Mostly tropical shrubs and trees, having alternate compound leaves, and small flowers formed in racemes. The plants are especially distinguished by their internal secretory system. Schizolysigenous balsam canals or gum-resinous canals (Fig. 167) occur

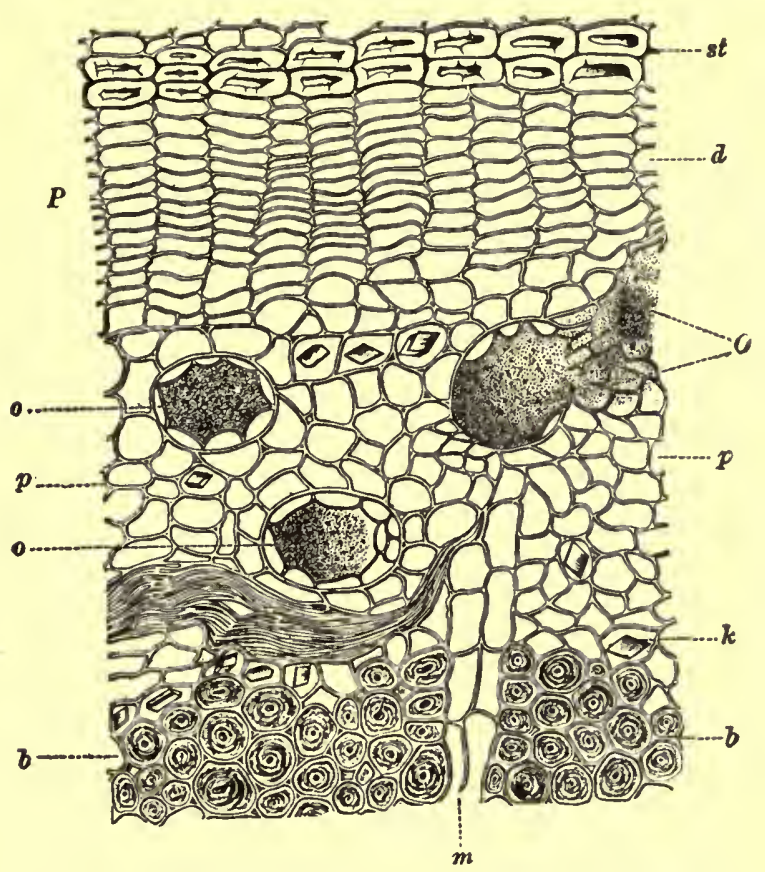

FIG. 167.-Transverse section of the bark of one of the Burseraceæ, probably Commiphora Myrrha: $P$, bark made up of sclerotic cells (st) and cork $(d)$; $o$, more or less spheroidal secretion canals, one of which $(O)$ shows the irregular spreading of the gum-resin; $m$, medullary rays; $b$, bast fibers; $k$, crystals of calcium oxalate; $p$, parenchyma.-After Vogl.

within the sclerenchymatous pericycle, also in the secondary cortex and medullary rays and occasionally in the primary cortex and pith. The epidermal layer in the leaves is usually modified to mucilage. The pericycle is a composite and continuous ring of sclerenchyma. The tracheæ as a rule have simple perforations, which are very large in the walls adjoining the parenchyma cells. Wood fibers also have simple pores, being occasionally septate. The medullary rays are, 
narrow. Calcium oxalate is secreted in the form of rosette aggregates or solitary crystals (Fig. 167). Glandular and non-glandular hairs are of a number of specific forms.

MrrRha.-Myrrh.-The dried gum-resin from the stem of Commiphora abyssinica and C. Schimperi (Fam. Burseraceæ), rather large shrubs indigenous to northeastern Africa (chiefly Somali Land) and southern Arabia. The gum-resin exudes naturally or from incisions made in the bark; it is first of a yellowish color, but soon hardens, becoming darker, and is then collected. There are two principal commercial varieties of Myrrh, the one known as African or Somali Myrrh, and the other as Arabian or Yemen Myrrh, the former being considered the better of the two.

Description.-In irregular, agglutinated tears or masses varying in size; externally rough and uneven, yellowish- or reddish-brown, covered with a yellowish powder; brittle, the fractured surface waxy, grandular, oily, slightly mottled, somewhat translucent in thin pieces; odor balsamic; taste aromatic, bitter and acrid.

Myrrh forms a brownish-yellow emulsion when triturated with water (distinction from other gum-resins); an ethereal solution treated with bromin vapor becomes reddish (distinction from East Indian myrrh); when moistened with nitric acid it becomes purplish (distinction from false myrrh or bdellium); not more than 65 per cent is insoluble in, alcohol.

\section{Inner Structure of the Bark.-(Fig. 167.)}

Powder.-In glycerin mounts the powder shows yellowish or yellowish-brown irregular fragments made up of a grayish matrix, containing yellowish or yellowish-brown oil globules, a few fragments of lignified tissues consisting of either sclerenchymatous fibers, or of small groups of stone cells, the individual cells of the latter having very thick, porous walls and being from 0.015 to $0.050 \mathrm{~mm}$. in length; occasional starch grains from 0.010 to 0.035 $\mathrm{mm}$. in diameter and varying from spheroidal to somewhat pearshaped grains.

Constituents.-A yellowish or yellowish-green, rather thick volatile oil, 2.5 to 8 per cent, having the characteristic odor of myrrh; resin, 25 to 40 per cent, composed of several constituents, one of which yields protocatechuic acid and pyrocatechin; gum, about 60 per cent, consisting of soluble and insoluble portions, which forms a mucilage that does not readily ferment; a bitter principle, sparingly soluble in water but soluble in alcohol; ash, 5 to 10 per cent.

The volatile oil of myrrh consists of cuminol (about 1 per cent), eugenol, meta-cresol, pinene, limonene, dipentene and two sesqui- 
terpenes. The acidity of old oil is due to free acetic, myrrholic and commiphorinic acids.

Adulterants.-Myrrh is frequently admixed with gums and other gum-resins, including several kinds of Bdellium, which are obtained from various species of Commiphora, and which are characterized by not giving a purplish color with nitric acid. Of these the following may be mentioned: African bdellium, which occurs in yellowishbrown masses, that are reddish in transmitted light and have a pepper-like odor and bitter taste; Indian bdellium, occurring in irregular, reddish-brown masses, covered with minute spicules of resin, and having a terebinthinate odor and an acrid taste; and opaque bdellium, which occurs in yellowish, hard, opaque masses, with a faint odor and bitter taste, and the alcoholic solution of which is colored black with solutions of ferric chloride. Thin pieces of a bark are frequently present in opaque bdellium.

Bisabol, or East Indian myrrh, is exported from eastern Africa and Asia; it closely resembles true myrrh, but is distinguished from it by the ethereal solution not becoming reddish with bromin vapor. Furthermore, on mixing 6 drops of a petroleum ether solution (one part of myrrh to 15 of ether) with 3 c.c. of glacial acetic acid and then adding this liquid carefully to 3 c.c. of concentrated sulphuric acid, a rose-colored zone is at first developed, and finally the entire acetic acid solution assumes the same color. With genuine myrrh the solution is colored a very pale rose color.

Allied Plants.-Opopanax is a balsam-like product obtained from Commiphora Kataf, a plant indigenous to Arabia, and is supposed to be the Myrrh mentioned in the Bible. It yields from 6 to 10 per cent of a greenish-yellow volatile oil with a pleasant balsamic odor; and also contains opo-resinotannol (a compound not yielding umbelliferon on distillation) both free and combined with ferulaic acid; free ferulaic acid; vanillin, and a gum containing bassorin.

Mulu Kilavary is a gummy exudation obtained from Commiphora Berryi, a plant growing in India. It occurs in yellowish-brown or dark-brown translucent fragments, having a conchoidal, oily fracture, and consists chiefly of gum, with a small quantity of a tasteless resin and a volatile oil.

\section{MELIACEA, OR MAHOGANY FAMILY}

A family of tropical and sub-tropical trees and shrubs, having mostly alternate and compound leaves and axillary clusters or racemes of flowers. The family is especially known for its yielding 
the mahogany wood, which is considered one of the most durable and valuable of cabinet woods. The true mahogany is obtained from Swietenia Mahogoni, a native of tropical America and formerly very abundant in Jamaica; now, however, probably all of the mahogany wood comes from Central America. It is cultivated to some extent in Florida and California as an ornamental tree. Other genera of this same family yield a wood which is substituted and sold for mahogany. There are quite a number of timbers, which are obtained from plants entirely unrelated to the Meliacex, that are also sold in commerce as mahogany.

In the Meliaceæ the tracheæ always have simple perforations, except when adjoining parenchyma cells, they possess bordered pores. The wood fibers have large lumina and are usually marked by simple perforations and occasionally have septate transverse walls. One of the marked characteristics of these plants is the presence of secretory cells in the pith, cortex and leaves; in the latter they give rise to transparent dots, which are readily apparent on holding the leaves to the light.

The epidermal cells are usually modified to mucilage. Bast fibers and stone cells occur in isolated groups in the pericycle, occasionally there being a ring of stone cells also in this region. Calcium oxalate is secreted in the form of rosette aggregates or solitary crystals. Both glandular and non-glandular hairs occur in a number of specific forms.

Cocillana.-The bark of Guarea Rusbyi (Fam. Meliaceæ), a tree indigenous to the eastern Andean slope in Bolivia. It is used by the natives as an emetic and has been introduced into medicine in the United States to some extent as an expectorant, it being said to resemble ipecac in its action on the respiratory organs.

Description.-In flattened or somewhat transversely curved pieces from 5 to $12 \mathrm{~cm}$. in length, 1 to $3 \mathrm{~cm}$. in width, and 3 to $5 \mathrm{~mm}$. in thickness; externally grayish-yellow or -brown with whitish patches of a lichen, roughly and unevenly fissured, having longitudinal furrows and occasionally transverse fissures; inner surface grayish-yellow, coarsely striate and often roughly fibrous from detached strands of bast fibers; fracture coarsely granular in the outer bark, and splintery fibrous in the inner bark; transverse surface with thick, light reddish-brown periderm, having numerous -yellowishwhite stone cells, inner bark tangentially, finely striate; odor slight; taste somewhat astringent, unpleasant and slightly nauseous.

Inner Structure--(Fig. 168.) Periderm of several layers of primary and frequently even secondary cortex, between which are 
included large groups of stone cells having very thick and porous walls; bast fibers in tangentially elongated groups separated by plates of parenchyma and sieve; the bast fibers attain a length of $0.750 \mathrm{~mm}$., the walls being nearly straight and attenuated at the ends; crystal fibers surround the groups of bast fibers, each cell of the former having a monoclinic rhombohedral crystal of calcium oxalate; medullary rays from 1 to 3 cells wide and from 15 to 20 rows. deep, the walls being porous and not infrequently lignified and occasionally having in the lumina reddish-amorphous masses which are insoluble in alcohol. The secretory cells are somewhat elongated and have a yellowish-white amorphous or granular content which is

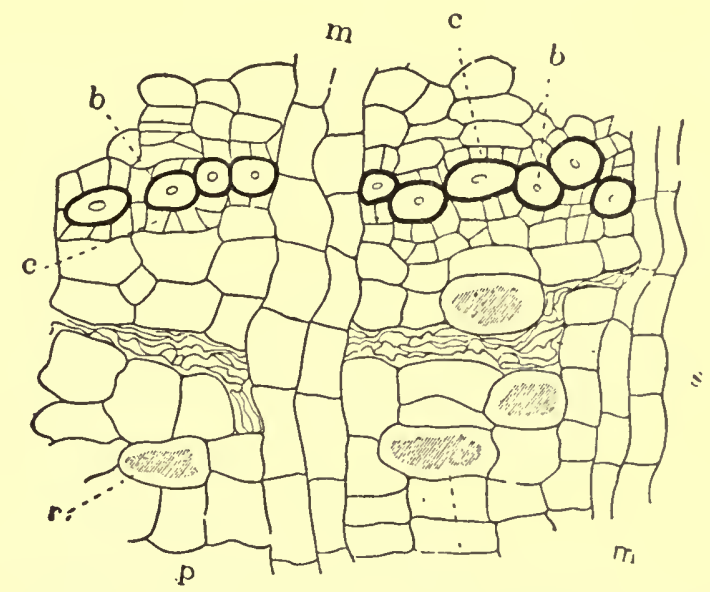

FIG. 168.-Cocillana. Transverse section of the inner bark: $m$, medullary rays; $b$, bast fibers; $s$, collapsed sieve; $r$, oleoresin secretion cells, showing an amorphous content; $p$, parenchyma; $c$, crystal fibers surrounding the bast fibers, each containing a crystal which is not illustrated in the drawing.-After Schrenk.

insoluble in alcohol and in dilute solutions of the alkalies, but soluble in chloroform and volatile oils; the starch grains are small, spheroidal and occur in the cortical parenchyma and cells of the medullary rays.

Constituents.-An alkaloid, Rusbyine; a mixture of resins, 2.5 per cent; a fixed oil, 2.5 per cent; a caoutchouc-like substance; and tannic acid.

Literature.-Schrenk, Drug. Bulletin, 1888, p. 222.

Azedarach.-The bark of the root of Melia Azedarach (Fam. Meliaceæ), a beautiful shade tree indigenous to Asia, and cultivated in Europe and the southern United States. It is known as Pride-of- 
China and Pride-of-India, on account of its rare beauty; Indian lilac, by reason of the resemblance of its flowers to the common syringa; and Bead tree or Pater-noster tree in allusion to the use of the seeds of the fruits in making of rosaries. The drupaceous green fruit is very astringent. When ripe it is yellow, sweet, and on drying it becomes purplish-black, retaining its fleshy character for many years. It is said to produce an intoxicating effect upon robins and is sometimes sprinkled with clothing in order to prevent the development of moths. The dried berries are also used much as those of Cocculus. The bark, preferably deprived of the periderm, is used to some extent in medicine.

Description.--In quills or irregularly flattened, somewhat transversely curved pieces, from 3 to $15 \mathrm{~cm}$. in length, 0.5 to $3 \mathrm{~cm}$. in width, and 2 to $7 \mathrm{~mm}$. in thickness; outer surface yellowish- or reddishbrown; nearly smooth with irregular lighter and darker patches; inner surface light brown, longitudinally striate and frequently with detached bast fibers; fracture short-fibrous; transverse surface showing a porous, reddish-brown cork or periderm, inner bark yellowish and tangentially striate, frequently lamellated; odor slight; taste sweetish, bitter and somewhat acrid.

Inner Structure.-Periderm of two or more layers of colorless, thin-walled, compressed cork cells, between which occur broad strands composed of large parenchyma cells and in among which are distributed the brownish tannin secretion cells forming long and frequently branching rows; inner bark consisting chiefly of starchbearing parenchyma, leptome and 3 or 4 interrupted circles of bast fibers separated by broad medullary rays; bast fibers very long, with irregular walls and oblique terminations, strongly lignified and having numerous long slit-like pores: calcium oxalate in rhombohedral crystals about $0.025 \mathrm{~mm}$. in diameter and arranged to form crystal fibers; the latter surround the groups of bast fibers, the walls . being thickened and strongly lignified, excepting where they adjoin the parenchyma cells; medullary rays from 1 to 8 cells wide, and in rows from 5 to 15 cells in depth; starch grains single and 2- or more compound, the individual grains from 0.003 to $0.015 \mathrm{~mm}$. in diameter, spheroidal, ellipsoidal irregularly polygonal and often with a long central cleft; secretion cells with a yellowish-brown oily content, single or united to form chains and distributed throughout the parenchyma tissues of the outer and inner bark.

Constituents.-A yellowish-white resin which appears to possess the anthelmintic properties ascribed to the drug. It has a very bitter taste, is insoluble in water but soluble in alcohol, ether, chloro- 
form, carbon disulphide, petroleum benzin and oil of turpentine. It is precipitated from alcoholic solutions by the addition of water.

Literature-Jacobs, Amer. Jour. Pharm., 1879, p. 443.

Azadirachta Indica.-Cortex Margoser, Indian Azadirach, Margosa or Neen Bark.-The dried bark of Azadirachta indica (Fam. Meliacex), a tree indigenous to the East Indies and rather widely distributed in the tropical countries of Asia and to some extent cultivated. It is used in India and the eastern colonies of Great Britain, as a simple bitter, replacing gentian and quassia.

Description.--Usually in flat, somewhat transversely curved pieces, from 5 to $15 \mathrm{~cm}$. in length, 1 to $3 \mathrm{~cm}$. in breadth, and 5 to 10 $\mathrm{mm}$. in thickness; outer surface grayish-brown, more or less fissuled and rough and scaly; inner surface yellowish-brown, longitudinally striate and fibrous; fracture short, fibrous; transverse surface somewhat radiate from the narrow, yellow medullary rays, crossed by alternating, tangentially arranged groups of brownish bast fibers, separated by lighter strands of leptome and parenchyma; inodorous taste of inner bark, bitter, while that of the outer bark is astringent.

Inner Structure.-Outer layer consisting of a number of thinwalled and nearly colorless cork cells; the parenchyma of the primary cortex contains either a brownish amorphous content or rosette aggregates of calcium oxalate, and in among which are distributed the large, somewhat thick-walled and elongated secretion cells; inner bark with tangentially elongated groups of bast fibers surrounded by crystal fibers, each having a rhombohedra crystal of calcium oxalate; separating the groups of bast fibers are the more or less collapsed leptome cells which are thin-walled, possessing rather large pores; medullary rays from 4 to 6 cells wide, those in the outer bark possessing a brownish amorphous content; the bast fibers are from 0.500 to $1 \mathrm{~mm}$. in length, about $0.020 \mathrm{~mm}$. in width and possessing large lumina; the bast parenchyma consists of spheroidal or polyhedral cells having a dark brown content; a small amount of starch is found in the parenchyma cells and medullary rays of the inner portion of the secondary cortex.

Constituents.-A bitter alkaloid, margosine; a bitter amorphous resin; margosic acid; and tannic acid.

Literature.-Mittlacher, Zeitschr. d. Allgem. öster. Apoth. Verein, 1900, p. 19. 


\section{POLYGALACE E, OR MILKWORT FAMILY}

A family of about 750 species, mostly herbs, except in the tropies where they may become shrubs and trees. The leaves are usually, alternate and exstipulate, the flowers are perfect and irregular, and the fruit is usually a capsule enclosing caruncled seeds. Among the histological features of this family the following may be mentioned: Small isolated groups of bast fibers occur in the pericycle of some of the species of Polygala. Only the transverse walls of the tracheæ are marked by simple pores. The wood fibers possess bordered pores, and the medullary rays are very narrow. The cells of the pith are sometimes lignified. In the leaves there are several important characteristics: (1) sclerotic cells are occasionally found in the loose mesophyll and palisade layer; (2) in Polygala there is a strong tendency for the epidermal cells to become papillose, thus resembling the leaves of Erythroxylon; and (3) terminal tracheids occur in the veins of Polygala. Calcium oxalate is secreted in the form of solitary crystals or rosette aggregates. Non-glandular hairs are mostly unicellular, occasionally uniseriate. Glandular hairs are wanting. In certain species of Polygala there are spheroidal aggregates of a crystalline nature and Solereder suggests that they may have been described by Chodat as lysigenous secretion cavities or oil cells in certain South American species of Polygala.

Senega.-Senega Root.-The dried root of Polygala Senega (Fam. Polygalaceæ), a perennial herb found in Canada and the eastern United States as far south as North Carolina and as far west as Alberta, Minnesota and Missouri. There are two representative commercial varieties - the northern, collected in Manitoba and in the State of Minnesota; the southern, from Virginia to Texas.

Description.-Southern Senega.-Nearly entire, with broken and detached rootlets, crowned with numerous buds and short stem-remnants, slenderly conica!, more or less tortuous, somewhat branched, 3 to $8 \mathrm{~cm}$. in length, 2 to $6 \mathrm{~mm}$. in thickness; externally dark yellow, the crown being rose-tinted, longitudinally wrinkled, slightly annulate, marked with circular scars of detached rootlets and in some cases by a keel, which is more prominent at the upper portion of the dried roots; side opposite keel more or less flattened; fracture short when dry, tough when damp; transverse section (Fig. 169) elliptical or triangular, showing a characteristic excentral development of lemon-yellow wood, which varies in outline from elliptical or ovate to irregularly fan-shaped, and is surrounded by an unevenly developed dark yellow cortex, being thickest outside the broadest strands 
of wood, and forming the keel on drying; odor slight, penetrating; taste sweetish and acrid.

Inner Structure.-An outer layer of several rows of tangentially elongated, light yellowish or yellowish-brown cells; outer bark of slightly thickened cells, containing a colorless or pale yellowish amorphous substance, which is liberated in the form of large globules upon the addition of a solution of potassium hydroxide; inner bark, the cells in radial rows, consisting of parenchyma, small groups of leptome, and medullary rays, the latter 1 to 3 cells wide all the cells in this zone show a collenchymatous thickening of the walls and contain an amorphous substance, similar to that found in cells of the outer bark; woody layer of tracheæ with bordered pores, wood fibers with oblique, simple pores, tracheids, and medullary rays, the
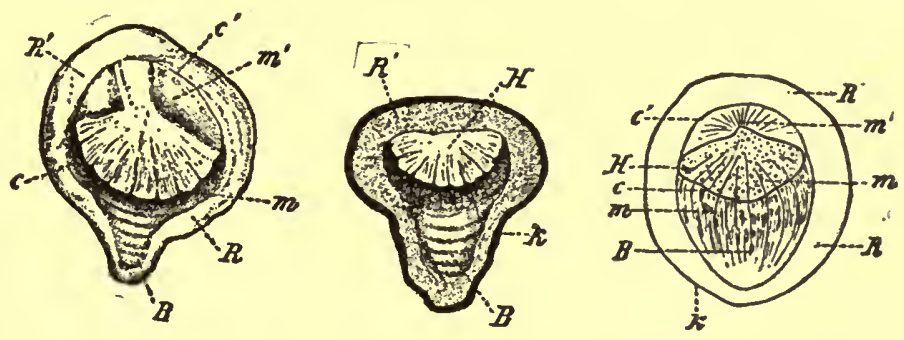

FIg. 169.-Transverse sections of senega, the two on the left being of the dry drug, and the one on the right showing the appearance after soaking the material in water: $R$, outer bark; $R^{\prime}$, bark on the side having abnormal development of wood; $B$, inner bark, which gives rise to the "keel" on the drying of the root; $H$, wood; $C, C^{\prime}$, cambium; $m$, medullary rays; $m^{\prime}$, parenchyma developed in place of wood on one side.-After Meyer.

latter being rather indistinct and resembling the wood fibers; tissues of the central layer of wood colored yellowish- or reddish-brown on the addition of a solution of potassium hydroxide.

Powder.-Light yellowish-brown or dark yellow; odor penetrating; slightly sternutatory; sclerenchymatous fibers thick-walled, non-lignified, with oblique simple pores; tracheæ about $0.175 \mathrm{~mm}$. in length, lignified, with simple and bordered pores; medullary-ray cells somewhat lignified, with large simple pores. Quillaja (Fig. 136) is distinguished from senega by having elongated monoclinic prisms of calcium oxalate, and numerous starch grains, lignified bast fibers and stone cells.

The following test is of some practical use in arriving at a comparative value of different samples of senega. It is based upon the presence of methyl salicylate, which occurs in greatest amount in 
the recently gathered drug, and that has been most carefully prepared for the market. Extract $10 \mathrm{gm}$. of powdered Senega by means of a Soxhlet apparatus, using 50 c.c. of ether to which 2 drops of hydrochloric acid have previously been added. Continue the extraction for four or five hours and then add sufficient ether to make the liquid measure 50 c.c. Take 25 c.c. of this solution and evaporate it on a water-bath to dryness, the residue should not weigh less than $0.300 \mathrm{gm}$. and upon dissolving the residue with 10 c.c. of chloroform, transferring it to a test-tube and pouring 5 c.c. of sulphuric acid beneath the solution, a reddish-brown color should be produced at the zone of contact and the sulphuric acid should show a slight green fluorescence, after the mixture has stood for twenty-four hours. If 10 c.c. of the original ethereal solution be poured into a beaker in which previously has been placed 10 c.c. of water and the mixture warmed on a water-bath until the ether has been evaporated, the aqueous solution, upon filtering and adding a few drops of a solution of ferric chloride, should become a bright pink-purple.

Manitoba Senega is 8 to $15 \mathrm{~cm}$. in length, 6 to $12 \mathrm{~mm}$. in thickness, externally dark brown and somewhat purplish near the crown.

Constituents.-The principal constituents are about 5 or 6 per cent of two glucosides: senegin, which resembles saponin, and polygalic acid, which is sternutatory. The root also contains 0.12 per cent of a volatile oil which is chiefly methyl salicylate; resin; pectin; sugar; and considerable proteins.

Allied Plants.--Saponin-like substances and methyl salicylate are found to a greater or less extent in other species of Polygala, of which at least forty have been used in medicine. Other genera of the Polygalaceæ seem to have constituents similar to Senega, as Comesperma of Australia and Monnina of South America.

The roots of Polygala angulata are collected in Brazil, and are commonly known as White Ipecac or poaya blanca. The roots resemble those of Senega, but are from 7 to $20 \mathrm{~cm}$. in length and from 1 to $9 \mathrm{~mm}$. in diameter. They are nearly cylindrical, more or less tortuous, light brown in color, longitudinally wrinkled and marked by numerous transverse fissures. The crown is surmounted with a number of stem bases which somewhat resemble the roots. They probably contain saponin, and on this their emetic properties depend.-Kraemer, Proc. A. Ph. A., 1900, p. 214.

Adulterants. - The rhizomes and roots of Cypripedium hirsutum and C. spectabile of the United States are said to be sometimes used as adulterants of Senega (Figs. 60 and 61). 


\section{EUPHORBIACEE, OR SPURGE FAMILY}

A large family of about 4000 species, which are very widely distributed. Outside of the fact that the flowers are subtended by an involucre, which resembles a calyx, and the fruit is a 3 -lobed capsule, there are no distinctive morphological features which extend throughout all the members of this family. It is ordinarily stated that the plants possess a milky acrid juice, but this is only true of some of the genera. There are no less than 8 different kinds of secretory tissues in this family. (1) Laticiferous Cells are especially characteristic of the Euphorbias. They occur in the pith, cortex and in the veins of the leaves and the contents in the living plants are generally milky and may contain starch grains, protein crystals, rosette aggregates of calcium oxalate and tannin.

Laticiferous Vessels occur in Hevea, one or more species of which yield caoutchouc, and in Manihot, the tuberous roots of which furnish tapioca starch. In the former the juice is of a milky character and in the latter in the nature of a watery sap. (3) Rows of laticiferous sacs are confined to the genus Micrandra. The cells form long chains and contain a sap, which, on drying, is colored gray. (4) Tanniferous Cells occur singly or in chains and have a brownish content. They are widely distributed in the Euphorbiaceæ. A secretory organ, consisting of very much Elongated Sacs having a brownish content, is found solely in the pith cells of Mallotus and some other genera. They are usually surrounded by a ring of small cells resembling an epithelium. (6) Idioblasts, or secretory cells with an oleo-resin content, are found in Ricinus, Croton, etc. The cells are large and contain a yellowish and strongly refractive secretion, giving rise to transparent dots in the leaves.

(7) Secretory Lacunæ, resembling the intercellular secretory receptacles, occur in some of the Leguminosæ. (8) Mucilage Lacunæ or groups of cells having mucilaginous walls, are found in a limited number of genera.

The pericycle is of varied composition, being either without any sclerenchyma or composed of a ring of mechanical tissues or in some instances composed of isolated groups of bast fibers, in the latter case the walls are lamellated. The tracheæ usually are marked by simple pores and scalariform perforations. In some instances, the latter type only being developed. The tracheal walls, adjoining parenchyma cells, may possess either simple or bordered pores. The wood fibers have either thick, somewhat mucilaginous walls and narrow lumina, or thin walls and large lumina, the transverse walls being occasionally septate. Calcium oxalate is usually secreted in the form 
of solitary crystals or rosette aggregates, occasionally occurring in the form of short rods, sphaerites, or in the form of $\mathrm{V}$ - or W-shaped crystals. Both glandular and non-glandular hairs occur in a number of specific forms. Stinging hairs are also found in a number of tropical genera.

Stillingia.-Queen's Root.-The root of Stillingia sylvatica (Fam. Euphorbiacex), a perennial herb indigenous to the southern United States. The root is collected in August, deprived of its rootlets, cut into transverse pieces and carefully dried.

Description.-(Fig. 170.) Cylindrical, tapering, and slightly branched, about $40 \mathrm{~cm}$. in length; usually cut into pieces 2 to 10 $\mathrm{cm}$. in length, 5 to $30 \mathrm{~mm}$. in diameter; externally dark brown, longitudinally wrinkled, rootlets or rootlet-scars few; fracture of bark fibrous; internally, cork, reddish-brown, thin; inner bark light reddish-brown (when fresh whitish), 0.5 to $4 \mathrm{~mm}$. in thickness, soft, spongy, with numerous resinous-tanniferous cells and easily separable from the porous, radiate wood; odor faint; taste bitter, acrid and pungent.

Inner Structure.-(Fig. 170.) In the thin lateral roots the epidermis is soon replaced by a thin-walled exodermis surrounding a cortical parenchyma, consisting of about 5 layers of mostly collapsed cells, which are without starch. The endodermis is thin walled (Fig. 170, $H$ ) and the pericambium shows several tangential divisions, giving rise to the cork, which later on forms the protective tissue around the secondary cortex, when the peripheral tissues from epidermis to endodermis become thrown off. There are in the stele three broad strands of primary leptome, in' which many stereids are scattered, a structure which is apparently not present in the other Euphorbiaceous drugs. The hadrome consists of the three primordial riys and generally somewhat wider vessels are developed on the inner flank of the leptome. There is no pith and the conjunctive tissue is but sparingly represented.

In slightly thicker roots there is a corresponding structure and the leptome here contains very many stereids; on the other hand the secondary leptome is destitute of stereome and is represented by exceedingly narrow strands in the now typical collateral vascular bundle (Fig. 170, I).

The thick fusiform roots show a strongly developed cork, consisting of thin-walled brownish cells; a cortex of nearly isodiametric, thin-walled, starch-bearing parenchyma, scattered strands of bast fibers occurring singly or in small groups, and reddish-brown tanniferous cells traversing the secondary cortex; the secondary leptome 

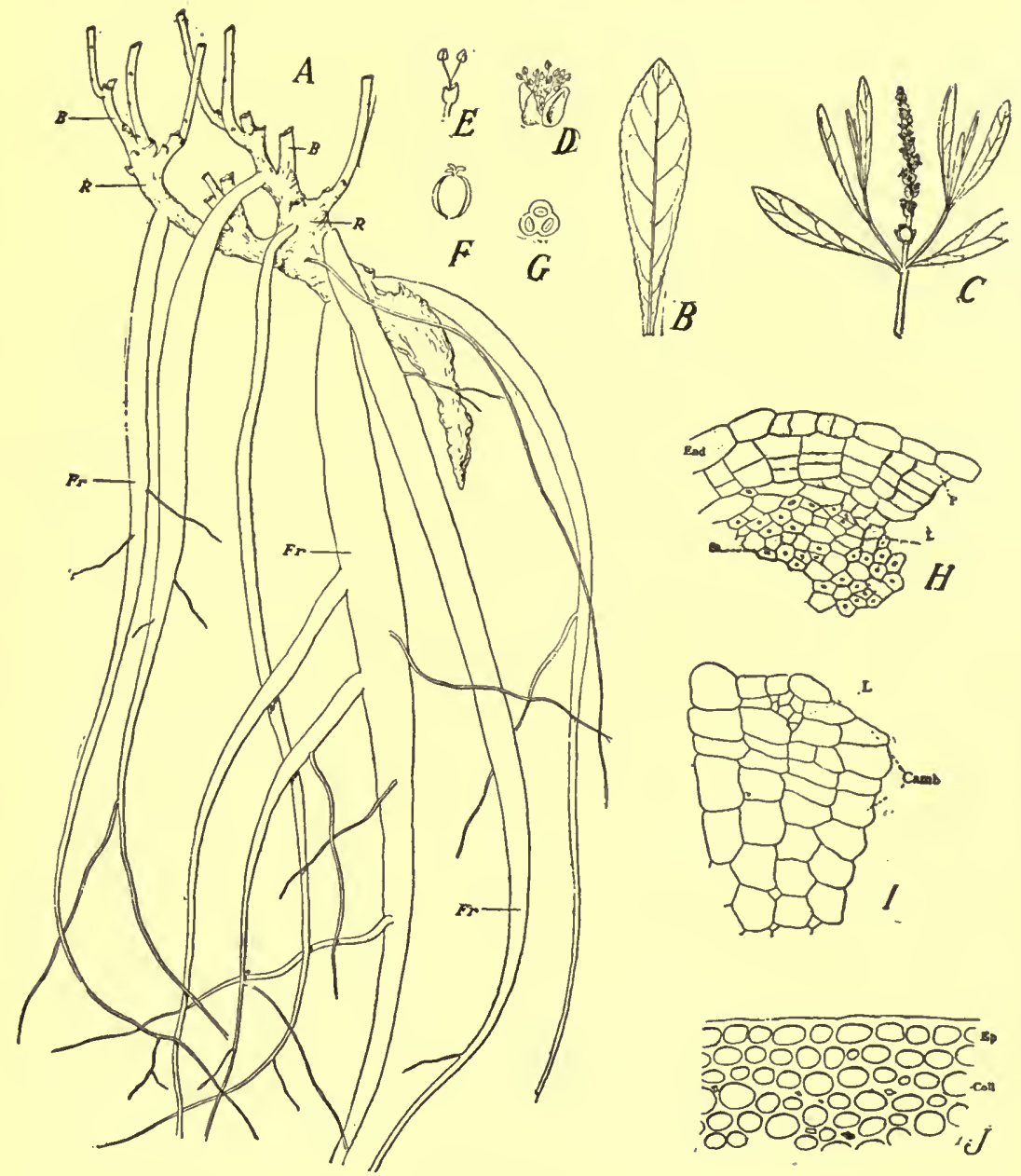

FIG. 170.-Stillingia: $A$, the rhizome $(r)$ of Stillingia sylvatica, showing the bases of the aerial shoots $(b)$, and the large fusiform roots $(f r) . \quad B$, one of the obovate, glandular, serrate leaves. $C$, the inflorescence consisting of a terminal spike of flowers, the staminate being above and the pistillate below. $D$, a cluster of staminate flowers with the bract and glands. $E$, a staminate flower. $F$, a pistil. $G$, a transverse section of the ovary. $H$, transversc section of a thin lateral root: End, endodermis; $P$, cork formed in the pericycle; $L$, leptome interspersed with stereids, or lignified sclerenchymatous cells $(S t) . \quad I$, transverse section of a root; $L$, leptome without stereids; $C a m b$, cambium. $J$, transverse section of an overground branch: $E p$, epidermis; Coll. collenchyma.-After Holm, Merck's Report, 1911, p. 36. 
contains no stereids, but is made up of strands of more or less collapsed sieve cells; cambium zone is distinct; the wood consists of medullary rays from 1 to 2 cells wide, separating the narrow wedges of xylem, the latter being mostly made up of wood parenchyma, a few wood fibers and occasional tracheæ; the primary vessels are still to be observed in the center of the stele; the bast fibers are very irregular in outline, more or less tuberculated, the walls being strongly thickened; calcium oxalate may occur in the form of rosette aggregates.

Powder.-Pinkish-brown or light reddish-brown; starch grains numerous, from 0.005 to $0.035 \mathrm{~mm}$. in diameter, mostly single, spheroidal, ellipsoidal, of variable shapes, and usually with a central cleft; fragments, with more or less tabular secretion cells containing a reddish-brown, amorphous, resinous substance; trache:e mostly with simple pores and associated with wood fibers, the walls being very thin, lignified and possessing numerous, transverse slit-like, simple pores and swelling perceptibly in potassium hydrate solution; bast fibers long, narrow, the walls thick and slightly lignified; fragments of reddish-brown cork cells; occasionally rosette aggregates of calcium oxalate, about $0.035 \mathrm{~mm}$. in diameter.

Constituents.-A volatile oil, with the odor and taste of the root, from 3 to 4 per cent; an acrid resin sylvacrol; an acrid fixed oil; 10 to 12 per cent of tannin; starch; calcium oxalate; ash about 5 per cent.

Literature.-Holm, Merck's Report, 1911, p. 36; Miller, Brooks and Rutledge, Jour. A. Ph. A., 1915, 4, p. 445.

Elastica.-Caoutchouc, India-Rubber.-The latex or milkjuice of Hevea braziliensis, and probably other species of Hevea (Fam. Euphorbiaceæ), trees indigenous to Brazil. The milk-juice is obtained by making incisions in the bark of the tree and is collected in small cups fastened to the trees. This is then poured into a larger vessel in which is placed a wooden paddle. The latter, with adhering latex, is dexterously revolved in an open fire until coagulated, new material being added from time to time until flask-shaped masses are formed which are then removed, and constitute the commercial article known as "bolacho." The best grade, known as Para Rubber, is official.

Description.-In elastic, flask-shaped masses or pieces varying in form and size; light, floating on water; externally brownish to brownish-black; internally brownish, consisting of a number of thin, alternate light and dark layers, due to the superimposed coats of latex formed during the drying process; odor slight, empyreumatic; nearly tasteless. 
Caoutchouc is insoluble in water, dilute acids, or dilute solutions of the alkalies; more or less soluble in chloroform, carbon disulphide, oil of turpentine, benzin and benzol. It melts at about $125^{\circ} \mathrm{C}$., remaining soft and adhesive after cooling.

Constituents.-Caoutchouc consists chiefly of two hydrocarbons, one of which is ductile and readily soluble in chloroform, and the other elastic and less soluble in chloroform; it also contains 1 to 2 per cent of resin, volatile oil, etc.

Allied Plants.-African rubber is obtained from several species of Landolphia and Kichsia africana (Fam. Apocynaceæ). Bahia rubber is derived from Hancornia speciosa (Fam. Apocynaceæ). Central American or Panama rubber is obtained from Castilloa elastica (Fam. Moraceæ). Ceará rubber is the product of Manihot Glaziovii (Fam. Euphorbiaceæ). East India rubber is the product of the commonly cultivated rubber plant, Ficus elastica (Fam. Moraceæ). Penang or Borneo rubber is the product of several species of Urceola (Fam. Apocynaceæ).

Vulcanization of Rubber.-Caoutchouc retains its elastic and other properties and is not affected by heat, if it is first purified and then mixed with sulphur or sulphides. Ordinary rubber articles are prepared in this manner. Hard rubber articles are manufactured from Borneo rubber, to which colophony, gum balata and caoutchouc are added; a number of mineral substances being added to cheapen as well as to color the final product.

Kamala.-Glandule Rottlere, Rottlera or Kameela.-The hairs obtained from the capsules of Mallotus philippinensis (Fam. Euphorbiaceæ), an evergreen shrub indigenous to southeastern Asia and widely distributed throughout tropical Asia and Australia. The native women and children go out to the foothills where the trees are growing and collect the glandular-hairy capsules. These are then thrown into large baskets in which they are rolled about, at the same time being rubbed with their hands, so as to remove the hairy covering. This impure powder is collected, passed through a sieve to remove the larger fragments and tissues, other than the hairs. Most of the commercial supplies are exported from Indo-China to London whence it is distributed to various European ports and purified.

Description.-(Fig. 171.) A fine, granular, brownish-red powder, consisting of yellowish-red, glandular hairs and grayish, stellate nonglandular hairs, also a small quantity of vegetable tissues. The glandular hairs consist of a very short 1-celled stalk, which is usually wanting in the drug, and a nearly spheroidal, multicellular head 
from 0.040 to $0.100 \mathrm{~mm}$. in diameter and consisting of from 20 to 50 ellipsoidal, somewhat spatulate separate cells, which are radiately arranged and inserted upon a short central stalk (Fig. 171, B). The non-glandular hairs are peltate, consisting of from 5 to 20 unicellular or uniseriate, thick-walled hairs, which are frequently somewhat

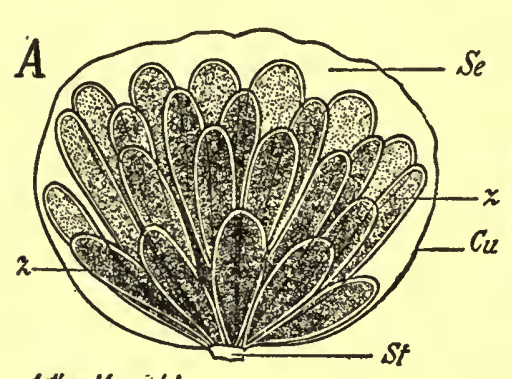

Anthur Meyer del.
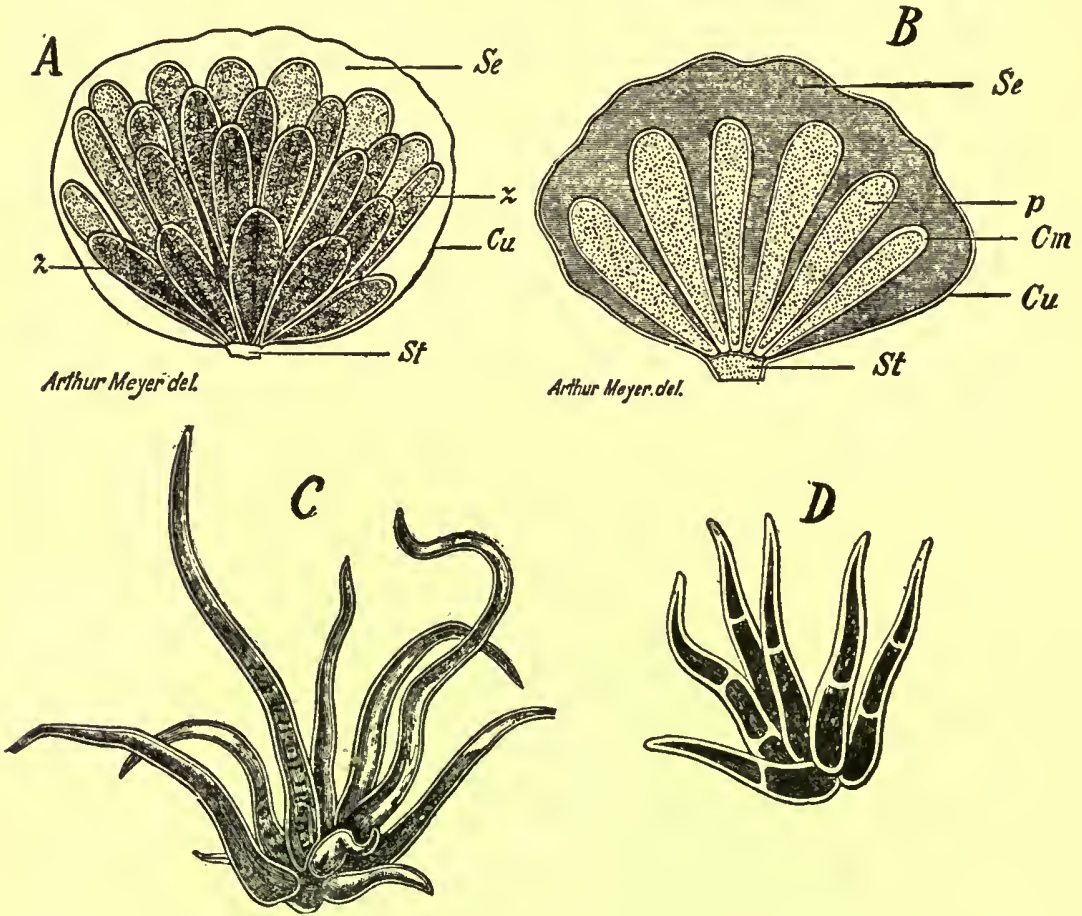

FIg. 171.-Kamala. A, glandular hair extracted with chloroform and mounted in a solution of hydrated chloral; St, short stalk; $C u$, cuticle; Se, resinous secretion; $Z$, elongated ovoid, somewhat spatulate separate cells and of which there are some 20 to 60 comprising the glandular hair. $B$, a longitudinal section through a glandular hair showing the position and arrangement of the individual cells; St, short stalk; $C u$, cuticle; $S e$, resinous secretion; $C m$, wall of individual cells; $P$, granular cytoplasm, peltate groups of unicellular $(C)$ and uniseriate $(D)$ non-glandular hairs. $-A$ and $B$, after Meyer; $C$ and $D$ after Vogl.

hooked at the end. Occasional fragments of the outer layers of the pericarp are also present. Irregular angular fragments of sand and other earthy or inorganic impurities may be present to the extent of 6 to 8 per cent.

Constituents.-The important constituent is about 80 per cent of a dark brownish-red resin composed of a crystalline principle, 
rottlerin; isorottlerin; two reddish-yellow resins; a coloring principle and wax. It also contains $\dot{a}$ trace of volatile oil, starch, sugar, tannin, oxalic and citric acids.

Cascarilla.-Cortex Cascarilles or Cascarilla Bark.The dried bark of Croton Eluteria (Fam. Euphorbiaceæ), a tree-like shrub indigenous to the West Indies. The commercial supplies are chiefly obtained from Nassau, Bahama Islands. The bark was formerly official and is now used to a limited extent in medicine. On account of the aromatic odor which it emits on burning, it is used in fumigating mixtures. It is largely used in flavoring liquors and in scenting tobacco.

Description.--In quills or transversely curved pieces, from 2.5 to $10 \mathrm{~cm}$. in length, 4 to $12 \mathrm{~mm}$. in width, and 0.5 to $3 \mathrm{~mm}$. in thickness; externally grayish-brown with patches of foliaceous lichens, having minute black apothecia, longitudinally wrinkled and transversely fissured; inner surface dark brown, longitudinally striate; fracture short, uneven, resinous; fractured surface showing an easily exfoliated cork, primary cortex more or less mottled from the whitish oil cells and the brownish resin cells; secondary cortex, dark reddish-brown with narrow, white medullary rays, between which are distributed the strands of leptome and secretion cells; odor aromatic, fragrant; taste aromatic and very bitter.

Inner Structure.-Corky layer consisting of large tabular or polygonal cells, the outer walls being very thick, and the inner walls relatively thin, having numerous small projections in which are imbedded minute rod-shaped crystals of calcium oxalate. It is supposed that the whitish color of the bark is due in part to these crystal cells. Phelloderm consisting of small thin-walled starchbearing parenchyma, colorless oil secretion cells having suberized walls, crystal cells containing rosette aggregates of calcium oxalate, and tannin secretion cells containing an orange- or reddish-brown amorphous content, which is colored deep blue with solutions of ferric salts; primary cortex having small groups of sieve and an interrupted circle of sclerenchymatous fibers, near which occur the laticiferous cells that are filled with a brownish colored secretion; secondary cortex with numerous medullary rays, 1 to 3 cells in width, and from 15 to 20 cells in height, each cell containing either a rosette aggregate or a monoclinic prism of calcium oxalate; between the numerous plates of more or less collapsed sieve occur numerous oil secretion cells, which are arranged in short rows, and a few bast fibers, having strongly thickened lamellated and somewhat undulate walls; the parenchyma cells of the secondary cortex contain either 
an orange or brownish-red tannin-like substance or crystals of calcium oxalate. The laticiferous cells do not occur in this part of the bark. The periderm often consists of a number of broad layers of cork cells, which sometimes penetrates through to the inner bark.

Powder.-Reddish-brown, having a somewhat clove-like odor; fragments of parenchyma containing starch grains or tannin, and among which occur the yellowish- or reddish-brown laticiferous cells; starch grains mostly single, occasionally 2 - to 3 -compound, the individual grains nearly spheroidal, from 0.003 to $0.013 \mathrm{~mm}$. in diameter; calcium oxalate in monoclinic prisms and rosette aggregates from 0.015 to $0.025 \mathrm{~mm}$. in diameter; characteristic somewhat lignified cork cells, in surface view, polygonal in outline, about $0.040 \mathrm{~mm}$. in diameter; showing unevenly thickened and lamellated walls, having irregular lumina, and containing small crystals of calcium oxalate; bast fibers, with strongly thickened, somewhat lignified walls; tracheæ, from adhering wood, having bordered pores, very few or wanting.

Constituents. - Cascarilla contains 1 to 1.5 per cent of a volatile oil, containing eugenol, limonene, an oxygenated portion, and some other constituents; 15 per cent of resin; a bitter principle, cascarillin; tannin and vanillin.

Literature.-Zörnig, Arzneidrogen.

Euphorbia Pilulifera.-Herba Euphorbie Pilulifere, Euphorbie Herba.-The over-ground portions of Euphorbia pilulifera (Fam. Euphorbiaceæ), an annual herb common in tropical and sub-tropical countries, being found in the United States from Texas to Arizona. The plant is gathered at the time of flowering or fruiting, the adhering roots removed, and carefully dried. Most of our commercial supplies are obtained from plants collected in India.

Description.-Usually in broken fragments; stems cylindrical, branching, light reddish-brown and covered with coarse bristly hairs; leaves opposite, short petiolate, from 15 to $40 \mathrm{~mm}$. in length and from 4 to $12 \mathrm{~mm}$. in breadth, nearly smooth and slightly pubescent on the veins, ovate or lanceolate, inequilateral, summit acute, base obtuse or somewhat rounded, minutely serrate, upper surface dark greenish-brown, lower surface light yellowish-brown, very brittle and usually very much broken in the commercial article; flowers appear to be axillary, but are really lateral (and often umbellate clustered), monœcious, having the fertile flowers in the middle of the cluster, both fertile and sterile flowers included in a cup-shaped 4- to 5-lobed involucre, resembling a calyx or corolla and having large, thick 
glands between the sinuses; fruit a light yellowish-brown, 3-locular capsule, about $1 \mathrm{~mm}$. in length and containing very minute, ovoidtetragonal seeds, which are distinctly wrinkled when mature; inodorous; taste slightly bitter.

Constituents.-An alkaloid, 0.1 per cent; a glucosidal substance, 0.4 per cent; several resins; caoutchouc; tannic acid; mucilage; sugar; protein; ash 8 to 12 per cent.

Allied Plants.-A number of species of Euphorbia growing in eastern and central North America are used in medicine. The roots of Euphorbia corollata were at one time used as an emetic. (Consult Holm, Merck's Report, 1910, p. 126.)

Semen Ricini.-Castor-oil Seeds or Castor Bean.-The ripe seeds of Ricinus communis (Fam. Euphorbiacex), an annual herb in temperate regions, but a shrub-like perennial in tropical and sub-tropical countries. The plant is indigenous to southern Asia and tropical Africa, and is extensively cultivated. There are a very great many varieties and the seeds vary in size and color. The larger seeds are imported from India, the smaller seeds coming from France and Italy.

Description.-Anatropous, elliptical-ovoid, somewhat compressed, from 8 to $18 \mathrm{~mm}$. in length, 4 to $12 \mathrm{~mm}$. in breadth and from 4 to 7.5 $\mathrm{mm}$. in thickness; externally grayish-brown, mottled, varying considerably in color, smooth and tortoise shell-like, with a prominent whitish caruncle at the somewhat pointed end, and from which there arises the narrow and somewhat raised raphe which extends, on the flat side or ventral surface, to the chalazal end of the seed; seed-coat thin, brittle, consisting of an outer grayish-brown testa and a thin whitish tegmen; endosperm large, white, oily and divided into two nearly equal portions usually having a lenticular cavity between them, and on either side of which is a thin foliaceous cotyledon, slightly detachable from the endosperm, and connected with the short caulicle and radicle, the latter directed towards the micropyle.

Inner Structure.-An epidermal layer of thin-walled tabular cells, the inner being somewhat porous and the outer somewhat thickened and variously colored; a broad band consisting of from 4 to 10 rows of large thin-walled, more or less collapsed cells usually referred to as star parenchyma, and from which layer the caruncle is developed; beneath this is a layer of radially elongated, thin-walled, colorless cells, having small triangular intercellular spaces; a fourth layer, made up of a single row of palisade-like stone cells, attaining a length of $2 \mathrm{~mm}$., having very thick, porous, yellowish-brown walls, and con- 
taining a brownish amorphous substance, in which is said to be included calcium silicate. This is the fundamental pigment layer of the seeds giving the basic color to the seeds, the mottling and variations being due to the pigments in the outer walls of the epidermal cells. A fifth layer consists of the more or less obliterated perisperm cells, containing rosette aggregates, and in which are included the fibrovascular bundles; the endosperm consists of an oily cytoplasm and numerous aleurone grains, the latter being spheroidal or ellipsoidal, about $0.020 \mathrm{~mm}$. in length, and composed of a large rhombohedral protein crystal and one or more globoids.

Constituents.-A fixed oil, known as castor oil, from 50 to 70 per cent, and consisting principally of triricinolein, together with considerable ricinisolein, palmitin and dihydroxystearin. Protein substances, about 20 per cent, and consisting of globulin, albumin, mucleoalbumin and glycoprotein. A very toxic alkaloid, ricine, which apparently is not removed in the extraction of the castor oil, but remains in the oil-cake, and though it is very poisonous to cattle does not affect poultry. It also contains a second alkaloid, ricinine; several ferments; an ester composed of methyl alcohol and ricininic acid; sugar 2.5 per cent; a bitter principle; resin; and gum. The seed-coat yields 10 per cent of ash; the endosperm but 3.5 per cent. Frabot has made a study of the foreign oils present in castor oil used for lubricating aviation engines.-Amer. Jour. Pharm., 1918, 90, p. 300 .

Lilerature.-Schlotterbeck, Beitrage zur Entwicklungsgeschichte pharmakog. wichtiger Samen. Inaug.-Diss., Bern.

Свотол.-Semen Tiglii or Croton Seed.-The ripe seeds of Croton Tiglium (Fam. Euphorbiaceæ), a small tree indigenous to tropical Asia and cultivated in the tropical countries of the Eastern Continent.

The seeds resemble those of Ricinus in size and general structure, except that they are not so smooth, being somewhat scaly, and have an almost uniform light reddish-brown color. The caruncle is usually absent in the commercial article. The perisperm layer is free from calcium oxalate, and the aleurone grains of the endosperm cells not infrequently have large rosette aggregates of calcium oxalate in place of the protein crystals.

Croton seeds contain from 30 to 60 per cent of a fixed oil, composed of the glycerides of the following acids: stearic, palmitic, myristic, lauric, oleic, tiglic, acetic, butyric, formic and valeric. Protein substances about 18 per cent; a very toxic albuminous substance, crotin, consisting of at least two principles, crotonglobulin 
and crotonalbumin; the alkaloid ricinine, also found in Ricinus; several ferments; ash from 4 to 6 per cent.

Transvaal Croton Bark.- The bark of the tree, Croton Gubouga S. Moore, a species widely spread in Nyasaland, Rhodesia and Portuguese East Africa.-In external appearance the bark is 2 to $3 \mathrm{~mm}$. thick, generally gray in color, with corky warts or longitudinal bands of cork. The bark possesses a persistently acrid, somewhat numbing taste. Microscopically, bast fibers, single and in groups, much thickened and distinctly striate, sclerenchyma cells, abundant; calcium oxalate crystals in prisms and rosettes numerous; a few small starch grains and small oil drops occur in the parenchyma and in the longitudinal section some elongated cells with the inner lamellæ of the walls suberized and containing yellowish granular secretion. Petroleum spirit yields 2.54 per cent of thick fatty oil, exceedingly acrid in taste. Alcohol yields 2.71 per cent of an acrid extractive. Alcohol of 50 per cent strength apparently extracts the drug.-Greenish, Pharm. Jour., 1918, 101, p. 289.

Cassava Starch.-Amylum Manihot, Para-OR Brazillan ARrowroot.- The starch grains obtained from the thickened roots of the bitter cassava (Manihot utilissima) and the sweet cassava (Manihot palmata Aipi), perennial herbs belonging to the Euphorbiacex, natives of South America and extensively cultivated in the West Indies, tropical South America and to some extent in Florida and other southern States. The plant is very easily grown and produces very large roots, weighing sometimes $5 \mathrm{~K}$. At harvest time the roots are dug, washed, cut and scraped, whereby the starch grains are released and finally obtained by methods, similar to those employed in the manufacture of potato starch. The starch is obtained in large quantities in Brazil from the root of the bitter cassava, the hydrocyanic acid being eliminated during the process of washing and drying. In Florida considerable starch is made from the sweet cassava. As this starch is sold very often at a price below even that of corn starch it is used to some extent in the arts, chiefly as a sizing for cotton fabrics.

Cassava starch occurs as a fine mobile powder, the grains being mostly single or 2- to 8-compound, the individual grains being somewhat plano-convex or bell-shaped, varying from 0.005 to $0.030 \mathrm{~mm}$. in diameter and having a distinct central circular or radiating cleft (Fig. 20).

Tapioca is formed by heating the cassava starch while it still contains a maximum degree of moisture. It is heated upon iron plates first at a low temperature, which is gradually increased until 
the starch grains are agglutinated into the familiar form of "pearl tapioca." Any other starch, if moistened and subjected to the same process of heating, will result in the production of forms similar to those of the genuine article. Tapioca is chiefly used in the making of puddings.

Cluytia Similis.-The entire plant of Cluytia similis (Fam. Euphorbiaceæ), indigenous to South Africa, is reputed to be of value as an antidote for anthrax and for the disinfection of anthraxinfected meat, while the root is stated to be eaten by some of the natives as an antidote for snake-bite poisoning. A chemical examination of the entire over-ground portion showed it to contain a small amount of a volatile oil; a quantity of sugar; potassium chloride; and a number of definite substances including several new compounds, viz., chrysophanol; fumaric acid; cluytinic acid; cluyty! alcohol, cluytyl cluytinate; cluytinasterol; triacontane; a mixture of fatty acids; a substance designated cluytianol, which is probably a phytosterol glucoside; and a compound which is probably trihydroxy-dihydro-anthraquinone.-Power, Jour. Chem. Soc., 1912, p. 2221 .

\section{ANACARDIACEE, OR SUMAC FAMILY}

A family consisting of about 400 trees or shrubs, sometimes climbing, and very abundant in the tropics and sub-tropies, a few being found in the temperate zones. The typical genus, Rhus, of which there are a number of species found in the United States, is characterized by compound leaves, small greenish-white or yellow flowers, occurring in terminal panicles, and drupaceous, often crimson-colored, fruits (Fig. 175). All of the plants of this family possess resincanals, which are situated in the phloem portion of the vascular bundle of the axis and leaves. In some few cases these are also found in the cells comprising the medullary rays, pith and cortex. In addition, tanninsacs occur more or less abundantly, and occasionally lysigenous mucilage cavities are present. More or less crescent-shaped groups of bast fibers occur in the pericycle, enclosing on the concave side a large resin canal; occasionally the pericycle is a composite and continuous ring of sclerenchyma. The tracheæ are usually marked with simple pores, occasionally having scalariform perforations. The wood fibers have simple pores and usually septate transverse walls. Calcium oxalate is secreted, in some of the cells of the cortical parenchyma, in the form of rosette aggregates or solitary crystals, the latter sometimes being arranged in longitudinal rows, associated with the 
bast fibers to form crystal fibers. The non-glandular hairs are mostly unicellular. Glandular hairs of a number of specific forms are developed.

Rhus Glabra.-Sumac Berries.-The fruit of Rhus glabra (Fam. Anacardiaceæ), a smooth, glaucous shrub (Fig. 172), indigenous to Canada and the United States, extending as far west as Arizona.

Description.-Drupe dry, superior, nearly globular, flattened, 3 to $4 \mathrm{~mm}$. in diameter, $2.5 \mathrm{~mm}$. in thickness, and with a slender peduncle about $2 \mathrm{~mm}$. in length; reddish externally, very pubescent, summit with a scar and with the remains of the style, base occasionally

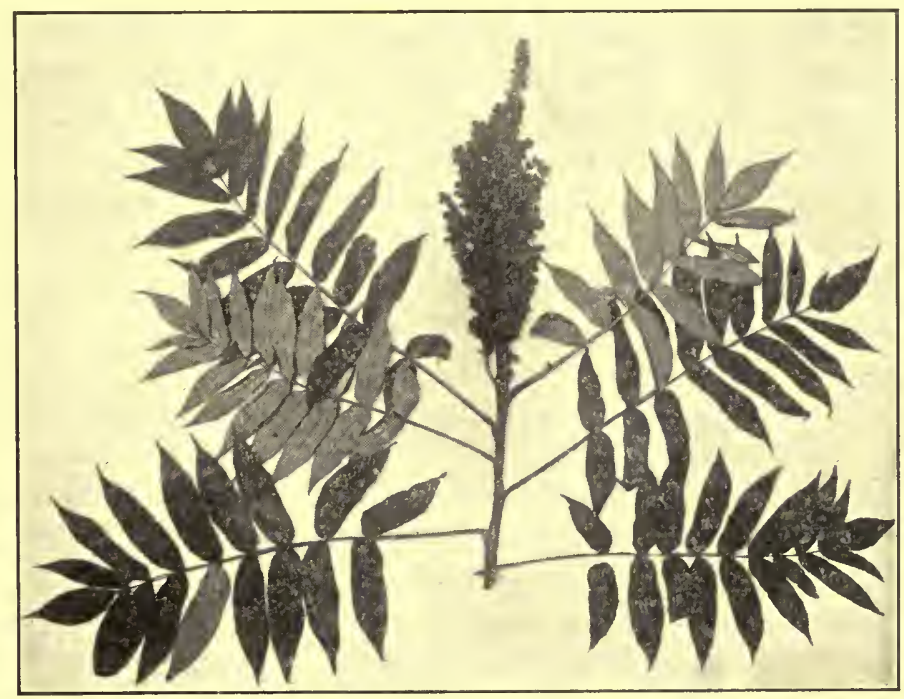

FIG. 172.-A fruiting specimen of Rhus glabra showing the compound leaves and the long panicle of fruits, the latter, while full-grown in August, do not ripen until Ocotber.

with the 5-cleft calyx; endocarp smooth, shiny, light red; 1-locular, 1-seeded; seed campylotropous, dark-brown, smooth, hilum marked by a distinct scar, reserve layer wanting, embryo curved; inodorous; taste acidulous and astringent.

Inner Structure.-For illustration of glandular and non-glandular hairs, consult Kraemer's Applied and Economic Botany, p. 280.

Powder.-Brownish-red, consisting of uniseriate, non-glandular hairs, filled with a bright-red cell sap, being more or less elliptical, ovoid or spatulate in outline and about $0.150 \mathrm{~mm}$. in length and 0.045 to $0.080 \mathrm{~mm}$. in width; the dividing wall is usually more or less 
oblique and the cells not infrequently contain rod-shaped crystals; some of the intermediate cells of the hairs may be collapsed and the reddish cell sap of all the cells of the hair may contain one or more air bubbles; fragments of endosperm frequent. Mounts in solutions of aniline sulphate and sulphuric acid stain the stone cells yellow, these are very small and possess irregularly thickened walls; fragments of embryo with rather small cells containing a fixed oil; occasional reddish colored fragments of epidermis and underlying spiral trachex of the mesocarp.

On mixing $1 \mathrm{gm}$. of powdered Rhus glabra witn 10 c.c. of hot water, shaking occasionally until cold and filtering and evaporating the solution in a watch crystal spontaneously, there should separate numerous feather-shaped crystals of Gallic Acid which polarize strongly with a distinct play of colors.

Constituents.-Tannic acid about 2 per cent; gallıc acid, and acid calcium and potassium malates. The percentage of acidity in the fruits, in terms of malic acid, varies from 6.5 to 8 per cent.

Allied Plants.-The fruits of the staghorn sumac, Rhus typhina, a shrub very abundant in the eastern United States, have replaced to some extent the fruit of Rhus glabra. The drupes of these two plants closely resemble each other both in form and size, but the latter are distinguished by being covered with long, nearly straight, needle-like, crimson hairs. These hairs are frequently over $2 \mathrm{~mm}$. in length, more or less undulate in outline and have relatively thicker walls. The constituents of Rhus typhina are probably similar to those of Rhus glabra, the total acidity in terms of malic acid ranging from 7.8 to 11.22 per cent, being much higher than in R. glabra.

Allied Drugs.-The leaves of Rhus glabra contain from 16 to 25 per cent of tannin. The galls formed on the petioles and leaves resemble the Chinese or Japanese galls and contain about 60 per cent of tannin and some gallic acid.

Literature.-Kraemer, Amer. Jour. Pharm., 1913, p. 398.

Rhus Toxicodendron.-Poison Ivy or Poison Oak.-The fresh leaflets of Rhus Toxicodendron (Rhus radicans), a woody vine belonging to the Anacardiaceæ, common in hedge rows, along fences and in thickets throughout the United States. The plant varies considerably and one or more distinct varieties are recognized. It either trails over the ground, or climbs by means of aerial roots, sometimes becoming quite shrublike (Fig. 173).

The leaves are 3 -foliate, the leaflets being ovate, acuminate, nearly entire, inequilateral and with short stalks; the flowers are 
green and in loose axillary panicles; the fruit is a globular, glabrous, grayish drupe.

The nature of the poisonous constituents of Poisin Ivy is not definitely known. It was originally considered to be in the nature
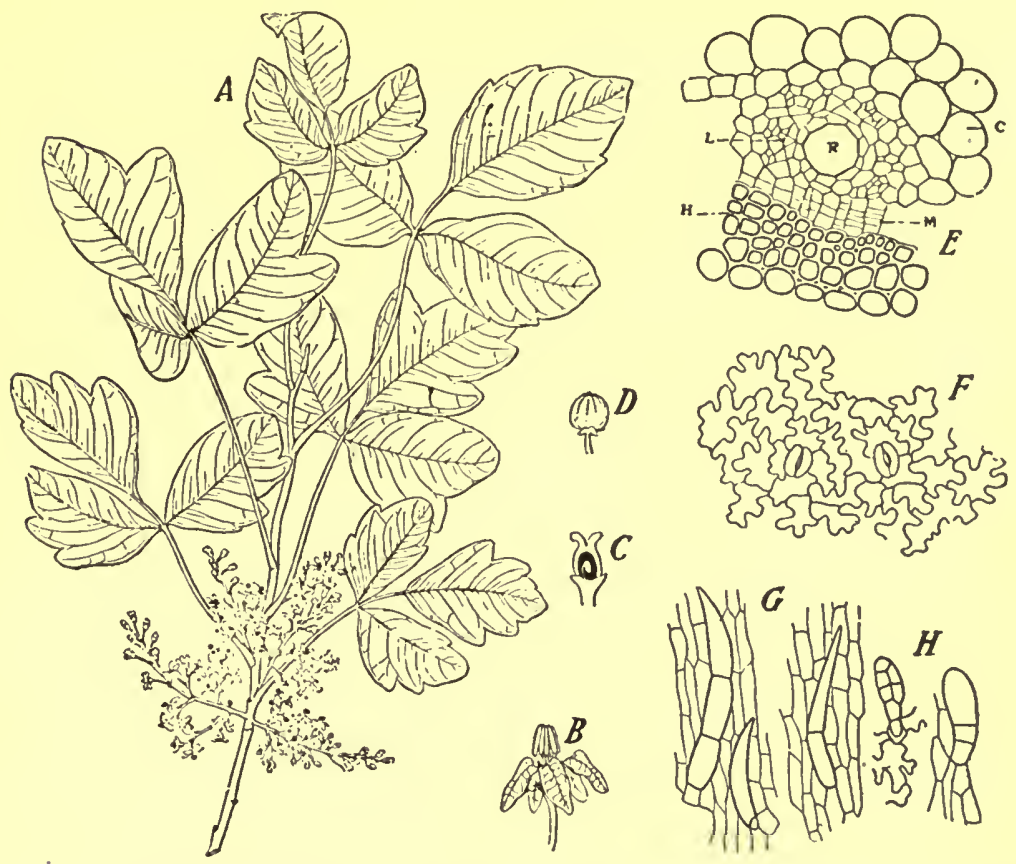

FIG. 173.-Rhus Toxicodendron: $A$, flowering branch showing the characteristic 3 -foliate, long petiolate leaves, the leaflets in the shrubby, climbing plants, being frequently dentate or lobed. The flowers are small, greenish and arranged in axillary panicles. $B$, a staminate flower. $C$, a longitudinal section through the pistil. $D$, a fruit which is sub-globular, nearly glabrous or slightly pubescent, the thin epicarp falling away eventually from the granular waxy, multicostate mesocarp. $E$, transverse section of inner portion of epicotyl; $C$, cells of cortex; $L$, leptome in which there is a single large resin canal $(R)$ such as is common to all the Anacardiacex; $M$, cambium; $I I$, hadrome in which there are a few spiral trachex and some young libriform. $F$, surface section of the dorsal or lower epidermis of a leaflet, showing the lateral undulate walls of the epidermal cells and two of the stomata, which lack subsidiary cells, and are raised slightly above the adjoining epidermis. $G$, several of the pointed, non-glandular hairs. $H$, two of the glandular hairs.-After Holm, Merck's Report, 1910, p. 95.

of a volatile principle. Pfaff and his pupils seemed to show that the poisonous principle was a non-volatile, brownish-red resin which 
is soluble in alcohol and called it toxicodendrol. Schwalbe, on the other hand, states that the poisonous substance is of a volatile nature, being formed in the laticiferous vessels and by osmosis is transferred to the hairs. The poison may be transmitted either by direct contact with the hairs, much as in the same manner with the nettles, or by volatilization of the oil when the hairs are broken. The experience of most plant collectors would seem to indicate that in Poison Ivy there is a volatile toxic constituent. On the other hand, Rost and Gilg were unable to find a volatile poison in either the hairs or pollen of Poison Ivy. In some experiments conducted by Warren on pollen grains, similar negative results were obtained. The poisonous principle occurring in several species of Rhus is an amber-red, non-volatile liquid. It is of a resinous nature combining with the alkali hydroxides to form nigrescent compounds and otherwise behaves like certain phenolic derivatives. The toxic resin exists in the plant in the form of an emulsion, which readily blackens with the alkali hydroxides. So delicate is this reaction, that minute amounts of the substance may be detected by means of the microscope, if the plant tissues are mounted in an alcoholic solution of potassium hydroxide.

Rhus Vernix.-Poison Sumac, Poison Elder or Poison Dogwood.-The plant is poisonous, like Rhus Toxicodendron, and probably contains the same principles. It is a shrub or small tree, found in swamps in the United States and Canada. The leaves are 7- to 13-foliate, with obovate or oval, acuminate, entire leaflets; the flowers are small, green, and in axillary panicles; the fruit resembles that of Rhus Toxicodendron.

Allied Plants.-Other species of Rhus are also poisonous, as the western Poison Oak (R. diversiloba) of the Pacific Coast, and the Japanese Lacquer or Varnish tree ( $R$. vernicifera and $R$. succedanea). The lacquer trees grow wild in both China and Japan, where they are also cultivated. The lac is obtained by incising the bark, and removing it with a pointed spatula. The grayish-white emulsion is strained and on exposure to air it changes to brown, becoming finally black. This change is due to the oxidizing enzyme, laccase. The natural lac (Kiurushi) contains a non-volatile, poisonous, resin-like principle and is closely associated with other resinous substances. When Japanese lac is thinned with camphor, or mixed with linseed oil, on drying in a moist atmosphere, it forms the most indestructible varnish known. Various pigments are used, as vermilion, gamboge, acetate of iron and other substances. The best glossy black colors are obtained by the addition of iron. 
Lithræa Caustica (Fam. Anacardiaceæ), a tree found in Chili, causes an inflammation of the skin like that caused by Rhus Toxicodendron. The plant contains a resin and a volatile oil. The poisonous properties are ascribed to a volatile substance resembling cardol.

Chinese and Japanese Gall.-Chinese galls are excrescences produced on Rhus semialata as a result of the stings of an Aphis. Japanese galls are similar formations occurring on Rhus japonica. (See p. 168.)

Literature.-Stevens, Amer. Jour. Pharm., 1906, p. 53; Warren, Ibid., 1913, p. 545; Bessey, Ibid., 1914, p. 112; McNair, Jour. Am. Chem. Soc., 1916, p. 1417; Acree, Ibid., p. 1421.

Mastiche.-Mastic.-The dried, resinous exudation from Pistacia Lentiscus (Fam. Anacardiaceæ), a large shrub indigenous to the Mediterranean region. The resin exudes through incisions made in the bark, and when dry is collected. The chief source of supply is the island of Scio.

Description.-Somewhat globular or ovoid tears, 3 to $7 \mathrm{~mm}$. in length, pale yellow or greenish-yellow, translucent, having a glasslike luster, comparatively free from a whitish dust; brittle; fracture conchoidal, becoming plastic when chewed; odor slight, balsamic; taste mild, terebinthinate.

Mastic is completely soluble in ether, acetone and volatile oils. It is almost completely soluble in alcohol, the solution giving an acid reaction with litmus paper.

Constituents.-About 90 per cent of a resin, consisting of $\alpha$-resin (mastichic acid), which is soluble in alcohol, and $\beta$-resin (masticin). which is insoluble in alcohol; a volatile oil, 1 to 2.5 per cent, with the balsamic odor of the drug and consisting chiefly of d-pinene. A small quantity of a bitter principle is also present, which is soluble in hot water and is precipitated by tannin.

Allied Plants.-Various other species of Pistacia found in India and northern Africa yield resins resembling mastic. American mastic is obtained from the Peruvian Peppertree (Schinus Molle). Similar resins are found in other genera of the Anacardiaceæ, as Astronium and Semecarpus.

Chios Turpentine is a product resembling mastic and is obtained from Pistacia Terebinthinus (Fam. Anacardiacex). It consists of 10 to 12 per cent of a volatile oil (consisting chiefly of pinene) and 80 to 90 per cent of resin.

Literature.-Lloyd, Amer. Jour. Pharm., 1917, 89, p. 1.

ANacardium.-West Indian Cashew.-The fruit of Anacardium 
occidentale (Fam. Anacardiaceæ), a tree indigenous to the West Indies and extensively cultivated in the tropics. The leaves are alternate and ovate and the flowers are red, very fragrant and borne in terminal panicles. The fruit (Fig. 174) consists of a fleshy, pearshaped receptacle having at its summit the kidney-shaped, drupaceous nut; the latter is about $3.5 \mathrm{~cm}$. in length, $2 \mathrm{~cm}$ in breadth

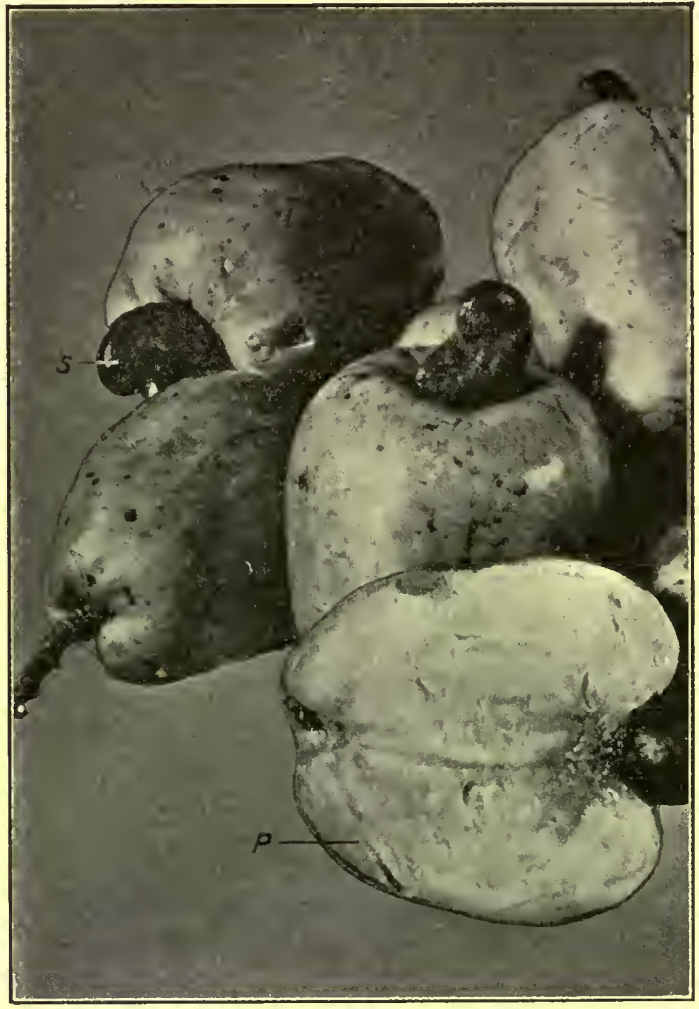

Fig. 174.-West Indian Cashew: The fruits are fleshy, complex, somewhat pear-shaped, consisting of the fleshy receptacle $(P)$, having at the summit the reniform drupaceous fruits $(S)$.-After Alacan.

and thickness; of a very dark brown color, nearly smooth; easily cut; pericarp about $4 \mathrm{~mm}$. in thickness, containing large ellipsoidal balsam-canals; the seed is reniform, having a thick reddish-brown seed-coat and enclosing a large embryo.

Inner Structure.-Epicarp consisting of a row of palisade-like stone cells, containing a brownish amorphous substance; the meso- 
carp consists of parenchyma having thin brown walls, in among which are numerous fibrovascular bundles and very large ellipsoidal balsam-canals which contain the vesicating principle, cardol; endocarp consisting of several rows of stone cells, some of which are very large and matted; seed-coat characterized by thin-walled cells containing tannic acid; the cotyledons are made up of parenchyma, containing an oily cytoplasm and starch grains, having the balsam canals beneath the epidermis.

Constituents.-Cardol, a yellowish or reddish oily, vesicating substance, becoming darker on exposure to the air, insoluble in water, soluble in alcohol, ether, chloroform, solutions of the alkalies and sulphuric acid, the latter solution becoming colored red. Also anacardic acid, and tannic acid. The seeds contain from 40 to 50 per cent of a fixed oil, consisting mostly of glycerides of oleic acid with some stearic acid and chloesterin.

Anacardium Orientale.-Oriental Cashew-nut.-The fruit of Semecarpus Anacardium (Fam. Anacardiaceæ), a tree indigenous to northwestern India and widely distributed in southern Asia. The fruits resemble those of the West Indian Cashew-nut and contain similar principles, viz., cardol, anacardic acid and tannic acid. They also contain an alkaloid, chuchunine, which resembles strychnine in its action.

The fleshy receptacle of the West Indian cashew after maturing is sweet and edible. In Brazil, a wine is made from it which is said to resemble Madeira wine. The resinous juice of the stem furnishes a varnish; and the fixed oil from the seeds is used in India for a floor dressing, to protect the people from the attacks of white ants.

Pistachio.-Pistachio-nut or Green Almond.-The seeds of Pistacia vera (Fam. Anacardiaceæ), a tree indigenous to western Asia and cultivated in the Mediterranean countries and also in California. These seeds are extensively used in confectionery and are from 10 to $25 \mathrm{~mm}$. in length, somewhat quadrangular in cross-section and consist of two fleshy green cotyledons. They are readily determined by the carmine or brown coloring matter in the seed-coat, which becomes green upon the addition of solutions of alkalies, and by the exceedingly small polygonal cells with porous walls of the inner epidermal layer of the seed-coat. Almond and other seeds dyed with coal-tar colors, are sometimes substituted for the genuine article.-Winton and Moeller, The Microscopy of Vegetable Foods, p. 315 . 


\section{CELASTRACE}

The plants are trees, shrubs or woody climbers, represented by about 350 species, which are widely distributed. The leaves are simple, the flowers are small and regular, the fruit is a somewhat fleshy dehiscent pod, and the seeds usually have a reddish or purplish aril. The plants are furthermore distinguished by the development of caoutchouc-containing elements in the phloem. These resemble laticiferous tubes, having narrow lumina and caoutchouc-like contents, which are soluble in chloroform, ether and similar solvents. They are frequently so abundant, as in Euonymus, that on breaking the bark, the fragments remain connected by the tough elastic threads. The bast fibers in this family are usually associated with crystal fibers and the sieve tubes frequently possess scalariform sieve-plates. The tracheæ show a tendency to develop scalariform perforations. Calcium oxalate is secreted in the form of solitary crystals or rosette aggregates. The cork-wings, which are peculiar to a number of species of Euonymus, are due to the development of cork in the parenchyma of the cortex. This usually arises at 4 different points, thus elevating the epidermis and giving the branches a 4-angled or slightly winged character.

Euonymus.-Wahoo Bark.-The dried bark of the root of Euonymus atropurpureus (Fam. Celastraceæ), a shrub (Fig. 175) indigenous to the central and eastern United States and Labrador.

Description:- Usually in transversely curved pieces, occasionally in single quills, 3 to $7 \mathrm{~cm}$. in length, 0.5 to $1.5 \mathrm{~cm}$. in diameter, bark 0.5 to $1 \mathrm{~mm}$. in thickness; very light; outer surface light brown, somewhat wrinkled, with scaly patches of soft cork, few lenticels, root-scars and adhering roots, which frequently perforate the bark; inner surface light brown, longitudinally striate, somewhat porous, occasionally with small pieces of yellow wood adhering; fracture short, with silky, projecting, caoutchouc fibers, cork light brown, inner and middle bark somewhat tangentially striate and with irregular, dark-brown bast areas; odor faint; taste bitter; acrid (Fig. 175).

The stem bark occurs in very long, fibrous strips with a grayishblack cork and should be rejected.

Inner Structure--(Compare with. Fig. 175). Periderm of numerous tangentially elongated, thin-walled cork cells, :-the outer layers being grayish-brown and somewhat compressed; the inner layers of somewhat rectangular, slightly lignified cells; primary cortex of isodiametric starch-bearing parenchyma, among which are distributed the laticiferous tubes having narrow lumina and a 
yellowish-brown caoutchouc-like content; inner bark of long, narrow wedges of phloem separated by the medullary rays, from 1 to 2 cells in width and from 10 to 20 rows in depth; phloem consisting of small groups of leptome separated by bast parenchmya containing starch, and intermixed with yellowish-brown latex cells; the latter also occurring in the medullary rays. In longitudinal section the caoutchouc fibers are frequently separated in the form of long, somewhat

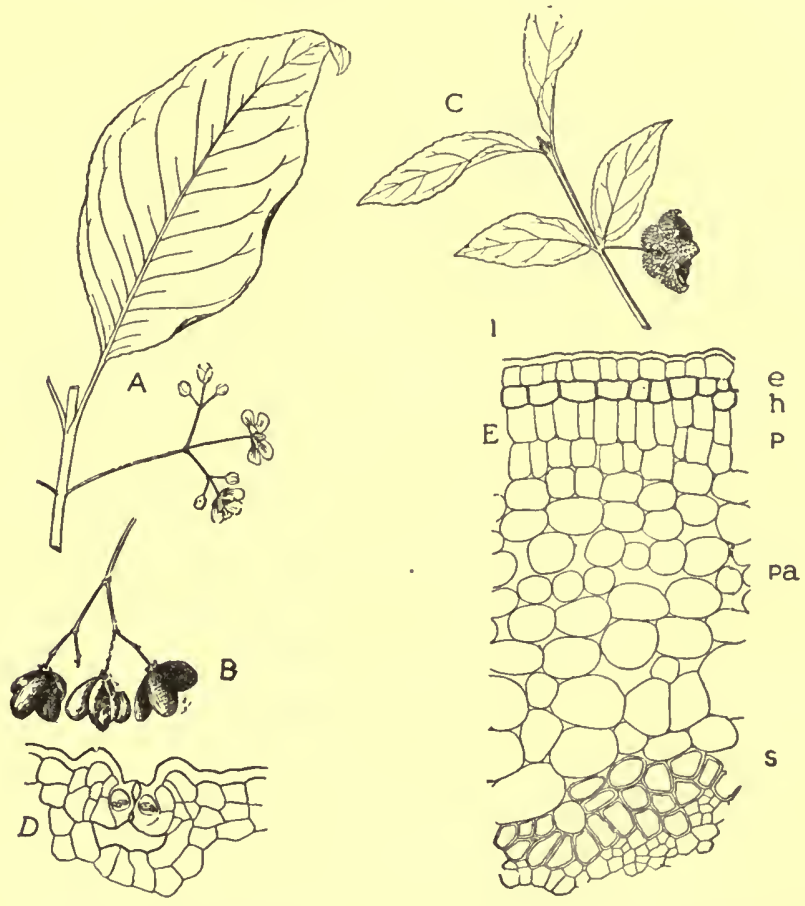

FIg. 175.-Euonymus atropropureus: $A$, flowering branch showing a distinctly petiolate leaf. $B$, cluster of the smooth capsular fruits. $E$, americanus: $C$, fruiting branch showing the opposite almost sessile leaves and axillary verrucose capsule. $D$, cross-section of stem showing a stoma sunk beneath the epidermis. $E$, cross-section of stem showing epidermis $(e)$, hypodermis $(h)$, palisade cells of cortex $(p)$, parenchyma cells $(p a)$, pericycle $(s)$ and portion of the leptome (i).-After Holm.

twisted, curved fibers, from 0.010 to $0.015 \mathrm{~mm}$. in thickness, having highly refracting colorless walls and usually contain a yellowishbrown caoutchouc-like substance.

Powder.-Light brown; bast fibers very long, having thin, non-lignified, porous walls, and frequently associated with long caoutchouc fibers, which are soluble in ether and chloroform; starch 
grains numerous, nearly spheroidal, from 0.003 to $0.012 \mathrm{~mm}$. in diameter; fragments of cork with nearly colorless thin walls; secretion cells with yellowish or brownish amorphous contents; calcium oxalate in rosette aggregates from 0.015 to $0.035 \mathrm{~mm}$. in diameter, the amount in different specimens showing some variation.

The stem-bark, as well as the whole twigs of E. atropurpureus, are frequently admixed with or substituted for Euonymus and these are distinguished by the presence of chloroplastids, the thick-walled epidermal cells around the deeply sunken stomata (Fig. 175) and the tracheal fragments.

Adulterants.-The bark of Wafer Ash (Ptelea trifoliata) is occasionally substituted. It occurs in quills or transversely curved pieces from 3 to $4 \mathrm{~mm}$. in thickness; outer surface light brown with transverse ridges and grayish-white lenticels; fracture short; broken surface pale yellow and waxy.

Constituents.-Volatile oil, 1.3 per cent; a phytosterol glucoside; dulcitol; starch; tannic acid; a mixture of fatty acids; furan- $\alpha$ carboxylic acid. Furthermore, four new crystalline alcohols were obtained, which were designated respectively, euonymol, euonysterol, homoeuonysterol, and atropurol. No evidence could be obtained of the presence of an active glucosidal substance in the bark, as had previously been affirmed.-Power, Jour. Chem. Soc., 1912, p. 1040.

Literature.-Youngken, Amer. Jour. Pharm., 1918, 90, p. 160; Holmes, Pharm. Jour., 1918, 100, p. 88.

Allied Plants.-E. europæus and other species of Euonymus are also used in medicine, and probably contain the same constituents.

\section{ACERACE $Æ$, OR MAPLE FAMILY}

Shrubs or trees, represented chiefly by the genus Acer, and of which there are about 100 species, growing abundantly in the United States, Canada, China and Japan. They possess opposite, 3 - to 5-lobed leaves, small, green, yellow, or crimson flowers, and a fruit consisting of 2 long-winged samaras. They are extensively used as shade trees and a great many horticultural varieties have been produced, those of Japan being known for their highly dissected leaves and their brilliant colorings. The wood of the maple is extensively employed in the manufacture of furniture, flooring and a variety of purposes. The sap of the Sugar or Rock maple (Acer saccharum), is the chief source of maple sugar. This is yielded in greatest quantities from the trees growing in New England, especially 
Vermont, and also in New York, Ohio and Indiana. The sugar is obtained at the beginning of spring when the growth of the buds and new leaves are about to develop. The trees are tapped about 1 or 2 M. from the ground, a tubular spile being driven into the wood and through which the sap flows into suitable receptacles. The sap is then refined and enters the market either as a syrup or a loaf sugar; the most palatable product, however, is that which is not refined and in which the syrup and crystals retain their natural yellow color. The yield per tree is from 1.5 to $3 \mathrm{~K}$. annually, and if the process is properly conducted, there is no damage to the trees. A small amount of sugar is also obtained from the black sugar maple (Acer saccharum nigrum) and the silver or white maple (Acer saccharinum).

Among the chief histological characters of this family the following may be mentioned. The pericycle consists of either isolated groups of bast fibers, or a composite ring of sclerenchyma. The tracheæ usually have narrow lumina and simple pores; the wood fibers also possess simple pores. Mucilaginous epidermal cells occur in a number of species, and in Acer Pseudo-platanus the epidermal cells, on the lower surface of the leaves, are modified to papillæ. Calcium oxalate occurs in the form of solitary crystals or large rosette aggregates. The non-glandular hairs are either unicellular or uniseriate. The glandular hairs are small and of a number of specific forms.

Acer Spicatum.-Mountain Maple Bark.-The dried bark of Acer spicatum (Fam. Aceraceæ), a shrub growing in the mountainous sections of the United States. The bark has for years been substituted for that of Viburnum Opulus.

Description.- In somewhat transversely curved pieces, attaining a length of $20 \mathrm{~cm}$.; bark about $1 \mathrm{~mm}$. in thickness; outer surface dark grayish-brown with numerous elliptical brown lenticels and grayish patches of foliaceous lichens with their small brownish-black apothecia; inner surface light brown, obscurely longitudinally striate, and with usually more or less of a thin layer of wood adhering; fracture short-fibrous, uneven; odor slight; taste astringent, bitter.

InNer Structure.-See Fig. 176.

Powder.-Grayish-brown, consisting of numerous coarse fibrous fragments; bast fibers having strongly lignified walls and associated with crystal fibers, each cell containing a monoclinic prism of calcium oxalate about $0.010 \mathrm{~mm}$. in diameter; numerous fragments of yellowish-brown or dark brown cork cells; calcium oxalate either in parenchyma cells or isolated, mostly in monoclinic prisms varying from 
0.010 to $0.050 \mathrm{~mm}$. in diameter; stone cells occasional, very irregular in outline and very unevenly thickened; starch grains relatively few,

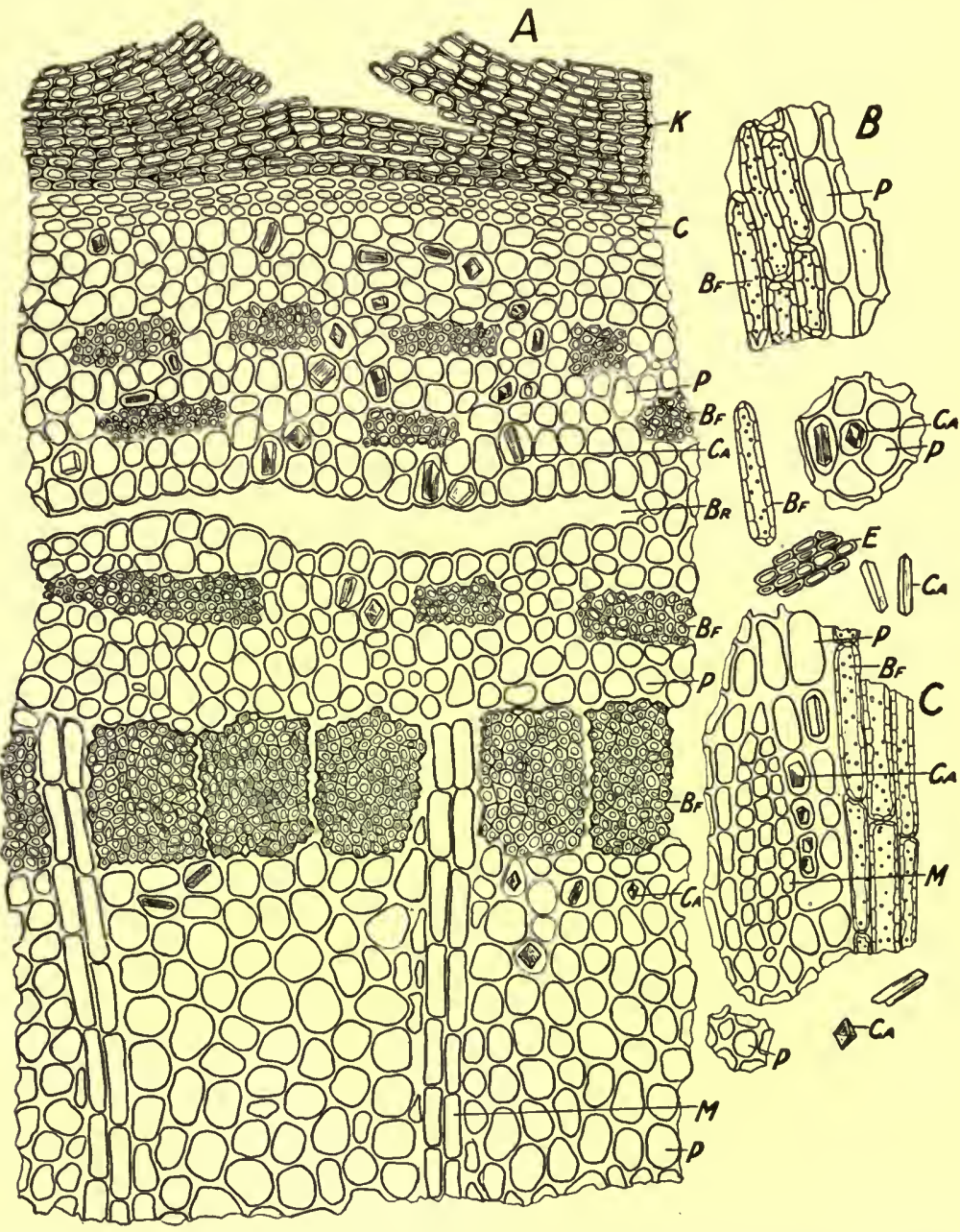

FIG. 176.-Acer spicatum: $A$, transverse section of bark showing cork $(K)$; a narrow row of thick-walled, tangentially elongated cells $(C)$; cortical parenchyma $(P)$; calcium oxalate $(C a)$; bast fibers $(B f)$; separation of cells $(B r)$; medullary rays $(M)$. $B$, fragments of powdered drug showing short bast fibers $(B f)$; parenchyma $(P)$; calcium oxalate $(C a)$ and cork $(E) . C$, tangential section, showing medullary rays $(M)$; calcium oxalate $(C a)$; parenchyma $(P)$; bast fibers $(B f)$. - Drawing by Haase.

occurring in compound aggregates, the individual grains being from $0.003 \mathrm{~mm}$. to $0.010 \mathrm{~mm}$. in diameter. 
Constituents.-Acer spicatum contains a substance which gives a crimson color with ammonia and which may be similar to the emodin of the common cathartic drugs. It also contains a principle which gives a blue color with ferrous sulphate solution similar to that obtained with rhubarb. (St. John, Am. Jour. Pharm., 1917, 89 , p. 10.)

Literature.-Farwell, Bull. of Pharm., 1913, p. 65.

\section{SAPINDACEE, OR SOAPBERRY FAMILY}

A large family of over 1000 species, chiefly tropical woody climbers. They are especially characterized by the presence of the glucoside saponin, which has the property of frothing with water so that some of them have been employed as substitutes for soap, as the fruits of Sapindus, a tree which is widely distributed from Arizona to northern Mexico. Several forms of secretory cells are also found in this family, the one being more or less spheroidal or irregular in shape and the other in the form of elongated tubular cells, frequently arranged in uniseriate rows. The contents vary from yellowish-brown to brownish-black and apparently contain saponin. Some of the secretion cells give a reaction with ferric salts for tannin. The pericycle is usually a composite and continuous ring of sclerenchyma. The tracheæ and wood fibers always possess simple pores, even where the walls are in contact with the parenchyma. Calcium oxalate is usually secreted in the form of solitary crystals or rosette aggregates occasionally as styloids or in microcrystals, when occurring in the latter form, they are usually confined to the epidermal cells. The walls of the epidermal cells are frequently modified to mucilage and the cells on the dorsal surface may be papillose. Glandular and non-glandular hairs occur in a number of specific forms.

Guarana.-A dried paste consisting of the crushed seeds of Paullinia Cupana (Fam. Sapindacex), a climbing shrub native of Brazil and Uruguay. The commerical product is obtained from cultivated plants. The ripe seeds are deprived of the appendage or aril, crushed, made into a doughy mass with water, tapioca sometimes being added to increase the adhesiveness, molded into forms and dried at a gentle heat. During the drying, the mass undergoes a kind of curing. Considerable skill is required in supervising the operation, which is performed by special workmen. In addition to its use in medicine, Guarana is used in the preparation of a beverage which is used like tea and coffee by the people of Brazil. 
Description.-Cylindrical sticks, 15 to $30 \mathrm{~cm}$. in length, 35 to 50 $\mathrm{mm}$. in diameter; externally blackish-brown, surface marked by depressions, but otherwise smooth; hard, heavy and brittle, the fracture being uneven; internally light brown to reddish-brown, somewhat variegated from the fragments of contused seeds; odor slight; taste astringent, bitter.

Powder.-Light pinkish-brown or dark brown; consisting mostly of irregular masses made up of parenchyma cells containing more or less altered starch grains; unaltered starch grains occasional, from 0.010 to $0.025 \mathrm{~mm}$. in diameter, varying from spheroidal and polygonal to ellipsoidal and broadly ovoid; occasional fragments with narrow elongated sclerenchymatous cells, the walls being thick, yellowish and non-lignified.

If $0.001 \mathrm{gm}$. of powdered guarana is added to a slide, upon which a drop of hydrochloric acid has been previously placed, and a drop of gold chloride T. S. is added and the mixture allowed to stand for a few minutes, crystals of caffeine gold chloride should separate in the form of orthorhombic plates and needles, the latter usually occurring in spheroidal aggregates and finally forming branching groups. For microphotograph of crystals of caffeine gold chloride, consult Kraemer's Applied and Economic Botany, p. 163.

Microcrystals of caffeine may be obtained upon heating 0.001 to $0.005 \mathrm{gm}$. of powdered guarana on a watch crystal, the sublimate being collected either upon a microscopic slide or another watch crystal. (See also p. 436.)

Constituents.-Caffeine 2.5 to 5 per cent; tannin (catechutannic acid) about 25 per cent; ash about 2 per cent. Guarana also contains considerable starch, a small amount of catechin, a volatile oil, an acrid, green fixed oil, and saponin.

\section{RHAMNACEE, OR BUCKTHORN FAMILY}

A family of over 500 species, consisting of shrubs or trees, often woody climbers, and rather widely distributed. The leaves are mostly simple and stipulate, the flowers are small and regular, and the fruit is a drupe or capsule. 'The twigs of some of the species as Rhamnus cathartica, possess stout thorns, hence the name buckthorn as applied to this species and the family. Many of the plants are characterized by the presence of methyl-anthraquinone derivatives, which give a bright red color with solutions of the alkalies. These derivatives are found in the medullary rays and distributed among the parenchyma cells of the cortex. Some of the plants 
of this family contain either idioblasts having brown contents, secretory cavities containing a brown amorphous substance, or mucilage cavities. The latter when present are of lysigenous origin, and are distributed in the parenchyma of the cortex and in the veins of the leaves. The walls of the epidermal cells sometimes are modified to mucilage. The leaf-teeth are differentiated into glands and the non-glandular hairs are either unicellular, uniseriate or stellate. Glandular hairs do not occur. The tracheæ are marked by simple pores except when in contact with the medullary rays, the dividing wall possesses bordered pores. The wood fibers are marked by simple perforations.

Rhamnus Purshianus.-Cascara Sagrada.-The bark of Rhamnus Purshianus (Fam. Rhamnaceæ), a shrub indigenous to northern California, Washington, Oregon and the southwestern part of British America. The bark is collected in spring and early summer, and kept at least one year before being used.

Description.--Usually in flattened or transversely curved pieces, occasionally in quills 2 to $10 \mathrm{~cm}$. in length, 1 to $3 \mathrm{~cm}$. in breadth, bark 1 to $3 \mathrm{~mm}$. in thickness; outer surface dark brown or brownishred, frequently completely covered with grayish or silvery whitish lichens, several of which are peculiar to this bark, and with small groups of brownish apothecia, longitudinally wrinkled, sometimes with numerous lenticels 3 to $6 \mathrm{~mm}$. in width and occasionally with adhering mosses, inner surface light yellow or reddish-brown, smooth, longitudinally striate, turning red when moistened with solutions of the alkalies; fracture short, with projections of bast fibers in the inner bark, the medullary rays 1 to 2 cells in width, forming converging groups; in cross-section the cambium margin is indistinctly crenate; odor slight, distinct; taste bitter, slightly acrid and disagreeable.

Inner Structure.-(Figs. 177 and 178.) Periderm of usually a number of layers of rectangular thin-walled, yellowish-brown or reddish-brown cork cells, a number of which have a brown amorphous content; a hypodermis of several layers of collenchymatous cells having a dark-brown color; primary cortex of tangentiallyelongated cells and numerous large groups of stone cells having very thick, strongly lignified, finely lamellated walls, and in which the lumina are very small; medullary rays 1 to 4 cells in width, 15 to 25 cells in height, the contents being frequently colored red upon the addition of solutions of the alkalies; bast fibers in tangentially elongated groups in the inner bark, the walls being thick and strongly lignified; crystal fibers around the bast fibers with individual crystals from 0.008 to $0.015 \mathrm{~mm}$. in length; parenchyma with spher- 


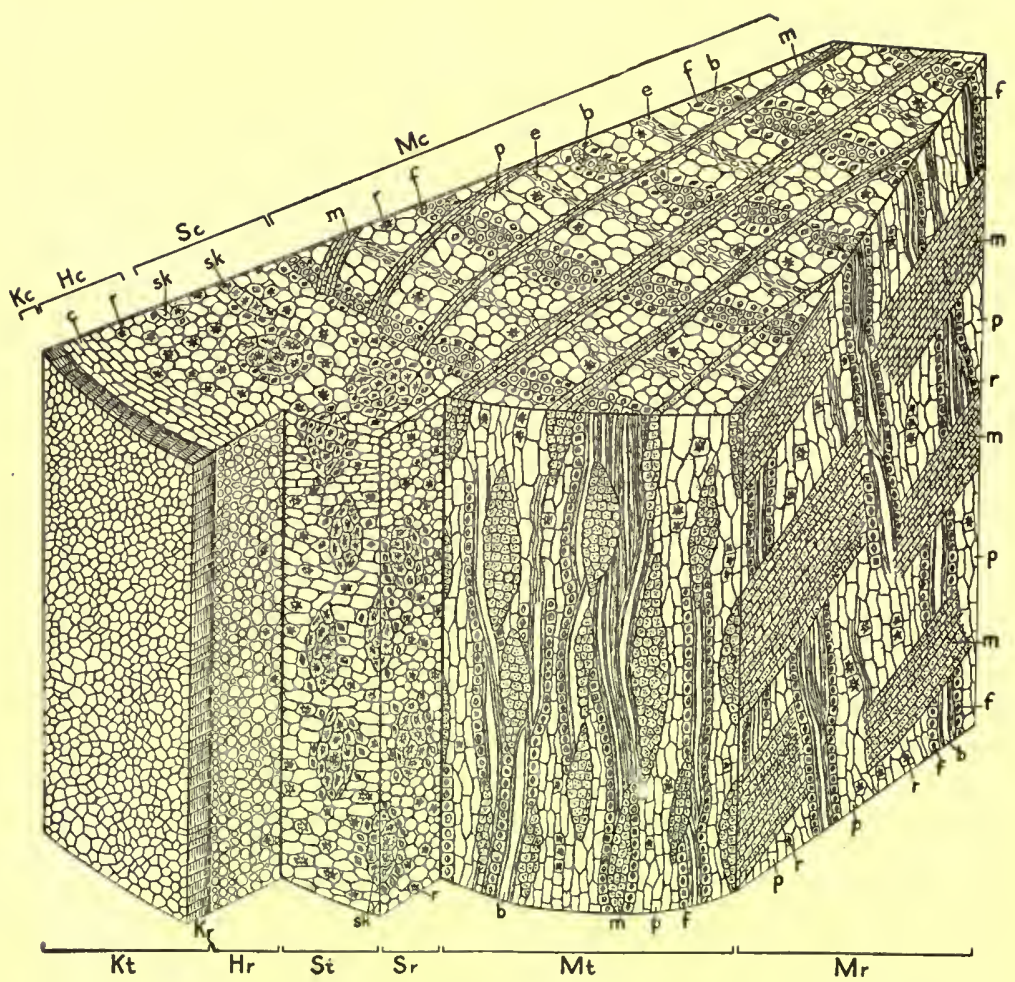

Fig. 177.-The outer bark and part of the inner bark of Rhamnus Purshianus in transverse, radial-longitudinal, and tangential-longitudinal sections.

$M c$, transverse section of inner bark.

$M t$, tangential-longitudinal section of inner bark.

$M r$, radial-longitudinal section of inner bark.

$S c$, transverse section of stone cell area.

- $S t$, tangential-longitudinal section of stone cell area.

$\mathrm{Sr}$, radial-longitudinal section of stone cell area.

$H c$, transverse section of outer layers of cortex.

$H r$, radial-longitudinal section of outer layers of cortex.

$K c, K t, K r$, transverse tangential-longitudinal and radial longitudinal sections of cork.

$\dot{b}$, bast fibers.

$f$, crystal fibers.

$p$, parenchyma.

$e$, sieve.

$s k$, stone cells.

$m$, medullary ray cells.

$c$, collenchyma. 
oidical starch grains about 0.003 to $0.008 \mathrm{~mm}$. in diameter, or with calcium oxalate either in rosette aggregates or prisms from 0.010 to $0.020 \mathrm{~mm}$. in diameter.

Powder.-(Fig. 178.) Light brown to olive-brown; consisting largely of groups of bast fibers with their associated crystal fibers, the latter being usually distinguished with difficulty, unless the material has been mounted in a solution of hydrated chloral and thoroughly cleared by boiling; almost equally numerous are the groups of stone cells which are frequently associated with paren. chyma containing large rhombohedra of calcium oxalate; frag-

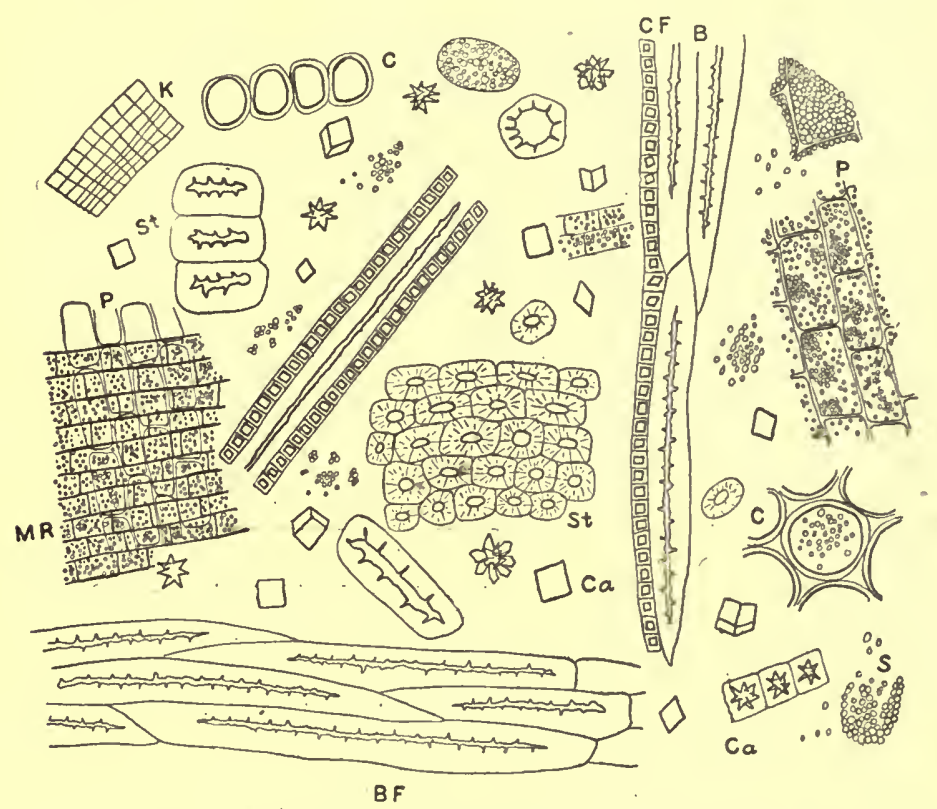

FIg. 178.-Rhamnus Purshianus: $B, B F$, bast fibers; $C F$, crystal fibers; $C a$, calcium oxalate crystals; $S$, starch grains; $P$, parenchyma; $M R$, medullary rays; $S t$, stone cells; $C$, thick-walled, parenchyma of outer cortex; $K$, cork.

ments of parenchyma and medullary ray cells colored red upon the addition of solutions of the alkalies; starch grains either free or in parenchyma cells, the individual grains being somewhat spheroidal, from 0.003 to $0.008 \mathrm{~mm}$. in diameter; calcium oxalate in monoclinic prisms or rosette aggregates from 0.010 to $0.020 \mathrm{~mm}$. in diameter; occasional fragments of yellowish- or reddish-brown cork.

Constituents.-The nature of the active constituents of this drug is not known. It may contain the glucoside cascarin (purshianin), which on hydrolysis yiclds emodin and one or more active 
principles; and the neutral principle chrysarobin, which yields chrysophanic acid (see Rhubarb). The bark apparently contains emodin; isoemodin, a principle which is isomeric with emodin, insoluble in ammonia and resembles a similar principle in Frangula; a

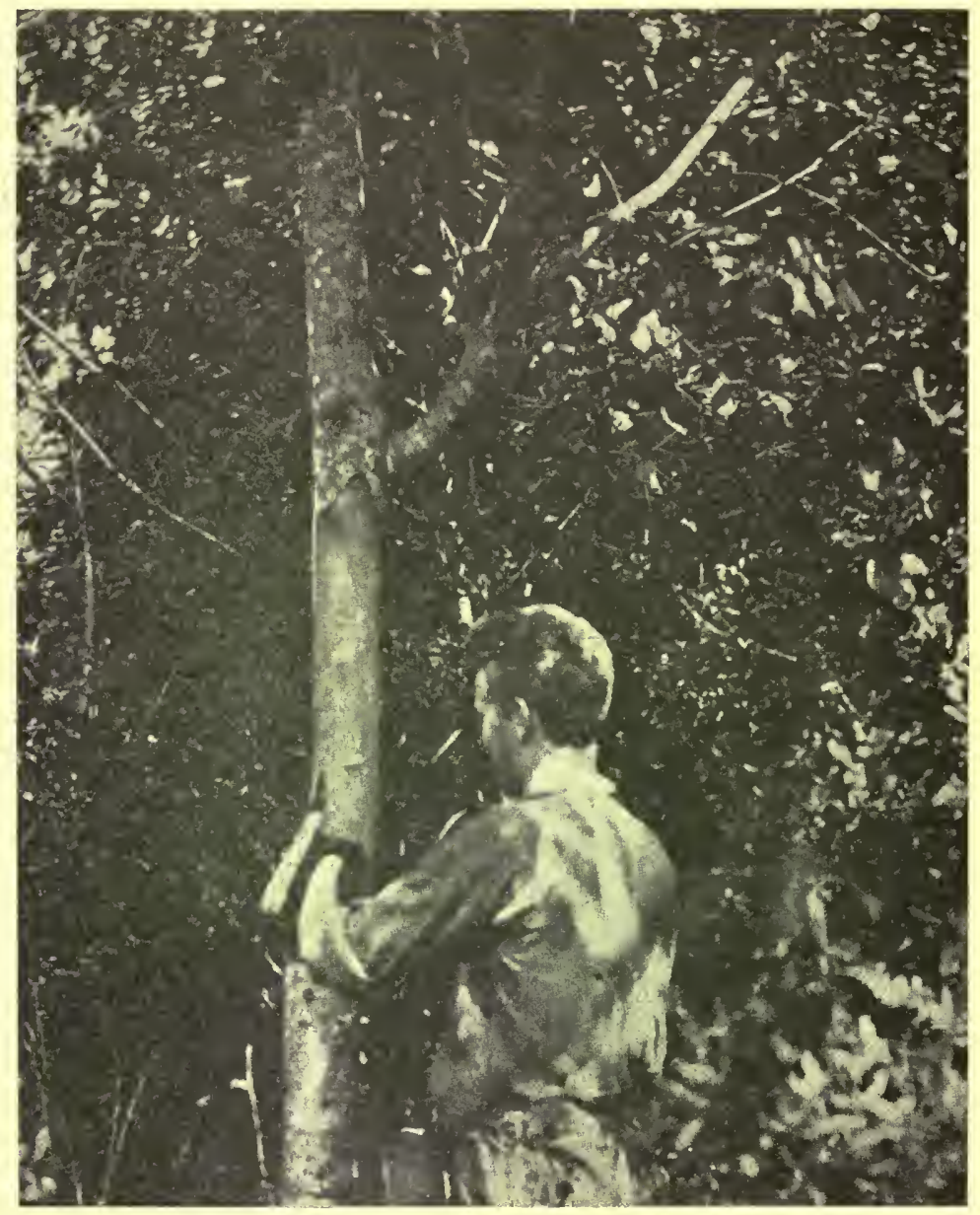

Fig. 179.-Peeling Cascara bark in Washington forests. Mlustrating a method employed in commercial collection, and the dense forest in which the collector must work.-After Johnson and Hindman.

principle which yields on hydrolysis syringic acid; a fat consisting of rhamnol arachidate; a bitter principle; several resins; tannin; glucose; starch; calcium oxalate; and ash about 7 per cent. 


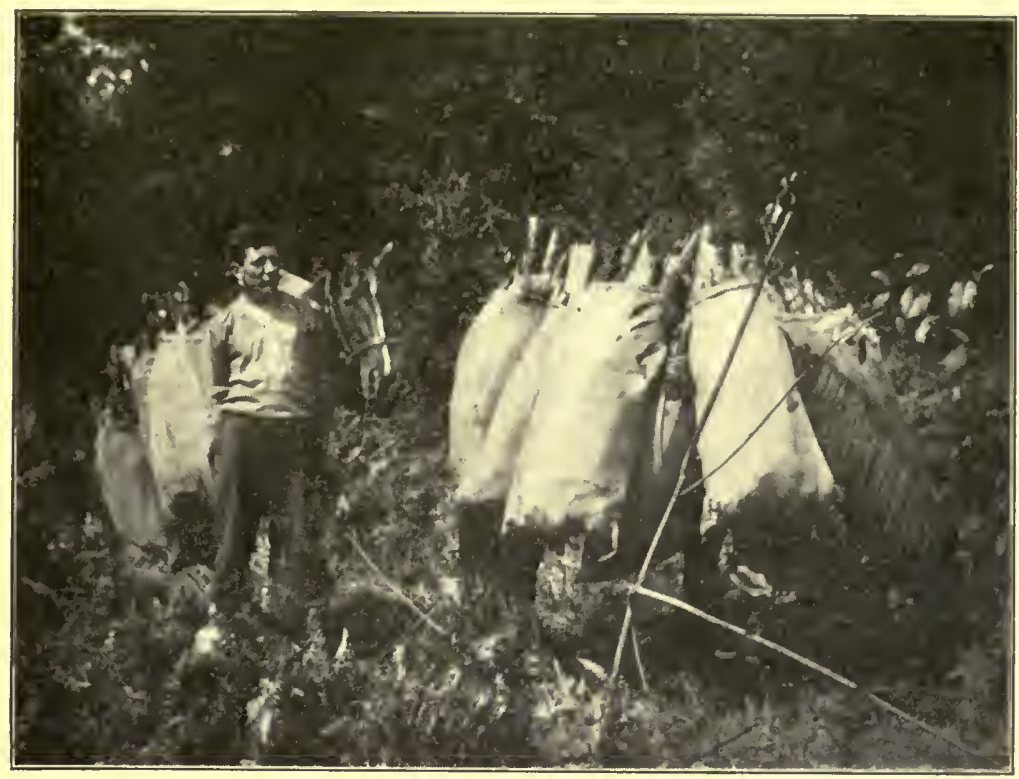

FiG. 180.-Transporting Cascara bark on pack horses to wagon road.-After Johnson and Hindman.

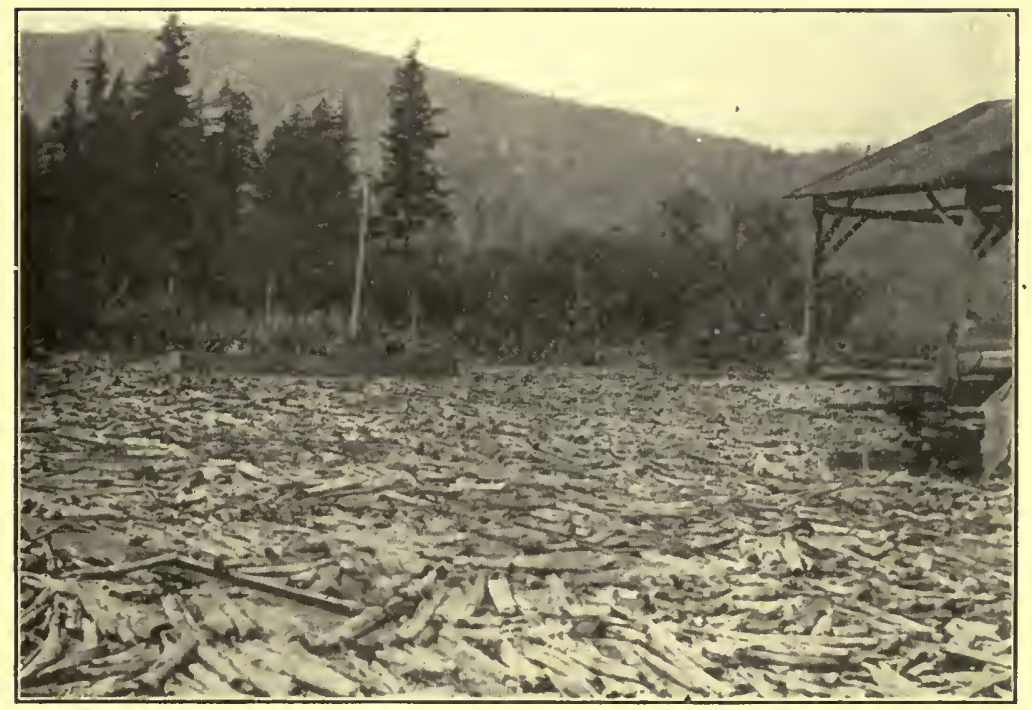

Fig. 181.- Sun-drying Cascara bark on platform of abandoned saw-mill.After Johnson and Hindman. 
Cascara bark contains from 0.0137 to 0.0223 per cent of manganese. Many other laxative drugs contain manganese, and Westman and Rowat have suggested the establishment of a manganese

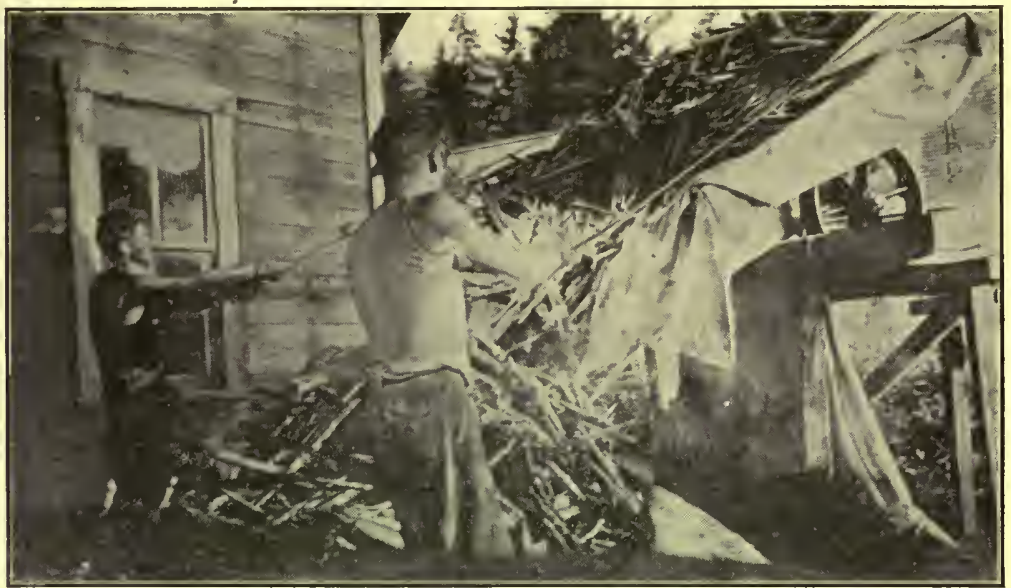

Fig. 182.-A means of moving dried Cascara bark to bark cutter.-After Johnson and Hindman.

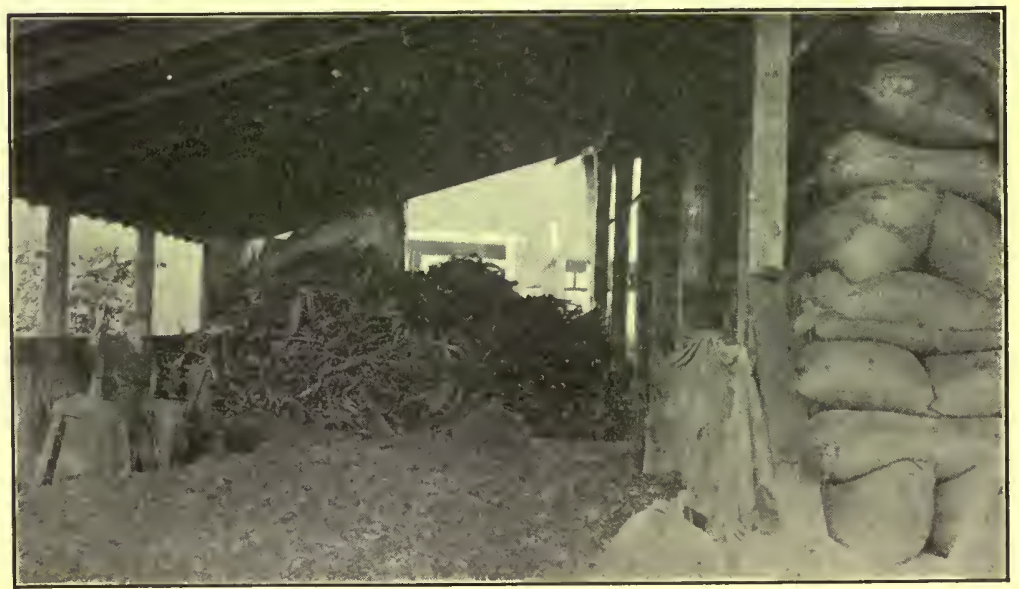

Fig. 183.-Cutting and sacking dried Cascara bark.-After Johnson and Hindman.

number for the valuation of the extracts of this class of drugs. Amer. Jour. Pharm., 1918, 90, p. 271.

Rhamnus Californica, a shrub indigenous to southern California and the neighboring States, yields a bark which closely resembles 
that of Rhamnus Purshianus, but may be distinguished by the following characters: It occurs in quills, transversely curved or flattened pieces, the bark usually being thinner. The color is reddishbrown, the bark being uniformly covered with grayish lichens having numerous black apothecia; the inner surface is light or dark brown,

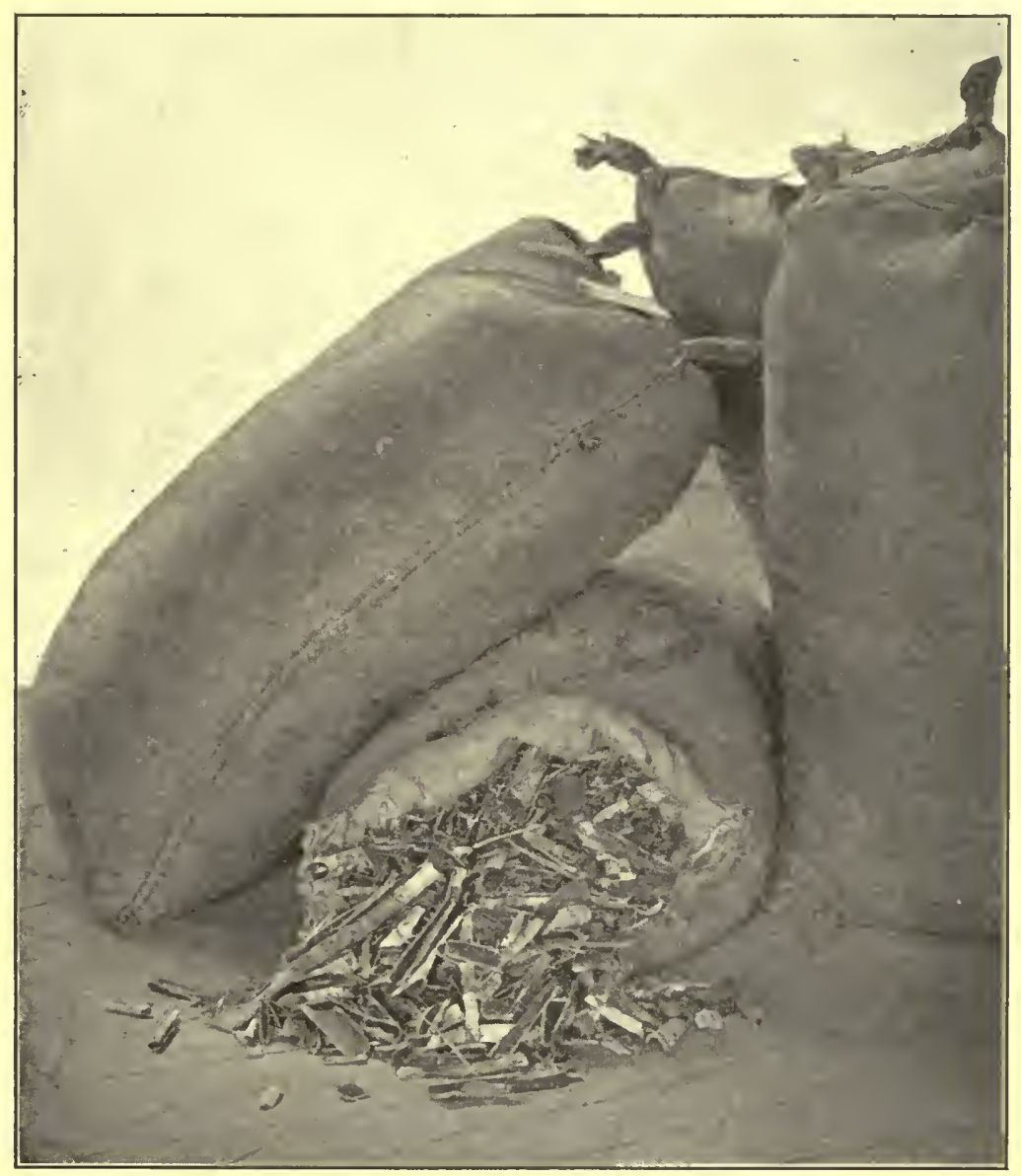

Fig. 184.- Original packages of Cascara Sagrada (Rhamnus Purshianus).After a photograph by Parke, Davis \& Co.

smooth and finely striate; the fracture, odor and taste are similar to Rhamnus Purshianus. The histology of Rhamnus californica closely resembles that of Rhamnus Purshianus. In the former the collenchymatous cells are lárger and the walls somewhat thicker; the medullary rays extend in more or less parallel, wavy rows and are from 
1 to 7 cells in width, and from 10 to 30 cells in height; the cambium margin is distinctly crenate or undulate due, to the shrinking inward of the tissues at each of the medullary rays; nearly all of the cells, with the exception of the lignified tissues, contain the oxy-methylanthraquinones and are colored pinkish-red upon the addition of the solutions of the alkalies.

Adulterant.-The bark of Prunus padus has been used as an adulterant. (Jour. A. Ph. A., 1916, 5, p. 303.)

Literature.-Kraemer, Amer. Jour. Pharm., 1912, p. 385; Johnson and Hindman, Ibid., 1914, p. 387; Gathercoal, Jour. A. Ph. A., 1915, p. 65.

Frangula.-Alder Buckthorn Bark.-The dried bark of the stem and branches of Rhamnus Frangula (Fam. Rhamnacex), a shrub indigenous to Europe, northern Africa and central Asia, and naturalized in northern New Jersey and Long Island. The bark is collected in spring and kept at least one year before being used, so as to render inert the irritating and nauseating principles, which are destroyed by a ferment during the curing of the drug. The same results are said to be obtained by heating the bark at $37.7^{\circ} \mathrm{C}$. for 48 hours.

Description.-In single or double quills, seldom in transversely curved pieces, often crushed and flattened, from 2 to $20 \mathrm{~cm}$. in length, 1 to $3 \mathrm{~cm}$. in diameter, bark 0.3 to $1 \mathrm{~mm}$. in thickness; outer surface dark brown or purplish-black, longitudinally wrinkled, with numerous lenticels 1 to $5 \mathrm{~mm}$. in length, and with grayish patches of foliaceous lichens and groups of light brown or brownish-black apothecia, older bark with a brownish, roughened cork; inner surface yellowish or dark brown, smooth, longitudinally striate, and reddened by solutions of the alkalies; fracture short, with projecting bast fibers in inner bark, being somewhat longer and coarser in thick bark; odor slight; taste slightly bitter, astringent and acrid.

Inner Structure-(Fig. 185.) Periderm of several layers of rectangular brown cork cells, having a purplish-black content, distinguishing it from the cork of Rhamnus Purshianus which is reddishbrown; primary cortex of thin-walled, starch-bearing parenchyma and cells containing either a yellowish- or purplish-brown amorphous substance, or numerous rosette aggregates of calcium oxalate from 0.010 to $0.025 \mathrm{~mm}$. in diameter; inner bark with bast fibers in narrow, interrupted rows, having thick, strongly lignified, yellowish walls and narrow lumina, each group being surrounded by a layer of crystal fibers, in which the prismatic crystals of calcium axalate vary from 0.007 to $0.015 \mathrm{~mm}$. in diameter; medullary rays 1 to 2 cells in width, 
occasionally 3 ; cells of the parenchyma and medullary rays having starch grains about $0.003 \mathrm{~mm}$. in diameter.

Powder.-Yellowish-brown or light pinkish-brown; bast fibers lignified, much thickened, with numerous pores; crystal fibers containing small monoclinic prisms of calcium oxalate; calcium oxalate also in rosette aggregates or monoclinic prisms, from 0.005 to $0.025 \mathrm{~mm}$. in diameter; starch grains nearly spheroidal, about $0.003 \mathrm{~mm}$. in diameter, not numerous; parenchymatous cells with yellowish- or purplish-brown contents, colored red by solutions of alkalies.

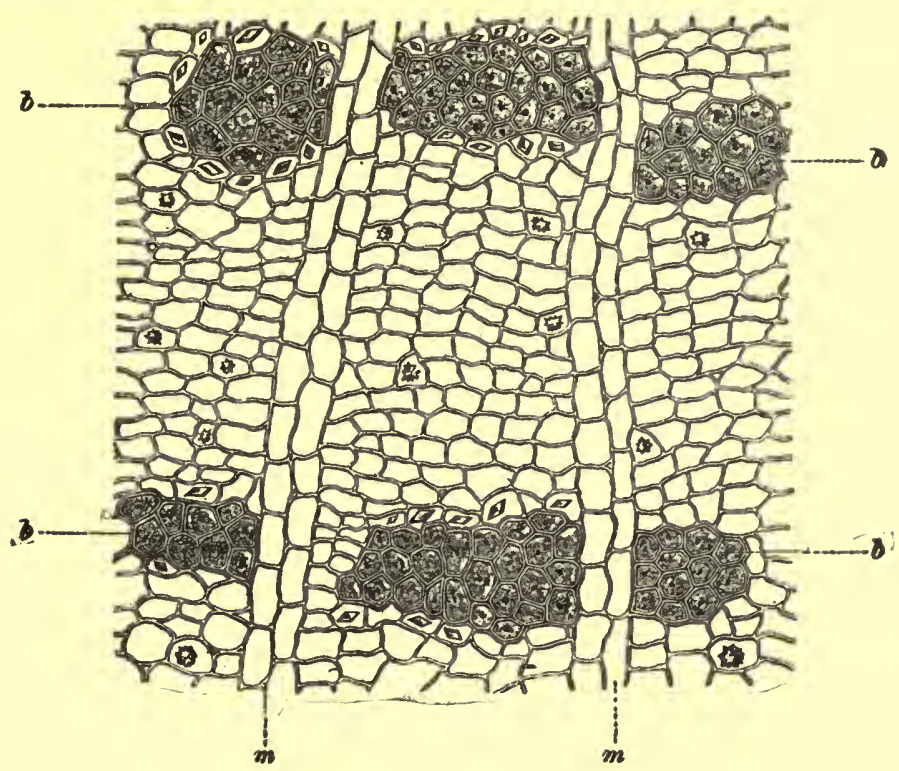

FIC. 185.-Transverse section of inner bark of Rhamnus Frangula: $b$, bast fibers, surrounded by crystal fibers; $m$, medullary rays; parenchyma containing rosette aggregates of calcium oxalate.-After Vogl.

Constituents.-A glucoside frangulin (rhamnoxanthin), which forms yellow crystals, is insoluble in water and nearly so in alcohol, gives a bright purple color on the addition of solutions of the alkalies, and on hydrolysis yields rhamnose and emodin (see Rhubarb). It also contains the glucoside pseudofrangulin (frangulic acid), which yields pseudoemodin; rhamnozanthin, a coloring principle; a volatile oil; tannin; starch; calcium oxalate; and ash 5 to 6 per cent.

Allied Plants.-The bark of Rhamnus carniolica has been substituted for R. Frangula. It occurs in quills or transversely curved pieces, the bark being from 1 to $3 \mathrm{~mm}$. in thickness; externally cork 
reddish-brown, having numerous grayish lichens and obscure lightbrown lenticels from 1 to $2 \mathrm{~mm}$. in width; inner surface grayish or dark brown and longitudinally striate; fracture short-fibrous; odor slight; taste bitter and astringent. The older pieces are distinguished by having a deeply fissured cork and groups of stone cells. In the younger bark the medullary rays are from 4 to 7 cells in width.

Rhamnus Catharticus.-Fructus Rhamni Catharticæ, Buckthorn Berries.-The ripe fruit of Rhamnus catharticus (Fam. Rhamnaceæ), a thorny shrub, indigenous to northern Africa and central Asia, widely distributed in Europe, and naturalized locally in the eastern United States. The fruits are collected when they are ripe, in September and October, and used either in the fresh or dried condition. Most of the supply of the drug is obtained from Hungary.

Description.-When fresh, nearly globular or ovoid, from 4 to 8 mm. in diameter; externally greenish-brown or purplish-black, having at the upper portion a ring-like disc with 4 calyx teeth, and at the lower portion a short stalk, which is usually lacking in the dried fruit; epicarp dark violet; sarcocarp greenish; endocarp light yellow, papery; 4-locular, containing a single seed in 2 or 3 of the locules; seeds anatropous, triangular-convex; the raphe extending in a deep ridge; externally dark reddish-brown and internally light brown; odor slight and unpleasant; taste sweetish, bitter and acrid. The pericarp colors the saliva yellowish.

Inner Structure.-(Fig. 186.) An epidermal layer of dark violet, thick-walled cells; a hypodermis of 5 rows of collenchymatous cells, some of which contain rosette aggregates of calcium oxalate; sarcocarp composed mostly of thin-walled radially elongated cells, among which are the large secretion cells having a yellowish, highly refracting, oily content; an endocarp of several layers, the outer consisting of stone cells having small prisms of calcium oxalate, a layer beneath of tabular cells, a third layer the cells having crystals of calcium oxalate, and an inner layer of sclerenchymatous fibers; inner epidermis of pericarp of large thin-walled cells, containing a yellowish amorphous substance; seed-coat having an epidermal layer made up of thick-walled porous cells, beneath which are several layers or more or less collapsed cells; cells of endosperm and embryo contain an oily cytoplasm and numerous aleurone grains. Sections of the pericarp of the fresh fruit are colored purplish-red upon the addition of acids and bright green on addition of solutions of the alkalies.

Constituents.-Rhamnoemodin, being apparently the most active principle (see Rhubarb). A mixture of 3 distinct coloring principles 
consisting chiefly of rhamnocitrin, which forms golden-yellow crystals and on hydrolysis yields $\beta$-rhamnocitrin; and rhamnolutin, which
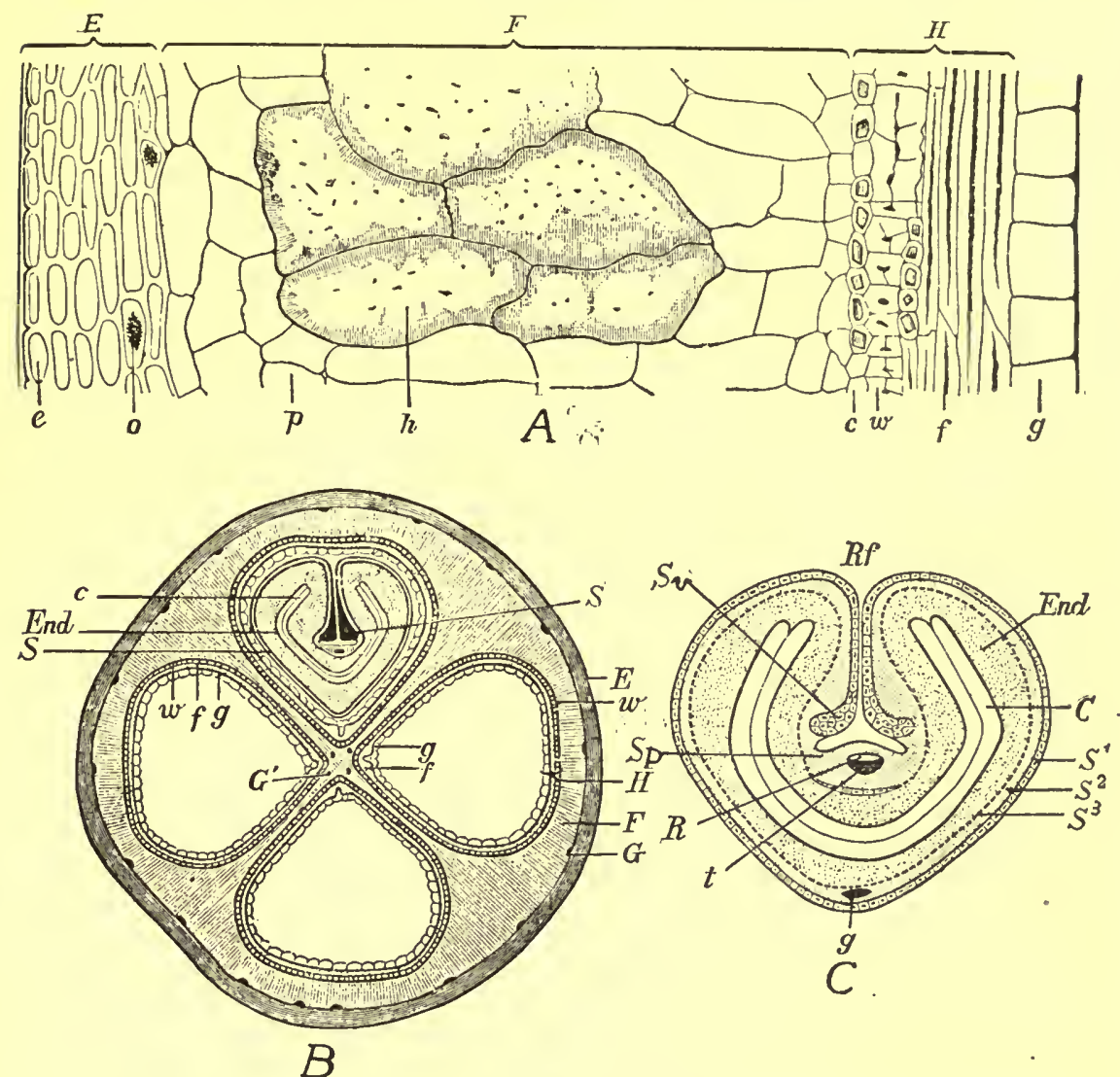

Frg. 186.-Rhamnus cathartica: $A$, cross-section through wall of the pericarp; $E$, epicarp; $F$, sarcocarp; $H$, endocarp; $e$, epidermis; $o$, calcium oxalate in cells of hypodermis; $p$, parenchyma; $h$, secretion cells containing a substance which is insoluble in alcohol or hydrated chloral solutions, soluble in solutions of potassium hydroxide, and colored reddish-brown or greenish with ferric chloride solutions; $c$, calcium oxalate cells of endocarp; $w$, sclerotic cells; $f$, stereome cells. $B$, cross-section of entire fruit, showing one seed; $E, F, H, g, f, w$, as in $A ; S$, seed-coat; $S^{\prime}$, outer wall of seed-coat; End, endosperm; $c$, cotyledons; $g$, vascular bundle. $C$, cross-section of a seed: $S^{1}, S^{2}, S^{3}$, different layers of the seed-coat; $R$, vascular bundle of raphe; $t$, position of vessels of mestome strand; $g$, mestome strand; $R f$; cleft in which raphe is situated; End, endosperm; $C$, cotyledons; $S v$, cells with thick walls; $S p$, parenchymatous cells.-After Meyer.

crystallizes in yellow needles and is isomeric with luteolin and fisetin; also a small quantity of rhamnochrysin which forms orange needles. 
The berries also contain a bitter principle, a violet anthocyanin, chlorophyll, an amorphous sugar, pectin, gum, and yield from 3 to 5 per cent of ash.

Allied Plants. - The fruits of Rhamnus cathartica, as well as of R. infectoria (known as French berries) and of R. saxatilis (called Persian berries) have been used as yellow dyes. The fruits of several species growing in China yield a green indigo.

\section{MALVACE $Æ$, OR MALLOW FAMILY}

A family of about 800 species, widely distributed. The plants are mostly herbs, with simple leaves, regular flowers (having the stamens united into a column, which encloses the styles) and a capsular fruit. They are characterized by the presence of several types of mucilage secretory organs. (A), epidermal cells in which the walls become metamorphosed to mucilage; (B), parenchyma cells in the axis and leaves in which the walls undergo a mucilaginous modification; (C), lysigenous mucilaginous cavities which are sometimes differentiated as canals and occur in both the pith and cortex. In the roots of Althæa the walls of the parenchyma cells of the vascular bundles are likewise modified to mucilage. Secretory cavities of schizogenous origin and containing a yellowish or yellowish-brown amorphous substance, are found in Gossypium and some other genera. The phloem portion of the vascular bundles is of a characteristic structure in that the wedges of phloem, in cross-section are coneshaped, having the broad end near the cambium and conversely the broadest portion of the medullary ray wedges near the primary cortex. The phloem is likewise stratified into alternate strands of leptome and tangentially elongated groups of bast fibers (Fig. 189). The tracheæ and wood fibers usually possess either simple or bordered pores, occasionally the tracheæ have spiral thickenings. Calcium oxalate is secreted in the form of solitary crystals or rosette aggregates. The non-glandular hairs are usually stellate, but they may be of a number of other forms. The glandular hairs show a number of modifications in the different genera.

AltheA.-Althæa Radix, Althæa Root, Marshmallow Root, Eibischwurzel.-The dried root of Althæa officinalis (Fam. Malvaceæ) a perennial herb native of central and southern Europe, and naturalized in the United States, occurring in the marshes from Massachusetts to Pennsylvania. The commercial supply is obtained from plants cultivated in Germany, France and Holland. The roots are collected from plants of the second year's growth, and the periderm 
and rootlets are removed. The drug frequently is seen in commerce in small pieces about $5 \mathrm{~mm}$. in diameter having a uniform grayishwhite color, otherwise resembling the entire root.

Description.-Nearly entire, cylindrical, tapering, 10 to $20 \mathrm{~cm}$. in length, 5 to $20 \mathrm{~mm}$. in diameter; externally very light brown, obscurely 4- to 6-angled, deeply furrowed longitudinally, covered with detachable bast fibers, with few circular root-scars; fracture of bark tough, fibrous, of wood short and granular; internally light brown, finely radiate, bark 0.5 to $2 \mathrm{~mm}$. in thickness, and easily separable from the wood, cambium zone marked by a distinct brown line, wood porous; odor faint, aromatic; taste sweetish, mucilaginous.

Inner Structure.-See Fig. 187.
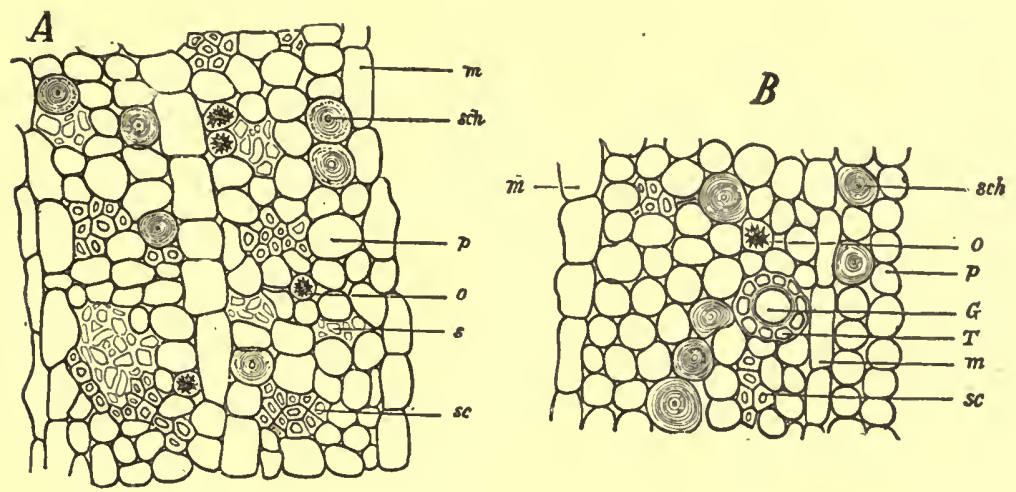

Fig. 187.-Althæa Radix: $A$, transverse section of portion of the bark; $m$, medullary rays; $s c h$, mucilage cells; $p$, parenchyma; $s$, leptome plates; $s c$, groups of bast fibers; $o$, rosette aggregates of calcium oxalate. $B$, transverse section through a portion of the wood; $G$, trachæa, having porous walls; $T$, tracheid-like wood fibers; $s c$, wood fibers; $p$, wood parenchyma; $m$, medullary rays; $s c h$, mucilage cells; $O$, rosette aggregates of calcium oxalate.-After Meyer.

Powder.--Very light brown; groups of sclerenchymatous fibers, the latter having thick more or less lignified walls; starch grains numerous, from 0.005 to $0.020 \mathrm{~mm}$. in diameter, ellipsoidal, usually having a long central cleft; tracheæ with scalariform thickenings or with bordered pores; calcium oxalate crystals few, in rosette aggregates, $0.020 \mathrm{~mm}$. to $0.030 \mathrm{~mm}$. in diameter.

Constituents.-Mucilage 25 to 35 per cent; asparagin (amidosuccinamide) 1 to 2 per cent, which occurs in hard crystals having an acid reaction, insoluble in alcohol but soluble in 50 parts of cold water; starch about 35 per cent; pectin about 10 per cent; sugar 
about 10 per cent; ash about 5 per cent. An infusion of althæa is colored bright yellow with dilute solutions of the alkalies.

Asparagin ( $\beta$-asparagin, the monamide of aspartic acid) is an amido compound which is most widely distributed throughout the vegetable kingdom. It is not only found in reserve organs as the tubers of the potato and dahlia, the roots of althæa, belladonna, etc., and the seeds of the chestnut tree, but it also occurs in young shoots as of asparagus and in peas, beans, and other members of the Leguminosæ. Asparagin has also been detected in some of the fungi as the Agaricineæ and certain of the Myxomycetes. Unlike certain derivatives of urea it is a plastic product playing a very important rôle in plant metabolism. On account ô its crystalline character and solubility in water, it is classed among the translocatory substances, appearing not only when proteids are being utilized by the plant, but when they are being formed. The crystals of asparagin are formed rather easily from the expressed juices of young shoots, and may be obtained even in sections upon mounting them in glycerin. The crystals vary in length from $0.3 \mathrm{~mm}$. to $1.5 \mathrm{~mm}$.

Asparagin occurs in two forms, one of which is lævo-rotatory and the other dextro-rotatory; the former is the one usually present in plants. At $17.5^{\circ}$ C. 1 part of asparagin is soluble in 47 parts of distilled water; at $98^{\circ}$ C., 1 part is soluble in 1.9 parts of distilled water. ${ }^{1}$

Allied Plants. - The roots of a number of other genera of this family are used for similar purposes, as those of Kosteletzyka pentacarpa of southern Europe; Hibiscus Bancroftianus of the West Indies; Malvaviscus pentacarpus of Mexico; H. Rosa Sinensis of tropical Asia and cultivated; Althæa rosea of the Levant and cultivated; and Sida ovalis of Peru. Mucilage is also found in the flowers and leaves of one or more species of Malva, Sida, Pavonia, Hibiscus, Pachira and Eriodendron.

AlthæA FoliA.-Marshmallow Leaves, Eibischblätter.-The leaves of Althæa officinalis (Fam. Malvacæa), a perennial herb common in the salt marshes of New England and New York, naturalized from Europe and cultivated quite extensively. The leaves are gathered at the time of flowering of the plant during June and July, and carefully dried.

Description.-Leaves broadly ovate, having petioles about 2.5 $\mathrm{cm}$. in length; lamina from 5 to $10 \mathrm{~cm}$. in length and 3 to $8 \mathrm{~cm}$. in breadth; summit acute, base somewhat truncate or heart-shaped;

${ }^{1}$ Grattarola, Zeitschr. f. Krystallog., 1892, p. 618. For microphotographs of Asparagin, consult Kraemer's Applied and Economic Botany, p. 168. 
margin dentate and usually more or less 3-lobed; both surfaces grayish-green, densely velvety pubescent, the midrib and veins of the first order prominent on the lower surface; inodorous; taste mucilaginous.

InNer Structure.-See Fig. 188.

Powder.-Grayish-green; fragments of non-lignified, stellate hairs, usually occurring in clusters of from two to six, having dis. tinctly porous basal portions and attaining a length of $0.600 \mathrm{~mm}$., the walls being about $0.008 \mathrm{~mm}$. in thickness; occasional multicellular glandular hairs with short stalks; calcium oxalate in rosette
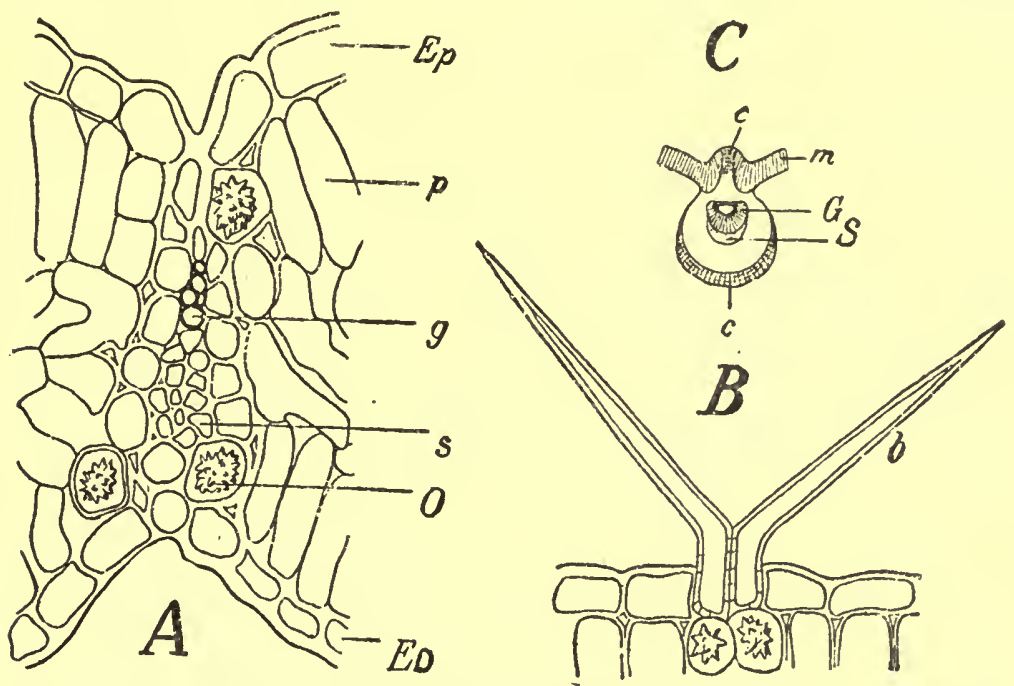

Fig. 188.-Althxa Folia; $A$, transverse section through a vein of the leaf; $E p$, epidermal cells on the ventral surface; $p$, palisade cells; $g$, tracheæ; $s$, leptome; $O$, rosette aggregates of calcium oxalate; $E d$, epidermal cells of the dorsal or lower surface. $B$, longitudinal section through stellate hair on dorsal surface, and showing the calcium oxalate crystals in the cells beneath. $C$, transverse section through one of the principal veins; $c$, collenchyma; $m$, mesophyll; $G$, tracheæ; $S$, leptome.-After Meyer.

aggregates from 0.015 to $0.025 \mathrm{~mm}$. in diameter; fragments of epidermal tissue with stomata, the latter being about $0.025 \mathrm{~mm}$. in length; mucilage cells distinguished by their highly refracting contents; usually a few pollen grains, spheroidal, covered with spines, and about $0.100 \mathrm{~mm}$. in diameter.-(Newcomb.)

Constituents.-The chemical constituents of the leaves have not been carefully investigated, and in addition to the usual constituents found in leaves, they contain an appreciable quantity of 
mucilage, to which their medical properties are due. They also yield from 10 to 15 per cent of ash.

MaLve Folia.-Mallow Leaves.-The dried leaves of Malva sylvestris and Malva neglecta (Fam. Malvaceæ).

Description.-Leaves long petiolate, orbicular or reniform, slightly truncate or cordate at the base, 10 to $20 \mathrm{~cm}$. in length, 15 to $20 \mathrm{~cm}$. in width, with three to seven shallow, angular or rounded lobes, venation palmate, margins crenate-dentate, pubescent on both sides; inodorous; taste very mucilaginous.

Inner Structure.-Epidermal cells mucilaginous, stomata, on both surfaces, each with three or four neighboring cells; hairs of three distinct types; $(a)$, small, short stalked glandular hairs; $(b)$, large onecelled curved hairs with thick walls and (c) stellate hairs having two to six cells (the latter especially numerous in M. sylvestris); palisade tissue of one or two rows of cells, the mesophyl of three or four rows; calcium oxalate in rosette aggregates; mucilage cells numerous.

Powder.-Light green; hairs characteristic, and calcium oxalate in rosette aggregates.

Gossypium Purificatum.-Purified Cotton.-The hairs of the seeds of Gossypium hirsutum, G. barbadense, and other species of Gossypium (Fam. Malvaceæ), biennial or triennial shrubs indigenous to sub-tropical Asia and Africa, and cultivated in all tropical and sub-tropical countries. The seeds are hand-picked, freed from dust by screens or drums, and the cotton removed in the cottongin. It is then freed from mechanical impurities, deprived of fatty and other substances and finally bleached. It is estimated that 1,000 million K. of cotton are produced annually. Long staple or sea-island cotton is obtained from G. hirsutum, while short staple or upland cotton is derived from G. barbadense.

Description.-A white, soft tufted mass, consisting of somewhat flattened, twisted and spirally striate, 1-celled, non-glandular hairs, from 2.5 to $4.5 \mathrm{~cm}$. in length; inodorous and tasteless.

Absorbent cotton is soluble in ammoniacal solution of cupric oxide, yields less than 1 per cent of ash, and on treating it with water, the solution should have a neutral reaction and not give any reaction with ammonium carbonate, barium chloride, mercuric chloride or silver nitrate.

Adulterants.-Various substances may be added to absorbent cotton to increase the rate of absorption of water, as chlorides of calcium, magnesium and zinc, glycerin and glucose; loading materials, as barium and calcium salts, and clay are added to inferior grades of the article. 
The hairs from immature seeds are known as "dead cotton" and are distinguished by having very thin walls, a thin outer layer of cutin, but lack the essential properties for technical uses.

Gossypi Cortex.-Gossypii Radicis Cortex, Cotton Root Bark.The dried bark of the root of Gossypium herbaceum and of other species of Gossypium (Fam. Malvaceæ), biennial or triennial herbs or shrubs indigenous to sub-tropical Asia and Africa, and now cultivated in all tropical and sub-tropical countries.

Description.-In flexible, transversely curved or slightly quilled pieces, 6 to $30 \mathrm{~cm}$. in length, 5 to $15 \mathrm{~mm}$. in diameter, bark 0.2 to 1 $\mathrm{mm}$. in thickness; outer surface light brown, longitudinally wrinkled, with small lenticels, periderm frequently exfoliated; inner surface light brown, longitudinally striate; fracture tough, fibrous, surface light brown, tangentially striate, readily separable into fibrous layers; odor faint; taste slightly astringent and acrid.

Inner Structure.-(Figs. 189 and 190.) Periderm consisting of a number of layers of rectangular or somewhat tabular cells, having thin, yellowish-brown walls; primary cortex consisting of parenchyma containing starch grains, tannin and large secretory cavities filled with a brownish amorphous content; inner bark having nearly closed rings of bast fibers arranged in interrupted concentric circles, separated radially by medullary rays and tangentially by the leptome tissue; bast fibers from 0.300 to $1.000 \mathrm{~mm}$. in length, about $0.015 \mathrm{~mm}$. in width, the walls being about $0.005 \mathrm{~mm}$. in thickness, strongly lignified and with very few pores, the ends being acute or markedly attenuate; medullary rays from 1 to 6 cells wide, the cells usually filled with starch, the grains being single or 2- to 4-compound, the individual grains spheroidal and from 0.003 to $0.020 \mathrm{~mm}$. in diameter; calcium oxalate in rosette aggregates, from 0.010 to $0.025 \mathrm{~mm}$. in diameter.

Powder.-Light brown; bast fibers long, narrow, thick-walled, lignified; starch grains somewhat spheroidal from 0.003 to 0.020 $\mathrm{mm}$. in diameter, single or compound; parenchymatous cells with irregular yellowish and reddish tannin masses; calcium oxalate crystals in rosette aggregates from 0.010 to $0.025 \mathrm{~mm}$. in diameter.

Constituents.-About 8 per cent of a peculiar, colorless acid resin, which is soluble in water and becomes reddish and insoluble on exposure to air. The drug also contains fixed oil; tannin; starch and calcium oxalate.

THE FLOwers of the cotton plant contain an interesting glucoside, gossypetin, which becomes green on oxidation and is colored orange- 


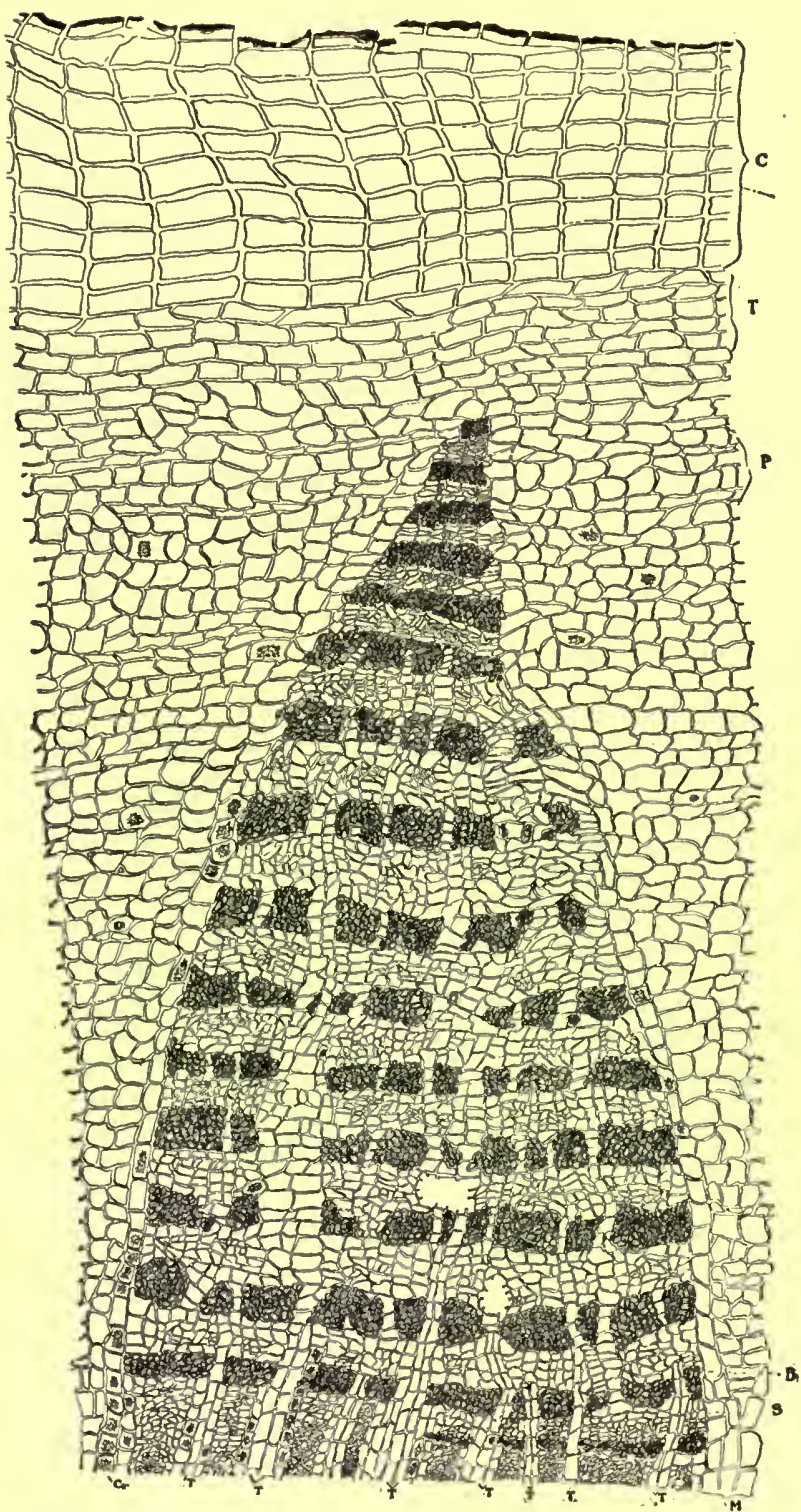

Frg. 189.-Transverse section of cottom root bark showing the characteristic cone-shaped strands of leptome: $C$, layers of cork; $C r$, rosette aggregates of calcium oxalate from 0.010 tc $0.025 \mathrm{~mm}$. in diameter; $B$, bast; $N$, medullary rays; $T$, cells containing tannin; $S$, leptome.-After Morgan. 


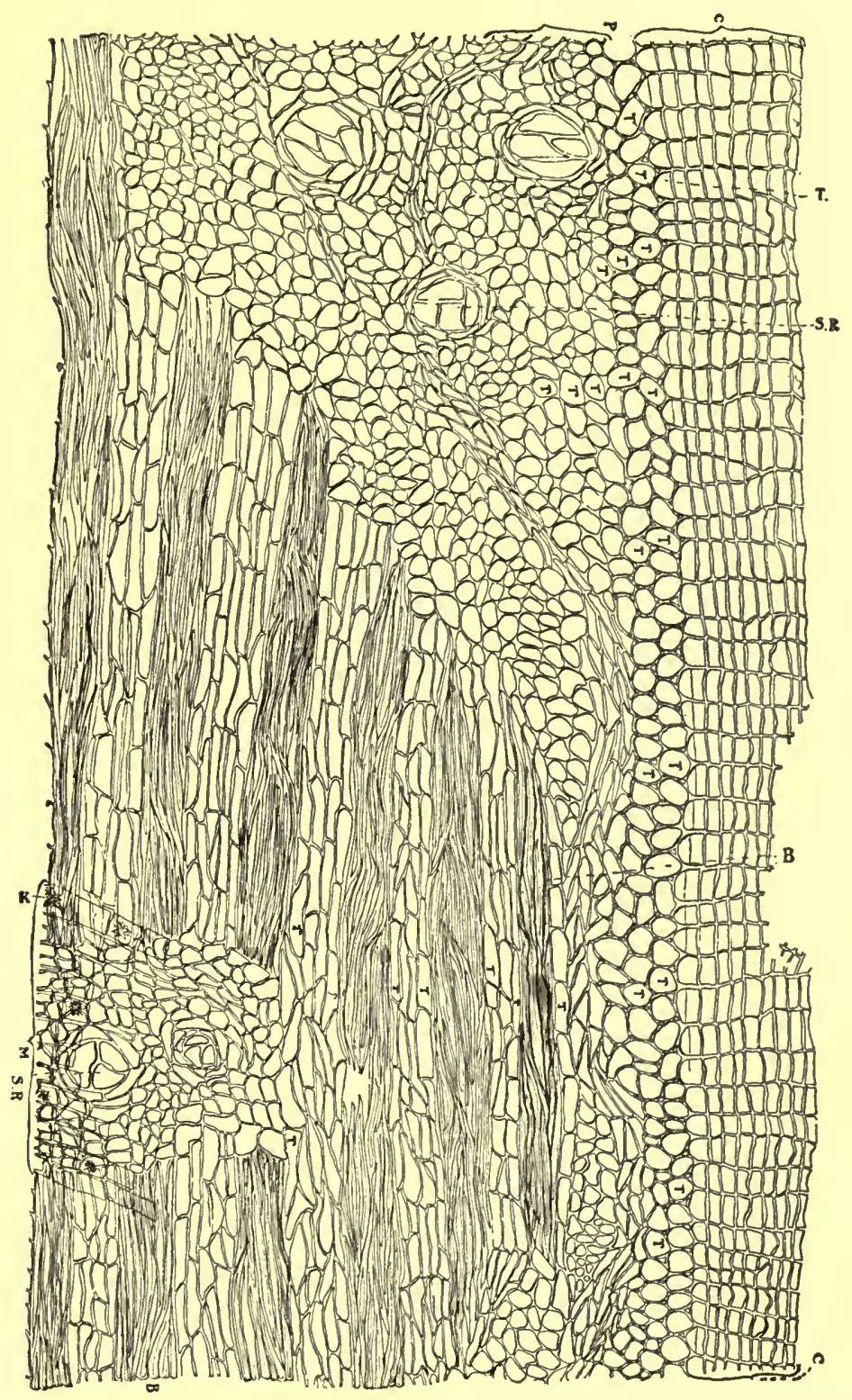

FIG. 190.-Longitudinal section of cotton root bark: $C$, cork cells; $P$, parenchyma; $B$, bast fibers; $S R$, secretory cavities, having a brownish, amorphous content; $M$, medullary rays; $T$, cells containing tannin; $K$, rosette aggregates of calcium oxalate from 0.010 to $0.025 \mathrm{~mm}$. in diameter.-After Morgan. 
red with solutions of the alkalies. It somewhat resembles a similar principle found in arbor vitæ (Thuja occidentalis).

Cottonseed contains 0.6 per cent of a toxic principle called Gossypol. It occurs in secretory cavities in all parts of the plant. It occurs in the cold-pressed oil to the extent of 1.5 per cent, from which it may be removed upon treatment with alkalies. (Carruth, Amer. Jour. Pharm., 1918, 90, p. 649.)

\section{STERCULIACEAE, OR COLA FAMIIY}

A small family of about 150 species of tropical and sub-tropical plants. They comprise a great many forms, some being lianes. They resemble those of the Malvaceæ very closely and are distinguished by their 2-locular anthers. The mucilage secretory organs occur as mucilaginous membranes; lysigenous mucilaginous cavities; and as schizogenous or lysigenous canals. In addition tannin-secretion cells are usually present. The tracheæ and wood fibers are marked by simple pores. Calcium oxalate is secreted in the form of solitary crystals and rosette aggregates, occasionally as prismatic crystals. Non-glandular hairs, although usually stellate, peltate or tufted, may occur in other specific forms. The glandular hairs are either unicellular, or made up of a few cells, and somewhat resemble those of the Malvaceæ.

Cola.-Kola, Kola Nut.-The kernel of the seed of Cola acuminata (Fam. Sterculiaceæ), a tree indigenous to Guinea, and now extensively cultivated in the West Indies and South America. The commercial supplies come principally from western Africa and the West Indies. The seed obtained from the West Indies is known commercially as Bichy or Bissy-bissy nut. The kernels are used in a fresh condition or the cotyledons are separated and dried.

Description.-Anatropous, plano-convex, polygonal, three- to six-sided, 18 to $35 \mathrm{~mm}$. in length and 5 to $20 \mathrm{~mm}$. in diameter; externally yellowish or yellowish-red when fresh, but becoming darker with age and on drying, with a shallow furrow indicating the line of union of the two cotyledons, micropyle forming a distinct cleft at one end, otherwise nearly smooth; easily cut when fresh, but hard when dry; without reserve layers, cotyledons unequal and varying from two to five in number, the hypocotyl small; odor distinct; taste astringent, somewhat sweet.

Powder.-Reddish-brown; starch grains numerous, from 0.005 to $0.045 \mathrm{~mm}$. in diameter, spheroidal, ellipsoidal, shell-shaped or irregularly oblong, occasionally with a protuberance on one side, 
many of the larger grains show lamellæ and a circular point of origin of growth or a central fissure, the larger grains show a distinct cross when examined with the micro-polariscope. The powder also exhibits numerous parenchyma cells about $0.065 \mathrm{~mm}$. in diameter, the walls being frequently reddish-brown in color.-(Newcomb.)

Constituents.-Starch 35 to 40 per cent, the grains resembling those of potato starch but uniformly smaller; caffeine 1.5 to 3.6 per cent; theobromine 0.02 to 0.09 per cent; 1.5 to 4 per cent of a tannin; an enzyme similar to the lipase found in nutmeg and black pepper which decomposes fats.

Caffeine or theine (trimethyl xanthine or methyl theobromine) also occurs in coffee, tea, cacao, guarana and Maté. It separates in the form of acicular crystals having a bitter taste, is soluble in water and alcohol, the solutions being neutral; and may be sublimed without decomposition on heating. On treating a small quantity of caffeine with a few drops of nitric acid or chlorin water and evaporating the solution to dryness on a water bath, the reddish-yellow residue is colored purplish by ammonia. A similar reaction is also obtained by treating the alkaloid with hydrochloric acid and a crystal of potassium chlorate, evaporating the solution and adding a drop of ammonia water to the residue.

While cafieine can be produced synthetically, it is usually prepared from tea and tea dust or sweepings. If crystallized from aqueous solutions it contains one molecule of water of crystallization which is wanting if it is crystallized from alcohol, chloroform or ether. The crystals from aqueous solutions may attain a length of $20 \mathrm{~mm}$.

At $25^{\circ} \mathrm{C}$. one part of caffeine is soluble in 45.6 parts of water; 53.2 parts of alcohol; 375 parts of ether; and 8 parts of chloroform.

Solutions of caffeine give with gold chloride and some other reagents crystalline precipitates. ${ }^{1}$ To prepare caffeine gold chloride the caffeine may be dissolved in distilled water, dilute alcohol, absolute alcohol or a mixture of equal parts of absolute alcohol and chloroform. One or two drops of the caffeine solution are placed upon a slide, to which is then added one or two drops of an aqueous solution of gold chloride. The two solutions are mixed by the use of a glass rod and then allowed to crystallize. Crystals of caffeine gold chloride are usually formed rather quickly, larger crystals being obtained from the more dilute solutions of caffeine. The crystal are also formed in solutions of caffeine acidulated with hydrochloric acid. The microscopic crystals of caffeine gold chloride vary in length from

${ }^{1}$ Nịcholson, Ann. Chem. Pharm., 1847 (62), p. 71; and E. Schmidt, Ibid., 1883 (217), p. 283. 
$0.4 \mathrm{~mm}$. to $4 \mathrm{~mm}$. They are said to be decomposed, at least in part, on washing. with either alcohol or water. The Pharmacopoia Helvetica gives the following micro-chemical test for determining the presence of caffeine in cola: Transverse sections of the cotyledons are placed in strong hydrochloric acid and slightly heated; then one or two drops of a solution of gold chloride are added and the sections pushed to one side. The liquid is allowed to evaporate and near the edge of the residue branching groups of needles of caffeine gold chloride separate. ${ }^{1}$

Theobromine (dimethyl-xanthine) also occurs in cacao and crystallizes in rhombic prisms, which are sparingly soluble in water and alcohol, the solutions being slightly acid. It sublimes on heating without decomposition, and forms crystallizable salts with mineral acids, which are readily decomposed with water. Theobromine on treatment with methyl iodide yields caffeine. Both caffeine and theobromine are also prepared synthetically.

Fresh kola nuts also yield from 0.3 to 0.4 per cent of a crystalline tannin-containing substance, kolatin, which is combined with the caffeine as kolatin-caffeine. The latter is unstable and is easily decomposed on curing or drying the drug. Kolatin resembles pyrocatechin in its reactions and appears to neutralize the physiological action of caffeine, and hence the dried kola nuts are more active than the fresh nuts.

The red color in diried kola seeds is due to an oxydase similar to that which causes the darkening of apples when freshly cut and exposed to the air. If the seeds are first heated in boiling water for 30 minutes and then dried they do not darken.

Allied Plants.-The seeds of a number of other plants are said to be sometimes admixed with kola, and of these the following may be mentioned: Cola Ballayi, a plant growing in the Gaboon, the seeds of which contain six cotyledons and are deficient in alkaloids. The seeds of Garcinia Cola (Fam. Guttiferæ) have been substituted for Cola under the name of "Staminate Cola." These seeds do not contain caffeine, but two resins which seem to have a physiological effect similar to Cola. The seeds of Pentadesma butyraceum, of Sierra Leone, have also been used as a substitute for Cola; they contain a fat, having a turpentine-like odor, which is used by the natives in place of butter, and hence the tree is known as the "Butter or Tallow tree."

CACAO.-Cocoa.-The prepared kernels of the ripe seeds of

${ }^{1}$ For photomicrographs of crystals of caffeine gold chloride, consult Kraemer's Applied and Economic Botany, p. 163. 
Theobroma Cacao (Fam. Sterculiacex), a small tree indigenous to the countries bordering the Gulf of Mexico and now cultivated in many tropical countries. The flowers arise from the older branches or trunk developing into a large, ovoid, fleshy fruit which is 10 -furrowed longitudinally, yellow or reddish, and contains five rows of seeds, 10 or 12 in each row (Fig. 191). Most of the cacao of the market is obtained from Ecuador (the Guayaquil variety being especially valued), Curaçao, Mexico, Trinidad, and the Philippine Islands. The seeds of the wild plants contain a bitter principle, the quantity of which is found to be greatly reduced in the plants when under cul-

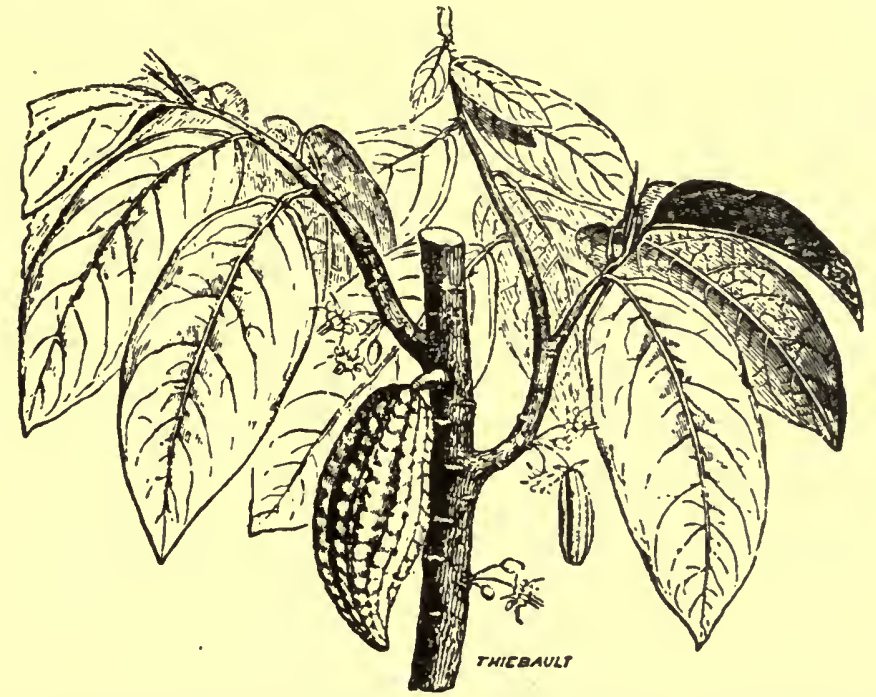

Fig. 191.-Cacao tree (Theobroma Cacao) showing the peculiar habit of the fruits in developing on the main axis as well as on the branches.-After Baillon.

tivation. The bitter principles in the raw product are more or less destroyed by the process of fermentation, to which the seeds are subjected in preparing them for use, which at the same time develops the aroma.

Description.-Irregularly ellipsoidal or ovoid, somewhat flattened, from 15 to $30 \mathrm{~mm}$. in length; externally reddish-brown to dark brown, having the hilum at the broader end, the chalaza at the narrow end and which are connected by a raphe which extends along the narrow edge and is somewhat branched at the chalazal end; seed-coat thin and shell-like, readily separable from the cotyledons; the latter are very fleshy, much folded and connected with 
a stout radicle, situated at the hilum portion of the seed; odor chocolate-like, and taste slightly bitter.

In the roasting of the seeds, the seed-coat is more readily detachable and the embryo more easily broken into smaller fragments. By a process of winnowing the seed-coat is separated and constitutes what is known in commerce as Cocoa Shells. The broken embryo constitutes the product known as cocoa nibs or cracked cocoa.

Plain chocolate or cocoa mass is obtained by grinding the broken cotyledons (cocoa nibs) in a mill and separating the pasty mass, which is molded into forms that usually weigh a pound. CocOA is the plain chocolate from which a part of the fat (cocoa butter) has been removed, the resulting product being then powdered. SweEt CHOCOLATE is plain chocolate to which sugar and various flavoring substances are added. MiLK chocolate is a sweet chocolate to which " milk powder" is added.

Powder.-Cacao Preparata or Cocoa.-(Fig. 192). Reddishbrown; consisting chiefly of protein grains, oil and starch grains, the latter from 0.003 to $0.008 \mathrm{~mm}$. in diameter; fragments with brownish or purplish-brown contents (cacao red); crystals of Cacao butter in small prisms or needles; few fragments of seed-coat consisting of hexagonal epidermal cells, and a peculiar mucilage layer of small tabular cells and a layer of nearly iso-diametric stone cells about 0.010 $\mathrm{mm}$. in diameter, having walls which are about $0.004 \mathrm{~mm}$. in thickness.

Cacao starch grains show a tendency to cohere and on gently heating a section in water, after removal of part of the oil with ether or chloroform, the compound grains swell into angular, rounded or irregular masses which vary from 15 to several hundred microns in diameter (Fig. 192, B). The smaller masses thus produced bear a close resemblance to the starch grains of corn and wheat. The central triangular marking of the mass, which resembles that of a corn starch grain, is formed from the adjoining walls of three individual grains. Most of the aggregates, however, swell into rounded masses $(0.035 \mathrm{~mm}$. in diameter) resembling wheat starch grains, and have a clearly defined wall with nearly homogeneous, hyaline contents. They may be distinguished from wheat starch by the use of dilute alkali or acid solutions, which cause an immediate breaking down of the masses without the successive changes in structure noticed on similar treatment of wheat starch grains.

Constituents.-The seeds contain 35 to 50 per cent of a fixed oil known as cacao butter and official as Oleum Theobromatis; 15 per cent of starch; 15 per cent of proteins; 1 to 4 per cent of theobromine; 0.07 to 0.36 per cent of caffeine, about 0.5 per cent of sugar, and also 
a small amount of tannin. The red color of the seed is due to a principle known as cacao-red, which is formed by the action of a ferment on a glucoside.

Cocoa Shells.-Little or no starch; oil globules; characteristic, brownish, adhesive fragments, possessing more or less hexagonal epidermal cells; peculiar, small, tabular mucilage cells and a layer of nearly isodiametric stone cells.
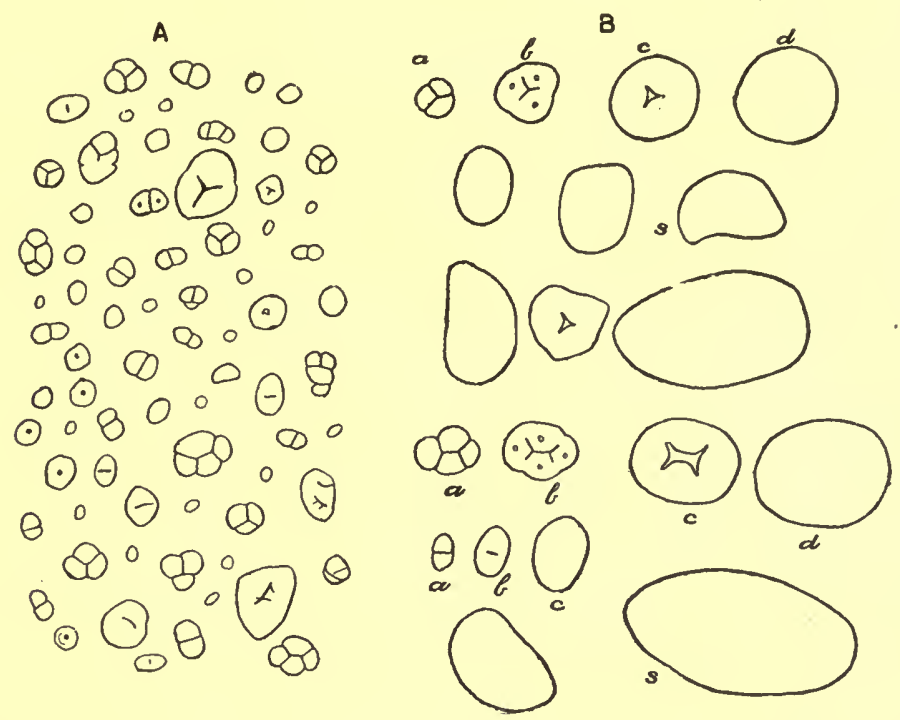

FIG. 192.-Cacao starch: $A$, starch grains of commercial cacao powder, or chocolate, after removal of the oil by means of ether. $B$, altered starch grains of cacao produced by making sections or scrapings of the raw cacao bean, removing the oil with ether, mounting on a slide in water and heating at a temperature of $70^{\circ} \mathrm{C}$., for a few seconds; $a, b, c, d$, successive stages in the alteration of 2-, 3-, and 4-compound grains, the various masses showing resemblance in size and form to the single grains of corn, wheat and even potato starch as seen in some of the swollen masses $(S)$.

Adulterants. - All chocolate products may be adulterated with any of the cereal starches, those of corn, wheat and rice being usually employed; Wasicky and Wimmer use a method for the detection of shells in cocoa based on the difference in appearance between shell and nib tissue when viewed through a microscope by ultra-violet light.-Amer. Jour. Pharm., 1918, 90, p. 215.

Literature.-Zwaluwenburg and Schlotterbeck, Proc. A. Ph. A., 1899 , p. 190. 
Thea. - Tea.-The prepared leaves and leafbuds of Thea sinensis viridis and Thea sinensis Bohea (Fam. Theaceæ), shrubs or trees with alternate, evergreen leaves. The Tea tree is indigenous to eastern Asia, and is now extensively cultivated in China, Japan, India, Java, Brazil, Sicily, Portugal and France, and to some extent in the southern United States (Fig. 193).

The fresh leaves of Thea do not have the properties which characterize the commercial article, the aroma and other qualities being developed after special treatment. Two general classes of tea are

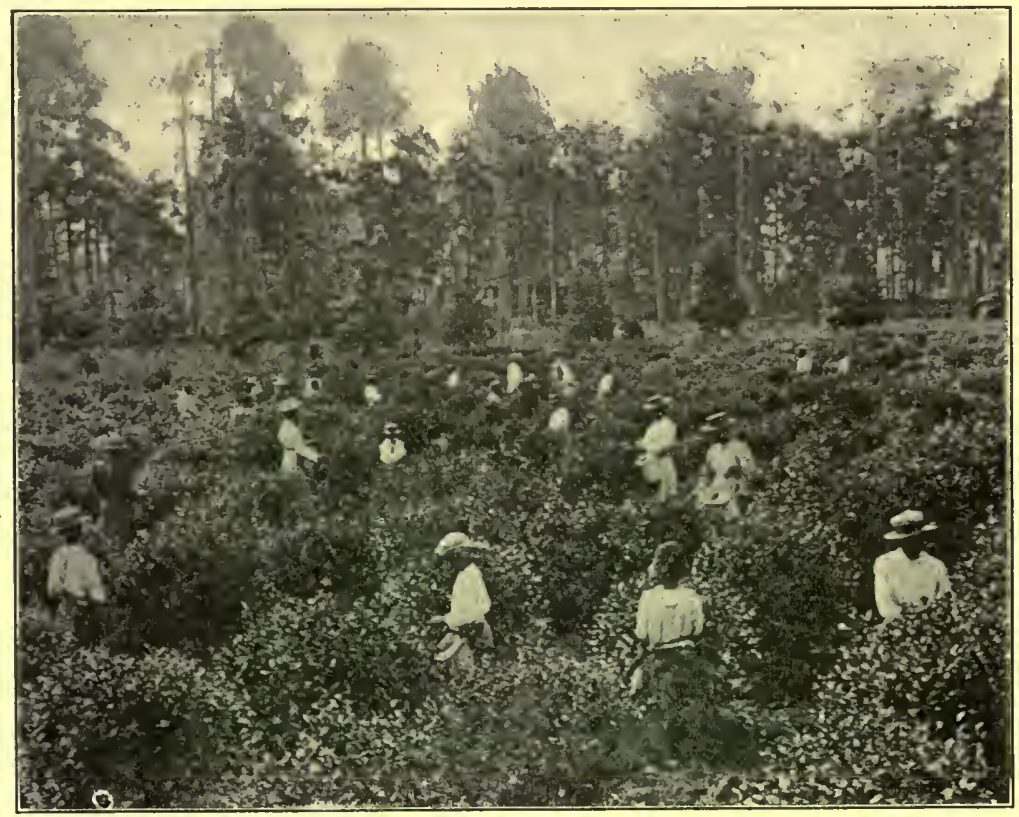

FIG. 193.-A, Tea plantation at Summerville, S. C.-From Bulletin 234, Bureau of Plant Industry, U. S. Department of Agriculture, Washington, D. C.

found in commerce, these depending on the mode of treatment. Those which are rapidly dried by means of artificial heat constitute Green Tea. The leaves which are slowly dried, permitting fermentation to set in, furnish Black Tea.

Description.-Usually in more or less crumpled masses; when entire, nearly elliptical or oblong lanceolate, short petiolate, from 2 to $10 \mathrm{~cm}$. in length; summit acute; base nearly spatulate, tapering into the short petiole, margin serrate or nearly entire; greenish or blackish-green, upper surface glabrous, lower surface smooth or hairy; 
more or less coriaceous; odor agreeable; aromatic; taste pleasantly bitter and astringent.

Inner Structure.-Tea leaves are distinguished from most other leaves by their large colorless stone cells or idioblasts, which frequently extend from the upper to the lower surfaces of the leaf. They vary in form and size, usually have very irregular walls and are somewhat branched.

Powder.-Dark green; large, elongated, irregular and colorless stone cells (idioblasts); numerous unicellular, long, thick-walled, nonglandular hairs $0.010 \mathrm{~mm}$. in width; rosette aggregates of calcium oxalate about $0.010 \mathrm{~mm}$. in diameter; characteristic stomata 0.030 to $0.060 \mathrm{~mm}$. in diameter, with 3 or 4 accompanying cells. Adulterants are distinguished by possessing chiefly other forms of calcium oxalate crystals and hairs.

Allied Plant.-Mate or Paraguay tea is distinguished by the stomata, which are much larger than the epidermal cells of the lower surface; the epidermal cells occurring near the veins are in nearly parallel rows and have a striated cuticle; sclerenchymatous fibers are associated with the trachex, and calcium oxalate occurs in rosette aggregates.

Adulterants.-Ash leaves (species of Fraxinus) have rather characteristic "horned" stomata, due to the increased thickening of the cutinous layers at the openings of the stomata; the epidermal cells are very wavy in outline. Camellia leaves contain idioblasts (similar to those in tea leaves) and calcium oxalate crystals, but the lower epidermis is thick-walled and more or less papillose. Cherry leaves (Prunus avium) have numerous small rosette aggregates of calcium oxalate in the lower epidermal cells. GromWELL leaves (Lithospermum officinale) have stiff, scythe-shaped hairs with centrifugal thickening of cuticle. MAPLE leaves (Acer Negundo) have non-glandular and glandular hairs, the latter with a 2- to 3-celled stalk and large, unicellular head. MEAdow-SwEET (Spiræa Ulmaria) has unicellular, thin-walled, non-glandular hairs, the basal walls of which are truncate; the glandular hairs have either a 3-celled or multicellular stalk and a large, multicellular head. Mountain Ash or European Rowan (Sorbus Aucuparia) possesses long, thin-walled, non-glandular hairs with rounded bases. MuLBERRY leaves (Morus alba and M. nigra) have cystoliths in epidermal cells, non-glandular and glandular hairs, the latter with a unicellular stalk and 5- to 9-celled head. OAK leaves (Quercus pedunculata and Q. sessilflora) have 2- to 3-celled, non-glandular hairs and stomata only on epidermis of lower surface. Sloz leaves (Prunus spinosa) 
have rather characteristic crystal fibers. STRawberRy (Fragaria vesca) has long, unicellular, non-glandular hairs, the basal portions of which have thick walls with simple pores, and glandular hairs consisting of a 3-celled stalk and large head, the cells swelling considerably in hydrated chloral solutions. The leaves of the WillowHERB (Epilobium angustifolium) contain numerous raphides and the non-glandular hairs are slightly wavy, rather broad and with rounded ends. WiLLow leaves (species of Salix) have small stomata (about $0.025 \mathrm{~mm}$. in diameter) with two accompanying cells; the hairs are crooked and with thin walls; the calcium oxalate occurs in rosette aggregates and monoclinic prisms. Wistaria (Kraunhia floribunda) has non-glandular hairs with 2 short basal cells and a long, thin-walled pointed cell; stomata only occur in the lower epidermis.

\section{GUTTIFERE, OR GAMBOGE FAMIYY}

A family of about 400 species of tropical trees and shrubs. They all possess schizogenous resin-canals in both the pith and cortex. Resin cavities are also found in the leaves of certain genera. Lysigenous mucilage receptacles are present in Quinia. The trachese are marked by simple pores; the wood fibers may possess either simple or bordered pores; and wood parenchyma occurs in rather broad strands in the xylem. 'Calcium oxalate is usually secreted in the form of solitary crystals or rosette aggregates, occasionally it occurs in small prismatic crystals, as in Garcinia. The stomata are especially characterized in having the subsidiary cells parallel to the pore. Non-glandular hairs are either unicellular or uniseriate. Glandular hairs are wanting.

Самвogia.-Gamboge.-A gum-resin obtained from Garcinia Hanburyi (Fam. Guttiferæ), a tree found growing on the Malabar coast and in Travancore. Spiral incisions are made in the bark of the trees, and the gum-resin which exudes is collected in hollow bamboo stems; it is then allowed to dry slowly, after which the bamboo is removed. It is chiefly exported by way of Singapore and is known commercially as pipe gamboge.

Description.-In cylindrical pieces, frequently hollow in the center, of variable length, 2 to $5 \mathrm{~cm}$. in diameter; externally grayishorange brown, longitudinally striate, due to the ridges on the inner surface of the bamboo canes in which they have been dried; hard; fracture short, the fractured surface being orange-red, waxy and somewhat porous; inodorous; taste very acrid. 
The Powder is bright yellow, sternutatory, and contains few or no starch grains; not more than 25 per cent should be insoluble in alcohol. The resin is soluble in solutions of the alkalies, with the production of an orange-red color.

Constituents.-Gum allied to arabin, 15 to 20 per cent; a resin known as cambogic acid, from 65 to 75 per cent; a volatile oil; ash, 1 to 3 per cent.

Cake Gamboge is collected in Saigon and Cochin from the same plant that yields pipe gamboge. The product is, however, collected in leaves and then allowed to dry. It occurs in irregular orange-red masses, weighing 1 to $2 \mathrm{~K}$., and is not so brittle as pipe gamboge, but is less uniform in composition and may contain impurities.

Allied Plants.-A drastic gum-resin is also obtained from Garcinia Morella and other members of the Guttiferæ, of India and Malaya, as G. collina, of New Caledonia; Vismia laccifera, of Brazil; Clusia rosea, of the West Indies and South America, and Clusia macrocarpa, of Guiana. Gamboge of a poor quality is obtained from Arasina Gurgi, of India.

Adulterants.-Gamboge is sometimes adulterated with vegetable fragments, inorganic substances, as sand, etc., and wheat or rice flour, which the powdered drug may contain to the extent of nearly 50 per cent.

\section{CISTACEE, OR ROCKROSE FAMILY}

A family of low shrubs and herbs, of which there are about 150 species. They are found chiefly in the northern countries of both hemispheres. They possess simple leaves, regular and perfect flowers, capsular fruits, and are especially characterized by their thick-walled, unicellular hairs, which are frequently united, forming stellate groups (Fig. 194). The glandular hairs are always uniseriate (Fig. 194). As pointed out by Holm the pericycle is a continuous ring including both sclerëids and sterëids, the former being in the nature of stone cells and the latter being in the nature of lignified sclerenchymatous fibers. The tracheæ are provided with simple pores and possess small lumina; the wood fibers have bordered pores; and the medullary rays are narrow. Calcium oxalate is secreted in the form of rosette aggregates.

Helianthemum.-Frostweed, Frost-wort.-The over-ground plant of Helianthemum canadense (Fam. Cistaceæ) a low shrub growing in dry, sandy soil from Massachusetts to North Carolina. The stem portions, with leaves and flowers, are collected in summer and carefully dried. 

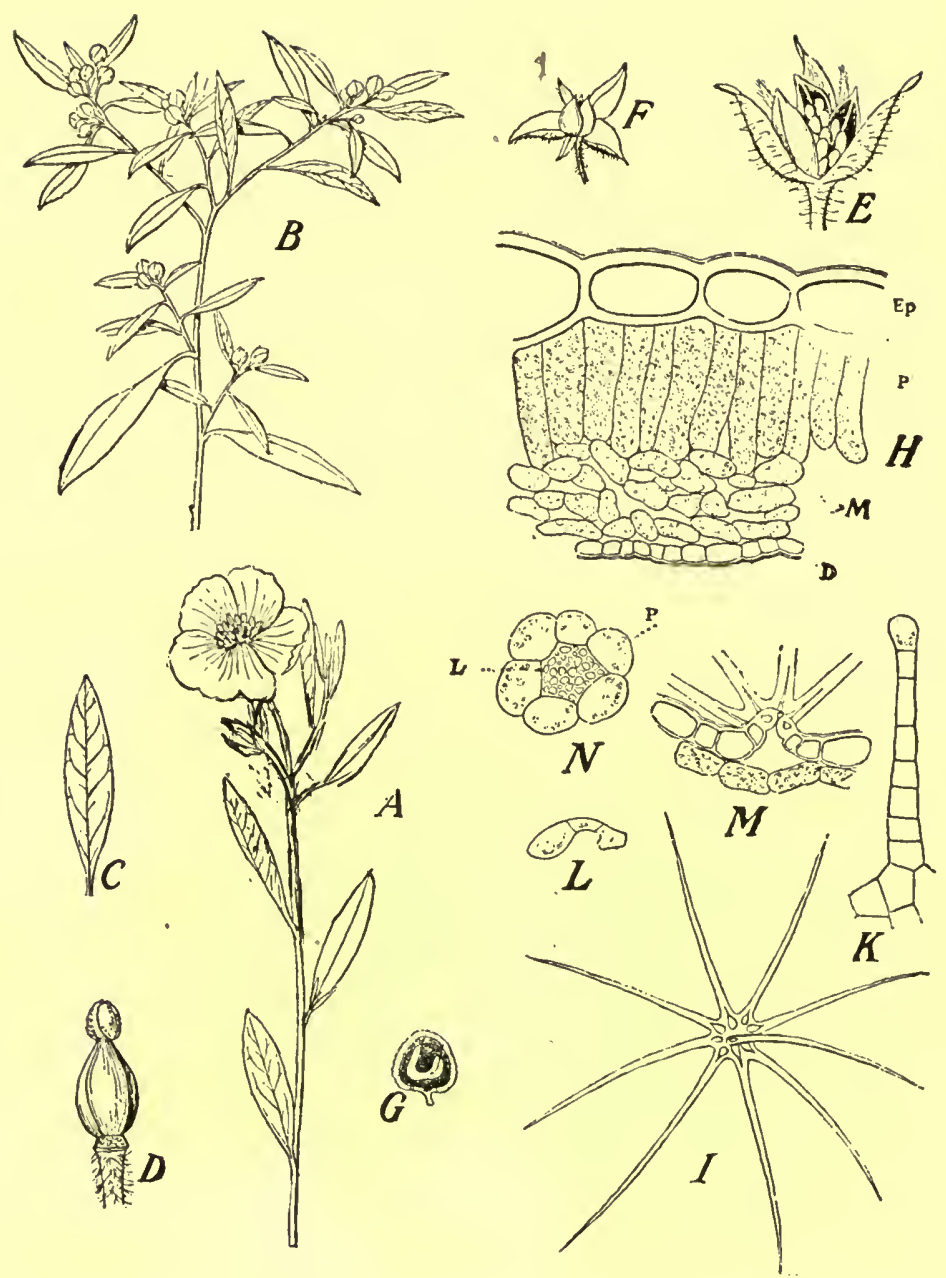

Fig. 194.-Helianthemum canadense: The plant produces two kinds of flowers, the normal or ephemeral, being terminal and having large yellow petals $(A)$; and others that are very small, axillary and apetalous $(B) . C$, one of the lanceolate leaves. $D$, a pistil from one of the normal flowers. $E$, an open capsule developed from one of the normal flowers and enclosing a number of small seeds. $F$, a capsule from one of the apetalous flowers. $G$, section through one of the small seeds showing the curved embryo. $H$, transverse section of leaf: $e p$, epidermal cells of ventral surface;" $P$, palisade cells; $M$, loose mesophyll; $D$, epidermal cells from the lower or dorsal surface. $I$, stellate hairs which are abundant on the dorsal surface of the leaf and occur to some extent also on the ventral surface. $K$, one of the longstalked glandular hairs which are abundant on the dorsal surface of the scale- 
Description.-Stems from 10 to $50 \mathrm{~cm}$. in length, nearly cylindrical, from 1 to $2 \mathrm{~mm}$. in diameter, purplish-brown and pubescent or puberulent. Leaves short-petiolate, lanceolate or oblanceolate, entire, with distinctly revolute margins, summit acute, somewhat mucronatetipped, upper surface dark green and rough pubescent, lower surface light greenish-brown and canescent; petaliferous flowers, when fresh bright yellow, on drying yellowish-brown and consisting of 5 sepals, an equal number of large petals, numerous stamens and a unilocular ovary, the latter becoming in fruit an ovoid capsule, which is about $5 \mathrm{~mm}$. in length and contains numerous, small blackish-brown seeds, which are somewhat triangular in section and covered with small, rounded, reddish-brown papillæ; apetalous flowers in axillary clusters nearly sessile, petals about $5 \mathrm{~mm}$. in length, stamens 4 in number, the capsule about $3 \mathrm{~mm}$. in length, enclosing from 6 to 10 small blackishbrown papillose seeds; odor aromatic; taste astringent and bitter.

InNer Structure.-See Fig. 194.

Constituents.-A small quantity of volatile oil; 10 per cent of tannic acid; a bitter principle which forms white crystals; and probably also a glucoside. The presence of small crystals of ice at the base of the stem in autumn is due to the deposition of globules of water on the stellate hairs which freeze, and hence the popular name frost-weed is given to the plant.

\section{BIXACEE, OR ANNATTO FAMIY}

These are shrubs or trees found in the Tropics, and are of interest, chiefly on account of the seeds of Bixa Orellana, which furnish the coloring matter known as AnNatTo (Orlean, Arnotta). The plant is found in tropical America and also in Polynesia and Madagascar. The seeds are covered with a fleshy arillus from which the coloring matter is prepared by means of water. The insoluble matter is collected, made into cakes and chiefly used for dyeing and coloring. Annatto contains a red crystalline principle, bixin, a yellow coloring principle, orellin, and an ethereal oil. The root of this plant also contains some coloring matter.

Taraktogenos KurziI.-Chaulmoogra Seeds.-The seeds of Taraktogenos kurzii (Fam. Bixaceæ), a native of Burma. The seeds on expression yield a fatty oil, commonly known as chaulmoogra oil.

like leaves. $L$, a short-stalked glandular hair. $M$, a transverse section through a stoma, partly covered with a stellate hair. $N$, a small mestome strand from the leaf showing a strand of leptome $(L)$, surrounded by a sheath $(P)$ of thin-walled parenchyma.-After Holm, Merck's Report, 1912, p. 38. 
Chemical analysis has shown it to consist to a large extent of the glyceryl esters of optically active acids. The acid present in the largest proportion has been designated as chaulmoogric acid; it also contains hydnocarpic acid.-Power, Jour. Chem. Soc., 1904, p. 838; 1907, p. 557; Shattopadhyay, Amer. Jour. Pharm., 1915, 473; Power Ibid., p. 493.

\section{WINTERANACEE, (CANELLACEE), OR CANELLA FAMIIY}

A small family of 4 genera, comprising in all about 8 species. They are mostly tropical or sub-tropical trees, having alternate evergreen leaves, golden-yellow flowers, and fleshy berry-like fruits. The phelloderm is characteristic in that the inner walls of the cells are strongly lignified. The pericycle does not contain any sclerenchymatous tissues. The secretory cells are distributed throughout the parenchyma of stems, roots and leaves. These cells are either spheroidal or ellipsoidal, possessing suberized walls, and contain a yellowish oily content. The tracheæ are marked by bordered pores and scaliform perforations; the wood fibers possess bordered pores; and the medullary rays usually become broader as they extend into the cortex. Calcium oxalate is secreted in the form of rosette aggregates or solitary crystals. Both glandular and non-glandular hairs are apparently wanting.

Canella.-Canellic Cortex, Contex Canelle, Albe, CAnella Bark, White Bark or White Cinnamon.-The bark of Winterana Canella (Canella alba), a small, evergreen tree belonging to the Winteranaceæ and indigenous to the West Indies and Florida. When the drug is collected the bark is divested of its very light grayish cork, the inner layer of periderm, consisting of stone cells, remaining. Most of the commercial supplies are obtained from New Providence, one of the Bahama Islands.

Description.- In quills or transversely curved pieces, from 1 to 3 $\mathrm{cm}$. in length, 1 to $4 \mathrm{~cm}$. in breadth, and 1.5 to $5 \mathrm{~mm}$. in thickness; outer surface light yellowish-brown to orange-brown, somewhat scaly, more or less reticulate, with transverse fissures and occasional patches of silvery-gray cork; inner surface yellowish-white, finely striate; fracture short, granular, outer bark with numerous yellowish-secretion cells, inner bark with wavy medullary rays; odor cinnamon-like taste aromatic, pungent, and somewhat bitter.

InNer Structure.-See Fig. 195.

Powder.-Light yellowish-brown or light reddish-brown; calcium oxalate in rosette aggregates, from 0.020 to $0.050 \mathrm{~mm}$. in 
diameter; starch grains simple or 2- to 3-compound, the individual grains being spheroidal or polygonal, from 0.005 to $0.020 \mathrm{~mm}$. in diameter and frequently with a central circular point of origin of

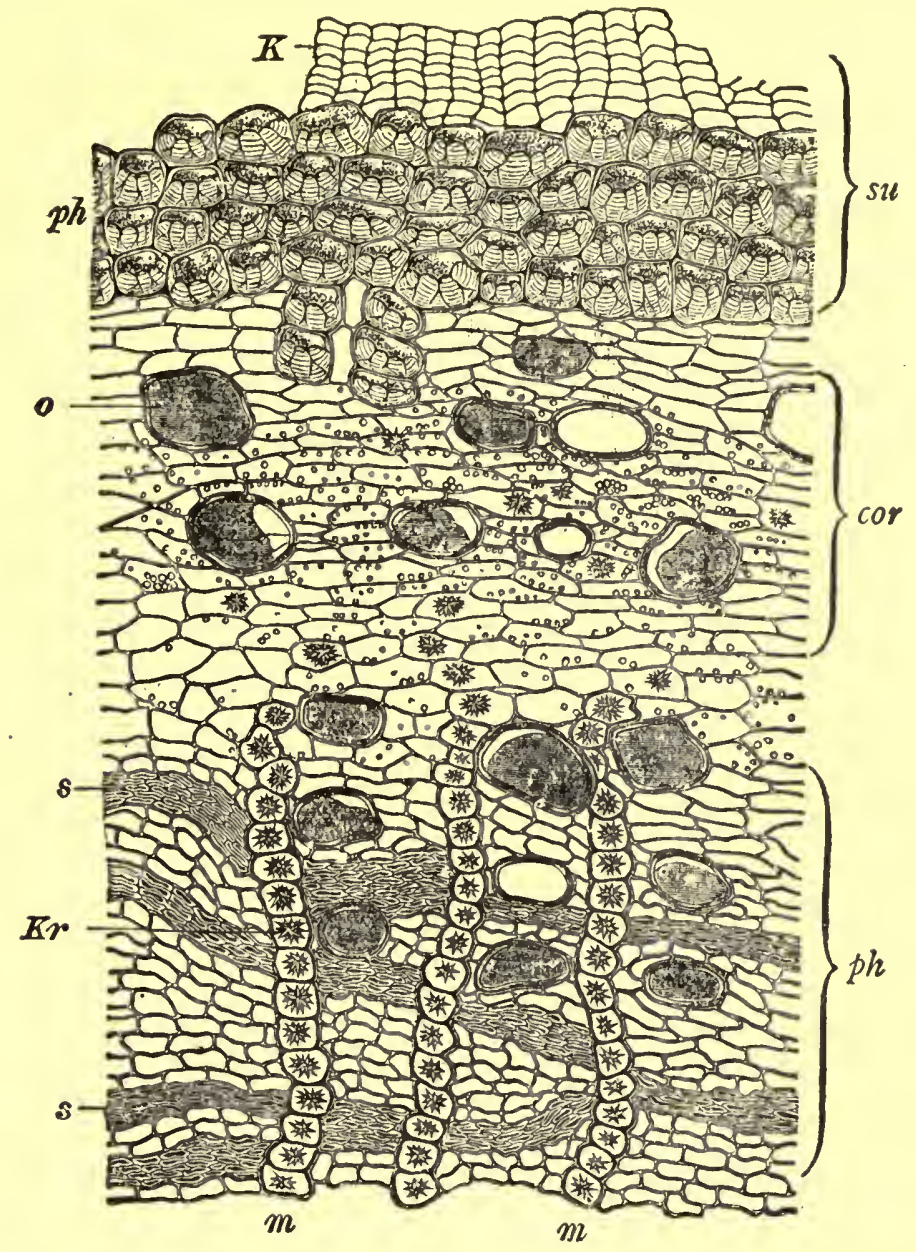

FIg. 195.-Canella: Transverse section of bark showing tissues of outer bark $(s u)$; middle bark or cortical region (cor); and inner bark $(p h) . K$, cork cells; $p h$, inner layer of periderm showing the cells with their strongly thickened, distinctly lamellated, porous and lignified inncr walls; $o$, oil cells with a yellowish oily content; $s$, collapscd cells of sieve; $K r$, rosette aggregates of calcium oxalate; $m$, medullary rays, each cell having a rosette aggregate of calcium oxalate.-After Tschirch.

growth; numerous stone cells of periderm, about $0.075 \mathrm{~mm}$. in diameter, the inner walls of which are considerably thickened, 
and with branching pores; numerous large oil cells with suberized walls.

Constituents.-Canella bark contains mannitol, resin and 0.5 to 1.28 per cent, of a volatile oil containing eugenol, cineol, caryophyllene and pinene.

Adulterants.-The barks of one or more species of Cinnamodendron of tropical America are sometimes substituted for Canella bark, but they are distinguished by containing tannin, which constituent is not found in Canella.

\section{TURNERACEA, OR DAMIANA FAMILY}

A small family of tropical plants, of which there are about 100 species, distinguished among other characteristics by the fact that they contain tannin cells in the primary cortex, which are frequently developed in the form of idioblasts. In the pericycle occur isolated groups of bast fibers. The tracheæ are marked with simple pores or scalariform thickenings, except when in contact with the parenchyma, when the dividing walls possess bordered pores. In the wood fibers bordered pores are usually present, although simple perforations may occur. Glandular and non-glandular hairs of a number of types are developed. Large nectarial glands oceur on the margin and base of the leaves of Turnera and other genera.

Damiana.-Folia Damianæ, Damiana Leaves.-The leaves and flowering tops of Turnera aphrodisiaca and T. diffusa (Fam. Turneraceæ), small shrubs indigenous to Brazil, the West Indies, Mexico and California (Fig. 196). The drug is chiefly imported from La Paz, Bolivia.

T. Aphrodisinca.--Leaves elliptical-ovate to obovate, from 1 to 3 $\mathrm{cm}$. in length, and 4 to $10 \mathrm{~mm}$. in breadth; short petiolate, summit acute, base spatulate, margin sharply dentate, upper surface pale green, smooth or somewhat glabrous, lower surface glabrous, having short glandular hairs; odor aromatic; taste somewhat bitter and acrid.

T. Diffusa.- The leaves elosely resemble those of T. aphrodisiaca, but are smaller, being about one-half their size, and are more hairy, being densely tomentose on the lower surface.

The stems, which are present in both species, vary from 2 to 10 $\mathrm{cm}$. in length, and from 0.5 to $2 \mathrm{~mm}$. in thickness; light-reddish brown or dark brown, smaller twigs being pubescent, the older marked by lenticular depressions due to cork formation; fracture short, fibrous; bark and pith small, wood porous, light yellow and resinous. 
The FLowers, which are sometimes intermixed with the drug, consist of a cylindrical calyx tube surmounted by 5 small teeth; petals oblong or obovate, adnate with the calyx tube; stamens 5 , united with the corolla; ovary superior, unilocular, having 3 long styles. Fruit a loculicidally dehiscent capsule, having a number of ovoid or

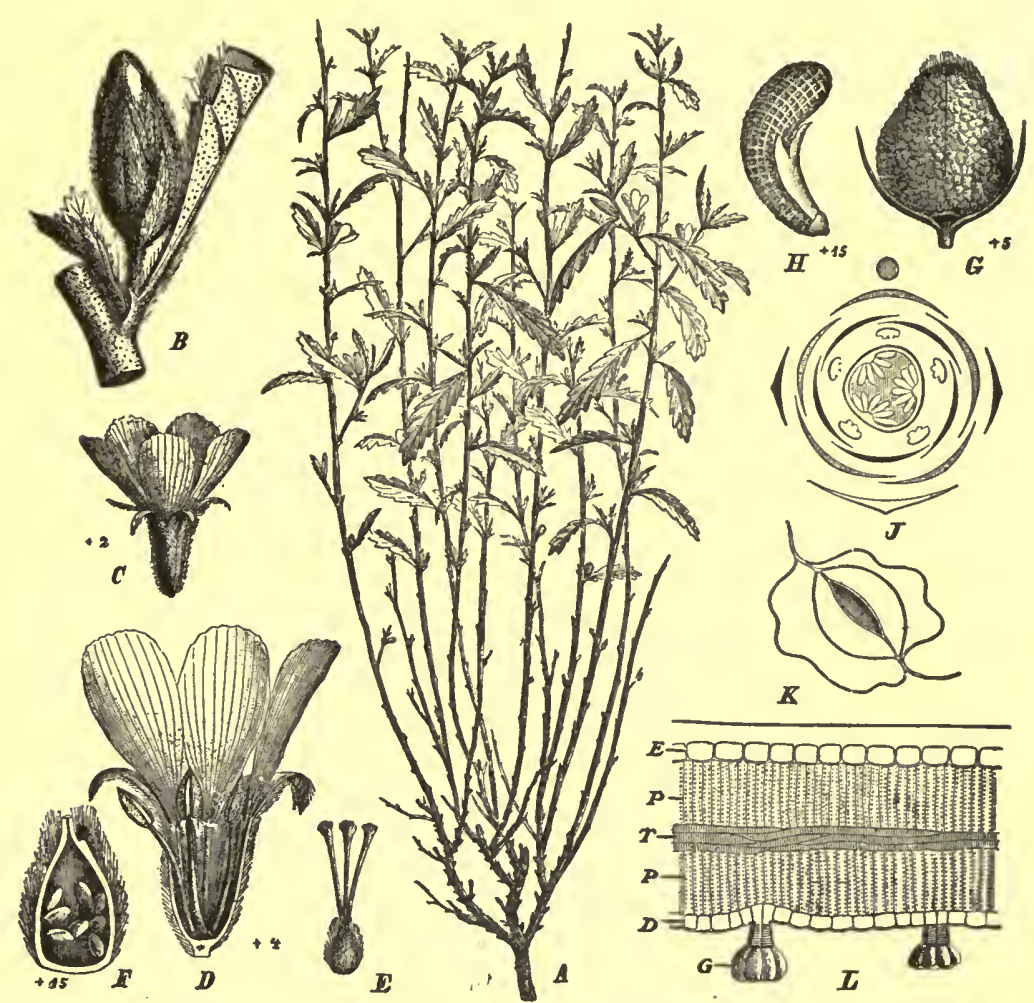

FIG. 196.-Turnera aphrodisiaca: $A$, portion of the plant showing the small serrate leaves. $B$, portion of twig showing the flower bud. $C$ and $D$, the flowers, the latter being in longitudinal section. $E$, ovary with three long styles. $F$, longitudinal section through the ovary showing a number of the ovules. $G$, the mature ovoid fruit. $H$, a crescent-shaped, reticulate seed, having a small, thin, membranous arillus. $K$, stoma with subsidiary cells parallel to the pore. $L$, transverse section through the leaf, showing upper epidermis (e); lower epidermis $(d)$, with 2 glandular hairs $(g)$; palisade cells $(P)$; and tracheæ $(T) . \quad J$, diagrammatic section of a flower of T. ulmifolia.$B$ and $J$ after Urban; the remainder after Gilg.

crescent-shaped reticulate seeds, with a thin, yellowish-white, membranous aril near the micropyle.

Inner Structure.-See Fig. 196. 
Powder.-Yellowish-green; non-glandular hairs numerous, from 0.500 to $0.800 \mathrm{~mm}$. in length and from 0.020 to $0.030 \mathrm{~mm}$. in width, having at the base small lumina and often being curved, so that the major portion of the hair lies somewhat parallel to the surface of the stem or leaf; fragments of the epidermis from the stems composed of somewhat rectangular cells attaining a length of $0.070 \mathrm{~mm}$. and a few broadly elliptical stomata, about $0.030 \mathrm{~mm}$. in length; subepidermal cells from the stems resembling those of the epidermis in shape but with lignified walls; tracheæ, spiral attaining a width about $0.020 \mathrm{~mm}$., and having bordered pores; tracheids from stems and strongly lignified thick-walled selerenchyma, few; lignified pith parenchyma with large simple pores; numerous fragments consisting of the epidermal cells and mesophyll of the leaf, the former with somewhat wavy vertical walls and associated with stomata attaining a length of $0.024 \mathrm{~mm}$., the cells usually containing green plastids; numerous crystals of calcium oxalate mostly in rosette aggregates from 0.015 to $0.030 \mathrm{~mm}$. in diameter, occasionally in prisms; few simple starch grains from the stem about $0.005 \mathrm{~mm}$. in diameter.(Newcomb.)

Constituents.-Volatile oil from 0.2 to 0.9 per cent; a nonglucosidal bitter principle, 7 per cent; a hard brown resin, 6.39 per cent; a mixture of a soft resin and chlorophyll, 8 per cent; tannic acid, 3.4 per cent; starch, 6 per cent; extractive, 10 per cent; a gummy substance, 13.5 per cent; and protein substances, nearly 15 per cent. Ash not more than 10 per cent.

\section{PASSIFLORACEAE, OR PASSION-FLOWER FAMILY}

The plants are mostly herbaceous or woody vines, and represented by about 325 species. They are most abundant in South America, a few of the species of Passiflora, however, being quite common in the southern United States. Nearly all of the plants have elongated tannin sacs and intercellular secretory canals, with a brownish content. The pericycle consists either of isolated groups of bast fibers or a composite and continuous ring of sclerenchyma. The tracheæ usually are marked by simple pores, except in the primary wood, when they possess scalariform thickenings. The wood fibers have both simple and bordered pores. Calcium oxalate is secreted in the form of solitary crystals or rosette aggregates. Non-glandular hairs are either unicellular or uniseriate, the former usually having a more or less hooked summit. Glandular hairs are usually of a woolly or shaggy type. Large nectarial glands are common to 
a number of the species. In the leaves several well-marked characteristics occur: (a) the epidermal layer is frequently modified to mucilage and occasionally is papillose; $(b)$ the cells of the mesophyll may contain spicular cells or crystal idioblasts.

Passiflora.-Wild Passion Flower or Passion Vine.-The leaves and flowering tops of Passiflora incarnata (Fam. Passifloraceæ), a perennial climbing herb, producing axillary tendrils, having alternate palmately lobed leaves and large showy flowers, which are supposed to typify the passion of Jesus and hence the popular name of these plants as given to them by the early Spanish settlers. The plants are indigenous to the southern United States, being found as far west as Missouri and Texas. They produce an abundance of flowers from May to July, and the drug is collected usually after some of the berry-like fruits have developed, being carefully dried and preserved.

Description.-Stems nearly cylindrical, yellowish- to purplishbrown, longitudinally striate, somewhat glabrous or slightly pubescent, internally with a thin bark, porous wood and hollow pith. Leaves more or less broken, when entire, 3- to 5-cleft, long petiolate, the lobes lanceolate-ovate, summit acute, margin serrate; light greenish-brown to dark purplish-brown, somewhat coriaceous, and either glabrous or slightly pubescent; petioles somewhat flattened, from 1 to $6 \mathrm{~cm}$. in length, light or purplish-brown, pubescent, and having 2 large nectarial glands in the upper portion, these being somewhat ellipsoidal from 1 to $2 \mathrm{~mm}$. in length and of a blackish color. Flowers solitary, on long peduncles, from 2 to $5 \mathrm{~cm}$. in breadth, the 5 sepals slightly united at the base and having at the crown several rows of purplish filaments, known as the corona; petals 4 to 5 , inserted on the calyx and of a yellowish-white color; stamens 5, monadelphous; ovary superior, unilocular, becoming in fruit a berry, from 4 to $5 \mathrm{~cm}$. in length, having 3 or 4 parietal placentæ, and numerous ovoid, flattened seeds having a yellowish or brown aril. The drug has a slight odor and a somewhat acrid taste.

Constituents. - Nothing is known in regard to the constituents of Passiflora; it is said, however, to possess traces of an alkaloid.

Allied Drugs.-The rhizome and roots of Passiflora incarnata and P. lutea are sometimes used in medicine. They occur in cylindrical pieces from 3 to $6 \mathrm{~mm}$. in diameter, light yellowish-brown and finely striate. The leaves alone are sometimes collected and a preparation sometimes is made from the freshly expressed juice of the plant. 


\section{CARICACEE, OR PAPAW FAMILY}

A family composed of two genera of latex-containing trees, growing in tropical America, the best known of which is the genus Carica. The latex occurs as a finely granular protoplasmic-like substance, which contains the peptonizing ferment papain, in articulated laticiferous tubes, which occur in the pith, cortex and xylem of roots and stems and are associated with the vascular bundles in leaves, even penetrating into the mesophyll. Guignard has found, in certain tannin and laticiferous cells, a ferment resembling myrosin and a glucoside agreeing with sinigrin, which occurs in black mustard seeds. In many of the parenchyma cells, Ruger has observed large granules of a spheroidal or irregular shape and strongly refractive, which are supposed to be one of the aldehydes. The pericycle is composed of isolated groups of bast fibers. The tracheæ are marked by simple pores or reticulate and scalariform thickenings. The medullary rays and wood fibers are replaced apparently with parenchyma.

Carica.-Papaw, Pawpaw or Papaya.-The desiccated latex of the fruit of Carica Papaya (Fam. Caricaceæ), furnishes a commercial article, which contains one or more proteolytic ferments. The seeds and leaves of this plant are also used to some extent in medicine.

The Papaw is a shrub (Fig. 197), indigenous to tropical America, also occurring in southern Florida, and has become naturalized in most of the tropical countries of the Old World. The trunks may attain a height of 4 or $5 \mathrm{M}$. and a thickness of $15 \mathrm{~cm}$. The trunk persists for a few years and is replaced by new shoots, which develop from a more or less fleshy rootstock. The leaves are long petiolate, yellowish-green, from 45 to $60 \mathrm{~cm}$. in diameter, consisting of from 5 to 7 lobes, the latter being more or less deeply divided into nearly entire lateral lobes. The veins and petioles are yellow or orange colored, the latter being hollow and frequently $1 \mathrm{~mm}$. in length; the flowers are yellow, monœcious and are produced continuously throughout the year. The staminate flowers are fragrant, contain large quantities of nectar, and are borne in long racemose cymes. The pistillate flowers are about $2.5 \mathrm{~cm}$. in length and occur 1 to 3 , in short-stalked cymes. The fruits are formed in clusters at the base of the leaf stalks. They are ovoid or ellipsoidal, obtusely short pointed, and vary in color from yellowish-green to bright orange. The fruits of the plants of southern Florida are usually not more than $10 \mathrm{~cm}$. in length. The fruits of tropical plants may attain a length of $30 \mathrm{~cm}$. and weigh 4 or $5 \mathrm{~K}$. The epicarp is thick, and adheres to the orange- 
colored, fleshy sarcocarp, which surrounds the central cavity containing a mass of nearly black seeds. The latter are spheroidal, and have an aromatic, pungent taste.

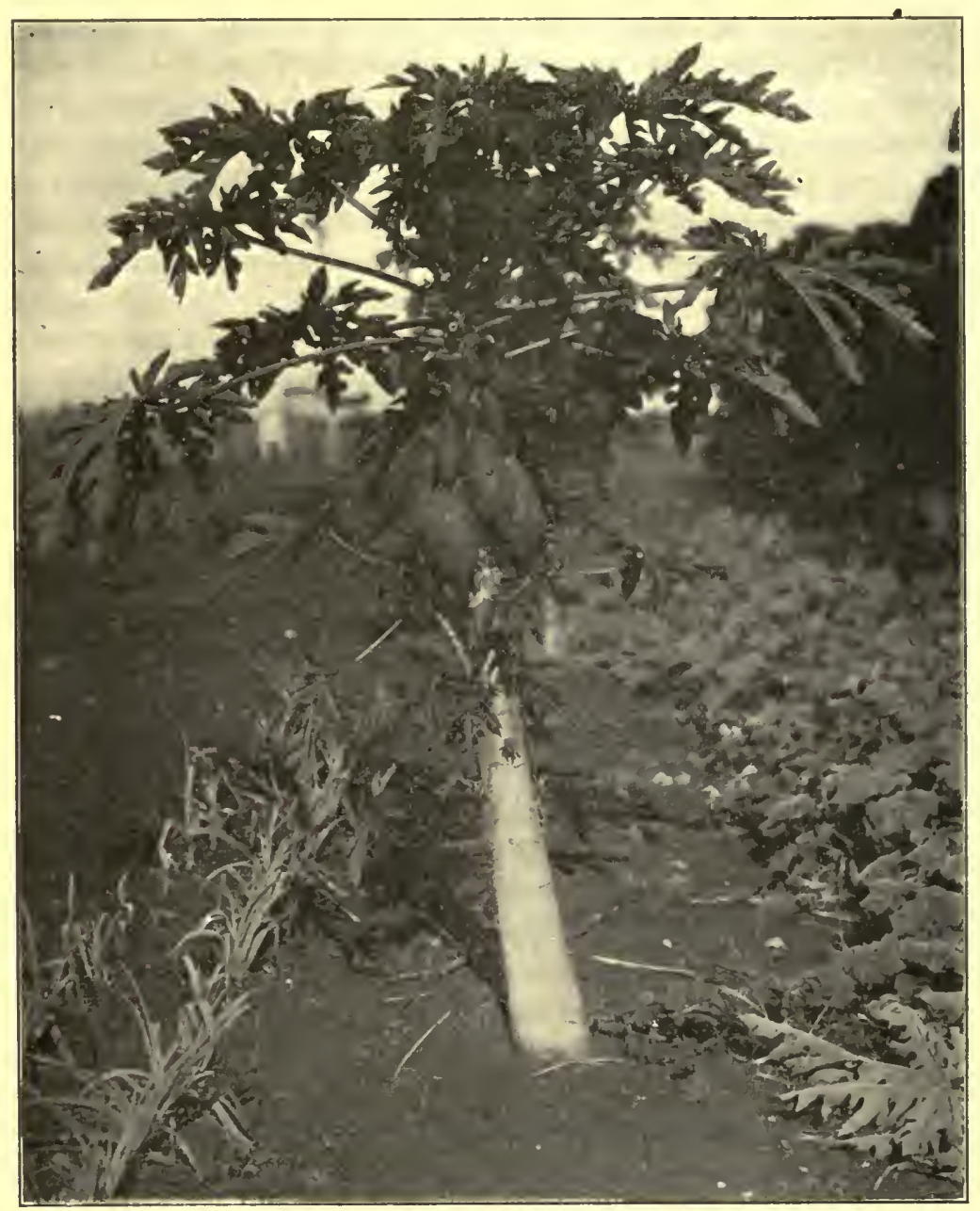

FIG. 197.-Papaw (Carica Papaya): A large shrub growing in Cuba and showing the large long-petiolate, deeply lobed leaves and the clusters of fruits beneath them.-After Alacan.

Constituents.-The alkaloid, carpaine, a cardiac tonic, occurs in the young leaves to the extent of 0.25 per cent; in older leaves it is found to the extent of about 0.1 per cent. It is only found in traces in the fruits, seeds and stems of the plant. The latex of 
the nearly full-grown green fruits and the leaves contain the proteolytic ferment, Papain, which occurs to the extent of 5.3 per cent. In addition to the proteolytic ferment, the latex of the papaw contains 4 other ferments: a coagulating, rennet-like ferment, which acts upon the casein of milk; an amylolytic ferment, having the power to digest starch; a clotting ferment similar to pectase; and a ferment possessing feeble powers of action upon fats.

Literature.-Kilmer, Amer. Jour. Pharm., 1901, p. 272.

\section{CACTACEE, OR CACTUS FAMILY}

A remarkable family of about 100 species of succulent plants, growing largely in the arid regions of Mexico, Brazil and other parts of America. They usually possess thick, fleshy stems, the structure of which is adapted to a desert climate, the foliage leaves being modified to thorns. Mucilage cells and lysigenous canals are common to all of the plants of this family. In addition there are crystal cells and laticiferous canals. Calcium oxalate is excreted in enormous quantities, sometimes being present to the extent of 85 per cent of the ash of the plant. It occurs in the form of large rosette aggregates, raphides, octahedra, and tetragonal and monoclinic prisms. Sometimes they occur as sphæro-crystals and may resemble half-compound starch grains in the arrangement of their needlelike crystals. Occasionally the crystals are contained in idioblasts. In alcoholic material sphæro-aggregates may crystallize out in some of the cells. In Epiphyllum curiously shaped protein bodies are distributed. The guard cells of the stomata are accompanied on both sides by one or more subsidiary cells parallel to the pore. The thorns are variously interpreted, as being either foliar organs, emergencies, i.e., multicellular hairs derived from both the epidermal and hypodermal layers, or transitions between leaf-prickles and trichomeprickles. The tracheæ possess either simple pores or spiral thickenings; the wood fibers usually have simple pores; and the medullary ray cells may become lignified. In addition, tracheid-like parenchymatous cells are found in the wood of Opuntia and other genera.

Cactus Grandiflorus, Herba Cacti Grandiflori, Nightblooming Cereus.-Cactus.- The stems and flowers of Cereus (Cactus) grandiflorus (Fam. Cactaceæ), a perennial, herbaceous or shrub-like plant, having thick succulent stems and producing large, fragrant flowers, which expand at night, lasting but a few hours. The plant is indigenous to Mexico, Central America and the West 
Indies, and is extensively cultivated as a house plant. The fresh stems and flowers only are employed in medicine (Fig. 198).

Description.-Stems cylindrical, 5- to 7-angled, branching; usually in pieces from 10 to $15 \mathrm{~cm}$. in length and from 1 to $3 \mathrm{~cm}$. in thickness; externally of a grass-green color and marked by alternate clusters of 6 to 8 prickly thorns, from 1 to $2 \mathrm{~mm}$. in length; internally bright

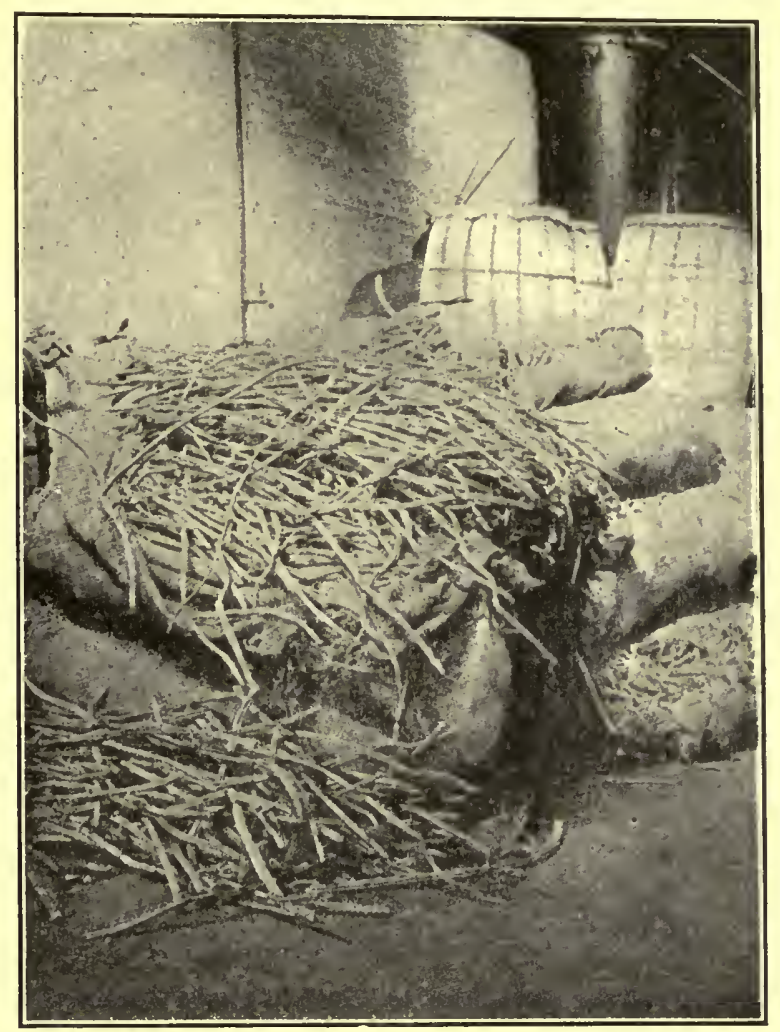

Fig. 198.-Cactus grandiflorus in burlap bags of about $150 \mathrm{lbs}$. Shipped from northern Mexico, in a fresh condition.-After Moser.

green, having a thick cortex with large mucilage cells and a small central woody cylinder. Occasionally producing at the nodes cylindrical, gradually tapering, irregularly curved, light grayish-brown roots from 5 to $20 \mathrm{~cm}$. in length and 1 to $2 \mathrm{~mm}$. in thickness.

The flowers are from 15 to $20 \mathrm{~cm}$. in diameter, subtended by a cylindrical stalk from 12 to $18 \mathrm{~cm}$. in length and about $1 \mathrm{~cm}$. in diameter; the latter consists of an ellipsoidal and nearly solid 
ovary at the basal portion, attaining a length of $4 \mathrm{~cm}$. and surmounted by a long, hollow calyx tube upon which are borne the numerous sepals in spiral series, varying from scale-like to long linear-lanceolate leaves; corolla of 5 spreading, elliptical, delicate petals about $8 \mathrm{~cm}$. in length and $3 \mathrm{~cm}$. in width, summit acute, base somewhat contracted; stamens numerous in 2 series, the one inserted upon the throat of the corolla tube forming a fring and the other in a somewhat ascending series from 5 to $8 \mathrm{~mm}$. inside the tube; style cylindrical, orange-brown, from 15 to $19 \mathrm{~cm}$. in length, about $2 \mathrm{~mm}$. in diameter and surmounted by a 15-rayed stigma, consisting of narrow, thread-like, papillose filaments, being about $2 \mathrm{~cm}$. in length.

InNer Structure.--See Fig. 199.

Constituents.-A glueoside, which is a cardiac stimulant; one or more resinous substances, and possibly also an alkaloid.

Mescal Buttons (Anhalonium) are the dried tops of several species of Lophophora growing in northern Mexico. The main axis of the plant is under the ground and from which arise a number of aerial shoots, which are more or less button-shaped or disk-like, being about 20 to $50 \mathrm{~mm}$. in diameter. In the center of the disk occur tufts of hairs which vary in the different species, and among which are usually found one or more pinkish flowers. The drug has been used like Cactus grandiflorus, and contains several alkaloids, namely, anhalonine (similar to pellotine), mescaline, anhalonidine and lophophorine. Alkaloidal principles are also found in other members of the Cactaceæ.

\section{THYMELEACEA, OR MEZEREON FAMILY}

A family of about 425 shrubs and trees, most abundant in Australia and South Africa, a few of the genera, however, being found in the United States. The plants have simple, deciduous or evergreen leaves; small, mostly perfect flowers; and the fruits are usually berry-like drupes. All of the plants are characterized by having in the cortex numerous groups of bast fibers. An intraxylary phloem, accompanied by bast fibers, occurs in the stem and is also present in the fibrovascular bundles of the petioles and leaves. 'The tracheæ possess simple pores; the wood fibers are marked by bordered pores; and the medullary rays are narrow. Calcium oxalate is secreted in the form of ordinary crystals, styloids, rosette aggregates and microcrystals. The plants do not possess any internal secretory cells or glandular hairs. The non-glandular hairs are usually unicellular. In the leaves there is a mucilaginous metamorphosis of the epidermal 

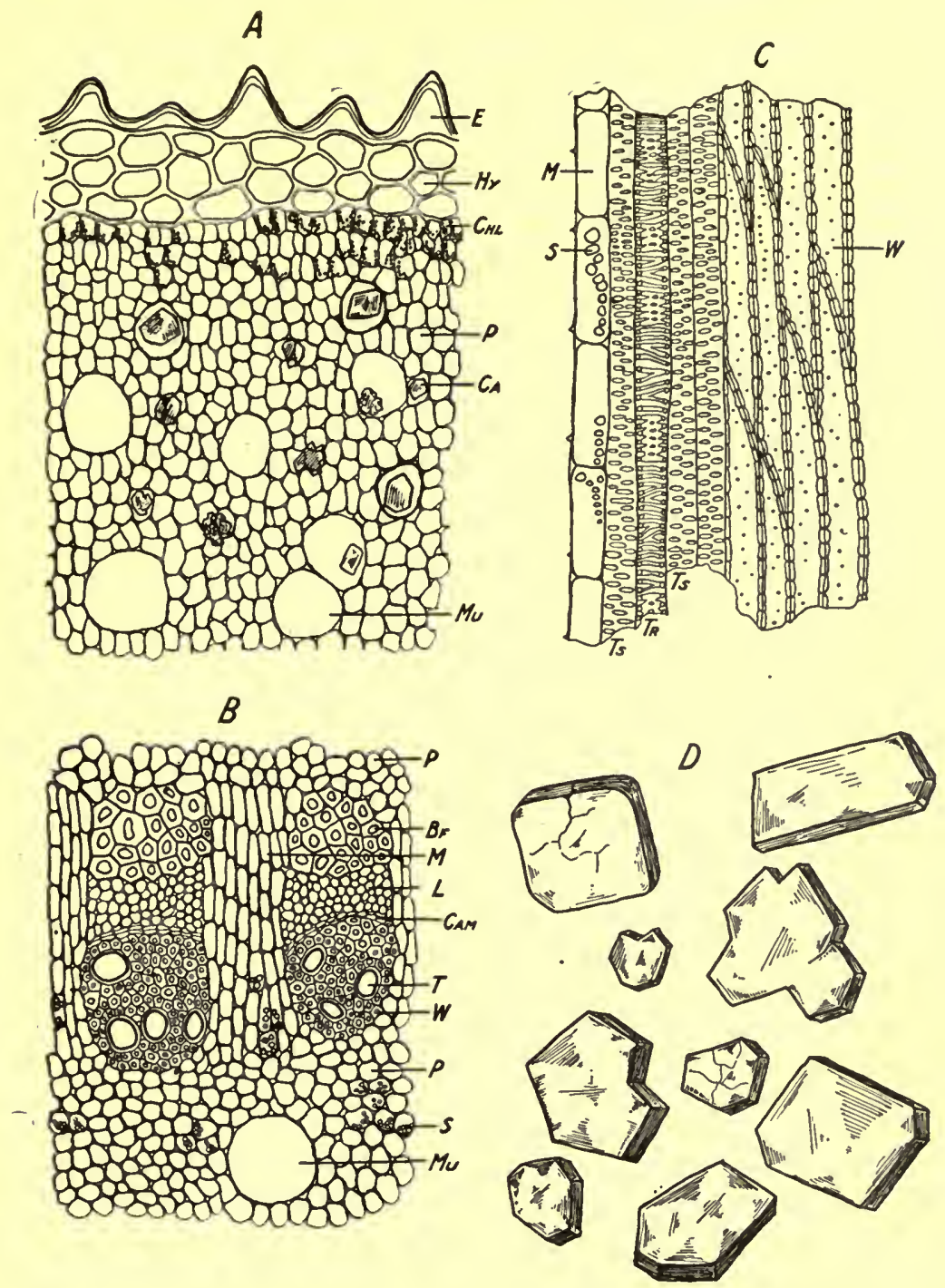

FIG. 199.-Cactus: $A$, transverse section of stem; $E$, papillose epidermis; $H y$, hypodermis; $P$, cortical parenchyma containing chloroplasts $(\mathrm{Chl}) ; \mathrm{Ca}$, solitary crystals of calcium oxalate from 0.015 to $0.400 \mathrm{~mm}$. in length; $M u$, mucilage cells. $B$, transverse section of the fibrovascular bundles: $B f$, bast fibers; $M$, broad medullary rays, the cells containing starch; $L$, leptone; $C a m$, cambium layer; $T$, trachex; $W$, wood fibers; $P$, starch-bearing parenchyma $(S)$, the grains from 0.003 to $0.010 \mathrm{~mm}$. in diameter; $M u$, mucilage cell. $C$, longitudinal section of xylem portion of bundle: $M$, parenchymatous cells containing starch $(S) ; T s$, tracheæ with large simple pores; $T r$, reticulate trachex; $W$, wood fibers. $D$, solitary crystals of calcium oxalate.Drawing by Haase. 
cells, the latter often becoming also papillose. The stomata usually occur only upon the upper or ventral surface of the leaf and are frequently enclosed in receptacles formed by the papillose elevations of the neighboring cells.

Mezereum.-Mezereon Bark.-The dried bark of Daphne Mezereum, D. Gnidium and D. Laureola (Fam. Thymelæaceæ), indigenous to Europe and Asia, and naturalized in New England and Canada. The bark is collected in early spring; it is dried and frequently made up into small bundles, the commercial supplies being obtained from Thuringia, southern France and Algeria.

Description.-In flexible, double quills or somewhat flattened strips, from 10 to $90 \mathrm{~cm}$. in length, 3 to $20 \mathrm{~mm}$. in breadth and from 0.3 to $1 \mathrm{~mm}$. in thickness; outer surface yellowish- or olive-brown (D. Mezereum) or purplish-brown (D. Gnidium) or purplish-gray (D. Laureola), smooth, numerous lenticels, giving a transversely striated appearance and occasionally with numerous circular brownish-black apothecia; inner surface yellowish-white, satiny lustrous, finely striate; fracture tough, fibrous, the inner bark lamellated; outer corky layer easily separable from the middle bark, which varies from light green to olive-brown, inner bark with small groups of whitish bast fibers; odor very slight; taste at first like green bark, becoming gradually pungent in the throat and extending to the rest of the mouth with increasing effect.

Inner Structure.-Periderm consisting of a broad band of cork, the outer cells being compressed and with yellowish-brown walls and the inner more or less tabular with nearly colorless walls; a hypodermis of 3 to 5 rows of collenchymatous cells, containing chloroplastids or a yellowish-green resinous substance; an inner bark consisting mostly of nearly colorless bast fibers occurring in loosely united groups and with thin, non-lignified, colorless walls; medullary rays few, uniseriate, and filled with somewhat spheroidal starch grains, from 0.003 to $0.015 \mathrm{~mm}$. in diameter.

Powder.-Light yellowish- or grayish-brown, sternutatory; bast fibers, numerous from 0.400 to $3 \mathrm{~mm}$. in length and about $0.015 \mathrm{~mm}$. wide, frequently more or less uneven or irregularly bent and considerably attenuated at the ends the walls being from 0.001 to 0.005 $\mathrm{mm}$. in thickness, colorless, non-lignified and free from pores; fragments of yellowish-brown cork cells and cells of medullary rays containing starch; starch grains relatively few, mostly spheroidal or ellipsoidal and varying from 0.003 to $0.015 \mathrm{~mm}$. in diameter, occasionally 2 - to 4 -compound. 
Constituents.-An acrid resin known as mezerein; a crystalline, bitter glucoside daphnin (isomeric with æsculin) occurring in greatest amount in the stem bark during the flowering and fruiting period; volatile and fixed oils; malic acid; several sugars; and starch.

Allied Drugs.-The berry-like fruits of Daphne Mezereum and D. Gnidium are sub-globular, dark brown or brownish-black, about $5 \mathrm{~mm}$. in diameter, each with a black seed. The fruits are acrid and pungent and contain 0.38 per cent of coccogonin, a principle which on sublimation gives off an odor of coumarin; 0.22 per cent of an acrid resin; and 31 per cent of a fixed oil, which absorbs oxygen on exposure to air and is in the nature of a drying oil.

The barks of a number of other plants of this family are used like that of Mezereum, as Daphnopsis Schwartzii of the West Indies, Lasiosiphon eriocephalus of India and Ceylon, and various species of Stellera, Struthiola and Thymelæa.

Lasiosiphon Meíssneríanus (Fam. Thymelæaceæ), a shrub indigenous to South Africa, where the root is stated to be used as a cure for snake-bite. The chief constituent of the root is an amorphous, acrid resin, from which only a phytosterol, $\mathrm{C}_{27} \mathrm{H}_{46} \mathrm{O}$, and $\approx$ mixture of fatty acids could be obtained.-Power, Amer. Jour. Pharm., 1911, p. 49.

\section{PUNICACEE, OF POMEGRANATE FAMILY}

A small family represented by a single genus, Punica, and of which there are two species. By some authors the plants are included with the Lythraceæ with which it has a number of morphological points in common. In the pericycle there are isolated groups of bast fibers, beneath which the cork develops. In the primary cortex occur large stone cells, either single or in small groups. The fibrovascular bundles are bi-collateral; bast fibers are wanting in the cortex; the tracheæ and wood fibers possess simple pores; and calcium oxalate is secreted in the form of rosette aggregates.

Granatum.-Pomegranate Bark.-The dried bark of the root and stem of Punica Granatum (Fam. Punicaceæ), a shrub indigenous to northwestern India, and cultivated in the sub-tropical regions throughout the world. The bark of the root is preferred to that of the stem, and by some the drug obtained from wild plants is also preferred. The bark deteriorates with age and should not be used after it is a year or two old.

STEM BARK.-Usually in transversely curved pieces, occasionally in single quills, 2 to $8 \mathrm{~cm}$. in length, 5 to $20 \mathrm{~mm}$. in diameter, bark 
0.5 to $2 \mathrm{~mm}$. in thickness; outer surface yellowish brown, with grayish patches of foliaceous lichens, brownish-black apothecia and small lenticels, longitudinally wrinkled; inner surface light yellow or yellowish-brown, finely striate, smooth; fracture short, even, phelloderm layer dark green, inner bark light brown, somewhat checkered; odor slight; taste astringent.

RоOT BARK.-Dark brown, with slight longitudinal patches and scales of cork, green phelloderm layer wanting, medullary rays extending nearly to the outer surface.

InNer Structure.-See Fig. 200.

Powder.-Yellowish-brown to dark greenish-brown; calcium oxalate crystals numerous, chiefly in rosette aggregates, also in rhombohedra, from 0.010 to $0.018 \mathrm{~mm}$. in diameter; starch grains numerous, from 0.002 to $0.010 \mathrm{~mm}$. in diameter; spheroidal, ellipsoidal, bi-convex, polyhedral, or irregular, and single or compound; fragments of whitish cork with strongly lignified walls; stone cells mostly single, occasionally in small groups, the individual cells 0.050 to $0.180 \mathrm{~mm}$. in length, the walls being very thick and strongly lamellated; occasional fragments of wood with long slightly lignified wood fibers associated with tracheæ possessing simple pores; tannin cells having an irregular yellowish-brown amcrphous content, producing a deep blue color with solutions of ferric salts; and occasional parenchymatous cells with marked centripetal thickenings; the powder of the root bark is free from chloroplastids; the cork cells are more numerous and the sclerenchymatous cells more irregular in shape.

Constituents.-Four alkaloids to the extent of 1 to 3 per cent in the root bark, but only about half as much in the stem bark. The most important of these alkaloids is pelletierine, the tannate of which is largely used in medicine. Pelletierine (punicine) is a colorless, volatile, liquid alkaloid, which readily absorbs oxygen and becomes dark on exposure to air. Its sulphate is lævo-rotatory. Isopelletierine (isomeric with pelletierine) is optically inactive and forms an amorphous sulphate. Methylpelletierine somewhat resembles pelletierine, but its hydrochloride is dextro-rotatory. Pseudopelletierine (methylgranatonine) occurs in prisms, is optically inactive, and resembles, in its reactions and decomposition products, tropinone. The latter is formed from tropine, a compound which results on the decomposition of most of the solanaceous alkaloids. Granatum also contains 20 to 22 per cent of a mixture of tannins, one of which yields gallic acid and the other ellagic acid. A yellow coloring principle, considerable starch and calcium oxalate are also present in the drug. 


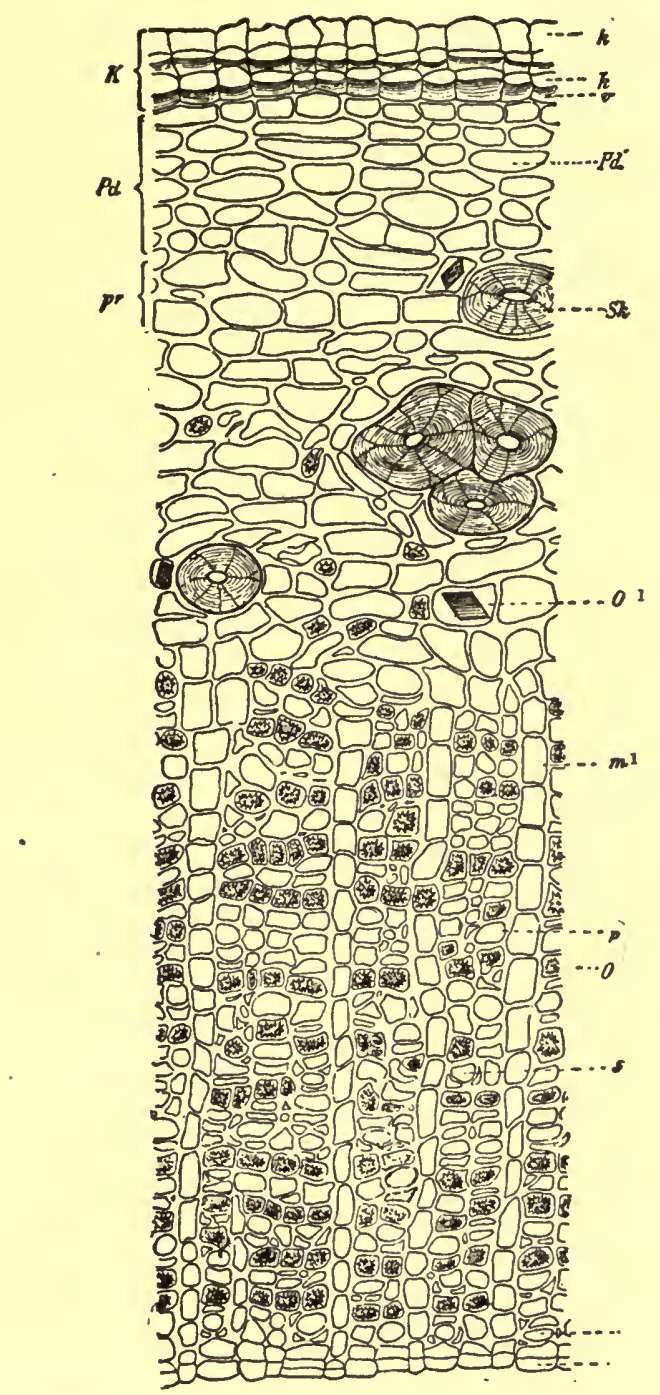

Fig. 200.-Transverse section of granatum: $K$, corky layer composed of thinwalled cork cells $\left(k^{1}\right)$ and thick-walled cork cells $(k)$ only the inner walls $(v)$ of which are thickened; $P d$, phelloderm cells; $p r$, a few parenchyma cells of the primary cortex; $S k$, stone cells with thick, lamellated walls and fine branching pores; $O$, rosette aggregates of calcium oxalate; $O^{1}$, monoclinic prisms of calcium oxalate; $m^{\prime}$, medullary rays; $s$, sieve cells; $s$, sieve cells; $p$, parenchyma cells; $c$, cambium.-After Meyer. 
Allied Drugs. - The rind of the fruit of Punica Granatum, known as pomegranate rind, occurs in irregularly curved yellowish-brown fragments about $2 \mathrm{~mm}$. in thickness. It contains 23.8 to 25 per cent of a tannin which is colored bluish-black with solutions of ferric salts.

\section{MYRTACEE, OR MYRTLE FAMILY}

A family of about 2000 shrubs and trees, chiefly indigenous to Australia and tropical America. The plants yield a large number of economic products and some, as the species of Eucalyptus, are to be classed among the leading timber trees of the world. The leaves are simple, the flowers are perfect, and the fruits are either fleshy and berry-like, or capsular. In certain species of Eucalyptus the leaves are both horizontal and vertical, and exhibit a dimorphic structure, the former being bifacial and the latter centric. In the leaves of Eucalyptus Globulus the cuticle is thick and coated with wax. Schizogenous secretory cavities are characteristic of the plants of this family, and are distributed throughout the parenchyma of the stems and leaves, giving to the latter pellucid-punctate areas. The secretory cavities arise very early in the development of the tissues; and the secretion, which is of an oily nature, develops in a resinogenous layer lining the cavity, the walls of which finally become more or less suberized. Tannin cells are of quite common occurrence in the parenchymatous region of the axis and leaves. Stone cells are sometimes present in the primary cortex. The inner bark usually consists of alternating layers of bast fibers and leptome. The tracheæ usually possess simple pores or scalariform thickenings, except when they are in contact with the wood parenchyma, when the dividing wall is marked by bordered pores. The medullary rays are usually from 1 to 3 cells wide. Calcium oxalate is secreted in the form of rosette aggregates and ordinary solitary crystals. The nonglandular hairs are usually unicellular and glandular hairs are wanting.

Eucalyptus.-The leaves of Eucalyptus Globulus (Fam. Myrtaceæ), a tree (Fig. 201), indigenous to eastern Australia and Tasmania, and cultivated in southern Europe, California and the southern United States. The leaves are collected from older portions of the tree and dried, the principal part of the commercial supply coming from the southern part of France.

Description.-Bilateral, lanceolate, scythe-shaped, 15 to $30 \mathrm{~cm}$. in length, 2.5 to $5 \mathrm{~cm}$. in breadth; summit acuminate; base somewhat unequal, acute; margin entire, revolute; surface light green, glabrous, with numerous small circular, reddish-brown depressions 
or projections in the neighborhood of the stomata and veins, consisting of cork cells ${ }^{1}$; midrib usually with a small groove on one side; veins of the first order diverging at an angle of about $55^{\circ}$, running to within $1 \mathrm{~mm}$. of the edge, where they anastomose, forming a vein parallel with the margin; petiole 2 to $3 \mathrm{~cm}$. in length, flattened and somewhat twisted; glandular-punctate; texture coriaceous; odor slightly aromatic; taste aromatic, somewhat bitter and cooling.

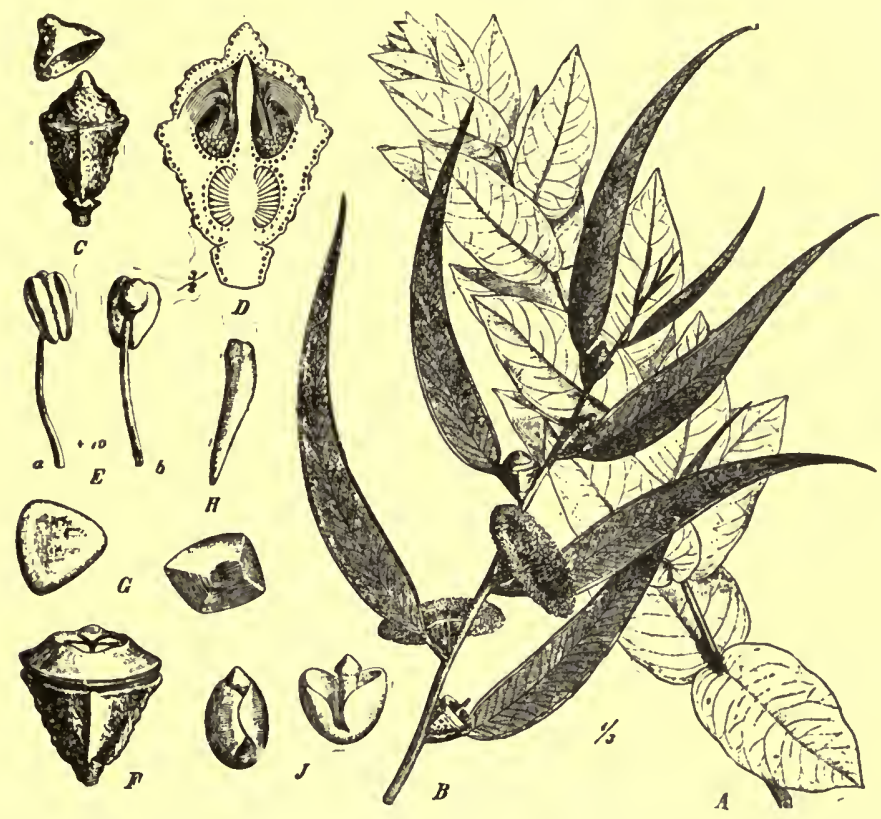

FIG. 201.-Eucalyptus Globulus; $A$, young branch with opposite, oblong, dorsiventral, sessile leaves. $B$, flowering branch with scythe-shaped, petiolate, scattered, bilateral leaves. $C$, flower-bud showing the detached upper portion of the perianth (operculum or lid) which covers the stamens until they are fully mature. $D$, longitudinal section of a flower-bud showing incurved filaments which curve outwards when the flower matures. $E$, stamens in two views. $F$, truncated capsule or pyxis. $G$, two fertile seeds. $H$, sterile seed, seeds of this kind usually being most numerous. $J$, two germinating plants. $-A$ and $F$, after Niedenzu; $G$ and $J$, after Müller.

Inner Structure.-The cells of the ventral surface have a thick cuticle, covered with wax; the mesophyll consists mostly of a number of layers of palisade cells among which are distributed large, spher-

1 These corky patches are due to the concentration of the salts in the leaves, some of the constituents setting up an irritation with subsequent changes in the tissues. 
oidal oil-secretion cavities with a yellow or orange oily content; near the middle of the leaf is a small layer of loose mesophyll in which are secreted crystals of calcium oxalate in the form of rosette aggregates or rhombohedra, from 0.015 to $0.25 \mathrm{~mm}$. in diameter; the epidermal cells on the dorsal surface resemble those on the ventral surface, but the stomata are more numerous; the fibrovascular bundles of the petiole and midrib have a more or less interrupted circle of slightly lignified bast fibers.

Powder.-Light green; calcium oxalate in rosette aggregates or monoclinic prisms, from 0.015 to $0.025 \mathrm{~mm}$. in diameter; fragments showing large yellowish- or orange-colored oil secretion cavities and numerous palisade layers; outer walls of epidermal cells about $0.020 \mathrm{~mm}$. in thickness. In leaves from younger parts of the tree, the outer walls of the epidermal cells from 0.005 to $0.008 \mathrm{~mm}$. in thickness, the palisade tissue is developed beneath the ventral surface only, while the stomata are present only on the dorsal epidermal layer.

Constituents.-Volatile oil 3 to 6 per cent, of which over 60 per cent is eucalyptol (cineol), the remainder consisting of d-pinene (eucalypten) and other terpenes; several resins, one of which is crystalline and colored brownish-red with ferric chloride; a neutral bitter principle; eucalyptic acid; tannic acid and calcium oxalate.

Allied Plants.-The following Eucalpyts yield an oil consisting principally of eucalyptol and pinene, and in which the eucalyptol exceeds 40 per cent, phellandrene being absent: Eucalyptus resinifera, E. polyanthema, E. Behriana, E. Rossii, E. pendula, E. dealbata, E. tereticornis linearis, E. rostrata borealis, E. maculosa, E. camphora, E. punctata, E. squamosa, E. Bridgesiana, E. goniocalyx, E. bicolor, E. viminalis, E. populifolia, E. longifolia, E. Maideni, E. Globulus, E. pulverulenta, E. cinerea, E. Stuartiana, E. Stuartiana var. cordata, E. Morrisii, E. Smithii and E. sideroxylon.

Literature.-Baker and Smith, A Research on the Eucalypts; McClatchie, the Eucalypts Cultivated in the United States, Bull. No. 35, Bureau of Forestry of the U. S. Department of Agriculture; Kraemer, Amer. Jour. Pharm., 1904, p. 177.

Eucalyptus Kino.-Australian Kino, Red Gum or Eucalyptus Gum.-The inspissated juice of Eucalyptus rostrata and other species of Eucalyptus. It occurs in masses or small fragments, which are of a ruby or garnet-red color (not reddish-black), somewhat dusty, but not so brittle as Malabar kino. It contains 40 to 50 per cent of tannic acid; kino red, and catechin. About 80 to 90 per cent is soluble in cold water, the solution having a neutral reaction. Austral- 
ian kino seems to be more unstable than Malabar kino and is converted into insoluble kino red, particularly if not thoroughly dried.

Eucalyptus kino is also obtained from the following species: Iron-bark tree (E. Leucoxylon), E. Gunnii, E. obliqua, E. piperata, E. falcifolia, E. stellulata, E. macrorhyncha, E. amygdalina radiata. Several species of Angophora yield a kino which is wholly soluble in alcohol and is entirely free from gum. So-called Botany Bay (Australian) kino was at one time supposed to be obtained from Eucalyptus resinifera.

Caryophyllus.-Cloves.-The flower-buds of Jambosa Caryophyllus (Syn. Eugenia Caryophyllata and E. aromatica) (Fam. Myrtaceæ), an evergreen tree, indigenous to the Molucca Islands, where it is also cultivated, as well as in Zanzibar, Ceylon and Java. The flower-buds are collected, dried in the sun or artificially, the color changing from a crimson to a brownish. The chief commercial supplies come from Amboyna, Penang and Zanzibar, the former two varieties being preferred.

Description.-About $15 \mathrm{~mm}$. in length, 3 to $6 \mathrm{~mm}$. in diameter, more or less cylindrical, dark brown, calyx epigynous with four incurved teeth about $3 \mathrm{~mm}$. in length, surmounted by a light-brown globular portion consisting of four, imbricated, glandular-punctate petals, which alternate with the calyx teeth; stamens numerous, crowded and incurved, style one, ovary.2-locular, with numerous ovules; odor and taste strongly aromatic.

Powder.-(Fig. 202.) Light brown to reddish-brown; pollen grains, from 0.015 to $0.020 \mathrm{~mm}$. in diameter, tetrahedral, somewhat spheroidal, with three pores; calcium oxalate crystals in rosette aggregates from 0.010 to $0.015 \mathrm{~mm}$. in diameter, occasionally in crystal fibers; sclerenchymatous fibers spindle-shaped, thick-walled, strongly lignified and with simple oblique pores; tracheæ spiral, thick-walled; oil secretory cavities and oil globules numerous. The powder of CLOVE STEMS is less aromatic and contains numerous yellow, nearly isodiametric and irregular, thick-walled stone cells, having numerous pores; and also scalariform and reticulate tracheæ. The powder of the fruit of cloves, or so-called MOTHER oF cLOves, contains numerous single, ellipsoidal and irregular polygonal starch grains, having an excentral point of origin of growth, and varying in length from 0.010 to $0.035 \mathrm{~mm}$. The pericarp of the fruit also contains numerous irregular stone cells and sclerenchymatous fibers, the latter being oblong and attaining a length of $5 \mathrm{~mm}$., the walls being very irregular in outline. 
Constituents.-The chief constituent is the volatile oil, which occurs to the extent of 15 to 20 per cent, and consists of caryophyllene and eugenol, the latter constituting 50 to 85 per cent of the oil. The darkening of old oil of cloves is supposed to be due to furfurol, an aldehyde formed on decomposition of some of the carbohydrates and albuminoids. Cloves also contain an odorless, tasteless principle caryophyllin, which crystallizes in silky needles and yields upon the addition of fuming nitric acid crystals of caryophyllinic acid; vanillin;

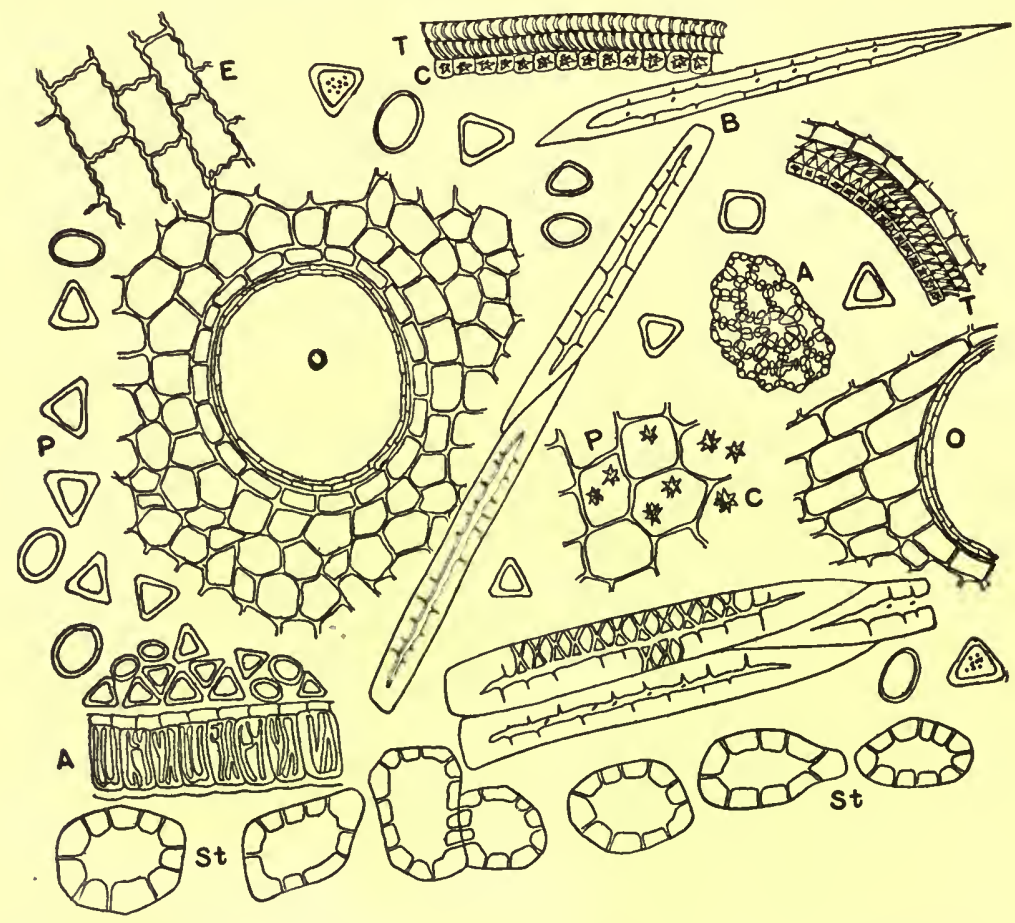

FIG. 202.-Powdered Cloves: $B$, bast fibers; $A$, cells of anther showing the characteristic markings or thickenings of the walls; $P$, pollen grains which appear triangular in outline when mounted in water; $O$, oil secretory cavities, the large one to the left being from a petal; $E$, surface view of epidermal cells of petal; $P$, parenchyma; $C$, calcium oxalate; $T$, tracheæ; $S t$, a number of stone cells from the young branches or twigs, the so-called "clove stems."

eugenin (isomeric with eugenol or eugenic acid), which resembles caryophyllin but becomes reddish with nitric acid; gallôtannic acid 10 to 13 per cent; calcium oxalate, and 5 to 7 per cent of ash.

Cloves are the dried flower buds of Caryophyllus aromaticus L. They contain not more than 5 per cent of clove stems, not less than 
15 per cent of volatile ether extract, not less than 12 per cent of quercitannic acid (calculated from the total oxygen absorbed by the aqueous extract), not more than 10 per cent of crude fiber, not more than 7 per cent of total ash, nor more than $\frac{5}{10}$ per cent of ash insoluble in hydrochloric acid. (U. S. Dept. Agric.)

Adulterants.-Clove stalks are less aromatic and yield from 4 to 7 per cent of volatile oil. The so-called mother of cloves is the nearly ripe fruit of Jambosa (Caryophyllus or clove tree, which furnishes cloves. The fruit is an ovoid, brownish berry about $25 \mathrm{~mm}$. in length; it is less aromatic than cloves and contains large, branching stone cells, or short bast fibers, and numerous pear-shaped or truncated starch grains from 0.010 to $0.040 \mathrm{~mm}$. in diameter. It is stated that artificial cloves have been made by using starch, gum and oil of cloves; or from dough and clove powder. These are easily distinguished by adding the spurious article to water, when the compound disintegrates.

Pimenta.-Allspice.-The fruit of Pimenta officinalis (Fam. Myrtaceæ), a tree indigenous to the West Indies, Mexico, Central America and Venezuela, where it is also cultivated, especially in Jamaica. The panicles are collected when the fruit is full grown but still green, and dried in the sun, the fruit being subsequently separated.

Description.-Drupe dry, inferior, sub-globular, 5 to $7 \mathrm{~mm}$. in diameter; externally dark brown, glandular-punctate; summit with four minute calyx teeth or forming a minute ring and surrounding the remnants of the somewhat depressed style; base with scar or pedicel or occasionally with a pedicel 4 to $6 \mathrm{~mm}$. in length; pericarp about $1 \mathrm{~mm}$. in thickness; internally light brown, 2-locular, 2-seeded, dissepiments thin; seeds campylotropous, plano-convex, slightly reniform, about $4 \mathrm{~mm}$. in length and about $3 \mathrm{~mm}$. in thickness, externally reddish-brown, smooth, somewhat wrinkled, shiny, internally dark brown, reserve layer wanting, embryo spirally curved, with a long, thick radicle and minute cotyledons; odor and taste aromatic, supposed to resemble those of a mixture of cloves and other spices, whence the name "Allspice."

InNer Structure.-See Fig. 203.

Powder.-Dark brown; rosette aggregates of calcium oxalate, occasionally in monoclinic prisms, from 0.010 to $0.020 \mathrm{~mm}$. in diameter; starch grains single or 2- to 3-compound, the individual grains somewhat spheroidal, from 0.003 to $0.015 \mathrm{~mm}$. in diameter, each with a distinct cleft at the middle; stone cells nearly isodiametric, thin-walled, with numerous simple pores and branched canals and 
nearly colorless contents; oil-secretion cavities with wine-colored contents; oil globules numerous; parenchymatous cells occasionally lignified, and with irregular reddish-brown tannin masses, which are colored greenish with ammonio-ferric sulphate solution; non-glan-

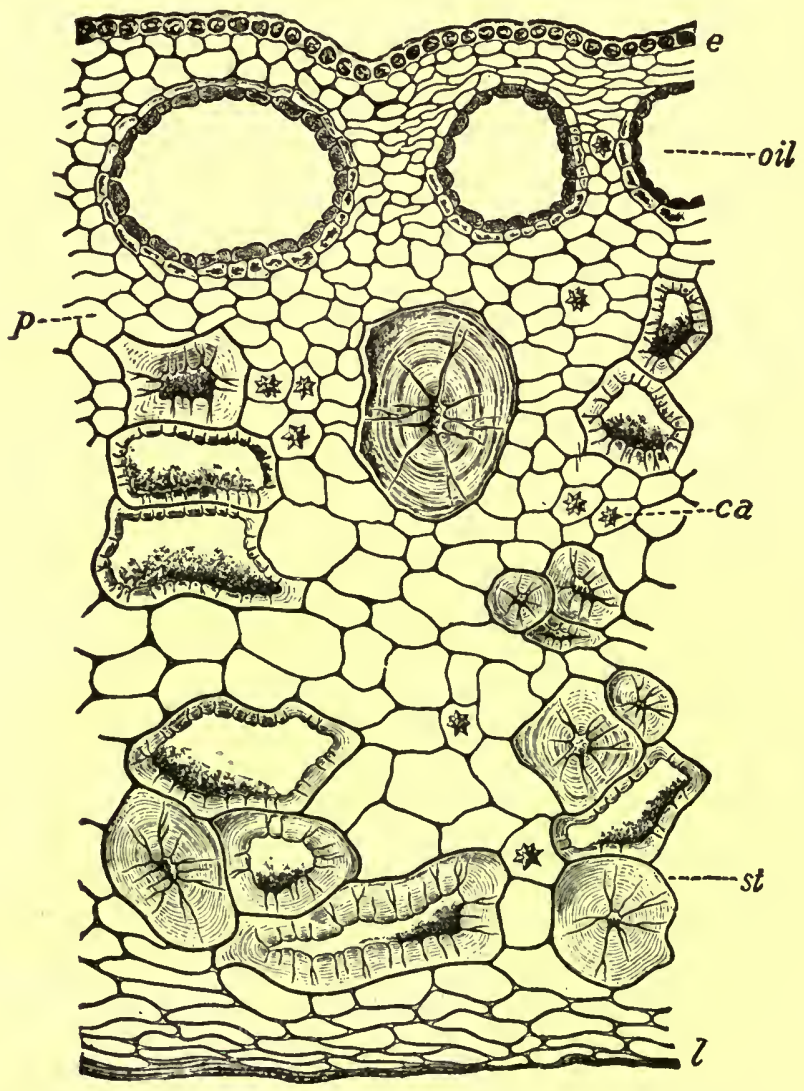

FIG. 203.-Pimenta: Outer wall of pericarp showing epidermal cells of epicarp (e); cells of mesocarp consisting of oil-secretory cavities (oil), stone cells (st) and parenchyma $(p)$ containing rosette aggregates of calcium oxalate $(c a)$; endocarp consisting of stone cells beneath which is a layer of more or less collapsed cells $(l)$.--After Moeller.

dular hairs from 0.100 to $0.200 \mathrm{~mm}$. in length, with very thick walls and narrow lumina, particularly towards the summit.

Allspice stems, which are always present to a greater or less extent in ground Pimenta, have rather characteristic unicellular hairs that are somewhat swollen on one side. 
Constituents.-Volatile oil ( 3 to 4 per cent) consisting of about 60 per cent of eugenol; resin; an acrid fixed oil about 6 per cent; tannic acid; starch; calcium oxalate; ash about 4 per cent.

Standard of Purity.-Allspice, pimento, is the dried, nearly ripe fruit of Pimenta officinalis (L.) Karst. It contains not less than 8 per cent of quercitannic acid (calculated from the total oxygen absorbed by the aqueous extract), not more than 25 per cent of crude fiber, not more than 6 per cent of total ash, nor more than $\frac{4}{10}$ per cent of ash insoluble in hydrochloric acid. (U. S. Dept. of Agric.)

Allied Plants.-A variety of $P$. officinalis yields a fruit with large drupes known as Tobasco or Mexican Allspice. The structure of this fruit resembles that of pimenta, as also does the Crown Allspice obtained from P. acris, a tree of tropical America, the fruits of which are 8 to $10 \mathrm{~mm}$. in length.

West Indian bay oil is distilled from the leaves of Pimenta acris, Kostel, and is used in the preparation of bay rum. The leaves of two varieties of $\mathrm{P}$. acris, known locally as "Bois d'Inde Citronelle" and "Bois d'Inde Anise," are frequently admixed with the leaves of the true bay to the great detriment of the oil subsequently distilled. The oil from the "Citronella " variety (P. acris var. citrifolia) contains citral and has the flavor of lemon. Why the oil from the "Anise" variety does not reach the desired standard is not yet clear. The varietal forms intermingle in extensive wild growths near the coasts of many of the West Indian islands and the leaves are gathered indiscriminately. Much harm has already resulted to the bay oil industry and it is a matter of great concern to the distillers that either some method be determined for distinguishing the undesirable leaves or that plantations of the true P. acris be established.

Adulterants.-Ground allspice has been adulterated with clove stems (Fig. 202), cocoa shells, and the endocarp of the olive.

The various spices have been adulterated with the following substances: The hulls of Sinapis alba (Figs. 127 and 128); walnut shells (Juglans regia, Fig. 70) which are distinguished by their colorless stone cells and brown parenchyma; and shells of the Brazil nut (Bertholletia excelsa, Fam. Myrtaceæ) which are identified by the isodiametric stone cells with colorless walls and dark-brown contents, and the brown parenchyma.

\section{COMBRETACEE, OR MYROBALANS FAMILY}

Mostly tropical trees and shrubs, comprising about 175 species. Like the Fagaceæ the plants of this family contain a tannin similar 
to gallotannic acid distributed throughout the parenchyma. Small groups of bast fibers are occasionally found in the pericycle. The fibrovascular bundles are bi-collateral, frequently having an intraxylary development of leptome. The tracheæ have simple pores, except when' in contact with the wood parenchyma, when bordered pores are developed. The wood fibers possess bordered pores and the medullary rays are narrow. Calcium oxalate is usually secreted in the form of rosette aggregates giving rise to translucent dots in the leaves. In the stems the calcium oxalate is in the form of crystal fibers accompanying the bast fibers. The non-glandular hairs are unicellular or consist of two horizontally placed cells connected at their bases. The glandular hairs possess either long or short stalks.

Combretum. - Jungle Plant.-The leaves of Combretum sundaicum (Fam. Combretaceæ), a woody climber, indigenous to Sumatra and used to some extent in the treatment of the opium habit, thereby receiving the name of "anti-opium plant."

Description.-More or less crumpled and mixed with rather large stem portions; leaves broadly elliptical or ovate, short petiolate, from 8 to $15 \mathrm{~cm}$. in length and 5 to $7 \mathrm{~cm}$. in breadth, summit acute, or acuminate, base rounded, margin entire or slightly wavy, upper surface light to dark greenish-brown, lower surface somewhat lighter in color, reticulate and marked by a distinct midrib and veins of the first order, the latter diverging at an angle of about $50^{\circ}$ and uniting with each other along the margin, coriaceous; petiole from 7 to $15 \mathrm{~mm}$. in length, having a shallow groove on the ventral surface; odor slight; taste slightly bitter and acrid.

Stems from 6 to $15 \mathrm{~cm}$. in length and from 3 to $15 \mathrm{~mm}$. in diameter, light brown or light reddish-brown, longitudinally striate, waxy, sometimes with long, grayish patches of cork, branches opposite; fracture short, fibrous, internally bark thin, light brown, wood large, porous and a small pith.

Inner Structure.-Epidermal layer of upper surface of rectangular or tabular cells, having very thick, colorless walls and each usually containing a large nucleus; palisade layer of two or three rows of rather short, narrow cells; loose mesophyll of 8 to 12 rows of thickwalled cells having large intercellular spaces and among which are distributed the fibrovascular bundles and cells containing calcium oxalate; epidermal cells of dorsal surface resembling those of the ventral surface; fibrovascular bundle of the veins, hemispherical in shape, consisting of a large crescent-shaped xylem, having in the sinus as well as at the periphery the strands of leptome and surrounded by a nearly continuous ring of narrow stereome or scleren- 
chymatous fibers; tracheæ with wide lumina, the walls marked by simple and occasionally bordered pores; sclerenchymatous fibers with thick, finely lamellated walls, being in some portions strongly lignified and often accompanied by crystal fibers, having octahedra of calcium oxalate from 0.010 to $0.020 \mathrm{~mm}$. in length; calcium oxalate also oceurs in large spheroidal cells of the mesophyll, producing transparent dots in the leaves, the crystals varying from 0.015 to 0.040 $\mathrm{mm}$. in diameter; stomata broadly elliptical and having the two neighboring cells parallel to the pore.

In the stem there is developed an outer layer of thin-walled epidermal cells; a strata of six or eight rows of thin-walled cells having a reddish-brown content; primary cortex of six to ten rows of tangentially elongated narrow cells filled with a brownish-black granular content, containing tannin; inner cortex composed of three or more thick, continuous rings of bast fibers, separated by uniseriate medullary rays, the cells having a blackish-brown tannincontent resembling that in the parenchyma cells of the primary cortex; bast fibers with very thick, lignified walls and possessing very small lumina; leptome in narrow, tangential strands separating the bast fibers; wood wedges having a few large tracheæ with very wide lumina, and numerous thick-walled wood fibers, separated by uniseriate medullary rays having very small and narrow cells.

Constituents.-Combretum has not been very carefully investigated. It contains a small quantity of resin and tannic acid and apparently does not contain either an alkaloid or a glucoside. At one time it was thought that it might contain caffeine and to this were ascribed its properties, but this has not been confirmed.

Uses.-The twigs and leaves are cut into pieces about 1 inch in length, the twigs separated from the leaves. The leaves are then roasted, mixed again with the twigs and a decoction made by boiling about 8 or 10 ounces of the mixture in 4 gallons of water, for several hours. The decoction is then strained and used before decomposition takes place. The opium habitue begins by mixing his ordinary dose of opium with 1 quart of the decoction. Three ounces of the mixture is taken at the same intervals to which he was accustomed to smoke the opium. The quantity of opium is gradually reduced and finally he uses only the decoction of Combretum. It is stated that almost any inert substitute can be used with equal beneficial results.

Literature.-Holmes, Pharm. Jour. (78), p. 77; Stanislaus and Wood, Jour. A. Ph. A., 1912, p. 34. 


\section{ARALIACEAE, OR GINSENG FAMILY}

A family consisting of about 450 species of plants which are widely distributed. They are perennial herbs, shrubs or trees. The leaves are mostly palmately lobed or compound; the flowers are small, perfect or polygamous, frequently occurring in umbels; the fruit is either a berry or a drupe. The plants are especially characterized by the presence of schizogenous secretion canals in the parenchymatous tissues of pith and cortex and in the veins of the leaves. They contain a volatile oil, resin, gum and occasionally a milky content. Schizogenous secretion cavities also are sometimes present giving a pellucid-punctate character to the leaves. In the root, resin canals are generally situated opposite the strands of primary xylem and phloem and in consequence there is an exceptional displacement of the young lateral branches. The tracheæ are marked by simple pores or scalariform thickenings, except when in contact with the parenchyma, when bordered pores are developed. The wood fibers usually possess simple pores. In a number of species of Aralia collateral medullary vascular bundles are developed, which are inversely orientated, i.e., the phloem being directed toward the center of the pith and the xylem being developed in the direction of the cortex. Weiss has shown that these bundles in Aralia racemosa appear first as normal bundles in the peripheral ring and only enter the pith later, at the same time undergoing a rotation through $180^{\circ}$. Calcium oxalate is usually secreted in the form of rosette aggregates, being only occasionally present in the form of solitary crystals. In the leaves there is usually a development of a hypodermal layer. The leaves are usually glabrous, but in the floral parts both glandular and non-glandular hairs of several different forms occur.

Aralia Racemosa.-American Spikenard, or Indian Root.The rhizome and roots of Aralia racemosa (Fam. Araliaceæ), a perennial herb growing in rich woodlands of the eastern United States and Canada. The plant grows to a height of 1 or $2 \mathrm{M}$., possesses a thick, fleshy rhizome; large, ternately-compound leaves; and numerous umbels of small, greenish flowers, which are arranged in large compound panicles. The fruits are small bright reddish, or reddish-purple drupes and give the plant a very handsome and striking appearance. The rhizomes are gathered in the fall, sometimes cut longitudinally to facilitate drying, and should be carefully dried and preserved. 
Description.-Rhizome oblique, sub-cylindrical, somewhat flattened and more or less branched and tortuous; from 5 to $15 \mathrm{~cm}$. in length and 3 to $7 \mathrm{~cm}$. in thickness; externally light brown, distinctly annulate, having on the upper surface numerous stem-scars from 2 to 3 $\mathrm{cm}$. in width, the older scars being deeply concave, and on the lower and lateral portions numerous, somewhat fleshy roots; the latter being terete, from 4 to $7 \mathrm{~cm}$. in length, from 0.5 to $2.5 \mathrm{~cm}$. in thickness, having a light- or purplish-brown color, marked by longitudinal furrows and occasional transverse ridges and scaly cork; fracture of cortex short and of the wood short-fibrous; inner surface whitish, spongy, bark thick with numerous oil secretion canals, wood distinctly radiate; odor aromatic; taste pungent and slightly acrid.

Powder.-Light brown; starch grains numerous, single or 2to 4-compound, the individual grains spheroidal or somewhat polyhedral, from 0.003 to $0.020 \mathrm{~mm}$. in diameter; calcium oxalate in rosette aggregates from 0.025 to $0.075 \mathrm{~mm}$. in diameter; tracheæ with simple pores or scalariform thickenings, occasionally bordered pores; sclerenchymatous fibers of pericycle with thick, strongly lignified, porous walls.

Aralia Nudicaulis.-American Wild or Virginian Sarsaparilla. - The rhizome of Aralia nudicaulis (Fam. Araliaceæ), a nearly prostrate perennial herb, producing a very long rootstock, a solitary pinately 3 - to 5 -foliate leaf and a naked scape with 2 to 7 umbels of green flowers. The plant is common in moist woodlands of the eastern United States and Canada.

Description.-The rhizome attains a length of many meters and is from 5 to $15 \mathrm{~mm}$. in thickness; externally grayish-brown, longitudinally wrinkled and somewhat annulate; fracture short; internally bark light brown, with numerous large oil secretion canals, wood yellowish, distinctly radiate, pith spongy, whitish; odor and taste aromatic.

InNer Structure.-See Fig. 204.

Powder.--Light brown; rosette aggregates or calcium oxalate from 0.035 to $0.070 \mathrm{~mm}$. in diameter; starch grains numerous, spheroidal, from 0.005 to $0.020 \mathrm{~mm}$. in diameter; tracheæ with scalariform thickenings, also simple and bordered pores; wood fibers long, with slightly thickened walls and simple pores; large oil secretion canals, and brown cork cells.

Constituents.-The rhizome contains about 0.33 per cent of a volatile oil, which is bitter and pungent; 3 per cent of resin; tannin, starch and rosette aggregates of calcium oxalate.

Literature.-Alpers and Murray, Proc. A. Ph. A., 1897, p. 183. 
Aralia Spinosa.-Prickly Elder, Angelica Tree, Hercules Club. - The bark of Aralia spinosa (Fam. Araliaceæ), a shrub or tree growing on banks of streams of the eastern United States. The bark is usually employed, although other parts of the plant possess medicinal properties.

Description.-In quills, or transversely curved pieces from 3 to 20 $\mathrm{cm}$. in length and 0.5 to $2 \mathrm{~cm}$. in width and bark 1 to $3 \mathrm{~mm}$. in thickness; externally grayish-brown, nearly smooth, irregularly wrinkled and having numerous lenticels; inner surface light yellowish-brown, finely reticulate and somewhat crystalline and usually with numerous bright, shining crystals; fracture short-fibrous; inner surface of

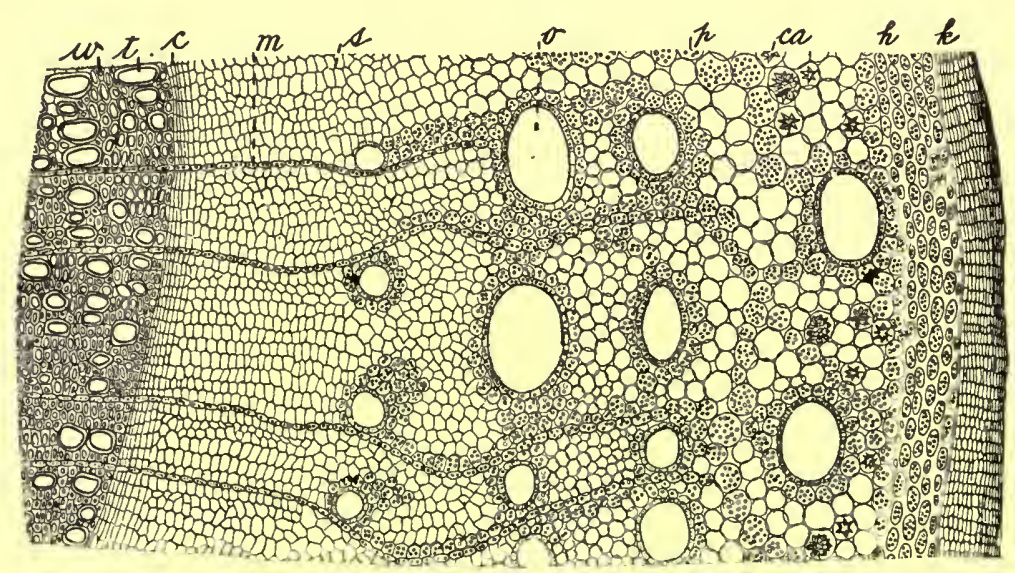

FIg. 204.-Aralia nudicaulis: Transverse section of rhizome showing cork $(k)$, hypodermis $(h)$, rosette aggregates $(c a)$ of calcium oxalate, parenchyma $(p)$ containing angular starch grains, oil secretion canals $(o)$, sieve $(s)$, medullary rays $(m)$, cambium $(c)$, tracheæ $(t)$, wood fibers $(w)$.

thin, easily separable dark brown cork and yellowish-white cortex; odor aromatic, taste bitter and acrid.

Constituents.-Volatile oil having a greenish-yellow color; an acrid resin, soluble in alcohol and insoluble in ether; a saponin (araliin); a tasteless resin; a crystalline substance and chlorophyll. 'The drug does not contain either tannic acid or an alkaloid.

Literature.-Lilly, Amer. Jour. Pharm., 1882, p. 433.

Ginsenc.-Radix Ginseng, Schinsent.-The roots, of Panax quinquefolium and P. Ginseng (Fam. Araliaceæ), perennial herbs, the former growing in rich woods in the eastern United States, and Canada, and the latter indigenous to the mountainous forests of eastern Asia and cultivated in northern China, Korea and Japan. 
The roots are gathered from 3- to 4-year-old plants, carefully cleaned and dried. The drug is extensively used in China and it has been estimated that about $40,000 \mathrm{~K}$. of ginseng are exported annually. The supplies are not only obtained from wild plants, but also from cultivated plants. The roots which are seen in the Chinese bazaars are yellowish-brown, very horny and somewhat translucent, indicating that they have been subjected to some special treatment. While the method is not generally known similar specimens may be prepared by boiling, for a short time, the recently gathered roots with freshly slaked lime. For illustrations of American-grown ginseng and Chinese root, consult Kraemer's Applied and Economic Botany, p. 105.

Description.-Cylindrical, usually fusiform, from 5 to $12 \mathrm{~cm}$. in length, and 1 to $2.5 \mathrm{~cm}$. in thickness; externally light yellowishbrown, distinctly annulate in the upper portion, and terminated at the crown by one or more stem scars, lower portion very much wrinkled, occasionally branching, and marked by a number of root scars; fracture short; internally light yellowish-brown, marked by a distinct dark brown cambium zone, a distinctly radiate wood and numerous oil secretion canals, which in older roots have a brownish-red resinous content; odor slightly aromatic; taste sweetish, mucilaginous and slightly bitter.

Constituents. - The active principle appears to be a glucosidal substance, panaquilon. It also contains a saponin; a bitter principle; a volatile oil containing a camphoraceous-like substance; resin; panacin; sugar; mucilage; and starch.

Allied Plants.-Chinese ginseng is yellowish-brown, translucent, and has a bitter, followed by a sweet and mucilaginous taste. Japanese ginseng is spindle-shaped, light yellow, hard and woody. The Korean ginseng is usually much branched, yellowish-brown or light brown, the roots being still attached.

Panax Repens.-The rhizome of Panax repens (Fam. Araliaceæ), a plant growing in Japan, is considered to have properties similar to those of ginseng.

Description.-Rhizome horizontal, nearly cylindrical, more or less curved, from 5 to $10 \mathrm{~cm}$. in length and 3 to $6 \mathrm{~mm}$. in thickness; externally yellowish-white, nodes considerably thickened and marked on the upper surface by circular stem scars; fracture horny; internally whitish, marked by small yellowish oil-secretion canals in the cortex, narrow wedges of collateral fibrovascular bundles separated by broad medullary rays, pith large.

Inner Structure.-(Fig. 205.) The cork consists of four to six rows of tabular. cells; a layer of cells nearly free from starch, the 
walls having large pores and reticulate thickenings; the parenchyma of the cortex contains considerable starch and calcium oxalate in the form of rosette aggregates; in among the. parenchyma cells occur large schizogenous oil canals, containing a yellowish oil, and are usually surrounded with eight secretion cells; the tracheæ or vessels show either simple or bordered pores and reticulate thicken-
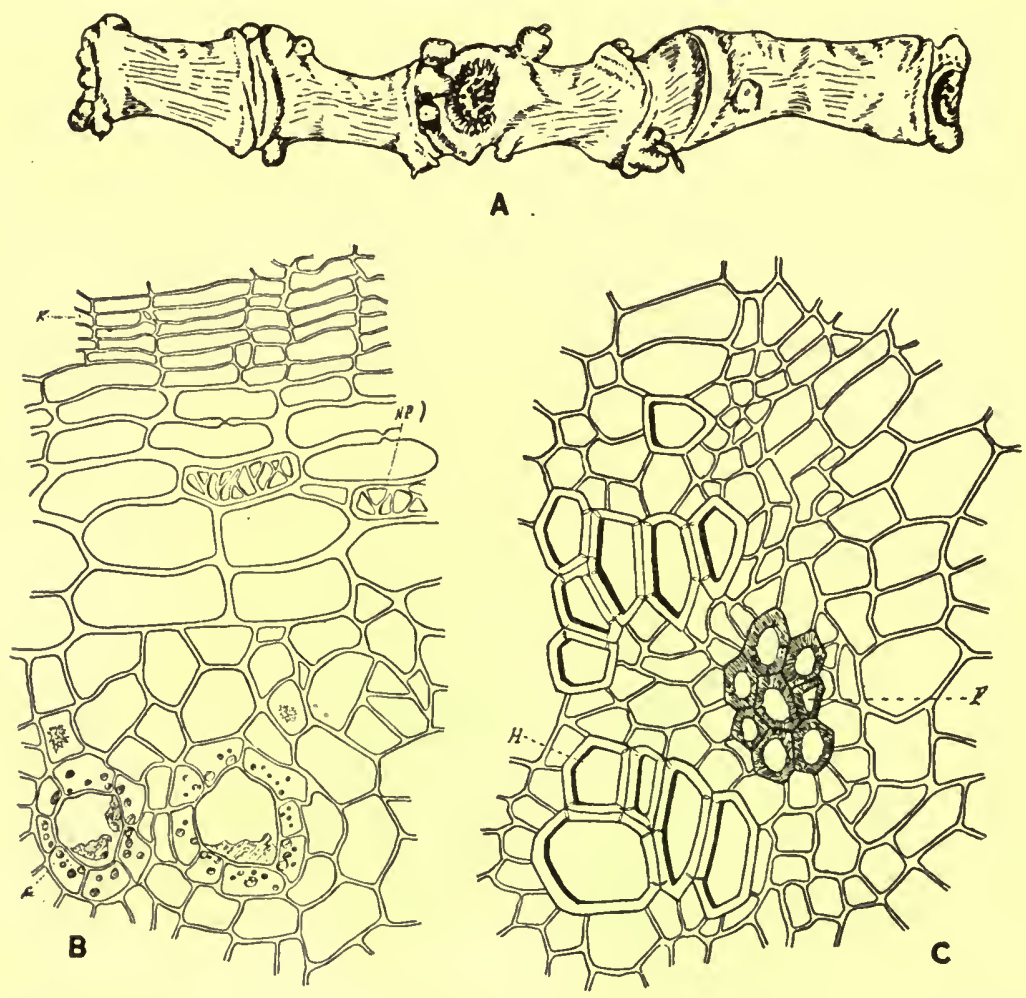

Fig. 205.-Panax repens: $A$, rhizome showing prominent nodes and scars of the over-ground stems. $B$, transverse section of the outer portion of the rhizome showing cork $(K)$, parenchyma with reticulate thickenings of the walls $(N P)$, and secretion reservoirs $(S e)$. $C$, transverse section of the woody portion showing the trachex $(H)$ and wood fibers $(F)$.-After Rosenthaler and Stadler.

ings; the wood fibers are about $0.560 \mathrm{~mm}$. in length and 0.015 to $0.025 \mathrm{~mm}$. in width; the parenchyma of the pith contains considerable starch. Saponin occurs in some of the parenchyma cells of cortex and pith and its presence may be determined by giving a violet-red color with concentrated sulphuric acid. 
Constituents.--Panax repens contains 20.8 per cent of saponin. The latter constituent is also present in ginseng and other members of the Araliaceæ, as Panax fruticosum, of tropical Asia; Aralia montana, of Java; Polyscias nodosa, of the Malay peninsula; Heptapleurum venulosum, of tropical Asia and Australia; and Trevesia sundaica, of Java.

Literature.-Rosenthaler and Stadler, Ber. d. d. pharm. Ges., 1907 , p. 450 .

\section{UMBELLIFERE, OR CARROT FAMILY}

A family of about 1600 species of herbs, which are widely distributed, being most abundant in the temperate zones. The leaves are alternate and mostly decompound; the flowers may be of various colors, but are always arranged in umbels; the fruit is a cremocarp, the morphological characters of which are relied upon in the taxonomic study of the species. The plants resemble in many respects the Araliaceæ. Schizogenous secretory canals are found in the primary cortex, pericycle, pith and occasionally in the secondary cortex. The contents of the canals being a volatile oil, resin or gum, which in the fresh state is either of a clear and aqueous character or of a milky consistency and of a white or yellowish color. There is usually a collenchymatous thickening of the cell walls of the primary cortex, corresponding to the ribs of the stems and fruits. Medullary vascular bundles occur in several modifications in the stem. The vascular bundles of the petiole are always isolated. In the root of Oenanthe the vascular bundles in the cortex are of the concentric type. The walls of the tracheæ and wood fibers usually possess simple pores. The pith of the internodes is usually hollow. Calcium oxalate is usually secreted in the form of rosette aggregates, but in the stem also occurs as solitary crystals. Non-glandular hairs occasionally are present and may be unicellular, stellate, multiseriate or abietiform. Glandular hairs are wanting.

AnIsum.-Anise.-The dried, ripe fruit of Pimpinella Anisum (Fam. Umbelliferæ), an annual herb, indigenous to Asia Minor, Egypt and Greece, and cultivated in South America, Germany, Spain, Italy and southern Russia.. The drug is derived from cultivated plants, and that obtained from Spain, and known as "Alicante Anise," is preferred.

Description.-Mericarps usually coherent and attached to a slender pedicel 4 to $10 \mathrm{~mm}$. in length; cremocarp ovoid, laterally compressed, 4 to $5 \mathrm{~mm}$. in length, about $2 \mathrm{~mm}$. in diameter, exter- 
nally greenish-brown or grayish-green, with ten yellowish, filiform, primary ribs, finely pubescent, summit with a ring-like disk and two projecting divergent styles about $0.5 \mathrm{~mm}$. in length; internally yellowish-brown, with a slender carpophore attached to each mericarp, the latter in section irregularly plano-convex, slightly concave on the commissural side and usually with two large vittæ on each face, dorsal surface with 30 to 40 vittæ; seed somewhat reniform in section, closely cohering to the pericarp, with a small embryo at the upper end of the reserve layer; odor and taste pleasantly aromatic.

Inner Structure.-(Fig. 206.) An epidermal layer with numerous papillæ and short, one-celled, non-glandular hairs having very thick, papillose walls; primary ribs each with a small fibrovascular bundle, surrounded by a few sclerenchymatous fibers; vittæ or oil secretory canals, 13 to 56 in number, extending as a more or less interrupted circle in the tissues of the mesocarp on the dorsal side of each mericarp; 2 large vittæ on the commissural surface, each separated from the other tissues of the mericarp by a large cavity due to shrinkage of the seed-coat; inner epidermis of pericarp consisting of a layer of narrow tangentially elongated cells closely united with the seed-coat, the inner walls of which are yellowish-brown and considerably thickened; endosperm of polygonal, thick-walled cells, filled with spheroidal or ellipsoidal aleurone grains, each containing a small rosette aggregate of calcium oxalate; the aleurone grains embedded in an oily protoplasm, the oil of which is liberated upon mounting sections in solutions of potassium hydrate or hydrated chloral, and appearing in the form of small globules; epidermal layer near the middle of the commissural surface composed of 2 or 3 rows of cells with thick, porous walls, and beneath which is a layer containing small groups of thick-walled cells resembling stone cells.

Powder.-Yellowish-brown; non-glandular hairs from 0.025 to $0.200 \mathrm{~mm}$. in length and from 0.010 to $0.015 \mathrm{~mm}$. in width, 1-celled, straight or curved, with numerous slight centrifugal projections; calcium oxalate in rosette aggregates from 0.002 to $0.003 \mathrm{~mm}$. in diameter, being present in the aleurone grains, which are about 0.006 $\mathrm{mm}$. in diameter; vittæ (in fragments) from 0.010 to $0.150 \mathrm{~mm}$. in width and showing a marked tendency to branch; long, narrow, brownish epidermal cells; sclerenchymatous cells of carpophore having simple pores and occasional scalariform thickenings.

Italian Anise is occasionally ADMIXED wITH CONIU⿴囗十 which is distinguished by the absence of hairs and vittæ and the presence of coniine, which is determined by the development of the characteristic odor on rubbing up the powder with alkalies or placing the 


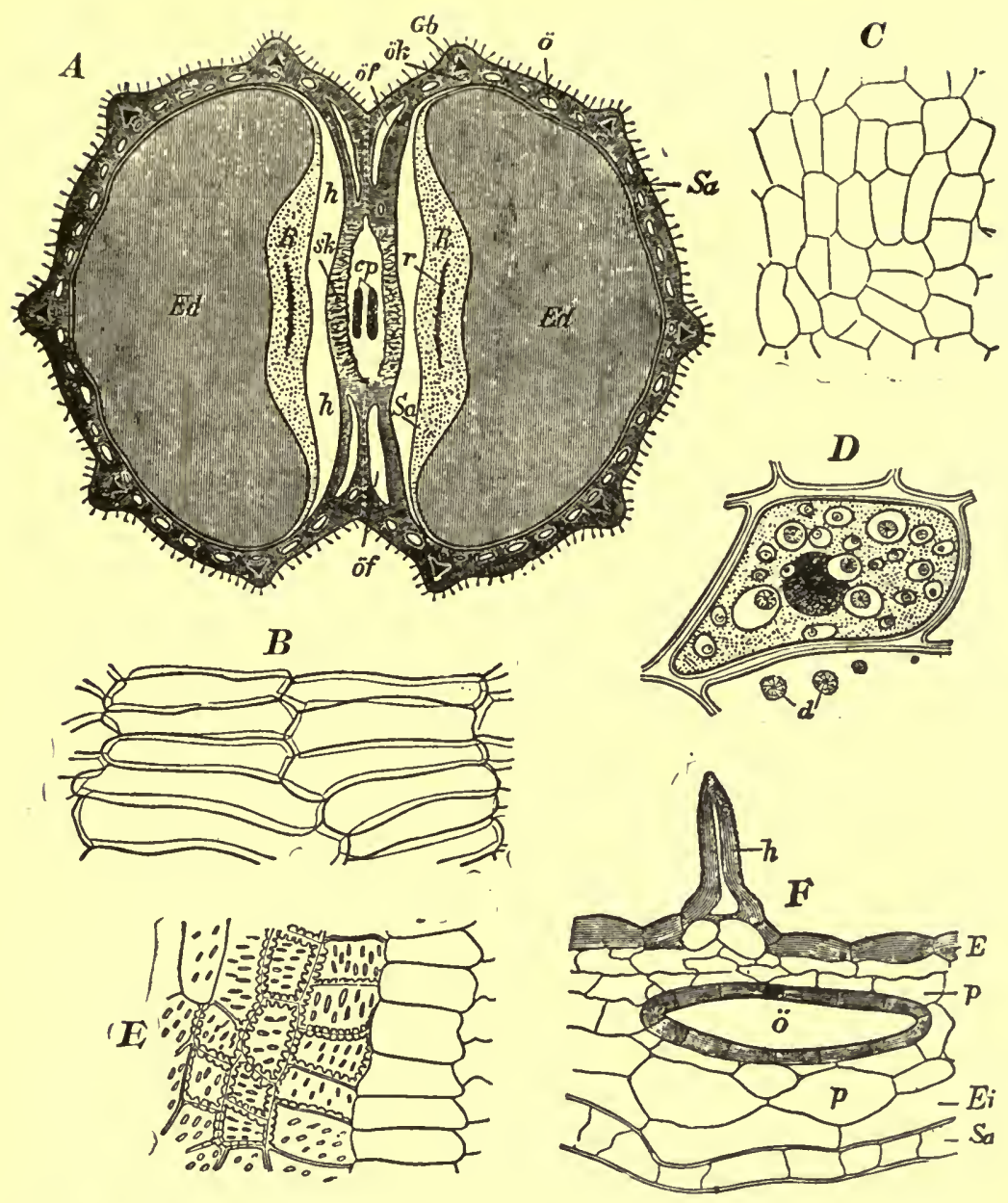

Fig. 206.-Anise: $A$, transverse section of cremocarp showing carpophore $(c p)$, wide vittæ $(\ddot{o} f)$ on ventral (commissural) surface and smaller vittæ $(\ddot{o}, \ddot{o} k)$ between the ribs on the dorsal surface, fibrovascular bundles of ribs $(G i b)$, sclerenchymatous fibers $(s k)$, an air cavity in the wall of the pericarp on the ventral side $(h)$, raphe tissue $(R)$ with fibrovascular bundle $(r)$, seed-coat $(S a)$ and endosperm $(E d) . \quad B$, inner epidermis of pericarp. $C$, epidermis of seed-coat. $D$, cell of endosperm showing a number of aleurone grains containing small rosette aggregates of calcium oxalate, a large nucleus in the center of the cell, and a few isolated aggregates of calcium oxalate $(d)$. $E$, sclerenchymatous cells of the inner epidermis of the pericarp in the neighborhood of the carpophore. $F$, transverse section of pericarp and seed-coat showing epidermal cells $(E)$ and a non-glandular hair having thick lamellated walls $(h)$, parenchyma $(p)$, a vitta $(\ddot{o})$, inner epidermis $(E i)$ and seed-coat $(\mathrm{Sa})$.- - After Meyer. 
powder in a solution of potassium or sodium hydrate. The following micro-chemical tests may be, useful in determining the presence of coniine, which occurs in the parenchyma and epidermal cells of the fruit: Ammonium vanadinate and sulphuric acid produce a blue color; iodin solution gives a reddish-brown color; and picric acid gives a granular precipitate.

Constituents.-Volatile oil ( 1 to 3 per cent) consisting of about 80 to 90 per cent of anethol (p-propenylanisol), and methyl-chavicol and terpenes; fixed oil 3 to 4 per cent; calcium oxalate; ash about 7 per cent.

Russian aniseed is used chiefly for the manufacture of the volatile oil.

Allied Drugs.-Illicum or star-anise yields an oil closely resembling that of anise. It contains 80 to 90 per cent of anethol, d-pinene, d-phellandrene, ethyl ether of hydroquinone and possibly safrol (see p. 299).

Adulterants.-Italian aniseed is sometimes contaminated with conium, and the fruits of some of the grasses and rushes as well.

Pimpernel (or Pimpinella), the roots of Pimpinella Saxifraga and P. magna, is used like anise. It occurs in fusiform pieces about 8 to $10 \mathrm{~cm}$. in length, 4 to $10 \mathrm{~mm}$. in diameter, externally yellowishbrown, fracture short, internally whitish, with numerous yellowish resin canals; the taste is acrid, pungent and aromatic. The drug contains a volatile oil; an acrid resin; a tasteless crystalline principle, pimpinellin; about 8 per cent of sugar; starch; and tannin.

Standard of Purity.-Anise, aniseed, is the dried fruit of Pimpinella anisum L. It contains not more than 9 per cent of total ash, nor more than $1 \frac{5}{10}$ per cent of ash insoluble in hydrochloric acid. (U. S. Dept. Agric.)

CARum.-Caraway.-The fruit of Carum Carvi (Fam. Umbelliferæ), a biennial herb indigenous to Europe and Asia, and cultivated in England, Germany, Holland, Norway, Russia, Sweden and the United States, being naturalized in the northern United States and parts of Canada. The plants are cut when the fruits are ripe, the latter being separated by threshing. The fruits from plants grown in Holland are preferred.

Description.-Mericarps usually separated; cremocarp oblong, laterally compressed, 4 to $6 \mathrm{~mm}$. in length, 2 to $3 \mathrm{~mm}$. in diameter, externally dark brown, surmounted by a small, somewhat globular stylopodium and 5 minute calyx teeth; primary ribs 10 in number, filiform, yellowish, between each of which are slight, secondary ribs; internally dark brown, mericarps curved, narrowed at both ends, 
and with a slender carpophore attached to each, the latter 5-angled in cross-section, the commissural surface with 2 vittæ, the dorsal surface with a vitta between each of the primary ribs; seeds irregularly oblong in section, with a small embryo at the upper end of the reserve layer; odor and taste aromatic.

Inner Structure.-(Fig. 207.) An epidermal layer of nearly rectangular cells having thick outer walls; several rows of tangentially elongated parenchyma cells, frequently more or less collapsed; a single, large, elliptical, brown, vitta or oil secretory canal between each of the ribs and surrounded by small epithelial or secretion cells; in each of the ribs a single fibrovascular bundle surrounded by a layer of thick-walled sclerenchymatous fibers; inner epidermis of broadly elongated cells with very thin side-walls being very frequently broken and closely coherent with the more or less brownish, collapsed cells of the seed-coat; commissural surface with 2 large vittæ and at the middle portion 2 large transverse hollow spaces formed by the separation of the tissues of the seed-coat on one side and the pericarp on the other, otherwise the cells resemble those on the dorsal surface; endosperm large, cells polygonal with thick walls and containing a fixed oil and aleurone grains, the latter usually containing a small rosette aggregate or prism of calcium oxalate.

Powder.-Yellowish-brown or dark brown; cells of endosperm with aleurone grains, each usually containing a rosette aggregate of calcium oxalate from 0.0005 to $0.001 \mathrm{~mm}$. in diameter; fragments with light yellow vittæ, together with nearly isodiametric or polygonal, yellowish-brown, inner epidermal cells of pericarp; fragments with tracheæ and sclerenchymatous fibers, the latter about $0.010 \mathrm{~mm}$. in width, slightly lignified and with numerous oblique pores.

Constituents.-Volatile oil from 5 to 7 per cent; fixed oil; tannin; calcium oxalate, and 5 to 8 per cent of ash.

Volatile oil of caraway contains 50 to 60 per cent of d-carvone (carvol), and 40 to 50 per cent d-limonene (carven). Caraway oil, particularly carvone, is colored yellow on exposure to air, and the old oil gives a reddish-violet color with ferric chloride solution.

Standard of Purity.-Caraway, caraway seed, is the dried fruit of Carum carvi L. It contains not more than 8 per cent of total ash, nor more than $1 \frac{5}{10}$ per cent of ash insoluble in hydrochloric acid. (U. S. Dept. Agric.)

Allied Drugs.-The seeds of Nigella sativa and N. damascena (Fam. Ranunculaceæ), are used in medicine and for flavoring like caraway. They are commonly known as Black Caraway. The seeds are ovoid, 3- to 4-angled, about $3 \mathrm{~mm}$. in length, externally 

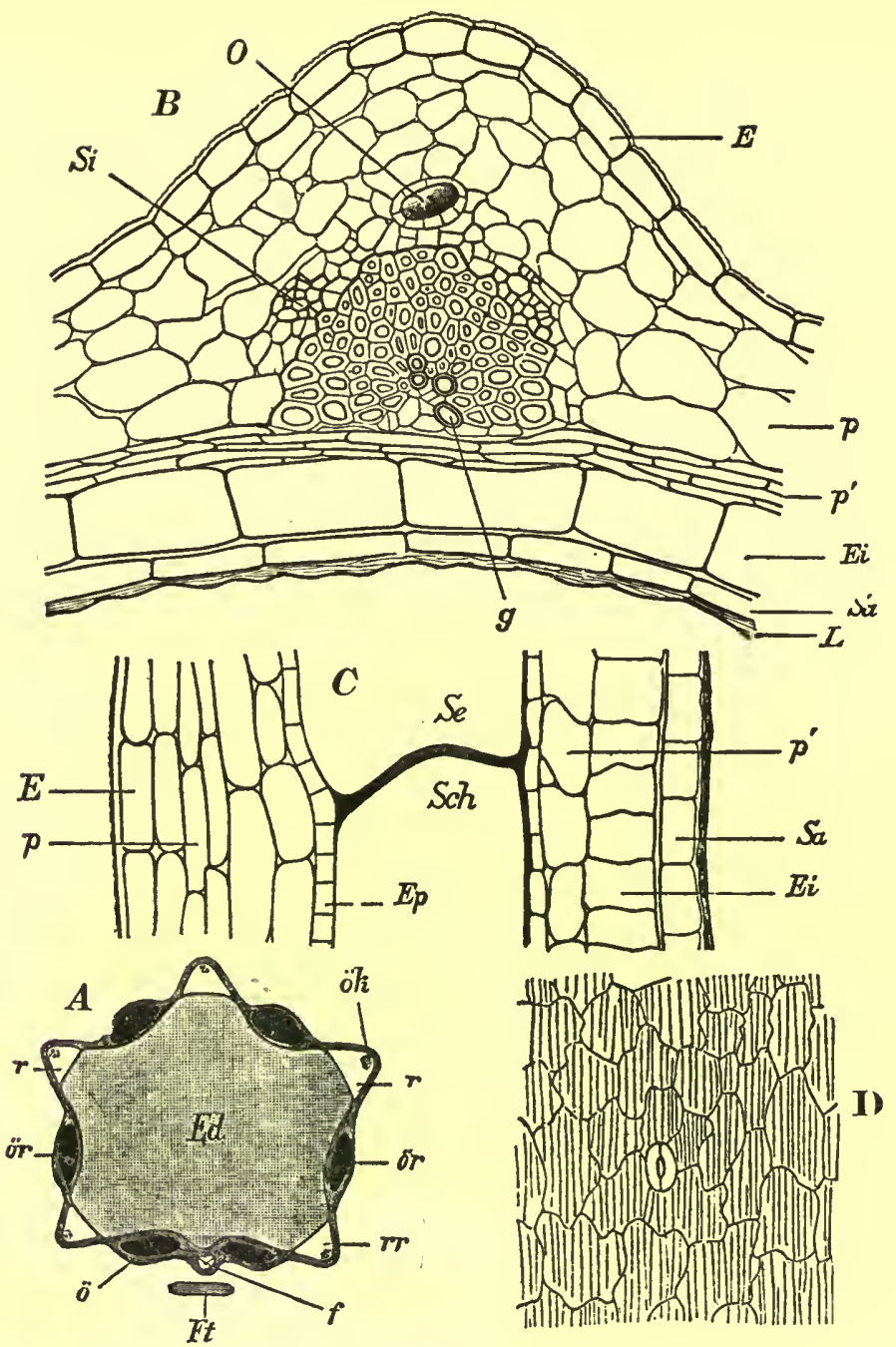

FIg. 207.-Caraway: $A$, transverse section of a mericarp and carpophore $(F t)$, showing vittæ $(\ddot{o}, \ddot{o} r)$, primary ribs $(r, r r)$, with fibrovascular bundle $(\ddot{o} k)$, tissue of raphe $(f)$ and endosperm $(E d)$. $B$, transverse section through a primary rib showing part of pericarp and seed-coat, outer epidermal cells $(E)$, a small vitta $(O)$, sieve $(S i)$, tracheæ $(g)$, around which are thick-walled sclerenchymatous fibers; parenchyma $\left(p, p^{\prime}\right)$, inner epidermis $(E i)$, outer epidermis of seed-coat $(S a)$ and collapsed cells $(L)$ of remainder of seed-coat. $C$, longitudinal section through part of a mericarp showing outer epidermis $(E)$, parenchyma $\left(p, p^{\prime}\right)$, epithelial cells $(E p)$ and separating wall $(S c h)$ of vittæ $(S e)$, inner epidermis of pericarp (Ei) and seed-coat $(S a)$. D, surface view of outer epidermis of fruit showing a single stoma.-After Meyer. 
black and reticulate; internally, having a large, oily reserve layer in which is embedded the small, greenish embryo. Black caraway contains 1.5 per cent of a volatile oil; 1.5 per cent of a glucoside, melanthin, which resembles saponin and helleborin; a fluorescent alkaloid, damascenin, giving the volatile oil from $\mathrm{N}$. damascena its fluorescence; another alkaloid, connigelline; and about 35 per cent of a fixed oil.

Due to the recent abnormal shortage of Indian dill-seed (Peucedanum Sowa) has been sold as a substitute but is very inferior to the Dutch caraway. Mogador caraway from Morocco is suitable only for distilling oil for perfuming soap. "Levant " caraway from Tunis, a novelty in the London market, is the most acceptable substitute for the Dutch article so far offered. North Russian caraway is especially suited for the flavoring of the liqueur known as kümmel, but yields very little volatile oil.

Conium.-Poison Hemlock.-The fruit of Conium maculatum (Fam. Umbelliferæ), a large biennial herb indigenous to Europe, and naturalized in North and South America and in various parts of Asia. The juice of this plant entered into the famous hemlock potion of the Greeks, and was employed by them in putting their criminals to death. The fruit is collected when full grown but still green from wild plants, carefully dried and preserved.

Description.-Mericarps usually separated; cremocarp broadly ovoid, slightly compressed laterally, 3 to $4 \mathrm{~mm}$. in length, about $2 \mathrm{~mm}$. in diameter, with a pedicel 3 to $5 \mathrm{~mm}$. in length, externally grayishgreen, with 10 straight more or less crenate yellowish ribs, stylopodium depressed, internally greenish-brown, with a slender carpophore attached to each mericarp, the latter 5-angled and somewhat reniform in cross-section and without any vittæ; seeds reniform, with a deep furrow on the commissural side, and with a small embryo at the upper end of the reserve layer; odor distinct; taste slight.

Inner Structure.-(Fig. 208.) An epidermal layer of slightly papillose cells; several layers of yellowish-brown cells, the inner and radial walls of which are somewhat thickened; a middle layer of thinwalled cells; and an inner layer of small rectangular cells having thick walls; in each of the ribs occurs a single fibrovascular bundle surrounded by a layer of thick-walled sclerenchymatous fibers; endosperm pentangular in outline and reniform on the inner surface and consisting of polygonal cells containing an oily cytoplasm and numerous aleurone grains, the latter containing rosette aggregates of calcium oxalate from 0.002 to 0.005 in diameter. 


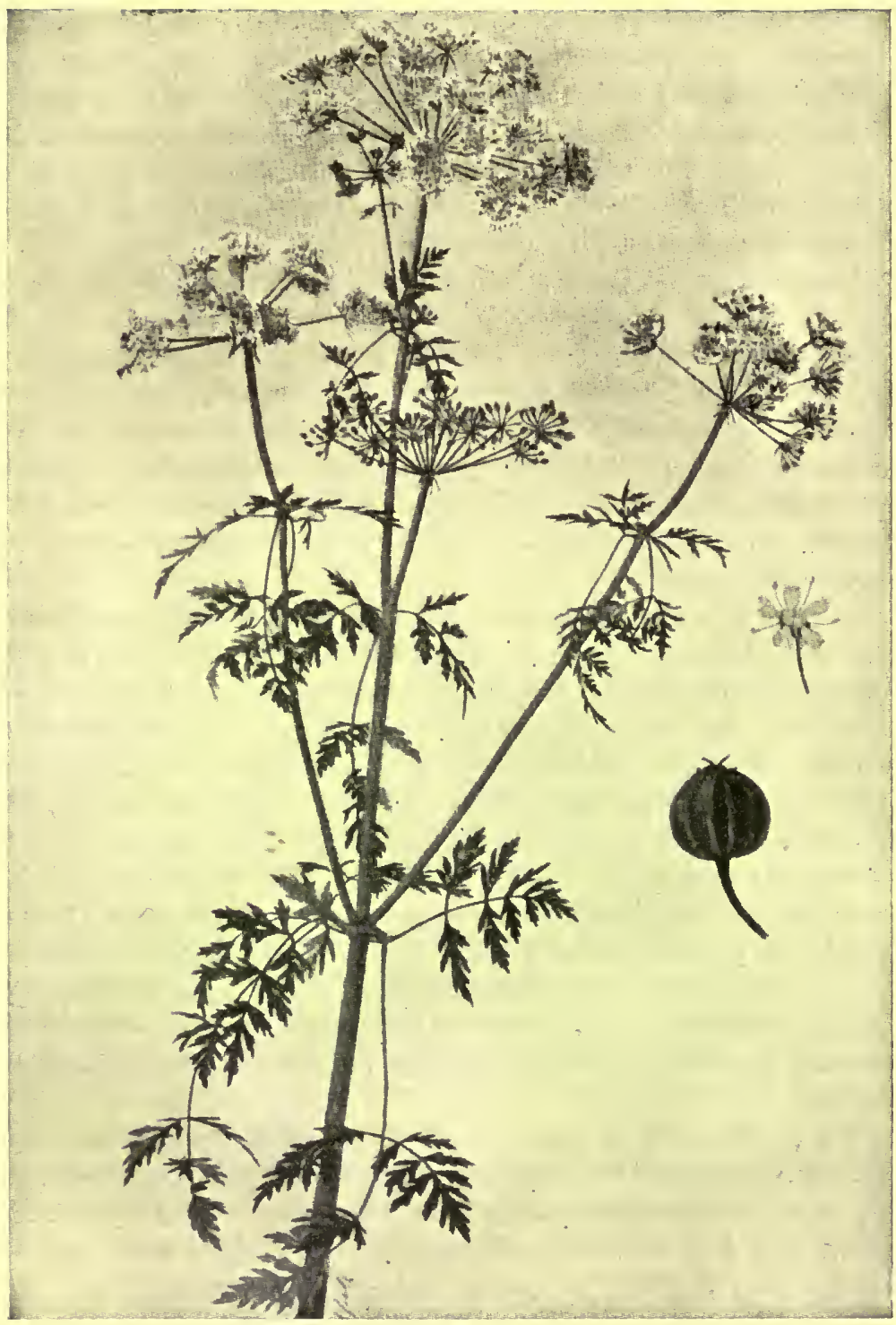

Fra. 208.-Conium maculatum, showing the large decompound leaves with pinnatifid leaflets, and the compound umbels of flowers; also showing a detached flower and one of the fruits, considerably enlarged.-From Bulletin No. 26, U. S. Department of Agriculture. 
Powder.-Grayish-green or yellowish-brown; calcium oxalate crystals in rosette aggregates, 0.001 to $0.002 \mathrm{~mm}$. in diameter, those in aleurone grains about $0.005 \mathrm{~mm}$. in diameter; parenchyma with chloroplastids and starch grains, 0.002 to $0.004 \mathrm{~mm}$. in diameter; sclerenchymatous fibers long, thin-walled, with numerous simple oblique pores; intermediate fibers with reticulated walls; cells of pericarp nearly isodiametric, yellowish, irregularly thickened, somewhat collenchymatous; oil globules numerous.

Constituents.-The most important constituent is the liquid alkaloid coniine (hexa-hydropropyl pyridine), which exists to the extent of 0.5 to 3 per cent; the drug also contains conydrine (oxyconiine), which crystallizes in plates, is dextro-rotatory and very poisonous; pseudoconydrine (an isomer of conydrine), which crystallizes in needles; $\gamma$-coniceine, which is a colorless, oily alkaloid with a disagreeable odor, and 18 times more poisonous even than coniine; volatile oil, fixed oil, starch, calcium oxalate, and yields about 6 per cent of ash.

Coniine is naturally combined in the drug with organic acids, from which it is liberated on treatment with alkalies, and may be readily extracted from the mixture by means of ether. When pure, coniine is a colorless, nearly odorless, liquid and forms a number of crystalline salts. On the addition of concentrated sulphuric acid to coniine the latter is colored blood red and afterwards green. The disagreeable odor in commercial coniine, as well as in conium, is due to the alkaloid coniceine.

Allied Drugs.-The entire fresh plant of Conium maculatum is used in the preparation of Succus Conii. It probably contains the same constituents as the fruit, but in smaller amounts. The root contains 0.018 to 0.047 per cent of total alkaloids; the stems 0.064 per cent; the leaves 0.187 per cent and the flowers and flower stalks 0.236 per cent.

Water Hemlock (Cicuta maculata) is a stout, perennial herb growing in wet meadows throughout the United States and Canada. The stems are streaked with purple, the leaves are pinnately compound, the leaflets being oblong-lanceolate and coarsely serrate; the flowers are white, occurring in large compound umbles. The fruit is ovoid, with prominent ribs and six conspicuous vittæ. The rhizome is large and fleshy and sometimes mistaken for parsnip. The fruits contain a volatile alkaloid, cicutine, which is said to resemble coniine, and about 1 per cent of a volatile oil resembling oil of cumin. The rhizome, stems and leaves contain a resinous substance, cicutoxin, which is said to be quite poisonous. 
Adulterant.-The leaves of the Lesser Hemlock or Fool's Parsley (Athusa cynapium) have been substituted. The leaflets are rhomboid-oval, deeply lobed, the segments being sometimes further lobed, narrow to linear abruptly pointed or blunt. The involucre is usually absent, a single bract sometimes being present. The involucels consist of three long, pendulous, linear awl-shaped stiff bracts. The fruit has broad cork-like ribs.-(Ewing, Stanford, Slevenger, Jour. A. Ph. A. 1919, 8, p. 385). Power and Tutin obtained a small amount of alkaloids resembling those of conium (Jour. Amer. Soc., 1905, 27, p. 1461).

Coriandrum.-Coriander.-The dried, ripe fruit of Coriandrum sativum (Fam. Umbelliferæ), an annual herb indigenous to the Mediterranean and Caucasian region, naturalized in the temperate parts of Europe, and cultivated there and in Africa and India. The fruit is collected when full giown from cultivated plants, from which it is separated by threshing, and dried. The fruits from plants grown in Russia and Thuringia are preferred. The young plants, particularly the leaves, as well as immature fruits, emit a disagreeable odor, whence the name Coriandrum.

Description.-Mericarps usually coherent; cremocarp (Fig. 209) nearly globular, 4 to $5 \mathrm{~mm}$. in diameter, externally light brown or rose-colored, with ten prominent, straight, longitudinal primary ribs, between which are faint, somewhat undulate secondary ribs, summit with 5 calyx teeth and a conical stylopodium about $0.5 \mathrm{~mm}$. in length internally with a slender carpophore attached to each mericarp, the latter grayish-purple, concavo-convex, with two vittæ on the commissural surface; seed plano-convex, with a small embryo at the upper end of the reserve layer; odor and taste aromatic.

Inner Structure.-(Fig. 209.) An epidermal layer of small thickwalled cells; several rows of thin-walled, more or less collapsed parenchyma separated from a broad zone of strongly lignified sclerenchymatous fibers, which extend as a continuous ring in the mesocarp of each of the mericarps; 2 or 3 layers of large, tangentially elongated, thin-walled, parenchyma cells, frequently with numerous, large, lysigenous, intercellular spaces; inner epidermis of large, tabular cells, the inner, yellowish walls being considerably thickened and closely coherent to the brownish cells of the seed-coat; commissural surface with 2 large elliptical vittæ, the cells of the pericarp separated from the seed-coat and forming a large elliptical cavity; endosperm distinctly reniform in outline and consisting of tabular or polygonal, thick-walled cells, containing numerous large aleurone grains, each with a rosette aggregate or prism of calcium oxalate. 
Powder.-Light brown; calcium oxalate crystals numerous, from 0.003 to $0.010 \mathrm{~mm}$. in diameter, mostly in rosette aggregates, either isolated or in aleurone grains; sclerenchymatous fibers irregularly curved, having thick, yellowish, lignified walls and numerous simple pores; globules of fixed oil numerous; fragments of light-yellow vittæ few, associated with elongated, polygonal, epidermal cells.

Constituents.-Volatile oil 0.5 to 1 per cent; fixed oil about 13 per cent; tannin; calcium oxalate; ash about 5 per cent. The volatile oil consists of about 90 per cent of d-linalool (coriandrol), about 5 per cent of d-pinene and some other constituents.

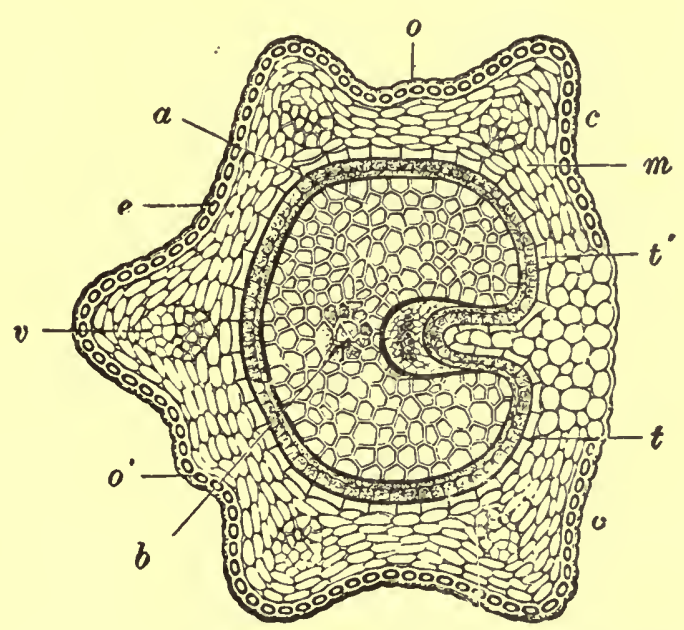

Frg. 209.-Cross-section of a mericarp of conium: $c, c$, commissural surface; $e$, portion without secondary ribs; $o$, portion showing slight development of secondary rib; $o^{\prime}$, secondary rib; $v$, fibrovascular bundle of pericarp $(m)$; $t, t^{\prime}$, layers containing coniine; $a$, endosperm; $b$, tissues of the embryo.After Flückiger.

The unripe fruits are said to yield a volatile oil that has a fetid, disagreeable odor, which it loses on keeping.

Standard of Purity.-Coriander seed is the dried fruit of Coriandrum sativum L. It contains not more than 7 per cent of total ash, nor more than 1.5 per cent of ash insoluble in hydrochloric acid. (U. S. Dept. Agric.)

Allied Plants.-Bombay or Indian Coriander are the fruits of a variety, of Coriandrum sativum imported from Bombay. The fruits are oval and yield less volatile oil than the official drug. (U. S. Dept. Agric.) 
Feniculum.-Fennel.-The fruit of Fœnieulum vulgare, and of the var. dulce (Fam. Umbelliferæ), perennial herbs indigenous to the Mediterranean region of Europe and Asia, and cultivated in France, Galicia, Germany, Roumania, Russia, India, and Japan. The fruit is collected when ripe and dried. That obtained from plants cultivated in Germany (Saxony and Thuringia), Galicia and Russia is preferred.

Description.-Mericarps usually separated; cremocarp oblong or nearly cylindrical, straight, 4.5 to $8 \mathrm{~mm}$. in length, 2 to $3 \mathrm{~mm}$. in diameter, externally yellowish-green, summit with a somewhat depressed disk, and a conical stylopodium about $0.5 \mathrm{~mm}$. in length, each mericarp with five prominent, yellowish, slightly winged primary ribs, internally somewhat greenish-brown, with a slender carpophore
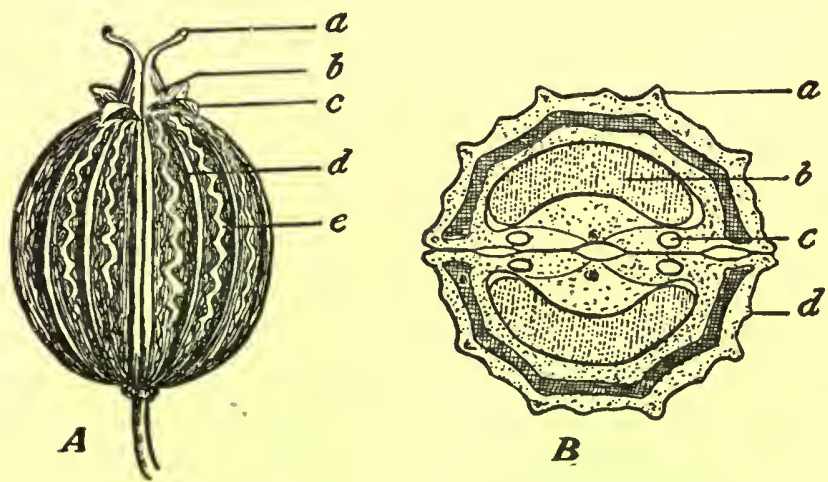

Fig. 210.-Coriander: $A$, cremocarp showing remains of two stigmas (a), stylopodia (thickened persistent styles) $(b)$, calyx teeth $(c)$, straight primary ribs $(d)$ and wavy, somewhat obscure, secondary ribs $(e) . \quad B$, transverse section of the cremocarp showing primary ribs $(a)$, secondary ribs $(d)$, vittæ $(c)$ on commissural side, and seed $(b)$. - After Bastin.

attached to each mericarp, the latter unequally 5-angled in crosssection, the commissural surface slightly grooved and with two vittæ, dorsal surface with a single vitta between each of the primary ribs; there may be, however, as many as 8 vittæ in each mericarp; seed irregularly plano-convex, with a small embryo at the upper end of the reserve layer; pedicel 3 to $10 \mathrm{~mm}$. in length; odor and taste aromatic.

Inner Structure.-(Fig. 211.) An epidermal layer of colorless cells which in surface view are rectangular or polygonal; a mesocarp consisting of several layers of thin-walled, isodiametric cells, several layers of thick-walled cells of a brownish color and inside of which 
are the fibrovascular bundles, situated below the ribs and the large vittæ or oil canals between them, being connected with reticulated sclerenchymatous cells, the latter being very characteristic of fennel; endocarp composed of narrow transversely elongated cells; seedcoat consisting of rather broad outer epidermal cells and several rows of collapsed or structureless cells, which are only clearly defined in the raphe; endosperm pentagonal in transverse section, consisting of polyhedral cells, containing an oily cytoplasm and numerous small aleurone grains, the latter enclosing small rosette aggregates of calcium oxalate.

Powder.-Yellowish-brown; calcium oxalate from 0.001 to 0.002 $\mathrm{mm}$. in diameter, usually in aleurone grains from 0.003 to $0.006 \mathrm{~mm}$.

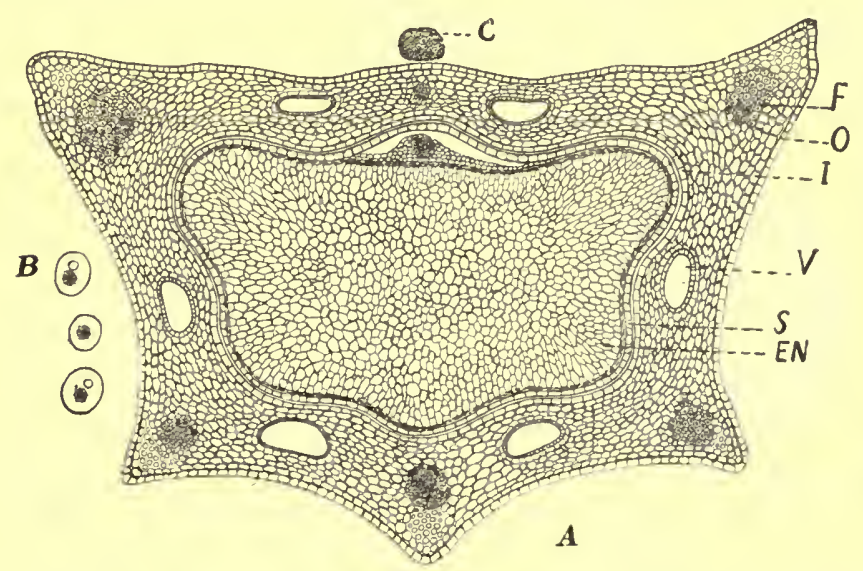

Fig. 211. $-A$, transverse section through a mericarp of fennel: $O$, outer epidermis of pericarp; $I$, inner epidermis of pericarp; $F$, fibrovascular bundles; $V$, vittæ or oil canals; $S$, seed-coat; $E N$, endosperm. $B$, isolated aleurone grains from cells of endosperm of fennel showing globoids and small rosette aggregates of calcium oxalate. $C$, section through the carpophore, which is composed chiefly of sclerenchymatous cells.

in diameter (Fig. 211); fragments containing yellowish-brown vittæ, from 0.100 to $0.200 \mathrm{~mm}$. in width; sclerenchymatous fibers few, strongly lignified and with numerous oblique, simple pores; parenchyma cells with more or less thick walls and simple pores and occasionally reticulately thickened; tracheæ few and either spiral or annular; in mounts made with solutions of potassium hydroxide or hydrated chloral numerous globules of a fixed oil separate.

Constituents.-Volatile oil 2 to 6.5 per cent; fixed oil about 12 per cent; calcium oxalate, and about 7 per cent of ash. 
The volatile oil of fennel contains 50 to 60 per cent of anethol; about 20 per cent of fenchone, which gives the fruit its characteristic odor and taste; chavicol (isomer of anethol); anise ketone; anisic aldehyde; anisic acid, d-pinene and dipentene.

The sweet or Roman fennel, obtained from plants (F. dulce) cultivated in southern France, has longer and somewhat curved mericarps, and yields about 2 per cent of oil, containing considerable anethol but no fenchone. Macedonian fennel oil contains considerable anethol, some limonene and phellandrene, but no fenchone. Wild bitter fennel oil, obtained from wild plants, contains scarcely any anethol, but consists in part of phellandrene and fenchone.

Standard of Purity.-Fennel seed is the dried fruit of cultivated varieties of Fœniculum vulgare Hill. It contains not more than 9 per cent of total ash, nor more than 2 per cent of ash insoluble in hydrochloric acid. (U. S. Dept. Agric.)

Adulterations.-Bitter Fennel, the fruit of Fœniculum piperitum, has been substituted. The fruits are much smaller, decidedly bitter, and the volatile oil is different in aroma. Fennel is frequently contaminated with wheat screenings, undeveloped fruits, various other umbelliferous fruits and dirt.

Allied Drugs.-The more or less fusiform root of Fœniculum vulgare is also used like fennel. It is 8 to $15 \mathrm{~cm}$. in length, of an aromatic odor and taste, and contains a volatile oil, resin, starch and sugar.

Petroselinum.-Fructus Petroselini, Garden or Common Parsley Fruit.-The ripe fruit of Petroselinum sativum (Fam. Umbelliferæ), a biennial herb, indigenous to southern Europe and Asia Minor and extensively cultivated, the leaves being used as a seasoning herb for culinary purposes. Pliny states that in his time there was not a salad or sauce used upon the table that did not contain it. The fruits are gathered in September and October and carefully dried.

Description.-Mericarps usually separated, somewhat crescentshaped, 2 to $3 \mathrm{~mm}$. in length, $1 \mathrm{~mm}$. in diameter; externally grayishbrown becoming grayish or brownish on aging, having 5 yellowish, filiform, prominent ribs, alternating with the coarsely roughened furrows; in transverse section nearly hemispherical, the commissural surface with 2 vittæ, or oil-canals, the dorsal surface usually with a single vitta, occasionally 2 vittæ, in the grooves between the primary ribs; endosperm large, oily, enclosing a small embryo; odor and taste characteristic and distinctly aromatic, especially when bruised. 
Inner Structure.-(Fig. 212.) An epidermal layer with thick: cuticularized papillose walls; several layers of small, thin-walled, more or less collapsed parenchyma cells; a single large brown elliptical vitta or oil-canal between each of the primary ribs and surrounded
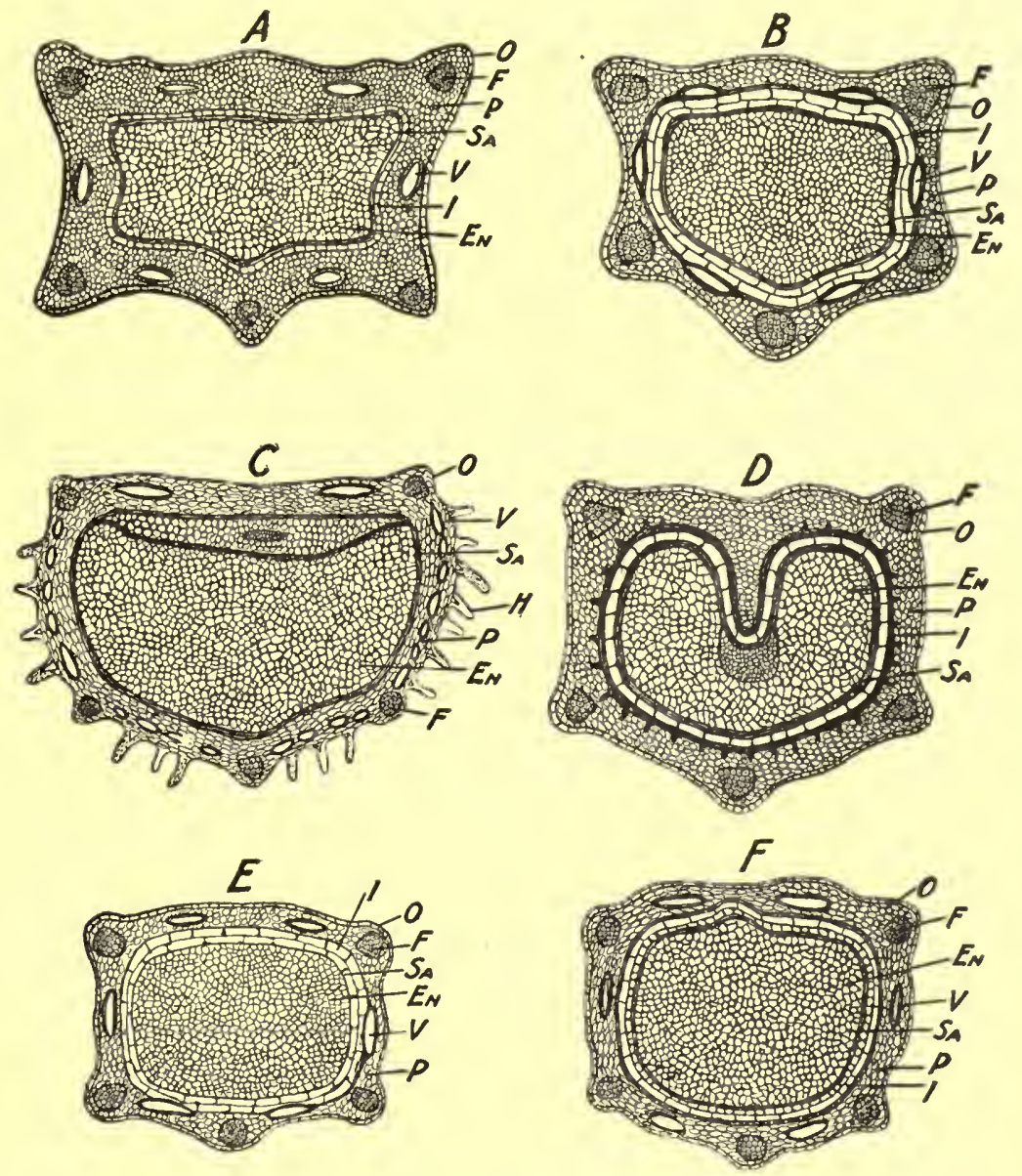

FIg. 212.-Transverse sections of Umbelliferous fruits: $A$, fœniculum; $B$, carum; $C$, anisum; $D$, conium; $E$, Apium graveolens; $F$, petroselinum. $O$, outer epidermis of pericarp; $H$, non-glandular hairs; $V$, vittx or oil canals; $F$, fibrovascular bundles; $l$, inner epidermis of pericarp; $S a$, seed-coat; $P$, parenchyma cells of middle layer or sarcocarp; En, endosperm. All of the fruits, with the exception of conium show vittæ or oil canals.-Drawing by Hogstad.

by a layer of comparatively large, yellowish-brown, tangentially elongated cells; a single fibrovascular bundle between each of the 
ribs and more or less surrounded by a few or occasionally numerous, sclerenchymatous fibers; inner epidermis of narrow, thin-walled, elongated cells closely cohering to the brownish tabular cells of the seed-coat; commissural surface usually with 2 large vittæ, a very.few stone cells and showing a slight separation of pericarp and seed-coat; endosperm of polyhedral, thick-walled, parenchyma cells containing an oily cytoplasm and numerous small aleurone grains, the latter each usually containing a small rosette aggregate of calcium oxalate. The vittæ usually contain yellowish oil globules or a resin-like mass adhering to the walls, and occasionally are divided by radial walls.

Powder.-Grayish-brown, mostly of large, irregular fragments; cells of endosperm with aleurone grains, each usually containing a rosette aggregate of calcium oxalate, from 0.003 to $0.007 \mathrm{~mm}$. in diameter; fragments with light yellow vittx and the yellowishbrown cells of the pericarp; fragments with narrow spiral tracheæ and more or less lignified sclerenchymatous fibers.

Constituents.-Volatile oil, from 1 to 3 per cent, consisting of a camphoraceous substance, apiol, and a terpene, probably l-pinene; a fixed oil, 6 per cent; resinous substances, 5 per cent; mucilage, 7 per cent; a fat, resembling stearic acid, 16.5 per cent; phyteumacolla, combined with potassium salts, 12.5 per cent; protein substances, combined with calcium phosphate, 3 per cent; crude fiber, 48.5 per cent; ash, 4 to 6 per cent.

Apiol is sometimes obtained from the fruit of the East Indian dill, Anethum sowa, and consists of a body heavier than water, and is apparently isomeric with the apiol from parsley oil. Dillapiol of commerce is a mixture of substances extracted from parsley fruits and occurs as a yellow, oily, non-volatile liquid.

Petroselini Radix.-Garden or Common Parsley Root.The fleshy roots of the Hamburg or turnip-rooted parsely, Petroselinum sativum, are sometimes cooked and eaten like parsnips. They also have some medicinal value. The roots are fusiform. resembling carrots, and are usually gathered in the fall and cut into pieces to facilitate drying. The pieces are light yellowish, having a short fracture when dry, and contain numerous yellowish or reddishbrown oil secretion canals. The odor is aromatic, and the taste sweetish and slightly pungent. It contains a small amount of volatile oil; and an amorphous glucoside, known as apiin, which is soluble in hot water and alcohol; also starch; and from 3 to 5 per cent. of ash.

ApII Fructus.-Celery Fruit or Celery Seed.-The ripe fruit of Apium graveolens (Fam. Umbelliferæ), a biennial herb, indigenous 
to England and extensively cultivated throughout the temperate regions of Europe and the United States, for its succulent leaf-stalks or fleshy roots and in France for its aromatic fruits, all of these being used for culinary purposes. The fruits are also used to a limited extent in medicine.

Description.-Mericarps usually separate; cremocarp ovoid, laterally flattened, the mericarps being somewhat crescent-shaped, from 1 to $2 \mathrm{~mm}$. in length and usually less than $1 \mathrm{~mm}$. in diameter; externally dark-brown, having 5 yellowish ribs, alternating with the somewhat roughened furrows; in transverse section, nearly regularly pentagonal with 2 vittæ or oil canals on the commissural side, and from 4 to 8 vittæ on the dorsal surface, i.e., from 1 to 3 in each of the grooves between the primary ribs; endosperm large, oily, enclosing a small embryo; odor distinct; taste aromatic, somewhat pungent.

Inner Structure.-(Fig. 212.) An epidermal layer of cells, having a thick, slighly papillose cuticle; sarcocarp of several rows of polygonal cells among which are distributed the large vittæ or oil canals (there being usually from 1 to 3 in each of the grooves between the primary ribs), and the small fibrovascular bundles consisting of a few tracheæ, surrounded by a group of strongly lignified sclerenchymatous fibers; endocarp of compressed brownish cells; seed-coat consisting of several layers of yellowish-brown, more or less collapsed cells; endosperm of thick-walled polyhedral cells, containing an oily cytoplasm, and numerous aleurone grains, the latter each containing a single rosette aggregate of calcium oxalate, from 0.002 to $0.006 \mathrm{~mm}$. in diameter.

Constituents.-A colorless volatile oil, from 2.5 to 3 per cent, consisting of d-limone and 90 per cent of hydrocarbons. The fresh celery leaves yield about 0.1 per cent of a volatile oil, having a greenish-yellow color and being soluble, forming a clear solution, with 10 parts of 90 per cent alcohol.

Standard of Purity.-Celery seed is the dried fruit of Apium graveolens L. It contains not more than 10 per cent of total ash, nor more than 2 per cent of ash insoluble in hydrochloric acid. (U.S. Dept. Agric.)

Literature.-Gildemeister and Hoffman (Trans. by Kremers), The Volatile Oils, p. 545.

ANGelics Radix.-Angelica Root.-The rhizome and roots of Angelica Archangelica (Fam. Umbelliferæ), a biennial plant indigenous to northern Europe and Siberia and extensively cultivated in Hungary and northern Europe. The large fleshy roots are gathered in the fall, cut longitudinally into pieces and carefully dried. It 
should be stored in tightly closed containers, to which a few drops of chloroform or earbon tetrachloride should be added from time to time, to prevent the development of insects.

Description.-Rhizome upright, nearly cylindrical, usually split into longitudinal pieces, from 5 to $10 \mathrm{~cm}$. in length and from 2 to 3.5 cm. in diameter; externally dark brown, upper portion with remnants of attached leaves, which are either of a light brown or purplishred color, more or less annulate from the scars of bud-scales, with a few circular root scars and numerous large fleshy roots; internally light yellow, cortex about $3 \mathrm{~mm}$. in thickness, light brown, having numerous radial rows of yellowish or yellowish-red oil canals, wood slightly radiate and porous, pith frequently with large apertures containing larvæ or winged insects; odor strongly aromatic; taste sweetish, aromatic and pungent.

Roots slightly tapering, from 6 to $18 \mathrm{~cm}$. in length and from 3 to $10 \mathrm{~mm}$. in diameter; externally grayish-brown to reddish-brown, longitudinally wrinkled and furrowed, with numerous root scars and slender branches; fracture short when dry, tough when damp; internally yellowish, cortex with numerous circles of radiating rows of oil canals containing glistening globules of oil; wood slightly radiate and porous.

Inner Structure.-A corky layer of thin-walled, reddish-brown cells; phelloderm consisting of several rows of collenchymatous cells; cortex of starch=bearing parenchyma and usually with large diaphragms, due to the separation of the cells in plates from each other in the process of drying; phloem consisting of broad wedges of leptome, bast parenchyma and radiating rows of large oil cavities; the latter are very long, from 0.100 to $0.200 \mathrm{~mm}$. in width, more or less equidistant from each other and the epithelial cells, lining the canals, are usually surrounded by a layer of thick-walled somewhat suberized cells: medullary rays from 3 to 8 cells in width and 10 to 20 rows in height; xylem consisting of narrow wood wedges (composed of wide tracheæ, having large lenticular simple pores) and starchbearing parenchyma, the wedges being separated by rather broad, starch-bearing medullary rays; the pith of the rhizome consists of numerous starch-bearing parenchyma and occasional oil canals; the walls of the parenchyma cells, associated with the tracheæ, and also the cells of the pith are frequently marked by scalariform perforations; starch grains numerous, occurring in the parenchyma and cells of the medullary rays in either single or compound grains, the individual grains being spheroidal or polyhedral and varying from 0.004 to $0.008 \mathrm{~mm}$. in diameter. 
Constituents. - Volatile oil from 0.35 to 1 per cent, nearly colorless when fresh, becoming yellowish-brown on keeping, and possessing an aromatic odor resembling a mixture of pepper and musk. It contains a terpene having the odor of pepper, phellandrene, cymol, etc. Angelica also contains 6 per cent of resin; angelic acid, 0.3 per cent; a bitter principle; a crystalline substance resembling hydro. carotin, and known as angelicin; valeric acid; tannic acid; starch; cane sugar; and ash from 6 to 8 per cent.

Angelicæ Fructus.-Angelica Fruit, commonly referred to as Angelica seed, has been used in medicine. It consists of the ripe fruits of Angelica Archangelica. The cremocarps are ovoid, pale yellowish-brown, from 4 to $8 \mathrm{~mm}$. in length, flattened upon the commissural face, and in transverse section show 6 large vittæ or oil canals; the odor and taste are similar to Angelica root. They yield about 1 per cent of a volatile oil having a similar composition to that obtained from the roots.

Herba Angelicæ.-The dried leaves and flowering tops, of Angelica Archangelica, yield about 0.1 per cent of a volatile oil and are used similarly as the roots and fruits of Angelica.

Sumbul.-The dried rhizome and roots of Ferula Sumbul (Fam. Umbelliferæ), a perennial herb indigenous to Turkestan. The drug is exported by way of Petrograd, and is commonly known as muskroot.

Description.-In cylindrical, sometimes branched, transverse segments, 3 to $10 \mathrm{~cm}$. in length and 1.5 to $7 \mathrm{~cm}$. in diameter, very light; externally light to dark brown, distinctly annulate, periderm easily separable; the upper part of the rhizome with occasional circular scars and leaf-remnants consisting of stout fibers; fracture short, fibrous but irregular; internally, light yellow, resinous, spongy, porous, arrangement of wood irregular, due to anomalous secondary cambiums, bark dark brown, about $0.5 \mathrm{~mm}$. in thickness; odor musk-like; taste bitter, pungent.

Inner Structure.-Epidermal cells having yellowish-brown walls; thick cortex consisting of the irregularly twisted tissues of leptome and parenchyma, among which are the large, uniseriate, oleo-resinous secretion canals; xylem made up of easily separable radiate wood wedges, between which are the starch-bearing medullary rays and oleo-resin canals, the latter containing a reddish brown or brownishblack resinous substance, similar to that found in the canals of the cortex; pith small.

Powder.-Grayish-brown or dark brown; tracheæ, from 0.030 to $0.100 \mathrm{~mm}$. in width, and having scalariform perforations, occa- 
sionally simple pores; large irregular brownish-black fragments of oleo-resinous secretion canals; occasional fragments of yellowishbrown epidermal cells; numerous yellowish-brown and reddishbrown fragments of oleo-resin; long, narrow fragments consisting of more or less collapsed leptome or sieve tissue; occasional fragments of well-defined parenchyma with a few nearly spheroidal starch grains, from 0.003 to $0.015 \mathrm{~mm}$. in diameter.

Constituents.-Volatile oil having the taste of peppermint, from 0.3 to 1 per cent; two balsamic resins, one soluble in alcohol and having the door and taste of the root, the other soluble in ether; umbelliferon; a bitter principle; fixed oil 17 per cent; ash about 8 per cent; starch and several acids, as angelic, valerianic and methyl crotonic.

Literature.-Heyl and Hart, Amer. Jour. Pharm., 1916, 88, p. 546. Asafetida.-Asafœtida, Asa Fœtida.-A gum resin obtained from the roots of Ferula Asafœtida, Ferula fœtida and other species of Ferula (Fam. Umbelliferæ), perennial herbs, indigenous to eastern Persia and western Afghanistan. Asafetida is obtained by incising the crown of the root, when the gum resin exudes, hardens and is then scraped from the root. It is exported by way of Bombay. .

Description.-In irregular masses composed of tears, from 1 to $2.5 \mathrm{~cm}$. in diameter, which when fresh are tough, yellowish-white and translucent or milky white and opaque, changing gradually to pinkish and finally reddish-brown, and becoming, on drying, hard and brittle; internally yellowish and translucent or milky white and opaque; odor persistent, alliaceous; taste bitter, alliaceous and acrid.

Asafetida has been offered on the market in the form of a soft mass, sometimes almost semi-liquid.

Asafetida yields a milk-white emulsion when triturated with water, which becomes yellowish on the addition of solutions of the alkalies. Treated with strong hydrochloric acid, the filtrate gives a blue fluorescence on making it alkaline with ammonia water (distinguishing it from ammoniac). The freshly fractured tears give a greenish color on the application of a few drops of 40 per cent nitric acid solution (distinguishing it from galbanum).

Not less than 60 per cent of Asafetida should dissolve in alcohol. The alcoholic solution becomes cherry-red, upon the addition of a few drops of a solution of phloroglucinol and a few drops of hydrochloric acid. An alcoholic solution of Asafetida becomes ôlive green, upon the addition of a solution of ferric chloride (absence of most foreign resins). An alcoholic solution of Asafetida is colored bluishgreen upon the addition of a few drops of hydrochloric acid, the 


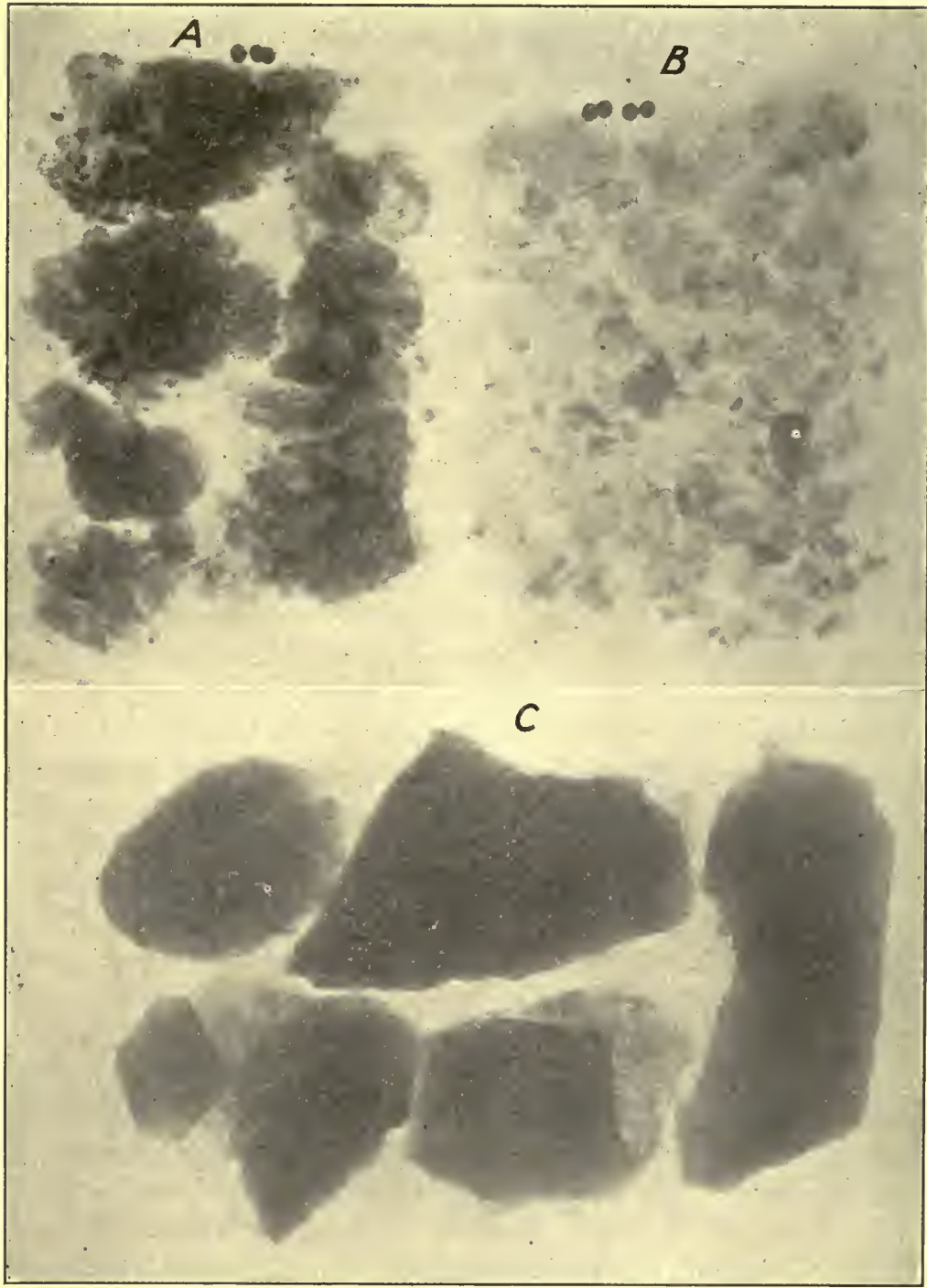

FIG. 213.-Asafetida. $X$-ray photographs of several kinds of Asafetida, the dark colored fragments being inorganic substances, through which the $X$ rays do not penetrate. $A$, mass of ordinary gum resin with considerable inorganic material. $B$, selected tears, which are almost wholly soluble in alcohol. $C$, stony Asafetida, consisting of fragments of gypsum which have been coated with a thin layer of Asafetida.-After Wilbert. 
color fading upon standing (absence of galbanum). An aqueous emulsion is not colored red upon the addition of a solution of sodium hypobromite (absence of ammoniac). A petroleum benzin solution should not give a bluish-green color upon shaking it with a solution (1 in 20) of copper acetate (detection of colophony).

In order to powder Asafetida it is dried at a temperature not higher than $30^{\circ} \mathrm{C}$. or placed over freshly burnt lime. It is comminuted, preferably at a low temperature, and diluents of starch of magnesium carbonate are sometimes added, in order to preserve it in the powdered form. It should be kept in tightly closed bottles. In a glycerin mount the powder shows irregular grayish (or gray streaked with brown) fragments which are opaque and become milky white on the edge from the presence of oil.

Constituents.-About 60 per cent of a reddish-brown amorphous resin (consisting of the ferulaic ester of asa-resinotannol) yielding on dry distillation umbelliferon; on treatment with sulphuric acid, resorcin, and on fusion with potassium hydrate, protocatechuic acid; from 3 to 6.7 per cent of a volatile oil, consisting in part of hexenyl sulphide, hexenyl disulphide, pinene and cadinene, and to which the odor of the drug is due; about 1.28 per cent of ferulaic acid (chemically related to vanillin, eugenol and cinnamic acid) which occurs in iridescent, tasteless, odorless needles and yields on fusion with potassium hydroxide, acetic, oxalic and protocatechuic acids. The drug also contains 0.06 per cent of vanillin; 0.60 per cent of free asa-resinotannol, and formic, acetic, valerianic and malic acids; and ash 5 to 10 per cent.

Adulterants.-Asafetida frequently contains other gum resins as galbanum or ammoniac, colophony or fragments of vegetable tissues, red clay, sand and stones; it is sometimes adulterated with dirty white, gritty masses of gypsum, at other times with barley or wheat flour or translucent gums. Recently it has been adulterated with pieces of rose-colored marble.

Ammoniacum.-Gummiresina Ammoniacum, Ammoniac.-A gum-resinous exudation from Dorema Ammoniacum (Fam. Umbelliferæ), a perennial herb indigenous to central and eastern Persia and the deserts near the Arabian Sea. The gum-resin occurs in secretion canals throughout the plant, and exudes as a result of insectpunctures and hardens upon the stems and petioles. Most of the drug is sent to Bombay, where it is garbled, and then shipped to London and various points in Europe.

Description.--In irregular, somewhat rounded tears, from 5 to $20 \mathrm{~mm}$. in diameter, occasionally agglutinated into larger masses; 
externally pale yellowish-brown, brittle when cold and breaking with a flat, conchoidal and waxy fracture; internally yellowish-white or light yellowish-brown; odor distinct; taste bitter and acrid.

When triturated with water it yields a yellowish-white emulsion, becoming reddish-violet upon the addition of a few drops of a solution of ferric chloride. The aqueous emulsion is colored yellowish, - becoming brown upon the addition of a solution of sodium hydrate. If 1 part of finely powdered ammoniac is boiled with 15 parts of hydrochloric acid, the solution filtered, and ammonia water added until there is an excess, the solution should not show a blue fluorescence (absence of galbanum).

Cczstituents.-A volatile oil, from 0.2 to 0.4 per cent; an acid resin (which is an ester of ammoresinotannol and salicylic acid) and, an indifferent resin, from 60 to 70 per cent; a gum resembling acacia, from 12 to 16 per cent; a trace of free salicylic acid; several volatile acids, acetic and caproic; ash from 2 to 10 per cent. None of the constituents contain either sulphur or umbelliferon.

Galbanum.-Gummiresina Galbanum, Galbanum-Gummiharz, -A gum-resinous exudation from Ferula galbaniflua and probably other species of Ferula (Fam. Umbelliferæ), perennial herbs indigenous to the prairies of northern and western Persia and Afghanistan. The gum-resin occurs in schizogenous secretion canals throughout the plant and exudes as a result of natural wounds to the trees, the exudation being sometimes facilitated by incising the stems above the roots. The product is collected, shipped to either Asia Minor or Bombay, whence it is exported to London, Trieste, and Marseilles.

Description.-Occurring in irregular masses, occasionally in tears, usually admixed with fragments of vegetable tissues; from 0.5 to $7 \mathrm{~cm}$. in diameter; externally bluish-green or orange-brown to almost brownish-black, somewhat oily on the surface; becoming soft and sticky by the heat of the hand; when cold, dry and brittle; fracture somewhat granular and waxy; internally light yellow or grayish-brown and shiny; odor balsamic; taste bitter and acrid.

Galbanum is only partly soluble in water or alcohol. When triturated with water, it yields a turbid milky fluid, which upon the addition of a drop of ammonia water, assumes a bluish fluorescence. Upon boiling galbanum with hydrochloric acid and allowing the solution to stand for an hour it becomes of a bright red color, changing to dark violet upon the addition of an equal amount of alcohol and heating to $60^{\circ} \mathrm{C}$. 
In order to powder galbanum the same means are employed as described under asafetida.

Constituents.-A volatile oil, 9.5 per cent; a resin soluble in alcohol, 63.5 per cent, which consists of 20 per cent of combined umbelliferon, 50 per cent of galbaresinotannol, and 0.25 per cent of free umbelliferon; gum and impurities, 27 per cent; and ash, 16 to 20 per cent.

Atrusa Crnapium.-Fool's Parsley.-This umbelliferous plant is indigenous to Europe and a common garden weed in the northern United States and Canada. Many cases of poisoning have been attributed to the misuse of the leaves of this plant for parsley. It contains a volatile alkaloid, resembling coniine in its physical and chemical properties. It also contains a small amount of d-mannitol. -Power, Jour. Amer. Chem. Soc., 1905, p. 1461.

CEnanthe Crocata.-European Water Hemlock.-A common European plant (Fam. Umbelliferæ), growing in wet and marshy places, and even growing in water. The roots, from their resemblance to parsnips, have been the cause of frequent and sometimes fatal poisoning. It has been used with beneficial results for the poisoning of rats and moles. The poisonous property appears to reside in the neutral portions of the petroleum and ether extracts of the resin. It does not contain an alkaloid. The constituents of the plant, besides considerable amounts of cane sugar, dextrose and lævulose were found to comprise a volatile oil; a colorless crystalline substance, which, on keeping, assumed a purple color; salicylic acid; triacontane; pentriacontane; a phytosterol; a phytosterol glucoside; and a mixture of fatty acids.-Power, Pharm. Jour., 1911 (87), p. 296.

Cicuta Maculata.-American Water Hemlock.-A biennial, umbelliferous plant growing in wet and marshy places of the northern United States and Canada. It produces a cluster of thick tuberous roots, a hollow, somewhat purplish stem, attaining a height of 1 to $2 \mathrm{~m}$., bearing pinnately compound leaves and large umbels of white flowers. This plant is probably responsible for more cases of poisoning in the United States than any other plants apart from the poisonous Amanitas. The herbage is often destructive to cattle and many children have eaten the leaves mistaking them for sweet cicely (Osmorhiza) or Angelica, and the fleshy roots have been mistaken for parsnips and Jerusalem artichokes. For illustrations of the habit and inner structure of this plant, consult Kraemer's Applied and Economic Botany, p. 642. It is said that the root, when dried, loses its active principle. The toxic constituent appears to be a yellowish amorphous substance, cicutoxine. It also contains a volatile oil 
and umbelliferon. The fruits of Cicuta yield from 3.8 to 4.8 per cent of a volatile oil, having an odor resembling chenopodium. They also contain a volatile alkaloid, resembling coniine, which is said to be present in the stems and leaves.

\section{CORNACEE, OR DOGWOOD FAMILY}

A small family of shrubs and trees, comprising 85 species. The leaves are simple or opposite, and the flowers are arranged in cymes or heads, which in the case of the flowering dogwood (Cornus florida) are subtended by 4 large, petal-like, white or pinkish bracts. Among the histological characters, the following may be mentioned. The pericycle contains either isolated groups of bast fibers or it is made up of a composite and continuous ring of sclerenchyma. The tracheæ possess very narrow lumina and are marked by scalariform perforations. The walls of the wood fibers possess either simple or bordered pores. The medullary rays are from 1 to 5 cells in width. Secretory elements are seldom present, although in Nyssa secretory cells occur in the leaves, and in Mastixia secretory canals are found in the pith. The epidermal cells of both leaf surfaces are provided with papillæ, and the walls are sometimes metamorphosed to mucilage. A distinct hypodermal layer is not infrequently developed beneath the upper surface of the leaf, and occasionally special idioblasts, containing crystals are developed. Calcium oxalate is usually secreted in form of rosette aggregates, solitary crystals, or microcrystals. The non-glandular hairs are mostly unicellular and are sometimes provided with verrucose thickenings of the cuticle. Glandular hairs of a number of special forms are present.

Convus.-Dogwood Bark.-The bark of the flowering dogwood, Cornus florida (Fam. Cornaceæ), a small tree quite common in dry woods of the eastern United States and Canada, producing in the spring, clusters of small flowers surrounded by an involucre, consisting of 4 corolla-like bracts; and in the fall a cluster of scarlet, drupaceous fruits. The bark of both the stem and roots is used to a limited extent in medicine and was employed, during colonial times, as a substitute for cinchona. The root bark is preferred. It is usually collected in the fall and carefully dried.

Description.-Root bark, in quills or transversely curved, chiplike fragments, from 0.5 to $5 \mathrm{~cm}$. in length, 0.5 to $1 \mathrm{~cm}$. in width, bark 1 to $4 \mathrm{~mm}$. in thickness; externally dark or reddish-brown, longitudinally furrowed, more or less scaly, and occasionally transversely fissured; inner surface pinkish- or purplish-brown, distinctly striate, 
with prominent lenticular elevations; fracture short; outer bark light brown having yellowish stone cells, inner bark light purplishbrown; odor slight; taste bitter and astringent. The stem bark usually occurs in quills having externally a dark gray or reddish-brown color and internally a thin, radiate, whitish inner bark.

Inner Structure.-Several layers of thick-walled pericambial cork, having in the thinner pieces the remnants of an endodermis, the outer walls of the latter being considerably thickened; primary cortex of several layers of thin-walled parenchyma containing either starch or tannin; inner bark of wedges of leptome and parenchyma separated by starch-bearing medullary rays, 1 cell in width. The stem bark is distinguished by the presence of solitary crystals of calcium oxalate in the parenchyma cells of the cortex; and by the presence in the inner bark of several interrupted circles of tangentially elongated groups of bast fibers. The fragments of wood show spiral tracheæ, tracheids, and thick-walled wood fibers.

Constituents.-A crystalline bitter principle, cornin, which is soluble in water and alcohol; a tasteless resin, insoluble in water and soluble in hot alcohol; tannic acid, 3 per cent; gallic acid; and an orange-colored fixed oil. The so-called cornin is a hydro-alcoholic extract prepared from the drug and is a mixture of principles.

Literature.-Holm, Merck's Report, 1909, p. 318.

\section{ERICACEÆ, OR HEATH FAMILY}

A large family of nearly 1500 species, mostly erect or prostrate shrubs, occasionally small trees, or sometimes herbs, and of very wide geographic distribution. The plants vary in their morphological characters, the leaves being deciduous or evergreen, the flowers regular or nearly so, and the fruit a capsule, berry or drupe. The tracheæ usually have small lumina, and the walls are provided with either scalariform perforations, bordered or simple pores. The wood and bast fibers have as a rule bordered pores. Calcium oxalate is secreted in the form of rosette aggregates or solitary crystals. Both glandular and non-glandular hairs occur of a variety of forms.

The family can be divided on morphological grounds into 3 subfamilies. 1. The Ericacese proper, in the flowers of which the calyx is free from the ovary, and the stomata are surrounded by more than 2 epidermal cells. This sub-family includes Rhododendron, Kalmia, Epigæa, Gaultheria, and other heath-like plants. 2. The VACCINIACEE, or whortle-berry sub-family, in the flowers of which the calyx adheres to the ovary, the latter developing into an edible 
berry-like fruit, surmounted by the short calyx teeth. The plants of this family are furthermore distinguished by the stomata having 2 neighboring or subsidiary cells which lie parallel to the pore. This sub-family includes the blueberry and huckleberry plants. 3 . The Monotropacese, or Indian pipe sub-family. These well-known saprophytes are free from chlorophyll and include the Indian pipe and beech drops. Some writers divide the Ericaceæ, by placing those plants in which the flowers have a polypetalous corolla into a subfamily by themselves. The latter include the Pyrolaces, which comprises about 20 species, including Pyrola, Chimaphila and possibly 2 other genera.

Chimarhila.-Pipsissewa or Prince's Pine.-The dried leaves of Chimaphila umbellata (Fam. Ericaceæ, sub-fam. Pyrolaceæ), a perennial herb indigenous to the United States and southern Canada and northern Europe and Siberia.

Description.-Lanceolate or oblanceolate, 2.5 to $5 \mathrm{~cm}$. in length, 8 to $18 \mathrm{~mm}$. in breadth; summit obtuse or acute; base acute or cuneate; margin sharply serrate; upper surface dark green, not mottled, glabrous, shiny; midrib and veins depressed, the latter diverging at an angle of about $60^{\circ}$ and uniting with each other near the margin; under surface yellowish-green; petiole about $1 \mathrm{~mm}$. in length; texture coriaceous, brittle; odor slight; taste astringent, bitter.

InNer Structure.-See Fig. 214.

Powder.-Yellowish-green, or dark green; calcium oxalate in rosette aggregates, from 0.035 to $0.060 \mathrm{~mm}$. in diameter; characteristic thick-walled cells of the lower epidermis having broadly elliptical stomata, which lack subsidiary cells; mesophyll containing plastids; parenchyma containing irregular, reddish-brown masses containing tannin; sclerenchymatous fibers of stem with relatively thick walls associated with spiral or annular tracheæ; also fragments containing a purplish pigment which is colored yellowish-red with acids and bright green with alkalies.

Arbutin is a bitter glucoside, which crystallizes in needles or prisms, and the cells containing it may be determined by the use of nitric acid, which colors them orange-yellow to dark reddish-brown. It occurs distributed in the cells of the loose mesophyll and palisade layers of Chimaphila. Arbutin yields, upon hydrolysis, glucose and hydrochinon. The latter substance is sublimable, and may be easily obtained as a microsublimate. The sections of the leaves of Chimaphila, or a small quantity of the powdered leaves, are first treated with a few drops of dilute hydrochloric acid or a solution of emulsin. 
If the material thus treated is placed upon a watch crystal, which is covered with another watch crystal, or a slide and gently heated upon an iron plate, or a strip of asbestos, a microsublimate of hydrochinon may be collected. The latter consists of long monoclinic rods and
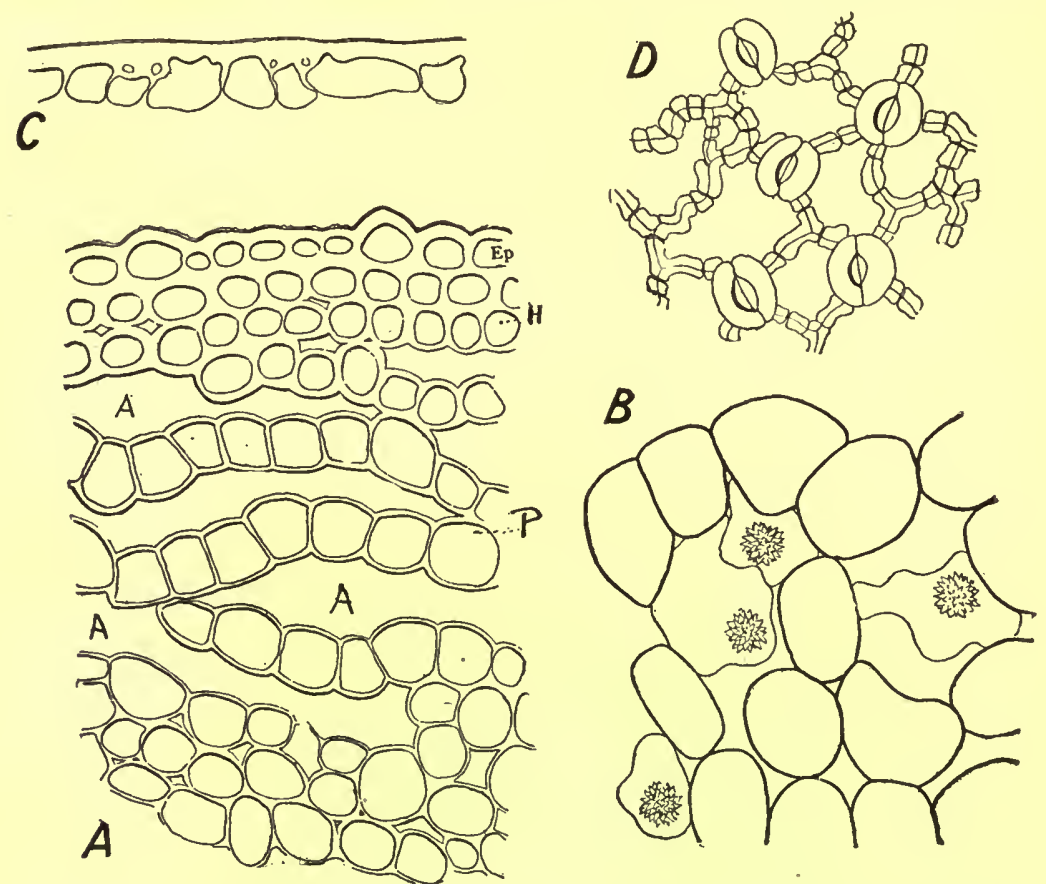

FIG. 214.-Chimaphila umbellata: $A$, transverse section of an aerial internode: $E p$, thick-walled, somewhat papillose epidermal cells; $H$, hypodermis composed of thick-walled collenchymatous cells; $P$, cortex of parenchyma traversed by very wide air-spaces $(A)$, due to the separation of the cells in several of the middle layers. The parenchyma contains chloroplastids which are not here shown; and in the air-spaces in alcoholic material there are usually numerous sphæro-crystals. $B$, transverse section of a portion of the pith of an internode, showing the moderately thickened parenchyma, intermixed with very thin-walled, irregular cells, which contain rosette aggregates of calcium oxalate. $C$, transverse section of the ventral epidermis showing the heavily thickened outer walls. $D$, surface view of the dorsal epidermis showing the thick, porous walls of the epidermal cells, and the characteristic stomata which lack subsidiary cells. The guard cells of the stomata are slightly raised above the surrounding epidermis, and the wide air-chambers are very shallow.-After Holm, Merck's Report, 1909 p. 143.

feather-like aggregates, which polarize light with a brilliant play of colors. Among confirmatory tests the following may be employed. 
The sublimate crystals, under a cover glass, are slowly soluble in cold water; very soluble in warm water, alcohol, ether or acetone. From the latter solution, hydrochinon crystallizes in prisms. The crystals are furthermore colored reddish-brown with ammonia water, and light green with a solution of ferric salts.

Constituents. - A neutral, tasteless principle, chimaphilin, occurring in golden-yellow needles; two glucosides-arbutin and ericolin (see Uva-Ursi); several other crystalline principles; a volatile oil; tannin 4 to 5 per cent; calcium oxalate; ash about 5 per cent.

Uva-Ursi.-Red Bearberry.-The leaves of Arctostaphylos Uva-Ursi (Fam. Ericacex), a procumbent shrub indigenous to Europe, Asia and the northern United States and Canada.

Description.-Obovate, spatulate, 18 to $30 \mathrm{~mm}$. in length, 6 to $10 \mathrm{~mm}$. in breadth; summit obtuse; base acute, tapering; margin entire, slightly revolute; upper surface dark green, glabrous, finely reticulate; under surface yellowish-green; petiole about $3 \mathrm{~mm}$. in length, slightly pubescent; texture coriaceous, brittle; odor slight; taste slightly bitter, astringent.

InNer Structure.-See Fig. 215.

Arbutin is localized in the loose mesophyll and palisade layers of the leaves and in the sub-epidermal layers of the petioles and stems. Its presence may be determined by the use of nitric acid, which colors the cells bright yellow or dark orange, the color gradually fading. Vanillic acid colors the cells bright red, distinguishing it from the leaves of Vaccinium myrtillus. Sections of leaves of UvaUrsi are colored bluish-black, with freshly prepared solutions of ferrous sulphate, distinguishing them from the leaves of Vaccinium VitisIdæa. The presence of arbutin may also be determined in the leaves, by the methods of microsublimation already given under Chimaphila.

Powder.-Yellowish-green to olive-green; fragments of polygonal epidermal cells associated with broadly elliptical stomata, about 0.035 $\mathrm{mm}$. in length, surrounded by 5 to 8 neighboring cells; cells of mesophyll with chloroplastids and frequently irregular masses of a carbohydrate; fragments of fibrovascular bundles having spiral tracheæ, and narrow, strongly lignified sclerenchymatous fibers, frequently also associated with crystal fibers having monoclinic prisms, from 0.006 to $0.015 \mathrm{~mm}$. in diameter; numerous fragments made up of cells having a yellowish-brown content which are colored a bluishblack upon the addition of a freshly prepared solution of ferrous sulphate.

Constituents.-Two glucosides-arbutin and ericolin; a crystalline, resinous principle, ursone; tannin about 5 per cent; gallic acid; 

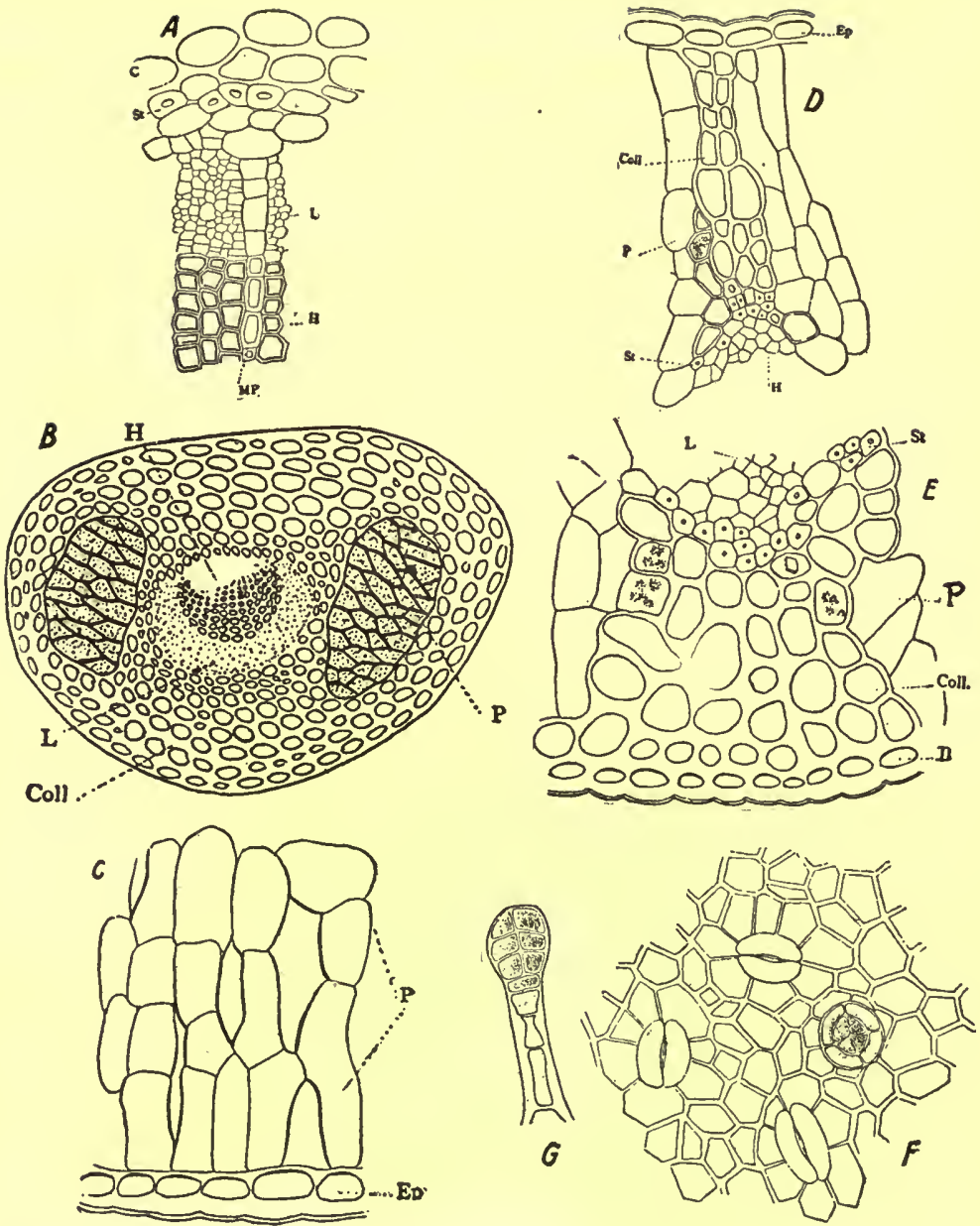

FIG. 215.-Arctostaphylos Uva-Ursi. A, transverse section of part of the stem: $C$, cells of cortex; St, pericycle composed of sclerenchymatous fibers; $L$, leptome; $H$, tracheæ; $M p$, a medullary ray. $B$, transverse section of petiole; Coll, collenchyma; $P$, large elliptical plates of parenchyma containing chloroplasts; $L$, leptome; $H$, hadrome or woody portion of the bundle. $C$, transverse section of leaf: $E d$, dorsal or lower epidermis; $P$, loose mesophyll, the cells of which, near the epidermis are palisade-like and toward the center of the blade are more nearly isodiametric. $D$, transverse section of ventral portion of midrib: $E p$, epidermal cells; $P$, cells containing chloroplasts; Coll, collenchyma; St, stereome; $H$, hadrome-parenchyma. $E$, transverse section of dorsal portion of midrib: $L$, portion of leptome; the other letters as in $D . F$, surface view of epidermal cells, showing the stomata and surrounding cells, which are alike on both surfaces of the leaf blade. $G$, one of the thin-walled glandular hairs of the stem.-After Holm, Merck's Report 1911, p. 95. 
ellagic acid; a yellow, crystalline coloring principle; calcium oxalate; ash about 3 per cent.

Arbutin forms colorless, bitter needles, which are soluble in water and alcohol, the solutions being colored azure blue upon the addition of an alkali followed by phosphomolybdic acid. It yields on hydrolysis hydroquinone (arctuvin) and methyl hydroquinone (see also Chimaphila).

Ericolin is a yellow, hygroscopic, bitter substance, which yields on hydrolysis the volatile oil ericinol. Ursone occurs in tasteless needles insoluble in water and capable of being sublimed.

Allied Plants.-Various other species of Arctostaphylos contain principles similar to Uva-Ursi. The leaves of trailing arbutus (Epigæa repens) contain ericolin and possibly arbutin. Ericolin occurs in a number of species of Ledum and Rhododendron, and European huckleberry (Vaccinium myrtillus), small cranberry (Oxycoccus palustris) and heather (Calluna vulgaris), all of Europe. The two latter plants are naturalized in New Jersey, the New England States and eastern Canada. A number of species of Rhododendron contain, in addition to andromedotoxin, the same principles found in Uva-Ursi. Marsh tea or narrow-leaved Labrador tea (Ledum palustre), growing in the northeastern United States and Canada, as well as northern Europe and Asia, contains ericolin, arbutin, an ethereal oil (the principal component of which is Ledum camphor), valerianic, acetic and butyric acids.

The leaves of Empetrum nigrum contain resin, benzoic acid, tannin, a wax, fructose and probably rutin. (Van Itallie, Jour. Pharm. et Chim., 1918, vii, 18, p. 180.

Literature.-Tunmann, Pharm. Zeit., 1906, p..757; Pharm. Zentralb., 1906, p. 945.

Gaultheria.-Folia Gaultheriæ, Spring or Creeping Wintergreen, Aromatic Wintergreen, Teaberry or Checkerberry.-The leaves of Gaultheria procumbens (Fam. Ericaceæ), a low, shrub-like perennial, producing slender creeping or subterranean stems, the branches ascending and from 5 to $15 \mathrm{~cm}$. in height. The leaves are alternate and evergreen, the flowers are white, and axillary, and the fruit is a bright red, globular, aromatic berry. The plant is exceedingly common in coniferous woods throughout the eastern United States and Canada.

The chief interest of this plant lies in its volatile oil, which is obtained by steam distillation. The chief sources of supply at one time were the New England States; it is now, however, obtained from New York, New Jersey, Pennsylvania, Virginia and Maryland. 
The plants are collected, chopped into small pieces, mixed with water and allowed to stand for about 12 hours, when distillation is effected by means of a copper still. The oil is generally further purified by rectification. Owing to the demand for this oil and the high prices obtained for it, it is frequently substituted by oil of birch.and adulterated with methyl salicylate. The leaves were used at one time in medicine, but they have been nearly entirely supplanted by the oil.

Description.-Leaves oblong or obovate, from 2.5 to $5 \mathrm{~cm}$. in length, and from 1.3 to $3 \mathrm{~cm}$. in breadth; summit acute, mucronate tipped; margin slightly revolute and serrate with bristle tipped teeth; coriaceous; upper surface dark green and shining, the midrib slightly raised, or depressed, under surface pale green, with 3 to 4 pairs of
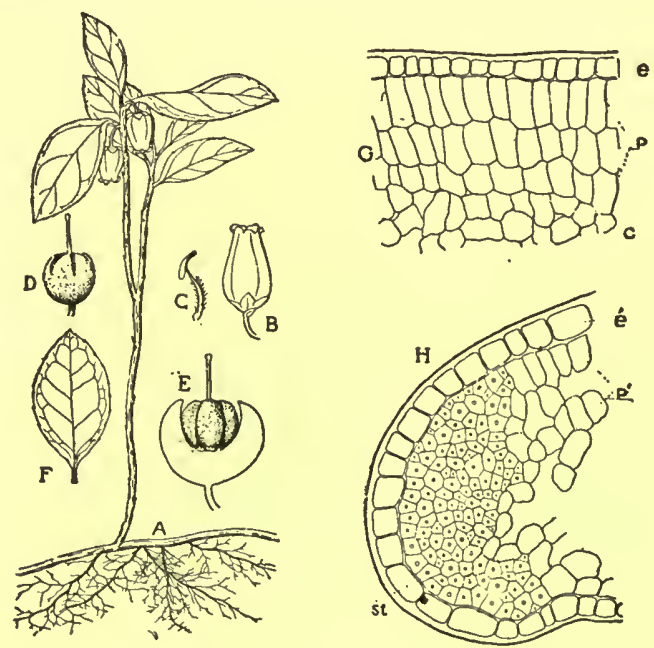

FIG. 216.-Gaultheria procumbens: $A$, entire plant showing horizontally creeping stolons and solitary axillary flowers. $B$, flower showing hypocrateriform corolla. $C$, stamen: $D$, young fruit. $E$, section of fruit showing the baccate or berry-like calyx which encloses the true fruit or capsule. $F$, leaf showing venation. $G$, cross-section of leaf showing epidermis $(e)$, three layers of palisade cells $(p)$, and chlorenchyma $(c)$. $H$, cross-section of margin of leaf showing in addition a large group of sterome cells.-After Holm.

veins of the first order which diverge at an angle from $10^{\circ}$ to $50^{\circ}$ from the midrib and unite with each other near the margin; odor distinct, aromatic; taste aromatic and astringent.

InNer Structure.-See Fig. 216.

Constituents.-From 0.5.to 1 per cent of a volatile oil, consisting chiefly of methyl salicylate. The oil also contains 1 per cent of the following constituents: tricontane; an aldehyde or 
ketone having an odor like œnanthic aldehyde; œnanthic alcohol; an ester which splits up into œnanthic alcohol and an acid resulting by oxidation from the œnanthic ketone. Enanthic alcohol and its ester possess the characteristic odor which distinguishes true oil of gaultheria from the artificial methyl salicylate.

Literature.-Holm, Merck's Report, 1908, p. 1.

\section{SAPOTACEF, OR GUTTA-PERCHA FAMILY}

A family of about 300 species of tropical trees and shrubs. The leaves are alternate and evergreen, the flowers are regular bisexual and occur in the axils of the leaves, and the fruits are berries. The plants are especially characterized by the presence of laticiferous sacs, which occur in rows and are distributed in the pith and cortex, and accompany the vascular bundles throughout the veins of the leaves. The latex is composed of irregular, doubly refracting, amorphous masses of caoutchouc, which when collected and dried furnishes the gutta-percha of commerce. To this family also belongs Achras Sapota, known as the sapodilla tree or "bully-tree," which is indigenous to tropical America, and furnishes the sapodilla plum. The latter resembles a russet apple in color and size, and possesses a milky acrid juice which disappears when the fruit matures and it develops a sweet taste and is edible. The seeds of the sapodilla are sometimes used in medicine and the latex obtained from the tree is used in the manufacture of a chewing gum.

Gutra Percha.-Gutta Pertscha or Gummi Plasticum.-The concrete, milky exudation of a number of species of Palaquium, and 1 or 2 species of Payena (Fam. Sapotaceæ), evergreen trees, indigenous to Indo-China and the East Indies. The laticiferous sacs occur in the pith of the tree, and there are various methods for collecting the latex, the most usual being to fell the trees, and make a series of incisions, about $3 \mathrm{~cm}$. in depth through the bark to permit the flow of the latex, which is then collected in suitable receptacles. The product solidifies forming a more or less porous mass. This is then placed in hot water and kneaded, so as to remove the wood and other grosser impurities. It is then converted into large blocks, weighing from 10 to $20 \mathrm{~K}$., which are shipped to Singapore and thence sent to London. It is estimated that a single tree will yield from 1.5 to $8 \mathrm{~K}$. of gutta percha.

The crude gutta percha, which is imported, contains considerable impurities, as fragments of wood and even a quantity of sand, and is further purified before it is finally distributed. 
Description.-Purified gutta percha comes in flattened pieces of variable sizes, and about $8 \mathrm{~mm}$. in thickness; it is hard, rather leathery, somewhat flexible and elastic, sinking in water, becoming plastic at $65^{\circ} \mathrm{C}$. and very soft, capable of being kneaded at a temperature of boiling water, and on cooling assumes its original form. Externally, it is yellowish, grayish-brown or dark brown; porous, somewhat fibrous and may be readily cut with a knife; internally it is grayish-white to reddish-yellow and frequently with reddish-brown streaks of darker colored material; odor slight and somewhat unpleasant.

Gutta percha also occurs in the form of cylindrical sticks from 3 to $5 \mathrm{~mm}$. in thickness, having a white, grayish-white or yellowish color and being somewhat pliable and elastic.

Gutta percha is usually preserved under water, as when exposed to the air it becomes brittle. It is insoluble in water, cold alcohol, ether, dilute acids and dilute solutions of the alkalies. About 90 per cent is soluble in chloroform, carbon tetrachloride, carbon disulphide, petroleum ether and oil of turpentine. It is partly soluble in boiling alcohol, and the filtrate, on cooling and evaporating, leaves a crystalline residue. Gutta percha is not acted on by acetic or hydrochloric acid; on the other hand sulphuric or nitric acid slowly dissolve it.

Constituents.-From 80 to 85 per cent of an amorphous hydrocarbon, gutta, which is soluble in chloroform, ether, petroleum ether, paraffin oil, fixed and volatile oils. Two oxidation products of gutta viz., (a) alban, from 4 to 16 per cent, which occurs as a whitish amorphous resin, and is soluble in hot alcohol; (b) fluavil, from 4 to 6 per cent, a yellowish amorphous resin, soluble in cold alcohol. It also contains a complex product, guttan, which seems to resemble gutta; and ash, from 3 to 5 per cent. Crude gutta percha contains in addition a small quantity of tannic acid and a sugar-like substance.

Literature.-Zörnig, Arzneidrogen.

\section{STYRACACEA, OR STYRAX FAMIIY}

A small family of about 75 species of trees and shrubs, mostly indigenous to tropical South America, a few representatives being found in the southern United States. The leaves are mostly simple and alternate, the flowers are regular and either in axillary clusters or racemes, and the fruit is either a berry, a drupe or a capsule. Very many of the plants contain a benzoic resin. This occurs in lysigenous, intercellular secretory receptacles, which develop in the 
wood and bark as a result of certain pathological phenomena. Among special histological characters the following are of some importance. The cork originates either in, or below the pericycle, the latter usually containing isolated groups of bast fibers. The walls of the tracheæ possess scalariform perforations or simple pores, and the wood fibers are usually marked by bordered pores. The stomata on the leaves are usually unaccompanied by subsidiary cells, although when present they are parallel to the pore. Non-glandular hairs are either stellate or in the form of peltate scales. . Calcium oxalate is secreted in the form of ordinary crystals or as rosette aggregates. Glandular hairs are wanting.

Benzoinum.-Benzoin.-A balsamic resin obtained from Styrax Benzoin, and probably other species of Styrax (Fam. Styracaceæ), trees indigenous to Java, Sumatra and Siam. The resin flows from incisions made in the bark, hardens, and is then collected, the commercial varieties being known as Siam and Sumatra Benzoin, the former being preferred. The composition of the resin varies according to the age of the tree, the youngest trees yielding the best product. The constituents of the commercial resin are not found in the tissues of the tree, but appear to develop as a pathological product due to an injury of the trees resulting from the manner of incising the bark, although probably the exposure of the resin to the air has an influence on the constituents.

Sumatra Benzoin.-In irregular masses composed of yellowishor reddish-brown tears of variable size and a reddish-brown and translucent or grayish-brown and opaque matrix; brittle, the tears internally being milky white; becoming soft on warming, and yielding benzoic acid on sublimation; odor agreeable, balsamic, resembling that of styrax; taste slightly aromatic. About 75 per cent is soluble in a solution of potassium hydroxide or in 95 per cent alcohol.

Siam Benzoin occurs in concavo-convex tears; it has a vanillalike odor and is almost completely soluble in solutions of the alkalies or in alcohol; it is further distinguished from the Sumatra variety in not containing cinnamic acid, and therefore does not yield benzaldehyde on boiling an acidulated solution with potassium permanganate.

Powder.-Light reddish-brown; consisting mostly of irregular, nearly colorless purplish-red fragments, containing rosette aggregates of small rod-like crystals. Upon heating, in a watch crystal or on a slide and covering with a slide microsublimate crystals of benzoic acid are obtained (Fig. 36).

Constituents of Sumatra Benzoin.-About 75 per cent of a resinous substance, benzoresin, which consists of two esters: (a) an ester 
of cinnamic acid and resinotannol (92.6 per cent), and (b) an ester of cinnamic acid and benzoresinol. Benzoresin on decomposition yields 30.3 per cent of CINNAMIC ACID, 64.5 per cent resinotannol, which is soluble in a concentrated sodium salicylate solution, and 5.2 per cent of benzoresinol.

Sumatra benzoin also contains traces of benzaldehyde and benzol; 0.1 to 1 per cent of vanillin; 1 per cent of the phenylpropyl ester of cinnamic acid; 2 to 3 per cent of styracin (cinnamic cinnamate); and 14 to 17 per cent of insoluble matter, consisting chiefly of woody tissues.

Constituents of Siam Benzoin.-It consists largely of a resinous substance, siabenzoresin, which is composed of about 90 per cent of an ester of benzoic acid and siaresinotannol, and about 10 per cent of an ester of benzoic acid and benzoresinol. Siabenzoresin on saponification yields 38.2 per cent of BENzOIC ACID, 56.7 per cent of siaresinotannol, and 5.1 per cent of benzoresinol.

Siam benzoin also contain 0.3 per cent of a neutral aromatic liquid, which is probably an ester of benzoic acid, the nature of the alcohol not having been determined as yet; 0.15 to 1.5 per cent of VANILLIN; a small quantity of free benzoic acid, and 1.3 to 3.3 per cent of impurities in the form of woody tissues. Penang Benzoin has an odor of styrax, and in composition resembles Siam benzoin. It contains considerable benzoic acid, and it and Palembang benzoin, also from Sumatra, arè a source of benzoic acid.

Literature.-Ludy, Arch. d. Pharm., 1893, p. 43; Tschirch, Die Harze und Harzbehälter.

\section{OLEACEE, OR OLIVE FAMILY}

A family of about 500 species of trees and shrubs, of wide distribution. The leaves are opposite, exstipulate, being either simple or odd-pinnate; the flowers are 2- to 4-parted, and usually arranged in panicles; the fruit is either a samara, drupe or berry. Several of the members of this family are widely distributed in the United States. The genus Fraxinus yields a number of our native, hardy and most ornamental trees. The white ash (Fraxinum americana) sometimes attaining a height of 40 or even $50 \mathrm{M}$. and being termed the Venus of the forest, the oak being known as the Hercules. To this family also belongs the olive, a tree indigenous to western Asia, and probably the Mediterranean region and which has been cultivated from remote antiquity for its edible fruit and the fixed oil (olive oil) which it yields. The fruit is a drupe, and when ripe is of a 
purplish color. The full grown, but still green fruits are pickled in brine and sent to market for table use. The olive fruit is in general structure like the peach or apricot, the sarcocarp layer containing the fixed oil. The endocarp or "olive stone" is not infrequently finely comminuted and used as an adulterant of pepper and other spices, as well as powdered drugs. Its presence is easily detected by the characteristic stone cells (Fig. 64).

Among the histological characteristics of the family, the following are of some importance in distinguishing it from some of the related groups. The fibrovascular bundles are of the bicollateral type. The non-glandular hairs are usually peltate. Calcium oxalate is secreted in the form of small acicular or prismatic crystals. The tracheæ usually possess simple pores only. In the mesophyll of the leaves, sclerenchymatous fibers or spicular cells are frequently developed.

Manna.-The dried, saccharine exudation from the stems of Fraxinus Ornus (Fam. Oleaceæ), a small tree indigenous to southern Europe, where it is also cultivated, particularly in Sicily. Manna is obtained by making transverse or oblique incisions in the bark, the exudation flowing down the side of the tree, where it hardens, or it is collected in special receptacles. Several commercial varieties are recognized: LARGE FLAKE manna, consisting of light-colored pieces 10 to $20 \mathrm{~cm}$. in length; and SMALL FLAKE manna, which occurs in smaller light yellowish-brown pieces. The former is preferred.

Description.--In irregular, 3-sided, more or less elongated pieces; one side being smooth and concave; externally yellowish-white; friable, somewhat waxy; internally whitish, porous and crystalline; odor suggestive of maple sugar; taste sweet, slightly bitter and acrid.

Constituents.-The principal constituent is mannitol (80 to 90 per cent), which crystallizes in colorless needles that are soluble in water and sparingly soluble in alcohol; on sublimation it yields a sweet, syrupy liquid, mannitan; the solutions of mannitol do not ferment nor are they decomposed with dilute acids. Manna also contains a green, fluorescent glucosidal principle, fraxin (resembling æsculin), which occurs in bitter, colorless prisms that are soluble in water and alcohol; dextrose, as high as 16 per cent; mucilage; resin, and 1.3 to 4 per cent ash.

Allied Products.-A number of other species of Fraxinus indigenous to Europe also yield manna. The term "manna" is applied to a number of exudations obtained from different sources and of 
varying composition. (Consult Ebert in Zeits. allgem. Oesterr. Apoth. Ver., 46, p. 427, 1908, and Apoth. Zeit., 24, p. 44, 1909.)

For crystals of mannitol, consult Kraemer's Applied and Economic Botany, p. 156.

Manna of inferior quality, known as "sorts," is obtained from incisions lower down on the stem, and consists of brownish-yellow, more or less agglutinated tears, which are sticky and but.slightly crystalline.

The leaves of a number of species of Eucalyptus (Fam. Myrtaceæ) secrete a manna-like carbohydrate, as E. Gunnii and E. resinifera. (Consult in this connection the plants considered under the Coniferæ, Leguminosæ and Myrtaceæ.)

Chionanthus.-Fringe Tree Bark.-The bark of the roof of Chionanthus virginica (Fam. Oleacex), a tall shrub indigenous to the southern United States and extensively cultivated. It produces a deep green, glossy foliage and delicate flowers which hang in loose, drooping, graceful panicles. It is very commonly grafted on some of the species of Fraxinus when it becomes more vigorous and attains a height of 8 or $9 \mathrm{M}$. The bark of the root has been used by the eclectics and is preferably used in the fresh condition, although the recently gathered bark is also employed.

Description.-Mostly in transversely curved pieces, occasionally in quills, from 2 to $8 \mathrm{~cm}$. in length, 0.6 to $3.5 \mathrm{~cm}$. in width and from 2 to $7 \mathrm{~mm}$. in thickness; hard and heavy; outer surface, yellowishor reddish-brown; rough, scaly, occasionally with numerous lenticels and irregular scars; inner surface light yellowish-brown to dark reddish-brown, distinctly striate; fracture short; inner surface, waxy, having a thin, reddish-brown corky layer, outer bark thick, whitish, inner bark having several concentric circles of stone cells; odor distinct; taste very bitter.

Inner Structure.-Periderm consisting of a thick layer of thinwalled, tangentially elongated cells, some of which possess a yellowishbrown, oily content; primary cortex of thick-walled cells containing numerous starch grains; inner bark with several concentric circles consisting of small groups of stone cells distributed in among the phloem; medullary rays 1 to 3 cells in width.

Powder.-Light yellowish-brown; fragments of starch-bearing parenchyma numerous; occasional groups of stone cells, the latter occurring in large plates and consisting of nearly isodiametric forms, short fibers, and more or less oblong cells, walls varying in thickness, frequently very thick, lamellated and having branching pores; occasional fragmients of yellowish-brown cork cells; starch grains single 
or compound from 0.003 to $0.025 \mathrm{~mm}$. in diameter, varying from spheroidal to somewhat flattened reniform, among which are planoconvex or polyhedral forms.

Constituents.- The drug apparently contains a bitter glucoside, chionanthin; possibly also a saponin; ash from 4 to 5 per cent.

Literature.-Schulz, Pharm. Zeitschr. f. Russl., 1893.

Fraxinus. - White Ash Bark.-The bark of Fraxinus americana (Fam. Oleaceæ), a large forest tree of the northern United States and Canada. Both the stem and root barks are collected, the latter being preferred. The bark is collected in the spring, from the branches and trunks of trees from 10 to 25 years of age. The outer periderm should be removed. Sometimes the root bark is collected at the same time.

Description.-In nearly flattened pieces from 10 to $15 \mathrm{~cm}$. in length, 2.5 to $7.5 \mathrm{~cm}$. in breadth and 3 to $10 \mathrm{~mm}$. in thickness; outer surface reddish-brown, irregularly furrowed and with numerous shallow patches, frequently with the yellowish-gray outer periderm present; inner surface yellowish-brown, nearly smooth, somewhat longitudinally striate; fracture uneven, short-fibrous; odor slight aromatic; taste bitter, slightly aromatic and acrid.

Inner Structure.-Periderm consisting of thick-walled concavoconvex and somewhat collapsed cells having a reddish-brown amorphous content; outer layers of cortex of several layers of very small parenchyma cells containing a light reddish-brown amorphous substance; inner and middle bark of concentric bands of sclerenchyma, consisting of radially elongated groups of bast fibers, large groups of stone cells in which are included frequently small groups of bast fibers separated by equally broad concentric bands of leptome and parenchyma; medullary rays 1 to 7 rows wide and 5 to 20 rows deep, containing either a colorless, or yellowish-brown, granular or amorphous content; stone cells very irregular, varying from 0.050 to 0.160 $\mathrm{mm}$. in length, having thick, finely lamellated, and slightly porous walls; bast fibers, attaining a length of $1.2 \mathrm{~mm}$., having thick porous walls, wavy margins and sharp pointed, more or less beaked and short branching ends.

Constituents.-A volatile oil; an alkaloid; several resins; starch and sugar; neither tannic nor gallic acids are apparently present.

Allied Drug.-The bark of the young twigs of Fraxinus excelsior, a tree growing in Europe and northern Asia, is used in European countries. It is collected in spring, consists of quills having a thickness of 2 to $3 \mathrm{~mm}$. The bark is externally grayish- or grayish-green, somewhat scaly; the inner surface light yellowish; the fracture is 
fibrous; taste bitter and astringent. It contains a crystalline glucoside, fraxin; a crystalline bitter principle, fraxinin; and tannic acid from 2 to 3 per cent.

Literature.-Power, Amer. Jour. Pharm., 1882, p. 99; Edwards, Ibid., p. 282.

Olea Europæa.-The leaves of the olive tree, Olea europæa (Fam. Oleaceæ), were employed many years ago as a remedy in intermittent fever, and quite recently attention has again been directed to their therapeutic value as a tonic and febrifuge. Both the leaves and the bark of the olive tree have, therefore, been subjected to a complete chemical examination, which has resulted in the isolation of a large number of new and interesting substances. From olive leaves have been isolated a crystalline substance, oleanol.-Power, Jour. Chem. Soc., 1908, pp. 891 and 904; 1913, p. 2050; also Pharm. Jour., 1908, (81), p. 714.

\section{LOGANIACEÆ, OR NUX-VOMICA FAMILY}

A family of about 400 species, which are widely distributed. The plants are variable in character, ranging from annual herbs to trees, some being twining and woody vines. The leaves are simple, the flowers regular, having tubular or somewhat campanulate corollas, and the fruit is either a berry or capsule. According to Solereder they may be divided-into 2 principal sub-groups: (1) The Leganioideæ, including Gelsemium, Spigelia, Strychnos, etc., in which an intraxylary phloem is always present and glandular hairs are wanting. In this group there is also a superficial development of cork. The Buddleioideæ, including a few genera in which glandular hairs are present, the cork originates in the pericycle, and there are no strands of phloem in the pith. Among other histological characters distinguishing this family, the following may be mentioned. The cork is frequently lamellated. There is usually a development of a ring of stone cells in the primary cortex, or outer layers of middle bark, as in certain species of Strychnos. The tracheæ possess simple pores, occasionally scalariform perforations, except when the walls are in contact with the cells of the medullary rays, when they develop bordered pores. The walls of the wood fibers have either simple or bordered pores. Calcium oxalate is secreted in a number of forms, viz., ordinary crystals, styloids, rosette aggregates, acicular or microcrystals. The structure of the leaf may be as follows: The walls of the upper epidermal cells may be metamorphosed to mucilage; a distinct hypodermis may be developed; in the mesophyll there may 
be distributed mucilage cells or branched spicular cells; the outer walls of the lower epidermal cells may be papillose, or even show cork formation. In the Loganioideæ the non-glandular hairs are either unicellular or uniseriate, those in Strychnos having a specific value. In Spigelia there are developed stellate hairs composed of single united cells, which are inserted upon a multicellular stalk. True glandular hairs, having flattened heads, are only found in Buddleioideæ.

Gelsemium.-Yellow Jessamine, Yellow Jasmine.-The dried rhizome and roots of Gelsemium sempervirens (Fam. Loganiaceæ), a smooth, perennial cliniber of the southern United States and Guatemala. The drug should be collected in autumn.

Description.-Rhizome horizontal, cylindrical, usually cut into pieces 3 to $20 \mathrm{~cm}$. in length, 4 to $30 \mathrm{~mm}$. in diameter; externally light brown, also somewhat purplish-brown, longitudinally wrinkled, transversely fissured; upper surface with few stem-scars; under and side portions with numerous roots and root-scars; fracture tough, wiry; internally light brown or pale yellow, bark about $1 \mathrm{~mm}$. in thickness; wood distinctly radiate, excentral, with four groups of intraxylary phloem, pith disintegrated; odor slight; taste bitter.

Roots light brown; 3 to $20 \mathrm{~cm}$. in length, 2 to $8 \mathrm{~mm}$. in thickness; internally light yellow, bark about $0.5 \mathrm{~mm}$. in thickness; wood distinctly radiate.

The overground stem is dark or reddish-brown, longitudinally wrinkled and has numerous lenticels and few, somewhat elliptical branch-scars; the bark is about $0.2 \mathrm{~mm}$. in thickness and somewhat greenish.

InNer Structure.--See Figs. 217 and 218.

The alkaloids are localized in the epidermal cells and in the parenchyma of the vascular bundles, and may be somewhat easily determined (Fig. 219). They also may be detected by the use of certain reagents. A solution of iodin and potassium iodide gives a reddish-brown precipitate; nitric acid colors the cells a deep yellow and in which needle-shaped crystals of the nitrates may separate; solutions of platinic chloride, gold chloride, or picric acid form yellow precipitates; phosphomolybdic acid gives a yellowish-white precipitate; vanadic and sulphuric acids produce a red color which is slowly changed to green. Other alkaloidal reagents also may be employed.

Powder.-Dark yellow; trachex with simple pores; sclerenchymatous fibers long, narrow, lignified; starch grains spheroidal, from 0.004 to $0.010 \mathrm{~mm}$. in diameter; calcium oxalate in long mono- 
clinic prisms, from 0.015 to $0.030 \mathrm{~mm}$. in diameter. In the powder of the overground stem collenchymatous cells, containing chloroplastids, are present.

The following test is rather expeditious in obtaining an approximate idea of the quantitative value of the drug. One gramme of the finely powdered gelsemium is mixed with 10 c.c. of a modified

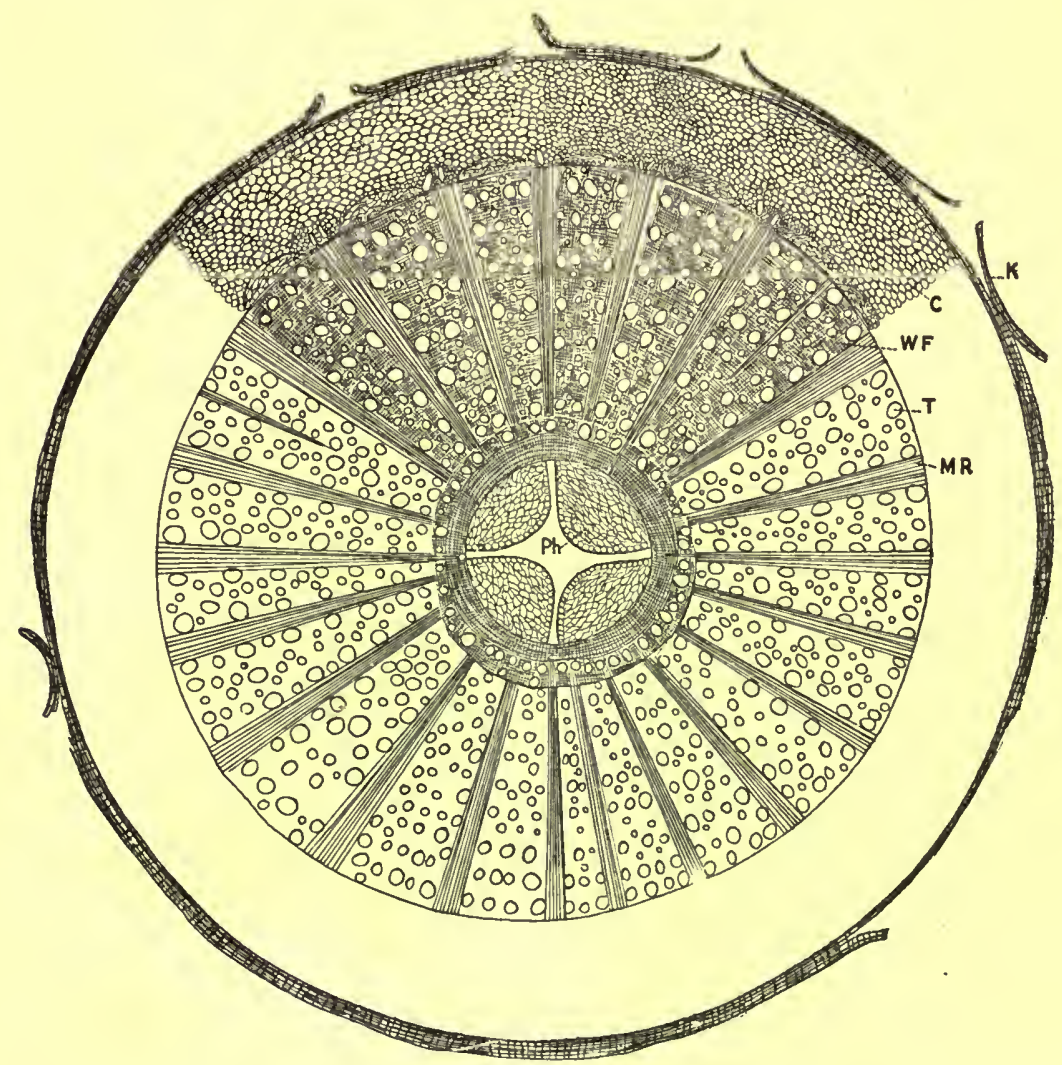

Frg. 217.- Transverse section of rhizome of gelsemium: $K$, cork; $C$, cortex; $W F$, wood fibers; $T$, tracheæ; $M R$, medullary rays; $P h$, intraxylary phloem.

Prollius fluid and allowed to macerate for from four to twenty-four hours. The solution is filtered into a small separatory funnel and 5 c.c. of dilute sulphuric acid ( 0.5 per cent) added, and after separation of the aqueous solution the latter is diluted with 5 c.c. of water.

A few drops of this separated solution ( 1 drop $=0.0000175$ gramme alkaloids), containing the alkaloids, when treated with the following reagents, should cause the rections noted: 


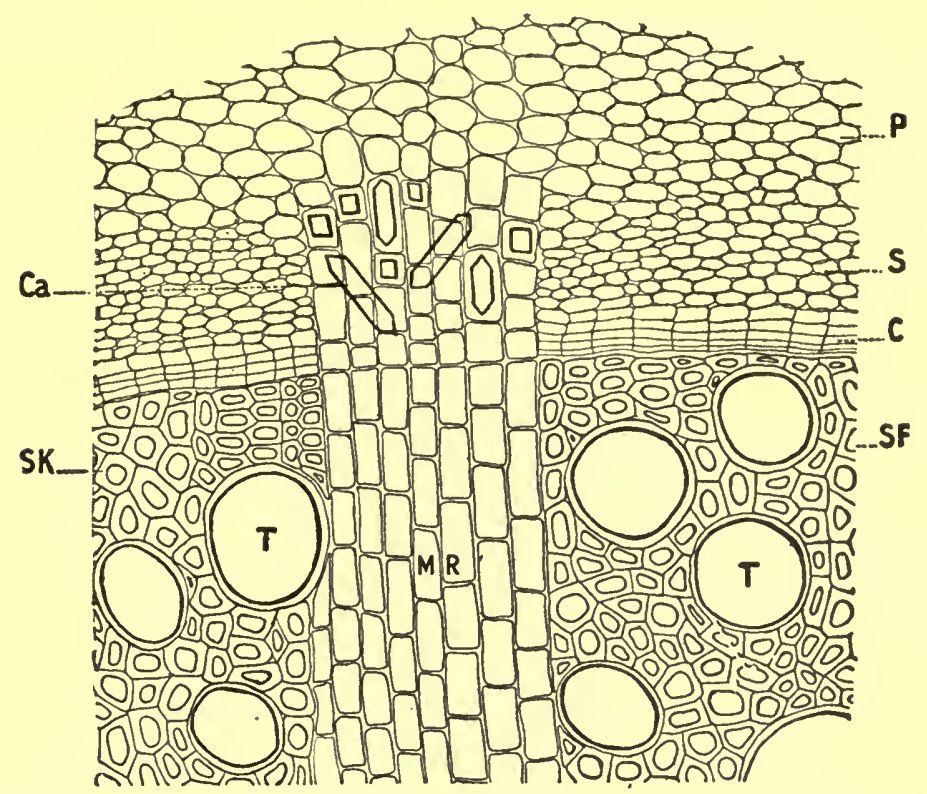

FIG. 218.-Transverse section of gelsemium near the cambium: $P$, parenchyma; $S$, sieve; $C$, cambium; $C a$, calcium oxalate crystuls; $S K, S F$, wood fibers; $T$, tracheæ; $M R$, medullary rays.

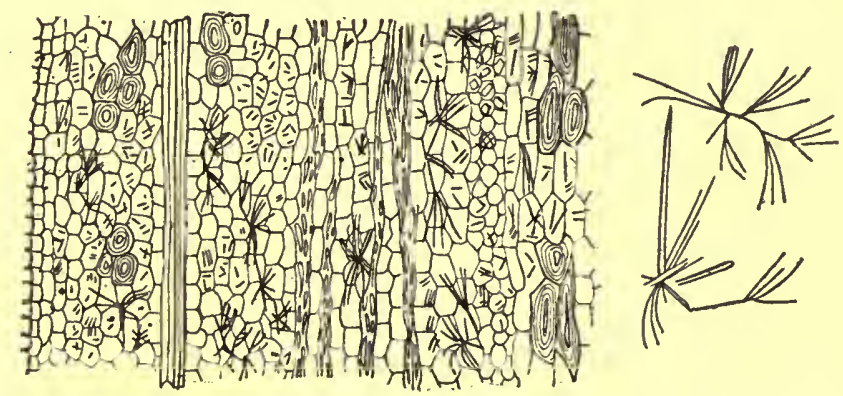

PIG. 219.-Gelsemium: $A$, longitudinal section of the rhizome showing the separation of acicular crystals of the nitrates of the several alkaloids. The sections are allowed to remain in a desiccator, exposed to the vapors of nitric acid, for about 12 hours. They are then mounted in paraffin oil, and allowed to stand for several hours, when the alkaloids should separate in the form of small needles throughout the parenchyma tissue. Some of the crystals form feather-shaped aggregates at or near the edges of the section, as shown to the right in the illustration. In the figure above are shown, also, the long prismatic crystals of calcium oxalate in the cells of the medullary rays, which are unaffected by the vapors of the acid.-After Tunmann. Pflanzenmikrochemie. 
Mayer's reagent produces an immediate yellow precipitate.

Ammonium molybdate produces a blue-colored solution which becomes more marked in a few minutes and the color may last for a number of hours.

Picric acid produces a slight yellowish precipitate.

Iodin and potassium iodide solution gives an orange-brown colored precipitate.

Constituents. - Two alkaloids of great toxicity, the one known as Gelsemine, crystallizes in silky needles and on the addition of concentrated nitric acid and heating the solution is colored reddish and then dark green; the other GELEEMININE, occurring in amorphous masses and forming yellowish amorphous salts, is colored greenish on the addition of nitric acid. In addition the drug contains traces of emodin monomethyl ether, together with scopoletin (a monomethyl ether of æsculetin). A subsequent investigation on the constitution of scopoletin has definitely established the fact that it is 4-hydroxy-5-methoxy-coumarin.

A method having been described in the literature for the detection of æsculin by microsublimation, which was regarded as being specially adapted for the identification of gelsemium, the opportunity was taken of correcting several errors of statement connected therewith. It has been noted by Power that gelsemium contains no æsculin, and, furthermore, that this glucoside cannot be sublimed, owing to its decomposition on heating. The crystalline sublimate obtained from gelsemium under the specified conditions consists of scopoletin.

Gelsemium also contains about 0.5 per cent of a volatile oil: about 4 per cent of resins; pentatriacontane; a phytosterol; a phytosterolin; several fatty acids; starch; and calcium oxalate.

Literature.-Thompson, Amer. Jour. Pharm., 1899, p. 422; Holm, Merck's Report, 1908, p. 86; Power, Jour. Chem. Soc., 1910, p. 2223; Ibid., 1911, p. 2131; Stevenson and Sayre, Jour. A. Ph. A., 1915,4 , p. 1458 .

Nux Vomica.-The dried, ripe seeds of Strychnos Nux vomica (Fam. Loganiaceæ), a small tree native of the East Indies and also found growing in the forests of Ceylon, on the Malabar Coast and in northern Australia. The fruit is a kind of berry with from three to five seeds, which are freed from the bitter pulp by washing, and dried before exportation. The seeds are also known as Quaker Buttons.

Description.--Orbicular, compressed, concavo-convex, sometimes irregularly bent, margin acute or rounded, 17 to $30 \mathrm{~mm}$. in diameter, 3 to $5 \mathrm{~mm}$. in thickness; externally grayish-yellow or grayish-green, covered with long hairs giving the seed a satiny luster, sometimes 
with adhering dark-brown fragments of the fruit pulp, hilum near the center of one side, and a more or less distinct ridge resembling a raphe extending from it to the micropyle; very hard when dry, tough when damp; internally whitish, horny, endosperm in two more or less

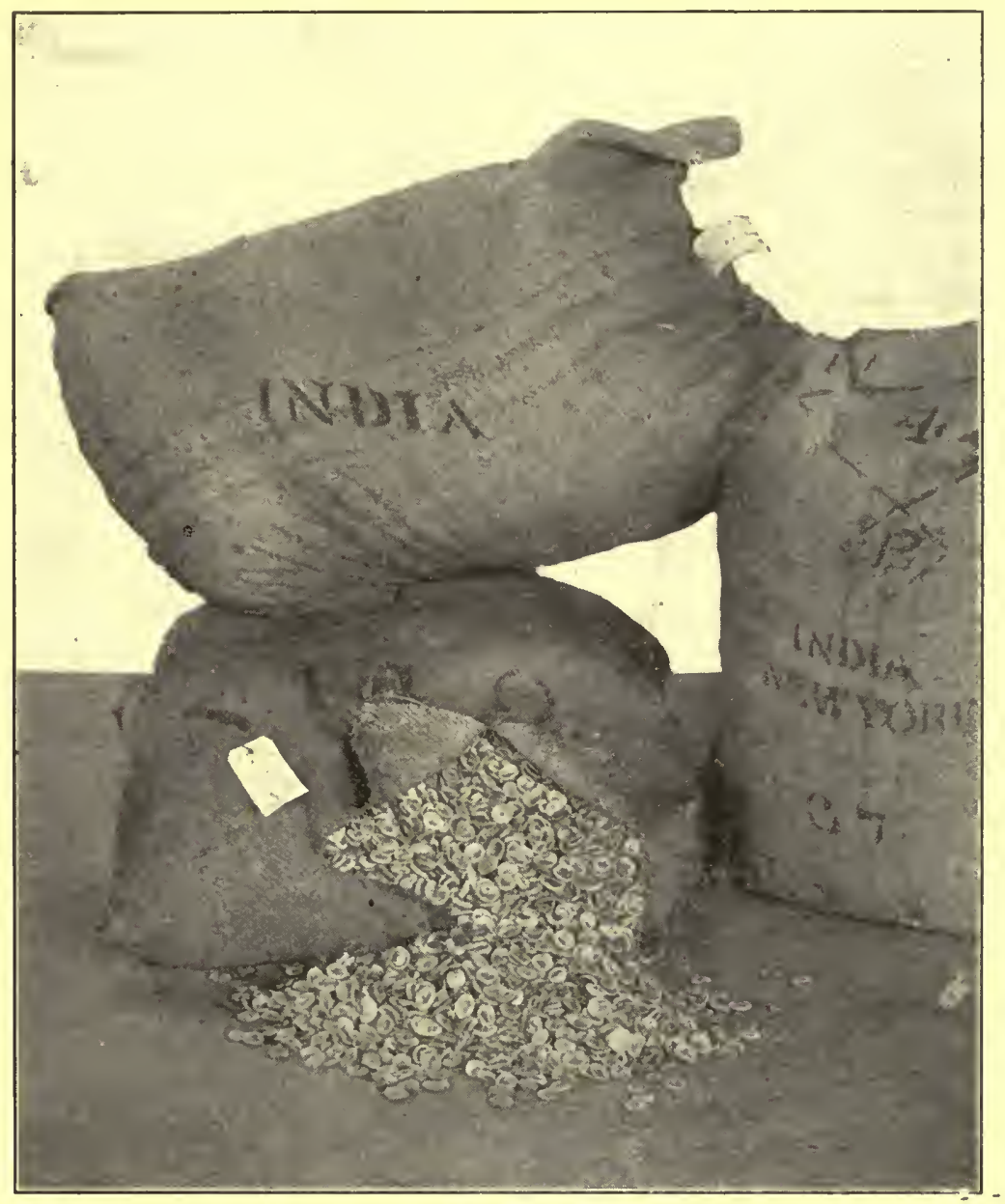

Fig. 220.-Original packages of Nux Vomica imported from India.-After a photograph by Parke, Davis \& Co.

regular concavo-convex halves, embryo small, situated near the micropyle, and with two heart-shaped cotyledons; inodorous; taste intensely and persistently bitter.

Inner Structure.-The epidermal cells of the seed-coat are thickwalled, very porous and are developed into long hairs, attaining a 
length of $1 \mathrm{~mm}$., the walls being nearly straight, strongly lignified and marked by longitudinal pores or folds; an inner layer of dark brown completely collapsed parenchyma cells, which in the vicinity of the raphe are somewhat turgid and enclose a fibrovascular bundle; the cells of the endosperm are of two kinds, those near the outer surface being more or less rectangular, the walls swelling but slightly in water; and those below which are irregularly polyhedral and having walls that swell quite perceptibly in water.

The walls of the endosperm cells consist of cellulose, are very thick and when examined with certain swelling reagents show not only lamellæ, but a radiate structure resembling pores. By some, these are considered to be protoplasmic strands, as they are easily stained with the aniline dyes. Kraemer compares them to the radial clefts of the starch grains of wheat.

The endosperm cells contain an irregular layer of protoplasm, in which is enclosed a fixed oil and aleurone grains, the latter consisting of large unequal globoids.

Powder-(Fig. 221.) Grayish-white; odor slight; taste intensely and persistently bitter; epidermal cells modified to strongly lignified hairs; endosperm cells containing a fixed oil and aleurone grains. Small, nearly spheroidal starch grains occur in the tissues of adhering fruit pulp. It is occasionally adulterated with olive endocarp and seeds of Metroxylon vitiense.

A qualitative test having some quantitative value in determining the strength of powdered nux vomica is as follows: 0.100 gramme of finely powdered nux vomica (calculated to contain 2.25 per cent of alkaloids) is shaken in the course of several hours with 500 e.c. of water. Ten c.c. of this solution, diluted with 90 c.c. of water; a few cubic centimeters of the dilute solution give the characteristic bitter taste of nux vomica. One c.c. of this dilution is calculated to contain 0.0000045 gramme of the alkaloids.

The following test is rather expeditious in obtaining an approximate idea of the quantitative value of nux vomica. One gramme of the powdered drug (calculated to contain 2.25 per cent of alkaloids) is mixed with 10 c.c. of a modified Prollius fluid ${ }^{1}$ and allowed to stand, with frequent agitation, from four to twenty-four hours. The solution is then filtered into a small separatory funnel and 5 c.c. of a dilute sulphuric acid ( 0.5 per cent) added, and after. separation of the aqueous solution the latter is diluted with 5 c.c. of water.

${ }^{1}$ Ether, 60 c.c.; alcohol, 7.5 c.c.; chloroform, 30 c.c.; ammonia, 2.5 c.c. It should be borne in mind in this connection that probably the modified Prollius solution does not extract all the alkaloids in the various drugs equally well. 
This solution of 10 c.c. contains 0.00225 gramme of the alkaloids of nux vomica. Calculating 20 drops as being equivalent to 1 c.c., we have $20 \times 10$ e.c. $=200$ drops. Then 200 drops of liquid contain approximately .00225 gramme of alkaloids and 1 drop contains $\frac{1}{200} \times .00225=.00001125$ gramme. A few drops of this solution, in a watch crystal, should give with the following reagents distinctive reactions.

Mayer's reagent, a pronounced white precipitate.

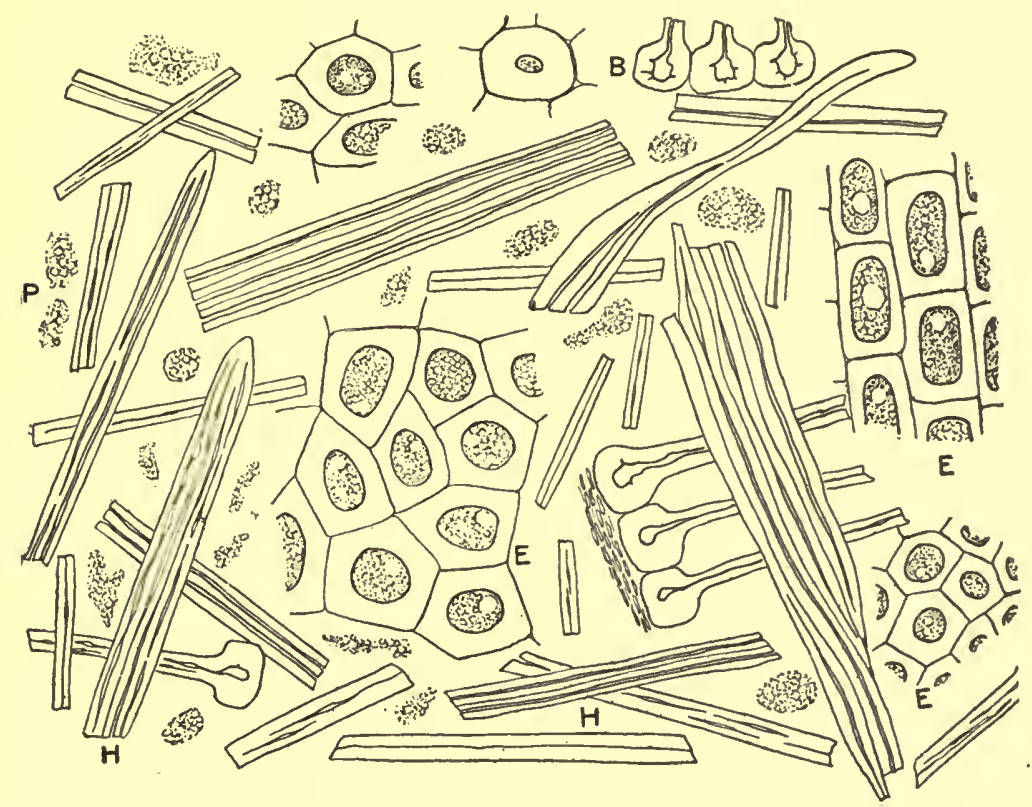

Fig. 221.-Nux Vomica: $H$, fragments of lignified hairs of seed-coat; $B$, basal portion of hairs; $E$, thick-walled parenchyma cells of endosperm containing one or more oil globules and protoplasm; $P$, isolated protoplasmic substance from endosperm cells.

Potassium permanganate and sulphuric acid, a purple color that is evanescent.

Potassium dichromate and sulphuric acid, a purple color that is more persistent.

Gold chloride solution gives a very slight yellow precipitate.

Constituents.-Ash 1 to 4 per cent; chlorogenic (formerly called igasuric) acid, which is dibasic acid and erystallizes in needles, the solutions giving a green color with solutions of ferric chloride; 1.5 to 5 per cent of alkaloids consisting of strychnine and brucine, the former comprising from one-third to one-half of the total amount. Strych- 
nine crystallizes in rhombic prisms and gives with concentrated sulphuric acid, in connection with potassium dichromate, a blue or violet color. Brucine forms rectangular octohedra and gives a deep-red color with nitric acid. A glucoside, loganin, is present in the seeds in small amount, but it is found in the pulp of the fruit to the extent of 5 per cent. The alkaloids are probably distributed in both the cell-contents and cell wall. Their presence in the wall is shown by the use of iodin solution and in the contents by the use of potassium dichromate and sulphuric acid. The thick cellulose walls give the hard, horny character to these seeds, as also the date seed. A small amount of starch is found in the fragments of adhering pulp. The seeds are sometimes made to look fresh by the use of a blue dye which is soluble in dilute alcohol.

Strychnine crystallizes in anhydrous orthorhombic crystals from alcoholic solutions. It forms crystallizable salts with the various acids, as well as double salts with platinic chloride and gold chloride. Of the salts, the sulphates are commercially the most important. According to Rammelsberg ${ }^{1}$ there are three strychnine sulphates: (1) An acid salt, with two molecules of water of crystallization $\left(\mathrm{C}_{21} \mathrm{H}_{22} \mathrm{~N}_{2} \mathrm{O}_{2} \cdot \mathrm{H}_{2} \mathrm{SO}_{4}+2 \mathrm{H}_{2} \mathrm{O}\right)$ and crystallizing in needles, crystal form not given. (2) A neutral salt with 5 molecules of water of crystallization $\left[\left(\mathrm{C}_{21} \mathrm{H}_{22} \mathrm{~N}_{2} \mathrm{O}_{2}\right)_{2} \cdot \mathrm{H}_{2} \mathrm{SO}_{4}+5 \mathrm{H}_{2} \mathrm{O}\right]$, orthorhombic (?), from hot aqueous solutions. (3) A neutral salt with six molecules of water of crystallization $\left[\left(\mathrm{C}_{21} \mathrm{H}_{22} \mathrm{~N}_{2} \mathrm{O}_{2}\right)_{2} \cdot \mathrm{H}_{2} \mathrm{SO}_{4}+6 \mathrm{H}_{2} \mathrm{O}\right]$, tetragonal, obtained from aqueous solutions at the ordinary temperature. This latter is the most characteristic form and is the one here described. At $25^{\circ} \mathrm{C}$. one part of strychnine sulphate is soluble in 31 parts of water; 65 parts of alcohol; and 325 parts of chloroform. It is nearly insoluble in ether. Crystals obtained on a microscopic slide from solutions in water, alcohol, dilute alcohol or a mixture of alcohol and chloroform vary in size from $0.40 \mathrm{~mm}$. to $2.0 \mathrm{~mm}$. (Figs. 222 and 223). ${ }^{2}$

Brucine is always associated in the plant kingdom with strychnine. It contains two methoxyl-groups and is looked upon as being di-methoxy-strychnine. If crystallized from hot water it contains 4 molecules of water of crystallization, but when crystallized

${ }^{1}$ C. Rammelsberg, Ber. d. deutsch. chem. Ges., 1881, 14, p. 1231; abstract in Zeitschr. f. Krystallog., 1884, 9, p. 108.

${ }^{2}$ A photomicrograph of tetragonal crystals of strychnine sulphate, showing side aspect in polarized light, is given in Kraemer's Applied and Economic Botany, p. 769.

Consult Groth's Physikalische Krystallographie (1905), 4th Ed., p. 431. 


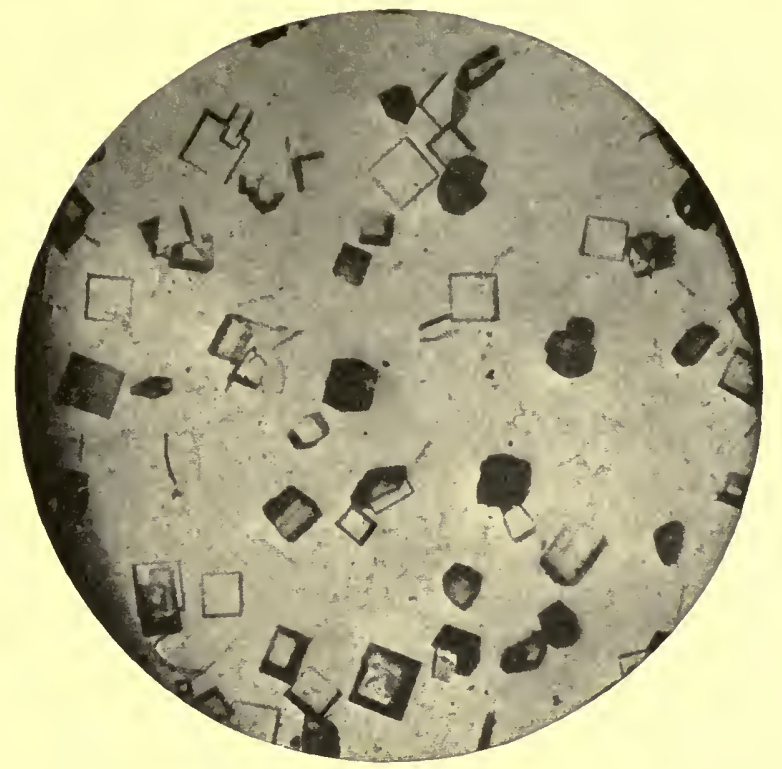

FIG. 222.-Strychnine sulphate: tetragonal crystals from aqueous solution, in ordinary light, showing basal and side aspects.

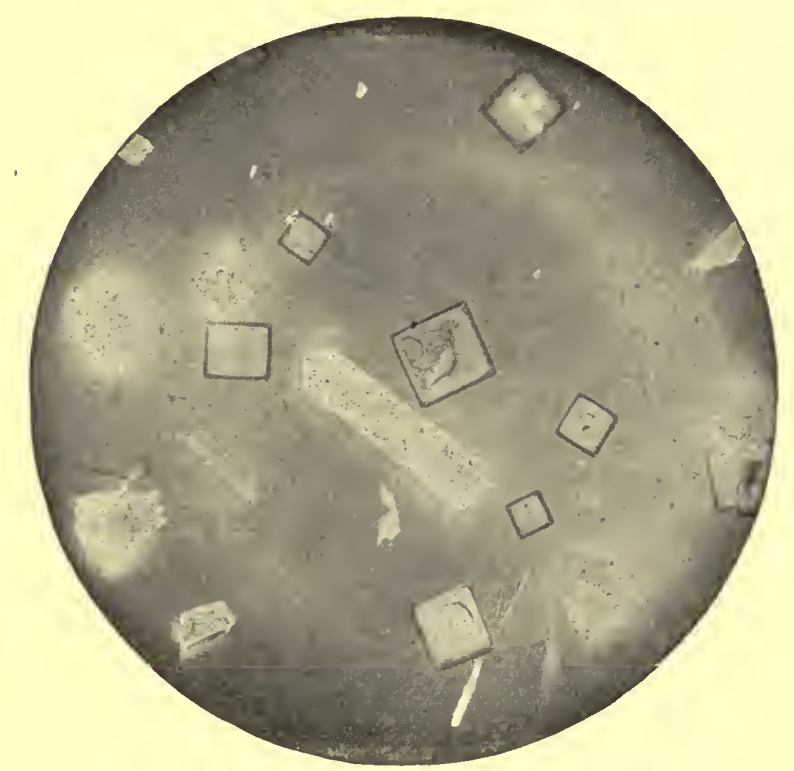

FIG. 223.-Strychnine sulphate: tetragonal crystals from aqueous solution, showing basal aspect in polarized light. Also one large crystal of a second form (orthorhombic?) of strychnine sulphate. 
from alcoholic solutions it contains but two molecules. ${ }^{1}$ A number of salts are used in medicine and the sulphate alone was examined. The crystals of brucine sulphate vary in length from 1 to $2.5 \mathrm{~mm}$. (Fig. 224).

Ignatia.-The seeds of Strychnos Ignatii (Fam. Loganiaceæ), a woody climber of the Philippine Islands, contain about the same amount of total alkaloids as nux vomica, of which one-third to twothirds is strychnine. The seeds are irregular, somewhat oblong or ovoid, pebble-like, 20 to $30 \mathrm{~mm}$. in length; grayish- or brownishblack, more or less translucent, and are nearly free from lignified hairs, such as are found in nux vomica.

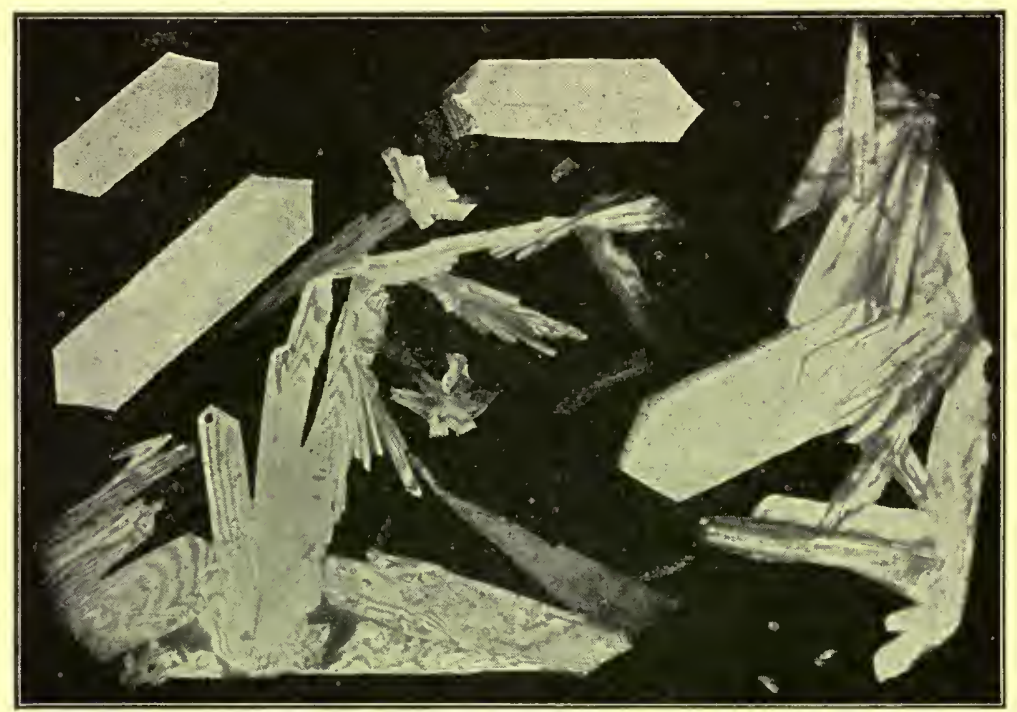

FIG. 224.-Brucine sulphate: orthorhombic erystals from aqueous solution.

Literature-Tschirch, Arch. d. Pharm., 1890, p. 203; Meyer, Wissenchaftliche Drogenkunde; Kraemer, Proc. Am. Phil. Soc., 1902, p. 174; Hill, Kew Bull., 1917, p. 121.

Spigelia.-Pinkroot.-The rhizome and roots of Spigelia marilandica (Fam. Loganiacex), a perennial herb indigenous to the southern United States. Spigelia should be collected in autumn, carefully dried and preserved, and not kept longer than two years.

Description.-Rhizome horizontal or slightly oblique, more or less branched, 1.5 to $3 \mathrm{~cm}$. in length, 2 to $3 \mathrm{~mm}$. in diameter; externally dark brown, slightly annulate from scars of bud-scales, the

${ }^{1}$ A. Oesterle, Grundriss der Pharmakochemie. 
upper portion with stem-scars or stem-remnants, under and side portions with numerous roots and root-scars; fracture short; internally, bark dark brown, 0.2 to $0.5 \mathrm{~mm}$. in thickness, wood yellow, slightly radiate, 1 to $1.5 \mathrm{~mm}$. in thickness, pith $1 \mathrm{~mm}$. in diameter; odor slightly aromatic; taste bitter, pungent.

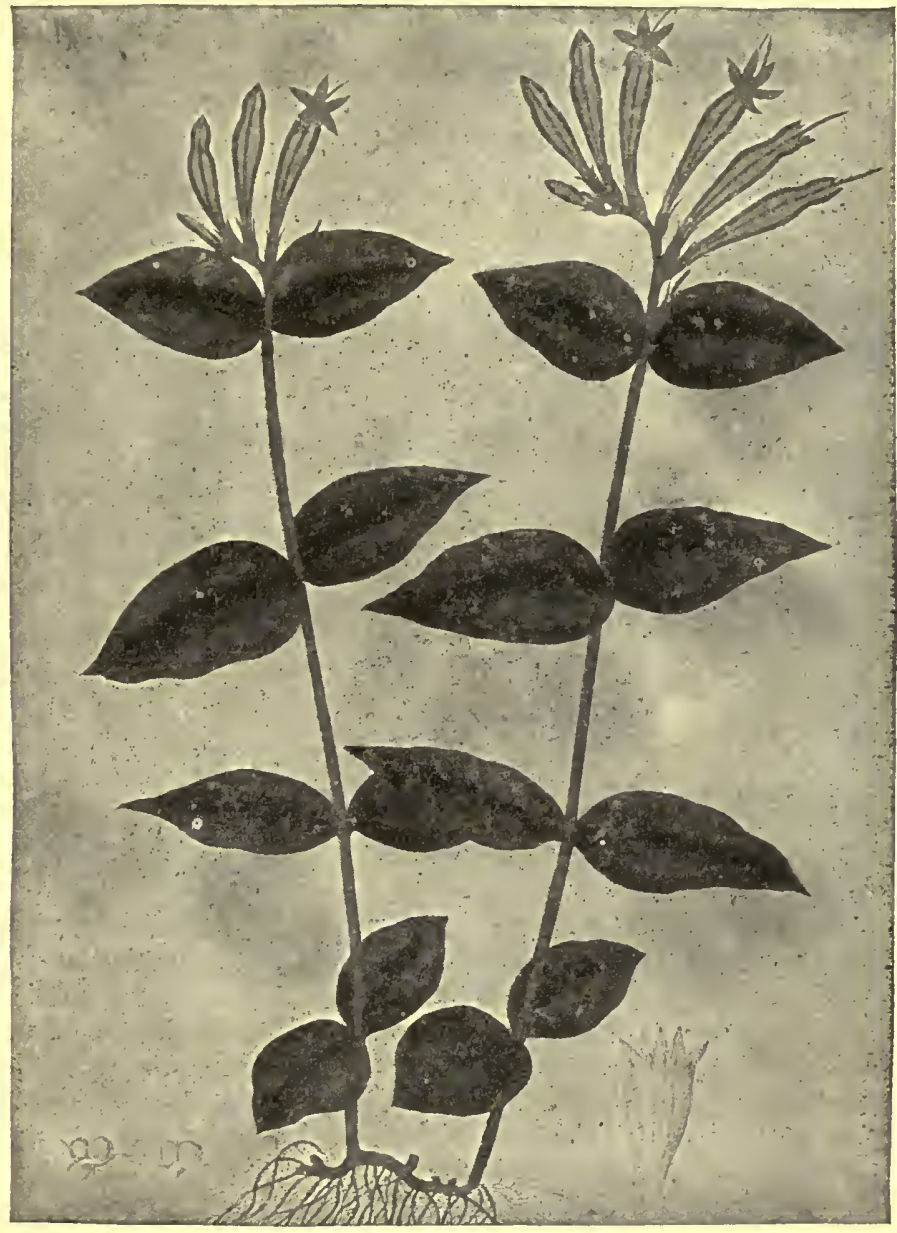

Carolina pink (Spigelia marilandica) showing the rhizome bearing two branches with opposite leaves, the flowers occurring in terminal scorpioid cymes.After Carson.

Roots 5 to $10 \mathrm{~cm}$. in length, about $0.3 \mathrm{~mm}$. in diameter, with numerous rootlets; externally dark brown, longitudinally wrinkled; internally light brown, wood nearly cylindrical, porous.

Inner Structure.-See Figs. 225 and 226. 


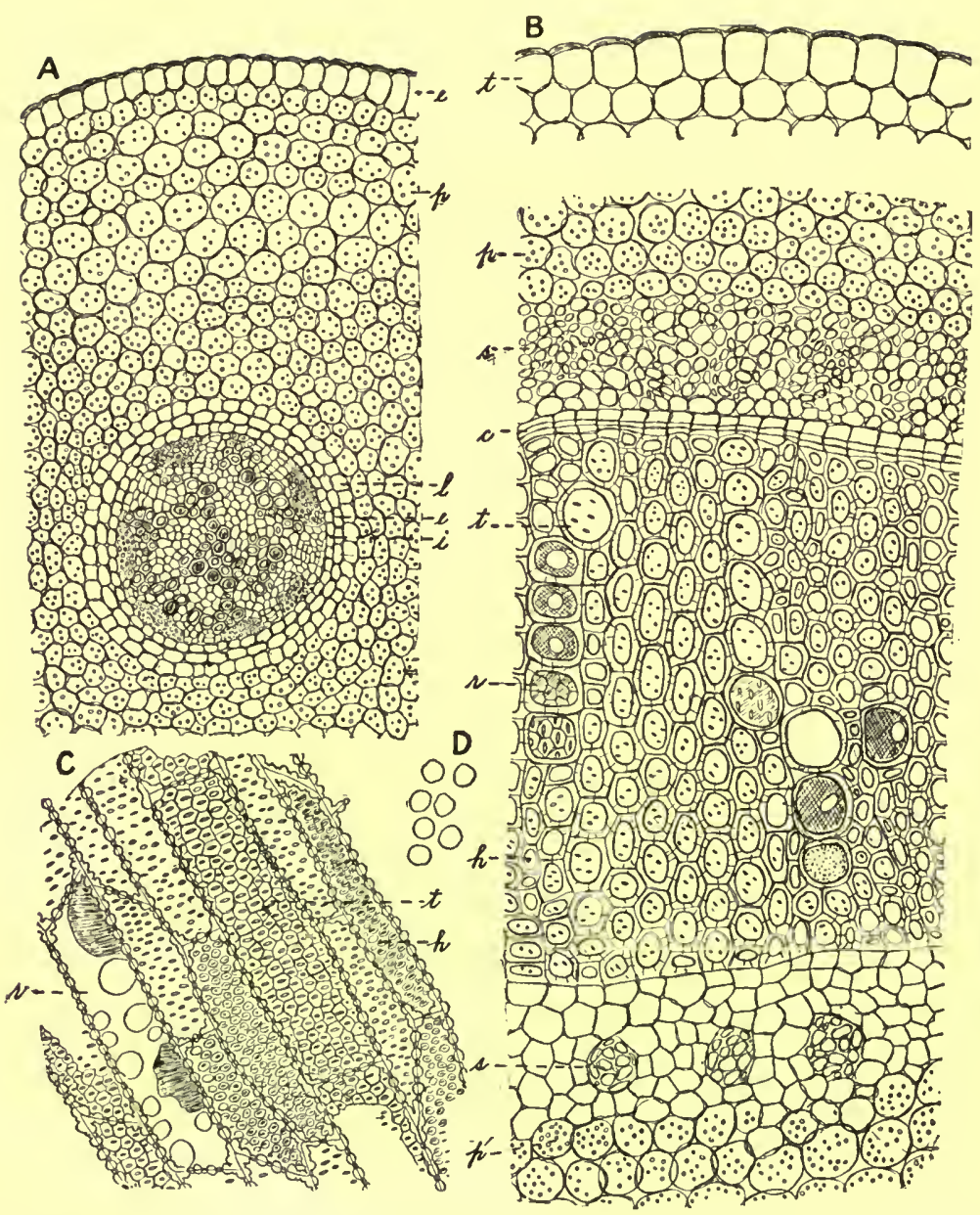

FIG. 225.-Pinkroot (Spigelia marilandica): $A$, transverse section of root showing epidermis $(e)$, parenchyma containing starch $(p)$, peripheral layer of central cylinder $(l)$, the cndodermis $(e)$, a pericambial layer $(i)$. The central cylinder consists of six to eight radial fibrovascular bundles, and some of the tracheæ contain a brown gummy substance. $B$, transverse section of rhizome showing epidermis $(t)$, the outer wall of which contains a yellowish-brown substance, parcnchyma $(p)$ of cortex containing starch, sieve of cortcx $(s)$, cambium $(c)$, tracheæ $(t)$, tracheæ $(r)$ containing globular or somewhat irregular yellowish-brown masses, trachəids $(h)$, internal sieve groups $(s)$, parenchyma of pith $\left(p^{\prime}\right)$ containing starch. $C$, longitudinal section of the woody part of the rhizome. $D$, isolated starch grains, which are from 0.020 to $0.005 \mathrm{~mm}$. in diameter. 
Powder.-Grayish-brown; starch grains spheroidal or slightly polygonal, from 0.002 to $0.006 \mathrm{~mm}$. in diameter; fragments containing lignified trachere and tracheids conspicuous; fragments of trachex with spiral thickenings relatively few; bast fibers few, very
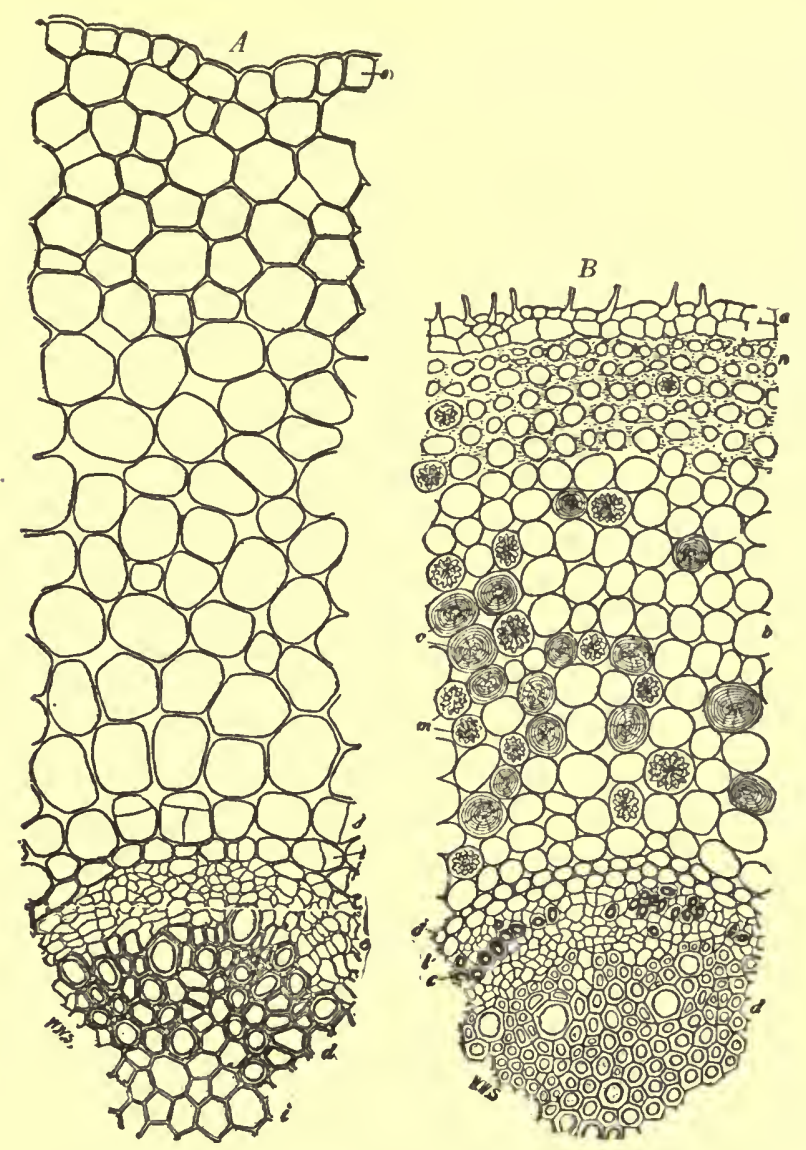

Fig. 226. $-A$, transverse section of the root of Spigelia marilandica: $a$, epidermis; $b$, cortex; $d$, xylem; e, cambium; $i$, pith; $j$, endodermis; $l$, pericycle $B$, transverse section of the root of Ruellia ciliosa: $a$, epidermis; $b$, cortex; $c$, bast fibers; $d$, xylem; $j$, endodermis; $l$, pericycle; $m$, cystoliths; $n$, collenchyma; $o$, sclereids or elongated stone cells.-After Stockberger.

long, non-lignified; occasional fragments of the reddish-brown epidermal cells.

Constituents.-A crystalline, volatile alkaloid, spigeline, which somewhat resembles coniine and nicctine and which forms precipi- 
tates with iodin or Mayer's reagent that are soluble in mineral acids; a bitter, acrid principle; volatile oil; resin; tannin; and starch.

Ruellia.-For a number of years true Spigelia has been substituted by or admixed with the rhizome and roots of east Tennessee pinkroot (Ruellia ciliosa), a perennial herb, belonging to the Acanthacex and growing in woods and thickets of the southern United States. The rhizome is somewhat oblique, having the basal portions of the aerial shoots usually attached. It is yellowish-brown, possessing a central pith and thick, hard wood. The roots are cylindrical and vary from yellowish-brown to dark brown, nearly straight, somewhat wiry, the bark being easily detached, leaving the tough, wiry, light yellowish wood exposed.
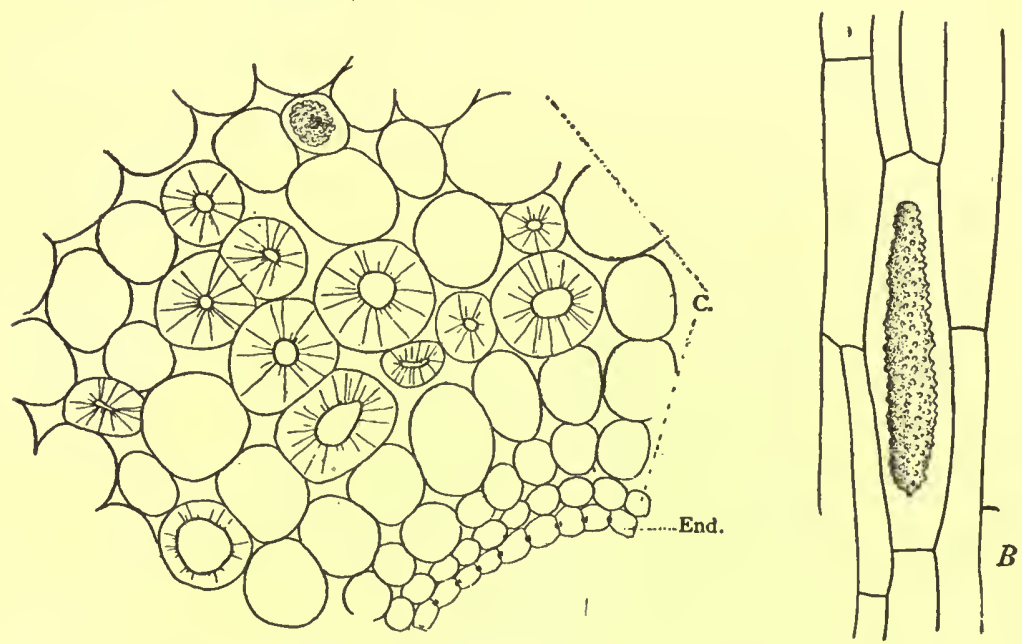

FIG. 227.-Ruellia ciliosa, the rhizome and roots of which are a common adulterant of spigelia. $A$, transverse section of a secondary root: $C$, cortical parenchyma with one cystolith and a number of stone cells with very thick walls and radiating simple pores: End, endodermis. $B$. longitudinal section of the same root, showing a single cell with an elongated cystolith, the encrustation being of calcium carbonate.-After Holm.

The histology of the rhizome of Ruellia is as follows: epidermal cells, tangentially elongated, the outer walls being much thickened; outer cortical layer composed of parenchyma cells, having collenchymatous thickenings of the wall, and cystolith-containing cells; inner cortical zone made up of thin-walled parenchyma, leptome and sclereids or strongly lignified, elongated stone cells having thick, porous and lamellated walls; endodermis distinct; xylem composed of a compact zone of porous tracheæ, and wood fibers; pith consisting 
of large thick-walled parenchyma; starch grains resembling those in Spigelia. The drug apparently contains a camphoraceous body which forms acicular crystals.

Phlox Carolina.-It has been supposed that among the other adulterants of Spigelia some of the commercial drug is derived from Phlox carolina or carolina pink. The latter is a perennial herb, belonging to the Polemoniaceæ, and growing in the woods of the southern United States. The rhizome is upright and is merely an extension of the over-ground stem (Fig. 228), comprising from 2 to 4 nodes. From each of the nodes arise 2 to 4 comparatively thick roots from 1 to $2 \mathrm{~cm}$. in length, unbranched and producing a large number of fine rootlets, especially near the ends.

The rhizome is very woody, the xylem occupying one-half of the radius of the section. The fibrovascular bundles are of the collateral type (Fig. 228) and there is a complete absence of intraxylary phloem, which is present in both Spigelia and Ruellia. The nature of the constituents in Phlox carolina is uncertain, as in the results published there is a question as to the authenticity of the material employed by the several investigators.

Literature.-Greenish, Amer. Jour. Pharm., 1891, p. 226; Holm, Ibid., 1906, p. 553; Stockberger, Pharm. Review, 1907; p. 2, Kraemer, Amer. Jour. Pharm., 1910, p. 470.

\section{GENTIANACEE, OR GENTIAN FAMUY}

A family of about 600 species of herbs, which are most abundant in temperate regions. The leaves are simple and usually opposite; the flowers are regular, and borne in terminal or axillary cymes; and the fruit is a capsule. The plants of this family invariably contain bitter principles. The primary cortex not infrequently contains collenchyma. A ring of sclerenchymatous tissues may or may not develop in the pericycle. Strands of interxylary phloem occur in Gentiana, Erythræa and other genera. The walls of the tracheæ possess simple pores only. The wood fibers are marked usually by bordered pores. The medullary rays are very narrow and sometimes entirely wanting. The non-glandular hairs are unicellular. In the parenchyma cells throughout Menyanthes occur intercellular branching hairs, having thick walls, which project into the intercellular spaces. At the margins of the leaves of Menyanthes there also occur hydathodes, or water storing cells. Calcium oxalate crystals are wanting. 


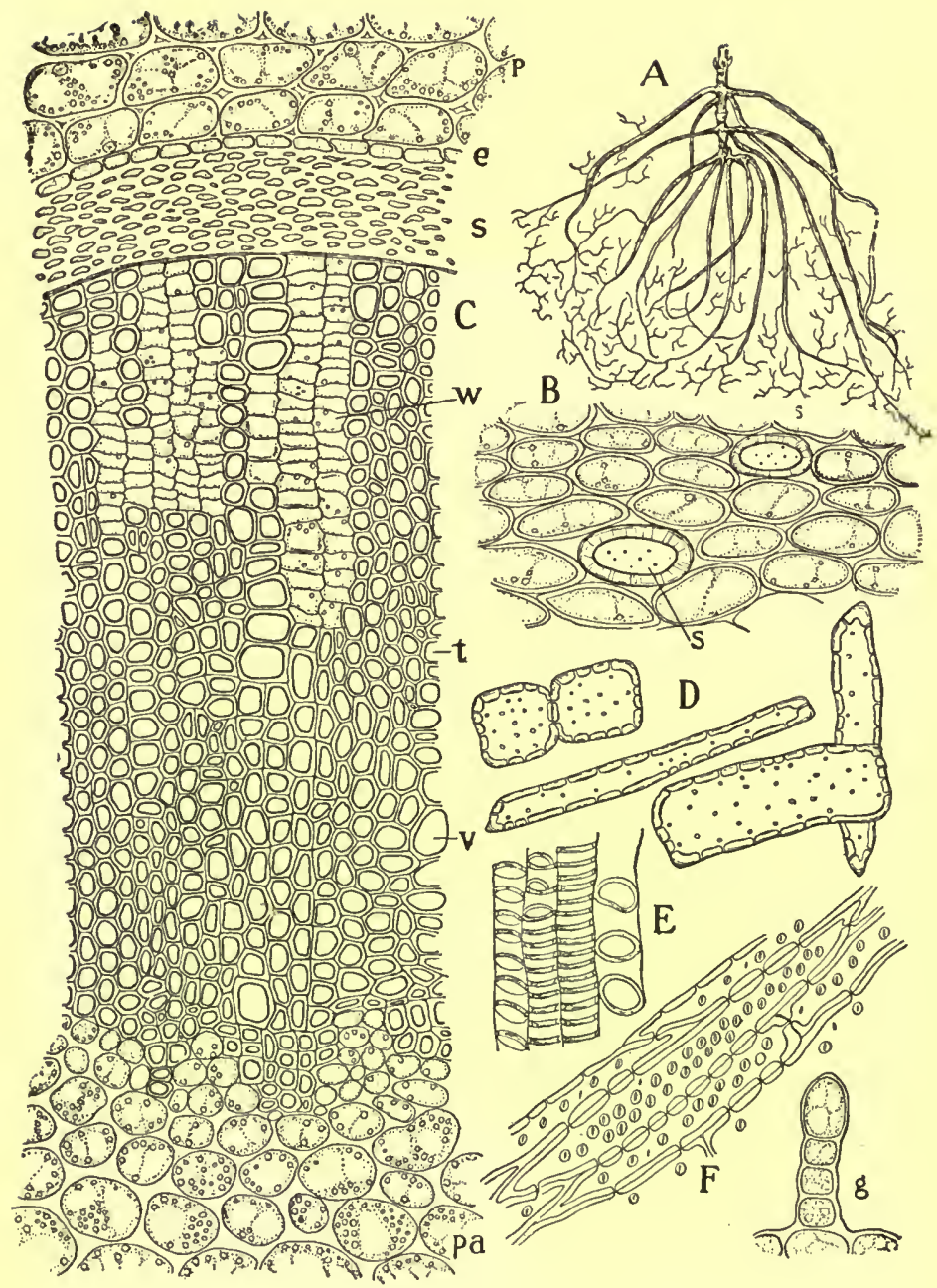

FIG. 228.-Phlox carolina: $A$, lower portion of plant showing long roots with numerous rootlets at the ends. $B$, parenchyma from cortex of rhizome showing two sclerotic cells $(s)$. $C$, cross-section of portion of rhizome showing parenchyma of cortex $(p)$ which contains protoplasm and starch grains endodermis $(e)$, leptome $(s)$, trachex $(v)$, libriform $(t)$, wood parenchyma $(w)$, parenchyma of pith containing starch grains and protoplasm $(p a)$. $D$, isolated sclerotic cells from cortex. $E$, tracheæ having annular and spiral thickenings. $F$, libriform cells. $G$, glandular hair from the leaf. 
Gentiana.-Gentian.-The rhizome and roots of Gentiana lutea (Fam. Gentianaceæ), a perennial herb (Fig. 229) indigenous to central and southern Europe and Asia Minor. The fleshy rhizomes and roots are collected in autumn and frequently cut into longitudinal pieces and slowly dried, during which latter process they develop a distinctive color and odor, losing thereby some of the gentiopicrin.

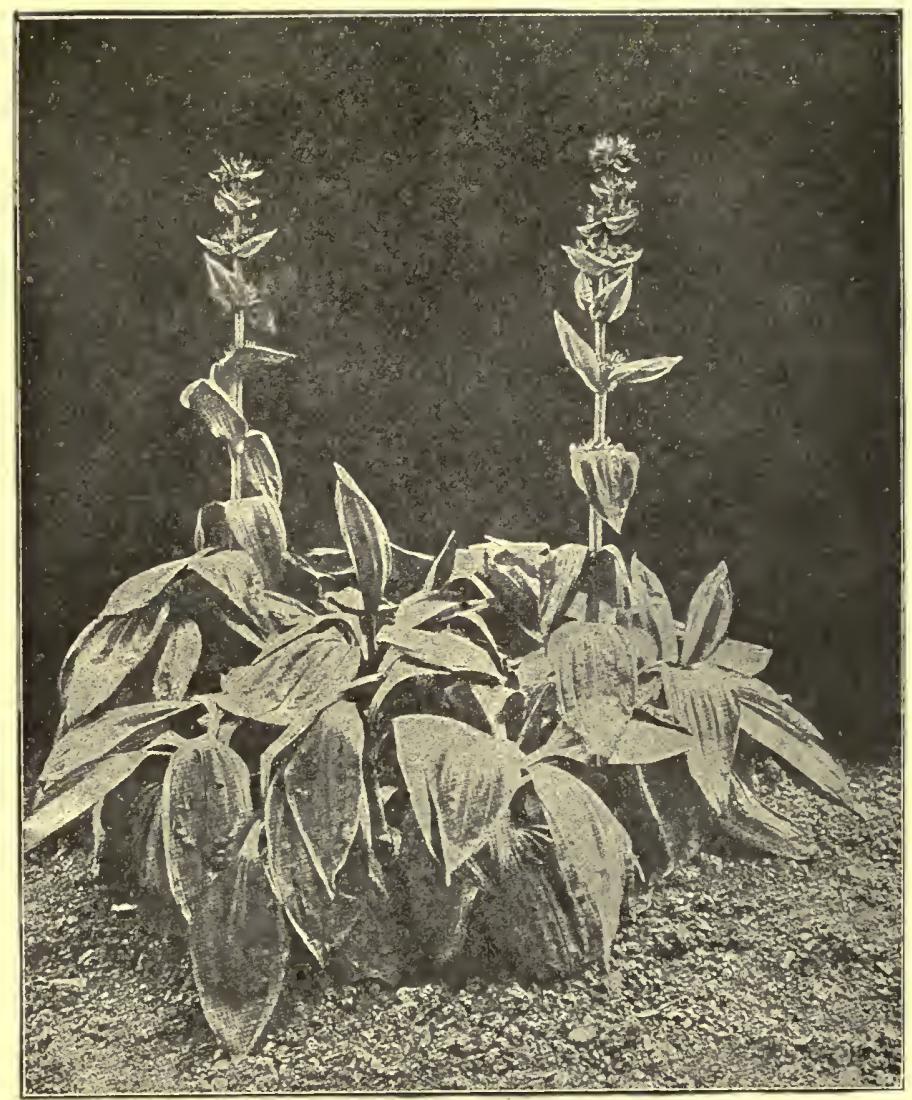

Fig. 229.-Gentiana lutea, growing in the Royal Botanic Society's Gardens (London).-After Pérrédès.

The commercial supplies are obtained from France, Germany, Spain and Switzerland.

Description.-Nearly cylindrical and sometimes branched, split longitudinally or broken into irregular pieces, 3 to $15 \mathrm{~cm}$. in length, 5 to $40 \mathrm{~mm}$. in diameter; externally light brown, the upper or rhizome portion annulate from scars of bud-scales, longitudinally wrinkled, 
and with few buds, stem- and root-scars, roots longitudinally wrinkled; fracture short when dry, tough and flexible when damp; internally dark yellow, bark 0.5 to $2 \mathrm{~mm}$. in thickness, porous, cambium zone distinct; odor heavy; taste bitter.

InNer Structure.-See Fig. 230.
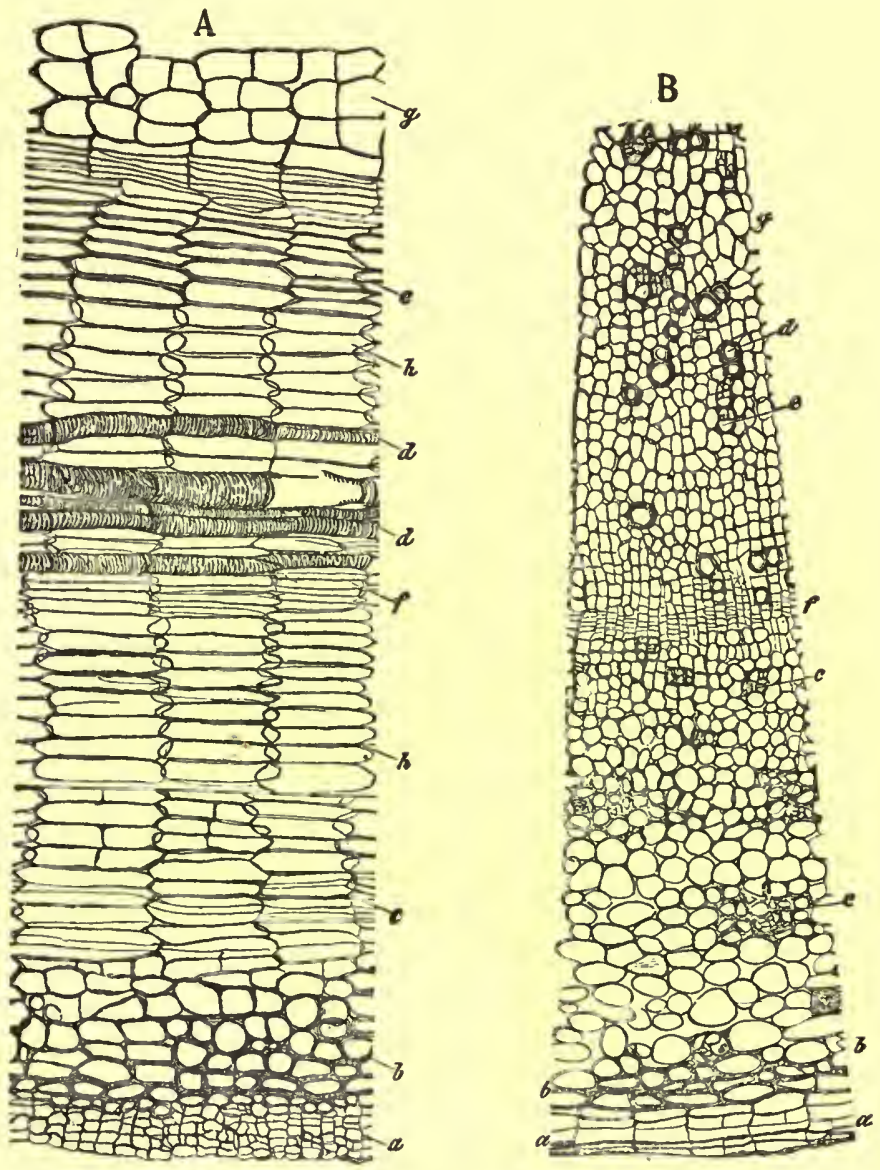

FIG. 230.-Longitudinal $(A)$ and transverse $(B)$ sections of gentian: $a$, cork; $b$, a kind of hypodermal layer; $c$, sieve; $f$, cambium; $e$, elongated fiber-like cells; $h$, somewhat elongated parenchyma cells; $g$, short parenchyma cells.After Meyer.

Powder.-Light brown or yellowish-brown; tracheæ having simple pores; intermediate fibers non-lignified, the walls being marked with irregular, simple, oblique pores; few globules of a fixed oil. Aqueous extract not less than 33 per cent. A substitute has been 
offered consisting of the exhausted drug to which aloes had been added. Ground olive endocarp has also been found in the powder.

A qualitative test having some quantitative value in determining the strength of powdered gentian is as follows: 0.500 gramme of the finely powdered drug is shaken with 500 c.c. of water for a few hours. Ten c.c. of the filtered solution are diluted with 10 c.c. of water. A few cubic centimeters of this solution should give the characteristic taste of gentian.

Constituents. - A bitter glucoside gentiopicrin, about 0.1 per cent, occurring in yellow needles which are readily soluble in water but less so in alcohol and to which the drug owes its peculiar bitterness and odor; a coloring principle gentisin (gentianin or gentisic acid), occurring in yellowish prisms which are soluble in alcohol but nearly insoluble in water, and becoming greenish-brown with solutions of ferric salts, whence some consider it to be a kind of tannin and have named it gentiotannic acid; quercitrin, or an allied product, crystallizing in yellowish needles; gentianose, a crystalline carbohydrate which occurs in the fresh root and which does not reduce Fehling's solution; 12 to 15 per cent of glucose; and pectin. Gentian also contains two other glucosides: gentiamarin, which is amorphous, has a disagreeable bitter taste and gives a slight darkening with iron salts; and gentianin, which occurs in yellowish needles, gives a greenish-black color with solutions of ferric salts and on hydrolysis yields gentienin, xylose and glucose.

Allied Plants.-The rhizomes and roots of various other Europeán species of Gentiana are sometimes collected and employed medicinally, as of Gentiana purpurea, collected in Switzerland, and G. pannonica and G. punctata, collected in Austria. The rhizome and roots of Elliott's gentian, Gentiana Elliottii, indigenous to the southeastern part of the United States, was at one time official in this country.

The root of American Columbo, also known as yellow gentian (Frasera carolinensis), a perennial herb growing in the eastern United States and Canada, resembles in the whole condition the true gentian, but is of a lighter color (see Calumba).

Chirata.-The entire plant of Sweertia Chirata (Fam. Gentianaceæ), an annual herb indigenous to the mountains of northern India. The plants are collected after the capsules are fully formed, dried and made into bundles.

Description.-Usually in flat bundles tied with strips of bamboo and about $1 \mathrm{M}$. in length, $15 \mathrm{~cm}$. wide and $7 \mathrm{~cm}$. in thickness. Root simple, tapering, about $7 \mathrm{~mm}$. in thickness near the crown; externally 
yellowish-brown, wrinkled, with few rootlets; internally, bark whitish, about $2 \mathrm{~mm}$ : in thickness, wood yellow, porous, radiate. Stem cylindrical, flattened, quadrangular above, each angle with a decurrent wing, about $1 \mathrm{M}$. in length, 4 to $6 \mathrm{~mm}$. in thickness, yellowishor purplish-brown, longitudinally wrinkled, internodes 3 to $8 \mathrm{~cm}$. in length; internally, bark yellowish-brown, very thin, easily separable, wood yellowish, slightly porous, radiate, 0.5 to $1 \mathrm{~mm}$. in thickness, pith lemon-yellow, 2 to $3 \mathrm{~mm}$. in diameter, easily separable from the wood, sometimes wanting. Leaves opposite, ovate-lanceolate, about $6 \mathrm{~cm}$. in length, $2.5 \mathrm{~cm}$. in diameter; summit acuminate; base somewhat amplexicaul; margin entire; upper and under surfaces brownish-green, midrib prominent and with 3 to 7 parallel lateral veins. Inflorescence a large panicle; flowers numerous, regular; calyx about $4 \mathrm{~mm}$. in length and with 4 lanceolate divisions; corolla yellow, rotate, about $10 \mathrm{~mm}$. in length, with 4 lanceolate lobes, each with a pair of nectaries near the base; stamens 4 , inserted at the base of the corolla tube; style slender, with two recurved stigmas; ovary l-locular, with 2 parietal placentas. Fruit a superior, ovoid, pointed, yellowishbrown, bicarpellary, unilocular capsule. Seeds numerous, anatropous, somewhat oblong, flattened, about $0.5 \mathrm{~mm}$. in length, testa reticulate; embryo small, straight, embedded in the endosperm. Odor slight; taste extremely bitter.

Powder.-Dark yellow; tracheæ spiral, scalariform or with simple pores; sclerenchymatous fibers long, narrow, thick-walled, more or less lignified, and with oblique pores; parenchymatous cells of pith large, slightly lignified, and with numerous simple pores; pollen grains oblong or ellipsoidal, very prickly, about $0.035 \mathrm{~mm}$. in diameter; collenchymatous cells with yellowish-brown resin and tannin masses.

Constituents.-A bitter glucoside chiratin, which is precipitated by tannin and yields on hydrolysis two bitter principles; ophelic acid and chiratogenin, the latter being insoluble in water. Ophelic acid is a brown hygroscopic substance which is readily soluble in water and alcohol and on heating with Trommer's reagent causes the deposition of yellowish cuprous oxide. The drug also contains resin, tannin and 4 to 8 per cent of ash.

Allied Plants.-Other species of Sweertia, as well as other bitter plants known in India as " chiretta," find their way into the market, but are, however, easily distinguished from the true drug.

Centaurium.-Herba Centauri Minoris, Centaurea Minore, Lesser Centaury Tops or Bitter Herb.-The over-ground plant of Centaurium umbellatum (Erythræa Centaurium), an annual 
herb belonging to the Gentian family, indigenous to Europe and naturalized in Canada and from Massachusetts to Indiana, growing commonly in waste places. The plant is gathered at the time of flowering in July, when some of the fruits have partially matured. The roots are separated, and the plants are tied into small bundles, from 3 to $6 \mathrm{~cm}$. in diameter, and dried. The drug is official in a number of the foreign Pharmacopœias, and the name Centaurium was applied to it by the old herbalist, in allusion to its supposed priceless medicinal value.

Description.-Stems obscurely 4-angled, or cylindrical and somewhat winged, from 20 to $30 \mathrm{~cm}$. in length, corymbosely branched above; externally light green, light yellowish-brown or dark brown, finely longitudinally striate, and glabrous, having narrow membranous light brown wing-like ridges which are caused by an extra development of collenchyma; fracture fibrous, pith hollow. Leaves opposite, sessile, linear, oblong or elliptical, the latter from 2 to 3.5 $\mathrm{cm}$. in length and from 2 to $10 \mathrm{~mm}$. in width; summit acute, margin entire; greenish-brown and glabrous. Flowers, in dense terminal cymes, calyx tubular having long linear segments; corolla salvershaped, rose pink, when fresh or carefully dried, otherwise light brown; stamens 5, yellow, inserted on the corolla tube, the anthers becoming more or less spirally twisted; ovary unilocular, style filiform. Fruit an ovoid capsule, 2-valved containing numerous small reticulated seeds; odor distinct; taste persistently bitter.

Inner Structure.--Stems having a layer of epidermal cells with strongly thickened outer walls; cortex of several rows of cells; zone of leptome, small; xylem consisting of a closed ring of tracheæ, wood fibers and thick-walled parenchyma. The leaves consist of an upper epidermal layer made up of cells which are developed to short papillæ, the walls being strongly thickened and the cuticle finely wrinkled; palisade layer with 2 rows of cells; mesophyll consisting of several layers of thin-walled cells; lower epidermis resembling those of the upper surface but showing more numerous stomata; epidermal layer of calyx made up of thick-walled cells developed to short papillæ, and in which the lumina is very sinall. Pollen grains spheroidal, yellow, nearly smooth and having 3 pores.

Constituents.-A bitter principle; a volatile oil; a resin; erytaurin, a colorless crystalline glucoside; erythrocentaurin, a crystalline, tasteless principle, which is colored red on exposure to the light. Also mucilage and wax. Centaurium should yield not less than 25 per cent of aqueous extract; and the ash should be not more than 4 per cent. 
Sabatia.-Sabbatia, American Centaury, Square Stemmed Sabbatia or Rose Pink.-The over-ground plant of Sabatia (Sabbatia) angularis (Fam. Gentianacex), a biennial herb growing in rich soil and moist meadows throughout the eastern United States and Canada. The plant is collected at the time of flowering, during the summer, and the commercial drug frequently consists of only the stems with their capsular fruits.

Description.-Stems distinctly 4-angled, except in the lower portion which may be somewhat cylindrical, branching, the upper branches being opposite; externally very light green to light yellowish- or pinkish-brown; glabrous throughout and having at the angles a thin membranous wing-like ridge, due to the extra development of collenchyma; fracture fibrous; pith hollow. Leaves cordate-ovate or oblong, summit acute, base usually more or less clasping, margin entire; thin, of an olive-green color and palmately 3 - to 5-nerved. Flowers consisting of a deeply 5-parted calyx having lanceolate or linear teeth; corolla rotate, 5-parted, the segments being obovate-elliptical, about $1.5 \mathrm{~cm}$. in length and when fresh or carefully dried of a rose-pink color otherwise pinkish-brown; stamens 5 , having linear anthers, becoming more or less recurved and revolute; ovary oblong, having a long style and a bi-cleft stigma which at first is connivent, later spreading and after fertilization, becoming more or less twisted. Fruit, a 2-valved, oblong or ovoid capsule, tipped with the slender remains of the style, dark brown in color and covered with a resin. Seeds numerous ellipsoidal, deeply reticulate from 0.200 to $0.400 \mathrm{~mm}$. in length.

Inner Structure.-The stems consist of a thick-walled epidermal layer, the cuticle being much wrinkled; a cortex of several layers of chlorophyll-containing parenchyma; endodermis and pericycle not distinct; the stele of a small zone of leptome, and a compact xylem made up chiefly of wood fibers and thick-walled parenchyma and relatively few trachex; the intraxylary leptome is situated at the periphery of the pith, being frequently quite separated from the xylem; pith of thin-walled parenchyma at the periphery, free from starch, being hollow at the center. The structure of the leaf is very simple, the chlorenchyma being almost homogeneous in structure, and the stomata, which are confined to the dorsal surface, lack subsidiary cells.

Constituents.-A bitter principle, 3.75 per cent; erythrocentaurin; a volatile oil; a greenish resin; mucilage; sugars; ash 2.85 per cent.

Literature.-Hankey, Amer. Jour. Pharm., 1891, p. 335. 
Menyanthes.-Folia Menyanthidis, Folia Trifolit Fibrini, Menyanthes Leaves or Marsi Buckbean Leaves.-The leaves of Menyanthes trifoliata (Fam. Gentianaceæ), a low perennial herb, having thick, horizontal rhizomes and growing in bogs in the northern United States, and from Greenland to Alaska. The plant is indigenous to Europe and Asia and the leaves are official in several of the foreign Pharmacopœias. The leaves are gathered in May or June, at the time of the flowering of the plant, and carefully dried.

Description.-Leaves, 3-foliate, having long sheathing petioles; the latter from 7 to $15 \mathrm{~cm}$. in length, dark brown and finely striate, usually much flattened and considerably twisted; leaflets usually much broken in the drug, when entire, nearly sessile, elliptical or ovate, from 2 to $6.5 \mathrm{~cm}$. in length and 1 to $4 \mathrm{~cm}$. in breadth, summit obtuse or rounded, base spatulate, margin entire, occasionally somewhat undulate, olive-green and glabrous; odor distinct, slight; taste very bitter.

Inner Structure.-Petiole consisting of parenchyma, having large intercellular spaces, which shrink to such an extent in the drying of the drug as to give it a spirally twisted character. In addition, there are usually about 12 fibrovascular bundles, which are arranged in an interrupted circle, enclosed by a distinct endodermis. The upper and lower surfaces of the leaves are much alike, consisting of polygonal cells, which are developed to papillæ and in which the cuticle is thick and much wrinkled; the palisade cells are short cylindrical and occur in 2 to 4 layers beneath the upper epidermis; the loose mesophyll layer consists of nearly isodiametric cells having large intercellular spaces.

Constituents.-A bitter glucoside, menyanthin, yielding on hydrolysis glucose and menyanthol. A mixture of fatty acids, occurring in the form of esters of cholesterin and ceryl alcohol. A reddish-yellow coloring principle, resembling carotin, also cane sugar and chlorophyll. Menyanthes should yield not less than 23 per cent of aqueous or diluted alcohol extractive and not more than 10 per cent of ash.

\section{APOCYNACEA, OR DOGBANE FAMILY}

A large family, comprising over 1000 perennial herbs, shrubs and trees. They are very widely distributed, occurring mostly, however, in tropical regions. The leaves are usually opposite, the flowers regular and 5-merous, and the fruits are either follicles or drupes. Non-articulated laticiferous tubes are present in all parts of the 
plants of this family. These tubes are very early developed, being present even in the embryo. They occur in the pith, are distributed throughout the tissues of the bark, and are associated with the vascular bundles in the veins of the leaf. They usually have thin walls, narrow lumina, and the contents may be a caoutchouc-like substance, so that on the fracture of the bark it may be drawn out into thin threads as in the Celastraceæ. The latex may also contain starch grains and distinct nuclei. Secretory cells are also present in the barks of some of the genera, as Aspidosperma. Bast fibers occur in the pericycle, either singly, or in groups. The walls of the trachex are usually marked with simple pores, except when in contact with the medullary rays, when the dividing wall possesses bordered pores. The wood fibers have either simple pores or bordered pores. The medullary rays are narrow. Strands of intraxylary phloem occur in the pith. Calcium oxalate is secreted in the form of solitary crystals, styloids or rosette aggregates. The non-glandular hairs are either unicellular or uniseriate. Glandular hairs are wanting, except in the leaves of the oleander, in which the hairs consist of several rows of elongated cells, which are covered with a palisade-like secretory epidermis. In the oleander the stomata are situated in deep pits, which are covered with long hairs. In the leaves of Aspidosperma the palisade cells are often more or less lignified. In the leaves of Strophanthus the subsidiary cells of the stomata are parallel to the pores.

Apocynum.-Canadian Hemp.-The dried root of Apocynum cannabinum (Fam. Apocynacex), a perennial herb growing in fields and thickets in the United States and southern Canada (Fig. 231).

Description.-Cylindrical, somewhat branched, usually broken into pieces 4 to $10 \mathrm{~cm}$. in length, 5 to $10 \mathrm{~mm}$. in diameter; externally light brown, longitudinally wrinkled and transversely fissured, with few rootlets or rootlet-scars; fracture short; internally, bark light brown, $1 \mathrm{~mm}$. in thickness, easily separable from the lemon-yellow, porous, slightly radiate wood; odor slight; taste of bark bitter and acrid, of wood slightly bitter.

Stem fragments are distinguished by having a comparatively thin, finely fibrous bark and a hollow center.

InNer Structure.-See Fig. 232.

Powder.-Light brown or dark brown; starch grains-numerous, from 0.003 to $0.015 \mathrm{~mm}$. in diameter, spheroidal, ellipsoidal, ovoid, pyriform or more or less irregular, and with a hyaline central cleft sometimes more or less altered, swollen; numerous fragments of strongly lignified wood fibers, associated with trachex mostly having 
bordered pores, occasionally with spiral thickenings; fragments of cork layer few, the walls being of a reddish-brown color; an oceasional fragment with long, narrow, thin-walled lacticiferous tubes, having a yellowish-brown, granular content.

Constituents.-Cynotoxin (apocynamarin), a dilactone of Kiliani's oxydigitogenic acid, or of an isomeride, forms small rhombic pyramids, which are sparingly soluble in water and the usual organic

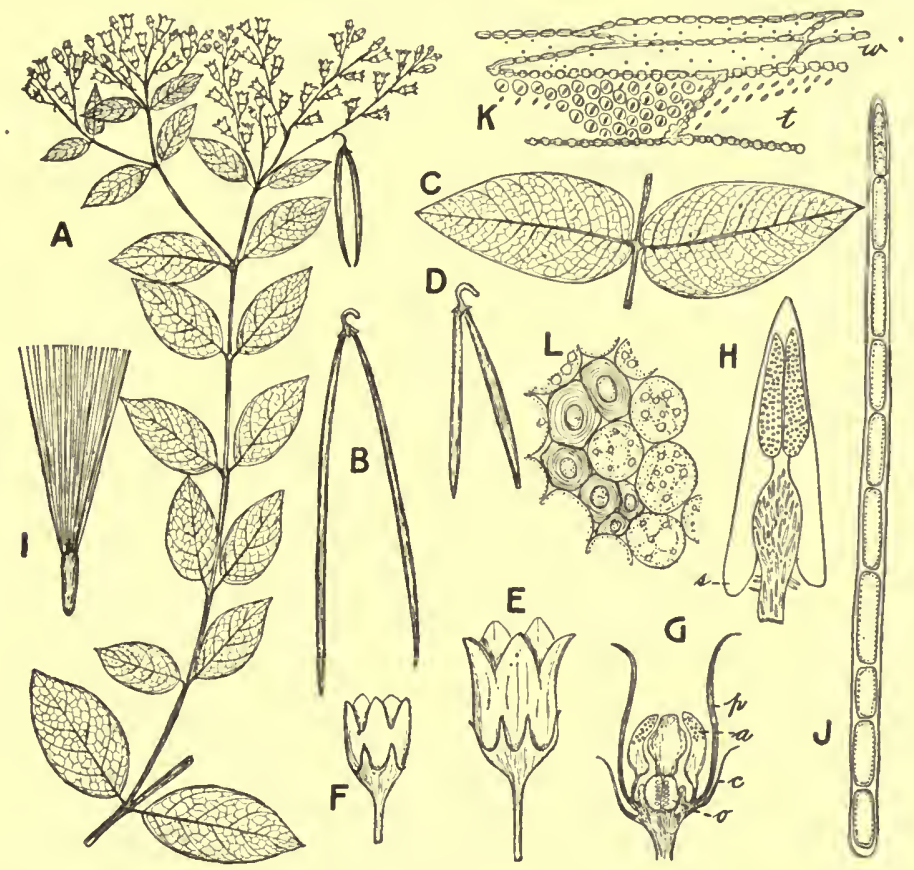

Frg. 231.-Apocynum androsæmifolium: $A$, flowering branch; $B$, a fruit consisting of 2 follicles; $E$, flower; $G$, longitudinal section of flower; $H$, single stamen with long spurs $(s) ; J$, uniseriate hair from leaf; $K$, tracheæ with bordered pores $(t)$ and wood fibers $(w) ; L$, a few bast fibers and adjoining parenchyma cells containing starch. Apocynum cannabinum: $C$, two of the opposite, nearly scssile leaves; $D$, fruit; $F$, flower; $I$, seed with coma of long, l-celled, hyaline hairs.

solvents, and is extremely bitter. Apocynin ( 0.2 per cent) occurs in slender colorless prisms with a slight odor of vanillin, and is apparently identical with acetovanillon. There are also present a glucoside, apocynein; a volatile oil; resin; tannin; starch; and from 10 to 11.6 per eent of ash.

Apocynum androsæmifolium.--The plant somewhat resembies A. cannabinum, but is distinguished by the petiolate leaves, the larger 
flowers and follicles (Fig. 231). The root resembles that of A. cannabinum, but is easily distinguished by the presence of small groups of stone cells in the outer cortex (Fig. 232).
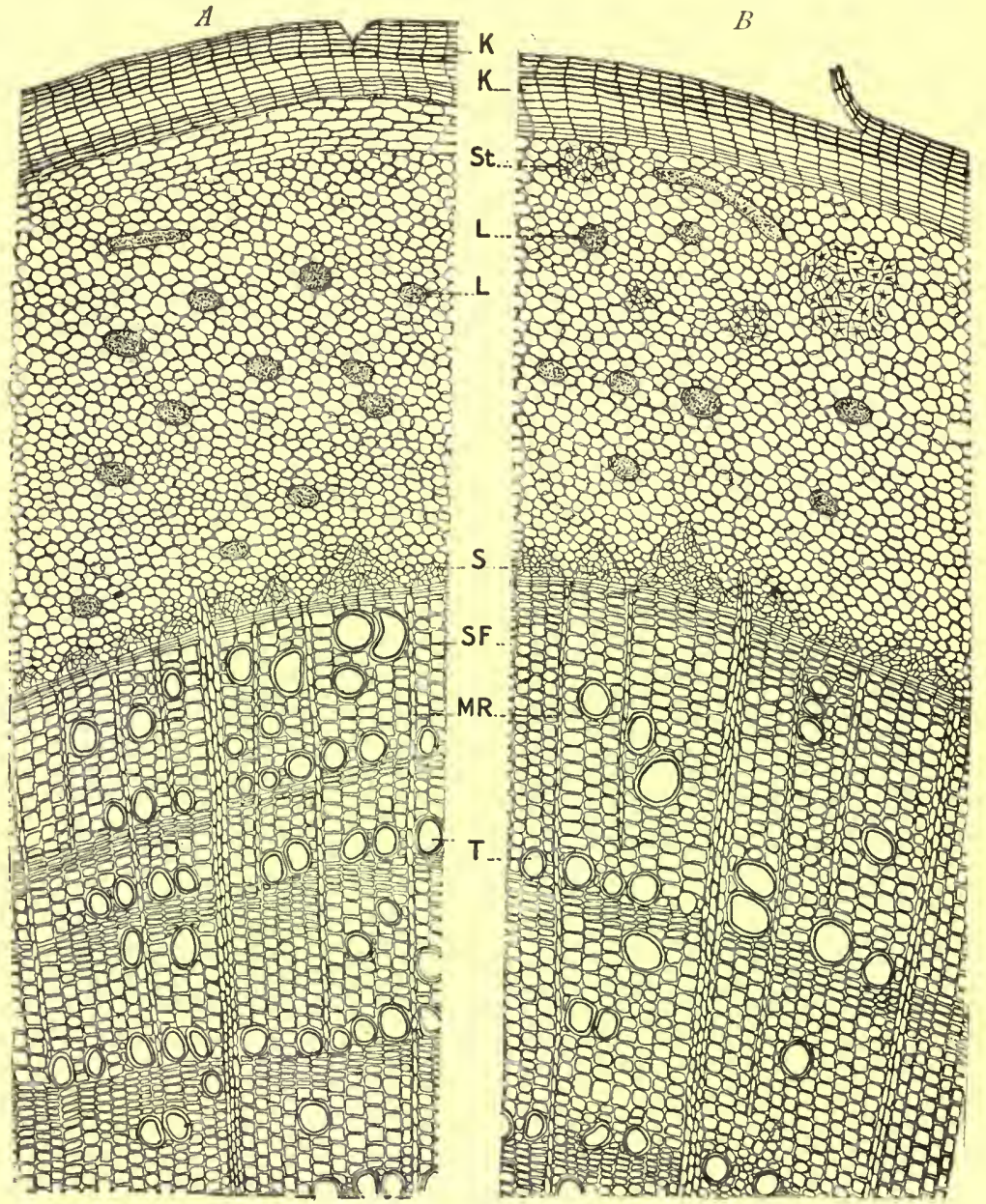

Fig. 232.-A, transverse section of the root of Apocynum cannabinum showing cork $(K)$; laticiferous tubes $(L)$ in the cortex; sieve $(S)$, beneath which is the cambium zone; wood fibers $(S F)$, tracheæ $(T)$, and medullary rays $(M R)$. B, transverse section of the root of Apocynum androsæmifolium showing in addition groups of stone cells $(S t)$ in the cortex.

Literature.-Holm, Merck's Report, 1910, p. 277; Power, Jour. Chem. Soc., 1909, p. 734.

Strophanthus.-The ripe seeds of Strophanthus Kombe (Fam. Apocynacex), a twining shrub found in Zambesi and other parts of 
eastern Africa. The plumose awns at the summit of the seeds are usually removed before exportation (Fig. 233).

Description.-Hemi-anatropous, oblong-lanceolate or spatulate, acute or acuminate, unevenly flattened and in transverse section deltoid or plano-convex, 8 to $15 \mathrm{~mm}$. in length, 3 to $5 \mathrm{~mm}$. in breadth, 1 to $1.5 \mathrm{~mm}$. in thickness; externally yellowish-green, covered with long hairs giving a silky appearance to the seed, the raphe extending as a distinct ridge from the hilum about half the length of the seed; fracture short; internally whitish, endosperm about $0.2 \mathrm{~mm}$. in

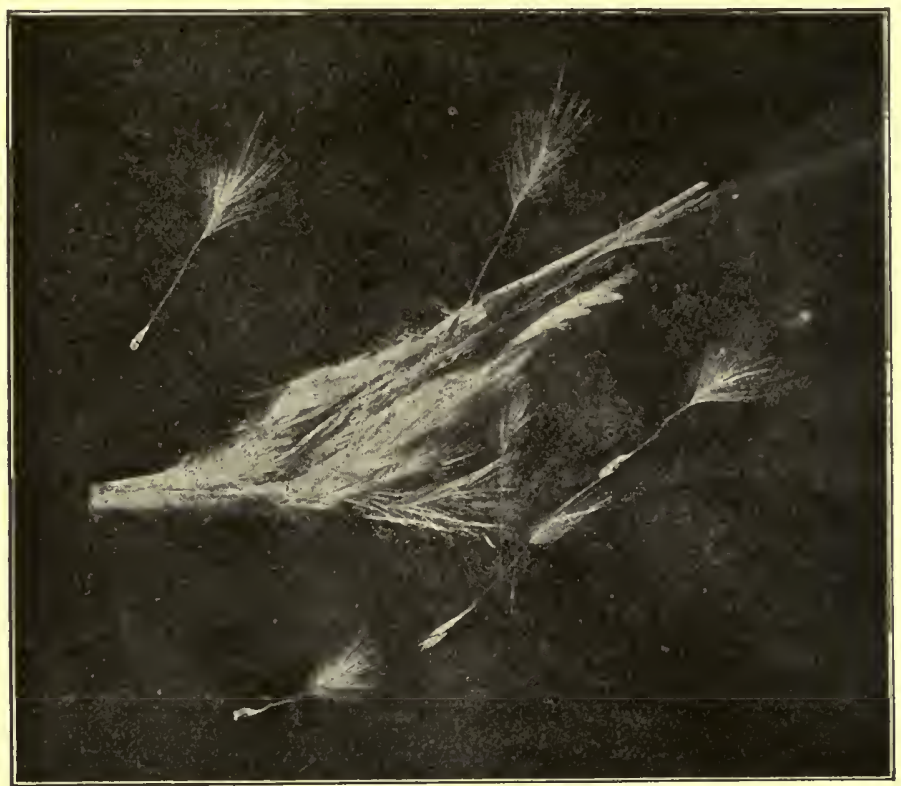

FIG. 233.-A dehiscent follicle of strophanthus showing plumose seeds.

thickness, embryo 6 to $12 \mathrm{~mm}$. in length and 1 to $2 \mathrm{~mm}$. in breadth, cotyledons plano-convex, about $1 \mathrm{~mm}$. in breadth, hypocotyl conical, $2 \mathrm{~mm}$. in length; inodorous except when broken; taste very bitter.

When treated with 90 per cent sulphuric acid the endosperm, in about 65 per cent of the seeds, becomes green, turning to brownishgreen and not reddish; the cotyledons become red or purple and finally green, in some instances.

Inner Structure.-(Fig. 234.) Outer epidermal layer having numerous, non-glandular hairs, which are from 0.200 to $0.800 \mathrm{~mm}$. in length, usually more or less bent, thin-walled and slightly lignified, thickened and porous at the base; an inner layer of somewhat col- 
lapsed cells and which are more or less turgescent in the raphe, in among the cells of which is included a small fibrovascular bundle, having numerous spiral trachex; endosperm of polygonal cells with slightly thickened walls and containing an oily cytoplasm small

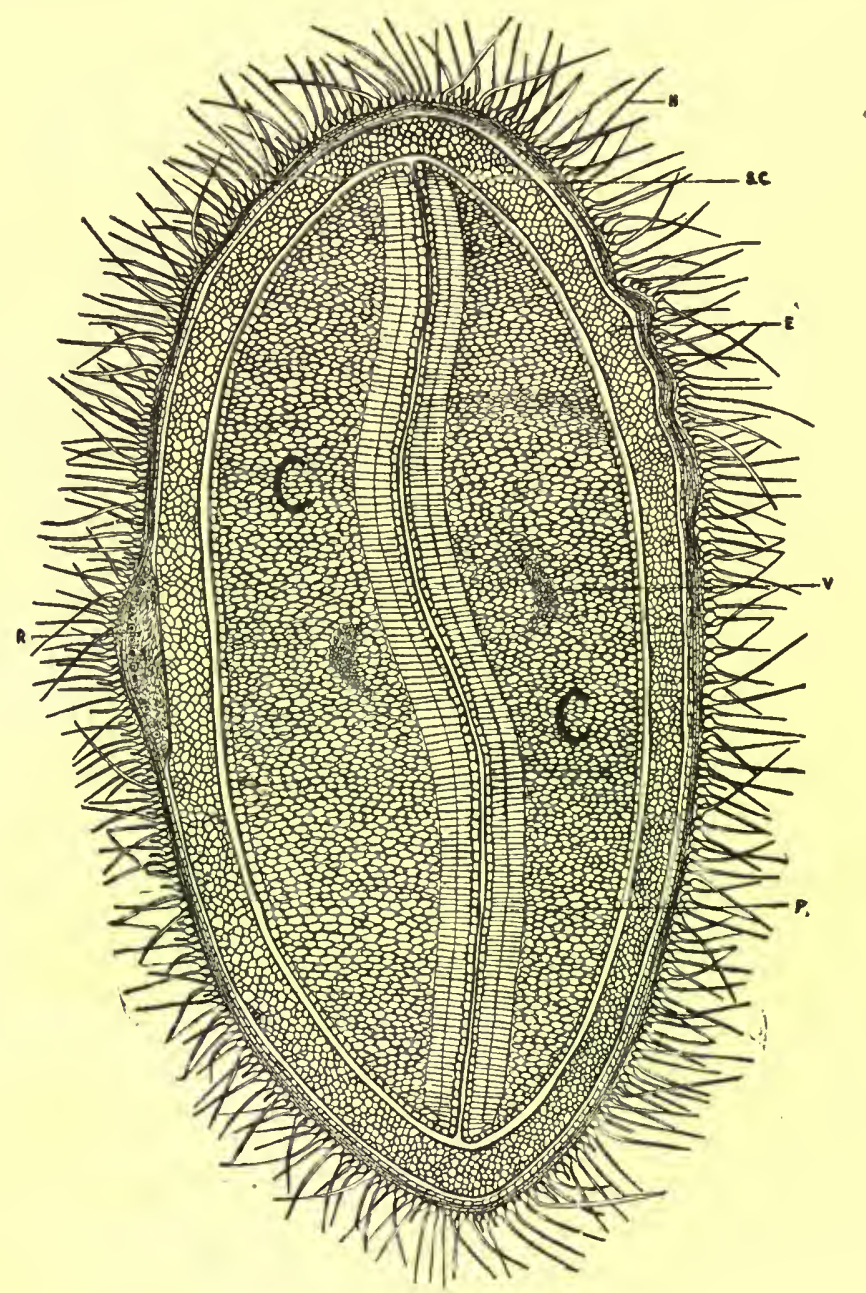

FIG. 234.- Transverse section of strophanthus seed; $S C$, seed-coat with unicellular non-glandular hairs $(H) ; R$, raphe; $E$, endosperm; $C, C$, cotyledons with fibrovascular bundle $(V)$ and palisade cells $(P)$.

aleurone grains, and strophanthin, the latter being colored bright green upon the addition of sulphuric acid; in the center occur two large plano-convex cotyledons having a distinct epidermal layer, a 
few fibrovascular bundles and numerous parenchyma cells containing an oily cytoplasm, small aleurone grains and occasionally a small amount of strophanthin.

Powder--(Fig. 235.) Grayish-brown; consisting chiefly of thin-walled parenchyma cells and fragments of long, thin-walled hairs; mounts made with solutions of potassium hydrate or hydrated chloral show numerous oil globules; many of the fragments of the endosperm are colored greenish upon the addition of sulphuric acid;

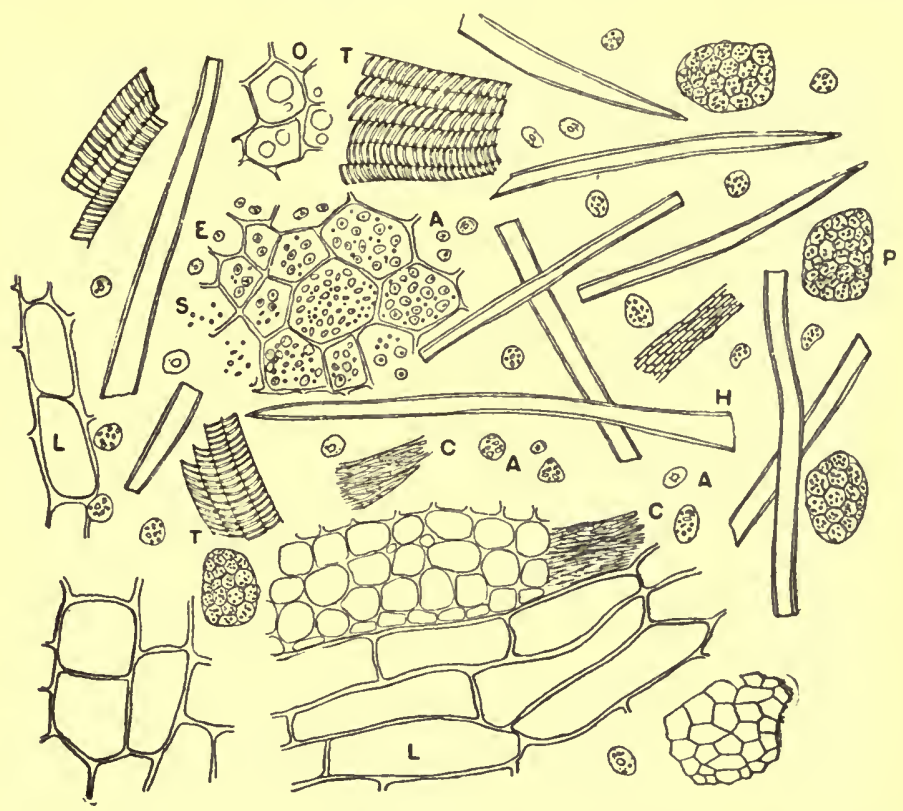

Fig. 235.-Strophanthus: $H$, fragments of upper portion of non-glandular hairs;

$L$, basal portion of non-glandular hairs; $E$, cells of endosperm with aleurone grains $(A)$ and starch grains $(S) ; P$, parenchyma of cotyledons with aleurone grains; $T$, trachex; $C$, collapsed cells of seed-coat; $A$, aleurone grains; $O$, parenchyma containing oil globules.

neither crystals of calcium oxalate nor stone cells are present; starch grains occasional, ellipsoidal, about $0.004 \mathrm{~mm}$. in diameter.

Constituents.-Strophanthin, a crystalline glucoside occurring chiefly in the endosperm and varying from 0.95 to 3 per cent; strophanthin is colored greenish with sulphuric acid, and yields on hydrolysis, glucose and a crystalline body, strophanthidin; the other constituents are kombic acid and about 30 per cent of a fixed oil.

Another principle, pseudo-strophanthin, has been isolated from the seeds of some undetermined species of Strophanthus. This 
principle appears to be more powerful than strophanthin, but is less satisfactory as a heart tonic.

Strophanthus Hispidus. - The seeds of this plant were at one time considered inferior to those of S. Kombe. This has been shown to be erroneous and they are now quite extensively employed. They resemble the seeds of S. Kombe but are of a light or dark brown color, nearly smooth and very sparingly hairy. The bases of the hairs are more strongly lignified. The endosperm layer is not colored so distinctly green with sulphuric acid.

Allied Plants.-The seeds of other species of Strophanthus, growing in the same regions with $\mathrm{S}$. Kombe, sometimes occur in commerce. Of these the following may be mentioned. The seeds of Strophanthus gratus are spindle-shaped, somewhat flattened, of a light yellow or orange-brown color, nearly free from hairs and have a peculiar bitter taste. The cells of the endosperm are colored reddish, becoming violet, with 90 per cent sulphuric acid. The seeds of S. sarmentosus, a small tree growing in Africa, from Senegal to Kongo Free State, are shorter, thicker and more sparingly hairy than those of S. Kombe. The seeds of Kickxia africana (Fam. Apocynaceæ), a tree growing in western tropical Africa, are spindle-shaped, not flattened, slightly twisted, not hairy and of a reddish-brown color. The cotyledons are somewhat folded and not parallel as in Strophanthus Kombe. With sulphuric acid the seeds are colored brown, changing to red.

Adulterants.-The seeds of Strophanthus sarmentosus contain calcium oxalate and give a red color on treatment with sulphuric acid. (U. S. Dept. Agric.)

Literature--Rowe, A. Ph. A., 1916, 5, p. 1183.

Aspidosperma.-Quebracho, Cortex Quebracho, Quebracho Blanco or Quebracho Bark.-The dried bark of Aspidosperma Quebracho blanco (Fam. Apocynaceæ), a large tree indigenous to the western provinces of the Argentine Republic, Chile, Bolivia and southern Brazil. The name Quebracho is often applied to other trees, the bark of which is very hard, alluding to the fact that in felling the trees the sharp-edged tools applied to them are considerably dulled and nicked, by the sclerenchymatous tissues of the bark. The commercial supplies are obtained from the vicinity of Catamarca and Santiago, in northwestern Argentine Republic.

Description.-In irregular chips or in longitudinal pieces attaining a length of $20 \mathrm{~cm}$. and a width of $6 \mathrm{~cm}$., bark from 1 to $3.5 \mathrm{~cm}$. in thickness; periderm from 3 to $20 \mathrm{~mm}$. in thickness, brownish-gray or reddish-brown and deeply furrowed, frequently reticulate with longitudinal and transverse fissures, the crevices being occasionally lined 
with the mycelia of a grayish mould; outer surface of bark from which the cork has been separated, light brown or reddish-brown and usually more or less roughened; inner surface occasionally with adhering wood, otherwise light yellowish-brown to light reddish-brown, longitudinally finely striate and porous; fracture short-fibrous with projecting bast fibers; nearly inodorous; taste bitter and slightly aromatic.

Inner Structure.-Bark consisting of a number of strands of reddish-yellow cork, separated by large groups of stone cells, isolated bast fibers and parenchyma; inner bark having starch-bearing medullary rays, from 1 to 5 cells in width, separating narrow wedges, composed of large proninent groups of stone cells in which are occasionally included one or more thick-walled bast fibers, the latter usually single, very thick walled, strongly lignified, and surrounded with crystal fibers and starch-bearing parenchyma.

Powder.-Reddish-brown; bast fibers single, very long and surrounded by crystal fibers, the crystals being in prisms frequently terminated by pyramids, and from 0.008 to $0.030 \mathrm{~mm}$. in length; stone cells in large, thick groups composed of numerous more or less tabular cells; cork cells more or less polygonal in outline with thick slightly lignified walls; starch grains, from 0.003 to $0.025 \mathrm{~mm}$. in diameter, single or 2- to 4-compound, the individual grains spheroidal, ovoid or more or less plano-convex.

Constituents.-About 1.5 per cent of 6 different alkaloids, the most important of which are aspidospermine, 0.17 per cent and quebrachine, 0.28 per cent. Aspidospermine is colored brownish with sulphuric acid and potassium dichromate, changing to cherryred or purplish. Quebrachine is colored yellow with perchloric acid. The other alkaloids are: aspidosamine, which is colored blue by sulphuric acid and potassium dichromate; aspidospermatine, which is colored deep red by perchloric acid; quebrachamine, which resembles quebrachine but has a much lower melting point; also hypoquebrachine. In addition, quebracho contains 3.5 per cent of tannic acid; a cholesterin-like body, quebrachol; a sugar, quebrachit; and a white or greenish-white ash, about 10 per cent.

Allied Plants.-The bark of Aspidosperma Quebracho colorado contains 20 per cent of tannic acid. A commercial extract is made from the bark, which is used in the tanning of leather. 


\section{ASCLEPIADACEÆ, OR MILKWEED FAMILY}

A small family of perennial herbs, comprising about 85 species. They are most abundant in North America. The leaves are opposite or whorled; the flowers usually have a 5-parted corona between the corolla and stamens, which is adnate to one or the other; the fruits are follicles. The anatomical characters resemble very closely those of the Apocynaceæ. Laticiferous cells have the same general characters and are distributed throughout the plants, as in the Apocynaceæ. The fibrovascular bundles are of the bicollateral type. Cork originates either in the epidermal layer or sub-epidermally, the cells being mostly thin-walled and tabular. In the pericycle occur either solitary or small groups of bast fibers. The latter are not found in the secondary cortex. The walls of the tracheæ and wood fibers are provided with either simple or bordered pores. Calcium oxalate is secreted in the form of solitary crystals or rosette aggregates. Both the glandular and non-glandular hairs are either unicellular or uniseriate.

Asclepias.-Pleurisy Root or Orange Milkweed Root.The rhizome and roots of Asclepias tuberosa (Fam. Asclepiadaceæ), a perennial herb (Fig. 236) growing in dry or sandy soil in the eastern United States and from Arizona to Texas. It is distinguished from all the other species of Asclepias in not having any laticiferous cells. The flowers are orange colored and very beautiful. The root grows deep in the soil and is usually collected in the fall. The larger fusiform rhizome and roots are cut longitudinally to facilitate drying. The drug should be carefully dried and preserved.

Description.-Usually in broken pieces, frequently split longitudinally; when entire fusiform, from 5 to $15 \mathrm{~cm}$. in length and from 0.5 to $3 \mathrm{~cm}$. in thickness; externally light orange-brown, deeply longitudinally furrowed, having a few short roots and root scars; occasionally somewhat annulate in the upper portion, crown with several short stem bases and occasionally deep elliptical scars; fracture of thin pieces short, of thicker pieces tough; inner surface having a thin outer layer of orange-yellow stone cells; cortex thin, whitish; xylem, slightly radiate and having numerous cavities due to the shrinking of the parenchyma and medullary rays; pith wanting except in the rhizome portions, where it is whitish and contains numerous yellowish stone cells; odor slight; taste starchy, slightly bitter and acrid.

Inner Structure.-Cork of several layers of thin-walled, tangentially elongated, slightly lignified cells, which are usually wanting 
in the older roots; outer cortex composed of a nearly closed ring of tangentially elongated groups of stone cells, the walls being bright yellow, very thick and marked by prominent branching pores; inner bark composed mostly of starch-bearing parenchyma, and cells containing rosette aggregates of calcium oxalate, the phloem occurring

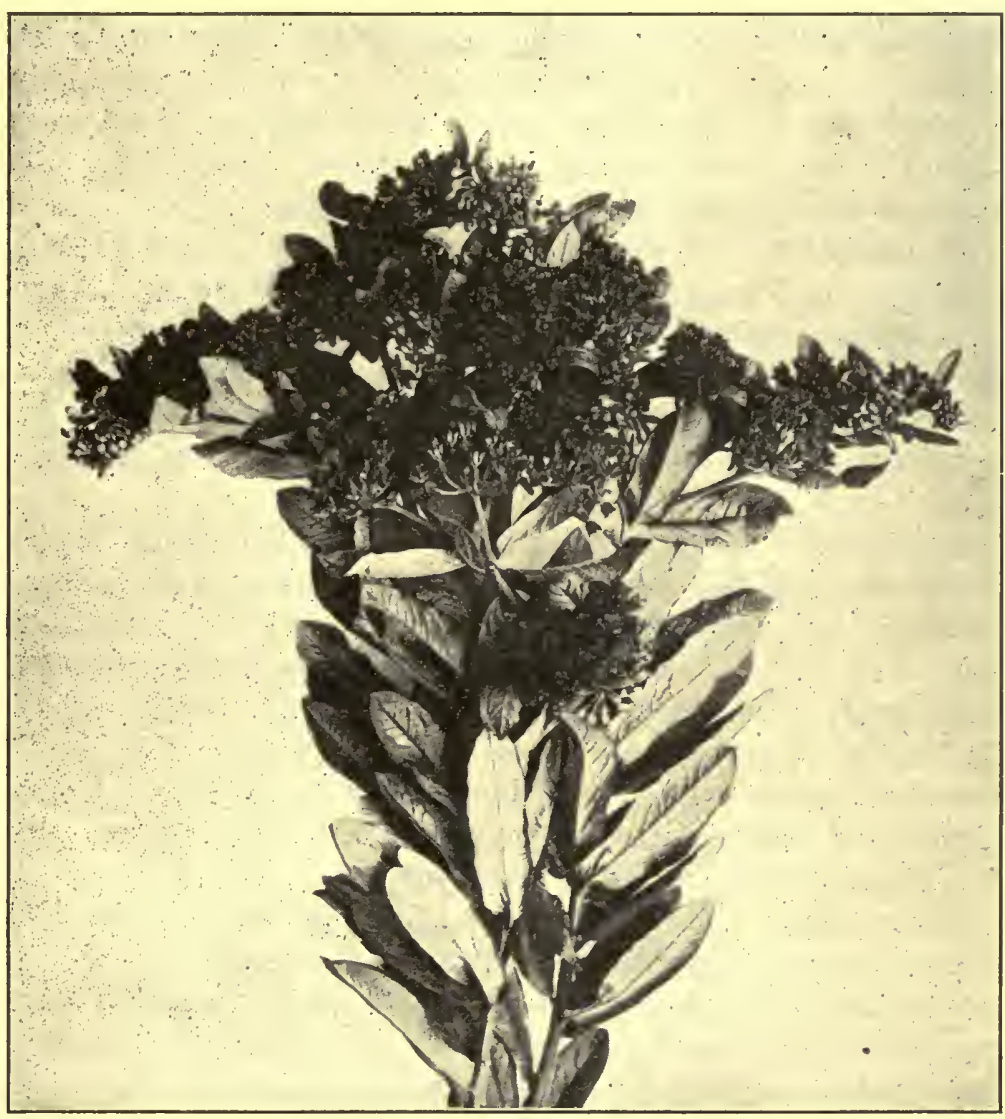

Fig. 236.-Aselepias tuberosa.-Butterfly weed, Pleurisy root, Orange Milkweed. A hairy, perennial herb, very leafy, branching at the summit, and having bright, orange-colored flowers in umbels or flat-topped cymes.After Brown.

as a narrow strand outside the wood wedges, the latter composed mostly of wood parenchyma and wood fibers among which are distributed a few wide tracheæ having simple pores; medullary rays very broad consisting of thin-walled, radially elongated starch-bearing cells; pith in rhizome composed of starch-bearing parenchyma, 
calcium oxalate and large groups of yellowish stone cells, resembling those occurring in the outer bark; calcium oxalate in rosette aggregates from 0.015 to $0.040 \mathrm{~mm}$. in diameter; starch grains occurring in the cells of the parenchyma and medullary rays, numerous, from 0.003 to $0.015 \mathrm{~mm}$. in diameter, single and 2- to many-compound, the individual grains spheroidal, plano-convex and irregularly polyhedral, having a large central circular marking or transverse fissure.

Powder-Light brown, consisting of numerous starch grains, either isolated or in parenchyma cells; large groups of orange-yellow stone cells; a few wide tracheæ, having either simple pores or scalariform perforations, and associated with short wood fibers, having thin porous walls.

Constituents.-A yellowish glucoside, asclepiadir, having the taste of the drug and apparently the active principle. It is soluble in hot water and alcohol, colored green with sulphuric acid and pink with nitric acid, changing to purple. Asclepias also contains a volatile oil; several resins; tannic acid; starch; pectin; gum; a fixed oil; and calcium oxalate.

Condurango.-Cortex Condurango, Condurango Bark.-The bark of Marsdenia Condurango (Fam. Asclepiadaceæ), a somewhat prostrate or climbing shrub, indigenous to the lofty mountains of Ecuador and Peru. The bark is official in several of the European Pharmacopœias and is coming into prominence, as an aromatic bitter, in the United States.

Description.-In single quills or transversely curved pieces, from 4 to $13.5 \mathrm{~cm}$. in length, and from 1 to $6 \mathrm{~mm}$. in thickness; outer surface light grayish-brown to dark brown, nearly smooth and with numerous lenticels, or having a more or less soft-scaly and considerably roughened cork, occasionally with brownish-black apothecia of a lichen; inner surface grayish-white or light brown, longitudinally striate; fracture short and granular or short-fibrous; odor slightly aromatic, especially marked in the fresh drug; taste bitter and aromatic.

Inner Structure.-A periderm consisting of from 5 to 10 rows of thin-walled cork cells frequently having yellowish-brown contents; a layer of phelloderm of 8 to 10 rows of cells, containing either starch grains or membrane crystals of calcium oxalate, the latter in prisms from 0.010 to $0.035 \mathrm{~mm}$. in length; a primary cortex of collenchyma containing chloroplasts, starch grains, and rosette aggregates of calcium oxalate from 0.015 to $0.040 \mathrm{~mm}$. in diameter; a pericycle or pericambium of tangentially elongated parenchyma cells, with groups 
of bast fibers and laticiferous cells in an interrupted circle; middle bark with large groups of stone cells, varying from nearly isodiametric to elongated, sometimes very irregular in form; inner bark with medullary rays 1 to 2 cells wide, numerous laticiferous cells accompanied by small groups of sieve cells, parenchyma containing either starch grains or rosette aggregates of calcium oxalate, and an occasional isolated bast fiber or small groups of stone cells.

Powder.-Light yellowish-brown; stone cells in large groups, the individual cells being more or less irregular in shape having very thick, porous walls, the lumina being usually filled with air; calcium oxalate chiefly in rosette aggregates, occasionally in single prisms, mostly from 0.015 to $0.020 \mathrm{~mm}$. in diameter; starch grains, from 0.003 to $0.015 \mathrm{~mm}$. in diameter, mostly single, frequently 2- to 4compound; bast fibers non-lignified, very long and from 0.010 to $0.035 \mathrm{~mm}$. in width; fragments of thin-walled latex cells from 0.015 to $0.025 \mathrm{~mm}$. in diameter and filled with a granular substance; fragments of cork grayish- or light yellowish-brown.

Upon macerating $1 \mathrm{gm}$. of powdered Condurango with 5 c.c. of water and filtering, the filtrate should be clear; and on boiling becomes cloudy, assuming its original transparency when cool (due to the properties of condurangin).

Constituents.-Several glucosidal combinations of condurangin. The latter being completely soluble in cold water and precipitated upon heating the aqueous solution. It is also soluble in benzene and gives a green color with molybdic and sulphuric acids. $\beta$-condurangin is also insoluble in water, but is not affected by Froehde's reagent. Condurango also contains 12 per cent of tannic acid; 0.75 per cent of a deliquescent crystallizable acid; a yellowish-white resin; a small quantity of starch; a fixed oil; a fermentable sugar; and 10 to 12 per cent of ash.

\section{CONVOLVULACEA, OR MORNING GLORY FAMIIY}

A family of about 900 species, being very abundant in the tropics. They are either herbs or shrubs, some being more or less trailing and frequently climbing The leaves are alternate, the flowers have gamopetalous corollas, and the fruits are capsules. A number of the plants are cultivated and some of them as the common morning glory (Ipomoea purpurea) are well known for their showy flowers of different colors. One of the most useful plants of this family is the SWEET POTATO vine (Ipomoea Batatas), a perennial herbaceous vine 
extensively cultivated in tropical countries on account of the edible tuberous roots. The roots contain from 3 to 10 per cent of sugar and 9 to 15 per cent of starch, which occurs in larger proportion in plants grown in sub-tropical countries. The starch is a commercial product and is known as sweet-potato starch or BraziLian ARRow-Root. The starch grains are either single or 2- to 6-compound, the individual grains from 0.005 to $0.055 \mathrm{~mm}$. in diameter, mostly plano-convex, resembling cassava starch grains, also spheroidal and polyhedral forms occur.

The plants of the Convolvulaceæ possess a number of interesting anatomical characteristics. Secretory cells, having suberized walls, occur either as isolated cells or arranged in long vertical rows. They are either oblong or flask-shaped and contain a milky content, which is either colorless or yellowish-brown and soluble in alcohol. Laticiferous vessels, consisting of a non-suberized, thick-walled, tubular, latex-receptacles, have been found only in Dichondra. The fibrovascular bundles with few exceptions are of the bi-collateral type. The tracheæ possess simple pores. The wood fibers are marked by bordered pores and the medullary rays are narrow. Calcium oxalate is secreted in the form of small needles, small rods, solitary crystals and rosette aggregates, the latter sometimes occurring in the idioblasts of the leaves. The non-glandular hairs usually consist of 2 cells, the lower or stalk having a suberized wall. The glandular hairs usually have a unicellular stalk and a multicellular head. In the leaves, the subsidiary cells are placed parallel to the pores of the stomata. A very complicated anomalous structure is seen in the fleshy roots of jalap and scammony.

JALAPA.- Jalap.-The tuberous root or tubercle of Exogonium Purga (Fam. Convolvulaceæ), a perennial twining herb, native of the eastern slopes of the Mexican Andes, and cultivated in Jamaica and India. The roots are collected in the fall and dried by artificial means, the larger ones being first cut into longitudinal pieces. Mexico furnishes the principal part of the commercial supply, which is exported from Vera Cruz.

Description.-Fusiform, irregularly ovoid or pyriform, upper end more or less rounded, lower end obtuse or slightly acuminate; 3 to $8 \mathrm{~cm}$. in length, 1 to $5 \mathrm{~cm}$. in diameter; externally dark brown, deeply and irregularly furrowed longitudinally, otherwise nearly smooth or wrinkled, with numerous lenticels 2 to $4 \mathrm{~mm}$. in length and few circular rootlet-scars; fracture horny and resinous; Internally dark brown and marked by more or less distinct, secondary, concentric cambium zones; odor fruity; taste starchy and slightly acrid. 
Tubercles which have a specific gravity less than 1.275 and are white internally should be rejected.

InNer Structure.-See Fig. 237.

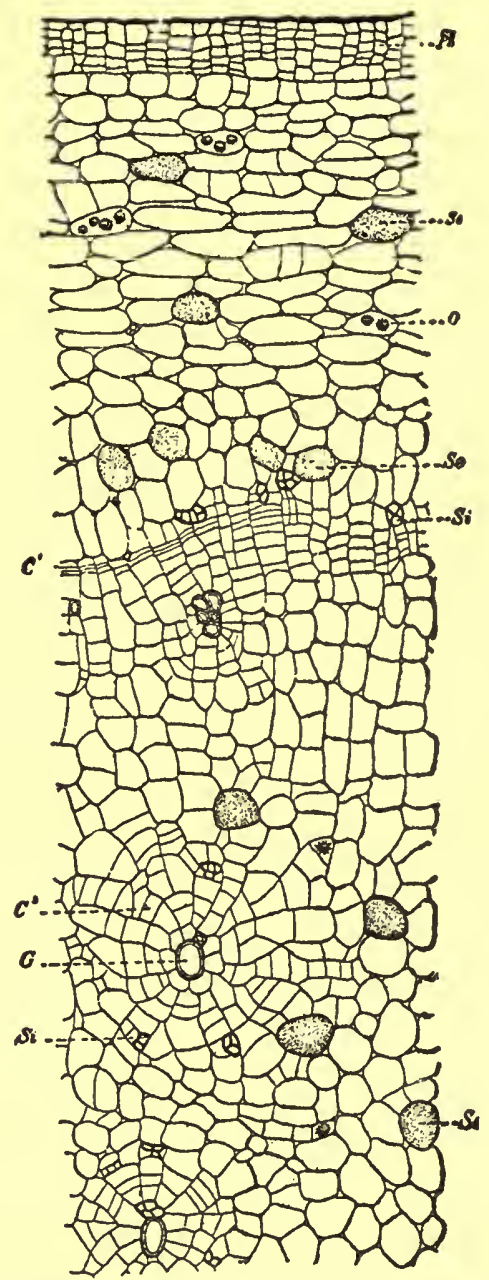

Fig. 237.-Transverse section of jalap: $P h$, cork cells; $S e$, resin-secretory cells; $O$, rosette aggregates of calcium oxalate; $S i$, sieve cells; $G$. tracheæ; $C^{1}$, primary cambium; $C^{2}$, secondary cambium.-After Meyer.

Powder.-(Fig. 238.) Dark yellow or light brown; crystals of calcium oxalate in rosette aggregates, 0.010 to $0.035 \mathrm{~mm}$. in diameter; starch grains ellipsoidal and ovoid, with somewhat excentral lamellæ, from 0.005 to $0.035 \mathrm{~mm}$. in diameter, 1- to 3-compound 
and in some cases more or less swollen; resin secretory-cells yellowish brown; sclerenchymatous fibers few, with simple pores. Tubers deficient in resin are lighter in color, contain more starch and less calcium oxalate.

Constituents.-Resin 8 to 12 per cent, 85 to 90 per cent of which is insoluble in ether. Power and Rogerson (J. Am. Chem. Soc., 1910 , p. 80) isolated from the ethereal extract of the resin a new dihydric alcohol (ipurganol) which crystallizes in colorless needles and yields color reactions similar to those given by the phytosterols. From the chloroform extract they isolated a small amount of $\beta$ methylæsculetin. The petroleum ether extracts showed the pres-

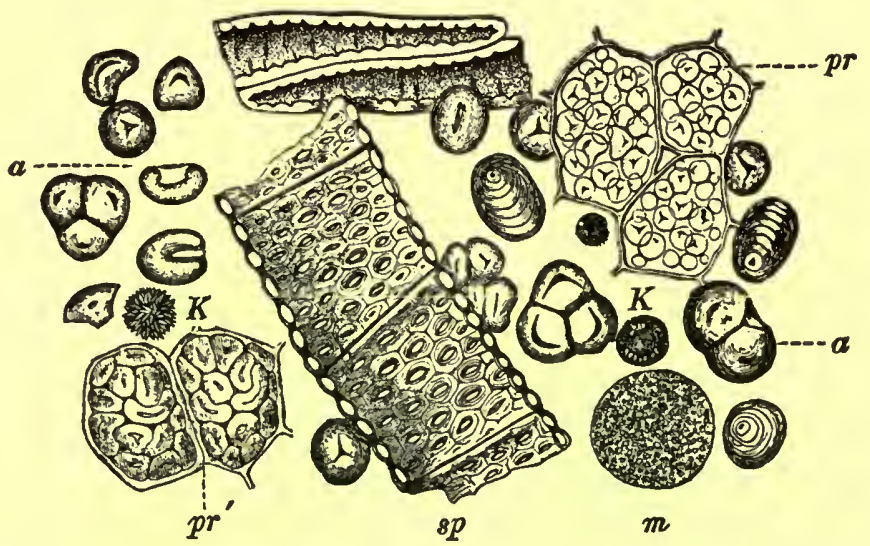

Fig. 238.-Jalap: $p r$, parenchyma containing unaltered starch grains; $p r^{\prime}$, parenchyma containing swollen starch grains; $a$, starch grains; $K$, rosette aggregates of calcium oxalate; $m$, globular mass of resin; $s p$, fragment of tracheæ showing bordered pores.-After Vogl.

ence of palmitic and stearic acids in the free state. On treatment with alkalies and dilute sulphuric acid some of the extracts of the resins yield a number of acids and there are indications that a portion of the chloroform extract of the resin is of a glucosidal nature. The alcohol extract of the resin, which represented 38.8 per cent of the total resin, was obtained, after treatment with animal charcoal, in the form of a nearly white powder. When subjected to alkaline hydrolysis with baryta, this alcohol extract yielded a number of organic acids together with a hydrolyzed resin of very complex composition. Jalap also contains a volatile oil, calcium oxalate. starch, gum and sugar.

Allied Plants.-Brazilian Jalap.-During the war several jalap substitutes were offered. One of these, known in Brazil as Batata de 
Purga and Batata Purgante, is the root of Piptostegia Pisonis Mart. (Fam. Convolvulaceæ). It occurs in transverse circular or oval sections, from 3 to $8 \mathrm{~cm}$. in diameter and 0.3 to $0.8 \mathrm{~cm}$. in thickness. The cut surface is marked with several concentric rings having a pale grayish-brown color and numerous dots of a translucent pale resin. It contains about 20 per cent of resin and differs from that of other drugs obtained from this family (Scoville, Jour. A. Ph. A. 1918, 7, p. 785; Farwell, ibid., p. 852; Ewing and Clevenger, ibid., p. 855).

Resina Drastica.-The drug comes from Mexico and in a general way resembles Mexican Scammony. The pieces represent both transverse and longitudinal sections of a root somewhat resembling Brazilian Jalap but are of a darker color. The cut surface is shortfibrous, due to the projections of the fibrovascular bundles. The amount of resin is 19.2 per cent. It is of a deep lemon-yellow color and gives with ferrous sulphate a dark green color resembling true Scammony resin. (Scoville, Jour. Indust. Eng. Chem., 1919, 11, p. 335.)

Turpeth Root or Indian Jalap is the root of Operculina Turpethum, a plant growing in the East Indies. It contains a resin consisting chiefly of turpethin and turpethein, a glucosidal, ethersoluble resinoid substance.

Male Jalap or Orizaba is the root of Ipomœa orizabensis, a plant indigenous to Mexico. The drug consists of the entire, spindleshaped roots, or of more or less rectangular pieces, and contains about 10 per cent of scammonin.

Ipomœ simulans, indigenous to the eastern slope of the Mexican Andes, yields the Tampico jalap, which is more or less uniform in thickness, somewhat tortuous, and without any lenticels; it contains about 10 per cent of resin, which is completely soluble in ether and resembles scammonin.

Wild jalap is the tuberous root of Ipomœa pandurata, a plant growing in the eastern and southern United States. It contains 1.5 per cent of an active resin.

From the aerial stems of the common morning glory (Ipomœa purpurea Roth) Power and Rogerson (Am. Jour. Pharm., 1908, p. 251) isolated a volatile oil and 4.8 per cent of a soft resin of which 15.5 per cent is soluble in ether.

The roots and stems of Ipomoea fistulosa, of South America, yield 0.2 per cent of jalapin (orizbin), hexose, wax and tannin.

Literature.-Snyder, Jour. A. Ph. A., 1916, 5, p. 34.

Compound Powder of Jalap.-Consisting of powdered jalap and potassium bitartrate. Very light brown; consisting of numerous 
sharp-angular, colorless fragments, mostly somewhat rectangular and with straight edges, varying from 0.030 to $0.300 \mathrm{~mm}$. in length, insoluble in water or solutions of hydrated chloral and very strongly polarizing with a rich display of colors (fragments of crystals of potassium bitartrate), numerous starch grains of Jalap, readily distinguished without the use of a solution of iodin, usually single, occasionally 2 - to 3 -compound, and varying from 0.003 to $0.035 \mathrm{~mm}$. in diameter; occasional fragments of laticiferous cells or vessels having yellowish-brown walls, or tracheæ with bordered pores, and rosette aggregates of calcium oxalate from 0.010 to $0.035 \mathrm{~mm}$. in diameter occurring in Jalap.

Scammonie Radix.-Levant Scammony Root.-The root of Convolvulus Scammonia (Fam. Convolvulaceæ), a percnnial twining herb indigenous to the countries bordering the eastern Mediterranean. On account of the difficulty in securing the pure resin of scammony, the root of this plant is now largely used as the source of the resin, the latter being the drastic purgative principle.

Description.-Nearly cylindrical, more or less fusiform, occasionally in broken pieces; from 10 to $25 \mathrm{~cm}$. in length and 1 to 4.5 $\mathrm{cm}$. in thickness; externally grayish to reddish-brown; usually distinctly twisted, deeply longitudinally furrowed, marked by distinct root scars, otherwise nearly smooth excêpt for the lenticels and abraded cork, the upper portion terminated usually by a number of short stem branches; hard and heavy; fracture tough, irregular with projecting wood fibers; internally somewhat mottled, showing yellowish, porous wood-wedges separated by whitish parenchyma containing starch and resin; bark thin; odor slight, resembling that of jalap; taste somewhat sweetish becoming slightly acrid.

Inner Structure.-A thin corky layer consisting of yellowishbrown, thin-walled, lignified cork cells; primary cortex having numerous stone cells occurring singly or in small groups, the walls being moderately thick, porous and not strongly lignified; parenchyma with numerous starch grains and monoclinic prisms of ealcium oxalate; fibrovascular bundles numerous, circular or elliptical with a well-developed xylem consisting of wide tracheæ surrounded with slightly lignified wood fibers; phloem prominent and in which are included the large resinous laticiferous cells; the parenchyma surrounding the bundles are more or less collapsed and contain either starch grains or calcium oxalate crystals.

Powder-Light grayish-brown; starch grains, from 0.003 to $0.018 \mathrm{~mm}$. in diameter, mostly single, occasionally 2- to 4-compound the grains showing occasionally a central cleft; calcium 
oxalate crystals in monoclinic prisms from 0.010 to $0.045 \mathrm{~mm}$. in length, fragments of leptome associated with yellowish-brown resinous laticiferous cells; tracheæ mostly with reticulate thickenings or simple and bordered pores and associated with short wood fibers having prominent oblique pores; stone cells of variable shape and varying from 0.040 to $0.110 \mathrm{~mm}$. in length, the walls being from 0.006 to $0.012 \mathrm{~mm}$. in thickness, slightly lignified and traversed with prominent often branching pores; lignified cork cells relatively few.

Constituents.- The root contains from 4 to 13 per cent of resin, which is of an exceedingly complex nature, consisting to a large extent of the glucosides and methyl pentosides of jalapinolic acid and its methyl ester. Also from 20 to 33 per cent of dextrose; 2.5 per cent of saccharose; tannic acid; and gum.

Scammoniæ Mexicana Radix.-The root of Mexican Scammony, Ipomœa orizabensis, a perennial, twining shrub indigenous to Mexico, is also often seen on the market and on account of the high resin content, the latter is to some extent sold for or admixed with that obtained from Levant Scammony. It is not infrequent to find the two drugs confused, that is, the one under the label of the other.

Mexican Scammony usually occurs in nearly flattened, transverse segments, varying from 2 to $12 \mathrm{~cm}$. in diameter and from 1 to $5.5 \mathrm{~cm}$. in thickness; externally light to dark brown, very deeply wrinkled, fragments showing the crown frequently have portions of the cylindrical rhizome attached, having large circular stem scars; fragments of the lower portion of the roots having numerous short, cylindrical, somewhat spirally twisted root branches; fracture tough, fibrous; inner surface light brown; characterized by alternating zones of collateral fibrovascular bundles formed by successive cambiums, separated by broad strands of parenchyma and brown resinous laticiferous cells; odor distinct, somewhat aromatic and resembling jalap.

The inner structure of Mexican scammony is as follows: A thin outer corky layer consisting of several rows of brownish, thin-walled, narrow tabular cells; phelloderm of several layers of colorless, thinwalled cells; a broad cortical layer made up of thick-walled, tangentially elongated cells, containing either starch grains or crystals of calcium oxalate and numerous large brownish resinous laticiferous cells, containing not infrequently a yellowish-brown, amorphous content; alternate rings or zones of collateral fibrovascular bundles separated by broad medullary rays; fibrovascular bundles consisting of wide tracheæ marked by simple pores, and associated with numerous, relatively thick-walled wood fibers, having bordered pores; 
cambium distinct; leptome narrow in somewhat hemispherical strands outside of the xylem wedges; resinous laticiferous cells, numerous, having a yellowish-brown, amorphous content, and occurring throughout the parenchyma and medullary rays; calcium oxalate crystals numerous, chiefly in the form of rosette aggregates, only occasionally occurring in the form of rhombohedra, from 0.015 to $0.040 \mathrm{~mm}$. in diameter; starch grains numerous, single 2- to 3 -compound, the individual grains from 0.005 to $0.035 \mathrm{~mm}$. in diameter, varying from spheroidal, ellipsoidal, plano-convex, to somewhat polyhedral, and usually with a transverse central cleft.

Mexican scammony root yields from 6 to 18 per cent of a glucosidal resin, and of which about 71 per cent is soluble in ether. The root also contains a pale yellow volatile oil, scopoletin, and $3: 4$-dihydroxycinnamic acid. The petroleum ether extract of the resin contains hentriacontane, a phytosterol, cetyl alcohol, and a mixture of fatty acids. The ether extract contains ipuranol, $\mathrm{d}-\alpha$-methylbutyric acid, and a product which on hydrolysis yields jalapinolic acid.-Power and Rogerson, Jour. Chem. Soc., 1912, p. 1.

Scammonis Resina.-Levant Scammony Resin.-A gum-resin obtained by incising the root of Convolvulvus Scammonia (Fam. Convovulaceæ), a perennial, twining herb indigenous to Syria, Asia Minor and Greece. The incisions are made in the upper part of the root in June, and the exuding gum-resin is collected in mussel shells, the product from a number of roots being mixed together, after which it is allowed to dry. The principal points of export are Smyrna and Aleppo. The natural exudation, free from extraneous matter, is known as native or virgin scammony.

Smyrna Scammony.-In circular, flattened cakes, 10 to $12 \mathrm{~cm}$. in diameter and about $1 \mathrm{~cm}$. in thickness or irregular, angular pieces of variable size; greenish-gray or brownish-black, often covered with a grayish-white powder, formed by the rubbing of the pieces against one another in transportation; very brittle; fracture sharp; internally porous, lustrous and of a uniform brownish-black color, being more or less translucent in thin fragments; odor peculiar, somewhat cheese-like; taste slightly acrid.

Scammony is easily powdered and forms a milky emulsion with water. It does not effervesce on the addition of diluted hydrochloric acid (absence of calcium carbonate); an alcoholic solution is not colored blue on the addition of tincture of ferric chloride (absence of guaiac resin); ether dissolves not less_than 70 per cent (distinction from jalap resin), and when the residue on evaporation of the ethereal solution is dissolved in a hot solution of potassium hydrate it is not 
reprecipitated on the addition of diluted sulphuric acid. The saponification number of genuine scamınony resin is from 238 to 240.5 .

Constituents.-From 75 to 95 per cent of a glucosidal resin (scammonin), which is completely soluble in ether; gum, 5 to 8 per cent; ash, not more than 3 per cent. Scammonin is apparently identical with the resin in Ipomœa orizabensis and the ether-soluble resin in jalap. It occurs as a white powder, which on treatment with alkalies yields the glucoside scammonic acid. The latter on hydrolysis decomposes into scammonolic acid and glucose. An anhydride of scammonolic acid, scammonol, some valerianic acid and sugar are formed on treating scammonin with mineral acids. The peculiar cheese-like odor of the resin is due to the formation of a volatile, fatty acid during the drying process.

Adulterants.- Scammony is adulterated with inorganic substances, various starchy products, foreign resins, such as guaiac, and an extract of the juice of the root of Convolvulus althæoides, a plant indigenous to the countries of the Mediterranean.

Montpelier Scammony is the natural exudation of Marsdenia erecta (Fam. Asclepiadaceæ), a plant indigenous to southern Europe. It contains 50 to 60 per cent of starch, 10 to 21 per cent of resin, and yields 11 to 18 per cent of ash.

Literature.-Power, Jour. Chem. Soc., 1912, p. 398.

\section{HYDROPHYLLACEÆ, OR WATERLEAF FAMILY}

A family of about 160 species of herbs and shrubs, mostly indigenous to western North America. The leaves are opposite, the flowers are regular and 5-merous, and the fruits are capsular. From the supposition, that in the springtime the leaves of the plants were filled with water; the family received its name. There is no special anatomical structure indicating on what this might be based. The leaves differ in structure very little from those of other plants. The leaves are bifacial and the stomata usually occur only on the lower surface, being surrounded by an indefinite number of ordinary epidermal cells. The non-glandular hairs are usually unicellular, rarely uniseriate, occasionally encrusted with calcium carbonate, or may contain a cystolith-like body. Glandular hairs are widely distributed and are of a number of distinct types. Calcium oxalate occurs in the form of rosette aggregates. The general structure of the plants of this family is given under Eriodictyon. 
ERIodictyon.-Yerba Santa.-The dried leaves of Eriodictyon californicum (Syn. E. glutinosum), Fam. Hydrophyllaceæ, an evergreen shrub indigenous to the mountains of California and northern Mexico.

Description.-Usually broken into fragments; lamina lanceolate, 7 to $15 \mathrm{~cm}$. in length, 1 to $3 \mathrm{~cm}$. in breadth; summit acute; base acute, slightly tapering into the petiole; margin nearly entire or unevenly serrate; upper surface yellowish-green, glabrous, resinous; under surface grayish-green, reticulate, minutely tomentose between the reticulations, midrib light yellow, prominent; petiole 5 to 10 $\mathrm{mm}$. in length; texture coriaceous, brittle; odor and taste balsamic.

Inner Structure.-Cells of upper epidermis somewhat papillose, which in surface view are polygonal, the walls being nearly straight or slightly undulate, the cuticle being striated; deep seated, resinous glandular hairs also occur on the upper epidermis, which resemble those of the Labiatæ having usually a 1-celled stalk and a 6- to 8celled glandular head, about $0.100 \mathrm{~mm}$. in diameter; palisade cells very narrow, from 2 to 6 rows deep containing numerous chloroplastids; cells of loose mesophyll very few; fibrovascular tissues not strongly developed except in the midrib and more prominent veins; lower epidermal cells having undulate, polygonal walls and in addition to the glandular hairs there occur numerous 1-celled, much contorted, thick-walled, non-glandular hairs.

Stems usually show a sub-epidermal cork, the cells having wide lumina and thin walls; primary cortex of 10 to 20 rows of more or less rounded parenchyma cells; pericycle consisting of a nearly closed ring of bast fibers; leptome in a narrow zone outside the xylem wedges; the latter consisting of tracheæ, having narrow lumina and marked by spiral thickenings and simple pores, and associated with lignified wood fibers having bordered pores; medullary rays one cell in width; pith very large, the walls of the cells being strongly lignified and with numerous simple pores.

Powder.-Dark green; non-glandular hairs numerous, unicellular, much contorted and from 0.120 to $0.250 \mathrm{~mm}$. in length; glandular hairs having a 1-celled stalk and a 6 - to 8-glandular head; fragments of stems show tracheæ having spiral thickenings and simple pores, associated with lignified wood fibers; parenchyma cells of pith possess thick, porous, strongly lignified walls.

Constituents.-A resin consisting of pentatriacontan, cerotinic acid, formic acid, butyric acid and probably also triacontan, phytosterin, xanthoeriodictyol, priodonal and a phenol, chrysoeriodictyol. The latter occurring to the extent of 0.009 per cent and 
forming golden yellow, tabular crystals. Xanthoeriodictyol, 0.019 per cent, occurring in golden yellow needles. Also a volatile oil; a crystalline body, eriodictyonon (homoëriodictyol); a tannin, giving a green color with ferric salts; sugar; fixed oil; and gum.

Literature.-Tutin, Jour. Chem. Soc., 1910, p. 2054.

\section{BORAGINACEAE OR BORAGE FAMILY}

A family of about 1200 species which are especially abundant in the Mediterranean region and extending into central Europe and Asia. The plants are mostly herbaceous and rough, hairy. The leaves are generally alternate and the inflorescence is one-sided (dorsi-ventral). The family is characterized by both glandular and non-glandular hairs. Of special importance are the unicellular cystolith-hairs (bristle hairs). Calcium oxalate occurs in the forms of prisms, rosette aggregates and microcrystals.

Alkanna.-Alkanet.-The root of Alkanna tinctoria (Fam. Boraginaceæ), a perennial herb, indigenous to southeastern Europe and Asiatic Turkey and also cultivated for its coloring principle.

Description.-Fusiform, simple, 3 to $30 \mathrm{~cm}$. in length, 5 to $20 \mathrm{~mm}$. in diameter; externally deep reddish-purple, or maroon color, sometimes twisted deeply furrowed, the outer layers readily separating in papery strips, the crown being frequently several-headed and consisting of the bases of the leaves which are bristly hairy; fracture short; internally bark thin, wood yellowish brown; odor slight; taste insipid or faintly bitter and stringent.

Constituents.-A coloring principle, Alkannin (Anchurin), amorphous and resin-like. The amount varies from 5 to 6 per cent, is insoluble in water, soluble in alcohol, chloroform, ether and oils. The solutions in alkalies are of a deep blue color changing to red on the addition of acids. Gawalowski separated Alkannin into two acids: (a) alkanic acid soluble in ether and alcohol and turning blue with alkalies; $(b)$ anchuric acid soluble in benzene and turning green with alkalies.

Adulterants.- Syrian Alkanet, the root of Macrotonia cephalotes (Fam. Boraginaceæ) is readily distinguished. The roots vary from 20 to $40 \mathrm{~cm}$. in length 2 to $5 \mathrm{~cm}$. in thickness, many-headed and of a black-violet somewhat metallic color. (Ewing and Clevenger, Jour. A. Ph. A., 1918, 7, p. 591.) It contains a very large quantity of coloring matter, apparently of equal tinctorial strength and it is suggested that it may prove to be a valuable substitute for true Alkanet. 


\section{VERBENACEE, OR VERVAIN FAMIIY}

A family of 1200 species of shrubs or trees, especially distributed in the tropics and sparingly represented in the cooler regions. The leaves are opposite or verticillate; the flowers are irregular, having a bi-labiate or irregular corolla, and didynamous stamens; the fruits are either drupe-like or somewhat capsular, consisting of 2 to 4 nutlets. The stems are not infrequently quadrangular in section. The tracheæ and wood fibers usually have simple pores. The stomata are surrounded by a number of ordinary epidermal cells, occasionally they possess 2 subsidiary cells which are distributed transversely to the pore. Calcium oxalate occurs in the form of small acicular or prismatic crystals. The glandular hairs have a unicellular or uniseriate stalk, the head being composed of 6 to 8 cells. A number of types of non-glandular hairs occur in the various genera of this family. An anomalous structure is developed in some of the lianes.

Verbena.-American Blue Verbain or Wild Hyssop.-The over-ground plant of Verbena hastata (Fam. Verbenaceæ), a perennial herb, growing in moist meadows throughout the central and eastern United States. The plant is gathered at the time of flowering, during the summer, and should be carefully dried and preserved.

Description.--Stems quadrangular, attaining a length of 1 or more M., and from 1 to $6 \mathrm{~mm}$. in diameter; externally reddishbrown, longitudinally wrinkled and having a deep furrow between the ribs, rough puberulent throughout; internally yellowish-white with a thin brown bark, a yellowish-white quadrangular wood and a hollow pith. Leaves opposite, long petiolate, from 4 to 15 $\mathrm{cm}$. in length and 0.7 to $4 \mathrm{~cm}$. in width; lanceolate or oblong-lanceolate, summit acute tapering; base rounded, inequilateral; margin sharply serrate; upper surface greenish-brown, glabrous; lower surface purplish-green, rough puberulent, with a prominent midrib and veins of the first order, the latter diverging at an angle of about $65^{\circ}$ and uniting near the margin; petioles 1 to $3 \mathrm{~cm}$. in length, slender, and rough puberulent; odor distinct; taste bitter.

Constituents.-A glucoside, verbenalin, which crystallizes in needles and is apparently non-toxic. Also a bitter principle, tannic acid, emulsin, and invertin.

Lippia Mexicana.-Orosul, Regaliz de Cuba.-The leaves of Lippia dulcis (Fam. Verbenaceæ), a trailing shrub, widely distributed in tropical America. The leaves are gathered at the time of the flowering of the plant, from November to March, and carefully dried. 
Description.-Leaves more or less crumpled; when entire, ovatelanceolate, petiolate, summit acute or acuminate, base cuneate, somewhat unequal, margin coarsely serrate; olive-green to greenishbrown, glandular-hairy, midrib and veins of the first and second order prominent; petioles from 5 to $10 \mathrm{~mm}$. in length; odor aromatic; taste sweetish, terebinthinate and slightly pungent.

Inner Structure.-The leaves are especially characterized by the long-pointed, unicellular, thick-walled hairs from 0.150 to $0.300 \mathrm{~mm}$. in length, and containing a cystolith at the base; glandular hairs having short stalks and a 6- to 8-celled head, the latter from 0.015 to $0.030 \mathrm{~mm}$. in diameter, and having a nearly colorless content; epidermal cells wavy in outline; stomata elliptical, from 0.015 to $0.035 \mathrm{~mm}$. in length, and having the neighboring cells transverse to the pore.

Constituents.-A volatile oil containing a camphor, lippiol; tannic acid, colored greenish with ferric salts; and a yellow coloring principle resembling quercetin.

Lippia Scaberrima.-An aromatic drug of South Africa reputed to possess remarkable hæmostatic properties. The drug contains about 0.25 per cent of a volatile oil; a crystalline alcohol, lippianol; two yellow crystalline substances; a glucosidal substance; and a number of acids and esters.-Power and Tutin, Amer. Jour. Pharm., 1907, p. 449.

\section{LABIATE, OR MINT FAMILY}

A large family of herbs and shrubs, comprising about 3000 species and widely distributed. There are about 40 different genera of the Labiatæ represented in the United States. They are characterized by having square stems, opposite leaves, bilabiate flowers and small indehiscent fruits consisting of 4 nutlets. The plants of the Labiatæ are especially characterized by the development of glandular hairs containing a volatile oil. These hairs consist of a short unicellular stalk, and a glandular head consisting of 6 or 8 cells, the upper portion being raised like a bladder owing to the great accumulation of volatile oil. In the dried drug material these hairs usually appear as spheroidal bodies, about $0.100 \mathrm{~mm}$. in diameter filled with a yellowish oily secretion, in which the cellular structure is frequently not easily discernibie. The non-glandular hairs occur in a number of specific forms. In the stomata the subsidiary cells lie transverse to the pore. Calcium oxalate is secreted in the form of small needles or short rods, rarely as rosette aggregates. The 
tracheæ and wood fibers have simple pores. There is a strong development of sub-epidermal collenchyma, especially in the angles of the stems and branches. A secondary development of the fibrovascular bundles occurs in the older stems of thymus.

Scutellaria.-Skullcap.-The dried herb of Scutellaria lateriflora (Fam. Labiatæ), a perennial herbaceous plant growing in wet places in the United States and Canada. The plant blooms from July to September, when the herb should be collected.

Description.-Stem quadrangular, 1 to $4 \mathrm{~mm}$. in diameter, varying in color from yellowish-green to purplish-red, mostly glabrous below and hairy above. Leaves (Fig. 239) ovate, ovate-oblong, or ovate-lanceolate, opposite, 1.5 to $8 \mathrm{~cm}$. in length, 0.5 to $2.5 \mathrm{~cm}$. in breadth; summit acute or acuminate; base acute, rounded or subcordate; margin coarsely serrate; upper surface dark green, glabrous; under surface light green, nearly smooth, veins of the first order diverging at an angle of $65^{\circ}$, curving upward and anastomosing near the margin; petiole 2 to $10 \mathrm{~mm}$. in length. Flowers axillary and solitary above or in 1-sided racemes; calyx campanulate, toothed, about $2 \mathrm{~mm}$. in length; corolla white or blue, about $6 \mathrm{~mm}$. in length, the limb 2-lipped; stamens 4, didynamous, hairy, the anthers of the upper pair with 2 pollen sacs, the lower with one; style unequally 2-cleft and ovary deeply 4-parted. Fruit (Fig. 239) consisting of 4 ellipsoidal, distinctly tuberculate, light brown nutlets about $1 \mathrm{~mm}$. in length, borne on an enlarged torus known as the gynobase, and enclosed by the persistent bilabiate calyx, the upper part of which becomes helmet-shaped after fertilization, whence the name "Skullcap "; odor slight; taste bitter.

InNer Structure.-See Fig. 239.

Powder.-Dark green; non-glandular hairs, 1- to 3-celled, 0.100 to $0.200 \mathrm{~mm}$. in length, the walls with numerous slight centrifugal projections, the basal cell being large, broadly cylindrical, and the apical cell narrow and with a sharp, frequently recurved summit; glandular hairs with a 1- to 2-celled stalk and large, glandular head, composed of 6 or 8 cells divided by vertical walls, indistinct; pollen grains nearly spheroidal or ellipsoidal, smooth and from 0.015 to $0.025 \mathrm{~mm}$. in diameter; fragments of corolla colored light pink with hydrated chloral solution; narrow tracheæ with scalariform and reticulate thickenings, or bordered pores; sclerenchyniatous fibers narrow, with walls from 0.004 to $0.005 \mathrm{~mm}$. in thickness and marked by simple pores; epidermal cells of stem and corolla with distinct striations; the stomata broadly elliptical and with very small openings. In Scutellaria canescens the non-glandular hairs are 3- to 
5-celled and vary in length from 0.3 to $1 \mathrm{~mm}$; the glandular hairs have a 4-celled stalk and 8-celled head, are larger and more prominent than in S. lateriflora; and the stomata are narrowly elliptical (Fig. 239).

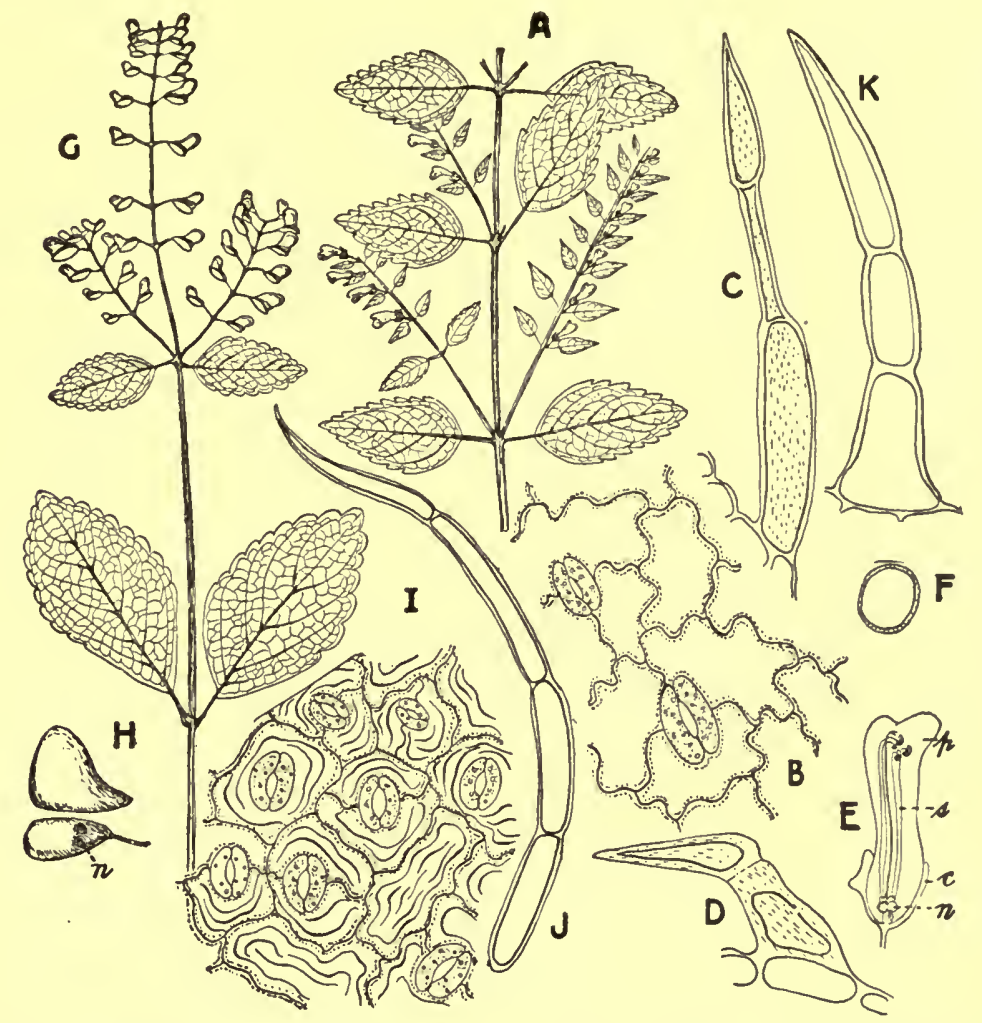

FIG. 239.-Scutellaria lateriflora: $A$, portion of branch showing the ovate, serrate leaves and the axillary one-sided racemes. $B$, lower surface of leaf showing elliptical stomata. $C, D$, hairs from the stem and lower surface of leaf. $E$, section of flower showing calyx $(c)$, with crest on one side, 2-lipped corolla $(p)$, the didynamous stamens $(s)$, and 4-locular ovary $(n) . \quad F$, pollen grain $0.018 \mathrm{~mm}$. in diameter. Hairy skullcap (Scuttellaria pilosa). G, branch showing crenate leaves and helmet-shaped capsular fruits. $H$, capsule after dehiscence showing nutlets $(n)$. Scutellaria canescens: $I$, view of lower surface of leaf showing numerous broadly elliptical stomata and wavy cuticle. $J, K$, hairs from the leaf.

Constituents. - A bitter crystalline glucoside scutellarin; a small quantity of volatile oil, of which little is known.

Allied Plants.-Several species of Scutellaria growing in the United States are sometimes substituted for the genuine drug, 
nearly all of which have the flowers in terminal panicled racemes. Heart-leaved skullcap (Scutellaria cordifolia) is densely glandular pubescent, even the corolla being hairy; Hairy skullcap (S. pilosa) is pubescent below, with numerous glandular hairs above, and the corolla is nearly glabrous; Hyssop skullcap (S. integrifolia) has linear entire upper leaves; in Marsh skulleap (S. galericulata) the flowers occur in the axils of the nearly sessile, narrow leaves. The European skullcap (S. altissima) has broad, ovate, glabrous leaves and terminal panicles of blue flowers.

Substitutes.-Scutellaria canescens, a plant growing west of the Mississippi, furnishes much of the drug on the market. The plant is more robust than S. lateriflora; the leaves are oblong, petiolate, 10 to $12 \mathrm{~cm}$. in length, 3 to $5 \mathrm{~cm}$. in breadth, very hairy on the under surface, with prominent veins, and crenate-dentate margins; and the flowers are large, blue and in terminal racemes (Fig. 239).

Literature.-Holm, Merck's Report, 1911, p. 247.

MarRubium.-White Horehound.-The leaves and flowering tops of Marrubium vulgare (Fam. Labiatæ), a perennial herb indigenous to Europe and Asia, and cultivated in various parts of Europe and the United States, being naturalized in waste places from Texas and Mexico to Maine and Ontario.

Description.-Stem quadrangular, yellowish- or grayish-green, 3 to $5 \mathrm{~mm}$. in diameter, very pubescent; internodes 2 to $5 \mathrm{~cm}$. in length. Leaves broadly ovate, opposite, 1.5 to $6 \mathrm{~cm}$. in length, 8 to $25 \mathrm{~mm}$. in breadth; summit obtuse; base acute or rounded; margin coarsely crenate; upper surface dark green, pubescent, veins depressed, those of the first order diverging at an angle of about $65^{\circ}$ and branching near the margin; under surface grayish-green, very pubescent, veins prominent; petiole 0.5 to $3 \mathrm{~cm}$. in length, very pubescent. Flowers sessile, in axillary clusters; calyx tubular, about $5 \mathrm{~mm}$. in length, 5 - to 10-nerved, very pubescent and with 10 recurved, bristle-like lobes; corolla whitish or light brown, about $7 \mathrm{~mm}$. in length, upper lip erect, entire or bifid, lower lip 3-lobed, the middle lobe the largest and emarginate; stamens four, included. Nutlets brownish-black, ellipsoidal, slightly compressed, about 1.5 $\mathrm{mm}$. in length, nearly smooth. Odor slight aromatic. Taste aromatic and bitter.

Inner Structure.-Non-glandular hairs of 3 types;- (a) short, unicellular hairs; (b) long-pointed, unicellular hairs, having papillose walls; and (c) branched or tufted, multicellular hairs, having from 6 to 15 cells radiating from a central stalk. Glandular hairs of 2 types having either a short, or long stalk, and a 2- to 8-celled gland- 
ular head. Epidermal cells of both surfaces more or less tabular, the walls being but slightly undulate.

Powder.-Dark green; non-glandular hairs frequently considerably twisted, 1- to 7 -celled, thin-walled, smooth, frequently arranged in stellate groups of 6 to 15, and spreading from the base; glandular hairs with 1-celled stalk and 4- to 8-celled glandular head; pollen grains spheroidal about $0.025 \mathrm{~mm}$. in diameter, and with numerous spinose projections; tracheæ spiral, annular or reticulate, slightly lignified; sclerenchymatous fibers thin-walled, nonlignified and with few simple pores.

Constituents.-A bitter, somewhat acrid principle, marrubiin 0.02 to 4 per cent, which forms prismatic crystals and is sparingly soluble in water; several other bitter principles; a volatile oil; a resin; and tannin.

Allied Plants.-Black horehound or Marrubium peregrinum, an herb of the old world, possesses ovate or lanceolate, dentate-serrate, grayish, hairy leaves and flowers having straight calyx-lobes. Ballota nigra (Fam. Labiatæ) has cordate, rough-hairy, dark green leaves, pale purple flowers and a disagreeable odor. Water horehound or Lycopus europæus possesses ovate-lanceolate, lobed or divided leaves, the calyx lobes being triangular.

Adulterant.-The commercial drug consists at times of Ballota hirsuta. (U. S. Dept. Agric.)

Mentha Piperita.-Peppermint.-The leaves and flowering tops of Mentha piperita (Fam. Labiatæ), a perennial herb (Fig. 240) indigenous to Europe, naturalized in the eastern and central United States and Canada, and cultivated in Michigan and New York. Peppermint should be collected during dry weather, in August and September, when the plant is in flower, and carefully dried and preserved. Peppermint is cultivated in Michigan chiefly for its volatile oil. This State produces annually over $6800 \mathrm{~K}$. of peppermint oil. Wayne County, in New York State, produces 1480 K.; Indiana State, $1280 \mathrm{~K}$., and other localities about $40 \mathrm{~K}$. annually. Japan produces about 70,000 K. annually; England, $9000 \mathrm{~K}$; France, 3000 K.; Russia, 1200 K.; Germany, 800 K., and Italy, 600 K.

Description.-Stem quadrangular, 1 to $3 \mathrm{~mm}$. in diameter, purplish-green, with scattered deflexed hairs, internodes 1.5 to $5 \mathrm{~cm}$. in length. Leaves ovate-lanceolate, opposite, 1.5 to $8 \mathrm{~cm}$. in length, 0.5 to $2.5 \mathrm{~cm}$. in breadth; summit acute; base acute or rounded; margin sharply serrate; upper surface dark green, midrib and veins rose-colored, the latter diverging at an angle of about $60^{\circ}$, curving upward and uniting near the margin; under surface light green, 
slightly pubescent on the veins, glandular-pubescent; petiole 4 to 10 $\mathrm{mm}$. in length, slightly pubescent. Inflorescence in axillary whorls or in compact spikes; peduncle wanting or about $3 \mathrm{~mm}$. in length, pedicel about $1 \mathrm{~mm}$. in length; calyx tubular, equally 5-toothed, about $2 \mathrm{~mm}$. in length, purplish, glandular-punctate; corolla tubular, nearly regular, 4 -cleft, about $3 \mathrm{~mm}$. in length, purplish; stamens four, erect, distant. Nutlets ellipsoidal, about $0.4 \mathrm{~mm}$. in diameter, blackish-brown. Odor aromatic; taste aromatic, followed by a cooling sensation.

InNer Structure.-(Fig. 240).

Crystals of menthol may be observed in the glandular hairs of Mentha piperita, if the sections are kept at a temperature near $0^{\circ} \mathrm{C}$, , or by placing the sections in a freshly preserved solution of ammonium nitrate (50 per cent.). The crystals separate in aggregates consisting of small needles. Photomicrographs of menthol in form of small rods and aggregates of needles are illustrated in Kraemer's Applied and Economic Botany, p. 326.

Powder.-Dark green; non-glandular hairs 1- to 8-celled, thinwalled, with numerous papillose projections; glandular hairs two kinds, 1- or 3-celled stalk and 1- or 8-celled glandular head; pollen grains somewhat spheroidal, smooth, about $0.035 \mathrm{~mm}$. in diameter; tracheæ spiral, or with simple and bordered pores, and slightly lignified; sclerenchymatous fibers thin-walled, non-lignified, with numerous oblique pores. Contamination with M. spicata is said to be common.

Constituents.-Volatile oil, containing 50 to 60 per cent of menthol, about 1 per cent; resin and tannin. American peppermint oil consists of about 17 different chemical constituents, a larger number than is found in any other oil. The most important constituent is the stearoptene menthol, of which 40 to 45 per cent is free and 8 to 14 per cent is combined in various esters. Menthol occurs in colorless, acicular crystals, which are insoluble in water but soluble in alcohol, and on boiling with a sulphuric acid solution ( 50 per cent) it becomes of a deep blue color, the acid solution becoming brown. American peppermint oil also contains: Acetaldehyde, isovaleraldehyde, acetic acid, valerianic acid, pinene, phellandrene, cineol, l-limonene, menthone, menthyl acetate, menthyl iso-valerianate, menthyl ester, a lactone cadinene, amyl alcohol, and dimethyl sulphide.

English Peppermint oil is very highly prized on account of its fine aroma and pleasant taste. It consists of 50 to 60 per cent of free menthol, 3 to 14 per cent of menthol combined as esters, and 9 to 12 per cent of menthole, a substance capable of being trans- 
formed into menthol. This oil also contains: Phellandrene, limonene, cadinene, acetic acid and iso-valerianic acid.

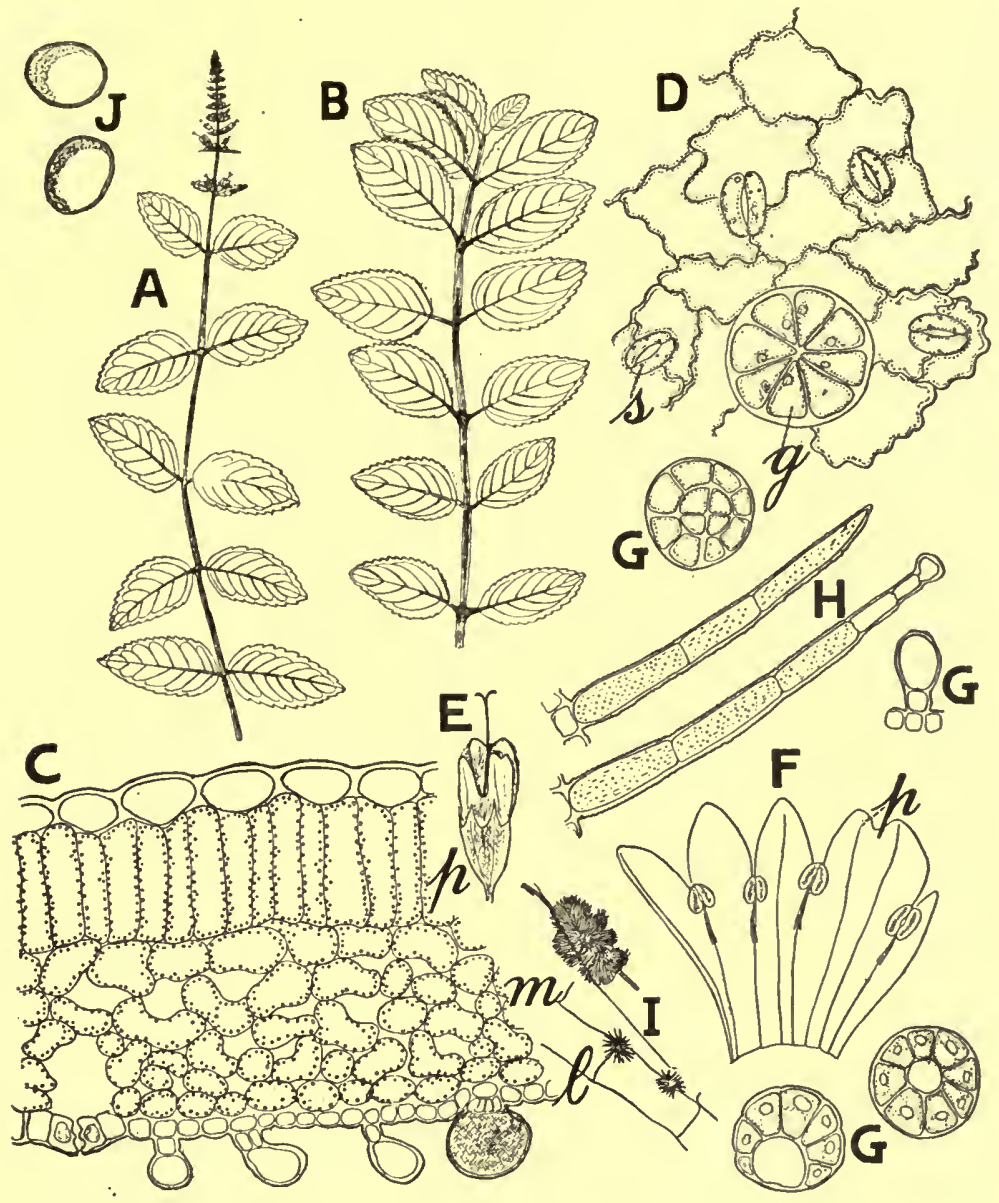

FIG. 240.-Peppermint (Mentha piperita): $B$, portion of shoot showing petiolate leaves. $C$, transverse section of leaf showing several forms of glandular hairs on lower surface, loose parenchyma $(m)$ and palisade cells $(p) . D$, lower surface of leaf showing stoma $(s)$ and glandular hair $(g)$. Spearmint (Mentha spicata): $A$, portion of shoot showing flowers and nearly sessile leaves. $E$, flower. $F$, outspread corolla showing cleft posterior lobe $(p)$ and the four adnate, included stamens. $G, H$, hairs from calyx. $I$, sphere crystals (sphærites) of a carbohydrate found in the corolla and style. $J$, pollen grains.

Japanese Peppermint oil is obtained from Mentha arvensis piperascens. The oil has a bitter taste and consists of free men- 
thol, 65 to 85 per cent; menthol combined as esters, 3 to 6 per cent; and a body isomeric with borneol.

Mentha Viridis.-Spearmint.-The leaves and flowering tops of Mentha spicata (Syn. Mentha viridis), Fam. Labiatæ, a perennial herb (Fig. 240), indigenous to Europe and cultivated and naturalized in various parts of North America. It should be collected in the same manner as peppermint.

Spearmint is extensively cultivated in Michigan and New York, these States producing annually about $500 \mathrm{~K}$. of volatile oil.

Description.-Closely resembling peppermint (see Mentha piperita), but the stems are usually more purple, the leaves sessile or nearly so, inflorescence either in slender, interrupted cylindrical spikes or crowded lanceolate spikes (Fig. 240); odor and taste aromatic, characteristic, the taste not being followed by a cooling sensation.

Constituents.-Volatile oil, about 0.3 per cent in the fresh leaves; resin, and tannin. American oil of spearmint consists of about 56 per cent of carvone, a considerable amount of l-limonene and"possibly also l-pinene. The constituent giving the oil its characteristic odor is not known.

Allied Plants.-Russian spearmint oil is obtained from an undetermined plant and consists of l-linalool, 50 to 60 per cent; 20 per cent of cineol, 5 to 10 per cent of l-carvone and possibly also l-limonene.

German Spearmint oil is obtained from Mentha crispa, which is regarded as a cultural variety of M. arvensis. The plant is sparingly naturalized in the United States from Europe. It somewhat resembles M. piperita, but is distinguished by its cuspid, irregularly dentate leaves. It yields an oil containing carvone.

Hedeoma.-American Pennyroyal.-The leaves and flowering tops of Hedeoma pulegiodes (Fam. Labiatæ), an annual herb indigenous to the eastern and central United States and Canada. Pennyroyal should be collected in July or August and dried.

Description.-Stem quadrangular, 1 to $2 \mathrm{~mm}$. in diameter, light or reddish-brown, with numerous spreading hairs. Leaves elliptical or ovate, opposite, 15 to $35 \mathrm{~mm}$. in length, 5 to $14 \mathrm{~mm}$. in breadth; summit obtuse; base tapering into the petiole; margin remotely serrate; upper surface dark green, pubescent on the nerves, slightly glandular-hairy; under surface light green, pubescent, "glandularhairy, veins of the first order diverging at an angle of $45^{\circ}$ to $65^{\circ}$, curving upwards and uniting near the margin; petiole 3 to $6 \mathrm{~mm}$. in length, with numerous spreading hairs and slightly laminate in the upper portion. Inflorescence in six-flowered axillary whorls; calyx 
tubular, about $5 \mathrm{~mm}$. in length, ovoid or slightly curved on the lower side near the base, bilabiate, upper lip 3-toothed, lower lip with two linear-lanceolate divisions, 13-nerved, longitudinally striate, pubescent; corolla about the size of the calyx, purplish, pubescent, upper lip erect, flat, emarginate, the lower spreading and 3-lobed; fertile stamens two, exserted, ascending, the sterile upper pair rarely with anthers. Nutlets nearly spheroidal or ovoid, about $0.5 \mathrm{~mm}$. in diameter; odor strongly aromatic; taste aromatic.

Inner Structure.-The leaves have a bi-facial structure; the epidermal cells are undulate, except over the veins where the walls are nearly straight; the non-glandular hairs are uniseriate, curved and pointed, consisting of from 1 to 3 cells, having a striated cuticle; the glandular hairs are of 2 types having short stalks and either a 2- or 8-celled glandular head. The stomata are broadly elliptical having a pair of subsidiary cells transverse to the pores, the cells of the stomata frequently contain large sphero-crystals. In the young internodes of the stems the outline of the stele is circular in transverse sections, in contrast with the quadrangular outline of the cortex, while in the older stem portions the stele becomes gradually quadrangular by the continued divisions of the interfasicular cambium. There is no ring of sclerenchyma in the pericycle and the endodermis consists of large, thin-walled cells which are free from starch.

Powder.-Dark green; non-glandular hairs slightly curved, 2to 3-celled, thick walled, with numerous slight centrifugal projections; glandular hairs with 1-celled stalk and 2- to 8-celled glandular head; pollen grains somewhat spheroidal, about $0.035 \mathrm{~mm}$. in diameter, nearly smooth; tracheæ spiral or with simple and bordered pores; sclerenchymatous fibers long, thin-walled, lignified, with numerous simple pores; epidermal cells having sphero-crystals or irregular masses of a carbohydrate.

Constituents.-Volatile oil, a bitter principle and tannin. The dried leaves yield about 3 per cent of volatile oil, while the dried stems and leaves yield only 1.3 per cent. The volatile oil is official and consists chiefly of a ketone pulegone, which gives the oil its peculiar properties. The oil also probably contains two other ketones: (a) hedeomol and (b) another resembling menthone. Several acids have also been found in this oil: formic, acetic and isoheptylic.

Allied Plants.-Mentha Pulegium, or European Pennyroyal, apparently contains principles similar to the American pennyroyal, and is distinguished from the latter by the more or less oval, serrate 
leaves, the cymose inflorescence and the four-lobed corolla. The oil of European pennyroyal closely resembles that of Hedeoma and is frequently substituted for it.

Wild Mint (Mentha canadensis), a perennial herb common in wet places in the United States, has ovate-oblong or lanceolate leaves, in the axils of which whorls or globular clusters of flowers arise. The plant has an odor of pennyroyal and yields 1.25 per cent of a volatile oil from which pulegone and thymol or carvacrol have been isolated.

Water Mint (Mentha aquatica), a plant found in wet places from New England to Delaware, yields about 0.34 per cent of a volatile oil having the odor of pennyroyal.

Oil of Russian pennyroyal contains pulegone, but the botanical origin is not known.

Literature.-Holm, Merck's Report, 1908, p. 115.

SALvia.-Sage.-The leaves of Salvia officinalis (Fam. Labiatæ), a perennial herb indigenous to southern Europe, and cultivated in England; France, Germany and the United States, both for use as a drug and as a pot herb. The leaves are collected when the plants are in flower, and carefully dried in the shade.

Description.-Oblong-lanceolate or ovate, 2 to $10 \mathrm{~cm}$. in length, 1 to $2.5 \mathrm{~cm}$. in breadth; summit acute; base rounded or somewhat heart-shaped, frequently lobed; margin crenulate; upper surface grayish-green, densely pubescent when the leaves are young, the older leaves being nearly smooth, midrib and veins depressed; under surface light grayish-green, midrib prominent, veins of first order diverging at an angle of $55^{\circ}$ and running nearly parallel to the margin, minutely reticulate and densely pubescent; petiole 1 to $4 \mathrm{~cm}$. in length, upper side grooved, grayish-purple; texture velvety, more or less pliable; odor aromatic; taste aromatic and bitter.

Inner Structure.-Non-glandular hairs, numerous, uniseriate, consisting of 2 to 5 cells, the lower being thick-walled and containing air. Glandular hairs of 3 types: (a) one having a 2- to 4-celled stalk, and a small 1-celled head; $(b)$ another having a 1-celled stalk and a 2-celled head; (c) a third without a stalk and having an 8-celled glandular head, containing a brownish secretion. Cells of upper epidermis polygonal in surface view and thick-walled. Cells of lower epidermis having in surface view undulate and thin walls.

Powder.-Dark green; consisting of numerous characteristic non-glandular hairs, also reddish glandular hairs as described above.

Constituents.-Volatile oil 0.5 to 2.5 per cent, containing pinene, cineol, thujon and borneol; a bitter principle somewhat resembling 
marrubiin; resin; and tannin, or a principle closely resembling it in its astringency and behavior with ferric salts.

Standard of Purity.- Sage is the dried leaf of Salvia officinalis L. It contains not less than 1 per cent of volatile ether extract, not more than 25 per cent of crude fiber, not more than 10 per cent of total ash, nor more than 1 per cent of ash insoluble in hydrochloric acid. (U. S. Dept. Agric.)

Allied Plants.-The oil from Muscatel Sage (Salvia Sclarea) has an odor of lavender and apparently contains linalyl acetate.

Adulterants.-Greek Sage (Saliva triloba). Leaves are smaller, thicker, with short petioles and the surface is more woolly. Spanish Sage, the leaves of Saliva lavandæulfolial, are considerably smaller than the official article, possess relatively long petioles and entire margins. (U. S. Dept. Agric.)

Thymus.-Herba Thymi, Common or Garden Thyme.-The leaves and flowering tops of Thymus vulgaris (Fam. Labiatæ), a small evergreen shrub indigenous to Spain and Italy and extensively cultivated both in Europe and the United States. The leafy and flowering tops are gathered in May or June and carefully dried. The commercial supplies are obtained from Germany and New York State, where it is cultivated to a great extent.

Descrpition.-Stems slender, quadrangular, pubescent, more or less curved, about $15 \mathrm{~cm}$. in length and $1 \mathrm{~mm}$. in thickness, externally light grayish-brown, pubescent, the older woody portions purplish-brown, pith hollow. Leaves lanceolate or ovate oblong, about $10 \mathrm{~mm}$. in length and 3 to $5 \mathrm{~mm}$. in breadth; summit acute, base tapering into a short petiole, margin entire and revolute, both surfaces grayish-green and glandular hairy, the veins of the midrib and first and second order prominent, those of first order diverging at an angle of about $65^{\circ}$ and ending free near the margin. Flowers, in axillary clusters or in terminal glomerules; calyx 13-nerved, bilabiate, the lower 2-cleft, the lobes having awl-shaped, linear divisions; corolla bi-labiate and about $3 \mathrm{~mm}$. in breadth; stamens 4 , straight and exserted; ovary 4-parted and having a 2-cleft style; nutlets ovoid, about $0.5 \mathrm{~mm}$. in diameter, smooth.

Inner Structure.-Non-glandular hairs of 3 kinds: (a), unicellular, sharp pointed, about 0.060 in length and having thick, papillose walls; (b), uniseriate, sharp pointed, consisting of 2 to 3 cells, from 0.200 to $0.300 \mathrm{~mm}$. in length and having thick papillose walls; (c), uniseriate, consisting of 2 or 3 cells, the terminal one being somewhat curved or hooked. Glandular hairs of 2 kinds: (a), consisting of a short stalk, embedded in the epidermal layer and a unicellular head or secreting 
cell; (b), without a stalk and having an 8- to 12-celled secreting head, the latter being yellowish-brown in color and about $0.015 \mathrm{~mm}$. in diameter, giving the leaves a glandular punctate appearance. Calyx having 6- to 8-celled uniseriate hairs, which are long pointed, from 0.300 to 0.400 in length, the walls being thin and the lumina of the lower cells filled with air. In the stem the endodermis is distinct; the pericycle is made up of a narrow ring of sclerenchymatous fibers; and the medullary rays of the xylem are 1 cell in width.

Constituents.-A yellowish-red volatile oil, from 1 to 2.6 per cent, consisting of thymol, cymene, thymene and a small quantity of l-pinene. Spanish oil of thyme is often of a dark green color and contains from 50 to 70 per cent of carvacrol, but no thymol. Thyme also contains tannic acid.

Standard of Purity.-Thyme is the dried leaves and flowering tops of Thymus vulgaris L. It contains not more than 14 per cent of total ash, nor more than 4 per cent of ash insoluble in hydrochloric acid. (U. S. Dept. Agric.)

Allied Plant.-Thymol may be obtained from horsemint (Monarda didyma). See bulletin 372, U. S. Dept. Agric.

Adulterants.-The leaves and tops of Cretan Dittany, Origanum Dictamnus, a native of the Isle of Crete in the eastern Mediterranean Sea, are sometimes sold as thyme. The stems are nearly cylindrical, reddish-brown, from 0.5 to $2 \mathrm{~mm}$. in diameter. The leaves are broadly elliptical, light greenish-gray and densely tomentose. The bracts are purplish-brown and the corolla dark purple. The plant yields a volatile oil containing about 85 per cent of pulegone.

The leaves and tops of Origanum creticum, known as Spanish HoPS, is also sold for thyme. The plant is indigenous to southern Europe and consists of numerous cylindrical or somewhat quadrangular stems of a yellowish or light brown color; a number of elliptical or ovate, short petiolate leaves, about $10 \mathrm{~mm}$. in length, being grayish-green, glandular hairy and with 5 palmate veins; and numerous ovoid or cylindrical spikes having grayish-green imbricated bracts and enclosing in fruit the ovoid nutlets; the latter being elliptical, yellowish-brown, about $1 \mathrm{~mm}$. in length and having the epidermal cells modified to papillæ. The plant yields from 2 to 3 per cent of a volatile oil containing from 60 to 85 per cent of carvacrol. The oil, from different sources, varies in color and in the carvacrol content. Ocymum viride, native of west Africa, yields 0.45 per cent of volatile oil which contains 52 per cent of thymol. Bot. Abstracts, 1918, 1, p. 114. 
Literature.-Guérin, Rept. Pharm., 1919, 30, p. 49.

Marjoram.-Herba Majoranfe, Sweet or Garden Marjoram. -The leaves and flowering tops of Origanum Majorana (Majorana hortensis), Fam. Labiatæ, an annual herb indigenous to southern Europe, northern Africa and western Asia and extensively cultivated as a pot or seasoning herb.

Description.-Leaves ovate or broadly elliptical, petiolate; from 1 to $4 \mathrm{~cm}$. in length and 0.6 to $20 \mathrm{~mm}$. in width; summit acute or obtuse; base acute, unequal; margin entire or somewhat repand toothed; both surfaces grayish-green, soft-downy, and glandular hairy. Flowers purplish-red, in cylindrical or ellipsoidal spikes, having imbricated bracts of the same color as the flowers. Stems purplish-red, obscurely or distinctly quadrangular, purplish-brown, finely longitudinally striated and hairy; odor distinct; taste aromatic and somewhat pungent.

Inner Structure.-(Fig. 241.) Non-glandular hairs, uniseriate, composed of 2 to 7 cells, the lower being broad, the upper narrow and frequently curved, the walls being thick, strongly papillose. Glandular hairs of 2 kinds: (a), having a 2- to 4-celled stalk and a 1- to 2-celled head; (b), with a 1-celled stalk and an 8- to 12-celled glandular head, the latter containing a light yellowish oily content and being about $0.015 \mathrm{~mm}$. in diameter. Epidermal cells of the upper surface somewhat polygonal, having unequal porous walls. Epidermal cells of lower surface having undulate walls with unequal porous thickenings, and broadly elliptical stomata, the latter having the two subsidiary cells transverse to the pore.

Standard of Purity.-Marjoram is the dried leaves, with or without a small proportion of the flowering tops of the Majorana hortensis Moensch. (U. S. Dept. Agric.)

Adulterations.-The leaves of Tanner's sumac, Coriaria myrtifolia (Fam. Coriariaceæ) have been substituted. These are readily distinguished (see Fig. 241).

Constituents.-From 0.7 to 0.9 per cent of a greenish or yellowishgreen volatile oil, consisting of about 85 per cent of a mixture of borneol and camphor. Marjoram also contains a tannin, which is colored green with ferric salts; and ash from 12 to 19 per cent, of which from 2 to 2.5 per cent consists of sand.

Literature.-Nestler, Arch. Chem. Mikros., 1913, Heft 1 and 2; Hanausek and Winton, Microscopy of Technical Products, 1907, p. 300; Kraemer, Pacific Pharm., 1917, 11, p. 13; Beringer, Amer. Jour. Pharm., 1918, 90, p. 555; Collin, Ibid., p. 823. 
LAVANDUla.-Lavender Flowers.-The carefully dried flowers of Lavandula vera D.C. (L. officinalis chaix), Fam. Labiatæ, a small shrub, native of southern Europe and cultivated in Europe as far north as Norway and also in the United States. The leaves and flowers of lavender were used by the ancients to perfume their
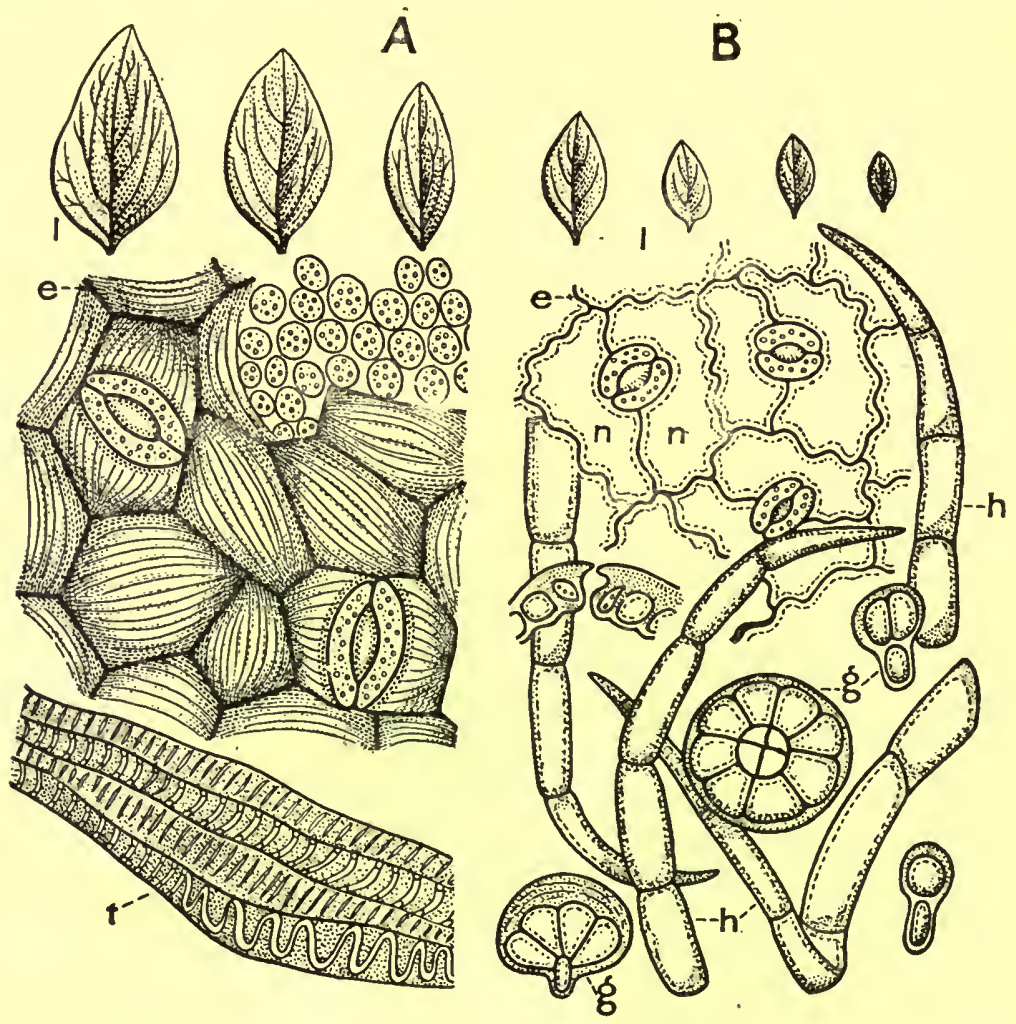

Fra. 241.- $-A$, Coriaria. $l$, entire leaves; $e$, surface view of the lower epidermis showing two of the stomata with two neighboring cells which are situated parallel to the pore of the stoma; $t$, several of the trachea. The epidermal cells showing a striated cuticle similar to the neighboring cells. $B$, Marjoram leaves, $l$, entire leaves; $e$, surface view of the lower epidermis showing three stomata, the neighboring cells $(n)$ being at right angles to the pores of the stomata; $h$, uniseriate non-glandular hairs; $g$, typical 8-celled glandular hairs.

baths. The flowers are still extensively used for the perfuming of linen. The commercial supplies of lavender flowers come from southern Europe and are exported to the Barbary states, Turkey and America. The lavender plant is also essentially cultivated for its volatile oil. 
Description.-Florets, bi-labiate from 5 to $8 \mathrm{~mm}$. in length, having a short stalk or being nearly sessile; calyx, tubular about $4 \mathrm{~mm}$. in length, obscurely 5-toothed, prominently nerved and dark blue in color, the lower portion being somewhat grayish and hairy, the corolla about $4 \mathrm{~mm}$. in length, dark blue or bluish-brown, tubular, limb being two-lipped; stamens 4 inserted; tube of corolla with characteristic corkscrew-like hairs which are glandular; odor, strongly aromatic and distinct; taste, aromatic, slightly pungent and somewhat bitter.

Constituents. - A pale yellow or yellowish-green, very fragrant volatile oil from 0.8 to 2.8 per cent, the principal constituent of which is l-linalyl acetate, which occurs to the extent of 30 to 45 per cent in the French oil. It also contains an ester of butyric acid and possibly also esters of butyric and valerianic acid. According to the amount of linayl acetate the French lavender oils are divided into two classes: (a) Those with more than 36 per cent of ester, possessing the finest and most intense aroma, being produced in the southern French Alps. (b) Those having from 30 to 36 per cent of ester. The English oils contain from 7 to 11 per cent of linalyl acetate and are also known for their fragrancy having a cineol-like odor.

Adulterants.-Oil of lavender is adulterated with turpentine oil, cedarwood oil and spike oil. The latter is obtained from Lavandula spica DC. A plant which grows in the same sections with lavender in the Mediterranean countries. Spike oil has a camphor-like odor reminding one of a mixture of lavender and rosemary. Spike oil contains a camphor which is not present in genuine lavender oil. It also contains borneol, cineol, linalool, and probably terpineol.

Collinsonia.-Rhizoma Collinsonie, Stoneroot, Клотroot or Horse-Balar Root.-The rhizome and roots of Collinsonia canadense (Fam. Labiatæ), a perennial herb, growing in moist woods throughout the central and eastern United States. The rhizomes with adhering roots are gathered in the fall and employed in either the fresh or dried condition.

Description.-Rhizome horizontal, irregularly branched, the termination of the branches rounded and knotty; from 3 to $15 \mathrm{~cm}$. in length, and 1 to $2 \mathrm{~cm}$. in thickness; externally light or dark yellowish-brown, roughened from the sharp ridges of bud scales, short conical buds and root bases, upper surface having very shallow stemscars; very hard, tough; inner surface light yellowish having a thin bark, a narrow layer of wood, and a very large pith; odor slight; taste slightly pungent. Roots filiform, dark brown, more or less curved and branching at the ends. 
Inner Structure.-An outer strata of lamellar cork, i.e., composed of layers of different width alternating with each other, the walls being yellowish brown; cortex composed of a few rows of more or less tabular or rectangular cells containing starch; stele cylindrical consisting of small collateral fibrovascular bundles, separated by very broad strands of radially elongated, starch-bearing parenchyma, the walls being strongly lignified; pith large, composed of polyhedral parenchyma cells, having moderately thick and strongly lignified walls. Starch grains numerous, mostly single, occasionally 2-compound, the individual grains from 0.002 to $0.025 \mathrm{~mm}$. in length and varying greatly in shape from narrow cylindrical, more or less ellipsoidal, to pear-shaped, fusiform and reniform grains. The hardness of the root is due to the large amount of lignified tissue.

Constituents.-A saponin-like glucoside; a resin soluble in ether, partly soluble in alcohol; also organic acids; tannic acid; mucilage and wax.

Adulteration.-A rhizome of unknown origin is occasionally seen on the market, which is horizontal, slightly branched, from 2 to $4 \mathrm{~cm}$. in length and $1 \mathrm{~cm}$. in thickness; externally purplish-brown, distinctly annulate and deeply wrinkled, having on the upper surface a number of short stem-branches or large circular concave stem-scars; lower and side portions with numerous circular reddish root scars and short roots; internally brownish-red having a thin cortex, a narrow, distinctly radiate wood, and a large depressed pith; inodorous and slightly pungent.

The inner structure shows an outer epidermal layer; a hypodermal layer of narrow tangentially elongated cells, having a light reddishbrown amorphous content; a rather thin cortex composed of starchbearing parenchyma, having also a reddish-brown content, and cells containing rosette aggregates of calcium oxalate; the xylem consists of narrow wedges of tracheæ and wood fibers, separated by very broad rays of parenchyma cells containing the same contents as the cortical parenchyma; pith composed of parenchyma, resembling that of the cortex; calcium oxalate crystals, numerous, in rosette aggregates, from 0.010 to $0.025 \mathrm{~mm}$. in diameter; starch grains single, from 0.005 to $0.020 \mathrm{~mm}$. in diameter, mostly narrow-ellipsoidal or spindle-shaped, varying from spheroidal to fusiform and often very irregular.

Literature.-Holm, Merck's Report, 1909, p. 87; Lochman, Amer. Jour. Pharm., 1885, p. 228. 


\section{SOLANACEE, OR NIGHTSHADE FAMILY}

The plants are of varied form, most abundant in tropical regions and the family comprises about 1500 species. The leaves are usually alternate; the flowers are mostly regular, excepting in Hyoscyamus; the anthers are connivent, the pollen sacs being apically or longitudinally dehiscent; and the fruits are inferior berries or capsules.
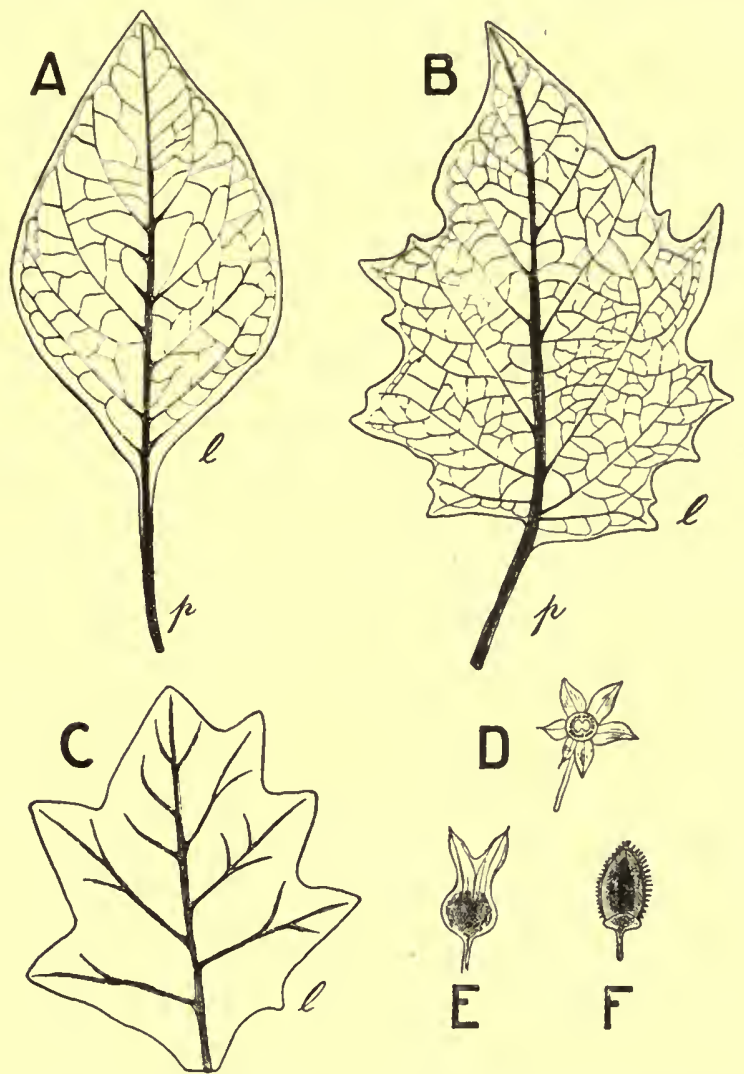

Fra. 242.-Leaves and fruits of solanaceous drugs: $A, D$, Belladonna, the inferior berry, cut transversely, showing numerous seeds; $B, F$, Stramonium, the fruit being a spinose capsule; $C, E$, Hyoscyamus, the fruit being a Pyxis, surmounted by the large calyx lobes.

The plants are usually malodorous and furnish a number of important economic products, including potato (Solanum tuberosum), tomata (S. Lycopersicum), egg-plant (S. Melongena), tobacco (Nicotiana Tabacum), as well as a number of drugs to which special attention will be given. 
The plants do not possess any special internal secretory tissues. Furthermore, bast fibers are not usually found in the secondary cortex, except possibly in Atropa Belladonna. The tracheæ have simple pores, occasionally bordered pores as in the roots of Atropa Belladonna. The wood fibers usually possess thin walls having simple pores, or thick walls marked by bordered pores. The medullary rays of the xylem are generally narrow and wood parenchyma is scantily developed. In Atropa, Datura, Solanum and Scopolia an intraxylary leptome is frequently developed and in which sclerenchymatous fibers may occur. The walls of the pith cells are usually not lignified, except in Duboisia and some other genera. Calcium oxalate is secreted in the form of solitary crystals, rosette aggregates or sphenoidal microcrystals. The stomata are usually surrounded by ordinary epidermal cells. Both glandular and non-glandular hairs occur in a great variety of forms.

Belladonne Folia.-Belladonna Leaves.-The leaves and flowering tops of Atropa Belladonna (Fam. Solanaceæ), a perennial herb (Figs. 243 and 244), native of central and southern Europe, Asia Minor and Persia, and cultivated in England and Germany, from which countries most of the commercial supply is obtained. The leaves and tops are gathered when the plants are in flower, and used fresh or after being dried. Sievers has shown that a drug of good quality may contain as high as 20 per cent of stems, the latter being from 7 to $8 \mathrm{~mm}$. in diameter when green. (Amer. Jour. Pharm., 1918, 90, p. 838.)

Description.-Usually in irregular, matted fragments. Stem hollow, cylindrical, flattened, longitudinally furrowed and wrinkled, 1.5 to $7 \mathrm{~mm}$. in diameter, internodes from 2.5 to $6.5 \mathrm{~cm}$. in length. Leaves (Fig. 242) single or in unequal pairs, broadly ovate or somewhat elliptical, 6 to $15 \mathrm{~cm}$. in length, 2.5 to $7 \mathrm{~cm}$. in breadth; summit acuminate; base acute, somewhat unequal and tapering into the petiole; margin entire; upper surface dark green, glabrous, epidermis with distinct papillæ; under surface grayish-green, slightly pubescent on the veins, epidermis distinctly sinuate, midrib dark brown, the veins of the first order diverging from it at angles of about $45^{\circ}$ and running nearly parallel to near the margin; petiole dark brown, 5 to $15 \mathrm{~mm}$. in length and semicircular in cross-section; texture fragile. Flowers solitary, pedicel 1.5 to $2 \mathrm{~cm}$. in length; calyx deeply 5-cleft, about $1 \mathrm{~cm}$. in length, outer surface slightly pubescent; corolla 5parted, about $2 \mathrm{~cm}$. in length, campanulate, yellowish purple; stamens five, included; style somewhat exserted. Fruit, a superior berry, glnbular, dark green, 7 to $10 \mathrm{~mm}$. in diameter, 2-locular, many 
seeded. Seeds campylotropous, somewhat reniform, flattened, light brown; testa finely pitted, with a curved embryo embedded in the endosperm; odor distinct, heavy; taste somewhat disagreeable.

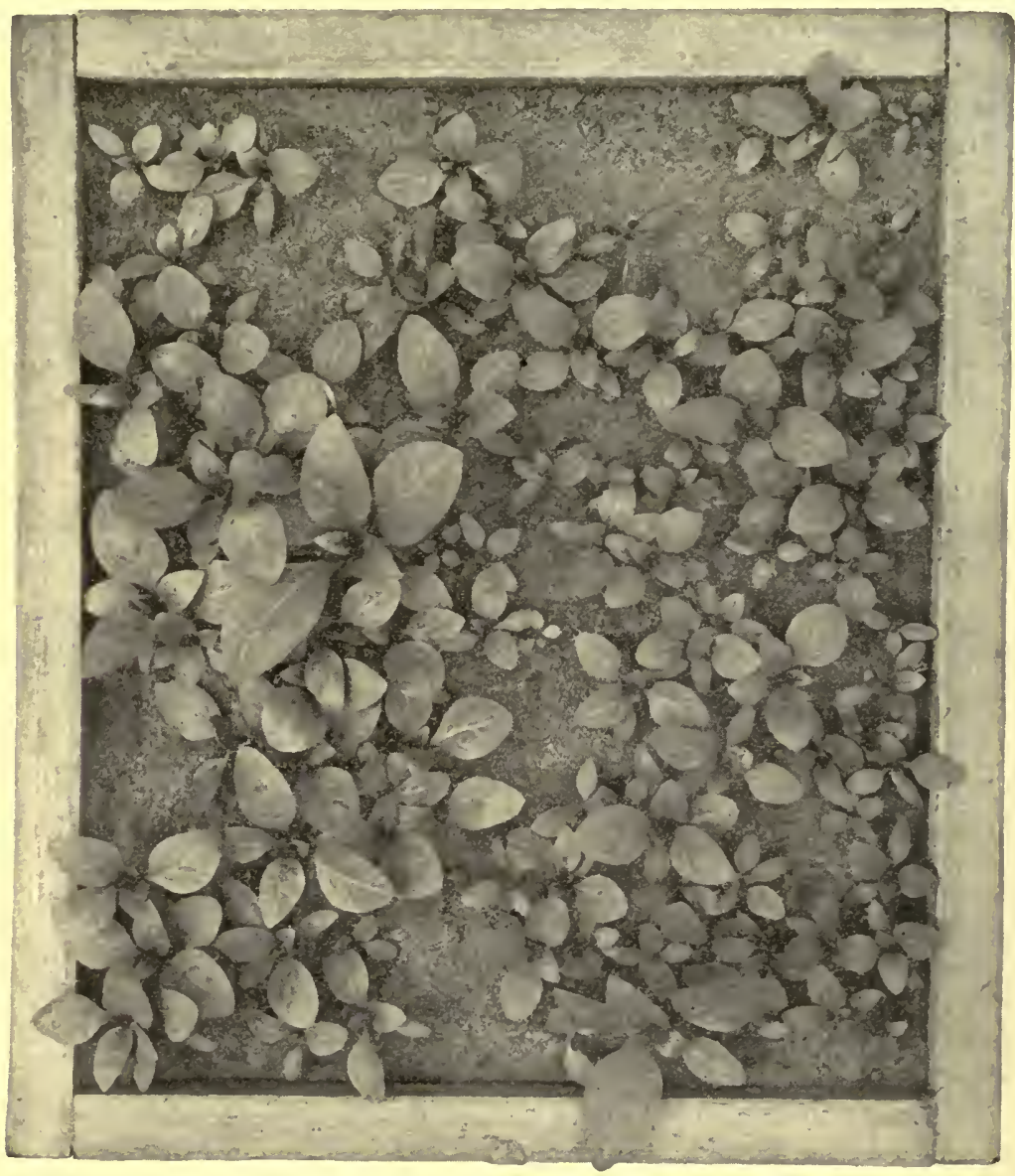

FIG. 243.-Plants from 300 large belladonna seeds seven weeks after sowing, showing the unequal development of seedlings.-After Sievers, Amer. Jour. Pharm., 1914, p. 494.

Inner Structure.-(Fig. 245.) Leaves bifacial; both the lower and upper epidermis consist of cells, having thin undulate walls, stomata and hairs, these latter being more abundant on the dorsal surface; a layer of short palisade cells; a crystal layer composed of parenchyma, the nearly isodiametric cells being filled with sphenoidal microcrystals; several layers of loose mesophyll, among which are 
included the bicollateral fibrovascular bundles occurring in the veins; non-glandular hairs, uniseriate, consisting of from 2 to 5 cells; glandular hairs of 2 types: (a), having a 2- to 3-celled stalk and a 1-celledsecreting head; $(b)$, having a 1-celled stalk and 4- to 10-celled secreting head. It has been variously stated that calcium oxalate also

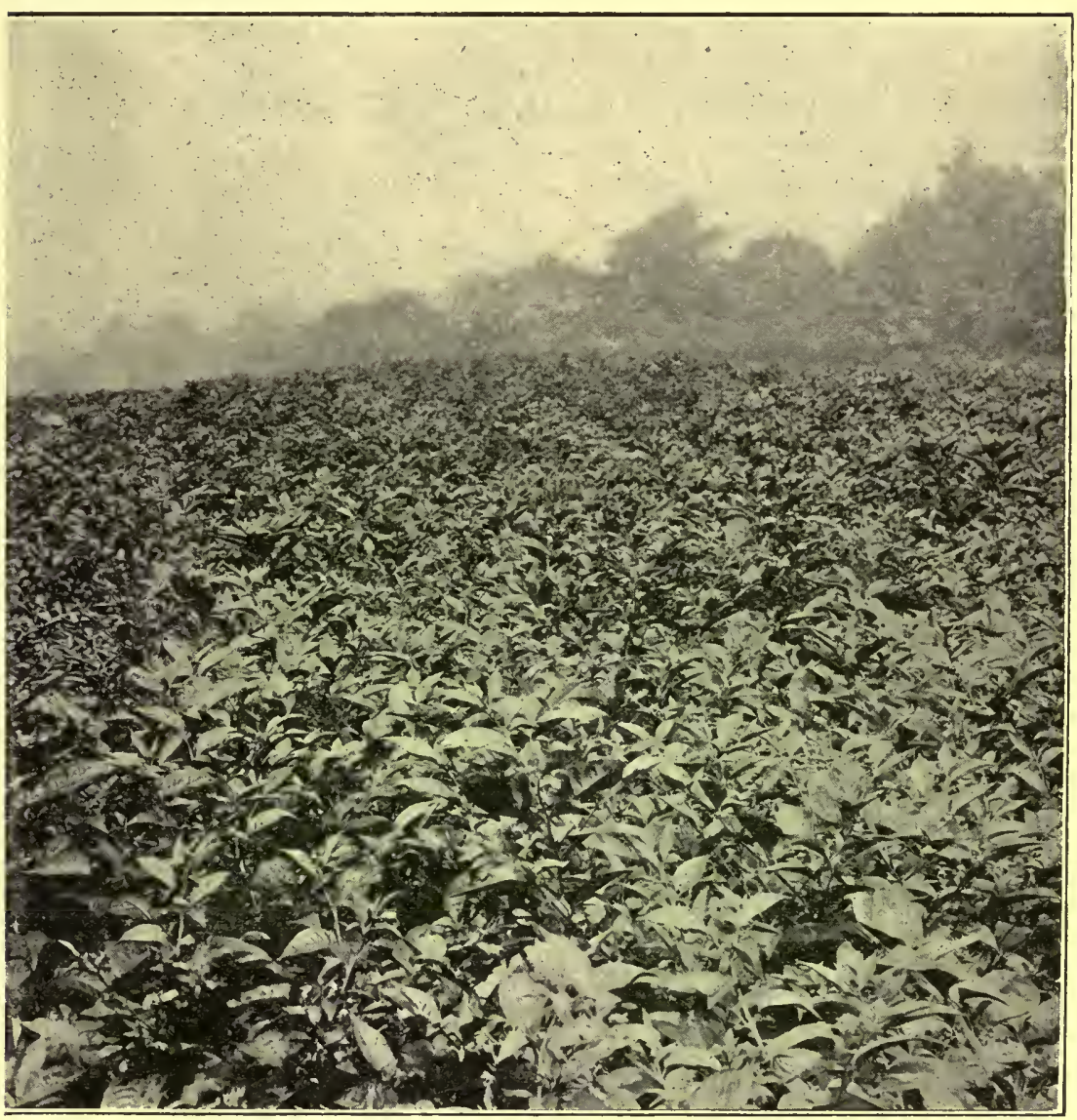

Fig. 244.-Atropa Belladonna; first year's plant, grown at The H. K. Mulford Co. Drug Farm, Glenolden, Pa.-After Borneman, Amer. Jour. Pharm., 1912 , p. 550.

occurs in the leaves in the form of rosette aggregates and acicular crystals. If true these forms are of very seldom occurrence.

In the stem there occurs an outer epidermal layer having a thin cuticle; a primary cortex of parenchyma, the cells being separated by large intercellular spaces; an endodermis, beneath which in the 
pericycle occurs an interrupted circle of bast fibers occurring either single or in small groups, the walls of which are relatively thin and slightly lignified (Fig. 245); a few layers of leptome; xylem consisting of a few tracheæ associated with numerous wood fibers (Fig. 245); an internal phloem having small isolated groups of bast fibers

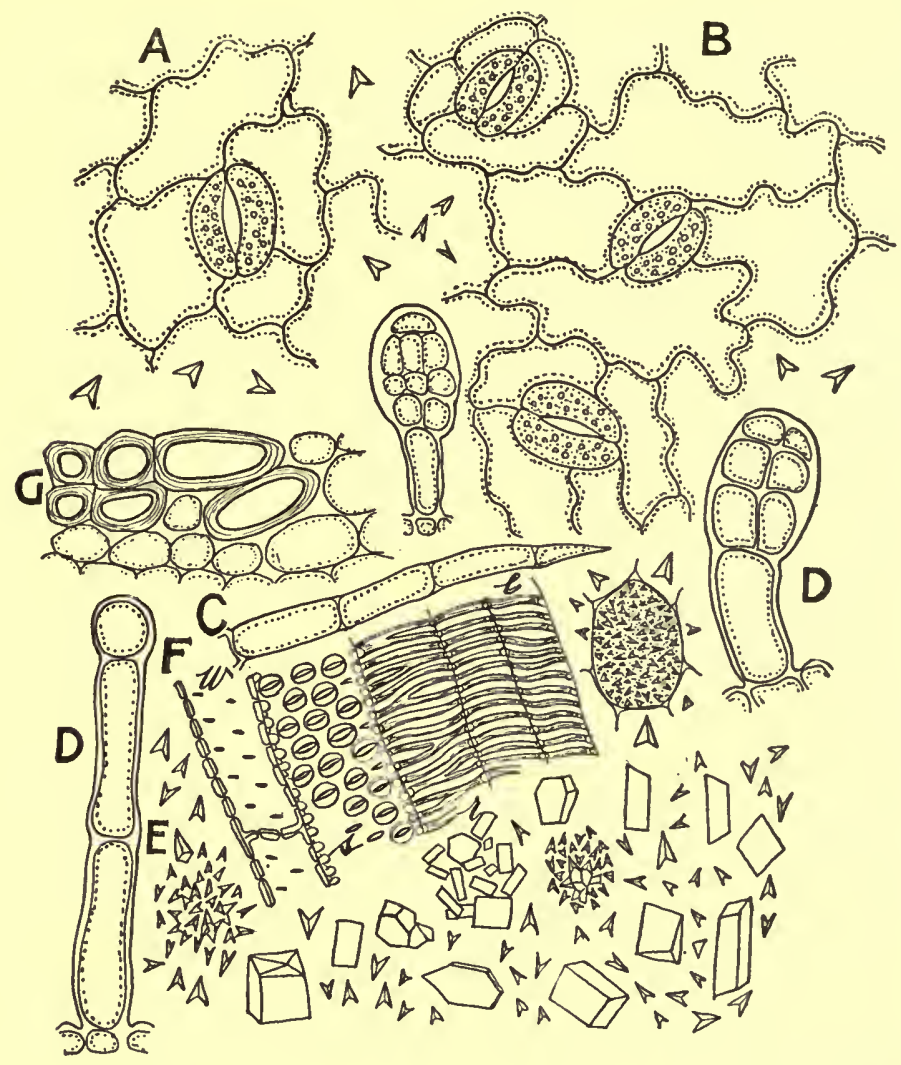

FIG. 245.-Belladonna: $A$, surface view of cells of the epidermis, showing also a stoma. $B$, surface view of cells of the lower epidermis and 3 stomata. $C$, a non-glandular hair. $D$, several types of glandular hairs. $E$, numerous crystals of calcium oxalate in the form of sphenoidal microcrystals and small prisms. $F$, fragment of xylem showing the wood fibers having simple pores, and several tracheæ with bordered pores and reticulate perforations. $G$, transverse section of a portion of the stem showing thick-walled bast fibers.

similar to those found in the inner bark; pith of large irregular parenchyma cells.

Powder.-(Fig. 245.) Dark green; especially characteristic of the powder, cleared with solutions of potassium hydroxide or chloral 


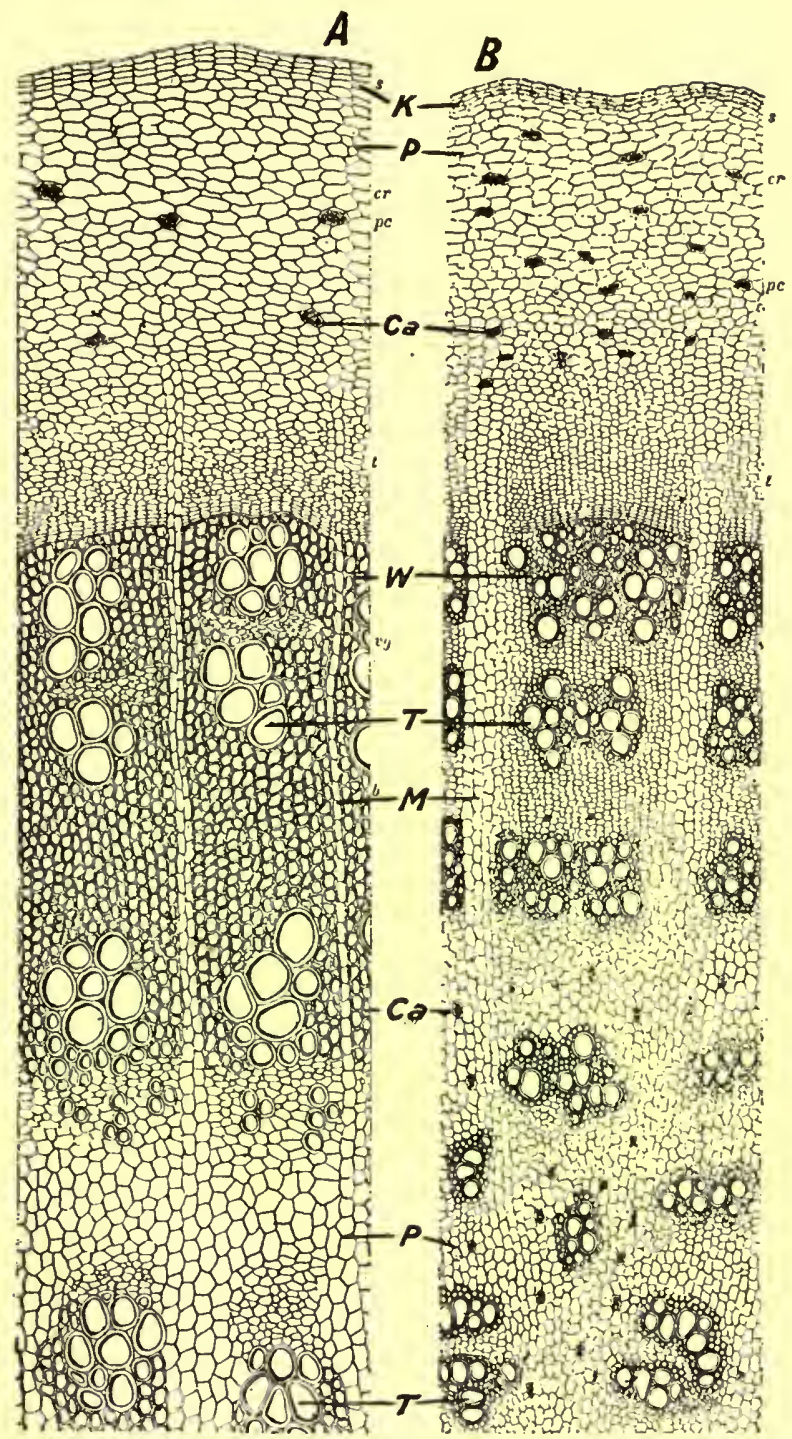

FIG. 246.-Belladonna root: $A$, transverse section of older root in which the xylem or woody portion is fully developed, showing cork cells $(K)$; starchbearing parenchyma $(P)$; microcrystals of calcium oxalate $(\mathrm{Ca})$; wood fibers $(W)$; trachex $(T)$; medullary rays $(M)$. $B$, transverse section of a lateral root in which the xylem portion is not so fully developed, letters same as in A.-After Collin. 


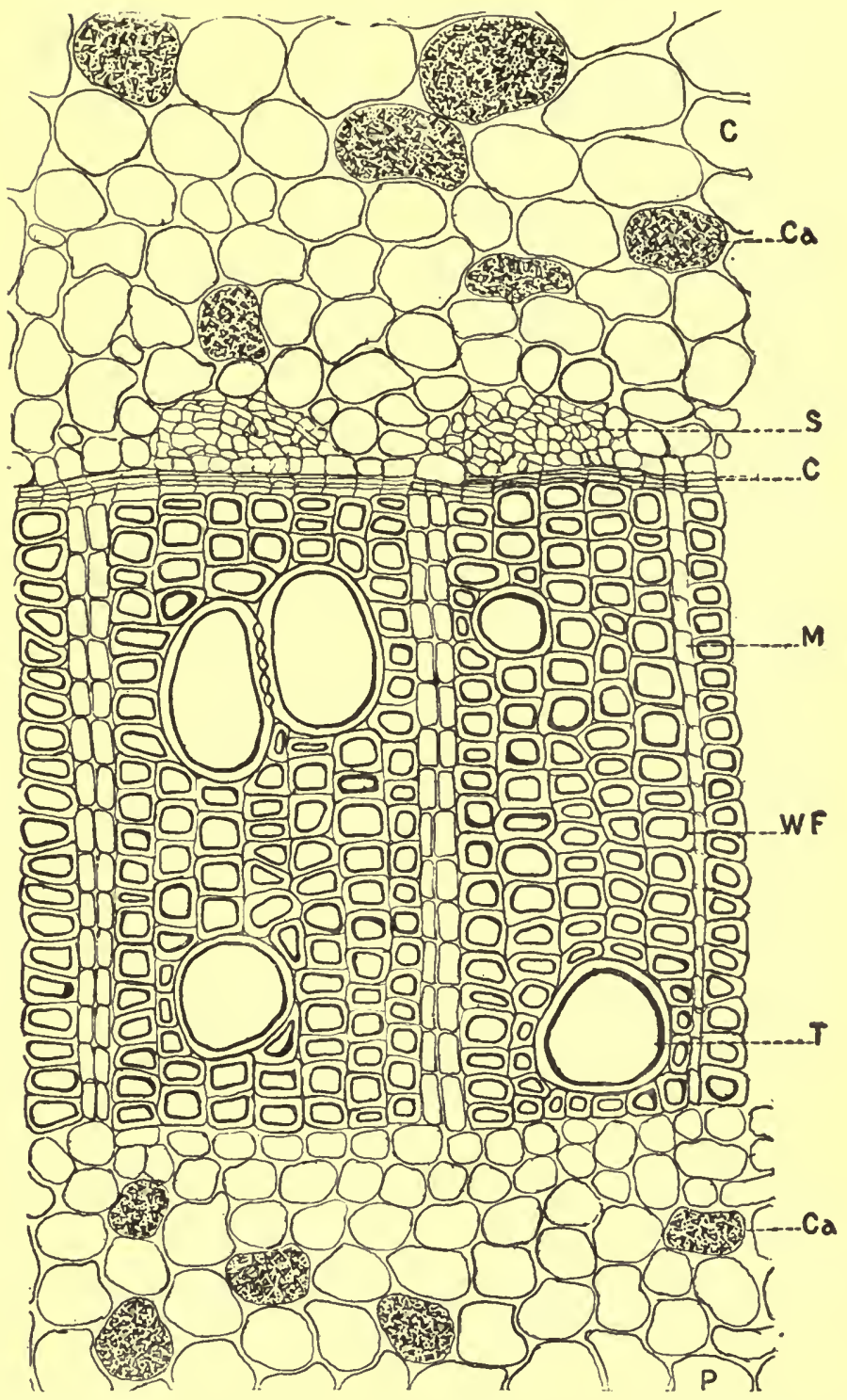

FIG. 247.-Transverse section of a somewhat woody root of belladonna near the cambium: $C$, parenchyma of the cortex, some of the cells showing sphenoidal microcrystals of calcium oxalate $(C a)$; $S$, leptome; $C$, cambium; $M$, medullary rays; $W F$, wood fibers; $T$, trachex; $P$, parenchmya of pith, some of the cells having microcrystals of calcium oxalate. 
hydrate, is the crystal layer, in which the cells filled with microcrystals are grayish-black and somewhat larger than the surrounding cells; non-glandular hairs few, uniseriate, 2- to 5-celled; glandular hairs few, of two kinds, stalks 1- to 3-celled, glandular heads 1- to many-celled; tracheæ with annular, spiral, scalariform or reticulate thickenings and with bordered pores; starch grains and pollen grains few; occasional fragments of the stems having slightly lignified bast fibers.

Constituents.-Several alkaloids amounting to from 0.3 to 0.7 per cent, of which hyoscyamine (see Hyoscyamus) exists in largest

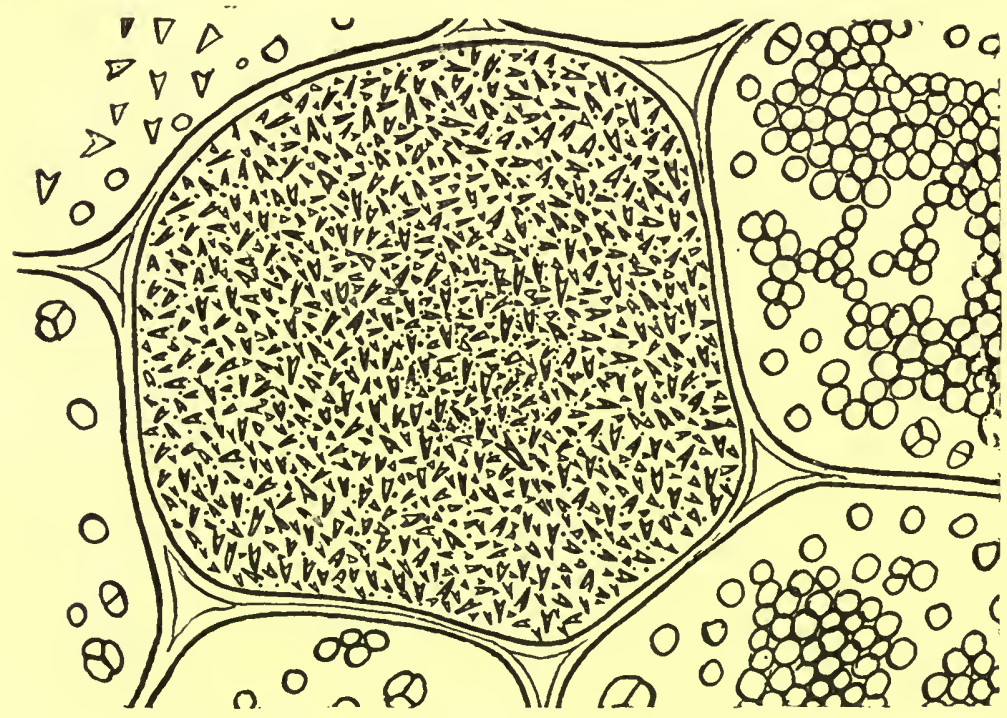

Fig. 248.-Belladonna root: Transverse section of a parenchyma cell filled with sphenoidal microcrystals of calcium oxalate, the surrounding cells, which are shown in part, contain starch grains.

proportion. The drug also contains hyoscine (scopolamine), atropine, formed from hyoscyamine, and belladonnine, formed from atropine; a fluorescent principle $\beta$-methyl-æsculetin (atrosin or chrysatropic acid), which resembles a similar principle found in gelsemium; malic acid and calcium oxalate in the form of sphenoidal microcrystals (Fig. 248).

Atropine (Fig. 251) is a powerful mydriatic alkaloid which occurs in colorless or white acicular crystals that are soluble in alcohol but sparingly soluble in water. It is optically inactive and may be sublimed without decomposition. The aqueous solutions are, how- 
ever, easily decomposed, acquiring a yellow color and a disagreeable odor. On treating atropine with nitric acid and potassium hydrate a violet color is produced. On hydrolysis atropine yields tropin and tropic acid. Upon heating atropine with nitric acid so as to cause the loss of a molecule of water the alkaloid apoatropine (atrogamine or anhydro-atropine) is formed, which has been isolated from belladonna root and which does not possess any mydriatic properties.

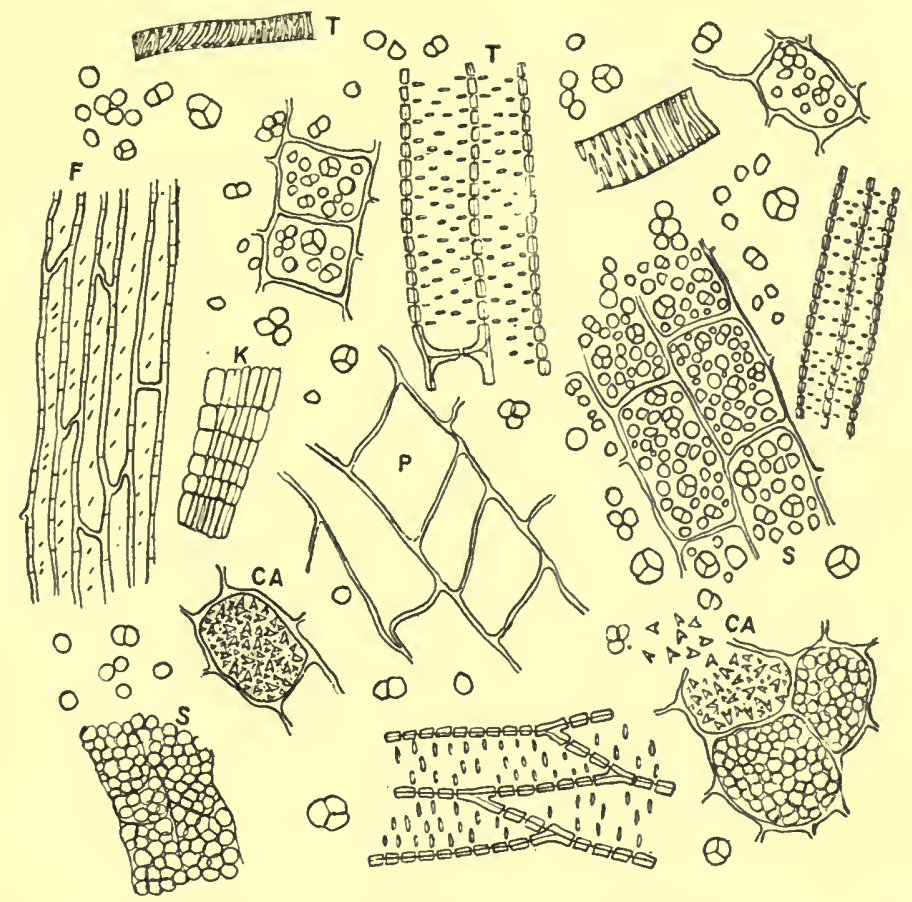

FIG. 249.-Belladonna root: $S$, parenchyma cells containing starch; $C A$, cells containing sphenoidal microcrystals of calcium oxalate; $K$, cork; $T$, fragments of tracheæ having annular markings or simple pores; $P$, parenchyma; $F$, wood fibers with narrow oblique pores.

On heating apoatropine with hydrochloric acid or upon simply heating it for some time alone the base belladonnine (oxyatropine) is formed. ${ }^{1}$

The amount of alkaloids varies in different parts of the plant and has been given as follows: Roots, 0.4 per cent; stems, 0.04 per cent;

${ }^{1}$ Charles O. Lee. Micro-chemistry of the Alkaloids of Datura. Jour. A. Ph. A., 1918, 7, p. 504. 
leaves, 0.35 per cent; unripe berries, 0.19 per cent; ripe berries, 0.21 per cent; and seeds, 0.33 per cent.

Adulterants.-The leaves of Scopolia carniolica (Fig. 252) and Phytolacca decandra (Fig. 85) have been recently reported as sub-

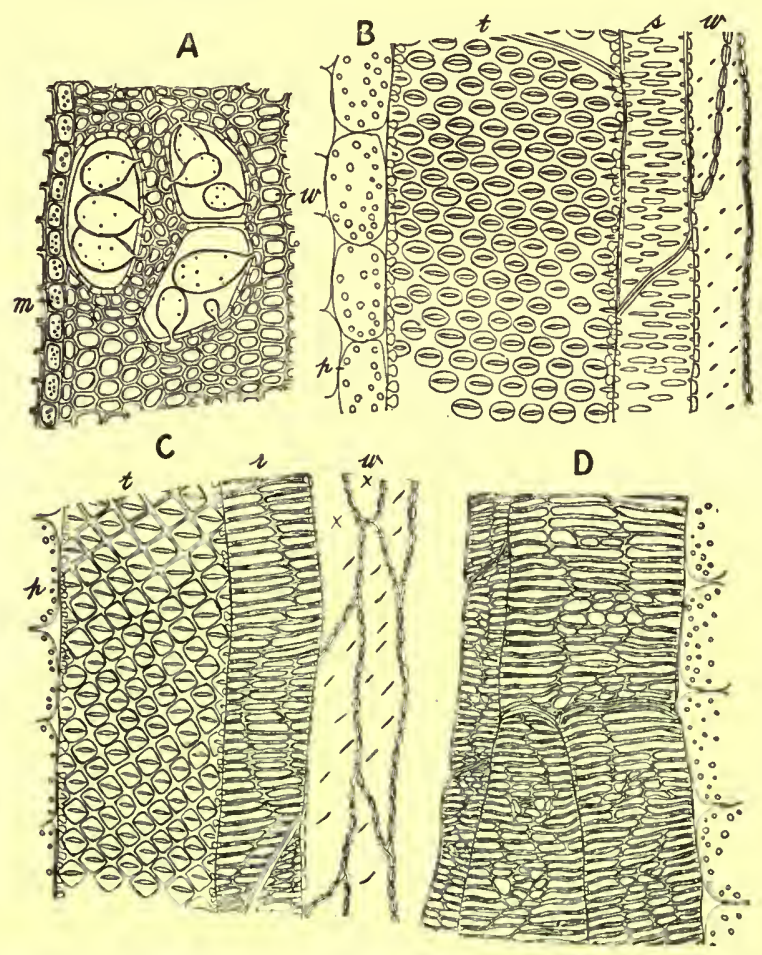

FIG. 250.-Different kinds of tracheæ. A, transverse section of stem of grapevine (Vitis vinifera) showing three tracheæ from the older wood containing tyloses; $w$, wood fibers; $m$, medullary rays. The tyloses, or thyllen, are in the nature of ingrowths from the wood fibers and protrude through the adjoining pores, at the end of the season's growth, closing the cavities of the tracheæ. $B$, longitudinal section of belladonna root showing a large trachea with bordered pores $(t)$, a trachea with simple pores $(s)$, wood fiber with oblique pores $(w)$ and parenchyma $(p)$ containing starch. $C$, longitudinal section of phytolacca root showing a trachea with bordered pores $(t)$, trachea with reticulate thickening $(r)$, wood fibers $(w)$ and parenchyma $(p)$ containing starch. $D$, longitudinal section of scopola rhizome showing the characteristic wide, reticulate tracheæ and portion of cells of parenchyma containing starch.

stitutes. The leaves of Solanum nigrum have been substituted for true Belladonna. 
Literature.-Miller, Amer. Jour. Pharm., 1913, p. 291; Carr, Ibid., 1913, p. 487; Sievers, Ibid., 1914, pp. 97 and 483; Newcomb, Ibid., 1914, p. 531, and 1915, p. 1; Sievers, Ibid., 1916, 88, p. 193.

Belladonne Radix.-Belladonna Root.-The root of Atropa Belladonna (Fam. Solanacex), a perennial herb (Figs. 243 and 244), native of central and southern Europe, and cultivated in England and Germany, from which countries most of the commercial supply is obtained. The roots are collected in autumn from plants one to four years old and carefully dried.

Description.-Cylindrical, slightly tapering, somewhat twisted or split into longitudinal pieces, 5 to $15 \mathrm{~cm}$. in length, 4 to $25 \mathrm{~mm}$.

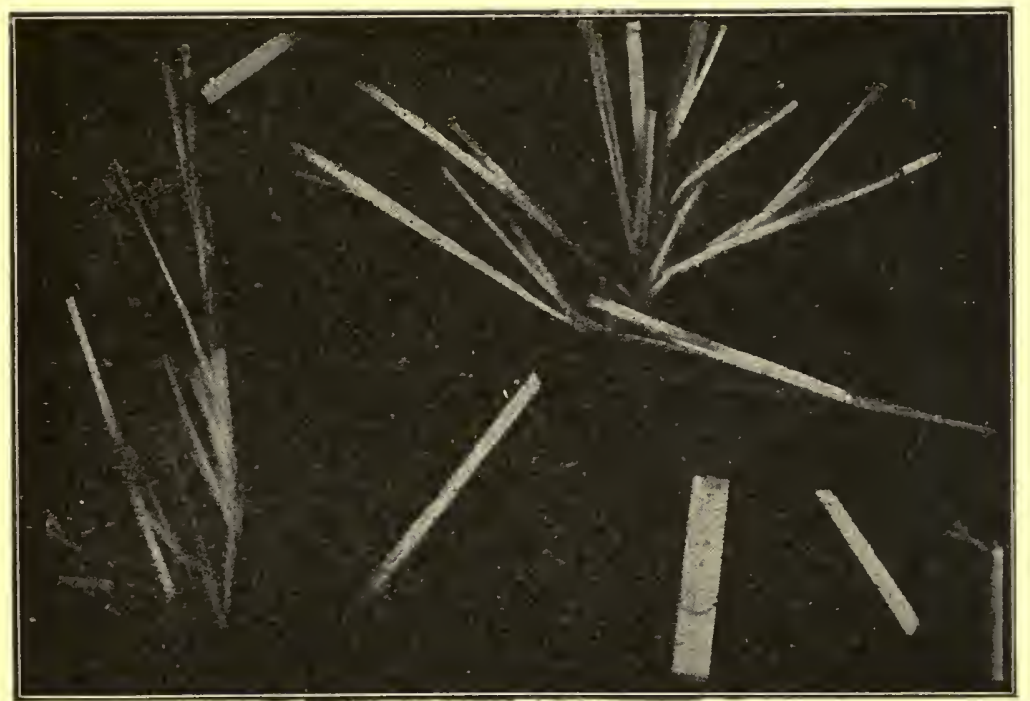

FIG. 251.-Atropine: Long orthorhombic prismatic crystals from an alcoholic solution.

in diameter; externally light brown, smooth, longitudinally wrinkled or fissured, sometimes with transverse ridges and with rootlet-scars or fragments of rootlets; fracture short, mealy when dry and emitting a dust consisting of starch grains and fragments of cells, tough when damp; internally light yellow, slightly radiate, bark 0.5 to $2 \mathrm{~mm}$. in thickness, not fibrous and adhering closely to the wood, cambium zone distinct; odor narcotic; taste sweetish, acrid.

Roots that are shrunken, spongy, dark brown and free from starch should be rejected, as also old woody roots and stem-remnants.

Phytolacea roots (Figs. 85 and 250) and Althæa (Fig. 187) are 
distinguished from belladonna root by having numerous sclerenchymatous fibers, while inula has neither starch nor spheroidal microcrystals of calcium oxalate.

InNer Structure.-See Figs. 246, 247, 248 and 250.

Powder.-(Fig. 249.) Light brown; odor distinct, heavy, especially marked on heating with water; in addition to the starch grains the most marked characteristic feature is the cells containing the microcrystals which, on clearing the fragments with solutions of potassium hydrate or chloral hydrate, appear in contrast to the surrounding cells in the form of grayish-black cells of various forms; in the broken parenchymatous cells the forms of the crystals are readily distinguished, and are from 0.03 to $0.10 \mathrm{~mm}$. in length; starch grains numerous, from 0.003 to $0.030 \mathrm{~mm}$. in diameter, spheroidal, plano-convex, polyhedral, and 2- to 6- or more compound; fragments of cork cells and tracheæ with wood fibers few. Occasional fragments of stems showing long thin-walled and slightly lignified bast fibers (Fig. 245).

Constituents.-There are two principal alkaloids-hyoscyamine and atropine-which together amount from 0.2 to 1 per cent, the proportions of these varying according to the age of the root, the hyoscyamine, however, usually being in excess. The atropine (Fig. 251) appears to be derived from its isomer hyoscyamine and not to preëxist in the root; a small amount of scopolamine (hyoscine) is also present. Other alkaloids, as belladonnine, apoatropine, etc., have been isolated, but these are decomposition products of hyocyamine. The drug also contains a fluorescent principle, B-methyl æsculetin, considerable starch and calcium oxalate in the form of sphenoidal microcrystals. See also Hyoscyamus, Belladonnæ Folia and Stramonium.

Adulterants.-Belladonna root is sometimes admixed with poke root, this admixture is readily detected by the presence of raphides of calcium oxalate (Fig. 85) and the markings of the tracher (Fig. 250). Scopola rhizome is also sometimes added or entirely substituted for belladonna root. For its determination, see Scopola, p. 592.

Allied Plants.-Mandragora or European mandrake is the root of Atropa Mandragora. The drug occurs in fusiform, somewhat bifurcated pieces and contains two mydriatic alkaloids: mandragorine (isomeric with atropine) and an alkaloid resembling hyoscyamine. Around this drug cluster many curious traditions. It was regarded with great veneration by the ancients, who recognized its narcotic properties. 
Literature.-Kraemer, Amer. Jour. Pharm., 1908, p. 459.

Scopola.-Belladonna Scopolia.-The dried rhizome of Scopolia carniolica (Fam. Solanaceæ), a perennial herb growing in the region of the eastern Alps, Carpathian Mountains and neighboring

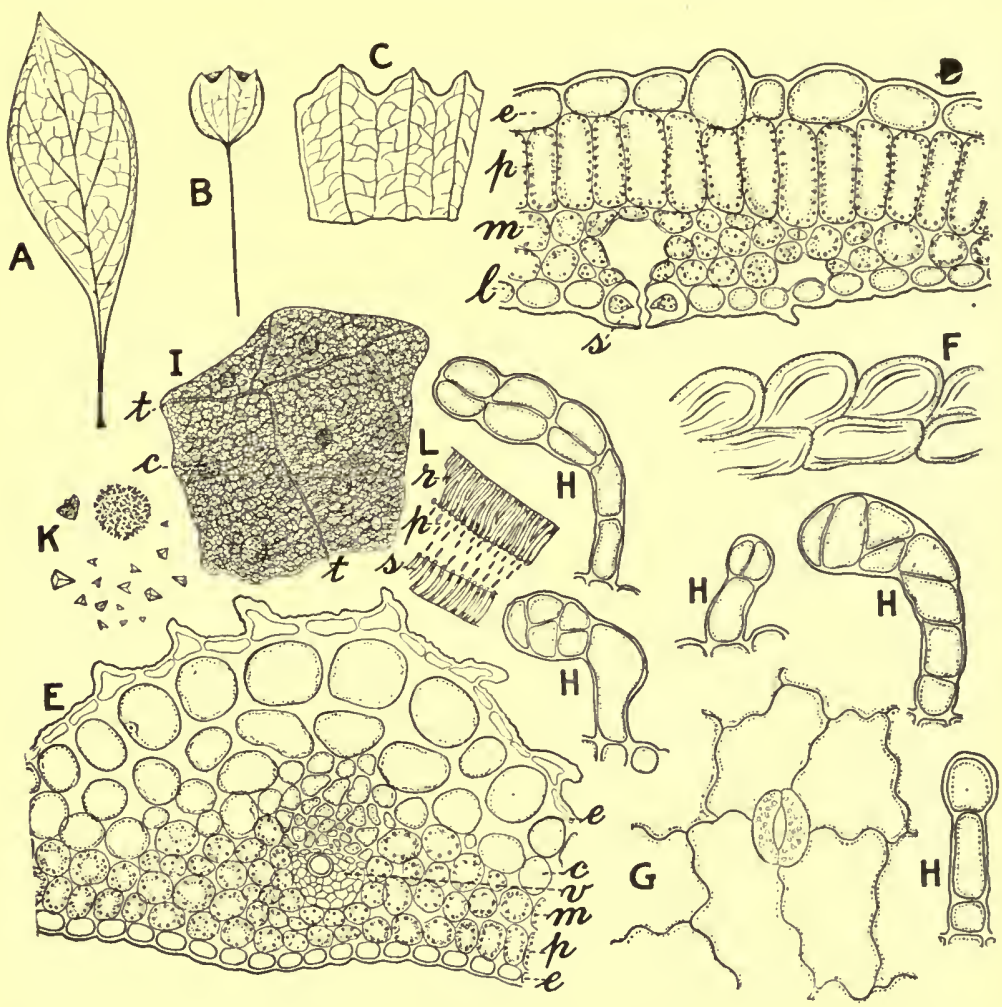

FIG. 252.-Scopolia carniolica: $A$, leaf. $B$, a fruit showing long stalk and slightly lobed calyx. $C$, portion of calyx showing broadly acute lobes. $D, E$, transverse sections of leaf showing upper epidernis (e), palisade cells $(p)$, loose parenchyma $(m)$, collenchyma $(c)$, lower epidermis $(l)$, fibrovascular bundle with a single trachea $(v)$, stoma $(s) . \quad F$, epidermal cells of lower surface showing foldings due to irregularity of the outer walls. $G$, epidermal cells and stoma from lower surface. $H$, glandular hairs (which are only occasionally present). I, fragment of leaf showing spiral tracheæ $(t)$ cells containing sphenoidal microcrystals of calcium oxalate $(c) . K$, isolated crystals of calcium oxalate, which sometimes occur in aggregates from 0.025 to $0.040 \mathrm{~mm}$. in diameter. $L$, fragment of stem showing tracheæ with reticulate thickening $(r)$, simple pores $(p)$ and spiral thickening $(s)$.

regions. Atropa Belladonna and Scopolia carniolica are closely related. The former belongs to the Solaneæ-Lyciinæ, or group of 
plants characterized by tubular corollas and berry-like fruits (Fig. 242 ) and the latter to the Solaneæ-Hyoscyaminæ, or plants with funnel-shaped corolla and transversely dehiscent capsular fruits (Fig. 252). To this latter sub-group also belongs the genus Hyoscyamus and botanically Scopolia appears to be more closely allied to Hyoscyamus than to Belladonna.

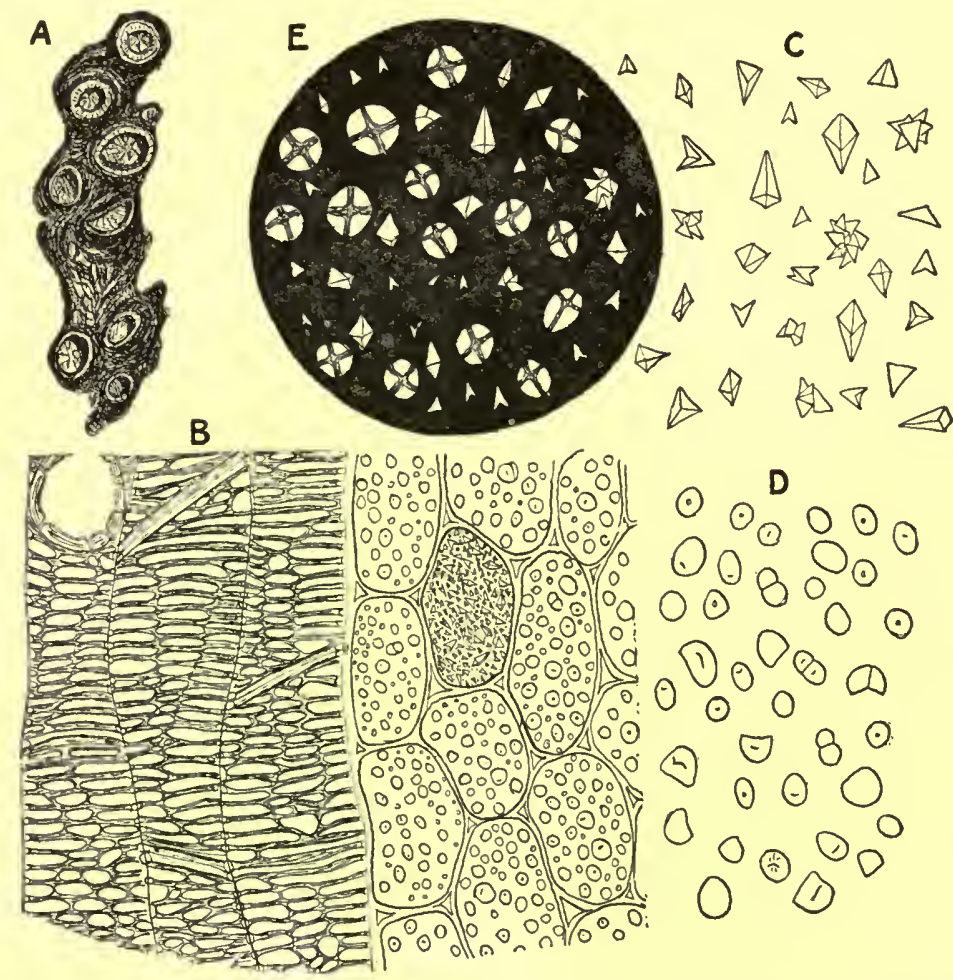

FIg. 253.-Scopola (Scopolia carniolica): $A$, rhizome showing prominent stem scars. $B$, longitudinal section showing reticulate tracheæ, parenchyma cells containing starch and sphenoidal microcrystals of calcium oxalate. $C$, individual erystals which separate from sections or in the powder, the single crystals being from 0.005 to $0.010 \mathrm{~mm}$. in diameter and the aggregates being about $0.015 \mathrm{~mm}$. in diameter. $D$, isolated starch grains, which are from 0.005 to $0.020 \mathrm{~mm}$. in diameter. $E$, field showing starch grains and crystals of calcium oxalate under polarized light.

Description.-Rhizome horizontal (Fig. 253), nearly cylindrical, somewhat tortuous, usually cut longitudinally into pieces 5 to 12 $\mathrm{cm}$. in length, 7 to $15 \mathrm{~mm}$. in diameter; externally grayish-brown, longitudinally furrowed, slightly annulate, with numerous circular 
stem-scars about $5 \mathrm{~mm}$. in diameter, under portion with root-scars and root-remnants; fracture short, mealy; internally whitish or light grayish-brown, bark $1 \mathrm{~mm}$. or less in thickness, wood slightly radiate, pith rather large, horny; odor slight; taste starchy, sweetish, acrid.

The roots, which are attached to the rhizome or in separate pieces, are cylindrical, tapering, varying in diameter from 2 to $10 \mathrm{~mm}$., longitudinally wrinkled, and marked by lenticular, whitish areas, resembling lenticels.

InNer Structure.-See Fig. 253.

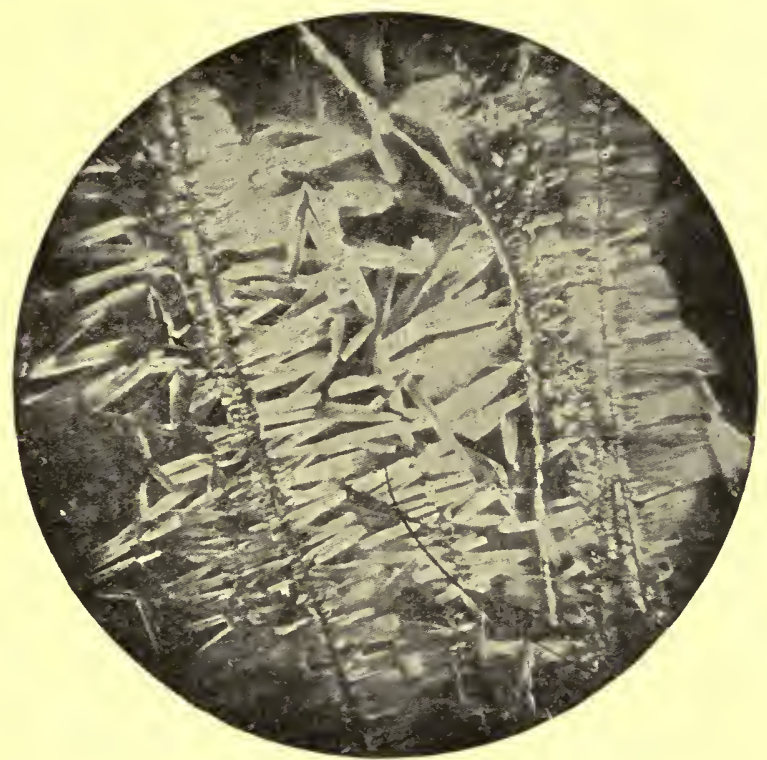

FIG. 254.-Scopolamine hydrobromide: Crystal aggregates from an alcoholic solution.

Constituents.-About 0.6 per cent of total alkaloids, including atropine, hyoscyamine and scopolamine (hyoscine). Scopolamine is official as a hydrobromide (Fig. 254), and exists in the drug to the extent of 0.06 per cent. Scopolamine decomposes into scopoline and atropic acid when treated with boiling baryta water. Scopoline resembles tropine, a principle formed from atropine and hyoscyamine, when similarly treated.

Scopolia Leaves (Fig. 252) are used in medicine like belladonna leaves, and are said to be sometimes admixed with them. They are obovate, slightly acuminate, and taper gradually into the rather long petiole. The calyx lobes are relatively short, and the capsular 
fruit (1)yxis) is almost completely enclosed by the calyx tube (Fig. 252, B). A very few glandular hairs with a 1- or 2-celled stalk and 2 - to 6-celled head may be present occasionally (Fig. 252, H). In addition to tracheæ with annular and spiral markings, and simple pores there are in the stem, tracheæ with reticulate markings, but those with bordered pores do not occur. The crystals of calcium oxalate resemble those in belladonna. In glycerin preparations spherite aggregates resembling those of carbohydrates are present, especially in the calyx. Acicular crystals sometimes separate in chloral preparations, but as they are isotropic they are apparently not calcium oxalate. The epidermis of the leaves, particularly the cells of the under surface, are irregularly papillose, giving a tuberculate appearance on transverse section (Fig. 252, E), and in surface view a deeply wrinkled or folded character to the walls. As in the rhizome, bast fibers and wood fibers are apparently not present. There is, however, a strongly developed layer of collenchymatous cells in the stem, the thickenings being more uniform and more marked than those in the collenchymatous cells of belladonna.

Allied Plants.-Japanese belladonna is the rhizome of Scopolia japonica, growing in Japan, and closely related to S. carniolica. The drug resembles scopola and apparently contains the same principles. The rhizomes of six other species of Scopolia are also used.

Literature.-Kraemer, Amer. Jour. Pharm., 1908, p. 459.

Hyoscyamus.-Henbane.-The leaves and flowering tops of Hyoscyamus niger (Fam. Solanaceæ), an annual or biennial herb (Figs. 255 to 261), probably indigenous to Europe, western Asia and northern Africa and cultivated in Germany, Russia, England and the northern United States and Canada, and also naturalized in waste places. The leaves are collected shortly after flowering from biennial plants of the second year's growth, and carefully dried and preserved. The commercial article comes chiefly from Germany.

Description.-Usually in irregular, matted fragments. Stem hollow, cylindrical, flattened, longitudinally furrowed and wrinkled 3 to $4 \mathrm{~mm}$. in diameter; internodes 1 to $3.5 \mathrm{~cm}$. in length. Leaves ovate or ovate-lanceolate, 5 to $10 \mathrm{~cm}$. in length, 2 to $7 \mathrm{~cm}$. in breadth, summit acuminate; base amplexicaul; margin acutely four-lobed; upper surface dark green and pubescent; under surface grayishgreen and glandular-pubescent; midrib yellowish-green, from which veins of the first order diverge at an angle of from $10^{\circ}$ to $35^{\circ}$ and pass into the lobes; texture fragile. Flowers solitary and with a pedicel about $4 \mathrm{~mm}$. in length; calyx tubular, 5-toothed, about 10 $\mathrm{mm}$. in length, outer surface very pubescent; corolla 5-parted, the 
lobes more or less unequal, somewhat spreading, the tube purplish, the limb yellowish, reticulate from purplish veins; stamens five, declined, mostly exserted; stigma capitate. Fruit, a two-locular

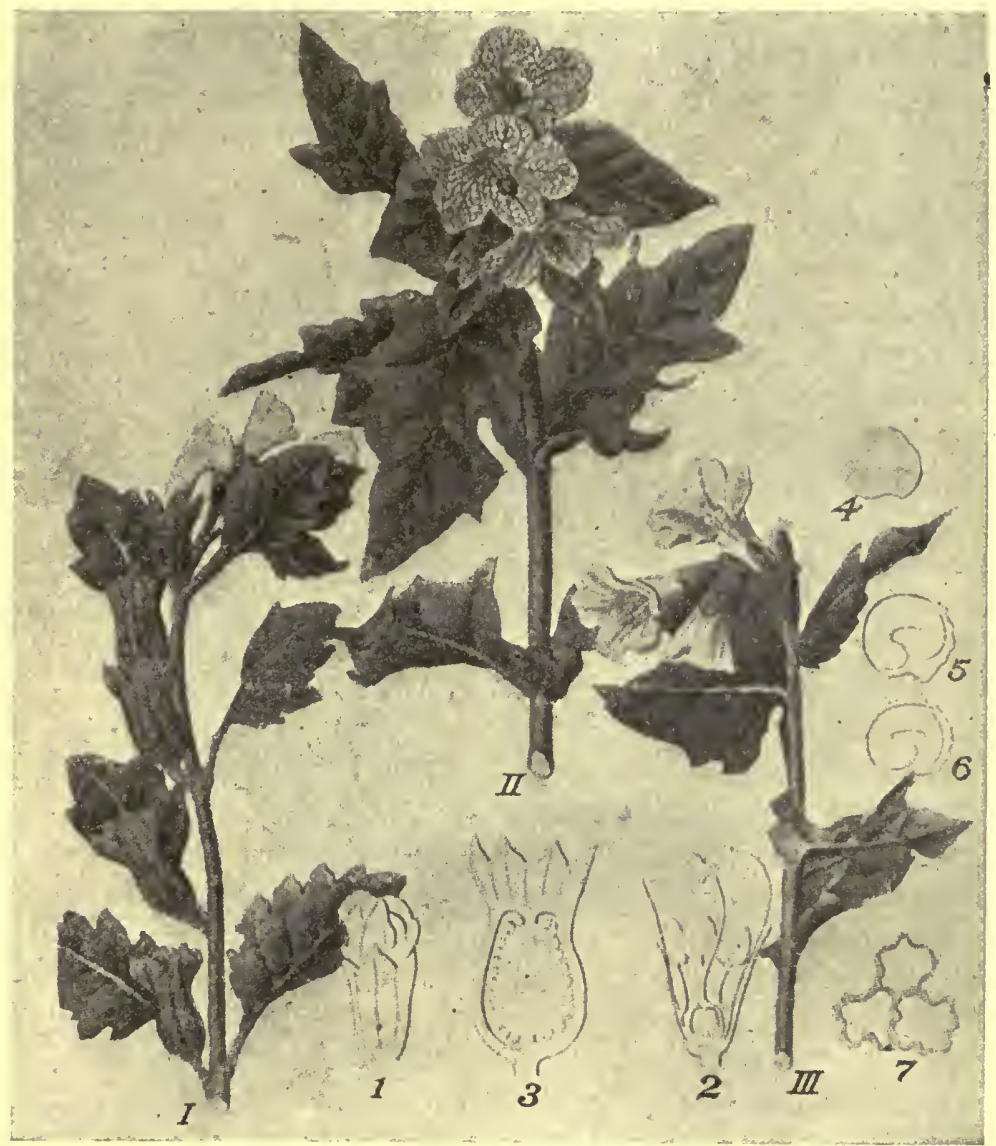

Fig. 255.-Photographic reproduction of Plate 2 in Vol. XX Reichenbach's Icones Floræ Germanícæ et Helveticæ: I, Hyoseyamus albus L.; II, Hyoscyamus niger L.; $I I I$, Hyoscyamus niger L. var. pallidus Koch. 1, Alabastrum, ut videas æstivationem imbracatem; 2, Flos transsectus; 3, Fructus transsectus vides operculum pyxidis; 4, Semen; 5, 6, Semina transsectus; 7, Areæ testæ.-After Farwell, Amer. Jour. Pharm., 1915, p. 100.

pyxis. Seeds numerous, campylotropous, somewhat reniform, flattened, $1 \mathrm{~mm}$. in length, light brown, finely pitted, with a curved 
'embryo embedded in the endosperm; odor distinct; taste bitter and 'somewhat acrid.

Inner Structure.-(Fig. 262.) Somewhat resembling in structure belladonna leaves, but the crystal layer contains monoclinic prisms of calcium oxalate, the hairs are different as well as more abundant, and the epidermal cells are but slightly undulate.

Powder.-(Fig. 262.) Grayish green or dark green; calcium oxalate in single or twin monoclinic prisms from 0.010 to 0.025 $\mathrm{mm}$. in diameter, occasionally in rosette-shaped crystals; non-

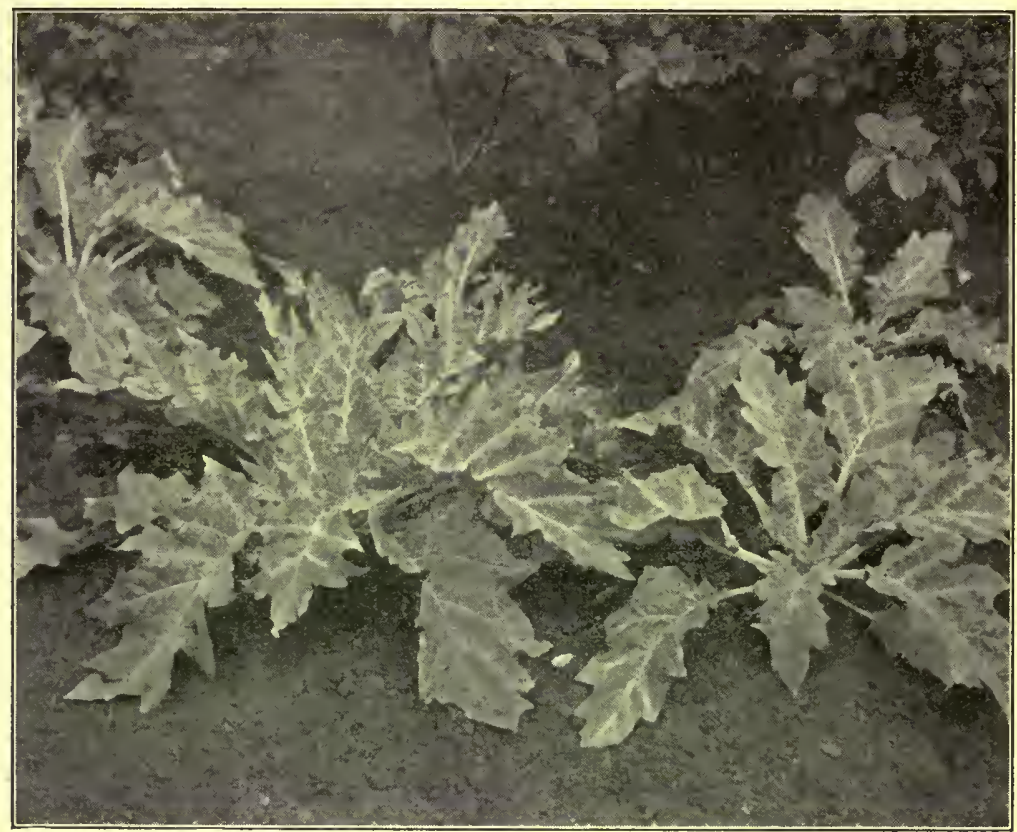

Fig. 256.-Hyoscyamus niger, biennial. Portion of a plot showing rosette character of the leaves and their long petioles.-After Newcomb.

glandular hairs, unicellular or uniseriate, consisting of 2 to 10 cells; glandular hairs, either uniseriate or having a 1- to 4-celled stalk and a 6- to 8- or more celled head; fragments of midrib showing strong development of collenchyma with large intercellular-spaces; fragments of epidermis having broadly elliptical stomata, 0.030 to 0.035 $\mathrm{mm}$. in length, having 3 to 4 neighboring cells; fragments of tracheæ with wood fibers, having thin, porous walls and showing little or no lignification. 


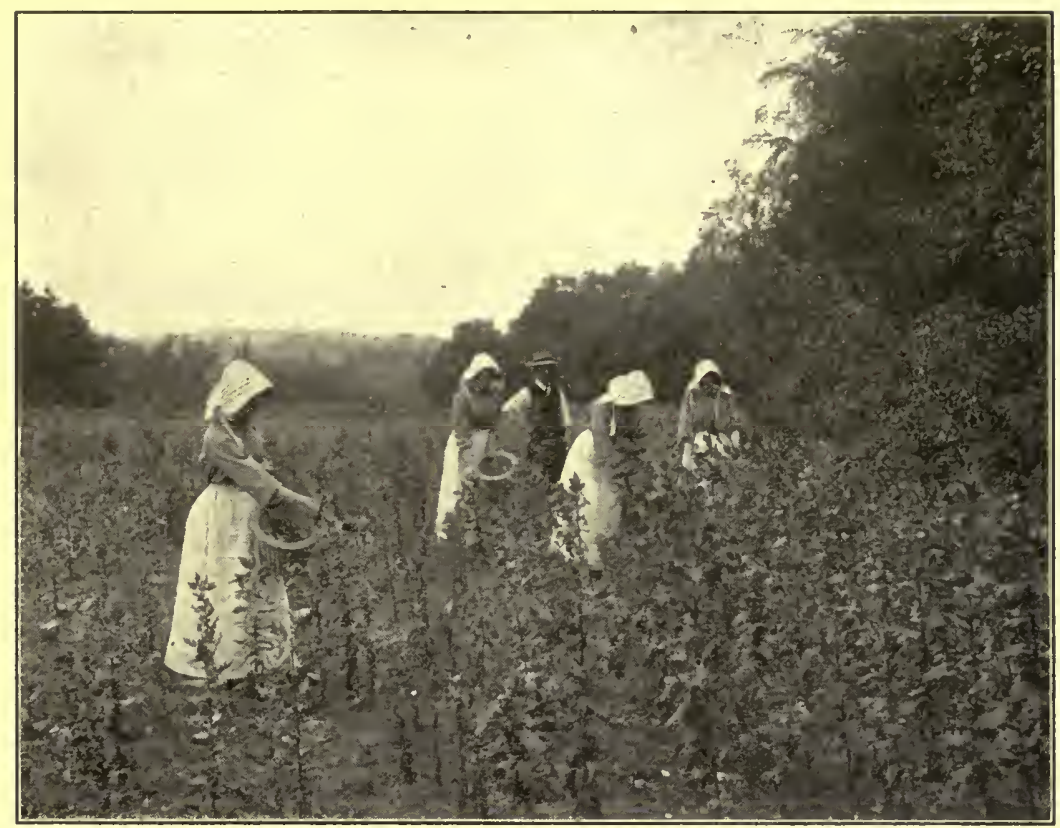

FIG. 257.-Gathering Hyoscyamus. Wellcome Materia Medica Farna-After Carr. Amer. Jour. Pharm., 1913, p. 482.

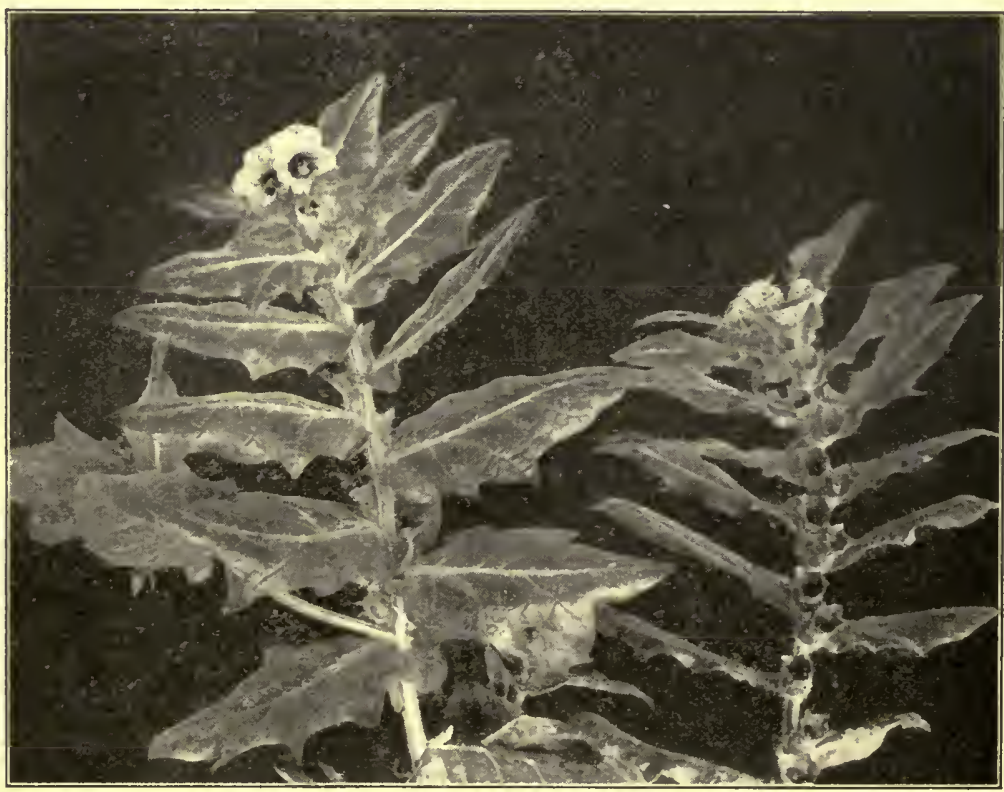

FIG. 258.-Flowering branches of Hyoseyamus niger, annual.-After Newcomb, Amer. Jour. Pharm., 1914, p. 533. 


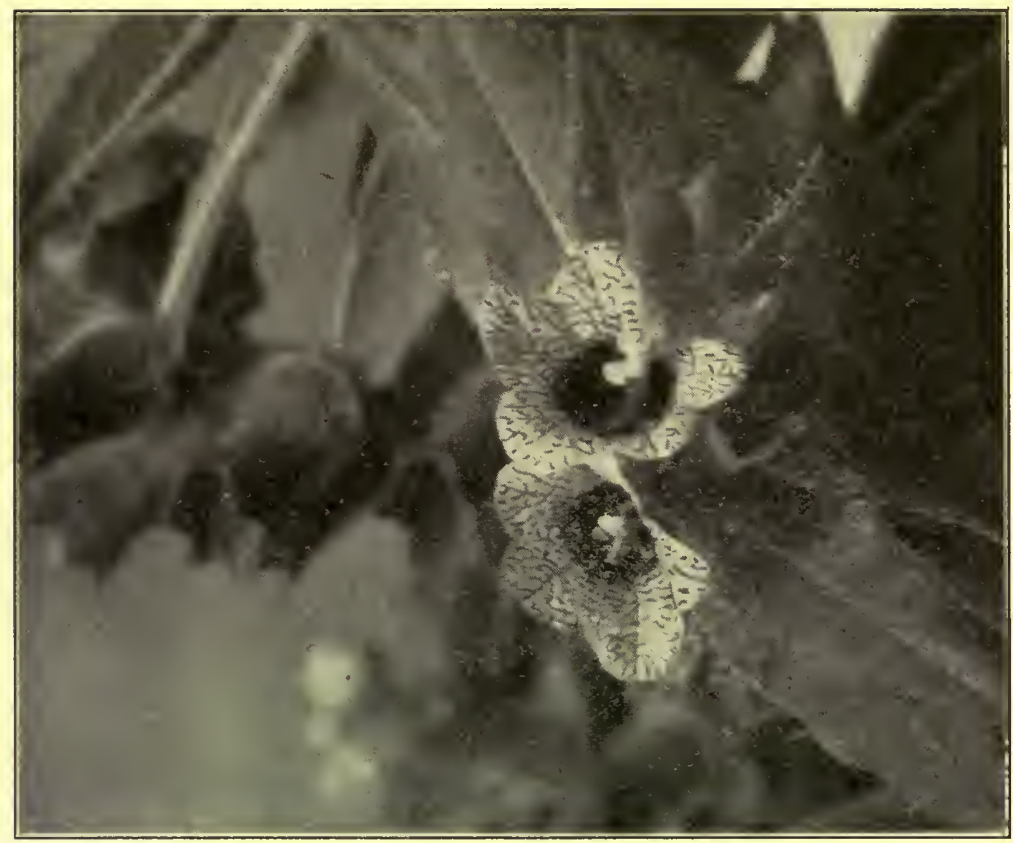

Frg. 259.-Flowers of Hyoscyamus niger, annual.-After Newcomb

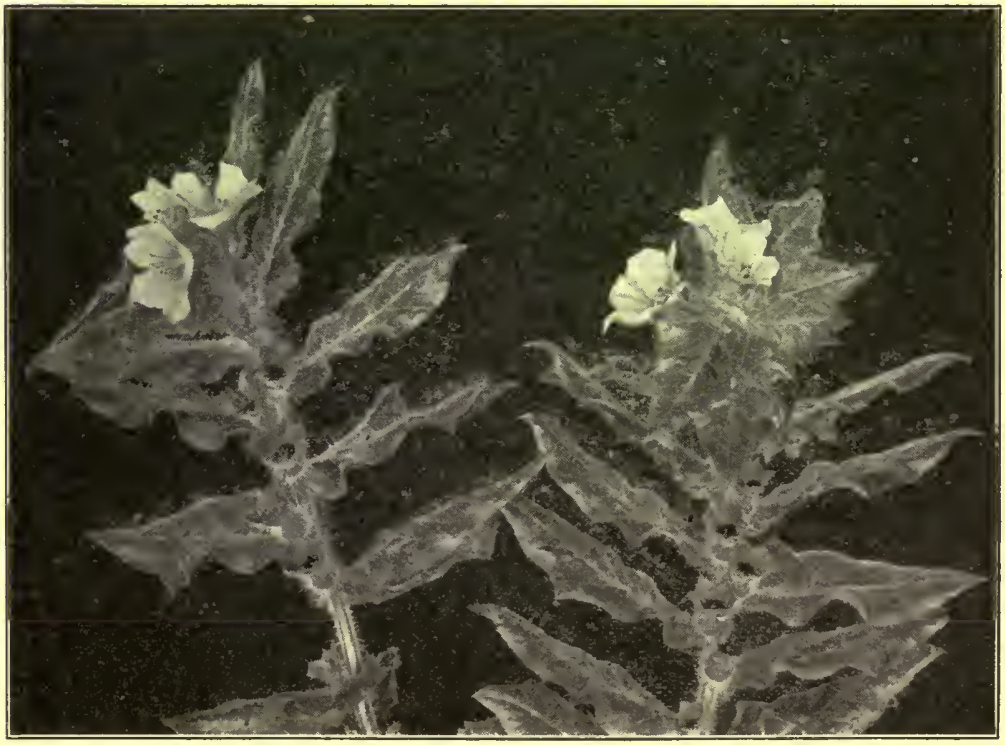

Fic. 260.-Flowering branches of Hyoscyamus pallidus.-After Newcomb. 
Constituents.-The alkaloids hyoscyamine and hyoscine (scopolamine) 0.08 to 0.15 per cent, of which three-fourths is hyoscyamine; an odorous principle in the nature of a butyric ether or butyrin; a glucosidal bitter principle, hyospicrin; potassium nitrate, about 2 per cent, and calcium oxalate.

Hyoscyamine (an isomer of atropine) occurs in colorless, silky needles with an acrid, disagreeable taste, partly soluble in water, soluble in alcohol, and is readily decomposed into atropine. It forms crystalline salts, of which the hydrobromide is official. Hyoscine forms prismatic erystals, which are soluble in water and alcohol, and yields scopoline (oscine) and tropic acid.

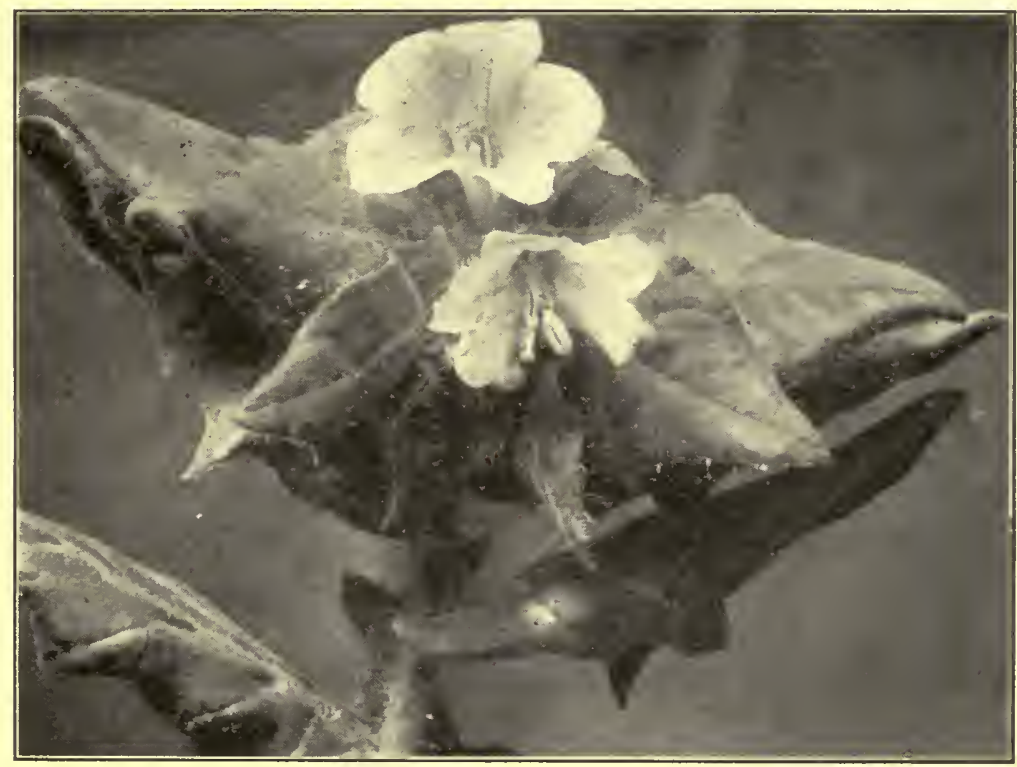

Frg. 261.-Flowers of Hyoscyamus pallidus.-After Newcomb.

Newcomb and Hayner obtained 0.156 per cent of alkaloids in the flowering tops of Hyoscyamus niger and 0.13 per cent of alkaloids in H. pallidus (Amer. Jour. Pharm., 1916, 88, p. 1).

Hyoscyamus Muticus.-The leaves and flowering tops of Hyoscyamus muticus, a plant growing in Egypt, are sometimes admixed with and substituted for Hyoscyamus niger. It yields about 1.34 per cent of alkaloids, consisting in a large part of Hyoscyamine. Its presence in either the crude or powdered drug of Hyoscyamus may be determined by the characteristic branching non-glandular hairs occurring on both the stems and leaves (Fig. 263). 
Allied Plants.-Hyoscyamine is also found in Datura Stramonium, Atropa Belladonna, Anisodus luridus, Duboisia myoporoides, Lactuca sativa and $\mathrm{L}$. virosa, the two latter plants belonging to the Compositæ. Hyoscine (scopolamine) is also present in belladonna root, the seeds of Hyoscyamus niger, the leaves of Datura Stramonium,

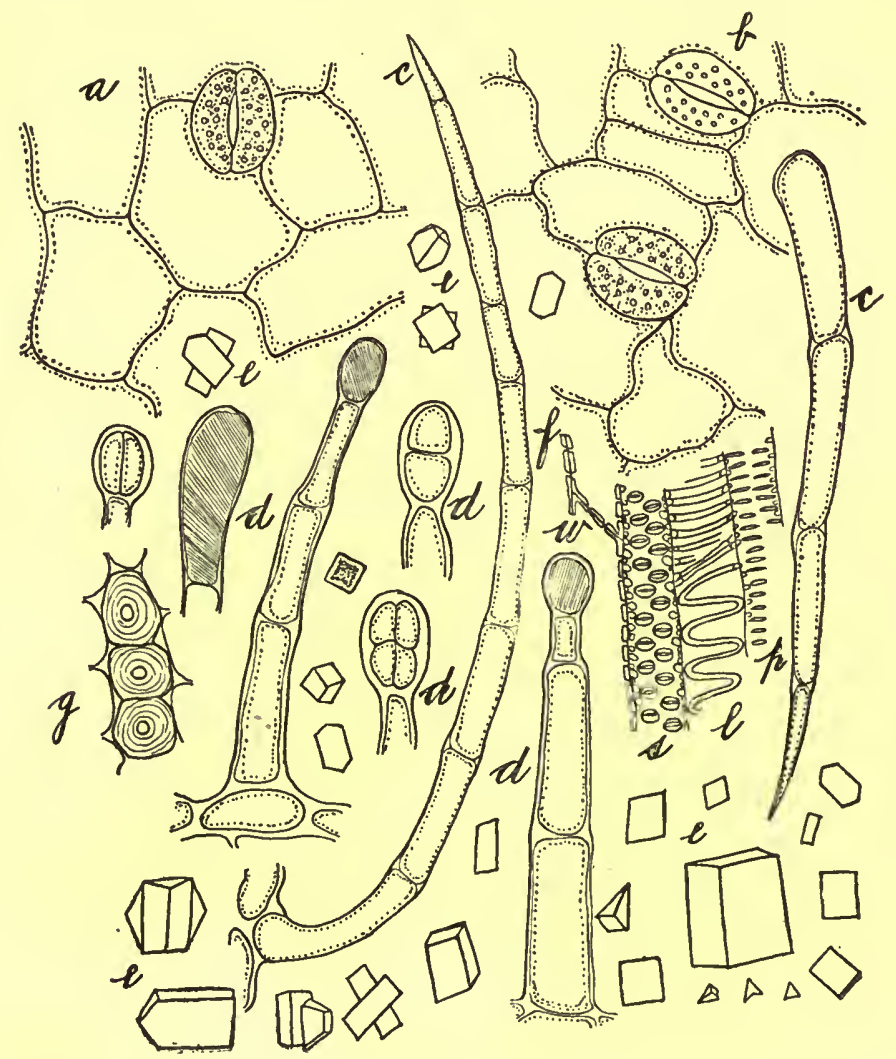

FIG. 262.-Hyoscyamus: $a$, surface view of cells of the epidermis, showing also a single stoma; 3 , surface view of cells of "the lower epidermis and 2 stomata; $c$, uniseriate non-glandular hairs; $d$, glandular hairs; $e$, monoclinic prisms of calcium oxalate; $f$, fragment of xylem showing the wood fibers $(w)$, and tracheæ having simple pores $(p)$, bordered pores $(s)$, and spiral thickenings $(l) ; g$, three bast fibers in transverse section.

Datura iastuosa of the East Indies, the leaves of Düboisia myoporoides and the roots of Scopolia japonica and S. atropoides.

Duboisia leaves are obtained from Duboisia myoporoides, a large shrub indigenous to Australia. They are short-petiolate, 7 to 10 $\mathrm{cm}$. in length, 1.5 to $2.5 \mathrm{~cm}$. in breadth, having an acute or narrow 
summit and base, and entire or somewhat revolute margin. In the drug they usually occur in broken fragments, which are thin, greenish, brown, and have a slight distinct odor and bitter taste. They con-

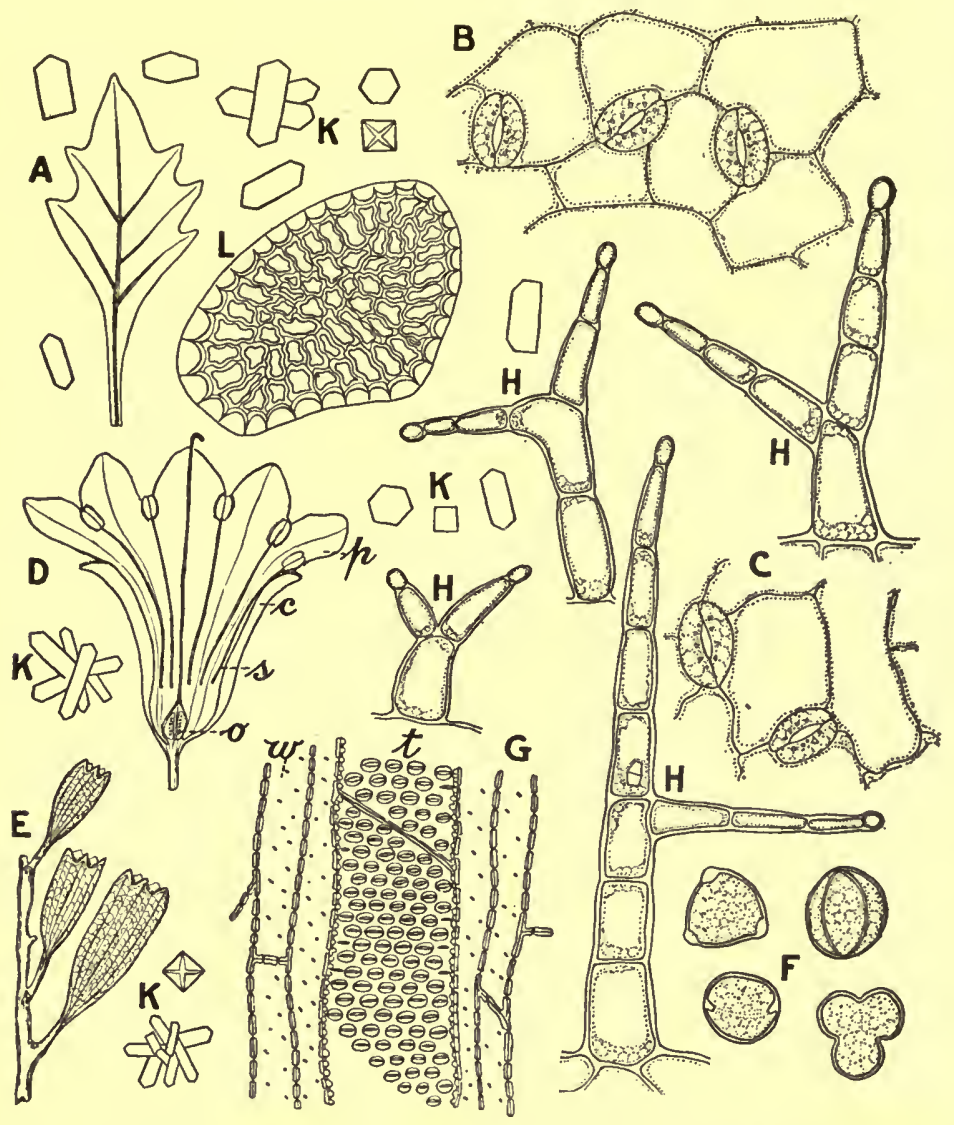

Fia. 263.-Hyoscyamus muticus: $A$, leaf. $B$, portion of upper surface of leaf. $C$, portion of lower surface. $D$, section of flower showing calyx $(c)$, lobed corolla $(p)$, stamens inserted on corolla tube $(s)$, ovary $(o) . E$, portion of stalk with fruits showing cylindrical calyx. $F$, pollen grains in different views. $G$, portion of xylem of stem showing tracheæ $(t)$ with bordered pores, wood fibers $(w)$ with oblique simple pores. $H$, characteristic branching hairs found on the stem, leaves and calyx. $K$, crystals of calcium oxalate. $L$, seed with epidermal cells having wavy walls, those at the edge being seen in section and showing that the outer wall is not thickened.

tain in addition to hyoscyamine (duboisine) and hyoscine, the alkaloid pseudohyoscyamine, which occurs in small needle-shaped crystals that are difficultly soluble in water but readily soluble in alcohol. 
Duboisia Leichardtii also contains a large amount of alkaloids, resembling those of Duboisia. Pituri or Australian tobacco is the leaf of Duboisia Hopwoodii, and is used in Australia like tobacco. It contains 2.5 per cent of a liquid alkaloid piturine, which has a pungent odor and taste, and closely resembles nicotine.

Literature.-Miller, Amer. Jour. Pharm., 1913, p. 295; Carr, Ibid.; 1913, p. 487; Newcomb, Ibid., 1914, p. 531, and 1915, p. 1; The Chemistry of the Duboisias, Amer. Jour. Pharm., 1918, 90, p. 34; Mueller, Jour. A. Ph. A, 1918, 7, p. 127; Koch, Amer. Jour. Pharm., 1919, 91, p. 68.

Stramonium.-Stramonium Leaves.-The leaves and flowering tops of Datura Stramonium (Fam. Solanaceæ), commonly known as Jimson Weed or Jamestown Weed, an annual herb (Figs. 242 and 264 ), probably indigenous to the region of the Caspian Sea, naturalized in waste places in Europe and North America, and cultivated in France, Germany and Hungary. The leaves and tops are collected when the plant is in flower, and are carefully dried and preserved, the chief portion of the commercial supply being obtained from cultivated plants.

Description.-Usually in irregular, matted fragments. Stem cylindrical, flattened, longitudinally furrowed and wrinkled, 2 to $5 \mathrm{~mm}$. in diameter; internodes 1.5 to $2 \mathrm{~cm}$. in length. Leaves ovate (Fig. 242), 6 to $20 \mathrm{~cm}$. in length, 2 to $12 \mathrm{~cm}$. in breadth; summit acuminate; base unequal, one side extending 3 to $12 \mathrm{~mm}$. below the other; margin irregularly sinuate-lobed, the lobes acute; upper surface dark green, nearly glabrous, under surface yellowish-green, glabrous, slightly pubescent on the veins, midrib dark brown, veins of the first order diverging from it at an angle of $45^{\circ}$ to $65^{\circ}$, dividing near the margin and the main branches passing into the lobes; petiole dark brown, 0.5 to $4.5 \mathrm{~cm}$. long, circular in cross-section; texture fragile. Flowers solitary, pedicel 2 to $10 \mathrm{~mm}$. in length, calyx 5toothed, about $4 \mathrm{~cm}$. in length, separating transversely near the base at maturity, the upper part falling away; corolla funnel-shaped, yellowish- or purplish-white, about $8 \mathrm{~cm}$. in length, limb plaited, 5-lobed; stamens five, included, inserted near the middle of the corolla tube; stigma slightly 2-lobed. The immature fruit (Fig. 242) somewhat conical, 4-valved. Seeds numerous; odor disagreeable; taste unpleasant, nauseous.

InNer Structure.-See Fig. 264.

Powder.-(Fig. 265.) Brownish-green or dark green; calcium oxalate usually in rosette aggregates, from 0.010 to $0.020 \mathrm{~mm}$. in diameter, occasionally in prisms, and in the cells near the bi-collateral 
vascular bundles of the veins in the form of sphenoidal microcrystals; non-glandular hairs usually only present on the younger leaves, uniseriate, consisting of 2 to 5 cells and from 0.200 to $0.500 \mathrm{~mm}$. in length, the lower cells being very broad and the cuticle throughout being very papillose; glandular hairs few, with 1 - to 2 -celled stalks and usually 2- to 4-celled, glandular heads; tracheæ annular or spiral, fragments of the tracheal wall frequently detached; stomata

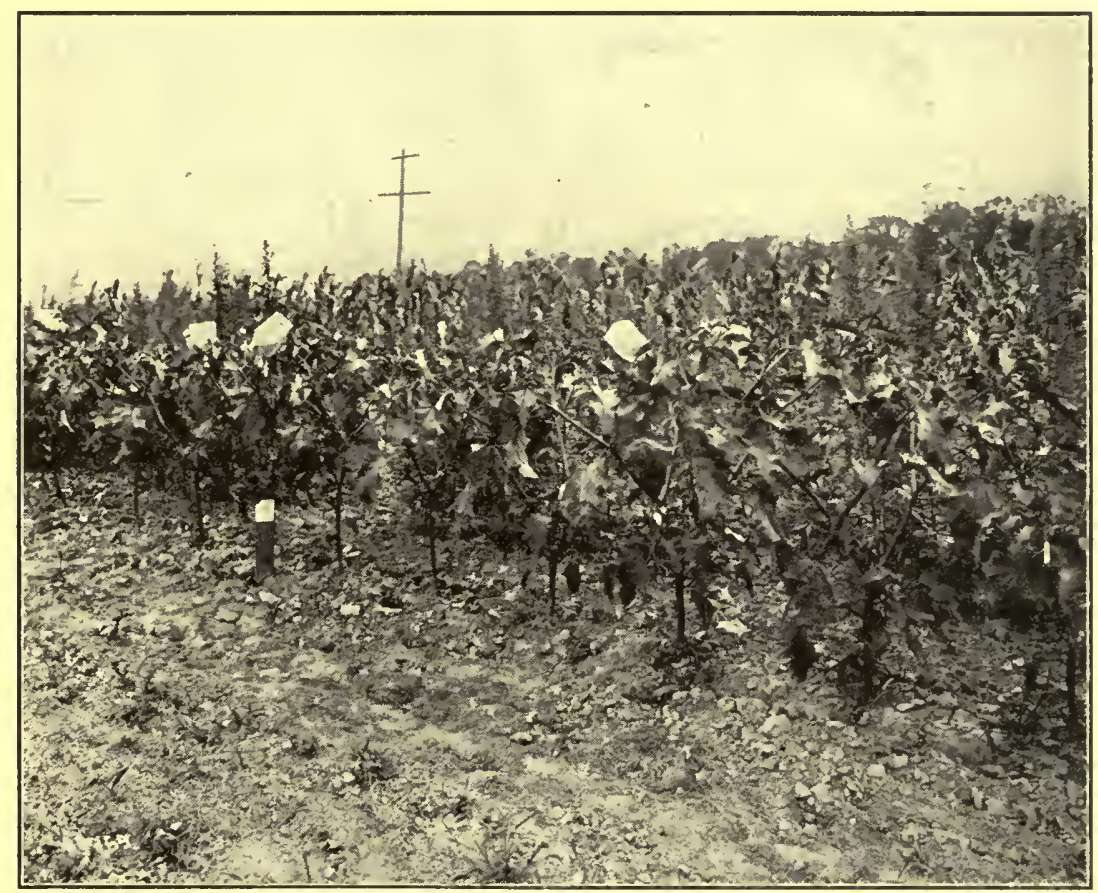

Fig. 264.-Breeding plot of Stramonium at the Experimental Farm of Eli Lilly \& Company, Indianapolis, Ind.

elliptical, about $0.025 \mathrm{~mm}$. in length and having 3 to 5 neighboring cells; cells of the mesophyll containing numerous small chloroplastids.

Constituents. - The important constituents of Stramonium leaves are similar to those of belladonna'leaves, the amount of total alkaloids, however, being about one-half less ( 0.2 to 0.4 per cent). The substance known as daturine is a mixture of hyoscyamine and atropine, the former being in excess (see Belladonnæ Folia and Hyoscyamus). Stramonium leaves also contain a volatile oil, resin, and yield about 17 per rent of ash, containing considerable potassium nitrate. 
The amount of total alkaloids varies in different parts of the same plant and has been reported as follows: Roots, 0.2 per cent; stems, 0.02 per cent; leaves, 0.35 per cent, and seeds, 0.25 per cent.

Koch (Amer. Jour. Pharm., 1919, 91,.p. 11) finds that the ratio of leaves to stems is about 47.5 to 52.5. The ratio of leaf to stem and root, the leaf represents 41 per cent of the whole. Furthermore he finds that the entire plant of stramonium, with or without the root, can be harvested without the total alkaloidal content falling below 0.25 per cent. (See also Amer. Jour. Pharm., 1919, 91, p. 186.)

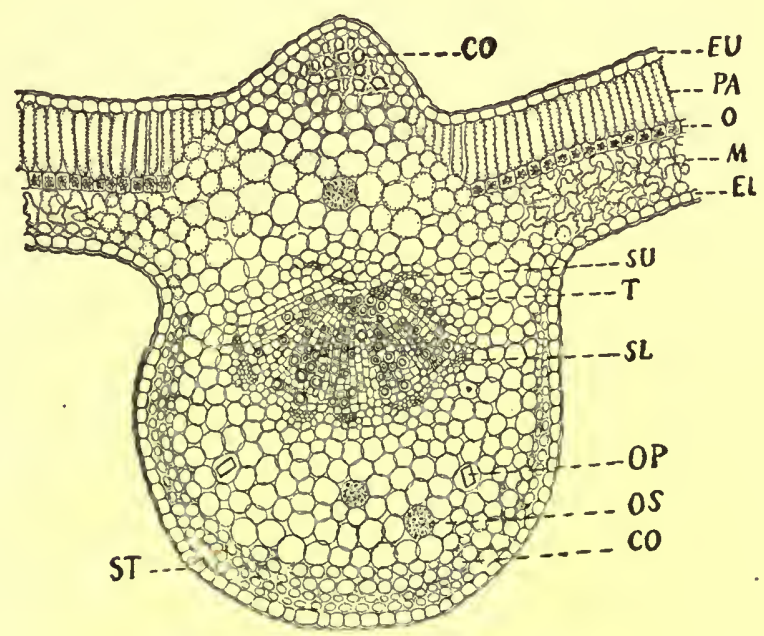

FIG. 265.-Transverse section of midrib of leaf of stramonium: $E U$, upper epidermis; $C O$, collenchyma; $P A$, palisade cells; $O$, layer of cells containing rosette aggregates of calcium oxalate; $M$, loose mesophyll; $E L$, lower epidermis; $O P$, prisms of calcium oxalate; $O S$, sphenoidal microcrystals of calcium oxalate; $S T$, stoma; $T$, tracheæ; $S U$, sieve on upper side of xylem; $S L$, sieve on lower side of xylem, this arrangement of sieve and tracheæ forming bi-collateral fibrovascular bundles.

Stramonii Semen (Stramonium Seed).-Campylotropous, reniform, flattened, about 3 to $4 \mathrm{~mm}$. in length, 2 to $3 \mathrm{~mm}$. in breadth; externally bluish-black, minutely reticulate; hard but easily cut lengthwise along the edge; internally whitish, the reserve layer occupying about one-half the seed, the embryo crook-shaped; odor slight, disagreeable when the drug is bruised; taste bitter.

The powder is brownish-black or grayish-black; epidermal cells having thick somewhat mucilagionous outer walls, and small lumina hoving a dark brown content; sub-epidermal layer of thick-walled, 
nearly colorless cells with distinct, crescent-shaped lamellæ in the radial walls and reticulate pores. The cells of the endosperm contain considerable oil and more or less numerous aleurone grains, the latter having 1 or 2 crystalloids and a number of globoids.

Stramonium seeds contain about 25 per cent of fixed oil; proteins; about 0.4 per cent of alkaloids, consisting principally of hyoscyamine, together with a small proportion of atropine and scopolamine (hyoscine); ash 2 to 3 per cent.

The Purple Stramonium (Datura Tatula) which is naturalized in the United States from tropical America resembles D. Stramonium, but the stems and flowers are purplish. The constituents in the two plants are similar. Several other species are also used in medicine, as Datura arborea indigenous to Chile and Peru, and cultivated for its handsome flowers. The leaves contain 0.44 per cent of total alkaloids.

Adulterant.-The drug from Spain and France has been entirely substituted by the leaves of Xanthium macrocarpum (Fam. Compositæ). The leaves are smaller yellowish-green and prickly hairy. There are several types of hairs the one being lignified. (Guérin, Amer. Jour. Pharm., 1918, 90, p. 885).

Literature.-Kraemer, Torrey Bot. Club, 1900, p. 37; Miller and Meader, Amer. Jour. Pharm., 1912, p. 446.

CAPsicum.-Cayenne or Chilli Pepper.-The dried ripe fruit of one or more species of Capsicum, probably Capsicum fastigiatum, Capsicum frutescens, and Capsicum minimum (Fam. Solanaceæ), shrubs indigenous to tropical America, and cultivated in tropical Africa, India, America, and Japan. There are 2 principal varieties, African and Japanese. The African CAYenne or chillies come chiefly from the ports of Mombasa and Zanzibar, British East Africa, and are usually designated in the trade by the name of the port from which shipped. These fruits are usually imported in the whole condition and are ground for use. The Japanese Chillies come from the port of Kobe, Japan, and are used chiefly in the unground condition for the preparation of the so-called "chilli sauce."

Description.-Oblong, conical, laterally compressed; the African cayenne from 10 to $15 \mathrm{~mm}$. in length and the Japanese from 15 to 44 $\mathrm{mm}$. in length, with an inconspicuous 5 -toothed calyx and sometimes a slender, straight pedicel about $15 \mathrm{~mm}$. in length; externally brownish-red (African cayenne) or bright red (Japanese cayenne), glabrous, shiny, somewhat translucent, more or less shriveled; summit acute, base somewhat rounded; pericarp coriaceous, thin; inner surface 
with two or three distinct longitudinal ridges, longitudinally striate, 2- or 3-locular, dissepiments thin, united below; seeds 10 to 20, campylotropous, irregularly circular or obovate, flattened, pointed, about 3 to $4 \mathrm{~mm}$. in diameter, $0.5 \mathrm{~mm}$. in thickness, edge slightly thickened, embryo curved, embedded in the endosperm; odor dis-

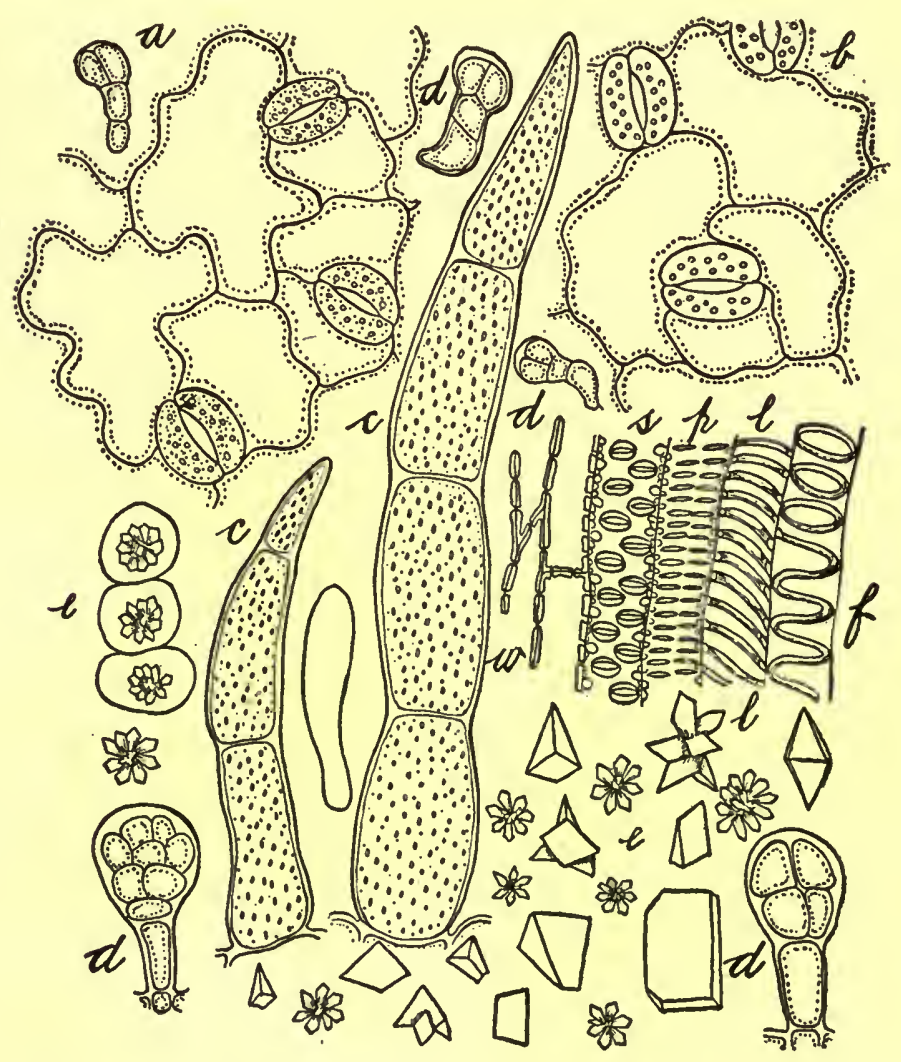

Fra. 266.-Stramonium: $a$, upper epidermis with 3 stomata; $b$, lower epidermis and 2 stomata; $c$, non-glandular hairs, the cuticle strongly papillose; $d$, glandular hairs; $e$, various forms of calcium oxalate crystals; $f$, portion of xylem showing wood fibers $(w)$, and tracheæ having simple pores $(p)$, bordered pores $(s)$ and annular and spiral thickenings $(l)$.

tinct. The pericarp of African chillies have a slightly acid and pungent taste; the seeds a sweetish, bland and pungent taste; and the dissepiments are extremely pungent. The pericarp of Japanese chillies have a slightly bitter acid, and mildly pungent taste; the 
seeds being sweetish, bland and mildly pungent; and the dissepiments are extremely pungent.

Inner Structure.-See Fig. 267.

Powder.-Yellowish-brown or brownish-red; taste very pungent and characteristic; stone cells of two kinds, either nearly isodiametric, uniformly thickened and with middle lamella slightly ligni-

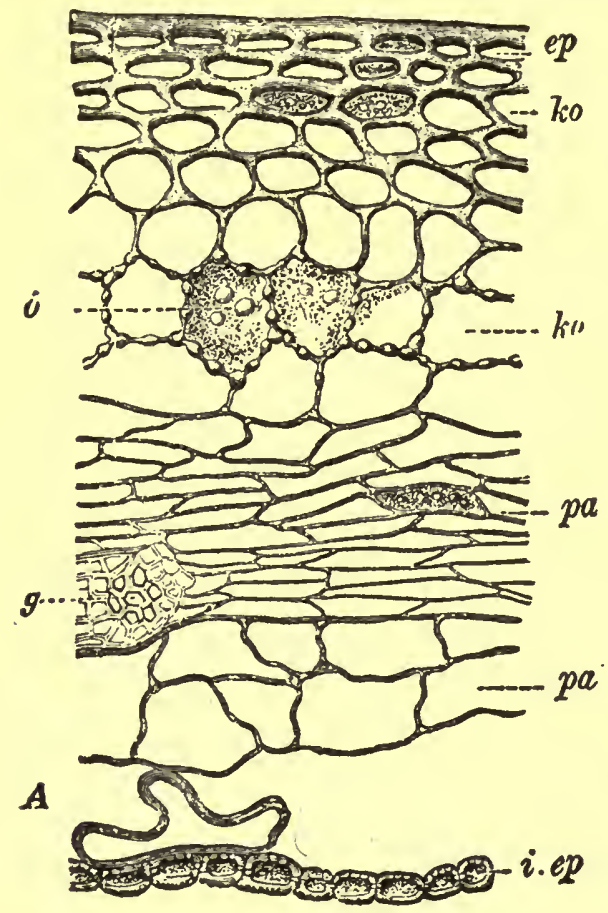

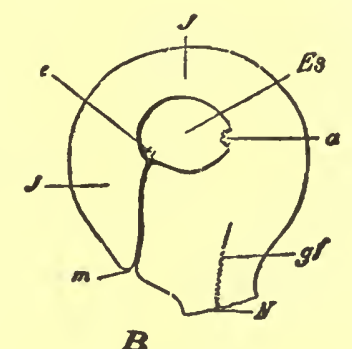

$\boldsymbol{B}$

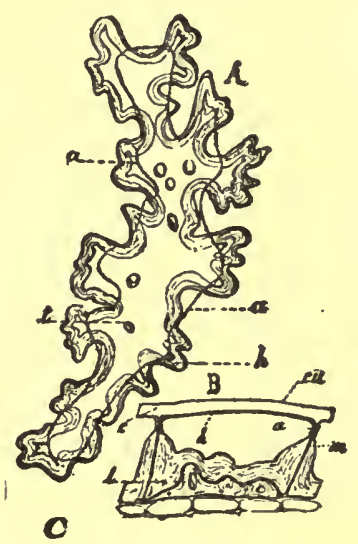

FIG. 267.-Garden pepper (Capsicum annuum): $A$, transverse section of pericarp showing epidermis $(e p)$; hypodermis $(k o)$, secretion cells having thick, porous suberized walls and contain oil $(o)$ and resin; parenchyma $(p a)$; fibrovascular bundle $(g)$; inner epidermis $(i, e p)$ composed of thick, lignified, porous cells. $B$, diagram of fertilized ovule showing hilum $(N)$, micropyle $(m)$, integument $(J)$, fibrovascular bundle $(g f)$, embryo-sac $(E s)$ egg-cell $(e)$, antipoda. cells $(a) . \quad C$, longitudinal and transverse sections of a stone cell from the epidermis of the seed-coat showing the characteristic sinuous-thickened. lignified inner and side walls.- $A$, after Hanausek; $B, C$, after Meyer.

fied, or somewhat elongated on surface view, convolutely thickened on the inner and side walls and strongly lignified; starch grains from unripe fruits somewhat spheroidal, from 0.003 to $0.007 \mathrm{~mm}$. in diameter, single or compound; glandular hairs of calyx having 1- to 
3-celled stalks and multicellular glandular heads; collenchymatous cells with suberized walls and containing yellowish-red oil globules and irregular masses of chromoplastids; epidermal cells, polygonal, the cuticle being striated.

Powdered capsicum is sometimes admixed with about 1 per cent of a fixed oil to improve its appearance, and such powders are likely to contain in addition some of the commercial starches or by-products obtained in the manufacture of cereal products.

Constituents.-Two crystalline pungent principles which are found principally in the dissepiments of the fruit: capsaicin, which is slightly soluble in water and is volatile at $115^{\circ} \mathrm{C}$. forming irritating vapors; and capsacutin, which is so powerful that 1 part in 11,000,000 of water has a distinct pungent taste. Capsicum also contains a volatile alkaloid resembling coniine; a volatile oil with an odor of parsley; resin; a small quantity of starch; a fixed oil, consisting of oleic, palmitic and stearic acids; and yields 4 to 6 per cent of ash.

The red coloring principle of the pericarp is very slightly soluble in alcohol, but soluble in ether, petroleum ether, carbon disulphide and chloroform.

Allied Drugs:-A capsicum of inferior quality known as BомBAY PEPPER is obtained from plants growing in the vicinity of the River Niger in Africa. The fruits are dull yellow or brown in color, 2 to 3 $\mathrm{cm}$. long and about $10 \mathrm{~mm}$. in diameter.

At the present time a considerable amount of a small spheroidal chilli pepper known as " cherries" is imported from India.

Paprika, also known as Hungarian Pepper or Paprika, Turkish Pepper or Paprika, or Garden Pepper. This is a large fruited pepper obtained from a variety of Capsicum annuum growing in Hungary. Its origin is somewhat obscure. It apparently is indigenous to America and can be traced from its introduction into Spain thence to Greece, Turkey and Hungary. Paprika is recognized by the German Pharmacopœia. The fruits when fresh are 5 to $10 \mathrm{~cm}$. in length, 5 to $7 \mathrm{~cm}$. in diameter, more or less inflated, externally of a bright green, yellow or red color; the pericarp is 2 to $3 \mathrm{~mm}$. in thickness, enclosing a large cavity, which has 1 or 2 dissepiments at the base, and contains numerous flattened seeds about 3 to $5 \mathrm{~mm}$. in diameter.

Standard of Purity.-Red pepper is the red, dried, ripe fruit of any species of Capsicum. It contains not more than 8 per cent of total ash, nor more than 1 per cent of ash insoluble in hydrochloric acid.

Cayenne Pepper, Cayenne, is the dried, ripe fruit of Capsicum frutescens L., Capsicum baccatum L., or some other small-fruited 
species of Capsicum. It contains not less than 15 per cent of nonvolatile ether extract, not more than 1.5 per cent of starch, not more than 28 per cent of crude fiber, not more than 7 per cent of total ash, nor more than 1 per cent of ash insoluble in hydrochloric acid.

Paprika is the dried, ripe fruit of Capsicum annuum L. It contains not more than 8.5 per cent of total ash, nor more than 1 per cent of ash insoluble in hydrochloric acid. The iodin number of its extracted oil is not less than 125, nor more than 136 .

Hungarian paprika is paprika having the pungency and flavor characteristic of that grown in Hungary.

(a) Rosenpaprika, Rozsapaprika, Rose Paprika, is Hungarian paprika prepared by grinding specially selected pods of paprika, from which the placentæ, stalks, and stems have been removed. It contains no more seeds than the normal pods, not more than 18 per cent of non-volatile ether extract, not more than 23 per cent of crude fiber, not more than 6 per cent of total ash, nor more than .4 per cent of ash insoluble in hydrochloric acid.

Königspaprika, King's Paprika, is Hungarian paprika prepared by grinding whole pods of paprika without selection, and includes the seeds and stems naturally occurring with the pods. It contains not more than 18 per cent of nonvolatile ether extract, not more than 23 per cent of crude fiber, not more than 6.5 per cent of total ash, nor more than .4 per cent of ash insoluble in hydrochloric acid.

Pimenton, Pimiento, Spanish Paprika, is paprika having the characteristics of that grown in Spain. It contains not more than 18 per cent of nonvolatile ether extract, not more than 21 per cent of crude fiber, not more than 8.5 per cent of total ash, nor more than 1 per cent of ash insoluble in hydrochloric acid. (U. S. Dept. Agric.)

Paprika is usually imported into the United States in a ground condition, 3 grades being recognized in commerce: (A), Rosenpaprika or Rozsapaprika, the best grade, possesses a beautiful red color and has a savory taste. It is prepared from the selected pericarp and seeds which are carefully washed before being ground, the stems and placentæ being removed. (B), Königspaprika or Kiralypaprika is prepared by grinding the entire pods including not only the seeds but the stems. (C). Mercantilpaprika is prepared from the spotted pods, remaining from the selection for the finer grades, and from the pods containing flaws and also contains the stems, seeds and other parts. The last grade has a pale yellow color and is much more pungent. 
Pimenton or Pimiento, also known as Spanish Paprika, is the fruit of a large-fruited pepper, a variety of Capsicum annuum, growing in Spain. The succulent pericarp is much used for stuffing of olives, while the dry pod is ground as a spice. The pods are nearly spheroidal from 2.5 to $4 \mathrm{~cm}$. in length and 4 to $6 \mathrm{~cm}$. in diameter, of a bright red color, and with no perceptible pungency. The pericarps have a sweet acid taste and a peculiar odor. The seeds have a very slight bitter, bland taste, with a slight odor. The placentæ are dark red in color and have a taste similar to the pericarp. Like the Hungarian pepper it is usually imported in the ground condition.

Literature.-Tolman and Mitchell, Bull. No. 163, Bureau of Chemistry, U. S. Dept. of Agriculture.

Dulcamara.-Stipites Dulcamare, Caules Dulcamare, True BitTersweEt.-The young branches of Solanum Dulcamara (Fam. Solanaceæ), a somewhat woody climber, indigenous to Europe and Asia, growing in moist thickets in the northern United States and Canada, and to some extent cultivated. The leaves are ovatecordate, frequently having 2 lobes or leaflets at the base; the corolla is blue, the stamens yellow and exserted; and the fruit is an ovoid or sub-globular red berry. The latter are sometimes eaten by children with fatal effects. The woody, 2 or 3 year old, twigs are gathered in the early spring or the late fall, cut into small pieces and dried.

Description.-In short cylindrical or elliptical pieces, from 3 to $6 \mathrm{~mm}$. in length and having a diameter from 4 to $6 \mathrm{~mm}$.; outer surface light yellowish or greenish brown, longitudinally wrinkled or furrowed and frequently showing leaf scars and a development of scaly cork; easily broken into 3 or 5 fragments; inner surface showing a thin, yellowish-brown corky layer, a small, dark-brown, somewhat lamellated cortex, a broad, yellowish, porous wood, and a large hollow pith; odor slight, distinct; taste of bark bitter, and of wood sweetish.

Inner Structure.-Epidermal layer having a thin cuticle which is present in the young twigs, and is usually replaced in the older stems by a layer of cork; cortical parenchyma consisting of a few strata of thin-walled cells, containing chloroplastids; pericycle of an interrupted circle of small groups of bast fibers; fibrovascular bundles, bi-collateral, separated by uniseriate medullary rays; secondary cortex of narrow strands of leptome and parenchyma containing sphenoidal microcrystals; xylem having numerous. wood fibers, a few tracheæ and wood parenchyma; small strands of intraxylary leptome; pith hollow, having a few large parenchyma cells at the periphery. 
Powder.-Light yellowish brown; fragments of numerous lignified wood fibers having bordered pores, and associated with a few wide tracheæ possessing simple pores; occasional non-lignified bast fibers and fragments of yellowish-brown cork; sphenoidal microcrystals from 0.003 to $0.007 \mathrm{~mm}$. in diameter; starch grains few, nearly spheroidal, from 0.005 to $0.012 \mathrm{~mm}$. in diameter; occasional long unicellular hairs having thick walls and a papillose cuticle.

Constituents.-A bitter glucosidal principle, dulcamarin, soluble in water and alcohol and yielding upon hydrolysis glucose and dulcamaretin, the latter being tasteless. About 0.03 of a gluco-alkaloid, solanine, which forms prisms and is soluble in amyl alcohol, slightly soluble in hot alcohol, only sparingly soluble in boiling water, and upon hydrolysis yields dextrose and a crystalline alkaloid, solanidine. Also ash, having a greenish color, not more than 6 per cent.

Solanine occurs in all parts of the potato plant and under certain conditions may accumulate in the tubers. It occurs from 0.79 to 0.41 parts per 1000 parts of potatoes. It may be present in sprouting potatoes in a sufficient amount to cause serious poisoning. (Harris and Cockburn, Amer. Jour. Phar., 1918, 90, p. 722.)

Adulterants.-The following drugs have been substituted for Dulcamara: The stems of false bittersweet (Celastrus scandens) which are more woody and not hollow; hop stems which are rough hairy; and the rhizome of Saponaria which is terete and wrinkled (Fig. 86).

Solanum Carolinense.-Horse Nettle.-The ripe fruit of Solanum carolinense (Fam. Solanaceæ), a perennial herb, propagating extensively by rhizomes and growing in dry fields and waste places throughout the eastern and central United States. The stem is erect, branched, rough-pubescent, and covered with stout, yellowish prickles (Fig. 268). The leaves are oblong-ovate, sinuate lobed, hairy and prickly like the stem. The flowers are regular and arranged in unilateral racemes; the calyx is 5-parted, the lobes being lanceolate or acuminate; the corolla is 5-lobed, rotate, light blue; the stamens, of which there are 10, are orange yellow and connivent; the ovary is 2-locular, becoming in fruit a superior globose berry. The latter is collected when ripe, during the summer, and carefully dried.

Description.-Globular, pericarp much shriveled; from 7 to 18 $\mathrm{mm}$. in diameter; externally, when fresh, orange yellow, becoming yellowish brown or greenish brown on drying, epicarp nearly smooth and shiny and usually much wrinkled and subtended by the 5 -lobed hairy calyx; pericarp very thin and membranous, brittle; placentæ 
more or less fleshy and on which are borne numerous seeds; the latter are broadly elliptical or somewhat reniform, flattened, campylotropous, about $2 \mathrm{~mm}$. in length, yellowish or dark brown and nearly smooth, endosperm large, embryo curved: odor slight; taste slightly bitter and acrid.

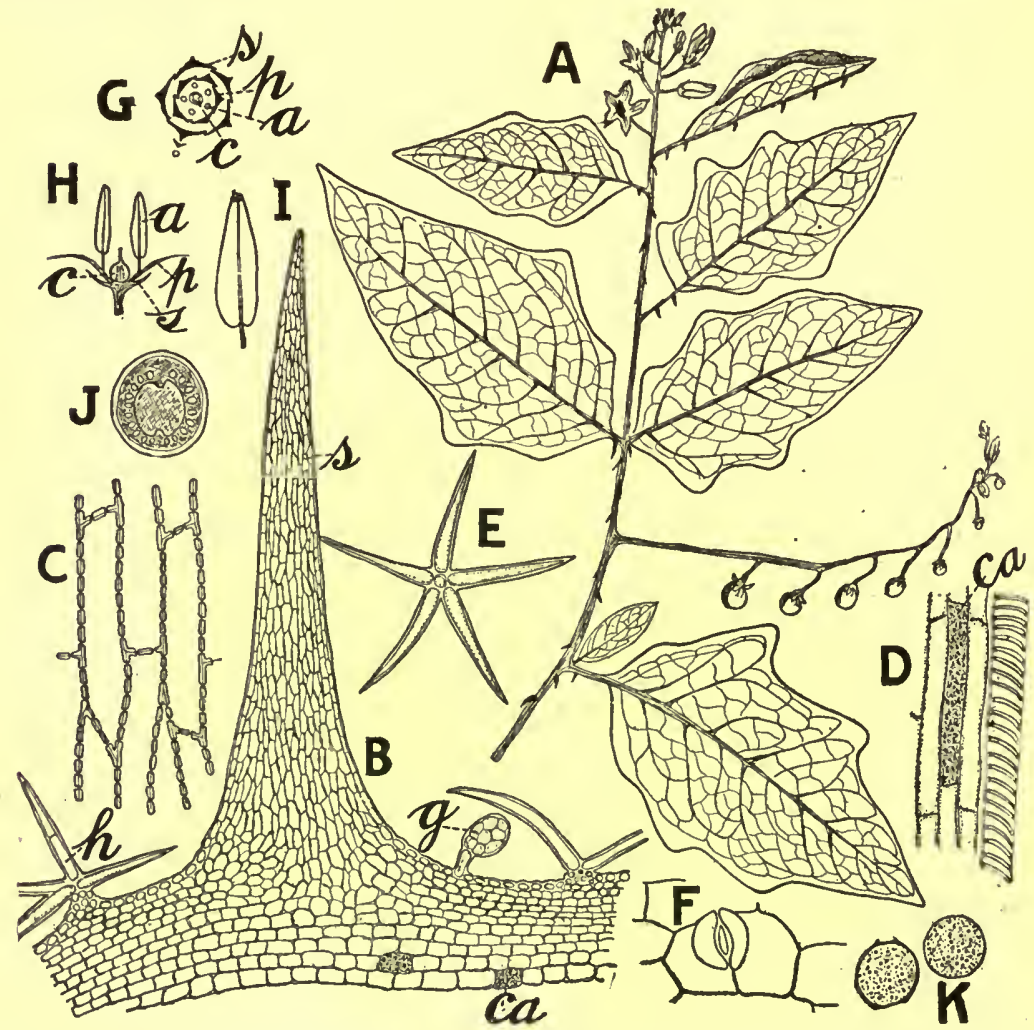

FIG. 268.-Horse nettle (Solanum carolinense): $A$, portion of shoot showing flowers and fruits and spines on leaves and stem. $B$, longitudinal section of spine $(s)$ and portion of stem showing glandular $(g)$ and non-glandular $(h)$ hairs, and cells containing sphenoidal microcrystals $(c a)$. $C$, thick-walled, strongly lignified cells of spine. $D$, portion of fibrovascular bundle showing microcrystals $(c a)$ of calcium oxalate in the cells accompanying the sieve. $E$, stellate, non-glandular hair. $F$, stoma of stem. $G$, diagram of crosssection of flower showing sepals $(s)$, petals $(p)$, stamens $(a)$, ovary $(c) . H$, longitudinal section of flower. $I$, stamen showing terminal pores. $J$, cross-section of 2 -locular berry. $K$, pollen grains about $0.030 \mathrm{~mm}$. in diameter.

Constituents.-An alkaloid, solnine, which crystallizes in orthorhombic prisms, that are insoluble in water and very soluble in 
chloroform and hot alcohol, and have an acrid and bitter taste, leaving a persistent tingling sensation on the tongue. The drug also contains solanine.

Literature.-Lloyd, Amer. Jour. Pharm., 1894, p. 161.

Manaca.-Radix Manaca, Franciscera or Brunfelsia.-The dried root of Brunfelsia Hopeana (Fam. Solanaceæ), a large shrub growing along streams in Brazil and other parts of tropical America. While all parts of the plants are used in Brazil the root has only been introduced into general medicine very recently.

Description.-Usually in pieces, from 6 to $10 \mathrm{~cm}$. in length and from 1 to $2 \mathrm{~cm}$. in thickness; externally reddish-brown, much wrinkled and with a scaly cork, which with the thin cortex is easily separable from the light yellowish wood; very tough; inner surface, bark thin, reddish-brown, wood large and very finely radiate; inodorous; taste sweetish and slightly bitter.

INNER STRUCTURE.-(Fig. 269.)

Constituents.-Manacine, a very poisonous alkaloid, resembling strychnine in its physiological actions. It also contains manaceine, and a resinous substance which is apparently identical with æsculetin, occurring in the bark and seeds of the horse chestnut tree.

Adulterants. - A large fusiform root, has been sold for manaca, being about $30 \mathrm{~cm}$. in length and from 2 to $5 \mathrm{~cm}$. in diameter; it has a very scaly membranous cork, a dark brown cortex and a large yellowish-white wood. The taste at first is aromatic, resembling orange peel, becoming acrid and pungent, leaving a persistent tingling sensation on the tongue. The origin of this root is unknown, although it is probably somewhat related to true Manaca.

TABAcum.-Folia Nicotianæ, Leaf Tobacco.-The dried leaves of the Virginia Tobacco plant, Nicotiana Tabacum (Fam. Solanaceæ), a tall annual herb indigenous to tropical America and widely cultivated. The stem is simple, giving rise to large, pubescent, ovate, entire, decurrent leaves, the veins of which are prominent and more or less hairy. The flowers are long, tubular, pink or reddish and occur in terminal spreading cymes. The various forms of tobacco are made from the leaves, which are hung in barns, whereby they undergo a slow drying or process of curing. Other species of Nicotiana are also cultivated, as N. persica, which yields Persian tobacco; and $\mathrm{N}$. rustica, the source of Turkish tobacco.

Inner Structure.-See Winton and Moeller, The Microscopy of Vegetable Foods.

Powder--Greenish-brown; non-glandular hairs, 3 to 6-celled, with a broad basal cell and not infrequently branching apical cells; 


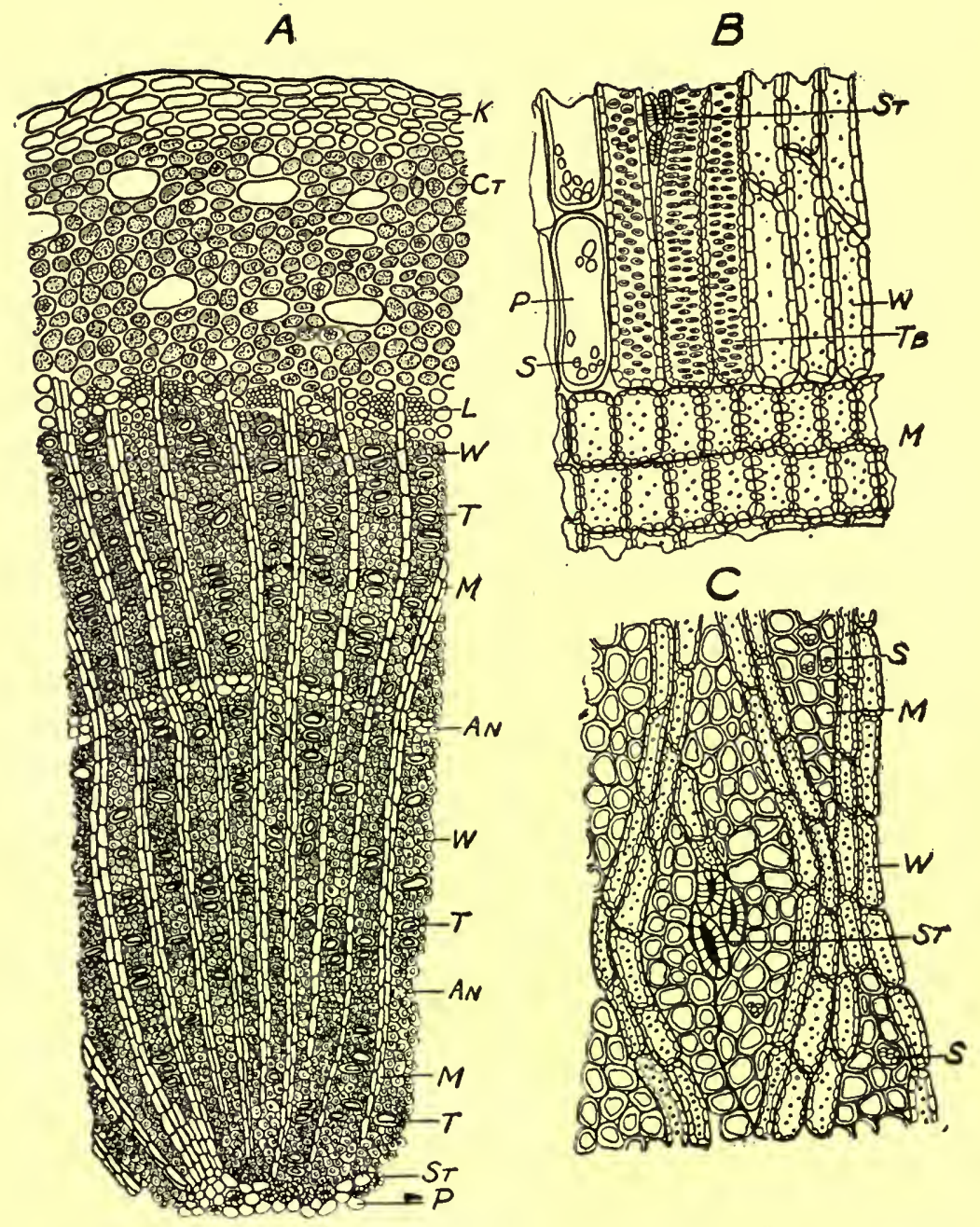

Fig. 269.-Manaca: $A$, transverse section of root: $K$, thin-walled cork which arises in the epidermal layer; $C t$, cortex consisting mostly of starch-bearing parenchyma, and cells containing either rosette aggregates of calcium oxalate or a yellowish-brown amorphous content; the larger cells of which are mostly spheroidal in shape and usually lined with a thin layer of protoplasm; $L$, small strands of leptome; $W$, wood fibers; $M$, medullary rays consisting mostly of rectangular cells, having thick, porous walls; $A n$, cells marking the rings of growth between the spring and fall wood as also of the cambium, usually filled with a yellowish-brown, amorphous substance; $S t$, stone cells, usually developed between the wood fibers and medullary rays. $B$, longitudinal section showing tracheæ having bordered pores $(T b)$; parenchyma 
glandular hairs of two kinds, either with a 1-celled stalk or a 3- to 5celled stalk, the head in each case being rather small and with 8 to 9 cells; stomata large and with 2 or 3 neighboring cells; epidermal cells striated and somewhat granular on surface view; the cells of the mesophyll with a greenish-brown content, and some of them with sphenoidal microcrystals. The following leaves have been used as adulterants: Chestnut (Fig. 73), cherry, rose, melilot, cabbage, chicory, beet, and lappa. In the manufacture of plug tobacco various other substances are added; as, licorice (Figs. 140 and 141), cloves (Fig. 202), anise (Fig. 206), orris root (Fig. 46), vanilla (Fig. 57), tamarinds, prunes, besides other substances.

Constituents.-Tobacco leaves contain from 0.6 to 9 per cent of the alkaloid nicotine; an aromatic principle nicotianin or tobacco camphor, to which the characteristic flavor is due and which is formed during the curing of the leaves. The dried leaves yield from 14 to 15 per cent of ash, consisting in large part of potassium nitrate.

\section{SCROPHULARIACEE, OR FIGWORT FAMILY}

A large family, represented by nearly 2500 species of herbs, shrubs or trees. The plants are characterized by having gamopetalous corollas, which are either nearly regular or usually 2-lipped, the stamens being frequently didynamous, and the fruits are usually capsular. Among the anatomical characteristics the following may be mentioned. Neither a sub-epidermal collenchyma nor a sclerenchymatous ring in the pericycle are developed. The walls of the tracheæ and wood fibers usually have simple pores, except when the former are in contact with the parenchyma cells, bordered pores are developed. Calcium oxalate is secreted in the form of small prisms, octahedra or acicular crystals. The non-glandular hairs are of four different kinds: (a), unicellular; (b), uniseriate; (c), unicellular, having cystoliths; and $(d)$, multicellular, or branching, as in Verbascum and Pawlonia. The glandular hairs are of several types: (a), Those having a unicellular stalk and a unicellular secreting head; (b), having a 2- or more-celled glandular head; (c), peltate-glandular. The mesophyll of the leaves contain not infrequently crystals of carotin, or protein substances. In Scrophularia, idioblasts contain-

$(P)$; starch grains $(S)$, being from 0.004 to $0.015 \mathrm{~mm}$. in diameter; wood fibers $(W)$; thick-walled medullary ray cells $(M)$; stone cells $(S t) . \quad C$, tangential section showing medullary ray cells $(M)$; $\operatorname{starch}(S)$; wood fibers $(W)$; stone cells $(S t)$.-Drawing by Haase. 
ing tannin extend from the epidermal layers to the fibrovascular bundles.

Digitalis.-Fox Glove.-The leaves of Digitalis purpurea (Fam. Scrophulariaceæ), a biennial herb (Figs. 270, 271, 272 and 274) in various parts of Europe, and the western United States and Canada, also extensively cultivated. The leaves are collected throughout the summer from July to September, during the flowering of the plant, the best product being gathered in June prior to the expansion of the flowers. The leaves are carefully dried in the shade (preferably with the leaves on the stem as in the drying of tobacco), and stored so

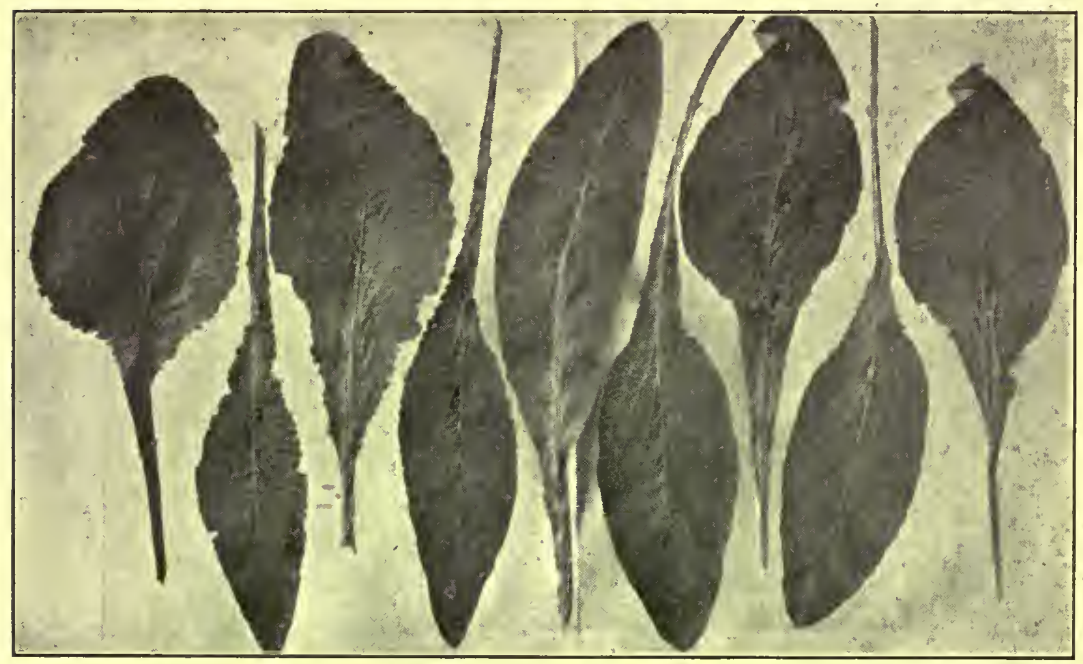

FIG. 270.-Digitalis purpurea: Leaf variations in different plants. It will be noted that the leaves vary in shapes, margins and character of the petioles. There is also considerable difference in the color of the leaves and their surfaces. These variations seem too great and diversified to be explained as individual variabilities.-After Miller, Amer. Jour. Pharm., 1913, p. 300.

(probably indigenous to central and southern Europe, and naturalized) that they will not become moulded. While ordinarily the leaves of the second year's plant are only collected, the leaves of the first year seem to be more active. It has also been considered that the leaves from cultivated plants are superior to those from wild plants, but this is probably due to the more careful drying and storing of the former.

The most active digitalis is not necessarily the best from a pharmacological point of view, and pharmacologists prefer to use 
those preparations which show a maximum of therapeutic action with a minimum of side effects, such as the nauseant and emetic. It is not known at what period digitalis possesses this advantage,
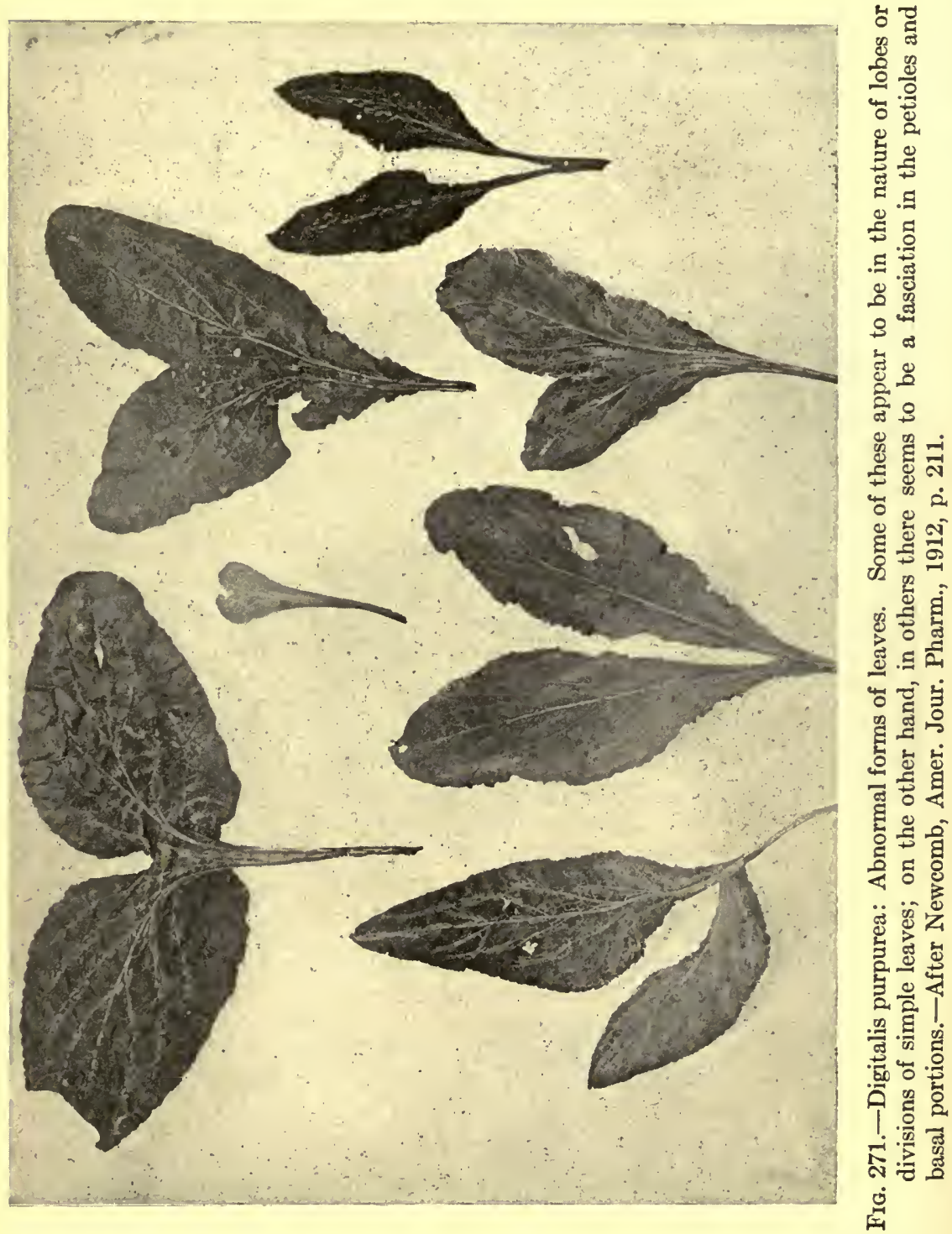

or how it may be developed, if at all, during the process of drying. In recent years it has been proposed that digitalis leaves should be carefully dried, stored in bottles or tight tin cans in which a bottle 
containing freshly burnt lime is placed, the latter container being covered with perforated parchment, but Hatcher's work would seem to show that this is unnecessary. Again, it is frequently emphasized that the leaves should not be kept longer than one year, but the drug may be kept indefinitely, if the leaves have been carefully selected, properly dried and stored. Newcomb and Rogers found that the petioles of Digitalis were from one-fourth to one-fifth as active as the entire leaf. The active principles are in the cells within

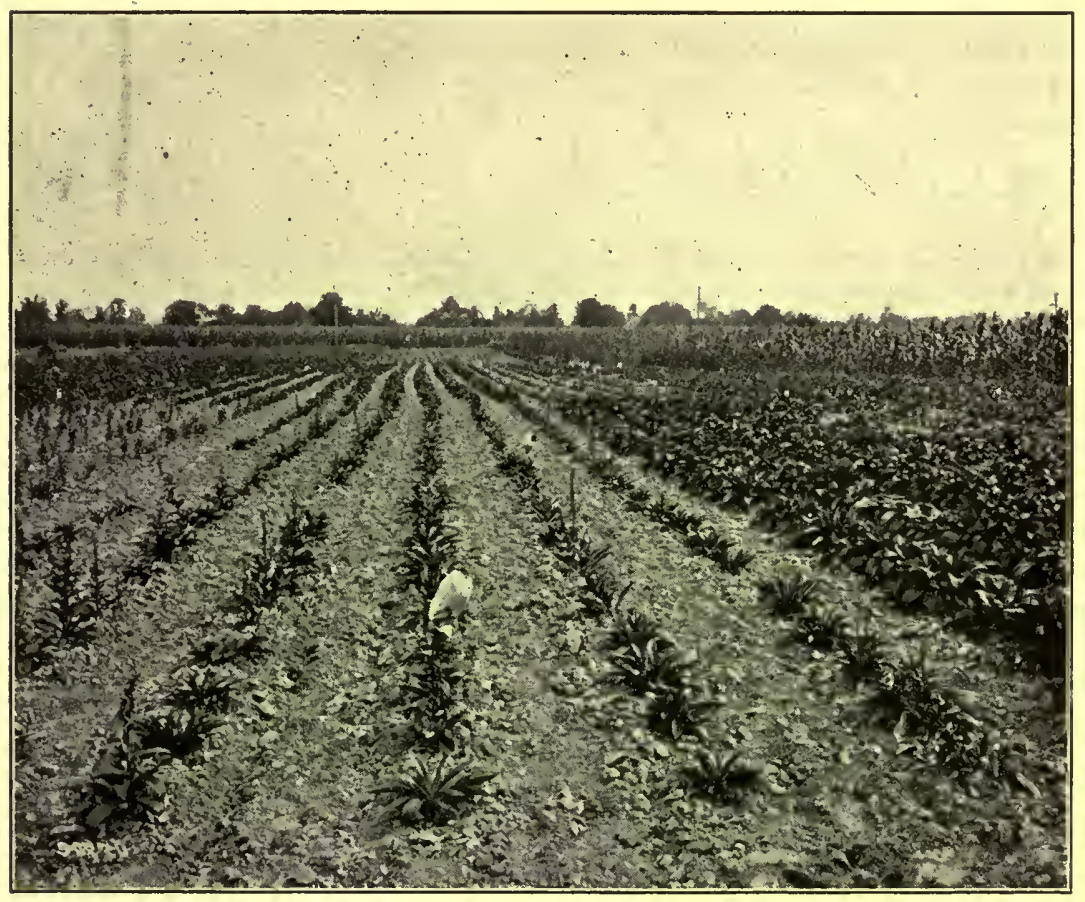

FIG. 272.-Cultivation of Digitalis: A general view of the Experimental Farm of Eli Lilly \& Co. showing the testing and breeding of various species and varieties of Digitalis.-After Miller, Amer. Jour. Pharm., 1913, p. 298.

the leaf and apparently not developed in the hairs. The quality of digitalis is improved by separating the dirt siftings as much as possible. Most of the commercial supplies were obtained from England, Austria, Hungary, and the Harz and Vosges mountains of Europe, but much of the drug is now produced in the United States.

In a study on the effect of temperature on drying digitalis leaves Hamilton (Amer. Jour. Pharm., 1919, 91, p. 177), obtained the following results. 
Oven drying has no advantage over a reasonably rapid air drying of digitalis leaves.

The drying causes a marked deterioration when conducted in an oven at a high temperature.

The fresh drug has greater toxicity than the dried drug.

No products more highly toxic than those present in the crude drug are developed during the process of drying.

Description.-Usually more or less crumpled and broken into fragments; lamina ovate-oblong or ovate-lanceolate, 10 to $25 \mathrm{~cm}$. in length, 5 to $15 \mathrm{~cm}$. in breadth; summit obtuse or rounded; base somewhat cuneate, tapering into the petiole; margin dentate or crenate, the divisions with a yellowish-brown gland-like summit; upper surface dark green, minutely hairy, somewhat wrinkled, with a single water-pore near the summit of each tooth; under surface grayish-green, midrib grayish-brown, prominent, from which veins of the first order diverge at angles of $45^{\circ}$ to $65^{\circ}$ and unite with one another near the margin, and from which arise other anastomosing veins, giving a distinctly reticulate appearance; distinctly pubescent on the veins and frequently on the reticulations; petiole about onethird the length of the lamina or in the upper leaves nearly wanting, grayish-brown, laminated; texture fragile; odor distinct; taste bitter.

Leaves that are more than $30 \mathrm{~cm}$. in length are usually rejected, as also the tuft of radical leaves of the first-year plant.

InNer Structure.-See Figs. 273 to 276.

Powder.-Dark green; non-glandular hairs, uniseriate, of 2 to 8 (usually 2 to 5 ) cells, from 0.145 to $0.435 \mathrm{~mm}$. in length, some of the cells being frequently collapsed; glandular hairs few, small, with a 1- or 2-celled stalk and 1- or 2-celled glandular head; numerous irregular fragments of lamina showing epidermal cells having undulate walls and scattered stomata or occasional water-pores.

Localization of the Active Glucosides. - With means of sodium picrate reagent (one drop of 1 per cent picric acid solution mixed with one drop of 10 per cent sodium hydroxide solution) applied to sections, the cells containing the glucosides are colored orange within one or two minutes. In all the species of Digitalis studied, including D. purpurea, lutea, ambigua, the glucosides were thus located in the epidermal cells, the non-glandular hairs, in the endodermis of the vascular bundles and some times in the subepiderml collenchyma. The leaf margin (epidermis and endodermis) gave the strongest reaction, the base of the petiole only a very faint one. Baljet, Schweiz. Apoth. Ztg., 1918, 56, p. 247. 
Constituents.-Several crystalline glucosides, including digitoxin ( 0.2 to 0.3 per cent), digitalin and digitonin, the former two being the more important. The drug also contains a volatile oil containing a stearoptene digitalosmin, which has the odor of digitalis and a nau-

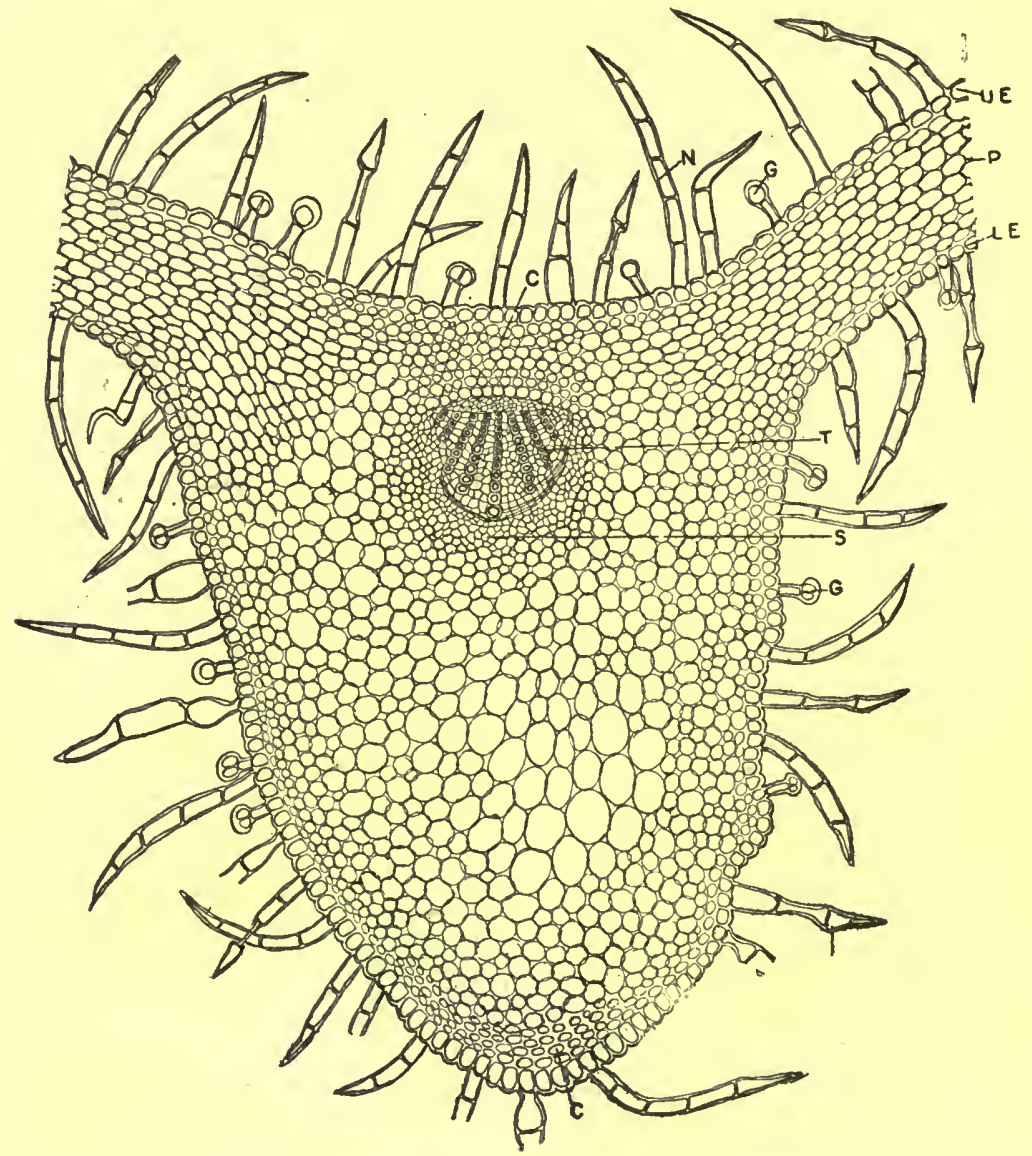

Fig. 273.-Transverse section of digitalis leaf, through one of the veins: $U E$, upper epidermis; $P$, chlorenchyma (mesophyll), containing chloroplastids; $L E$, lower epidermis; $G$, glandular hairs; $N$, non-glandular hairs; $C$, collenchyma; $T$, trachex or vessels; $S$, leptome or sieve.

seous, acrid taste; a volatile principle, antirrhinic acid;-somewhat resembling valerianic acid; digitalic acid, separating in white needles; two coloring principles, one red and the other yellow, resembling chrysophan, a glucoside found in rhubarb; an oxydase ferment which occurs in the recently dried leaves; a small quantity of tannic acid; 
and ash 10 to 16 per cent (consult Merck, Amer. Jour. Pharm., 1913, p. 36).

Digitoxin (Fig. 277) is a most powerful heart stimulant and yields on hydrolysis digitoxose and digitoxigenin. It occurs in white,

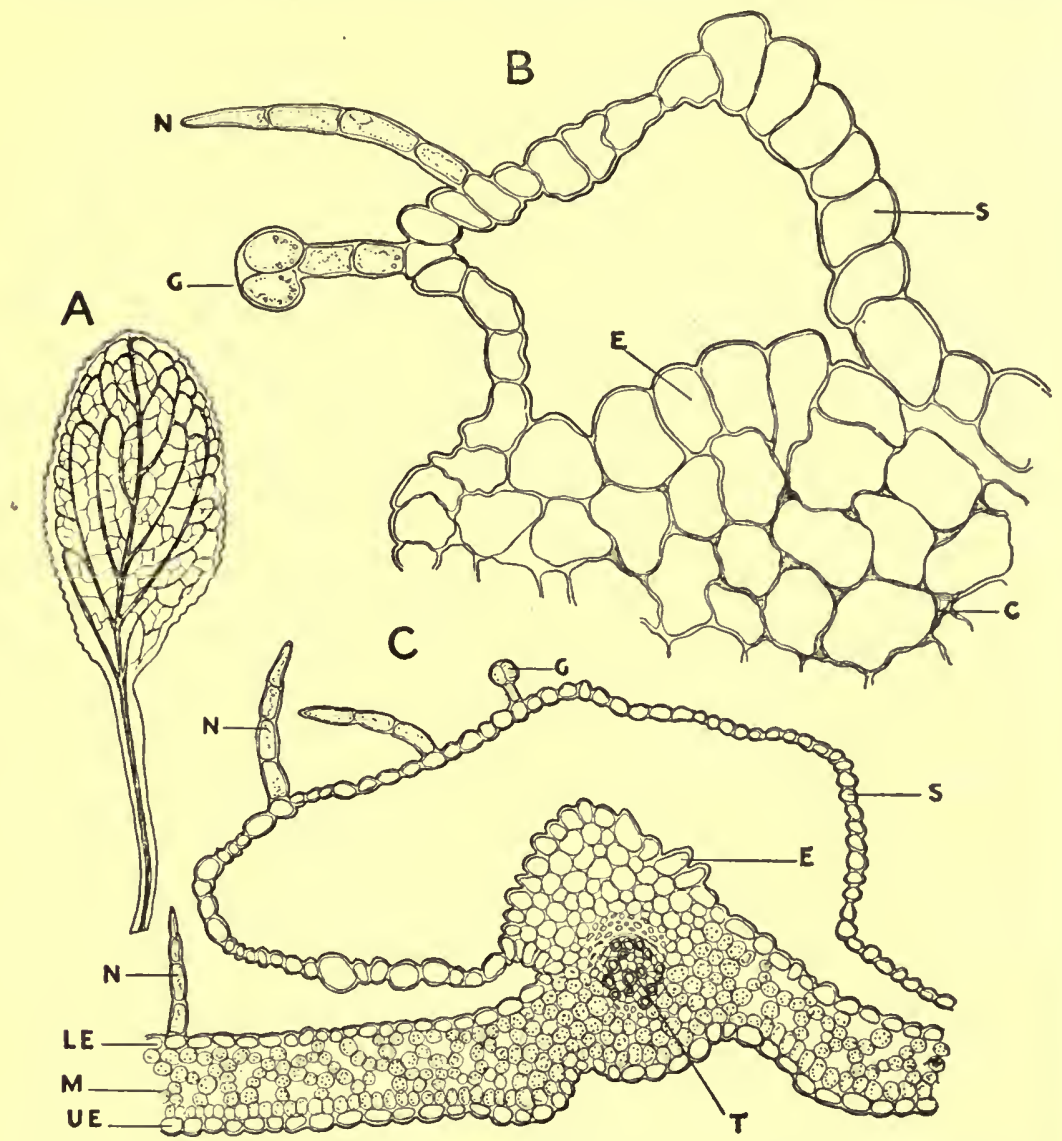

FIG. 274.-Digitalis: $A$, a typical leaf showing the winged or laminate petiole and the veins of the first order which diverge from the mid-vein at very acute angles. $\quad B$, transverse section of portion of leaf showing the separated or additional epidermal layer $(S)$; epidermal layer $(E)$; glandular hair $(G)$; non-glandular hair $(N)$; collenchyma $(C) . C$, transverse section near one of the veins showing considerable of the separated or extra epidermal layer $(S)$; with two non-glandular hairs $(N)$ and glandular hair $(G)$; epidermal layer $(E)$; lower epidermis $(L E)$; chlorophyl layer $(N)$; upper epidermis $(U E)$; trachex or vessels $(T)$.

needle-shaped crystals which are insoluble in water, but more or less soluble in alcohol, of a bitter taste and colored deep green with 
hydrochloric acid. According to Schmiedeberg and Kiliana digitoxin is a chemically uniform substance being present in the leaves, but not in the seeds.

Digitoxin (solubile) Cloetta is an amorphous modification of digitoxin, and is only distinguished from the latter by the smaller

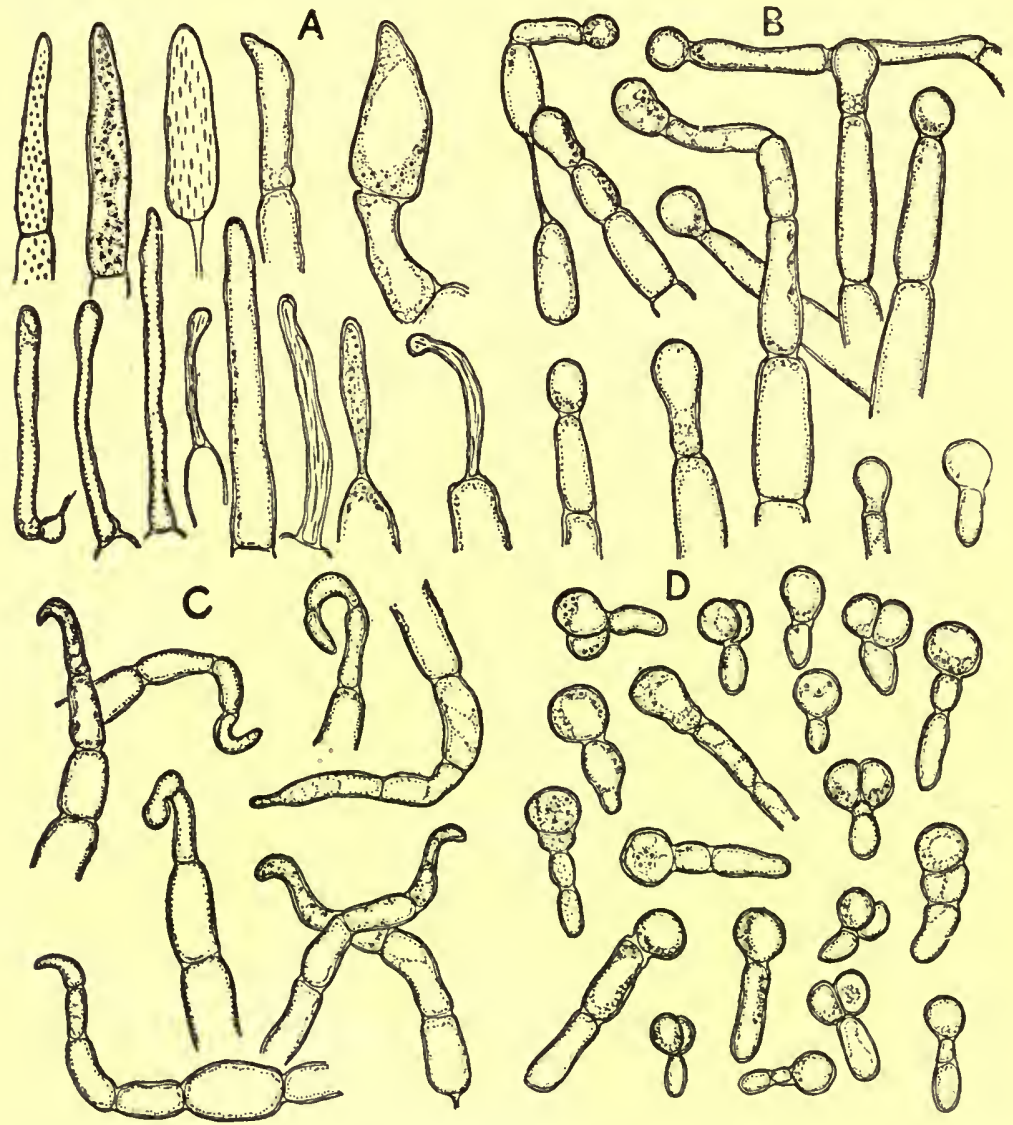

FIG. 275.-Various forms of hairs of digitalis: $A$, various forms of apical cells. $B$, uniseriate, glandular hairs very common in leaves of cultivated plants. $C$, various non-glandular hairs showing crooked or bent apical cells. $D$, various forms of glandular hairs with short stalks.

size of its molecule and its greater solubility in water. Kiliani, however, is of the opinion that digitoxin Cloetta (digalen) is identical with digitalein.

Digitoxine Pharmacopée française is essentially identical with digitoxin. The French Pharmacopoia requires, inter alia, that 
the preparation shall give a green color when dissolved in concentrated sulphuric acid, whereas commercial digitoxin gives a brown color on solution.

Digitalin (digitalinum verum) is a heart stimulant and yields on hydrolysis digitalose and digitaligenin. It occurs in white, rather characteristic granules which are sparingly soluble in water and more

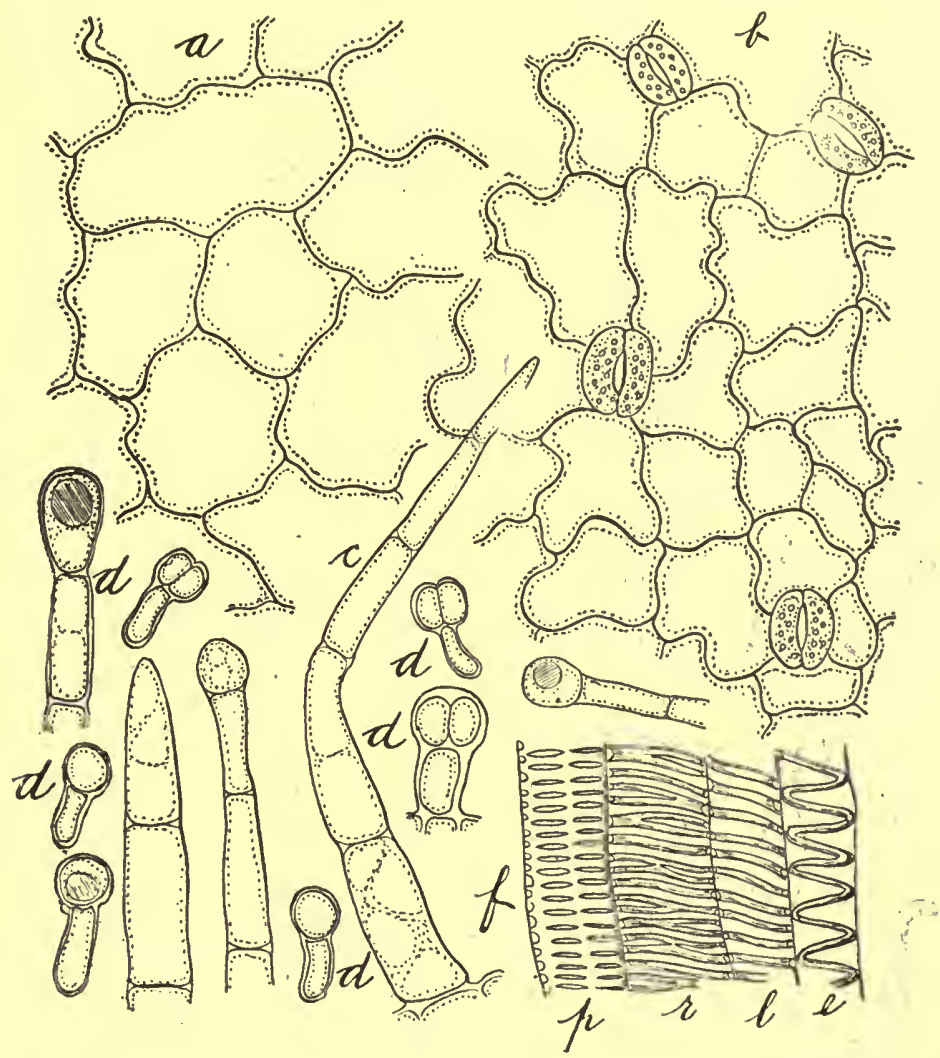

FIG. 276.-Digitalis: $a$, surface view of upper epidermis, showing slightly undulate walls; $b$, lower epidermis, the cells having distinct undulate walls, 4 stomata also being shown; $c$, a uniseriate non-glandular hair; $d$, several forms of glandular hairs; $f$, section of portion of xylem, showing trachex having simple pores $(p)$, reticulate thickenings $(r)$, annular markings $(l)$ and spiral thickening $(e)$.

or less soluble in alcohol, forming yellowish-colored solutions with concentrated hydrochloric or sulphuric acids. If the latter acid contains a trace of ferric sulphate solution a permanent bluish-red color is produced. 
Digitalin with no other specification is a vague term, and should be avoided in the literature and in practice in order to eliminate a source of error and of confusion. The same applies to digitalinum and digitaline.

Digitalin, amorphous. This designation is probably chiefly intended to cover digitalinum Gallicum (digitaline chloroformique) of the French pharmacopœias of 1866 and 1895, a substance which is completely soluble in chloroform. But it must be remembered that digitalinum verum and digitalinum Germanicum are also amorphous.

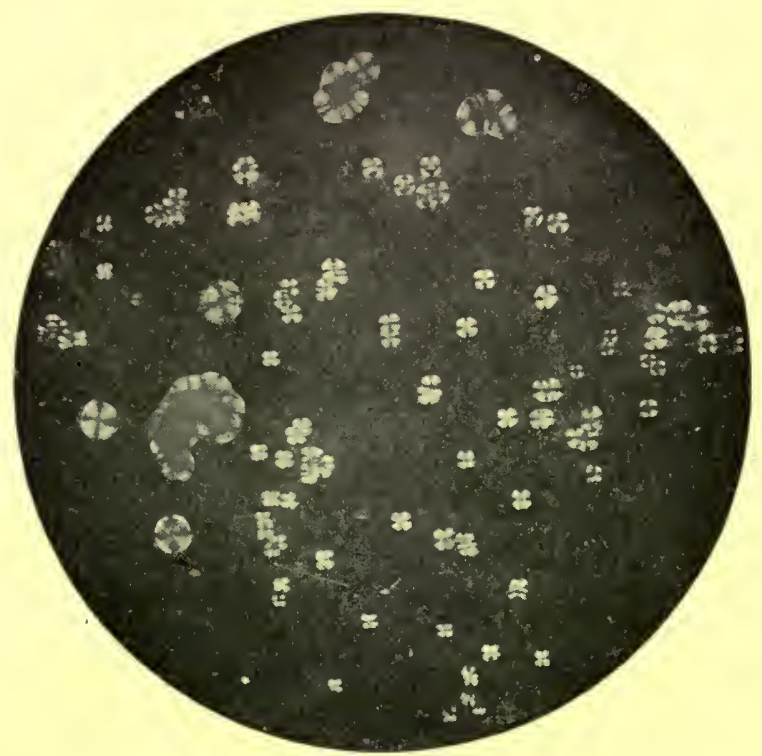

FIG. 277.-Digitoxin: sphero-crystals from an alcoholic solution.

Digitalin (um) crystallisatum has so far been used as a synonymous term for digitonin. As this is misleading it would be better to avoid its use altogether. In commerce, however, names which have once been introduced are difficult to get rid of.

Digitalin Homolle is a mixture of glucosides and their products of decomposition, contained in digitalis leaves, and is practically insoluble in water.

Digitalin Homolle-Quevenne is the constituent of digitalin Homolle which is insoluble in a mixture of alcohol and ether.

Digitalin Kiliani is identical with digitalinum verum.

Digitalin Nativelle is a crystalline product prepared from digitalis leaves, which is probably not unlike digitoxin in constitution. Ac- 
cording to Schmiedeberg and Kiliani, it is a mixture of several substances.

Digitalin Schmiedeberg is a chemically uniform, amorphous body of the formula $\left(\mathrm{C}_{5} \mathrm{H}_{8} \mathrm{O}_{2}\right)_{7}$.

Digitalinum fluidum was the name given by Engelhardt to a liquid, volatile, oily substance obtained from digitalis leaves, and which he regarded as the active component of digitalis.

Digitalinum Pharmacopée française, 1908, is identical with digitoxine Pharm. franç.

Digitalinum Gallicum amorph. is obtained from digitalis leaves according to the method given in the Pharmacopée française, 1884. It also bears the name of " digitaline chloroformique." It is completely soluble in chloroform and practically insoluble in water.

Digitalinum Gallicum crystallisatum is either digitalin Nativelle or digitoxine Pharm. franç. 1908.

Digitalinum Germanicum is an amorphous product obtained from digitalis seeds, and is soluble in water. It consists principally of digitalinum verum, digitalein and digitonin.

Digitonin resembles in its physiological action quillajasaponin, and on hydrolysis yields dextrose, galactose and digitogenin. It is crystalline, soluble in water, somewhat soluble in alcohol, and remains colorless on treatment with hydrochloric acid; but a dilute sulphuric acid solution becomes garnet-red in color on boiling for some time.

Digitonin, when anhydrous, occurs as an amorphous body, while with $5 \mathrm{H}_{2} \mathrm{O}$ it is a crystalline, chemically uniform body.

Digitonin, amorphous, is digitonin Schmiedeberg.

Digitonin cryst, is digitonin Kiliani.

Digitonin Kiliani is pure, crystalline, hydrated digitonin $\left(\mathrm{C}_{34} \mathrm{H}_{92} \mathrm{O}_{28}+5 \mathrm{H}_{2} \mathrm{O}\right)$.

Digitonin Schmiedeberg is amorphous, anhydrous, digitonin. According to Kraft, digitonin Schmiedeberg and digitonin Kiliani are not identical; he therefore suggests the designation "digitsaponin " for digitonin Schmiedeberg.

Digitalein Nativelle was described by Nativelle as a physiologically active glucoside, soluble in water and obtained from digitalis leaves.

Digitalein Schmiedeberg is a glucoside soluble in water. Kiliani at first doubted the chemical individuality of the digitalein of Schmiedeberg. Keller and Hondas also took it to be digitonin. But Kiliani proved later that the seeds and leaves of digitalis contain a cardiac poison, soluble in water, which contains no digitalin, the 
physiological activity of which, therefore, precludes its identity with digitonin. Kiliani and Windaus suspected the presence of a lactone in digitalein, because its neutral aqueous solution gives an acid reaction on standing. This proves digitalein to be a distinct substance, of uniform composition. Kraft, on the other hand, accepts the nomenclature of digitalein only as a generic term for all the active glucosides which are soluble in water and are present in digitalis. $\mathrm{He}$ also places in this class, gitalin, an amorphous glucoside.

Digitaléne Buignet represents the glucosides of digitalis leaves, which are soluble in water.

Digitalon is the lactone of digitalonic acid. The name " digitalon" is also given to a special preparation-a solution of all the glucosides present in digitalis - to be used subcutaneously in doses of 0.5 to 1 c.c.

Gitalin is a glucoside which was obtained by Kraft from digitalis leaves. It is soluble in 600 parts of cold water. According to Schmiedeberg, it corresponds in strength in its physiological action to digitalinum vorum.

The ash of Digitalis contains iron, calcium, magnesium, manganese, sodium, potassium and silica. The ash of leaves from cultivated plants usually averages higher than that obtained from wild plants. (Rogers and Newcomb, Amer. Jour. Pharm., 1918, 90, p. 239.)

Determination of the Chemical Value of Digitalis.-Tschirch AND Wolter (Schweiz. Apoth Zeitg., 1918, 56, 470, 495, 512), have experimented with four species of digitalis leaves. Their results show that the best methods of extraction is that of ReedVanderkleed but that it requires much time, six days. For solvents they used ether, acetic ether, absolute alcohol, amyl alcohol, benzene, carbon tetra-chloride, chloroform, and acetone. Chloroform dissolves only part of the active substances contained in the drug; with absolute alcohol all of the active substances pass into the extract; benzene does not dissolve all of them; acetone is the best solvent for determining the chemical value of digitalis. The authors employed a modified method of Keller, the leaves of the digitalis being first subjected for extraction by ether in order to remove the oils and chlorophyl. After removing the ether by distillation, the leaves were extracted with absolute alcohol. After purification with lead, the entire glucosides were isolated by acetone, the acetone being separated from the liquid by the addition of sodium chloride. In this manner they obtained a complete exhaustion of the drug and the extract thus obtained has been called pandigiton and is said to possess all the physiological properties of digitalis. 
Allied Drugs.-The seeds of Digitalis purpurea are about $1 \mathrm{~mm}$. or less in diameter, yellowish or dark brown, oblong or spatulate in section, more or less plano-convex and somewhat tuberculate. They contain apparently the same principles as the leaves. The seeds contain digitoxin which is said to be different from that obtained from the leaves and is known as $\alpha$-digitoxin.

The leaves of Digitalis grandiflora, growing abundantly in Switzerland, appear to be as efficient as those of Digitalis purpurea.

Spanish Digitalis.-The stems, leaves, flowers and capsules of Digitalis Thapsi. The drug resembles mullein being of a yellowishgray or of a yellowish-green color. Leaves in fragments, rarely entire, 3 to $15 \mathrm{~cm}$. in length and 2 to $3 \mathrm{~cm}$. in width, narrowly oblong or oblong-lanceolate, gradually tapering into a broad sessile base, margin coarsely denticulate, mid-vein prominent with 4 to 6 inconspicuous pairs of veins, both surfaces soft velvety covered with glandular hairs. Stems slender, $0.5 \mathrm{~mm}$. long, green or purplish and densely covered with gland-tipped, 3- to 7-celled hairs. Flowers occasional and purplish. Capsules ovoid, about $15 \mathrm{~mm}$. in length, greenish or pale brownish, usually partially separated and opening at the summit by a large pore. Odor slight; taste bitter and slightly acrid. It resembles Strophanthus in its pharmacologic properties and is about three times as toxic as Digitalis purpurea. (Farwell and Hamilton, Am. Jour. Pharm., 1917, 89, p. 147.)

Digitalis Ambigua.-This species grows abundantly in Austria and the leaves seem to show a therapeutic activity equal to official Digitalis. (Chem. Zeit,, Vol. 41, p. 99.)

Adulterants.-The leaves of other cultivated varieties of Digitalis have been substituted for those of D. purpurea, as those of the Mammoth Foxglove (D. monstrosa), which is distinguished by producing long, spike-like racemes which are terminated by one large flower.

The leaves of Matico (Fig. 66) have numerous stomata and the non-glandular hairs are from 2- to 6-celled. The leaves of Salvia Scalarea (Fam. Labitx) possess non-glandular hairs somewhat resembling Digitalis, but the glandular hairs are of the labiate type with large, 8-celled, glandular heads. The leaves of Verbascum Phlomoides (Fam. Scrophulariaceæ) have multicellular, branching, non-glandular hairs resembling those of $\mathrm{V}$. thapsus, and small glandular hairs resembling those of digitalis. The non-glandular hairs of Inula Conyza (Fam. Compositæ) are 3- to 4-celled with thick walls, the basal cell being broad and truncate.

Literature.-Newcomb, Amer. Jour. Pharm., 1911, 529; Borneman, Ibid., 1912, p. 547; Miller, Ibid., 1913, p. 297; Hatcher, Drug. 
Circ., 1914, p. 517 and p. 607; Hatcher, Amer. Jour. Pharm., 1918, 90, p. 24; Newcomb and Rogers, Amer. Jour. Pharm., 1918, 90 p. 580 .

LEPTANDRA.-Culver's Root.-The dried rhizome and roots of Leptandra virginica (Fam. Scrophulariacex), a perennial herb growing in meadows and moist woods of the eastern and central United States and Canada. The rhizome and roots are collected in autumn from plants of the second year's growth. When fresh the drug has an almond-like odor and a bitter, nauseous taste, which it loses in a measure on drying, and may be kept indefinitely.

Description.-Rhizome horizontal, nearly cylindrical, somewhat branched, 4 to $10 \mathrm{~cm}$. in length, 3 to $8 \mathrm{~mm}$. in diameter; externally light brown to brownish-red; annulate from circular scars of budscales, upper surface with conical buds, short stem-remnants or stemscars, the under and side portions with numerous roots or root-scars; fracture tough; internally, bark dark brown, 0.3 to $1 \mathrm{~mm}$. in thickness, wood about 0.5 to $1.5 \mathrm{~mm}$. in thickness, pith light brown or brownish-black; odor slight; taste bitter, slightly acrid.

Roots from 1 to $4 \mathrm{~cm}$. in length, 0.5 to $1 \mathrm{~mm}$. in diameter, externally smooth; longitudinally wrinkled fracture short; internally, bark brownish-black, wood light brown.

Inner Structure.-(Fig. 278.) Rhizome consisting of an epidermal layer having thin walls, which is replaced in older rhizomes by the products of the phellogen; cortex of starch-bearing parenchyma; a pericycle having a closed ring of several rows of stereids or elongated sclerenchymatous fibers; fibro vascular bundles collateral; radiate strands of phloem consisting of leptome and numerous thin-walled parenchyma; xylem consisting of wedges of thick-walled wood fibers and a few porous tracheæ; medullary rays 1 cell in width; primary and secondary hadrome separated by a stratum of thin-walled parenchyma, the cells of which do not become lignified.

Roots consisting of epidermal cells having thick, lamellated outer walls; a hypodermis or layer of thin-walled, non-contractile cells; cortex of parenchymatous cells, the outer layers being more or less thick-walled; endodermis of thin-walled cells showing Casparyan spots on the radial walls; pericambium of a single layer; stele in lateral roots diarch, having 2 isolated rays of hadrome, and in thicker roots pentarch, having numerous tracheids and thickwalled libriform.

Stems resemble the rhizome, but are characterized by the presence of long, uniseriate, non-glandular hairs, and nearly sessile glandular hairs, the latter having a 4-celled summit. 

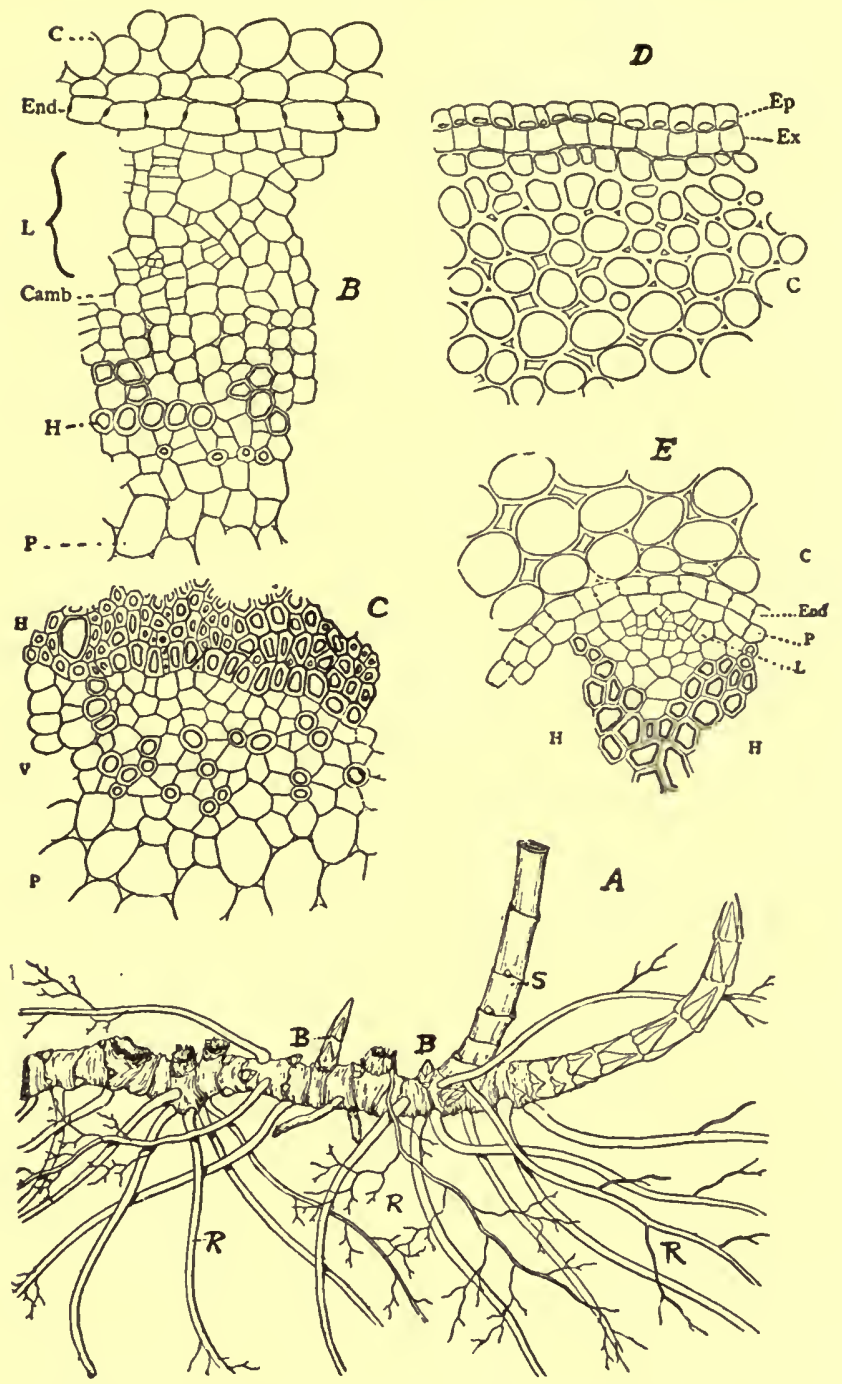

Fia. 278.-Leptandra: $A$, rhizome showing the roots $(R)$, buds $(B)$, and the base of an aerial stem. $B$, transverse section of inner portion of a stolon. $C$, cortex: End, endodermis; $L$, a deep strand of phloem having small sieve groups and thin-walled parenchyma; $C a m b$, cambium; $H$, primary tracheæ bordering on the pith $(P) . \quad C$, transverse section of part of the stele of the main rhizome: $H$, the secondary hadrome, showing numerous, thick-walled wood fibers and a single trachea. $D$, transverse section of outer portion of a root: $E p$, epidermal cells having thick outer walls; $E x$, hypodermis; $C$, cortex. $E$, transverse section of a portion of the root-stele: $C$, cortex; End, endodermis; $P$, pericambium; $L$, leptome; $H$, hadrome.-After Holm, Merck's Report, 1913, p. 61. 
Powder.-Dark brown; fragments of parenchyma containing a light brown or brownish-black resin, the latter frequently closely coherent with the starch grains in the cells and preventing the separation of the individual grains; starch grains numerous, nearly spheroidal or more or less polygonal and from 0.002 to $0.008 \mathrm{~mm}$. in diameter; tracheæ having spiral thickenings, with simple or bordered pores; wood fibers having thick lignified porous walls, resembling tracheids; fragments containing a pigment which is colored pink or violet upon the addition of solutions of hydrated chloral; epidermal cells of the root having thick lamellated walls.

Constituents.-An amorphous substance having an intensely bitter and nauseous taste, and yielding on hydrolysis a resinous material, and cinnamic and p-methoxycinnamic acids. Also a phytosterol which has been designated verosterol; a volatile oil; tannic acid; a sugar; a resin; d-mannitol, p-methoxycinnamic acid, and 3:4-dimethoxycinnamic acid. The last-mentioned acid had not previously been observed to occur in nature.-Power, Jour. Chem. Soc., 1910, p. 1944.

Verbasci Folia.-Herba Verbasci, Common Mullein Leaves.The leaves of Verbascum Thapsus (Fam. Scrophulariaceæ), a biennial herb naturalized from Europe and growing in fields and waste places in the eastern and central United States, often becoming a common weed. The leaves are gathered during summer, at the time of flowering of the plant, and carefully dried.

Description.-Leaves, elliptical, ovate, short petiolate, from 6 to $30 \mathrm{~cm}$. in length and 2.5 to $10 \mathrm{~cm}$. in breadth; summit acute or rounded, margin dentate, base decurrent, narrowed into the petiole; pale grayish-green and densely, wooly-hairy throughout; very thick, rather tough; inodorous; taste mucilaginous and slightly bitter.

Inner Structure.-Especially characteristic are the branched multicellular candelabra hairs, which consist of an upright, uniseriate main axis, from which whorls of from 2 to 8 ray-cells arise at certain points, the individual cells being from 0.150 to $0.400 \mathrm{~mm}$. in length and contain not. infrequently one or more air-bubbles; glandular hairs 2-celled, consisting of a stalk, from 0.030 to $0.065 \mathrm{~mm}$. in length and having a nearly spheroidal secreting cell at the summit; epidermal cells strongly undulate, stomata broadly elliptica, about $0.030 \mathrm{~mm}$. in length and having 3 to 5 neighboring cells.

Constituents. - The drug contains an amorphous bitter principle; mucilage; a trace of a volatile oil; and from 1 to 2 per cent of resin, part of which is soluble in ether.

Literature.-Holm, Merck's Report, 1914, p. 4. 
Verbasci Flores.-Mullein Flowers.-The flowers of Verbascum phlomoides and V. thapsiforme (Fam. Scrophulariaceæ), biennial herbs indigenous to central and southern Europe and western Asia, the former being naturalized to some extent from New England to Kentucky, and resembling V. Thapsus, but the leaves are nearly sessile and only slightly decurrent. The corollas, with the adhering stamens, are gathered during dry weather in July or August and carefully dried.

Description.-Corallas zygomorphic, either rotate and about $2 \mathrm{~cm}$. in breadth (V. thapsiforme), or somewhat funnel-shaped and about $1.5 \mathrm{~cm}$. in breadth (V. phlomoides); golden yellow when fresh, becoming yellowish-brown on drying; dorsal surface pubescent, the lobes being ovate, the 2 upper being smaller than the 3 lower; stamens inserted on the corolla, unequal, the 2 upper being longer and glabrous, while the 3 lower are smaller, the filaments being very pubescent; odor distinct, sweet; taste mucilaginous and sweet.

Inner Structure.-Lower surface having numerous stellate or branching multicellular hairs, and glandular hairs of several types: (a), having a 1- or more-celled stalk and a 1- or 2-celled glandular head; and $(b)$, glandular hairs resembling the Labiatæ; epidermal cells polygonal, the walls more or less undulate, in the lumina are numerous small yellowish chromoplastids; mucilage cells are distributed among the loose mesophyll; the hairs of the filaments of the short stamens are long, somewhat club-shaped, having a rounded summit, thin walls and frequently contain sphero aggregates of hesperiden. (Consult Kraemer's Applied and Economic Botany, p. 153.) Pollen grains, spheroidal, about $0.030 \mathrm{~mm}$. in diameter, frequently having a light red oily content, the outer walls being smooth and marked by 3 pores.

Constituents.-Invert sugar, 10.4 per cent; mucilage; volatile oil; a glucosidal coloring principle; cane sugar; and 5 to 6 per cent of ash.

Literature.-Vogl, Pharmakognosie, p. 128.

\section{RUBIACEÆ, OR MADDER FAMLY}

A large family of about 5500 species, most abundant in tropical regions but having representatives in nearly all parts of the world. They vary from herbs to trees; the leaves are usually opposite, stipulate and possess entire margins; the flowers are perfect, the corollas being gamopetalous and of a variety of forms; and the fruit is a capsule, berry, or drupe. Among the anatomical features the following 
are the more prominent. The secretory elements are of a number of forms: (a), glandular hairs, consisting of several rows of cells, may occur on the stipules; $(b)$, the epidermal cells occasionally contain a resinous secretion: $(c)$, cells containing resin are sometimes present in the mesophyll; $(d)$, secretory cells containing a brownish content are found in the leaves of a number of genera and are probably widely distributed; (e), elongated secretory sacs have been observed in Cinchona, Cascarilla, and other genera; and finally $(f)$, a group of secretory cells tending to form internal glands. The fibrovascular bundles are collateral; the walls of the tracheæ have either simple pores or scalariform perforations; and the wood fibers usually possess bordered pores, occasionally simple pores.. Calcium oxalate is secreted in a great many different forms, including rosette aggregates, sphenoidal microcrystals, small acicular crystals, raphides and styloids, occasionally in the form of large rhombohedra, or crystal fibers. The subsidiary cells of the stomata are arranged parallel to the pores. Non-glandular hairs are either unicellular or uniseriate. External glandular hairs are wanting.

Cinchona.-Cinchona Bark.-The dried bark of the stem and branches of various species of Cinchona (Fam. Rubiaceæ), trees indigenous to South America, and cultivated in the East Indies, Jamaica, Mexico and the Portuguese possessions in northwest Africa and from which countries the commercial supplies are obtained. There are two principal commercial varieties: (1) Red Cinchona, which is yielded by Cinchona succirubra, and its varieties, trees indigenous to southern Ecuador and northern Peru; and (2) Calisava BARK or yellow Cinchona, yielded by Cinchona Calisaya and its varieties, trees indigenous to Peru and Bolivia, and also obtained from C. Ledgeriana, a tree indigenous to Bolivia and cultivated in Java and the British Indies. When the trees are from 6 to 9 years old they possess the maximum amount of alkaloids and the bark of the trunk as well as the roots is removed and allowed to dry. The bark of the stem is used in the manufacture of galenicals, while the root bark is employed for the extraction of the alkaloids, especially quinine. Owing to the fact that light influences the production of quinine in the plant, it was formerly customary to cover the bark of the trunk with moss or other materials, and this is known as " mossed bark." For a time the cultivators followed the practice of removing the bark in alternate strips from the trunk, the denuded places being again covered, after which another layer of bark developed, very rich in alkaloids and known as "renewed bark." The outer bark, consisting of the periderm layer and some of the cortex, is flattened 
out and allowed to dry under pressure, and constitutes the "flat" (or Tambla) bark (Fig. 279). The older methods of cultivation have been entirely replaced by the selection of seeds from those plants that run high in alkaloids. The yield and quality of alkaloids in the bark are also improved by hybridizing the best trees irrespective of their species. For instance, much of the best Calisaya bark is obtained from Cinchona Ledger iana Calisaya.

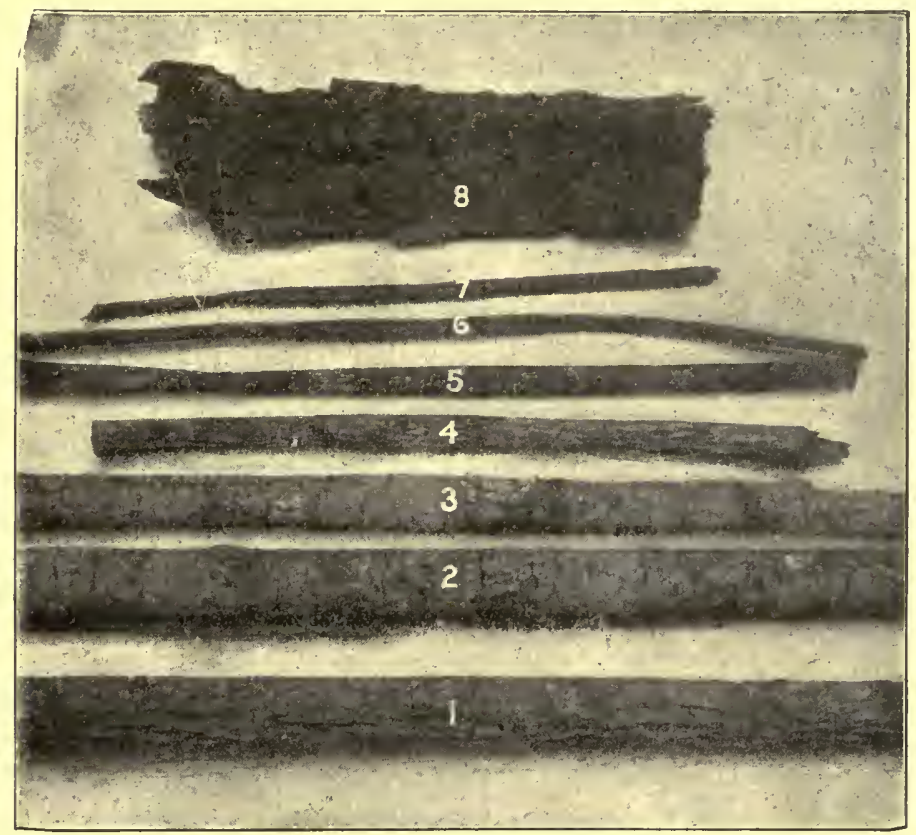

FIG. 279.-Commercial cinchona barks: 1, 2, 3, yellow cinchona having transverse fissures; 4,5 , red cinchona, the former showing longitudinal furrows; 6, 7, Loxa bark (Cinchona pallida); 8, flat bark (Cinchona calisaya). About $\frac{1}{5}$ actual size.

About 80 per cent of the Cinchona bark of commerce is now obtained from trees cultivated in Java. It is estimated that about $6,000,000 \mathrm{~K}$. of Cinchona bark are annually exported from this Island alone. India furnishes about 1,000,000 K. annually and about $1,000,000 \mathrm{~K}$. are produced by the remaining countries, Ceylon, Africa and South America.

Red Cinchona.--Usually in double quills or rolled pieces which are cut into lengths from 25 to $40 \mathrm{~cm}$. in length, 15 to $20 \mathrm{~mm}$. in diameter, bark 2 to $5 \mathrm{~mm}$. in thickness; outer surface reddish or dark 
brown, with grayish patches of foliaceous lichens, longitudinally wrinkled, with few usually widely separated transverse fissures; inner surface reddish-brown, distinctly striate; fracture smooth in

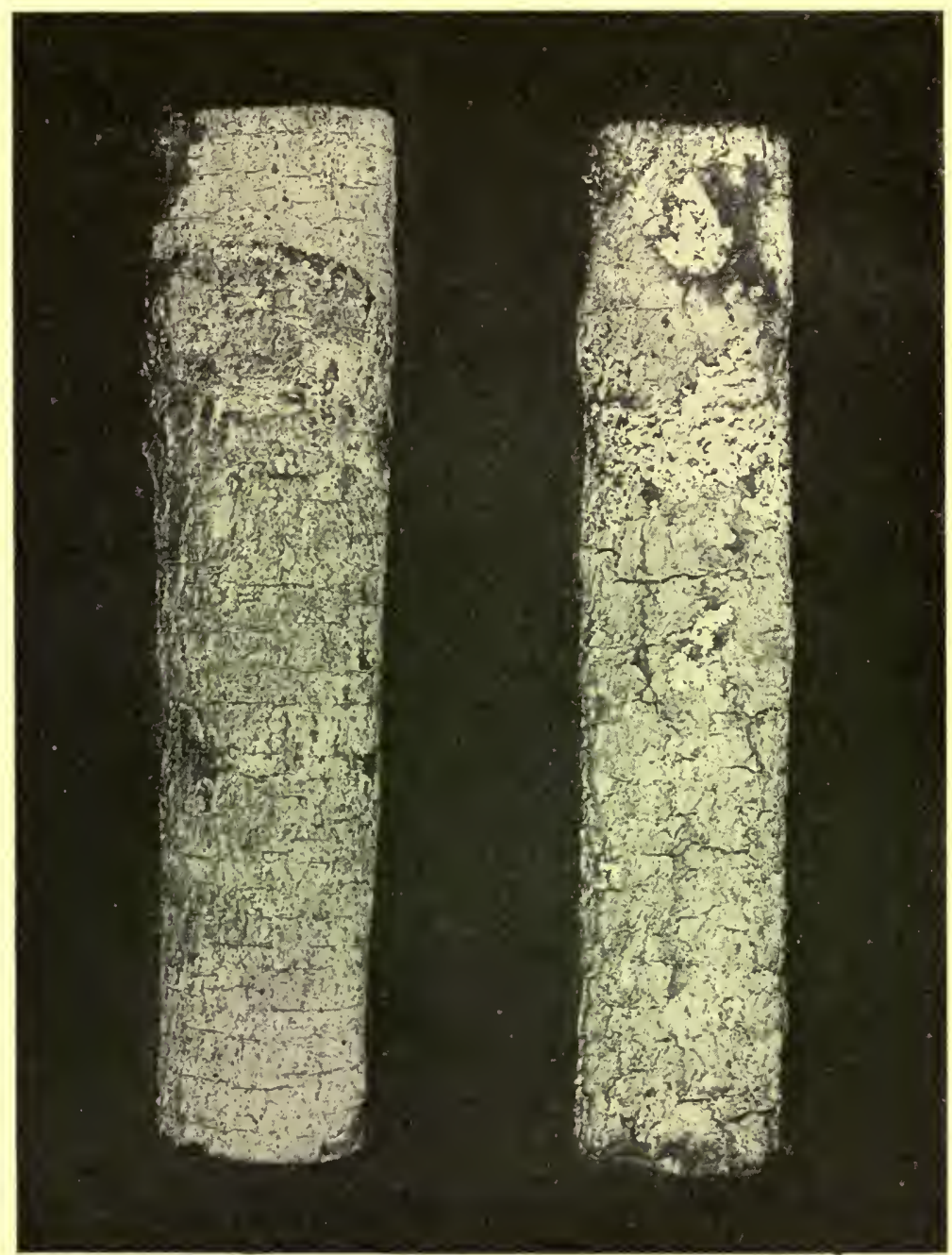

FIg. 280.-Typical specimens of Cinchona succiruba from Java. From a photograph by Powers-Weightman-Rosengarten Co., Philadelphia.

periderm, in inner bark with projecting bast fibers; odor distinct; taste bitter, astringent.

InNer Structure.-See Figs. 280 and 281. 
PowDer.-(Fig. 282.) Light brown; bast fibers spindle-shaped, yellowish, 0.030 to $1.350 \mathrm{~mm}$. in length, with thick, strongly lignified, lamellated walls having slit-like, oblique pores; sphenoidal microcrystals of calcium oxalate numerous; parenchymatous cells with

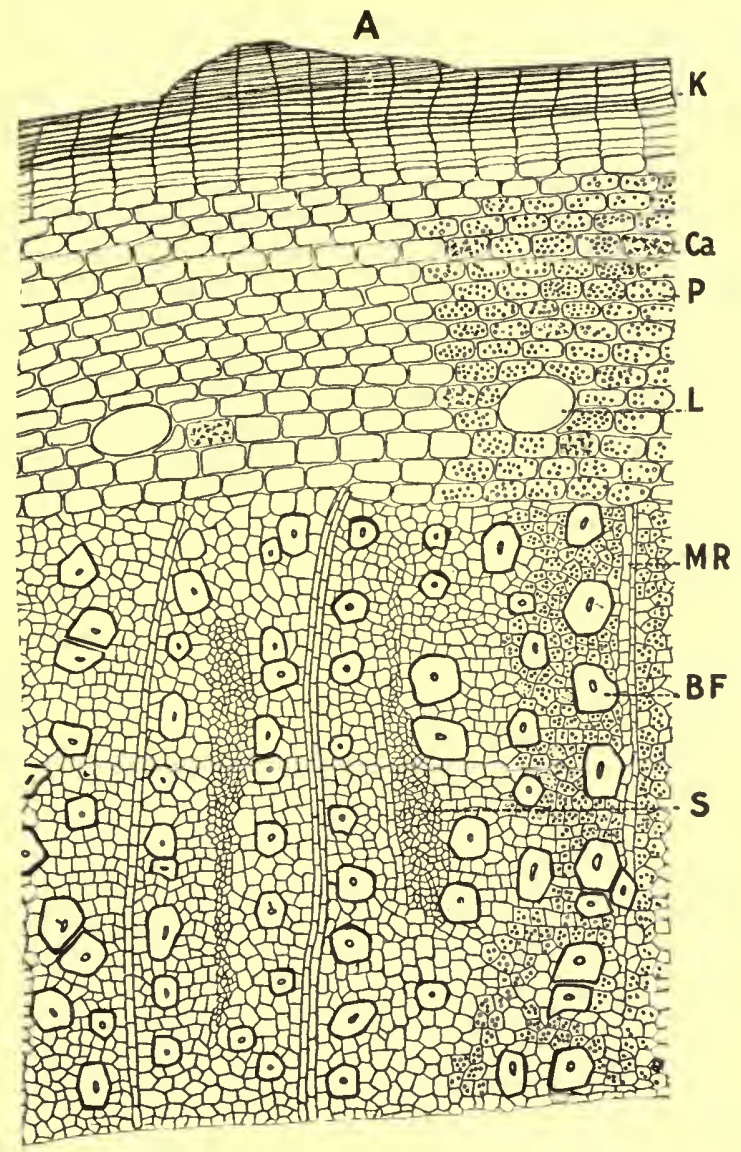

B

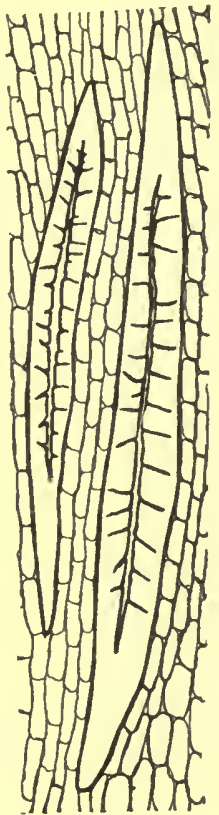

Frg. 281.-A, transverse section of red cinchona; $K$, cork; $C a$, sphenoidal microcrystals of calcium oxalate; $P$, parenchyma containing starch: $L$, secretory sacs containing gum, resin and tannin; $M R$, medullary rays; $B F$, bast fibers; $S$, sieve. $B$, longitudinal section of same showing two porous bast fibers surrounded by parenchyma cells.

reddish-brown tannin masses; starch grains relatively few, either single or 2- to 5-compound, the individual grains from 0.003 to 0.010 . $\mathrm{mm}$. in diameter.

The following test is distinctive for red Cinchona. If $\mathbf{1} \mathrm{gm}$. 
of powdered Cinchona is heated in a test tube, a tarry distillate is formed having a bright red color.

Calisaya Bark.-Gray or brownish-gray, with numerous patches of foliaceous lichens, having brownish-black and reddish-brown apothecia, and numerous transverse fissures, which give the bark a very characteristic appearance.

The trunk bark is comparatively thick, while renewed bark is comparatively smooth and uniform in color.

INNER Structure.-(Fig. 280.)

Powder.-(Fig. 282.) Reddish-brown; the tissues and cell contents resemble those of red Cinchona; the starch grains are

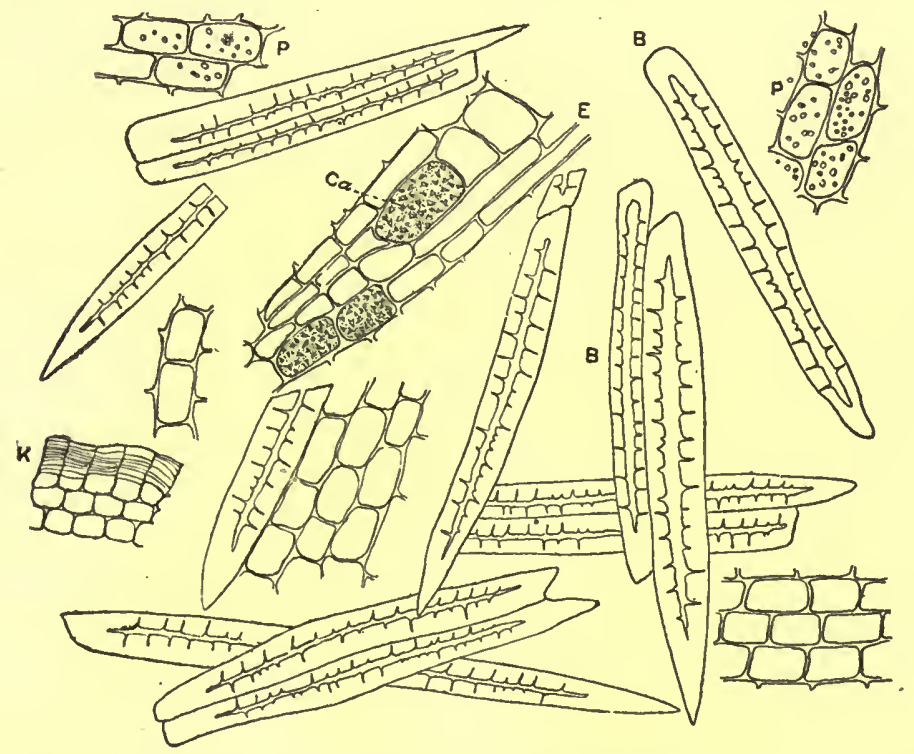

Fig. 282.-Cinchona: $B$, bast fibers; $C a$, sphenoidal microcrystals of calcium oxalate; $P$, parenchyma containing few small spheroidal starch grains; $E$, sieve; $K$, cork.

relatively more numerous and larger, occurring in spheroidal, planoconvex and polygonal grains, from 0.003 to $0.015 \mathrm{~mm}$. in diameter, also in 2- to 5-compound grains.

The following test is distinctive for yellow Cinchona. If $1 \mathrm{gm}$. of powdered calisaya bark is heated in a test tube, a tarry distillate is formed having a purplish-red color and a somewhat granular appearance.

A qualitative test having some quantitative value in determining the strength of powdered Cinchona is as follows: $0.500 \mathrm{gm}$. of pow- 
dered Cinchona (containing 7 per cent of total alkaloids, of which 3 per cent is quinine) is mixed with 500 c.c. of water and shaken occasionally in the course of several hours with 500 c.c. of water; 10 c.c. of this solution are then diluted with 50 c.c. of water, a few cubic centimeters of this solution, when swallowed, still give the characteristic taste of the alkaloids of Cinchona. One c.c. of this solution contains 0.000005 gramme of quinine, or about 0.000011 gramme of total alkaloids.

The following test is rather expeditious in obtaining an approximate idea of the quantitative value of the drug. One gm. of pow-

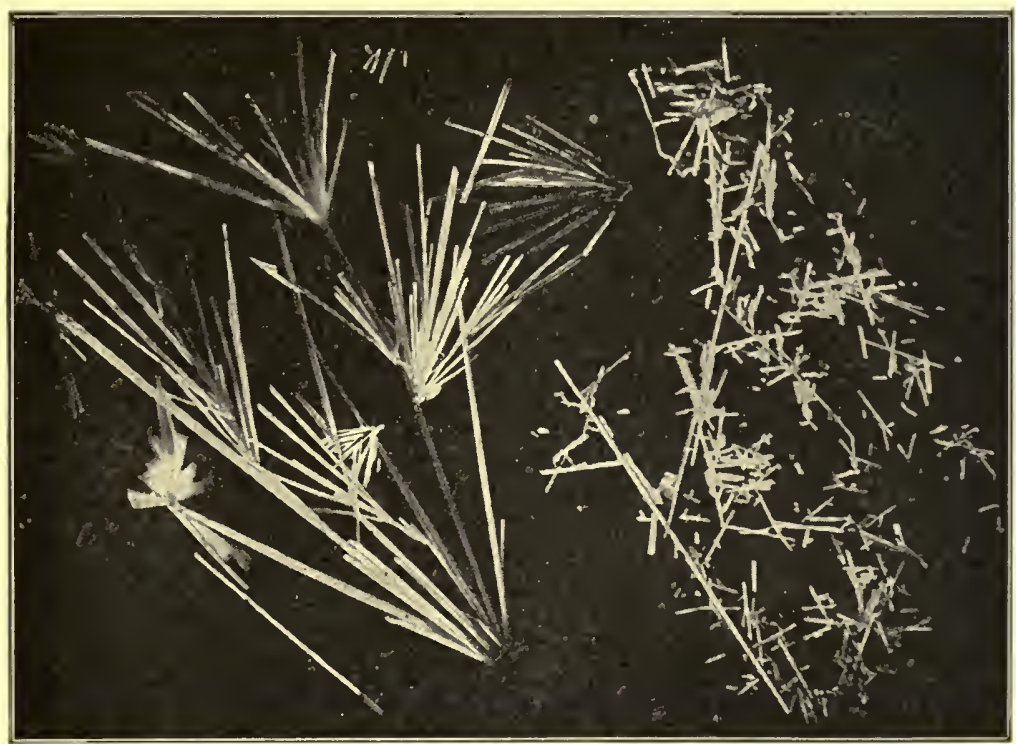

FIG. 283.-Quinine sulphate: Long orthorhombic needles from a dilute alcoholic solution.

dered Cinchona (containing 7 per cent of total alkaloids, of which 3 per cent is quinine) is macerated over night with 10 c.c. of a modified Prollius solution. The solution is filtered into a small separating funnel and 5 c.c. of a dilute sulphuric acid ( 0.5 per cent) solution are added. After agitation and allowing to stand until the two liquids separate, the aqueous solution containing the alkaloids is separated. This solution, which is slightly fluorescent, is rendered neutral with dilute ammonia water, and one drop contains about 0.00015 gramme of quinine. (1) One drop of this solution is mixed with nine drops of water, and upon the addition of a drop of bromine water followed by an excess of ammonia water the thalleioquin reaction readily takes 
place. (2) If one drop of the neutral solution be mixed with four drops of water and a drop of bromine water, followed by a drop of a solution of ferrocyanide of potassium, and then an excess of ammonia water, a red coloration is immediately produced, which disappears shortly.

Constituents.-The alkaloids are chiefly formed in the parenchyma cells of the middle layers of the bark. Cinchona contains a large number of alkaloids, of which the most important are quinine, quinidine, cinchonine and cinchonidine. The total alkaloids amount to about 6 or 7 per cent, of which from one-half to two-thirds is qui-

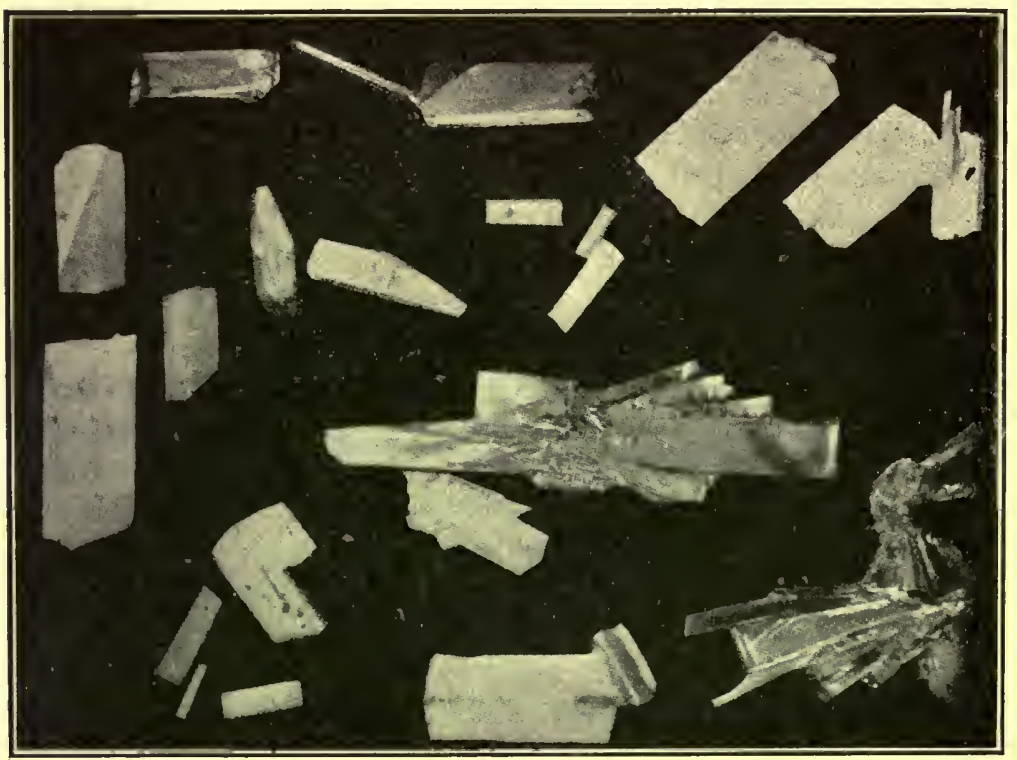

FIG. 284.-Cinchonine sulphate: Orthorhombic crystals from a saturated aqueous solution.

nine in the yellow barks, whereas, in the red barks, cinchonidine exists in greater proportion. Quinine occurs in small crystals which are sparingly soluble in water, soluble in alcohol and readily form crystallizable salts with acids. On the successive addition of dilute sulphuric acid, bromine or chlorine water and ammonia water, the solution becomes of an emerald-green color (thalleioquin test). QuiNidine, an isomer of quinine, crystallizes in rhombohedra or monoclinic prisms which are nearly insoluble in water and otherwise conforms to the characteristics given for quinine. The solutions of quinidine are, however, dextrorotatory, while those of quinine are 
lævorotatory. Cinchonine separate sin lustrous prisms or needle 5 which are nearly insoluble in water, and does not give the thalleioquin test, but forms a white precipitate upon the addition of dilute sulphuric acid, bromine water and ammonia. Cinchonidine crystallizes in prisms and resembles cinchonine in many of its properties. Its solutions, however, are lævorotatory, while those of cinchonine are dextrorotatory.

The other important alkaloids of Cinchona which have been separated are: Quinamine, hydroquinine, hydroquinidine, hydrocinchonidine and homocinchonidine. Of the other alkaloids which have been isolated the following may be mentioned: Conquinamine, paranine, paracine and quinamidine. Among the other constituents of Cinchona are: Kinic acid from 5 to 9 per cent, which forms colorless rhombic prisms and yields a sublimate consisting of golden crystals of kinone (quinone) on treatment with manganese peroxide and sulphuric acid; kinovin (quinovin) an amorphous, bitter glucoside, to the amount of 0.11 to 1.74 per cent; cinchotannic acid from 2 to 4 per cent, which decomposes into the nearly insoluble cinchona red, occurring in red barks to the extent of 10 per cent; considerable starch; calcium oxalate in the form of sphenoidal microcrystals; and ash about 3 per cent. The red color in cinchona bark is due to an oxydase similar to that which causes the darkening of fruits when cut. If the fresh bark is heated in boiling water for 30 minutes and then dried it does not become red.

Quinine Sulphate $\left[\left(\mathrm{C}_{20} \mathrm{H}_{24} \mathrm{~N}_{2} \mathrm{O}_{2}\right)_{2} \cdot \mathrm{H}_{2} \mathrm{SO}_{4}+7 \mathrm{H}_{2} \mathrm{O}\right]$.

The alkaloid quinine $\left(\mathrm{C}_{20} \mathrm{H}_{24} \mathrm{~N}_{2} \mathrm{O}_{2}\right)$ is the methoxy-derivative of cinchonine and separates in anhydrous crystals from hot aqueous solutions. If the hot solution, in dilute alcohol, is kept for some time at $30^{\circ} \mathrm{C}$, then on cooling long silky needles form. There is another modification, occurring as a flaky powder and containing three molecules of water of crystallization $\left(\mathrm{C}_{20} \mathrm{H}_{24} \mathrm{~N}_{2} \mathrm{O}_{2}+3 \mathrm{H}_{2} \mathrm{O}\right)$, which is official. Some authors consider, however, that there is only one molecule of water of crystallization in this hydrous salt. ${ }^{1}$ The hydrous salt has a M. P. of $57^{\circ}$ while the anhydrous crystals melt at $175^{\circ}$. Quinine is a strong base, forming, with acids, basic and neutral salts. The neutral sulphate is largely used and is here considered.

There are several modifications of quinine sulphate: (1) The neutral sulphate containing eight molecules of water of crystallization $\left[\left(\mathrm{C}_{20} \mathrm{H}_{24} \mathrm{~N}_{2} \mathrm{O}_{2}\right)_{2} \cdot \mathrm{H}_{2} \mathrm{SO}_{4}+8 \mathrm{H}_{2} \mathrm{O}\right]$, is obtained upon neutralizing the base with sulphuric acid and crystallizing from hot water. Upon exposing the former over sulphuric acid it loses six molecules

${ }^{1} \mathrm{O}$. A. Oesterle, Grundriss der Pharmakochemie. 
of water of crystallization giving $\left[\left(\mathrm{C}_{20} \mathrm{H}_{24} \mathrm{~N}_{2} \mathrm{O}_{2}\right)_{2} \cdot \mathrm{H}_{2} \mathrm{SO}_{4}+2 \mathrm{H}_{2} \mathrm{O}\right]$. This same salt is formed upon re-crystallizing (1) from hot alcoholic solutions. (3) The acid sulphate or bisulphate contains seven molecules of water of crystallization $\left(\mathrm{C}_{20} \mathrm{H}_{24} \mathrm{~N}_{2} \mathrm{O}_{2} \cdot \mathrm{H}_{2} \mathrm{SO}_{4}+7 \mathrm{H}_{2} \mathrm{O}\right)$, is also official, and has been described. ${ }^{1}$ (4) There is also a tetrasulphate of quinine having the formula $\left(\mathrm{C}_{20} \mathrm{H}_{20} \mathrm{~N}_{2} \mathrm{O}_{2} \cdot 2 \mathrm{H}_{2} \mathrm{SO}_{4}+7 \mathrm{H}_{2} \mathrm{O}\right){ }^{2}$

At $25^{\circ} \mathrm{C}$. one part of quinine sulphate (containing $8 \mathrm{H}_{2} \mathrm{O}$ ) is soluble in 720 parts of water; 86 parts of alcohol; 400 parts of chloroform. It is readily soluble in a mixture of chloroform (2 parts) and absolute alcohol (1 part); and one part is soluble in 36 parts of glycerin at $25^{\circ} \mathrm{C}$. It is only sparingly soluble in ether. When erystallized from a dilute alcoholic solution, upon a microscopical slide, the individual needles may attain a length of $4 \mathrm{~mm}$. (Fig. 226).

Allied Plants.-Loxa or Huanco (Cinchona pallida) bark is obtained from Cinchona officinalis, a shrub indigenous to Ecuador, which was the species first discovered. The plant is cultivated in nearly all the large cinchona plantations and yields a bark (Fig. 279) that contains 1 to 4 per cent of total alkaloids, from one-half to two-thirds of which is quinine.

Cuprea Bark is obtained from Remijia Purdieana and R. pedunculata, of central and southern Colombia. It has a copper-red color, is hard, compact and heavy, contains numerous transversely elongated stone cells and 2 to 6 per cent of alkaloids, of which one-third may be quinine. Cinchonidine has never been isolated from this bark. Cuprea bark also contains caffeate of quinine and caffeic acid, of which there is about 0.5 per cent and which closely resembles the same acid obtained from caffeotannic acid in coffee.

Literature.-Howard, Bull. Imperial Inst., 1918, 16, Pt. 3.

IpeCacuanha.-Ipecac.-The dried root of Cephaëlis Ipecacuanha [Uragoga Ipecacuanha (Fam. Rubiaceæ)], a shrub indigenous to Brazil, and sparingly cultivated near Singapore. The commercial supply is obtained from Matta Grosso, Brazil, and is known as Rio, Brazilian or Para Ipecac. The roots are gathered during the dry season and dried as quickly as possible, being placed in the sun during the day and covered at night, so that in the course of 2 or 3 days they are ready for market.

The roots of Cephälis acuminata, a plant closely related to Cephaëlis Ipecacuanha and indigenous to the northern and central portion of the United States of Colombia, are exported from Car-

${ }^{1}$ Th. Hjortdahl, Zeitsch. f. Krystallog., 1879, p. 303; see also Hahn, Arch. d. Pharm., 1859, p. 148.

${ }^{2}$ Brühl, Die Pflanzen-Alkaloide, p. 182. 
tagena and Savanilla, and are known commercially as Cartagena Ipecac. Two commercial sub-varieties of Ipecac are also recognized, depending upon the proportion of wood and bark in the drug. Specicimens in which the wood is more pronounced are known as "wiry roots," while those which are characterized by a thicker bark are called "fancy" or "Bold " roots.

Rio or Braziliar. Ipecac.-Cylindrical, more or less tortuous, 5 to $15 \mathrm{~cm}$. in length, 1 to $5 \mathrm{~mm}$. in diameter; externally dark brown, irregularly annulate, sometimes transversely fissured, having occasional rootlets or rootlet-scars; fracture of bark brittle, of the wood tough; internally, bark light brown, 0.5 to $1 \mathrm{~mm}$. in thickness, easily separable from the dark-yellow, non-porous wood; odor slight; taste bitter, acrid.

Stems cylindrical, attaining a length of $10 \mathrm{~cm}$. and a thickness of $2 \mathrm{~mm}$., dark brown, finely longitudinally wrinkled and having a few elliptical scars.

Inner Structure.--See Fig. 285.

Powder.-(Fig. 286.) Light brown, or dark yellow; starch grains numerous, 2- to 6 -compound, the individual grains spheroidal or polyhedral, from 0.003 to $0.017 \mathrm{~mm}$. in diameter; calcium oxalate in raphides from 0.015 to $0.040 \mathrm{~mm}$. in length; tracheids having either bordered pores or oblique slit-like pores. The stem bark shows a few, slightly elongated stone cells, from 0.030 to $0.045 \mathrm{~mm}$. in length, having thick lignified walls and simple, branching pores.

An aqueous infusion of ipecac gives a copious precipitate with potassio-mercuric iodide solution; a hydro-alcoholic infusion gives a yellow precipitate with picric acid, or if hydrochloric acid and potassium chlorate are added, the solution becomes orange-red with a reddish fluorescence.

Cartagena Ipecac closely resembles the Rio or Brazilian ipecac, but the roots are uniformly thicker (4 to $7 \mathrm{~mm}$. in diameter), of a brownish-gray color, and the annulations are less pronounced.

The stems are usually more slender, 5 to $10 \mathrm{~cm}$. in length, 1 to $1.5 \mathrm{~mm}$. in diameter, nearly smooth or longitudinally wrinkled; bark $0.1 \mathrm{~mm}$. in thickness, with bast fibers either single or in groups; pith distinct, $0.5 \mathrm{~mm}$. in diameter.

In the powder of Cartagena Ipecac the starch grains are uniformly larger, being from 0.004 to $0.015 \mathrm{~mm}$. in diameter, otherwise the tissues and cell contents resemble those of Rio Ipecac.

Constituents. - Ipecac contains three alkaloids ( 2 to 3 per cent)emetine, cephaëline and psychotrine, that are said to be contained chiefly in the bark, which makes up about 90 per cent of the drug. 

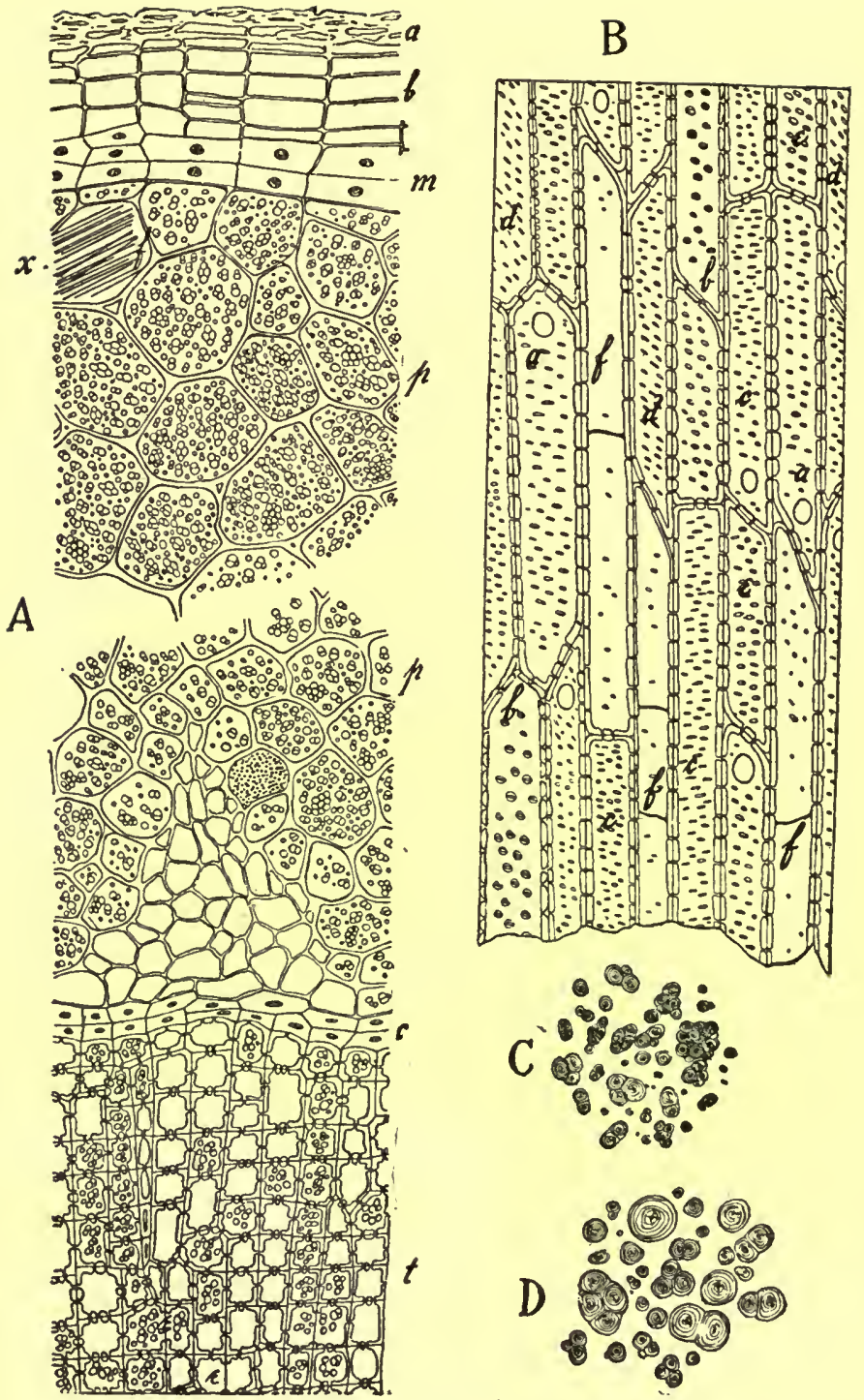

Fig. 285.-Ipecac: $A$, transverse section of Rio ipecac showing outer layers of cork $(a)$; cork cells $(b)$; phellogen $(m)$; parenchyma containing starch $(p)$; raphides $(x)$; cambium $(c)$; tracheids $(t)$. $B$, longitudinal section of a portion of the wood showing tracheal-like tracheids $(a)$; tracheids with bordered pores $(b)$, linear pores $(c)$ and oblique linear pores $(d)$; transition tracheids $(e)$; tracheids with delicate pores $(f) . C$, starch grains of Rio ipecac. $D$, slightly larger starch grains of Cartagena ipecac.-After Schneider. 
Emetine (methyl-cephaëline) is white, amorphous, forms crystalline salts, becomes darker on exposure to light, and with Froehde's alkaloidal reagent (consisting of $0.01 \mathrm{gm}$. of sodium molybdate in 1 c.c. of concentrated sulphuric acid) becomes dirty green, changing to a bright green on the addition of hydrochloric acid. Cephaëline occurs in silky needles, forms amorphous salts and is quite unstable, becoming yellow even in the dark. With Froehde's reagent, cephaëline changes to purple, becoming deep blue on the addition of hydro-

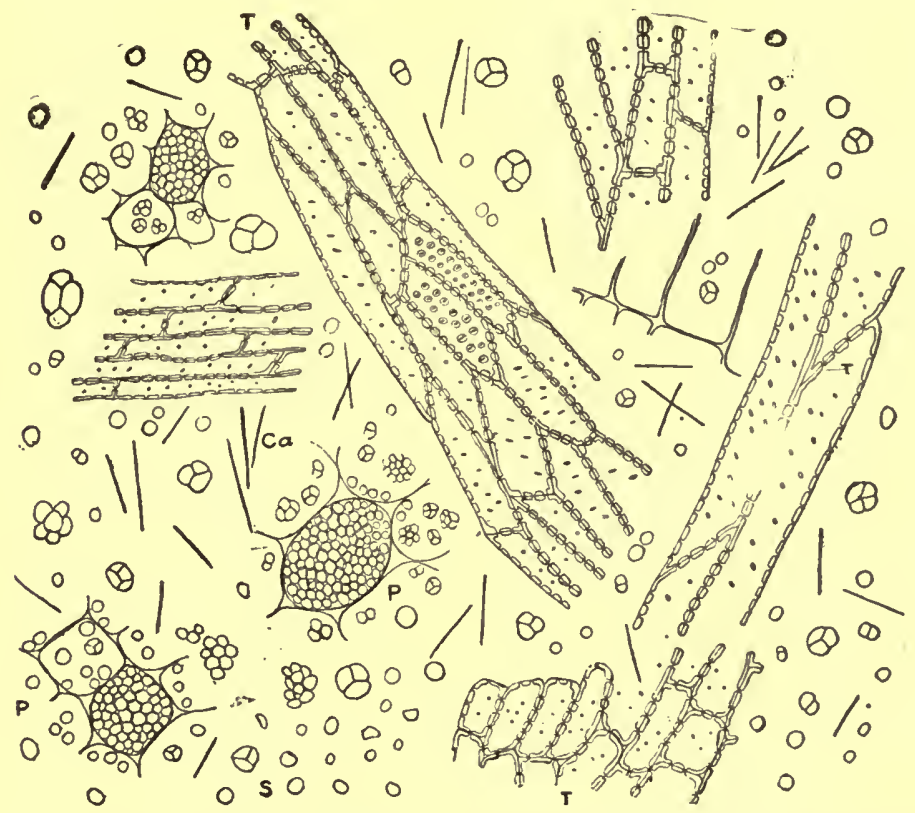

FIG. 286.-Rio ipecac: $T$, tracheids; $P$, parenchyma containing starch; $S$, starch grains; $C a$, raphides of calcium oxalate.

chloric acid. Psychotrine is amorphous, quite unstable, and becomes purplish with Froehde's reagent; changing to green on the addition of hydrochloric acid. Ipecac also contains 2.25 per cent of ipecacuanhic acid, with which the alkaloids are combined; a glucoside resembling saponin; about 40 per cent of starch; and calcium oxalate in the form of raphides.

The total amount of alkaloids in Rio and Cartagena ipecac not only varies, but there is a difference in the proportions of emetine the expectorant alkaloid) and cephaëline (the emetic alkaloid); in Rio ipecac the proportion is one-third cephaëline to two-thirds eme- 
tine, while in Cartagena ipecac there are four-fifths cephaëline to onefifth emetine.

Allied Plants.-A number of drugs, some of which resemble ipecac, sometimes find their way into commerce, and, while they all possess emetic properties, none of them contain emetine. The following drugs obtained from plants of the Rubiaceæ have been substituted for Ipecac. Undulated (or Farinaceous) Ipecac from Richardsonia scabra, a plant growing in tropical and sub-tropical America, is an undulate, annulate rost, the bark of which is nearly as thick as the yellowish, soft wood. Striated ipecac from Cephaëlis emetica, a plant growing in South America, is a dark purplish-brown root, with a few transverse fissures and a thick bark in which starch is absent. Several members of the Rosaceæ contain emetic principles and the roots of the following plants growing in the United States have been substituted for Ipecac: American Ipecac [Gillenia (Porteranthus) stipulata]; the root is annulate, and somewhat resembles ipecac, but has a thinner bark with numerous resin cells; and Indian Physic (G. trifoliata), the roots of which resemble those of American Ipecac but are not annulace.

The roots of several of the plants of the Euphorbiaceæ are used as emetics. Ipecac spurge is the root of Euphorbia Ipecacuanha, a plant common in sandy soil of the eastern United States. The roots are $30 \mathrm{~cm}$. or more in length, about $1 \mathrm{~cm}$. in thickness, nearly cylindrical, light brown; internally the wood is yellow and the bark white, having numerous laticiferous vessels. The taste is sweet, somewhat acrid and bitter. Ipecac spurge contains crystalline resin, euphorbon; probably a glucoside, and starch. Purging or Emetic root is obtained from the large flowering spurge (Euphorbia corollata), a plant found in sandy soil east of the Mississippi. The root resembles the Ipecac spurge but is dark brown or brownish-black externally, and the constituents are similar (p. 398).

The following emetic drugs are obtained from plants belonging to the Violaceæ: Ionidium, or the so-called White Ipecac, is obtained from the root of Hybanthus Ipécacuanha of Brazil. It is easily distinguished from ipecac by being somewhat branched, larger and having a thin bark. An emetic principle is also present in the roots of other species of Hybanthus, the root of Anchieta salutaris of Brazil, and possibly also in the rhizome of Viola odorata.

A few emetic drugs are also obtained from plants belonging to the Meliaceæ. The alkaloid naregamine is found in the Goanese Ipecac derived from Naregamia alata of the East Indies. The alkaloid rusbyine is found in the bark of Cocillana (Guarea Rusbyi) of 
Bolivia, a drug (see p. 383) having properties similar to those of Ipecac. The roots of several of the Polygalas (Fam. Polygalaceæ) possess emetic properties, viz.: P. scoparia of Mexico and P. angulata of Brazil (see p. 389). The root of the latter plant, which is also known as White Ipecac (Poaya blanca) resembles senega, is free from starch and contains considerable saponin.

Substitutes of Ipecac.-The root of Richardsonia scabra has simple and compound starch grains from 0.020 to $0.040 \mathrm{~mm}$. in diameter; the root of Triosteum perfoliatum and the bark of Naregamia alata contain starch grains and rosette aggregates of calcium oxalate, the latter containing in addition orange-red secretion cells; the root of Heteropteris pauciflora (Fam. Malpighiaceæ) is free from starch, but contains rosette aggregates of calcium oxalate, brown pigment cells and stone cells.

Literature.-Schneider, Jour. of Pharmacology, 1897, p. 1; Paul and Cownley, Amer. Jour. Phar., 1901, pp. 57 and 107; Zörnig, Arzneidrogen.

Semen Coffex.-Coffee Seed or Coffee Bean.-The ripe seeds of Coffea arabica (Fam. Rubiaceæ), a small evergreen tree or shrub with lanceolate, acuminate, entire, slightly coriaceous, dark green, short-petiolate leaves, which are partly united with the short interpetiolar stipules at the base. The flowers are white, fragrant, and occur in axillary clusters. The fruit is a small, spheroidal or ellipsoidal drupe with two locules, each containing one seed, or coffee bean. The coffee plant is indigenous to Abyssinia and other parts of eastern Airica, and is widely cultivated in tropical countries, notably in Java, Sumatra, Ceylon, and Central and South America, particularly Brazil, over 600,000 tons being produced annually in the latter country. The yield of one tree is between 0.5 and $5 \mathrm{~K}$. There are two methods of freeing the seeds from the parchment-like endocarp: (a), the fruits are allowed to dry and are then broken; in (b), which is known as the wet method, the sarcocarp is removed by means of a machine, and the two seeds with the parchment-like endocarp are allowed to dry in such a manner as to undergo a fermentation, and after drying the endocarp is removed. The green seeds are sent into commerce and roasted. This process causes the seeds to swell, changes their color to dark brown, and develops the characteristic odor and flavor due to the formation of caffeol and other substances.

Description.-Elliptical, plano-convex, about $10 \mathrm{~mm}$. in length and $8 \mathrm{~mm}$. in width; externally dark brown, smooth, having on the flattened side a longitudinal or somewhat curved cleft, due to the 
folding of the endosperm, and in which is contained the parchmentlike seed-coat; hard, easily broken, and containing at the basal portion of the endosperm, a small embryo; odor distinct, aromatic; taste pleasantly bitter.

Inner Structure.-Seed-coat fragmentary on the surface of the seeds, and parchment-like in the groove and characterized by the presence of numerous stone cells, occurring singly or in small groups, from 0.100 to $1 \mathrm{~mm}$. in length and 0.015 to $0.050 \mathrm{~mm}$. in breadth, the cells varying in size and in form, and possessing relatively thick, porous and strongly lignified walls; endosperm large, composed of irregularly thickened, porous cellulose walls, and containing sugar, tannic acid, a fixed oil, caffeine and occasionally aleurone grains; embryo small and usually bursts through the endosperm, on soaking the green seeds overnight.

Powder.-Dark brown; characteristic fragments of seed-coat made up of parenchyma and spindle-shaped stone cells, from 0.2 to $1 \mathrm{~mm}$. in length and from 0.015 to 0.050 in width, the latter occurring singly or in pairs, having more or less thickened porous walls. The cells of the endosperm have brownish-colored, porous walls, about $0.010 \mathrm{~mm}$. in thickness, and contain oil, aleurone and starch. Ground coffee varies in the fineness of the particles, which are lighter than water and float on the surface. This is an important distinction between genuine coffee and the "substitutes" or "imitation" products which sink on being mixed with water.

Constituents.-Coffee seeds contain from 1 to 2 per cent of caffeine; from 3 to 5 per cent of tannin; about 15 per cent of glucose and dextrin; 10 to 13 per cent of a fatty oil consisting chiefly of olein and palmitin; 10 to 13 per cent of proteins; and yield 4 to 7 per cent of ash. The official caffeine is derived in part from coffee seeds. For description, tests and methods of detecting caffeine, see p. 436.

In the roasting of coffee there is a change in the physical character of the seeds, as well as a change in some of the constituents The aroma is supposed to be due to an oil known as coffeol, which is said to be a methyl ether of saligenin.

Coffee increases in weight in storage. In paper bags and cartons, the maximum increase in weight is reached in the fall months. During the winter months there is a loss in weight, while during the spring and summer there is little change. (Doolittle and Wright, Amer. Jour. Pharm., 1915, p. 524.)

Coffee Hulls, also known as Sultan or Sacca coffee, are sometimes si bstituted for coffee. These consist of the outer layer of the pericarp and are characterized by a layer of somewhat curved, elongated 
cells which lie close to one another (palisade cells), and the walls of which are mucilaginous and stained by safranin and methylene blue, the yellowish protoplasmic contents not being affected.

Carob Bean [Ceratonia Siliqua (Fam. Leguminosæ)] in a ground condition is not only used as cattle food, but has been substituted for coffee. It is distinguished by the sclerenchymatous and crystal fibers, and the cells of the mesocarp, which contain reddish-brown, spiral masses that are colored a deep violet or blue on heating with solutions of the alkalies.

Coffee Substitutes.-The following are commonly employed: Chicory; a number of the cereals and cereal products (Fig. 21). Among leguminous seeds: soja beans (p. 346), lupines, peas, beans and the seeds of Cassia fotida. In addition, under the name of Mogdad Coffee, the seeds of Cassia occidentalis are used in various tropical countries. The seeds are free from starch and the cells of the endosperm are thick-walled and contain a brown protein substance.

Of Coffee adulterants the following may be mentioned: Ground ivory nut (Phytelephas macrocarpa), which is distinguished by the thick-walled cells of the endosperm; and the ground kernels of the acorns of several species of Quercus, which are readily identified by the elongated, more or less swollen, distorted starch grains which have a prominent, elongated cleft in the middle (Fig. 72).

Literature.-Griebel, Bot. Abstracts, 1919, 1, p. 219.

\section{CAPRIFOLIACEE, OR. HONEYSUCKLE FAMILY}

A small family of plants, mostly indigenous to the northern hemispheres, and of a great diversity of forms, as regards habit, leaves, flowers and fruits. The cork is usually superficial, except in Sambucus and Viburnum, where it is formed inside the bast fibers. Secondary bast fibers are developed in nearly all of the genera, excepting Viburnum (consult Figs. 287 and 288). The tracheæ usually possess scalariform perforations; the wood fibers have bordered pores; and the medullary rays are mostly narrow. Internal secretory organs are wanting, except in Sambucus, where tannin secretory cells occur. The non-glandular hairs are unicellular stellate, peltate or tufted. The glandular hairs are of 2 kinds: (a), having a uniseriate stalk and a spheroidal or ellipsoidal secreting summit, as in Lonicera, Sambucus, Triosteum and Viburnum; or (b), peltate having a unicellular stalk and shield of 3 to 7 cells as in Diervilla. 
Viburnum Prunifolium.-Black Haw Bark.-The dried bark of the root of Viburnum prunifolium or of V. Lentago (Fam. Caprifoliaceæ), shrubs or small trees indigenous to the eastern and central United States. The root bark is more highly esteemed than that of the stem and branches.

Stem Bark.-In transversely curved pieces, or irregular oblong chips, 1.5 to $6 \mathrm{~cm}$. in length, 0.5 to $1.5 \mathrm{~cm}$. in diameter, bark, 0.5 to $1.5 \mathrm{~mm}$. in thickness; outer surface brownish-red or grayish-brown, longitudinally wrinkled, periderm occasionally exfoliated, with occasional grayish patches of foliaceous lichens and numerous lenticels; inner surface yellowish- or reddish-brown, longitudinally striate; fracture short, periderm brownish-red, inner bark with numerous light yellow groups of stone cells; odor slight; taste astringent and bitter.

Root Bark.-Somewhat resembling the stem bark, but smoother externally, without lichens and having fewer lenticels.

InNer Structure.-See Fig. 287.

Powder.-Dark brown; calcium oxalate in rosette aggregates or occasionally in rhombohedra, from 0.015 to $0.035 \mathrm{~mm}$. in diameter; crystal fibers usually having rosette aggregates and occasional monoclinic prisms of calcium oxalate; stone cells large, irregular, thickwalled and strongly lignified, bast fibers comparatively few, lignified.

Constituents.-A bitter, somewhat resinous principle, viburnin; valerianic (viburnic) acid and other organic acids; resin; tannin; calcium oxalate; ash about 10 per cent.

Adulterants.-The barks of one or more allied species, especially Viburnum dentatum, are said sometimes to be substituted for the official bark.

Viburnum Opulus.-Cramp Bark.-The dried bark of the stem and branches of Viburnum Opulus (Fam. Caprifoliaceæ), a shrub with nearly erect branches indigenous to the northern United States and southern Canada, and also found growing in Europe and Asia.

Description.--In transversely curved pieces, occasionally in single quills, from 1 to $10 \mathrm{~cm}$. in length and 5 to $10 \mathrm{~mm}$. in width; bark 0.5 to $1.5 \mathrm{~mm}$. in thickness; outer surface light grayish- to blackishbrown; irregularly wrinkled, somewhat scaly, frequently with fine longitudinal and transverse fissures, and numerous prominent brownish lenticels; inner surface light yellowish or reddish-brown, fine'y longitudinally striate, fracture short, irregular; inner surface light brown, the middle bark marked by a light-yellow ring enclosing small groups of bast fibers; odor distinct, like valerianic acid; pleasantly bitter.

Inner Structure.-See Fig. 288. 
Powder.-Light grayish-brown; calcium oxalate in rosette aggregates from 0.010 to $0.040 \mathrm{~mm}$. in diameter; starch grains from 0.002 to $0.006 \mathrm{~mm}$. in diameter, usually present in parenchyma and cells of medullary rays; fragments of parenchyma containing a

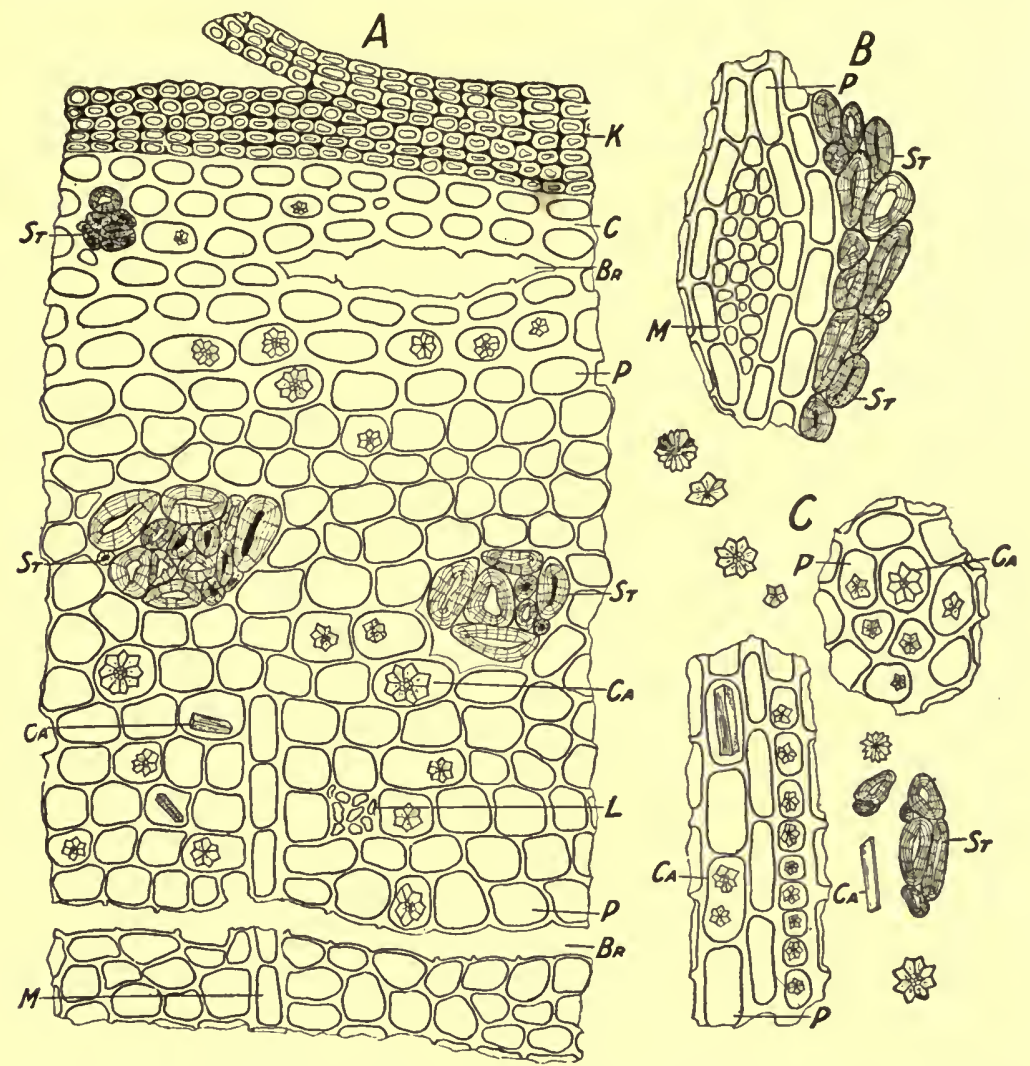

FIg. 287.-Viburnum Prunifolium: $A$, transverse section of a part of the bark: $K$, cork; $C$, cells of primary cortex; $S t$, stone cells, which are distributed not only in the cortical area but in the strands of phloem between the medullary rays; $B r$, rifts between the parenchyma cells, which in the inner portion causes a layering of the bark; $C a$, calcium oxalate usually occurring in the form of rosette aggregates; $L$, groups of sieve cells; $P$, parenchyma; $M$, a medullary ray. $B$, tangential section showing the bi-convex groups of medullary rays and surrounding tissues. $C$, fragments seen in the powdered drug, the letters as in A.-Drawing by Haase.

yellowish-brown amorphous substance; primary bast fibers occasional, having thick more or less undulate walls, which are slightly lignified, the ends being somewhat obtuse; fragments of cork consisting of more or less rectangular cells, having thick, lignified walls. 


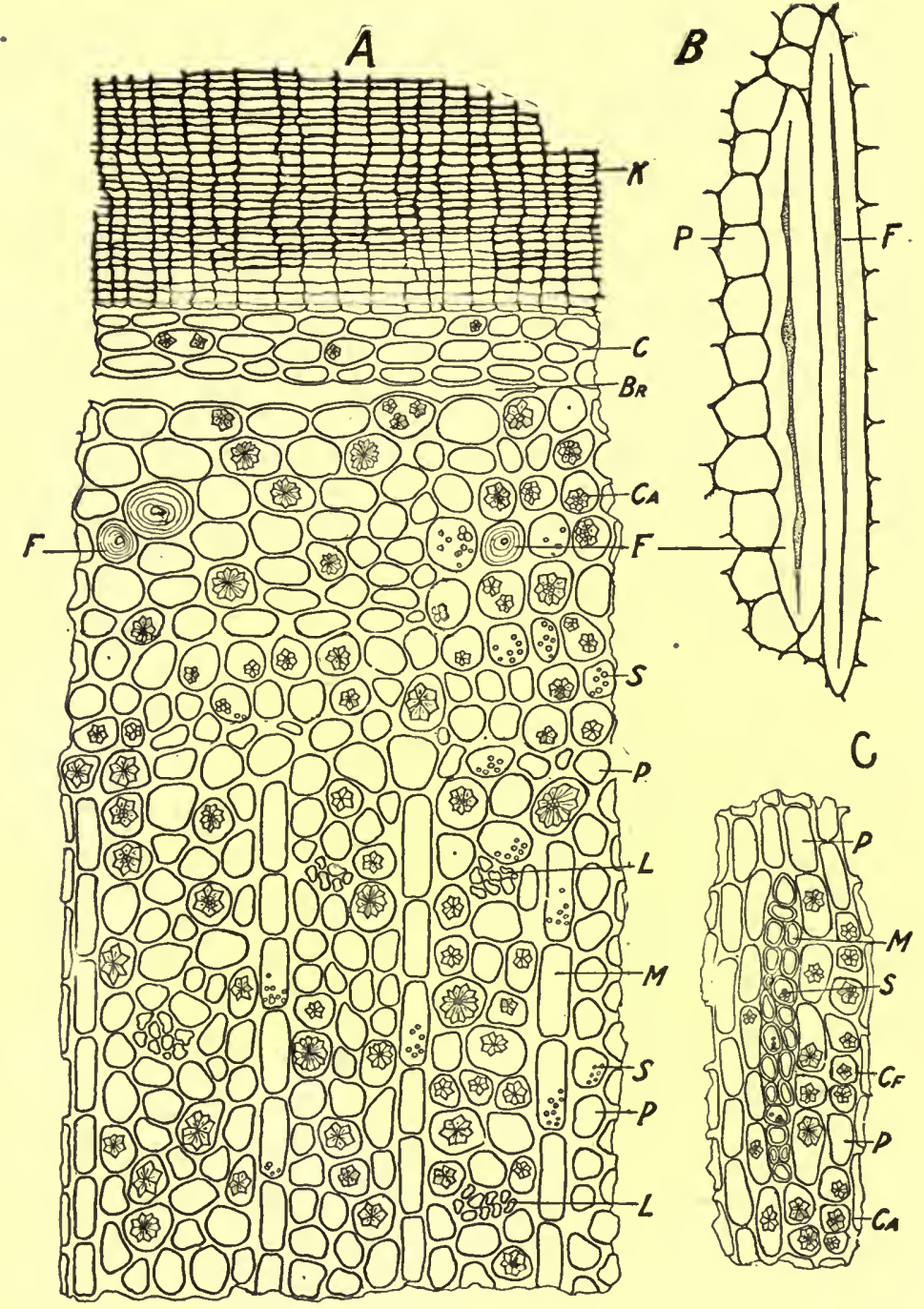

Fig. 288.-Viburnum Opulus: $A$, transverse section of the bark; $K$, cork; $C$, cells of the primary cortex; $F$, bast fibers; $B r$, separation of the cells, forming a layering in the bark; $C a$, rosette aggregates of calcium oxalate; $-S$, starch grains; $P$, parenchyma; $L$, small groups of sieve cells; $M$, medullary rays, showing starch grains in some of the cells. $B$, longitudinal section showing 2 bast fibers and the surrounding parenchyma. $C$, tangential section showing the group of medullary rays $(M)$.-Drawing by Haase. 
Constituents.- The constituents resemble those of Viburnum prunifolium.

Ádulterants.- The bark of Mountain Maple (Acer spicatum) has been substituted for Viburnum opulus. The former is distinguished (Fig. 176) by the numerous rhombohedra crystals of calcium oxalate and large groups of bast fibers.

Literature.-Viehoever, Ewing, Clevenger, Jour. A. Pha. A., 1918 7, p. 944.

SAmbucus.-American or Sweet Elder Flowers.-The flowers of Sambucus canadensis (Fam. Caprifoliaceæ), a shrub growing in rich or moist soil throughout the eastern and central United States. The plant has odd-pinnate leaves; small white flowers, which are borne in flat cymes; and deep purple or nearly black drupes. The latter are edible and sometimes used in making of a wine. The flowers are gathered in early summer during the dry and hot weather, carefully dried and preserved.

Description.-Usually shriveled and crumb-like, from 1 to $2 \mathrm{~mm}$. in diameter, light and dark yellowish-brown; calyx, ovoid having 5 minute teeth; corolla, white when fresh, light brown on drying, urnshaped and possessing 5 spreading lobes; stamens 5 , inserted at the base of the corolla; ovary 3-locular, and containing an ovule in each loculus; odor aromatic; taste mucilaginous and slightly aromatic.

Inner Structure.-Pollen grains numerous, spheroidal, about $0.020 \mathrm{~mm}$. in diameter, nearly smooth, and having 3 pores; calyx having broadly conical hairs, about 0.075 in length, the cuticle being distinctly striated.

Constituents.-American elder flowers have not been investigated as to their chemical composition. It is very probable, however, that they contain principles similar to the European elder (Sambucus nigra). The latter contains a volatile oil, which at ordinary temperatures is a semi-solid mass, having a light yellow- or greenishyellow color. It has the odor of elder blossoms, which becomes especially pronounced when considerably diluted. Elder flowers also contain mucilage; tannic acid; and yield not more than 8 per cent of ash.

\section{VALERIANACEAE, OR VALERIAN FAMILY}

A family of about 275 herbs, mostly indigenous to the northern hemispheres. The leaves are opposite; the flowers are usually small, the ovary being inferior; and the fruits are dry and indehiscent. The secretion cells have suberized walls, and contain a volatile oil. In 
the rhizome and roots of valerian the volatile oil is developed in the sub-epidermal layer. The walls of the tracheæ and wood fibers are marked by simple pores, except in the primary xylem when the tracheæ possess scalariform perforations. The non-glandular hairs are usually unicellular. The glandular hairs are small, having either a uni- or multicellular stalk, and a multicellular summit. Calcium oxalate is wanting.

VALERIANA.-Valerian.-The rhizome and roots of Valeriana officinalis (Fam. Valerianacex), a perennial herb indigenous to Europe and Asia, and cultivated in Holland, Germany, England and the New England States, being more or less naturalized in this country as far south as New York and New Jersey. The rhizome is collected in autumn, cut into longitudinal slices and dried by artificial heat. There are several commercial varieties, and it is said that some of the drug is derived from Valeriana sylvatica.

Description.-Rhizome upright, slightly ellipsoidal, more or less truncate at both ends, from 2.5 to $4 \mathrm{~cm}$. in length, and 1 to $2 \mathrm{~cm}$. in diameter, usually cut longitudinally into two, four or more pieces; externally dark brown, the upper portion having circular stem- and leaf-scars, the sides sometimes with short branches or stolons from 5 to $8 \mathrm{~cm}$. in length, with numerous roots and few root-scars; fracture short, horny; internally light brown; odor pronounced, becoming stronger on keeping the drug; taste somewhat aromatic.

Roots 3 to $10 \mathrm{~cm}$. in length, 0.5 to $1 \mathrm{~mm}$. in diameter, longitudinally wrinkled, and brittle.

Inner Structure.-An epidermal layer of papillose cells, some being modified to root hairs; a sub-epidermal layer containing suberized secretion cells and in which are usually numerous small globules of a volatile oil and occasionally small prismatic crystals; the cells of the cortical parenchyma are filled with starch, some of the cells near the hypodermis containing a few oily globules; an endodermis of thin-walled cells surrounding a pericambium; a central cylinder having 3 to 5 fibrovascular bundles; tracheæ with simple and bordered pores. Older roots show a large pith of starch-bearing parenchyma, a secondary thickening in the fibrovascular bundles and a periderm of a few layers of cells. Sections of the rhizome show a thin periderm, a cortical parenchyma having scattered fibrovascular bundles, a layer of altered cells of the endodermis, numerous more or less twisted, collateral, fibrovascular bundles and a large pith.

Powder.-Light to dark brown; starch grains numerous, from 0.003 to $0.020 \mathrm{~mm}$. in diameter, spheroidal, plano-convex, polyhedral, 2- to 4-compound and each usually with a central cleft; tracheæ 
having simple and bordered pores or scalariform and reticulate thickenings, accompanied by narrow sclerenchymatous fibers, the walls of the latter being thin, porous, and strongly lignified; occasional fragments of epidermis with root hairs, and fragments of cork.

Constituents.-Volatile oil 0.5 to 3 per cent, of which 9.5 per cent is bornyl valerate. It also contains bornyl formate, acetate and butyrate; borneol; pinene; camphene, and a sesquiterpene. The odor of valerian is due to the isovalerianic acid which is formed from the bornyl valerate by the action of an oxydase during the drying of the drug. The fresh drug contains 0.015 per cent of an alkaloid and also a glucoside and a resin, all three of which are physiologically active, the two former being unstable. The drug also contains free formic and acetic acids and malates; tannin; saccharose; and starch.

Allied Plants.-Kesso root oil is obtained from Japanese Valerian (Valeriana angustifolia). The constituents are similar to those of the volatile oil in Valerian, but it contains in addition kessyl acetate and kessyl alcohol. Mexican Valerian, derived from V. mexicana, yields an oil containing about 89 per cent of isovalerianic acid. Indian valerian is as valuable as English-grown valerian and more agreeable to the taste. The Japanese valerian has an unpleasant flavor and gives a different taste to the tincture.

The small rhizomes of Valeriana celtica, a plant growing in the Styrian Alps, yield a volatile oil with an odor resembling that of Anthemis and patchouly.

Adulterants and Substitutes.-The most dangerous admixture that has been reported is Veratrum, which is readily distinguished (Figs. 30 and 31). Cypripedium macranthum (Fam. Orchidaceæ), of Germany (Figs. 60 and 61), has been used as a substitute for valerian.

\section{CUCURBITACEE, OR PUMPKIN FAMIIY}

A family of 650 species of mostly tropical, more or less prostrate or climbing vines. The leaves are usually palmately lobed; the stamens are more or less united either by their filaments or tortuous anthers, and the fruits are fleshy and indehiscent. The fibrovascular bundles are bi-collateral and always separated by broad strands of parenchyma. In the herbaceous stems there is always a closed ring of sclerenchyma in the cortex and the fibrovascular bundles are arranged in 2 interrupted circles. In the fleshy perennial roots and shrub-like stems, showing a secondary growth, broad medullary rays are developed. Furthermore there may also occur from 5 to 7 
concentric rings of bundles, the sclerenchyma of the cortex being reduced to isolated groups of sclerenchymatous fibers. The lepton.e is developed in other parts of the plant than in the fibrovascular bundles. The tracheæ are wide and the walls possess simple pores. The non-glandular hairs are unicellular or uniseriate and the cuticle is sometimes spinose, as the hairs on the leaves of Bryonia, Cucumis, Cucurbita and Ecballium. The glandular hairs have a short uniseriate stalk and a 4-celled summit. Cystolith and cystolith-like structures are of common occurrence in a number of genera. Calcium oxalate is occasionally secreted in the form of solitary crystals.

Colocinntis.-Bitter Apple.-The fruit of Citrullus Colocynthis (Fam. Cucurbitacex), a perennial herbaceous vine, indigenous to warm, dry regions of Africa and Asia, and cultivated in the northwestern provinces of India and the countries bordering the Mediterranean. The fruit is collected in autumn when ripe, and after removal of the epicarp by paring, is quickly dried in the sun or by artificial means. The commercial supplies are obtained from Turkey and Spain, the finer grade coming from Turkey. Attempts have been made to grow Colocynth in England and in New Mexico. The fruits are much larger than the official, and while very bitter appear to be less active than the fruits obtained from wild plants. The seeds should be removed from the pulp before it is used.

Description.-Berry nearly globular, 6 to $7 \mathrm{~cm}$. in diameter (Fig. 289); light; externally yellowish-white; internally, with three longitudinal, somewhat elliptical fissures, 8 to $14 \mathrm{~mm}$. in width; seeds numerous, ovoid, compressed, yellowish-green and borne on the divided parietal placentas between the fissures; odor slight; taste very bitter.

InNer Structure.-See Fig. 290.

Powder.-Light yellow; consisting chiefly of fragments of parenchymatous cells and occasional fragments of tracheæ; very few lignified tissues of the seed-coat, showing the characteristic stone cells which are nearly isodiametric, or irregular, having either straight undulate and strongly lignified walls, marked by simple pores; globules of fixed oil and aleurone grains very few. The powder in which seeds are present contains numerous oil globules, and the outer epidermal cells have reticulated thickenings; the stone cells have usually undulate walls, which are more or.less porous and strongly lignified.

Constituents.-The activity of Colocynth is due to at least two principles, one of which is an amorphous alkaloid, and the other is represented by the ether and chloroform extracts of the resin. Colo- 
cynth contains, furthermore, a considerable proportion of $\alpha$-elatern, but apparently none of the physiologically active $\beta$-elaterin. It has, moreover, been shown that the products obtained from colocynth
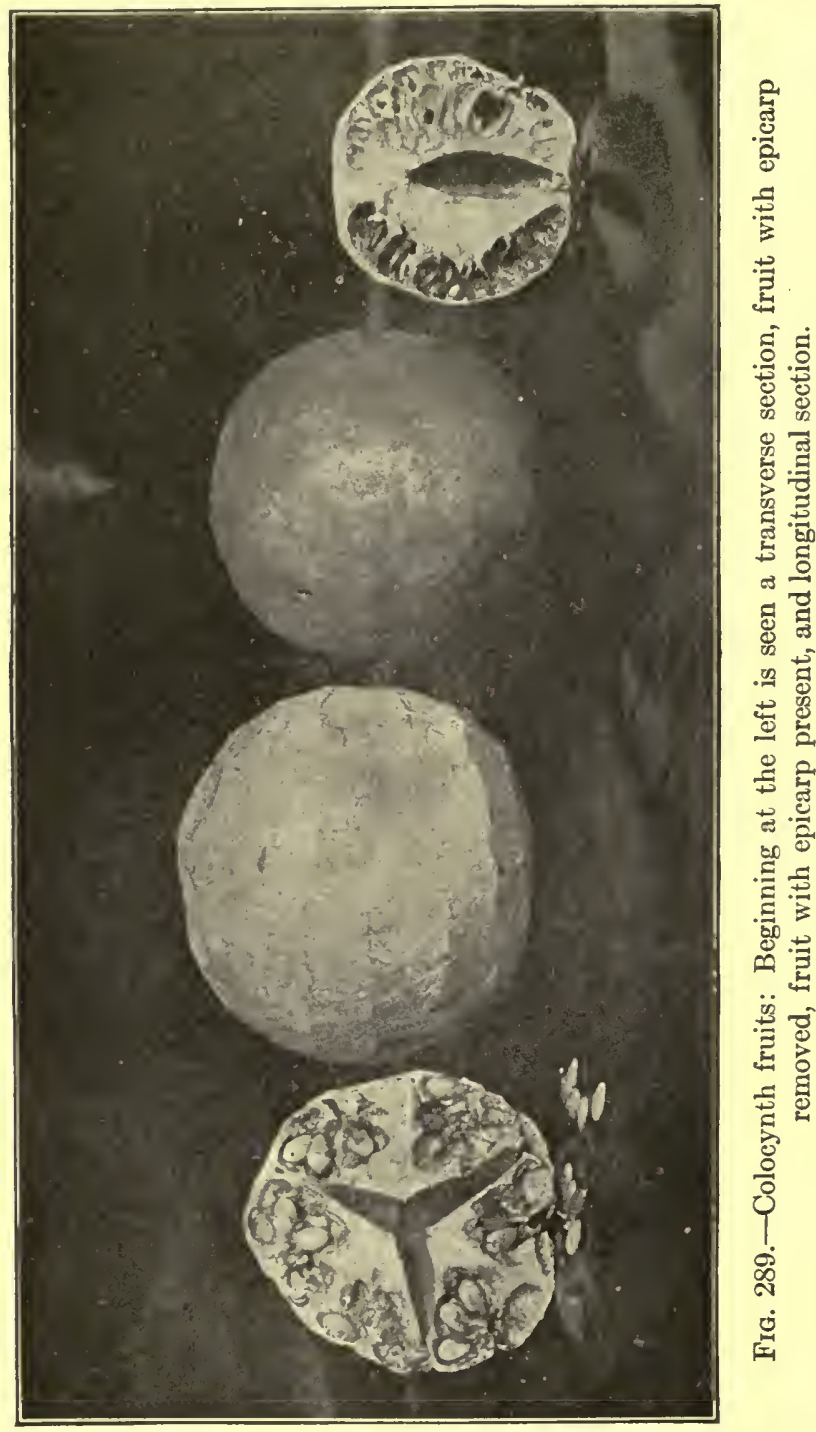

by previous investigators, which were designated "colocynthin," " colocynthitin," etc., do not represent pure substances, but are mixtures of a very indefinite nature, and that the amount of glucosidic substance in the fruit is extremely small. The substance to which the 
name "citrullol" was originally assigned has recently been shown to consist of a phytosterol glucoside. The seeds contain about 15 per cent of a fixed oil.-Power, Jour. Chem. Soc., 1910, p. 99.

Pepo.-Pumpkin Seed.-The ripe seeds of Cucurbita Pepo (Fam. Cucurbitaceæ), a procumbent herb, native of tropical America

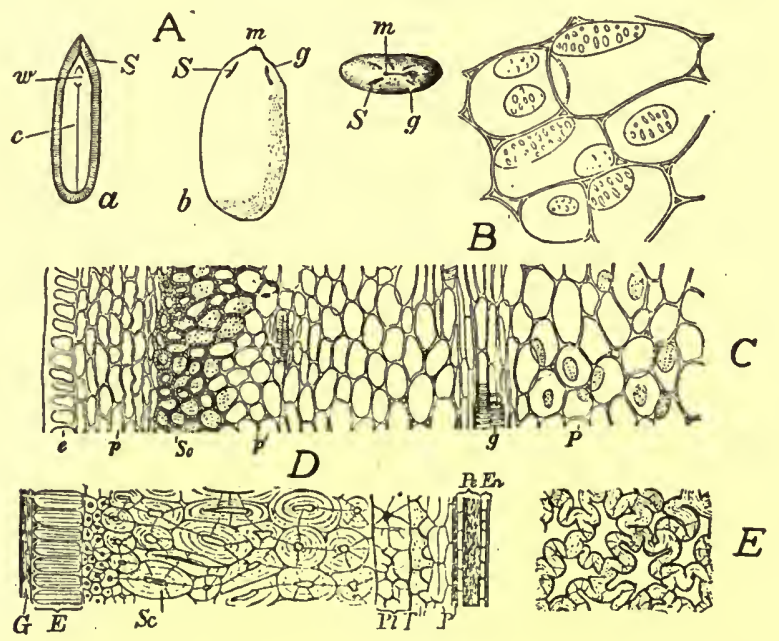

Fig. 290.-Citrullus Colocynthis: $A$, seed: $a$, in longitudinal section, and $b$, surface view; $S$, deep clefts or fissures; $m$, micropyle; $g$, hilum; $w$, radicle; $c$, cotyledons. $B$, parenchyma cells of ripe fruit showing simple pores, the walls are colored blue with chlor-zinc-iodide. $C$, longitudinal section of wall of pericarp of ripe fruit showing $e$, epidermis; $p$, parenchyma; $S c$, sclerotic cells which gradually pass into a thick-walled parenchyma consisting of small cells $\left(p^{\prime}\right) ; g$, spiral vessels; $P$, isodiametric, porous parenchyma cells, containing air and of which the fruit for the most part consists. $D$, cross-section of seed-coat showing $G$, an outer layer which is more or less easily separable from the rest of the seed and the walls of which are somewhat mucilaginous; $E$, epidermis of palisade-like cells; $S c$, sclerotic cells; $P l$, a layer of tabular cells with undulate walls; $T$, a layer of small somewhat branching cells, the walls of which are not strongly thickened and either porous or reticulate; $P$, several layers of parenchyma and the collapsed epidermis; $P e$, perisperm; $E n$, endosperm $E$, tangential section of tabular sclerotic cells of seed-coat shown in $P l$ in Fig. D.-After Meyer.

and possibly tropical Asia, and long cultivated in tropical and temperate zones.

Description.-Anatropous, broadly elliptical, acute, acuminate or truncate, flattened, about $20 \mathrm{~mm}$. in length, $10 \mathrm{~mm}$. in breadth, about $2 \mathrm{~mm}$. in thickness; externally white or light yellow, very 
smooth or somewhat rough from adhering fruit pulp, marked by a shallow groove or slight ridge parallel to and within $1 \mathrm{~mm}$. of the margin; raphe not conspicuous, hilum characterized by a minute depression; seed-coat consisting of two distinct layers-the outer white and coriaceous and the inner dark green and membranaceous; embryo white, straight, with a small hypocotyl and two plano-convex cotyledons; slightly odorous when contused; taste bland.

Inner Structure.-The outer epidermal layer consists of palisadelike cells, the outer walls usually being torn off so that it appears as though the seeds were covered with very long hairs; a sub-epidermal layer consisting of 5 to 12 rows of cells having slightly thickened, lignified and porous walls; a layer of strongly lignified stone cells, elliptical in outline; a single layer of small cells resembling those of the sub-epidermal layer; several rows of spongy parenchyma cells with characteristic reticulate markings and separated from each other by large intercellular spaces; several layers of parenchyma cells, the inner layer being more or less collapsed and having on the inner portion a single epidermal layer the cells having rather thick walls; the perisperm cells are usually more or less collapsed; the endosperm consists of a single layer of cells filled with small aleurone grains; the cotyledons consist of thin-walled, isodiametric, elongated, or palisadelike cells containing a fixed oil and numerous small aleurone grains.

Powder.-Yellowish-white; starch grains few, spheroidal from 0.002 to $0.004 \mathrm{~mm}$. in diameter and occurring in the cells of the outer epidermis and endosperm; characteristic, ellipsoidal, lignified, porous, thick-walled stone cells, from 0.045 to $0.100 \mathrm{~mm}$. in diameter; yellow pigment cells of seed-coat; oil and protein grains in embryo.

Constituents.-Fixed oil about 40 per cent; starch about 30 per cent; proteins; a resin. There is no indication of the presence of any principle possessing anthelmintic properties. Any therapeutic value must be attributed solely to mechanical action of the sharp edges of the bruised seeds.

Allied Plants.-The seeds of other species of Cucurbita are also used in medicine; in Italy C. maxima and in the West Indies C. occidentalis are the sources of the drug.

The seeds of other members of the Cucurbitaceæ are also employed in medicine; they include the seeds of watermelon (Citrullus vulgaris), cucumber (Cucumis sativus), muskmelon (Cucumis melo) and lagenaria (Cucurbita Lagenaria).

Watermelon seeds contain a fixed oil resembling in composition that obtained from pumpkin seed. It also contains a resin which consists in part of a crystalline compound, cucurbitol. 
Literature.-Power, Jour. Amer. Chem. Soc., 1910, pp. 346 and 360.

Bryonia.-Bryony.-The roots of Bryonia alba and B. dioica (Fam. Cucurbitaceæ), perennial vines indigenous to central and

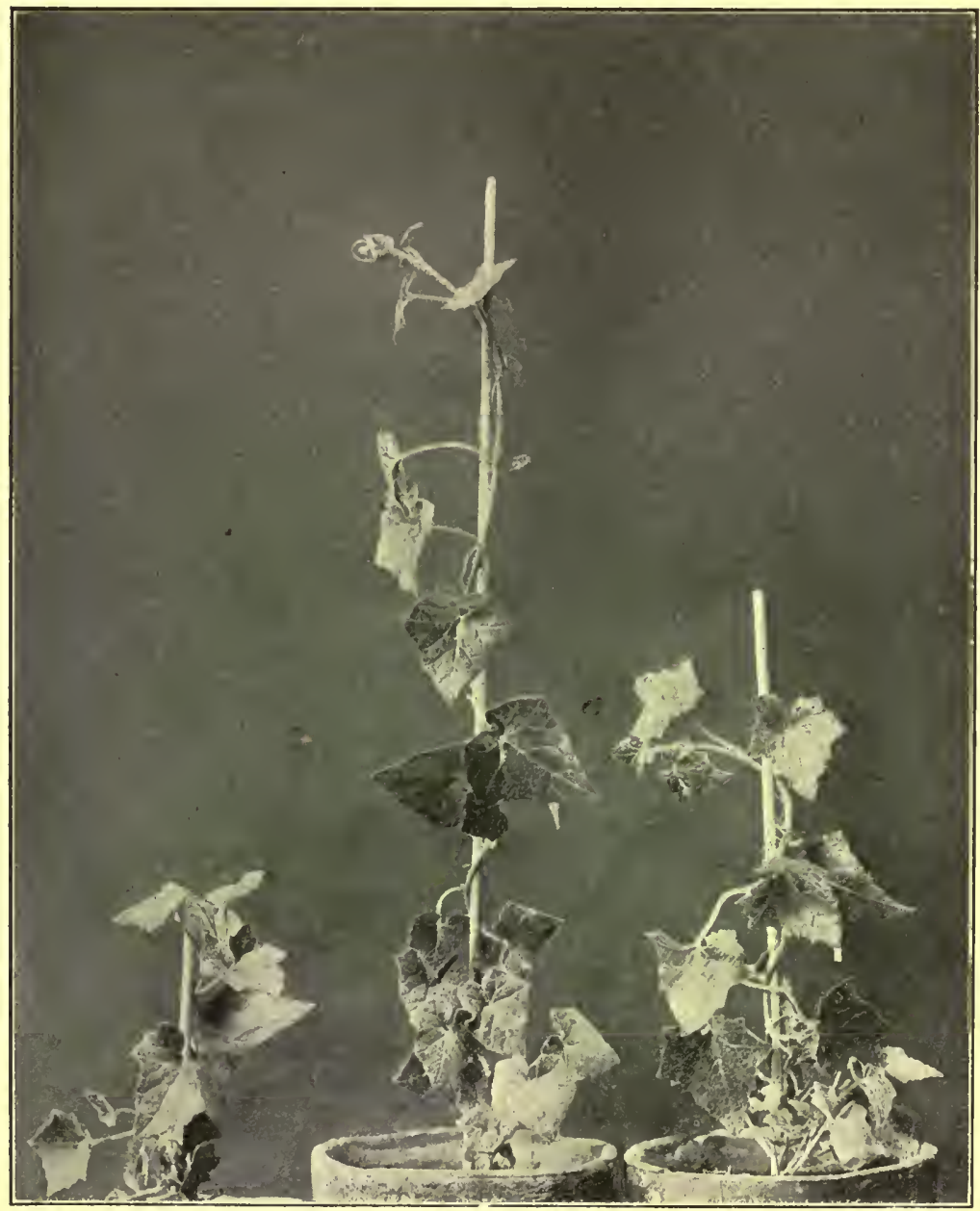

Fig. 291.-Bryonia dioica: Seedlings grown in the botanical gardens, University of Minnesota,-After Newcomb.

southern Europe. The former is found in central and eastern Europe, produces black berries and is sometimes referred to as black bryony. The latter (Fig. 291) is found in central and southern Europe, especially in the Mediterranean countries, and produces red beiries. 
The root is gathered in the summer or fall, cut transversely into pieces and is either used in the fresh or dried condition.

Description.-In nearly circular disks, from 2.5 to $10 \mathrm{~cm}$. in diameter, and from 4 to $18 \mathrm{~mm}$. in thickness; outer surface light yellowishbrown and very roughly wrinkled; the transverse surface, brownishwhite or yellowish-white, showing a cortex about $2 \mathrm{~mm}$. in width, a very broad radiate xylem, made up of 4 concentric zones, pith small, frequently depressed and often showing a small group of primary tracheæ; fracture short; odor aromatic, when kept in tightly closed containers; taste bitter and acrid.

Inner Structure.-Cork consisting of numerous, tangentially elongated, thin-walled, yellowish cells; cortex made up of thin-walled, tangentiall yelongated, starch-bearing parenchyma; inner bark of narrow strands of leptome and parenchyma, separated by broad medullary rays, among which are distributed secretion cells containing a somewhat granular content and being distinguished by their somewhat cylindrical shape; xylem consisting of radial rows of very wide tracheæ, surrounded by parenchyma, and separated by very broad medullary rays; the tracheæ are marked by reticulate perforations or simple pores, and vary in width from 0.075 to $0.350 \mathrm{~mm}$; starch grains from 0.005 to $0.020 \mathrm{~mm}$. in diameter, single or 2- to 6-compound, usually having a large central cleft and varying in shape from spheroidal to plano-convex and somewhat polyhedral grains, occasionally altered or swollen, the latter varying from 0.020 to 0.035 $\mathrm{mm}$. in diameter.

Powder.-Oyster-white; consisting of numerous starch grains, very wide reticulate tracheæ and occasional fragments of cork. The powder is colored purplish and reddish-brown with sulphuric acid.

Constituents.-A brown amorphous glucoside, having a bitter taste and yielding on hydrolysis a resin and dextrose; an amorphous brownish-yellow alkaloid, possessing an intensely bitter taste; a crystalline phytosterol glucoside, bryonol; an optically -inactive phytosterol; a crystalline neutral substance; a small amount of a volatile oil; a sugar; a mixture of fatty acids; and an enzyme which hydrolyses the above-mentioned amorphous glucosidic constituent, and also effects the hydrolysis of amygdalin and salicin. It has been shown that the product designated by previous investigators as "bryonin" must have consisted of a complex mixture, and that the purgative property of the root resides chiefly in its resinous and alkaloidal constituents.

Literature.-Power and Moore, Jour. Chem. Soc., 1911, p. 937. 
Elaterinum.-Elaterin.-A mixture of principles deposited from the juice of the full grown, but unripe fruit of Ecballium Elaterium (Fam. Cucurbitaceæ), a decumbent, perennial herb, indigenous to the countries of the Mediterranean region, and cultivated to some extent in central Europe, and at Mitchan and Hitchin, England. The fruit is ovoid, fleshy, about $4 \mathrm{~cm}$. in length, when unripe, of a pale green color and covered with numerous, uniseriate glandular hairs. When ripe, the fruit separates suddenly from the stalk, the juice with the seeds being forcibly ejected from the aperture left by the detached peduncle. This phenomenon is due to the transferral of the juice from the outer layers of the pericarp to the central cavity, the pressure becoming so great as to finally cause the cells to break at their weakest point. In order to obtain the juice, it is therefore necessary to collect the unripe fruits, which are sliced longitudinally, the juice being obtained by slight pressure. The juice is allowed to stand for 2 hours, and the deposit, which is formed, is collected on cheese cloth, rapidly drained and then dried between layers of filter paper, using porous bricks and a gentle heat. The resulting product is known in commerce as elaterium.

Elaterium usually occurs in rectangular pieces, from 3 to $4 \mathrm{~cm}$. in diameter and about $5 \mathrm{~mm}$. in thickness. When fresh, it is of a greenish-brown color, changing to a light grayish-brown on keeping. It has a granular fraoture, a somewhat aromatic odor, and an acrid, bitter taste. It consists of 40 per cent of elaterin; 17 per cent of a resin; 6 per cent of starch, and small quantities of other principles.

Elaterin.-Recent investigations show that this substance is a mixture of two principles, possessing widely different properties, $(a)$, From 60 to 80 per cent of a lævorotatory principle, $\alpha$-elaterin, which is completely devoid of purgative action; and (b), a small quantity of a dextrorotatory constituent, $\alpha$-elaterin, which possesses strong purgative properties. The studies of Power and Moore (Jour. Chem. Soc., 1909, p. 1985; 1910, p. 1797), serve to establish the fact that elaterin exists in the fruit in a free state, and not in the form of a glucoside, as a previous investigator had affirmed. Various products heretofore regarded as definite constituents of the fruit were likewise shown to have consisted of more or less complex mixtures.

\section{CAMPANULACEE, OR BLUEBELL FAMILY}

A family of about 1500 species, which are widely distributed, those occurring in temperate regions being perennial herbs, while those of the tropics include shrubs and trees. The leaves are alter- 
nate, the flowers are regular, and have either bell-shaped or somewhat bi-labiate corollas; the fruits are either capsules or berries. A very striking characteristic of the family is the occurrence of inulin in place of starch. Laticiferous tubes are abundantly developed in Lobelia, even occurring in the pith, the branches penetrating the tissues of the xylem and uniting with the tubes in the cortex. They are also found in other genera. The tracheæ are narrow, and the walls are marked by either simple or bordered pores. The wood fibers usually possess bordered pores. The leaf-teeth are usually terminated by glands, and in close proximity to them on the upper surface are large water pores. The non-glandular hairs are unicellular, being occasionally silicified. Calcium oxalate and glandular hairs are wanting.

Lobelia.-Indian or Wild Tobacco.-The leaves and flowering tops of Lobelia inflata (Fam. Campanulaceæ), an annual herb (Fig. 292) indigenous to the eastern and central United States and Canada, and cultivated in New York and Massachusetts. Lobelia should be collected after a portion of the capsules have become inflated, carefully dried and preserved.

Description.-Stem cylindrical, somewhat angular, slightly winged light brown, with numerous spreading hairs, internodes 2 to $3 \mathrm{~cm}$. in length. Leaves elliptical or ovate-lanceolate, alternate, 4 to $9 \mathrm{~cm}$. in length, 8 to $39 \mathrm{~mm}$. in breadth; summit acute or acuminate; base obtuse or acute; margin irregularly denticulate, the divisions with a yellowish-brown, gland-like summit; upper surface yellowish-green or light brown and with scattered bristly hairs; under surface light brown, with numerous bristly hairs, the veins of the first order diverging at an angle of about $65^{\circ}$ and curving upward near the margin; petiole either wanting or about $1 \mathrm{~mm}$. in length. Inflorescence in leafy spikes; pedicel about $3 \mathrm{~mm}$. long; calyx 5-parted about $5 \mathrm{~mm}$. in length, the subulate lobes about as long as the tube; corolla 5parted, tubular, about as long as the calyx, pale blue, upper portion cleft nearly to the base, the lobes on either side of the cleft erect or recurved, the other three united; stamens with anthers united above into a curved tube; stigma 2-lobed, ovary 2-locular. Fruit an ovoid, inflated capsule 5 to $8 \mathrm{~mm}$. in length, opening at the summit, adhering to which are the calyx teeth. Seeds numerous, brownish, somcwhat ellipsoidal or ovoid, about $0.7 \mathrm{~mm}$. in length, coarsely reticulate. Odor slight; taste mild, becoming acrid.

Inner Structure. - See Fig. 292.

Powder.-Dark green; non-glandular hairs elongated-conical, from 0.300 to $0.600 \mathrm{~mm}$. in length; fragments of stem with tracheæ 


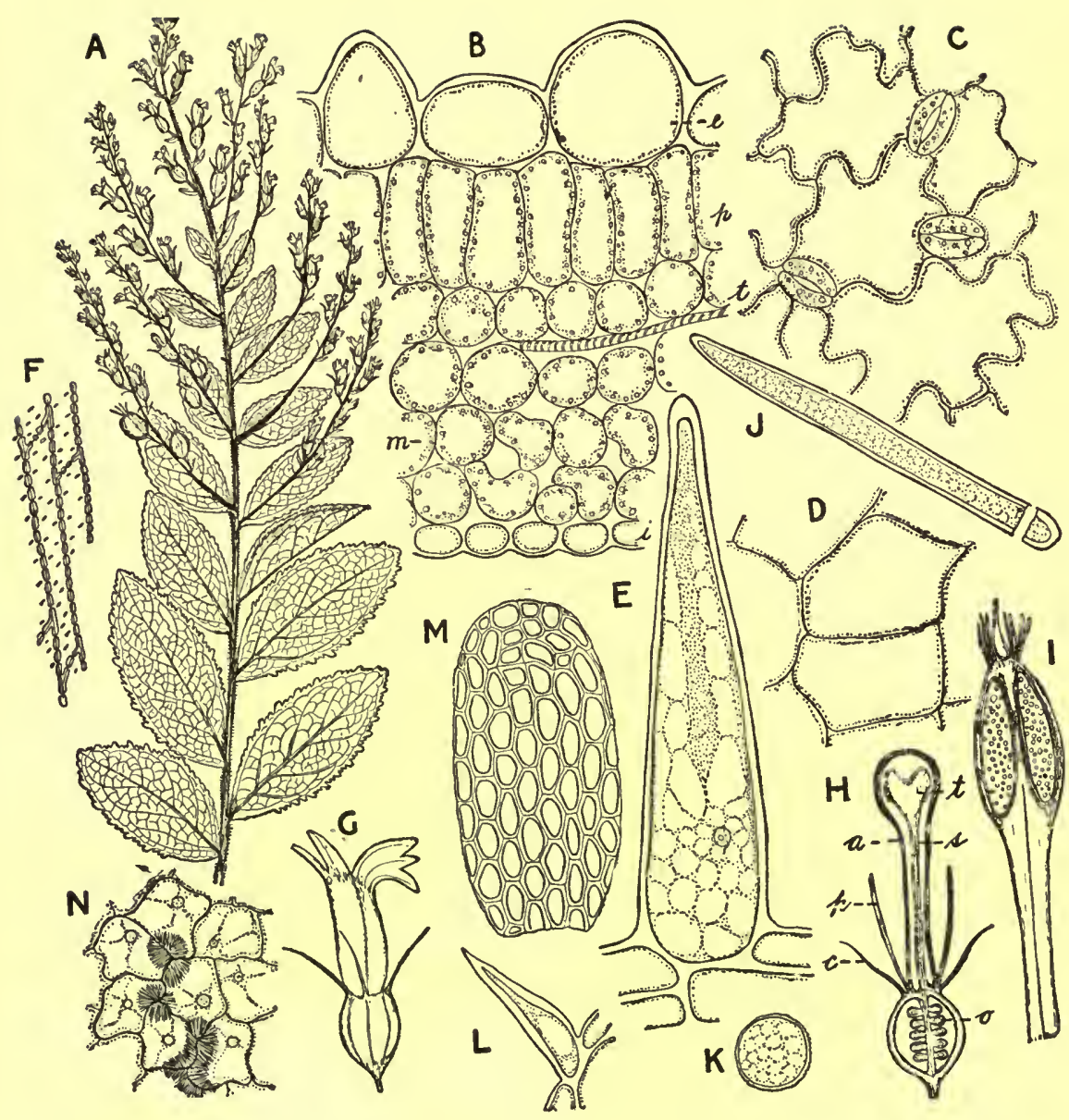

Fig. 292.-Indian tobacco (Lobelia inflata): $A$, upper portion of shoot showing the dentate-denticulate lcaves and the inflated capsules which develop soon after fertilization; $B$, transverse section of leaf showing the large epidermal cells $(e)$, palisade cells $(p)$, trachex $(t)$ loose parenchyma $(m)$ and lower epidermis $(i) ; C$, surface section of lower epidermis showing 3 elliptical stomata; $D$, surface section of upper epidermis; $E$, one of the hairs which are found on the stems and leaves; $F$, wood fibers of the stem; $G$, a flower; $H$, longitudinal section of flower showing the ovary with ovules $(o)$, stylc $(s)$, hairy bifid stigma $(t)$, united stamens $(a)$, corolla $(p)$ and calyx $(c)$; $I$, longitudinal section of stamen showing the hairy summit; $J$, hair from stamen; $K$, pollen grain; $L$, hair from calyx; $M$, seed with reticulate seed-coat; $N$, upper epidermis of corolla showing spherite crystals of a carbohydrate. 
showing annular or spiral thickenings or simple pores associated with narrow wood fibers, the walls of the latter being rather thin, more or less lignified and porous; fragments of epidermis of leaf with elliptical stomata, $0.025 \mathrm{~mm}$. in length, and usually with 3 or 4 neighboring cells; pollen grains nearly spheroidal, 0.015 to $0.030 \mathrm{~mm}$. in diameter; seeds strongly reticulate, the seed-coat composed of yellowishbrown, polygonal cells, having thick walls; fragments of branched laticiferous ducts having a granular content.

Constituents.-An amorphous, acrid, emetic alkaloid lobeline, which decomposes readily on heating, and is contained in greatest amount in the seeds; a non-acrid but pungent volatile oil, lobelianin; a colorless, tasteless, crystalline, neutral principle inflatin, which is intimately associated with the alkaloid; and lobelic acid, which is combined with the alkaloid lobeline. Lobelacrin is regarded as the lobelate of lobeline. The seeds contain in addition a fixed oil, which when pure is bland, non-acrid and somewhat resembles that of linseed. The oil usually seen on the market is of a greenish color and quite acrid and is said to contain all the active principles of the drug.

Allied Plants.-Red lobelia or Cardinal flower, Lobelia cardinalis, and blue lobelia, L. syphilitica, as well as a large number of other species of Lobelia, are used to some extent in medicine. Lobelia nicotianæfolia of India and Delissea acuminata of the Hawaiian Islands have properties similar to Lobelia inflata.

Adulterants.-The seeds of mullein (Verbascum Thapsus) are commonly used as an adulterant of Lobelia seeds, but are distinguished from them by not being reticulate.

\section{COMPOSITA, OR COMPOSITE FAMILY}

The largest family of phænogamous plants, comprising probably more than 10,000 plants, which are very widely distributed. They are distinguished from all other plants in that the inflorescence is a head or capitulum (Fig. 296), consisting of one or two kinds of flowers, arranged on a common torus, and subtended by a number of bracts, forming an involucre. The flowers are epigynous and the fruit is an achene, usually surmounted by the persistent calyx, which consists of hairs, bristles, teeth or scales, which are known collectively as the pappus (Fig. 294).

The individual flowers are called florets (Figs. 293 to 295), and may be hermaphrodite or pistillate, monœcious, diœcious, or neutral. Depending upon the shape of the corolla, two kinds of flowers are recognized, one in which the corolla forms a tube, which is 5-lobed 
or 5-cleft, known as tubular flowers (Fig. 293); and one in which the petals are united into a short tube, with an upper part that forms a large, strap-shaped, usually 5 -toothed limb, known as ligulate flowers (Figs. 293 and 294).

In some of the plants of the Compositæ the head consists of ligulate flowers only, but in the larger number of plants the head is composed of both tubular and ligulate flowers or tubular flowers alone and accordingly two main groups or sub-families are distinguished. The sub-family in which all of the flowers are ligulate is known as Ligulifloræ, or Cichoriaceæ, by those who give the group the rank of a family. This group includes plants like dandelion, chicory, lettuce, and Hieracium. The group or sub-family in which the flowers are all tubular or ligulate on the margin only is known as the Tubulifloræ. When the head consists only of tubular flowers it is called discoid, but when ligulate flowers are also present it is called radiate. When the heads are radiate, as in the common daisy, the TUBULAR FLOwERS are spoken of as disk-flowers, and the ligulate flowers as RAY-FLOWERs. The disk-flowers are usually perfect, while the ray-flowers are pistillate or neutral (without either stamens or pistils). By some systematists the Tubulifloræ are divided into groups which have been given the rank of families. This division is based especially on the characters of the stamens. In a small group represented by the ragweed and known as the Ambrosiaceæ, the anthers, while close together (connivent), are not united, and the corolla in the marginal or pistillate flowers is reduced to a short tube or ring. In a large group, which includes probably 10,000 species and which is considered to be the Compositæ proper, the stamens in the tubular flowers are syngenesious and the marginal or ray-flowers are distinctly ligulate. This group includes the daisy, sunflower, golden-rod, aster, thistle, and most of the plants which yield official drugs.

The Compositæ are characterized by having inulin, in the cellsap of the parenchyma cells, especially in the underground organs. Inulin usually occurs in solution, but may be caused to separate, by the addition of alcohol, in the form of sphærite aggregates which resemble in structure starch grains, but the aggregates are not enclosed by distinct membrane. Laticiferous vessels are common to all of the plants of the Cichoriaceæ. These vessels occur either on the inner face of the strands of leptome or are distributed in the pericycle of the stems. Schizogenous resin-canals are distributed among the parenchyma cells of the primary cortex and pith, of a large number of the genera of the Tubulifloræ. Secretory cavities and elongated 
secretory cells are also found in a number of genera. The walls of the trachex possess either simple pores or occasionally scalariform perforations. The wood fibers are marked by simple pores. The non-glandular hairs are usually uniseriate. The glandular hairs are widely distributed and polymorphic. The stomata are usually surrounded by 3 or more epidermal cells. Calcium oxalate is secreted occasionally in the form of small needles or octahedra, and very rarely in the form of rhombohedra or rosette aggregates.

ArNica.-Arnica Flowers.-The dried, expanded flower-heads of Arnica montana (Fam. Compositx), a perennial herb indigenous to central Europe, and growing in the mountains of Switzerland, Asia and western North America. On account of the involucre and torus
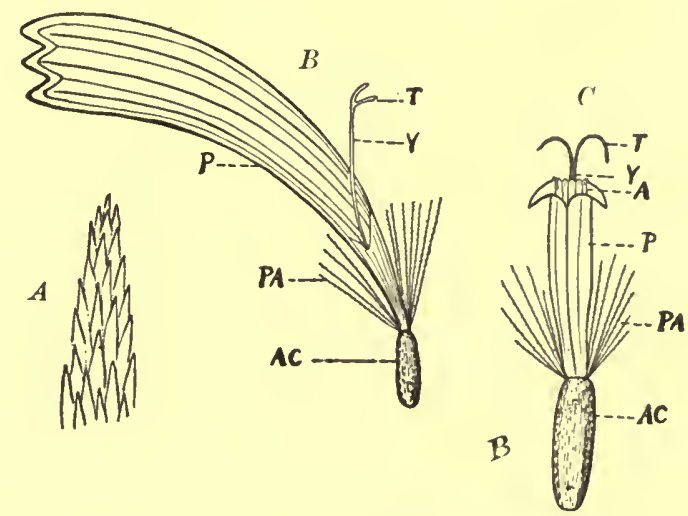

FIG. 293.-Arnica florets: $A$, overlapping, bristly hairs of pappus; $B$, ray or ligulate floret; $C$, disk or tubular floret. $A C$, inferior ovary becoming in fruit an achene; $P A$, pappus; $P$, corolla; $A$, anthers; $Y$, style; $T$, bifid stigma.

being injured by the larvæ of the insect Trypeta arnicivora, these parts are removed and the florets alone used.

Description.-Sub-globular or truncate-conical, about $15 \mathrm{~mm}$. in diameter; involucre campanulate, bracts twenty to twenty-four in two rows, linear-lanceolate, dark green, pubescent glandular; torus solid, slightly convex, deeply pitted, bristly hairy; ray or ligulate florets (Fig. 293), fourteen to twenty, about $2 \mathrm{~cm}$. in length, bright yellow, pistillate, corolla 3-toothed, 7- to 12-veined, very pubescent and glandular below, ovary about $4 \mathrm{~mm}$. in length, erect, pubescent and glandular, pappus consisting of a single row of about thirty rough bristles; disk or tubular florets (Fig. 293), forty or fifty, about $17 \mathrm{~mm}$. in length, perfect, bright yellow, corolla 5-toothed, very 
glandular and pubescent below, ovary about $6 \mathrm{~mm}$. in length, glandular and pubescent; achene spindle-shaped, dark brown, finely striate, glandular-pubescent and surmounted by a pappus (Fig. 293) of white barbed bristles about $7 \mathrm{~mm}$. in length; odor distinct; taste bitter and acrid.

Powder.-Yellowish-brown; pollen grains spheroidal, from 0.025 to $0.035 \mathrm{~mm}$. in diameter, having 3 pores and a cuticle with numerous spinose thickenings; non-glandular hairs of three kinds: (a), either unicellular; (b), uniseriate, 5- to 6-celled, or (c), consisting of a pair of united unicellular hairs with numerous pores on the dividing wall; glandular hairs of three kinds: (a), either with a large unicellular stalk and unicellular glandular head; $(b)$, with a stalk of a single row of 4 cells and a 1-celled glandular head; or (c), a stalk of a double row of 5 cells and a 2-celled glandular head; pappus consisting of a multicellular axis with unicellular branches (Fig. 293).

Constituents.-A bitter crystalline principle, arnicin, about 4 per cent; and volatile oil 0.04 to 0.07 per cent, consisting of a butyraceous substance.

Adulterants.-Arnica flowers are not infrequently adulterated with the flowers of various other Compositæ, or even entirely substituted by them; of these may be mentioned the flowers of Calendula officinalis (see Calendula); species of Inulu, the achenes of which are glabrous; and Tragopogon pratensis, the ligulate florets of which are 5 -toothed at the summit (Fig. 294).

The flowers of Inula britannica are smaller, the ligulate flowers are 4-veined, the receptacle is smooth and the achene is about 1 mm. in length. (U. S. Dept. Agric.)

ANTHEMIS.-Roman or English Chamomile.-The expanded flower-heads of Anthemis nobilis (Fam. Compositæ), a perennial herb indigenous to southern and western Europe and cultivated in Belgium, England, France, Germany, Hungary and the United States, and naturalized from Rhode Island to Michigan and south to Delaware. The flowers are collected from cultivated plants, and dried by artificial means, the principal supplies coming from Belgium, France and Saxony.

Description.-Globular, compressed, 1.5 to $2 \mathrm{~cm}$. in diameter; involucre hemispherical, with two or three rows of imbricated, nearly equal, somewhat elliptical, very pubescent scales, having a greenish middle portion and a yellowish margin; torus conical or convex, solid, 3 to $4 \mathrm{~mm}$. in height, occasionally hollow, and sometimes containing the larvæ of an insect; chaff-scales resembling the involucral scales, about $2 \mathrm{~mm}$. in length; ligulate florets numerous, 6 to $10 \mathrm{~mm}$. 

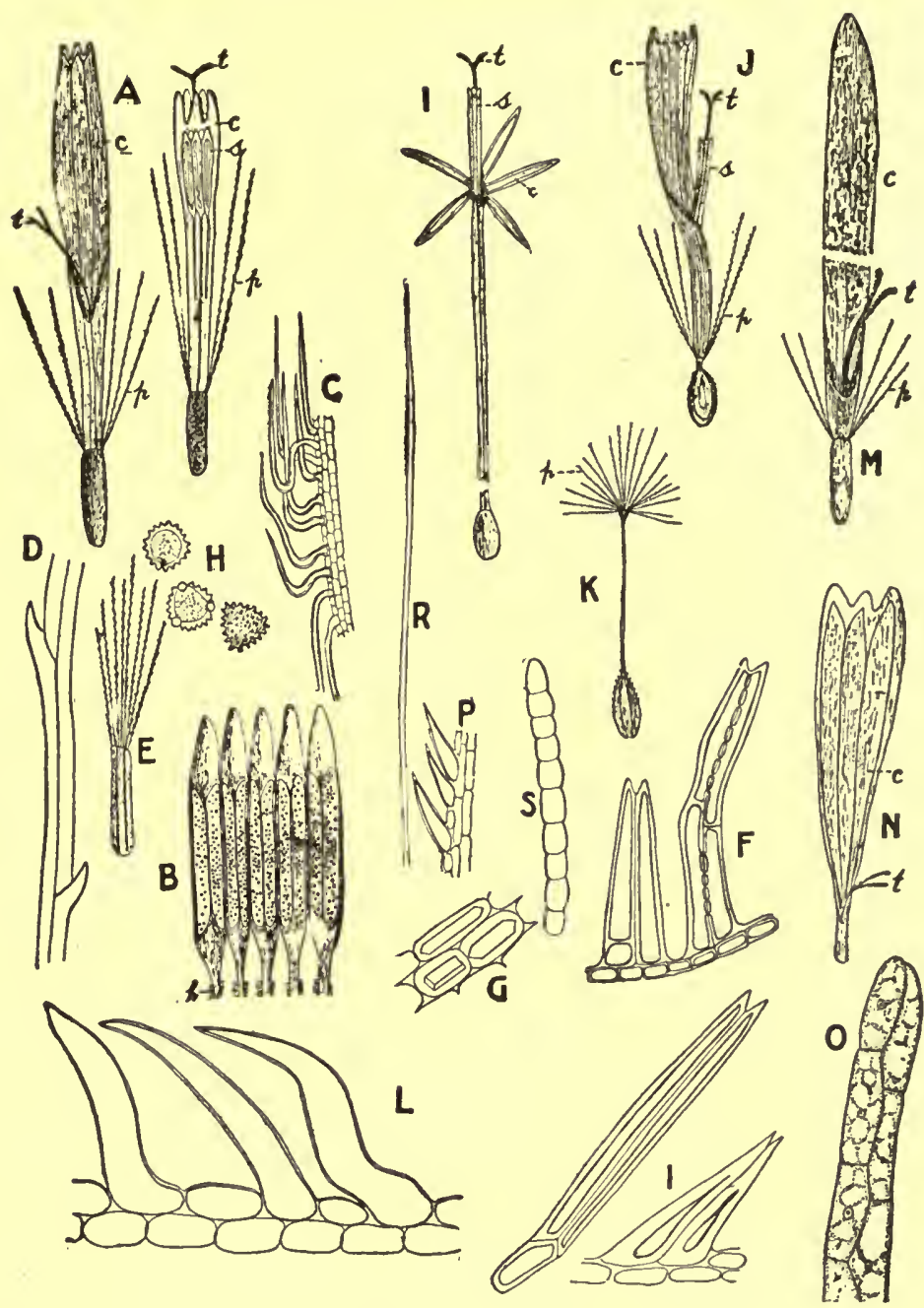

Frg. 294.-Flowers of the following Compositæ: $A-H$, Inula Helenium; $I$, Carthamus tinctorus; $J-L$, Taraxacum officinale; $M$, Tussilago Farfara; $N, O$, Calendula officinalis; $P-S$, Tragopogon pratensis; $T$, Tagetes tenuifolia.

$A$, ligulate and tubular florets of Inula Helenium; $B$, united anthers of same showing hairs $(h)$ on the filaments; $C$, hairs of filaments magnified; $D$, portion of barbed hair of pappus; $E$, akene; $F$, double hairs of /akene; $G$, cells of epidermis of akene containing prisms of calcium oxalate about $0.025 \mathrm{~mm}$. in length; $H$, pollen grains. $I$, tubular floret of safflower (Carthamus tinctorius). $J$, ligulate floret of dandelion (Taraxacum officinale); $K$, one of the akenes showing spreading pappus on long stalk which develops after fertilization; $L$, hairs of corolla. $M$, ligulate floret of coltsfoot (Tussil- 
in length, corolla white, 3-toothed, 4-nerved, ovary about $1 \mathrm{~mm}$. in length, glandular, style slender, stigma bi-cleft; tubular florets few or none, lemon-yellow, perfect; achene oblong, pappus none; odor distinct; taste aromatic and bitter.

Inner Structure.-Bracts having scattered, somewhat thickwalled, unicellular hairs and occasional sessile glandular hairs; pollen grains, occasional, spheroidal about $0.030 \mathrm{~mm}$. in diameter, the cuticle being very prickly; sclerenchymatous fibers about 0.010 $\mathrm{mm}$. in width and having very thick walls; papillæ of corolla and stigma; small rosette aggregates of calcium oxalate occasionally present; characteristic cells of anther.

Constituents.-Volatile oil, which is bluish-green when fresh, 0.8 to 1 per cent; a bitter crystalline glucoside anthemic acid (see Matricaria); 5.25 per cent of resin; 1.50 per cent of a bitter crystalline wax; and tannin. The volatile oil consists principally of the isobutyl, amyl and hexyl esters of butyric, angelic and tiglic acids, and anthemol, an isomer of camphor.

Matricaria.-Wild or German Chamomile.-The flower-heads of Matricaria Chamomilla (Fam. Compositæ), an annual herb, indigenous to Europe and western Asia, and naturalized in Australia and certain parts of the United States, including New York and Pennsylvania. The flower-heads are collected, when they are mature or expanded, from wild plants.

Description.--Rounded, conical, 3 to $10 \mathrm{~mm}$. in breadth; peduncle 0.5 to $3.5 \mathrm{~cm}$. in length, nearly glabrous; involucre hemispherical, scales twenty to thirty, imbricated, oblanceolate, the middle portion brownish, margin whitish, pubescent; torus ovoid, becoming conical and hollow, deeply pitted, naked, 3 to $5 \mathrm{~mm}$. in height, about $1.5 \mathrm{~mm}$. in diameter; ray or ligulate florets, twelve to eighteen, pistillate, about $12 \mathrm{~mm}$. in length, corolla white, 3-toothed, 4-veined; disk or tubular flowers, numerous, yellowish, perfect, oblong, small, somewhat glandular, about $2.5 \mathrm{~mm}$. in length; achenes somewhat obovoid, about $0.5 \mathrm{~mm}$. in length; faintly 3 - to 5 -ribbed; pappus none, or forming a membranous crown; odor distinct; taste aromatic and bitter.

Inner Structure.-Pollen grains numerous, from 0.018 to 0.025 $\mathrm{mm}$. in diameter, nearly spheroidal or triangular from the 3 pores,

ago Farfara). $N$, ligulate floret of marigold (Calendula officinalis); $O$, one of the hairs of corolla. $P$, pappus of yellow goat's-beard (Tragopogon pratensis); $R$, one of the long slender hairs in the pappus; $S$, hair from akene. $T$, two double hairs from akene of Tagetes tenuifolia, $c$, corolla; $t$, stigma; $s$, stamens; $p$, pappus. 
the cuticle being very prickly; fragments of corolla with sessile, 8-celled glandular hairs; characteristic cells of anther; stigma with papillæ; cells of achenes having scalariform perforations in the walls; sclerenchymatous fibers of involucral scales.

Constituents.-Volatile oil, about 0.25 per cent of a viscid consistency and an intense blue color. The color is due to azulene, a similar principle being present in the volatile oils derived from Absinthium, Achillea (yarrow), Sumbul and Valerian. The flowers are also said to contain a bitter principle, anthemic acid, which forms colorless, silky needles soluble in water and alcohol, and anthemidin, which separates from the alcoholic solution in the form of a tasteless crystalline compound. Malic acid and tannin are also present in the drug. The oil when distilled from the involucre soon changes to yellow, finally becoming brown; while the oil from the flowers alone retains its deep-blue color even when exposed to light for some weeks.

Adulterants.-In Anthemis arvensis the receptacle is solid and conical and the involucral scales are lanceolate. In Anthemis Cotula the peduncles are slightly pubescent and the ligulate flowers neutral.

Spanish Chamomile, the flowering heads of wild-grown Anthemis nobilis, contain more volatile oil and bitter principles than the cultivated and are probably more active, but more liable to produce nausea. (Ballard, Jour. A. Ph. A., 1918, 7, p. 952.)

Literature.-Meyer, Wissenchaftliche Drogenkunde, Vol. II., p. 299; also Kraemer's Applied and Economic Botany, p. 396.

Calendula.-Marigold.-The ligulate florets of Calendula officinalis (Fam. Compositæ), an annual herb indigenous to southern Europe and the Levant, and widely cultivated as a garden plant. The flowers are collected when fully expanded, and then dried.

Description.-Florets usually without the ovary; corolla bright yellow, 15 to $25 \mathrm{~mm}$. in length, 1- to 3-toothed, 4- or 5-veined, margin nearly entire, tube sometimes inclosing the remains of a filiform style and bifid stigma, pubescent on the outer surface; ovary oblong, about $0.5 \mathrm{~mm}$. in length, pubescent; odor distinct; taste faintly saline, slightly bitter.

Powder.-(Figs. 44 and 294.) Bright yellow; epidermal cells narrow, elongated, having sinuous walls, numerous oily globules and irregular chromoplastids; pollen grains spheroidal about $0.040 \mathrm{~mm}$. in diameter, having 3 pores and the cuticle being spinose; nonglandular hairs consisting of a double row of cells having a 1- or 2celled summit; calcium oxalate in rosette-aggregate crystals about 
$0.040 \mathrm{~mm}$. in diameter. On adding the powder to water the latter becomes a pale straw-color.

Constituents.-Volatile oil; an amorphous bitter principle; a gummy substance, calendulin, which forms with water a transparent mucilage that is not precipitated by tannin; and resin.

Allied Plants.-The florets of various Compositæ are sometimes admixed with or substituted for Calendula, of which the following may be mentioned together with their principal distinguishing characteristics (Fig. 294). The ligulate corolla of Taraxacum officinale is 5-toothed; the ligulate corolla of Arnica montana is 7-to 12-veined; the ligulate corolla of Tussilago Farfara is linear, about $13 \mathrm{~mm}$. in length and about $0.3 \mathrm{~mm}$. in breadth, summit acute, entire; and the ray florets of Tagetes patula are somewhat spatulate, about $20 \mathrm{~mm}$. in length and $10 \mathrm{~mm}$. in width, sometimes marked with darker stripes, and have undulate margins.

Santonica.-Levant Wormseed.-The flower-heads of Artemisia Cina (Fam. Compositæ), a small shrub indigenous to the deserts in Russian Turkestan. In recent years the Russian Government has divided the region bounded on the east by the mountain chain of the Kara-tau, and on the west by the river Syr Darja, into 5 districts, and leased the right of collection for 1 year to the highest bidder in public auction. The flower-heads are collected in July and August before they expand, and carefully dried and preserved. If the flower-heads are unexpanded and quickly dried they will yield over 3 per cent of santonin; just so soon as the flower matures, however, there is a rapid disappearance of the anthelmintic principle.

Description.-Oblong or ellipsoidal, 2 to $4 \mathrm{~mm}$. in length, 1 to 1.5 $\mathrm{mm}$. in diameter; involucre ovoid, consisting of twelve to eighteen closely imbricated, ovate or ovate-lanceolate, glandular, somewhat shiny bracts, about $2 \mathrm{~mm}$. in length, with a yellowish-green or greenishbrown middle portion and whitish margin; torus flat, naked, with three to six unexpanded, perfect tubular flowers about $1.5 \mathrm{~mm}$. in length and completely inclosed by the upper bracts: ovary oblong; pappus wanting; odor distinct; taste aromatic.

InNer Structure.-See Fig. 295.

Powder.-Light brown; pollen grains spheroidal from 0.015 to $0.020 \mathrm{~mm}$. in diameter, nearly smooth and having 3 pores; glandular hairs of two kinds, either with 1 or 2 short cells or with 2 to 3 pairs of cells. If a few c.c. of an alcoholic (95 per cent) extract of santonica is heated with a few drops of potassium hydrate solution, a reddish color is produced.

Constituents.-A crystalline neutral principle, santonin, which 
occurs to the extenc of 2 to 3.5 per cent just before the expansion of the flowers; volatile oil about 2 per cent, consisting chiefly of cineol, some terpineol, terpinene and inactive pinene; a crystalline principle artemisin, which is apparently oxysantonin; and a resin. Santonin crystallizes in rhombic prisms, becoming yellow on exposure to light; it is nearly insoluble in water, sparingly soluble in alcohol; and colored red by alcoholic solutions of the alkalies.
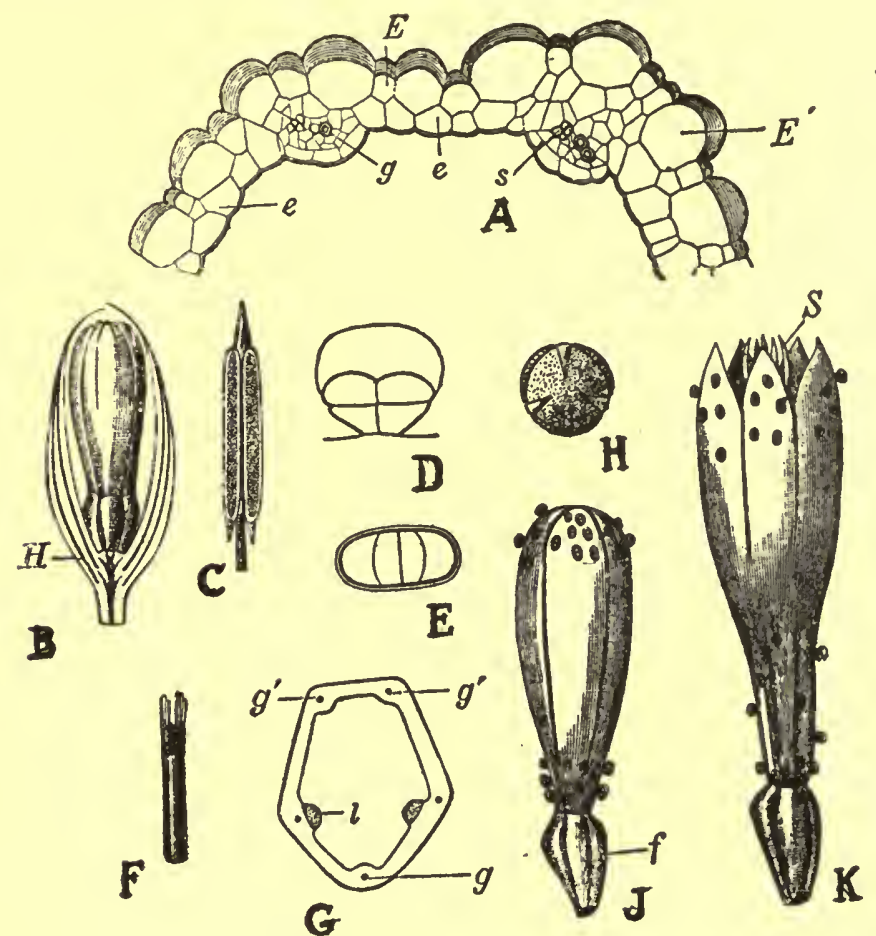

FIG. 295.-Santonica: $A$, transverse section of the wall of the ovary; $E, E^{\prime}, e$, epidermal cells; $g$, trachex, $s$, leptome. $B$, longitudinal section through a flower bud showing involucre $(H)$; $C$, stamen; $D$, glandular hair of a budscale; $E$, glandular hair as viewed from above; $F$, style; $G$, transverse section of the wall of the ovary showing tracheæ $\left(g, g^{\prime}\right)$ and conducting cells traversed by pollen tube $(l) ; H$, pollen grain; $J$, flower bud showing ovary $(f) ; K$, expanded flower showing stamens $(S)$.-After Meyer.

Allied Plant.-Artemisia gallica, a plant abundant in France, contains santonin and about 1 per cent of a volatile oil.

Adulterants.-A santonin-free santonica has been recently found in the markets of Europe and this country.-Enz., Apoth. Zcit., 1913, p. 514; LaWall, Jour. A. Ph. A., 1913, p. 596. 
The seeds of Quisqualis indica (Fam. Combretaceæ) furnish a substitute for Santonica. The plant grows wild in the tropical regions of Asia, America, and Africa. The best drug comes from the province of Szetchouan, which furnishes it in large quantities. The seeds contain an active principle resembling santonin and possess anthelmintic properties. The maximum dose is 7.5 g. for adults. Devenport, Schweiz. Apoth Zeitg., 1918, 56, p. 522.

Pyrethri Fuores.-Insect Flowers, Pulvis Insecticidus or Insect Powder.-The unexpanded or partly expanded flower heads of Chrysanthemum cinerariifolium and C. roseum or C. Marschallii (Fam. Compositæ), perennial herbs (Fig. 296), resembling in habit the common white or field daisy (C. Leucanthemum). The Dalmatian insect powder is obtained from $\mathrm{C}$. cinerariifolium, a perennial herb indigenous to Dalmatia and Herzegovina, where it. is also cultivated as well as in northern Africa, Néw York and California. The Persian insect flowers are derived from C. roseum and C. Marschallii, perennial herbs growing in the Caucasus regions, Armenia and northern Persia. The flowers, from 2- to 6-year-old plants, are collected. The stems are cut, the flower heads being torn off by a combing machine, carefully dried and preserved. The finest and most powerful insect powder is obtained from the closed or only partly expanded flowers, providing they are properly dried and preserved.

Dalmatian Flowers.-Heads hemispherical, about $12 \mathrm{~mm}$. in diameter, consisting of a short, rounded, conical torus or receptacle; a straw-colored involucre, consisting of 2 or 3 series of scales; numerous yellow, tubular flowers; and a circle of cream-colored ray flowers. Involucral scales of 2 kinds: ( $a$ ), the outer being lanceolate, having a pronounced keel, somewhat hairy and of a light brown color on the outer surface, and smooth, shiny and of a straw-yellow color on the inner surface; $(b)$, inner scales spatulate, much longer than the outer scales and having a white membranous margin. Torus or receptacle, broadly conical or somewhat flattened and rounded, grayish-yellow, and somewhat roughened from the scars of the tubular florets. Rayflorets ligulate, pistillate, the corolla varying in length from 1 to 2 $\mathrm{cm}$., having about 15 delicate veins and 3 short, obtuse or rounded teeth, the middle tooth often being much smaller than the other two. Disk-florets, tubular, about $6 \mathrm{~mm}$. in length, perfect, having a 5-lobed, yellow corolla, about $1.5 \mathrm{~mm}$. in length and borne on the ovary, the latter being 5 -ribbed, the pappus forming a short-toothed crown. Stems either wanting or attaining a length of $3 \mathrm{~cm}$. and 
having a diameter of $1 \mathrm{~mm}$.; cylindrical, grayish- or yellowish-green, pubescent and having 9 to 12 prominent ribs.

Persian Flowers.- Heads flattened top-shaped, about $12 \mathrm{~mm}$. in diameter, and resembling the Dalmatian flowers. The involucral scales are greenish-brown having a dark brown membranous margin:

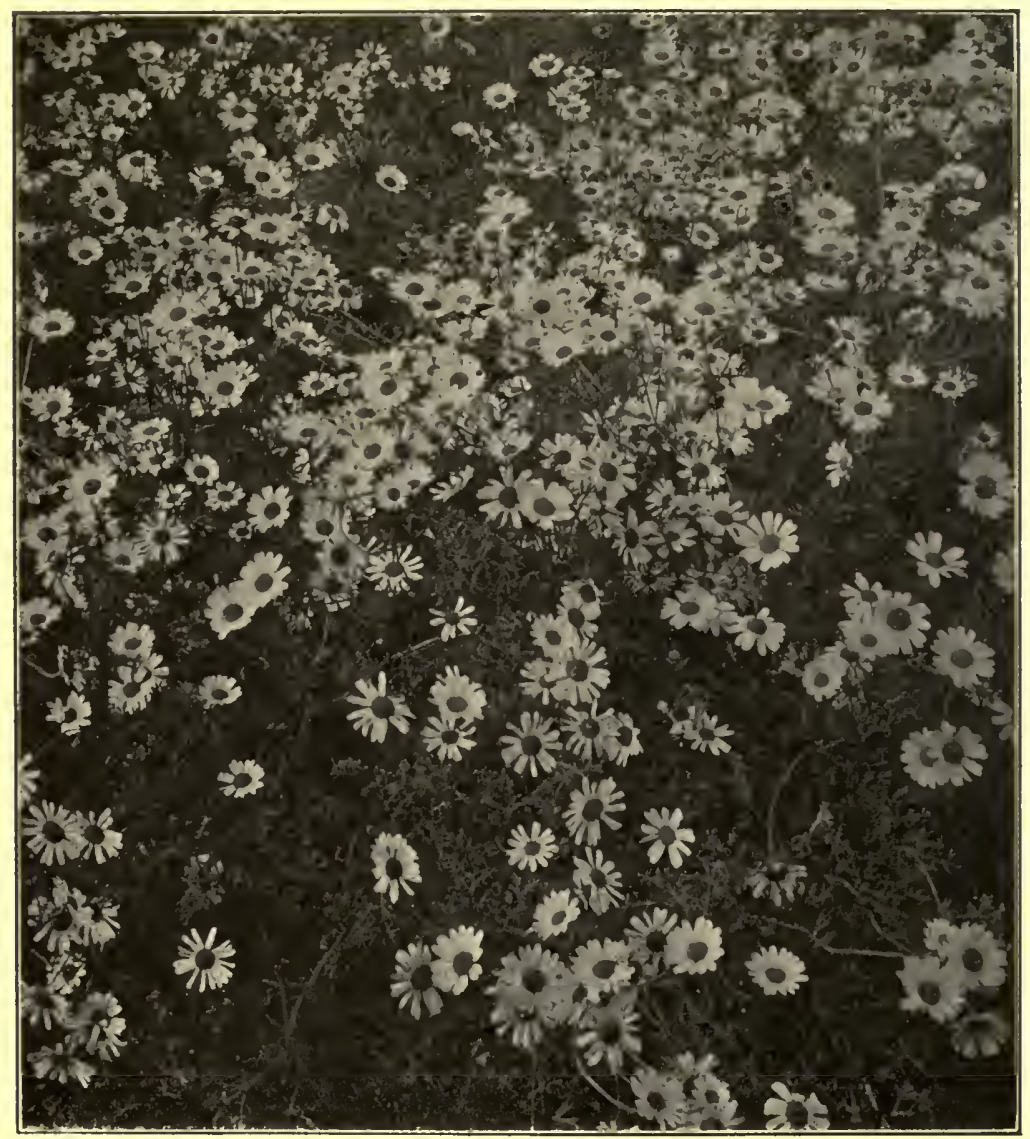

Frg. 296.-A portion of a plot of Chrysanthemum cinerariifolium, the flowers, which somewhat resemble the common white or field daisy, furnish the Dalmatian insect powder.-After Newcomb.

the ray florets are reddish-brown or reddish-purple, attaining a length of $15 \mathrm{~mm}$., being somewhat plicate, unequally blunt, 3-toothed and having 7 veins; disk florets tubular, yellow, the corolla scarcely longer than the brownish, 10-striate ovary, the latter having a membranous pappus. 
Powder.-(Fig. 297.) Dalmatian powder, light yellowish-brown; Persian powder, light brown; fragments of the ovary, corolla and flower stalk contain brownish resin secretion canals, the contents of which are soluble in hot alcohol, colored yellowish upon the addi-

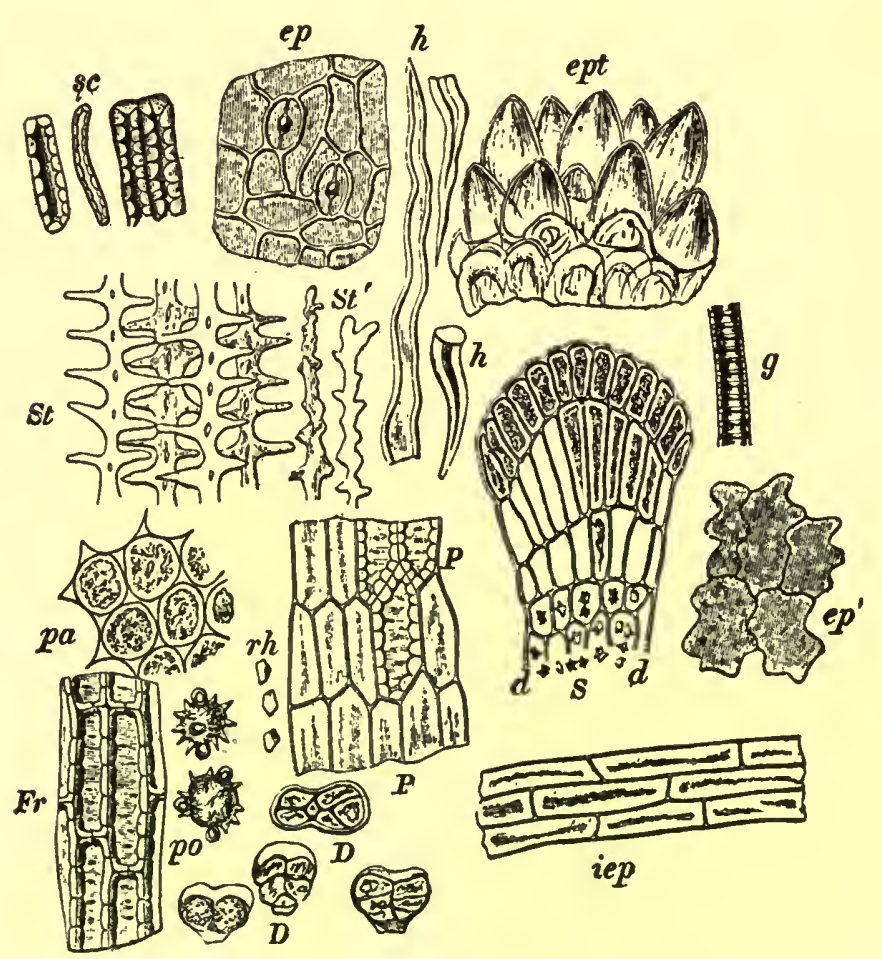

FIG. 297.-Flores Pyrethri (Insect flowers): $s c$, stone cells; ep, upper epidermis of a bract; $h, h$, non-glandular hairs of bracts; ept, papillæ on the upper surface of the ligulate corolla; $S t, S t^{\prime}$, loose parenchyma of the ligulate corolla; $g$, a trachea of a bract with annular thickening; $S$, tooth of a tubular floret, some of the cells of which contain rosette aggregates of calcium oxalate; $e p^{\prime}$, epidermis of the under surface of a ligulate corolla; $P$, section of pappus showing some of the lignified cells, some of which contain monoclinic prisms as shown at $r h ; p a$, parenchyma of a bract; $F r$, somewhat thickened, porous cells of the pericarp of the achenes; $D$, glandular hairs found on the wall of the ovary; $p o$, pollen grains; iep, cells of the involucre between the bracts.-After Hanausek.

tion of a solution of potassium hydroxide, which fades on the addition of an excess of acetic acid. Furthermore, upon the addition of either sulphuric acid or hydrochloric acid, the contents are colored yellow- 
ish-green, finally changing to brownish-black. Nitric acid produces a yellowish-brown color. The addition of ferric chloride to the powder colors some of the fragments greenish-black. Outer epidermal layer of the involucral scales consist of $(a)$, polygonal cells, having a striated cuticle; $(b)$, numerous T-hairs consisting of a 2-celled stalk and a horizontal needle-shaped unicellular summit; $(c)$, sessile glandular hairs, having a 2- to 8-celled secreting head. Fragments of pistil show club-shaped, sessile, glandular hairs; small prisms of calcium oxalate; and brownish-resin canals. Fragments of corolla show elongated outer epidermal cells, having a striated cuticle, and a few stomata, the latter being surrounded by 4 or 5 accompanying cells. Inner epidermal cells of the corolla modified to papillæ, the walls on surface view polygonal, the summit of the papillæ appearing as irregular circular central folds from which radiate the cuticular folds or striations. The vascular bundles of the scales show lignified sclerenchymatous cells and fibers. Fragments of achene show colorless thin-walled cells of pericarp and rectangular, thick-walled, porous and strongly lignified cells of the seed-coat, also a long, brown resin canal, extending throughout the entire length of achene.

Constituents.-Insect flowers contain from a trace to 0.5 per cent of a volatile oil, the Persian flowers containing the larger proportion, and the amount decreasing with the maturing of the flowers. They also contain two resins, varying from 4 to 7 per cent, the larger amount being found in the Dalmatian flowers; a small quantity of a glucoside and a volatile acid.

The toxic principle is Pyrethron, an amber-yellow, syrupy substance which is the ester of certain unidentified acids, and on saponification yields the alcohol pyrethrol which crystallizes in fine needles. The acids combined in the ester pyrethron do not give crystalline salts.

Allied Plants.-A large number of plants have been used as insecticides. A list of these with reference to literature are given by Roark (Amer. Jour. Pharm., 1919, 91, p. 25 and 91).

Adulteration.- The flowers of one or more of the Compositæ are substituted for or admixed with the genuine insect flowers. Of these the following may be mentioned: Common field or ox-eye daisy (Chrysanthemum Leucanthemum); and the yellow immortelle or everlasting (Helichrysum arenarium). It is stated that sometimes the entire stem with leaves are ground up with the flowers. Powdered insect flowers, which are bright yellow in color, have usually added to them powdered curcuma or chrome yellow (chromate of lead). 
Literature-Hanausek and Winton, The Microscopy of Technical Products, p. 310; Sievers, Pharm. Era, 1918, 51, p. 121; Faes, Schweiz. Apoth. Ztg., 1918, 56, p. 429.

Grindelia.-The leaves and flowering tops of Grindelia squarrosa, G. camporum and G. cuneifolia (Fam. Compositæ), perennial herb of western North America. Grindelia robusta, or gum plant growing on the borders of California and Mexico and extending to Minnesota and in British America from Manitoba to the Saskatchewan; Grindelia camporum, the common gum plant of California, is found extensively in the western and central portion of California; Grindelia cuneifolia and its variety palugosa is indigenous to the marshes of upper California. Grindelia is collected in early summer, when the leaves and flowering tops are covered with a resinous exudation, and dried.

Grindelia Squarrosa.-Stem cylindrical, lemon-yellow or rosecolored, 2 to $3 \mathrm{~mm}$. in diameter, longitudinally wrinkled, glandularhairy, nearly glabrous, resinous; internodes 8 to $35 \mathrm{~mm}$. in length. Leaves oblong or linear-lanceolate, from 1 to $5 \mathrm{~cm}$. in length; summit acute; base sessile or amplexicaul; margin entire or spinosely toothed; upper surface light green or yellowish-green, covered with resin and with occasional black disks of a species of Puccinia; under surface grayish-green, somewhat resinous; texture somewhat coriaceous, brittle when dry. Heads many-fiowared, truncate-conical or depressed urceolate, about 1 to $2 \mathrm{~cm}$. in diameter, with numerous lanceolate-acuminate, imbricate and resinous involucral bracts having more or less recurved tips; corus flat, deeply pitted; ray-flowers brownish-yellow and pistillate; tubular flowers yellowish-brown, perfect. Achenes slightly curved, 4 -angled, about $3 \mathrm{~mm}$. in length, commonly (but not always) corky-thickened and having a broad truncate summit, those toward the center narrower and thinner walled and with smaller areola; odor, aromatic; taste, aromatic and bitter.

Grindelia Camporum.-The leaves are broadly oblong or spatulate and shorter than those of G. squarrosa; the achenes are distinctly crescent-shaped and bi-auriculate at the summit.

Grindelia Cuneifolia.-The leaves are cuneate-oblong, from 2 to 10 $\mathrm{cm}$. in length, having a very distinct midrib and a sheathing amplexicaul base. They are also less coriaceous and of a dark green or greenish-brown color. The stigmas are very long, acute and pubescent and the achenes are bi-auriculate.

InNer Structure-See Fig. 298.

Powder.-Light greenish-brown or yellowish-brown; especially 
characteristic are the groups of broadly elliptical stomata about $0.035 \mathrm{~mm}$. in length, having wide pores, which project above the leaf surface; and the depressed, multicellular, glandular hairs, having an irregular, ellipsoidal summit, about $0.065 \mathrm{~mm}$. in diameter; cells of mesophyll spheroidal, filled with large chloroplasts, and about 0.010

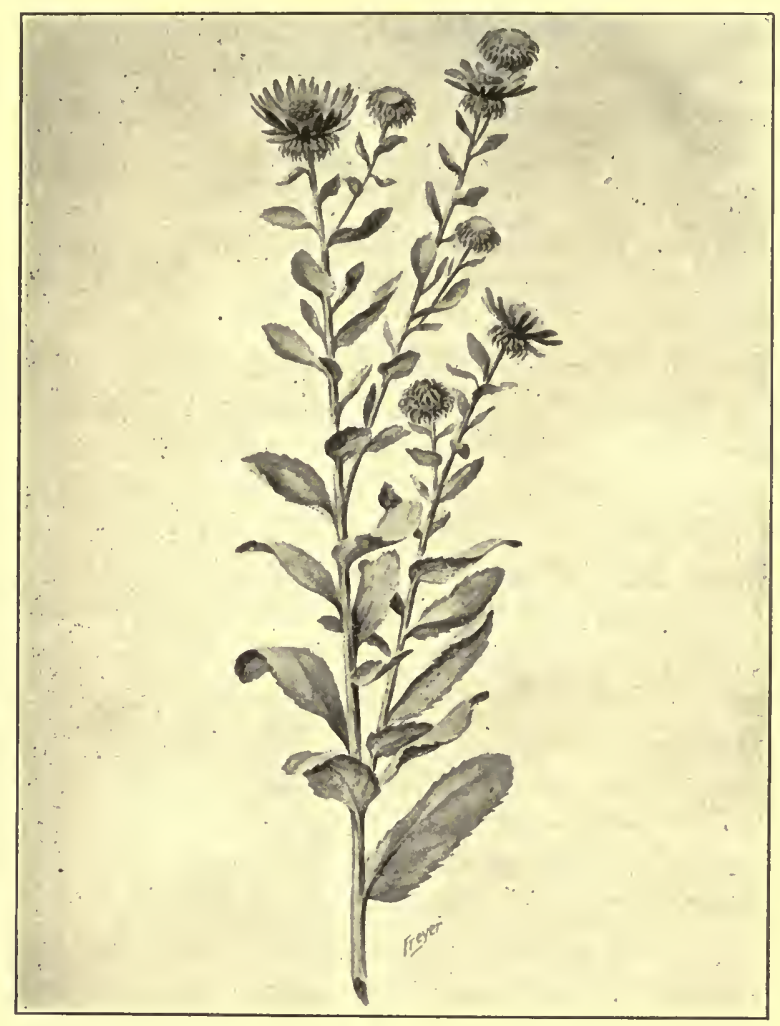

FIG. 298.-Scaly Grindelia (Grindelia squarrosa). Flowering plants showing the oblong, sharply serrate, sessile leaves; and the heads, composed of numerous imbricated, squarrosely tipped or spreading scales, the yellow ligulate, ray florets directed upwards, and the central cone of numerous tubular florets.From Bulletin 219, Bureau of Plant Industry, U. S. Department of Agriculure.

$\mathrm{mm}$. in diameter; large, somewhat elongated, thick-walled, colorless cells of water-storage tissue, mounts in glycerin usually show the precipitation of a granular resinous mass, and acicular or narrow rodshaped crystals; pollen grains, spheroidal, about $0.035 \mathrm{~mm}$. in diameter, having 3 pores and a spinose cuticle; stem fragments 
showing tracheæ having annular and spiral thickenings and simple or bordered pores, associated with numerous narrow, strongly lignified wood fibers; pith cells more or less tabular and containing a layer of protoplasm in which are embedded numerous spheroidal granules.

Constituents.-Resinous substances amounting to about 21 per cent, including a soft greenish resin soluble in petroleum ether, a dark-colored resin soluble in ether and a dark-colored, amorphous resin soluble in alcohol; a lævorotatory sugar l-glucose; tannin $\mathbf{1 . 5}$ per cent; a volatile oil having the characteristic odor or the drug; and about 8 per cent of ash. The drug has also been reported to contain two glucosides, 0.8 per cent. (G. squarrosa) to 2 per cent (G. robusta), somewhat resembling the saponins in quillaja and senega; and a bitter crystalline alkaloid, grindeline.

Allied Plants.-Other species of Grindelia growing in the western United States and Mexico are similarly employed, as G. hirsutula, the stems of which are purplish-red and pubescent; and G. glutinosa, in which the leaves are glabrous, rounded at the summit, the pappus being 5 - to 8-toothed.

Literature.-Perrédès, Proc. A. Ph. A., 1906, p. 370; Power and Tutin, Ibid., 1905, p. 192, and 1907, p. 337.

Eupatorium.-Boneset.-The leaves and flowering tops of Eupatorium perfoliatum (Fam. Compositæ), a perennial herb (Fig. 300) indigenous to eastern and central North America. Boneset is collected in July and August and dried.

Description.-Usually in more or less broken fragments. Stem cylindrical, somewhat quadrangular, flattened, about $3 \mathrm{~mm}$. in diameter, longitudinally wrinkled, tomentose; internodes 5 to $8 \mathrm{~cm}$. in length. Leaves lanceolate, opposite, 10 to $20 \mathrm{~cm}$. in length, 2 to $4 \mathrm{~cm}$. in breadth; summit acuminate; base connate-perfoliate; margin crenate-serrate; upper surface dark green, midrib and veins depressed, reticulate, glabrous, except near the margin; under surface yellowish- or brownish-green, midrib prominent, reticulate, very tomentose, with glistening yellow resin masses. Flowers in large cymost panicles; heads 10 - to 15 -flowered, about $5 \mathrm{~mm}$. in length, torus flat; involucre light green, oblong, the scales, imbricate, linearlanceolate, hairy; corolla 5-toothed, whitish; anthers purplish, included; style deeply cleft, much exserted. Achenes 5-angled, pappus consisting of a single row of about twenty rough bristles; odor aromatic; taste bitter.

Inner Structure.-In the leaves, the epidermal cells are undulate, especially on the dorsal surface, the stomata being slightly raised 

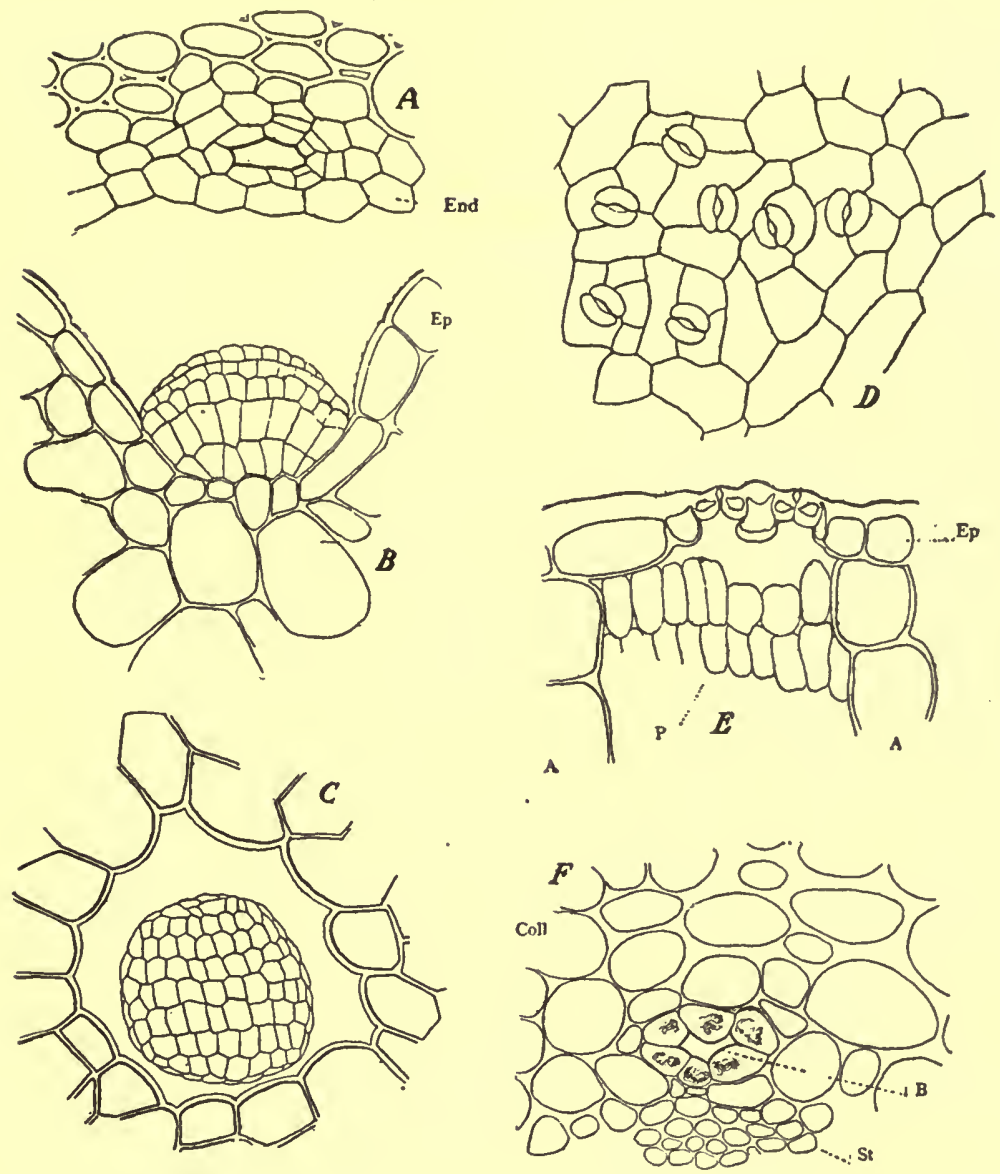

'IG. 299.-Grindelia squarrosa: $A$, transverse section of a portion of the stem, showing a large resin canal bordering on the endodermis $(E n d) . \quad B$, transverse section of a portion of a leaf showing the epidermal cells $(E p)$, and a large sessile glandular hair, in the depressed epidermal layer. $C$, surface view of a glandular hair, situated in a wide cavity of the epidermis. $D$, surface view of the epidermal cells from the dorsal surface of the leaf, showing a small group of stomata. $E$, transverse section of the dorsal layers of the leaf, showing the epidermal cells $(E p)$, having thick outer walls and 2 of the stomata; palisade cells $(P)$; and part of the water-storage tissue $(A) . F$, transverse section of part of a midrib of the leaf; Coll, collenchyma; $B$, a resin canal; St, the stereomatic pericycle.-After Holm, Merck's Report, 1910, p. 310. 
above the adjoining epidermis and without subsidiary cells; the non-glandular hairs are of 2 kinds: (a), uniseriate and filiform; (b), uniseriate, thick-walled, pointed and more or less curved; glandular hairs short, and capitate; the mid-vein is composed of 3 separate mestome strands, surrounded by large thin-walled waterstorage tissue. Resin canals are formed in the vicinity of the endodermis in both the stem and leaves.

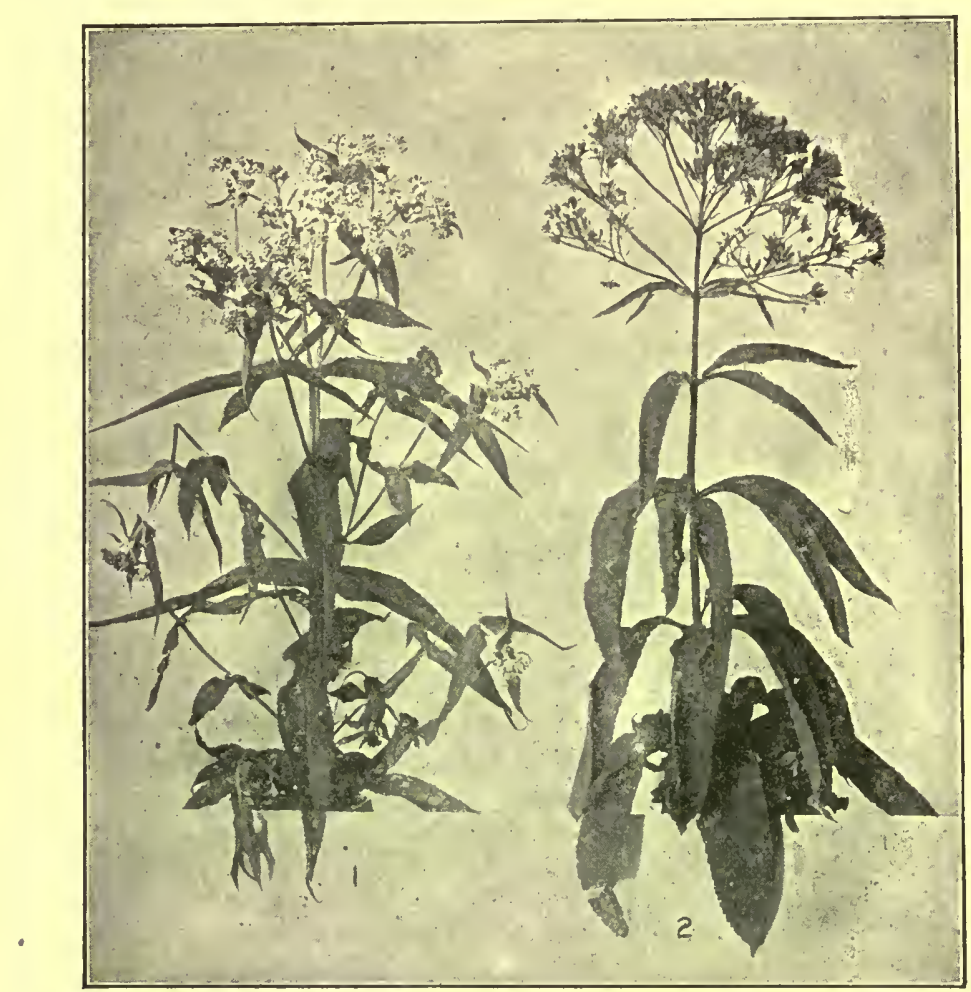

Fig. 300.-1. Eupatorium perfoliatum with opposite, connate-perfoliate leaves and cymose-paniculate inflorescence. 2. Eupatorium purpureum with verticillate, petiolate leaves, and a large terminal panicle of flowers.

Powder.-Dark green; non-glandular hairs 2- to 8-celled, thinwalled, finely striate, $(a)$ having an acute end cell and (b) having a rounded summit; glandular hairs either 6- to 8-celled in a double row, and with a 2-celled glandular head, or short-stalked and with a 4- to 12-celled glandular head; pollen grains ellipsoidal, 0.010 to $0.020 \mathrm{~mm}$. in diameter and with numerous centrifugal projections; pappus occurring as a multicellular axis about $0.030 \mathrm{~mm}$. in diameter 
and with short, unicellular, alternate branches; tracheæ spiral, annular, or with bordered pores; sclerenchymatous fibers thinwalled, non-lignified, having few, simple, oblique pores.

Constituents.-Volatile oil; a bitter, crystalline glucoside, eupatorin; resin; a crystalline wax; a glucosidal coloring principle related to tannin but crystallizing in small yellow needles, and giving an orange-red precipitate with lead acetate solution; a glucosidal tannin, which is colored deep green with ferric chloride and gives a yellow precipitate with lead acetate solution; gallic acid; ash 7.5 to 9.9 per cent.

Allied Plants.-Purple boneset or Joe-pye weed (Eupatorium purpureum), a common herb (Fig. 370) in low grounds in eastern and central North America, is a tall stout herb, with oblong-lanceolate leaves, 3 to 6 in a whorl and light purplish-red flowers in dense corymbs. Purple boneset contains a volatile oil, 0.07 per cent; a yellow crystalline principle euparin, which somewhat resembles quercitrin; resin, 0.25 per cent; calcium oxalate, 1.82 per cent; and ash, 14 per cent. Dog-fennel (E. fæniculaceum), a perennial herb, with alternate, 1- to 2-pinnately parted leaves and white flowers, which is common in the Southern States, yields a volatile oil which contains considerable phellandrene.

The root of Eupatorium perfoliatum contains about 5 per cent of inulin.

Literature.-Holm, Merck's Report, 1908, p. 326.

Absinthium.-Common Wormwood or Absinth.-The leaves and flowering tops of Artemisia Absinthium (Fam. Compositæ), a shrubby, perennial herb, growing in waste places in the northern United States and Canada. It is cultivated in Europe, northern Africa, New York, Michigan, Nebraska and Wisconsin. The volatile oil is used in the preparation of the French Absinthe. The leaves and flowering tops are gathered during the summer or early fall, carefully dried and preserved.

Description.-Leaves from 5 to $12 \mathrm{~cm}$. in length, 2- to 3-pinnately divided, the lobes being obovate or lanceolate, entire or toothed, the lower being long petiolate; heads greenish-yellow, hemispherical or ovoid and arranged in panicles, the involucral scales being in 2 series, the inner linear and having membranous margins, the florets are all tubular, the outer ones sometimes being neutral. The herb is aromatic and very bitter.

Inner Structure.-Non-glandular hairs of 2 kinds: (a), unicellular, very long; (b), T-hairs consisting of a 1- to 4-celled stalk, bearing a single horizontal cell at the summit; glandular hairs having 
a 1- or 2-celled stalk, and a glandular summit consisting of 4 to 8 cells; pollen grains spheroidal, about $0.030 \mathrm{~mm}$. in diameter, nearly smooth, and having 3 pores; calcium oxalate in rosette aggregates about $0.010 \mathrm{~mm}$. in diameter; tracheæ either spiral or having simple pores, associated with slightly thickened, lignified, porous libriform.

Constituents.-The fresh drug contains about 0.5 per cent of a volatile oil which is of a dark green or blue color, has a bitter, persistent taste but not the pleasant odor of the plant, and consists of d-thumone (absinthol), thujyl alcohol, free and combined with acetic, isovalerianic and palmitic acids, phellandrene and cadinene. The other constituents of the drug include a bitter glucosidal principle, absinthiin, which forms white prisms and yields on hydrolysis a volatile oil; a resin; starch; tannin; succinic acid, potassium succinate, and about 7 per cent of ash.

Achillea.-Yarrow or Milfoil.-The leaves and flowering tops of Achillea Millefolium (Fam. Compositæ), a common roadside weed (Fig. 301), naturalized from Europe and Asia, and contains about 0.1 per cent of a dark blue volatile oil with a strongly aromatic odor and a small amount of a bitter alkaloid, achilleine. The roots of yarrow, on the other hand, yield a volatile oil with a valerian-like odor.

Achillea Nobilis of Europe contains an oil resembling that of yarrow, but it is of finer quality and has a spice-like taste. Achillea moschata, an alpine plant of Europe, yields three alkaloids and a volatile oil containing cineol, and is used in Italy in the preparation of the liquor, "Esprit d'Iva." Achillea tanacetifolia yields a blue volatile oil having the odor of tansy.

Tanacetum.-Tansy.-The leaves and flowering tops of Tanacetum vulgare (Fam. Compositæ), a perennial aromatic herb (Fig. 302 ), indigenous to Europe, extensively cultivated and naturalized in the United States. The leaves are large and pinnately divided, and the flowers, both tubular and ligulate, are yellow, the heads being in terminal corymbs.

The powder is yellowish-green; non-glandular hairs few, 4- to 5-celled, about $0.150 \mathrm{~mm}$. in length, the individual cells being somewhat oblong and with yellowish-brown contents; glandular hairs on achenes with short stalk and large, ellipsoidal head; involucral bracts with a row of transparent marginal cells and central portion with narrow, thick-walled, libriform cells having numerous simple pores; pollen grains spheroidal, thick-walled and with numerous spinose, centrifugal projections; narrow tracheæ having scalariform 


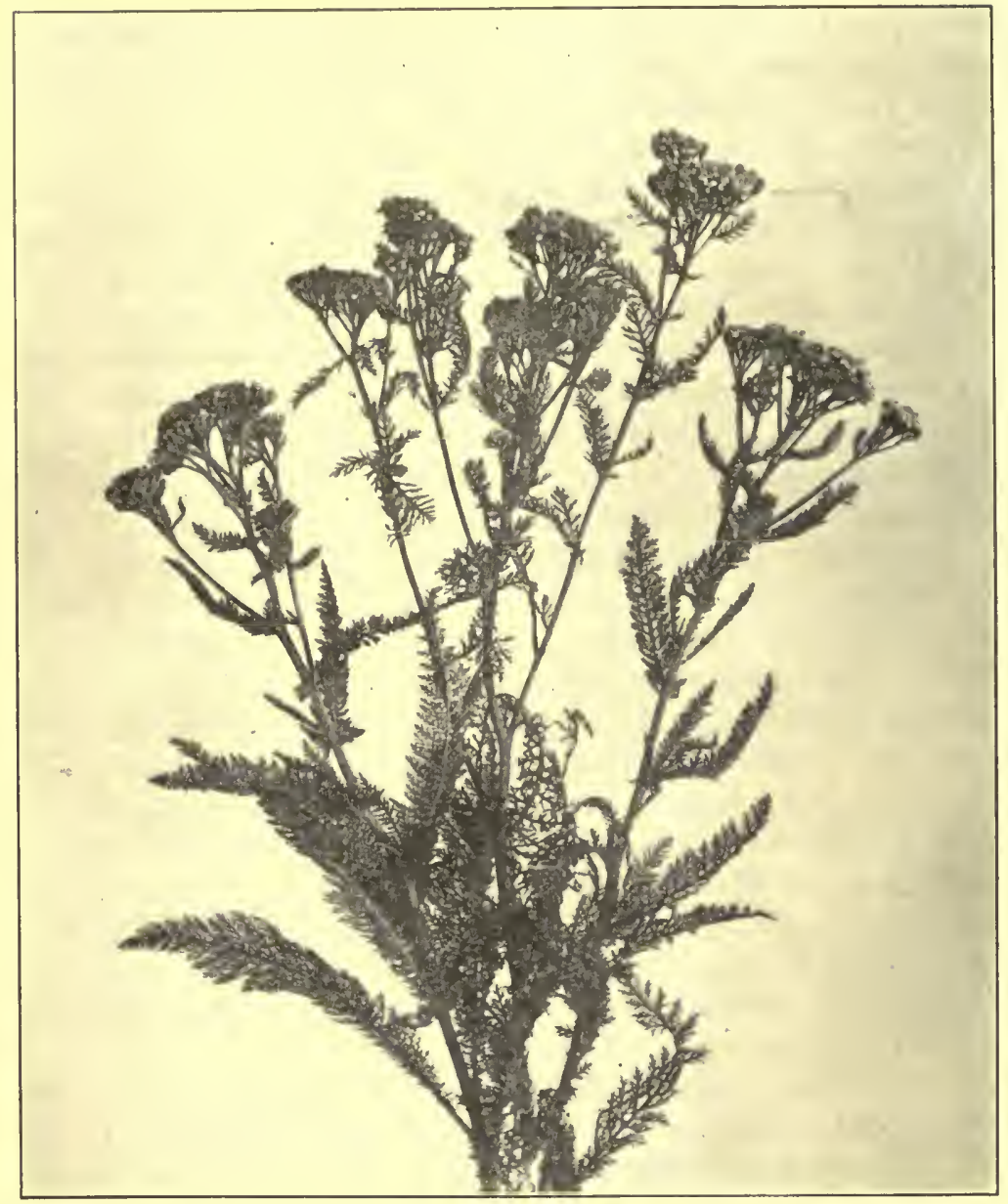

FIG. 301.-Achillea Millefolium. Common yarrow. A very common hardy weed, persisting along roadsides and waste places when nearly all other vegetation is destroyed. Although not flowering until June the leaves are among the first to emerge from the ground in the early spring. Stems simple, occasionally branched above; leaves lanceolate in outline, pinnately dissected; flowers white to crimson, in compound, flat-topped corymbs. The generic name alludes to the supposition that Achilles discovered the virtues of the plant, and the specific name alludes to the numerous divisions of the leaf.After Brown. 
and reticulate perforations or bordered pores; sclerenchymatous fibers thin-walled and free from pores.

Tansy yields from 0.1 to 0.3 per cent of a volatile oil, consisting of thujone, borneol and camphor; and also contains 3 resins.

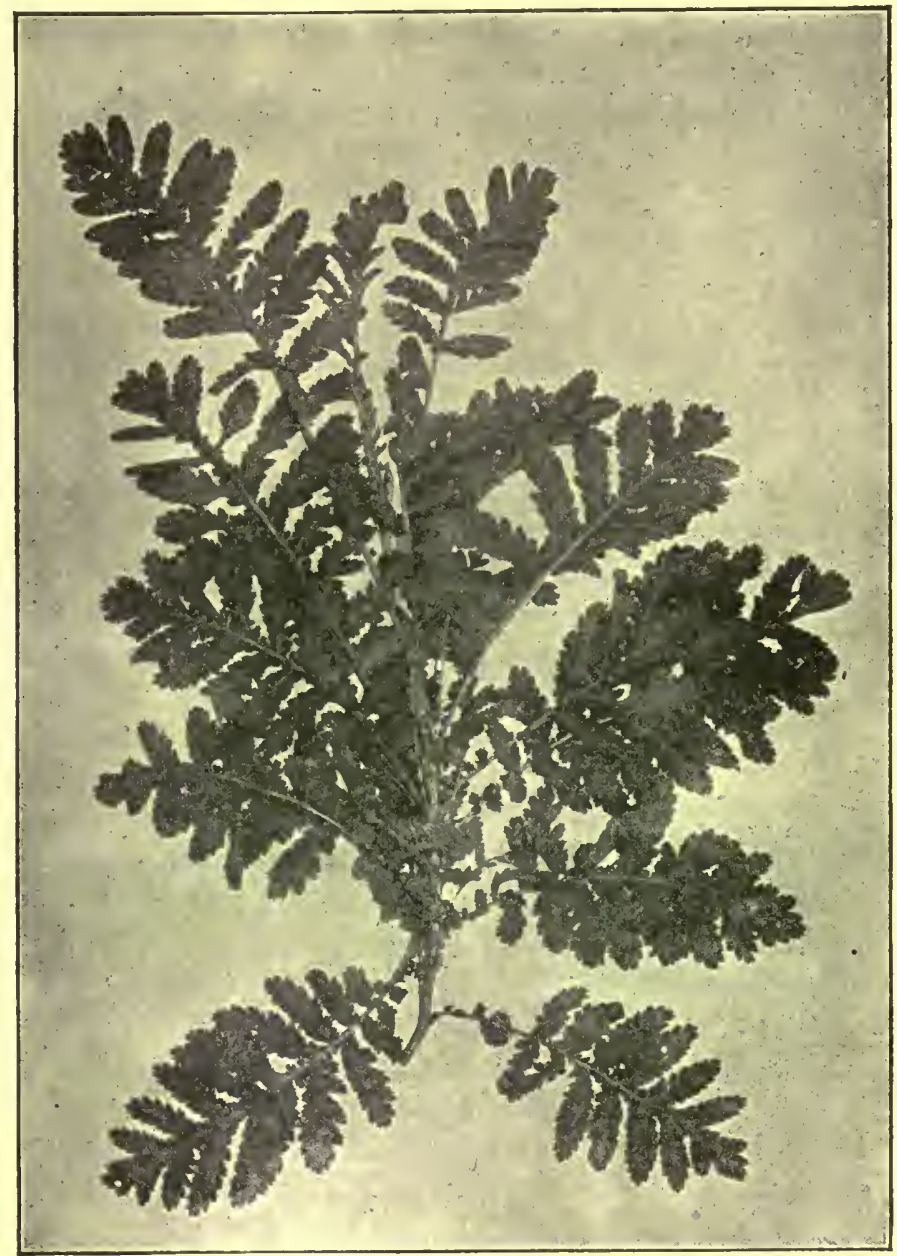

FIG. 302.-Branch of Tansy (Tanacetum vulgare) showing closely alternating, deeply pinnatifid or pinnately divided leaves, the divisions being linear, oblong and variously lobed and incised.

Folita Farfare.-Tussilago or Colts Foot.-The leaves of Tussilago Farfara (Fam. Compositæ), a low perennial or acaulescent herb, indigenous to Europe and growing in wet places and along 
roadsides in the northern United States and Canada. The variegated variety, the leaves of which have a creamy white margin, is a common ornamental plant, thriving in shady places. The leaves are gathered in June and July, after the flowering of the plant, carefully dried and preserved.

Description.-Usually in broken pieces; leaves ovate-reniform, long petiolate, from 8 to $15 \mathrm{~cm}$. in length; summit acute, base cordate, margin angulately lobed, and dentate having reddish-brown teeth; ventral surface, dark green and glabrous; dorsal surface white tomentose, having prominent 5 to 9 palmate-veins; odor slight; taste mucilaginous and slightly bitter.

Inner Structure.-Epidermal cells of dorsal surface polygonal, the cuticle being finely papillose; epidermal cells of the ventral surface undulate, having numerous stomata and hairs; non-glandular hairs unicellular consisting of 3 to 6 cells, the upper cells being very long, irregularly twisted and matted together; very characteristic are the 6 -sided intercellular spaces beneath the broadly elliptical stomata, which are about $0.050 \mathrm{~mm}$. in width.

Constituents.-A small quantity of volatile oil; about 2.6 per cent of a bitter glucoside; a caoutchouc-like substance; mucilage; gallic acid; dextrin; about 6.2 per cent of albuminous substances; and ash from 15 to 20 per cent.

Literature--Meyer, Wissenchaftliche Drogenkunde, Vol. II., p. 216.

Pyrethrum.-Pellitory.-The root of Anacylus Pyrethrum (Fam. Compositæ), a perennial herb indigenous to northern Africa and southern Europe, the commercial article coming from Algeria. The root is collected in autumn and dried.

Description.-Nearly cylindrical, slightly tapering, or broken into irregular pieces, 2.5 to $10 \mathrm{~cm}$. in length, 3 to $20 \mathrm{~mm}$. in diameter; externally dark brown, wrinkled and somewhat furrowed longitudinally, with few rootlets or rootlet-scars; crown somewhat annulate from scars of bud-scales, and sometimes tufted with coarse fibers of fibrovascular tissue or having long, soft-woolly, nearly straight, onecelled hairs; fracture short and horny when dry, tough when damp; bark dark brown internally, with two circular rows of resin canals, 0.5 to $1 \mathrm{~mm}$. in thickness, and closely adhering to the light yellow, radiate, porous wood, in the medullary rays of which resin canals are also found; odor distinct, penetrating; taste pungent, acrid.

Powder.-Light to dark brown; parenchymatous cells with irregular crystalloidal masses of inulin; periderm having nearly isodiametric stone cells, the contents of which are yellowish-brown; 
tracheæ reticulate, narrow; sclerenchymatous fibers few; resin canals containing yellowish-brown amorphous masses of a volatile oil and resin.

Constituents.-An alkaloid pyrethrine, which occurs in colorless, acicular crystals, has an intense pungent taste, and which is decomposed by alkalies into piperidire (a pungent principle occurring in black pepper) and pyrethric acid, a principle resembling piperic acid. Pyrethrum also contains a brown acrid resin, two other acrid resins, a volatile oil and about 50 per cent of inulin.

Allied Plants.-German pellitory, the root of Anacyclus officinarum, is smaller; the bark contains but one row of secretion reservoirs, which are wanting in the medullary rays; and the roots contain tannin in addition to the constituents found in Pyrethrum.

TARAXACUM.-Dandelion.-The root of Taraxacum officinale (Fam. Compositæ), a perennial herb indigenous to Europe and Asia, but now naturalized in all civilized parts of the world. The root should be collected in spring or in autumn either directly before or after the vegetative activity of the plant. It is used in either the fresh or dried condition, the principal supply of the dried root coming from Europe. The pith of the rhizome portion is liable to be attacked by insects. The product should be stored in tightly closed containers, to which a few drops of chloroform or a carbon tetrachloride should be added, from time to time, to prevent the development of insects.

Description.-Somewhat cylindrical, tapering, more or less flattened, slightly branched or broken into irregular pieces 6 to 15 $\mathrm{cm}$. in length, 5 to $15 \mathrm{~mm}$. in diameter; externally light brown, wrinkled, with numerous rootlet-scars; crown simple or branched slightly annulate from numerous leaf-bases; fracture short, horny when dry, tough when damp; internally, bark light brown, 2 to 6 $\mathrm{mm}$. in thickness, made up of concentric layers of laticiferous vessels and sieve alternating with white parenchyma, wood lemon-yellow, 1 to $4 \mathrm{~mm}$. in thickness, porous and non-radiate; odor slight; taste bitter.

Inner Structure.- - See Fig. 303.

Powder.-Light brown; parenchyma containing irregular crystalloidal masses of inulin; laticiferous vessels yellowish-brown; tracheæ reticulate; intermediate fibers non-lignified, with irregular simple and oblique pores.

Adulterant.-The roots of one or more species of Lactuca have been substituted. The wood is radiate, the tracheæ being one cell wide alternating with medullary rays two or three cells in width. (U. S. Dept. Agric.) 
Constituents.-A bitter, amorphous, dark-colored substance; inulin about 25 per cent; a volatile oil; an enzyme; levulose; choline; $\rho$-hydroxyphenylacetic acid; $3: 4$-dihydroxycinnamic acid;
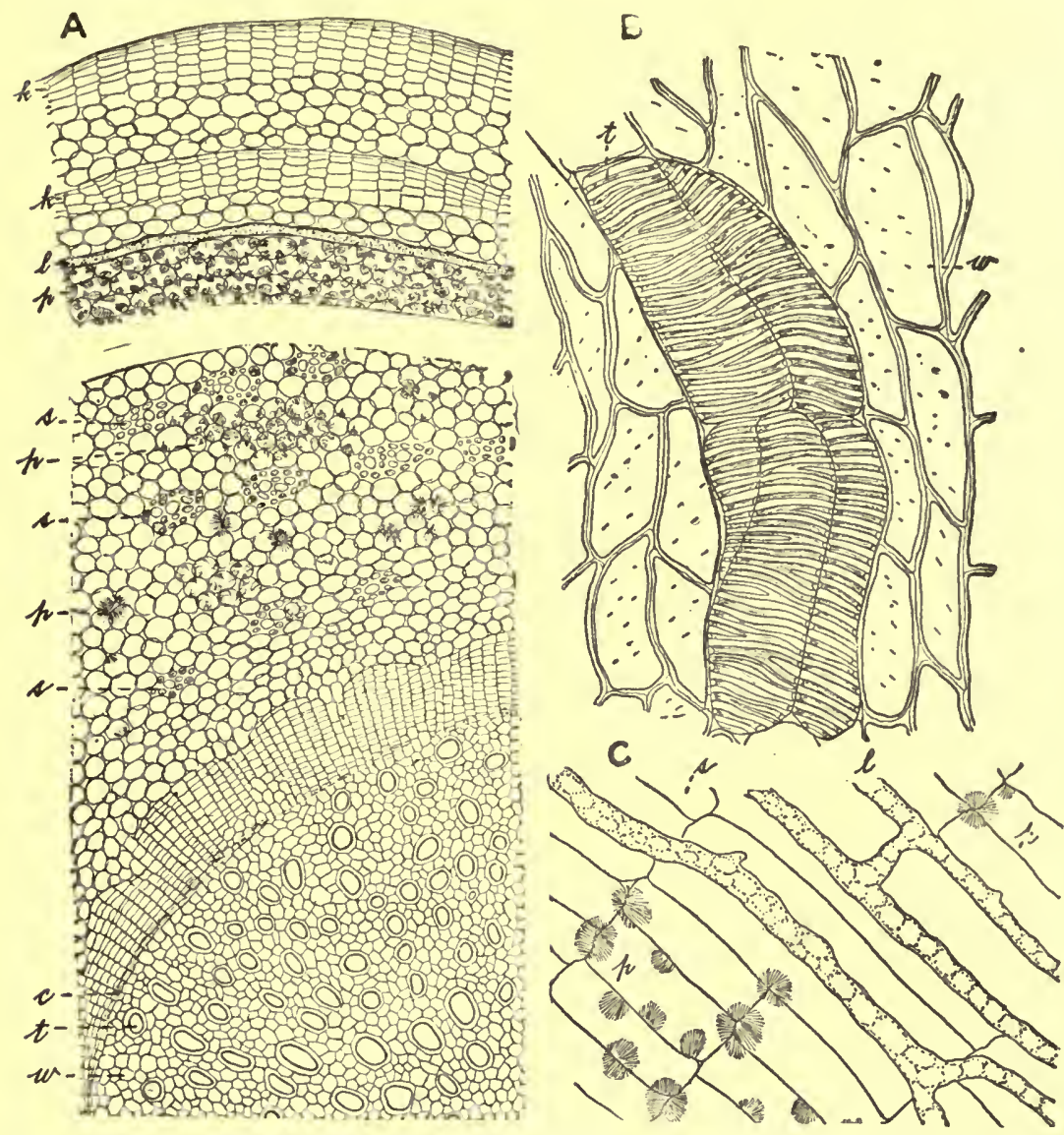

Fig. 303.--Taraxacum: $A$, transverse section of root showing cork (k), parenchyma containing inulin $(p)$, laticiferous vessels $(l)$, phloem groups $(s)$ composed of sieve and laticiferous vessels, cambium $(c)$, trachex $(t)$, modified, non-lignified wood fibers (Ersatzfasern) $(w) . \quad B$, longitudinal section of xylem showing several of the reticulate trachex and the modified wood fibers with oblique pores that are apparent in preparations, made with chlor-zinciodide. $C$, longitudinal section of a phloem group showing branching laticiferous vessels $(l)$, sieve cells $(s)$, and parenchyma $(p)$ containing sphere crystals of inulin.

a mixture of fatty acids; two new monohydric alcohols, taraxasterol and homotaraxasterol; and a substance which had been desig- 
nated "cluytianol" (see Cluytia similis, p. 401), but which apparently is a phytosterol glucoside.

Literature.-Power, Jour. Chem. Scc., 1912, p. 2411.

Cichorium.-Chicory, Succory or Blue Dandelion Root.The rhizome and roots of Cichorium Intybus (Fam. Compositæ), a perennial herb, indigenous to Europe and localized throughout the northern United States and Canada. The rhizome, with its continuation, the root, is upright, fusiform, and deep seated. They are gathered in the autumn and cut transversely to facilitate drying. The product should be stored in tightly closed containers, to which a few drops of chloroform or carbon tetrachloride should be added, from time to time, to prevent the development of insects.

Chicory somewhat resembles Taraxacum, but the outer surface is light or dark brown, and irregularly, often spirally wrinkled; the inner surface shows a thick bark, having radiating strands of phloem; a yellowish wood having narrow radiating medullary rays, and xylem wedges with broad tracheæ.

Chicory, when ground, is used as a substitute for coffee. The fragments are irregular, dark brown in color, soft and having a sweetish taste. When placed in water, the fragments sink, imparting to the solution a yellowish-brown color. Under the microscope the fragments show irregular masses of inulin in the parenchyma cells; branching latex vessels from 0.005 to $0.010 \mathrm{~mm}$. in width; tracheæ short, more or less cylindrical, with pointed ends, from 0.100 to 0.200 $\mathrm{mm}$. in length and 0.020 to $0.040 \mathrm{~mm}$. in width, having large, elliptical, simple pores. Associated with the tracheæ are slightly thickened, elongated parenchyma cells with narrow, oblique pores.

Chicory is sometimes adulterated with the roots of dandelion, carrot, beet and turnip, as well as cereal products.-Winton and Moeller, Microscopy of Vegetable Foods, p. 438.

InULA.-Elecampane.-The rhizome and roots of Inula Helenium (Fam. Compositæ), a large perennial herb, indigenous to central Europe and Asia, and naturalized from Canada to North Carolina. The rhizome with branching roots, of 2- or 3-year old plants, are collected, either in the spring or fall, cut longitudinally, carefully dried and preserved. Sometimes the roots are cut transversely and occasionally the outer corky layers are removed.

Description.-When entire fusiform, irregularly branching, the crown being somewhat annulate and surmounted by a stem scar, the lower portion being longitudinally wrinkled; the pieces, very irregular in shape, varying in length from 3 to $8 \mathrm{~cm}$., and 0.6 to $4 \mathrm{~cm}$. in diameter; externally light to dark brown, longitudinally wrinkled, 
with short roots or circular root scars, and occasionally having the cork more or less abraded, showing a grayish-white cortex; inner surface of the longitudinal pieces, either flattened or shallow, light brown or grayish-brown, longitudinally striate and showing a more or less distinct, dark brown cambium; fracture tough, horny and somewhat uneven; inner surface light brown, showing a distinct cambium and numerous large resin canals in both the xylem and cortex; odor distinct, aromatic; taste sweetish, aromatic, slightly acrid and pungent.

Inner Structure.-Rhizomes occasionally show the characteristic, uniseriate hairs of the epidermis (Fig. 304); periderm usually narrow, consisting of somewhat rectangular, thin-walled brownish cells; cortex of inulin-containing parenchyma, the inner layers having radial strands of phloem, consisting of leptome and parenchyma, separated by broad medullary rays, containing spheroidal resin canals (Fig. 304), the latter from 0.100 to $0.200 \mathrm{~mm}$. in diameter, the canals being lined with thin-walled epithelial cells; cambium distinct; xylem consisting of radiating wedges, composed of numerous parenchyma cells and a few tracheæ and wood fibers, separated by broad medullary rays, interspersed with resin canals similar to those in the cortex; pith composed of inulin-containing parenchyma.

In thick rhizomes, the xylem occurs in a broad continuous ring consisting of numerous, thick-walled and strongly lignified wood fibers, surrounding the tracheæ, and in the cortex there is a strong development of bast fibers, in the form of semi-circular groups, outside the strands of leptome.

The roots show a similar structure to the rhizome, but the primary tracheæ are associated with elongated thin-walled, lignified cells, having reticulate perforations.

In the intercellular spaces, between the parenchyma cells, occur occasionally a yellowish-brown or brownish-black carbon-like substance, termed phytomelane. For further discussion of this subject, with illustrations, consult Kraemer's Applied and Economic Botany, pp. 258-261.

Powder.-Very light brown; on boiling with water it emits a distinct aromatic, pepper-like odor, distinguishing it from belladonna; inulin (Fig. 304), in parenchyma cells, mostly in the form of separate, irregular, colorless granules, varying from 0.010 to 0.030 $\mathrm{mm}$. in diameter; fragments of yellowish-brown or reddish-brown resin masses; tracheæ having narrow lumina and large elliptical perforations, occasionally bordered pores; wood fibers very narrow, strongly lignified and marked by numerous simple pores; fragments 
of cork rectangular or somewhat polygonal, and having relatively thin brownish-walls, the cells usually containing a granular cytoplasm and a nucleus; small groups of narrow, elongated sclerenchymatous fibers; fragments of resin canals with thin-walled epithelial cells.

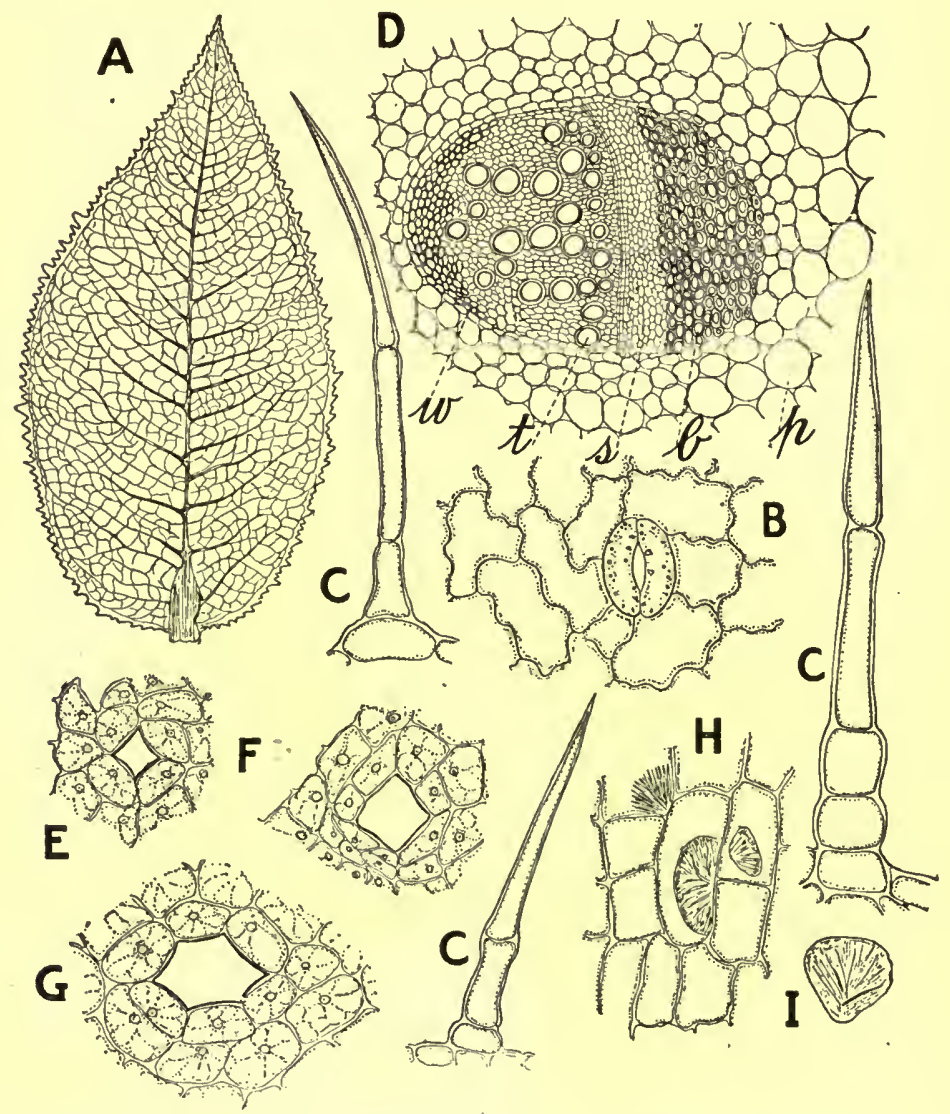

FIG. 304.-Elecampane (Inula Helenium): $A$, one of the smaller leaves near the inflorescence. $B$, under surface of the leaf. $C$, hairs of leaf. $D$, transverse section of petiole showing parenchyma $(p)$, lignified bast fibers $(b)$, sieve $(s)$, tracheæ $(t)$, and somewhat thickened cells of wood $(w) . E, F, G$, successive stages in the development of the intercellular or schizogenous oleo-resin canals of very young roots. $H$, sphere-crystals of inulin as seen in the root after treatment with alcohol. $I$, single sphere-crystal.

Constituents.-Inulin from 35 to 45 per cent; from 1 to 2 per cent of alantöl, a crystalline or somewhat oily substance, consisting chiefly of alantolacton and small quantities of alantolic acid, alantol 
camphor and isoalantolacton; a bitter principle; mucilage; inulenin; and pseudoinulin.

Adulteration.--Through carelessness, belladonna root is sometimes substituted for inula. The former is characterized in contain-

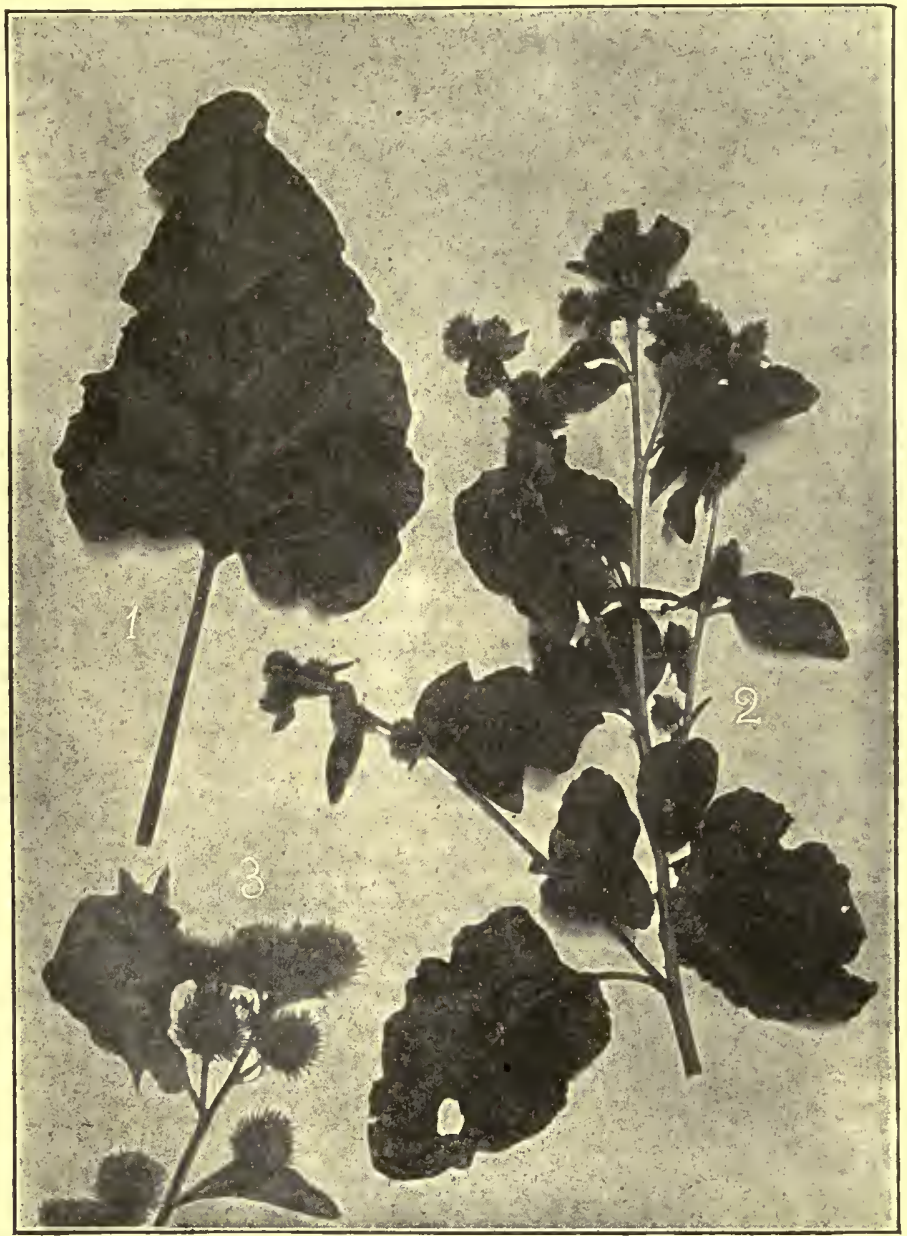

FIG. 305.-Burdock (Arctium Lappa) showing large basal leaf, a flowering branch, and at the lower left-hand corner a few of the burs on which a bat has been caught and apparently held until it died.

ing starch and having a distinct heavy odor (see Belladonnæ Radix).

LAPPA.-Burdock.-The root of Arctium Lappa and of other species of Arctium (Fam. Compositæ), biennial herbs (Fig. 305) indigenous to Europe and northern Asia, and naturalized in waste 
places in the United States and Canada. The fleshy root is collected in autumn from plants of the first or second year's growth, and carefully dried.

Description.-Nearly cylindrical, slightly tapering, or broken and split longitudinally into pieces, 10 to $20 \mathrm{~cm}$. in length, 5 to 20 $\mathrm{mm}$. in diameter; externally, bark dark brown, longitudinally wrinkled, with few rootlets or rootlet-scars, crown somewhat annulate from scars of bud-scales and sometimes surmounted by a soft, woolly tuft of leaf-remains having unicellular, twisted hairs; fracture short, horny when dry, tough when damp; internally light brown, radiate, bark 2 to $3 \mathrm{~mm}$. in thickness, wood porous, cambium zone distinct; odor slight; taste mucilaginous, slightly bitter.

Old woody roots in which the pith is more or less obliterated and which have been collected from the fruiting plant should be rejected.

Inner Structure.-Periderm consisting of thin-walled, brownish, rectangular cork cells; cortex consisting of inulin-containing parenchyma, the inner layer having narrow strands of leptome; cambium distinct; xylem composed of narrow wedges, made up mostly of wood parenchyma, and a few thin-walled wood fibers and wide tracheæ, separated by broad medullary rays; the wood parenchyma and medullary rays contain inulin in the form of highly refractive, irregular masses, varying from 0.006 to $0.045 \mathrm{~mm}$. in length; tracheæ from 0.050 to $0.150 \mathrm{~mm}$. in width, and marked by numerous narrow, simple pores, and occasionally accompanied by narrow thinwalled wood fibers. Tissues of the pericycle and primary.cortex are commonly seen in the outer layers of the bark. The outer cortical region of young roots, shows an interrupted circle of resin canals, which are wanting in older roots.

Powder.-Light yellow; parenchymatous cells with irregular crystalloidal masses of inulin; tracheæ few, having long slit-like simple pores occasionally associated with a few narrow sclerenchymatous fibers.

Constituents.-Inulin about 45 per cent; about 0.07 per cent of a volatile oil; a bitter principle; about 0.04 per cent of a fixed oil; tannic acid; mucilage; a sugar; and ash, about 5 per cent.

The fruits of Lappa contain a bitter crystalline alkaloid, lappine; $\mathbf{1 . 1 5}$ per cent of a resin; and $\mathbf{1 5 . 4}$ per cent of a light yellow fixed oil. -Trimble and Macfarland, Amer. Jour. Pharm., 1885, p. 127.

ARNICE RADIx.-Arnicæ Rhizoma Arnica Root.-The rhizome and roots of Arnica montana (see Arnica flores). The well-developed, rather fleshy rhizomes are gathered in the fall and carefully dried. 
Description.--Rhizome horizontal or oblique; cylindrical, more or less curved and sometimes S-shaped; from 2 to $10 \mathrm{~cm}$. in length and 0.5 to $5 \mathrm{~mm}$. in thickness, externally reddish- or purplish-brown, somewhat annulate from scars of bud scales; upper surface having short stem bases, lower and under portions with numerous long coarse roots; fracture short; cortex grayish-white, about $0.075 \mathrm{~mm}$. in diameter and having a circle of resin canals, wood yellow about 0.300 $\mathrm{mm}$. in width, pith white, large; odor distinct; taste pungent, bitter and acrid.

Roots grayish- or purplish-brown, unbranched, more or less curved or frequently S-shaped, varying from 3 to $15 \mathrm{~cm}$. in length and 0.5 to $1 \mathrm{~mm}$. in thickness; longitudinally or somewhat spirally wrinkled; fracture short, somewhat tough.

Inner Structure.-Periderm consisting of a few layers of brownish cork cells, and usually containing brownish amorphous masses; cortex of inulin-containing parenchyma, having in the inner bark an interrupted circle of large resin canals, which often contain a yellowish-brown amorphous substance, either within the epithelial cells or lining the cavity of the canal; fibrovascular bundles collateral, consisting of narrow, hemispherical strands of leptome and parenchyma, and conical plates of xylem composed of numerous, narrow tracheæ and wood parenchyma and usually having a middle layer of libriform; medullary rays broad, the cells containing inulin; pith composed of nearly spheroidal, inulin-containing parenchyma cells, which are separaied by large intercellular spaces.

Constituents.-From 0.5 to 1 per cent of a volatile oil, consisting chiefly of the methyl ether of hydrothymoquinone and the phloryl ester of isobutyric acid, also the methyl ether of a phlorol. In addition, Arnica rhizome contains an amorphous substance, arnicin; about 10 per cent of inulin; tannic acid; gum; wax; several organic acids; and ash from 8 to 15 per cent.

Adulterants. - The rhizome and roots of a number of other drugs are sometimes substituted for arnica. These are distinguished by the absence of resin canals.-Consult Zörnig, Arzneidrogen, Vol. I., p. 444.

Echinacea.-The rhizome and roots of Brauneria angustifolia and B. pallida (Fam. Compositæ), perennial herbs; the former being the purple cone-flower of the southwestern United States and the latter occurring throughout the central United States and extensively cultivated, and known as the cone-flower. The rhizomes are collected from well-developed plants in the autumn and carefully dried. 
Description.-Nearly entire, cylindrical, very slightly tapering, 10 to $20 \mathrm{~cm}$. in length, 4 to $8 \mathrm{~mm}$. in diameter; externally, grayish brown, light brown or purolish-brown, slightly annulate in the upper

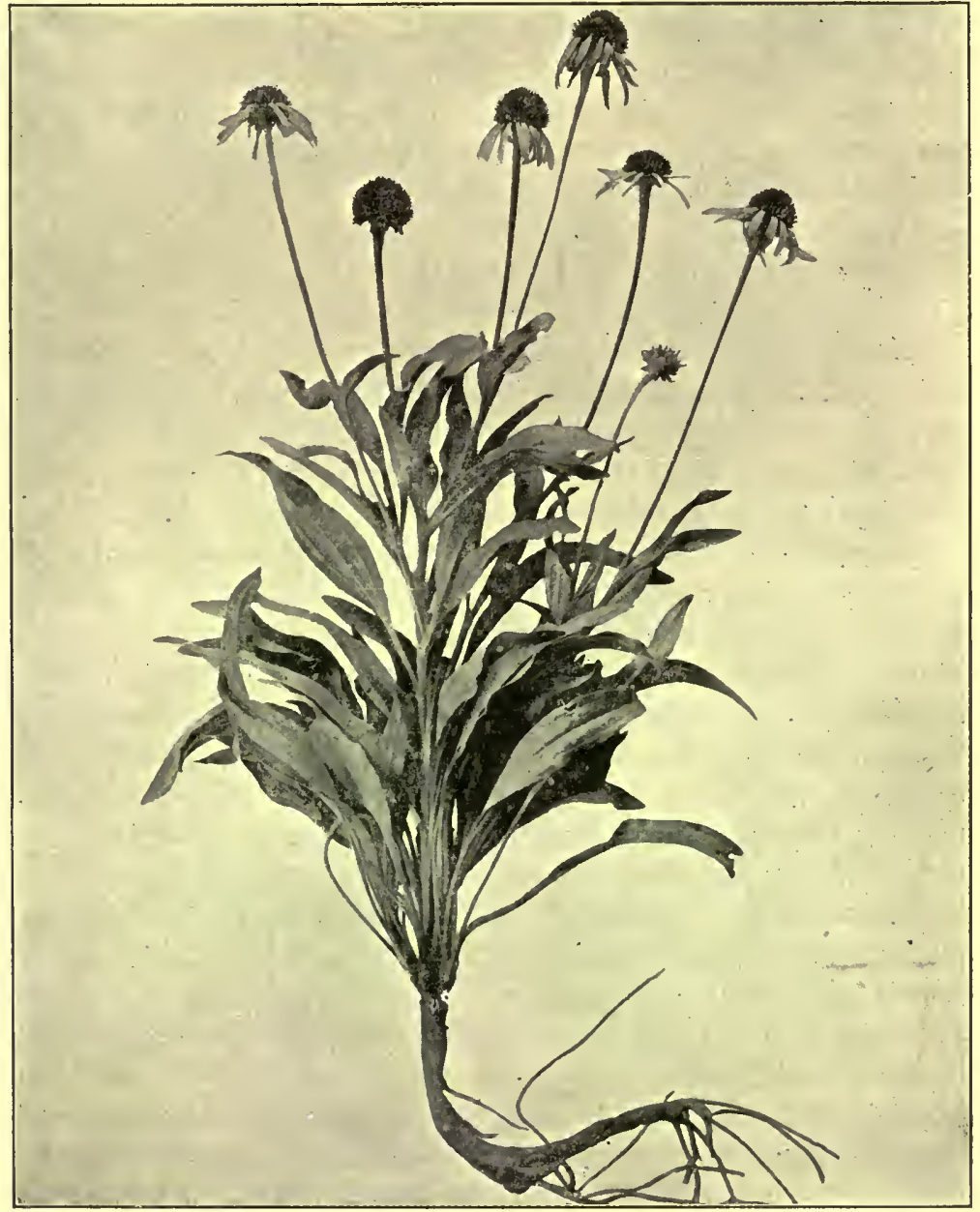

FIg. 306.-An entire plant of Brauneria angustifolia showing the lanceolate 3nerved leaves and the conical heads with reflexed ligulate, ray florets.-From Year Book, U. S. Department of Agriculture.

portion, with occasional V-shaped stem scars, somewhat wrinkled longitudinally, or furrowed and occasionally slightly spirally twisted; fracture short, fibrous; internally, bark less than $1 \mathrm{~mm}$. in thickness, wood thick and composed of alternate light yellowish and black 
wedges; the rhizome having a circular pith; odor faint, aromatic; taste sweetish, followed by an acrid and tingling sensation resembling that of aconite, but lacking the persistency and numbing qualities of the latter.

\section{INNER Structure.-See Fig. 307.}

Constituents.-Inulin 5.9 per cent; inuloid, 6 per cent; sucrose, 7 per cent; vulose, 4 per cent; betaine, 0.1 per cent; resins, 1.9 per cent, consisting of 2 isomeric phytosterols; phytosterolin; and the following fatty acids, oleic, linolic, cerotic and palmitic. Echinacea probably also contains a glucoside.

Literature.-Kraemer and Sollenberger, Amer. Jour. Pharm., 1911, p. 315; Heyl and Hart, Jour. Amer. Chem. Soc., 1915, p. 1769.

Senecio.-Golden Senecio or Ragwort, Life Root.-The overground plant of Senecio aureus (Fam. Compositæ), a perennial herb, growing in swamps and wet meadows throughout the northern and central United States. The leaves and flowering tops are gathered in the early summer and carefully dried.

Description.-Consisting of a grop of bcsal leaves and a leafy flowering scape. Basal leaves, orbicular or oblong, long petiolate, the lamina from 1 to $6 \mathrm{~cm}$. in length, and 1 to $5 \mathrm{~cm}$. in breadth; summit rounded, the base acute or cordate, the margin crenatedentate; both surfaces olive-green or purplish-green, considerably wrinkled, glabrous, the mid-vein and lower veins of the first order prominent, the latter diverging at a very scute angle and uniting near the margin; petioles from 3 to $8 \mathrm{~cm}$. in length, having 8 to 10 prominent ribs, light brown and frequently covered at the base with soft woolly hairs. Flowering stalk from 15 to $40 \mathrm{~cm}$. in length, having 8 to 10 prominent ribs, olive-green, when young, usually covered with soft woolly hairs, which are easily detachable, leaving the stems glabrous; leaves alternate, the upper sessile, the lower being petiolate, having a lanceolate outline and being usually lacinate-pinnatifid. Flowers, in open corymbs, the heads having slender peduncles which vary from 3 to $7 \mathrm{~cm}$. in length; involucral scales, linear, erect-connivent; ray florets 8 to 12 having golden yellow ligulate corollas; tubular florets yellow and perfect; achenes hairy and having a white pappus, about $6 \mathrm{~mm}$. in length; odor distinct, aromatic; taste acrid and somewhat bitter and pungent.

Inner Structure.-Epidermal cells of the lower surface having strongly undulate walls, the stomata being narrowly elliptical; about $0.030 \mathrm{~mm}$. in length, the neighboring cells being transverse to the pore; the cells of the upper surface resemble those of the lower surface, the walls, however, being only slightly undulate; transverse 


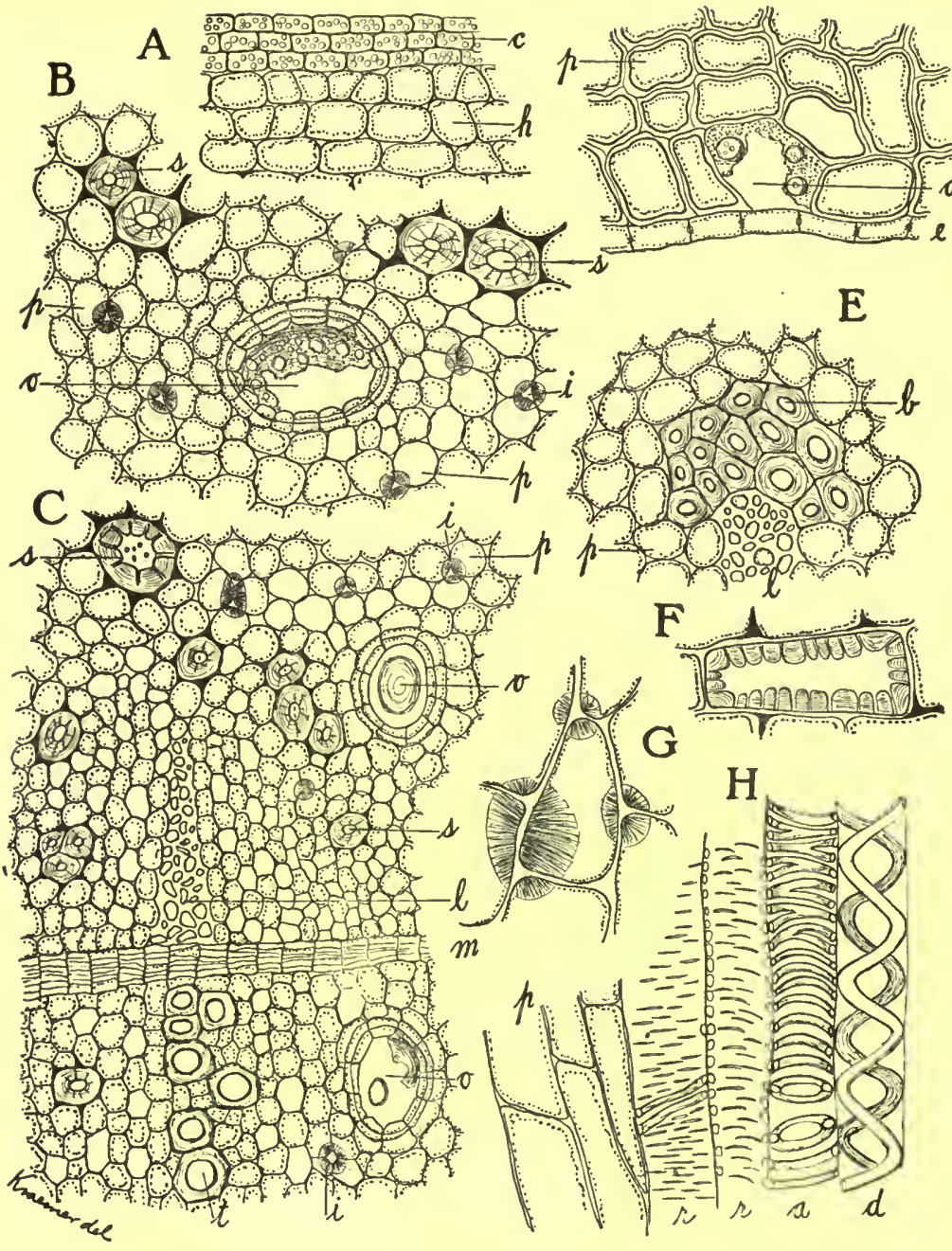

FIG. 307.-Echinacea: $A$, cross-section of outer layers of root, showing cork $(c)$ and hypodermis $(h)$. B, cross-section of cortex showing parenchyma $(p)$, sphero-crystals of inulin (i), stone or sclerotic cells $(s)$ and oleo-resin reservoirs or canals $(o)$. $C$, cross-section of portion of fibrovascular bundle showing leptome or sieve $(l)$, cambium $(m)$, trachea or vessels $(t)$, oleo-resin canals $(o)$, stone cells $(s)$, parenchyma $(p)$ and inulin crystals $(i) . D$, crosssection near endodermis showing endodermal cells with suberized radial walls or Casparyan spots (c), cndodermal resin canal (o), and parenchyma $(p) . \quad E$, cross-section of underground stem or rhizome showing a group of bast fibres $(b)$, lcptome or sieve $(l)$, and parenchyma $(p) . \quad F$, a sclerotic or stone cell. $G$, parenchyma with sphero-crystals of inulin adhering to the walls. $H$, longitudinal section showing various forms of trachea or vessels; $d$, double spiral; $a$, annular; $r$, with simple pores; $p$, adjoining parcnchyma. 
sections of the petiole are somewhat arrow-shaped, showing 2 to 4 layers of sub-epidermal collenchyma and from 8 to 10 fibrovascular bundles; the stems show a strong development of collenchyma at the ribs, and the fibrovascular bundles are arranged in a closed ring, each being surrounded by a strong development of stereome, pith hollow; woolly hairs of the stems and petioles very long thin-walled and from 0.015 to $0.040 \mathrm{~mm}$. in width; non-glandular hairs on the leaves few, uniseriate about $0.250 \mathrm{~mm}$. in length, and consisting of 5 or 6 short, cylindrical cells, having thin walls and an oily content; achenes covered with club-shaped or spatulate hairs, about $0.180 \mathrm{~mm}$. in length and finely transversely or obliquely striate; pappus multicellular, having at the jointed portions, short, sharp-pointed cells.

Constituents.-The drug has not been subject to any careful investigation, but it may contain principles similar to those found in Senecio Jacobæa (see Allied Plants).

Allied Plants.-Senecio Jacobæa, indigenous to Europe and Asia and localized to some extent in the New England States and Canada, somewhat resembles Senecio aureus. It contains about 10 per cent of a mixture of glucosides, senecionin and senecin; 2.5 per cent of a volatile oil; 0.98 per cent of a fatty substance, soluble in ether; 0.88 per cent of a mixture of fatty acids; and 0.8 per cent of ash.

Literature.-Altan, Pharm. Post, 1906, p. 485.

Lactucarium.-The dried milk-juice of Lactuca virosa and other species of Lactuca (Fam. Compositæ), biennial herbs largely indigenous to central and southern Europe and sultivated in France, England and Germany, certain species being more or less naturalized in the United States. Lactucarium is obtained by cutting off the tops of the stems; and when the latex which exudes is partially hardened, it is collected and dried in hemispherical earthen cups until it can be cut into pieces, which are usually four in number, these being further dried.

Description.-In irregular, angular pieces or quadrangular sections, one surface of which is convex; externally dull reddish- or grayish-brown; fracture tough, waxy; internally light brown or yellow. ish, somewhat porous; odor distinct, opium-like; taste bitter.

Lactucarium is partly soluble in alcohol and in ether, and about 50 per cent is soluble in water, but the solution should not give a reaction for starch.

Powder.-Grayish-brown and dark brown, irregular and rather angular masses; with alkalies they become reddish-brown and then a dirty brown; with sulphuric acid they are but slightly affected. 
Constituents.-Three bitter principles: lactucin, which occurs in white rhombic prisms that are sparingly soluble in water; lactucopicrin, a brown, amorphous, very bitter principle which is readily soluble in water and alcohol; and lactucic acid, a yellow, very bitter substance crystallizing with difficulty and colored red by alkalies. The drug also contains about 50 per cent of a colorless, odorless and tasteless crystalline principle, lactucerin (lactucon); $\beta$ - and $\alpha$ lactucerol in the form of acetates; volatile oil; mannitol; organic acids, as citric, malic and oxalic, and 7 to 10 per cent of ash.

A mydriatic alkaloid has been found in Lactuca virosa and in $\mathrm{L}$. muralis.

Dicoma Anomala.-A small plant (Fam. Compositæ), which is known in South Africa by the Kaffir name of in-nyongwane. A chemical examination showed it to consist of a small amount of an essential oil, a reducing sugar; a colorless, crystalline glucoside; a yellow amorphous product, which, on hydrolysis with alkali, gave 3:4-dihydroxycinnamic acid; an amorphous alkaloid; hentriacontane; a phytosterol; and a mixture of fatty acids. The airdried plant contained about 6 per cent of resinous material, from which a number of the above-mentioned substances were isolated.-Power; Pharm. Journ., 1913, p. 694.

\section{- ANIMAL DRUGS}

A number of animal drugs are used in medicine and a few are official in all of the Pharmacopœias. As a rule their study is much neglected by students of pharmacy and more attention should be given them, as they furnish some of the most important drugs used by man. Among the more valuable are, cantharides, cochineal and musk. In certain instances more or less definite principles are isolated, as pepsin, the proteolytic ferment found in the stomach of the hog; pancreatin, a mixture of enzymes existing in the pancreas of the hog and the ox; and wool fat, the purified fat of sheep's wool. During recent years very great interest has been manifested in the study of animal organs and a number are used either in the dried condition, or in the form of extracts, and in some cases, as from the suprarenal glands of the sheep, definite principles are extracted and employed.

Coccus.-Cochineal.-The female insect enclosing her young larvæ Coccus Cacti (Fam. Coccidæ). The cochineal insect feeds upon various species of the Cactaceæ, more especially the Nopa plant, Nopalea (Opuntia) coccinellifera, a native of Mexico and 
Peru. It has spread into other parts of Central and South America and has been introduced into the West Indies, East Indies, Canary Islands, southern Spain, Algeria, and is said to be found in Florida and California.

The FEMALE INSECT is without wings, about $2 \mathrm{~mm}$. in length and consists of from 9 to 12 segments. It is somewhat globular, becoming later distinctly ovoid. In general appearance, as it creeps over the cactus stems, it is convex on the upper (dorsal) surface, and somewhat flattened or concave below. It is covered with a protective secretion or wax which is formed as a glandular secretion by the "wax pores" Fig. 308, w, and wax hairs. The antennæ are rather short, consisting of 8 parts. The thread-like beak or proboscis, forming a sucking apparatus, is very fully developed. There are 3 pairs of legs, which in the commercial article do not show more than 3 joints. Projecting from the posterior portion of the abdomen there are 2 short hairs or bristles, which are also wanting in the commercial article.

The MALE is more elongated and ellipsoidal in outline and is provided with 2 perfectly transparent wings which reach beyond the extremity of the abdomen and cross each other longitudinally on the back. The head is distinguished from that of the female in being furnished with a rudimentary beak and with 2 long feathery antennæ. It is said that the male insect is reproduced in large numbers; the larvæ in the commercial cochineal does not show this to be the case. Upon performing their functions the male insects die and are blown away. They are therefore not present in the commercial article.

Life History.-The female insect after fecundation grows larger as the young larvæ develop, becoming eventually about twice her original size. She meanwhile attaches herself to the surface of the stems of the cacti, her body penetrating into the upper layer of cells. The upper or dorsal surface becomes more or less cartilaginous in structure and more or less convex in shape. The lower surface is drawn toward the upper surface and in this membranous cradle the larvæ are developed. It requires about eight days for the larvæ to become full grown, when they are said to resemble the parents with the exception that they are covered with a short hairy coating. In another week they attain maturity and the females of the new generation are ready to form broods in their turn. The life history of the cochineal insect is completed in about six weeks, two weeks being required for the development of the mature insect from the egg; during the next two weeks the female crawls over the fleshy 


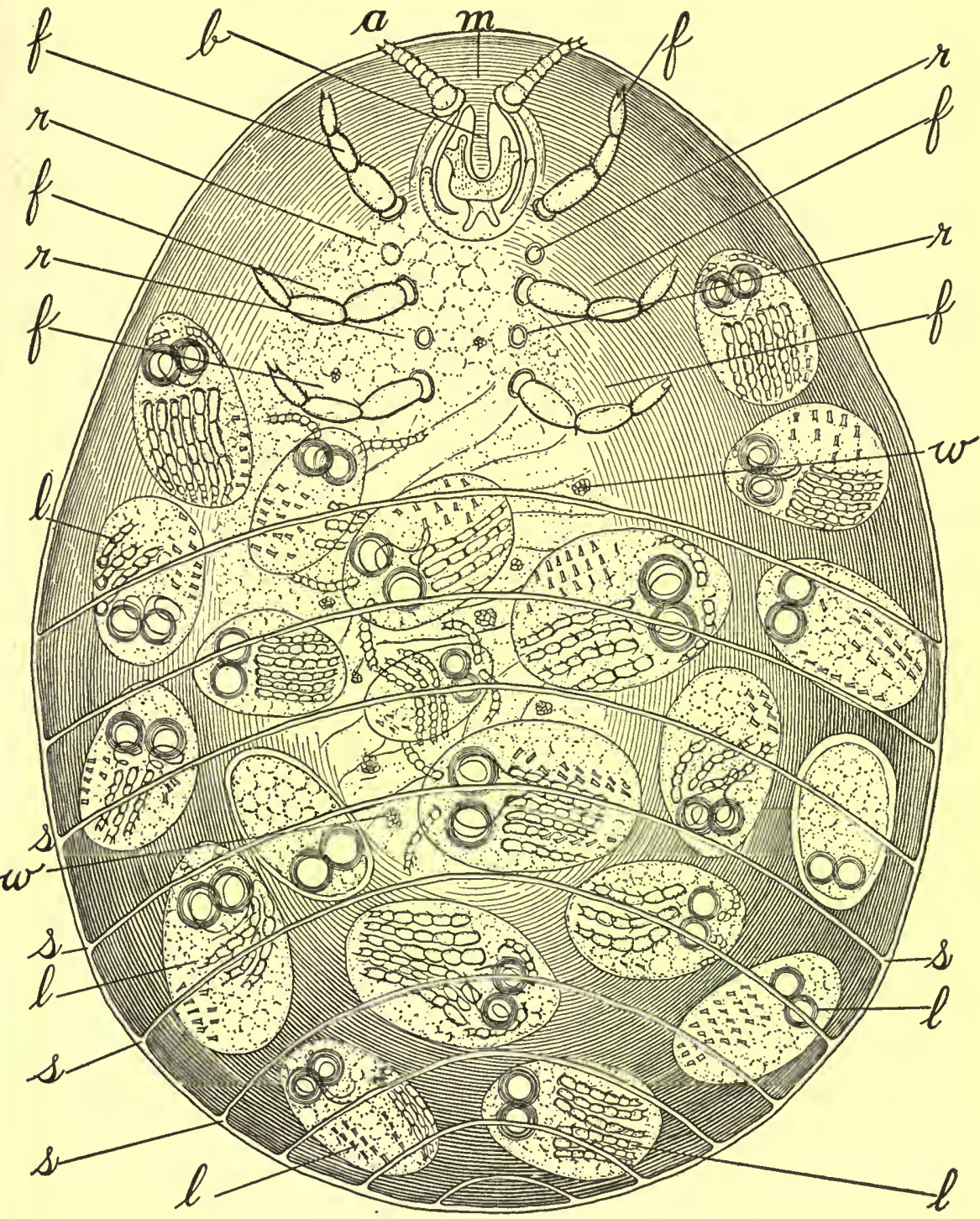

FIG. 308.-Diagram of cochineal insect of commerce, showing an ovoid sac-like membranous cradle enclosing numerous young larvæ $(l)$. Parts of the mother insect: $m$, mouth part; $b$, beak or proboscis; $a$, antennæ; $f$, three pairs of legs; $r$, respiration channels or breathing pores; $s$, segments in abdominal region; $w$, wax-pores. 
stems of the cacti, the male in the meanwhile being able to fly about; then the female attaches herself to the tissues of the Nopal plants, her body becoming a membranous cradle for the larvæ of the next generation, and after which she dies. From three to five generations of the cochineal insect may be produced in a single year. The first generation usually is richer in coloring matter and is considered the most valuable. It is estimated that from an area of about an acre of Nopal plants approximately 100 kilos of cochineal may be gathered; this would represent about $14,000,000$ of the dried insects of commerce. The cochineal of commerce consists of the membranous cradle of the female which is removed by the planters from the Nopal plants. They are then subjected to steam or hot water and dried, or they may be dried by direct heat.

Description.-The commercial article consists of small concavoconvex fragments about $5 \mathrm{~mm}$. in length, and of a dark garnet color. When cleared ${ }^{1}$ it shows the insect to be a hollow vesicle of an ovoid or plans-convex shape having in the upper portion some of the "emains of the mother insect (Fig. 308). The mouth part with a more or less developed beak or rostrum is always present, the beak sometimes being extended and recurved in a narrow elliptical form in the direction of the abdomen. One or both of the antennæ are frequently present, showing 5 to 7 parts. The joints of the legs are usually more or less detached, the point of insertion usually only being indicated by large yellowish-brown elliptical scars. In between each of the legs on both sides are situated 2 distinct pores, resembling in form and color the point of attachment of the legs, and which are tracheæ or respiration canals. In the abdominal region, which

${ }_{1}$ The following method is useful in destroying the coloring matter, rendering it possible to study the cochineal insect. A convenient quantity, as $10 \mathrm{gm}$., of commercial cochineal is macerated with 100 c.c. of water containing 2 or 3 per cent of an alkali. The mixture is allowed to stand for an hour or so, the contents being poured over a piece of wire gauze. The insects remain on the gauze and are then washed with a few litres of water. The insects, from which the coloring matter has been partly removed, are then transferred to 150 c.c. of hydrogen peroxide solution and allowed to stand for a few hours with occasional gentle stirring. The mixture is again transferred to the gauze, the excess of hydrogen peroxide being washed off and the insects transferred to a weak alkali solution in which they are macerated for six or eight hours. The mixture is poured upon the wire gauze and washed ..ith water until the filtrate runs practically colorless. The insects on the gauze are then transferred to dilute alcohol to which a few drops of hydrochloric acid have been added. This now renders them translucent and ready for microscopical study. They may be mounted in chloral solution or a solution of chloral and glycerin and examined. 
is very large, the larvæ are borne (Fig. 308), and these usually are seen to be in several stages of development (Figs. 309 and 310).

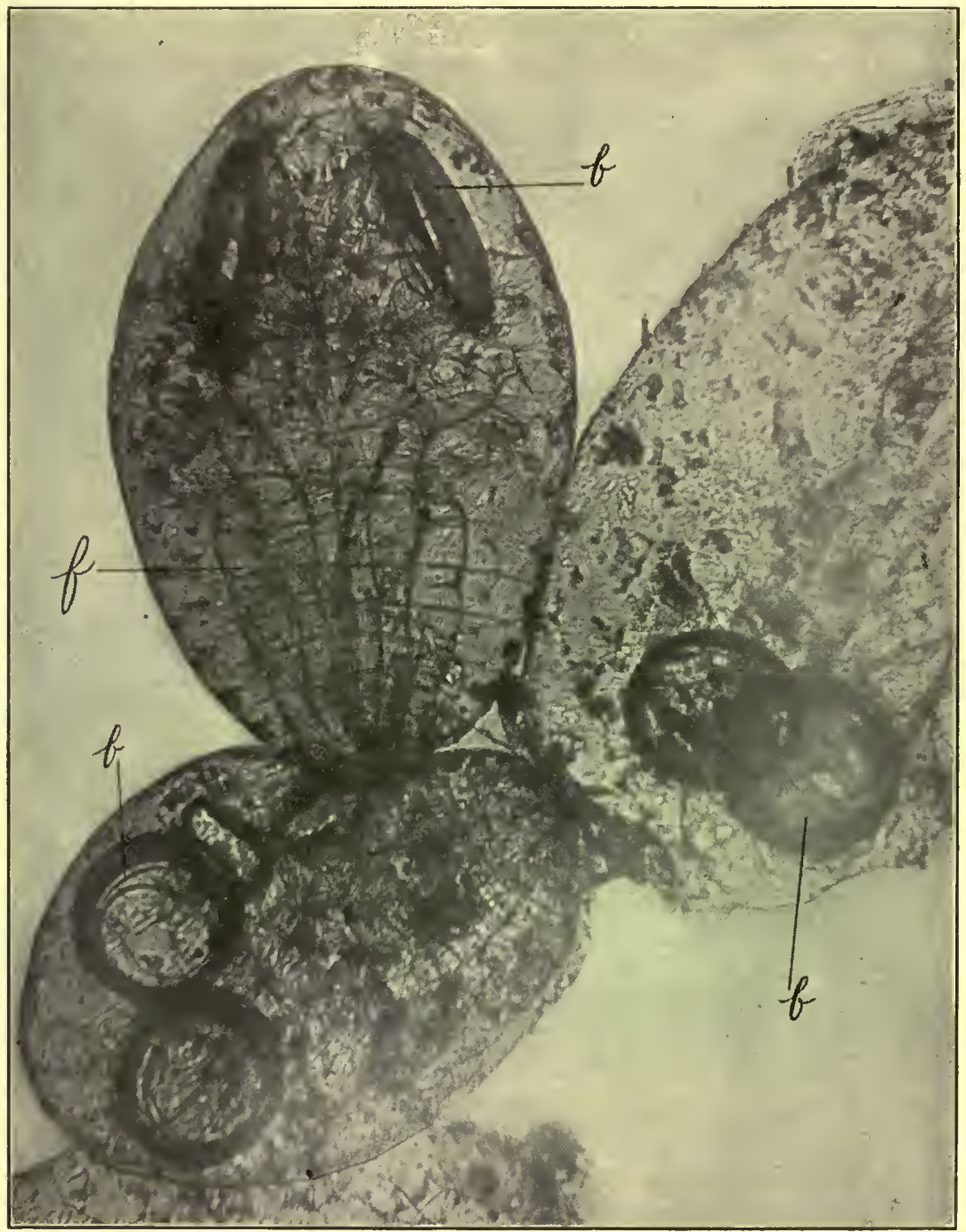

Fig. 309.-Microphotograph of several of the numerous larvæ found in the mother insect and in which are to be seen the eharacteristic beaks $(b)$; and the three pairs of legs $(f)$ still enelosed in the sae-like membrane of one of the larvæ.

Constituents.-From 9 to 10 per cent of a glucosidal, colonin principle, carminic acid (carmine red). It is methyldioxy-naphtho- 
quinone, and forms crystals, which are very soluble in water, alcohol and ammonia; partly soluble in ether; and insoluble in fixed and volatile oils. Cochineal also contains 0.5 to 4.2 per cent of a wax, coccerin; from 1.5 to 2 per cent of myristin; from 4 to 6 per cent of a mixture of fats and fatty acids; and ash, from 0.5 to 6 per cent.

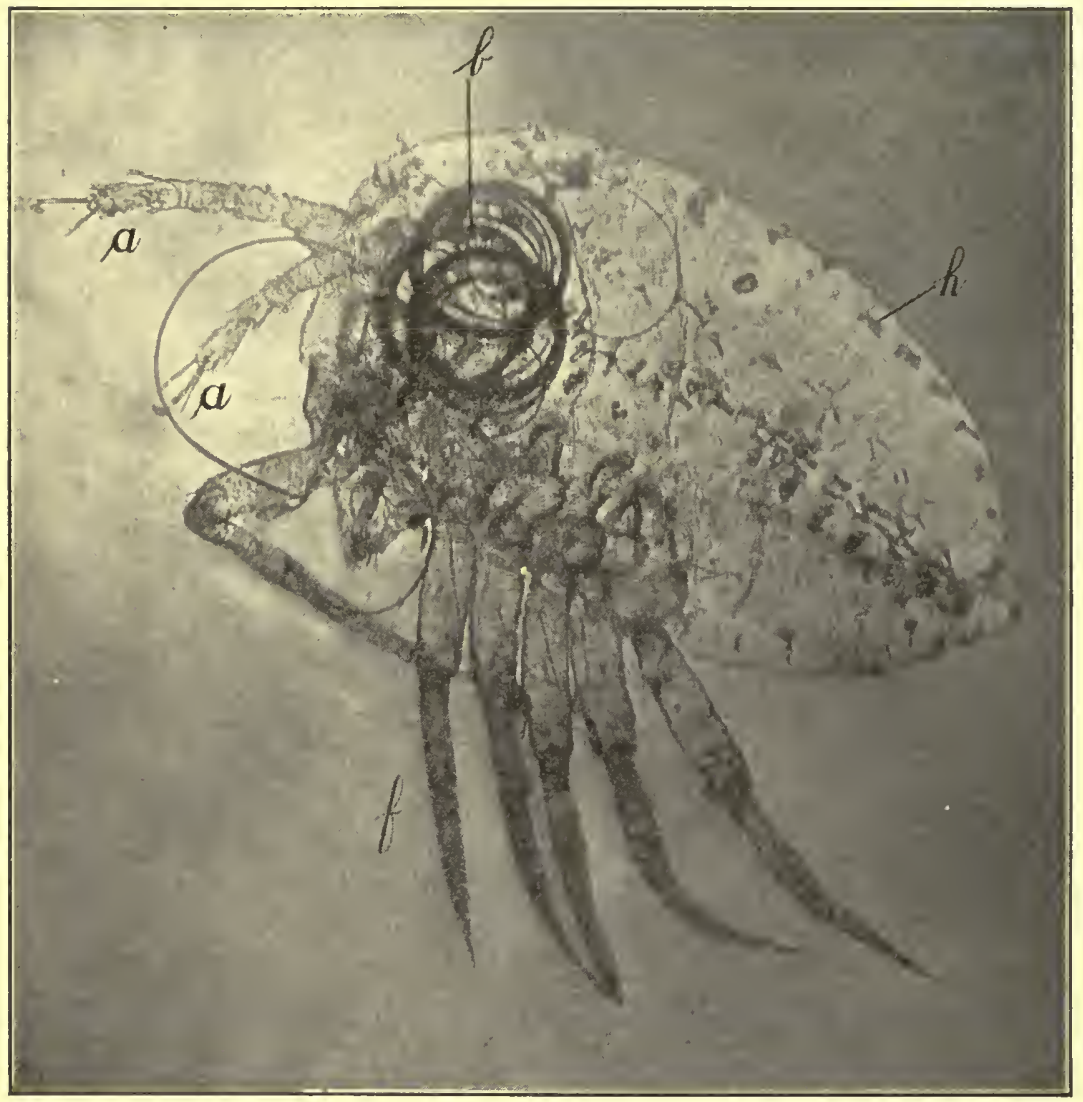

FIG. 310.-Microphotograph of larva in cochineal insect of commerce showing: outspreading antennæ $(a)$ and feet $(f)$; the characteristic beak or proboscis $(b)$; and wax-hairs on the body $(h)$.

The carmin of commerce is a mixture of principles and is extremely subject to adulteration with inorganic salts. It should not yield more than 12 per cent of ash.

Commercial Grades.-There is considerable variation in the quality of the commercial article, depending upon the locality in which the insects are cultivated, the crop of the season that is har- 
vested and the manner in which the insects are killed. The most valuable variety is known as "Madres" and represents the first brood of the season. This corresponds to the variety formerly known as "Zacatillo," which was exported from Mexico. At one time Honduras shipped the best commercial article. At the present time, the greater quantity comes from Teneriffe, one of the Canary Islands.

According to the fancy of the broker or exporter several grades of cochineal are recognized. Broadly speaking, the terms "Silver grain," " black grain," and " granilla " are used, but there are intermediate qualities variously designated as gray, black-gray, silvergray, silver-black, rosy-black, red and foxy and these again may be qualified by the terms fair, bold, fine and so forth. The commercial variety known as " granilla" represents probably nothing more than the smaller females in which the larvæ usually show but a very slight development. The color is due to the mode of preparation for the market. If dried in trays in the sun, or in an oven at a moderate temperature (about $65^{\circ} \mathrm{C}$.) for four or five hours, and subsequently in the sun, the waxy substance is not melted and the silver grain is the result. If they are dried at a higher temperature than $106^{\circ} \mathrm{C}$., the melting point of the wax on hot iron plates, the black-grain is the result. The red tint of the rosy-black is said to be produced if they are put in bags and dipped in boiling water to kill them before drying, and that of the foxy silver grain is produced by sifting the insects when not perfectly dry so that some of the coloring matter tinges the surface. The black grain usually obtains a higher price than the silver grain. Both the black and silver grain are sometimes adulterated to meet the demand for a cheap article. The black grain is sometimes met with having the concave side filled with grains of a magnetic iron sand. The silver grain is said to be weighted with sulphate of barium or carbonate of lead and the very white appearance is given by powdered talc or other white powder.

Literature.-Kraemer, Amer. Jour. Pharm., 1913, p. 344.

Cantharis.-Cantharides.-Spanish Flies.-The beetle, Cantharis vesicatoria (Fam. Meloïæ). This coleopterous insect is found upon certain shrubs of the Caprifoliaceæ and Oleaceæ, growing in southern and central Europe. The insects are gathered during June or July, by shaking the shrubs or beating them with poles, and collecting the insects upon cloths spread upon the ground. They are then thrown into suitable vessels, and killed by means of chloroform, ether, or similar drugs. After which they are carefully dried, at a temperature not higher than $40^{\circ} \mathrm{C}$. The commercial article 
is subject to the attack of other insects and a few drops of chloroform or carbon tetrachloride should be added from time to time to preserve them. The commercial supplies are obtained chiefly from southern Russia, Hungary (Fig. 312) and Spain and to some extent from Roumania, Poland and Sicily.

Description.-(Fig. 311, A). Oblong, somewhat flattened, from 1.5 to $2.5 \mathrm{~cm}$. in length and 4 to $8 \mathrm{~mm}$. in breadth, and of a brilliant green or bluish-green metallic luster, being somewhat golden-green underneath; head triangular, about $3 \mathrm{~mm}$. in length, separated into 2 lateral lobes by a longitudinal ridge or furrow; antennæ from 4 to 6 $\mathrm{mm}$. in length, consisting of 11 uniseriate joints, the upper being somewhat spheroidal and of a black color; mandibles stout and partly concealed; eyes comparatively small; neck distinct; pro-

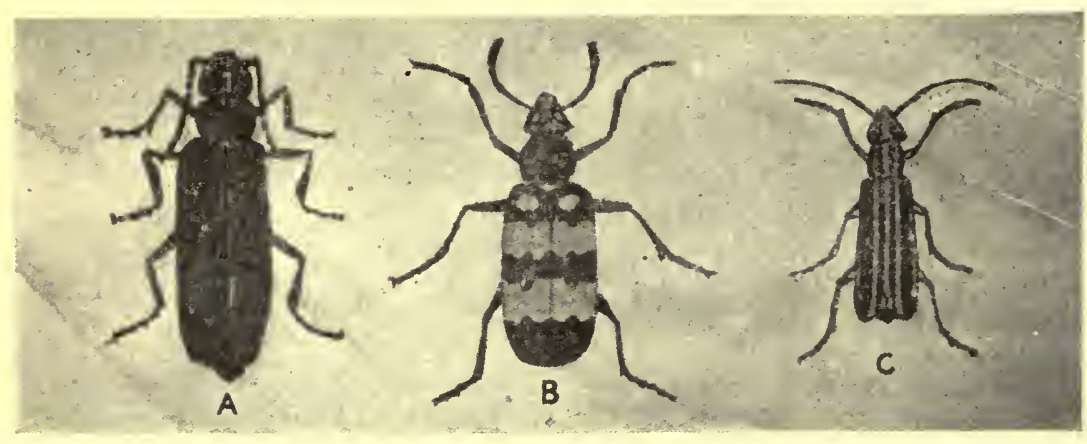

FIG. 311. $-A$, Cantharis vesicatoria. $B$, Mylabris Cichorii. $C$, Cantharis vitta.-After Snyder.

thorax angulate, 4-sided; body covered with fine scattered hairs and having 6 long, hairy, black legs, the first and second pair having 5 tarsal joints, the hind pair being 4 parted and having 2 claws at the summit; elytra or wing sheaths elongated, nearly equal, almost completely covering the wings, upper portion finely wrinkled, having a brilliant green metallic lustre and possessing 2 parallel lines; under surface brown; wings 2 , membranous, transparent, light brown and longer and broader than the wing cases; odor distinct; penetrating and disagreeable; taste at first slight, afterwards pungent and very acrid.

Powder.-(Fig. 313). Grayish-brown, with shining green particles and a number of long, pointed, 1-celled hairs about $0.5 \mathrm{~mm}$. in length and $0.002 \mathrm{~mm}$. in width at the base. 
Constituents.-The vesicating principle, CANTHARIdin, is the lactome or anhydride of cantharidinic acid. It occurs from 0.4 to 0.8 per cent, crystallizes in colorless prisms, being without odor and taste, nearly insoluble in water, cold alcohol, carbon disulphide and benzol, and soluble in hot alcohol, chloroform, waxes and fixed and volatile oils. In addition, about 12 per cent of a fixed oil, con-

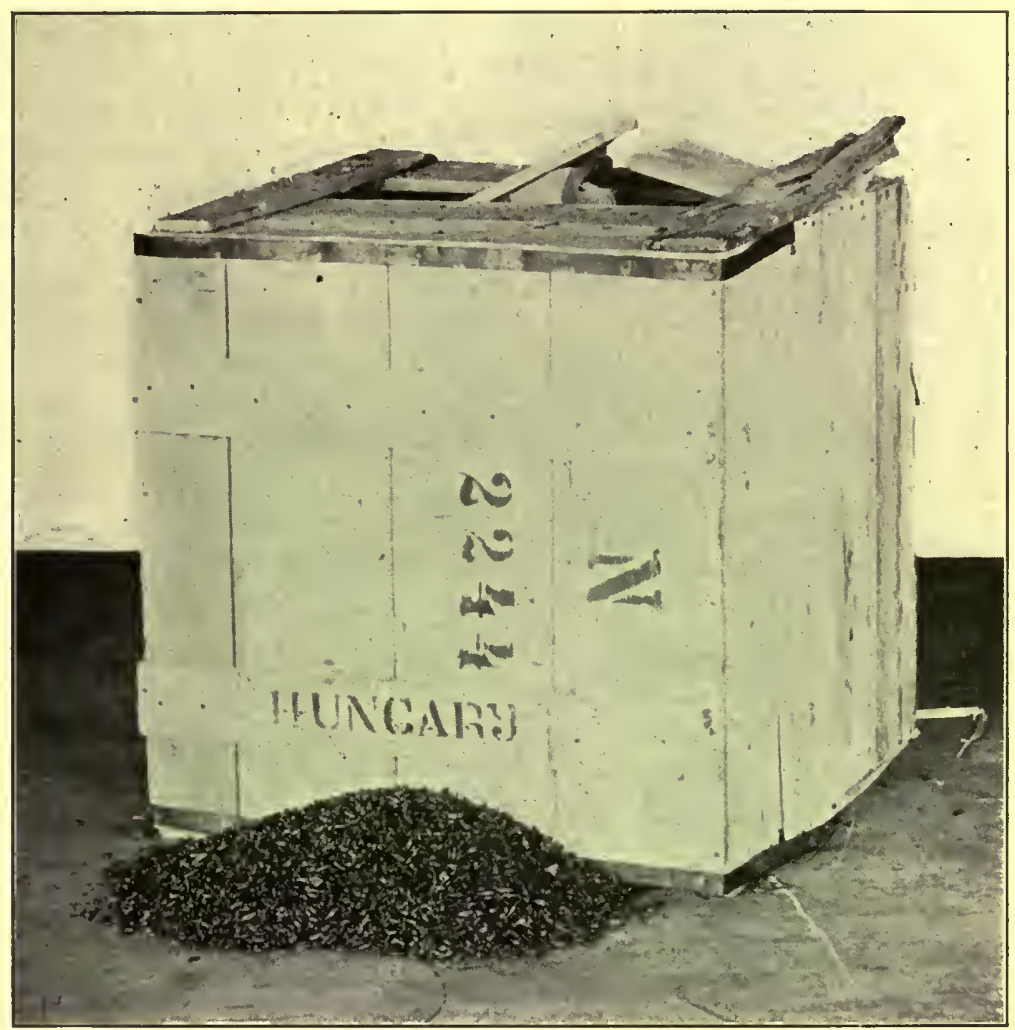

FIg. 312.-Original package of Spanish Flies (Cantharis) imported from Hungary. -After a photograph by Parke, Davis \& Co.

sisting of the glycerides of stearic, palmitic and oleic acid; a resin; and the following organic acids; formic, acetic and uric. The yield of ash is from 6 to 8 per cent.

Mylabris or Chinese blistering-flies are obtained from Mylabris Cichorii, a coleopterous insect indigenous to the East Indies and China. They are elongated oval or cylindrical (Fig. 311, B), from 1.8 to $2.5 \mathrm{~cm}$, in length and from 4 to $11 \mathrm{~mm}$. in breadth, elytra or 
wing-sheaths black with 2 broad brownish-yellow, occasionally golden-yellow bands and at the anterior portion a pair of nearly circular brownish-yellow spots; heads somewhat triangular and of a jet black color; mandibles stout and large, partly concealed; antennæ

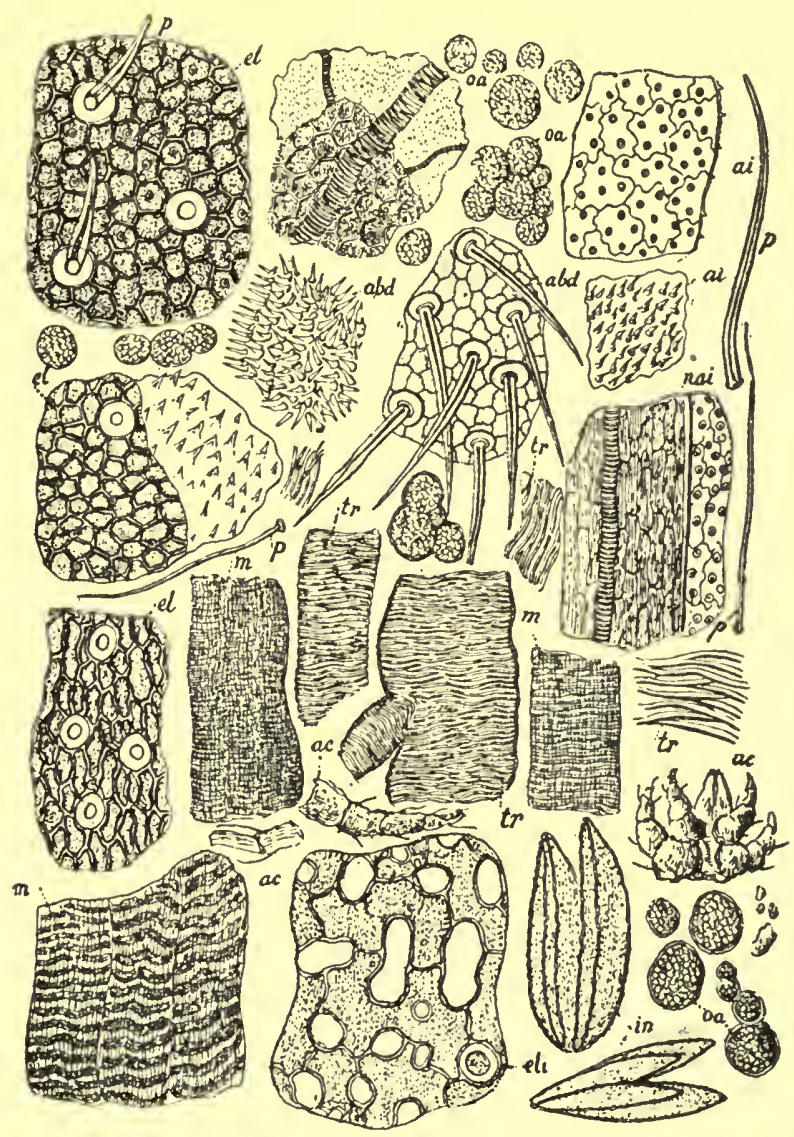

FIG. 313.-Cantharides (Cantharis vesicatoria): $a b d$, fragments of abdomen; $a i$, fragments of wings; $a c$, fragments of mites; $e l$, fragments of elytra showing the external surface; eli, fragments of elytra showing internal surface, when cleared with Javel water; $m$, fragments of muscles; in, undetermined fragments; oa, eggs of mites; $p$, hairs from abdomen, thorax and wings.-After Collin.

clavate, 11 jointed; eyes large and compound; prothorax wedgeshaped, black; the femora of first and second pair of legs are covered with yellowish hairs, while the third pair hairs are nearly glabrous and black; odor and taste slight, resembling cantharis. 
The powder of Myalbris is dark brown, and contains numerous, slender, sharp-pointed, blackish hairs, from 0.200 to $0.600 \mathrm{~mm}$. in length and about $0.003 \mathrm{~mm}$. in width at the base.

American Blistering Beetles. - A number of species of Cantharis, especially the potato fly (Cantharis vittata), indigenous to the United States, have pronounced vesicating properties. They are smaller than $\mathrm{C}$. vesicatoria and the elytra are black, having a mediun and marginal stripe of yellow.

Literature.-Snyder, Amer. Jour. Pharm., 1908, p. 545.

Moschus.-Musk.-The dried secretion from a special follicle of Moschus moschiferus (Fam. Moschieæ). The musk deer inhabits the mountainous regions of the northern provinces of China, Thibet and Siberia, extending to the elevated tablelands of the Balkan Sea. The musk sac is found only in the buck deer and is located on the abdomen between the umbilicus and the preputial follicle. The animals are hunted in the spring and early summer and killed, the musk sac removed as quickly as possible and carefully dried, the sacs of animals about 6 years old being preferred. They are placed in small, rectangular cases (Catties) lined with tin foil, shipped to Shanghai and thence exported to Europe.

Description.-The musk sac is nearly ovoid and from 4 to $7 \mathrm{~cm}$. in length, the upper surface being smooth, the lower convex and covered with grayish-brown hairs, which are concentrically arranged around a small orifice. The secretion in the fresh state is of an unctuous consistence, which dries in the form of irregular granules from 1 to $2 \mathrm{~mm}$. in diameter, of a light brown or brownish-black color, being shiny and somewhat oily, having a peculiar penetrating and persistent odor, and an aromatic, bitterish taste.

Upon the addition of a few grains of musk to 2 c.c. of chloroform in a watch crystal the grains float on the surface. Upon stirring, with a glass rod, the solution remains nearly colorless, and as it evaporates there separates, around the particles, a small quantity of a whitish oil or fatty substance.

The amount of musk soluble in water varies from 50 to 75 per cent. The aqueous solution should be of a dark-brown color, having a strong aromatic odor and a slightly acid reaction. The undissolved portion consists of irregular fragments containing a finely granular substance; in addition there are numerous rod-like bacteria held in suspension, and occasionally the haphæ of a fungus.

The amount of musk soluble in alcohol should not be less than 10 per cent, the solution being of a light yellowish-brown color and should become slightly turbid upon the addition of water. 
Upon the addition of a few grains of musk to 2 c.c. of alcohol contained in a watch crystal, the grains sink to the bottom, and upon stirring with a glass rod, a pale brown solution is obtained, being very slightly cloudy and leaving a somewhat oily stain upon the upper portion of the watch crystal as the alcohol evaporates; the undissolved portion of residue resembles that obtained with the aqueous mixture, except in that the particles are less disintegrated.

Constituents.-From 0.5 to 2 per cent of a colorless, viscid volatile oil, consisting of a ketone having the odor of musk. Also fat, resin, cholesterin, protein substances, ammonium salts, calcium salts; and about 5 per cent of ash. Musk should not lose more than 15 per cent of moisture when dried in a desiccator over sulphuric acid.

Civetta.-Civet.-An unctuous secretion contained in a special pouch in both the male and female Civets, Viverra Civetea and V. Zibetha (Fam. Viverrieæ). The former is indigenous to Africa and the latter to southern Asia. The animals are sometimes kept in captivity, the secretion being removed by means of a small spoon, a few uubic centimeters being obtained from each animal at intervals of a few days. The secretion is dried and at first is of a yellowish color, becoming dark brown and has a strong musk-like odor, becoming pleasant on dilution and is used both alone and for fixing other odors. The American Civet-cat of Mexico is not a true Civet, but is related to the raccoon and is similar in its haunts and habits to the latter.

Adulterants.-Musk is sometimes adulterated with dried blood, colophony, catechu, asphalt, glass, sand, meat, small seeds and fragments of wood, all of which are readily detected.

\section{POWDERED DRUGS}

Many of the powdered drugs, spices and food products resemble each other closely in form, color and other properties, and it is therefore necessary that some outline for their identification be prepared. Two kinds of keys may be arranged: $(a)$, In the one, the scheme of separation is dependent entirely upon the histological characters of the drugs under consideration. This method has been followed by Schneider in his work on "Powdered Drugs." (b), A second method is to arrange the powdered substances into fundamental groups, based on the color of the substances; these are then subdivided according to the anatomical characteristics of the powders. The 
author ${ }^{1}$ prefers the latter method, and the following key, involving the examination of nearly 300 different substances, will be found helpful in practice and render expeditious the examination of even complex mixtures. A complete microscopical description of each of the powdered drugs, has already been given throughout the text, and these descriptions, as also the statements under inner structure, should be referred to by the analyst. It is very important when possible to compare the specimen under examination with authentic material. It will be found convenient to arrange all drugs having a similar color upon a single card, which can be filed away in suitable compartments, and at the same time easily accessible when needed for comparison.

Adulterants.-Powdered drugs are frequently adulterated either by the use of wheat middlings or with exhausted powders, i.e., those from which the active or important constituents have been extracted. The following examples serve to illustrate the methods in use: Powdered cloves are occasionally admixed with the exhausted powder, or the exhausted powder alone to which a small quantity of oil of cloves and some coloring matter are added, is sold as powdered cloves. Exhasuted gentian, to which has been added a small quantity of a bitter drug like aloes, is sold in place of the genuine drug. In some cases, as in that of ground flaxseed, an attempt is rnade to supply the deficiency in oil of the exhausted product by adding a petroleum oil. In the case of a number of drugs, such as rhubarb, licorice and belladonna root, much of the commercial powder consists, in part at least, of the exhausted powder. In order to guard against the use of exhausted drugs there is a disposition to lay considerable stress upon the amount of extractive (aqueous, alcoholic or ethereal) yielded by different drugs. In many instances drugs that are worm-eaten, or admixed with other drugs or plant parts, are used in the preparation of powdered drugs.

Reagents.-For the rapid differentiation and study of the characteristic tissues and cell-contents of the powder it is necessary to employ reagents which render the particles more or less transparent and at the same time do not destroy their characters. The most satisfactory reagent of this kind for general purposes is an aqueous solution of chloral or a solution of chloral and glycerin; about a milligram of the powder is mounted in a few drops of the solution, the preparation is gently heated, then allowed to cool, and examined; if it is not sufficiently transparent, it is heated again. The reagent causes a swelling of the cell-wall and is not applicable in the study of

${ }^{1}$ Kraemer, Amer. Jour. Pharm., 1898, pp. 506, 558, and 607. 
starch grans, but it is very useful in the study of mechanical tissues, hairs and calcium oxalate.

After having determined the presence of starch, a separate mount of the powder in water is made and the size and markings of the grains noted.

For the examination of more or less lignified cells, mounts are made, either in phloroglucin or aniline sulphate solution; in some cases it is advantageous to apply these solutions after the specimen has been previously treated with chloral. Sometimes it is desirable to study the mechanical cells more closely, and Schulze's macerating fluid may be used for isolating them.

Examination.-Before making a microscopical examination of coarsely comminuted or powdered drugs or foods it is desirable to mix a small quantity of the material with a little water contained in a watch crystal or small beaker and note such features as the following: (1) If the particles sink or float. In all genuine coffee, for instance, the particles rise to the surface, whereas in the substitutes and adulterants they sink. (2) If the particles disintegrate. All artificial products, as coffee and nutmeg, when made from exhausted powders or spurious substances, slowly disintegrate, leaving a fine sediment. (3) The color of the solution. A chelidonium powder, for instance, gives a golden-yellow solution, as also do many drugs containing berberine and allied principles. (4) Behavior of the solution and particles toward alkalies or dilute hydrochloric acid. Drugs containing oxymethyl-anthraquinone derivatives, as senna, rhubarb, aloes, frangula and cascara sagrada, are colored a deep red with alkalies. The particles of ruellia give a distinct effervescence with hydrochloric acid particularly if the mixture is slightly heated. The presence or absence of starch may be determined by heating the mixture, to which has been added a few drops of dilute hydrochloric acid, filtering, and adding iodine to the filtrate when cool. The odor of the mixture, particularly on warming, is of considerable value, as in the detection of belladonna in inula or of conium in anise. The odor is also of value in recognizing the specimen, as very many drugs have a characteristic odor. The odor of a specimen is sometimes, however, misleading, as a number of substances not at all related may have a similar odor. The odor of elm bark, for instance, is possessed by other substances, as fenugreek and wheat middlings, particularly if these substances are kept in closed vessels.

The fixed oil, which occurs in considerable quantity in many seeds, interferes with their microscopical examination, and it is necessary to remove this before making mounts of the material. 
This can be accomplished by treating the powder with chloroform, xylol, acetone, ether, or other similar solvents. Alcohol as a rule is not a good solvent for these oils. The solvent may be added directly to the mount and the solution absorbed by means of filter paper. The following drugs and foods contain fixed oil and should be treated in this way: Almond, anisum, cacao, cardamom, carum, conium, coriandrum, cubeba, ergota, linum, macis, myristica, pimenta, pepo, piper, sinapis alba, sinapis nigra, staphisagria, strophanthus, and the various cereal products.

All powders contain a certain amount of fragments of cell walls and other materials which are more or less alike in the different powders, and it is important that this fact be borne in mind in order that attention may be especially directed to those elements of the powder which have a diagnostic value. The latter, while relatively few in number, are easily identified and the distinguishing features readily determined in nearly all cases.

\section{KEY FOR THE STUDY OF POWDERS}

\section{POWDERS OF A GREENISH COLOR}

\section{Crystals of Calcium Oxalate present.}

A. Crystals in rosetwe aggregates.

a. Glandular and non glandular hairs present.

Cystoliths of calcium carbonate.......... Cannabis Indica

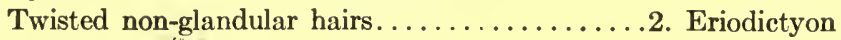

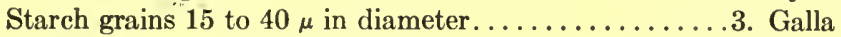
Large multicellular glandular hairs............ Humulus Numerous pollen grains................ Insect Powder Glandular hairs few................ Stramonii Folia

b. Glandular hairs wanting.

Hairs with slight projections.............. Pilocarpus

Characteristic stone cells................... Tea

c. Glandular and non-glandular hairs wanting.

Sphere-crystals of a carbohydrate.............. Buchu

Crystals 1 to $2 \mu$ in protein grains............ Conium

Crystals $15 \mu \ldots \ldots \ldots \ldots \ldots \ldots \ldots \ldots \ldots \ldots . \ldots \ldots$. Castanea

Crystals 40 to $60 \mu \ldots \ldots \ldots \ldots \ldots \ldots \ldots$. Chimaphila

Outer wall of epidermal cells very thick.......13. Eucalyptus

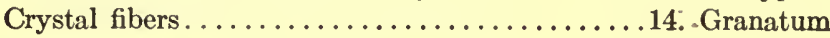

$B$. IN MONOCLINIC PRISMS.

a. Glandular and non-glandular hairs present.

Crystals about $10 \mu \ldots \ldots \ldots \ldots \ldots \ldots \ldots$. Hyoscyamus 
B. IN MONOCLINIC PRISMs.-Continued.

b. Only non-glandular hairs present.

Characteristic stone cells........16. Cardamomum (Ceylon) Crystal fibers.................. Hamamelidis Folia Fragments reddish with alkalies............... Senna Non-glandular hairs few.................. Uva Ursi

c. Glandular and non-glandular hairs wanting.

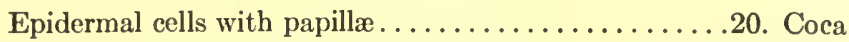

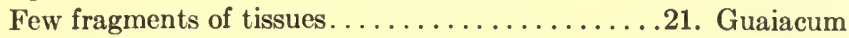
Few crystal fibers and non-glandular hairs......22. Uva Ursi

C. In CRYSTAL FIBERs.

Rosette-shaped crystals numerous..........23. Granatum Crystal fibers few.................... Uva Ursi

D. In SPHENOIDAL Micro-CRYStals.

a. With hairs.

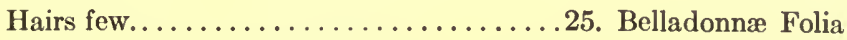
Non-glandular hairs numerous.............26. Tabacum Starch grains 10 to $35 \mu \ldots \ldots \ldots \ldots 27$. Solanum Carolinense

b. Hairs few or wanting.

Starch grains 5 to $7 \mu \ldots \ldots \ldots \ldots \ldots$. Dulcamara

\section{Calcium Oxalate Crystals wanting.}

A. Cystoliths of calcium carbonate present.

Glandular and non-glandular hairs . . . . . 29. Cannabis Indica Stone cells characteristic................ Ruellia

\section{B. Calcium carbonate wanting.}

a. Glandular and non-glandular hairs present.

$\alpha$ Fragments of pappus present.

Pollen grains 10 to $20 \mu \ldots \ldots \ldots \ldots \ldots$. Eupatorium

Pollen grains about $25 \mu \ldots \ldots \ldots \ldots \ldots . \ldots . \ldots .$. Grindelia

$\beta$ Fragments of pappus wanting.

1. Glandular hairs with 1- and 2-celled heads.

Non-glandular hairs characteristic......33. Digitalis

2. Glandular hairs with 1- to 8-celled head.

Odor characteristic .............. Hedeoma

Non-glandular hairs twisted ........35. Marrubium

Non-glandular hairs 1- to 8-celled.

36. Mentha Piperita

Non-glandular hairs 1- to 3-celled.....37. Scutellaris Non-glandular hairs parallel with surface of leaf

38. Salvia 


\section{B. Calcium carbonate wanting.-Continued.}

$b$. Glandular hairs wanting.

$\alpha$ With non-glandular hairs.

1. Pollen grains

* Hairs numerous.

Non-glandular hairs 1-celled.........39. Lobelia

Non-glandular hairs 1- to 6-celled......40. Matico

** Hairs very few.

Cells of non-glandular hairs very short, oblong.

41. Tanacetum

2. Pollen grains wanting.

Hairs 1-celled, with thick walls.......42. Scoparius

$\beta$ Non-glandular hairs wanting.

Starch grains present...............43. Cardamomum

With tracheids....................... Sabina

Without starch grains...............44. Staphisagria

Aqueous solution of a golden-yellow color..45. Chelidonium

\section{POWDERS OF A YELLOWISH COLOR}

\section{Fragments of Vegetable Tissue present.}

A. Containing starch.

a. With calcium oxalate crystals.

$\alpha$ In rosette aggregates.

Crystal fibers..................... 46. Frangula

Isodiametric stone cells..............47. Galla (Aleppo)

Starch grains swollen................... 48. Jalapa

Calcium oxalate crystals 50 to $100 \mu \ldots \ldots \ldots \ldots$. 49 . Rheum

$\beta$ In monoclinic prisms.

Characteristic starch grains ..............50. Calumba

Starch grains swollen..................51. Curcuma

Crystal fibers..................... Fe. Frangula

Long sclerenchymatous fibers..........53. Gelsemium

Tracheæ with bordered pores...............54. Quassia

$\gamma$ In crystal fibers.

With cork fragments.........55. Glycyrrhiza (Spanish)

Without cork fragments......56. Glycyrrhiza-(Russian)

$\delta$ In raphides.

Tracheids with bordered pores..........57. Ipecacuanha

Long sclerenchymatous fibers...........58. Phytolacca

Endodermal cells with thick walls....55. Veratrum Viride 
A. Containing starch.-Continued.

b. Calcium oxalate wanting.

$\alpha$ Stone cclls present.

Characteristic starch grains...........60. Calumba

$\beta$ Stone cells wanting.

1. Starch grains 15 to $30 \mu$ in diameter.

With yellow oil-secretion cells........61. Zingiber

2. Starch grains 5 to $15 \mu$ in diameter.

Long non-lignified bast fibers........62. Mezereum Ducts large.....................63. Pareira

Lignified sclerenchymatous fiber......64. Serpentaria Powder lemon-yellow. ..............65. Berberis

3. Starch grains less than $5 \mu$ in diameter.

Crystals of alkaloids with sulphuric acid. .66. Hydrastis

4. Starch grains altered.

Large cells with swollen grains.......67. Curcuma

\section{B. Starch gralns Few or none.}

a. Calcium oxalate crystals present.

$\alpha$ In rosette aggregates.

Non-glandular hairs.................68. Anisum

Oil-like globules in epidermis. . . . . . . . .69. Calendula

Non-glandular hairs wanting..........70. Fœniculum

$\beta$ In monoclinic prisms.

Crystals 15 to $20 \mu \ldots \ldots \ldots$. . 71. Aurantii Amari Cortex

Crystals 20 to $30 \mu \ldots \ldots \ldots \ldots 72$. Aurantii Dulcis Cortex

$\gamma$ In raphides.

Crystals 0.1 to $1 \mathrm{~mm}$. long................. Scilla

b. Calcium oxalate crystals wanting.

$\alpha$ Sclerenchymatous cells or fibers present.

1. Dark pigment cells wanting.

Stonc cells with thickened inner walls. .74. Sinapis alba Stone cells ellipsoidal, uniformly thickened...75. Pepo

Parenchyma cells large, thin-walled....76. Colocynthis

2. Pigment cells present.

Stone cells with thickened inner walls.77. Sinapis Nigra

Characteristic sclerenchymatous cells and fibers.

78. Fenugreek 
2. Pigment cells present.-Continued.

Short sclerenchymatous fibers.........79. Linum

A colorless layer of cells with minute starch grains.

80. Cydonium

$\beta$ Sclerenchymatous tissue wanting.

1. Pollen grains numerous.

Fragments of pappus..........81. Arnicx Flores

Pollen grains smooth.......... . 82. Sambucus

Pollen grains spinose...........83. Matricaria

2. Pollen grains few.

Pollen grains prickly.............84. Calendula

Pollen grains nearly smooth..........85. Crocus

Corolla white.................86. Anthemis

Bitter, ducts scalariform...........87. Chirata

3. Pollen grains wanting.

* Fibrovascular tissue present.

Containing inulin masses.......... 88. Lappa

Sclerenchymatous fibers numerous.... 89. Senega

Starch and scalariform tracheæ....90. Aspidium

** Fibrovascular tissue wanting.

Few fragments of tissues.........91. Cambogia

Large glandular hairs..........92. Lupulinum

Tetrahedral spores...........93. Lycopodium

\section{Few or No Fragments of Vegetable Tissue.}

A. Giving off odor of sulphur dioxide on heating.

Rounded masses in chains..............94. Sulphur Lotum

Rounded masses in irregular groups.......95. Sulphur Præcipitatum

B. No OdOR OF SULPHUR DIOXIDE ON HEATING.

a. Ncarly colorless in glycerin mount.

Transparent, irregular masses...........96. Mastiche

$b$. Yellowish in glycerin mount.

$\alpha$ Containing oil globules.

Irregular masses..............97. Scammonium

$\beta$ Transparent or translucent.

Soluble in cold alcohol ............... Colophony

Insoluble in cold alcohol...............99. Sandarac

Reddish with alkalies............. Aloo. (Cape)

$\gamma$ More opaque.

Light or grayish particles............101. Ammoniac

Yellowish particles................102. Cambogia 


\section{POWDERS OF A BROWNISH COLOR.}

\section{Fibrovascular Tissue present.}

A. Containing starch.

a. Calcium oxalate crystals present..

$\alpha$ In rosette aggregates.

1. With sclerenchymatous fibers.

* Containing oil, resin or tannin masses.

Sclerenchymatous fibers few..103. Belladonnse Radix Starch grains 4 to $20 \mu \ldots \ldots$. 104. Gossypii Cortex Starch grains 3 to $7 \mu$, compound......105. Rubus Crystals 10 to $35 \mu \ldots \ldots \ldots \ldots \ldots \ldots$. . . Juglans Crystals 35 to $70 \mu \ldots \ldots \ldots$. . Aralia Nudicaulis Starch grains 15 to $30 \mu \ldots \ldots \ldots \ldots$. . Stillingia Modified bast fibers........... 109. Euonymus Red with alkalies..............110. Rumex Fibers few................110a. Canella

** No resin or tannin masses.

Crystals about $25 \mu \ldots \ldots \ldots \ldots \ldots 11$. Althæa

2. Sclerenchymatous fibers wanting.

* Containing tannin.

$\dagger$ With oil-secretion reservoirs.

Starch grains ellipsoidal....112. Fruit of Clove Reddish brown tannin masses...113. Pimenta

†† Oil-secretion reservoirs wanting.

Light-brown tannin masses.......114. Galla Calcium oxalate 45 to $70 \mu \ldots .115$. Geranium Calcium oxalate 50 to $100 \mu \ldots \ldots 116$. Rheum

** Without tannin.

Sphenoidal micro-crystals.. .117. Belladonnæ Radix

$\beta$ Crystals in monoclinic prisms and pyramids.

Crystal fibers.....................118. Frangula

Sclerenchymatous fibers charactcristic......119. Krameria Crystal fibers and stone cells......120. Rhamnus Purshiana Crystals in stone cells..............121. Juniperus

$\gamma$ Crystal fibers present.

1. Sclerenchymatous fibers strongly lignified.

* Colored reddish with alkalies.

Without stone cells..........122. Frangula With stone cells.......123. Rhamnus Purshiana 
1. Sclerenchymatous fibers strongly lignified.-Continued.

** Not colored reddish with alkalies.

Stone cells characteristic......124. Quercus Alba Stone cells characteristic. . . 125. Prunus Virginiana Taste bitter, acrid.........126. Myrica Cerifera Taste sweetish, slightly bitter.

127. Pulvis Glycyrrhizæ Compositus

2. Sclerenchymatous fibers not strongly lignified.

Fragments of ducts...............128. Calamus

No fragments of ducts.............129. Ulmus

$\delta$ Calcium oxalate in raphides.

1. Raphides not more than $10 \mu$ long.

No fragments of ducts.........130. Cinnamomum

Fragments of ducts present........131. Sarsaparilla

2. Raphides 40 to $45 \mu$ long.

Spherical starch grains 3 to $12 \mu \ldots \ldots 132$. Convallaria Thick-walled parenchyma with simple pores.

133. Cypripedium

Ellipsoidal starch grains 7 to $20 \mu .134$. Veratrum Viride

3. Raphides $200 \mu$ long.

Starch grains 4 to $15 \ldots \ldots \ldots \ldots \ldots . \ldots 35$. Hydrangea

€ Calcium oxalate in sphenoidal micro-crystals.

Sclerenchymatous fibers few.......136. Belladonnæ Radix Bast fibers characteristic.............137. Cinchona

b. Calcium oxalate crystals wanting.

$\alpha$ With non-glandular hairs.

Greenish fragments with sulphuric acid..138. Strophanthus

$\beta^{*}$ Non-glandular hairs wanting.

1. Sclerenchymatous fibers present.

* Tracheæ numerous.

† Starch grains 2 to $5 \mu$ in diameter.

Ducts large and with bordered pores,

139. Cimicifuga

Thick-walled parenchyma with simple pores.

140. Cypripedium

Scalariform ducts..........141. Leptandra

Tracheæ with reddish contents...142. Spigelia 
* Tracheæ numerous.-Continued.

$\dagger+$ Starch grains 5 to 15 or $20 \mu$ in diameter.

Characteristic starch grains...143. Zingiber Odor of coumarin............ T44. Tonka Chocolate taste..........145. Cocoa Shells Fragments of milk vessels.....146. Apocynum Raphides $45 \mu$ long.......147. Convallaria Raphides 6 to $8 \mu$ long......148. Sarsaparilla Ducts with bordered pores.......149. Sumbul Stone cells characteristic......150. Valeriana Stone cells............151. Methysticum

** Tracheæ few or none.

Characteristic bast fibers........152. Cinchona Raphides about $5 \mu$ long..... 153. Cirinamomum hort sclerenchymatous fibers........154. Coffee Starch grains 7 to $20 \mu$, compound...155. Sassafras

2. Sclerenchymatous fibers wanting.

* Stone cells present.

† Giving tannin reaction with ferric salts.

Stone cells characteristic........156. Cacao Altered starch grains......... 157. Guarana Stone cells characteristic........158. Piper Thick-walled endosperm cells.

159. Colchici Semen

†† Not becoming blue or green with ferric salts.

Starch grains 4 to $12 \mu \ldots \ldots$. A 160 . Aconitum Starch grains 25 to $40 \mu \ldots .161$. Physostigma

** Stone cells wanting.

Starch grains 7 to $20 \ldots \ldots$. Colchici Cormus Altered starch grains............163. Guarana Numerous oil globules...........164. Myristica Amylo-dextrin starch grains.........165. Macis Few fragments of vegetable tissue....166. Opium Starch grains 5 to $12 \mu \ldots \ldots \ldots 167$. Podophyllum Odor characteristic..........168. Chenopodium

B. Starch grains few or None.

a. Containing calcium oxalate.

$\alpha$ In rosette aggregates.

1. Small crystals in aleurone grains.

With non-glandular hairs. . . . . . . . . 169. Anisum

Calcium oxalate 0.5 to $1 \mu \ldots \ldots \ldots \ldots$. Carum

Calcium oxalate 3 to $7 \mu \ldots \ldots \ldots$. 171. Coriandrum

Calcium oxalate 1 to $2 \mu \ldots \ldots \ldots \ldots$. . F . Fniculum 
$\alpha$ In rosette-shaped crystals.-Continued.

2. Crystals not less than $10 \mu$ in diameter.

* Pollen grains numerous.

Crystals numerous..........173. Caryophyllus

Crystals few............. 174. Insect Powder

** Pollen grains few.

$\dagger$ Ducts present.

Glandular and non-glandular hairs..175. Cusso

$\uparrow \uparrow$ Ducts wanting.

Stone cells few.......176. Viburnum Opulus

Stone cells numerous.

177. Viburnum Prunifolium

$\beta$ Calcium oxalate in monoclinic prisms.

1. Numerous seeds.

Characteristic odor.

178. Vanilla

2. Seeds wanting.

Stone cells few ............ Viburnum Opulus

Stone cells numerous, characteristic.

180. Viburnum Prunifolium

Numerous oil globules..........181. Xanthoxylum

$\boldsymbol{\gamma}$ Calcium oxalate in crystal fibers.

Stone cells characteristic...........182. Quercus Alba

b. Calcium oxalate wanting.

$\alpha$ Containing pollen grains.

Non-glandular hairs numerous.........183. Arnicæ Flores

Spherical pollen grains...............184. Crocus

Non-glandular hairs few..............185. Santonica

$\beta$ Pollen grains wanting.

1. Stone cells numerous.

Fragments wine-colored with sulphuric acid.

186. Cubeba

Characteristic stone cells.........187. Delphinium Green fluorescence in chloral mount.

188. Stramonii Semen

Ducts reticulate..............189. Pyrethrum

2. Stone cells wanting.

Non-lignified intermediate fibers . . . . . . 190. Gentiana

Few fragments of tissues............191. Opium

Tracheæ with elongated, narrow pores.

192. Taraxacum

Tracheæ with large, simple pores........193. Chicory

Ducts spiral, annular or with simple pores.

194. Triticum 


\section{Without Fibrovascular Tissue.}

A. With cellular tissues.

Spores about $7 \mu \ldots \ldots \ldots \ldots \ldots \ldots \ldots \ldots \ldots . \ldots \ldots$. Ustilago

Numerous oil globules................... E6. Ergota

Thick-walled cells of capsules . . . . . . . . . . . . 197. Opium

Gragments of woody tissues............... Go . Gowder

B. Without cellular tissues.

a. Possessing oil.

Grayish fragments..................... Asafetida

Yellowish or yellowish-brown fragments.......200. Myrrha

b. Without oil.

$\alpha$ Remaining opaque in glycerin.

Characteristic odor...........2J1. Aloes (Socotrine)

Characteristic odor...............202. Benzoinum

Grayish opaque fragments...........203. Elaterinum

Brownish angular masses..........204. Lactucarium

$\beta$ More or less translucent in glycerin.

Dark brown.................205. Aloes (Curaçao)

Yellowish-brown............206. Aloes (Socotrine)

With acicular crystals..............207. Gambir

With rhombohedral crystals............208. Catechu

Fragments translucent, deep red..........209. Kino

\section{POWDERS OF A REDDISH COLOR}

\section{Containing Starch.}

Very light pink, crystals present...............210 Quillaja

Reddish, crystals wanting................. Sanguinaria

\section{Without Starch.}

A. Stone cells present.

Characteristic stone cells...............212. Capsicum

Characteristic stone cells.................213. Illicum

Mucilage cells and sclerenchymatous fibers. . . . . . . 214. Cydonium

Characteristic glandular hairs............215. Rhus Glabra

Non-glandular hairs 0.5 to $2 \mathrm{~mm}$. long.....216. Rosæ Caninæ Fructus

Woody tissues only.................... Willow Charcoal

B. Stone Cells wanting.

$a$. With wood fibers.

Coloring principle soluble in water.......218. Hæmatoxylon

Coloring principle insoluble in water...219. Santalum Rubrum

b. Wood fibers wanting.

Blue with sulphuric acid..............220. Crocus

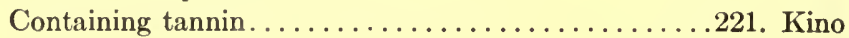

Large glandular hairs. . . . . . . . . . . 222. Lupulinum 
b. Wood fibers wanting.-Continued.

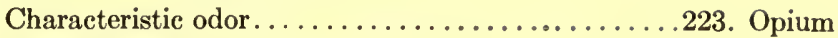

Epidermal cells with papillæ...........224. Rosa Gallica

Fragments of anthers............225. Rosa Centifolia

Long slender styles...................226. Zea

\section{POWDERS OF A WHITISH APPEARANCE.}

\section{Plant Tissues or Cell-Contents recognizable.}

A. Only unaltered starch grains present.

Excentral and fissured point of origin of growth.

227. Maranta Starch

Excentral and circular point of origin of growth.228. Potato Starch

Polygonal grains..................229. Corn Starch

Small, polygonal, compound grains.......230. Rice Starch

Ellipsoidal, point of origin of growth indistinct.321. Wheat Stareh

Characteristic grains.............232. Other Starches

b. Altered and unaltered starch grains present.

Becomes pasty on addition of cold water........233. Dextrin Becomes pasty with hot water............234. Sago

Disintegrates with water..........235. Sago (Imitation)

c. Plant tissues in addition to starch.

$\alpha$ Do not readily dissolve or swell in cold water.

Polygonal starch grains.............236. Corn Meal Free from hairs..................237. Corn Bran Starch grains 5 to $40 \mu$ in diameter......238. Wheat Flour Hairs with thick walls and narrow lumen.

239. Wheat Middlings

Starch grains 20 to $60 \mu$ in diameter.....240. Rye Flour Thin-walled hairs with large lumen....241. Rye Middlings Starch grains 5 to $25 \mu$ in diameter.....242. Barley Flour Sclerenchyma fibers with brown contents.

243. Buckwheat Flour

Starch grains 2 to $10 \mu$ in diameter.......244. Rice Flour Hairs broader near the middle..........245. Oat Meal Lignified hairs, starch grains few.......246. Nux Vomica Characteristic starch grains..........247. Orris Root Very long prisms of calcium oxalate.......248. Quillaja Raphides of calcium oxalate............249. Bryonia Aromatic vdor..................249a. Calamus Thin-walled bast fibers..............249b. Ulmus 
c. Plant tissues in addition to starch.-Continued.

$\beta$ Soluble or swelling in cold water to form a sticky mass.

Starch and fragments of ducts.......250. Tragacantha

B. Without starch.

a. Calcium oxalate present.

Raphides 0.1 to $1 \mathrm{~mm} \ldots \ldots \ldots \ldots \ldots \ldots \ldots \ldots \ldots \ldots \ldots$. Scilla

b. Calcium oxalate wanting.

Characteristic lignified hairs............252. Nux Vomica

Characteristic stone cells...............253. Almond

\section{Absence of Plant Tissues.}

A. Soluble in water.

Forming a mucilage with water.............. Acacia

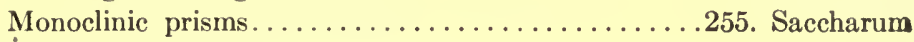

B. INSOLUble in water.

a. Soluble in alcohol.

Irregular fragments..................256. Camphora

b. Insoluble in alcohol.

$\alpha$ Reddish color with sulphuric acid.

Gritty; monoclinic prisms of various sizes.

257. Saccharum Lactis

$\beta$ No color reaction with sulphuric acid.

1. Soapy feel.

Broken crystals. . . . . . Talc

2. Soluble in acetic acid.

* With effervescence.

In prisms or irregular angular fragments.

259. Precipitated Calcium Carbonate

An amorphous powder......260. Prepared Chalk

Rhombic crystals or irregular fragments.

261. Barium Carbonate

** Without effervescence.

Rounded masses........262. Heavy Magnesia Very light............263. Light Magnesia

3. Insoluble in acetic acid.

* Soluble in nitric acid.

Tetragonal or cubical crystals.

264. Precipitated Calcium Phosphate

Acicular crystals........265. Calcium Sulphate

Rhombic prisms or crystals of various sizes.

266. Barium Sulphate

Irregular fragments..........267. Terra Alba 


\section{INDEX}

\section{A}

Abele, 158

Abrin, 347

Abrus, 347

Absinthium, 682

Acacia, 330

Acer, 411

- spicatum, 652

Achillea, 683

Acid, Abietic, 40

—, Arabic, 331

-, Aurantiamaric, 372

-, Cetraric, 27

-, Chrysophanic, 189

—, Embelic, 147

-, Filicic, 32

—, Gallic, 169

-, Guaiaconic, 361

-, Helvellic, 24

-, Kinic, 640

-, Krameric, 339

-, Lichenostearic, 27

-, Luparmaric, 179

-, Lycopodic, 34

-, Maizenic, 16, 52

-, Melilotic, 136, 346

-, Resin, 44

-, Resinolic, 40

-, Sandaracolic, 47

-, Santalic, 330

—, Saporubic, 202

-, Sinapic, 60

-, Tangic, 6

-, Tannic, 168

Aconite, 213

-, Leaves, 218

Aconitine, 217

Aconitum, 213

Acorin, 74

Actinostrobus, 47
Adder's Tongue, 107

Adiantum, 34

Adonis, 227, 228

Adulteration, $\mathrm{xv}$

Ethusa Cynapium, 501

Agar-agar, 8

Agaric, 16

Agaricus spores, 14

Agropyron repens, 51

Ague Root, 98

Aletris, 98

Algæ, 5

Algin, 7

Alkanet, 562

Alkanna, 562

Allium, 94

Allspice, 468

-, Adulterants, 470

Almond, Bitter, 294

-, Green, 408

-, Sweet, 297

Aloes, 86

- Barbadoes, 90

- Cape, 91

- Crown, 91

- Curaçao, 90

- Detection of, 93

- Jaffarabad, 93

- Natal, 93

- Socotrine, 88

- Uganda, 91

- Zanzibar, 89

Aloin, 91

Althæa, 427

Altingia, 294

Amanita, 18

Amaryllis, 109

Ammoniac, 499

Amygdala Amara, 294

- Dulcis, 297 
Amylum, 54

- Marantæ, 128

Anacardium, 406

Andropogon, 64

Anemone, 222

Anesthetics, Synthetic Local, 358

Angelica Fruit, 496

- Root, 494

- Tree, 475

Angiosperms, 50

Angustura, 374

Anhalonium, 457

Animal Drugs, 699

Anise, 246, 478

—, Japanese Star, 247

Annatto, 446

Anona muricata, 202

Anthemis, 667

Anthoxanthum, 136

Anti-opium Plant, 471

Anti-serums, 1

Apii Fructus, 493

Apiol, 493

Apocynum, 541

Apple, Bitter, 655

- Jelly, xiii

Apron, Devil's, 5

Aracex, 73

Aralia, 473

Araroba Depurata, 339

Araucarias, 36

Arbor Vitæ, 48

Arbutin, 504, 506

Archegoniates, 29

Archil, 28

Areca Nut, 71

Arecoline, 71

Argel, 320

Aristolochias, 184

Arnica Flowers, 666

-, Root 692

Arnicin, 667

Aronwurzel, 73

Arrow Poison, 110

Arrowroot, 129, 400

-, Brazilian, 553

-, East Indian, 123

- Starch, 62

Artemisia Cina, 671

Arum Family, 73
Asafetida, 497

Asarum, 184

Asclepias, 549

Asparagin, 429

Aspen, 158

Aspidium, 29

Aspidosperma, 547

Astragalus, 332

Atropa Belladonna, 581

Atropine, 587

Aurantium, 371

Azedarach, 384

Azolitmin, 29

B

Bacillariaceæ, 9

Bacillus bulgaricus, 3

Bacteria, 1

Bacterins, 2

Bacteriology, Applied, 5

Ballota hirsuta, 568

Balsam, Canada, 45

- Fir, 45

—, Oregon, 45

Balsamum Peruvianum, 341

- Tolutanum, 342

Baptisia, 343

Barberry Family, 230

Barley, 63

- Flour, 60

Bassorin, 333

Bayberry, 158

Bdellium, 382

Bean Starch, 62

Bearberry, Red, 506

Beech, 165

Beetles, Blistering, 709

Belladonna Leaves, 581

- Root, 590

Benzoin, 512

Berberidaceæ, 230

Berberine, 211, 235

Berberis, 233, 235

Beri-beri, 58

Bermuda Grass, 52

Betel Nut, 71

Bethroot, 107

Betula, 162

- alba, 38

Bhang, 174 
Bichy Nut, 435

Birch, 162

- tar, 38

Birthroot, 107

Bistort, 195

Bitter Almonds, 294

- Dock Root, 194

- Panus, 23

Bittersweet, True, 611

Blackberries, 302

Blackberry Bark, 301

Black Cohosh, 219

- Haw, 649

Bladder Wrack, 6

Blazing Star, 78

Bloodroot, 275

Bluebell Family, 661

Blue Cohosh, 236

Boldo, 248

Boneset, 679

Borage Family, 562

Borneol, 187

Botanical origin, $\mathrm{xxi}$

Bougies, 5

Bouncing Bet, 200

Bran, Corn, 58

-, Rice, 58

-, Wheat, 59

Brauneria, 694

Brayera, 303

Broom, 320

Brucea, 379

Brucine, 525

Brunfelsia, 614

Bryonia, 659

Bryophytes, 29

Buchu, 368

Buckthorn Bark, 423

- Family, 415

Buckwheat Family, 189

- Flour, 60

Bully tree, 510

Buphane Disticha, 110

Burdock, 692

Burgundy Pitch, 43

Butternut, 160

Cacao, 437

Cactus Family, 455
Cadinene, 39

Cæsalpinaceæ, 311

Cæsalpinia, 330

Caffeine, 415, 436, 647

Calabar Bean, 323

Caladiums, 73

Calamus, 74

Calendula, 667, 670

Calf's Foot Root, 73

Calisaya, 637

Callitris, 47

Caltrop, 359

Calumba, 240

Camellia, 442

Camphor, 257

Camwood, 330

Canada Balsam, 45

- Pitch, 44

- Turpentine, 45

Canaigre, 169

Candleberry, 158

Canella, 447

Cannabis, American, 176

- Indica, 173

Canna Starch, 62

Cantharidin, 707

Cantharis, 705

Caoutchouc, 393

Capsicum, 606

Caraway, 481, 484

- Oil, 482

Carbo Ligni, 156

Cardamom, 125, 127

Cardinal Flower, 664

Carica, 453

Carob Bean, 648

Carrageen, 7

Carrot Family, 478

Carthamus, 112

Carum, 481

Carven, 482

Carvol, 482

Carya, 159

Caryophyllus, 466

Cascara Sagrada, 416

Cascarilla, 396

Cashew-nut, Oriental, 408

-, West Indian, 407

Casimiroa, 373

Cassava Starch, 63, 400 
Cassia, 255, 256, 316

Cassia Fistula, 320

Castanea, 165, 169

Castor Bean, 398

Catechu, 333, 334

Caulophyllum, 236

Cayenne Pepper, 606

Cedar, 50

Celandine, 274

Celery seed, 493

Centaurium, 537

Cephæline, 644

Cephælis, 641

Cereus, 455

Cetraria, 26

Chamælerin, 79

Chamælirium, 99

Chamomile, English, 667

-, German, 669

Charcoal, Wood, 156

Chaulmoogra Seeds, 446

Chavica officinarium, 146

Checkerberry, 508

Chelidonine, 274

Chelidonium, 274

Chenopodium, 196

Cherry Bark, Wild Black, 298

- Leaves, 442

Chestnut, 165, 169

Chicory, 689

Chilli Pepper, 606

Chimaphila, 504

Chinquapin, 170

Chionanthus, 515

Chirata, 536

Chrysin, 157

Chocolate, 439

- Adulterants, 440

Choline, 76

Chondrus, 7

Chrysanthemum, 673

Chrysarobin, 339, 340

Cichorium, 689

Cimicifuga, 219

Cinchona, 633

Cinchonine, 640

Cinnamein, 342

Cinnamon, 250, 254

-, White, 447

Civet, 710
Civet Adulterants, 710

Cladonia, 28

Claviceps purpurea, 11

Clitocybe Illudens, 22

Cloves, 466

Clove Bark, 256

Clover, Red Blossoms; 345

-, Yellow Sweet, 345

Cluytia Similis, 401

Coca, 352

Cocaine, 356

Cocculus, 107, 241

Coccus, 699

Cochineal, 699

Cochlospermum, 333

Cocillana, 383

Cocoa, 437

Cocoanut, 71

—, Double, 72

- Shells, 72

Codeine, 270

Coffee, Bean, 646

-, Fig, 180

- Substitutes, 648

Cohosh, Black, 219

-, Blue, 236

Cola, 435

Colchicine, 86

Colchicum Corm, 84

- seed, 86

Colic Root, 98, 109

Collection of drugs, xxii, xxiv, .xxvii

Collinsonia, 578

Colocynthis, 655

Colophony, 39

Columbo, American, 536

Combretum, 471

Commelinaceæ, 76

Commercial origin, xxii

Composite Family, 665

Condurango, 551

Coniferæ, 36

Coniferin, 37

Coniine, 486

Conium, 479, 484

Convallaria, 96

Convallariæ Flores, 98

Convallamarin, 98

Copaiba, 340

Coprinus, Spores of 14 
Copra, 72

Coptis, 223

- Root, 224

Coriander, 487

Coriandrum, 487

Coriaria, 576

Corn Bran, 58

- Dent, 56

- Flint, 56

- Meal, 56

- Silk, 52

- Smut, 14

- Sugar, 56

Cornicularia aculeata, 28

Cornus, 502

Corydalis, 278

Corylus, 162

Coto, 262

Cotton Purified, 431

- Root Bark, 432

Cough Grass, 51

Coumarin, 136, 328, 346

Coumarouna, 134

Cramp Bark, 649

Cranesbill, Spotted, 349

Cresote, 42

Cretan Dittany, 575

Crinum, 96

Crocin, 112

Crocus, 110

Croton, Bark, 400

- Eluteria, 396

Cryptograms, 29

Cubeb, 149

Cubeba, 149

Cuckow Pint Root, 73

Cucumber seeds, 658

Cucurbita, 658

Cudbear, 28

Culver's Root, 629

Cuprea bark, 641

Curcuma, 122, 130

Curled dock, 193

Cuskus Root, 64

Cusparia Bark, 374

Cusso, 303

-, loose, 305

Custard Apple Family, 202

Cycads, 36

Cycas, 63
Cydonium, 308

Cynips tinctoria, 167

Cytisine, 345

Cypripedium, 137, 389

\section{D}

Daisy, Field, 676

Dalmatian Flowers, 673

Damiana, 449

Dandelion, 687

- Root, Blue, 689

Daphne, 460

Datura species, 601

Day Flower, 76

Death Camas, 83

- Cup, 20

Delphinium, 222

Derris Ulignosa, 348

Destroying Angel, 20

Dextrin, 63

- White, 63

- Yellow, 63

Diastase, 64

Diatoms, 9

Dicentra, 278

Dicoma Anomala, 699

Dicotyledons, 140

Digitalin, 621, 624

Digitalis, 617

-, Adulterants, 628

Digitalon, 627

Digitonin, 626

Digitoxin, 622

Dioscorea, 108

Dittany Cretan, 575

Divining rod, 164

Dogbane, Family, 540

Dog Grass, 51

Dog's tongue, 136

- tooth Violet, 107

Dogwood Family, 502

-, Poison, 405

Douglas spruce, 45

Dragon's Blood, 337

Drosera, 285

Drybalanops, 258

Dryopteris, 29

Duboisia, 601

Dulcamara, 611 
Dulce, 489

Dumb Cane, 73

\section{$\mathrm{E}$}

Ecballium Elaterium, 661

Ecgonine, 358

Echinacea, 694

Egg Plant, 580

Eibischwurzel, 427

Elastica, 393

Elaterin, 661

Elaterium, 661

Elder, Flowers, 652

-, Poison, 405

-, Prickly, 475

Elecampane, 689

Elettaria Cardamomum, 125

Elm, Bark, 172

Embelia, 147

Embelic Acid, 147

Emetine, 644

Emodin, 190

Empleurum, 370

Entada, 326

Enzymes, 26

Epigæa, 503

Ergot, 11

Ergotoxine, 13

Ericaceous plants, 159

Ericolin, 508

Eriodictyon, 561

Erythronium, 107

Erythrophloeum Guineense, 348

Erythroxylon, 352

Eucalyptol, 465

Eucalyptus, 336, 463

Eugenia Smithii, 335

Eugenol, 470

Euonymus, 409

Eupatorium, 679

Euphorbia, 397

Euphorbias, 390

Everlasting, 676

Evernia prunastri, 28

Evernin, 28

Exogonium Purga, 553

\section{F}

Faex Compressa, 26

False Unicorn Root, 78
Fagaceæ, 42

Fagus, 165

Fennel, 489, 491

Fenugreek, 326

Fern, Sweet, 159

Ferns, 29

Ferula, 497

Ficus, 179

Fig, 179

Figwort Family, 616

Filbert, 164

Filicin, 32

Filixic anhydride, 32

Filmaron, 33

Fir, 158

Fish Berries, 241

Flag, Larger Blue, 113

-, Poison, 113

-, Water, 113

Flax, 350

Flaxseed, 351

Flour, Barley, 60

-, Buckwheat, 60

-, Rice, 58

-, Rye, 60

-, Wheat, 59

Fly amanita, 19

Fœniculum, 489

Fœnum Græcum, 326

Folia Gualtheriæ, 508

Fool's Parsley, 487

Fox Glove, 617

Franciscera, 614

Frangula, 423

Fraxinus, 516

Fringe Tree Bark, 515

Frostweed, 444

Frostwort, 444

Fucus, 6

Fumitory Family, 276

Fungi, 11

—, Poisonous, 18

Galanga, 124

Galbanum, 500

Galega, 345

Galipidine, 375

Galium, 136

Galla, 167 
Galls, 168, 169

Gambir, 334

Gamboge, 443

Ganja, 174

Garcini Hanburyi, 443

Garlic, 94

Gaultheria, 508

Gelatin, Chinese, 8

-, Japan, 8

Gelose, 9

Gelsemine, 521

Gelsemium, 518

Gemmæ Populi, 157

Gentian, 532, 534

Geranium, 349

Germ, Wheat, 59

Gigartina, 8

Gilead Buds, Balm of, 157

Ginger, 117

-, coated, 117

-, Crystallized, 117

-, exhausted, 122

-, Jamaica, 117

-, limed, 122

-, peeled, 117

-, scraped, 117

-, Wild, 184

Ginseng, 475

- Family, 473

Gitalin, 627

Glandulæ Rottleræ, 394

Glycine, 346

Glycyrrhiza, 311

Gnetaceæ, 36

Gnoscopine, 272

Goa Powder, 340

Goat's Rue, European, 345

Golden Seal, 208

Goldthread, 223

Goosefoot Family, 196

Gossypium Purificatum, 431

Gracilaria, 8

Gramineæ, 51

Granatum, 460

Grape-Root, Oregon, 233

Grass, couch, 51

- dog, 51

- Family, 51

- quick, 51

- sweet vernal, 136
Grass vanilla, 136

Great Aspen, 158

Green Gill, 22

Grindelia, 677

Gromwell Leaves, 442

Ground Pine, 35

Guarana, 414

Guarea Rusbyi, 383

Guaiac resin, 360

Guaza, 174

Guiaci Lignum, 360

Gum Arabic, 330

-, Artificial, 331

-, Eucalyptus, 465

--, Indian, 331

- Mesquite, 331

- resin, 443

-, Spruce, 45

- Wattle, 331

Gummi Plasticum, 510

Gums, 331, 332, 333

Gutta-Percha Family, 510

Guttiferæ, 443

Gymnosperms, 36

\section{H}

Habitat, xxi

Hæmatoxylon, 329

Hagenia, 303

Hamamelis, 288

Hancornia, 394

Harmine, 177 ,

Hazel-nut, 164

Heath Family, 503

Hedeoma, 571

Hedysarum, 314

Helianthemum, 444

Helichrysum, 676

Hellebore, American, 79

-, Black, 84

-, European, 79

-, False, 84, 227

-, Green, 227

-, White, 79

Helleborin, 84

Helonias, 78, 99

Hejvella amara, 24

Hemlock, American Water, 501

- Bark, 44

-, Eurpean Water, 501 
Hemlock Pitch, 44

-, Poison, 484

-, Water, 486

Hemp, Canadian, 541

-, East Indian, 173

-, Manilla, 110

-, Sisal, 110

Henbane, 595

Heptapleurum, 478

Hercules Club, 475

Hevea, 393

Honeysuckle Family, 648

Hops, 177

-, Spanish, 575

Hordenine, 64

Horehound, Black, 568

—, White. 567

Horsebalm-root, 578

Horse Nettle, 612

Humulus, 177

Hydrangea, 286

Hydrangin, 287

Hydrastine, 211

Hydrastis, 208

Hydrophyllacex, 561

Hyoscyamine, 591, 600

Hyoscyamus, 595

Hyoscine, 600, 601

Hypocreaceæ, 11

Hyssop, Wild, $5 f 3$

I

Iceland Moss, 26

Ignatia, 527

Illicum, 246

Ill-scented Wake-robin, 108

Immortelle Yeliow, 676

India-Rubber, 393

Indian Apple, 231

- Root, 473

Indigo, Red, 28

- Root, Wild, 343

Infusorial Earth, 9

Inga, 354

Insect Powder, 673

Insects in drugs, xxiii

Inula, 689

Invertase, 26

Iodin in algæ, 6

Ionidium, 645
Ipecac, 273, 641, 642, 645

Ipecacuanha, 641

Ipomoea, 556

Iridis Rhizoma, 115

Iris, 110, 115

Irish Moss, 7

Ironbark Tree, 466

Ivory nut, ground, 648

\section{J}

Jaborandi, 365

Jack-bean, 326

Jack-in-the-pulpit, 73

Jack-o'-lantern, 22

Jalap, 553

-, Compound Powder of, 556

-, Substitutes, 556

Jamaica Ginger, 117

Jambosa Caryophyllus, 466

Jamestown Weed, 603

Japan Gelatin, 8

Jasmine, 518

Jateorhiza, 240

Jequiritin, 347

Jequirity, 347

Jervine, 82

Jessamine, 518

Jimson Weed, 603

Joe-pye weed, 682

Juglans, 159

Jungle Plant, 471

Juniper Berries, 48

Juniperus, 39, 48

Kalmia, 503

Kamala, 394

Kava-kava, 153

Kefir, 4

Kesso root, 654

Kichsia, 394

Kieselguhr, 9

Kino, 335, 337

-, Australian, 465

Kiurushi, 405

Knotroot, 578

Kola, 435

Kordofan Gum, 331

Ko-sam seeds, 379

Kosteletzyka, 429

K 
Kousso, 303

Krameria, 337

I

Labiatæ, 564

Labrador Tea, 508

Lacquer, Japanese, 405

Lacmus, 29

Lactarius, 22

Lactuca, 687

Lactucarium, 698

Lady's Slipper, 137

Lagenaria, 658

Laminaria, 5

Landolphia, 394

Lappa, 692

Larch Bark, 43

Larcis Cortex, 43

Laricina Terebinthina, 42

Larkspur Seed, 222

Lasiosiphon, 460

Latalia Radix, 124

Laticiferous cells, 390

Lauraceæ, 250

Laurel, 250

-, Cherry, 300

Lavandula, 577

Lavender Flowers, 577

Lecanora tartarea, 29

Ledum, 508

Leea, 339

Leguminosæ, 310

Lemon, 373

Lepiota Morgani, 22

Leptandra, 629

Liatris, 79

Lichens, 26

Licorice, Compound Powder, 315

- Root, 311, 314

Life Root, 696

Lignum benedictum, 360

- guiaci, 360

- Juniperi, 49

- sanctum, 360

- Santali, 182

— vitæ, 360

Liliaceæ, 76

Lily of the Valley, 96

Limonum, 373

Linseed, 350
Linum, 350

Lipase, 71

Lippia, Mexicana, 563564

Liquidambar, 292

Liquorice, 311, 314

- Seed, Wild, 347

Lithræa Caustica, 406

Litmus, 29

Litsea, 152

Lobelia, 662

Lobeline, 664

Lodoicea, 72

Loganiaceæ, 517

Logwood, 329

Lophophora, 457

Lupulin, 179

Lycopodiacex, 34

Lycopodium, 34

Lythraceæ, 460

M

Mace, 206, 208

Macis, 206

Macleya, 272

Maclura, 173

Madder Family, 632

Magnolia, 245

Magnoliaceæ, 245

Mahogany Family, 382

Mahonia, 230

Maidenhair, 34

Male Fern, 29

Mallow Family, 427

Malt, 63, 64

Maltose, 24

Maltum, 63

Malva, 431

Malvaceæ, 427

Manaca, 614

Mandelonitrile, 299

Mandragora, 591

Mandrake, 231, 591

Mangrove Extract, 335

Manihot, 394

Manna, 514

Mannitol, 514

Maple Charcoal, 156

— Family, 411

-, Mountain, 652

Maranta, 129 
Maranta Starch, 62

Margosa, 386

Marigold, 670

Marjoram, 576

Marrubium, 567

Marsdenia, 560

Marshmallow Leaves, 429

- Root, 427

Mastic, 406

Maté, 422

Matico, 147

Matricaria, 669

May Apple, 231

Meadow Sweet, 442

Meal, Corn, 56

-, Flaxseed, 352

-, Linseed, 352

Meconine, 272

Meliaceæ, 382

Melilotus, 136, 345

Menispermum, 238

Mentha Piperita, 568

- Viridis, 571

Menthol, 569

Menyanthes, 540

Mescal Buttons, 457

Metchnikoff's theory, 3

Methyl salicylate, 510

Methysticum, 153

Mexican Tea, 197

Mezerein, 460

Mezereon Family, 457

Mezereum, 459

Micro-chemistry, xvi

Microscope, Use of, xiii, xix

Middlings, Wheat, 60

Milfoil, 683

Milkweed Family, 549

- Root, Orange, 549

Milkwort Family, 387

Minosacere, 311

Mint, 573

- Family, 564

Monarda didyma, 575

Monimiaceæ, 248

Monkshood, 213

Monocotyledons, 51

Moonseed, Canada, 238

Moraceæ, 173

Morning Glory Family, 552
Morning Glory Stems, 556

Morphine, 268

-, Compound Powder of, 274

Morus, 442

Moschus, 709

Moss, bog club, 35

- fir club, 35

- stiff club, 35

Mountain Ash, 442

Mulberry, 173

- Family, 173

- Leaves, 442

Mullein, 631, 632, 664

Mulu Kilavary, 382

Muscarine, 23

Mushrooms, Poisonous, 18

Musk, 709

Muskmelon, 658

Mustard, 279-285

-, Black, 283

- Dakota, 284

- Family, 279

- Field, 284

- Sarepta, 284

- Yellow, 279

- White, 279

Myrica, 158

Mylabris, 707

Myristica, 203

Myrobalans Family, 470

Myrrh, 381

Myrtacex, 463

Myrtle family, 463

Napelline, 217

Narceine, 272

Narcissine, 110

Narcissus, 110

Narcotine, 271

Naregamia, 645

Narindin, 372

Naringin, 372

Natural origin, $\mathbf{x x i}$

Nectandra, 261

Neen Bark, 386

Nephelium, 323

Nettle, 170

- family, 170

-, horse, 613 
Nettle, Stinging, 180

Nicotiana, 614

Nicotine, 616

Nigella, 482

Nightshade Family, 580

Nitrogen-fixing bacteria, 4

Nut areca, 71

- Brazil, 470

- Buffalo, 181

- Kola, 435

- oil, 181

Nutgall, 167

Nutmeg, 203, 205

Nux Vomica, 521

- - Family, 517

- - Strychnos, 375

O

Oak, 165

- Leaves, 442

-, Poison, 403

Oenanthe Crocata, 501

Oil, Almond, 295

-, Cade, 39

—, Castor, 399

-, Caraway, 482

-, Chenopodium, 196

-, Clove, 468

-, Cocoanut, 72

-, Juniper, 49

-, Kesso root, 654

-, Kien, 39

—, Lavender, 578

-, Palm, 72

-, Peru Balsam, 342

-, Pine needle, 38

-, Sandalwood, 182, 184

—, Spike, 578

-, Spearmint, 571

—, Tar, 42

-, Turpentine, 38

-, Vetiver, 65

Olea, 517

Olive Family, 513

— endocarp, 147

Opium, 266, 273

Orange Peel, Sweet, 371

- -, Bitter, 372

Orcein, 28

Orchid, 130
Orchil, 28

Orchis, 136

Ordeal bean, 323

Oregon Balsam, 4.5

Orlean Annatto, 528

Ornithogalum Thyrsoides, 108

Orosul, 563

Orris Butter, 116

- Root, 115

Oryganin, 58

Oryza sativa, 55

Osmunda Claytoniana, 34

Oxymethylanthraquinone, 317

Pachira, 429

Palaquium, 510

Palms, 67

Palmæ, 67

Panax Ginseng, 475

- Repens, 476

Panus Stipticus, 23

Papain, 455

Papaver, 263

Papaverine, 271

Papaw, 453

Papaya, 453

Papilionaceæ, 310

Paprika, 609, 610

Para-Coto, 263

Para Rubber, 393

Paraguay Tea, 442

Pareira, 243

Parilla, Yellow, 238

Parsley, Fool's, 501

-, Fruit, 491

一, Root, 493

Passiflora, 452

Passion Flower, 451

Pasteur's Solution, 25

Pater Noster tree, 385

Paullinia Cupana, 414

Pawpaw, 453

Pea Starch, 63

- Peganum Harmala, 177

Pelletierine, 461

Pellitory, 686

Peltigeria aphthose, 28

Pennyroyal, 571, 572

Peperomia, 146 
Pepo, 657

Pepper, 142

—, Acheen, 146

- Adulterations, 147

-, Black, 142

-, Bombay, 609

-, Cayenne, 606, 609

-, Chilli, 606

- Shells, 146

- Substitutes, 147

-, White, 146

Peppercorns, 146

Peppermint, 568

Peppertree, Peruvian, 406

Persian Flowers, 674

Persio, 28

Peru Balsam, 341

Petroselinum, 491

Phæsophyceæ, 6

Pharmacognosy, xiii

Pharmacopœia, xxii

Phaselous Multiflorus, 347

Phlox Carolina, 532

Physostigma, 323

Physostigmine, 323

Phytolacca, 198, 199, 589

Picea, 45

Picea Liquidæ, 42

Picraena, 377

Picrasma, 376

Picrotoxin, 243

Pilocarpine, 368

Pilocarpus, 365

Pimenta, 468

Pimiento, 610

Pimpernel, 481

Pimpinella, 481

Pinaceæ, 36

Pine Bark, 36

-, Family, 36

— pollen, 35

—, Prince's, 504

Pink, Carolina, 532

- Family, 200

Pinkroot, 527

Pinus Alba, 36

Piper, 142

Piperaceæ, 142

Piperine, 145

Pipsissewa, 504
Pistacia Lentiscus, 406

Pistachio, 408

Pitch, 44

Pix Burgundica, 43

- Canadensis, 44

- Liquida, 41

Pleurisy Root, 549

Podophyllum, 231

Poison, Bulb, 110

- flag, 110

- hemlock, 484

- ivy, 403

- oak, 403

Poke Root, 198, 591

Polygala, 387

Polygalaceæ, 387

Polygonacex, 187

Polypodiaceæ, 29

Pomegranate Bark, 460

Pomegranate Family, 460

Pop-corn, 55

Poplar, 155

Poppy, 263

Populus, 155

Potato plant, 612

- Starch, 62

-, Sweet, 552

Potentilla, 309

Powdered Drugs, 711

Powder, Rice, 58

Powders, Key for Study, 713 .

Preservation of Drugs, xxiii, xxvi

Prickly Ash, 362

- Cedar, 39

Pride of China, 385

- India, 385

Prince's Pine, 504

Protopine, 272

Prune, 309

Prunicine, 461

Prunum, 309

Prunus, 442

- Virginiana, 298

Pseudotsuga, 45

Psychotrine, 644

Pteridium, 33

Pteridophytes, 29

Pteris, 33

Pterocarpus, 330

Pulsatilla, 222 
Pulse Family, 310

Pumpkin Family, 655

— Seed, 657

Punica, 460

Purging Cassia, 320

Pussy-willow, 155

Pyrethri Flores, 673

Pyrethrum, 686

Pyrolace:x, 504

\section{Q}

Quality of drugs, xxiv

Quassia, 376

Quassin, 377

Quebracho, 547

Queensland arrowroot starch, 63

Quercus, 165

Quick Grass, 51

Quillaja, 302

Quince Seed, 308

Quinine, 639

\section{R}

Radix Coptidis, 224

- Iwarancusæ, 64

- Lapathi, 194

- Palmæ Christi, 140

- Salep, 139

- Saponariæ Rubra, 200

Ragwort, 696

Ranunculaceæ, 208

Rasamala, 294

Raspberries, 302

Red algæ, 5

— bearberry, 506

- cedar, 50

- fir, 45

- gum, 465

- Indigo, 28

- Saunders, 330

- water, 110

Redwood, 330

Regaliz de Cuba, $5<3$

Remijis, 641

Resin, 39, 40, 41

Resina Drastica, 556

Rhamnaceæ, 416

Rhamnus Catharticus, 425

- Frangula, 423

- Purshianus, 416
Rhatany, 337

Rhein, 190, 191

Rheopurgarin, 191

Rheum, 189

Rheumatism Root, 109

Rhizoma Aronis, 73

Rhizophora, 335

Rhododendron, 503

Rhodophycex, 5

Rhubarb, 189

Rhubarb, Compound Powder of, 193

Rhus Glabra, 402

- Toxicodendron, 403

- Vernix, 405

Rice Bran, 58

- Flour, 58

- Powder, 58

- Starch, 58

Richardsonia, 646

Ricini, Semen, 398

Robinia Pseudo-Acacia, 348

Roccella, 28

Rockrose Family, 444

Root, Orris, 115

Rosacere, 294

Rosa caninæe fructus, 307

Rosa Gallica, 305

Rose Family, 294

- Hips, 307

— Pink, 539

- Red, 305

Rosin, 39, 40

Rottlera, 394

Rubber, India, 393

—, Para, 393

- Vulcanization, 394

Rubiaceæ, 632

Rubus, 301

Rue, 362

Ruellia, 531

Rumex, 193

Rumicin, 194

Russula Emetica, 23

Rutacex, 362

Rye Flour, 60

Sabadilla seeds, \&3

Sabal, 68

Sabatia, 539 
Sabina, 49

Sabinol, 50

Saccharomyces, 24

Safflower, 113

Saffron, True, 110

一, Spanish, 110

Sage, 573

Sago, Imitation, 63

- Starch, 63

Salep, 139

Salicaceæ, 155

Salicin, 156

Salix, 155

Salvia, 573

Sambucus, 652

Sandalwood, 182

Sandarac, 47

Sanguinaria, 275

Santalacex, 181

Santalum Album, 182

- Rubrum, 330

Santonica, 671

Sapindacex, 414

Sapodilla, 510

Saponaria officinalis, 200

Sapotaceæ, 510

Saprophytic plants, 130

Sarcocolla, 333

Sarsaparilla, 99

-, American, 107

-, American Wild, 474

—, Central American, 99

—, Honduras, 99

-, Jamaica, 104

-, Mexican, 99, 104

一, Virginian, 474

Sassafras, 258

- Pith, 261

Savin, 49

Saw Palmetto, 68

Saxifrage Family, 286

Scammony, 557

—, Levant Resin, 559

—, Mexican, 558

-, Montpelier, 560

—, Smyrna, 559

Scarlet Runner Bean, 347

Schinsent, 475

Schizomycetes, 1

Schœnocaulon, 83
Scilla, 95

Scillitoxin, 96

Scoparius, 320

Scopola, 592, 594

Scopolia carnoilica, 589

Scrophulariacere, 616

Scutellaria, 565

Selenipedium Chica, 133

Semecarpus, 408

Semen Arccæ, 71

Senecio, 696

Senega, 387

Senna, 316

Sequoias, 36

Serpentaria, 186

Serpentarin, 187

Serpentary, English, 195

Serums, 3

Sesquiterpene, 39

Seven Barks, 286

Shikimmi fruits, 247

Sida; 429

Siliceous Earth, 9

Simaruba, 378

Simarubacex, 375

Sinapis Alba, 279

- Nigra, 283

Skimrni fruits, 247

Skullcap, 565

Sleepy Grass, 65

Slippery Elm, 172

Sloe Leaves, 442

Sloanine, 612

Smilax, 99

Snake Root, 186, 187

-, Black, 219

-, Canada, 184

Snowdrop flowers, 110

Soap Bark, 302

Soapberry Fanily, 414

Soaproot, Red, 200

Soapwort, 200

Solanacex, 580

Solanum, 589, 612

Sorbus Leaves, 442

Soursop, 202

Soy Bean, 346

Spanish Flies, 705

Sparteine, 320

Spearmint, 571 
Spiderwort Family, 76

Spigelia, 527

Spikenard, 107

-, American, 473

Spruce gum, 45

Spurge Family, 390

Squill, 95

Squirrel Corn, 278

Staff-tree Family, 409

Staphisagria, 221

Starch, 52

-, Arrowroot, 62

-, Bean, 62

-, Canna, 52

- Cassava, 63

-, Corn, 55, 56

-, Maranta, 62

-, Pea, 63

-, Potato, 62

-, Rice, 58

-, Queensland arrowroot, 63

—, Sago, 63

-, Sweet Potato, 63

—, Tapioca, 63

-, Wheat, 59

一, Yam, 62

Starches, Miscellaneous, 62

Stavesacre, 221

Sterculiaceæ, 435

Sterocaulon pascale, 28

Stillingia, 391

Stipa, 67

Stipa Vaseyi, 65

Stoneroot, 578

Storax, 292

Stramonium, 601, 603, 606

Strasburg turpentine, 43

Strawberries, 302

Strawberry, 443

Strophanthin, 546

Strophanthus, 543

Strychnine, 525

Study of drugs, xxvii

Styracex, 511

Styrax, 292

Styrax Family, 511

Styrol, 293

Sugar Corn, 56

- Grape, 180

- Maplc, 412
Sumac, 401

Sumbul, 496

Sundew, 285

Swamp Pink, 78

Sweeria, 537

Sweet birch, 162

- clover, 345

- fern, 159

— flag, 74

- gale, 158

- potato Vine, 552

- scented bed straw, 136

- vernal grass, 136

Swietenia, 382

\section{$\mathbf{T}$}

Tabacum, 614

Tabasco, 470

Tacamahac, 157

Tacca, 129

Taliow tree, 437

Tamarind, 321

Tambla Bark, 634

Tanacetum, 683

Tangic acid, 6

Tansy, 683

Tapioca, 130, 400

Tar, 41

一, Birch, 38

Taraktogenos, 446

Taraxacum, 687

Taxaccæ, 36

Tea, 441

- Adulterants, 442

-, Mexican, 197

—, Paraguay, 442

Teaberry, 508

Tents, 5

Tephrosia, 319

Terebinthina, 37

Terebinthina Canadensis, 45

- Laricinia, 42

- Veneta, 42

Terminalia, 335

Terra Japonica, 334

- Silicea, 9

Thalictrum, 213

Thallophytes, 1

Than, 335

Thea, 441 
Thebaine, 271

Theine, 436

Theobromine, 437

Thuja, 48

Thujin, 48

Thyme, 574

Thymelaaeex, 457

Thymus, 574

Tinospora, 240

Tobaceo, 614, 662

-, Adulterants, 616

-, Indian, 662

Toddalia, 213

Tolu Balsam, 342

Toluifera Pereira, 341

Tomato, 580

Tonka, 134, 326

Tormentilla, 309

Tradescantia, 76

Tragacanth, 332

Tragopogon, 667

Trifolium, 346

Trilisia, 136

Trilline, 108

Trillium, 107

Triosteum, 648

Tritiein, 52

Triticum, 51

Tsuga, 44

Tubereulins, 2

Turiones Populi, 157

Turkey Corn, 278

Turmerie, 122, 130

Turnere, 449

Turneraeeæ, 449

Turpentine, 37, 42

Turpeth root, 556

Tussilago, 685

Ulmacex, 172

Ulmus, 172

Umbelliferæ, 497

Uncaria, 334

Unicorn Root, 98

Urginea, 95

Ursone, 508

Urtica, 180

Urticaceæ, 170
Usnea barbata, 28

Ustilaginaeex, 14

Ustilago, 14

Uva-ursi, 506

Vaecines, 1

Valerian, 653

- Adulterants, 654

Valerianacese, 653

Valuation of drugs, xxvi

Vanilla, 130, 134

Vanillin, 133, 513

Vanillons, 134

Varnish Tree, 405

Veniee Turpentine, 40

Venus Hair, 34

Veratrine, 83

Veratrum, 79, 82

Verbascum, 631

Verbena, 563

Verbenaceæ, 563

Vervain Family, 563

Vetiver, 64

Viburnum, 649

Violet, Dog's Tooth, 107

Virus, 1

Vitaceæ, 136

Vitis, 136

Vouacapoua, 339

\section{W}

Wahoo Bark, 409

Walnut, 159

Walnut Shells, English, 162

Water flag, 113

— hemloek, 486

Waterleaf Family, 560

Watermelon Seeds, 658

Wax Myrtle, 158

Weymouth Pine, 36

Wheat Bran, 59

- Flour, 59

- Germ, 59

- Starch, 59

- Middlings, 59

White Ash Bark, 516

- Cedar, 48 
- Cinnamon, 447

- Oak, 165

- White Pine Bark, 36

Whortleberry, 504

Wild Cherry, 298

- Ginger, 184

Willow, 155, 443

Winterana, 447

Wintergreen, 508

Wistaria, 443

Witchhazel, 288

- Bark, 290

- Leaves, 288

- Twigs, 292

Wood Charcoal, 156

Wolfsbane, 218

Wormseed, American, 196

—, Levant, 671

Wormwood, 682

$\mathrm{X}$

Xanthoxylum, 362

Xylopia, 147

\section{$\mathbf{Y}$}

Yam Root, 109

-, Starch, 62

Yarrow, 683

Yeasts, 24

Yellow Dock, 193

- Jessamine, 518

- Parilla, 238

- Root, 122

Yerba Santa, 561

Z

Zanthium macrocarpum, 606

Zanthoxylum, 362

Zapote blanco, 373

Zea, 52

- Mays, 52

Zedoaria, 124

Zingiber, 117

Zygadenine, 83

Zygadenus, 83

Zygophyllacex, 359

Zymase, 26 







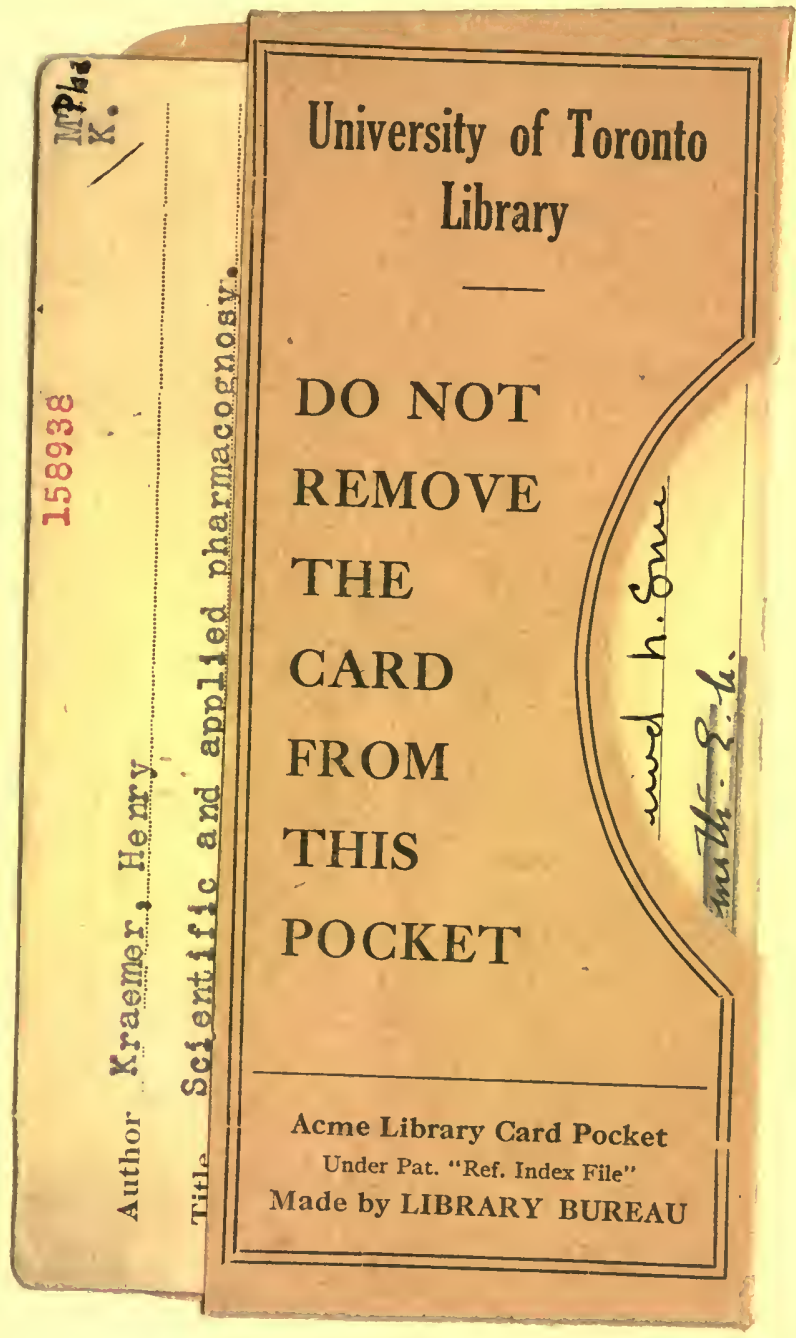




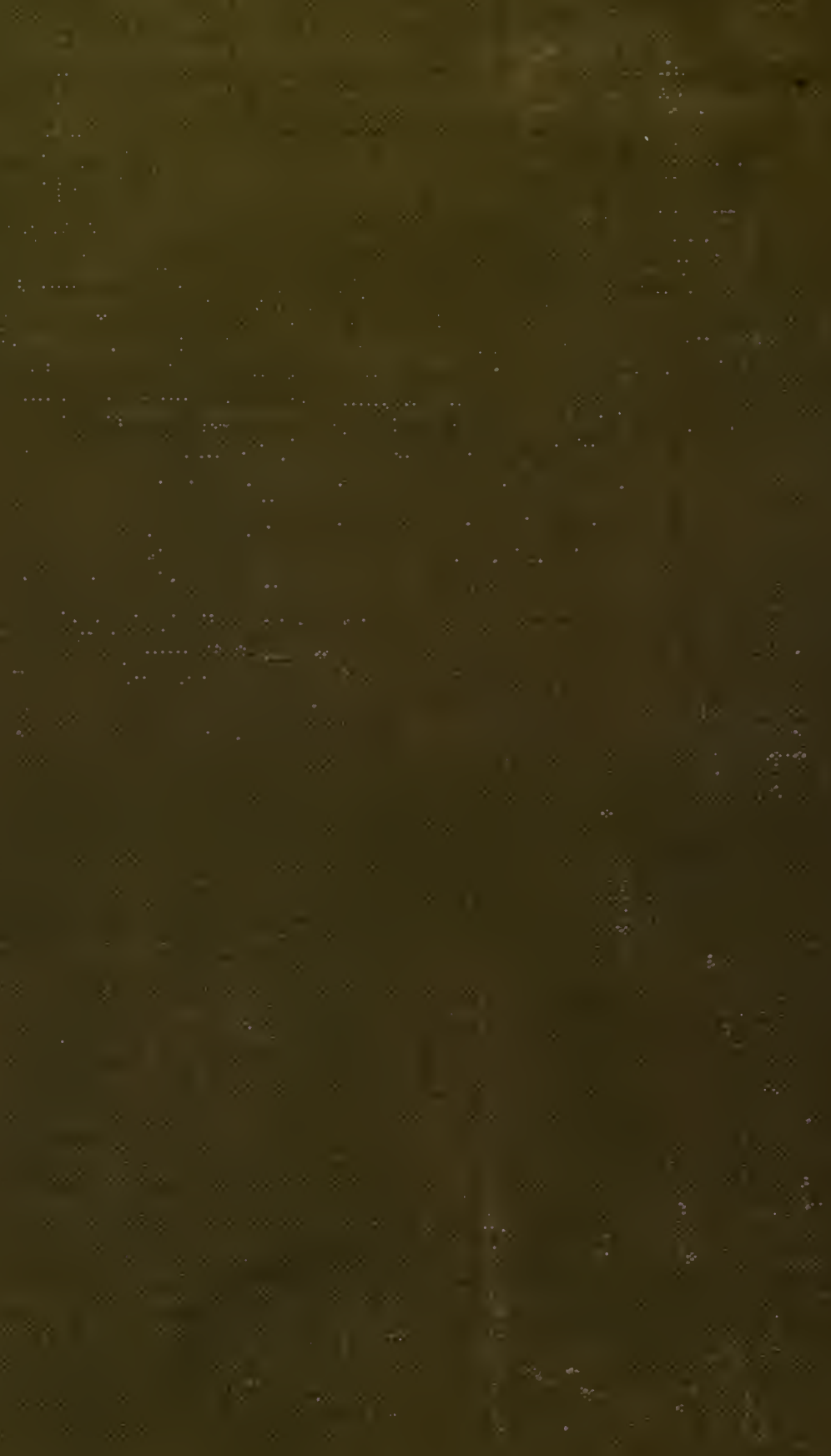

